\title{
Resource-Economical Synthesis by Selective Metal-Catalyzed C-H Activations
}

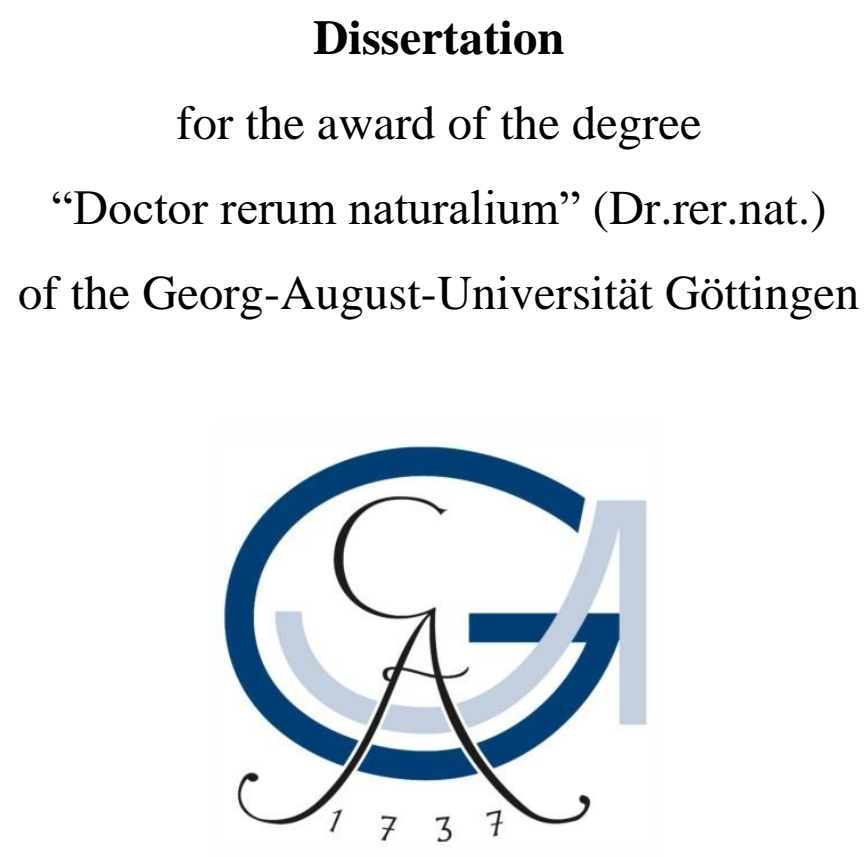

within the doctoral program of chemistry of the Georg-August-Universität School of Science (GAUSS)

Submitted by

Uttam Dhawa

From Kolkata, India

Göttingen, 2021 



\section{Thesis Committee}

Prof. Dr. Lutz Ackermann, Institute of Organic and Biomolecular Chemistry

Prof. Dr. Manuel Alcarazo, Institute of Organic and Biomolecular Chemistry

\section{Members of the Examination Board}

Reviewer: Prof. Dr. Lutz Ackermann, Institute of Organic and Biomolecular Chemistry

Second Reviewer: Prof. Dr. Manuel Alcarazo, Institute of Organic and Biomolecular Chemistry

\section{Further members of the Examination Board}

Prof. Dr. Dr. h.c.mult. Lutz F. Tietze, Institute of Organic and Biomolecular Chemistry

Prof. Dr. Ricardo Mata, Institute of Physical Chemistry

Dr. Michael John, Institute of Organic and Biomolecular Chemistry

Dr. Daniel Janßen-Müller, Institute of Organic and Biomolecular Chemistry

Date of the oral examination: 15.04 .2021 



\section{List of Abbreviations}

\begin{tabular}{|c|c|}
\hline$\AA$ & Ångström \\
\hline Ac & acetyl \\
\hline acac & acetyl acetonate \\
\hline Alk & alkyl \\
\hline AMLA & ambiphilic metal-ligand activation \\
\hline$[\alpha]_{\mathrm{D}}$ & specific rotation at $589 \mathrm{~nm}$ \\
\hline aq. & aqueous \\
\hline Ar & aryl \\
\hline atm & atmospheric pressure \\
\hline BHT & 2,6-di-tert-butyl-4-methylphenol \\
\hline BIES & base-assisted internal electrophilic substitution \\
\hline $\mathrm{Bn}$ & benzyl \\
\hline Boc & tert-butyloxycarbonyl \\
\hline $\mathrm{Bu}$ & butyl \\
\hline $\mathrm{Bz}$ & benzoyl \\
\hline calc. & calculated \\
\hline cat. & catalytic \\
\hline CMD & concerted-metalation-deprotonation \\
\hline conv. & conversion \\
\hline $\mathrm{Cp}^{*}$ & pentamethylcyclopentadienyl \\
\hline Cy & cyclohexyl \\
\hline $\mathrm{CyH}$ & cyclohexane \\
\hline$\delta$ & chemical shift \\
\hline d & doublet \\
\hline DCE & 1,2-dichloroethane \\
\hline dd & doublet of doublet \\
\hline DFT & density functional theory \\
\hline DG & directing group \\
\hline DME & dimethoxyethane \\
\hline $\mathrm{DMF}$ & $N, N$-dimethylformamide \\
\hline $\mathrm{dt}$ & doublet of triplet \\
\hline EI & electron ionization \\
\hline
\end{tabular}




\begin{tabular}{|c|c|}
\hline equiv & equivalent \\
\hline ES & electrophilic substitution \\
\hline ESI & electronspray ionization \\
\hline Et & ethyl \\
\hline FG & functional group \\
\hline $\mathrm{g}$ & gram \\
\hline GC & gas chromatography \\
\hline $\mathrm{h}$ & hour \\
\hline Hal & halogen \\
\hline Het & hetero atom \\
\hline Hept & heptyl \\
\hline Hex & hexyl \\
\hline HFIP & hexafluoro-2-propanol \\
\hline HPLC & high performance liquid chromatography \\
\hline HR-MS & high resolution mass spectrometry \\
\hline $\mathrm{Hz}$ & Hertz \\
\hline$i$ & iso \\
\hline IR & infrared spectroscopy \\
\hline IES & internal electrophilic substitution \\
\hline$J$ & coupling constant \\
\hline KIE & kinetic isotope effect \\
\hline $\mathrm{L}$ & ligand \\
\hline$m$ & meta \\
\hline $\mathrm{m}$ & multiplet \\
\hline M & molar \\
\hline$[\mathrm{M}]^{+}$ & molecular ion peak \\
\hline $\mathrm{Me}$ & methyl \\
\hline Mes & mesityl \\
\hline $\mathrm{mg}$ & milligram \\
\hline $\mathrm{MHz}$ & megahertz \\
\hline $\min$ & minute \\
\hline $\mathrm{mL}$ & milliliter \\
\hline mmol & millimol \\
\hline
\end{tabular}




\begin{tabular}{|c|c|}
\hline M. p. & melting point \\
\hline MS & mass spectrometry \\
\hline$m / z$ & mass-to-charge ratio \\
\hline NCTS & $N$-cyano-4-methyl- $N$-phenyl benzenesulfonamide \\
\hline NMC & $N$-Methylcaprolactam \\
\hline NMTS & $N$-cyano- $N$-(4-methoxy)phenyl- $p$-toluenesulfonamide \\
\hline NMP & $N$-methylpyrrolidinone \\
\hline NMR & nuclear magnetic resonance \\
\hline$o$ & ortho \\
\hline $\mathrm{OA}$ & oxidative addition \\
\hline OPV & oil pump vacuum \\
\hline$p$ & para \\
\hline $\mathrm{Ph}$ & phenyl \\
\hline $\mathrm{PhMe}$ & toluene \\
\hline PMP & para-methoxyphenyl \\
\hline Piv & pivaloyl \\
\hline ppm & parts per million \\
\hline $\operatorname{Pr}$ & propyl \\
\hline PTSA & $p$-Toluenesulfonic acid \\
\hline py & pyridyl \\
\hline pym & pyrimidine \\
\hline pyr & pyrazol \\
\hline q & quartet \\
\hline RT & room temperature \\
\hline $\mathrm{s}$ & singlet \\
\hline sat. & saturated \\
\hline SPS & solvent purification system \\
\hline$t$ & tert \\
\hline $\mathrm{t}$ & triplet \\
\hline $\mathrm{T}$ & temperature \\
\hline THF & tetrahydrofuran \\
\hline TLC & thin layer chromatography \\
\hline TM & transition metal \\
\hline
\end{tabular}




$\begin{array}{ll}\text { TMP } & \text { 3,4,5-trimethoxyphenyl } \\ \text { TMS } & \text { trimethylsilyl } \\ \text { Ts } & \text { para-toluenesulfonyl } \\ \text { TS } & \text { transition state } \\ t_{r} & \text { retention time } \\ w t \% & \text { weight percentage } \\ \mathrm{UV} & \text { ultraviolet } \\ \mathrm{X} & \text { (pseudo)halide }\end{array}$




\section{Table of Contents}

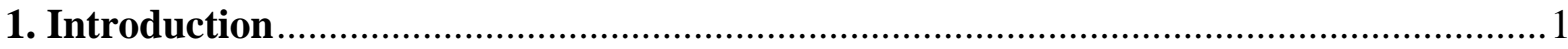

1.1. Transition Metal-Catalyzed C-H Activation .......................................................

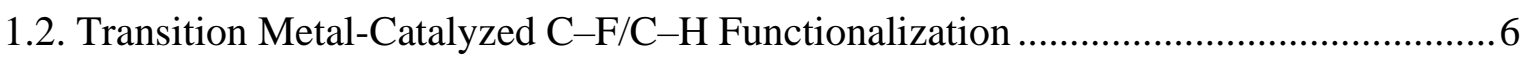

1.2.1. Precious Transition Metal-Catalyzed C-F Functionalization ..............................6

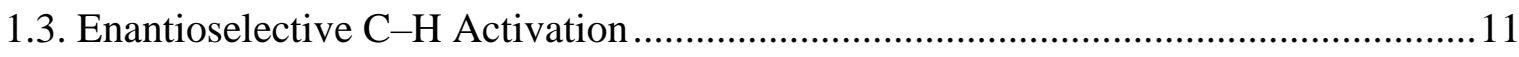

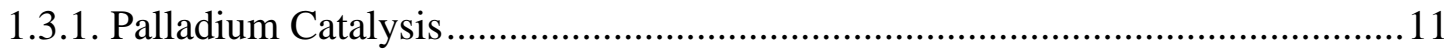

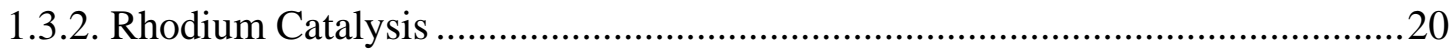

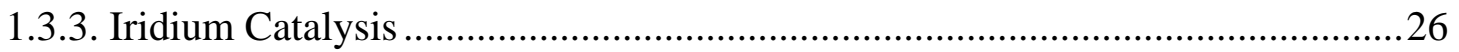

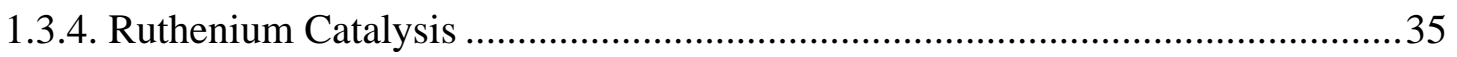

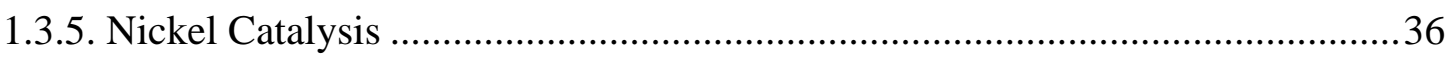

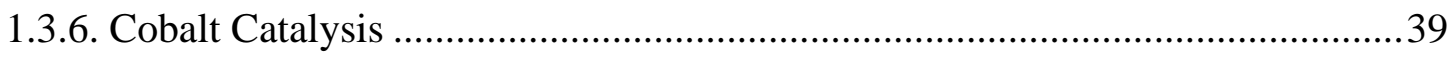

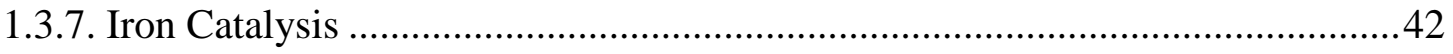

1.4. Transition Metal-Catalyzed Oxidative C-H Activation towards Resource Economy.44

1.4.1.1. Palladium-Catalyzed C-H Olefinations with Chemical Oxidants ..................44

1.4.1.2. Cobalt-Catalyzed C-H Activations with Chemical Oxidants ........................48

1.4.1.3. Copper-Catalyzed C-H activations with Chemical Oxidants .........................52

1.4.2. Electrochemical Transition Metal-Catalyzed C-H Activation ...........................56

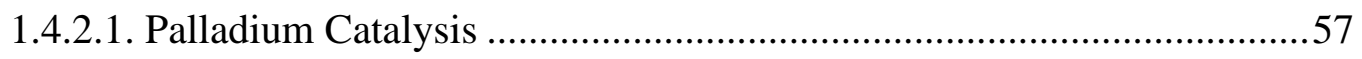

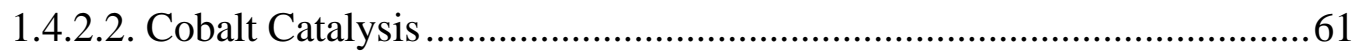

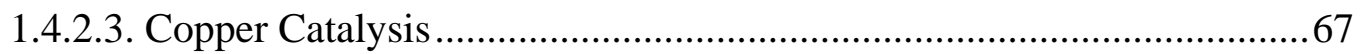

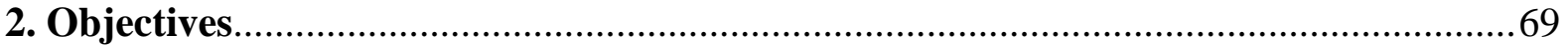

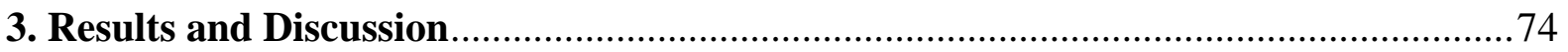

3.1. Manganese(I)-Catalyzed (Per)Fluoro-Allylative and Alkenylative C-F/C-H

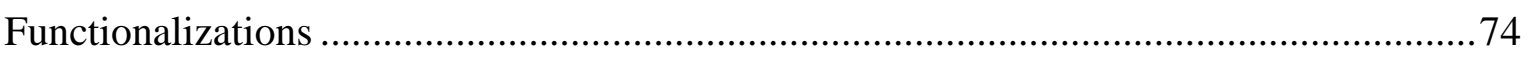

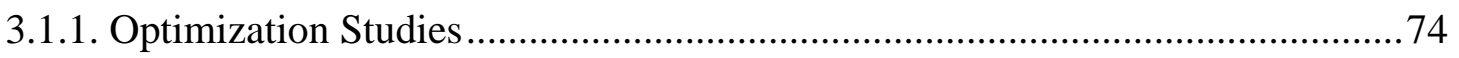

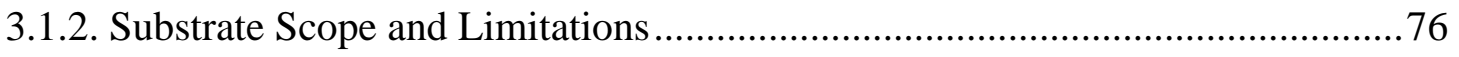

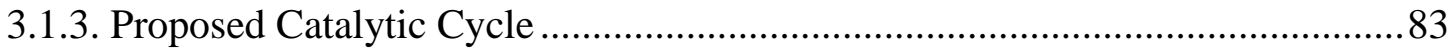

3.2. Ruthenium(II)-Catalyzed $E$-Selective Allylative C-F/C-H Functionalization ............85

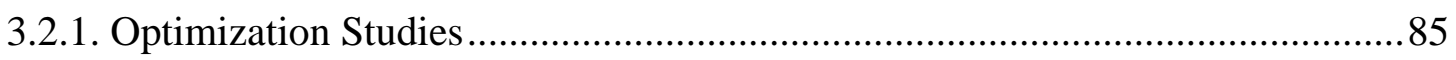

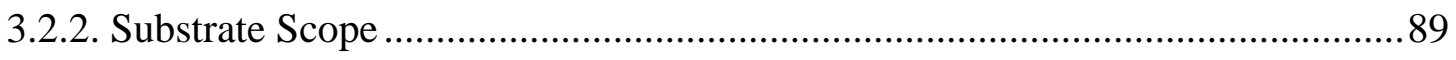

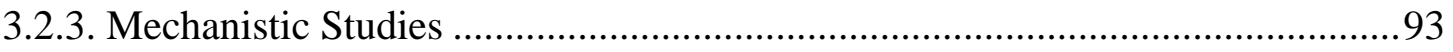

3.2.4. Proposed Catalytic Cycle ................................................................................. 95 
3.3. Enantioselective Cobalt(III)-Catalyzed C-H Activation .97

3.3.1. Optimization Studies....

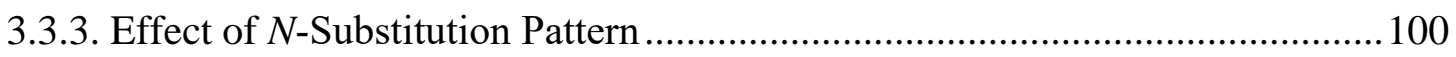

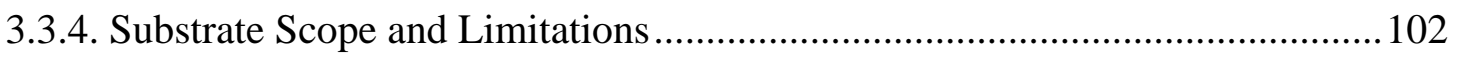

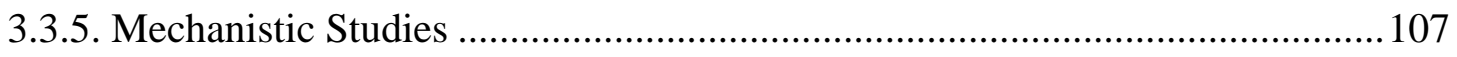

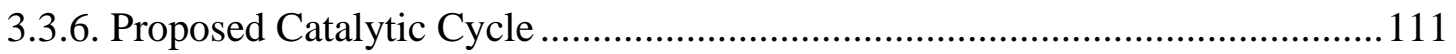

3.4. Ruthenium(II)-Catalyzed Enantioselective C-H Activation ...................................113

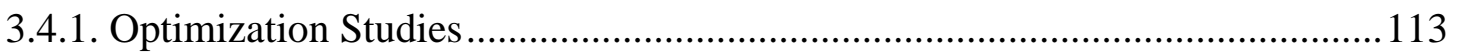

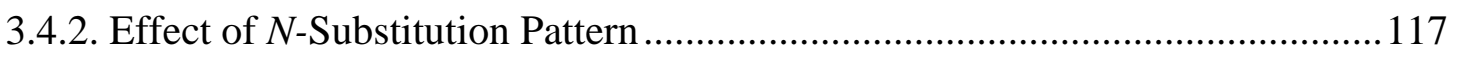

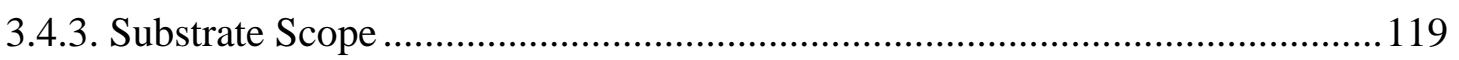

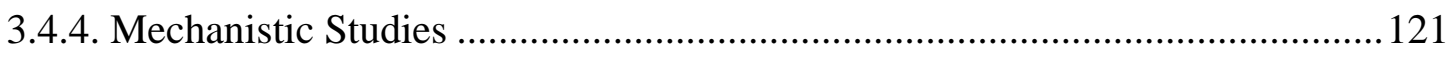

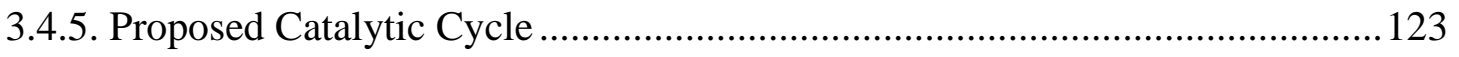

3.5. Copper-Catalyzed Alkyne Annulation by C-H Alkynylation .................................125

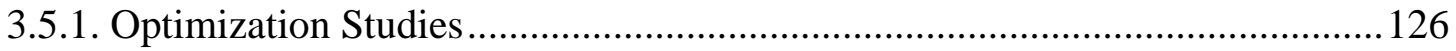

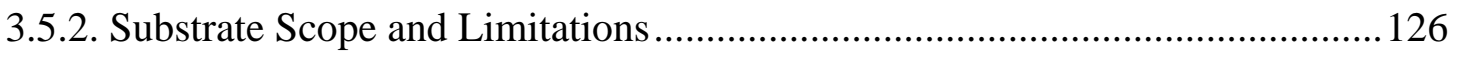

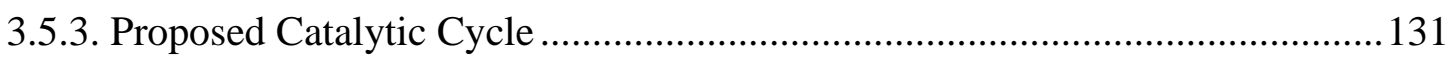

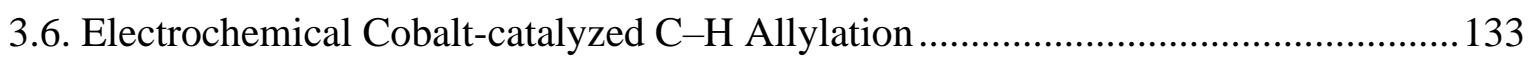

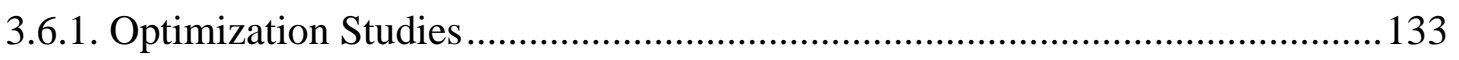

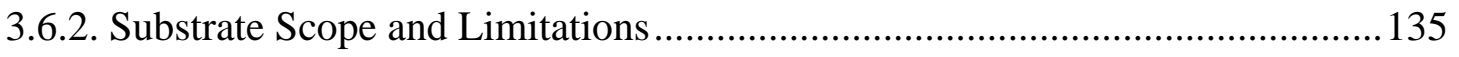

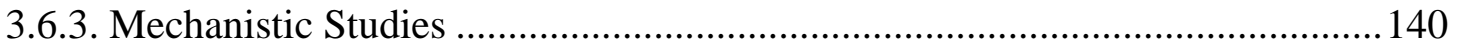

3.6.4. Proposed Catalytic Cycle ............................................................................... 143

3.7. Enantioselective Palladaelectro-Catalyzed C-H Activations ................................... 146

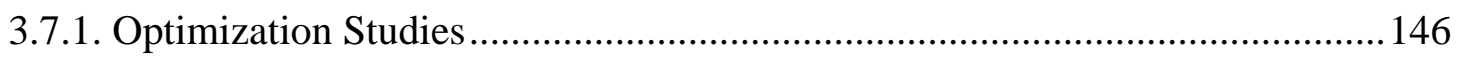

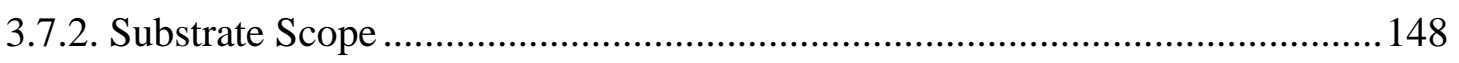

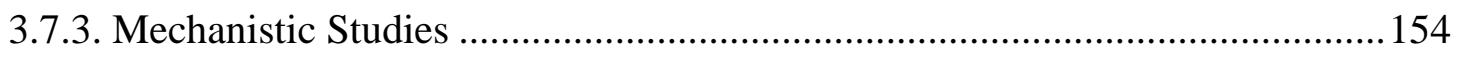

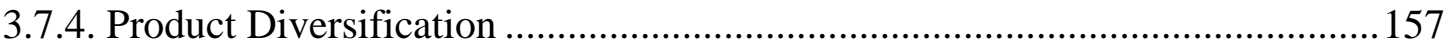

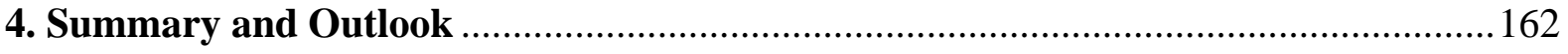

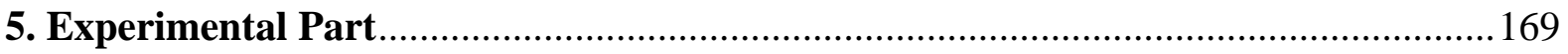

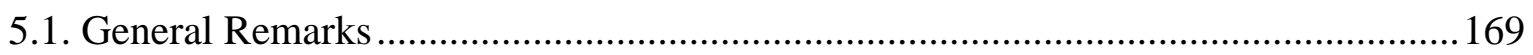

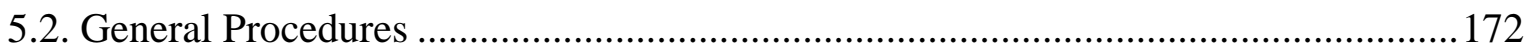

5.3. Manganese(I)-Catalyzed Allylative C-H/C-F Functionalization ............................ 177

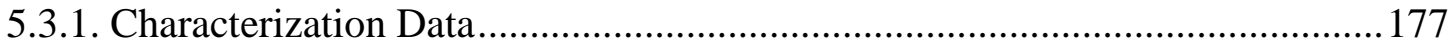

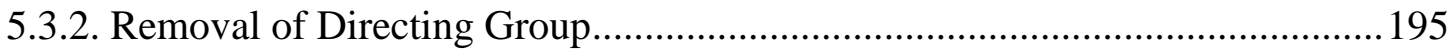

5.4. Ruthenium(II)-catalyzed C-F/C-H functionalization............................................. 196 
5.4.1. Characterization Data

5.4.2. Mechanistic Studies

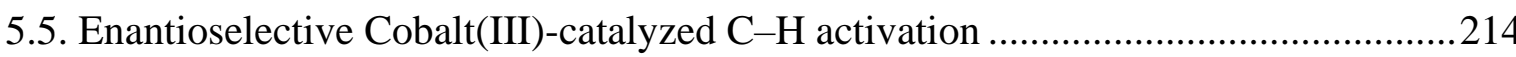

5.5.1. Analytical Data of Novel Chiral Acids ..........................................................214

5.5.2. Characterization Data of the Alkylated Products ...........................................218

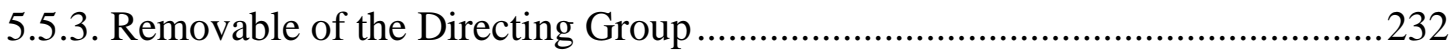

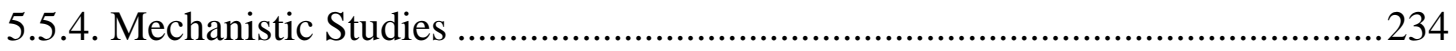

5.6. Ruthenium(II)-Catalyzed Enantioselective C-H Activation ...................................239

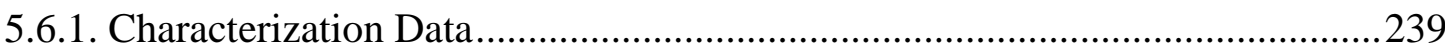

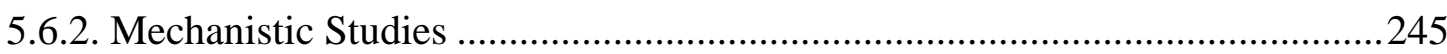

5.7. Copper-catalyzed Alkyne Annulation by C-H Alkynylation .................................249

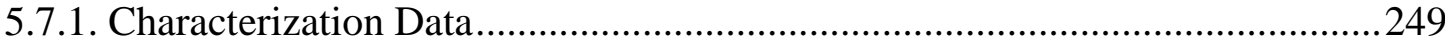

5.8. Electrochemical Cobalt-catalyzed C-H Allylation .................................................263

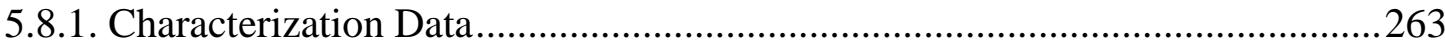

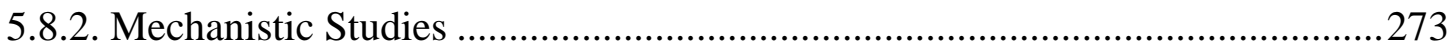

5.9 Enantioselective Palladaelectro-Catalyzed C-H Activations ...................................227

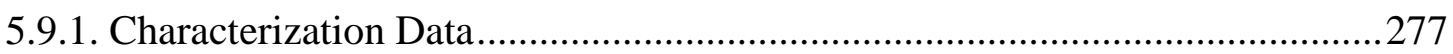

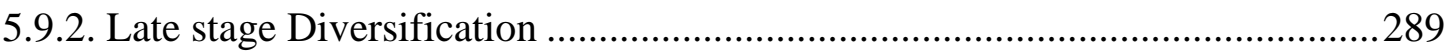

5.9.3. Mechanistic Studies for the Atroposelective C-H Activation .........................299

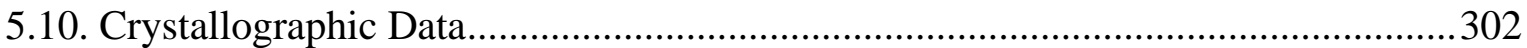

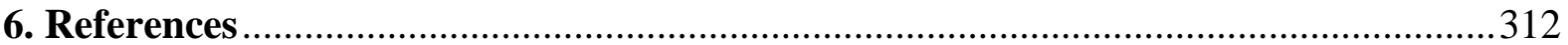

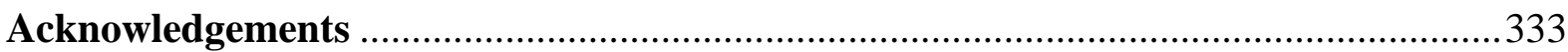

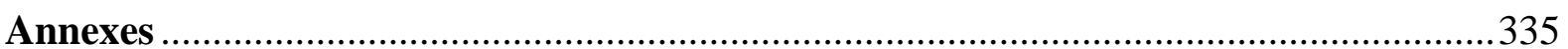





\section{Introduction}

Organic synthesis has paramount importance in science and society. Since the emergence of organic synthesis in early $19^{\text {th }}$ century as marked by revolutionary discovery of the preparation of urea by Wöhler in 1828 in Germany, ${ }^{[1]}$ organic synthesis has changed the world with its gigantic applications for the benefit of society. ${ }^{[2]}$ Organic synthesis has direct impact on several new domains ranging from the development of modern medicines to the production of nutritional goods, cosmetics, functional materials, including polymers, plastic, among others. Despite the vast applications of organic synthesis in resolving societal issues, there are rising concerns for the economical and environmental impact of its processes. Consumption of nonrenewable resources, including energy and materials, emissions of toxic and hazardous waste have detrimental effect on the environment. ${ }^{[3]}$

Thus, efforts have been devoted to the discovery and emergence of resource-economical, environmentally-benign strategies in the field of organic synthesis, ${ }^{[4]}$ providing the guidelines of green chemistry as put forwarded by Anastas and Warner in their 12 Principles of Green Chemistry. ${ }^{[5]}$ Among these guidelines, the application of catalytic processes rather than stoichiometric transformations, easily available starting materials, minimization of waste formations, mild reactions conditions are of prime importance to elevate the power of organic transformations to the standards of Nature and beyond. ${ }^{[6]}$

\subsection{Transition Metal-Catalyzed C-H Activation}

Initial discoveries in the rich history of transition metal-catalyzed cross-coupling reactions ${ }^{[7]}$ originate from the pioneering, 150 years old, reactions by Glaser ${ }^{[8]}$ and Ullman ${ }^{[9]}$ on copperpromoted or -catalyzed cross-coupling reactions. These intriguing studies set the stage for metal-catalyzed $\mathrm{C}-\mathrm{C} / \mathrm{C}-\mathrm{Het}$ bond forming reactions between two structural units. ${ }^{[10]}$ Nevertheless, starting from the 1950s palladium started to gain its market value with the development of well known palladium on charcoal ${ }^{[11]}$ and Lindlar catalysts. ${ }^{[12]}$ Later, Hafner discovered the famous Wacker process for the syntheses of acetaldehyde which became a benchmark study on exhibiting the potential of palladium in the synthesis of organic molecules. ${ }^{[13]}$ Meanwhile, Heck found the application of palladium catalyst in cross-coupling reactions with organomercurial compounds. ${ }^{[14]}$ Few years later, almost at the same time, Mizoroki ${ }^{[15]}$ and later $\operatorname{Heck}^{[16]}$ independently demonstrated palladium-catalyzed cross couplings between organic halides and alkenes, the Mizoroki-Heck reaction. With this pioneering study, the last five decades have witnessed a gigantic progress in metal-catalyzed 
cross-coupling reactions. A broad range of organometallic coupling partners has been employed, which has originated in a series of named reactions, like Suzuki-Miyaura, ${ }^{[17]}$ Negishi, ${ }^{[18]}$ Kumada-Corriu ${ }^{[19]}{ }^{H i y a m a},{ }^{[20]}$ Stille $^{[21]}$ and Sonogashira-Hagihara ${ }^{[22]}$ crosscoupling reactions. Furthermore, the Tsuji-Trost reaction ${ }^{[23]}$ and the Buchwald-Hartwig amination $^{[24]}$ should be mentioned in the context of palladium-catalyzed chemistry. These important discoveries and their highly practical applications both in academia and in industry were recognized with the 2010 Nobel Prize to Heck, Negishi and Suzuki for palladium catalyzed cross-coupling reactions. ${ }^{[25]}$

Despite enormous developments, transition metal-catalyzed cross-coupling reactions ${ }^{[26]}$ associated with several limitations. The need of the pre-functionalized starting materials as well as air- and moisture-sensitive organometallic coupling partners jeopardize the atom-economy and sustainability of this otherwise powerful approach. More importantly, the generation of stoichiometric, potentially toxic organometallic compounds as by-products are highly undesirable to conserve the environmental integrity.

In stark contrast, metal-catalyzed direct $\mathrm{C}-\mathrm{H}$ activation represents a more sustainable approach towards excellent atom- and step-economy, given the ubiquitous presence of $\mathrm{C}-\mathrm{H}$ bonds in organic molecules. ${ }^{[27]}$ Thereby, $\mathrm{C}-\mathrm{H}$ activation offers more environmentally-benign, practical approaches for large-scale syntheses without the lengthy prefunctionalization of starting materials, thereby providing improved step-economy and preventing concurrent undesired waste generation. Thus over the past years, transition metal catalyzed $\mathrm{C}-\mathrm{H}$ activation has surfaced as a powerful tool to improve the efficacy of molecular synthesis with notable applications in late-stage diversification, ${ }^{[28]}$ material sciences, ${ }^{[29]}$ and pharmaceutical industries, ${ }^{[30]}$ among others. Nevertheless, the applications of cost-effective Earth-abundant $3 \mathrm{~d}$ transition metals ${ }^{[31]}$ further enhance the sustainability of the $\mathrm{C}-\mathrm{H}$ activation ${ }^{[32]}$ approach (Scheme 1). 


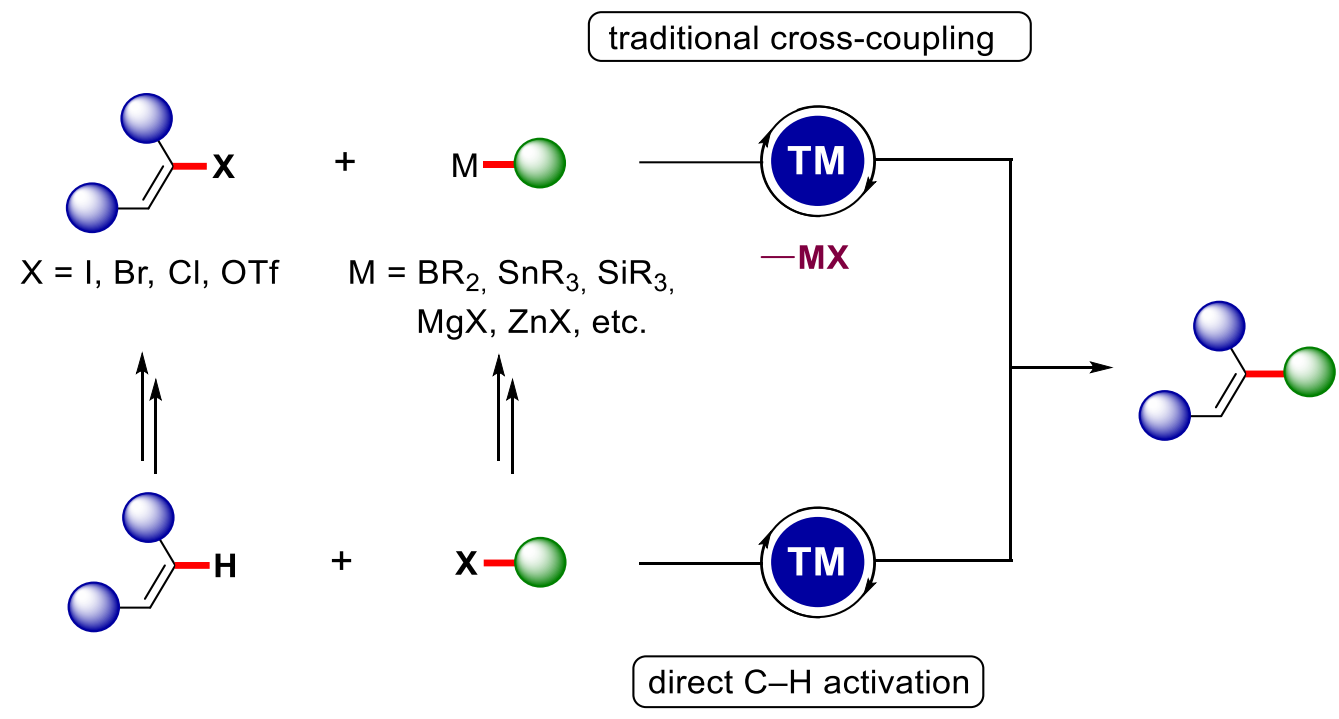

Scheme 1. Traditional cross-coupling $v s \mathrm{C}-\mathrm{H}$ Activation.

Despite the enormous importance of organometallic $\mathrm{C}-\mathrm{H}$ activation approach, the formation of $\mathrm{C}-$ Metal bond from $\mathrm{C}-\mathrm{H}$ bond is far more challenging as the $\mathrm{C}-\mathrm{H}$ bond is generally stronger than the $\mathrm{C}-\mathrm{X}$ bond. ${ }^{[33]}$ Thus, over the past years several studies have been directed towards elucidating the mechanistic pathways of the key $\mathrm{C}-\mathrm{H}$ activation step to enable better catalytic processes. In this respect, different modes of action have been proposed for the elementary $\mathrm{C}-\mathrm{H}$ metalation event. ${ }^{[34]}$ These include: a) the oxidative addition pathway is more feasible for late transition metal at lower oxidation states, where achieving higher oxidation states are much easier (Scheme 2a). b) In contrast, $\sigma$-bond metathesis is more prominent for early transition metals where concerted breaking of $\mathrm{C}-\mathrm{H}$ bond and formation of $\mathrm{C}-\mathrm{Met}$ bond occurs (Scheme 2b). c) Electrophilic substitution pathway is proposed for late transition metals in high oxidation states usually in polar medium (Scheme 2c). d) Like $\sigma$-bond metathesis, 1,2addition pathways are more feasible for early transition metals featuring multiple unsaturated double bonds (Scheme $2 \mathrm{~d}$ ). This type of pathway operates via $\left[2{ }_{\sigma}+2 \pi\right]$ reaction. e) Finally, the most common pathway is the base-assisted $\mathrm{C}-\mathrm{H}$ cleavage, where generally carboxylate bases $^{[34 a]}$ are involved in the proton abstraction (Scheme 2e). 
(a) oxidative addition

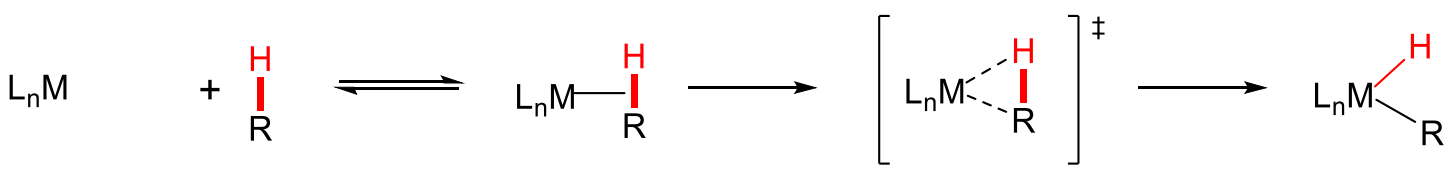

(b) $\sigma$-bond metathesis

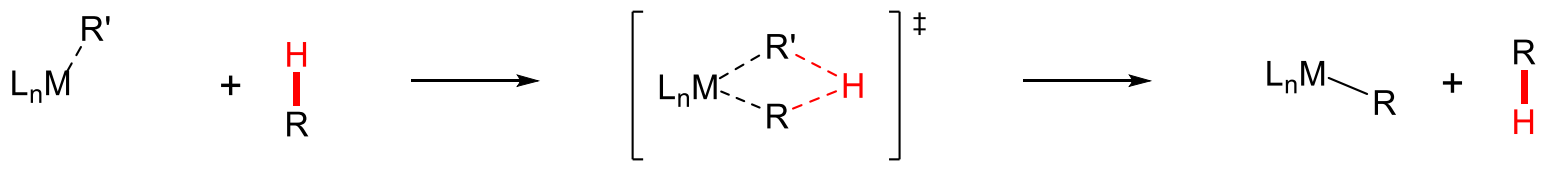

(c) electrophilic substitution

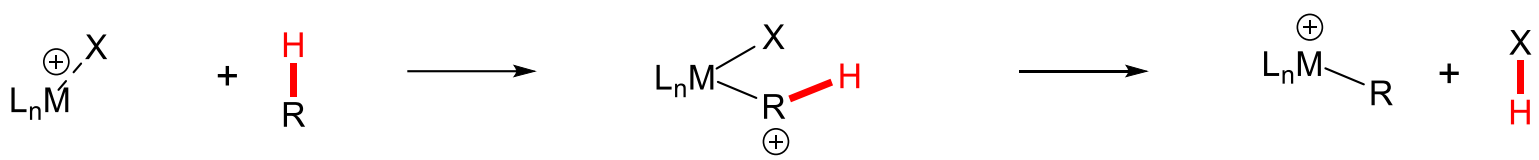

(d) 1,2-addition

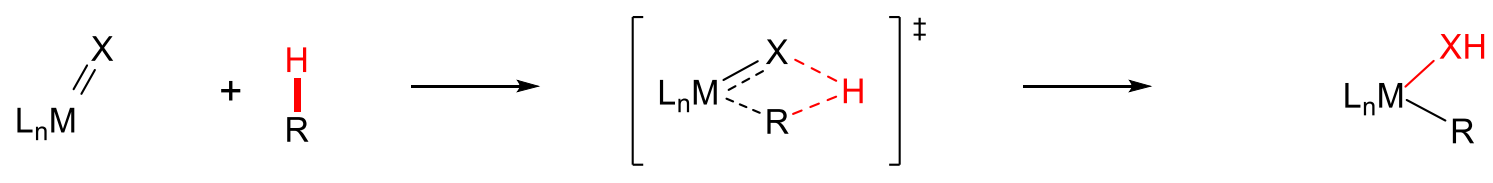

(e) base assisted metalation
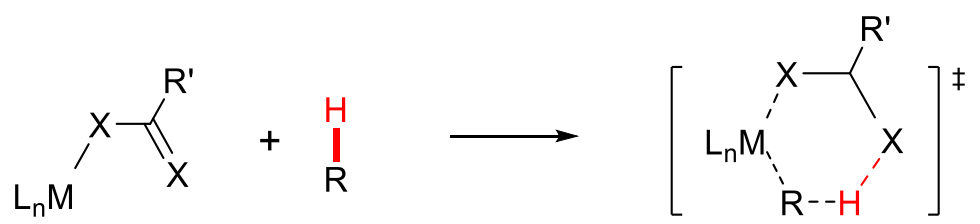<smiles>[R][Y4]([R])=[X]([R])[H]</smiles>

Scheme 2. Mechanistic pathways for organometallic $\mathrm{C}-\mathrm{H}$ activation.

Consequently, base-assisted $\mathrm{C}-\mathrm{H}$ metalation has been studied in greater details, giving rise to several distinct pathways. Among them, CMD (concerted metalation deprotonation) or AMLA (ambiphilic metal-ligand activation) and BIES (base-assisted internal electrophilic substitution) pathways have been suggested. The term CMD was named by Fagnou/Gorelsky, ${ }^{[35]}$ whereas AMLA was disclosed through computational studies by MacGregor/Davies, ${ }^{[36]}$ although both mechanism presents similar six-membered transition state, where both metalation and deprotonation occur simultaneously. While for BIES mechanism ${ }^{[37]}$ which was introduced by Ackermann, electrophilic substitution type $\mathrm{C}-\mathrm{H}$ activation occurs by carboxylate additives. In contrast to CMD/AMLA, the selectivity of BIES type $\mathrm{C}-\mathrm{H}$ activation is not controlled by kinetic $\mathrm{C}-\mathrm{H}$ acidity (Scheme 3 ). 


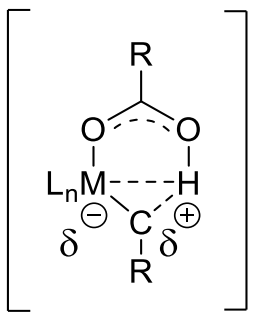

CMD/AMLA

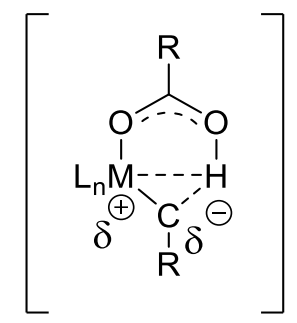

BIES

Scheme 3. Comparison of transition state structures in base-assisted metalation.

The control of regioselectivity remains an arduous task owing to subtle reactivity difference of omnipresent $\mathrm{C}-\mathrm{H}$ bonds. Nonetheless, in recent years several strategies have evolved to address this challenging issue. These include: a) the substrate's electronic bias by exploiting its inherent more acidic positions. b) Likewise, steric bias forces the activation at the less hindered $\mathrm{C}-\mathrm{H}$ bond. Unfortunately, these strategies depend on the nature of the substrates, thereby minimizing its generality. In this regard, introduction of directing group (DG) ${ }^{[27 d, 38]}$ with Lewis basic functionalities plays a crucial role for proximity-induced $\mathrm{C}-\mathrm{H}$ activations (Scheme 4). In addition, the elegant use of the functional groups embedded within the molecules, as directing groups is an alternative atom-economical approach. Thus, considerable efforts have been made towards weakly co-ordinating ${ }^{[39]}$ and removable directing groups. ${ }^{[40]}$

(a) electronic bias<smiles>[X]c1[X]c2ccccc2[nH]1</smiles>

(b) steric bias

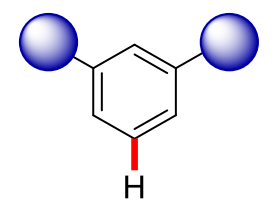

(c) directing group

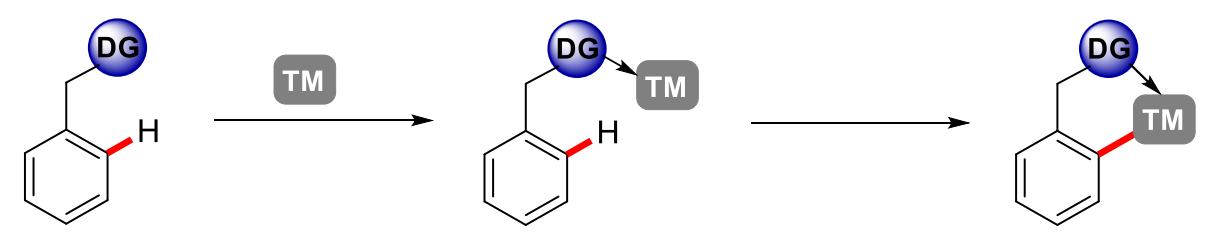

Scheme 4. Selectivity-control in $\mathrm{C}-\mathrm{H}$ activation.

Moreover, recently transient directing groups have gained considerable attention as it avoids the additional steps to install and remove the DG, instead it generates in situ DG in a reversible transient manner. ${ }^{[41]}$ 


\subsection{Transition Metal-Catalyzed $\mathrm{C}-\mathrm{F} / \mathrm{C}-\mathrm{H}$ Functionalization}

Fluorinated organic compounds have gained considerable attention in pharmaceutical, agrochemical and material sciences due to their unique chemical and physical properties. ${ }^{[42]}$ The installation of the small, highly electronegative fluorine atom on organic compounds significantly enhances their solubility and metabolic stability. ${ }^{[43]}$ Notably, fluoroalkenes are considered as important fluorinated molecules due to their enhanced biological properties. ${ }^{[44]}$ Therefore, there is a strong demand to get access to the fluorinated building blocks. Among various routes to synthesis fluorinated scaffolds, transition metal-catalyzed fluorination reactions have emerged as a promising approach. ${ }^{[43 a, 45]}$ Alternatively, the selective activation of $\mathrm{C}-\mathrm{F}$ bonds is step-economical route to synthesize highly functionalized fluorinated molecules. ${ }^{[42 a, 42 b]}$ In this context readily available polyfluorinated molecules can be selectively derivatized to form the $\mathrm{C}-\mathrm{C}$ bonds by transition metal-mediated $\mathrm{C}-\mathrm{F}$ bond activation. ${ }^{[46]}$

\subsubsection{Precious Transition Metal-Catalyzed C-F Functionalization}

An early example of defluorinative coupling of 1,1-difluoroethylene with aryl halides was elegantly achieved using palladium as catalyst by Heitz in 1991. ${ }^{[47]}$ In their pioneering contribution, an arylpalladium(II) iodide species was formed in the presence of triethylamine which underwent insertion into 1,1-difluoroethylene $\mathbf{1}$ to form $\beta$, $\beta$-difluorinated phenethylpalladium(II) species (Scheme 5). Thus, the formed palladium(II) species readily underwent $\beta$-fluorine elimination to furnish $\alpha$-fluorostyrenes $\mathbf{3}$, synthetically valuable building blocks for fluoropolymers.

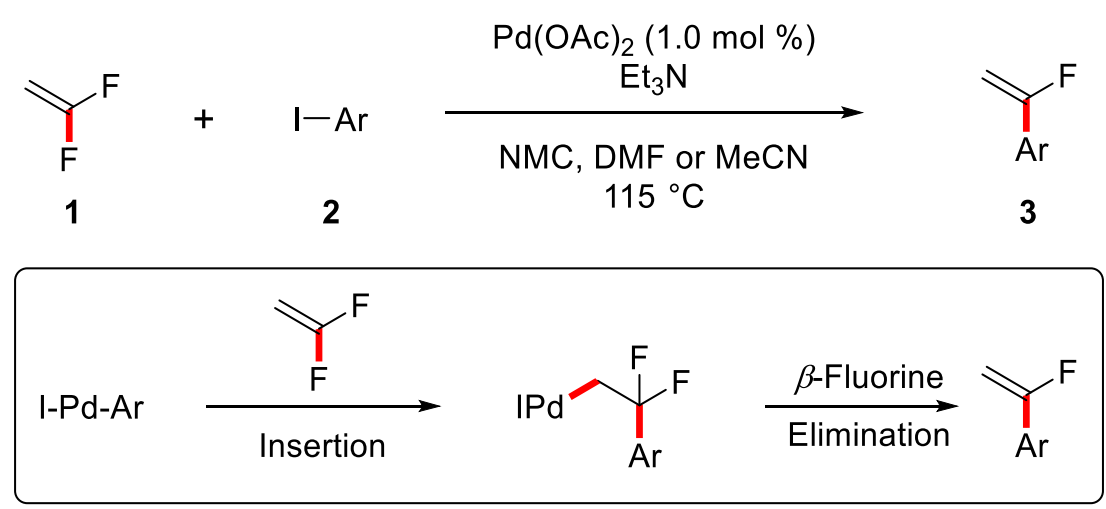

Scheme 5. Palladium-catalyzed defluorinative coupling through $\beta$-fluoro elimination.

After a decade, in 2005 Ichikawa reported an intramolecular Heck-type 5-endo-trig cyclization of oxime derivatives containing 1,1-difluoro-1-alkene motifs 4. ${ }^{[48]}$ A combination of $\mathrm{Pd}\left(\mathrm{PPh}_{3}\right)_{4}$ and $\mathrm{PPh}_{3}$ enabled the facile $\beta$-fluorine elimination for the synthesis of 5-fluoro-3H-pyrroles 5 (Scheme 6a). Later, the same group extended this strategy to 2-(trifluoromethyl)allyl ketone $O$ - 
pentafluorobenzoyloximes 6 for Heck-type of cyclization to form exo-difluoromethylene 7 unit via exclusively $\beta$-fluorine elimination (Scheme $6 \mathrm{~b}$ ). ${ }^{[49]}$ These elegant findings through fluorine elimination set the stage for further developments in the area of transition metal-catalyzed $\mathrm{C}-$ F bond activation.

(a)<smiles>[R]C(=NOC(=O)OCC)C([R])([R])C(=O)F</smiles>

4

(b)<smiles>[R5]C=C(C(F)(F)F)C([R])([R])C([R])=NO[O+]</smiles>

6

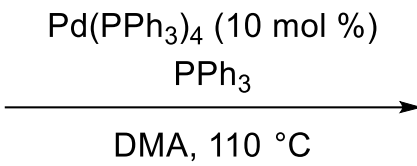

DMA, $110^{\circ} \mathrm{C}$

DMA, $100^{\circ} \mathrm{C}$

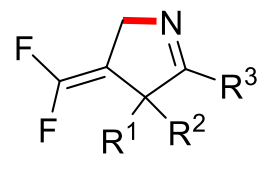

7

Scheme 6. Heck-type 5-endo-cyclization.

Taking inspiration from these studies, insertion of fluoroalkenes into metal species have been intensively studied in recent years. ${ }^{[46]}$ Transmetalation of organometallic reagents from main group elements to transition metals is the key step, preceding the insertion into the fluoroalkenes. It is noteworthy to mention that this type of reactivity is largely restricted to organosilicon and organoboron compounds. In an early report in 2008, Murakami showed the potential of rhodium catalysis for the formation of arylrhodium(I) species with aryl boronic esters 9 which underwent insertion into $\mathrm{C}-\mathrm{C}$ double bond and subsequently selective $\beta$-fluorine elimination delivered gem-difluoroalkenes $\mathbf{1 0}$ (Scheme 7). ${ }^{[50]}$

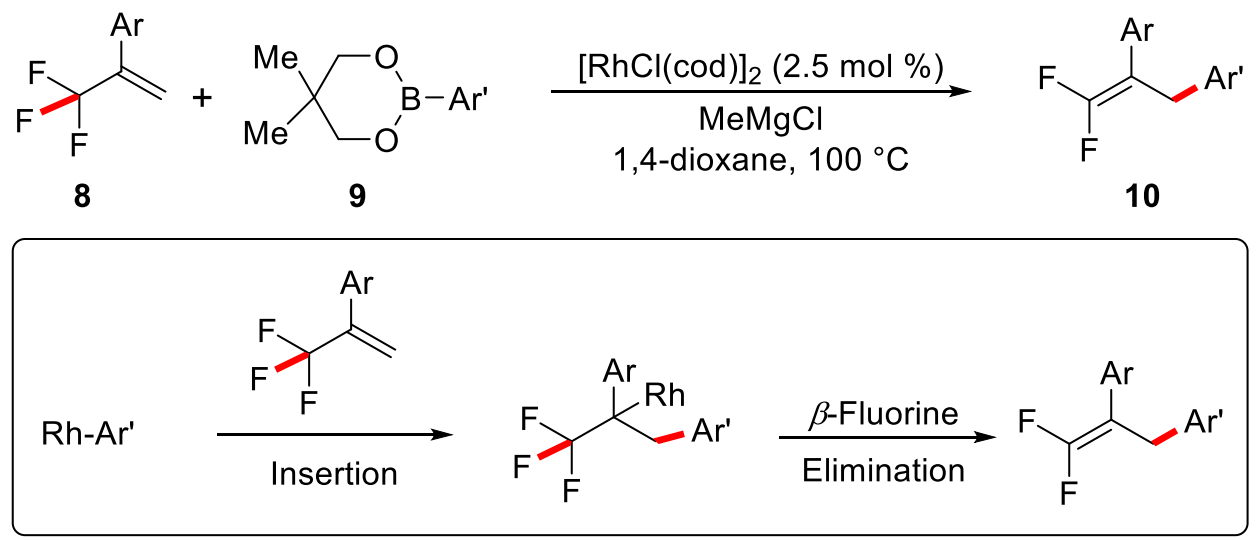

Scheme 7. Rhodium-catalyzed arylation by $\beta$-fluorine elimination.

Later, Toste described redox-neutral process for the palladium-catalyzed defluorinative coupling of 1-aryl-2,2-difluoroalkenes 11 with boronic acids $\mathbf{1 2}$ via $\beta$-fluoride elimination to 
synthesis monofluoroalkene 13 building blocks (Scheme 8). ${ }^{[51]}$ Notably, these mild reaction conditions tolerated various sensitive functional groups to afford monofluorostilbene products with excellent diastereoselectivity.

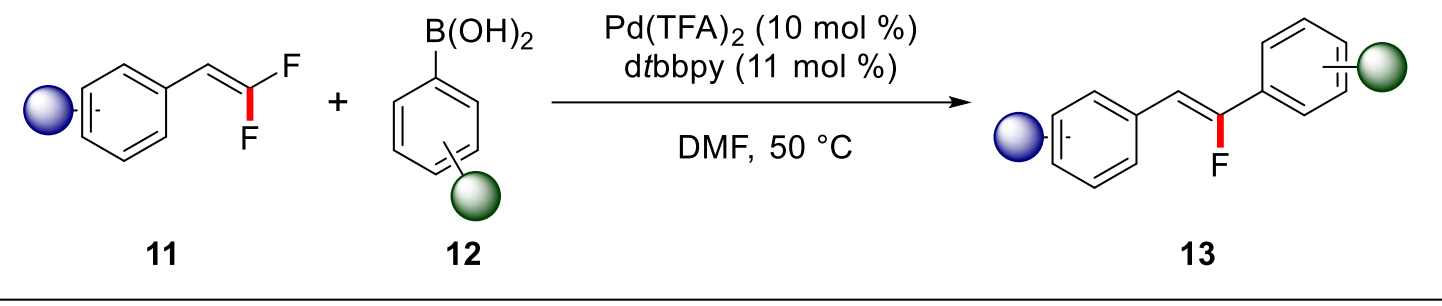<smiles>FC(=Cc1ccc2c(c1)OCO2)c1ccccc1</smiles>

$62 \%$<smiles>Cc1ccc(/C=C(\F)c2ccc(CO)cc2)cc1Br</smiles>

$47 \%$<smiles>CC(C)(C)OCc1ccc(Nc2cccc(C(F)=Cc3ccc(C(C)(C)C)cc3)c2)cc1</smiles>

$59 \%$

Scheme 8. Palladium-catalyzed defluorinative coupling.

Recently, the merger of $\mathrm{C}-\mathrm{F}$ activation with challenging $\mathrm{C}-\mathrm{H}$ cleavage has become a research area of topical interest for the synthesis of highly valuable fluorinated scaffolds. Loh made a significant advancement in this research area by achieving $\mathrm{C}-\mathrm{F} / \mathrm{C}-\mathrm{H}$ activation using $\mathrm{Cp} * \mathrm{Rh}(\mathrm{III})$ catalyst (Scheme 9). ${ }^{[52]}$ The authors utilized redox-neutral conditions for the $\alpha$ fluoroalkenylation with 1,1-difluoro-1-alkenes 11 through chelation-directed rhodium(III)catalyzed $\mathrm{C}-\mathrm{H}$ bond cleavage of (hetero)arenes 14. Notably, in situ generated hydrogen fluoride had beneficial effect in the outcome of the reaction possibly due to the hydrogen bond involvement in the activation of $\mathrm{C}-\mathrm{F}$ bond.

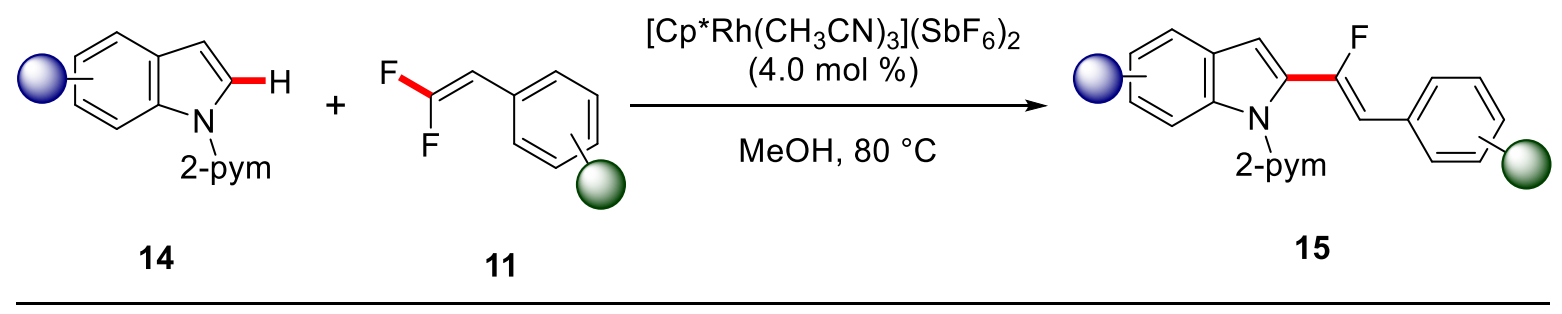<smiles>COc1ccc(/C=C(\F)c2cc3c(C(C)=O)cccc3n2[TeH])cc1</smiles>

$64 \%$
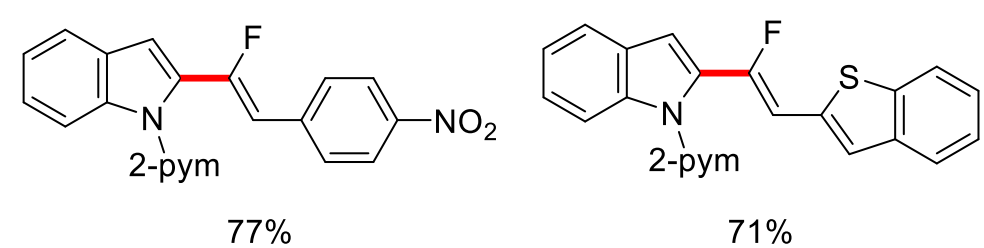

Scheme 9. Rhodium-catalyzed C-H/C-F activation. 
In 2017, Li and Wang achieved the synthesis of different types of fluorinated heterocycles by directing group governed distinct reactivities (Scheme 10). ${ }^{[33]}$ The authors employed a $\mathrm{Cp} * \mathrm{Rh}(\mathrm{III})$ complex with 2,2-difluorovinyl tosylate 17 as the coupling partner to control the selectivity over $\mathrm{C}-\mathrm{N}$ formation versus $\beta$-fluorine elimination, by using $\mathrm{N}-\mathrm{OMe}$ and $\mathrm{N}-\mathrm{OPiv}$ benzamides 16 and 19. Annulated dihydroisoquinolin-1(2H)-ones 18 bearing a gem-difluorides substituent at the $\mathrm{C} 4$ position were formed when $\mathrm{N}-\mathrm{OPiv}$ benzamides were used whereas for $\mathrm{N}-\mathrm{OMe}$ benzamide, mono fluoroalkene $\mathbf{2 0}$ was formed by $\beta$-fluorine elimination which was further treated under acidic condition to afford 4-fluoroisoquinolin-1(2H)-one 21. In addition, this reaction protocol tolerated a wide range of functional groups under mild reaction conditions.

(a) Synthesis of gem-difluorinated dihydroisoquinolin1(2H)-ones

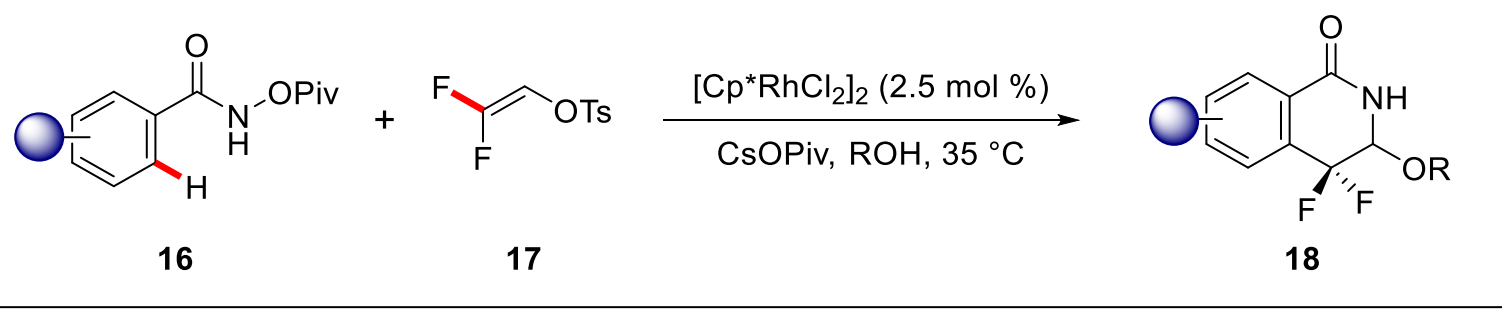<smiles>COC1NC(=O)c2ccccc2C1(F)F</smiles>

$71 \%$<smiles>COC1NC(=O)c2cc(Br)ccc2C1(F)F</smiles>

$73 \%$<smiles>COC1NC(=O)c2cc(C)c([N+](=O)[O-])cc2C1(F)F</smiles>

$59 \%$<smiles>O=C1NC(OPO)C(F)(F)c2ccccc21</smiles>

$56 \%$

(b) Synthesis of 4-fluoroisoquinolin-1(2H)-ones

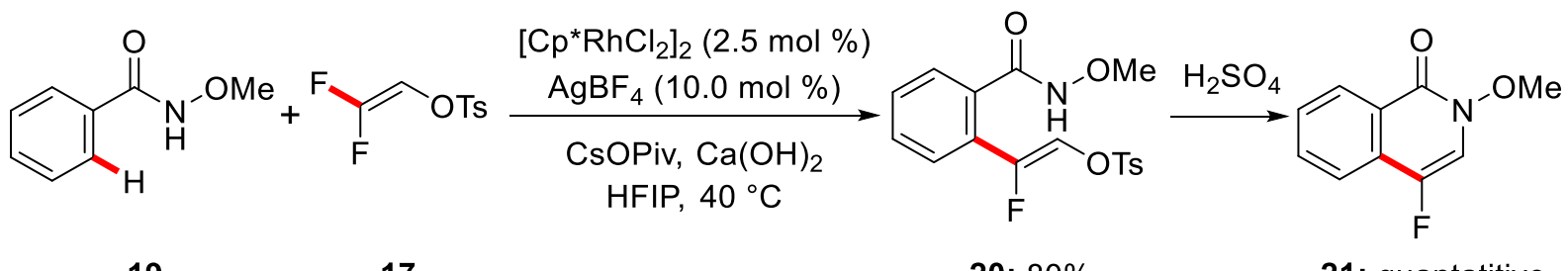

19

17

20: $80 \%$

21: quantatitive

Scheme 10. Rhodium-catalyzed coupling of benzamides with 2,2-difluorovinyl tosylate 17.

Shortly thereafter, Wang and Loh presented a unique way to synthesize five membered lactams 23 using $\alpha, \alpha$-difluoromethylene alkynes 22 via $\mathrm{Cp} * \mathrm{Rh}(\mathrm{III})$-catalyzed two fold $\mathrm{C}-\mathrm{F}$ bond cleavage (Scheme 11). ${ }^{[54]}$ Oxidant-free reaction conditions were employed for the defluorinative [4+1] annulation reaction for the synthesis of alkynyl substituted isoindolin-1ones 23. A plethora of $\alpha, \alpha$-difluoromethylene alkynes 22 worked efficiently as one carbon reaction partner with a migration of $\mathrm{C}-\mathrm{C}$ triple bond. It should be duly noted that this 
methodology presents one of the scarce examples in the literature where sp carbon atom of alkyne was used as a one-carbon coupling partner.

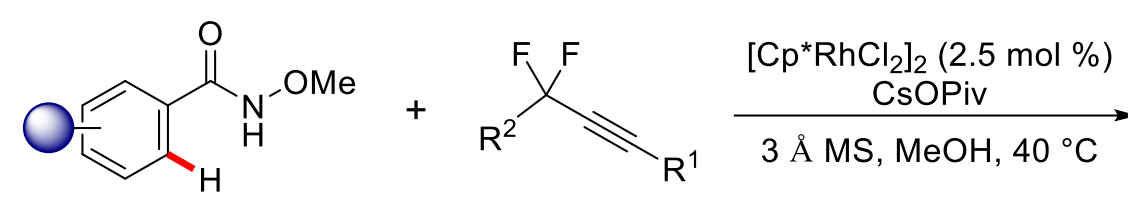

19<smiles>CON1C(=O)c2ccccc2C1(Br)C#CCc1ccccc1</smiles>

$85 \%$<smiles>[R]C#CC1([R])c2ccccc2C(=O)N1OC</smiles>

23<smiles>CCCCCCCC#CC1(C(=O)O)c2cc(C(C)(C)C)ccc2C(=O)N1OC</smiles>

$77 \%$

Scheme 11. Cp*Rh(III)-catalyzed [4+1] annulation via C-F Bond activation.

In 2018, an iridium(III)-catalyzed double $\mathrm{C}-\mathrm{H}$ functionalization of $\mathrm{C}\left(\mathrm{sp}^{2}\right)-\mathrm{H}$ and $\mathrm{C}\left(\mathrm{sp}^{3}\right)-\mathrm{H}$ bonds of anisoles was reported (Scheme 12). ${ }^{[55]}$ A catalytic combination of $\mathrm{Cp} * \operatorname{Ir}(\mathrm{III})$ complex 25 and ancillary sulfoxide ligand 22 was employed to enable the sequential cleavage of $\mathrm{C}-\mathrm{H}$ bonds of anisoles 24. The authors proposes a $\beta$-fluorine elimination which leads to the formation of fluoroallene species and in the following steps, subsequent $\beta$-H elimination delivered the chromene scaffolds $\mathbf{2 8}$. Likewise, a wide array of anisoles $\mathbf{2 4}$ and difluoroalkynes 22 were tested which were efficiently coupled to from the chromene products 28 .

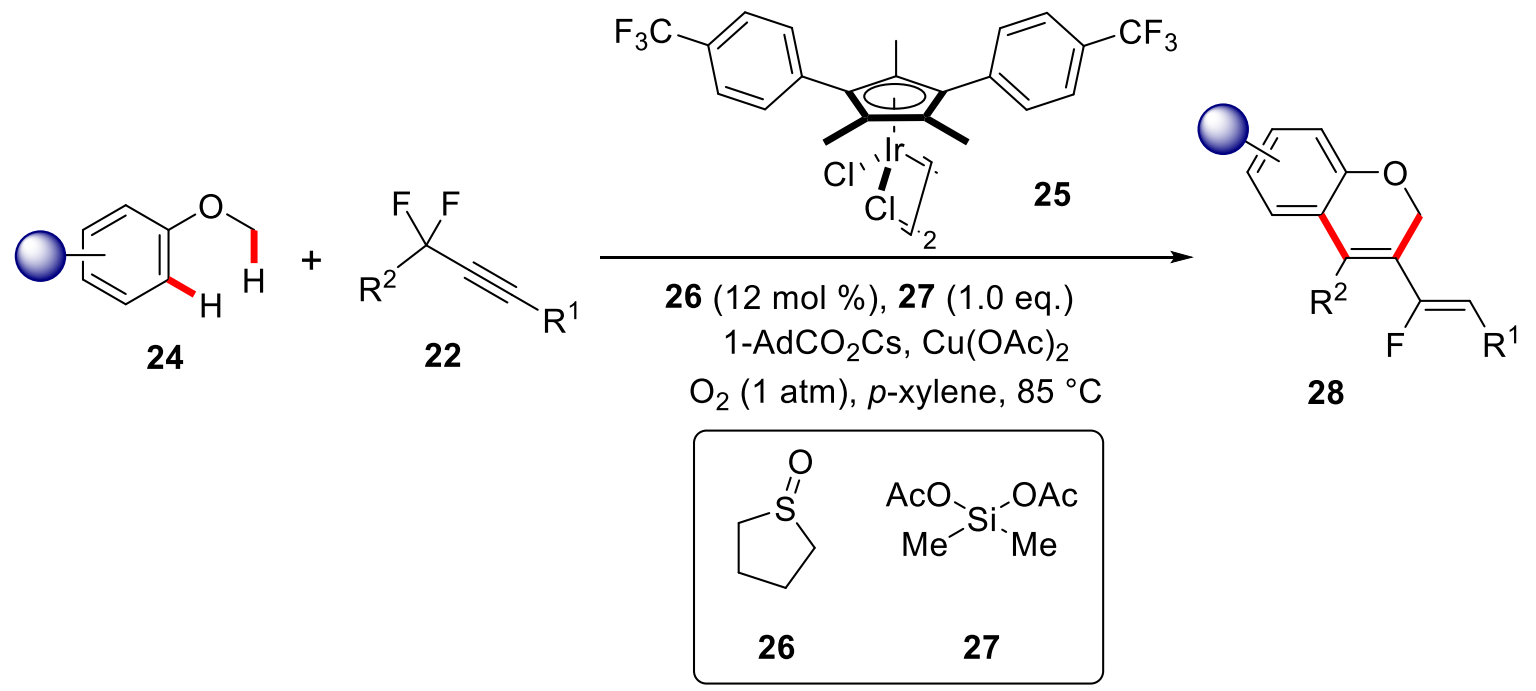

Scheme 12. Iridium-catalyzed double $\mathrm{C}-\mathrm{H}$ bond activation of anisoles $\mathbf{2 4}$. 


\subsection{Enantioselective $\mathrm{C}-\mathrm{H}$ Activation}

The direct activation of inert $\mathrm{C}-\mathrm{H}$ bonds represents a very attractive, atom- and step-economic approach for providing new synthetic transformations. ${ }^{[27,56]}$ However, enantioselective $\mathrm{C}-\mathrm{H}$ functionalization represents a valuable strategy for the construction of complex chiral compounds from simple precursors by selectively activating particular $\mathrm{C}-\mathrm{H}$ bonds. Thus, over the past years transition metal complexes have been identified as powerful catalysts for the enantioselective $\mathrm{C}-\mathrm{H}$ functionalization reactions. ${ }^{[57]}$ In this context, $4 \mathrm{~d}$ and $5 \mathrm{~d}$ transition metals were mainly employed to enable full selectivity control. ${ }^{[58]}$ With the rising concerns for the prices and toxicities of precious transition metals, recent focus has shifted towards Earthabundant and cost-effective transition metals ${ }^{[31]}$ for successful execution of stereocontrolled organometallic $\mathrm{C}-\mathrm{H}$ activations. ${ }^{[59]}$ In addition to organometallic $\mathrm{C}-\mathrm{H}$ activations, outersphere processes have also been realized which do not involve the formation of direct metalcarbon bond. ${ }^{[60]}$ This type of mechanism is more prominent for metal-carbenoid and -nitrenoid insertion reactions (Scheme 13). ${ }^{[61]}$ So, outer-sphere mechanisms are not discussed here.

(a) Inner-sphere mechanism

[M]

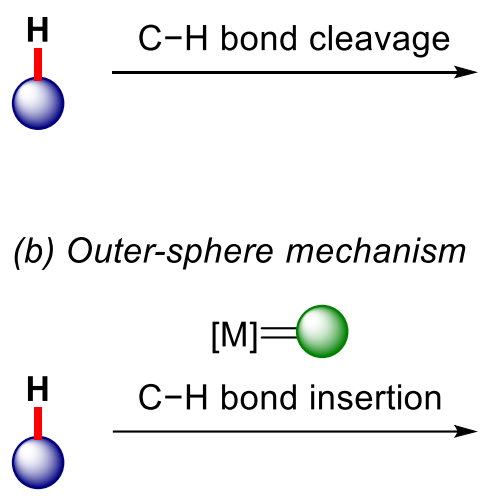

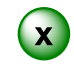

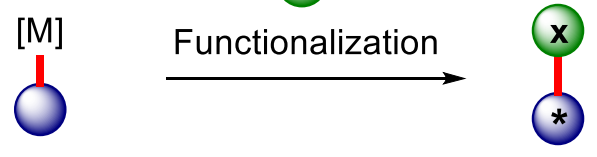

Scheme 13. Mechanistic classification for enantioselective $\mathrm{C}-\mathrm{H}$ activations.

\subsubsection{Palladium Catalysis}

Since the pioneering studies by Sokolov in 1977 on the introduction of mono-protected chiral amino acids for the enantioselective stoichiometric $\mathrm{C}-\mathrm{H}$ palladation (Scheme 14), ${ }^{[62]}$ palladium has become the most commonly applied transition metal for enantioselective organometallic $\mathrm{C}-\mathrm{H}$ activations. Consequently, a large variety of chiral ligands have evolved for a successful outcome of palladium-catalyzed $\mathrm{C}-\mathrm{H}$ activation reactions, with commonly used phosphorusbased ligands, such as TADDOL, BINOL and BINAP as well as monoprotected amino acids (MPAA). ${ }^{[63]}$ 


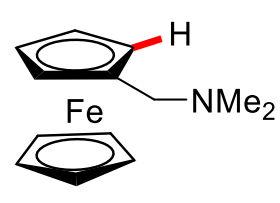

29

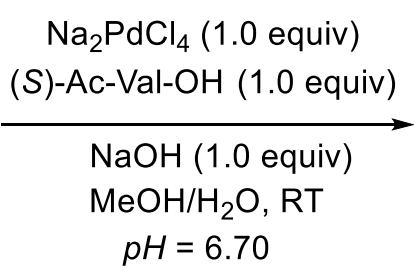

$p H=6.70$

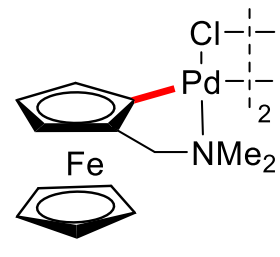

30: $89 \%, 65 \%$ ee

Scheme 14. Enantioselective stoichiometric C-H palladation of ferrocene 29.

\subsubsection{Phosphorus-Based Ligands}

In 2009, Cramer achieved enantioselective palladium(0)/palladium(II) $\mathrm{C}-\mathrm{H}$ functionalization in an intramolecular desymmetrization reaction. ${ }^{[64]}$ The authors utilized a TADDOL-derived monodentate phosphine $\mathbf{3 2}$ ligand to induce high enantioselectivity for intramolecular arylation with vinyl triflates $\mathbf{3 1}$. This protocol provided access to a wide variety of chiral indane motifs 33 containing quaternary stereogenic centers with high enantioselectivities (Scheme 15a). Later, a phosphoramidite-type of TADDOL based ligand $\mathbf{3 5}$ proved viable for the arylation of bromides 34 in the formation of dibenzazepinones $\mathbf{3 6}$ (Scheme 15b). ${ }^{[65]}$ 
(a) Arylation with vinyl triflates

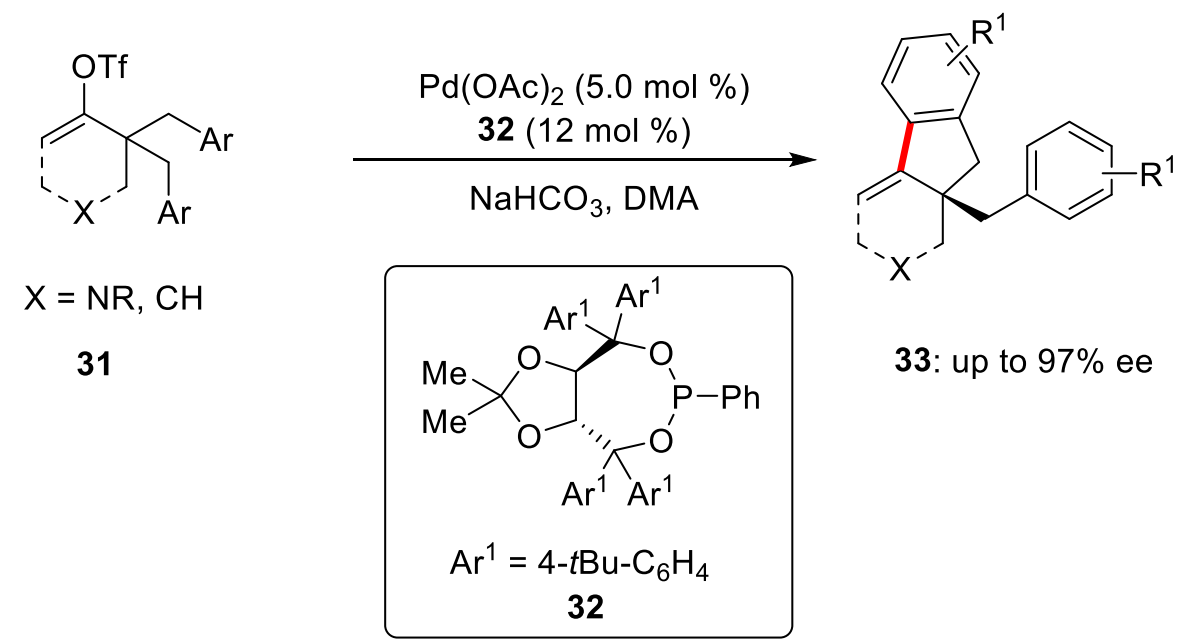

(b) Asymmetric synthesis of dibenzazepinones<smiles>[R]Cc1ccc(C([R])(C(=O)N([R])c2ccc[R1](Br)c2Br)c2ccc([R4])cc2)cc1</smiles>

34

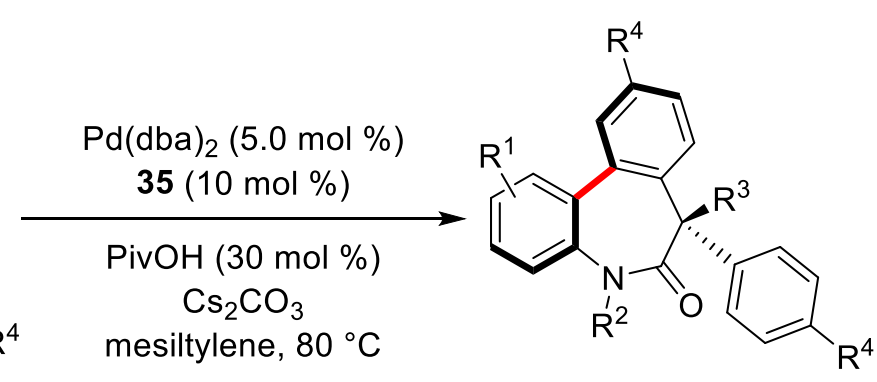

36: up to $95 \%$ ee<smiles>CN(C)P1OC(c2ccccc2)(c2ccccc2)C2OC(C)(C)O[C@H]2C1(c1ccccc1)c1ccccc1</smiles>

Scheme 15. Palladium-catalyzed enantioselective intramolecular arylation.

The potential of TADDOL-based ligands was also shown towards the formation of $P$ stereogenic phosphinic amides, as independently reported by Duan ${ }^{[66]}$ and Ma. ${ }^{[67]}$ Also, Gu reported TADDOL ligand-facilitated asymmetric induction in an atroposelective cyclization protocol. ${ }^{[68]}$

In addition, SPINOL-derived chiral phosphoric acid $\mathbf{3 9}$ was found as the best ligand for the palladium-catalyzed atroposelective olefination of arenes 37 (Scheme 16). ${ }^{[69]}$ Later, the same strategy was employed to free amine $\left(-\mathrm{NH}_{2}\right)$ substrates. ${ }^{[70]}$ 


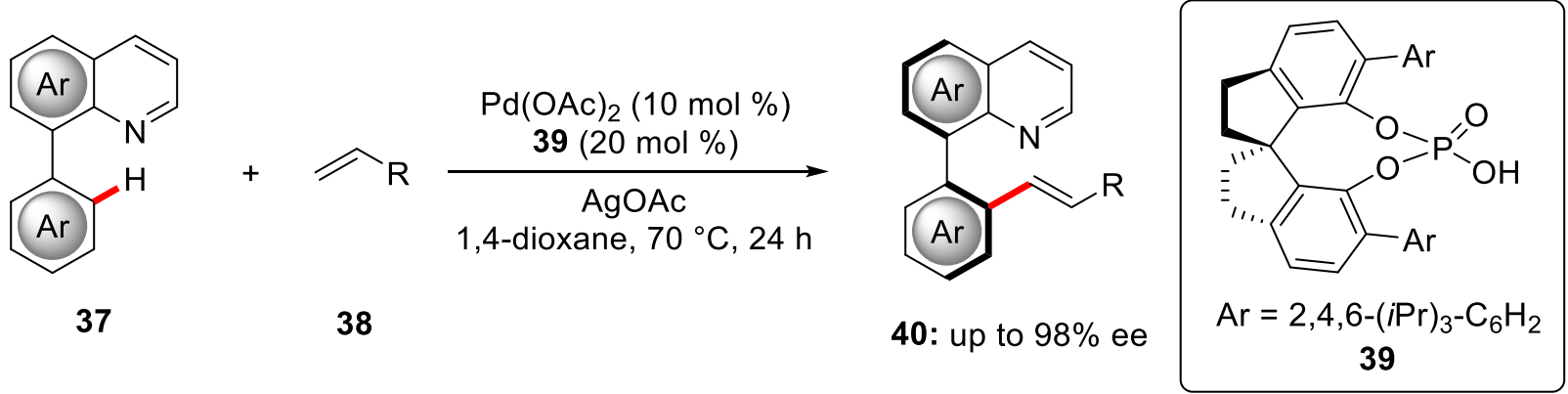

Scheme 16. Palladium-catalyzed atroposelective olefination of arene 37.

Furthermore, the Josiphos-type ligand $\mathbf{4 2}$ was utilized in combination with palladium catalysis for the intramolecular $\mathrm{C}-\mathrm{H}$ arylation to syntheses highly enantio-enriched silicon-based ring systems $\mathbf{4 3}$ (Scheme 17). ${ }^{[71]}$

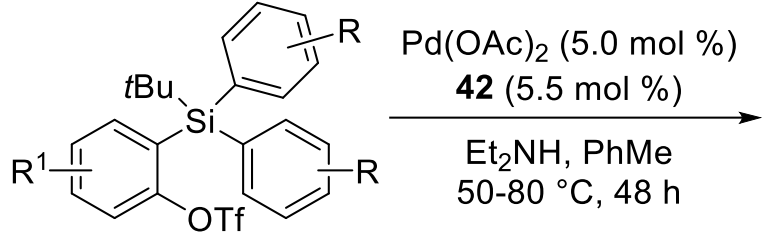

41

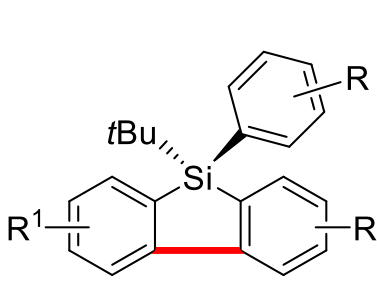

43: up to $99 \%$ ee

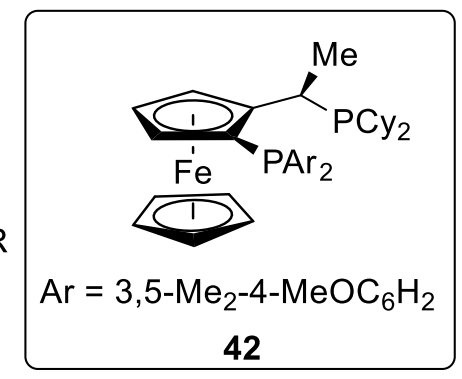

42

Scheme 17. Palladium-catalyzed desymmetrization of 2-(arylsilyl)aryl triflates 41.

It is noteworthy that a bifunctional phosphine-carboxylate ligand was also applied for enantioselective palladium-catalyzed arylation reactions by Baudoin. ${ }^{[72]}$ In 2017, Cramer reported $\mathrm{C}-\mathrm{H}$ alkenylation of ketene aminal phosphate with a phosphine ligand, containing both point and axial chirality. ${ }^{[73]}$

\subsubsection{Monoprotected Amino Acids as Chiral Ligands}

Since the introduction of mono-protected amino acids (MPAA) by Sokolov as chiral ligands, ${ }^{[62]}$ their application in combination with palladium catalysis has significantly propelled this emerging research area. ${ }^{\text {[63a] }}$ An elegant study by $\mathrm{Yu}$ in 2008 demonstrated the potential of MPAAs as viable ligands for this class of transformations. The utilization of a bulky mentholderived amino acid ligand 45 enabled the desymmetrization of diaryl(2-pyridyl)methane derivatives 44 with alkyl boronic acids 12 with high enantioselectivities (Scheme 18). ${ }^{[74]}$ 


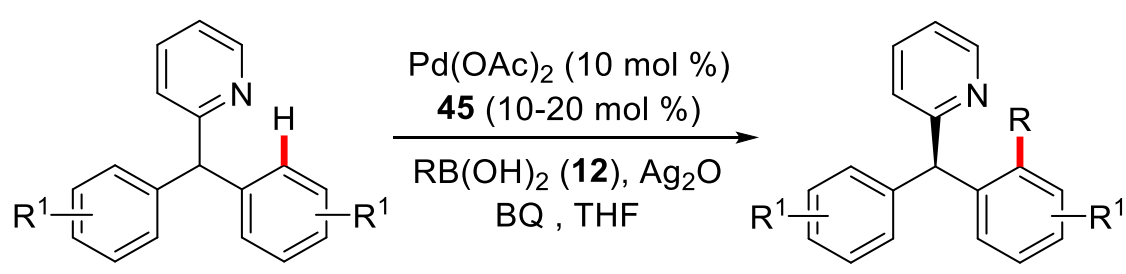

44

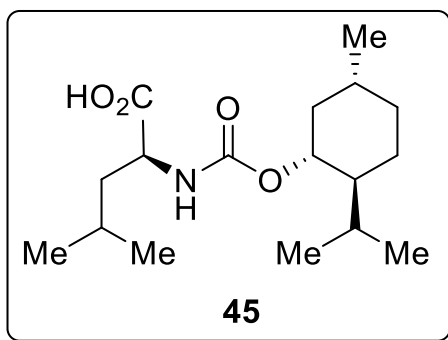

Scheme 18. Palladium-catalyzed desymmetrization using MPAA 45.

Later, Yu achieved desymmetrization of $\alpha, \alpha$-diphenylacetates ${ }^{[75]}$ and diarylmethylamines ${ }^{[76]}$ by merging similar type of MPAA complex with palladium catalysis. In the former case, sodium salt $\mathbf{4 7}$ was reacted with styrene derivatives $\mathbf{4 8}$ under oxygen atmosphere (Scheme 19a). Later, the same group extended this approach to diarylmethylamines $\mathbf{5 1}$ using molecular iodine as both a reagent and an oxidant using leucine derivative $\mathbf{5 3}$ as the chiral ligand (Scheme 19b).

(a) Palladium-catalyzed olefination of $\alpha$, $\alpha$-diphenylacetates<smiles>[R]c1cccc(C([R])(C(=O)[O-])c2c[R1]ccc2)c1</smiles>

47

48

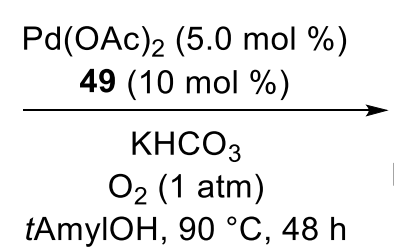

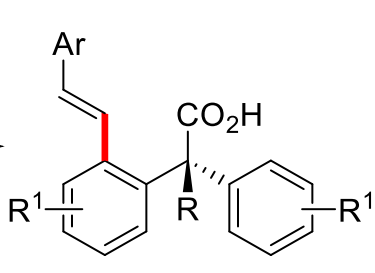

50: up to $97 \%$ ee

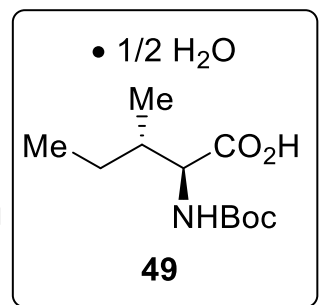

49

(b) Palladium-catalyzed $\mathrm{C}-\mathrm{H}$ iodination of diarylmethylamines

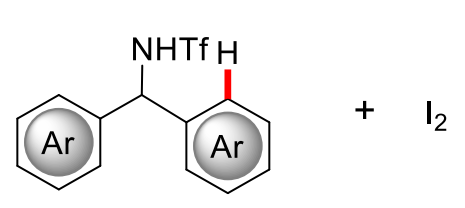

51

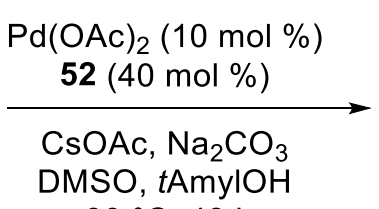

$30{ }^{\circ} \mathrm{C}, 48 \mathrm{~h}$

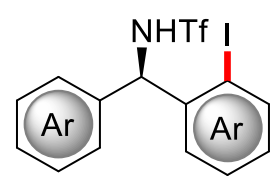

53: up to $99 \%$ ee

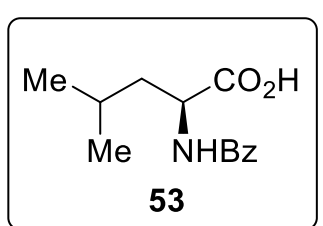

53

Scheme 19. Palladium-catalyzed olefination of $\alpha, \alpha$-diphenylacetates 47 and iodination of diarylmethylamines 51.

In subsequent studies, MPAAs have emerged as powerful ligands for palladium-catalyzed desymmetrization of diarylmethylamines ${ }^{[77]}$ and diarylphosphinamides ${ }^{[78]}$ with arylboronic acid pinacol esters, providing the desymmetrized products with high enantioselectivities.

Enantioselective transformations of ferrocenes via direct $\mathrm{C}-\mathrm{H}$ activation are a key subject area to synthesize planer chiral ferrocenes in a step-economical way (Scheme 20). Consequently, building on the great success of MPAAs ligands, enantioselective arylation with arylboronic acids $^{[79]} \mathbf{1 2}$ as well as olefination of ferrocenes ${ }^{[80]} \mathbf{2 9}$ have been feasible by the judicious choice of MPAAs ligand. In addition, You developed further transformations towards enantioselective biaryl couplings of ferrocenes $\mathbf{2 9}$ with heteroarenes $\mathbf{6 0} .^{[81]}$ 


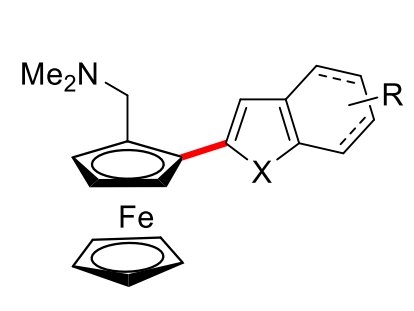

62: up to $99 \%$ ee

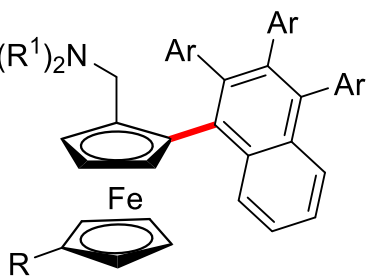

59: up to $98 \%$ ee<smiles></smiles>

60 $\mathrm{Pd}(\mathrm{OAc})_{2}(10 \mathrm{~mol} \%)$ $61(10 \mathrm{~mol} \%)$ $\mathrm{BQ}, \mathrm{K}_{2} \mathrm{CO}_{3}$ $\mathrm{H}_{2} \mathrm{O}, \mathrm{O}_{2}$ DMA, $80^{\circ} \mathrm{C}$

3
$>$

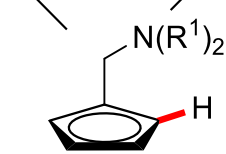

$$
\mathrm{Ar} \frac{\overline{\overline{58}}}{\mathrm{Ar}}
$$

$$
\mathrm{Pd}(\mathrm{OAc})_{2}(10 \mathrm{~mol} \%)^{\mathrm{R}}
$$
$56(20 \mathrm{~mol} \%)$ TBAB, $\mathrm{K}_{2} \mathrm{CO}_{3}$ DMA, $60^{\circ} \mathrm{C}$ 29<smiles>CC(C)[C@H](N)C(=O)OC(=O)O</smiles>
54<smiles>O=C(O)C(Cc1ccccc1)N[C@@H](Cc1ccccc1)C(=O)O</smiles><smiles>CCC(C)C(N[B]OC(=O)OC(C)(C)C)C(=O)O</smiles>

$$
\operatorname{ArB}(\mathrm{OH})_{2}(12)
$$

$\mathrm{Pd}(\mathrm{OAc})_{2}(10 \mathrm{~mol} \%)$ $54(20 \mathrm{~mol} \%)$

TBAB, $\mathrm{K}_{2} \mathrm{CO}_{3}$ DMA, $60^{\circ} \mathrm{C}$

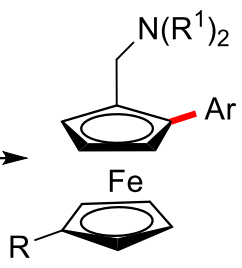

55: up to $99 \%$ ee<smiles>[R]C=[13CH]</smiles>
$\mathrm{Pd}(\mathrm{OAc})_{2}(10 \mathrm{~mol} \%)$ $56(20 \mathrm{~mol} \%)$

TBAB, $\mathrm{K}_{2} \mathrm{CO}_{3}$ DMF, $60^{\circ} \mathrm{C}$

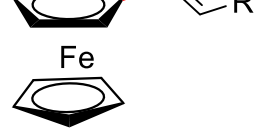

57: up to $99 \%$ ee

Scheme 20. Palladium-catalyzed asymmetric functionalization of ferrocenes 29.

In 2016, Yu made a contribution towards the development of palladium-catalyzed iodination of chiral arylalkylamines as well as $\beta$-amino acid and $\beta$-amino alcohol derivatives utilizing MPAAs as chiral ligands (Scheme 11). ${ }^{[82]}$ This protocol was not restricted to the iodination, the same group extended this strategy towards olefins ${ }^{[83]} \mathbf{3 8}$ and arylboronic acid pinacol esters $^{[84]} \mathbf{7 0}$ as the coupling partners. (Scheme 21). 
<smiles>[R]C[C@@H](N[CH])c1ccccc1I</smiles>

63: up to $97 \%$ ee $\quad 67$ : up to $97 \%$ ee<smiles>N#[N+][C@@H](C(=O)O)c1ccccc1</smiles>

64: up to $95 \%$ ee<smiles>[R]C=Cc1ccccc1C([Y10])C(=O)O</smiles>

69: up to $93 \%$ ee $\mathrm{X}=\mathrm{O} / \mathrm{NH}$<smiles>[R]C=C</smiles>

38 tAmylOH, $30-40{ }^{\circ} \mathrm{C}$

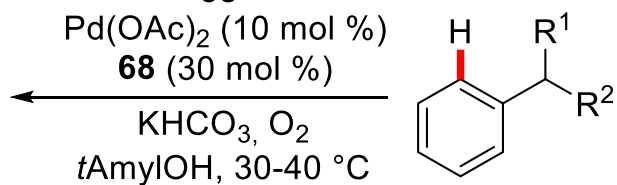

$63,64,65$
$\mathrm{Pd}(\mathrm{OAc})_{2}(10 \mathrm{~mol} \%)$

$66(40 \mathrm{~mol} \%)$

$\mathrm{CsOAc}, \mathrm{Na}_{2} \mathrm{CO}_{3}$ DMSO/tAmylOH, $20^{\circ} \mathrm{C}$

$\mathrm{Ar}-\mathrm{BPin}$

70

$\mathrm{Pd}(\mathrm{OAc})_{2}(10 \mathrm{~mol} \%)$ $69(15 \mathrm{~mol} \%) \rightarrow+$

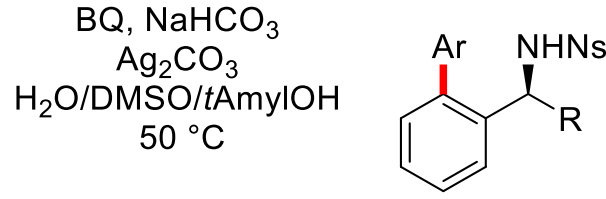

$B$ $Y_{\mathbf{N H B O C}}^{\mathrm{CONHOMe}}$<smiles>[R]C(N)c1ccccc1</smiles>

65: up to $99 \%$ ee
72: up to $96 \%$ ee

Scheme 21. Palladium-catalyzed enantioselective functionalization of arenes using MPAAs.

Subsequently, synthesis of axially chiral biaryls via kinetic resolution was disclosed by palladium-catalyzed $\mathrm{C}-\mathrm{H}$ iodination using MPAAs. ${ }^{[85]}$ Similar strategy enabled the atroposelective olefination of biaryls containing $\mathrm{P}(\mathrm{O}) \mathrm{Ph}_{2}$ as the directing group. ${ }^{[86]}$ In a recent study, Shi employed L-pyroglutamic acid as chiral ligand for the atroposelective synthesis of axially chiral styrenes. ${ }^{[87]}$

\subsubsection{Chiral Transient Auxiliaries}

Since the contribution by $\mathrm{Yu}$ on enantioselective $\mathrm{C}\left(\mathrm{sp}^{3}\right)-\mathrm{H}$ activations ${ }^{[88]}$ by transient directing group (TDG), novel methods have evolved over the past years for chiral transient directing group $^{[41]}$ approaches in synergistic $\mathrm{C}-\mathrm{H}$ activation. In this context, Shi efficiently employed chiral TDGs for the synthesis of axially chiral biaryls. In 2017, Shi reported atroposelective olefination of racemic biaryl containing aldehydes $\mathbf{7 3}$ in the presence of commercially available L-tert-leucine as the chiral TDG using oxygen as the terminal oxidant. ${ }^{[89]}$ Later, this efficient protocol was successfully extended by Shi to various other coupling partners including olefins 
38, ${ }^{[89]}$ protected alkynyl bromides $\mathbf{7 5},{ }^{[90]}$ allyl acetate derivatives $\mathbf{7 9}^{[91]}$ and 4-vinyl-1,1dioxolan-2-one $\mathbf{7 7}^{[91]}$ (Scheme 22).

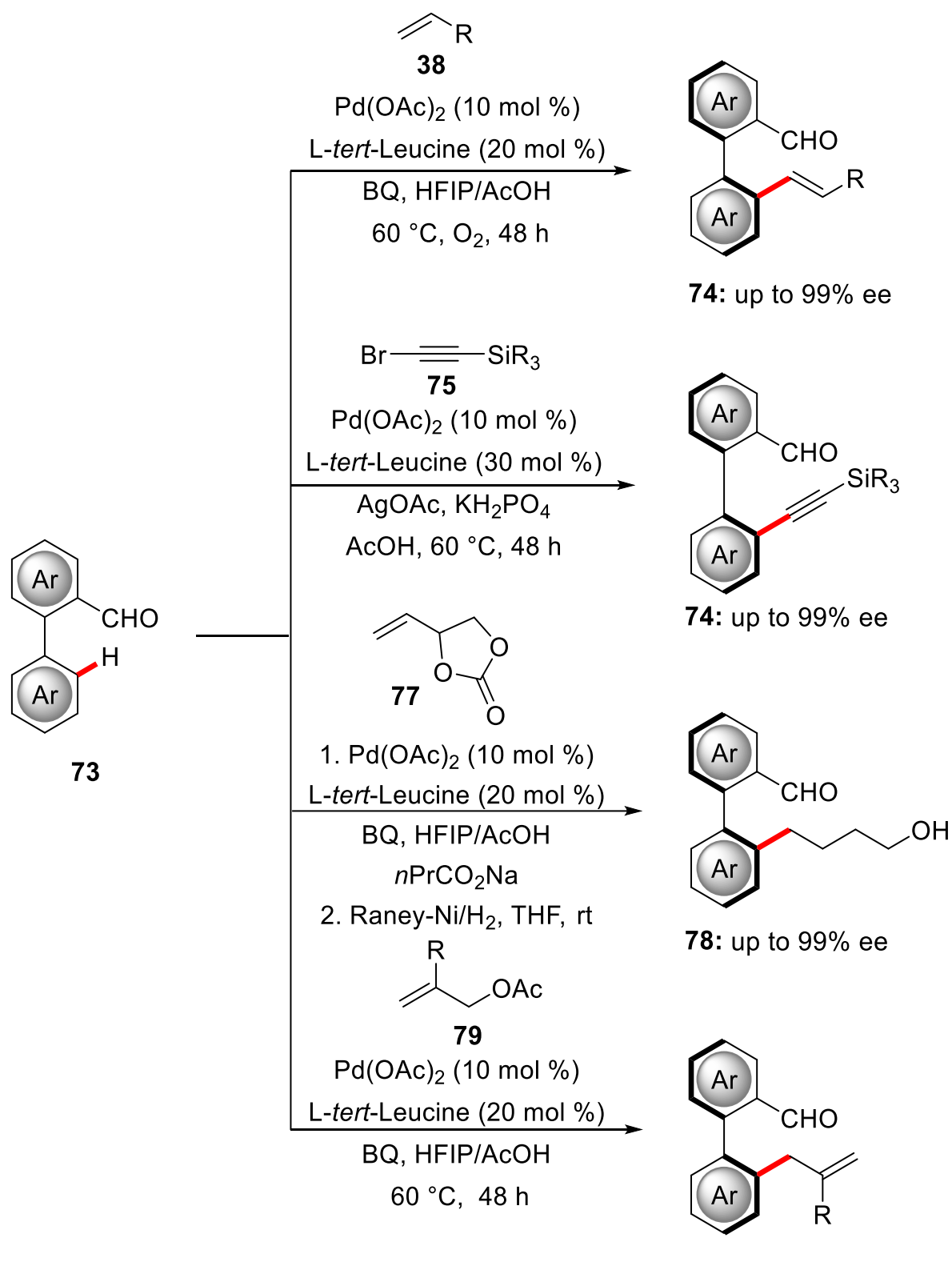

80: up to $99 \%$ ee

Scheme 22. Palladium-catalyzed atroposelective transformations of biaryls using TDG strategy.

Concurrently, related reaction conditions were employed for the synthesis of $\mathrm{N}-\mathrm{C}$ axially chiral scaffolds by $\mathrm{Shi}^{[92]}$ and Xie. ${ }^{[93]}$

Another powerful approach was demonstrated for the synthesis of axially chiral scaffolds by introducing chiral auxiliaries. This strategy was mainly explored by the groups of Colobert and Wencel-Delord. Enantio-enriched sulfoxides $\mathbf{8 1}$ containing sulfur as the stereogenic center, 
were used as chiral auxiliaries for successful olefination, ${ }^{[94]}$ acetoxylating and halogenation, ${ }^{[95]}$ as well as arylation ${ }^{[96]}$ reactions (Scheme 23).

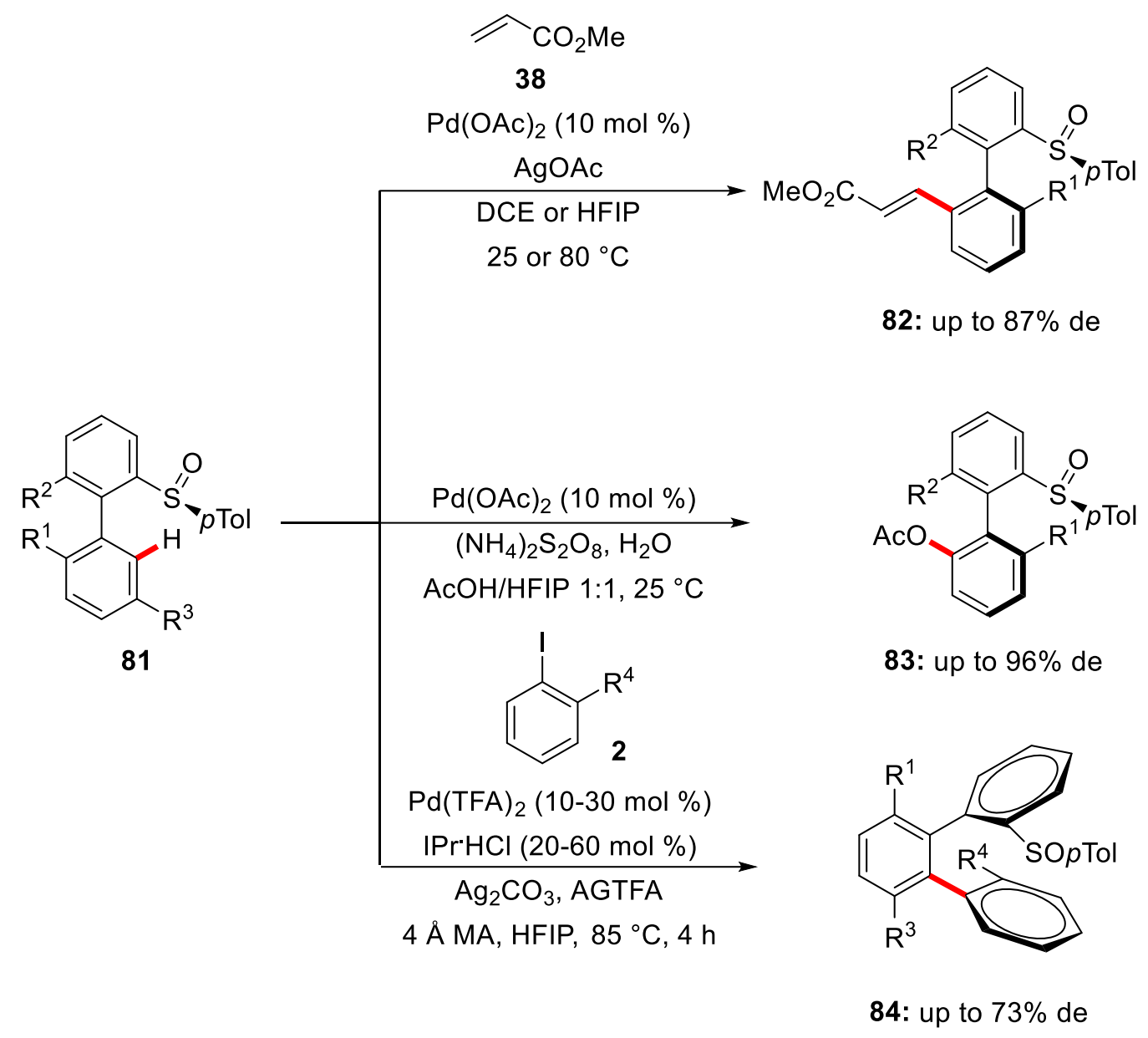

Scheme 23. Palladium-catalyzed diastereoselective C-H activation of biaryls $\mathbf{8 1}$.

In 2018, an interesting strategy was put into practice by $\mathrm{Yu}$ for the enantioselective remote meta-C-H activation using a chiral norbornene as a transient mediator. ${ }^{[97]}$ This concept was further applied by Zhou for three-component coupling reactions involving aryl iodides $\mathbf{2}$, aryl bromides $\mathbf{8 5}$ and variety of terminating reagents $\mathbf{3 8}$ including olefins, alkynes, cyanide, boronic acids and ketones (Scheme 24). ${ }^{[98]}$ 


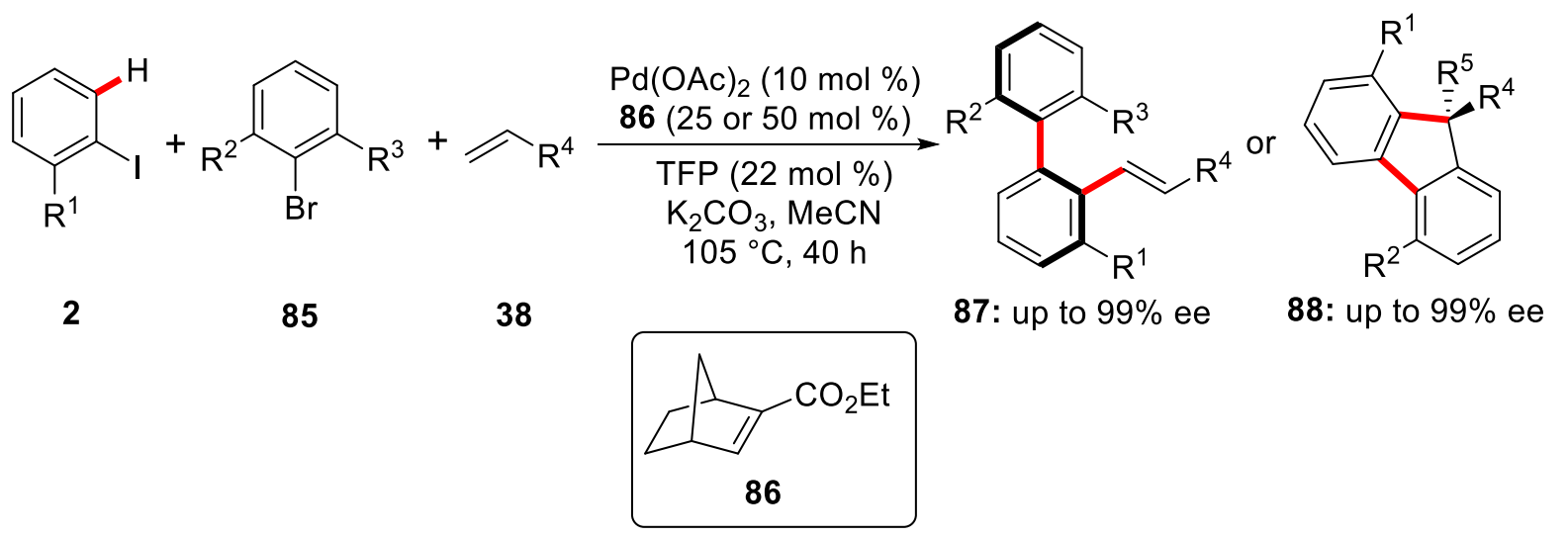

Scheme 24. Palladium/chiral norbornene cooperative catalysis towards chiral biaryls.

\subsubsection{Rhodium Catalysis}

\subsubsection{Ligand-Induced Asymmetric C-H Activation}

Early pioneering studies on rhodium(I)-catalyzed enantioselective $\mathrm{C}-\mathrm{H}$ activations can be traced back to the elegant contributions of Murai ${ }^{[99]}$ and Ellman/Bergman. ${ }^{[100]}$ Murai applied a monodentate phosphine ligand for a rhodium(I)-catalyzed enantioselective hydroarylation protocol. ${ }^{[99]}$ Later, Ellman/Bergman presented intramolecular imine-directed hydroarylation of ketimines 89 (Scheme 25). The key to success was the use of BINOL-based chiral ligands 90 or 91 to achieve high enantioselectivities for this cyclization protocol.<smiles>[R]C=C([R])[X]c1cccc(C([R])=NBr)c1</smiles>

89

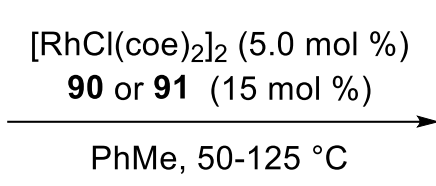

92: up to $96 \%$ ee

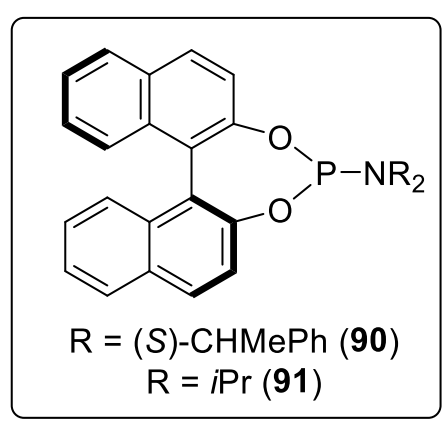

Scheme 25. Rhodium-catalyzed hydroarylation of ketimine 89.

This early pioneering studies have set the stage for various enantioselective annulation reactions using alkynes and alkenes as coupling partners by the aid of chiral biphosphine ligands. ${ }^{[101]}$

Considering the high importance of enantioselective hydroarylation reactions, a number of reports have been documented in the literature. In a recent study, Matsunaga employed a hybrid catalyst, namely a 1:1 mixture of $\mathrm{Cp} * \mathrm{Rh}(\mathrm{III})$ and $(S)$-BINSate anion for the addition of 2phenylpyridine 93 with $\alpha, \beta$-unsaturated ketones 94. ${ }^{[102]}$ Also the scope was further extended to 6-arylpurines 97 with a modified $(R)$-SPISate spirocyclic anion based catalyst (Scheme 26). 
<smiles>[R]1=[R]=CC=CC=C1c1c[R1]ccn1</smiles>

93

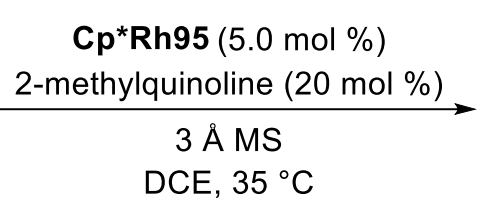

DCE, $35^{\circ} \mathrm{C}$<smiles>[R][R]1cccc(C([R3])CC([R])=O)c1-c1[R]:[R]ccc1</smiles>

96: up to $95 \%$ ee

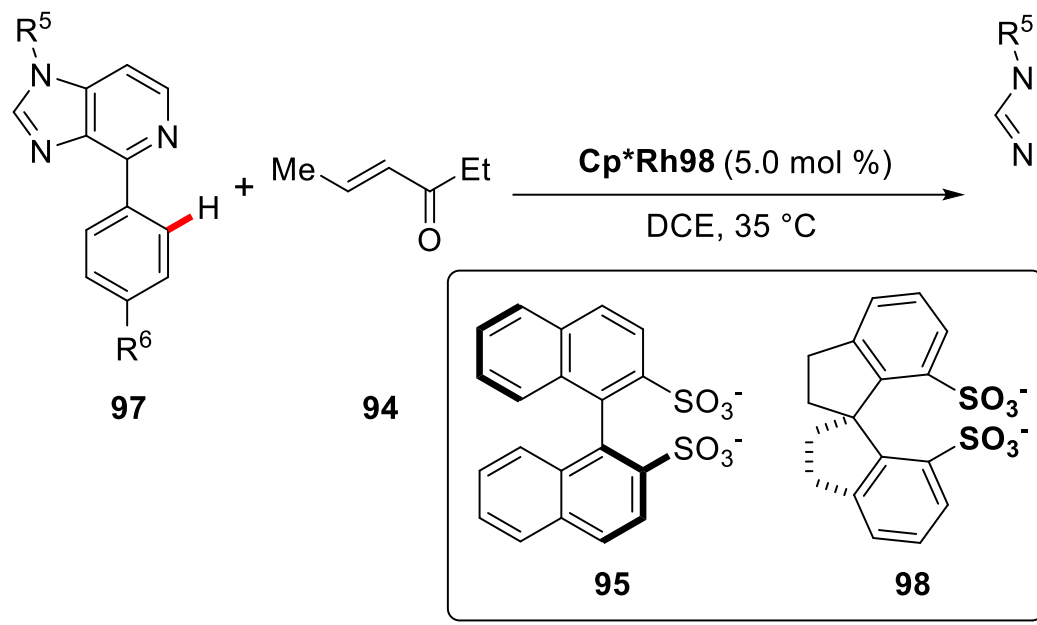

Scheme 26. Rhodium-catalyzed $\mathrm{C}-\mathrm{H}$ activation using chiral anions.

Subsequently, Matsunaga reported the merger of a chiral carboxylic acid 102 with $\mathrm{Cp} * \mathrm{Rh}$ (III) complex for the synthesis of 1,4-dihydroisoquinolin-3(2H)-one derivatives 103 via a desymmetrization process (Scheme 27). ${ }^{[103]}$<smiles>COC(=N)C(=O)OC</smiles>

(a) $\left[\mathrm{Cp}^{*} \mathrm{RhCl}_{2}\right]_{2}(2.5$ or $1.0 \mathrm{~mol} \%)$<smiles>[R][R]1cccc(C(NC)c2ccccc2)c1</smiles>
$102(12$ or $4.8 \mathrm{~mol} \%)$ $\mathrm{Ag}_{2} \mathrm{CO}_{3}, \mathrm{MeOH}, 60^{\circ} \mathrm{C}$

(b) $\mathrm{LiCl}, \mathrm{H}_{2} \mathrm{O}$, DMSO, $130^{\circ} \mathrm{C}$ 100<smiles>O=C(O)c1c([Al])cc2ccccc2c1-c1c(P(=O)([Al])[Al])ccc2ccccc12</smiles><smiles>[R][R]c1ccc([C@H]2c3ccccc3CC(=O)N2C)cc1</smiles>

103: up to $96 \%$ ee

Scheme 27. Rhodium-catalyzed $\mathrm{C}-\mathrm{H}$ activation using chiral carboxylic acid $\mathbf{1 0 0}$. 
In 2019, a protocol for highly enantioselective arylation of ferrocenes $\mathbf{1 0 4}$ was reported by You. ${ }^{[104]}$ The authors employed a TADDOL-based chiral ligand $\mathbf{1 0 5}$ to synthesis planar chiral ferrocenes $\mathbf{1 0 6}$ by thioketone directed $\mathrm{C}-\mathrm{H}$ activation (Scheme 28).
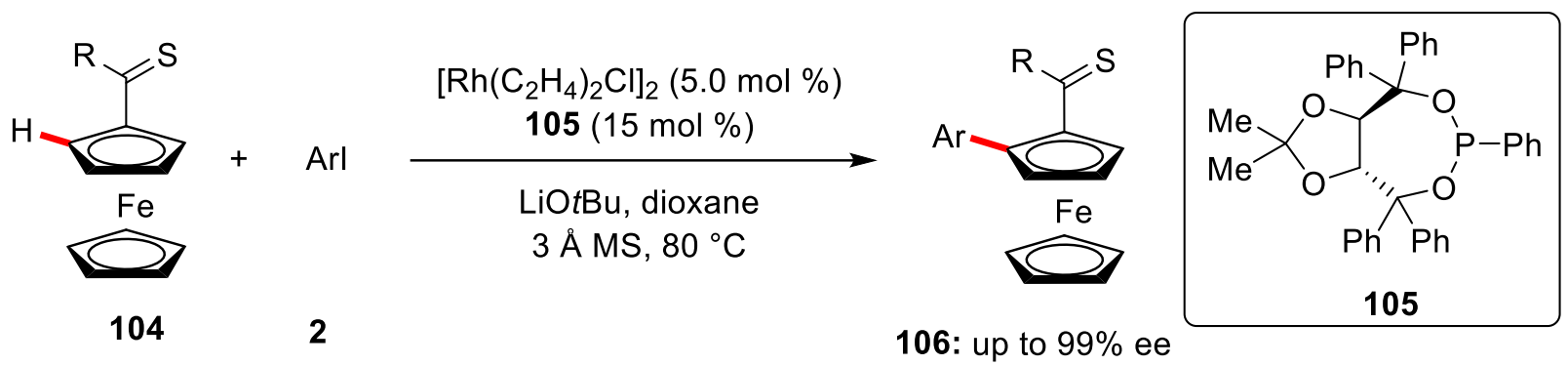

Scheme 28. Rhodium-catalyzed C-H arylation of ferrocenes.

TADDOL-derived monodentate phosphonite has also been applied by You in atroposelective $\mathrm{C}-\mathrm{H}$ arylation reactions to synthesis highly enantioenriched chiral biaryls. ${ }^{[105]}$

\subsubsection{Chiral $\mathrm{Cp}^{\mathrm{x}}$-Based Catalysts}

Apart from the use of exogenous chiral ligands with $\mathrm{Cp} * \mathrm{Rh}(\mathrm{III})$ complexes, another powerful approach involves the use of chiral cyclopentadienyl-based $\left(\mathrm{Cp}^{\mathrm{x}}\right)$ complex to gain high levels of selectivity control. ${ }^{[106]}$ The application of these complexes was demonstrated by Cramer for the annulation of hydroxamic acid derivatives 107 with olefins 94 to provide the annulated products 109 with excellent enantioselectivities (Scheme 29a). ${ }^{[107]}$ Using a bulky OTIPS substituent on $\mathrm{Cp}^{\mathrm{x}}$ complex Rh111 enabled the functionalization of hydroxymates $\mathbf{1 9}$ with allenes 110 in high enantioselectivity (Scheme 29b). ${ }^{[108]}$ 
(a) Rhodium-catalyzed enantioselective $\mathrm{C}-\mathrm{H}$ annulation

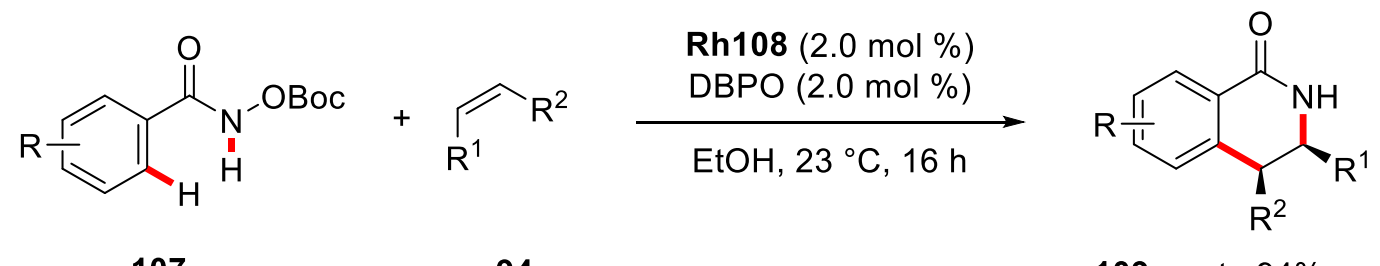

107

94

109: up to $94 \%$ ee

(b) Rhodium-catalyzed enantioselective $\mathrm{C}-\mathrm{H}$ allylation<smiles>[R][I-]NC(=O)c1cc[R]cc1</smiles>

19

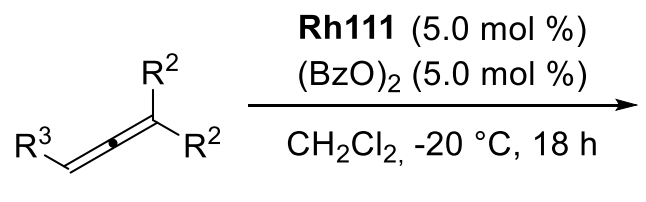

110<smiles>[R]C([R])=CC([R])C1=C(C(=O)NOC)C=C[R1]C=C1</smiles>

112: up to $98 \%$ ee

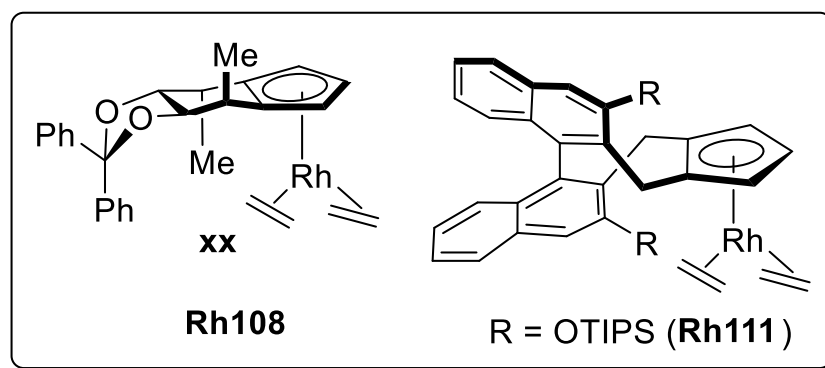

Scheme 29. Rhodium-catalyzed enantioselective C-H annulation.

In subsequent reports, similar chiral $\mathrm{Cp}^{\mathrm{x}}$ complexes have found application in enantioselective intramolecular reactions to synthesize cyclized scaffold. ${ }^{[109]}$ Later, chiral isoindolone derivatives 115 were synthesized using diazo compounds 113 via rhodium-catalyzed $\mathrm{C}-\mathrm{H}$ activation (Scheme 30). ${ }^{[110]}$

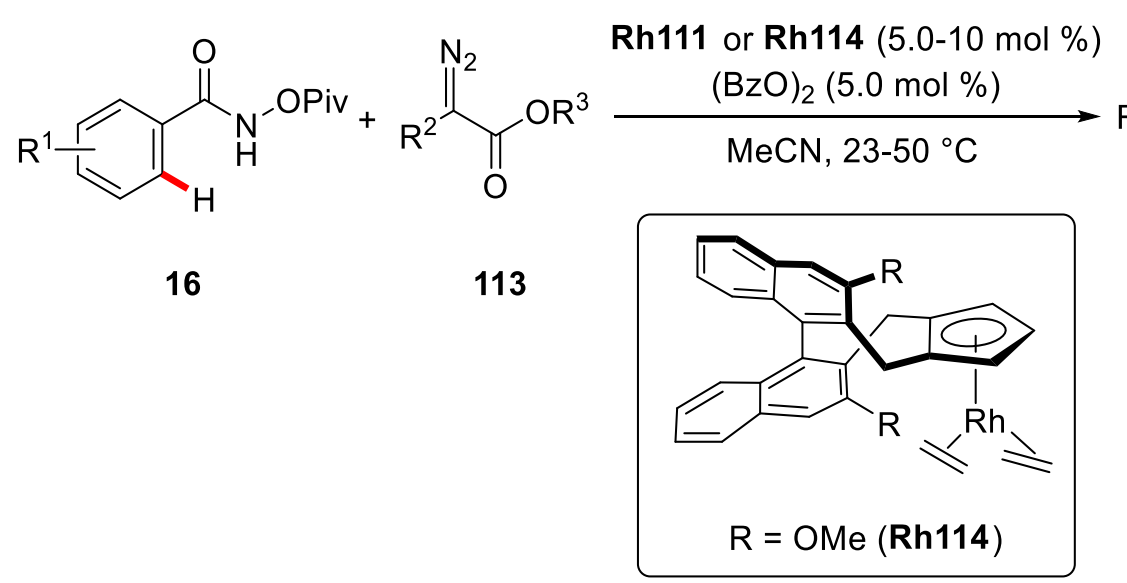

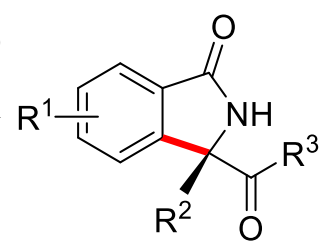

115: up to $93 \%$ ee

Scheme 30. Rhodium-catalyzed enantioselective synthesis of isoindolones $\mathbf{1 1 5}$. 
Chiral $\mathrm{Cp}^{\mathrm{x}}$ complex was also effective for enantioselective [3+2] spiroannulation reactions as demonstrated by You. Quaternary stereogenic centers 118 were formed under oxidative conditions (Scheme 31). ${ }^{[111]}$<smiles>[R]c1ccc2c(-c3ccccc3)c(O)c([R])cc2c1</smiles>

116

$$
\left.\right|_{\mathrm{R}^{4}} ^{\mathrm{R}^{5}}
$$

117

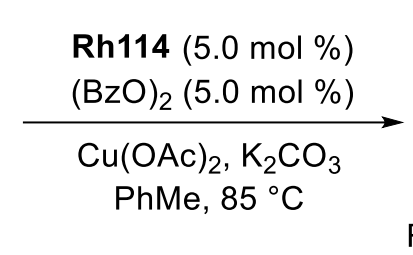<smiles>[R]CCC12C(=O)C([R])=Cc3cc([R])ccc3C1(C[R])c1ccccc1C2[R]</smiles>

118: up to $94 \%$ ee

Scheme 31. Rhodium-catalyzed spiroannulations.

In 2017, Ellman showed the potential of similar type of chiral $\mathrm{Cp}^{\mathrm{x}}$ complex $\mathbf{R h 1 2 1}$ for enantioselective rhodium(III)-catalyzed $\mathrm{C}-\mathrm{H}$ bond addition to nitroalkenes $\mathbf{1 2 0}$ (Scheme 32). ${ }^{[112]}$

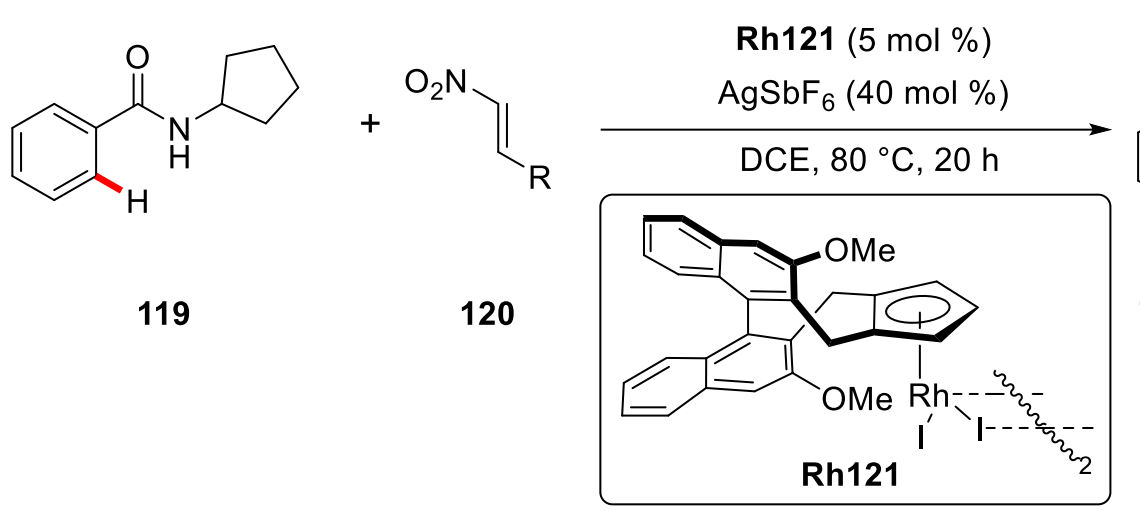

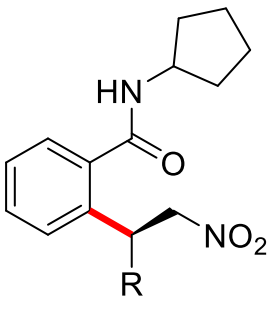

122: up to $82 \%$ ee

Scheme 32. Rhodium-catalyzed enantioselective dual $\mathrm{C}-\mathrm{H}$ activation.

Later, a three component reaction involving arene, terminal alkenes, and aminating agent was achieved by the same group. The authors utilized the same chiral rhodium complex Rh121 for the synthesis of $\alpha$-methyl branched amines 125 with moderate to good enantioselectivities (Scheme 33). ${ }^{[113]}$<smiles>CO/N=C(\C)c1ccccc1</smiles>

123<smiles>[R]c1noc(=O)o1</smiles>

124

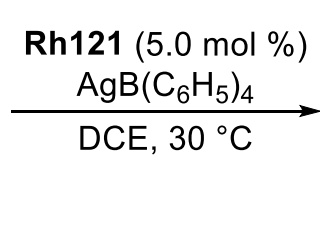

125: up to $84 \%$ ee

Scheme 33. Rhodium-catalyzed enantioselective three component reaction.

You also showed the application of chiral $\mathrm{Cp}^{\mathrm{x}}$ rhodium complexes $\mathbf{R h 1 1 1}$ for successful atroposelective $\mathrm{C}-\mathrm{H}$ olefination reactions with alkenes 38 (Scheme 34$).{ }^{[114]}$ In subsequent 
studies, a SPINOL-type ligand $\mathbf{R h 1 2 7}$ provided improved enantioselectivities as shown by the same group. ${ }^{[115]}$

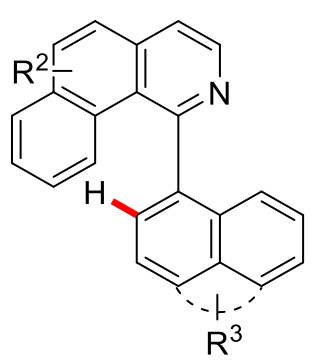

126

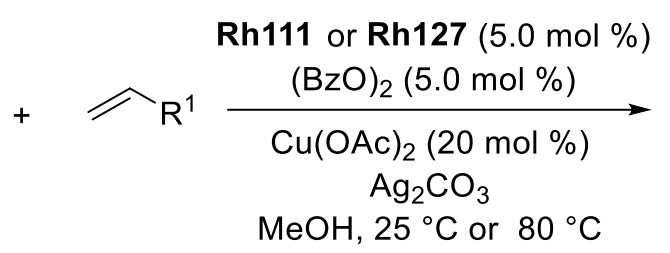

38

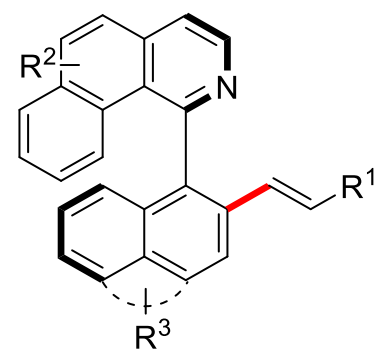

128
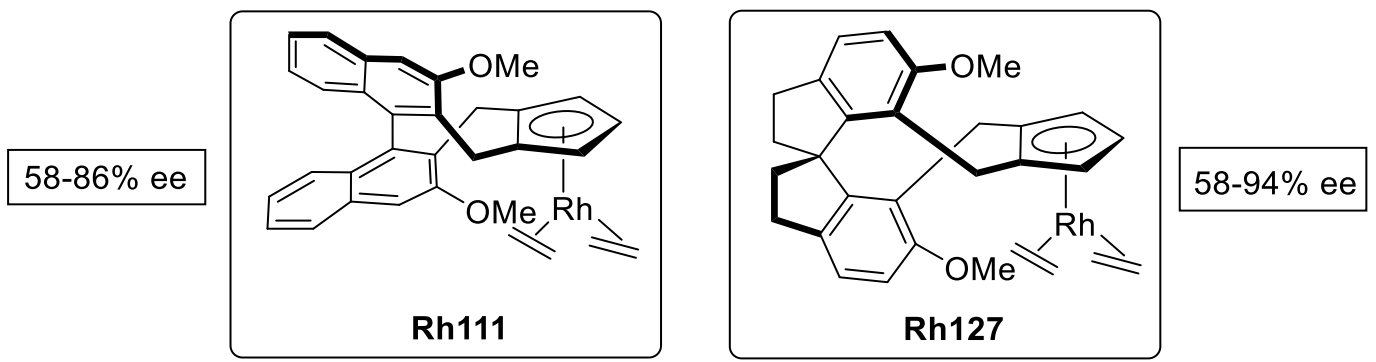

Scheme 34. Rhodium-catalyzed atroposelective C-H olefination.

Later, in 2019, Wang employed the same chiral rhodium(III) complex Rh127 for the synthesis atropo-stable indolinone derivatives $\mathbf{1 3 0}$ via dual $\mathrm{C}-\mathrm{H}$ activation in an oxidative alkyne annulation conditions (Scheme 35). ${ }^{[116]}$

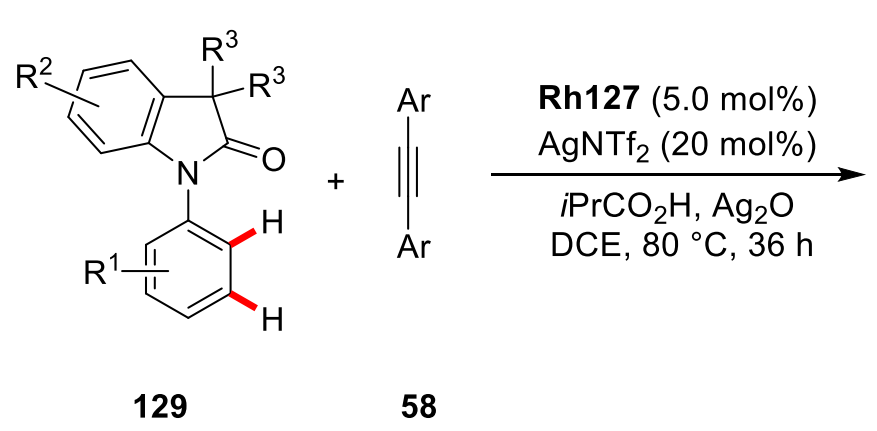

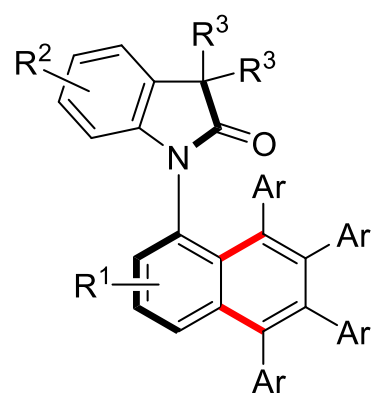

130: up to $99 \%$ ee

Scheme 35. Rhodium-catalyzed atroposelective synthesis of $\mathrm{C}-\mathrm{N}$ axially chiral biaryls.

In addition to the aforementioned reports, successful approaches have been described for the atroposelective synthesis of biaryls using chiral $\mathrm{Cp}^{\mathrm{x}}$ complex with notable contributions from $\mathrm{Li}^{[117]}$ as well as Antonchick and Waldmann. ${ }^{[118]}$

Despite significant advances, it is noteworthy to mention that the multi-step syntheses of chiral $\mathrm{Cp}^{\mathrm{x}}$ and pre-coordination to metal catalysts limit the atom-economy of this strategy. 


\subsubsection{Other Strategies}

In 2012, Ward and Rovis devised a completely different approach to enantioselective $\mathrm{C}-\mathrm{H}$ activation using rhodium catalysis. Here, a $\mathrm{Cp}^{*}$ ligand was linked with biotin derivative that binds to streptavidin in a host-guest type interaction typical for enzymes providing environment for asymmetric induction. The initial potential of this catalytic system was tested for enantioselective annulation of hydroxymates $\mathbf{1 6}$ and olefins 94 at room temperature (Scheme 36). ${ }^{[119]}$ Later, the same group improved the versatility of this catalytic system towards the synthesis of $\delta$-lactams in high yields and enantioselectivity. ${ }^{[120]}$

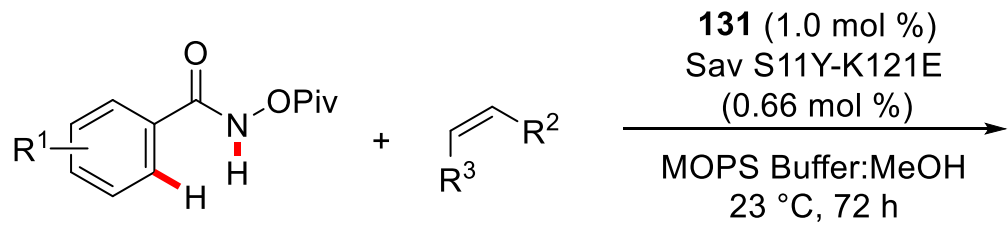

16
94

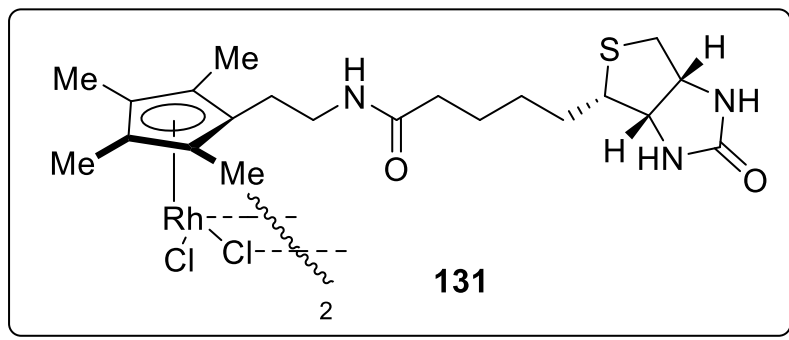

Scheme 36. Rhodium-catalyzed $\mathrm{C}-\mathrm{H}$ activation with artificial metalloenzymes.

The use of chiral transient directing group was largely limited to palladium catalysis, until recently, Wang employed this strategy to rhodium catalysis in their enantioselective synthesis of chiral phthalides from simple aldehydes. ${ }^{[121]}$

\subsubsection{Iridium Catalysis}

Over the past years, owing to unique properties of iridium catalysts, there has been a considerable increase in the use of iridium complexes for the development of novel and selective enantioselective $\mathrm{C}-\mathrm{H}$ transformations. ${ }^{[122]}$

In 2000, Togni documented an early example of an iridium-catalyzed enantioselective $\mathrm{C}-\mathrm{H}$ hydroarylation of norbornene 132 with benzamide 133. ${ }^{[123]}$ An iridium complex bearing cyclopentadienyl $(\mathrm{Cp})$ and chiral ligand $(R)$-MeO-BIPHEP 134 enabled the intermolecular enantioselective hydroarylation to provide the alkylated product $\mathbf{1 3 5}$ in $94 \%$ ee, albeit with a low yield of $12 \%$ (Scheme 37). 


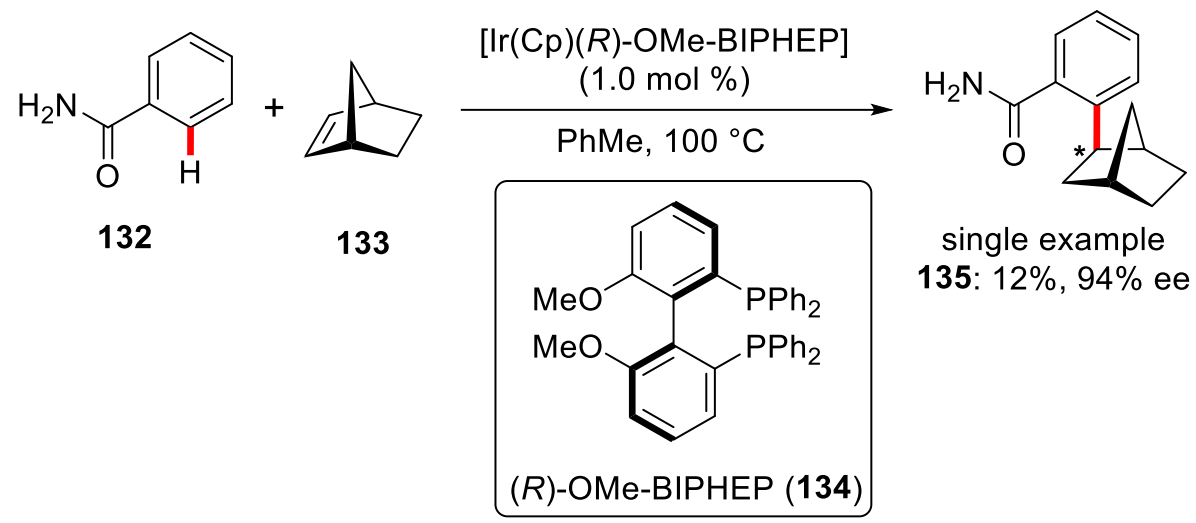

Scheme 37. Early example of iridium-catalyzed enantioselective hydroarylation of norbornene 133.

In 2008 , in a related study Shibata employed $\left[\operatorname{Ir}(\operatorname{cod})_{2}\right] \mathrm{BF}_{4}$ as the catalyst and $(R)-\mathrm{MeO}-$ BIPHEP 137 as the chiral ligand to achieve a single example of enantioselective $\mathrm{C}-\mathrm{H}$ addition of 2'-methylacetophenone 136 to norbornene $\mathbf{1 3 3}$ with $58 \%$ yield and $70 \%$ ee (Scheme 38). ${ }^{[124]}$

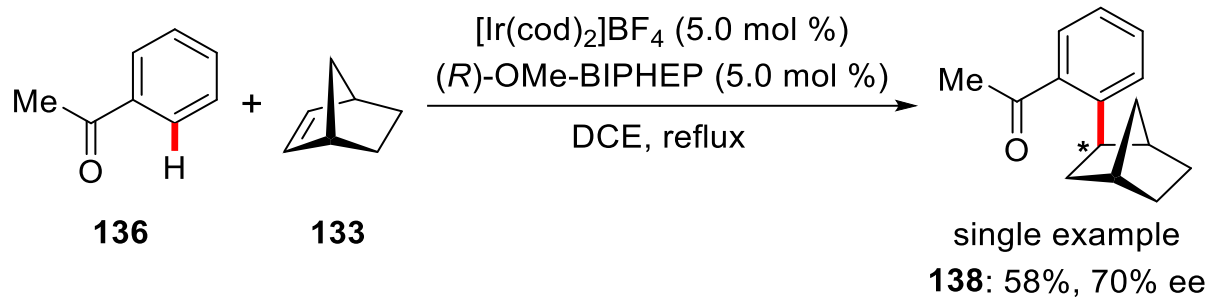

Scheme 38. Iridium-catalyzed enantioselective hydroarylation 2'-methylacetophenone 136.

In 2013, Hartwig disclosed enantioselective $\mathrm{C}-\mathrm{H}$ additions of heteroarenes to bicycloalkenes 133 with the cooperation of (S)-DTBM-SEGPHOS 140 as the chiral ligand to provide highly enantioenriched alkylated products 141 (Scheme 39). ${ }^{[125]}$ Notably, the reaction occurred efficiently with heteroarenes, including indoles, thiophenes, pyrroles and furans, selectively reacting on the $\mathrm{C}-\mathrm{H}$ bonds adjacent to the heteroatoms. Even for unprotected indoles, $\mathrm{C} 2$ alkylation was observed in contrast to its typical reactivity at the $\mathrm{C} 3$ position. A broad range of functional groups was tolerated to form the alkylated products with good yields and excellent enantioselectivities. 


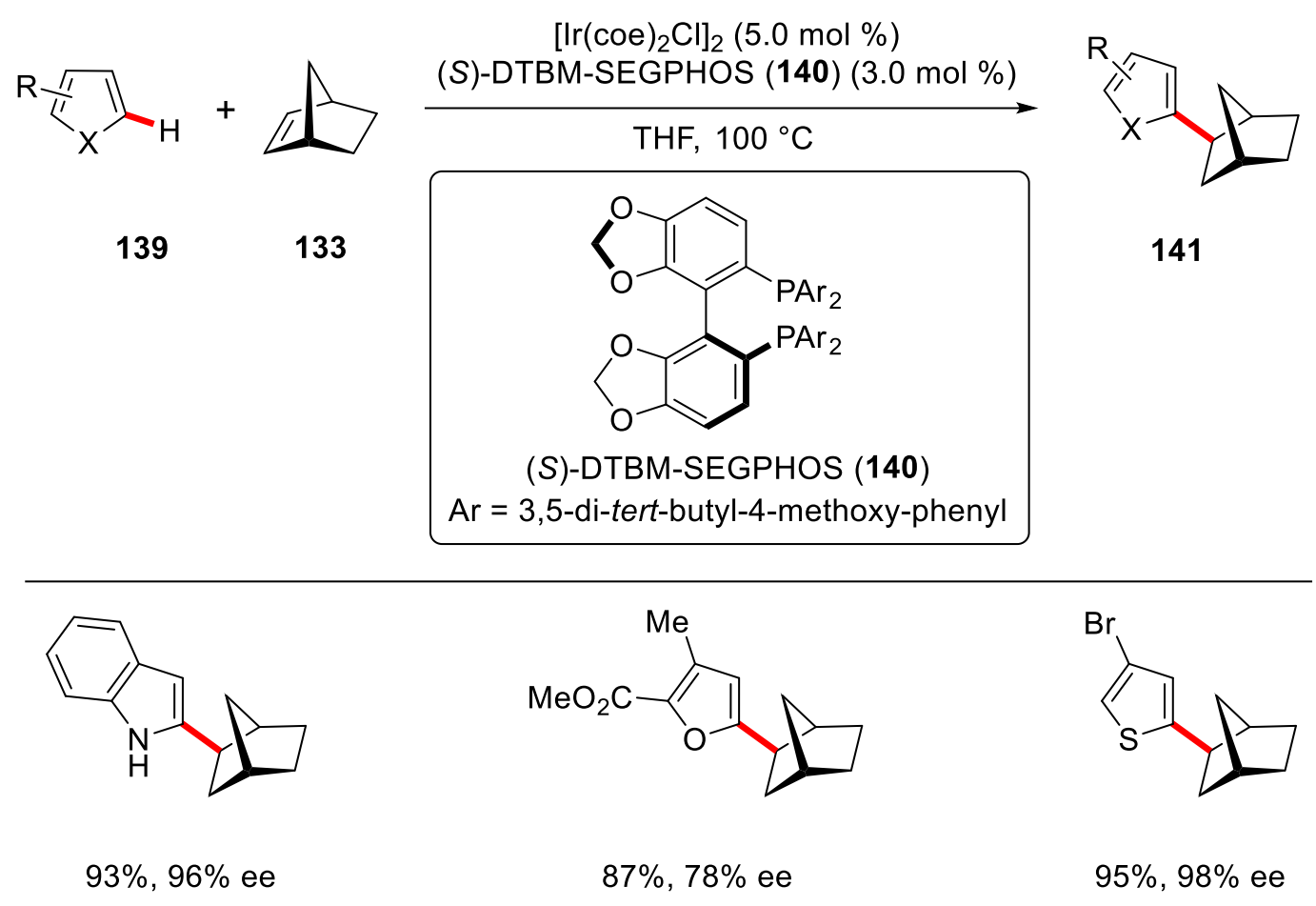

Scheme 39. Iridium-catalyzed enantioselective hydroarylation of bicycloalkanes.

Thereafter, a combination of cationic iridium complex and newly designed sulfur linked bis(phosphoramidite) ligand $[(R, R)-\mathrm{S}-\mathrm{Me}-\mathrm{BIPAM}] 143$ was applied by Yamamoto for amideand ketone-directed 142 enantioselective $\mathrm{C}-\mathrm{H}$ hydroarylation of bicycloalkanes 133 (Scheme 40). ${ }^{[126]}$ 


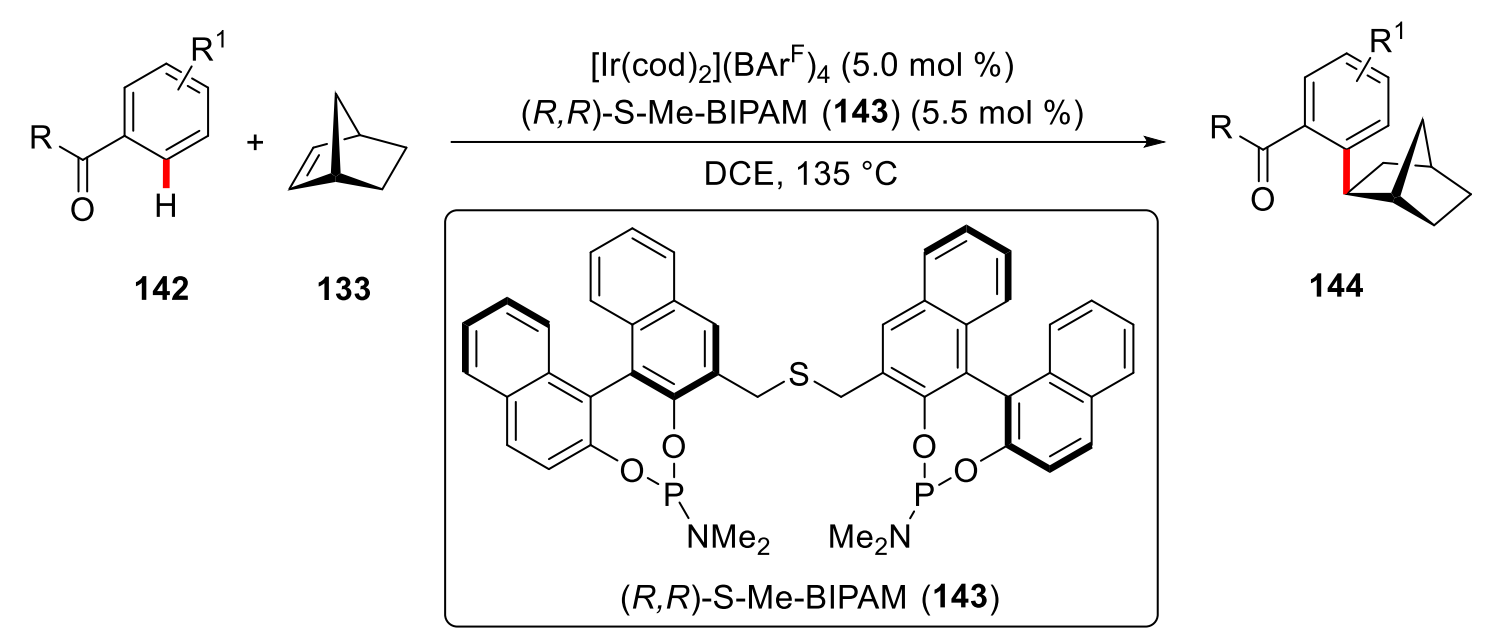

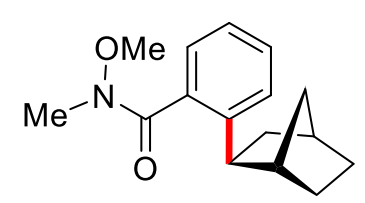

$64 \%, 99 \%$ ee

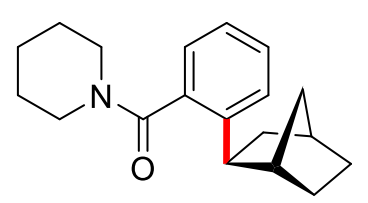

$91 \%, 99 \%$ ee

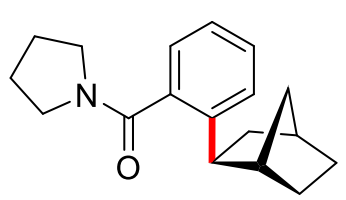

$91 \%, 97 \%$ ee

Scheme 40. Enantioselective additions to norbornenes 133.

Later, Nishimura observed a similar reactivity in an example of enantioselective $\mathrm{C}-\mathrm{H}$ alkylation of $N$-sulfonylbenzamides 145 using $(R, R)$-QuinoxP* as the chiral ligand (Scheme 41). ${ }^{[127]}$<smiles>Cc1cccc(C(=O)NS(=O)(=O)[O-])c1</smiles>

145

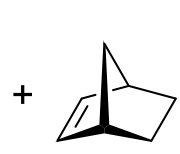

133

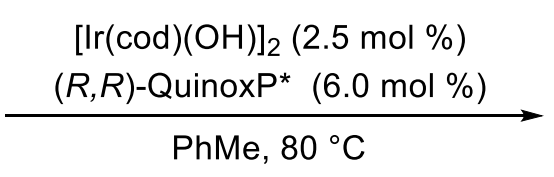

Single example 146: $98 \%, 81 \%$ ee

Scheme 41. Enantioselective C-H alkylation of $N$-sulfonylbenzamides 145.

While early enantioselective transformations were mainly limited to bicycloalkenes as olefin coupling partners, recently a broad variety of olefin partners has been employed. Intrigued by their previous racemic work on intermolecular $\mathrm{C} 2$-alkylation of $\mathrm{N}$-protected indoles with terminal alkenes, ${ }^{[128]}$ in 2015 Shibata applied a combination of iridium(I) catalyst and chiral diphosphine ligands $(S)$-SEGPHOS or $(S)$-Xyl-BINAP to enable the highly enantioselective intramolecular version of this protocol (Scheme 42). ${ }^{[129]} \mathrm{C} 3$-substituted ketone directed intramolecular C2 alkylations were achieved with this catalytic system to furnish highly enantioenriched annulated indoles 148 with high yields and enantioselectivities. 


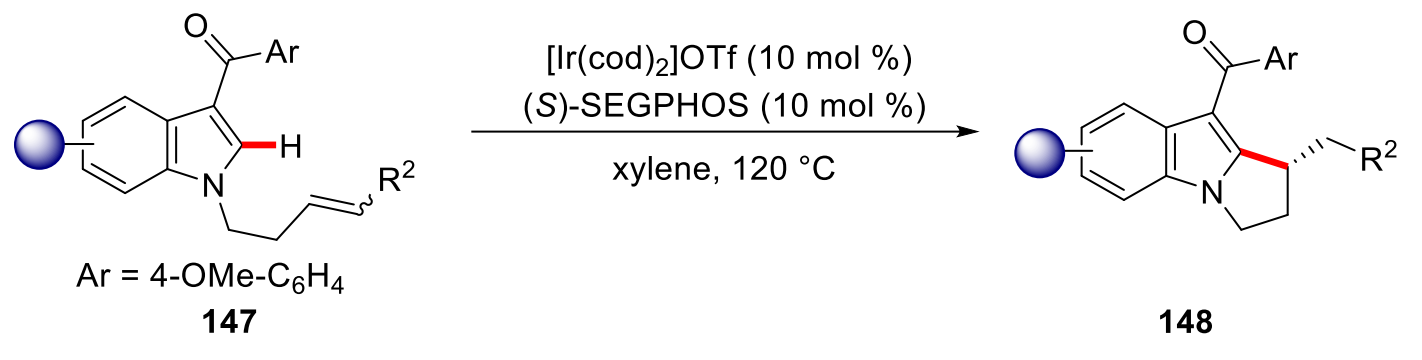<smiles>COc1cccc2c1c(C(=O)C(Br)Br)c1n2CCC1C</smiles>

$90 \%, 92 \%$ ee<smiles>CC1CCn2c1c(C(=O)Br)c1cc(Br)ccc12</smiles>

$61 \%, 91 \%$ ee<smiles>CC1CCn2c1c(C(=O)Br)c1cccc(F)c12</smiles>

$81 \%, 88 \%$ ee

Scheme 42. Enantioselective C-H alkylation of indole derivatives 148.

The same group reported a catalytic system which set the stage for first iridium-catalyzed enantioselective $\mathrm{C}\left(\mathrm{sp}^{2}\right)-\mathrm{H}$ alkylation of ferrocene by the aid of 1-isoquinolyl moiety 149 as the directing group (Scheme 43). ${ }^{[130]}$ The key to success was represented by the use of a combination of iridium(I) complex and an analogue of Carreira's diene ligand $\mathbf{1 5 0}$ to introduce planer chirality in ferrocene. ${ }^{[131]}$ Thus various sensitive functional groups on olefin coupling partners 38 were tolerated to afford the alkylated products $\mathbf{1 5 1}$ in good yields and excellent enantioselectivitites.

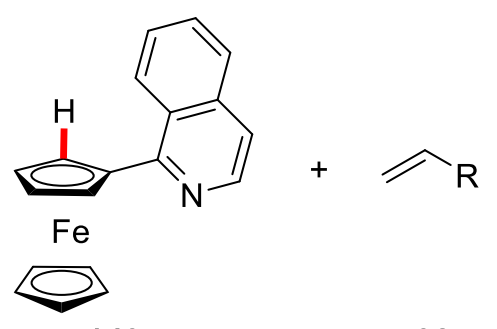

149

38

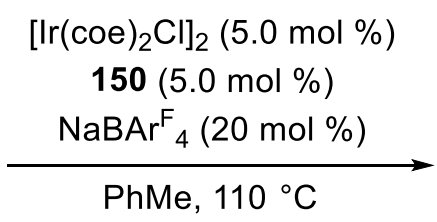

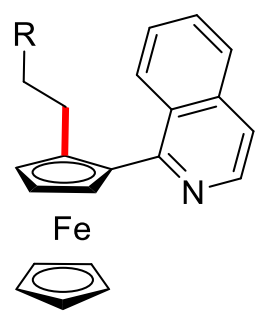

151

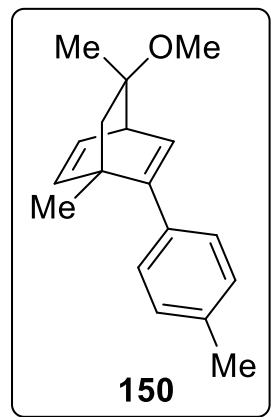

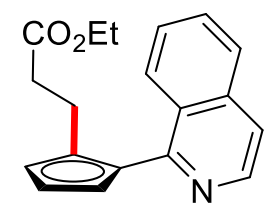

$\mathrm{Fe}$

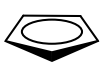

$88 \%, 90 \%$ ee

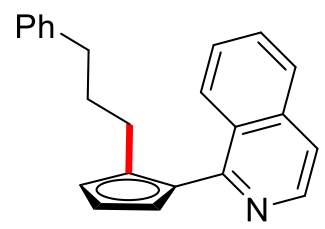

$\mathrm{Fe}$

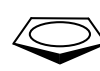

$83 \%, 88 \%$ ee

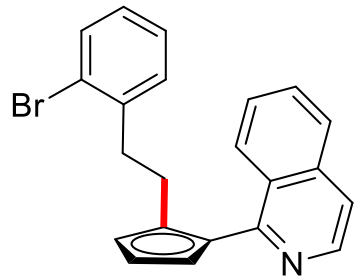

$\mathrm{Fe}$

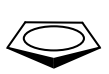

$92 \%, 83 \%$ ee

Scheme 43. Enantioselective C-H alkylation of ferrocenes 149. 
In contrast, efficient branch-selective, highly enantioselective iridium-catalyzed hydroarylations of styrenes and $\alpha$-olefins of anilides were disclosed. ${ }^{[132]}$ Key to success for achieving anilide 152 directed enantioselective ortho- $\mathrm{C}-\mathrm{H}$ activation was the development of a chiral bisphosphite ligand $\mathbf{1 5 3}$ to generate tertiary benzylic stereocenters in high enantioselectivity and high atom economy (Scheme 44a). Also, the authors extended this strategy to hydroheteroarylation of terminal olefins 38 with thiophene 155 using a ferrocenebased bisphosphonate ligand 156. With this tailored ligand 157, a diverse range of $\alpha$-olefins 38 were found as amenable substrates to provide the alkylated thiophenes 157 without compromising the yields and selectivities (Scheme 44b). 
(a) Enantioselective alkene hydroarylation

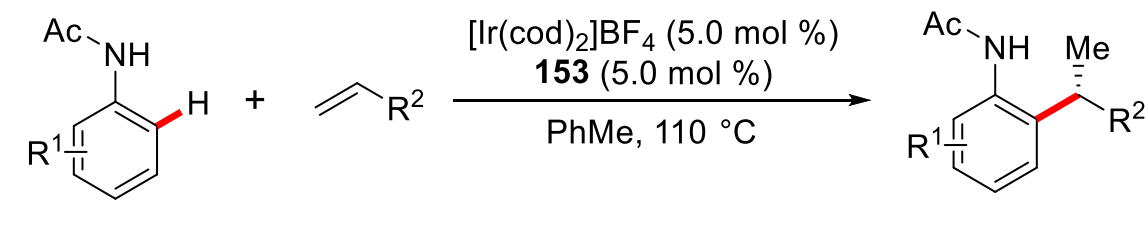

152

38

154<smiles>[CH2]C(=O)Nc1ccc(O)cc1[C@H](C)c1ccccc1</smiles>

$82 \%, 92.5: 7.5$ e.r.<smiles>C[C@H](c1ccccc1)c1ccc(Br)cc1NC1CC1</smiles>

$69 \%, 94: 6$ e.r.<smiles>CC(C)Nc1c(C(C)C(C)(C)C)ccc2c1CCC2</smiles>

$81 \%, 95: 5$ e.r.

(b) Enantioselective alkene hydroarylation

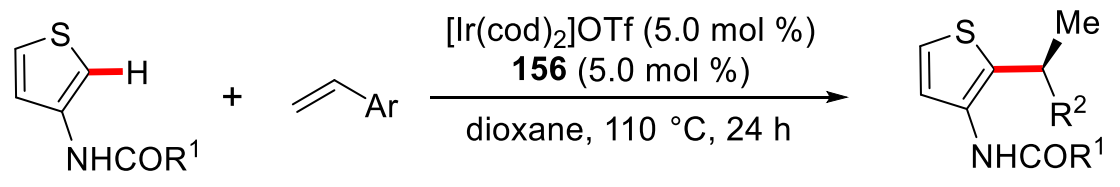

155<smiles>CC(C)C(=O)Nc1ccsc1[C@H](C)c1ccccc1</smiles>

$77 \%, 97.5: 2.5$ e.r.
38<smiles>CCCCC(C)c1sccc1NC(=O)C(C)C</smiles>

$83 \%, 98: 2$ e.r.<smiles>CC(C)C(=O)Nc1ccsc1[C@H](C)CCC[O-]</smiles>

$82 \%, 92: 8$ e.r.

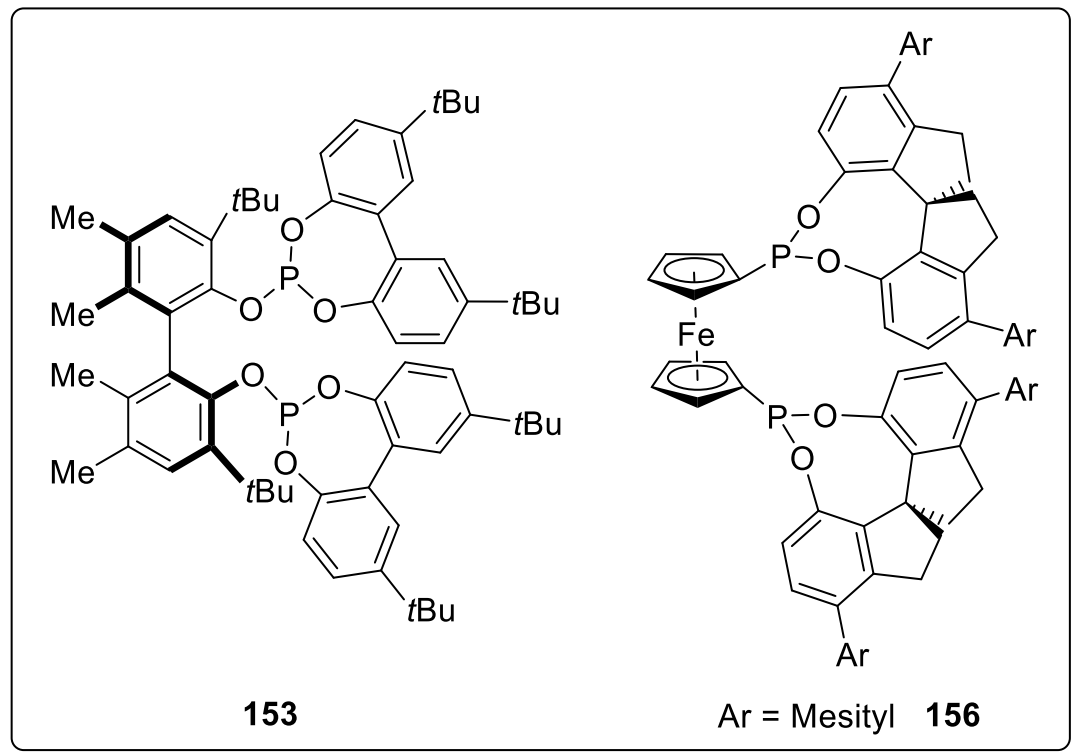

Scheme 44. Enantioselective hydroarylation of terminal olefins 38 . 
In line with intramolecular hydroarylations, Rueping and Cavallo, very recently, expanded this approach towards oxygen tethered internal olefins 158 through amide and ketone directed $\mathrm{C}-$ $\mathrm{H}$ activation (Scheme 45). ${ }^{[133]}$ Here the use of $(R, R)$-QuinoxP* as chiral ligand proved to be crucial to achieve high enantioselectivities with the combination of a cationic iridium(I) catalyst. Thus, biologically relevant chiral dihydrobenzofurans 159 were obtained. Notably, this protocol also provided access to quaternary stereocenter with high enantioselectivity, albeit with lower yield.

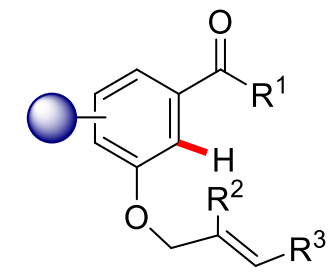

158 $\left[\operatorname{lr}(\operatorname{cod}) \mathrm{Cl}_{2}(2.5 \mathrm{~mol} \%)\right.$

$(R, R)$-QuinoxP* $(7.0 \mathrm{~mol} \%)$

$\frac{\mathrm{NaBAr}_{4}(10 \mathrm{~mol} \%)}{\mathrm{PhMe}, 70^{\circ} \mathrm{C}}$

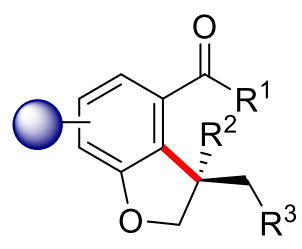

159<smiles>CC(=O)c1cccc2c1[C@@](C)(Cc1ccccc1)CO2</smiles>

$34 \%, 91 \%$ ee<smiles>CNC(=O)c1cccc2c1[C@H](Cc1ccccc1)CO2</smiles>

$80 \%, 91 \%$ ee<smiles>CC(=O)c1cccc2c1[C@H](Cc1ccccc1)CCO2</smiles>

$29 \%, 58 \%$ ee

Scheme 45. Enantioselective intramolecular $\mathrm{C}-\mathrm{H}$ alkylation.

Besides numerous reports on enantioselective $\mathrm{C}-\mathrm{H}$ alkylations, enantioselective hydroarylations of electron rich olefins using iridium complexes have remained elusive until very recently. ${ }^{[134]}$ In 2015 , Nishimura developed iridium catalyzed hydroarylation of vinyl ethers 160 via directed $\mathrm{C}-\mathrm{H}$ activation. Promising results were obtained after initial screening with chiral diene $(S, S)$-Fc-tfb*, which provided the desired chiral ether 161 with $77 \%$ ee (Scheme 46a). Later the same group succeeded to achieve highly enantioselective alkylation of $N$-sulfonylbenzamides 145 with vinyl ethers 160 utilizing an iridium complex bearing the chiral diene $(S, S)$-Me-tfb* (Scheme 46b). Moreover, the authors were able to expand this methodology to azoles containing $\mathrm{N}-\mathrm{H}$ bonds by the aid of a $(R, R)$-QuinoxP* ligand (Scheme 46c). 
(a)<smiles>c1ccc(-c2ccccn2)cc1</smiles>

93

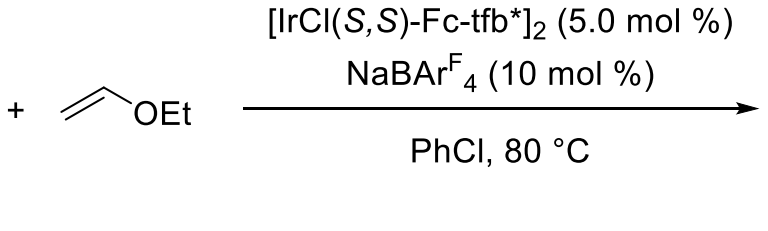

160

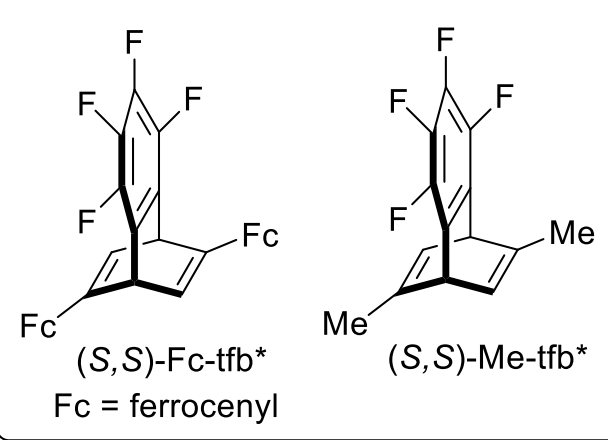

(b)<smiles>CCCOC=[C+]c1cccc(C)c1C(=O)NS(C)(=O)=O</smiles>

145

160<smiles>CCOC(C)=c1ccccc1=C(C)OCC</smiles>

161: $82 \%, 77 \%$ ee

(c)

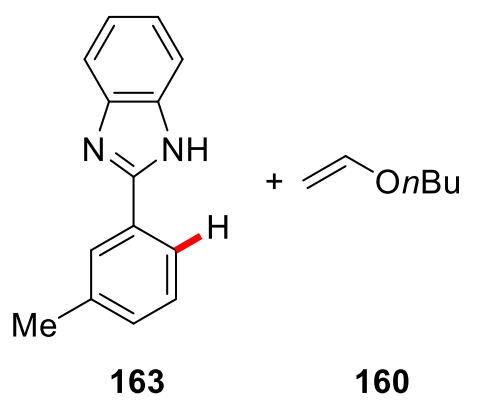

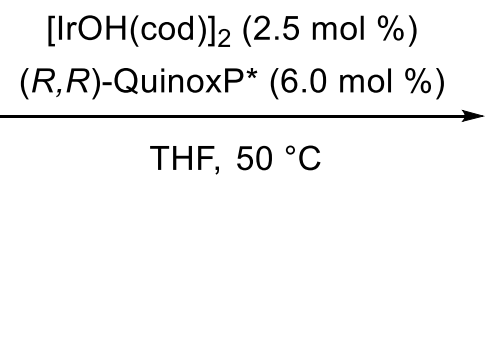<smiles>CCOC(C)c1ccc(C)cc1-c1nc2ccccc2[nH]1</smiles>

Scheme 46. Enantioselective hydroarylation of electron-rich olefins $\mathbf{1 6 0}$.

On a different note, the Shibata group in 2009 reported for the first time iridium-catalyzed enantioselective addition to carbon-heteroatom double bonds. ${ }^{[135]}$ A moderate enantioselectivity of $72 \%$ ee was observed when a chiral bisphosphine ligand was employed to synthesize enantioenriched oxindole derivative. Later, Yamamoto and coworkers were able to extend this protocol to high enantioselectivity using a chiral bidentate bis-phosphoramidite ligand 166 by the aid of an amide directing group (Scheme 47). ${ }^{[136]}$ 
<smiles>[R]C(=O)C(=O)Nc1cc([R])cc(C(=O)N(C)C)c1</smiles>

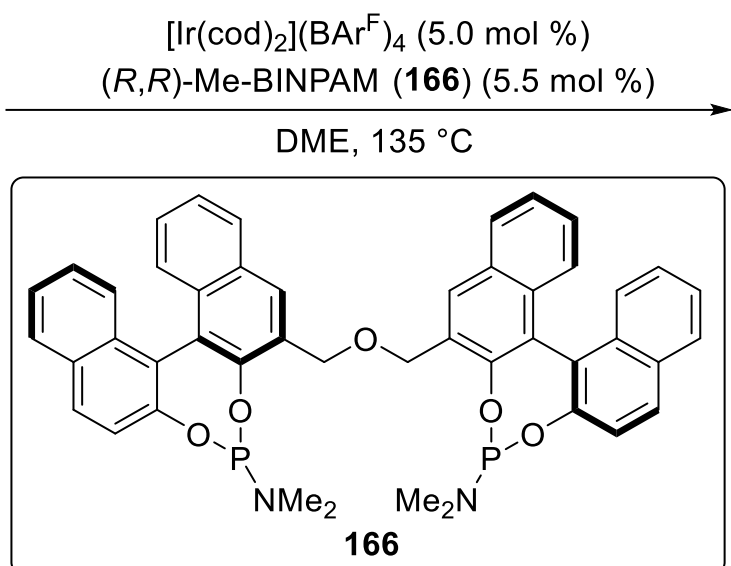<smiles>[R]c1cc2c(c(C(=O)N(C)[18F])c1)[C@@]([R])(O)CN2</smiles>

Scheme 47. Enantioselective intramolecular $\mathrm{C}-\mathrm{H}$ additions.

\subsubsection{Ruthenium Catalysis}

Over the past decades, versatile and cost-effective ruthenium(II) arene complexes ${ }^{[137]}$ have shown enormous success in various $\mathrm{C}-\mathrm{H}$ activation reactions. ${ }^{[27 \mathrm{t}, 39,138]}$ Despite of these major advances, enantioselective $\mathrm{C}-\mathrm{H}$ transformations with comparatively inexpensive ruthenium catalysts remains considerably underdeveloped.

Very recently, Cui and co-workers developed enantioselective ruthenium(II)-catalyzed intramolecular $\mathrm{C}-\mathrm{H}$ hydroarylations of nitrogen-tethered olefin aldehydes 168 (Scheme 48a). ${ }^{[139]}$ The key to success was represented by the use of a commercially available $\alpha$ methylamines 169 as chiral TDG for the synthesis of highly enantioenriched indoline derivatives 171. The optimization studies showed that addition of catalytic amounts of protected chiral carboxylic acid $\mathbf{1 7 0}$ was beneficial for the outcome of the reaction. Shortly after, Wang and coworkers concurrently achieved similar reactivities with the oxygen-tethered olefin aldehydes $\mathbf{1 7 2}$ by the aid of an $\alpha$-chiral amine as the chiral TDG (Scheme $48 \mathrm{~b}$ ). ${ }^{[140]}$ This methodology set the stage for the highly efficient synthesis of 2,3-dihydrobenzofurans $\mathbf{1 7 3}$, containing all-carbon quaternary stereocenters in high yields and excellent enantioselectivities. 
(a) Synthesis of indoline derivatives

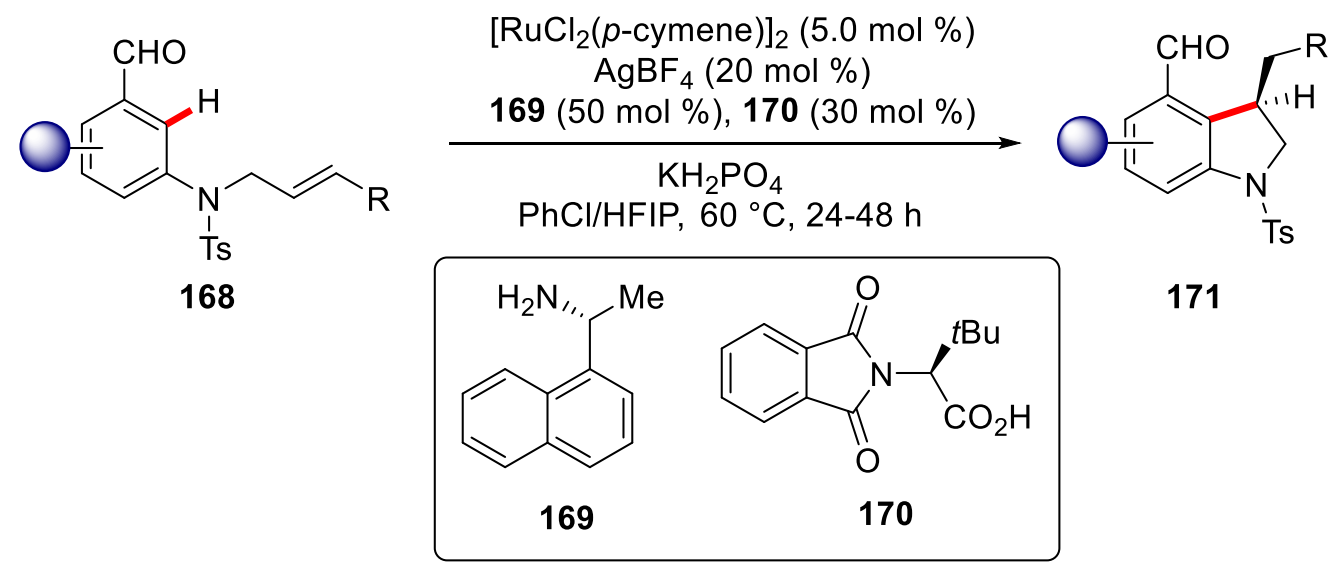<smiles>O=Cc1cccc2c1[C@H](Cc1ccccc1)CN2[13I]</smiles>

$87 \%, 94 \%$ ee<smiles>CCC1CN([13F])c2cccc(C=O)c21</smiles>

$92 \%, 96 \%$ ee<smiles>C[As](C)OCC[C@H]1CN([As])c2cccc(C=O)c21</smiles>

$76 \%, 91 \%$ ee

(b) Synthesis of 2,3-dihydrobenzofurans<smiles>[R]CC(=C)C[X]c1ccccc1C=O</smiles>

172

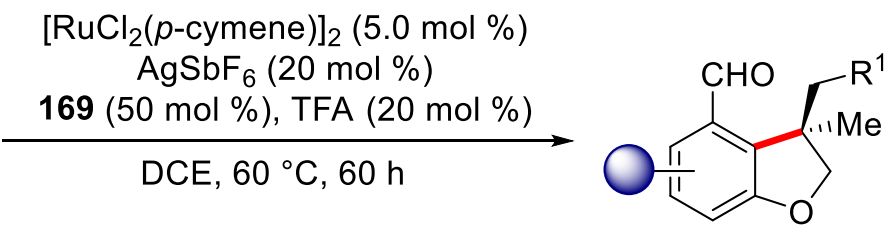

173<smiles>C[C@]1(COc2ccccc2)COc2cccc(C=O)c21</smiles>

$96 \%, 98 \%$ ee<smiles>C[C@]1(COBr)COc2ccc([N+](=O)[O-])c(C=O)c21</smiles>

$95 \%,>99 \%$ ee<smiles>CC(=O)OC[C@]1(C)CN(C)c2cccc(C=O)c21</smiles>

$18 \%, 70 \%$ ee

Scheme 48. Enantioselective ruthenium(II)-catalyzed C-H alkylation.

\subsubsection{Nickel Catalysis}

The complexes of nickel have emerged as efficient catalysts for their versatile applicationsin $\mathrm{C}-\mathrm{H}$ activation reactions ${ }^{[141]}$ with notable applications in hydroarylations ${ }^{[142]}$ type reactivity. ${ }^{[32 c]}$ 


\subsubsection{Intramolecular Reactions}

Over the past years, a significant progress has been observed for the nickel-catalyzed enantioselective intramolecular $\mathrm{C}-\mathrm{H}$ activations. In 2009, Nakao and Hiyama reported a racemic protocol for intramolecular $\mathrm{C}-\mathrm{H}$ alkylation of pyridines with tethered olefins by a cooperative nickel/Lewis acid manifold. ${ }^{[143]}$ Later, Cramer achieved preliminary success in enantioselective version of this protocol by using a chiral isoquinoline-based N-heterocyclic carbene $^{[144]} 176$ to provide endo-cyclized products 174 in 78.5:21.5 e.r. (Scheme 49a). ${ }^{[145]}$ Later, further improvement of this protocol was reported by the same group. A modified acenaphthene backbone contained NHC ligand 178, which was developed based on previous ligand design by Gawley, ${ }^{[146]}$ was found to be crucial to achieve excellent enantioselectivities in the presence of MAD (methylaluminium bis(2,6-di-tert-butyl 4-methylphenoxide) as a Lewis acid (Scheme 49b). ${ }^{[147]}$ Further developments in this direction were reported by Ye, where TADDOL-based HASPOs $\mathbf{1 8 0}$ were employed to promote nickel-aluminum bimetallic catalysis for highly enantioselective exo-selective intramolecular $\mathrm{C}-\mathrm{H}$ cyclization of imidazole derivatives 181 (Scheme 49c). ${ }^{[148]}$

Despite these advances, enantioselective cyclizations were limited to the use of pyrophoric organoaluminium reagents as additives ${ }^{[149]}$ which significantly restrict the substrate scope. To address this issue, Ackermann realized an aluminum-free reaction conditions for nickel catalyzed intramolecular highly enantioselective transformation. The unprecedented use of nickel/JoSPOphos ${ }^{[150]}$ manifold enabled the endo-cyclization of imidazoles with unactivated alkenes 182 (Scheme 49d). ${ }^{[151]}$

Later, Cramer employed chiral SIPR ligand 186 with bulky flanking groups for highly enantioselective nickel(0)-catalyzed endo-cyclization of indoles and pyrrole 185 (Scheme 49e). ${ }^{[152]}$ This approach was further extended by Shi to pyridines 188 utilizing a bulky chiral NHC ligand 189 in the presence of MAD as Lewis acid (Scheme 49f). ${ }^{[153]}$ Shortly thereafter, the same group devised similar strategy in the presence of a bulky chiral NHC ligand to synthesis enantioenriched fluorotetralins by achieving endo-selective $\mathrm{C}-\mathrm{H}$ annulation of polyfluoroarenes with excellent enantioselectivities. ${ }^{[154]}$ 
(a)<smiles>[R]C=C([R])CCn1c([2H])cccc1=O</smiles>

$\mathrm{Ni}(\operatorname{cod})_{2}(10 \mathrm{~mol} \%)$

175 (15 mol \%)

$\underset{\mathrm{PhMe}, 80^{\circ} \mathrm{C}, 24 \mathrm{~h}}{\stackrel{\mathrm{AlMe}_{3}(40 \mathrm{~mol} \%)}{\longrightarrow}}$

174<smiles>[R]C1c2cccc(=O)n2CC[C@@H]1[R]</smiles>

176: up to $57 \%$ ee

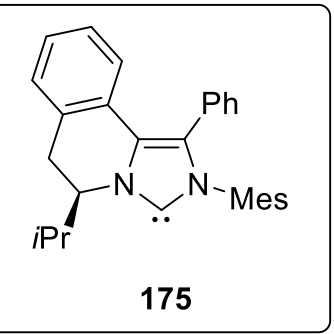

(b)

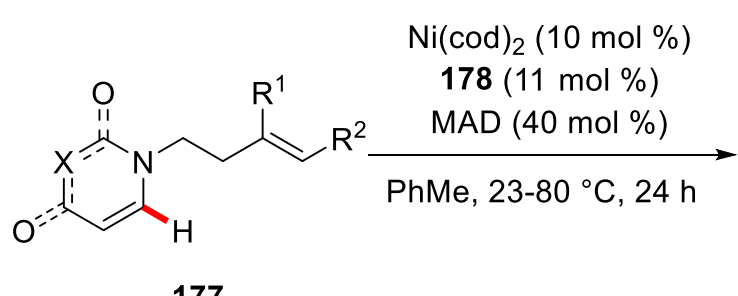

177<smiles>[R]C1CCn2c(cc(=O)[X]c2=O)C1[R]</smiles>

179: up to $98 \%$ ee

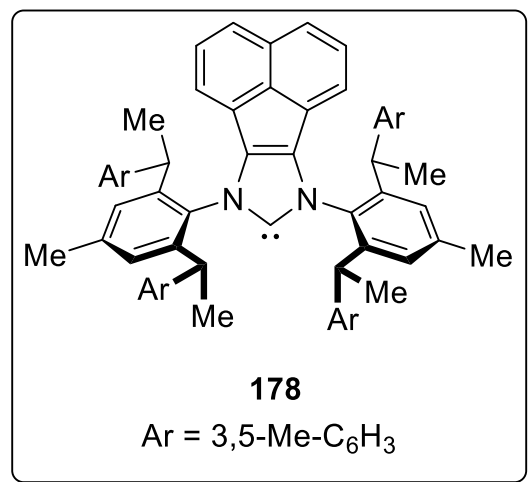

(c)<smiles>[R]C([R])=CCCn1c([TlH])nc2ccccc21</smiles>

179

(d)<smiles>[R]C(=C)CCn1c([2H])nc2ccccc21</smiles>

182

(e)<smiles>[R]C(=C)CCn1ccc2ccccc21</smiles>

185

(f)

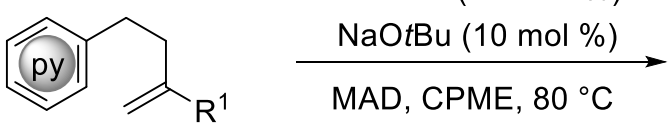

188

$\mathrm{Ni}(\operatorname{cod})_{2}(5.0 \mathrm{~mol} \%)$

$\mathrm{Ni}(\mathrm{cod})_{2}(5.0 \mathrm{~mol} \%)$

$186 \cdot \mathrm{HCl}(5.5 \mathrm{~mol} \%)$

$\mathrm{NaOtBu}(25 \mathrm{~mol} \%)$

$\mathrm{Ni}(\operatorname{cod})_{2}(5.0 \mathrm{~mol} \%)$

$189 \cdot \mathrm{HCl}(5.5 \mathrm{~mol} \%)$

MAD, CPME, $80^{\circ} \mathrm{C}$
$\mathrm{Ni}(\mathrm{cod})_{2}(5.0 \mathrm{~mol} \%)$ HASPO $180(5.0 \mathrm{~mol} \%)$ $\underset{\mathrm{PhMe}, 100{ }^{\circ} \mathrm{C}, 1-5 \mathrm{~h}}{\mathrm{AlMe}_{3}(20 \mathrm{~mol} \%)}$

181: up to $99 \%$ ee

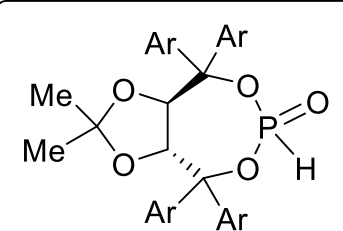

HASPO 180

$\mathrm{Ar}=3,5-\mathrm{tBu}-\mathrm{C}_{6} \mathrm{H}_{3}$
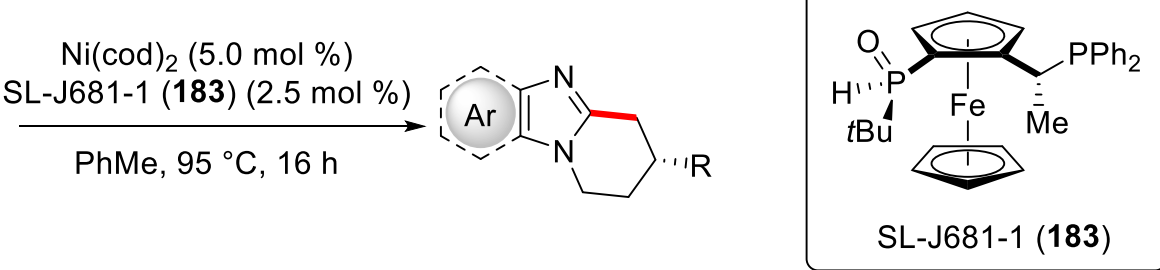

184: up to $98 \%$ ee<smiles>[R]C1CCn2c(nc3ccccc32)C1</smiles>

187: up to $95 \%$ ee

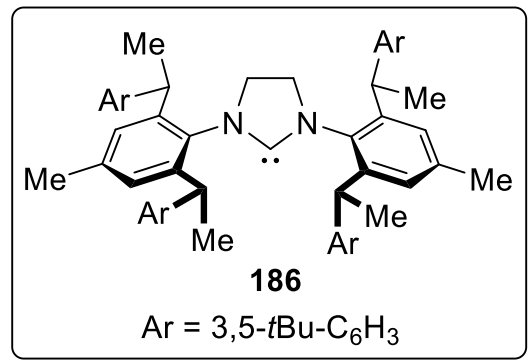

190: up to $99 \%$ ee

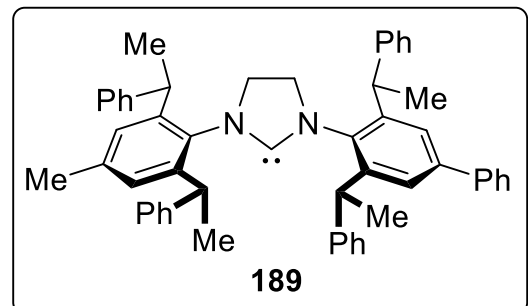

Scheme 49. Nickel-catalyzed enantioselective intramolecular $\mathrm{C}-\mathrm{H}$ activations. 


\subsubsection{Intermolecular Reactions}

Although numerous studies have been conducted on nickel-catalyzed intramolecular enantioselective hydroarylations, enantioselective intermolecular $\mathrm{C}-\mathrm{H}$ activations remain extremely scarce in the literature. Inspired by the previous racemic work on nickel/NHC catalyzed three-component coupling by Fukuzawa, ${ }^{[155]}$ an enantioselective version of this protocol was reported by Cramer and coworkers using a novel chiral NHC ligand 193 (Scheme 50). ${ }^{[156]}$ The key to success was the use of flanking $N$-aryl substituted Grubbs-type chiral $\mathrm{NHC}^{[157]} 193$ to provide annulated indanols 194 in a highly enantioselective fashion.

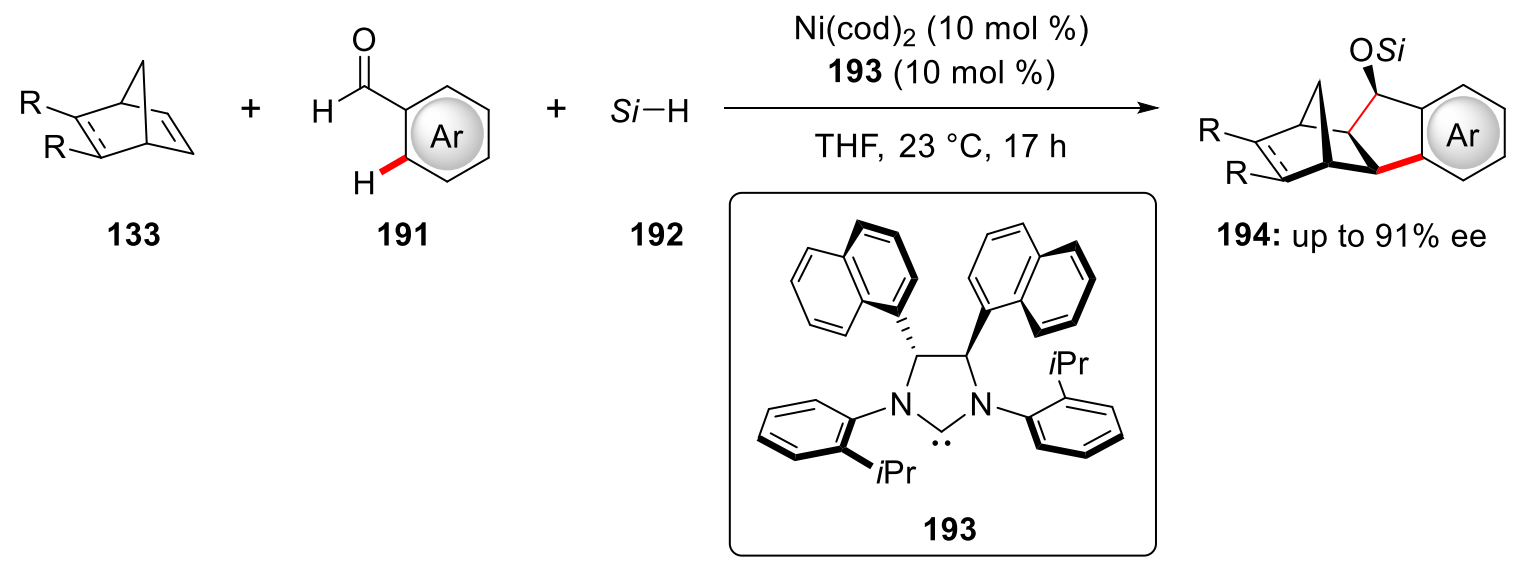

Scheme 50. Enantioselective reductive three-component coupling.

\subsubsection{Cobalt Catalysis}

Over the last few decades, cobalt complexes have turned out to be among most promising $3 \mathrm{~d}$ metals with numerous application to the functionalization of inert $\mathrm{C}-\mathrm{H}$ bonds. ${ }^{[31,32 \mathrm{~d}, 32 \mathrm{f}, 32 \mathrm{~g}, 32 \mathrm{j}]}$ In general, these reactions can be performed by two strategies. (a) So-called low-valent cobalt catalysis: ${ }^{[32 i]}$ These are commonly performed under reductive conditions, where readily available cobalt(II) salt are reduced in situ to form either a cobalt(0) complex or, more commonly, a cobalt(I)-complex, which undergoes oxidative addition to promote the functionalization. (b) Cobalt(III) catalysis is mainly performed using bench-stable high-valent cobalt(III) catalysts with cyclopentadienyl ligands. ${ }^{[32 f]}$ Early developments in the field of enantioselective cobalt-catalyzed $\mathrm{C}-\mathrm{H}$ functionalizations have been realized using low-valent cobalt chemistry.

\subsubsection{Cobalt Catalysis under Reductive Conditions}

In 2014, Yoshikai utilized a combination of $\mathrm{CoCl}_{2}$ as the catalyst and $(R, R)$-BDPP as the optimal chiral phosphine ligand to promote intramolecular hydroacylation of 2- 
alkenylbenzaldehydes 195 to deliver highly enantioenriched indanones 197 (Scheme 51a). ${ }^{[158]}$ The authors further extended this protocol to 2-acylbenzaldehydes 198 using a catalytic system of $\mathrm{CoBr}_{2}$ and $(R, R)-\mathrm{Ph}-\mathrm{BPE}$ for the synthesis of phthalides $\mathbf{2 0 0}$ building blocks in high enantioselectivity (Scheme 51b). Cobalt-chiral diphosphine catalytic systems provided the phthalide and indanone derivatives in good yields and with high enantio-control.

(a) Hydroacylation of olefins<smiles>[R]C(=C)c1ccccc1C=O</smiles>

195

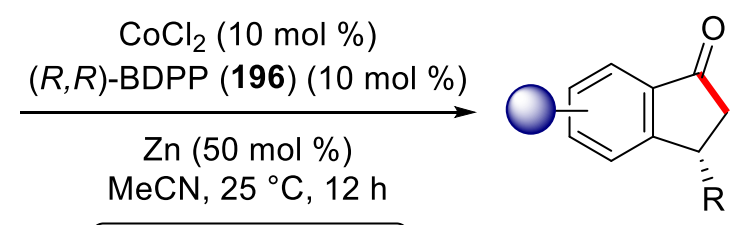

197<smiles>O=C1C[C@H](c2ccccc2)c2ccccc21</smiles>

$95 \%, 97 \%$ ee<smiles>CC1CC(=O)c2ccccc21</smiles>

$94 \%, 97 \%$ ee<smiles>CC1CC(=O)c2ccc(F)cc21</smiles>

$81 \%, 97 \%$ ee

(b) Hydroacylation of ketones<smiles>[R]C(=O)c1ccccc1C=O</smiles>

198

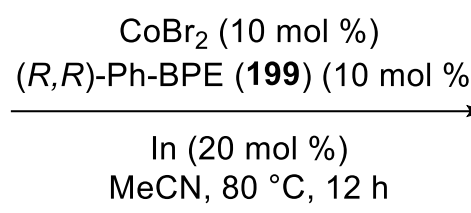

$\mathrm{MeCN}, 80^{\circ} \mathrm{C}, 12$

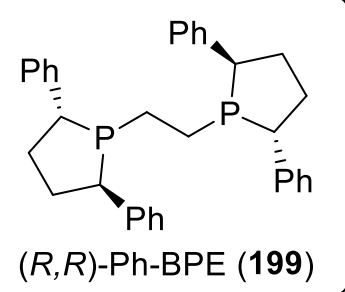<smiles>[R]C1OC(=O)c2ccccc21</smiles>

200<smiles>COc1ccc2c(c1)C(C)OC2=O</smiles>

$97 \%, 93 \%$ ee<smiles>CCOC(=O)c1ccc2c(c1)C(=O)OC2C</smiles>

$91 \%, 93 \%$ ee<smiles>O=C1OC(c2ccccc2)c2ccccc21</smiles>

$92 \%, 91 \%$ ee

Scheme 51. Enantioselective cobalt-catalyzed intramolecular hydroacylations.

Later, the same group extended this approach to more challenging trisubstituted alkenes for the step-economical synthesis of 2,3-disubstituted indanones 202 (Scheme 52). ${ }^{[159]}$ The authors achieved hydroacylations of 2-alkenylbenzaldehydes 201 bearing a trisubstituted olefin by 
using a catalytic system of $\mathrm{CoBr}_{2}$ and $(R, R)$-BDPP to provide the corresponding chiral cyclic ketones 202 in high yields and enantioselectivities. Notably, the outcome of the reaction was only hardly influenced by the $E / Z$ ratio of the starting olefin substrates.<smiles>[R]C=C([R])c1ccccc1C=O</smiles>

201

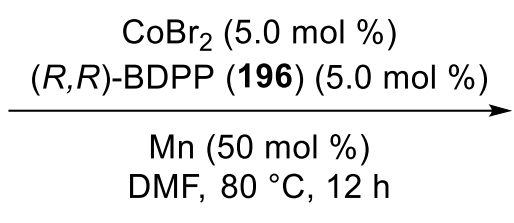

DMF, $80^{\circ} \mathrm{C}, 12 \mathrm{~h}$

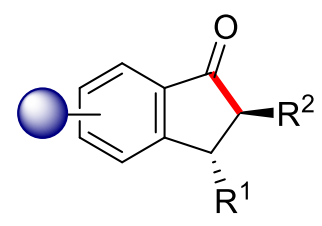

202<smiles>CCCCC1C(=O)c2cc(Cl)ccc2C1CCC</smiles>

$83 \%, 89 \%$ ee<smiles>O=C1c2c(ccc3ccccc23)C(c2ccccc2)C1c1ccccc1</smiles>

$87 \%, 86 \%$ ee<smiles>COc1ccc2c(c1)C(=O)C(c1ccccc1)C2C</smiles>

$89 \%, 98 \%$ ee

Scheme 52. Hydroacylation of trisubstituted alkenes 201.

Shortly thereafter, the versatile cobalt catalysis was applied by Dong and coworkers for a unique desymmetrization protocol for the intramolecular hydroacylation process to construct strained four-membered cyclobutanone derivatives 204 (Scheme 53). ${ }^{[160]}$ The authors were able to control the regioselectivity to enable the formation of four-membered cyclobutanone 204 in preference to the five-membered regioisomers. A cobalt catalyst derived from chiral diphosphine ligand $(S, S)$-BDPP enabled the synthesis of strained cyclobutanones 204 from $\alpha$ substituted dienyl aldehydes $\mathbf{2 0 3}$ with quaternary and tertiary stereogenic centers in high yields and with high enantioselectivities.<smiles>C=CC(C=C)[C@@H](Br)C=C</smiles>

203

$85 \%, 91 \%$ ee

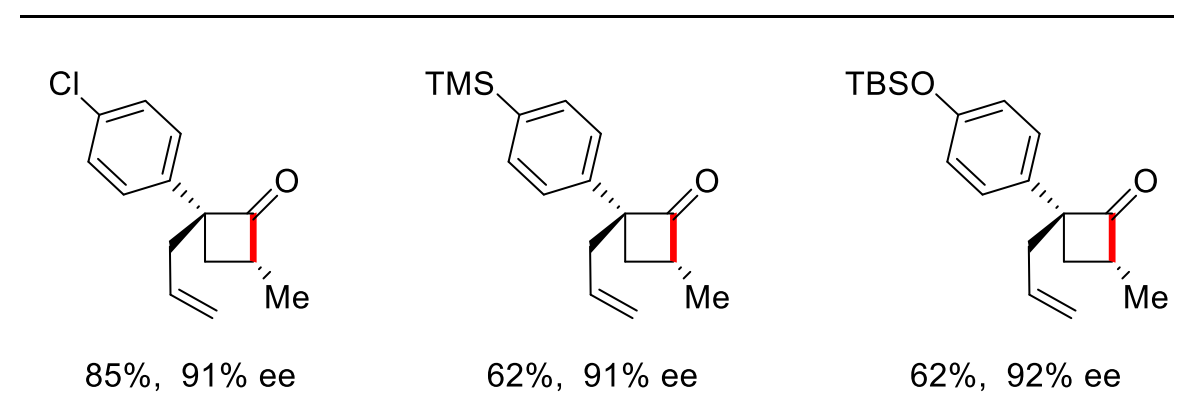

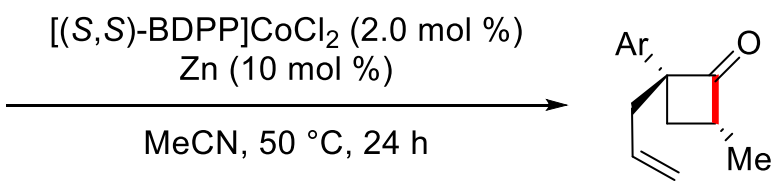

204

Scheme 53. Enantioselective hydroacylation towards cyclobutanes 204. 
In 2016, Yoshikai unraveled the low-valent cobalt catalyzed enantioselective $\mathrm{C}-\mathrm{H}$ alkylation of indole derivatives 205 with styrenes $48 .{ }^{[161]}$ Imine-directed $\mathrm{C}-\mathrm{H}$ alkylation was achieved in the presence of $\mathrm{Co}(\mathrm{acac})_{2}$ as catalyst and BINOL-derived phosphoramidiateds 206 as chiral ligand. Thus, enantioenriched 1,1-diarylethane derivatives were obtained in high yields and with high enantioselectivities.<smiles>CC(C)(C)On1c(/C=N\N=[W])cc2ccccc21</smiles>

205

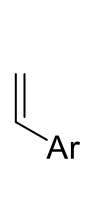

48

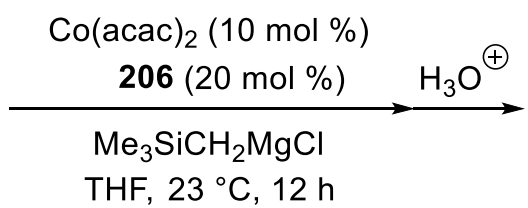

$\mathrm{THF}, 23^{\circ} \mathrm{C}, 12 \mathrm{~h}$

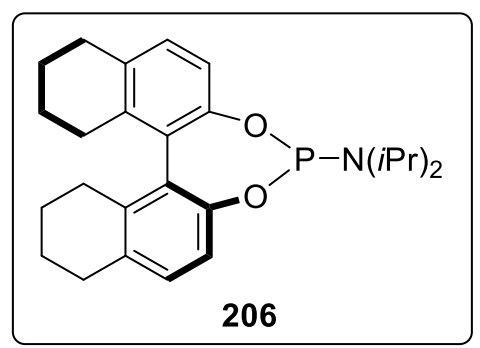

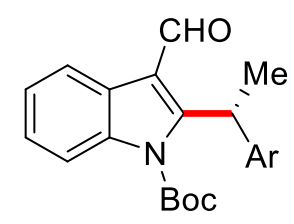

207<smiles>COc1ccc(C(C)c2c(C=O)c3ccccc3n2C(=O)c2ccccc2)cc1</smiles>

$88 \%, 86 \%$ ee<smiles>CC(c1cccc(Cl)c1)c1c(C=O)c2ccccc2n1C(=O)O</smiles>

$78 \%, 73 \%$ ee<smiles>COc1ccc(Cn2c([N+](=O)[O-])c(C=O)c3ccc(F)cc32)cc1</smiles>

$72 \%, 87 \%$ ee

Scheme 54. Enantioselective cobalt-catalyzed hydroarylation of styrenes $\mathbf{4 8}$.

\subsubsection{Iron Catalysis}

Iron is by far the most naturally abundant transition metal on Earth. Iron chemistry is promoted by low cost and low toxicities as well as a broad array of various oxidation states. This has been reflected in the increasing use of iron catalysts in molecular syntheses, pharmaceutical and agrochemical industries. ${ }^{[162]}$ This has set the stage for catalytic iron-catalyzed organometallic $\mathrm{C}-\mathrm{H}$ functionalization processes. While the field of iron-catalyzed $\mathrm{C}-\mathrm{H}$ activation is emerging, still the development of enantioselective $\mathrm{C}-\mathrm{H}$ transformation is highly desirable.

On this note, in 2018 Ackermann succeed to achieve first highly enantioselective ironcatalyzed organometallic $\mathrm{C}-\mathrm{H}$ activation (Scheme 55). ${ }^{[163]}$ The authors reported enantioselective $\mathrm{C}-\mathrm{H}$ secondary alkylation of (aza)indoles by the design of a novel bulky meta1-adamantyl substituted NHC 209 ligand which proved to be crucial for a high level of 
enantiocontrol. A plethora of diversely substituted indoles and azaindoles $\mathbf{2 0 8}$ were tested with styrenes and vinylmetallocenes $\mathbf{4 8}$ under the optimized reaction conditions. Thus, chiral C2alkylated products $\mathbf{2 1 0}$ were obtained in excellent yields and enantioselectivities.

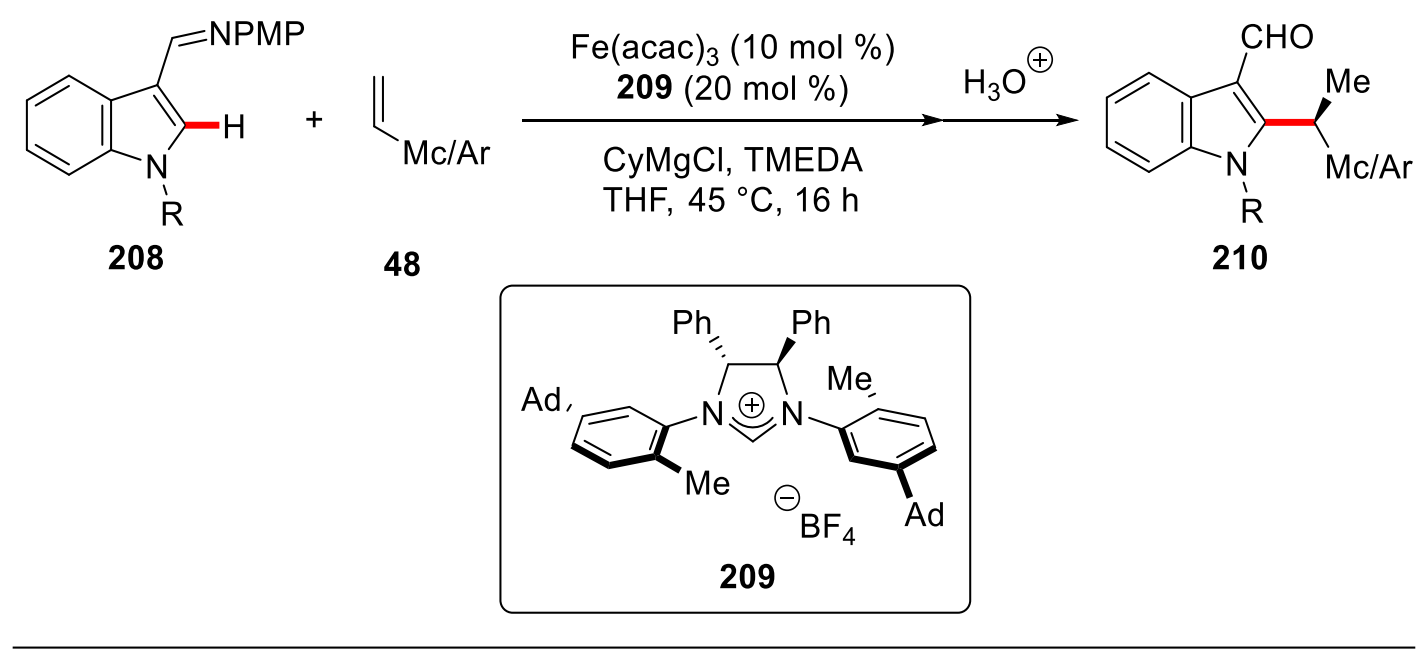<smiles>COc1ccc2c(c1)c(C=O)c(C(C)F)n2Cc1ccccc1</smiles>

$77 \%, 96: 4$ e.r.

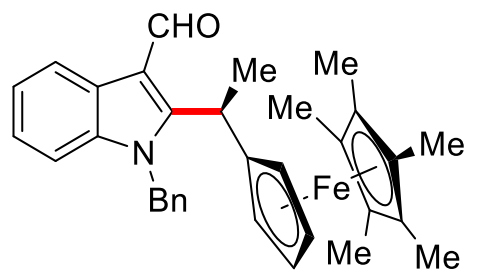

$58 \%, 95: 5$ e.r.<smiles>CC(F)c1c(/C=N\N)c2cccnc2n1Cc1ccccc1</smiles>

$53 \%, 90: 10$ e.r.

Scheme 55. Enantioselective iron-catalyzed C-H secondary alkylation. 


\subsection{Transition Metal-Catalyzed Oxidative $\mathrm{C}-\mathrm{H}$ Activation towards Resource Economy}

Transition metal-catalyzed $\mathrm{C}-\mathrm{H}$ activation has emerged as viable tool for molecular synthesis due to its high atom- and step-economy. ${ }^{[27,56]}$ In this regard, oxidative $\mathrm{C}-\mathrm{H}$ transformations are particularly attractive as they avoid the use of prefunctionalization. Yet, oxidant economy significantly contradicts the sustainable nature of synthetically attractive oxidative $\mathrm{C}-\mathrm{H}$ transformations. Unfortunately, oxidative $\mathrm{C}-\mathrm{H}$ activations heavily rely on expensive and toxic chemical oxidants including hypervalent iodine(III) and copper(II) or silver(I) salts, generating stoichiometric amounts of undesired chemical waste. Also, in recent years use of molecular oxygen has gained certain attention as terminal oxidant ${ }^{[164]}$ but its use with highly flammable organic solvents imposes safety issues. ${ }^{[165]}$

\subsubsection{Palladium-Catalyzed C-H Olefinations with Chemical Oxidants}

Mizoroki-Heck couplings have huge impact on synthetic chemistry for $\mathrm{C}-\mathrm{C}$ bond formation reactions. ${ }^{[15 b}$, 166] Given the significantly high importance of olefination reactions, Fujiwara-Moritani reaction even offers a better strategy for the introduction of olefins into arene $\mathrm{C}-\mathrm{H}$ bonds as it avoids the preactivation of the substrates. ${ }^{[167]}$ Yet, the use of large excess of substrates and lack of site-selectivity have jeopardized the application of Fujiwara-Moritani reaction to an extent. Thus, over the past decades directing group assisted $\mathrm{C}-\mathrm{H}$ activation has

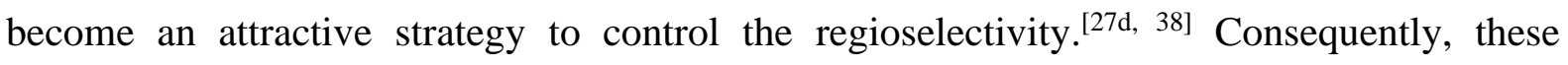
oxidative transformations are largely depended on the use of chemical oxidants for the reoxidation of metal centers. Here few representative examples have been provided to highlight the necessity of the expensive and toxic chemical oxidants for successful outcome of the palladium-catalyzed olefination reactions.

In an elegant study by De Vries and Van Leeuwen in 2002, palladium-catalyzed oxidative olefinations of anilides 211 were achieved at room temperature (Scheme 56a). ${ }^{[168]} 2.0 \mathrm{~mol} \%$ $\mathrm{Pd}(\mathrm{OAc})_{2}$ was employed as catalyst in combination with 3.0 equiv of BQ as terminal oxidant to obtain optimal yields for the olefination protocol.

In a related study, Shi reported palladium-catalyzed ortho-olefination of $N, N$ dimethylbenzylamines 213 (Scheme 56b). ${ }^{[169]}$ Among a series of tested chemical oxidants, stoichiometric amounts $\mathrm{Cu}(\mathrm{OAc})_{2}$ was found to be the best oxidant for this transformation. 
(a) Olefination of anilides<smiles>[R]C(=O)Nc1ccccc1</smiles>

211

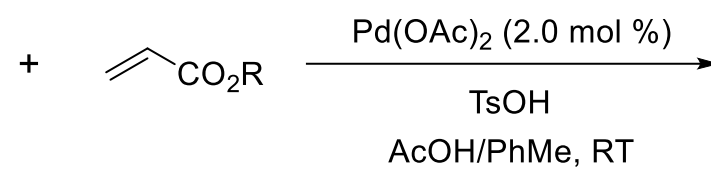

38<smiles>[R]OC([R])=CCc1ccccc1NC([R])=O</smiles>

212

(b) Olefination of N,N-dimethylbenzylamines<smiles>CN(C)Cc1ccccc1</smiles>

213<smiles>[R17]C([R])=C</smiles>

38

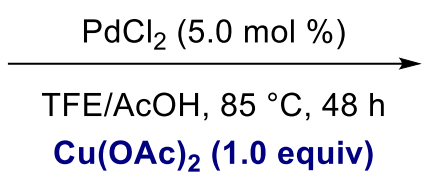

$\mathrm{Cu}(\mathrm{OAc})_{2}$ ( 1.0 equiv)<smiles>[R]C(=CC=[R])c1ccccc1CN(C)C</smiles>

214

Scheme 56. Palladium-catalyzed ortho-olefination in presence of chemical oxidants.

Later, Chang disclosed oxidative alkenylation and arylation of pyridine $N$-oxides 215 in the presence of silver based oxidant (Scheme 57). ${ }^{[170]}$

(a) alkenylation of pyridine $\mathrm{N}$-oxide<smiles></smiles>

215<smiles>C=CC(C)(C)C</smiles>

38

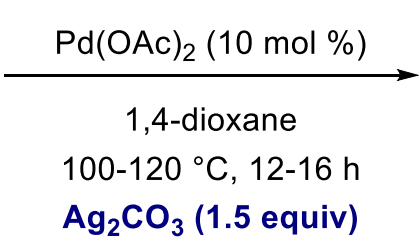

$\mathrm{Ag}_{2} \mathrm{CO}_{3}$ ( 1.5 equiv)<smiles></smiles>

216

(b) arylation with arenes<smiles>[O-][n+]1ccccc1</smiles>

215<smiles>c1ccccc1</smiles>

216

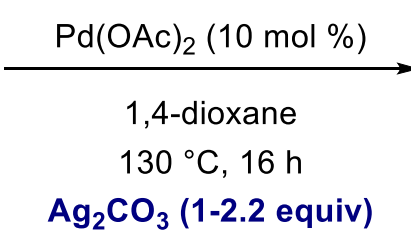

$\mathrm{Ag}_{2} \mathrm{CO}_{3}$ (1-2.2 equiv)

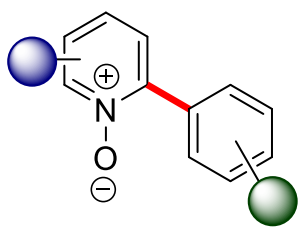

217

Scheme 57. Palladium-catalyzed oxidative alkenylation and arylation with silver-based oxidants.

In 2010, ortho-C-H olefination reaction for phenylacetic acids 218 was disclosed using oxygen at atmospheric pressure as the terminal oxidant (Scheme 58). ${ }^{[171]}$ 


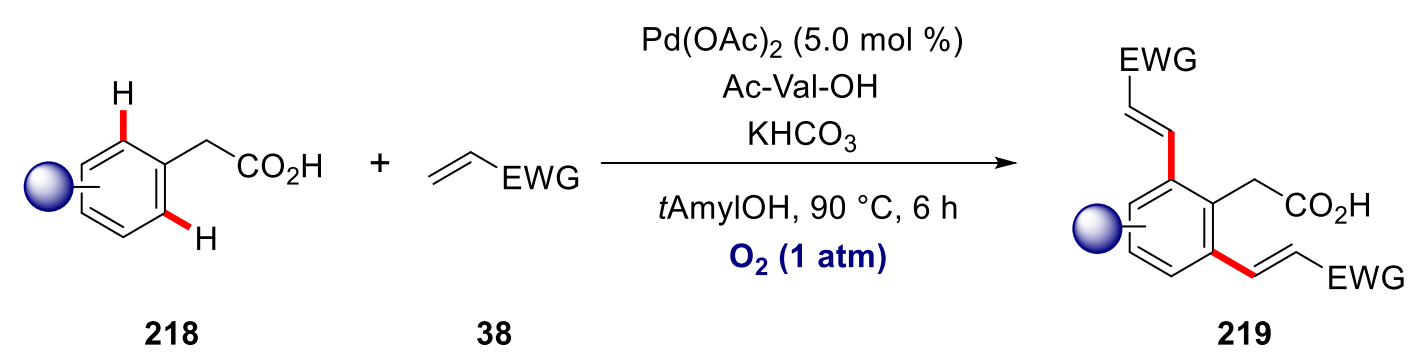

Scheme 58. Oxygen as terminal oxidant in ortho-C-H olefination reaction.

In 2010, a protocol for palladium-catalyzed $\mathrm{C}\left(\mathrm{sp}^{3}\right)-\mathrm{H}$ olefination was documented (Scheme 59). ${ }^{[172]}$ A superstoichiometric mixture of $\mathrm{Cu}(\mathrm{OAc})_{2}$ and $\mathrm{AgOAc}$ as oxidants provided the highest yield for this olefination protocol with a fancy directing group.<smiles>[R10]CC1CC([R1])C(=O)N1[13C](=O)[O-]</smiles>

Scheme 59. Palladium-catalyzed oxidative $\mathrm{C}\left(\mathrm{sp}^{3}\right)-\mathrm{H}$ olefination.

These examples set the stage for the further developments in palladium-catalyzed oxidative transformations with chemical oxidants with notable contributions from Gevorgyan, ${ }^{[173]}$ Shi, ${ }^{[174]} \mathrm{Yu},{ }^{[175]}$ among others. ${ }^{[27 \mathrm{~m}]}$

Despite these advances, the vast majority of $\mathrm{C}-\mathrm{H}$ olefination reactions required activated or electronically-biased olefins, such as acrylates and styrenes. In 2014, Maiti reported C-H olefination reactions with unactivated alkenes 223 as coupling partners (Scheme 60). ${ }^{[176]}$ The authors disclosed palladium-catalyzed chelation-assisted $\mathrm{C}-\mathrm{H}$ alkenylation of phenylacetic acid derivatives 222 with unbiased aliphatic alkenes 223 by the aid of 8 -aminoquinoline as the directing group. The key to success was the use of rac-BINAM as the ligand for this oxidative alkenylation protocol with 1 equiv of BQ under atmospheric pressure of oxygen as the oxidant.

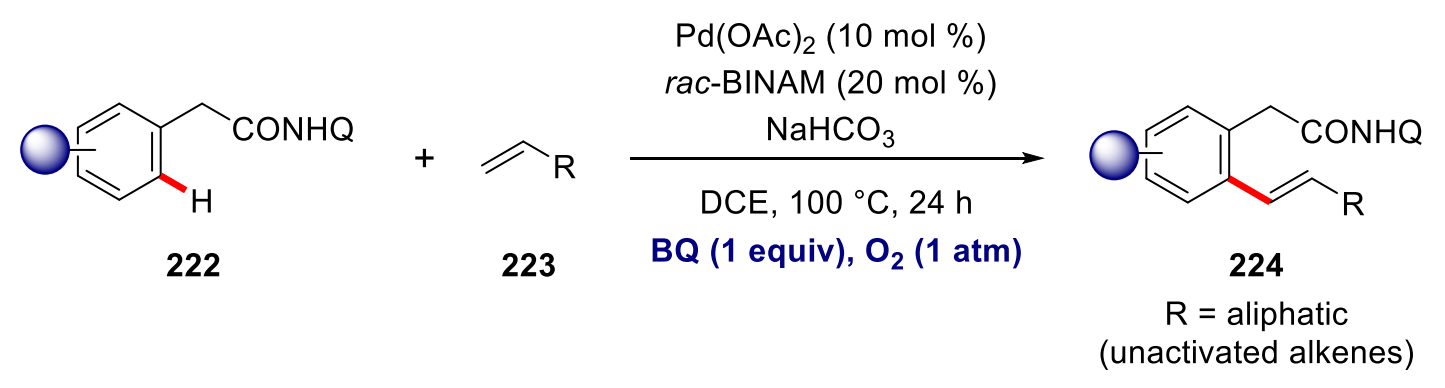

Scheme 60. Palladium-catalyzed $\mathrm{C}-\mathrm{H}$ olefination with unbiased olefins under oxygen atmosphere. 
In addition to the aforementioned reports, oxidative olefinations have also emerged as an attractive strategy for the enantioselective transformations including desymmetrization reactions and atroposelective transformations which have been comprehensively discussed in the previous chapter (cf. chapter 1.3.1.). ${ }^{[41 \mathrm{a}, 57-58,63 \mathrm{a}]}$

Other than directing group assisted $\mathrm{C}-\mathrm{H}$ activation, ${ }^{[27 \mathrm{~d}, 38]}$ ligand-assisted palladium catalyzed Fujiwara-Moritani type reaction has recently gained certain momentum. ${ }^{[177]}$ In 1969 , in a pioneering work palladium-catalyzed Fujiwara-Moritani reaction was reported to form $\mathrm{C}-\mathrm{C}$ bonds under oxidative conditions (Scheme 61a). ${ }^{[167 a, 178]}$ Later, Yu's study disclosed oxidative olefinations of electron-deficient arenes in the presence of 2,6-dialkylpyridine ligands. Significant contributions have also been made in the ligand-accelerated $\mathrm{C}-\mathrm{H}$ olefination reactions by $\mathrm{Yu},{ }^{[179]}$ Sanford ${ }^{[180]}$ Stahl. ${ }^{[181]}$ In these studies mainly pyridines $\mathbf{2 2 6}$ or 227 have been identified as the best ligands for the Fujiwara-Moritani reactions of simple arenes (Scheme 61b). Very recently, Fernández-Ibáñez identified inexpensive bidentate S,Oligands ${ }^{[37 \mathrm{a}, 182]} 229$ for non-directed $\mathrm{C}-\mathrm{H}$ olefination reactions of electron-rich and electronpoor arenes 216 (Scheme 61c). ${ }^{[183]}$ Similarly, these oxidative transformations are also limited to the use of superstoichiometric amounts of chemical oxidants which impeded the sustainability of this approach. 
(a) Early example of the Pd-catalyzed Fujiwara-Moritani reaction

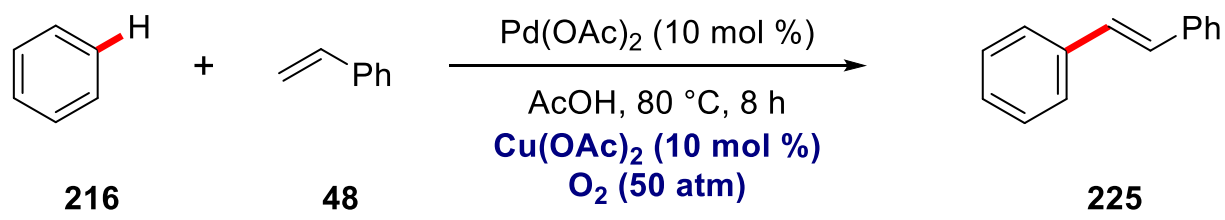

(b) 2-Pyridone ligand-accelerated non-directed $\mathrm{C}-\mathrm{H}$ functionalization

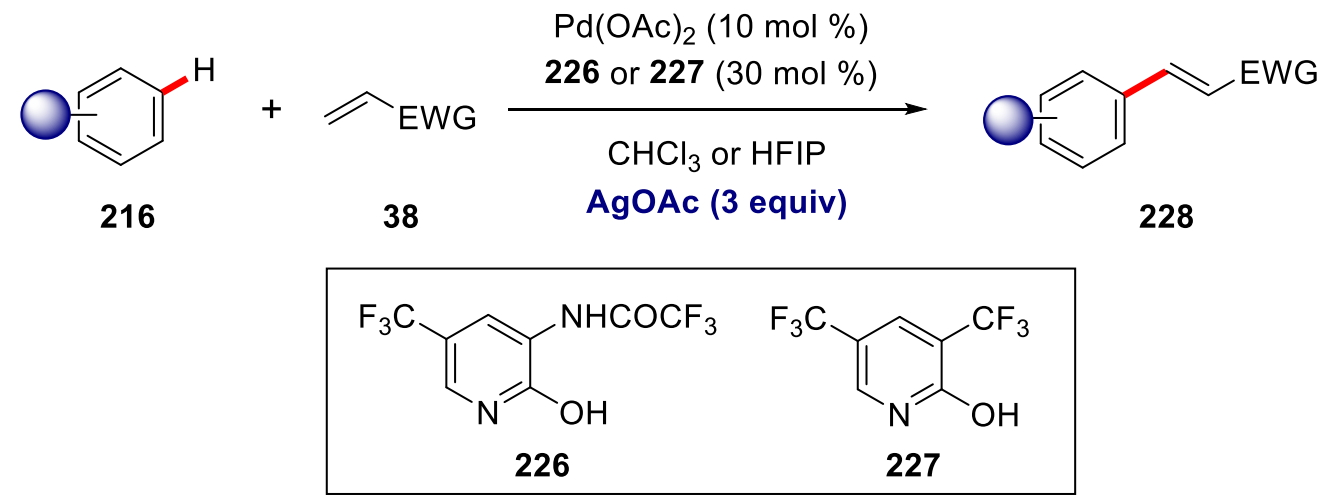

(c) S, O-Ligand-promoted non-directed $\mathrm{C}-\mathrm{H}$ functionalization

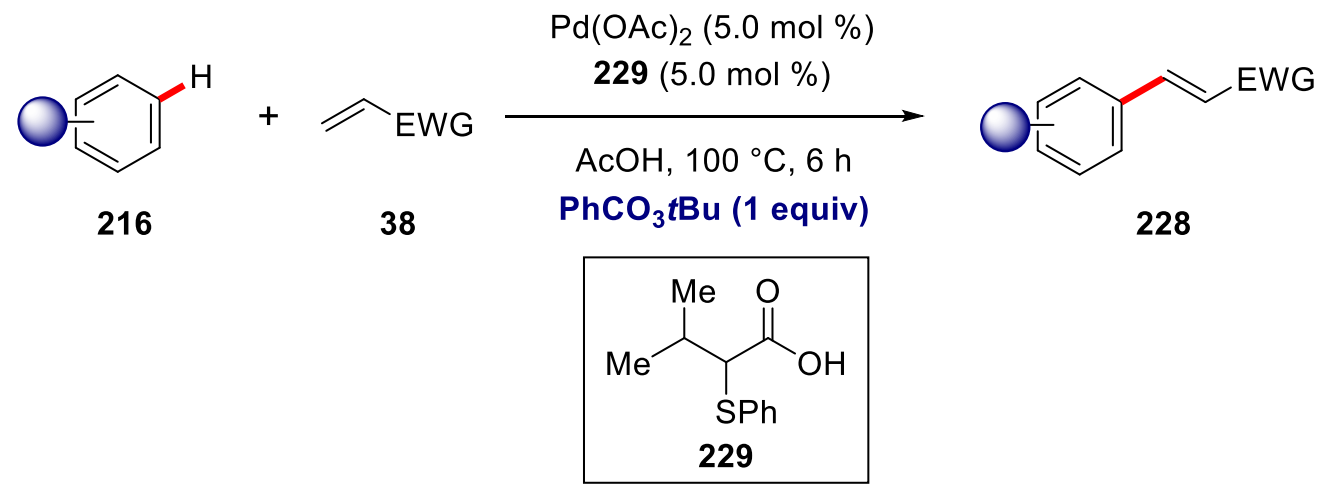

Scheme 61. Non-directed $\mathrm{C}-\mathrm{H}$ activation under oxidative conditions.

\subsubsection{Cobalt-Catalyzed C-H Activations with Chemical Oxidants}

Among the $3 \mathrm{~d}$ transition metals, bench-stable cobalt(II) salts have gained wide applications due to their commercial availability, easy set up and robustness. ${ }^{[32 a]}$ Starting from Daugulis's work on $\mathrm{C}-\mathrm{H} / \mathrm{N}-\mathrm{H}$ annulation of benzamides 229 with the aid of 8 -aminoquinoline as the directing group (Scheme 62a), ${ }^{[184]}$ cobalt-catalyzed oxidative $\mathrm{C}-\mathrm{H} / \mathrm{X}-\mathrm{H}$ annulation has emerged as a versatile step-economical way to synthesis decorated heterocycles. ${ }^{[164 \mathrm{~d}, 185]}$ In this context, in 2016 the Ackermann group utilized for the first time molecular oxygen as the terminal oxidant to achieve the oxidative cobalt-catalyzed synthesis of isoindolones 232 (Scheme 62b). ${ }^{[164 d]}$ 
(a) $\mathrm{C}-\mathrm{H} / \mathrm{N}-\mathrm{H}$ Activation by Daugulis

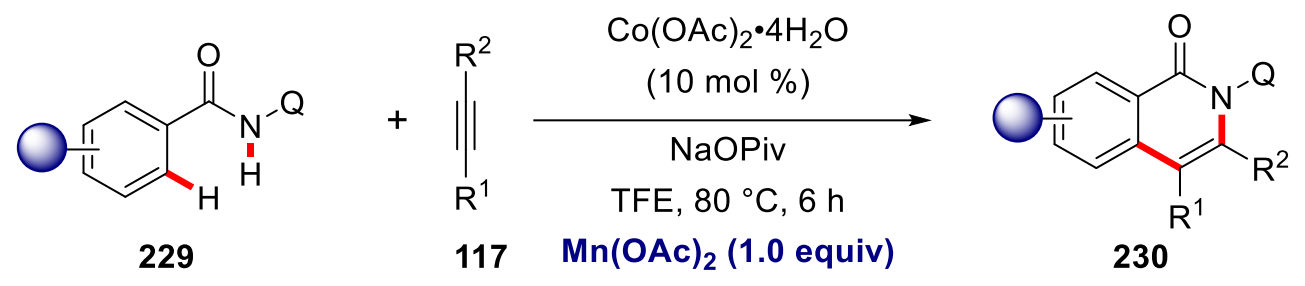

(b) $\mathrm{O}_{2}$ as the sole oxidant by Ackermann

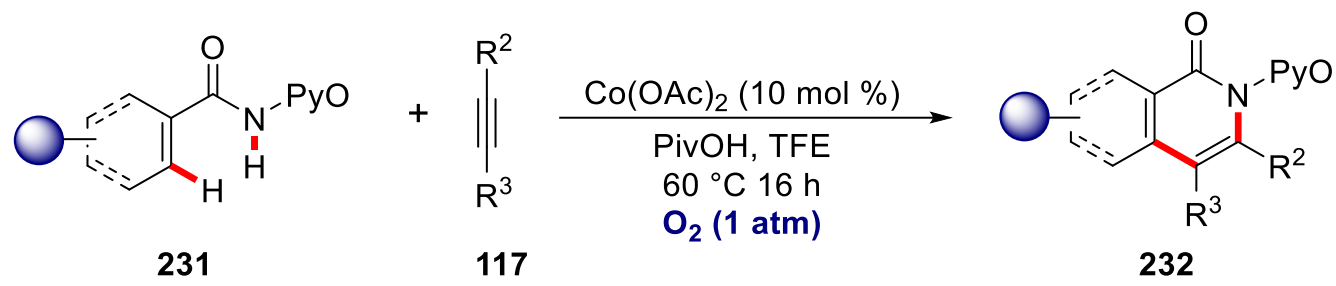

Scheme 62. C-H/N-H annulation of benzamides 231 with internal alkynes 117 under oxidative conditions.

Besides annulation with alkynes 117, alkenes 38/94 and allenes 110/236 have also found suitable application in the annulation protocol in the presence of chemical oxidants, with notable contributions from Daugulis, ${ }^{[186]}$ Ackermann, ${ }^{[185 f]}$ Cheng, ${ }^{[187]}$ Volla/Maiti (Scheme 63 and 64). ${ }^{[188]}$

(a) Daugulis

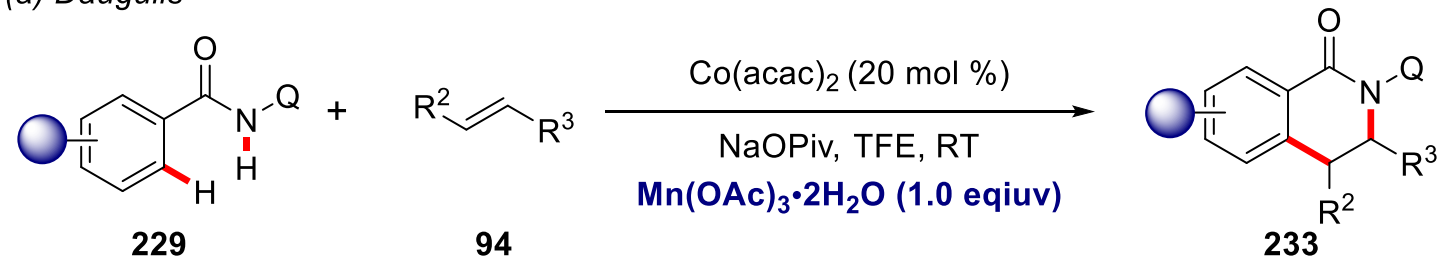

(b) Volla

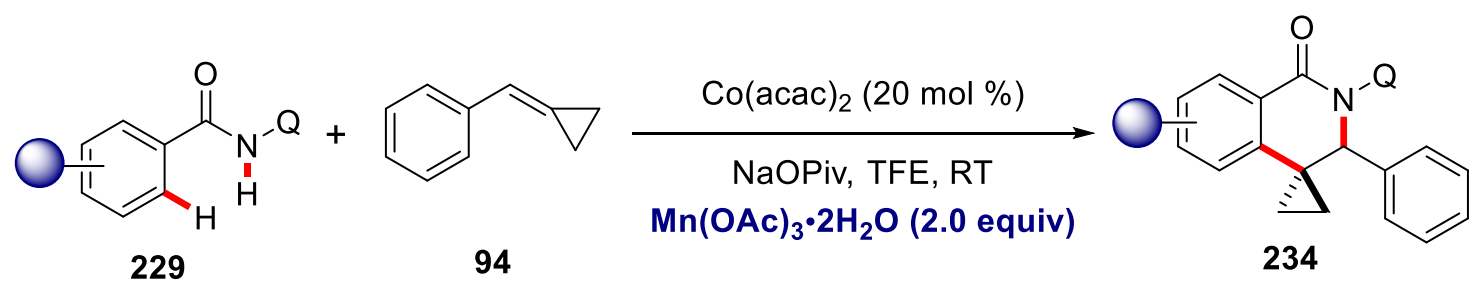

(c) Ackermann

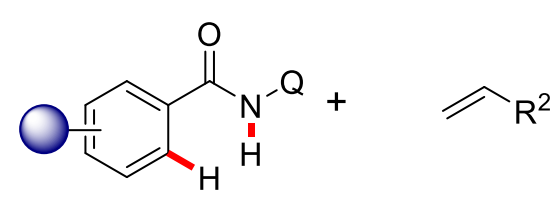

229
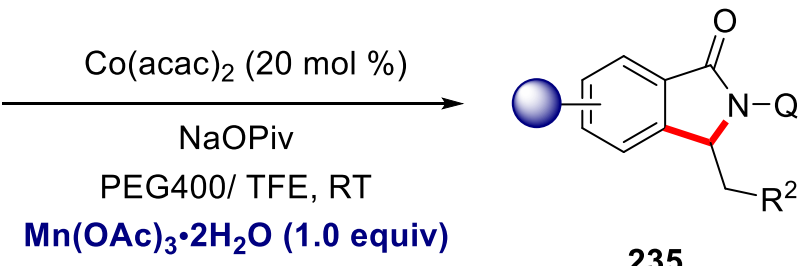

235

Scheme 63. Cobalt-catalyzed oxidative C-H/N-H annulation with alkenes 38 and 94. 
(a) Volla/Maiti

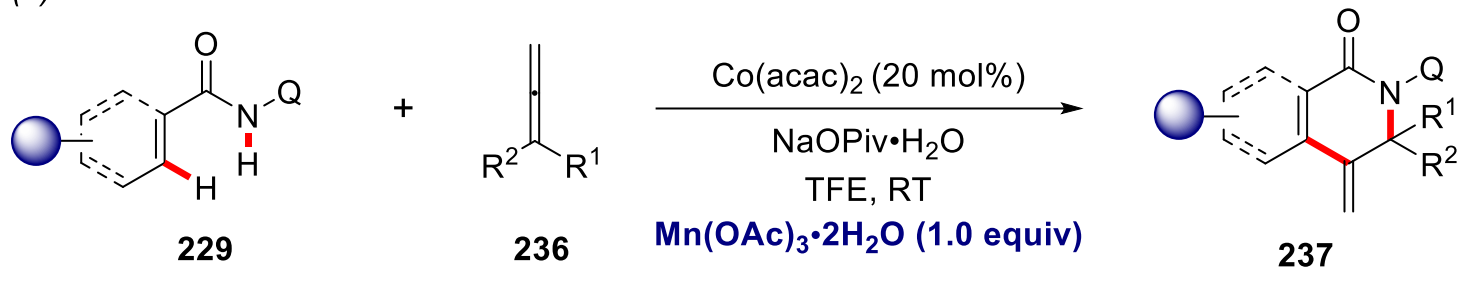

(b) Cheng<smiles>O=C(NO)c1ccccc1</smiles>

229<smiles>[R]C=C=C[R]</smiles>

110

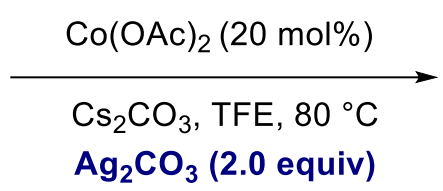

$\mathrm{Ag}_{2} \mathrm{CO}_{3}$ (2.0 equiv)<smiles>[R]Cc1c([R])c2ccccc2c(=O)n1O</smiles>

238

Scheme 64. Cobalt-catalyzed oxidative $\mathrm{C}-\mathrm{H} / \mathrm{N}-\mathrm{H}$ annulation with allenes 236 and $\mathbf{1 1 0}$.

Oxidative cobalt(II)-catalyzed $\mathrm{C}-\mathrm{H}$ activation was not limited to annulation reactions. Indeed, various $\mathrm{C}-\mathrm{C}$ and $\mathrm{C}-\mathrm{Het}$ bond forming reactions have been well studied in the literature. Balaraman reported the oxidative $\mathrm{C}-\mathrm{H}$ alkynylation by the aid of 8 -aminoquinoline as the directing group in the presence of $\mathrm{Co}(\mathrm{acac})_{3}$ as the catalyst and superstoichiometric amounts of $\mathrm{Ag}_{2} \mathrm{CO}_{3}$ to obtain the alkynylated products 239 (Scheme 65). ${ }^{[189]}$<smiles>CNC(=O)c1ccccc1</smiles>

229<smiles></smiles>

75

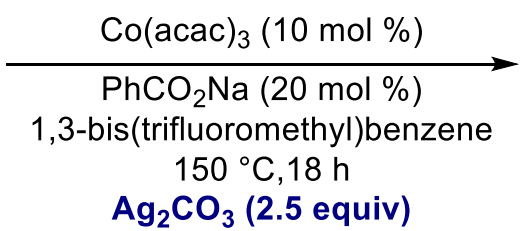

$\mathrm{Ag}_{2} \mathrm{CO}_{3}$ (2.5 equiv)

Scheme 65. Cobalt(II)-catalyzed oxidative C-H alkynylation.

Recently, a protocol for the synthesis of the bicyclo[n.1.0] ring system $\mathbf{2 4 1}$ was realized by Shi through oxidative multiple $\mathrm{C}\left(\mathrm{sp}^{3}\right)-\mathrm{H}$ functionalization strategy in the presence of superstoichiometric amounts of $\mathrm{Ag}_{2} \mathrm{CO}_{3}$ as the oxidant (Scheme 66). ${ }^{[190]}$<smiles>[R]C(C)(CCCNC=C)C(=O)NO</smiles>

240

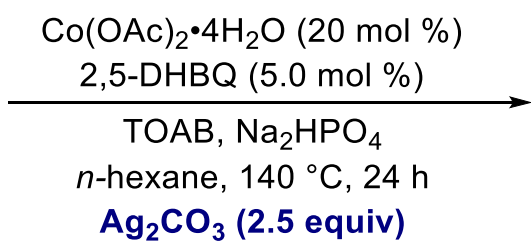

$\mathrm{Ag}_{2} \mathrm{CO}_{3}$ (2.5 equiv)

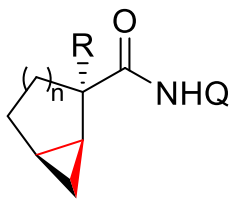

241

Scheme 66. Cobalt-catalyzed oxidative $\mathrm{C}\left(\mathrm{sp}^{3}\right)-\mathrm{H}$ functionalization.

Almost at the same time three independent reports were documented for the allylation of quinolinamides 229 with unbiased alkenes $\mathbf{2 2 3}$ under cobalt(II) catalysis by the groups of 
Jeganmohan, ${ }^{[191]}$ Chatani, ${ }^{[192]}$ and Maiti. ${ }^{[193]}$ Silver based chemical oxidants were employed for this oxidative allylation protocol. Jeganmohan used $\mathrm{Ag}_{2} \mathrm{O}$ as the oxidant, whereas Chatani employed $\mathrm{Ag}_{2} \mathrm{CO}_{3}$ as the oxidant in the presence of $\mathrm{Co}(\mathrm{OAc})_{2} \cdot 4 \mathrm{H}_{2} \mathrm{O}$ as the catalyst. Maiti observed optimal reactivity using $\mathrm{Ag}_{2} \mathrm{SO}_{4}$ as the oxidant in DCE as the solvent. Notably, all these studies provided allylic selectivity over styrenyl-type reactivity (Scheme 67).

(a) Chatani<smiles>O=C(NO)c1ccccc1</smiles>

229<smiles>[R]CC=CCCC</smiles>

223

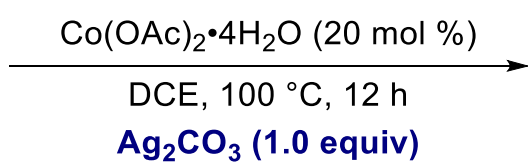

$\mathrm{Ag}_{2} \mathrm{CO}_{3}$ (1.0 equiv)<smiles>[R]C=CCc1ccccc1C(N)=O</smiles>

242

(b) Maiti<smiles>O=C(NO)c1ccccc1</smiles>

229<smiles>[R]CC=C</smiles>

223

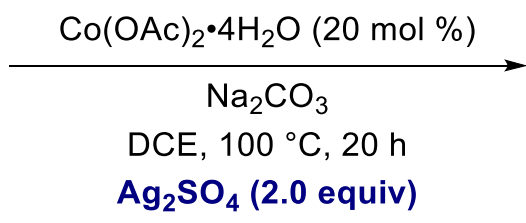

$\mathrm{Ag}_{2} \mathrm{SO}_{4}$ (2.0 equiv)<smiles>[R]C=CCc1ccccc1C(=O)NO</smiles>

242

(c) Jeganmohan<smiles>O=C(NO)c1ccccc1</smiles>

229

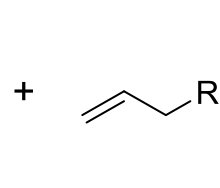

223

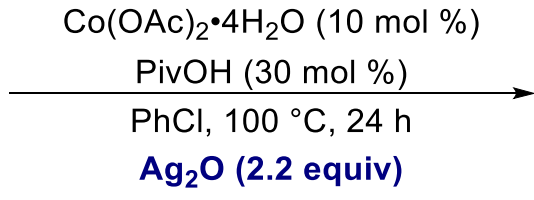

$\mathrm{Ag}_{2} \mathrm{O}$ (2.2 equiv)<smiles>[R]C=CCc1ccccc1C(=O)NO</smiles>

242

Scheme 67. Cobalt-catalyzed C-H allylation in the presence of silver based oxidants.

In addition, versatile cobalt catalysis was discovered as a viable tool to realize $\mathrm{C}-\mathrm{Het}$ bond forming reactions. Song and Niu reported oxidative cobalt-catalyzed $\mathrm{C}\left(\mathrm{sp}^{2}\right)-\mathrm{H}$ alkoxylation of amides $\mathbf{2 3 1}$ by the aid of a bidentate directing group (Scheme 68). ${ }^{[194]}$

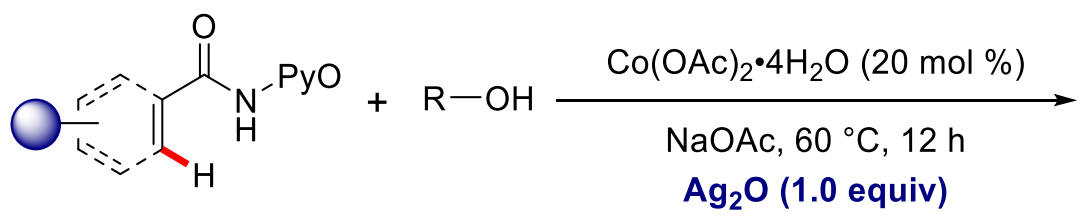

231<smiles>[R]Oc1ccccc1C(=O)N[Na]</smiles>

244

Scheme 68. Oxidative $\mathrm{C}\left(\mathrm{sp}^{2}\right)-\mathrm{H}$ alkoxylation of amides 231.

An intramolecular dehydrogenative $\mathrm{C}-\mathrm{H}$ amination was reported by Ge. ${ }^{[195]}$ This protocol proved viable for the synthesis of $\beta$ - and $\gamma$-lactams 246 by $\mathrm{C}\left(\mathrm{sp}^{3}\right)-\mathrm{H}$ bond activation (Scheme 69a). A silver based oxidant was found to be the most efficient for this amination protocol. Later, Song and Niu devised intermolecular $\mathrm{C}\left(\mathrm{sp}^{2}\right)-\mathrm{H}$ animation. ${ }^{[196]}$ With the aid of a bidentate 
$\mathrm{N}, \mathrm{O}$-auxiliary, ortho- $\mathrm{C}-\mathrm{H}$ aminations were feasible with secondary alkyl amines $\mathbf{2 4 7}$ (Scheme $69 \mathrm{~b})$. Here, $\mathrm{AgNO}_{3}$ was found to be the optimal oxidant in this reaction.

(a) Intramolecular dehydragenative amination<smiles>[R]C([R])C([R])([R])C(=O)NO</smiles>

245

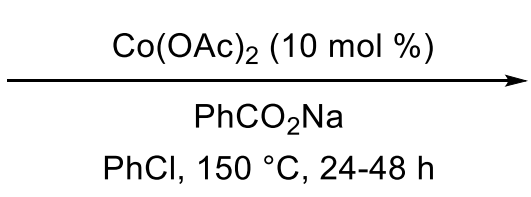

$\mathrm{Ag}_{2} \mathrm{CO}_{3}$ (2.5 equiv)

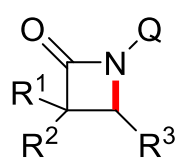

246

(b) Amination of $C\left(s p^{2}\right)-H$ bond

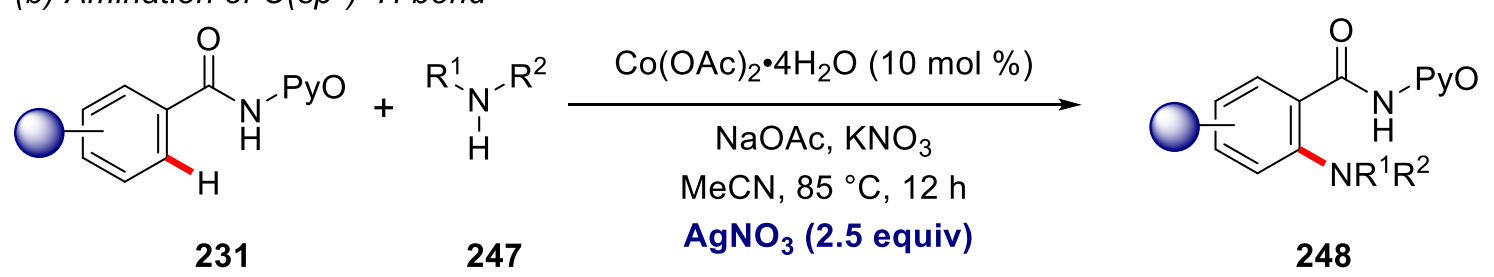

Scheme 69. Oxidative cobalt-catalyzed $\mathrm{C}-\mathrm{H}$ amination.

\subsubsection{Representative Examples on Copper-Catalyzed C-H activations with Chemical Oxidants}

Building upon elegant studies by Ullmann and Goldberg, ${ }^{[9,197]}$ copper complexes have been widely applied for $\mathrm{C}-\mathrm{C}$ and $\mathrm{C}-\mathrm{Het}$ bond forming reactions. In this context, copper-catalyzed $\mathrm{C}-\mathrm{H}$ arylation with aryl halides have been well studied by Daugulis, ${ }^{[198]} \mathrm{Miura}^{[199]}$ and Ackermann ${ }^{[200]}$ utilizing copper(I) catalysts. Besides aryl halides, diaryliodonium salts have been well investigated as arylating agents with copper complexes, with key reports by Gaunt, ${ }^{[201]}$ Glorius, ${ }^{[202]}$ Shi $^{[203]}$ and among others.

Moreover, oxidative $\mathrm{C}-\mathrm{H} / \mathrm{C}-\mathrm{H}$ couplings are an attractive strategy, which avoids prefunctionalized starting materials. Consequently, several examples have been documented on oxidative cross-coupling reactions in the presence of chemical oxidants. ${ }^{[204]}$ In a recent example, Shi utilized 2-(pyridin-2-yl) isopropyl amine (PIP) as directing group for oxidative coupling between benzamides 249 and thiophenes 60 using $\mathrm{AgNO}_{3}$ as oxidant (Scheme 70). ${ }^{[205]}$<smiles>CC(C)(NC(=O)c1ccccc1)c1ccccn1</smiles>

249<smiles>[PH3+]c1cc2ccccc2s1</smiles>

60

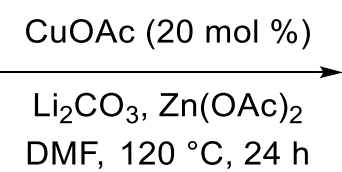

$\mathrm{AgNO}_{3}$

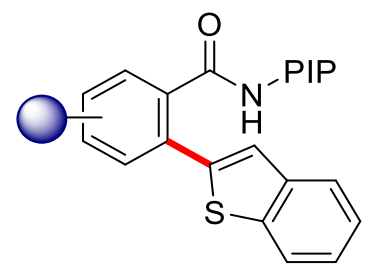

250

Scheme 70. Copper-catalyzed oxidative $\mathrm{C}-\mathrm{H} / \mathrm{C}-\mathrm{H}$ coupling.

In the light of oxidative transformations, copper catalyzed alkyne annulations represent a stepeconomical way to synthesis complex molecules. In this context, Jiang reported copper- 
catalyzed annulation between phenols $\mathbf{2 5 1}$ and internal alkynes $\mathbf{5 8}$ to synthesize benzofurans 252 under an atmosphere of oxygen (Scheme 71a). ${ }^{[206]}$ It is noteworthy to mention that orthoalkynylation was achieved using PIP as the bidentate directing group and silver-based chemical oxidant (Scheme 71b). ${ }^{[207]}$

(a) annulation of phenols with alkynes<smiles>Oc1ccccc1</smiles>

251

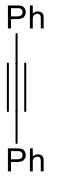

58

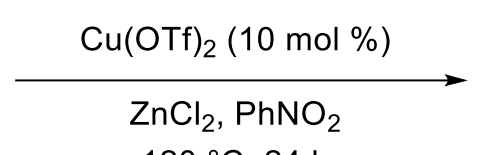

$120^{\circ} \mathrm{C}, 24 \mathrm{~h}$

$\mathrm{O}_{2}$<smiles></smiles>

252

(b) ortho-alkynylation of amides<smiles>CCNC(=O)c1ccccc1</smiles>

249<smiles>[In]#[In]</smiles>

253

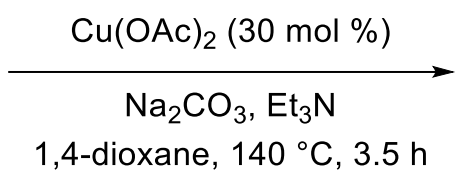

$\mathrm{Ag}_{2} \mathrm{CO}_{3}$<smiles>CCCNC(=O)c1ccccc1C#C[In+]</smiles>

Scheme 71. Copper catalyzed oxidative annulation and alkenylation.

You reported copper-mediated 8-aminoquinloine assisted $\mathrm{C}-\mathrm{H} / / \mathrm{N}-\mathrm{H}$ annulation to synthesize 3-methyleneisoindolin-1-ones derivatives 256 (Scheme 72a). ${ }^{[208]}$ Later, a related protocol was disclosed using catalytic amounts of $\mathrm{CuBr}_{2}$ and $\mathrm{O}_{2}$ as the sacrificial oxidant (Scheme 72b). ${ }^{[209]}$

(a) copper-mediated ortho-C-H activation

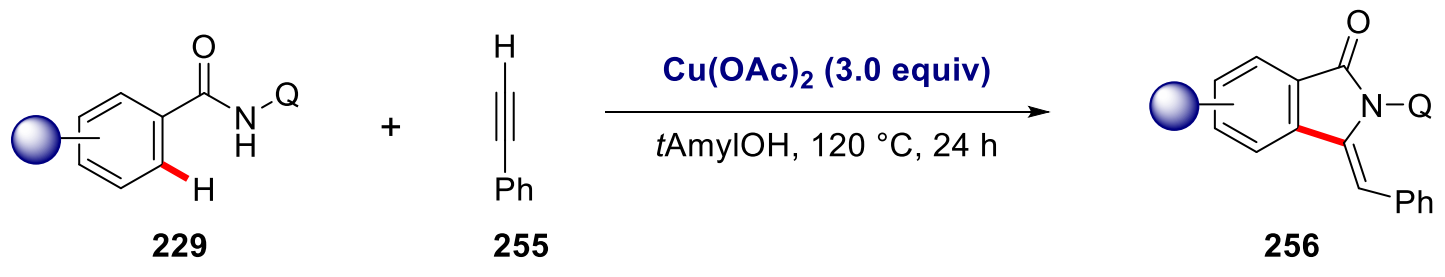

(b) copper-catalyzed ortho-C-H activation

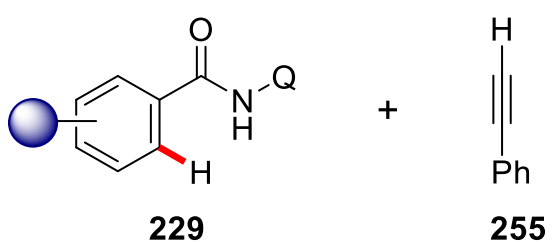

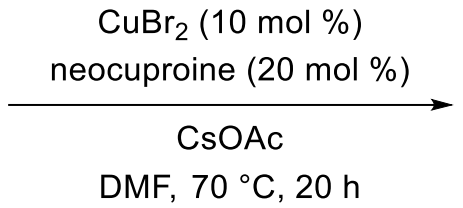

$\mathrm{O}_{2}$

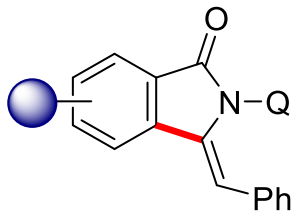

256

Scheme 72. Copper catalyzed synthesis of isoindolinones.

This protocol was further extended to challenging $\mathrm{C}\left(\mathrm{sp}^{3}\right)-\mathrm{H}$ activations. ${ }^{[210]}$ Here a combination of a copper(II) salt and $\mathrm{Ag}_{2} \mathrm{CO}_{3}$ was exploited for the alkenylation with alkynyl carboxylic acids 258 (Scheme 73). 


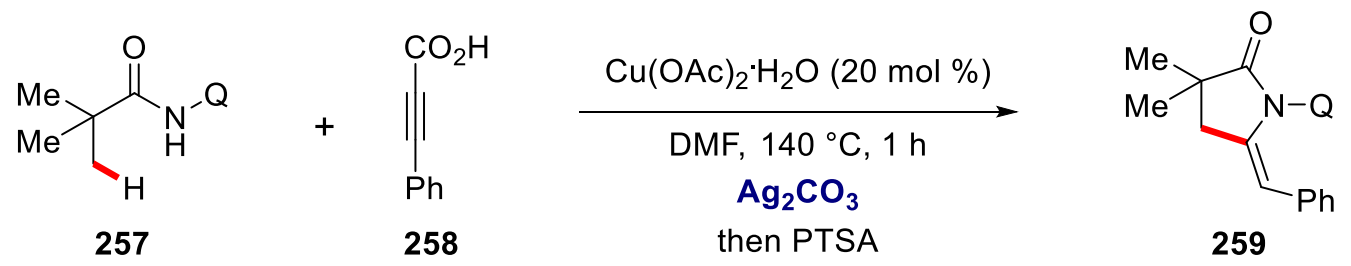

Scheme 73. $\mathrm{C}\left(\mathrm{sp}^{3}\right)-\mathrm{H}$ bond activation with alkynyl carboxylic acids.

Likewise, copper catalysis has also been extensively used in $\mathrm{C}-\mathrm{Het}$ bond forming reactions. Considering the importance of $\mathrm{C}-\mathrm{N}$ bonds, numerous reports have been documented for copper-catalyzed $\mathrm{C}-\mathrm{H}$ amination reactions using various amination sources. ${ }^{[211]}$ Furthermore, oxidative $\mathrm{C}-\mathrm{H} / \mathrm{N}-\mathrm{H}$ coupling have been realized between quinoline- $N$-oxide 215 and cyclic amines 247 in the presence of stoichiometric silver(I) oxidant (Scheme 74). ${ }^{[212]}$<smiles>[O-][n+]1cccc2ccccc21</smiles>

215

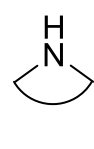

247

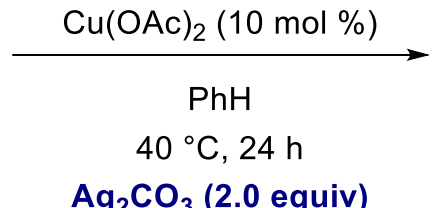

$\mathrm{Ag}_{2} \mathrm{CO}_{3}$ (2.0 equiv)

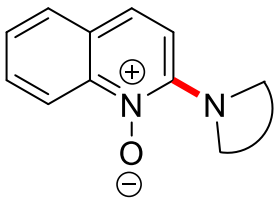

260

Scheme 74. Copper-catalyzed oxidative $\mathrm{C}-\mathrm{H}$ amination.

In 2013, ortho-amination of benzamides $\mathbf{2 2 9}$ have been reported by the Daugulis groups by the aid of 8-aminoquinoline as the directing group. ${ }^{[213]}$ This amination protocol required NMO as oxidant in the presence of cocatalytic $\mathrm{Ag}_{2} \mathrm{CO}_{3}$ as additive to improve the outcome of the reaction (Scheme 75a). In a related study, copper-catalyzed $\mathrm{C}-\mathrm{H}$ aminations have also been reported using PIDA as oxidant using picolinamide as the directing group (Scheme 75b). ${ }^{[214]}$

(a) amination of $C\left(s p^{2}\right)-H$ bond using NMO as oxidant

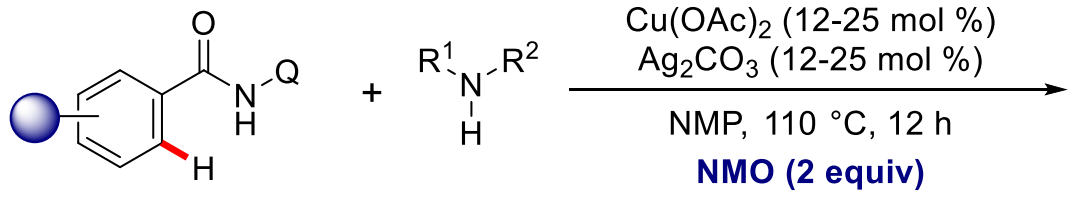

229<smiles>[R2]Nc1ccccc1C(=O)NO</smiles>

261

(b) amination of $C\left(s p^{2}\right)-H$ bond using PIDA as oxidant<smiles>O=C(Nc1ccccc1)c1ccccn1</smiles>

262

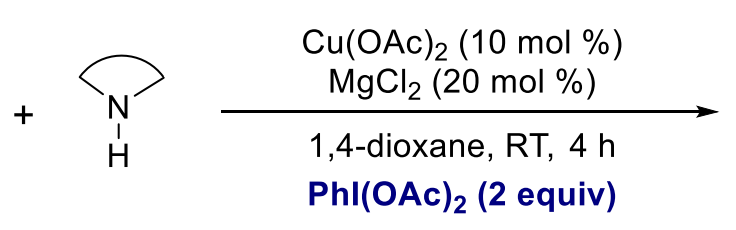

247<smiles>O=C(Nc1ccccc1N1CCC1)c1ccccn1</smiles>

263

Scheme 75. Copper catalyzed $\mathrm{C}\left(\mathrm{sp}^{2}\right)-\mathrm{H}$ aminations with chemical oxidants. 
Furthermore, intramolecular $\mathrm{C}\left(\mathrm{sp}^{3}\right)-\mathrm{H}$ amidations have been independently reported by Kuninobo/Kanai, ${ }^{[215]} \mathrm{Ge}^{[216]}$ and You (Scheme 76). ${ }^{[217]}$ These transformations were also limited to the use of chemical oxidants or $\mathrm{O}_{2}$ as the terminal oxidant.

(a) $\mathrm{Ge}$

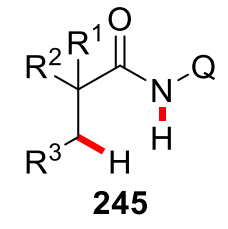

(b) Kanai

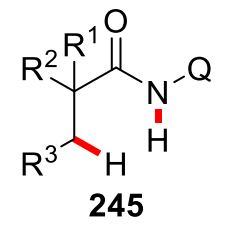

(c) You

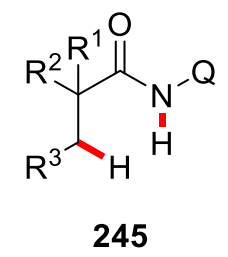

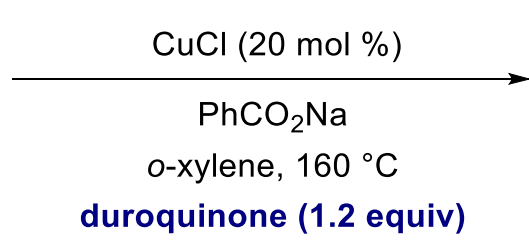
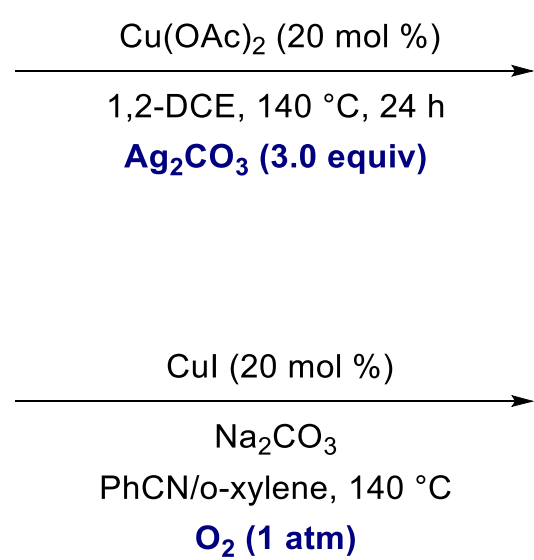
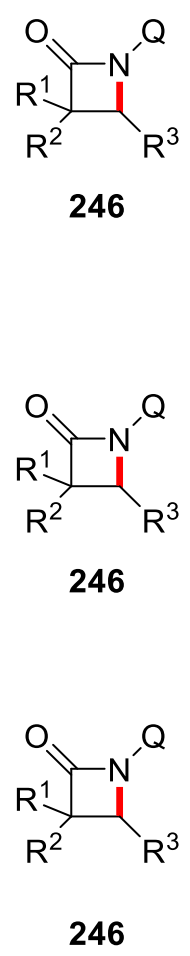

Scheme 76. Intramolecular $\mathrm{C}\left(\mathrm{sp}^{3}\right)-\mathrm{H}$ amidations.

Likewise, copper-catalyzed oxygenation has been well studied under oxidative conditions. Goosen employed AgOTf as the oxidant for ortho-alkoxylation of 2-phenyl pyridine 93 (Scheme 77a). ${ }^{[218]}$ A further study was published using $\mathrm{O}_{2}$ as the terminal oxidant (Scheme 77b). ${ }^{[219]}$ 
(a) Gooßen<smiles>C1=CC(c2ccccc2)=NCC1</smiles>

93

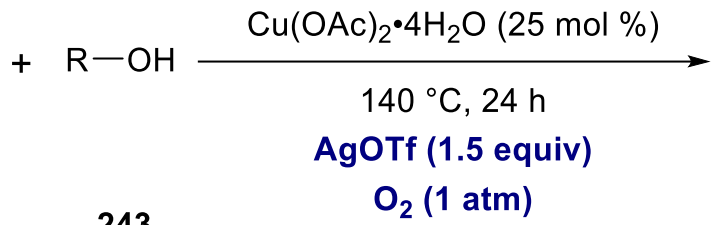

243
$\mathrm{O}_{2}(1 \mathrm{~atm})$<smiles>[R]Oc1ccccc1-c1ccccn1</smiles>

264

(b) Shen<smiles>c1ccc(-c2ccccn2)cc1</smiles>

93

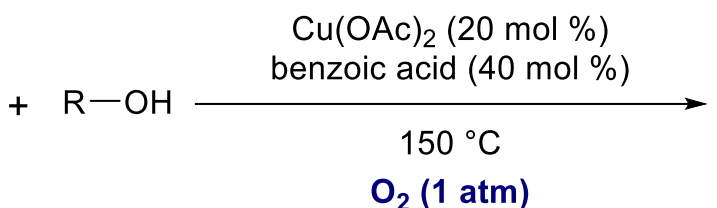

243<smiles>[R]Oc1ccccc1-c1ccccn1</smiles>

264

Scheme 77. copper-catalyzed oxidative oxygenation.

The low cost of copper catalysts has lead to the development of various copper-promoted $\mathrm{C}-\mathrm{H}$ activation reactions. In this context, $\mathrm{Ge}$ disclosed copper-promoted $\mathrm{C}-\mathrm{H}$ oxygenation of $\mathrm{C}\left(\mathrm{sp}^{3}\right)-\mathrm{H}$ bond directed by bidentate 8 -aminoquinoline group (Scheme 78$) .{ }^{[220]}$<smiles>[R]C([R])(C[2H])C(=O)NO</smiles>

245

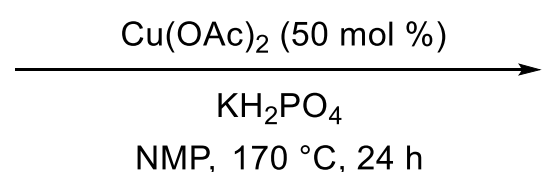

AgOAc (3.0 equiv)<smiles>[R]O[CH]C([R])([R])C(=O)NO</smiles>

265

Scheme 78. Copper-promoted $\mathrm{C}-\mathrm{H}$ oxygenation.

\subsubsection{Electrochemical Transition Metal-Catalyzed C-H Activation.}

In modern era there is an increasing demands for renewable energy sources, including the wind and solar energies. ${ }^{[21]}$ Thus, the use of electricity is highly desirable for chemical synthesis which opens up a new avenue for environmentally-benign strategy towards improved molecular synthesis. ${ }^{[222]}$ Moreover, chemical oxidants operate at a fixed potential, whereas electricity offers to control the potential and current for the desired transformation, thus enabling better selectivities of the reactions ${ }^{[223]}$ with optimal resource-economy. ${ }^{[224]}$

Building upon pioneering works of Kolbe ${ }^{[225]}$ and Shono, ${ }^{[226]}$ organic electrosynthesis ${ }^{[227]}$ has undergone a significant renaissance. Over the few decades there has been significant developments in organic electrosynthesis, exploiting the innate reactivity of organic molecules. Consequently, electrochemical and metal-free transformations exploiting the inherent reactivity have been well studied with notable contributions from Waldvogel, ${ }^{[228]}$ Baran, ${ }^{[229]}$ 
Yoshida, ${ }^{[230]}$ and $\mathrm{Xu},{ }^{[231]}$ among others. In this context, the merger of transition metal catalysis with electrosynthesis ${ }^{[232]}$ has shown an enormous potential for the activation of strong $\mathrm{C}-\mathrm{H}$ bonds. Thus, electrochemistry holds unique potential towards the development of environmentally-benign diverse $\mathrm{C}-\mathrm{H}$ functionalizations to form $\mathrm{C}-\mathrm{C}$ or $\mathrm{C}-\mathrm{Het}$ bonds, using electrons as green terminal oxidants in lieu of expensive chemical oxidants. ${ }^{[232]}$

\subsubsection{Palladium Catalyzed Electrochemical C-H Activation}

In 2007, Amatore and Jutand documented the merger of palladium-catalyzed $\mathrm{C}-\mathrm{H}$ activation with electrosynthesis. Hence, the authors reported on Fujiwara-Moritani-type ${ }^{[167]} \mathrm{C}-\mathrm{H}$ alkenylation reaction of $\mathrm{N}$-acetylanilines 266 in $\mathrm{AcOH}$ as reaction media (Scheme 79). ${ }^{[233]} \mathrm{Co}-$ catalytic amounts of $p$-benzoquinone were beneficial as redox mediators for this reaction, which was regenerated at the anode to recycle the palladium(II) species in the catalytic cycle. This early study set the stage for further developments in electrochemical palladium-catalyzed $\mathrm{C}-\mathrm{H}$ activation.

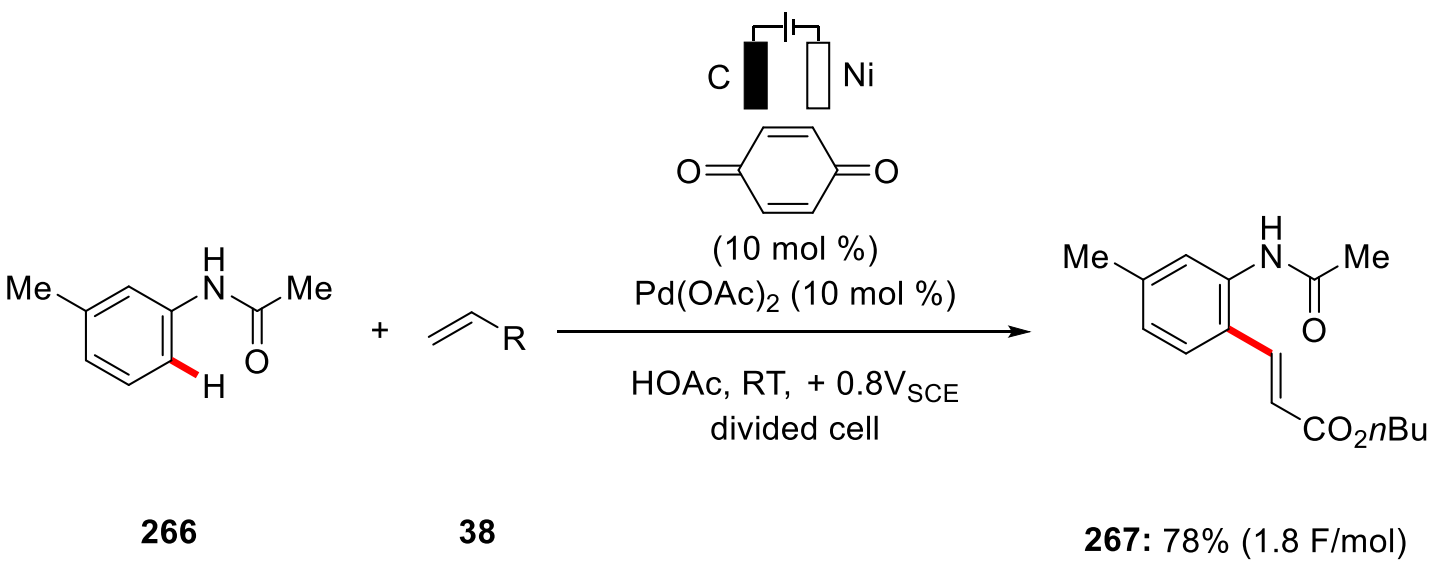

Scheme 79. Electrocatalytic Fujiwara-Moritani reaction.

In 2009, Kakiuchi exploited electrochemistry for the palladium-catalyzed halogenation of 2phenyl pyridine 93 with hydrogen halides. ${ }^{[234]}$ This protocol enabled the incorporation of synthetically useful halo groups on the aromatic rings without expensive halogenation reagents (Scheme 80). Instead, electricity was solely responsible to form the electrophilic $\mathrm{Cl}^{+}$species to enable improved direct halogenations. 


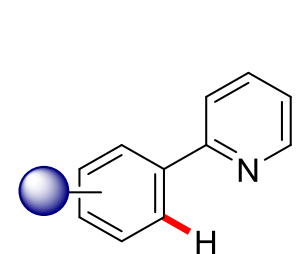

93

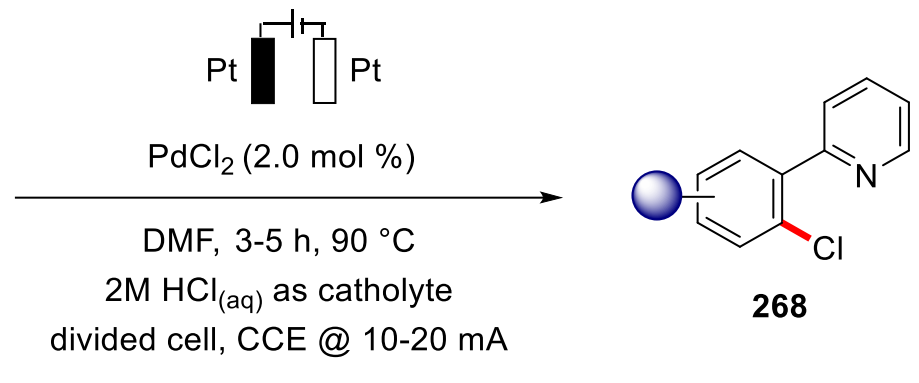<smiles>Clc1cccc(Cl)c1-c1ccccn1</smiles>

$94 \%$<smiles>Clc1ccc2ccccc2c1-c1ncccn1</smiles>

$95 \%$<smiles>Cc1cccc(Br)c1-c1ccccn1</smiles>

$95 \%^{a}$

Scheme 80. Electrochemical palladium-catalyzed halogenation of phenylpyridines 93.

${ }^{\mathrm{a}} \mathrm{PdBr} 2(2.0 \mathrm{~mol} \%)$ and $2 \mathrm{M} \mathrm{HBr}(\mathrm{aq})$ used.

In a related approach, later the same group extended the $\mathrm{C}-\mathrm{H}$ halogenation approach to $\mathrm{C}-\mathrm{H}$ iodinations (Scheme 81). ${ }^{[235]}$ Here, the authors utilized elemental iodine as the iodonium source to enable the $\mathrm{C}-\mathrm{H}$ iodinations in $\mathrm{MeCN}$ as reaction media. Notably, this iodination protocol was also compatible with KI as iodonium source.

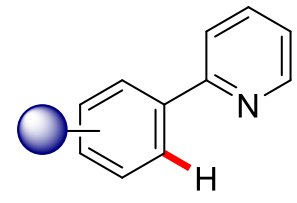

93<smiles>Cc1cccnc1-c1ccccc1I</smiles>

$70 \%$<smiles>Ic1ccccc1-c1ccccn1</smiles>

269<smiles>FC(F)(F)c1cccc(I)c1-c1ccccn1</smiles>

$79 \%$<smiles>Cc1cccnc1-c1ccc(C(F)(F)F)cc1I</smiles>

$70 \%$

Scheme 81. Electrochemical palladium-catalyzed iodination.

Later, ortho-C-H perfluoroalkoxylation of phenyl pyridines 93 with perfluroalkylated acids 270 was reported under mild reaction conditions (Scheme 82). ${ }^{[236]}$ This was an early example of electrochemical metal-catalyzed direct $\mathrm{C}-\mathrm{H}$ oxygenation reactions. ${ }^{[60,237]}$ 
<smiles>O=C(O)C(F)(F)c1ccccn1</smiles>

93

270

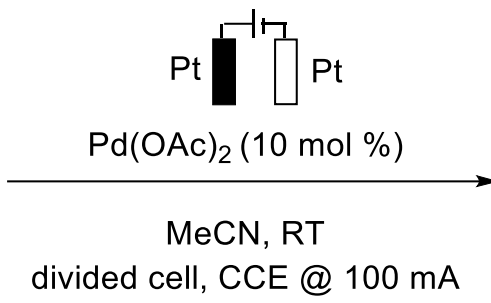

divided cell, CCE @ 100 mA<smiles>O=C(Oc1ccccc1-c1ccccn1)C(F)(F)F</smiles>

271: $73 \%$

Scheme 82. Palladium-catalyzed electrochemical C-H perfluorooxygenation.

Until recently, strongly-coordinating phenylpyridines and anilides were substrates of choice in the early developments of electrochemical transformations. In this context, Kakuichi later succeeded to achieve ortho-selective chlorination of electron-poor benzamides $\mathbf{2 7 2}$ by a modified chlorinated bidentate 8-aminoquinoline directing group (Scheme 83). ${ }^{[238]}$

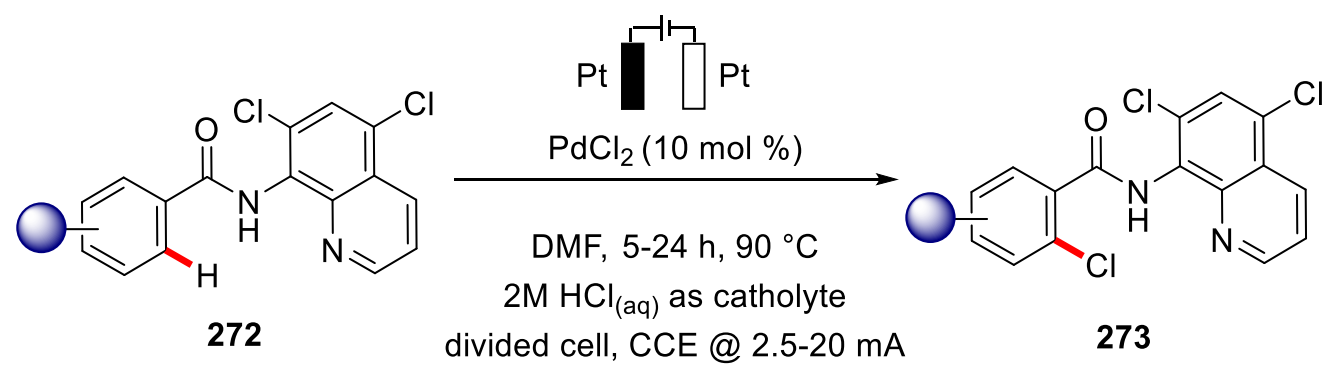<smiles>O=C(Nc1c(Cl)cc(Cl)c2cccnc12)c1cc(Br)ccc1Cl</smiles>

$78 \%$<smiles>Cc1cccc(Cl)c1C(=O)Nc1c(Cl)cc(Cl)c2cccnc12</smiles>

$86 \%$<smiles>O=C(Nc1c(Cl)cc(Cl)c2cccnc12)c1ccc([N+](=O)[O-])cc1Cl</smiles>

$60 \%$

Scheme 83. Electrochemical bidentate directing group assisted $\mathrm{C}-\mathrm{H}$ chlorination.

In 2017, a major contribution was achieved by Mei in electrochemical palladium catalyzed C$\mathrm{H}$ activation. Thus, Mei reported palladium-catalyzed $\mathrm{C}\left(\mathrm{sp}^{3}\right)-\mathrm{H}$ oxygenation of oxime derivatives 274 (Scheme 84) ${ }^{[239]}$ It is noteworthy to mention that this protocol offered a broad scope of synthetically useful oxime derivatives $\mathbf{2 7 5}$ under rather mild reaction conditions. 


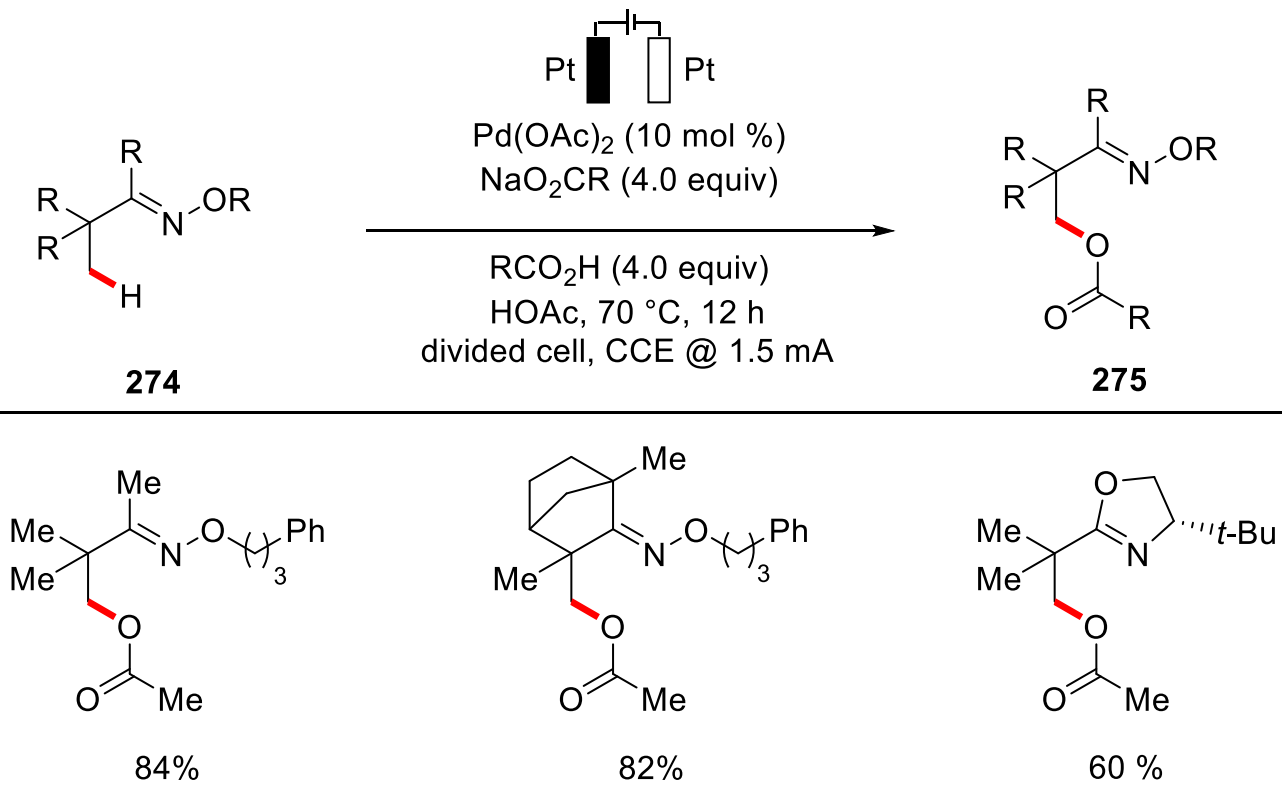

Scheme 84. Palladium-catalyzed $\mathrm{C}\left(\mathrm{sp}^{3}\right)-\mathrm{H}$ oxygenation.

In subsequent efforts, the same group reported efficient palladium-catalyzed oxidative ortho$\mathrm{C}\left(\mathrm{sp}^{2}\right)-\mathrm{H}$ methylation and benzoylation of oximes 276 with methyltrifluoroborates 277 and benzoyl acetic acids $\mathbf{2 7 9}$ as the coupling partners respectively (Scheme $85 \mathrm{a}$ and $85 \mathrm{~b}$ ). ${ }^{[240]}$ Also, the authors prepared cyclometalated palladacycle which was found to be a competent catalyst for the $\mathrm{C}-\mathrm{H}$ methylation reactions.

(a) Electrochemical Palladium-Catalyzed C-H Methylation<smiles>CON=C(C)c1ccccc1</smiles>

276

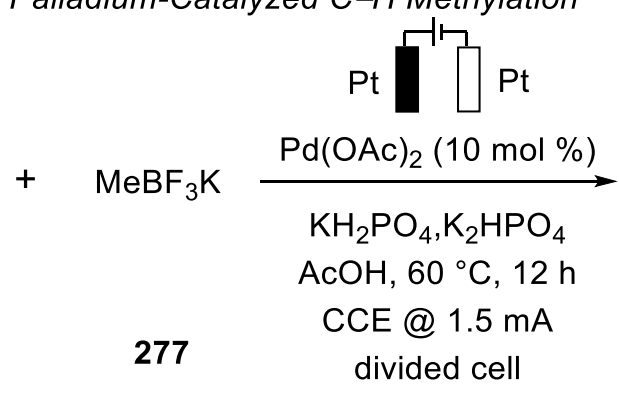

divided cell<smiles>CON=C(C)c1ccccc1C</smiles>

278: $89 \%$

(b) Palladium-Catalyzed Oxidative Benzoylation

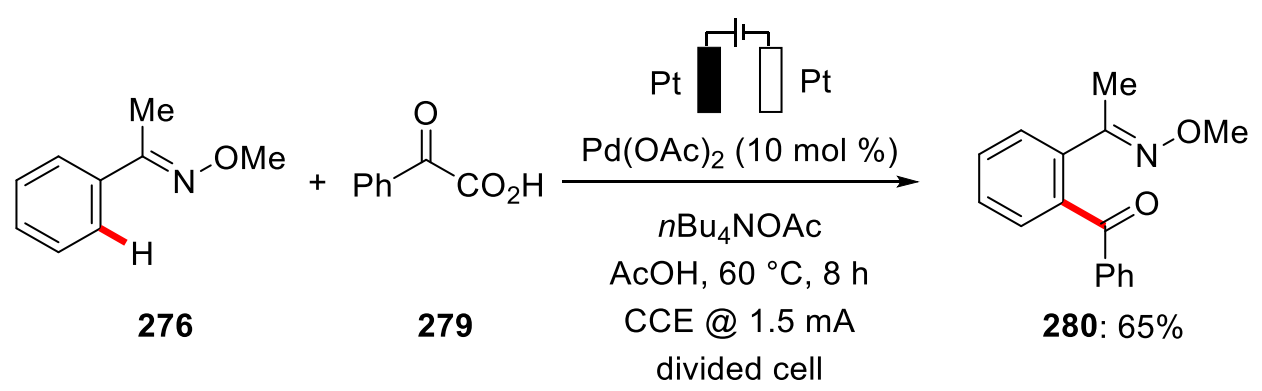

Scheme 85. Palladium-catalyzed C-H alkylation and benzoylation. 
In subsequent study, Sanford reported related electrochemical $\mathrm{C}\left(\mathrm{sp}^{2}\right)-\mathrm{H}$ and $\mathrm{C}\left(\mathrm{sp}^{3}\right)-\mathrm{H}$ oxygenations (Scheme 86 ).${ }^{[241]} \mathrm{A}$ broad range of directing groups was also found amenable in this protocol. In addition, this transformation tolerated an array of sensitive functional groups.

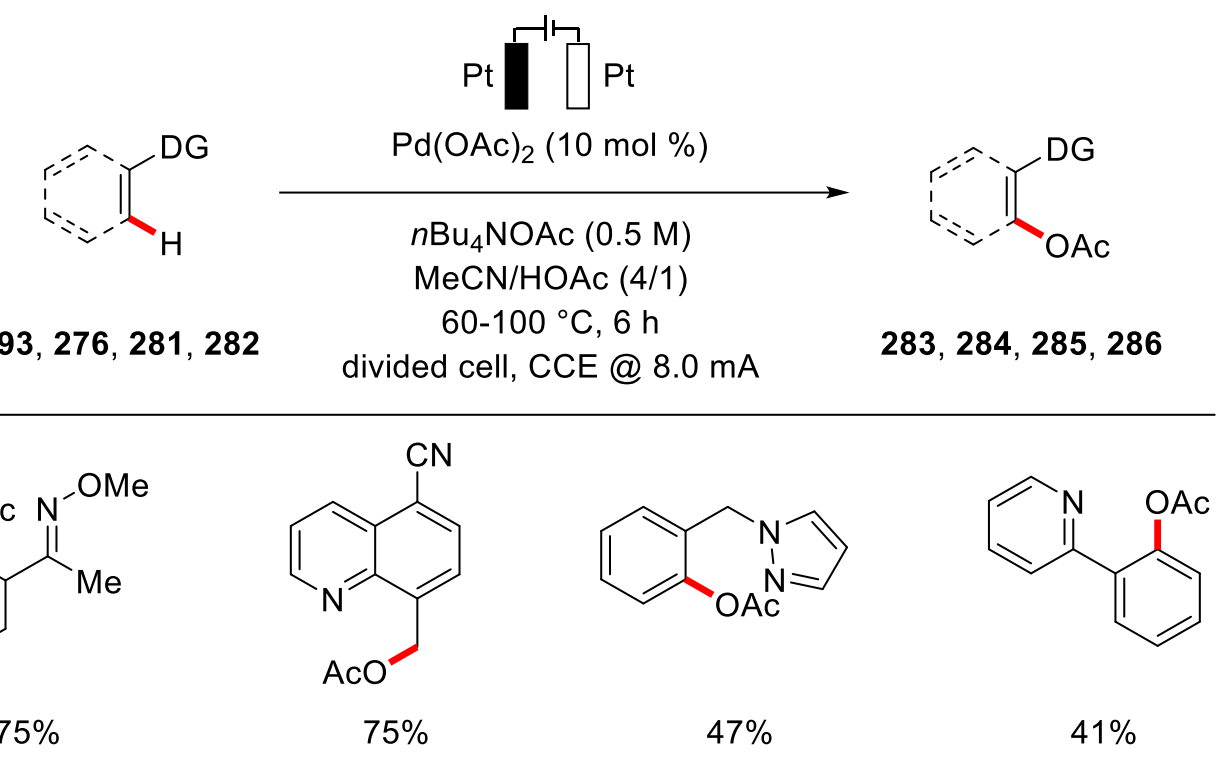

Scheme 86. Electrochemical C( $\left.\mathrm{sp}^{2}\right)-\mathrm{H}$ and $\mathrm{C}\left(\mathrm{sp}^{3}\right)-\mathrm{H}$ oxygenation.

\subsubsection{Cobalt-Catalyzed Electrochemical C-H Activation}

Over the past decades $\mathrm{C}-\mathrm{H}$ electrosynthesis has largely relied on precious $4 \mathrm{~d}$ and $5 \mathrm{~d}$ transition metals, prominently featuring expensive palladium, rhodium, ${ }^{[242]}$ iridium $^{[243]}$ and ruthenium ${ }^{[244]}$ complexes. In recent years, the prices of precious transition metals have increased significantly which has led to a growing demand in the use of Earth-abundant and cost-efficient $3 \mathrm{~d}$ metals as viable catalysts for molecular $\mathrm{C}-\mathrm{H}$ transformations. ${ }^{[232 \mathrm{c}]}$

\subsection{C-H Oxygenation}

Recently, versatile cobalt catalysts have become a powerful tool for oxidative electrochemical $\mathrm{C}-\mathrm{H}$ activations with notable contributions by Ackermann. ${ }^{[32 \mathrm{a}, 245]}$ In 2017, Ackermann reported the first electrochemical cobalt catalyzed $\mathrm{C}-\mathrm{H}$ oxygenation. ${ }^{[246]}$ To the best of my knowledge, this is the first example for electrochemical $\mathrm{C}-\mathrm{H}$ activation by Earth-abundant $3 \mathrm{~d}$ transition metals. Here, the authors elegantly employed a combination of $\mathrm{Cp}^{*}$-free $\mathrm{Co}(\mathrm{OAc})_{2} \cdot 4 \mathrm{H}_{2} \mathrm{O}$ as the inexpensive catalyst and $\mathrm{NaOPiv}$ as base for the electrochemical $\mathrm{C}-\mathrm{H}$ oxygenation of benzamides 231 with aliphatic alcohols 243 enabled by a $N, O$-bidentate directing group (Scheme 87). The key characteristic of this protocol was high levels of functional group tolerance at room temperature. 


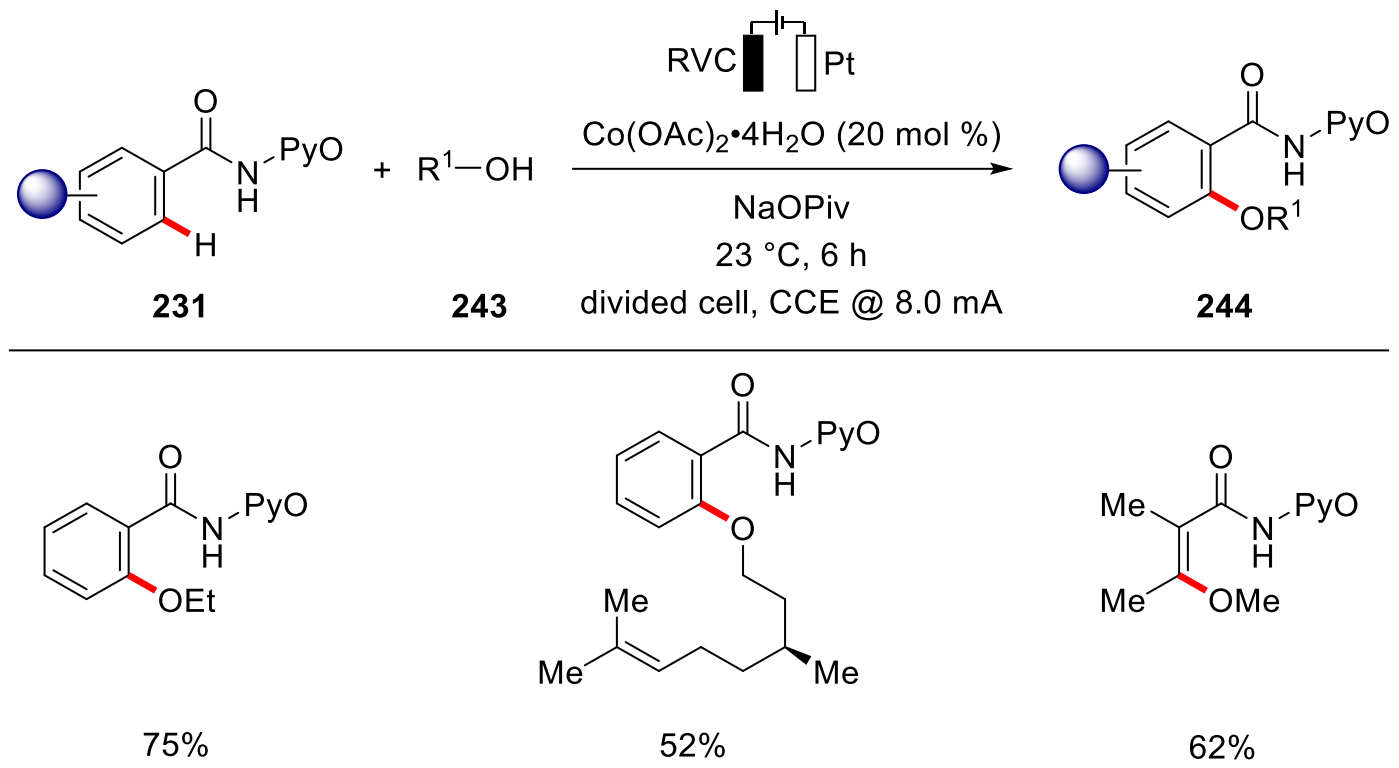

Scheme 87. Electrochemical cobalt-catalyzed C-H oxygenation.

\subsection{C-N Bond Formation}

Intrigued by the pioneering $\mathrm{C}-\mathrm{H}$ oxygenation, ${ }^{[246]}$ the electrooxidative direct $\mathrm{C}-\mathrm{H}$ amination of otherwise inert $\mathrm{C}-\mathrm{H}$ bonds of aromatic benzamides 231 was reported by Ackermann. ${ }^{\text {[247] }}$ The reaction was performed in the renewable solvent $\gamma$-valerolactone $(\mathrm{GVL})$ at $40^{\circ} \mathrm{C}$ in the absence of expensive and toxic metal oxidants. It should be duly noted that this was the first report for the use of biomass-derived solvent in electrocatalysis. ${ }^{[6,248]}$ The amination of benzamides 231 proceeded with diverse set of secondary amines 247 with $\mathrm{H}_{2}$ as the only stoichiometric byproduct, produced by cathodic reduction (Scheme 88). Thereafter, Lei reported similar reactivity utilizing 8-AQ as directing group for the $\mathrm{C}-\mathrm{H}$ amination with cyclic secondary amines in a divided cell set up. ${ }^{[249]}$ 


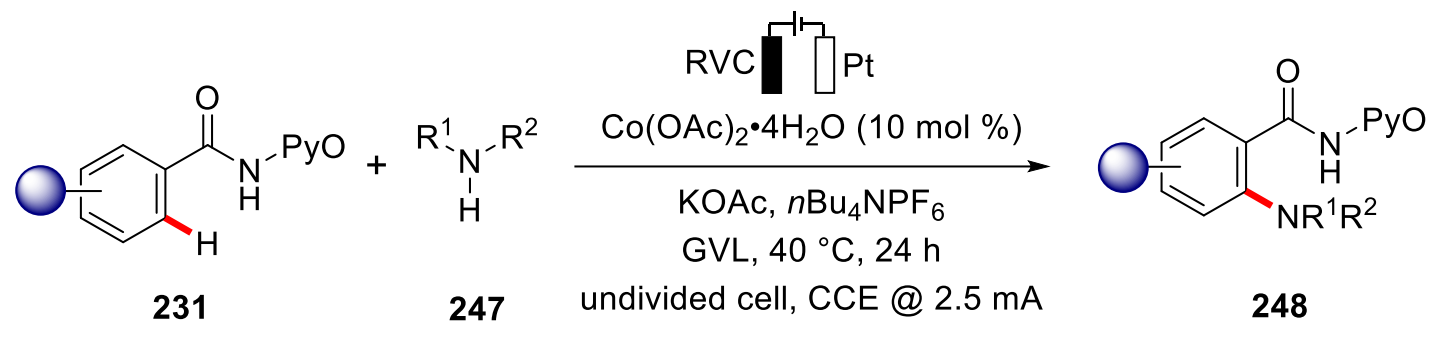<smiles>O=C(Nc1ccccc1)c1ccccc1N1CCSCC1</smiles>

$61 \%$

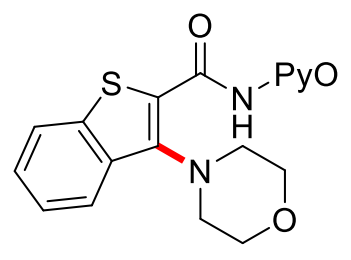

$62 \%$<smiles>CC(=O)c1ccc(C(=O)NNC(=O)c2ccccc2)c(N2CCOCC2)c1</smiles>

$65 \%$

Scheme 88. Cobaltacatalyzed electrooxidative $\mathrm{C}-\mathrm{H}$ amination.

\subsection{C-H Activation for Annulations.}

In 2018, an unprecedented electrochemical annulation of $\mathrm{C}-\mathrm{H}$ and $\mathrm{N}-\mathrm{H}$ bond with alkynes 255 was disclosed by Ackermann (Scheme 89). ${ }^{[250]}$ Notably, versatile and robust cobalt catalysis enabled the synthesis of isoquinolone motifs 287 by $\mathrm{C}-\mathrm{H} / \mathrm{N}-\mathrm{H}$ annulation of benzamides 231 in $\mathrm{H}_{2} \mathrm{O}$ as the reaction medium. A broad range of substrates was tolerated in this annulation protocol at room temperature, including benzamides, heterocycles, and alkenes bearing pyridine $N$-oxide as the directing group.

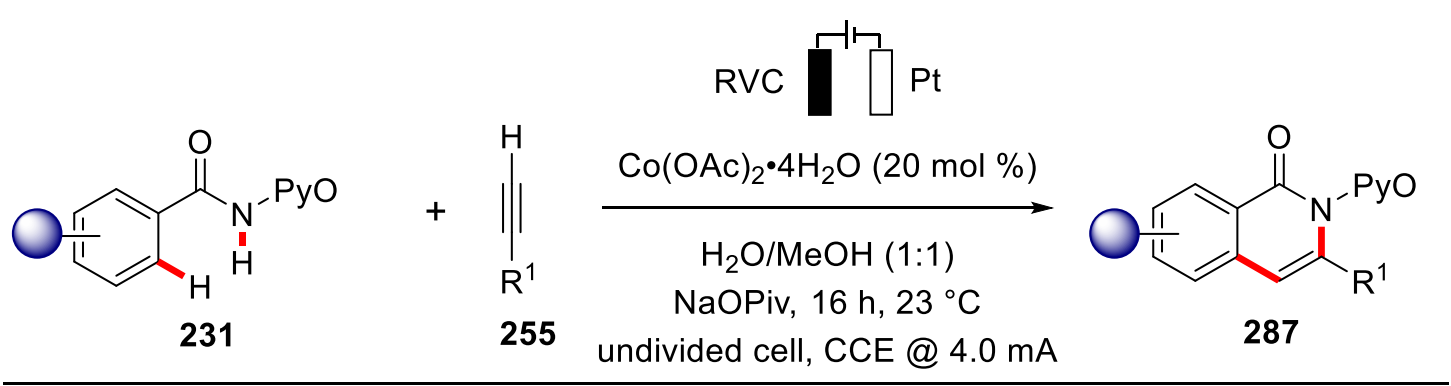<smiles>O=c1c2ccccc2cc(-c2ccccc2)n1P(O)c1ccccc1</smiles>

$76 \%$<smiles>O=c1c2ccsc2cc(-c2ccccc2)n1P(O)O</smiles>

$54 \%$<smiles>O=c1c2ccccc2cc(CCCCCl)n1P(O)O</smiles>

$60 \%$

Scheme 89. Electrooxidative $\mathrm{C}-\mathrm{H} / \mathrm{N}-\mathrm{H}$ annulation.

In subsequent reports, Lei extended this approach towards the [4+2] $\mathrm{C}-\mathrm{H} / \mathrm{N}-\mathrm{H}$ annulation of amides 229 with gaseous ethylene and ethyne (Scheme 90). ${ }^{[251]}$ Here, 8-aminoquinoline was found as the directing group of choice for efficient annulation reactions. 


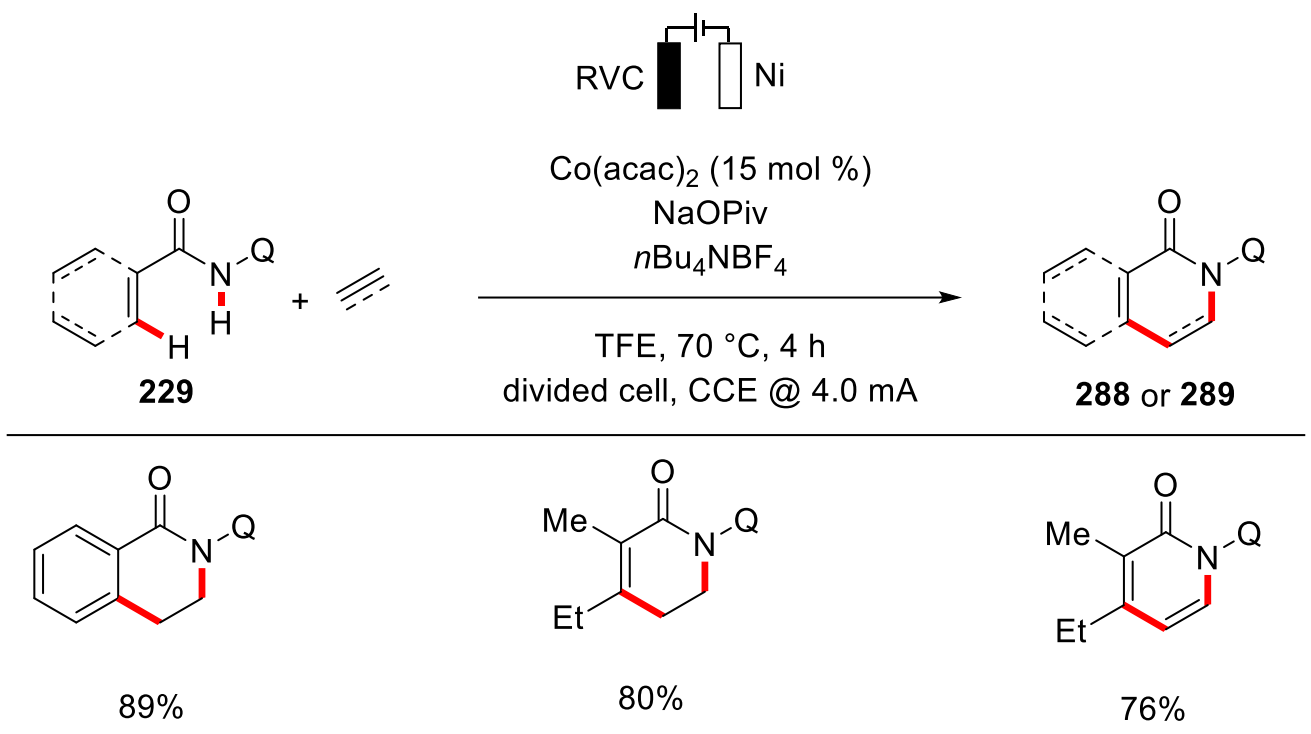

Scheme 90. Electrooxidative $\mathrm{C}-\mathrm{H} / \mathrm{N}-\mathrm{H}$ annulaiton with ethyne and ethylene.

In contrast to the previous reports, which were mainly limited to terminal alkynes, Ackermann showed the versatility of cobalt catalysis towards internal alkynes $\mathbf{1 1 7}$ for electrooxidative $\mathrm{C}-\mathrm{H} / \mathrm{N}-\mathrm{H}$ annulations (Scheme 91). ${ }^{[252]}$ A traceless hydrazide directing group enabled the annulation process at room temperature. Likewise, a wide range of internal alkynes $\mathbf{1 1 7}$ were found as suitable substrates. A key feature of this transformation was represented by the electroreductive hydrazide cleavage, using catalytic amounts of $\mathrm{SmI}_{2}$ to remove the benzhydrazide in a traceless manner.

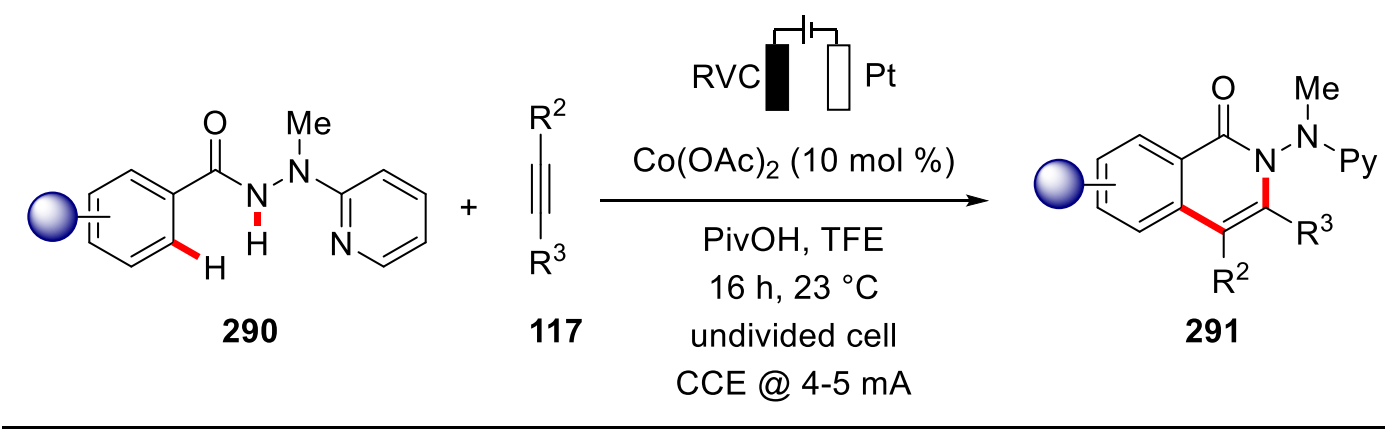<smiles>CC(C)c1c(C(C)C)n(N(C)C)c(=O)c2ccccc12</smiles>

$90 \%$<smiles>[R16]N([P])c1c(C(=O)OCC)c2ccccc2c(=O)n1CCC</smiles>

$55 \%$<smiles>CN(C)n1ccc2ccccc2c1=O</smiles>

$65 \%$

Scheme 91. Electrochemical C-H/N-H activation with internal alkynes 117.

Subsequently, a step-economical annulation was unraveled by Ackermann by the direct use of allenes 236 for electrochemical $\mathrm{C}-\mathrm{H} / \mathrm{N}-\mathrm{H}$ annulation process. ${ }^{[253]}$ Notably, various diversely 
substituted allenes $\mathbf{2 3 6}$ were tolerated and provided the corresponding products 238 with high regioselectivity (Scheme 92).

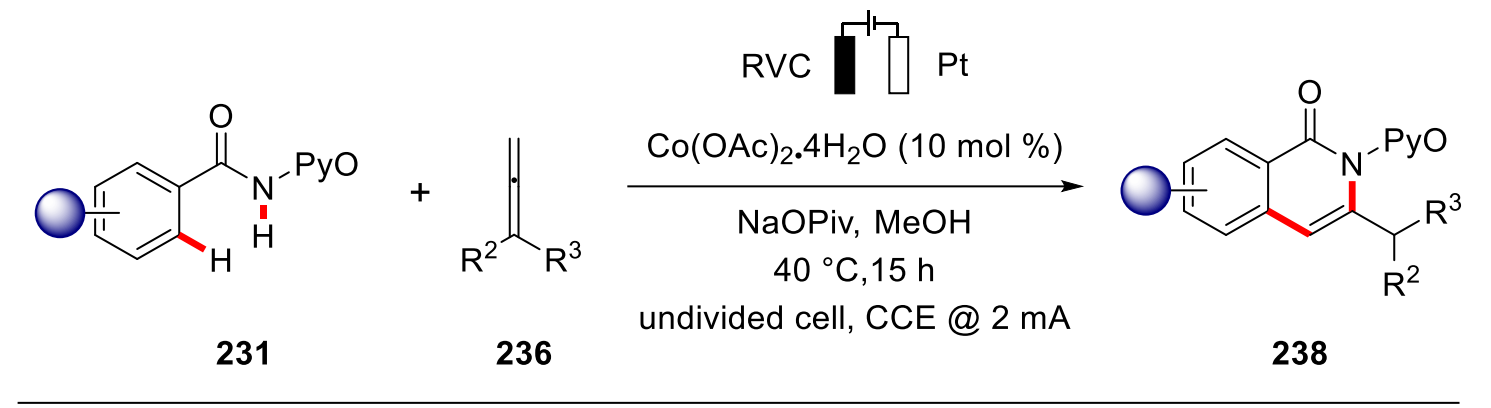<smiles>O=C(Cc1cc2ccccc2c(=O)n1PO)OCc1ccccc1</smiles>

$71 \%$<smiles>CC(c1cc2ccccc2c(=O)n1P(=O)(O)c1ccccc1)P(=O)(c1ccccc1)c1ccccc1</smiles>

$45 \%$<smiles>COc1ccc2c(=O)n(C(=O)O)c(C(C)P(=O)([O-])[O-])cc2c1</smiles>

$71 \%$

Scheme 92. Cobaltacatalyzed electrochemical $\mathrm{C}-\mathrm{H}$ activation with allenes.

In addition to annulations with alkynes $117 / 255$ and allenes 236, Lei and Ackermann independently reported the oxidative $\mathrm{C}-\mathrm{H} / \mathrm{N}-\mathrm{H}$ carbonylation with gaseous carbon monoxide. Lei utilized 8-aminoquinoline as the directing group for the $\mathrm{C}-\mathrm{H} / \mathrm{N}-\mathrm{H}$ carbonylation in the presence of catalytic amounts of cobalt catalyst. ${ }^{[254]}$ Likewise, the reaction was further extended to intermolecular variant in the presence of secondary amines (Scheme 93a). In addition to carbon monoxide, Ackermann also showed the versatility of cobalt catalysis with synthetically useful isocyanides 296 for $\mathrm{C}-\mathrm{H} / \mathrm{N}-\mathrm{H}$ annulation with benzhydrazides 290 (Scheme 93b). ${ }^{[255]}$ 
a) Lei<smiles></smiles>
229<smiles>C=CC=CC=[V]</smiles>

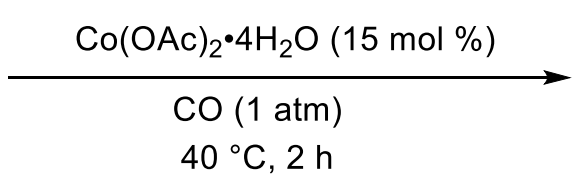
divided cell, CCE @ 15 mA<smiles>O=C1c2ccc3ccccc3c2C(=O)N1O</smiles>

292: $80 \%$<smiles>O=C(NO)c1sccc1C(=O)N1CCOCC1</smiles>

294: $78 \%$

b) Ackermann<smiles>[R7]N(C)N([Tl])C(=O)c1ccccc1</smiles>

290

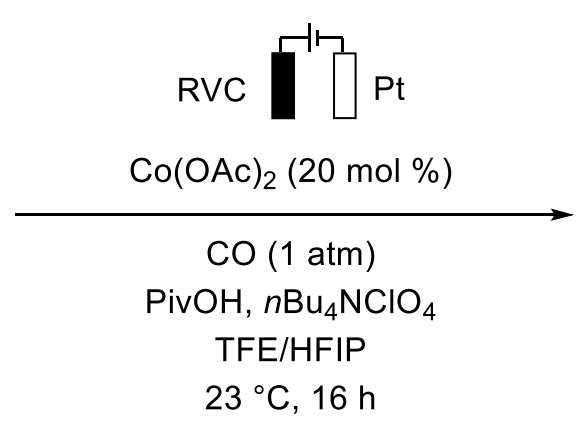

undivided cell, CCE @ 4.0 mA<smiles>[Y7]N(C)N1C(=O)c2ccccc2C1=O</smiles>

295: $71 \%$

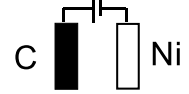
$80{ }^{\circ} \mathrm{C}, 3 \mathrm{~h}$

divided cell, CCE @ 6.0 mA

247 


\subsubsection{Copper Catalyzed Electrochemical C-H Activation}

While notable advances have been reported on Earth-abundant cobalt catalysis for sustainable electrocatalysis, ${ }^{[31]}$ a recent trend has shifted to other Earth-abundant metalla-electrocatalyzed $\mathrm{C}-\mathrm{H}$ transformations. Recently, Mei exploited the potential of copper catalysis for electrochemical $\mathrm{C}-\mathrm{H}$ amination reactions. It is noteworthy to mention that the authors achieved direct $\mathrm{C}-\mathrm{H}$ aminations of electron-rich anilides $\mathbf{2 9 8}$ at room temperature using electricity as green oxidant (Scheme 95a). ${ }^{[256]}$ The optimized electrocatalyst proved broadly applicable and showed high functional group tolerance. Shortly thereafter, in a related work, Nicholls and coworkers disclosed similar reactivity by the aid of 8-aminoquinoline directing group. ${ }^{\text {[257] }}$ The authors succeeded in achieving electro-oxidative aminations of amides 229 with amines 247 producing $\mathrm{H}_{2}$ as the sole byproduct (Scheme $95 \mathrm{~b}$ ). 


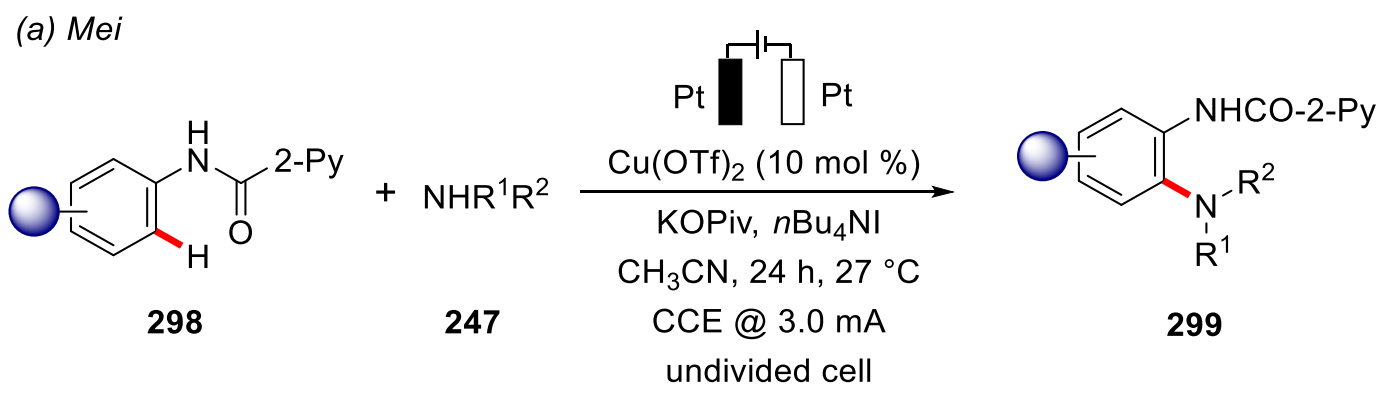<smiles>Cc1ccc(NC(=O)OCc2ccccc2)c(N2CCOCC2)c1</smiles>

$85 \%$<smiles>C#Cc1ccc(NC(=O)OCc2ccccc2)c(N2CCOCC2)c1</smiles>

$50 \%$<smiles>O=C(O)Nc1cccnc1N1CCOCC1</smiles>

$82 \%$

(b) Nicholls<smiles>O=C(NO)c1ccccc1</smiles>
$+\mathrm{NHR}^{1} \mathrm{R}^{2}$

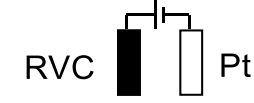<smiles>CC(=O)O[Mg][14C](=O)[O-]</smiles>
$\mathrm{MeCN}, 60{ }^{\circ} \mathrm{C}, 12 \mathrm{~h}$

229 247 CCE@3.0 mA undivided cell<smiles>[R]N([R])c1ccccc1C(N)=O</smiles>

248<smiles>O=C(NO)c1ccccc1N1CCOCC1</smiles>

$79 \%$<smiles>O=C(NO)c1ccc([N+](=O)[O-])cc1N1CCOCC1</smiles>

$50 \%$<smiles>CC(C)(C)c1ccc(C(=O)NO)c(N2CCSCC2)c1</smiles>

$63 \%$

Scheme 94. Copper-catalyzed electrochemical C-H amination. 


\section{Objectives}

Transition metal-catalyzed $\mathrm{C}-\mathrm{H}$ activation has been continuously evolving as an increasingly powerful approach in the emerging field of synthetic chemistry. ${ }^{[27,56]}$ The development of new molecular reactions continuous to be highly desirable in the advent of organic synthesis to elevate the productivity at lower cost. Thus, the objective of this thesis was to aim on the development of cost-effective and environmentally-benign metal-catalyzed selective $\mathrm{C}-\mathrm{H}$ activation reactions with olefins and alkynes with a major emphasis on the identification of resource-economical conditions. In addition, a considerable focus has been placed on the mechanistic understandings of these $\mathrm{C}-\mathrm{H}$ activations.

Over the past years, $\mathrm{C}-\mathrm{F}$ functionalization has emerged as a viable tool for the incorporation of fluorinated scaffolds into organic molecules. ${ }^{[42 a, 42 b]}$ Thus we became interested in exploiting the potential of inexpensive and versatile manganese catalysis for unprecedented $\mathrm{C}-\mathrm{F} / \mathrm{C}-\mathrm{H}$ functionalization through $\beta$-fluoride elimination (Scheme 95). Particularly, a broad substrate scope and mild reaction conditions should be of prime importance for the synthesis of diverse fluorinated scaffolds.

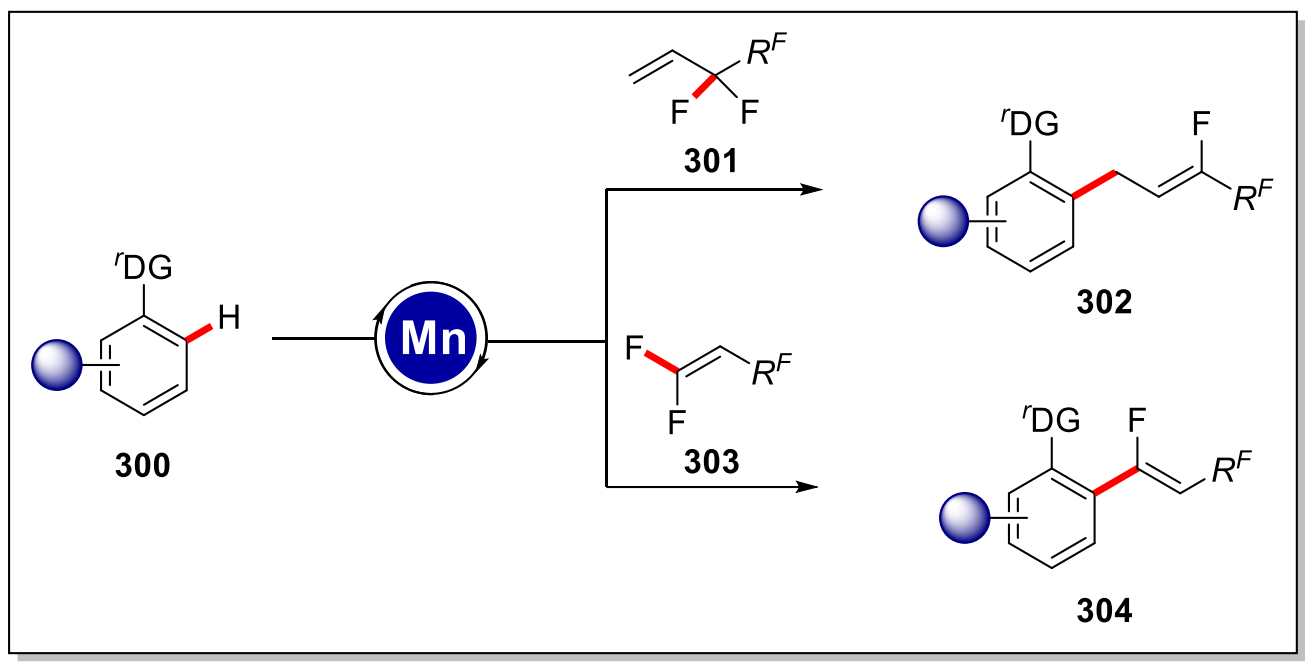

Scheme 95. Manganese(I)-catalyzed C-F/C-H functionalization.

Despite enormous advances in the application of ruthenium catalysts in organometallic $\mathrm{C}-\mathrm{H}$ activations, ${ }^{[27 t, 39,138]}$ challenging $\mathrm{C}-\mathrm{F}$ functionalization by ruthenium catalysis remained elusive. In this context, related studies of hydroarylations were achieved with unactivated alkenes and perfluoroalkylalkenes by Ackermann, ${ }^{[258]}$ which set the stage for the merger of $\mathrm{C}-\mathrm{H}$ activation with $\mathrm{C}-\mathrm{F}$ functionalization. In this regard, our aim was to develop a ligand enabled new strategy for a switch in chemoselectivity towards challenging $\mathrm{C}-\mathrm{F}$ functionalization, along with mechanistic studies (Scheme 96). 


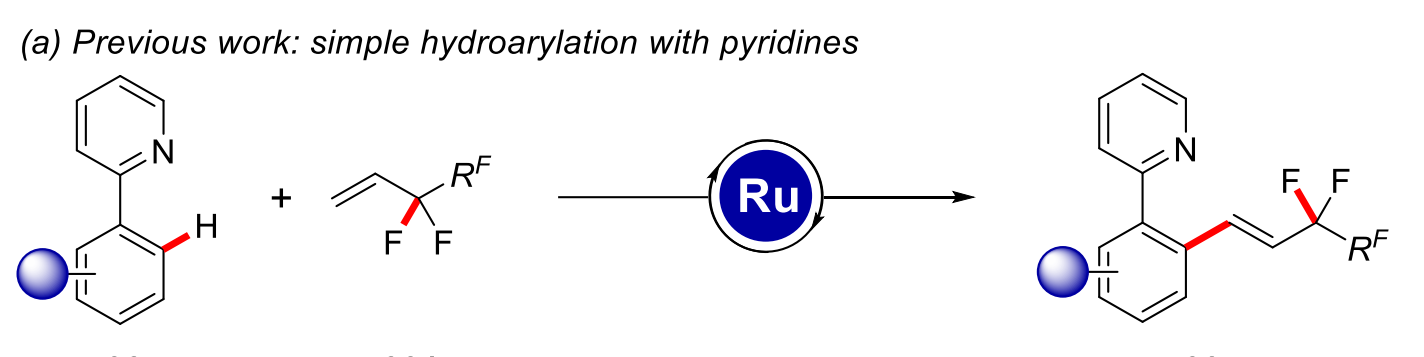

93

301

305

(b) This work: allylative $C-F / C-H$ functionalization with ketimines
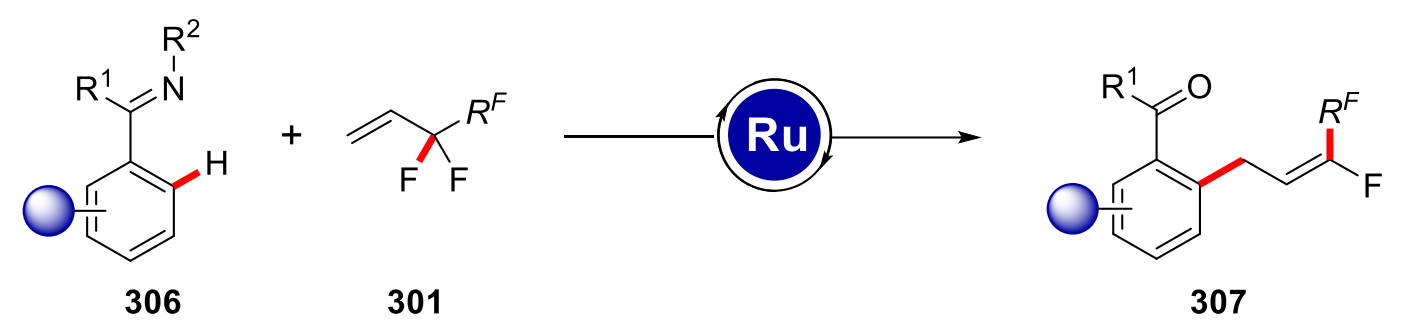

Scheme 96. $E$-selective C-H/C-F functionalization by ruthenium (II) catalysis.

The fascinating research area of enantioselective $\mathrm{C}-\mathrm{H}$ activation remains primarily dominated by $4 \mathrm{~d}$ and $5 \mathrm{~d}$ transition metals. ${ }^{[58]}$ Recent efforts have been directed more towards non-toxic Earth-abundant transition metals. ${ }^{[59]}$ Considering the importance of efficient and stepeconomical assembly of chiral molecules, novel enantioselective transformations utilizing cost-effective transition metals should be developed under sustainable reaction conditions. In this context, numerous studies on cobalt(III)-catalyzed $\mathrm{C}-\mathrm{H}$ activation have been developed due to their significant versatility. ${ }^{[31,32 \mathrm{~d}, 32 \mathrm{f}, 32 \mathrm{~g}, 32 \mathrm{j}]}$ Still enantioselective transformations with cobalt(III) catalysts have remained elusive and unexplored at the outset of this work. In this context, a combination of $\mathrm{Cp} * \mathrm{Co}$ (III) catalyst with a novel chiral acid was investigated for achieving high enantioselectivities in $\mathrm{C}-\mathrm{H}$ alkylation reactions. Furthermore, detailed mechanistic and computational studies were performed to unravel the mode of action (Scheme 97). 


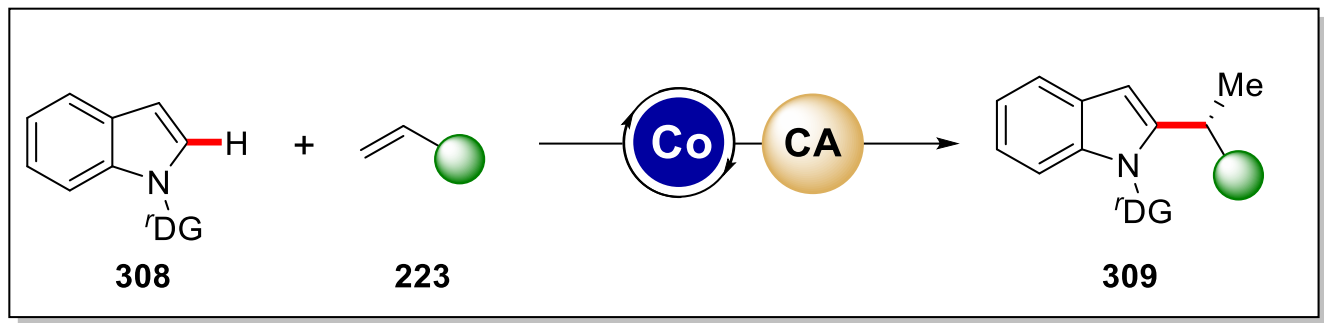

Scheme 97. Enantioselective cobalt(III)-catalyzed C-H activation enabled by chiral carboxylic acid cooperation.

In this regard, we also became interested in the development of new enantioselective transformations utilizing cost-effective ruthenium as the catalyst. While organometallic ruthenium catalyzed $\mathrm{C}-\mathrm{H}$ activations are well-investigated, ${ }^{[27 t, 39,138]}$ the enantioselective transformations remain underdeveloped. Thus, we decided to explore the versatility of ruthenium catalysts for the enantioselective $\mathrm{C}-\mathrm{H}$ alkylation reactions with the combination of a chiral acid, along with detailed mechanistic studies (Scheme 98).

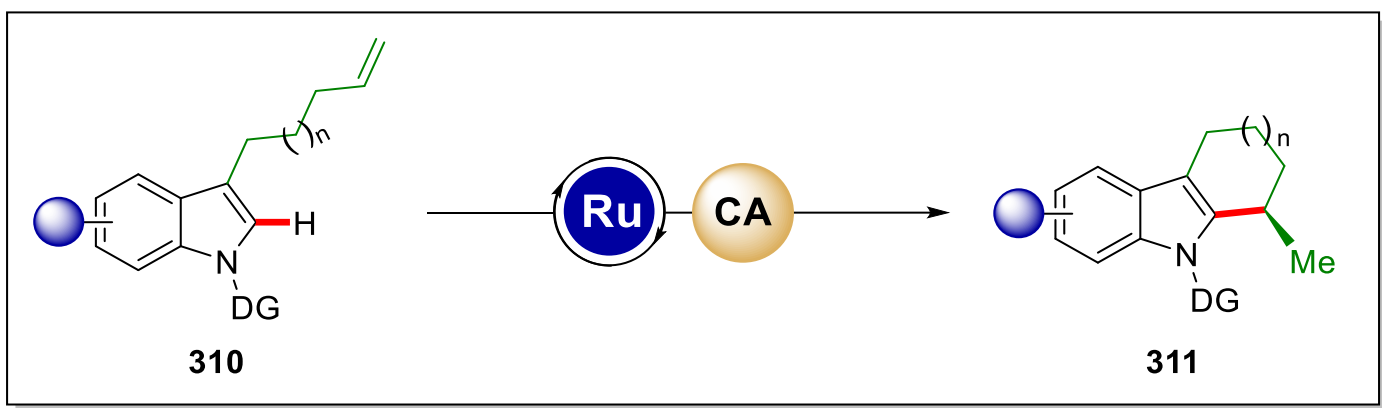

Scheme 98. Enantioselective ruthenium(II)-catalyzed C-H alkylation.

To harness the full potential of $\mathrm{C}-\mathrm{H}$ activation, metallaelectrocatalysis provides excellent resource economy for sustainable organic synthesis. ${ }^{[224]}$ Over the past years, the merger of $\mathrm{C}-$ $\mathrm{H}$ activation and electrosynthesis has emerged as a potent strategy, albeit early contributions were limited to palladium catalysis. ${ }^{[232]}$ In this context, the use of less toxic and inexpensive copper in oxidative electrochemical transformations offers an attractive strategy towards improved resource economy using electrons as green oxidant. Thus, inexpensive copper catalyst was intended to utilize in electrochemical conditions for oxidative annulation reactions with alkynes 255 and 258 (Scheme 99). 


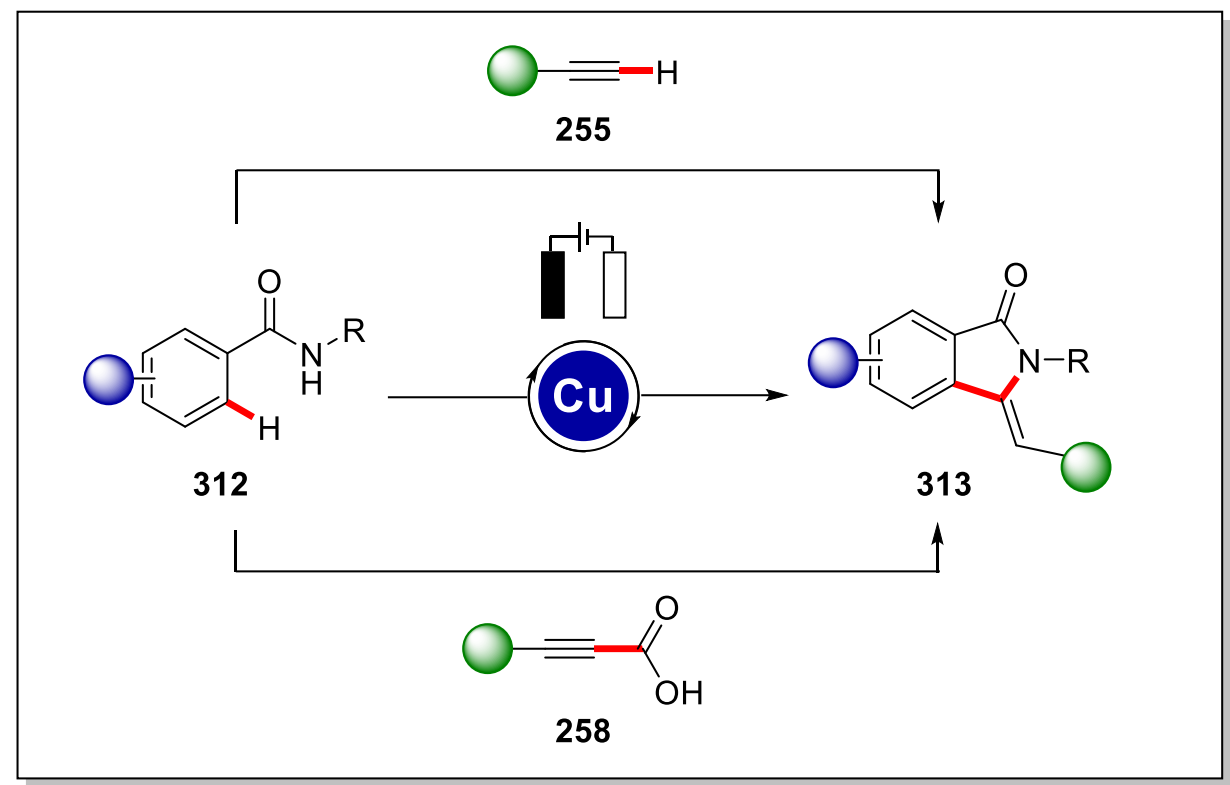

Scheme 99. Cupraelectro-catalyzed alkyne annulation.

In 2017, Ackermann reported the first cobalt-catalyzed electrochemical C-H activation where electro-oxidation of the cobalt catalyst is the key step. ${ }^{[246]}$ Since then, electrochemical oxidative transformations with Earth-abundant cobalt have gained enormous attention, employing electrons as traceless oxidant. ${ }^{[32 \mathrm{a}, 245]}$ In this context, $4 \mathrm{~d}$ and $5 \mathrm{~d}$ transition metal-catalyzed electrochemical transformations remained restricted to the use of activated alkenes as coupling partners. Thus, within this thesis, a new protocol for electrochemical $\mathrm{C}-\mathrm{H}$ allylation with unactivated alkenes was intended to address utilizing inexpensive and Earth-abundant cobalt catalysts. Detailed mechanistic studies were performed to delineate the unique reactivity with unbiased olefins (Scheme 100).

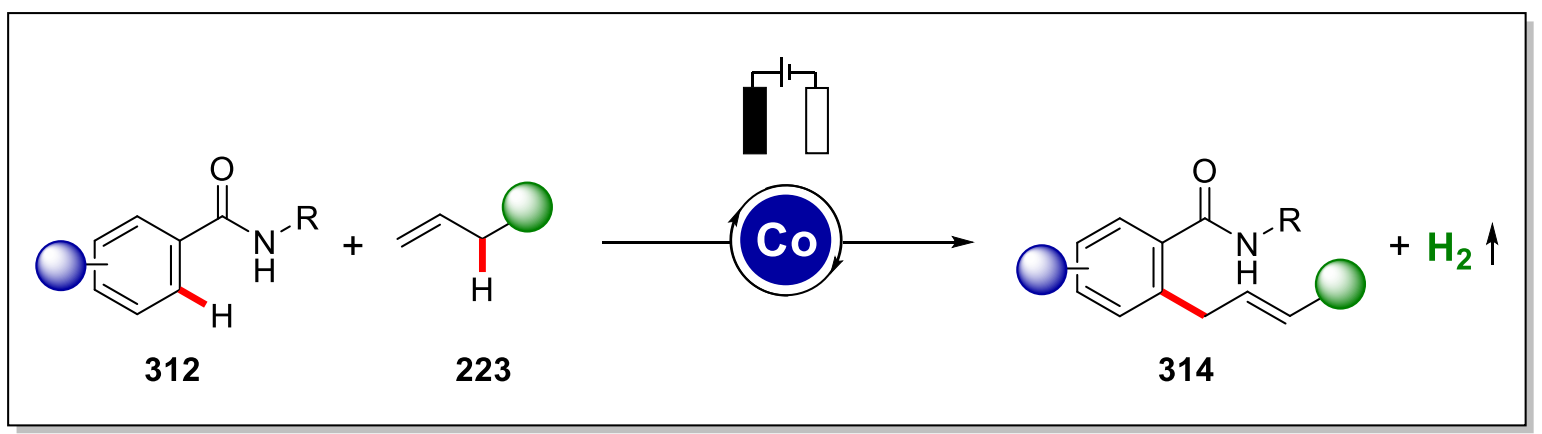

Scheme 100. Cobalt-catalyzed electrochemical C-H allylation.

To unleash the full potential of electrocatalysis towards perfect resource economy, enantioselective electrosynthesis is highly desirable as a new sustainable tool for the construction of chiral molecules. ${ }^{[232]}$ Despite significant advances in electrosynthesis, enantioselective metallaelectro-catalyzed $\mathrm{C}-\mathrm{H}$ activation remained unprecedented, 
showcasing the challenges in asymmetric electrosynthesis. Consequently, our focus was to develop the first enantioselective metallaelectro-catalyzed $\mathrm{C}-\mathrm{H}$ activation. Thus, our approach was directed towards electrochemical atroposelective synthesis of axially-chiral biaryls. In this regard, a sustainable protocol for the enantioselective electrochemical $\mathrm{C}-\mathrm{H}$ activation was addressed by the cooperation of transient directing group utilizing palladium as catalyst under mild reaction conditions. Furthermore, a major focus of our strategy was the late-stage diversification of axially chiral compounds to access target structures of value to asymmetric catalysis (Scheme 101).

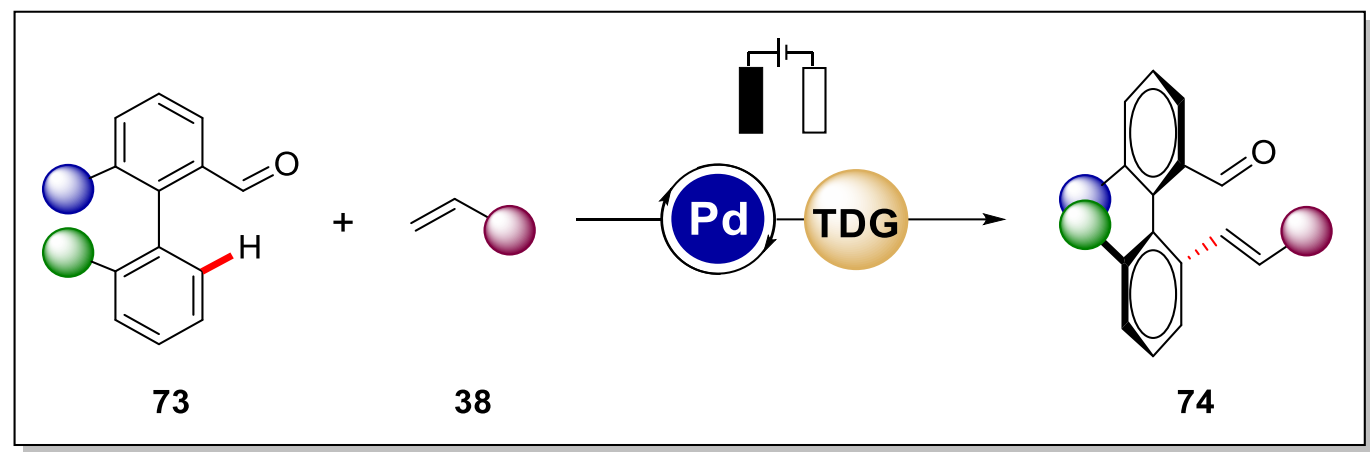

Scheme 101. Enantioselective metallaelectro-catalyzed $\mathrm{C}-\mathrm{H}$ activation. 


\section{Results and Discussion}

\subsection{Manganese(I)-Catalyzed (Per)Fluoro-Allylative and Alkenylative C-F/C-H Functionalizations}

In recent years, manganese catalysts have gained considerable attention owing to their inexpensive nature and low toxicities ${ }^{[32 \mathrm{~g}, 259]}$ with significant numbers of studies for various $\mathrm{C}-$ $\mathrm{H}$ additions onto $\mathrm{C}-\mathrm{C}$ or $\mathrm{C}-\mathrm{Het}$ multiple bonds and $\mathrm{C}-\mathrm{H}$ allylations reactions via $\beta$-oxygen or -carbon elimination. ${ }^{[260]}$ Recently, transition metal mediated $\beta$-fluorine elimination has become a viable tool for the transformation of $\mathrm{C}-\mathrm{F}$ bonds. ${ }^{[46]}$ Consequently, the merger of $\mathrm{C}-\mathrm{F}$ activation with challenging $\mathrm{C}-\mathrm{H}$ cleavages presents a sustainable and atom-economical approach to enable the selective synthesis of fluorinated molecules. ${ }^{[52-55]}$ Thus, we were interested in the development of catalytic $\mathrm{C}-\mathrm{F} / \mathrm{C}-\mathrm{H}$ activations by the aid of inexpensive and less toxic manganese catalysis.<smiles>CC(=O)NC[C@H]1CN(c2ccc(/C=C(\F)c3cccc(C=O)c3)c(F)c2)C(=O)O1</smiles>

protein synthesis inhibitor

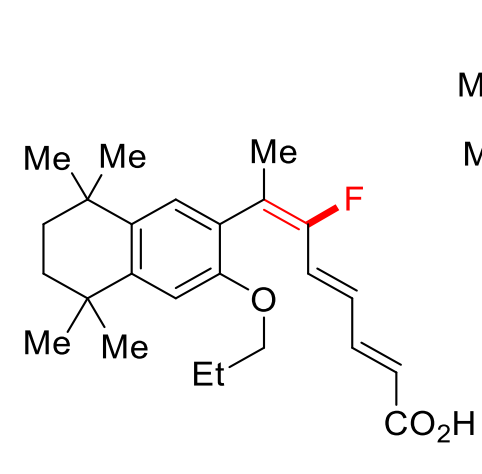

retinoid $\mathrm{X}$ receptor regulator<smiles>CC(C)C1C(=O)N[C@H](CO)Cc2cc(NC(=O)/C=C/C=C/c3ccc(/C=C/C(F)(F)F)cc3)ccc2N1C</smiles>

protein kinase $\mathrm{C}$ modulator

Scheme 102. Examples of bioactive fluoroalkenes

\subsubsection{Optimization Studies}

After initial optimization studies by $\mathrm{Dr}$. D. Zell for the allylative $\mathrm{C}-\mathrm{H} / \mathrm{C}-\mathrm{F}$ functionalizations of indole 315, almost quantitative yield was observed when indole 315a was reacted with perfluroalkylalkene 301a in the presence of catalytic amounts of $\operatorname{MnBr}(\mathrm{CO})_{5}$ and 2.0 equiv of $\mathrm{K}_{2} \mathrm{CO}_{3}$ in dioxane (Table 1, entry 1). It is noteworthy to mention that in the absence of the base, the yield of the desired product 316aa was significantly reduced, being suggestive of the formation of the corresponding fluoride salt which is possibly the driving force of the reaction (entry 2). Moreover, in a recent study the group of Ichikawa showed the potential of Lewisacids to enable the activation of inert $\mathrm{sp}^{3} \mathrm{C}-\mathrm{F}$ bond of the $\mathrm{CF}_{3}$ group through a Friedel-Craftstype mechanism. ${ }^{[261]}$ Thus, a series of Lewis acids, including $\mathrm{AlCl}_{3}, \mathrm{Et}_{2} \mathrm{AlCl}, \mathrm{BF}_{3} \cdot \mathrm{OEt}_{2}, \mathrm{TiCl}_{4}$, $\mathrm{ZrCl}_{4}$, and $\mathrm{FeCl}_{3}$ were tested under our optimized reaction conditions (entry 3-8), which, 
however failed to provide the desired $\mathrm{C}-\mathrm{F} / \mathrm{C}-\mathrm{H}$ functionalization product 316aa; highlighting the necessity of $\operatorname{MnBr}(\mathrm{CO})_{5}$ as the effective catalyst for this challenging transformation.

Table 1. Optimization for manganese(I)-catalyzed allylative $\mathrm{C}-\mathrm{F} / \mathrm{C}-\mathrm{H}$ functionalization. ${ }^{\text {[a] }}$

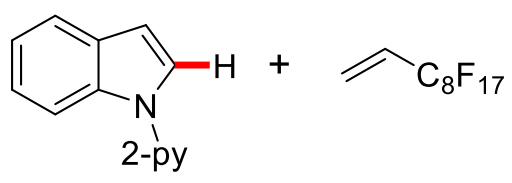

$315 a$

$301 \mathrm{a}$

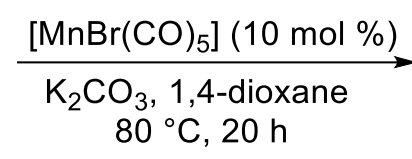

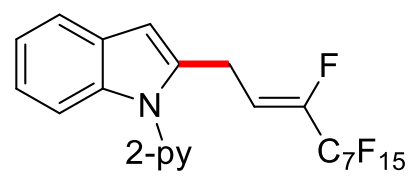

\begin{tabular}{|c|c|c|}
\hline Entry & Variation of the standard conditions & 316aa $[\%]^{[b]}$ \\
\hline 1 & none & 97 \\
\hline 2 & in the absence of $\mathrm{K}_{2} \mathrm{CO}_{3}$ & 7 \\
\hline 3 & $\mathrm{AlCl}_{3}$ in place of $[\mathrm{Mn}]$ & $---[c]$ \\
\hline 4 & $\mathrm{Et}_{2} \mathrm{AlCl}$ in place of $[\mathrm{Mn}]$ & $---[c]$ \\
\hline 5 & $\mathrm{BF}_{3} \cdot \mathrm{OEt}_{2}$ in place of $[\mathrm{Mn}]$ & $---[c]$ \\
\hline 6 & $\mathrm{TiCl}_{4}$ in place of $[\mathrm{Mn}]$ & $---[c]$ \\
\hline 7 & $\mathrm{ZrCl}_{4}$ in place of $[\mathrm{Mn}]$ & $---[c, d]$ \\
\hline 8 & $\mathrm{FeCl}_{3}$ in place of $[\mathrm{Mn}]$ & $---[c, d]$ \\
\hline
\end{tabular}

316aa

[a] Reaction conditions: 315a $(0.50 \mathrm{mmol}), 301 \mathrm{a}(1.00 \mathrm{mmol}),\left[\mathrm{MnBr}(\mathrm{CO})_{5}\right](10 \mathrm{~mol} \%)$, $\mathrm{K}_{2} \mathrm{CO}_{3}(0.50 \mathrm{mmol})$, solvent $(0.50 \mathrm{~mL}), 80{ }^{\circ} \mathrm{C}, 20 \mathrm{~h}$. [b] isolated yield. [c] Lewis acid (1.0 equiv). [d] Performed by Mr. V. Müller.

Next, we were interested in the incorporation of the $\alpha$-fluoroalkenyl motifs in to arenes using gem-difluoroalkenes $\mathbf{1 1}$ as the coupling partner, which is a very appealing class of synthetic intermediates with highly polarized $\mathrm{C}-\mathrm{C}$ double bonds. A comprehensive optimization study with indole 315a reflected the necessity of acetate base for increasing the reactivity to large extent, revealing $20 \mathrm{~mol} \% \mathrm{NaOAc}$ as additive to be optimal (Table 2, entry 1-3). Similarly, after probing various reaction temperatures, optimal reactivity was observed at $100{ }^{\circ} \mathrm{C}$, while higher reaction temperatures were detrimental to the yield of the desired product 317aa (entry 4-7). Notably, higher concentration of gem-difluoroalkenes improved the reactivity, albeit the overall difference in reactivity was less striking (entry 8-9). 
Table 2. Optimization for manganese(I)-catalyzed alkenylative $\mathrm{C}-\mathrm{F} / \mathrm{C}-\mathrm{H}$ functionalization. ${ }^{[\mathrm{a}]}$

\begin{tabular}{cccc} 
N15a & Temperature $\left[{ }^{\circ} \mathbf{C}\right]$ & Yield [\%] $]^{[\mathbf{b}]}$ \\
\hline Entry & NaAc [mol \%] & 100 & 74 \\
1 & 30 & 100 & 81 \\
2 & 10 & 100 & 40 \\
3 & 20 & 90 & 68 \\
4 & 20 & 95 & 70 \\
5 & 20 & 105 & 57 \\
6 & 20 & 120 & $60^{\text {[c] }}$ \\
7 & 20 & 100 & $85^{\text {[d] }}$
\end{tabular}

[a] Reaction conditions: 315a $(0.50 \mathrm{mmol}), \mathbf{1 1 a}(1.00 \mathrm{mmol}),\left[\mathrm{MnBr}(\mathrm{CO})_{5}\right](10 \mathrm{~mol} \%), \mathrm{K}_{2} \mathrm{CO}_{3}$ $(0.50 \mathrm{mmol}), \mathrm{NaOAc}(10-30 \mathrm{~mol} \%), 1,4-$ dioxane $(0.50 \mathrm{~mL}), 20 \mathrm{~h}$. [b] isolated yield. [c] 11a ( $0.60 \mathrm{mmol}) .[\mathrm{d}] \mathbf{1 1 a}(1.50 \mathrm{mmol})$.

\subsubsection{Substrate Scope and Limitations of $\mathrm{C}-\mathrm{H} / \mathrm{C}-\mathrm{F}$ Functionalizations}

With the optimized reaction condition in hand, we next investigated the versatility and robustness of allylative $\mathrm{C}-\mathrm{H} / \mathrm{C}-\mathrm{F}$ functionalizations (Table 3). Initially, a gram-scale reaction was carried out and the desired product 316aa was obtained without any significant loss of efficacy (entry 1). Next, various C5-substituted 2-pyridylindoles were tested under the optimized reaction condition (entries 2-4). Both electron-rich and electron-deficient indoles provided the desired products $\mathbf{3 1 6}$ in excellent yields and with good diastereoselectivities, albeit acetate base facilitated the reactivity for the substrate 315d (entry 4). Importantly, sterically-hindered C3 substituted indoles also afforded the corresponding desired products in good to excellent yields (entries 5-7). To our delight, challenging 7-azaindole $\mathbf{3 1 5 g}$, which is a key structural motif present in various anticancer drug molecules, was very efficiently converted to provide the desired allylative $\mathrm{C}-\mathrm{H} / \mathrm{C}-\mathrm{F}$ product 316ga in good yield and with good diastereoselectivity, although addition of acetate base and higher concentration of 301a 
were needed (entry 8). Furthermore, 1-(pyridin-2-yl)-1H-pyrrole (320a), 2-phenylpyridines (93a), benzo[h]quinoline (323a) also delivered the desired products in good yields under slightly modified reaction conditions (entries 9-11). However, cyano and nitro-substituted indoles $315 \mathrm{~h}$ and $\mathbf{3 1 5 i}$ remained untouched under the optimized condition (entries 12-13). In addition, 1-(pyridin-2-yl)-1H-benzo[d]imidazole (324a) and 9-(pyridin-2-yl)-9H-carbazole (326a) did not react under otherwise identical reaction conditions (entries 14-15).

Table 3. Scope of the manganese(I)-catalyzed allylative $\mathrm{C}-\mathrm{H} / \mathrm{C}-\mathrm{F}$ functionalization. ${ }^{\text {a] }}$

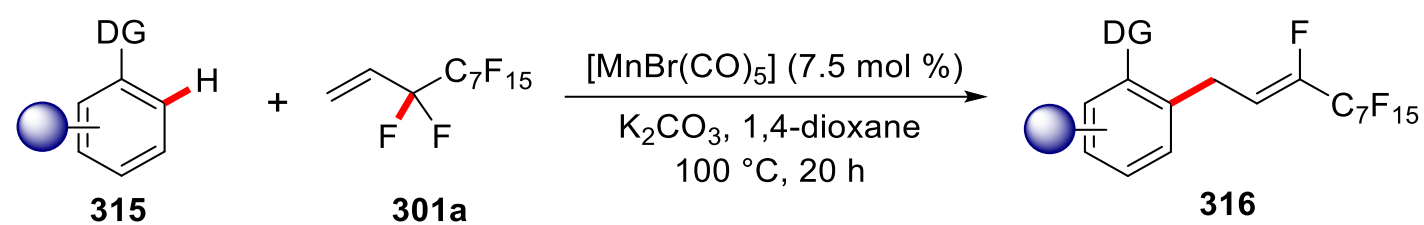

(n)


6<smiles></smiles>

7

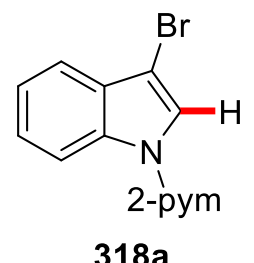

8

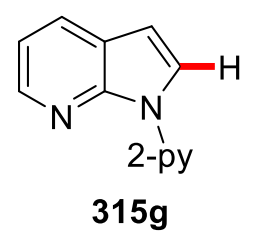

9<smiles>c1ccc(-n2cccc2)nc1</smiles>

$320 a$<smiles>c1ccc(-c2ccccn2)cc1</smiles>

93a

11<smiles>CC(C)(C)C1=CC=Cc2cccc3cccc1c23</smiles>

12<smiles>N#Cc1c(C#N)n([18OH])c2ccccc12</smiles><smiles></smiles><smiles>CP(=O)(OCCCCC(F)F)n1c(CC=C(F)C(F)F)c(Br)c2ccccc21</smiles><smiles>F/C(=C\Cc1cc2cccnc2n1[10PH])C(F)F</smiles>

316ga<smiles>FC(=CCc1cccn1-c1ccccn1)C(F)F</smiles>

321 aa<smiles>FC(=CCc1ccccc1-c1ccccn1)C(F)F</smiles>

322aa<smiles>FC(=CCc1cccc2ccc3cccnc3c12)C(F)C(F)F</smiles>

324aa<smiles>[R17]n1c(CC=C(F)C(F)F)c(C#N)c2ccccc21</smiles>

316ha
$10: 90 \quad 62 \%$

$12: 88 \quad 89 \%^{[\mathrm{d} . \mathrm{e}]}$

$20: 80 \quad 82 \%{ }^{[\mathrm{d}, \mathrm{e}]}$

$13: 87 \quad 62 \%$

$14: 86 \quad 58 \%^{[\mathrm{d}, \mathrm{f}]}$

$4: 96 \quad 54 \%^{[\mathrm{d}-\mathrm{f}]}$ 
13<smiles>O=[N+]([O-])c1ccc2c(ccn2[18O])c1</smiles>
$315 i$

14<smiles>[R7]n1cnc2ccccc21</smiles>

$324 a$

15<smiles>[R17]n1c2ccccc2c2ccccc21</smiles>

$326 a$<smiles>O=[N+]([O-])c1ccc2c(c1)cc(C/C=C(/F)C(F)F)n2P([18OH])[18OH]</smiles><smiles>[Y6]n1c(C/C=C(\F)C(F)F)nc2ccccc21</smiles>

$325 a a$

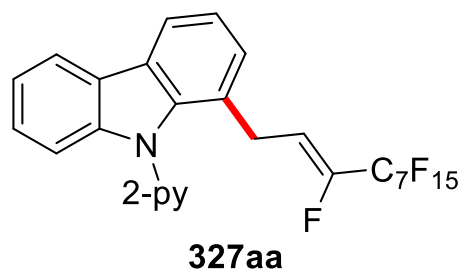

[a] Reaction conditions: $315(0.50 \mathrm{mmol}), 301 \mathrm{a}(0.60 \mathrm{mmol}),\left[\mathrm{MnBr}(\mathrm{CO})_{5}\right](7.5 \mathrm{~mol} \%)$, $\mathrm{K}_{2} \mathrm{CO}_{3}(0.50 \mathrm{mmol}), 1$,4-dioxane $(0.5 \mathrm{~mL}), 20 \mathrm{~h}$. [b] Yield of isolated product. [c] Reaction carried on $3.0 \mathrm{mmol}$ scale. [d] NaOAc $(30 \mathrm{~mol} \%)$ as additive. [e] 301a $(1.0 \mathrm{mmol})$. [f] $120^{\circ} \mathrm{C}$.

Furthermore, different perfluoroalkyl chain lengths were investigated under the optimized reaction conditions (Table 4). $1 \mathrm{H}, 1 \mathrm{H}, 2 \mathrm{H}$-Perfluorohexene (301b) and $1 \mathrm{H}, 1 \mathrm{H}, 2 \mathrm{H}$ perfluorododecene (301c) reacted efficiently with indole 315a and 2-phenylpyridine $\mathbf{9 3 b}$ to furnish the corresponding products 316ab-316ac and 322bc in good yields respectively (entries 1-3). In the latter case, an elevated reaction temperature and a higher concentration of 301c were necessary (entry 3). 
Table 4. Scope of the manganese(I)-catalyzed C-H/C-F functionalization with perfluoroalkylalkene. ${ }^{[\mathrm{a}]}$<smiles>Oc1ccccc1</smiles>

$315 / 93$<smiles>C=CC(F)(F)[PH-]</smiles>

301

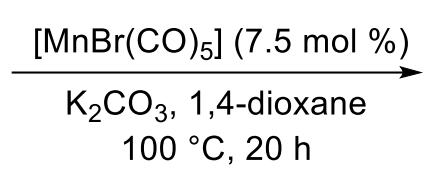
$100{ }^{\circ} \mathrm{C}, 20 \mathrm{~h}$

Entry Perfluoroalkylalkene

Product<smiles>C=CC(F)(F)CC(F)(F)F</smiles>

301b

2<smiles>C=CC(F)(F)CC(F)(F)[Se-]</smiles>

$301 \mathrm{C}$

3<smiles>C=CC(F)(F)CC(F)(F)[Se-]</smiles>

$301 \mathrm{c}$<smiles>[18O]n1c(C/C=C(\F)C(F)(F)F)cc2ccccc21</smiles>

$316 a b$

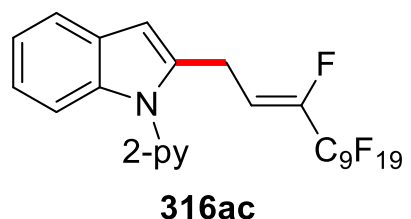

$11: 89$ $84 \%$

$8: 9257 \%[\mathrm{c}, \mathrm{d}]$<smiles>COc1ccc(-c2ccccn2)c(C/C=C(\F)C(F)(F)F)c1</smiles>

$322 \mathrm{bc}$

[a] Reaction conditions: 315/93 (0.50 mmol), 301 (0.60 mmol), [ $\left.\mathrm{MnBr}(\mathrm{CO})_{5}\right]$ (7.5 mol \%), $\mathrm{K}_{2} \mathrm{CO}_{3}(0.50 \mathrm{mmol}), 1,4-$ dioxane $(0.50 \mathrm{~mL}), 20 \mathrm{~h}$. [b] Yield of isolated product. [c] NaOAc (30 mol \%) as additive. [d] $301 \mathrm{c}\left(2.0\right.$ equiv) [e] $120{ }^{\circ} \mathrm{C}$.

Next, we turned our attention towards direct functionalization of peptides which holds significant potential in biomolecular chemistry for chemoselective ligation of peptide (Table 5). To our delight, protected amino acids 328a-328b underwent $\mathrm{C}-\mathrm{F} / \mathrm{C}-\mathrm{H}$ functionalization without racemization of the stereogenic centers, reflecting the mildness and versatility of the developed methodology (entries 1-2). In addition, more structurally complex dipeptide 328c also delivered the desired product 329ca with high levels of site-selectivity, albeit higher catalyst loading was needed to increase the turnover number (entry 3 ). 
Table 5. C-H/C-F functionalization with amino acids. ${ }^{[a]}$

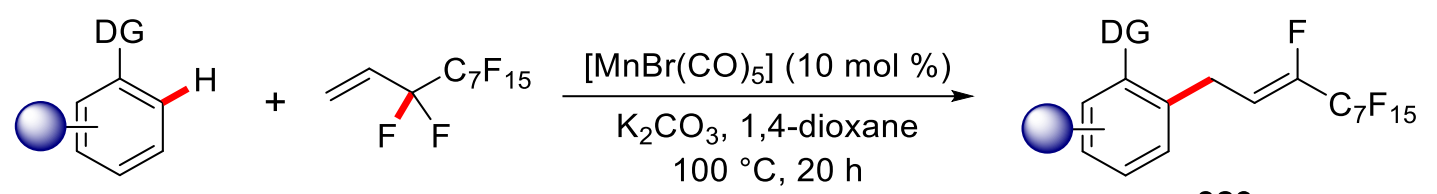

$301 \mathrm{a}$

329

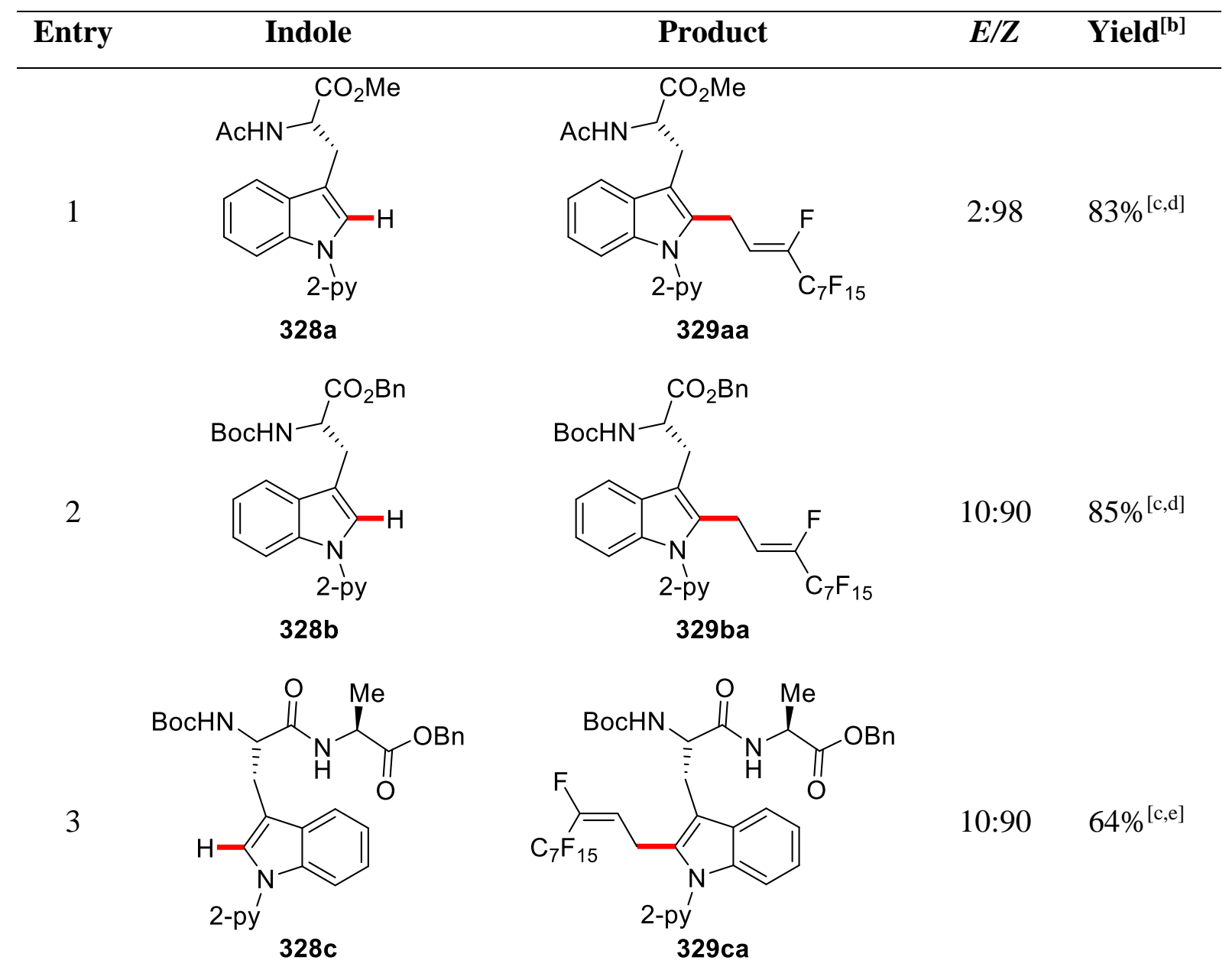

[a] Reaction conditions: 328a $(0.50 \mathrm{mmol}), 301 \mathrm{a}(0.60 \mathrm{mmol}),\left[\mathrm{MnBr}(\mathrm{CO})_{5}\right](10 \mathrm{~mol} \%)$, $\mathrm{K}_{2} \mathrm{CO}_{3}(0.50 \mathrm{mmol}), 1,4-$ dioxane $(0.50 \mathrm{~mL}), 20 \mathrm{~h}$. [b] Yield of isolated product. [c] NaOAc (30 mol \%) as additive. [d] 301a (2.0 equiv) [e] 301a (3.0 equiv), [Mn] (20 mol \%).

Moreover, on a pleasing note, challenging perfluoroalkenes $\mathbf{3 0 3}$ were found as suitable substrates for $\mathrm{C}-\mathrm{H}$ perfluoroalkenylations (Table 6). Indole 315a and sterically-demanding C3-substituted indole 315e provided the desired perfluoroalkenylation products in good yields and selectively delivered the $E$-isomers (entry 1-2). Even more challenging protected amino acids 328a-328b were also identified as amenable substrates for the perfluoroalkenylation, showcasing the versatility of our method (entries 3-4). However, higher catalyst loading was necessary for the pyrazole derivative 332a to afford the desired product 333ab in synthetically 
useful yield (entry 5). It is noteworthy to mention that all the perfluoroalkenylation products were selectively obtained as the $E$-isomer.

Table 6. Alkenylative $\mathrm{C}-\mathrm{F} / \mathrm{C}-\mathrm{H}$ functionalizations with perfluoroalkenes. ${ }^{[a]}$<smiles>Oc1ccccc1</smiles>

$315 / 328 / 332$<smiles>FC(F)=C(F)F</smiles>

303

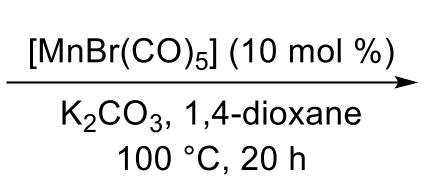
$100{ }^{\circ} \mathrm{C}, 20 \mathrm{~h}$<smiles>[O-]c1ccccc1C(F)=C(F)F</smiles>

$330 / 331 / 333$

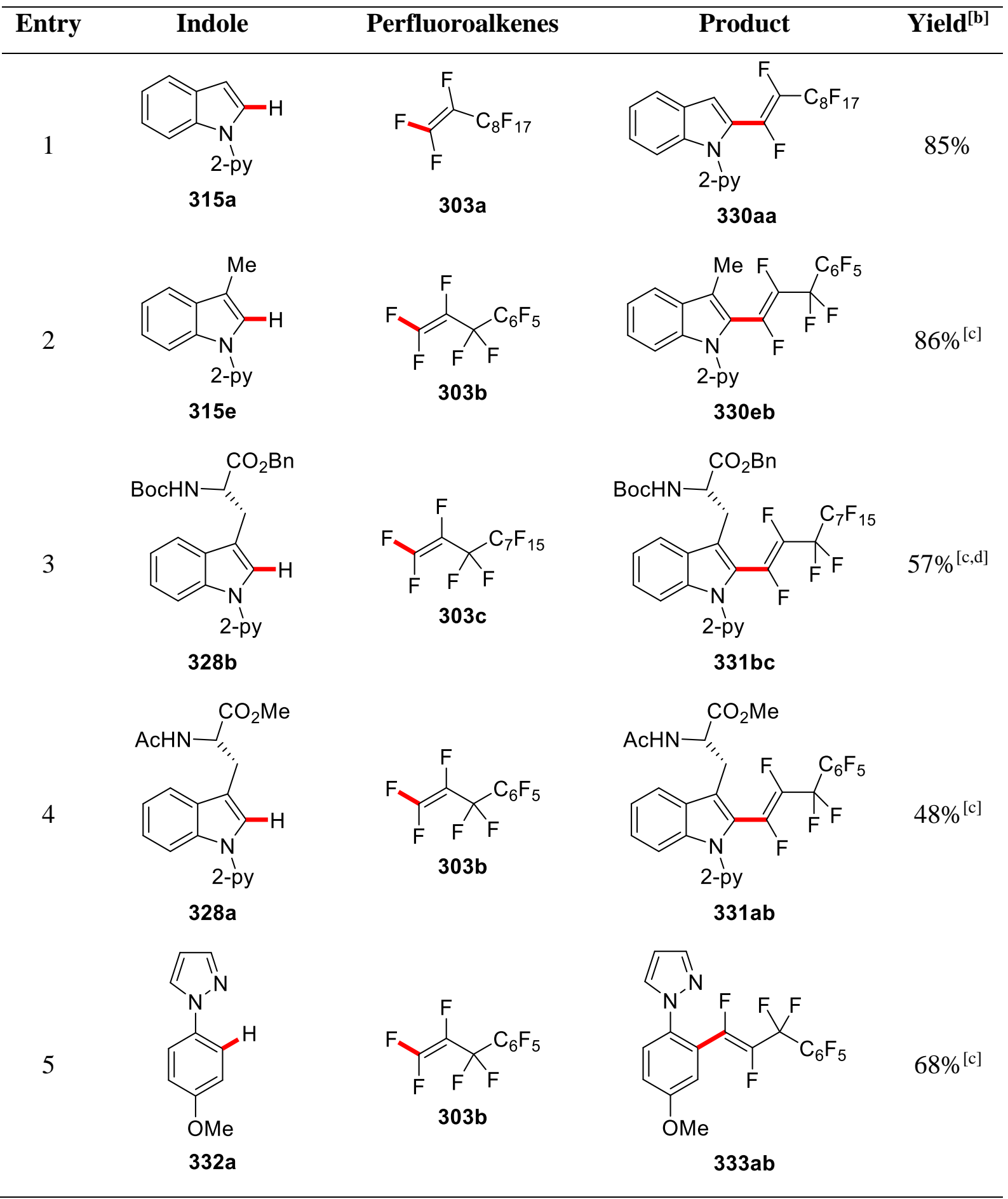


[a] Reaction conditions: 315/328/332 (0.50 mmol), 303 (0.60 mmol), [MnBr(CO)5] (10 mol $\%), \mathrm{K}_{2} \mathrm{CO}_{3}(0.50 \mathrm{mmol}), 1,4$-dioxane $(0.50 \mathrm{~mL}), 20 \mathrm{~h}$. [b] Yield of isolated product. [c] NaOAc $(30 \mathrm{~mol} \%)$ as additive. [d] [Mn] $(15 \mathrm{~mol} \%)$.

\subsubsection{Proposed Catalytic Cycle}

Detailed mechanistic studies by $D r$. D. Zell revealed a significant amount of H/D exchange at C2-position of the reisolated starting material 315a, which is suggestive of a reversible $\mathrm{C}-\mathrm{H}$ bond activation step. In addition KIE experiments by Dr. D. Zell and DFT studies by M. Bursch and Prof. S. Grimme supported a facile and reversible BIES-type C-H metalation event.

Thus, the proposed catalytic cycle initiates via a carbonate-assisted facile BIES C-H activation step to form the manganacycle 335 (Scheme 103). Then, fast coordination of perfluoroalkylalkene 301a with the manganacycle $\mathbf{3 3 5}$ and subsequent migratory insertion into the manganese-carbon bond forms intermediate 337. Next, rate-determining $\beta$-F elimination by the carbonate base preferentially forms the Z-configured product $\mathbf{3 1 6}$ as supported from DFT-calculations by $M$. Bursch and regenerates the initially formed bicarbonate complex 334 and completes the cycle. Formation of the potassium fluoride is possibly the driving force for the reaction, as in the absence of carbonate base the reactivity is significantly reduced. 


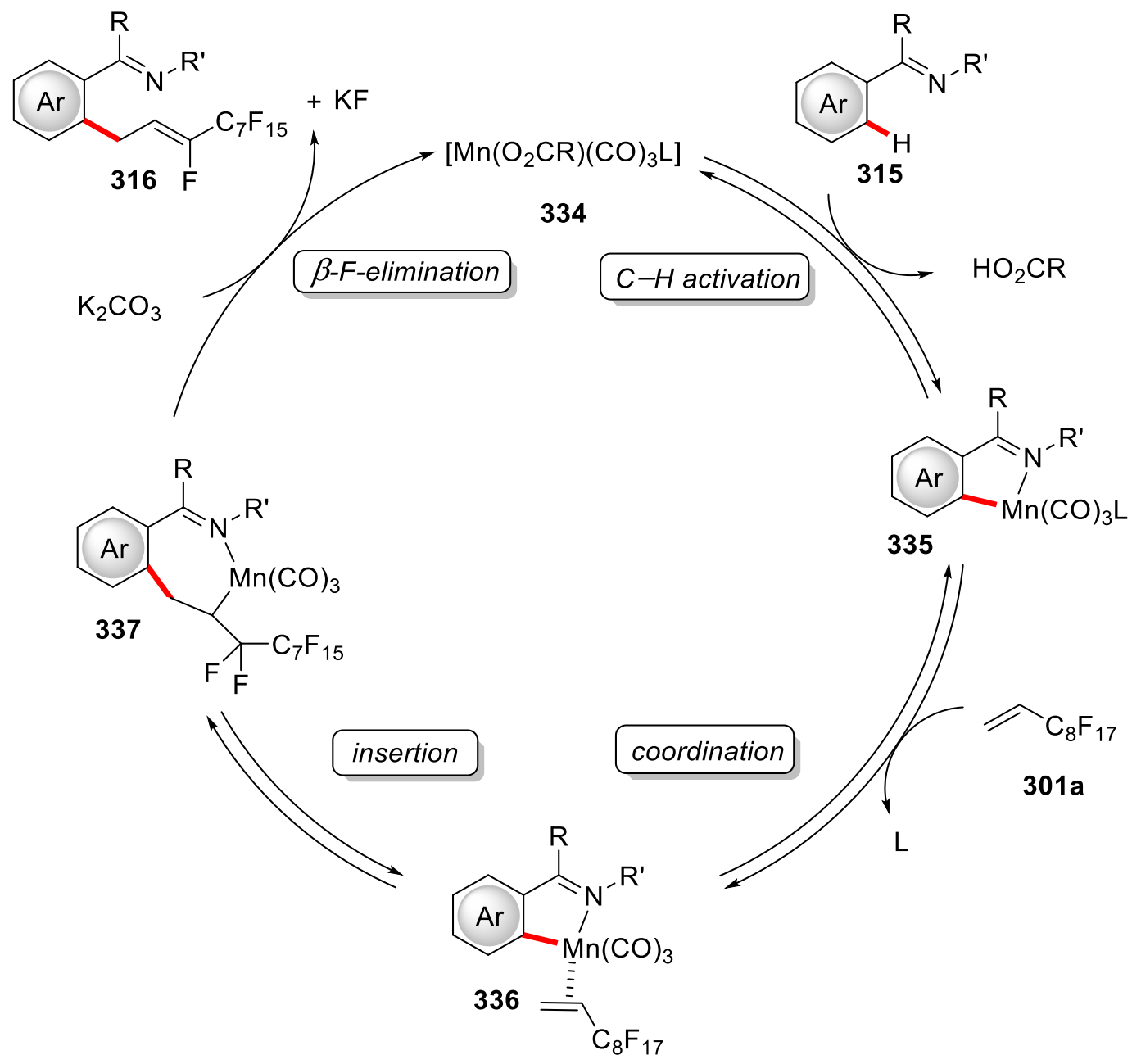

Scheme 103. Proposed catalytic cycle for the allylative $\mathrm{C}-\mathrm{F} / \mathrm{C}-\mathrm{H}$ functionalization. 


\subsection{Ruthenium(II)-Catalyzed $E$-Selective Allylative C-F/C-H Functionalization}

During last two decades ruthenium(II) complexes have been extensively studied in catalytic $\mathrm{C}-\mathrm{H}$ bond activation due to their cost-effectiveness as well as their robust and versatile reactivity. ${ }^{[27 t, 39,138]}$ Furthermore, metal-catalyzed hydroarylations reactions ${ }^{[262]}$ are particularly attractive because of their perfect atom-economy with significant progress realized by versatile ruthenium catalysts. ${ }^{[7]}$ In this context, early contributions were primarily realized with relatively unstable and expensive low-valent ruthenium catalysts such as $\left[\mathrm{RuH}_{2}(\mathrm{CO})\left(\mathrm{PPh}_{3}\right)_{3}\right]$, $\left[\mathrm{RuH}_{2}\left(\mathrm{PPh}_{3}\right)_{4}\right],\left[\mathrm{Ru}(\mathrm{CO})_{2}\left(\mathrm{PPh}_{3}\right)_{3}\right]$ or $\left[\mathrm{RuH}_{2}\left(\mathrm{H}_{2}\right)_{2}(\mathrm{PCy})_{2}\right]$. However, recently bench-stable $\left[\mathrm{Ru}\left(\mathrm{O}_{2} \mathrm{CR}\right)_{2}(p\right.$-cymene $\left.)\right]$ complex has been identified as powerful catalyst for various direct $\mathrm{C}-\mathrm{H}$ bond arylations, hydroarylations and oxidative annulation reactions. ${ }^{[263]}$ Thus far simple hydroarylations were reported with unactivated alkenes and perfluoroalkylalkenes by ruthenium(II)biscarboxylate catalysts. ${ }^{[258]}$ Despite significant advancement of atomeconomical hydroarylations, ruthenium(II)-catalyzed $\mathrm{C}-\mathrm{F}$ bond activations remains largely underexplored.

On this note, developments of step-economical protocols for the site-selective installation of fluorine-containing moieties into organic molecules are in great demand. Thereby, we were interested to achieve challenging ruthenium catalyzed $\mathrm{C}-\mathrm{F} / \mathrm{C}-\mathrm{H}$ functionalization-based $\mathrm{C}-\mathrm{H}$ allylations reactions via $\beta$-fluorine elimination.

\subsubsection{Optimization Studies}

The optimization study was commenced by probing various reaction conditions for the envisioned $\mathrm{C}-\mathrm{F} / \mathrm{C}-\mathrm{H}$ functionalization with synthetically useful ketimine 338 (Table 7). Initial study under ligand-free conditions did not deliver the desired product 307aa (Table 7, entry 1). Subsequently, we tested a set of representative ligands and solvents. Cyclohexane turned out to be the optimal solvent for the $\mathrm{C}-\mathrm{F} / \mathrm{C}-\mathrm{H}$ functionalization among other typical organic solvents (entries 2-9). It is noteworthy to mention that the presence of strong base delivered the hydroarylation product selectively under ligand-free conditions which was previously achieved by the Ackermann group using a pyridine directing group (entry 10). ${ }^{[258]}$ Among a variety of bases, $\mathrm{K}_{3} \mathrm{PO}_{4}$ provided slightly improved yields of the desired ketone 307aa upon one-pot hydrolysis (entries 11-16). Subsequently, a variety of electron-rich and electron-deficient phosphines were tested in cyclohexane. The best catalytic efficiency was realized in the presence of electron-deficient $\mathrm{P}\left(4-\mathrm{C}_{6} \mathrm{H}_{4} \mathrm{~F}\right)_{3}$ as ligand (entries 17-23), particularly employing the trimethoxyphenylketimine 340a as the substrate (entries 26-27). Moreover, higher or lower 
reaction temperatures failed to improve the yields of the desired product 307aa (entries 24-25). Finally, control experiment in the absence of the catalyst showed the necessity of the ruthenium catalyst for the envisioned $\mathrm{C}-\mathrm{F} / \mathrm{C}-\mathrm{H}$ functionalization (entry 29). The E/Z-diastereoselectivities were slightly influenced by the choice of the ligand, generally favoring the $E$ diastereomer, while only very minor amounts of the corresponding hydroarylation products 339aa of less than $2 \%$ were observed under the optimized reaction condition.

Table 7. Optimization for the ruthenium(II)-catalyzed allylative $\mathrm{C}-\mathrm{F} / \mathrm{C}-\mathrm{H}$ functionalization. ${ }^{[\mathrm{a}]}$

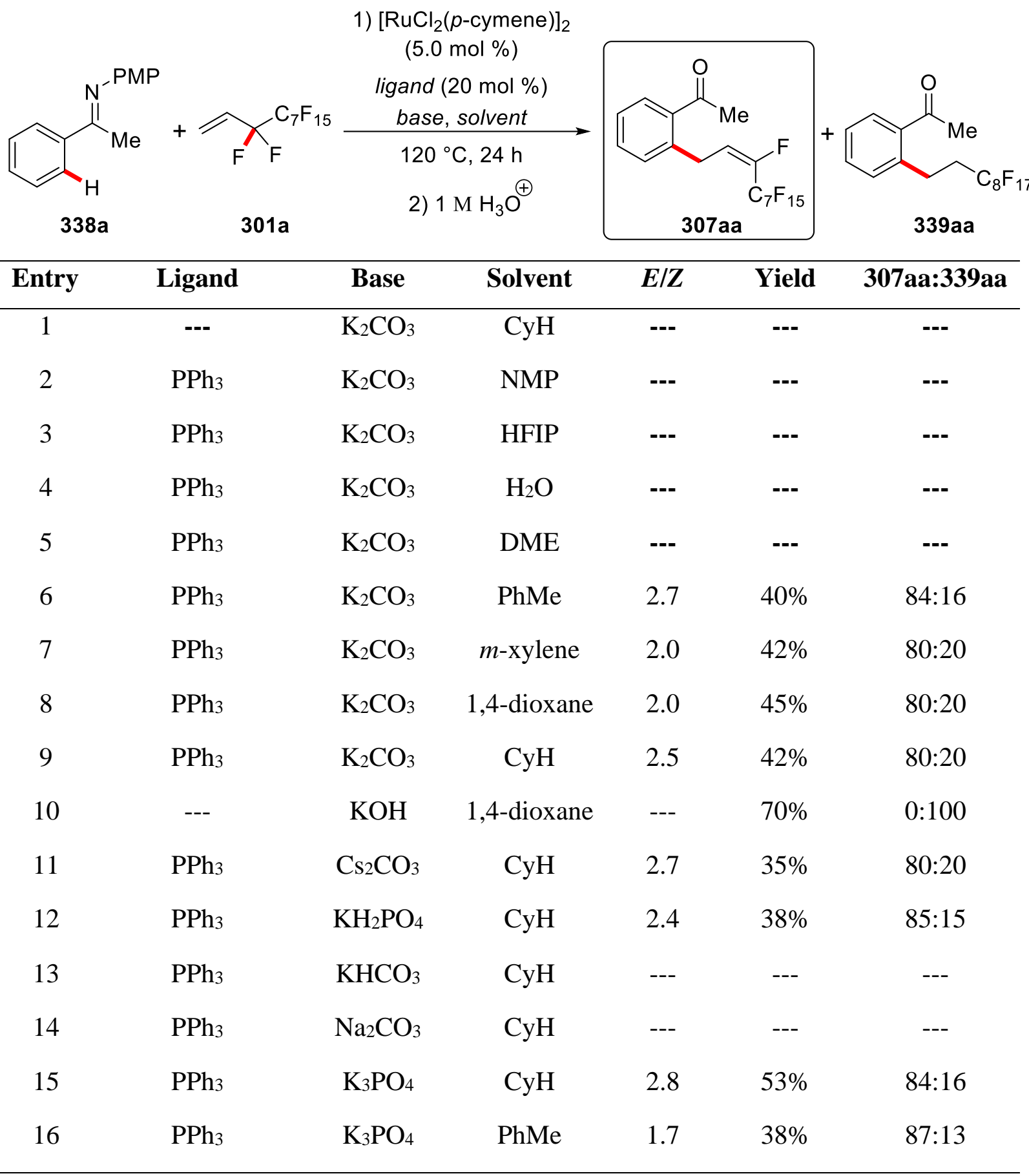




\begin{tabular}{ccccccc}
\hline 17 & $\mathrm{PCy}_{3}$ & $\mathrm{~K}_{3} \mathrm{PO}_{4}$ & $\mathrm{CyH}$ & 2.0 & $8 \%$ & $80: 20$ \\
18 & $d p p f$ & $\mathrm{~K}_{3} \mathrm{PO}_{4}$ & $\mathrm{CyH}$ & --- & --- & --- \\
19 & $\mathrm{P}(\mathrm{Cy}) \mathrm{Ph}_{2}$ & $\mathrm{~K}_{3} \mathrm{PO}_{4}$ & $\mathrm{CyH}$ & 2.7 & $35 \%$ & $60: 40$ \\
20 & $\mathrm{P}\left(4-\mathrm{C}_{6} \mathrm{H}_{4} \mathrm{Cl}\right)_{3}$ & $\mathrm{~K}_{3} \mathrm{PO}_{4}$ & $\mathrm{CyH}$ & 2.0 & $25 \%$ & $87: 13$ \\
21 & $\mathrm{P}\left(4-\mathrm{C}_{6} \mathrm{H}_{4} \mathrm{Me}\right)_{3}$ & $\mathrm{~K}_{3} \mathrm{PO}_{4}$ & $\mathrm{CyH}$ & 2.3 & $27 \%$ & $80: 20$ \\
22 & $\mathrm{P}\left(4-\mathrm{C}_{6} \mathrm{H}_{4} \mathrm{OMe}\right)_{3}$ & $\mathrm{~K}_{3} \mathrm{PO}_{4}$ & $\mathrm{CyH}$ & 3.0 & $28 \%$ & $94: 6$ \\
$23^{[\mathrm{b}]}$ & $\mathrm{P}\left(4-\mathrm{C}_{6} \mathrm{H}_{4} \mathrm{~F}\right)_{3}$ & $\mathrm{~K}_{3} \mathrm{PO}_{4}$ & $\mathrm{CyH}$ & 3.5 & $65 \%$ & $98: 2$ \\
$24^{[b, c]}$ & $\mathrm{P}\left(4-\mathrm{C}_{6} \mathrm{H}_{4} \mathrm{~F}\right)_{3}$ & $\mathrm{~K}_{3} \mathrm{PO}_{4}$ & $\mathrm{CyH}$ & 5.3 & $54 \%$ & $98: 2$ \\
$25^{[\mathrm{b}, \mathrm{d}]}$ & $\mathrm{P}\left(4-\mathrm{C}_{6} \mathrm{H}_{4} \mathrm{~F}\right)_{3}$ & $\mathrm{~K}_{3} \mathrm{PO}_{4}$ & $\mathrm{CyH}$ & 3.7 & $59 \%$ & $97: 3$ \\
$26^{[\mathrm{ee}]}$ & $\mathrm{P}\left(4-\mathrm{C}_{6} \mathrm{H}_{4} \mathrm{~F}\right)_{3}$ & $\mathrm{~K}_{3} \mathrm{PO}_{4}$ & $\mathrm{CyH}$ & 3.0 & $65 \%$ & $96: 4$ \\
$\mathbf{2 7}^{[\mathrm{bbe}]}$ & $\mathbf{P}\left(4-\mathrm{C}_{6} \mathrm{H}_{4} \mathrm{~F}\right)_{3}$ & $\mathbf{K}_{3} \mathrm{PO}_{4}$ & $\mathbf{C y H}$ & $\mathbf{3 . 5}$ & $\mathbf{7 3 \%}$ & $\mathbf{9 8 : 2}$ \\
$28^{[\mathrm{ff}]}$ & $\mathrm{P}\left(4-\mathrm{C}_{6} \mathrm{H}_{4} \mathrm{~F}\right)_{3}$ & $\mathrm{~K}_{3} \mathrm{PO}_{4}$ & $\mathrm{CyH}$ & 3.3 & $72 \%$ & $97: 3$ \\
$29^{[\mathrm{g}]}$ & $\mathrm{P}\left(4-\mathrm{C}_{6} \mathrm{H}_{4} \mathrm{~F}\right)_{3}$ & $\mathrm{~K}_{3} \mathrm{PO}_{4}$ & $\mathrm{CyH}$ & --- & --- & --- \\
\hline
\end{tabular}

[a] Reaction conditions: 338a $(0.50 \mathrm{mmol}), 301 \mathrm{a}(0.60 \mathrm{mmol}),\left[\mathrm{RuCl}_{2}(p \text {-cymene })\right]_{2}(5.0 \mathrm{~mol}$ $\%)$, ligand (20 mol \%), base (2.0 equiv), solvent $(1.0 \mathrm{~mL}), 120^{\circ} \mathrm{C}, 24 \mathrm{~h}$, isolated yields. [b] TMP-ketimine 340a. [c] $110{ }^{\circ} \mathrm{C}$. [d] $140{ }^{\circ} \mathrm{C}$. [e] 301a (1.50 mmol). [f] Base (3.0 equiv). [g] Without [Ru].

Next, we tested different directing groups for the envisioned allylative $\mathrm{C}-\mathrm{F} / \mathrm{C}-\mathrm{H}$ functionalization (Table 8). However, no conversion was observed with challenging aldimines 341a and 343a (entries 1-2). Also, $N$-(pivaloyloxy)benzamide 16a and $o$-toluic acid 346a failed to promote $\mathrm{C}-\mathrm{F} / \mathrm{C}-\mathrm{H}$ functionalization (entries 3-4). 
Table 8. Attempted directing groups for allylative $\mathrm{C}-\mathrm{F} / \mathrm{C}-\mathrm{H}$ functionalization. ${ }^{[\mathrm{a}]}$

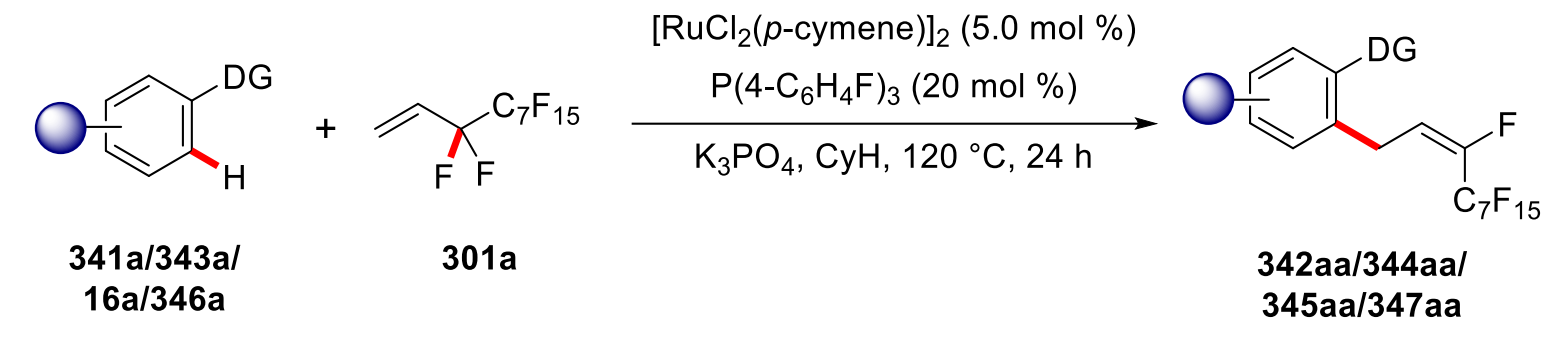

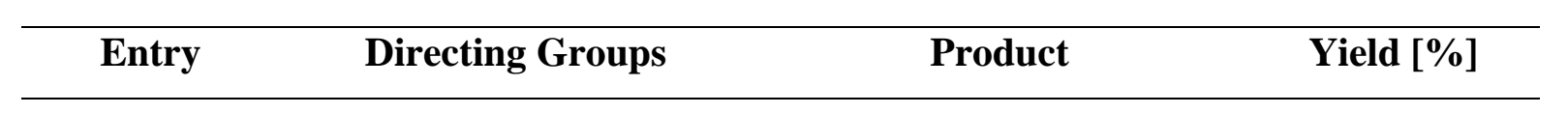

1<smiles>N=CN=Cc1ccccc1</smiles>

$341 a$

2<smiles>Cc1ccccc1/C=N/c1ncccc1C</smiles>

3<smiles>O=C(OCc1ccccc1)ONC(=O)c1ccccc1</smiles>

$16 a$

4<smiles>Cc1ccccc1C(=O)O</smiles><smiles>FC(=CCc1ccccc1C=NN=P)C(F)(F)C(F)(F)C(F)(F)F</smiles>

342aa<smiles>Cc1cccnc1/N=C/c1ccccc1C/C=C(/F)C(F)(F)F</smiles>

n.r.<smiles>O=C(NOc1ccccn1)c1ccccc1CC=C(F)C(F)(F)C(F)(F)C(F)(F)C(F)(F)C(F)(F)C(F)(F)C(F)(F)F</smiles>

$345 a a$<smiles>Cc1cccc(C/C=C(/F)C(F)(F)C(F)(F)F)c1C(=O)O</smiles>

347 aa

n.r.

n.r.

n.r.

[a] Reaction conditions: Imine $(0.50 \mathrm{mmol}), \mathbf{3 0 1 a}(1.50 \mathrm{mmol}),\left[\mathrm{RuCl}_{2}(p \text {-cymene })\right]_{2}(5.0 \mathrm{~mol}$ $\%), \mathrm{P}\left(4-\mathrm{C}_{6} \mathrm{H}_{4} \mathrm{~F}\right)_{3}(20 \mathrm{~mol} \%), \mathrm{K}_{3} \mathrm{PO}_{4}\left(2.0\right.$ equiv), $\mathrm{CyH}(1.0 \mathrm{~mL}), 120{ }^{\circ} \mathrm{C}, 24 \mathrm{~h}$, isolated yields. n.r. $=$ No Reaction. 


\subsubsection{Substrate Scope of C-F/C-H Functionalization}

Diversely substituted valuable ketimines $\mathbf{3 4 0}$ were tested under the optimized catalytic reaction conditions (Table 9). Both electron-rich and electron-poor arenes 340 were well tolerated under the reaction condition furnishing the desired products $\mathbf{3 0 7}$ in moderate to good yields with moderate $E / Z$ ratio. The robust ruthenium(II)catalysis manifold permitted $\mathrm{C}-\mathrm{F} / \mathrm{C}-\mathrm{H}$ functionalizations in high levels of chemo-, site- and regio-selectivity. Methyl and ethyl substituted ketimines 340a and 340b both furnished the products in good yields under the optimized reaction conditions (entries 1-2). Subsequently, various para-substituted ketimines 340c-340h were tested, providing the corresponding products $307 \mathbf{c a - 3 0 7 h a}$ in moderate to good yields (entries 3-8). Notably, the robust ruthenium(II)catalysis manifold proved to be tolerant of a set of synthetically meaningful electrophilic functional groups, including chloro and ester substituents (entries 7-8), which should prove invaluable for further late-stage diversification. The site selectivity was largely governed by steric repulsion for the metasubstituted arene 340i (entry 9). However, the versatile ruthenium(II)catalyst also showed limitations. Nitro and cyano-substituted ketimines $340 \mathbf{j}$ and $340 \mathbf{k}$ did not furnish the products 340ja and 340ka respectively, under the optimized reaction condition (entries 10-11). Also, heteroarene 348a failed to undergo the $\mathrm{C}-\mathrm{F} / \mathrm{C}-\mathrm{H}$ functionalizations (entry 12 ).

Table 9. Scope of the allylative C-H/C-F functionalizations. ${ }^{[a]}$<smiles>[Y19]N=C([R])c1ccccc1</smiles>

340
1) $\left[\mathrm{RuCl}_{2}(p \text {-cymene })\right]_{2}(5.0 \mathrm{~mol} \%)$<smiles>C=CC(F)(F)C(F)F</smiles>

$301 a$
$\underset{\mathrm{K}_{3} \mathrm{PO}_{4}, \mathrm{CyH}, 120{ }^{\circ} \mathrm{C}, 24 \mathrm{~h}}{\mathrm{P}\left(4-\mathrm{C}_{6} \mathrm{H}_{4} \mathrm{~F}\right)_{3}(20 \mathrm{~mol} \%)}$

2) $1 \mathrm{M} \mathrm{H}_{3} \mathrm{O}^{\oplus}$<smiles>[R]C(=O)c1ccccc1C/C=C(\F)C(F)F</smiles>

307

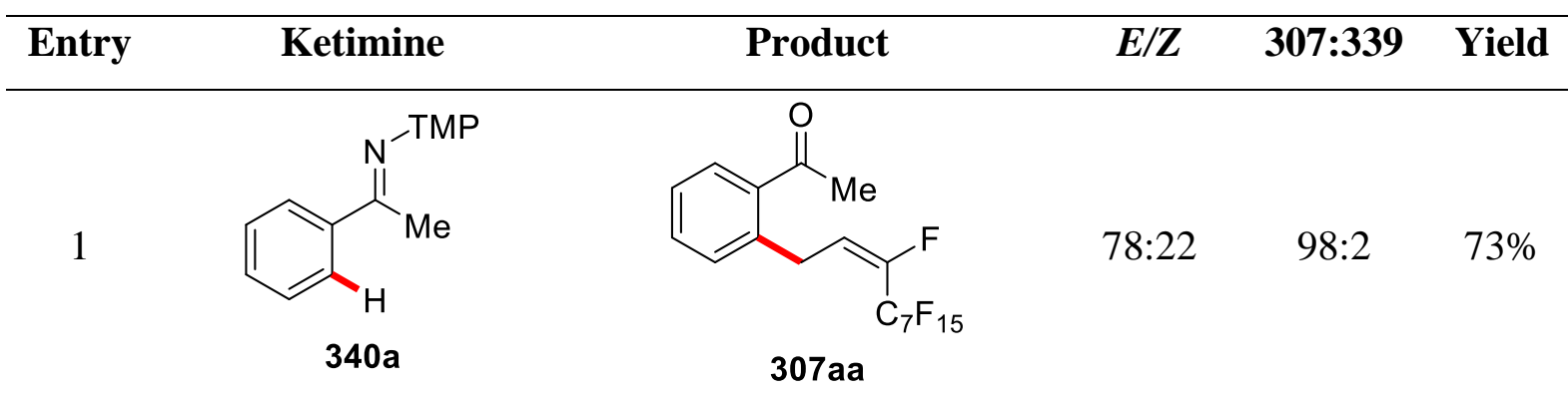


2<smiles></smiles>

3<smiles>CC(=NC(=O)c1ccc(C)cc1)c1ccccc1</smiles>

4<smiles></smiles>

5<smiles></smiles>

6<smiles>CC(=N[Na])c1ccc(C(F)(F)F)cc1</smiles>

7<smiles>CC(=O)c1ccc(/C(C)=N/N=[W])cc1</smiles>

8<smiles>[Y6]N=C(C)c1ccc(Cl)cc1[14CH3]</smiles><smiles>CCC(=O)c1ccccc1C/C=C(/F)C(F)(F)C(F)(F)C(F)(F)C(F)(F)F</smiles>

$75: 25$

99:1 $\quad 63 \%$

$84: 16 \quad 92: 8 \quad 62 \%$

$80: 20$ 99:1 $\quad 53 \%$ 307da<smiles>COc1ccc(C(C)=O)c(C/C=C(\F)C(F)(F)C(F)(F)F)c1</smiles>

$75: 25 \quad 98: 2 \quad 58 \%$

$72: 28 \quad 97: 3 \quad 54 \%$ $307 \mathrm{fa}$<smiles>CC(=O)c1ccc(C(C)=O)c(C/C=C(/F)C(F)(F)C(F)(F)C(F)(F)F)c1</smiles>
307ga<smiles>CC(=O)c1ccc(Cl)cc1C/C=C(/F)C(F)(F)C(F)(F)C(F)(F)F</smiles>
307ha
$70: 30 \quad 99: 1 \quad 48 \%$

$83: 17 \quad 98: 2 \quad 59 \%$ 
9<smiles>CC(=NN=P)c1cccc(C)c1</smiles>

$340 i$

10<smiles>CC(=N[14CH3])c1ccc([N+](=O)[O-])cc1</smiles>

$340 \mathrm{j}$

11<smiles>CC(=NN)c1ccc(C#N)cc1C#N</smiles>

12

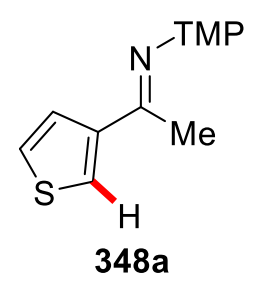<smiles>CC(=O)c1cc(C)ccc1CC=C(F)C(F)(F)C(F)(F)C(F)(F)C(F)(F)C(F)(F)C(F)(F)F</smiles>

307ia<smiles>CC(=O)c1ccc([N+](=O)[O-])cc1C/C=C(/F)C(F)(F)C(F)(F)C(F)(F)F</smiles>

307ja<smiles>CC(=O)c1ccc(C#N)cc1CC=C(F)C(F)(F)C(F)(F)C(F)(F)F</smiles>

307ka<smiles>C/C(=N\N=[W])c1ccsc1C/C=C(/F)C(F)(F)C(F)(F)F</smiles>

$74: 26$ 91:9

$63 \%$

n.r.

n.r.

n.r.

\section{9aa}

[a] Reaction conditions: 340 (0.50 mmol), 301a (1.50 mmol), $\left[\mathrm{RuCl}_{2}(p \text {-cymene })\right]_{2}$ (5.0 mol $\%), \mathrm{P}\left(4-\mathrm{C}_{6} \mathrm{H}_{4} \mathrm{~F}\right)_{3}(20 \mathrm{~mol} \%), \mathrm{K}_{3} \mathrm{PO}_{4}\left(2.0\right.$ equiv), $\mathrm{CyH}(1.0 \mathrm{~mL}), 120{ }^{\circ} \mathrm{C}, 24 \mathrm{~h}$, isolated yields.

The versatile ruthenium(II)-catalyzed $\mathrm{C}-\mathrm{F} / \mathrm{C}-\mathrm{H}$ functionalization was subsequently tested with other perfluoroalkylalkenes 301 (Table 10). Thereby, $1 H, 1 H, 2 H$-perfluoro-1-dodecene 301c was likewise smoothly converted into the corresponding products $\mathbf{3 0 7}$ with various substituted ketimines 340 in good yields and with good diasteroselectivities (entries 1-7), exploiting the removable nature of the ketimine within a user-friendly one-pot procedure. Similarly, a considerable variability with respect to the perfluoroalkyl chain length was observed. Likewise, $1 \mathrm{H}, 1 \mathrm{H}, 2 \mathrm{H}$-perfluoro-1-hexene $\mathbf{3 0 1 b}$ was tested under the reaction conditions with various unsubstituted 340a and para-substituted ketimines 340c-340d, furnishing the corresponding products with high levels of chemo-, diastereo-, and position-selectivities (entries 8-10). 
Table 10. C-F/C-H functionalization with perfluoroalkylalkenes 301. ${ }^{[\mathrm{a}]}$

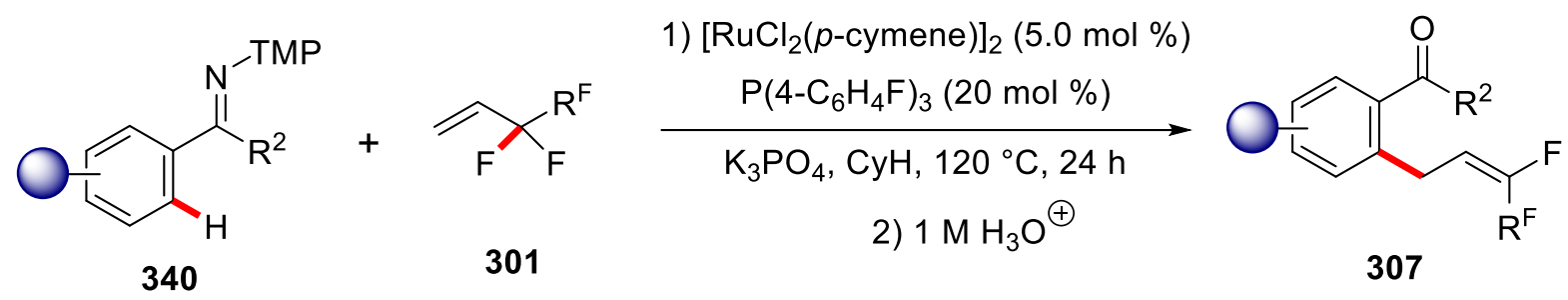

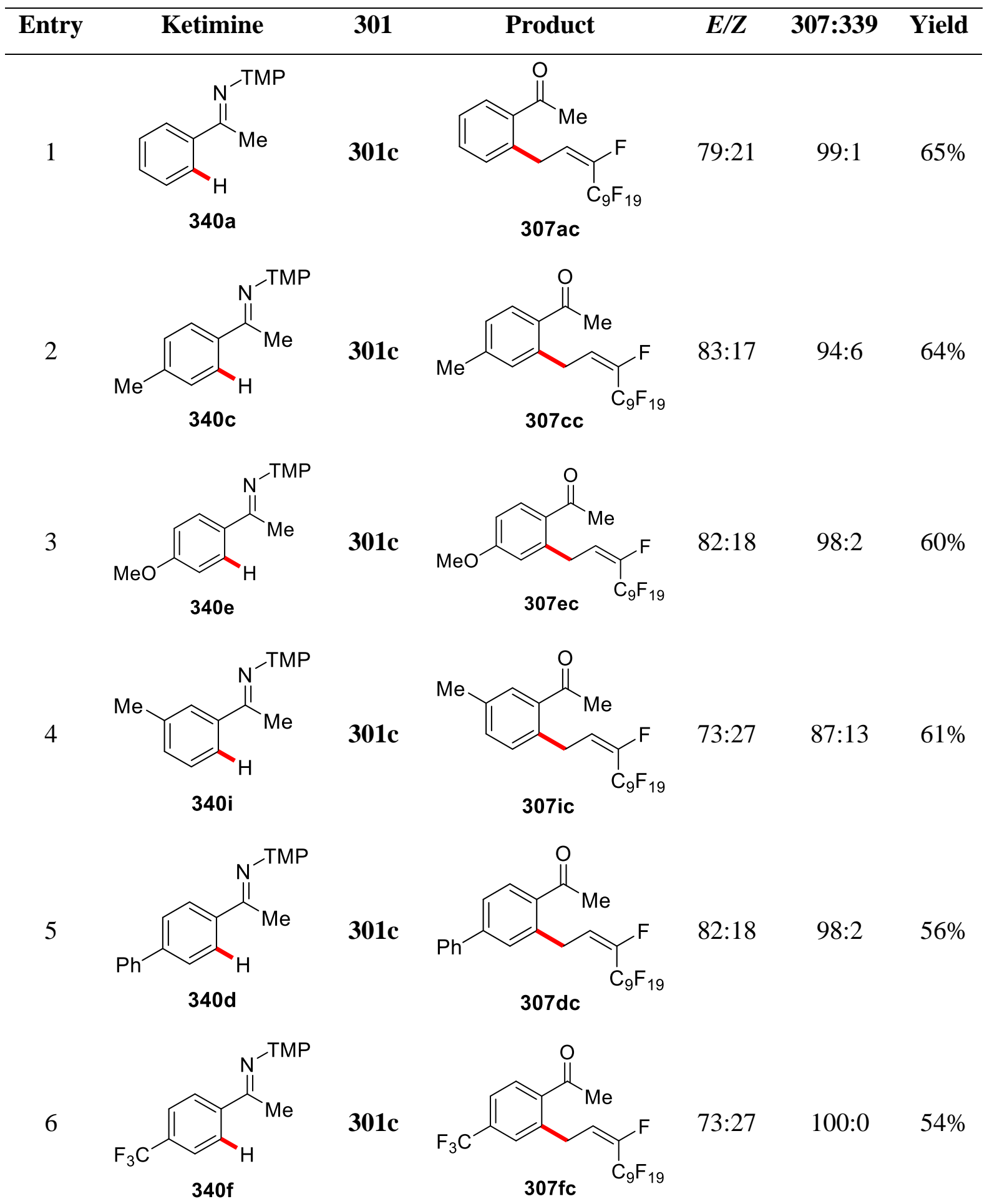


7<smiles>CC(N=[W])c1ccc(Cl)cc1O</smiles>

8<smiles>CC(=N[Na])c1ccccc1</smiles>

9<smiles>CC(=N[18F])c1ccc(C)cc1C(C)(C)C</smiles>

10<smiles>CC(=NN)c1ccc(-c2ccccc2)cc1</smiles>

301c<smiles>CC(=O)c1ccc(Cl)cc1CC=C(F)C(F)=[Fe]</smiles>
$76: 24$ $99: 1 \quad 60 \%$

301b<smiles>CC(=O)c1ccc(C)cc1C/C=C(\F)C(F)(F)C(F)(F)C(F)(F)C(F)(F)C(F)(F)F</smiles>

301b<smiles>CC(=O)c1ccc(-c2ccccc2)cc1C/C=C(/F)C(F)(F)C(F)(F)C(F)(F)C(F)(F)C(F)(F)C(F)(F)C(F)(F)C(F)(F)F</smiles>

$84: 16$

99:1 $52 \%$

[a] Reaction conditions: $340(0.50 \mathrm{mmol}), 301(1.50 \mathrm{mmol}),\left[\mathrm{RuCl}_{2}(p \text {-cymene })\right]_{2}(5.0 \mathrm{~mol} \%)$, $\mathrm{P}\left(4-\mathrm{C}_{6} \mathrm{H}_{4} \mathrm{~F}\right)_{3}(20 \mathrm{~mol} \%), \mathrm{K}_{3} \mathrm{PO}_{4}(2.0$ equiv $), \mathrm{CyH}(1.0 \mathrm{~mL}), 120{ }^{\circ} \mathrm{C}, 24 \mathrm{~h}$, isolated yields.

\subsubsection{Mechanistic Studies}

Considering the unique selectivity features of the ruthenium(II)-catalyzed $\mathrm{C}-\mathrm{F} / \mathrm{C}-\mathrm{H}$ functionalization, we became then intrigued to delineating its mode of action.

\subsubsection{Intermolecular Competition Experiment}

To this end, we performed an intermolecular competition experiment between electron-rich and electron-deficient arenes 340c and 340f, which revealed a preferential reactivity in favor of the more electron-rich substrate 340c (Scheme 104). This finding is in disagreement with a CMD/AMLA-type $\mathrm{C}-\mathrm{H}$ activation. Instead, a base-assisted internal electrophilic substitution (BIES)-type $\mathrm{C}-\mathrm{H}$ metalation is rather operative for the allylative $\mathrm{C}-\mathrm{F} / \mathrm{C}-\mathrm{H}$ functionalization. 


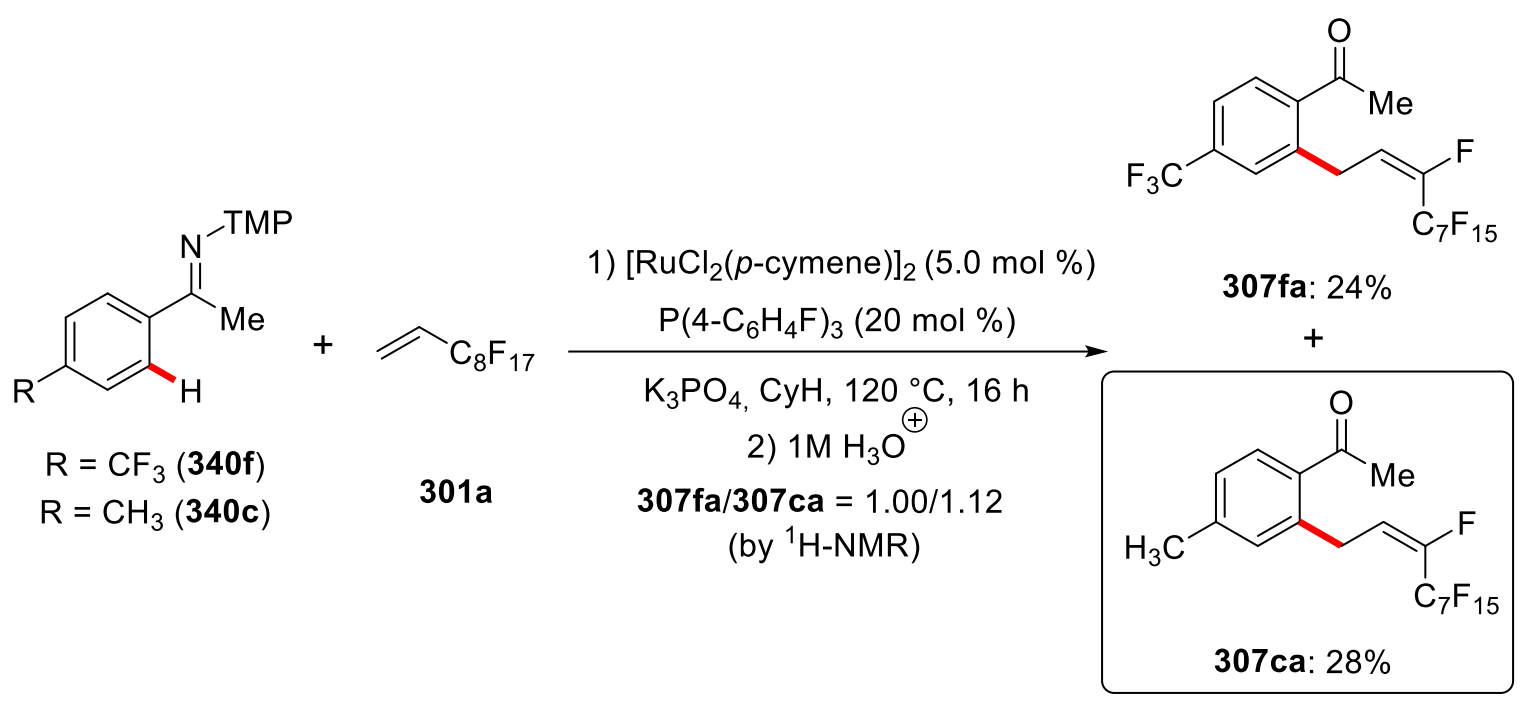

Scheme 104. Competition experiment between electron-rich and electron-deficient arenes.

\subsubsection{Deuterium Labeling Experiments}

Subsequently, we performed deuterium labeling experiments to gain insights into the $\mathrm{C}-\mathrm{H}$ ruthenation step (Scheme 105). The ruthenium(II)-catalyzed $\mathrm{C}-\mathrm{F} / \mathrm{C}-\mathrm{H}$ functionalization was performed in the presence of the isotopically-labeled $\mathrm{D}_{2} \mathrm{O}$ as co-solvent (Scheme 105). Here, we observed a considerable H/D exchange at the ortho-positions of the allylated product $[\mathrm{D}]_{\mathrm{n}}$ 307aa and the hydrolyzed starting material $[D]_{\mathrm{n}}-340 a$ '.
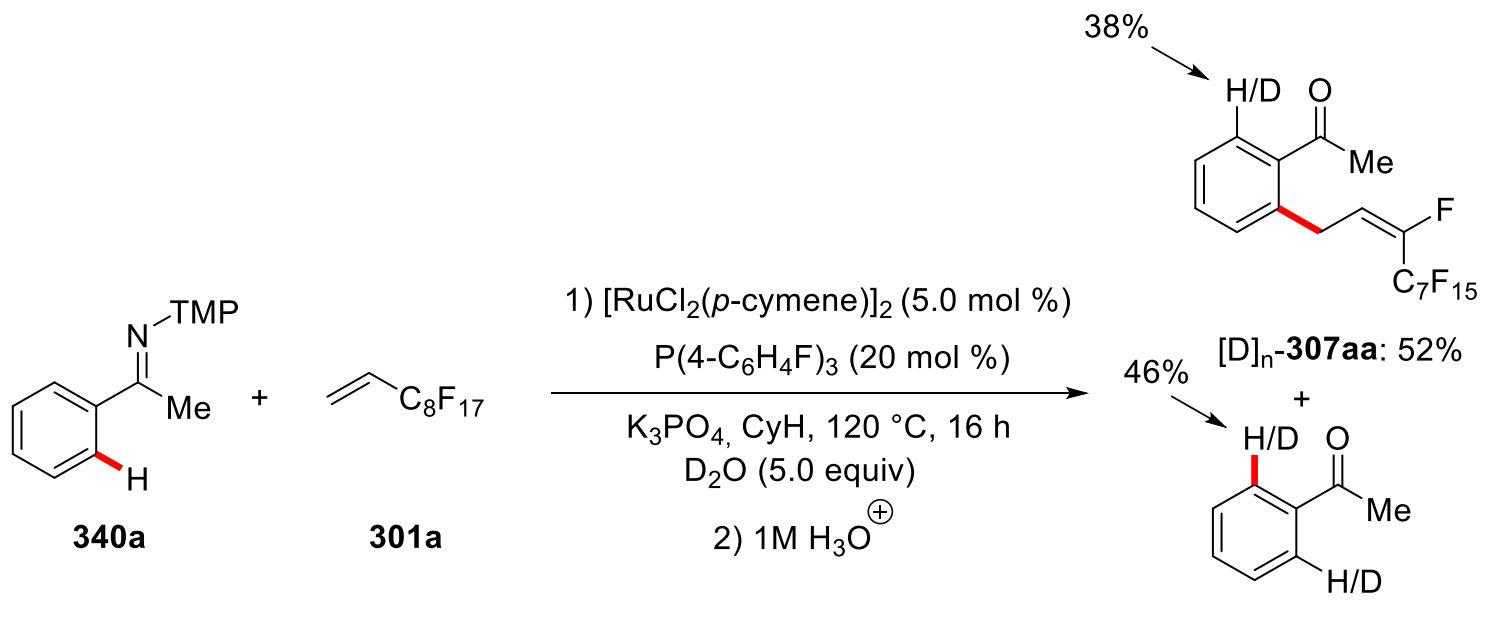

$[D]_{n}-340 a^{\prime}: 21 \%$

Scheme 105. Deuterium labeling experiments for $\mathrm{C}-\mathrm{F} / \mathrm{C}-\mathrm{H}$ functionalization.

\subsubsection{KIE Study}

Moreover, to gain further mechanistic understanding of the $\mathrm{C}-\mathrm{H}$ activation step, independent KIE-experiments were performed (Scheme 106). Thus, the substrate 340a and its deuterated analogue $[\mathrm{D}] 5-340 \mathrm{a}$ were employed for independent kinetic experiments (Scheme 106). We 
observed a very minor kinetic isotope effect (KIE) of $k_{\mathrm{H}} / k_{\mathrm{D}}=1.1$, suggestive of a facile and not turnover-limiting $\mathrm{C}-\mathrm{H}$ metalation event of the ruthenium(II)-catalyzed $\mathrm{C}-\mathrm{F} / \mathrm{C}-\mathrm{H}$ functionalization.<smiles>C=CC(F)(F)C(F)(F)F</smiles>

$340 a /\left[D_{5}\right]-340 a$
1) $\left[\mathrm{RuCl}_{2}(p \text {-cymene })\right]_{2}(5.0 \mathrm{~mol} \%)$

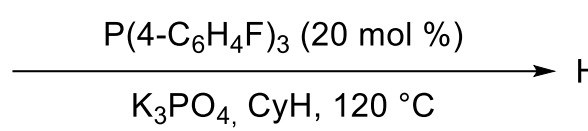
2) $1 \mathrm{M} \mathrm{H}_{3} \mathrm{O}^{\oplus}$ $k_{\mathrm{H}} / k_{\mathrm{D}}=1.1$

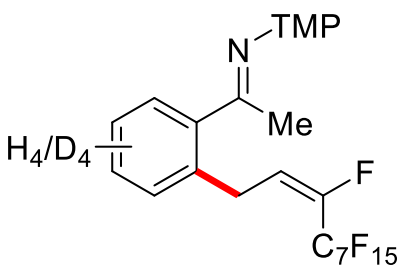

$307 a a /\left[D_{4}\right]-307 a a$

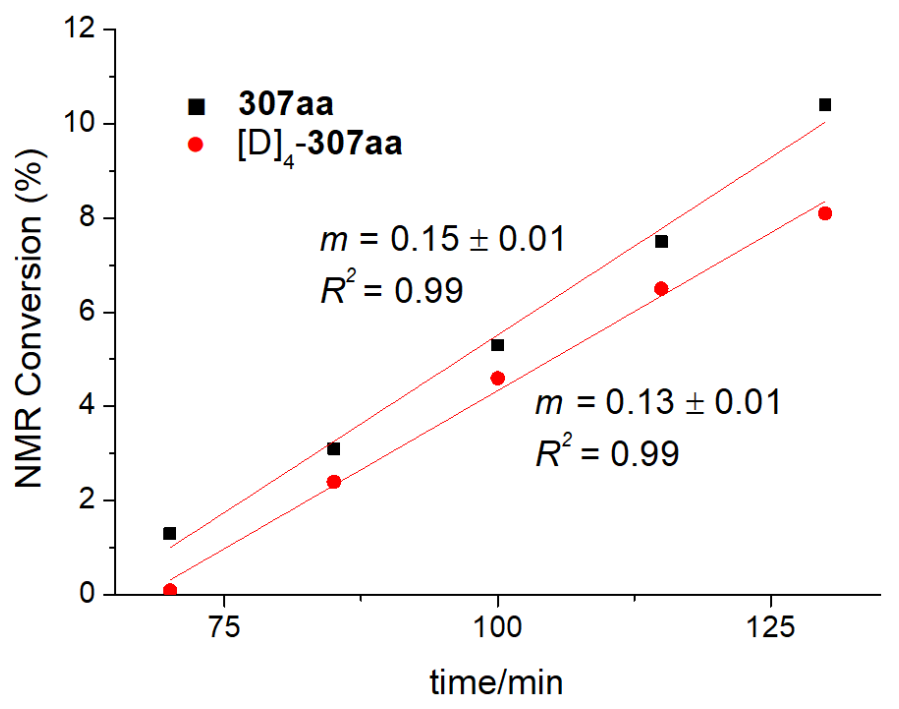

Scheme 106. Intramolecular KIE by independent experiments.

\subsubsection{Proposed Catalytic Cycle}

Based on our detailed mechanistic studies, the allylative ruthenium(II)-catalyzed $\mathrm{C}-\mathrm{H} / \mathrm{C}-\mathrm{F}$ functionalization of ketimines $\mathbf{3 4 0}$ is proposed to be initiated by a reversible and facile BIEStype $\mathrm{C}-\mathrm{H}$ cleavage to form the ruthenacycle 351 (Scheme 107). In the subsequent step, the ruthenacycle $\mathbf{3 5 1}$ is then coordinated by the perfluoroalkylalkene 301a in a fast and reversible step. In the following step, a migratory insertion into the ruthenium-carbon bond forms sevenmembered ruthenacycle intermediate $\mathbf{3 5 3}$ in a possibly irreversible process as there was no H/D exchange in the perfluoroalkylalkenes 301a. Finally, diastereo-selective base-mediated $\beta$-Felimination delivers the desired product 307, along with a subsequent ligand exchange regenerating the catalytically active species $\mathbf{3 5 0}$. 


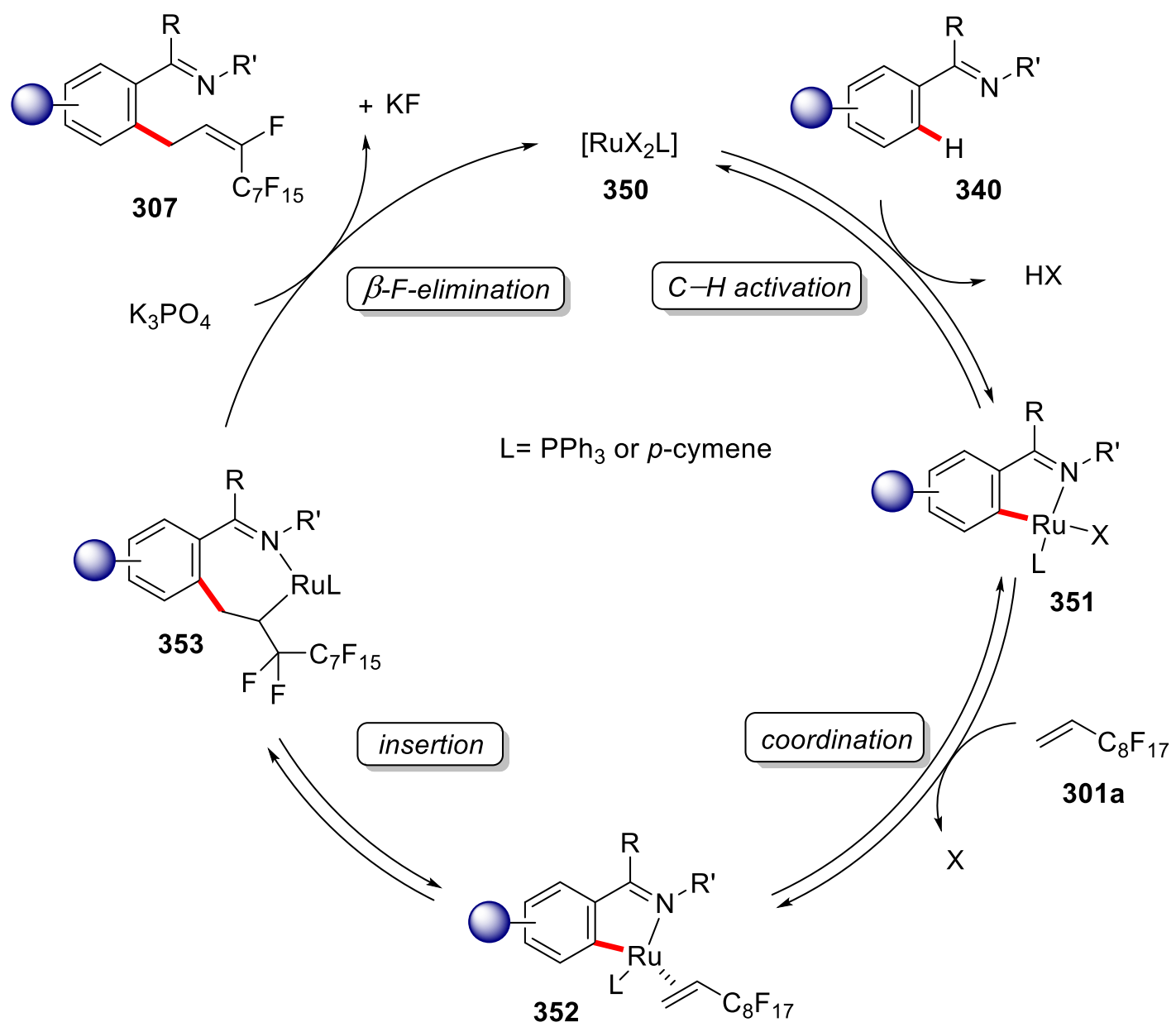

Scheme 107. Proposed catalytic cycle ruthenium-catalyzed $\mathrm{C}-\mathrm{F} / \mathrm{C}-\mathrm{H}$ functionalization. 


\subsection{Enantioselective Cobalt(III)-Catalyzed C-H Activation}

Despite numerous reports on precious $4 \mathrm{~d}$ and $5 \mathrm{~d}$ transition metal-catalyzed ${ }^{[57]}$ enantioselective $\mathrm{C}-\mathrm{H}$ activations, ${ }^{[58]}$ full selectivity control with $3 \mathrm{~d}$ metal catalysts remains a challenging area of research ( $c f$. chapter 1.3.). However, this area has gained major attention during the course of this doctoral thesis. ${ }^{[59]}$

In this context, enantioselective $\mathrm{C}-\mathrm{H}$ alkylations by $3 \mathrm{~d}$ transition metals were thus far largely achieved with superstoichiometric amounts of reactive Grignard reagent, which jeopardized the functional group tolerance of these transformations. It is noteworthy to mention that the Yoshikai group achieved the enantioselective cobalt(II)-catalyzed $\mathrm{C}-\mathrm{H}$ alkylation by the use of BINOL-derived phosphoramidites, ${ }^{[161]}$ whereas, the Ackermann group reported the first highly enantioselective iron-catalyzed $\mathrm{C}-\mathrm{H}$ secondary alkylation of (aza)indoles through the design of a novel bulky meta-1-adamantyl substituted chiral NHC ligand. ${ }^{[163]}$ But these transformations still required the use of superstoichiometric amounts of reactive Grignard reagent.

Despite significant advances in the use of cobalt(III) complexes in recent years for various $\mathrm{C}-$ $\mathrm{H}$ activation reactions, ${ }^{[264]}$ asymmetric cobalt(III)-catalyzed $\mathrm{C}-\mathrm{H}$ activation remained unexplored at the outset of this work, although very few examples of enantioselective cobalt(II)-catalyzed $\mathrm{C}-\mathrm{H}$ transformations have been reported under reductive conditions ( $c f$. chapter 1.3.6.). ${ }^{[59]}$ Furthermore, the Ackermann group reported a racemic highly branchselective cobalt(III)-catalyzed $\mathrm{C}-\mathrm{H}$ alkylation using stoichiometric amounts of Brønsted acid. ${ }^{[265]}$ Drawing inspiration from these studies, we were interested in the development of the first highly enantioselective cobalt(III)-catalyzed $\mathrm{C}-\mathrm{H}$ activation.

\subsubsection{Optimization Studies}

After extensive optimization with commonly used chiral carboxylic acids, ${ }^{[63,266]}$ initial results by $D r$. F. Pesciaioli showed the quest for the development of novel chiral acids for the challenging enantioselective cobalt(III)-catalyzed $\mathrm{C}-\mathrm{H}$ alkylation. Here is a brief overview of the initial studies from Dr. F. Pesciaioli (Scheme 108). 


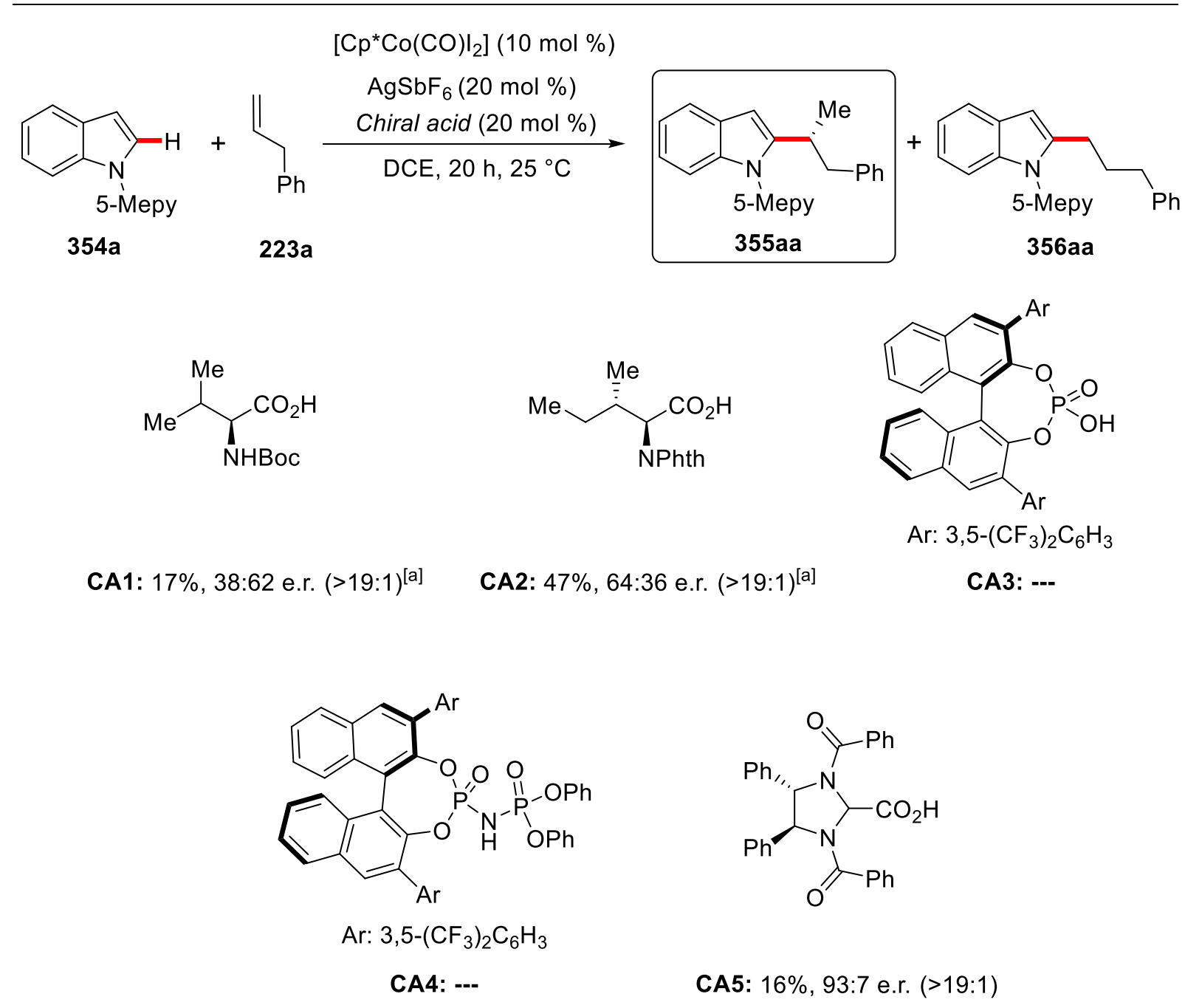

Scheme 108. Enantioselective cobalt(III)-catalyzed C-H alkylation performed by $D r . F$.

Pesciaioli. [a] Chiral acid (1.0 equiv). Markovnikov:anti-Markovnikov selectivities in parentheses.

After identifying the novel chiral acid scaffold CA5, ${ }^{[267]}$ further probing of additives and diversely substituted novel chiral acid CA5 were performed for achieving high levels of enantiocontrol (Table 11). Amberlyst 15 was found to have a beneficial effect for improving the catalytic efficacy as well as the enantioselectivity (entry 3). Further modifications to the phenyl rings on the chiral acids failed to increase the enantioselectivity (entries 4-5). Gratifyingly, by increasing the reaction temperature and prolonging the reaction time to 65 hours we were able to access the product 355aa in synthetically useful 61\% yield and with high enantioselectivity (92:8 e.r.) (entry 6). However, a slight decrease in yield was observed when a reduced amount of acid additive was employed (entry 7). The use of $\left[\mathrm{Cp}^{*} \mathrm{CoI}_{2}\right]_{2}$ as the catalyst also showed similar reactivity in terms of catalytic efficiency and enantioselectivity (entry 8). It is noteworthy to mention that a decrease in yield was observed when the reaction was 
performed for a shorter reaction time (entry 9), highlighting the need of longer reaction time for achieving synthetically useful yields of this challenging transformation.

Table 11. Asymmetric cobalt(III)-catalyzed C-H alkylation. ${ }^{[a]}$

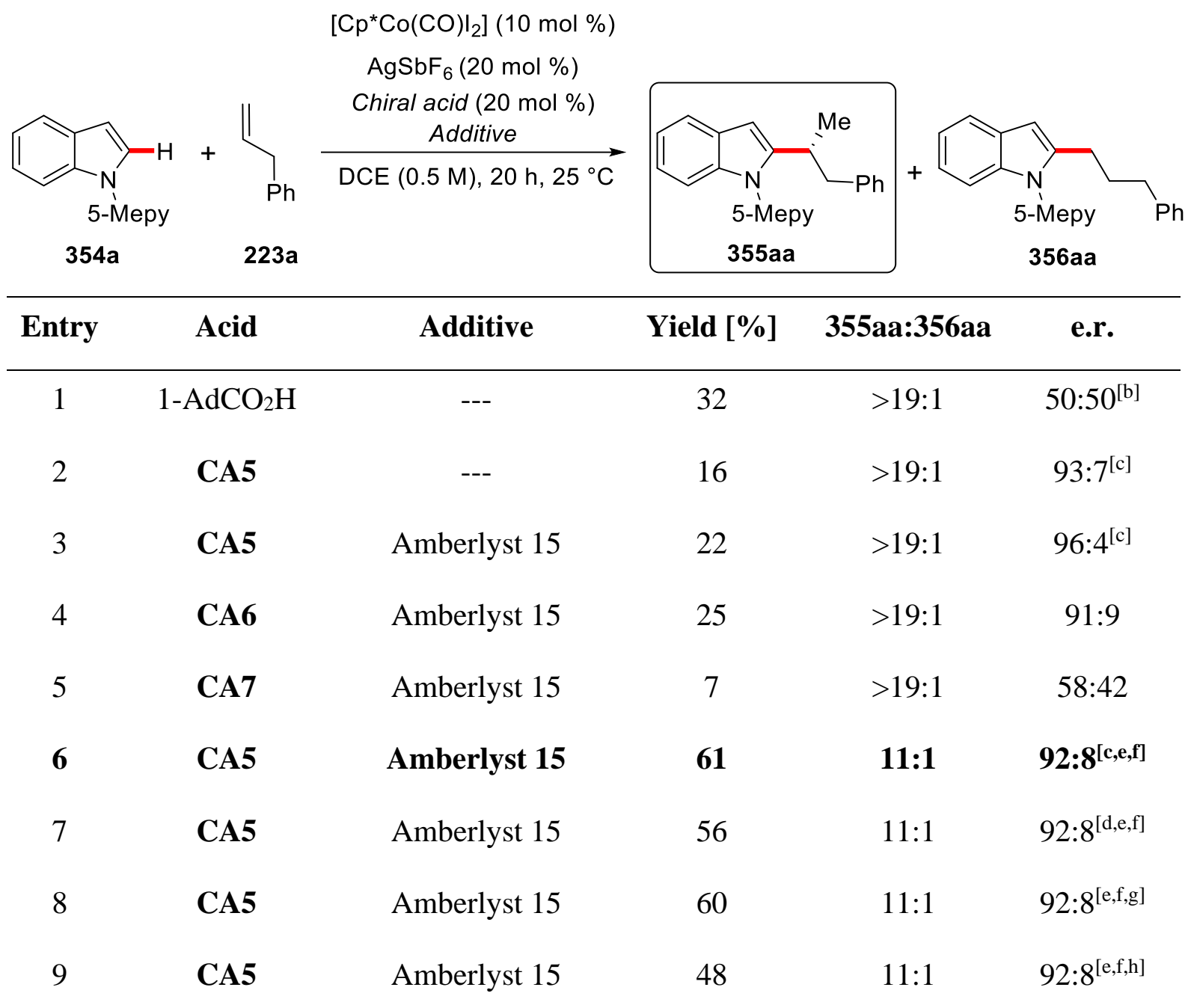

[a] Reaction conditions: 354a (0.50 mmol), 223a (1.50 mmol), [Co] (10 mol \%), $\operatorname{AgSbF}_{6}(20$ mol \%), chiral acid $(20 \mathrm{~mol} \%)$, additive (1.50 equiv), DCE $(0.50 \mathrm{M}), 25{ }^{\circ} \mathrm{C}, 20 \mathrm{~h}$, conversion determined by ${ }^{1} \mathrm{H}-\mathrm{NMR}$ with $\mathrm{Ph}_{3} \mathrm{CH}$ as the internal standard. [b] Acid (1.0 equiv). [c] performed by Dr. F. Pesciaioli. [d] Amberlyst 15 (1.0 equiv). [e] DCE (1.0 M), 65 h. [f] Isolated yields. [g] [Cp* $\left.\mathrm{CoI}_{2}\right]_{2}(5.0 \mathrm{~mol} \%)$. [h] $48 \mathrm{~h}$. 
<smiles>O=C(O)C1N(C(=O)c2ccccc2)[C@@H](c2ccccc2)[C@H](c2ccccc2)N1C(=O)c1ccccc1</smiles>

CA5<smiles>Cc1cccc(C(=O)N2C(C(=O)O)N(C(=O)c3cccc(C)c3)[C@H](c3ccccc3)[C@H]2c2ccccc2)c1</smiles>

CA6<smiles>O=C(O)C1N(C(=O)c2cccc3ccccc23)[C@H](c2ccccc2)[C@@H](c2ccccc2)N1C(=O)c1cccc2ccccc12</smiles>

CA7

\subsubsection{Effect of the $N$-Substitution Pattern}

With the optimized reaction conditions in hand, we next examined the effect of substituents on the pyridyl group for the enantioselective $\mathrm{C}-\mathrm{H}$ alkylation (Table 12). Unsubstituted pyridine 315a provided the product 357aa in nearly identical yield, but with lower enantioselectivity (entry 1). The same held true for 4-methyl-substituted pyridine, which provided the product 359ba in marginally lower yield and with decreased enantioselectivity (entry 2). Thus, 5methylpyridine (5-Mepy) was identified as being slightly superior in terms of enantioselectivities (entry 3 ). 
Table 12. $N$-substitution pattern in asymmetric $\mathrm{C}-\mathrm{H}$ alkylation. ${ }^{[a]}$<smiles>O=C(O)C1N(C(=O)c2ccccc2)C(c2ccccc2)[C@H](c2ccccc2)N1C(=O)O</smiles>

CA5 (20 $\mathrm{mol} \%)$

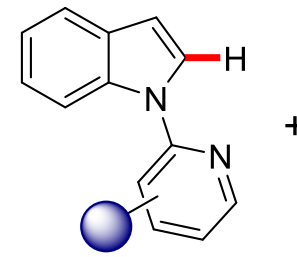

$315 / 358 / 354$

223a

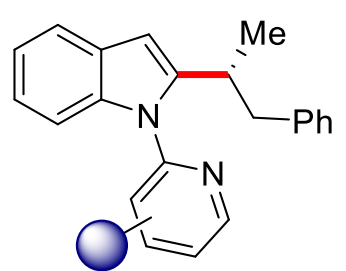

$357 / 359 / 355$

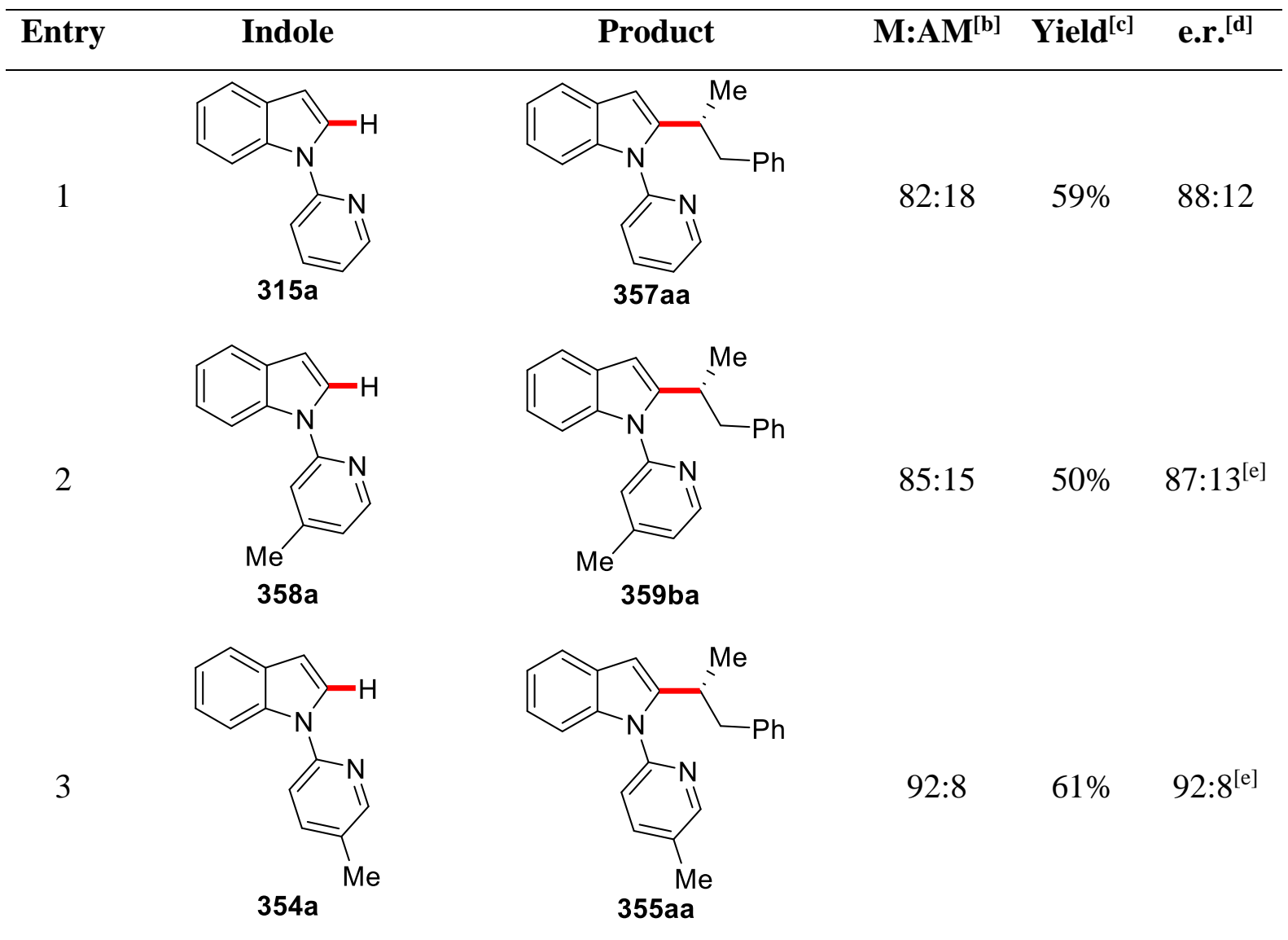

[a] Reaction conditions: Indole $(0.50 \mathrm{mmol}), \mathbf{2 2 3 a}(1.50 \mathrm{mmol}),\left[\mathrm{Cp} * \mathrm{Co}(\mathrm{CO}) \mathrm{I}_{2}\right](10 \mathrm{~mol} \%)$, $\mathrm{AgSbF}_{6}(20 \mathrm{~mol} \%), \mathbf{C A 5}$ (20 mol \%), Amberlyst 15 (1.50 equiv), DCE (0.50 mL, $\left.1.0 \mathrm{M}\right), 50$ ${ }^{\circ} \mathrm{C}$, 65 h. [b] All Markovnikov:anti-Markovnikov selectivities determined by ${ }^{1} \mathrm{H}-\mathrm{NMR}$ spectroscopy. [c] Yield of isolated product. [d] Determined by chiral HPLC analysis. [e] Performed by Dr. F. Pesciaioli. 


\subsubsection{Substrate Scope and Limitations of Asymmetric C-H Activation}

With the identified best catalyst, we tested the effect of the substitution on indoles 354 (Table 13). Our robust catalyst provided the desired $\mathrm{C} 2$ alkylated products 355 with high branched selectivities and with high level of enantiocontrol. Halogens at C5, including sensitive bromide and iodide, furnished the desired products $355 \mathrm{ba}$ and $355 \mathrm{ca}$ in high enantioselectivities (entries 2-3). Furthermore, the substrate 354d bearing an ester group was also tolerated under our mild and Grignard-free condition, delivering the $\mathrm{C} 2$ alkylated product $355 \mathrm{da}$ in good yield and with high levels of enantiocontrol (entry 4). Unfortunately, both cyano- and nitro-motifs 354e and 354f were however not acceptable under our optimized reaction condition (entries 5-6). In

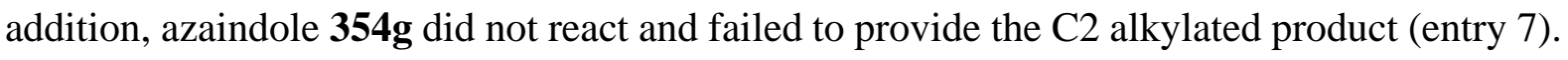

Table 13. Asymmetric $\mathrm{C}-\mathrm{H}$ activation with indoles $354{ }^{\text {[a] }}$

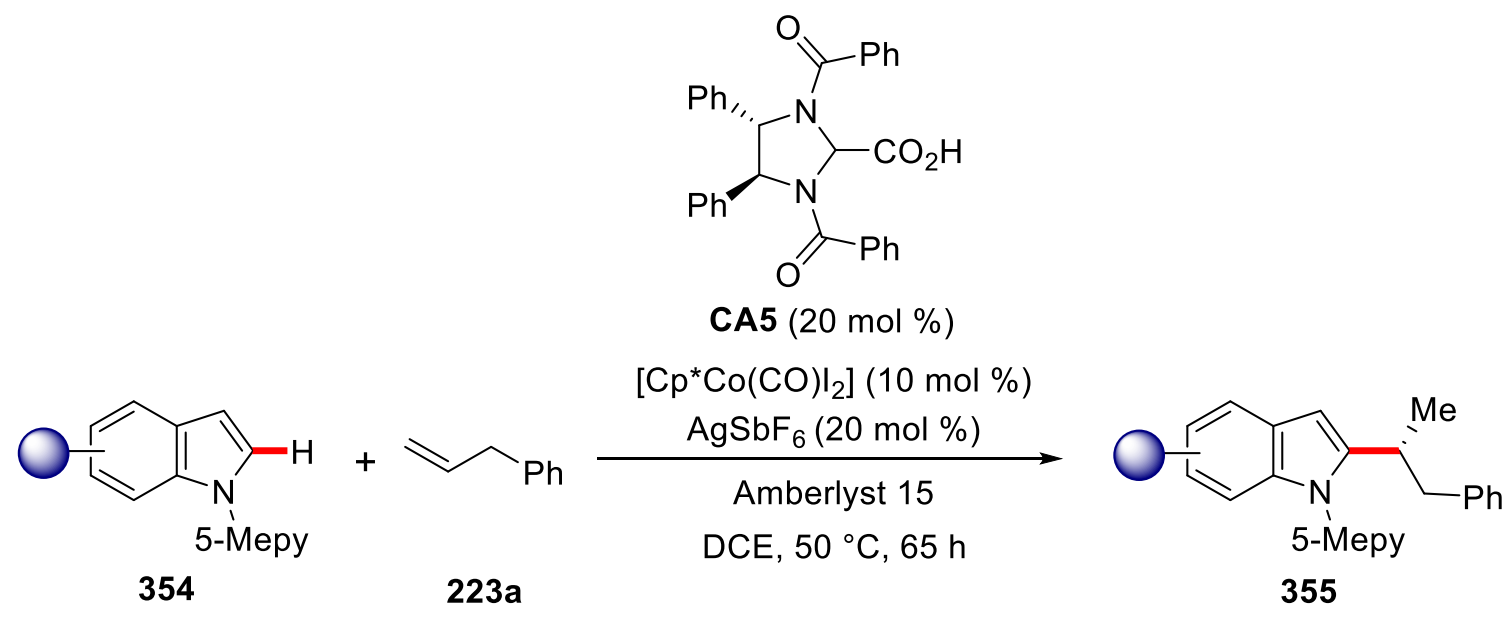

Entry


<smiles>COC(=O)c1ccc2cc(C(C)(C)C)n(C(C)(C)C)c2c1</smiles>
354d

5<smiles>Cn1ccc2cc(C#N)ccc21</smiles>

354 e<smiles>Cn1ccc2cc([N+](=O)[O-])ccc21</smiles>

$354 f$<smiles>Cn1ccc2cccnc21</smiles>

$354 \mathrm{~g}$<smiles>CCCCC(C)(C)c1cc2cc(C#N)ccc2n1C(C)(C)C(C)(C)C</smiles>

355 ea<smiles>CC(Cc1ccccc1)c1cc2cc([N+](=O)[O-])ccc2n1C</smiles>

$355 f a$<smiles>CC(Cc1ccccc1)c1cc2cccnc2n1C</smiles>

355ga

[a] Reaction conditions: indole $(0.50 \mathrm{mmol}), 223 \mathrm{a}(1.50 \mathrm{mmol}),\left[\mathrm{Cp} * \mathrm{Co}(\mathrm{CO}) \mathrm{I}_{2}\right](10 \mathrm{~mol} \%)$, $\mathrm{AgSbF}_{6}(20 \mathrm{~mol} \%), \mathbf{C A 5}(20 \mathrm{~mol} \%)$, Amberlyst 15 (1.50 equiv), DCE (0.50 mL, $\left.1.0 \mathrm{M}\right), 50$ ${ }^{\circ} \mathrm{C}, 65 \mathrm{~h}$. [b] Yield of isolated product. [c] Markovnikov:anti-Markovnikov selectivities in parentheses; determined by ${ }^{1} \mathrm{H}-\mathrm{NMR}$ spectroscopy. [d] Determined by chiral HPLC analysis.

Subsequently, we surveyed various unactivated olefins 223 to examine the effect of the substitution on the aryl ring (Table 14). Methyl substitution at the para-position furnished the desired product 355ab in slightly lower yield and enantioselectivity (entry 1). However, a methoxy substituent in the para-position provided the corresponding product 355ac in a similar yield and enantioselectivity as compared to compound 355ab (entry 2). Similarly, para-phenyl and fluoro gave the desired products 355ad and 355ae respectively in moderate yields and with good enantioselectivities (entries 3-4). Electron-rich disubstituted methoxy substituted olefin 223f was also tolerated, delivering the $\mathrm{C} 2$ alkylated product 355af in good yield and with high enantioselectivity (entry 5). Chloro (223g) and bromo (223i) groups did not hamper the reactivity, highlighting the mildness of our reaction conditions (entries 6 and 8). However, in the case of pentafluoro benzene $\mathbf{2 2 3 h}$ we observed a significant decrease in the enantioselectivity (entry 7). Other functionalities were tested, such as acetate, triflate, and ester, 
which afforded the products 355aj-355al in moderate yields and with good enantioselectivities (entries 9-11). However the acetate-substituted phenyl ring (223j) required a higher temperature to achieve good conversion (entry 9 ). At $60{ }^{\circ} \mathrm{C}$, product 355aj was formed in 55\% isolated yield and 88:12 er. As observed before, at a higher temperature the ratio of linear to branched product also increased significantly. ${ }^{[265]}$ Unfortunately, in case of the unactivated alkyl substituted alkenes 223n and 223o, we observed the products 355an and 355ao respectively in significantly decreased yields and enantioselectivities, reflecting the challenges of this transformation (entries 13-14). In addition, 2-substituted hydroxyl group failed to deliver the desired product 355ap in synthetically useful yields (entry 15).

Table 14. Asymmetric $\mathrm{C}-\mathrm{H}$ activation with alkenes 223. ${ }^{\text {[a] }}$

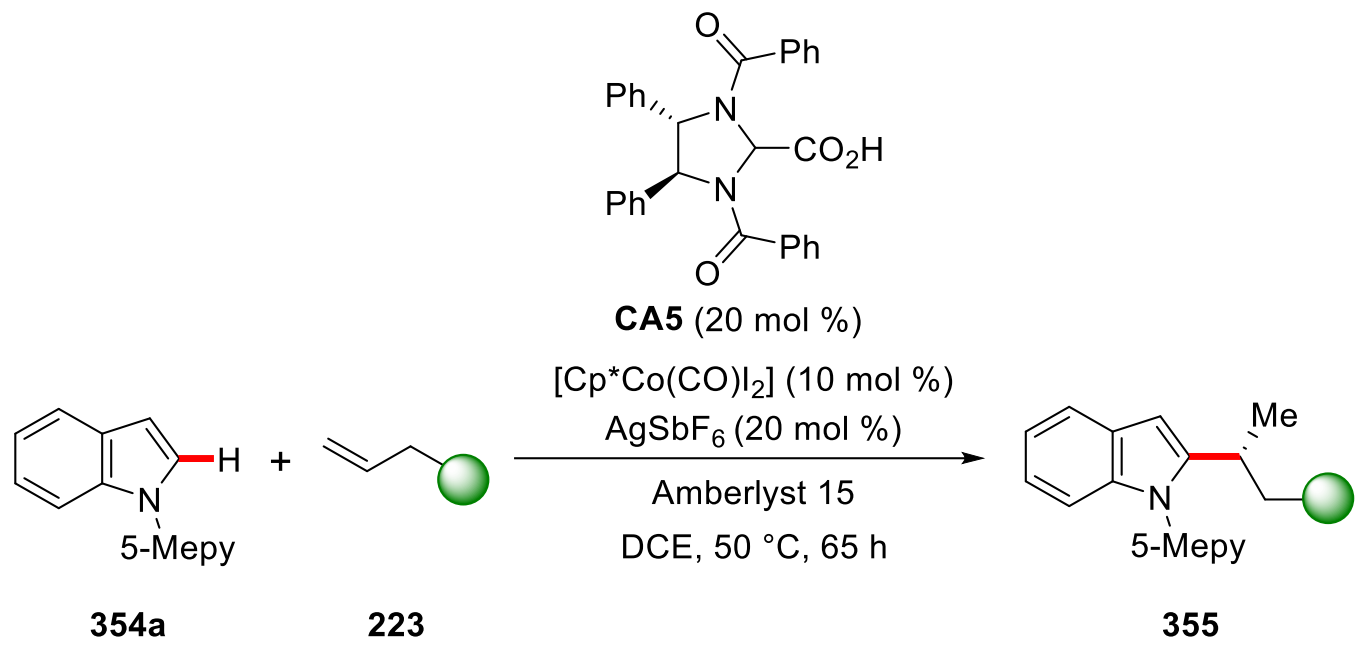

Entry


4<smiles>C=CCc1ccc(F)cc1</smiles>

223e

5<smiles>C=CCc1ccc(OC)c(OC)c1</smiles>

223f

6<smiles>C=CCc1ccc(Cl)cc1</smiles>

223g

7<smiles>C=CCc1c(F)c(F)c(F)c(F)c1F</smiles>

223h<smiles>C=CCc1ccccc1Br</smiles>

223i<smiles>C=CCc1ccc(OC(C)=O)c(OC)c1</smiles>

223j

10<smiles>C=CCc1ccc(Br)cc1</smiles>
223k

11<smiles>C=CCc1ccc(C(=O)OCC)cc1</smiles><smiles>CC(Cc1ccc(F)cc1)c1cc2ccccc2n1C</smiles>

$52 \%(94: 6) \quad 92: 8$

355ae<smiles>COc1ccc(CC(C)c2cc3ccccc3n2C(C)(C)C)cc1OC</smiles>

355af<smiles>CC(Cc1ccc(Cl)cc1)c1cc2ccccc2n1C</smiles>

355ag<smiles>CC(Cc1c(F)c(F)c(F)c(F)c1F)c1cc2ccccc2n1C</smiles>

$355 a h$<smiles>CCCCCCCCc1cc2ccccc2n1C(C)(C)CCc1ccccc1Br</smiles><smiles>COc1cc(CCc2cc3ccccc3n2C(C)(C)C)ccc1OC(C)=O</smiles>

355aj<smiles>CCOc1ccc(CC(C)c2cc3ccccc3n2C(C)(C)C)cc1</smiles>

355ak<smiles>CCOC(=O)c1ccc(CC(C)c2cc3ccccc3n2C(C)(C)C)cc1</smiles>

$56 \%(86: 14) \quad 86: 14$
$49 \%(86: 14) \quad 92: 8^{[\mathrm{e}]}$ $55 \%(75: 25) \quad 88: 12^{[\mathrm{f}]}$ $42 \%(96: 4) \quad 87: 13$ 
12<smiles>C=CCc1ccc(-c2ccccc2)cc1</smiles>

223m

13<smiles>C=CCCc1ccccc1</smiles>

14

$$
\underset{2230}{\mathrm{C}_{6} \mathrm{H}_{13}}
$$

15

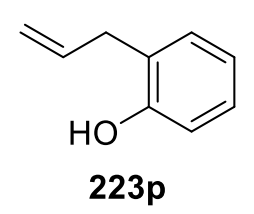

$\mathrm{Br}$<smiles>Cc1ccc2c(c1)cc(C(C)Cc1ccc(-c3ccccc3)cc1)n2[Y16](=O)[O-]</smiles><smiles>CC(CCc1ccccc1)c1cc2ccccc2n1C</smiles>

$34 \%(80: 20)$

$67: 33$

355an<smiles>CC(CCc1ccccc1)c1cc2ccccc2n1C</smiles>

$37 \%(90: 10)$

$72: 28$

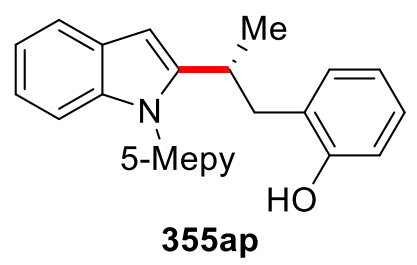

$<10 \%$

[a] Reaction conditions: 354 (0.50 mmol), $223(1.50 \mathrm{mmol}),\left[\mathrm{Cp} * \mathrm{Co}(\mathrm{CO}) \mathrm{I}_{2}\right](10 \mathrm{~mol} \%)$, $\mathrm{AgSbF}_{6}(20 \mathrm{~mol} \%), \mathbf{C A 5}$ (20 mol \%), Amberlyst 15 (1.50 equiv), DCE (0.50 mL, $\left.1.0 \mathrm{M}\right), 50$ ${ }^{\circ} \mathrm{C}$, 65 h. [b] Yield of isolated product. [c] Markovnikov:anti-Markovnikov selectivities in parentheses; determined by ${ }^{1} \mathrm{H}-\mathrm{NMR}$ spectroscopy. [d] Determined by chiral HPLC analysis. [e] Performed by Dr. F. Pesciaioli. [f] at $60{ }^{\circ} \mathrm{C}$. [g] 354b instead of 354a.

Furthermore, we were able to remove the pyridine orienting groups in a traceless fashion to generate the free indoles 357 (Table 15). Other than simple indole 355aa, dimethoxy 355da and ester substituted C2 alkylated products 355af were also transformed into the free indoles 357 by hydrogenation without erosion of the enantioselectivities (entries 1-3). Furthermore, single crystal X-ray diffraction confirmed that 357da was the $(R)$-enantiomer, and the other products were assigned by analogy. 
Table 15. Traceless removal of directing group. ${ }^{[a]}$

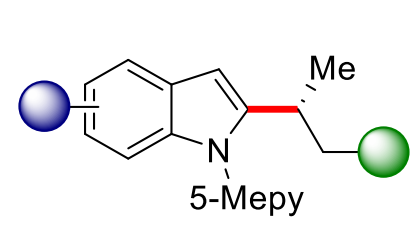

355
1) MeOTf (1.2 equiv)

$\mathrm{CH}_{2} \mathrm{Cl}_{2}, 0^{\circ} \mathrm{C}$ to $25^{\circ} \mathrm{C}, 6 \mathrm{~h}$

2) $\mathrm{Pd}(\mathrm{OH})_{2} / \mathrm{C}(10 \mathrm{wt} .-\%)$

$\mathrm{HCO}_{2} \mathrm{NH}_{4}$ (10 equiv)

$\mathrm{MeOH}, 60^{\circ} \mathrm{C}, 6 \mathrm{~h}$

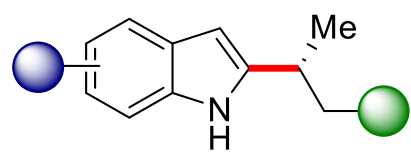

357

Entry

[a] Reaction conditions: (1) $355(0.20 \mathrm{mmol}), \mathrm{MeOTf}(0.22 \mathrm{mmol}), \mathrm{CH}_{2} \mathrm{Cl}_{2}(0.50 \mathrm{~mL}), 0{ }^{\circ} \mathrm{C}$ to $25^{\circ} \mathrm{C}, 6$ h. (2) $\mathrm{Pd}(\mathrm{OH})_{2} / \mathrm{C}(10$ wt. $-\%), \mathrm{HCO}_{2} \mathrm{NH}_{4}(2.0 \mathrm{mmol}), \mathrm{MeOH}(1.0 \mathrm{~mL}), 60{ }^{\circ} \mathrm{C}, 6 \mathrm{~h}$. [b] Yield of isolated product. [c] Markovnikov:anti-Markovnikov selectivities in parentheses; determined by ${ }^{1} \mathrm{H}-\mathrm{NMR}$ spectroscopy. [d] Determined by chiral HPLC analysis.

\subsubsection{Mechanistic Studies}

Given the novelty of the chiral acid CA5 and the high levels of enantioselectivity generated in this transformation, we were keen to delineate its mode of action. Therefore, detailed experimental and computational mechanistic studies were performed in order to gain insights into the reaction mechanism. 


\subsubsection{Kinetic Reaction Orders}

\subsection{Reaction Order with respect to Chiral Acid CA5.}

Initially, we determined the kinetic order of the reaction under the optimized reaction conditions with respect to the concentration of the chiral acid CA5 which was equal to $n=$ $0.904 \pm 0.03$, indicating a first order dependence on the concentration of chiral acid (Scheme 109). Next, we tested the order of the chiral acid under modified reaction conditions in the absence of the Amberlyst 15 additive. Quite strikingly, we found the order of the chiral acid without Amberlyst 15 was equal to $n=2.07 \pm 0.14$, which corresponds to an order of two. These findings suggest that the chiral acid CA5 may form a dimeric species in solution which is also in accordance with our non-linear effect study.

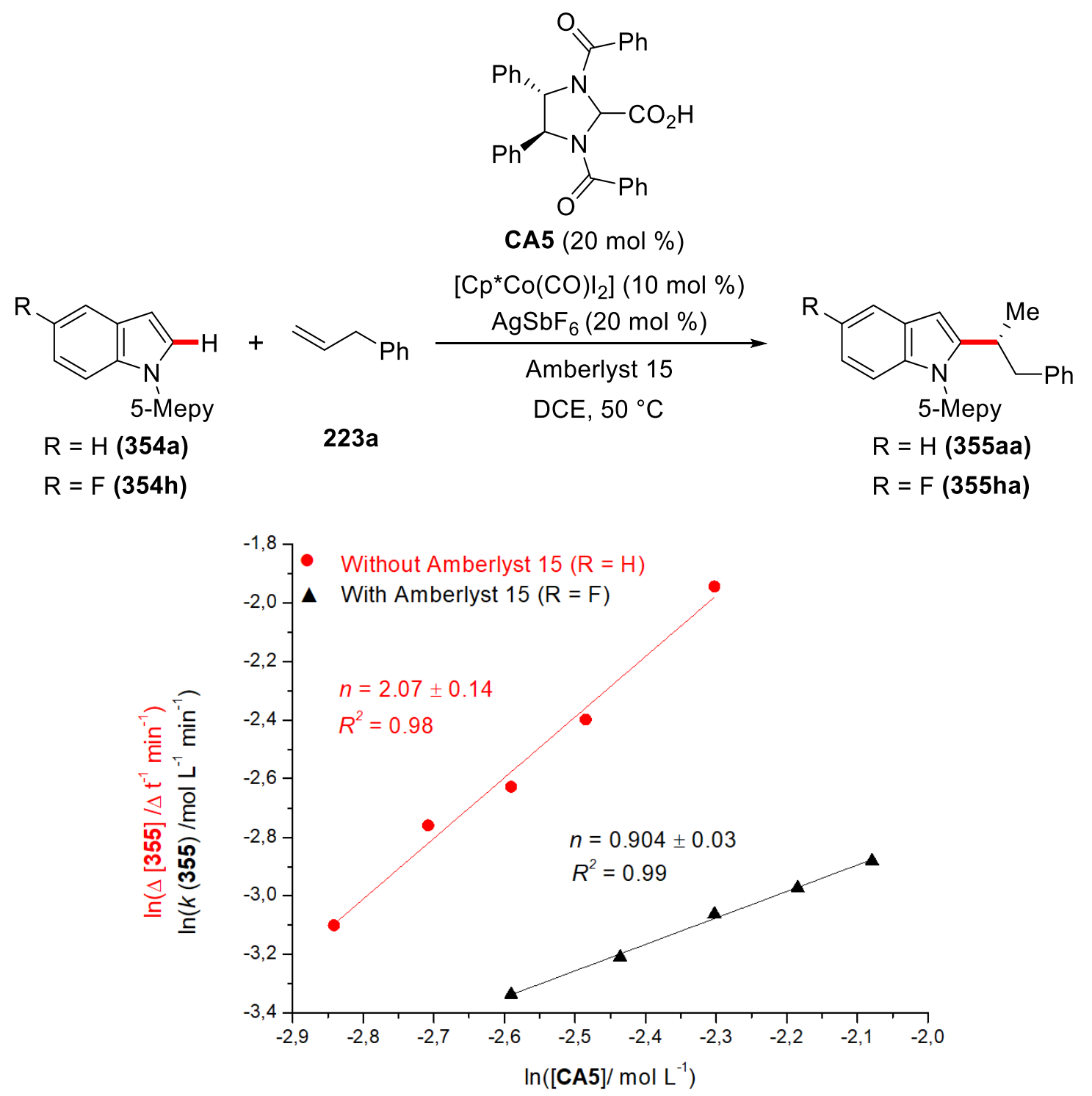

Scheme 109. Order in chiral acid CA5 with and without Amberlyst 15. 


\subsubsection{Non-Linear Effect Studies}

The deviation from the proportionality between the enantiomeric excess of the chiral ligand and the enantiomeric induction of the transformation was next investigated. We studied the non-linear effect in our enantioselective transformation in two distinct sets of conditions. In the first instance, the absence of a non-linear effect (NLE) excludes the formation of a multiligand containing catalyst or catalytically competent oligomer in the enantioselective Co(III)catalyzed $\mathrm{C}-\mathrm{H}$ alkylation. Then, the effect of the enantiomeric excess of the chiral acid CA5 over the enantiomeric induction of the transformation was investigated under Amberlyst 15free reaction conditions, which gave a considerable negative non-linear-effect. This arguably relates to the existence of a dimeric species in solution.

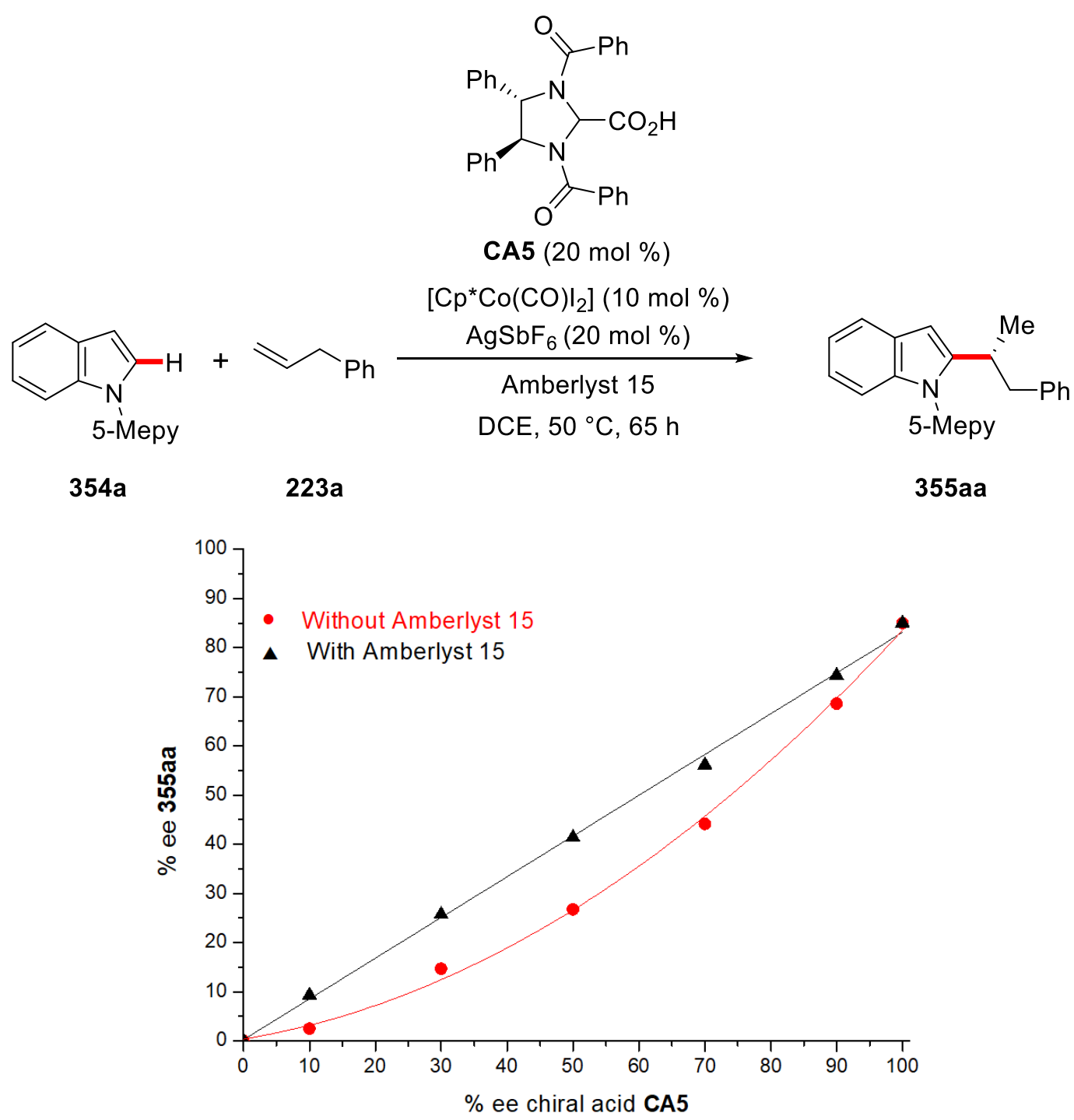

Scheme 110. Non-linear effect studies with and without Amberlyst 15. 


\subsubsection{Diffusion NMR Study}

To further investigate the presence of a dimeric chiral acid species in solution, we performed detailed diffusion controlled NMR spectroscopy in collaboration with Dr. Michael John (Figure 1). As diffusion NMR experiments resolve different compounds depending on their size and shape of the molecules, we prepared two NMR samples of chiral acid with and without the external acid TFA. Indeed, the diffusion coefficients were different and the ratio of diffusion coefficients indicated the formation of dimers in the absence of TFA. These findings can be rationalized by a hydrogen bond-stabilized dimeric resting state of the chiral acid which are supported by detailed NLE study and kinetic studies (vide supra).

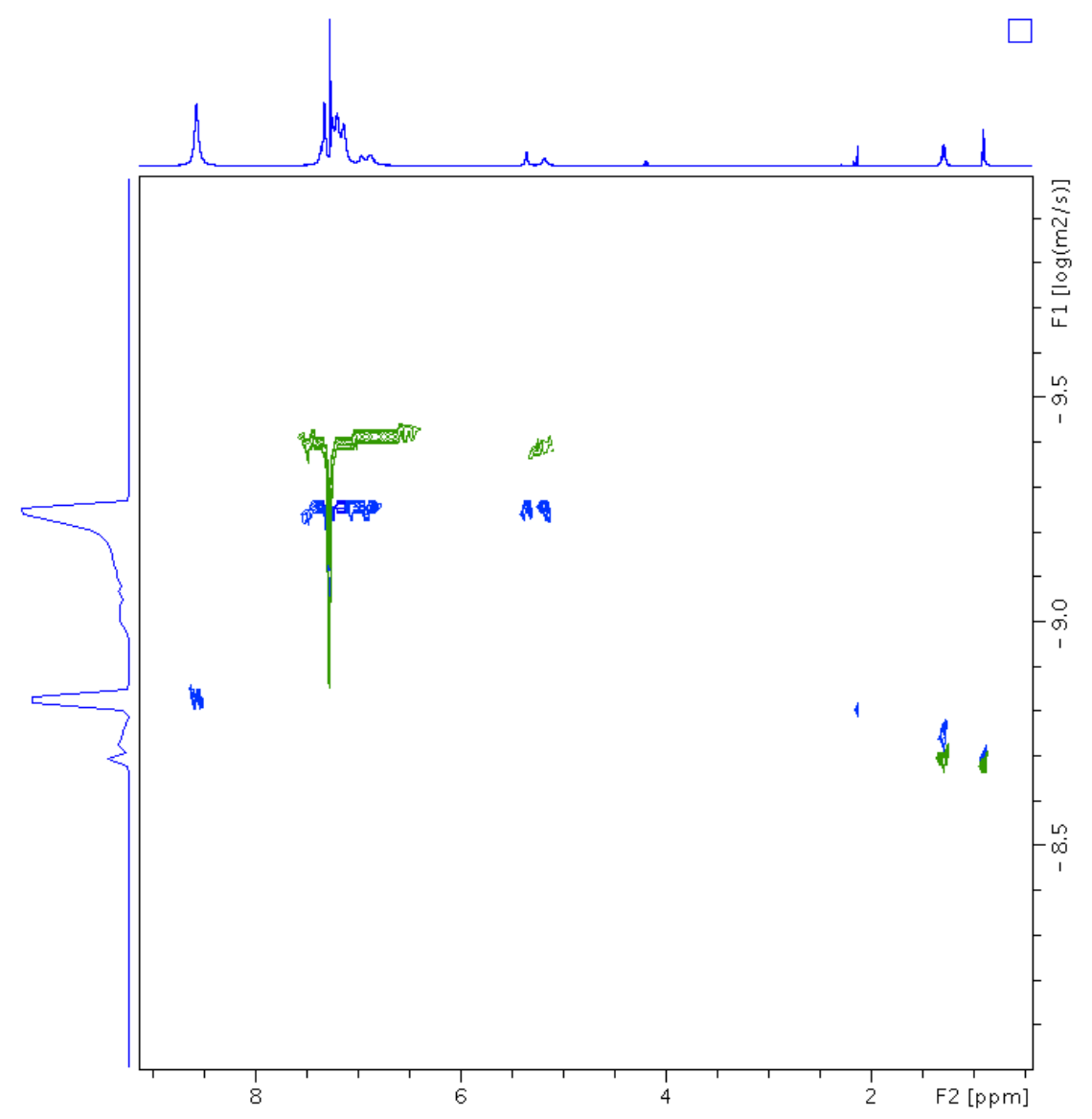

Figure 1. Overlay of DOSY spectra $\left(500 \mathrm{MHz}, 25^{\circ} \mathrm{C}, \mathrm{CDCl} 3\right)$ of CA5 (8 mg, $0.017 \mathrm{mmol}$, in $700 \mathrm{~mL}$ of $\mathrm{CDCl}_{3}$ ) in the presence (blue) and absence (green) of $0.063 \mathrm{mmol}$ of TFA. The ratio of diffusion coefficients $\left(5.5 \times 10-10 \pm 0.2 \times 10-10 \mathrm{~m}^{2} \mathrm{~s}^{-1} / 4.0 \times 10-10 \pm 0.2 \times 10-10 \mathrm{~m}^{2} \mathrm{~s}^{-1}=\right.$ 1.375) indicates the formation of dimers in the absence of TFA. DOSY spectra were recorded on a Bruker Avance III HD $500 \mathrm{MHz}$ instrument equipped with a Cryoprobe Prodigy. The pulse sequence dstebpgp3s was used, and the diffusion delay (d20) and gradient duration (p30) were set to 150 and $1 \mathrm{~ms}$, respectively. $n$ Hexane was used as internal standard. 


\subsubsection{H/D Exchange Experiment}

Next, we performed a $\mathrm{H} / \mathrm{D}$ exchange experiment with $\mathrm{CD}_{3} \mathrm{CO}_{2} \mathrm{D}$ as the co-solvent to probe the C-H activation elementary step (Scheme 111). As a result, a significant deuterium incorporation was observed at the $\mathrm{C} 3$-position of the product 355ia as well as at the $\mathrm{C} 3$ - and C7 positions in the starting material in accordance with previously reported racemic branchedselective cobalt(III)-catalyzed C-H alkylations. ${ }^{[265]}$ Notably, we observed a significant H/D scrambling in the $\mathrm{C} 2$-position of the re-isolated starting material $\mathbf{3 5 5 i}$ which clearly suggests a facile and reversible $\mathrm{C}-\mathrm{H}$ metalation step to be involved.

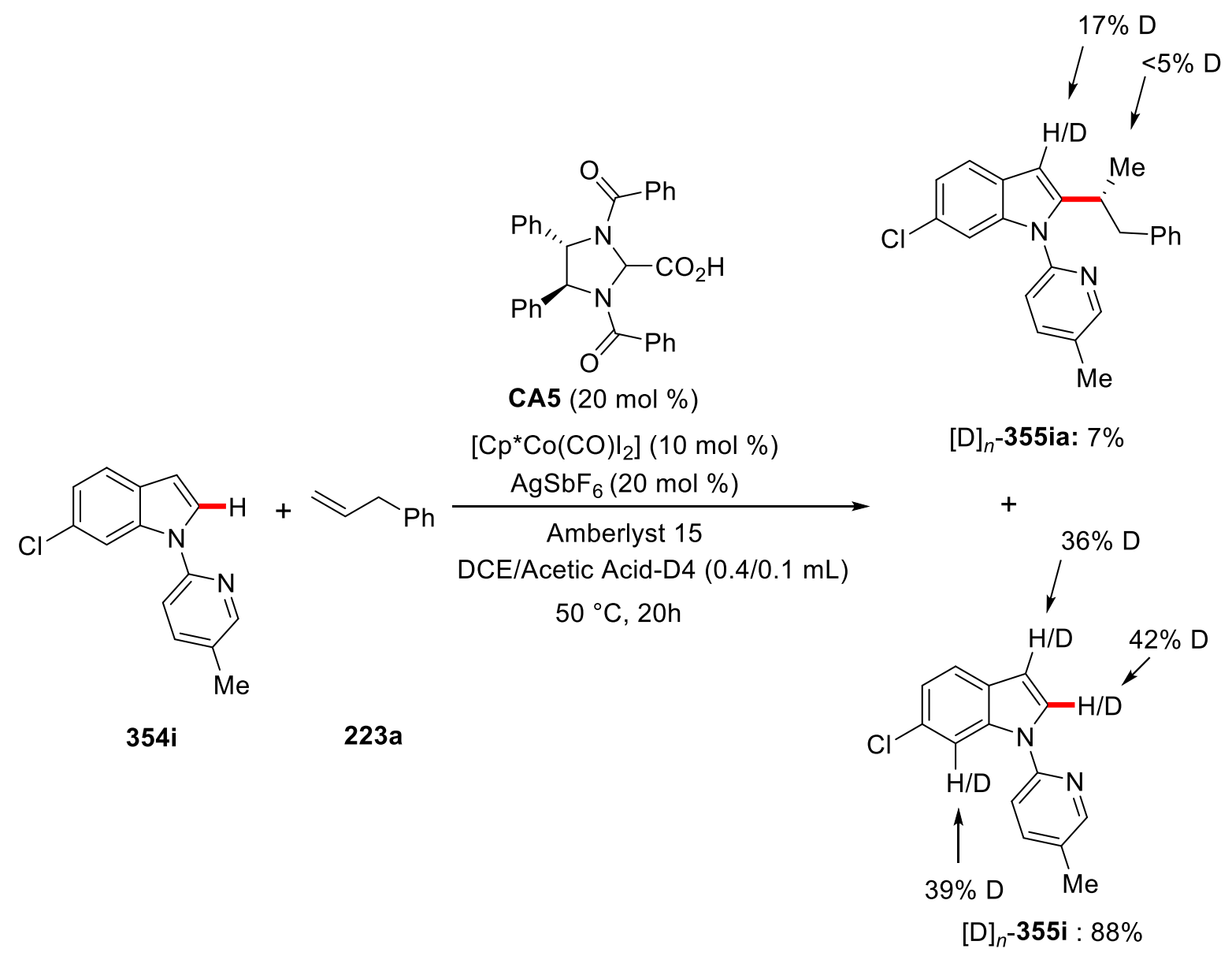

Scheme 111. H/D scrambling experiment for cobalt(III)-catalyzed C-H alkylation.

\subsubsection{Proposed Catalytic Cycle}

To gain deeper mechanistic insight into the enantioselective cobalt(III)-catalyzed $\mathrm{C}-\mathrm{H}$ alkylation by the co-operation of the novel chiral carboxylic acid CA5, detailed DFT-studies were performed by $D r . J . C$. A. Oliveira. Given that the H/D exchange experiment clearly suggested a reversible $\mathrm{C}-\mathrm{H}$ metalation step to be involved, migratory insertion and protodemetalation steps were interrogated by means of computational DFT studies. 
On the basis of our detailed mechanistic studies, we propose a plausible catalytic cycle initiated by a reversible and facile $\mathrm{C}-\mathrm{H}$ metalation to form the intermediate 359 (Scheme 112). Then, and following co-ordination of the alkene $\mathbf{2 2 3}$, a reversible migratory insertion into the cobaltcarbon bond proceeds to form racemic intermediate 361. Afterwards, in line with our DFTstudies, the turnover-limiting proto-demetalation step proceeds with chiral acid CA5, which acts as the proton source in the enantio-determining step. Thus, the $(R)$-enantiomer of intermediate 361 undergoes selective proto-demetalation with $\mathrm{C} 2$-symmetric chiral acid CA5 to generate the enantioenriched product $\mathbf{3 5 5}$.

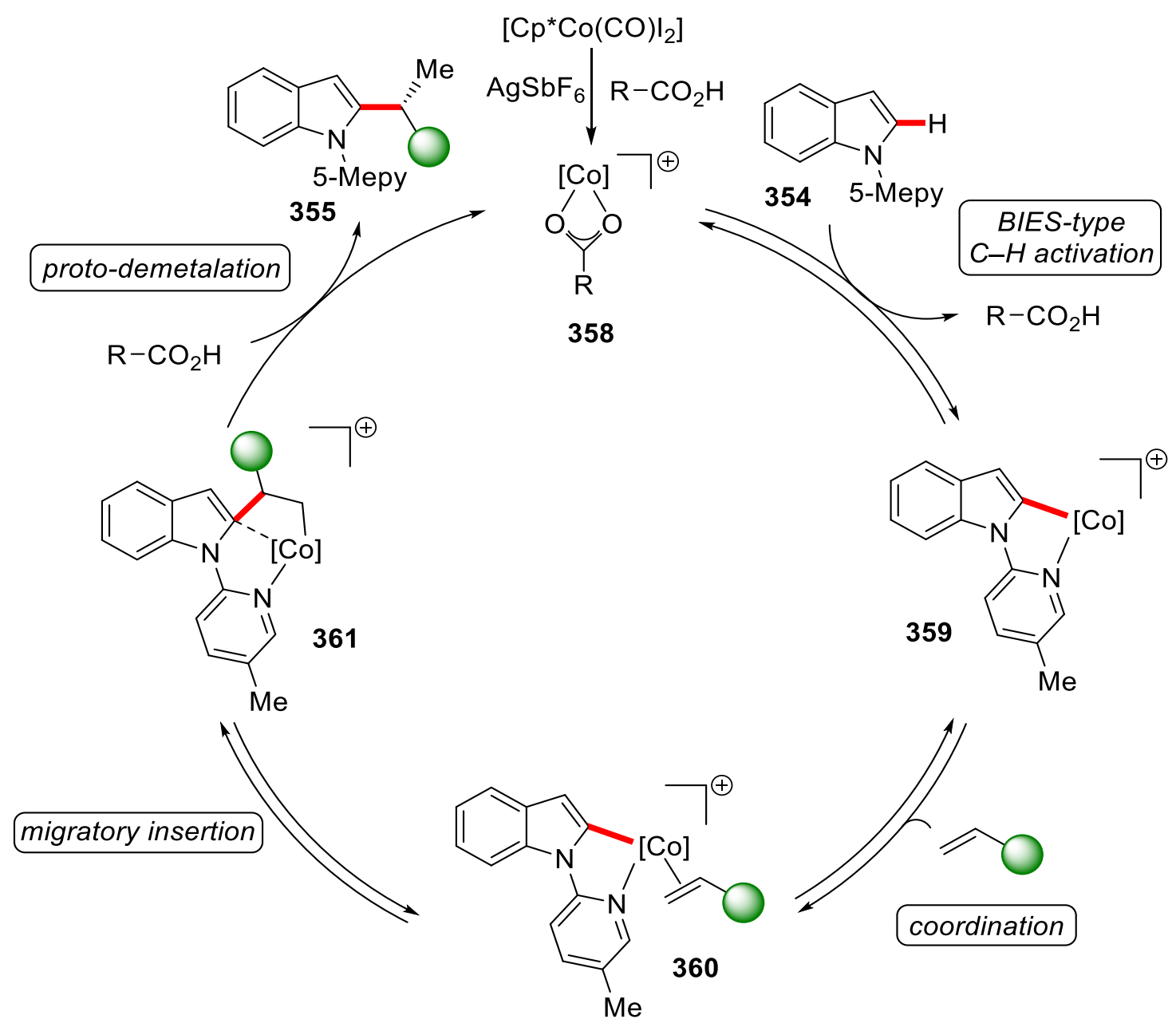

Scheme 112. Proposed catalytic cycle for the enantioselective $\mathrm{C}-\mathrm{H}$ alkylation. 


\subsection{Ruthenium(II)-Catalyzed Enantioselective C-H Activation}

Ruthenium(II) complexes have been recognized as powerful catalysts for various $\mathrm{C}-\mathrm{H}$ activation reactions, in particular for hydroarylation reactions. ${ }^{[27 t, 39,138]}$ Despite significant advancements, ruthenium-catalyzed enantioselective $\mathrm{C}-\mathrm{H}$ activations remain rare. ${ }^{[268]}$ This can be largely attributed to the absence of reactivity of pentamethylcyclopentadienyl ruthenium(II) complexes, which significantly jeopardizes the use of chiral $\mathrm{Cp}^{\mathrm{x}}$ ligands to achieve full selectivity control. ${ }^{[269]}$ Furthermore, it is noteworthy that the multi-step syntheses of $\mathrm{Cp}^{\mathrm{x}}$ ligands and pre-coordination to metal catalysts reduce the atom- and step economy to large extent. ${ }^{[106]}$

In light of enantioselective $\mathrm{C}-\mathrm{H}$ activation, the cooperative combination of chiral carboxylic acids (CCAs) with transition metals has become a successful tool for efficient enantioinduction. ${ }^{[34 a, 58 a]}$ While ruthenium-catalyzed enantioselective transformations are scarce in literature, in very recent reports, the groups of Cui ${ }^{[139]}$ and Wang ${ }^{[140]}$ independently reported ruthenium(II)-catalyzed enantioselective intramolecular hydroarylations by the cooperation of a chiral amine as the directing group ${ }^{[41]}$ where the enantio-induction was primarily governed by the chiral amine. Intrigued by our previous development of the first cobalt(III)-catalyzed enantioselective $\mathrm{C}-\mathrm{H}$ alkylations by the design of a novel $\mathrm{C} 2$-symmetric chiral acid, ${ }^{[270]}$ we became interested in devising a new enantioselective strategy for rutheniumcatalyzed asymmetric $\mathrm{C}-\mathrm{H}$ activations. Particularly the design of novel chiral carboxylic acids was envisioned to control the enantio-determining proto-demetalation step. ${ }^{\text {[63a, 271] }}$

\subsubsection{Optimization Studies}

The optimization studies were initiated by probing the effect of various classes of typical Brønsted acids for the enantioselective $\mathrm{C}$ 2-selective intramolecular $\mathrm{C}-\mathrm{H}$ alkylation of olefintethered indole 362a (Scheme 113). Over the past years, $N$-protected amino acids have evolved as powerful ligands particularly for palladium-catalyzed enantioselective $\mathrm{C}-\mathrm{H}$ functionalizations. ${ }^{[63 \mathrm{a}]}$ Thus, we initially started our optimization with this class of ligands in the presence of catalytic amounts of $\left[\mathrm{RuCl}_{2}(p \text {-cymene })\right]_{2}$ to furnish the desired cyclized indole derivative 363a at room temperature. The reaction worked very efficiently with both Boc- CA2 and phthaloyl- protected CA8 amino acids, enabling the cyclization with almost quantitative yields, albeit very poor levels of enantiocontrol were observed. Furthermore, well-defined chiral phosphoric acids $\mathbf{C A 9}{ }^{[266]}$ which have been broadly used in the enantioselective $\mathrm{C}-\mathrm{H}$ 
transformations failed to provide any reactivity, reflecting the quest for the development of novel chiral carboxylic acids for organometallic ruthenium-catalyzed enantioselective $\mathrm{C}-\mathrm{H}$ activation strategies. Recently we achieved the highly enantioselective cobalt(III)-catalyzed C$\mathrm{H}$ activation through the design of a novel C2-symmetric chiral carboxylic acid. ${ }^{[270]}$ Intrigued by this result, we surveyed this class of chiral carboxylic acids in the ruthenium-catalyzed enantioselective $\mathrm{C}-\mathrm{H}$ alkylation. We were pleased to observe an excellent yield of the desired cyclized product with C2-symmetric chiral acid CA5 with a promising enantioselectivity.

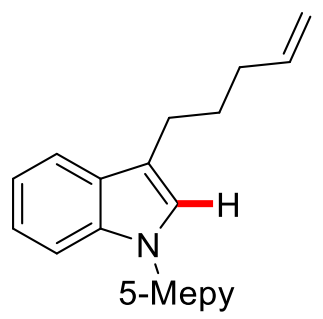

$362 a$
$\left[\mathrm{RuCl}_{2}(p \text {-cymene })\right]_{2}(5.0 \mathrm{~mol} \%)$

$\mathrm{AgSbF}_{6}(20 \mathrm{~mol} \%)$

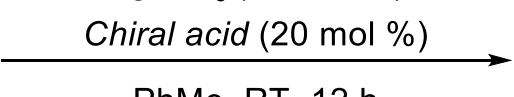

PhMe, RT, 12 h

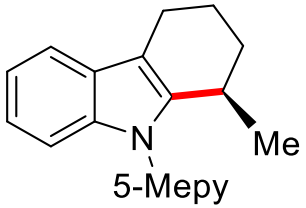

$363 a$<smiles>CCC(C)[C@H](N)C(=O)O</smiles>

CA2: $90 \%, 46: 56$ e.r.<smiles>CC(C)(C)[C@@H](P)C(=O)O</smiles>

CA8: $88 \%, 59: 41$ e.r.<smiles>O=P1(O)Oc2ccc3ccccc3c2-c2c(ccc3ccccc23)O1</smiles>

CA9: ---<smiles>O=C(O)C1N(C(=O)c2ccccc2)[C@@H](c2ccccc2)[C@@H](c2ccccc2)N1C(=O)c1ccccc1</smiles>

CA5: $92 \%, 84: 16$ e.r.

Scheme 113. Chiral acid screening for the enantioselective $\mathrm{C}-\mathrm{H}$ alkylation.

Next, various representative solvents were tested, but fell short in delivering the product $\mathbf{3 6 3 a}$ in improved enantioselectivity (Table 16, entries 1-5). Thus, toluene was found to be the optimal solvent (entry 5). Furthermore, we also probed the effect of additives for enantioselective ruthenium-catalyzed $\mathrm{C}-\mathrm{H}$ alkylations (entries 6-9). Nonetheless, in stark contrast to our previous report, ${ }^{[270]}$ Amberlyst 15 did not show a beneficial effect on the outcome of the reaction (entry 6). Similar results were obtained for other acid additives which provided the desired product 363a in almost quantitative yields, but lower levels of enantiocontrol were observed (entry 7-9). 
Table 16. Asymmetric ruthenium(II)-catalyzed $\mathrm{C}-\mathrm{H}$ activation. ${ }^{[\mathrm{a}]}$

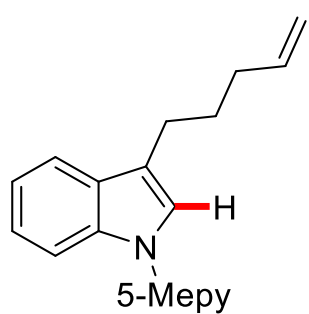

$362 a$
$\left[\operatorname{RuCl}_{2}(p \text {-cymene })\right]_{2}(5.0 \mathrm{~mol} \%)$ $\mathrm{AgSbF}_{6}(20 \mathrm{~mol} \%)$

CA5 $(20 \mathrm{~mol} \%)$

$\mathrm{PhMe}, \mathrm{RT}, 12 \mathrm{~h}$

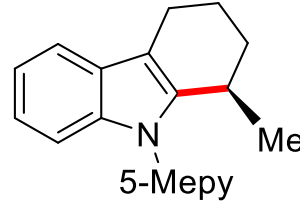

$363 a$

\begin{tabular}{ccccc}
\hline Entry & Additive & Solvent & Yield [\%] & e.r. $^{[\mathbf{b}]}$ \\
\hline 1 & --- & 1,2 -DCE & 93 & $76: 24$ \\
2 & --- & $o$-xylene & 55 & $70: 30$ \\
3 & --- & 1,4 -dioxane & 52 & $62: 38$ \\
4 & --- & PhCF 3 & 90 & $71: 29$ \\
$\mathbf{5}$ & --- & PhMe & $\mathbf{9 2}$ & $\mathbf{8 4 : 1 6}$ \\
6 & Amberlyst 15 & PhMe & 94 & $\mathbf{8 4 : 1 6}$ \\
7 & Amberlite CG50 & PhMe & 88 & $77: 23$ \\
8 & Citric Acid & PhMe & 95 & $78: 22$ \\
9 & MS13X & PhMe & 90 & $84: 16$
\end{tabular}

[a] Reaction conditions: 362a (0.25 mmol), [Ru] (10 mol \%), $\mathrm{AgSbF}_{6}(20 \mathrm{~mol} \%), \mathbf{C A 5}(20$ mol \%), Additive (1.50 equiv), PhMe $(0.50 \mathrm{~mL}), \mathrm{RT}, 12 \mathrm{~h}$, isolated yields. [b] Enantioselectivities determined by chiral HPLC.

Thereafter, diversely substituted novel chiral carboxylic acids were newly synthesized and probed in the envisioned enantioselective transformations of indoles (Scheme 114). Variation in meta-substitution provided the product 363a in lower enantioselectivity for both methyl CA10 and trifluoromethyl substituted arenes CA11. Similarly, 3,5-disubstituted methyl CA12 also failed to improve the enantioselectivity. However, we observed a beneficial effect of paraphenyl substituted chiral acids in improving the enantioselectivity. Among the tested electronrich and electron-deficient chiral scaffolds, para-methyl substituted chiral acid CA14 turned out to be superior for achieving high levels of enantiocontrol. Slightly bulkier ethyl-substituted CA15 was tested as well but provided inferior results compared to the methyl group. 


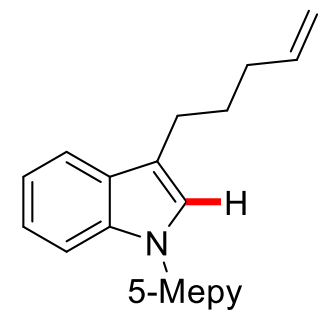

362a
$\left[\operatorname{RuCl}_{2}(p \text {-cymene })\right]_{2}(5.0 \mathrm{~mol} \%)$ $\mathrm{AgSbF}_{6}(20 \mathrm{~mol} \%)$

CA $(20 \mathrm{~mol} \%)$

PhMe, RT, $12 \mathrm{~h}$

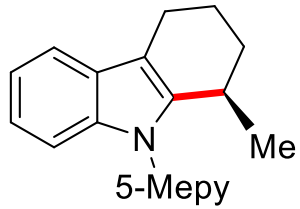

363a<smiles>Cc1cccc(C(=O)N2C(c3ccccc3)[C@@H](c3ccccc3)N(C(=O)c3cccc(C)c3)C2C(=O)O)c1</smiles>

CA10: 90\%, 76:24 e.r.<smiles>O=C(O)C1[C@H](c2ccccc2)[C@H](c2ccccc2)C(C(=O)c2ccc(F)cc2)N1C(=O)c1ccc(F)cc1</smiles>

CA13: 94\%, 77:23 e.r.<smiles>O=C(O)C1N(C(=O)c2cccc(C(F)(F)F)c2)[C@H](c2ccccc2)[C@@H](c2ccccc2)N1C(=O)c1cccc(C(F)(F)F)c1</smiles>

CA11: $88 \%, 82: 18$ e.r.<smiles>Cc1ccc(C(=O)N2C(C(=O)O)N(C(=O)c3ccc(C)cc3)[C@H](c3ccccc3)[C@H]2c2ccccc2)cc1</smiles>

CA14: 95\%, 85:15 e.r.<smiles>COC(=O)c1cc(C)cc(C)c1</smiles>

CA12: 93\%, 78:22 e.r.<smiles>CCc1ccc(C(=O)N2C(c3ccccc3)[C@@H](c3ccccc3)N(C(=O)c3ccc(CC)cc3)C2C(=O)O)cc1</smiles>

CA15: $90 \% \quad 72: 28$ e.r.

Scheme 114. Chiral acid screening for the enantioselective $\mathrm{C}-\mathrm{H}$ alkylation of indoles $\mathbf{3 6 2 a}$.

Next, we tested several variations of our standard conditions (Table 17). Remarkably, the reaction also occurred under silver-free reaction conditions using $\mathrm{NaSbF}_{6}$ or $\mathrm{NaPF}_{6}$ as the additive, albeit with slightly lower yields (entries 2-3). As previously observed, Amberlyst 15 did not improve the enantioselectivity, although the reactivity was not influenced (entry 4). Next, a series of several other metal catalysts, such as, $\left[\mathrm{OsCl}_{2}(p \text {-cymene })\right]_{2},\left[\mathrm{Cp} * \mathrm{Co}(\mathrm{CO}) \mathrm{I}_{2}\right]$, $\mathrm{Pd}(\mathrm{OAc})_{2},\left[\mathrm{Cp}^{*} \mathrm{IrCl}_{2}\right]_{2}$ and $\left[\mathrm{Cp}^{*} \mathrm{RhCl}_{2}\right]_{2}$ were tested, which failed to deliver the desired tetrahydrocarbazole derivative 363a in considerable enantioselectivity (entry 5-9). Likewise, ent-CA14 afforded the $(S)$-enantiomer of the tetrahydrocarbazole (entry 10). 
Table 17. Asymmetric ruthenium(II)-catalyzed C-H activation. ${ }^{[\mathrm{a}]}$

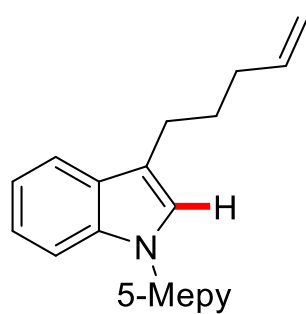

$362 a$
$\left[\operatorname{RuCl}_{2}(p \text {-cymene })\right]_{2}(5.0 \mathrm{~mol} \%)$ $\mathrm{AgSbF}_{6}(20 \mathrm{~mol} \%)$ CA14 $(20 \mathrm{~mol} \%)$ $\mathrm{PhMe}, \mathrm{RT}, 12 \mathrm{~h}$

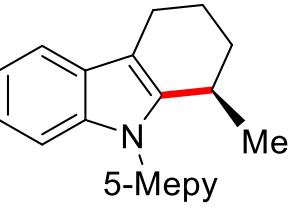

$363 a$

\begin{tabular}{cccc}
\hline Entry & Variation of Standard Condition & Yield[\%] & e.r. ${ }^{[\text {b] }}$ \\
\hline 1 & none & 95 & $85: 15$ \\
2 & $\mathrm{NaSbF}_{6}$ instead of $\mathrm{AgSbF}_{6}$ & $37^{[\mathrm{c}]}$ & $77: 23$ \\
3 & $\mathrm{NaPF}_{6}$ instead of $\mathrm{AgSbF}_{6}$ & $20^{[\mathrm{c}]}$ & $83: 17$ \\
4 & $\mathrm{Amberlyst}^{15}$ as additive & 94 & $85: 15$ \\
5 & {$\left[\mathrm{OsCl}_{2}(p-\mathrm{cymene})\right]_{2}$ as catalyst } & --- & --- \\
6 & {$\left[\mathrm{Cp}^{*} \mathrm{Co}(\mathrm{CO}) \mathrm{I}_{2}\right]$ as catalyst } & $<5$ & n.d. \\
7 & $\mathrm{Pd}_{(\mathrm{OAc})_{2} \text { as catalyst }}$ & --- & --- \\
8 & {$\left[\mathrm{Cp} * \mathrm{IrCl}_{2}\right]_{2}$ as catalyst } & --- & --- \\
9 & {$\left[\mathrm{Cp} * \mathrm{RhCl}_{2}\right]_{2}$ as catalyst } & 90 & $58: 42$ \\
10 & $\boldsymbol{e n t}-\mathrm{CA}_{14}$ was used & 94 & $15: 85$ \\
\hline
\end{tabular}

[a] Reaction conditions: 362a (0.25 mmol), [Ru] (10 mol \%), $\operatorname{AgSbF}_{6}(20 \mathrm{~mol} \%), \mathbf{C A 1 4}(20$ mol \%), PhMe (0.50 mL), RT, $12 \mathrm{~h}$, isolated yields. [b] Determined by chiral HPLC. [c] Conversion determined by ${ }^{1} \mathrm{H}-\mathrm{NMR}$ using $\mathrm{Ph}_{3} \mathrm{CH}$ as the internal standard. n.d. = not determined.

\subsubsection{Effect of $N$-Substitution Pattern}

Subsequently, we surveyed the substitution pattern on the pyridyl directing group for the enantioselective $\mathrm{C}-\mathrm{H}$ alkylation (Table 18). Hence, a similar yield was observed for the unsubstituted pyridine 364a, albeit lower enantioselectivity of the cyclized product 365a was obtained (entry 1). The 4-methyl-substituted pyridine 366a provided a marginally lower yield compared to the 5-methyl substituted substrate $\mathbf{3 6 2 a}$ as well as a lower enantioselectivity (entry 2). Thus, 5-methylpyridine (5-Mepy) 362a furnished the desired product 363a with the highest enantioselectivity (entry 3). 
Table 18. Effect of $N$-substitution pattern on asymmetric $\mathrm{C}-\mathrm{H}$ alkylation. ${ }^{\text {[a] }}$

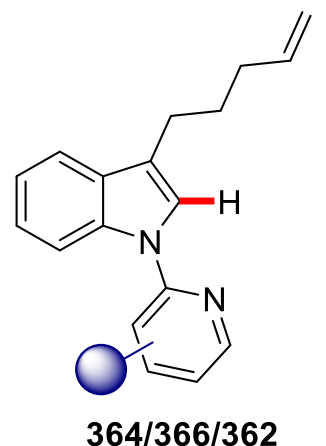

$\left[\mathrm{RuCl}_{2}(p \text {-cymene })\right]_{2}(5.0 \mathrm{~mol} \%)$ $\mathrm{AgSbF}_{6}(20 \mathrm{~mol} \%)$

CA14 $(20 \mathrm{~mol} \%)$

PhMe, RT, 12 h

1

Entry Indole

$364 a$

2<smiles>C=CCCCc1c(-c2cc(C)ccn2)n(-c2ccccc2)c2ccccc12</smiles>

$366 a$

3

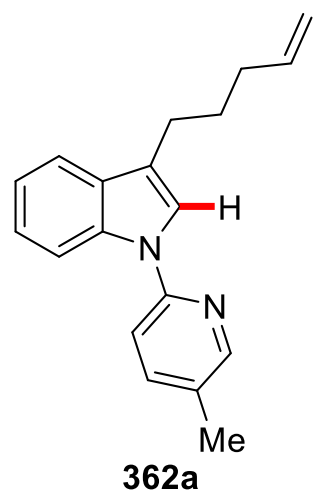

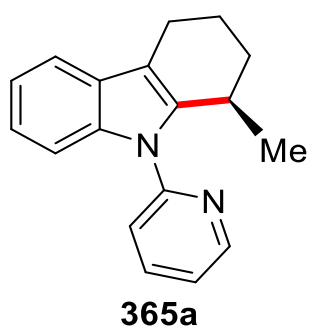<smiles>Cc1ccnc(-n2c3c(c4ccccc42)CCCC3C)c1</smiles>

$367 a$

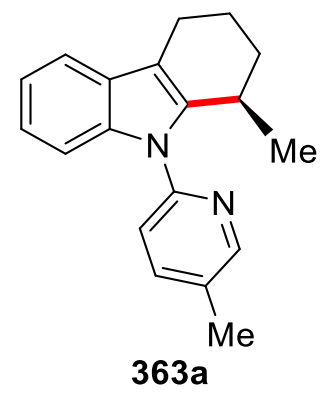

88

$76: 24$

90

$81: 19$

95

$85: 15$

[a] Reaction conditions: Indole (0.25 mmol), [Ru] (10 mol \%), AgSbF6 (20 mol \%), CA14 (20 mol \%), PhMe (0.50 mL), RT, 12 h, isolated yields. [b] Determined by chiral HPLC. 


\subsubsection{Substrate Scope of Asymmetric C-H Alkylation}

With the optimized catalyst in hand, various C5 and C6 substituted indoles $\mathbf{3 6 2}$ were tested (Table 19). Our approach provided the desired C2-cyclized products 363 in excellent yields and with good enantiocontrol independent of varying the sterics and electronics of the substituents. Both electron-rich and electron-deficient substrates furnished the desired products with good enantioselectivity under exceedingly mild reaction conditions (entries 1-5). Remarkably, halogens including fluoride and bromide were well tolerated in the versatile ruthenium(II) catalysis, which would prove invaluable for further late-stage diversifications (entries 4-5). Thus the desired products 363d-363e were obtained in high yields and moderate enantioselectivities. Furthermore, the reaction was also performed on a $1 \mathrm{mmol}$ scale with bromo substrate 362e, furnishing the product in an identical yield of $86 \%$ with $83: 17$ e.r. (entry 5). Additionally, the product 363e was recrystallized from dichloromethane, and analyzed by single crystal X-ray diffraction, clearly revealing the $(R)$-conformation of the stereocenter. The other products 363 were assigned by analogy. Thereafter, an extensive study of the scope of this enantioselective transformation was studied by $\mathrm{Dr}$. R. Connon and Mr. R. Steinbock.

Table 19. Asymmetric $\mathrm{C}-\mathrm{H}$ alkylation with indoles 362. ${ }^{\text {[a] }}$

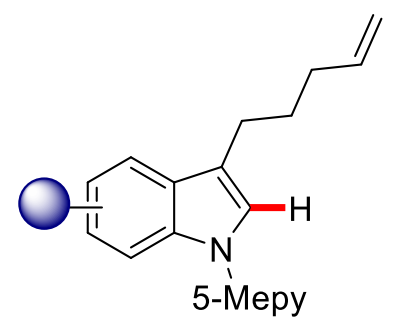

362
$\left[\mathrm{RuCl}_{2}(p \text {-cymene })\right]_{2}(5.0 \mathrm{~mol} \%)$ $\operatorname{AgSbF}_{6}(20 \mathrm{~mol} \%)$ CA14 (20 mol \%) PhMe, RT, $12 \mathrm{~h}$ 363

Entry Indole


2

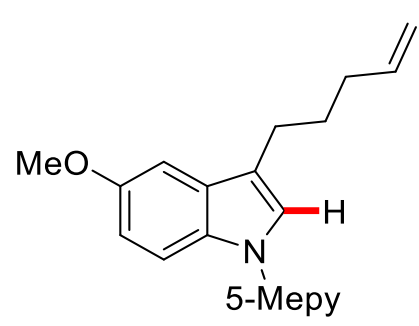

362b

3

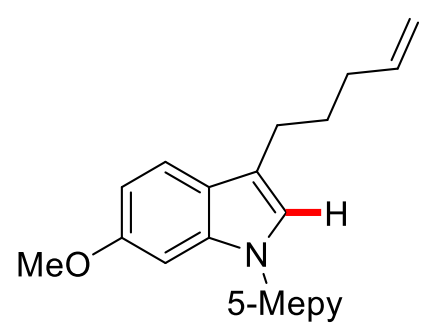

$362 c$

4

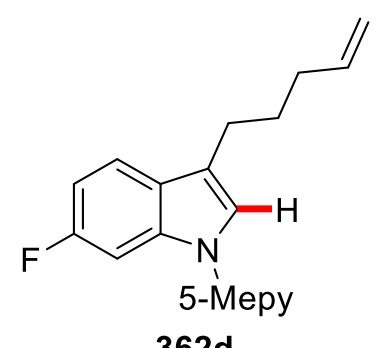

362d

5

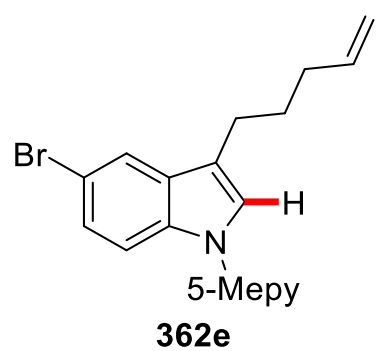<smiles>COc1ccc2c(c1)c1c(n2C(C)(C)C)C(C)CCC1</smiles>

89

$85: 15$

363b

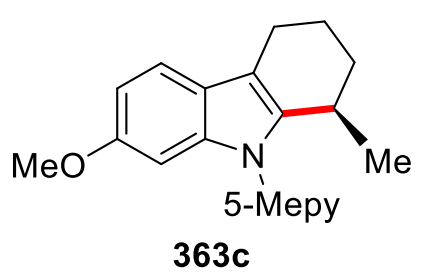

95

$84: 16$<smiles>CC1CCCc2c1n(C)c1cc(F)ccc21</smiles>

363d<smiles>CC1CCCc2c1n(C)c1ccc(Br)cc21</smiles>

88

$82: 18$

$86^{[\mathrm{c}]}$

$86: 14$

66

$86: 14$

$363 e$

[a] Reaction conditions: $362(0.25 \mathrm{mmol}),[\mathrm{Ru}]$ (10 mol \%), AgSbF $6(20 \mathrm{~mol} \%), \mathbf{C A 1 4}(20$ mol \%), PhMe (0.50 mL), RT, $12 \mathrm{~h}$, isolated yields. [b] Determined by chiral HPLC. [c] Performed on $1 \mathrm{mmol}$ scale.

We further became interested to extend this approach to the synthesis of larger rings (Table 20). Under our optimized reaction conditions, we observed a rather low conversion for the formation of seven-membered ring 369, albeit Amberlyst 15 proved to be beneficial here (entries 1-2). Further optimization was performed by Mr. R. Steinbock, showcasing that prolonged reaction time could provide cyclohepta $[b]$ indole derivative 369 in a synthetically useful yield of $51 \%$ with a good enantioselectivity of 82:18 e.r. (entry 3 ). Unfortunately, larger than 7-membered rings could not be formed under otherwise identical reaction conditions (entry 4). 
Table 20. Enantioselective $\mathrm{C}-\mathrm{H}$ alkylation for larger rings. ${ }^{[\mathrm{a}]}$

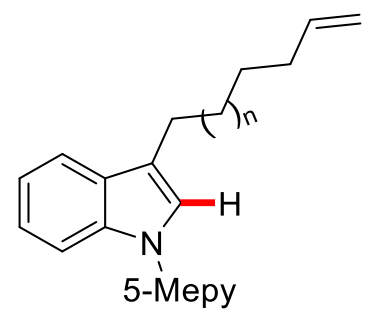

$\left[\mathrm{RuCl}_{2}(p \text {-cymene })\right]_{2}(5.0 \mathrm{~mol} \%)$ $\mathrm{AgSbF}_{6}(20 \mathrm{~mol} \%)$

CA14 (20 mol \%)

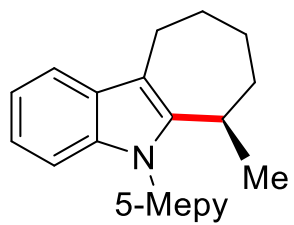

$368 / 370$

$369 / 371$

\begin{tabular}{ccccc}
\hline Entry & $\mathbf{n}$ & Variation of Standard Condition & Yield [\%] & e.r. $^{[\mathbf{b}]}$ \\
\hline 1 & 1 & none & 17 & $82: 18$ \\
2 & 1 & Amberlyst 15 as additive & 25 & $82: 18^{[\mathrm{c}]}$ \\
$\mathbf{3}$ & $\mathbf{1}$ & Amberlyst $\mathbf{1 5}$ as additive and $\mathbf{7 2} \mathbf{~ h}$ & $\mathbf{5 1}$ & $\mathbf{8 2 : 1 8 ^ { [ \mathbf { c } ] }}$ \\
4 & 2 & none & --- & --- \\
\hline
\end{tabular}

[a] General reaction conditions: 368/370 (0.10 mmol), [Ru] (10 mol \%), AgSbF6 (20 mol \%), CA14 (20 mol \%), PhMe (0.50 mL), RT, $20 \mathrm{~h}$, isolated yields. [b] Enantioselectivities determined by chiral HPLC. [c] Performed by Mr. R. Steinbock.

\subsubsection{Mechanistic Studies}

Given the unique selectivity shown by the chiral carboxylic acid CA14 for the intramolecular enantioselective $\mathrm{C}-\mathrm{H}$ alkylation in ruthenium(II)-catalysis, we were interested to unravel its mode of action. Therefore, detailed experimental and computational mechanistic studies were performed in order to gain insights into the reaction mechanism.

\subsubsection{H/D Exchange Experiment}

Initially, a H/D exchange experiment was conducted in toluene with isotopically-labeled $\mathrm{D}_{2} \mathrm{O}$ as the co-solvent to probe the $\mathrm{C}-\mathrm{H}$ activation step (Scheme 115). Significant H/D exchange was observed in the methyl-group in 363a and in the recovered starting material 362a. This observation can be rationalized by a facile and reversible $\mathrm{C}-\mathrm{H}$ ruthenation step. 


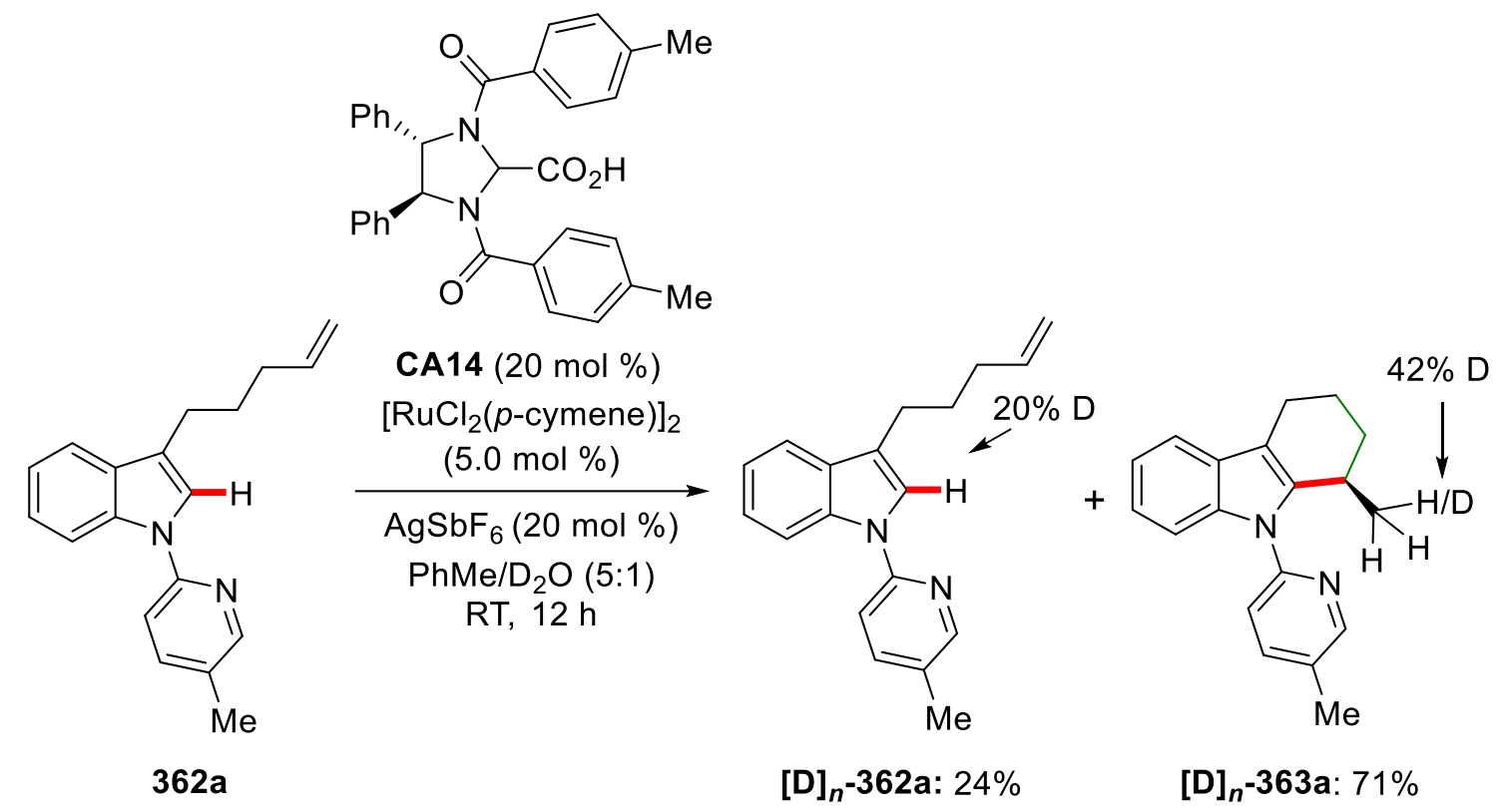

Scheme 115. H/D exchange experiment of the enantioselective $\mathrm{C}-\mathrm{H}$ alkylation.

\subsubsection{KIE Studies}

Furthermore, the intramolecular kinetic isotope effect (KIE) was determined for the substrate 362 and isotopically-labelled substrate $[\mathrm{D}]_{\mathrm{n}}-\mathbf{3 6 2 a}$, which showed a KIE of $k_{\mathrm{H}} / k_{\mathrm{D}} \approx 1.1$, which is in good agreement with the H/D exchange experiment, being suggestive of a fast and non rate-determining $\mathrm{C}-\mathrm{H}$ ruthenation (Scheme 116).

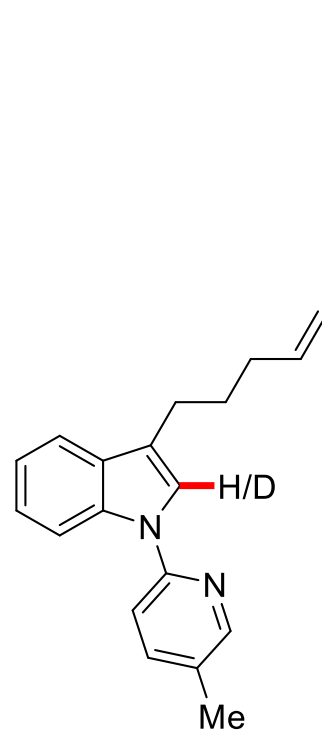

$362 \mathrm{a} /[\mathrm{D}]_{n}-362 \mathrm{a}$<smiles>Cc1ccc(C(=O)C2N(C(=O)c3ccccc3)[C@H](c3ccccc3)[C@@H](c3ccccc3)N2C(=O)c2ccc(C)cc2)cc1</smiles>

CA14 $(20 \mathrm{~mol} \%)$ $\left[\mathrm{RuCl}_{2}(p \text {-cymene })\right]_{2}$ $(5.0 \mathrm{~mol} \%)$

$\mathrm{AgSbF}_{6}(20 \mathrm{~mol} \%)$

PhMe, RT, $1.5 \mathrm{~h}$

$$
\mathrm{KIE}=1.1
$$

Scheme 116. KIE studies of the enantioselective $\mathrm{C}-\mathrm{H}$ alkylation. 


\subsubsection{Proposed Catalytic Cycle}

In addition to these experimental mechanistic studies, detailed DFT-studies were performed by Dr. J. C. A. Oliveira to gain mechanistic insights of enantioselective ruthenium(II)-catalyzed $\mathrm{C}-\mathrm{H}$ alkylation.

On the basis of our mechanistic studies, we propose a plausible catalytic cycle to commence with a fast $\mathrm{C}-\mathrm{H}$ activation step, as supported by the $\mathrm{H} / \mathrm{D}$ exchange experiments and the KIE study, to form the intermediate 373 (Scheme 117). Then, the generated ruthenacycle 373 undergoes a reversible alkene coordination to form $\mathbf{3 7 4}$, followed by a reversible migratory insertion into the ruthenium-carbon bond to form racemic intermediate 375 . In accordance with the computational studies, a process involving the turnover-limiting proto-demetalation step proceeds with chiral acid CA14, which acts as the proton source in the enantio-determining step. Finally, selective proto-demetalation occurs from the $(R)$-enantiomer of intermediate 375 with the chiral carboxylic acid CA14 to regenerate the catalytically active species $\mathbf{3 7 2}$ and releases the enantioenriched cyclized indole $\mathbf{3 6 3}$. 


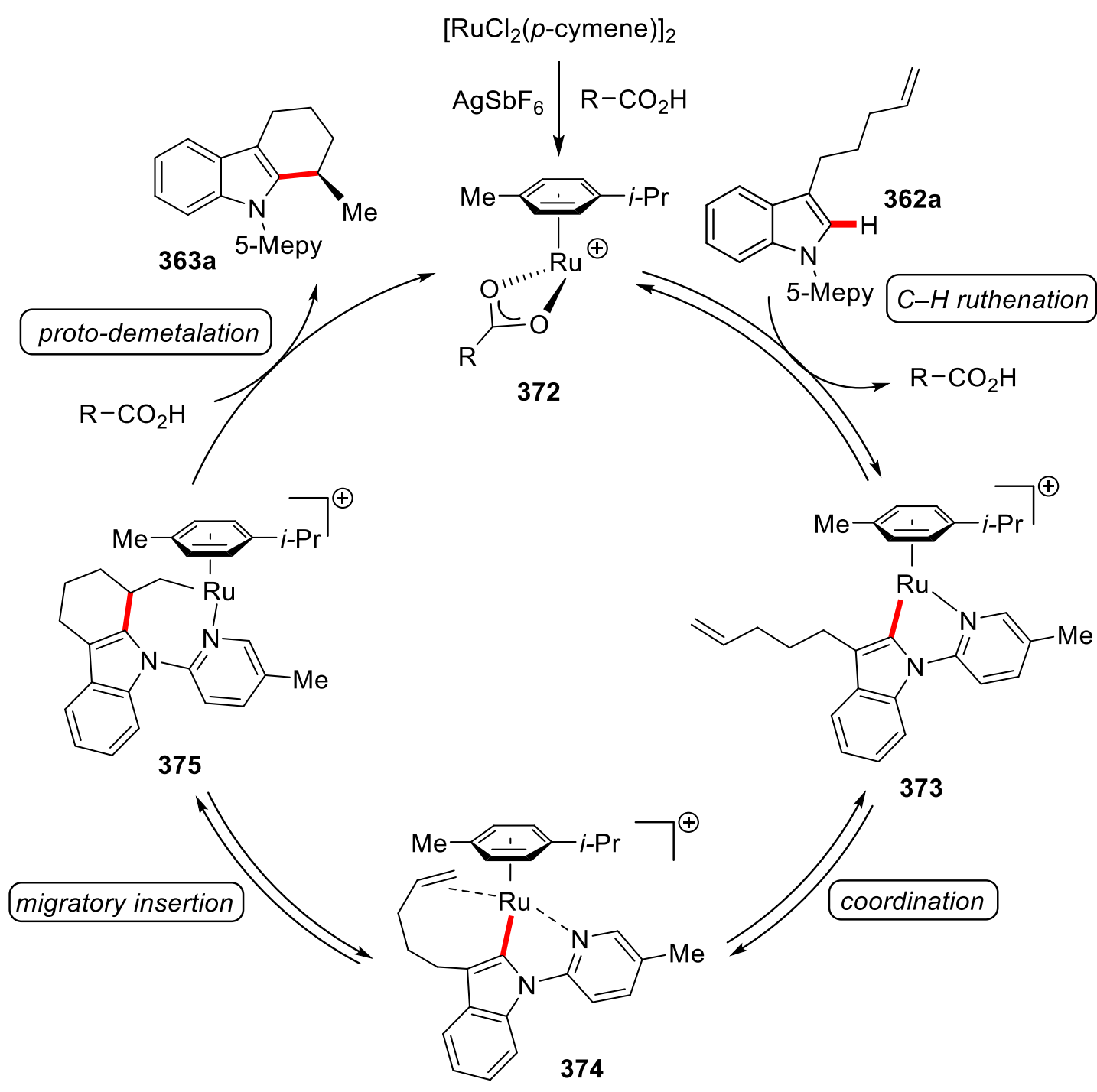

Scheme 117. Proposed catalytic cycle for enantioselective ruthenium(II)-catalyzed $\mathrm{C}-\mathrm{H}$ alkylation. 


\subsection{Copper-Catalyzed Alkyne Annulation by C-H Alkynylation}

In the last decade electro-organic synthesis has witnessed a considerable renaissance in order to achieve new reactivity towards improved resource economy. ${ }^{[224]}$ While early contributions on the synergistic merger of oxidative metal catalysis with electrosynthesis were limited to the use of expensive $4 \mathrm{~d}$ and $5 \mathrm{~d}$ transition metals, recent trends have shifted towards inexpensive $3 \mathrm{~d}$ transition metal catalysis. ${ }^{[232]}$ In this context, copper is one of the most abundant $3 \mathrm{~d}$ transition metals in the Earth's crust. ${ }^{[31]}$ Consequently, copper catalysts have emerged in the past few years as powerful tools for cost-effective $\mathrm{C}-\mathrm{H}$ activation reactions. Among others, copper catalysts have been widely used for $\mathrm{C}-\mathrm{H}$ arylations, aminations and alkyne annulation reactions ( $c f$. chapter 1.4.1.3). However, oxidative copper-catalyzed $\mathrm{C}-\mathrm{H}$ activations such as aminations or alkyne annulations had largely required toxic and expensive sacrificial oxidants, which jeopardize the atom-economy of the overall strategy. ${ }^{[31]}$

Surprisingly, electrochemical copper-catalyzed C-H activation was largely unexplored. Yet very recently, Mei reported copper-catalyzed electrochemical aminations with anilides through a proposed single electron transfer (SET) mechanism. ${ }^{[256]}$ Subsequently, similar electrooxidative aminations were independently reported by Nicholls ${ }^{[257]}$ using 8aminoquinoline as the directing group. However, electrochemical copper-catalyzed $\mathrm{C}-\mathrm{H}$ alkynylations $^{[209,272]}$ have thus far proven elusive. Thus, we became interested in the development of copper-catalyzed electro-oxidative alkyne annulation enabled by $\mathrm{C}-\mathrm{H}$ alkynylations of synthetically valuable benzamides to deliver bioactive five-membered isoindolones. It is noteworthy that isoindolones are core structural motifs of various pharmaceutical drugs and natural products with distinct biological activity. Hence, sustainable methods to synthesize highly functionalized isoindolones scaffolds are highly desirable (Figure 2). 


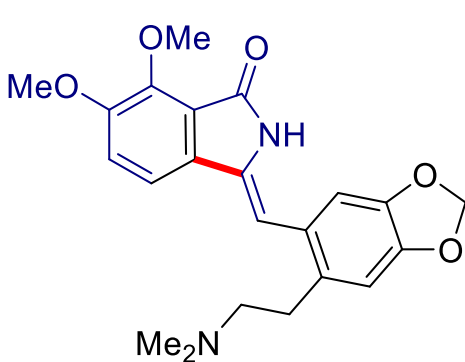

fumaridine

local anesthetic activity

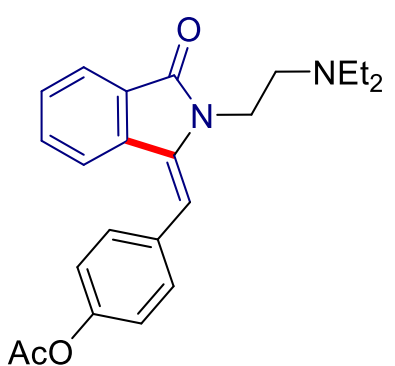

$\mathrm{AL}-12 \mathrm{~B}$

local anesthetic activity

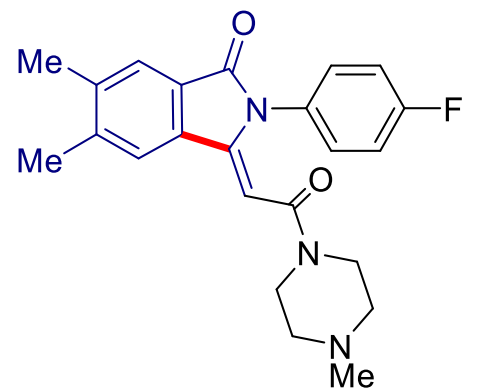

sedative activity

Figure 2. Examples of biologically important 3-methyleneisoindolin-1-ones derivatives.

\subsubsection{Optimization of the Copper-Catalyzed Electrochemical C-H Annulation}

Initial optimized reaction conditions for the envisioned copper-catalyzed electrochemical $\mathrm{C}-\mathrm{H}$ annulation were obtained by $D r$. C. Tian, in that benzamide 229a was reacted with phenyl acetylene 255a in an undivided cell set-up in the presence of $5.0 \mathrm{~mol} \%$ of $\mathrm{Cu}(\mathrm{OAc})_{2} \cdot \mathrm{H}_{2} \mathrm{O}$, one equiv of $\mathrm{NaOPiv}$ in DMA at $100{ }^{\circ} \mathrm{C}$ with a combination of graphite felt as anode and platinum as cathode. A constant current of $6.0 \mathrm{~mA}$ was applied to thereby provide the desired alkyne annulated product 256aa with 90\% yield $(Z / E=13: 1)$ (Scheme 118).<smiles>CNC(=O)c1ccccc1</smiles>

$229 a$

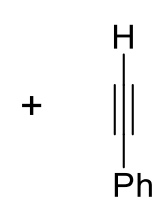

$255 a$

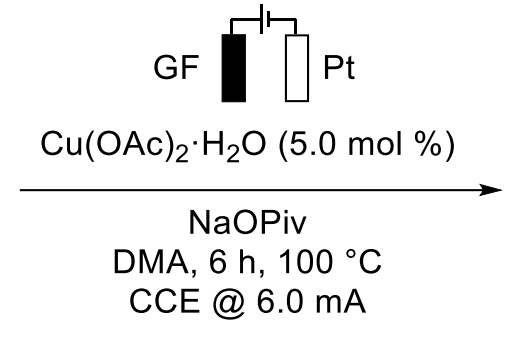

CCE @ $6.0 \mathrm{~mA}$<smiles>O=C1c2ccccc2/C(=C/c2ccccc2)N1O</smiles>

256aa: $90 \%(Z / E=13: 1)$

Scheme 118. Copper-catalyzed electrochemical C-H annulation.

\subsubsection{Substrate Scope and Limitations of the Electrochemical Copper-Catalyzed Alkyne}

\section{Annulation}

With the optimized reaction conditions in hand, we tested the versatility of differently substituted benzamides $\mathbf{2 2 9}$ for the electrochemical copper-catalyzed $\mathrm{C}-\mathrm{H}$ cascade annulation to test the generality and limitations of this reaction (Table 21). To our delight, sterically crowded ortho-substituted benzamides 229b and 229c efficiently provided the desired annulated products $\mathbf{2 5 6 b a}$ and $\mathbf{2 5 6} \mathbf{c a}$ in good yields, while for bulky ortho-phenyl-substituted benzamide 229c, an increased catalyst loading was required to improve the catalytic efficiency (entries 2-3). Even para-nitro substituted benzamide 229d was well tolerated by our robust catalysis (entry 4). Unfortunately, electron-rich 2-methoxybenzamide 229e failed to show any 
reactivity (entry 5). In addition, 2-phenyl- $N$-(quinolin-8-yl)acrylamide 376a and cyclohexene benzamide 378a remained untouched (entries 6-7).

Table 21. Cupraelectro-catalyzed C-H annulation with benzamides 229. ${ }^{\text {[a] }}$

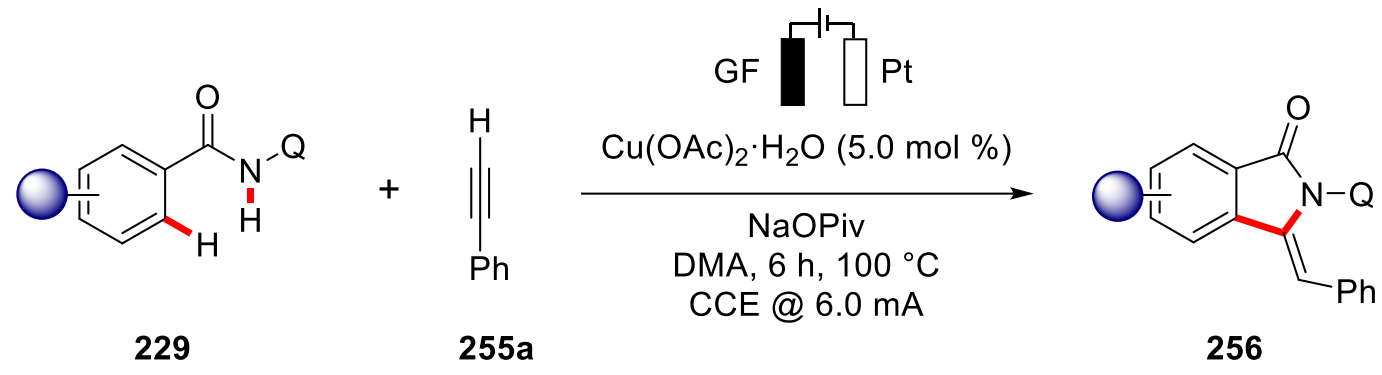

Entry


6<smiles>O=C(NO)/C(=C\c1ccccc1)c1ccccc1</smiles>

$376 a$

7<smiles>O=C(NO)C1=CCCCC1</smiles>

$378 a$<smiles>O=C1C(c2ccccc2)=C/C(=C/c2ccccc2)N1Cl</smiles>

377 aa<smiles>O=C1C2=C(CCCC2)C(=Cc2ccccc2)N1O</smiles>

379aa

[a] Reaction conditions: 229 (0.25 mmol), 255a (0.50 mmol), $\mathrm{Cu}(\mathrm{OAc})_{2} \cdot \mathrm{H}_{2} \mathrm{O}(5.0 \mathrm{~mol} \%)$, NaOPiv (1.0 equiv), DMA (4.0 mL), $100^{\circ} \mathrm{C}$, constant current at $6.0 \mathrm{~mA}, 6 \mathrm{~h}, \mathrm{GF}$ anode $(10 \mathrm{~mm}$ $\times 15 \mathrm{~mm} \times 6 \mathrm{~mm})$, Pt-plate cathode $(10 \mathrm{~mm} \times 15 \mathrm{~mm} \times 0.25 \mathrm{~mm})$, undivided cell, isolated yields. [b] $\mathrm{Cu}(\mathrm{OAc})_{2} \cdot \mathrm{H}_{2} \mathrm{O}(10 \mathrm{~mol} \%)$.

Likewise, a broad range of ortho-, meta- and para- substituted terminal alkynes $\mathbf{2 5 5}$ was tested under our optimized electrochemical reaction conditions to demonstrate the robustness of our catalyst (Table 22). In general, electron-rich 4-ethynyltoluene 255b, 4-ethynylanisole 255c and 2-ethynylanisole 255d were smoothly converted with good yields to the corresponding products 256ab-256ad (entries 1-3). Moreover, meta-chlorophenylacetylene 255e was also found as an amenable substrate, while electron-poor 4-ethynyltrifluoroluene $255 \mathbf{f}$ showed slightly lower reactivity (entries 4-5). To our satisfaction, a series of para-substituted halo groups was well tolerated, which should prove invaluable for late-stage diversification (entries 6-7). In addition, ester $\mathbf{2 5 5 i}$ and cyano-containing alkyne $\mathbf{2 5 5} \mathbf{j}$ were also chemo-selectively converted to deliver the desired isoindolinones 256ai and 256aj in good yields (entries 8-9). Electron-rich heterocycle thiophene acetylene $\mathbf{2 5 5 k}$ was also found to be amenable substrate in the cupraelectro-catalyzed annulation manifold, albeit higher catalyst loading was employed to improve the conversion (entry 10). A significant drop in reactivity was observed for the aliphatic alkyne $\mathbf{2 5 5 1}$ (entry 11), whereas the robustness of the copper-catalyzed annulation allowed excellent efficacy with alkyne bearing Boc-protected amino acid 255m (entry 12). As a limitation of the substrate scope, 4-ethynylpyridine 255n and ethynylcyclohexane 2550 remained unreacted under the optimized reaction conditions, as the remaining starting materials were recovered in almost quantitative yields (entries 13-14). 
Table 22. Cupraelectro-catalyzed C-H annulation with terminal alkynes 255. ${ }^{[\mathrm{a}]}$
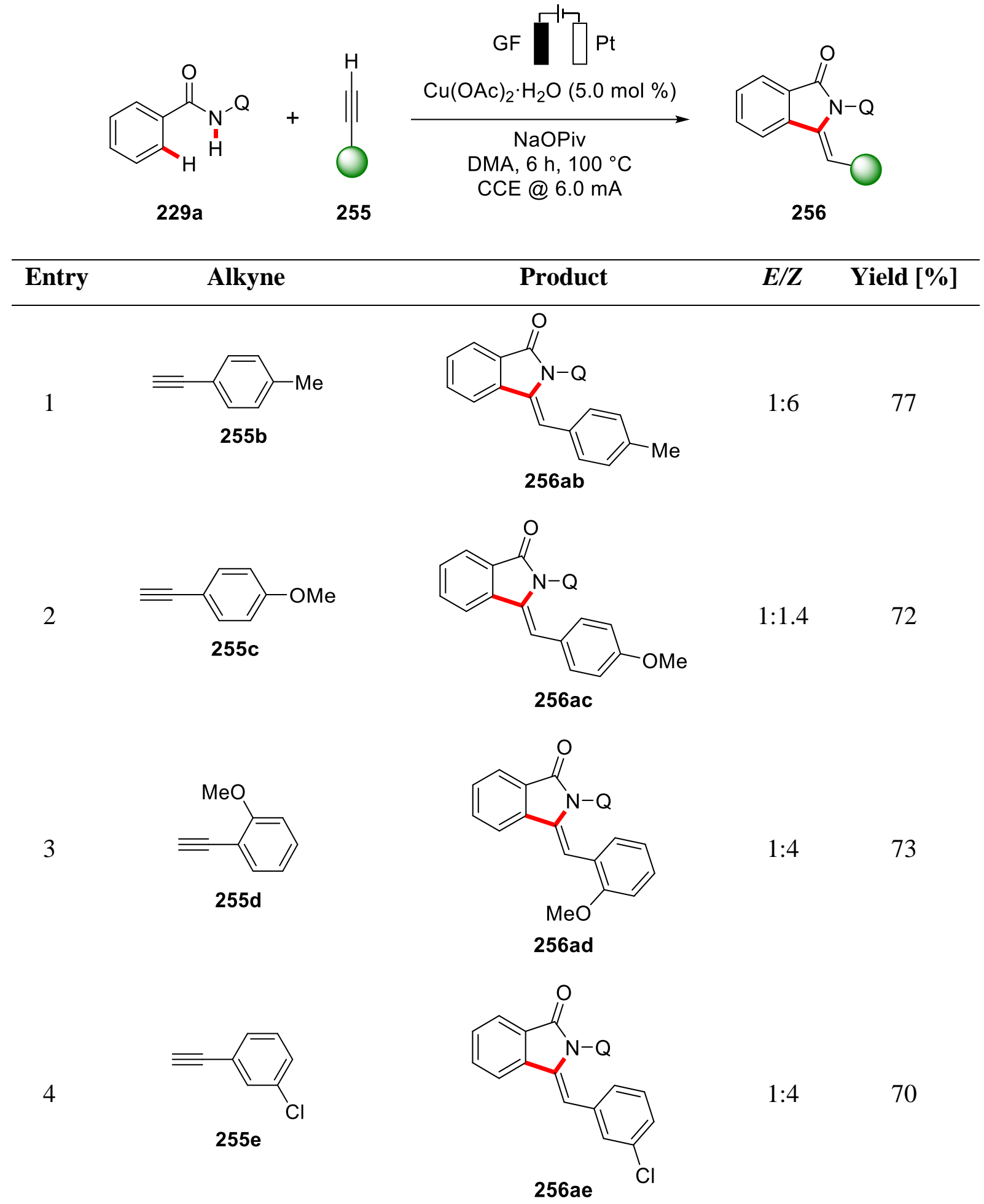
5<smiles>C#Cc1ccc(C(F)(F)F)cc1</smiles>

6<smiles>C#Cc1ccc(F)cc1</smiles>

7<smiles>C#Cc1ccc(Br)cc1</smiles>

8<smiles>C#Cc1ccc(C(=O)OCc2ccccc2)cc1</smiles>

9<smiles>C#Cc1ccc(C#N)cc1</smiles>

10

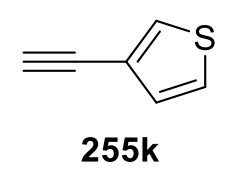<smiles>O=C1c2ccccc2/C(=C/c2ccc(C(F)(F)F)cc2)N1O</smiles>

256af<smiles>O=C1c2ccccc2/C(=C/c2ccc(F)cc2)N1O</smiles>

256ag<smiles>O=C1c2ccccc2/C(=C/c2ccc(Br)cc2)N1O</smiles>

256ah<smiles>CC(=O)c1ccc(/C=C2\c3ccccc3C(=O)N2O)cc1</smiles>

256ai<smiles>N#Cc1ccc(/C=C2\c3ccccc3C(=O)N2O)cc1</smiles>

256aj<smiles>O=C1c2ccccc2/C(=C/c2ccsc2)N1O</smiles>

256ak 
11

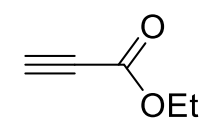

255I

12<smiles>C#Cc1cccc(NC(=O)C(Cc2ccccc2)NC(C)(C)C)c1</smiles>

$255 \mathrm{~m}$

13

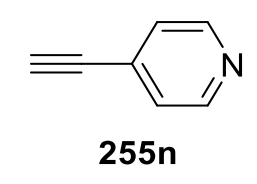

14

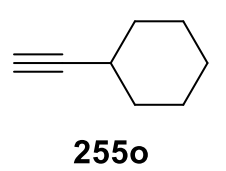<smiles>CCOC(=O)/C=C1\c2ccccc2C(=O)N1O</smiles>

256al

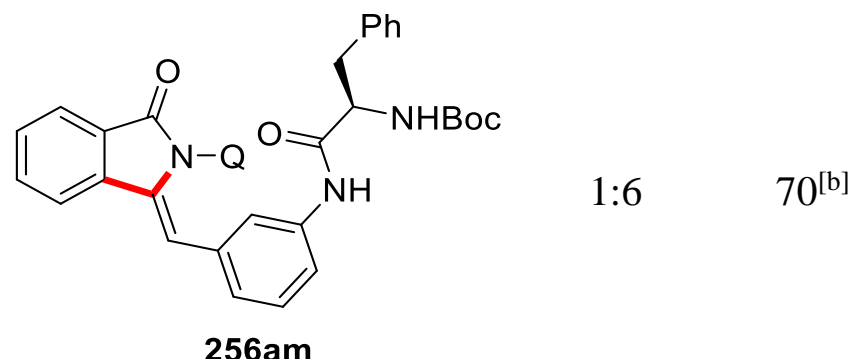

$1: 5$

$42^{[c]}$<smiles>O=C1c2ccccc2/C(=C/c2ccncc2)N1O</smiles>

256an

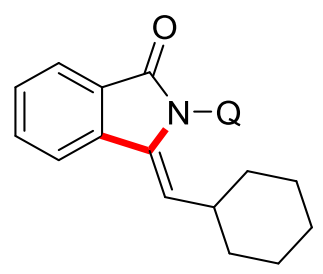

256ao

[a] Reaction conditions: 229a (0.25 mmol), $255(0.50 \mathrm{mmol}), \mathrm{Cu}(\mathrm{OAc})_{2} \mathrm{H}_{2} \mathrm{O}(5.0 \mathrm{~mol} \%)$, $\mathrm{NaOPiv}\left(1.0\right.$ equiv), DMA $(4.0 \mathrm{~mL}), 100^{\circ} \mathrm{C}$, constant current at $6.0 \mathrm{~mA}, 6 \mathrm{~h}, \mathrm{GF}$ anode $(10 \mathrm{~mm}$ $\times 15 \mathrm{~mm} \times 6 \mathrm{~mm})$, Pt-plate cathode $(10 \mathrm{~mm} \times 15 \mathrm{~mm} \times 0.25 \mathrm{~mm})$, undivided cell, isolated yields. [b] $\mathrm{Cu}(\mathrm{OAc})_{2} \cdot \mathrm{H}_{2} \mathrm{O}(10 \mathrm{~mol} \%)$. [c] $\mathrm{Cu}(\mathrm{OAc})_{2} \cdot \mathrm{H}_{2} \mathrm{O}(20 \mathrm{~mol} \%)$.

\subsubsection{Proposed Catalytic cycle for Copper-Catalyzed Electrochemical C-H Annulation}

Based on the mechanistic studies from $\mathrm{Dr}$. C. Tian and cyclic voltammetry analysis from $\mathrm{Mr}$. A. Scheremetjew, we have proposed a plausible catalytic cycle for the copper-catalyzed electrochemical C-H annulation (Scheme 119). First, the catalytic cycle initiates with the benzamide co-ordination to form copper(II) intermediate $\mathbf{3 8 1}$, which readily undergoes anodic oxidation to form catalytically competent copper(III) carboxylate species 382. Second, the catalytically competent species $\mathbf{3 8 2}$ undergoes facile carboxylate assisted $\mathrm{C}-\mathrm{H}$ activation to form 383. Third, ligand exchange with alkyne 255 forms species 384 and subsequent reductive 
elimination affords the alkenylated arene $\mathbf{3 8 6}$, which undergoes facile base-assisted cyclization to form the annulated product $\mathbf{2 5 6}$.

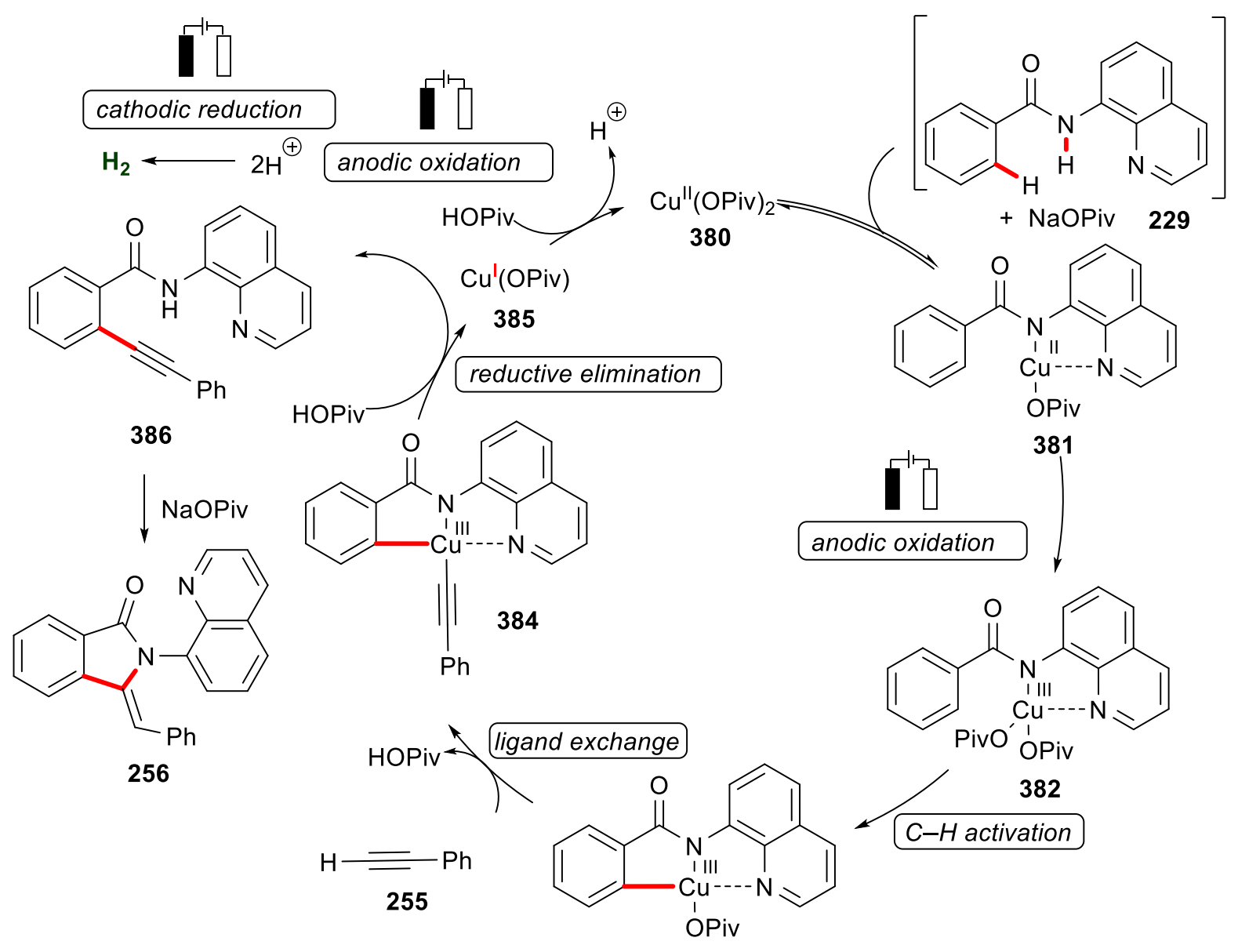

383

Scheme 119. Proposed catalytic cycle for cupraelectro-catalyzed alkyne annulation. 


\subsection{Electrochemical Cobalt-catalyzed C-H Allylation}

In recent years significant momentum was gained by the merger of transition metal-catalyzed oxidative $\mathrm{C}-\mathrm{H}$ activation with electrochemistry, enabling the use of electrons as sustainable redox equivalents. ${ }^{[232]}$ Since the pioneering report on cobalt-catalyzed oxidative $\mathrm{C}-\mathrm{H}$ oxygenation by the Ackermann group in $2017,{ }^{[246]}$ electrochemical cobalt catalyzed $\mathrm{C}-\mathrm{H}$ activation has been well studied by Ackermann and others. ${ }^{[32 \mathrm{a}, 245]}$ Moreover, electrochemical palladium- ${ }^{[233]}$ rhodium-, ${ }^{[242 e, 242 f]}$ iridium- ${ }^{[243 b]}$ and ruthenium- ${ }^{[244 \mathrm{~h}]}$ catalyzed organometallic $\mathrm{C}-\mathrm{H}$ activations are mainly restricted to activated alkenes, such as styrenes and acrylates. In sharp contrast, electrochemical $\mathrm{C}-\mathrm{H}$ activation with unactivated aliphatic alkenes is unexplored. Thus, Lei developed cobalt-catalyzed electrochemical $\mathrm{C}-\mathrm{H} / \mathrm{N}-\mathrm{H}$ annulations with simple ethylene, delivering solely the cyclized product. ${ }^{[251]}$ Considering that the control of chemo-selectivity is an important endeavor in organic synthesis, we became interested to study cobalt-catalyzed electrochemical $\mathrm{C}-\mathrm{H}$ activation with unactivated alkenes.

Direct $\mathrm{C}-\mathrm{H}$ allylations have really become an important method in terms of step-economy, and, consequently, there has been a significant development in ortho-C-H allylations. Over the past years, the synthetic community has witnessed a significant advancement in transition metal-catalyzed $\mathrm{C}-\mathrm{H}$ allylations primarily with prefunctionalized coupling partners, such as allyl halides or acetates. ${ }^{[273]}$ While very recently unactivated allylic coupling partners have been employed for oxidative $\mathrm{C}-\mathrm{H}$ allylation reactions, this approach largely required superstoichiometric amounts of chemical oxidants, which jeopardized its synthetic utility. ${ }^{[191-}$ ${ }^{193]}$ In this context, it is noteworthy that electrocatalyzed C-H allylations are as of yet unknown. Thus we were interested to develop cobaltaelectro-catalyzed $\mathrm{C}-\mathrm{H}$ allylations of synthetically meaningful benzamides and challenging unactivated alkenes.

\subsubsection{Optimization of the Electrochemical Cobalt(II)-Catalyzed C-H Allylation}

We initiated our optimization for the envisioned cobalt(II)-catalyzed $\mathrm{C}-\mathrm{H}$ allylation with ortho-substituted benzamide 229 f as the model substrate (Table 23). We performed our initial test reaction with benzamide 229 f and unactivated alkene 2230 in a user-friendly undivided cell set-up under a constant current electrolysis. We were pleased to exclusively observe allylated product $242 \mathrm{fo}$ with a catalytic amounts of inexpensive $\mathrm{Co}(\mathrm{OAc})_{2} \cdot 4 \mathrm{H}_{2} \mathrm{O}$ in the presence of NaOAc as the additive (entry 1). Next, we tested various carboxylate and carbonate additives, among which, NaOPiv was ideal, providing the desired allylated product $\mathbf{2 4 2 f o}$ in 
$60 \%$ yield (entries 1-5). Then, a series of representative solvents was tested (entries 5-10). To our delight, biomass-derived renewable $\gamma$-valerolactone (GVL) provided the optimal results (entry 5). ${ }^{[6,248]}$ Among other typical solvents, DCE gave comparable reactivity (entry 6), while other solvents showed either low conversion or no reaction at all (entries 7-10). It is noteworthy that a deep eutectic solvent system of choline chloride and urea was able to furnish the desired product 242fo, albeit in lower yield (entry 11). Furthermore, different reaction temperatures were tested, which revealed the optimal reactivity at $100{ }^{\circ} \mathrm{C}$, while higher or lower reaction temperatures reduced the yields (entries 12-13). Control experiments highlighted the necessity of the cobalt(II)-catalyst and the electricity (entries 14-15). It is noteworthy that orthounsubstituted benzamides afforded the corresponding products in lower yields with a mixture of styrenyl and allylic isomers. This revealed the necessity for the ortho-substitution to provide exclusively the $\beta$-H elimination product from the allylic proton in a unique manner via a conformationally-strained 7-membered metallacycle.

Table 23. Optimization studies for electrochemical cobalt(II)-catalyzed C-H allylation. ${ }^{\text {[a] }}$

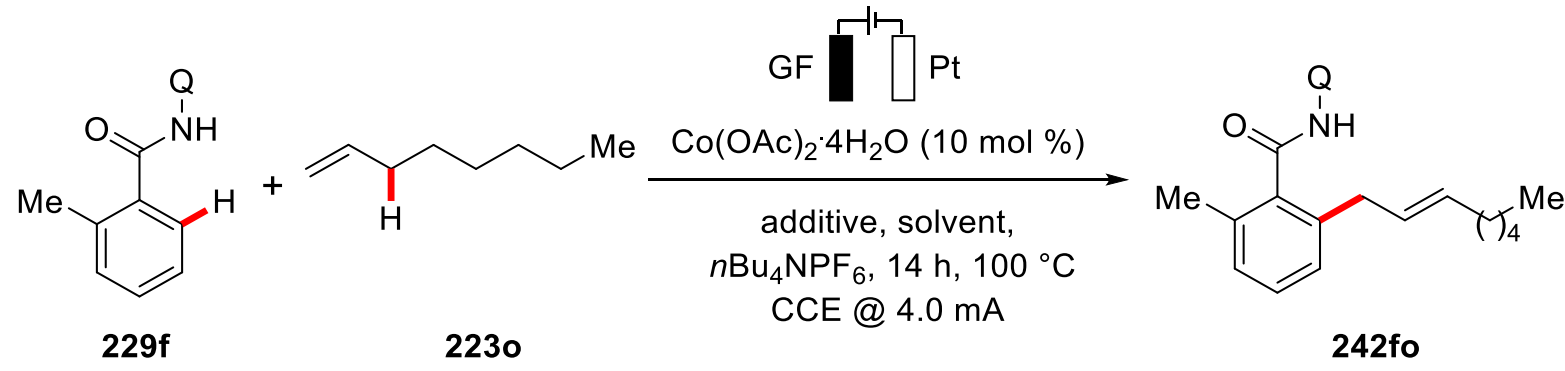

\begin{tabular}{cccc}
\hline Entry & Additive & Solvent & Yield [\%] \\
\hline 1 & $\mathrm{NaOAc}$ & $\mathrm{GVL}$ & 12 \\
2 & $\mathrm{KOAc}$ & $\mathrm{GVL}$ & 8 \\
3 & $\mathrm{Na}_{2} \mathrm{CO}_{3}$ & $\mathrm{GVL}$ & 19 \\
4 & $\mathrm{PivOH}$ & $\mathrm{GVL}$ & 49 \\
$\mathbf{5}$ & $\mathrm{NaOPiv}$ & GVL & $\mathbf{6 0}$ \\
6 & $\mathrm{NaOPiv}$ & $\mathrm{DCE}$ & 58 \\
$\mathbf{7}$ & $\mathrm{NaOPiv}$ & $\mathrm{TFE}$ & 28 \\
8 & $\mathrm{NaOPiv}$ & $\mathrm{MeCN}$ & 27
\end{tabular}




\begin{tabular}{|c|c|c|c|}
\hline 9 & $\mathrm{NaOPiv}$ & $\mathrm{MeOH} / \mathrm{H}_{2} \mathrm{O}$ & --- \\
\hline 10 & $\mathrm{NaOPiv}$ & $t \mathrm{BuOH} / \mathrm{H}_{2} \mathrm{O}$ & --- \\
\hline 11 & $\mathrm{NaOPiv}$ & Choline chloride/Urea (1:2) & $25^{[\mathrm{b}]}$ \\
\hline 12 & $\mathrm{NaOPiv}$ & GVL & $52^{[\mathrm{c}]}$ \\
\hline 13 & NaOPiv & GVL & $42^{[\mathrm{d}]}$ \\
\hline 14 & $\mathrm{NaOPiv}$ & GVL & --_[e] \\
\hline 15 & $\mathrm{NaOPiv}$ & GVL & $5^{[\mathrm{f}]}$ \\
\hline
\end{tabular}

[a] General reaction conditions: $229 f(0.50 \mathrm{mmol}), \mathbf{2 2 3 0}(1.50 \mathrm{mmol}), \mathrm{Co}(\mathrm{OAc})_{2} \cdot 4 \mathrm{H}_{2} \mathrm{O}(10 \mathrm{~mol}$ $\%$ ), additive (1.0 equiv), solvent $(4.0 \mathrm{~mL}), n \mathrm{Bu}_{4} \mathrm{NPF}_{6}\left(0.50\right.$ equiv), $100{ }^{\circ} \mathrm{C}$, constant current at $4.0 \mathrm{~mA}, 14 \mathrm{~h}$, GF anode $(10 \mathrm{~mm} \times 15 \mathrm{~mm} \times 6 \mathrm{~mm})$, Pt-plate cathode $(10 \mathrm{~mm} \times 15 \mathrm{~mm} \times$ $0.25 \mathrm{~mm}$ ), undivided cell, isolated yields. [b] In absence of $n \mathrm{Bu}_{4} \mathrm{NPF}_{6}$. [c] $120{ }^{\circ} \mathrm{C}$. [d] $80{ }^{\circ} \mathrm{C}$. [e] In absence of cobalt source. [f] No electricity.

\subsubsection{Substrate Scope and Limitations of the Electrochemical Cobalt-Catalyzed $\mathbf{C}-\mathbf{H}$} Allylation

After establishing the optimized reaction conditions, we next tested various $\mathrm{N}$-amide substituents in the cobaltaelectro-catalyzed $\mathrm{C}-\mathrm{H}$ allylation (Table 24). Pyridine- $N$-oxide 231a which worked very efficiently for electrochemical cobalt-catalyzed $\mathrm{C}-\mathrm{H}$ oxygenation, ${ }^{[246]}$ failed to deliver the allylated product 387a (entry 1). In addition, the recently used sulfonamide 388a for cobalt-catalyzed electrochemical alkyne annulation, ${ }^{[274]}$ proved to be inefficient for the desired $\mathrm{C}-\mathrm{H}$ allylation reaction (entry 2).

Table 24. Effect of the orienting group on the electrochemical $\mathrm{C}-\mathrm{H}$ allylation. ${ }^{[\mathrm{a}]}$

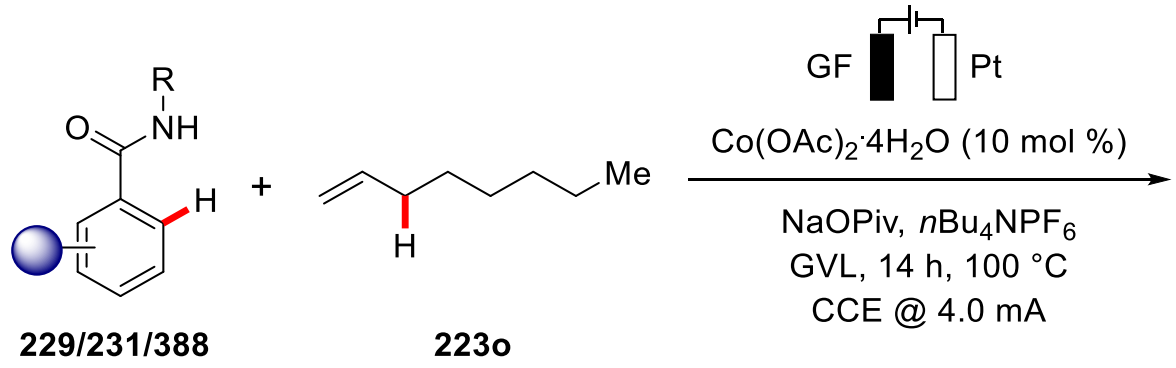<smiles>[R]NC(=O)c1ccccc1C/C=C/C(C)C</smiles>

$242 / 387 / 389$

\begin{tabular}{llll}
\hline Entry & Benzamide & Product & Yield [\%] \\
\hline
\end{tabular}


1<smiles></smiles>

2<smiles>Cc1cccc(S(=O)(=O)NO)c1</smiles>

$388 a$

3<smiles>CC(C)=CCc1cc(C(C)(C)C)cc(C)c1C(=O)Nc1cccc[n+]1[O-]</smiles><smiles>Cc1ccc(C/C=C/C(C)C)c(S(=O)(=O)NO)c1C</smiles>

$389 a$<smiles>CC(C)=CCc1cccc(C)c1C(=O)NO</smiles>

242 fo

[a] Reaction conditions: Benzamide $(0.50 \mathrm{mmol}), 2230(1.50 \mathrm{mmol}), \mathrm{Co}(\mathrm{OAc})_{2} \cdot 4 \mathrm{H}_{2} \mathrm{O}(10 \mathrm{~mol}$ $\%), \mathrm{NaOPiv}^{2}\left(2.0\right.$ equiv), $n \mathrm{Bu}_{4} \mathrm{NPF}_{6}\left(0.50\right.$ equiv), $\mathrm{GVL}(4.0 \mathrm{~mL}), 100{ }^{\circ} \mathrm{C}$, constant current at $4.0 \mathrm{~mA}, 14 \mathrm{~h}$, GF anode $(10 \mathrm{~mm} \times 15 \mathrm{~mm} \times 6 \mathrm{~mm})$, Pt-plate cathode $(10 \mathrm{~mm} \times 15 \mathrm{~mm} \times$ $0.25 \mathrm{~mm}$ ), undivided cell, isolated yields. [b] Performed by W. $\mathrm{Li}$.

With the optimized reaction conditions in hand, we next decided to assess the generality of the electrochemical cobalt-catalyzed $\mathrm{C}-\mathrm{H}$ allylation (Table 25). The mild reaction conditions in undivided cell set-up proved viable for sterically-hindered benzamides and various functional groups. Initially, the robustness of the ortho-substituted benzamides 229 was explored with challenging $n$-octene, and independent of the steric influence, the desired products $\mathbf{2 4 2}$ were formed with excellent allylic selectivity. To our delight, and in contrast to previous work on cobaltaelectro-catalyzed $\mathrm{C}-\mathrm{H}$ oxygenations, ${ }^{[246]}$ which was severely limited to orthosubstituted benzamides, in this present study larger substituents including methoxy, trifluoromethyl and phenyl provided the corresponding products with excellent levels of allylic selectivity (entries 2-4). Fortunately, electron-rich and electron-deficient arenes were smoothly converted with high chemo-selectivity. Even sterically-bulky substituents at the 5-position of the benzamides 229i and 229j did not affect the selectivity, and only a slight decrease in yields 
was observed (entries 6-7). In addition, halo-groups were tolerated, delivering the corresponding product $\mathbf{2 4 2 j o}$ which should prove invaluable for further late-stage diversifications, highlighting the potential of the cobaltaelectro-catalyzed $\mathrm{C}-\mathrm{H}$ allylation approach.

Table 25. Cobaltaelectro-catalyzed $\mathrm{C}-\mathrm{H}$ allylation with benzamides 229. ${ }^{[a]}$<smiles>O=C(NO)c1ccccc1</smiles>

229

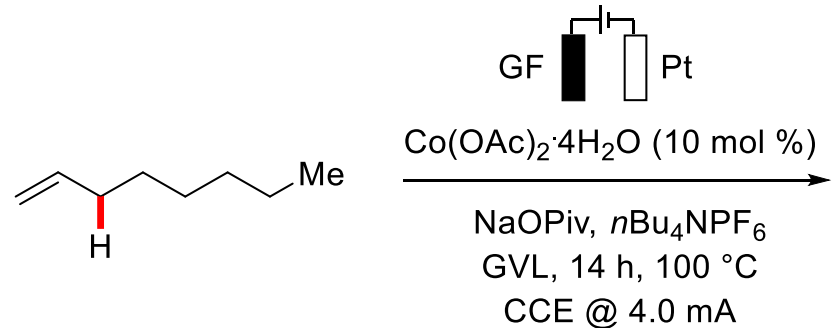

2230<smiles>CC(C)=CCc1ccccc1C(=O)NO</smiles>

242

Entry


5<smiles>Cc1cccc(C(=O)NO)c1C(=O)O</smiles>

6<smiles>Cc1ccc(C)c(C(=O)NO)c1</smiles>

229i

7<smiles>Cc1ccc(F)cc1C(=O)NO</smiles>

229j<smiles>Cc1ccc(CC=CC(C)C)c(C(=O)NO)c1C</smiles>

242ho<smiles>Cc1ccc(C)c(C(=O)NO)c1CC=CC(C)C</smiles>

242io<smiles>CC(=O)/C=C/Cc1c(F)ccc(C)c1C(=O)NO</smiles>

242jo

[a] Reaction conditions: $229(0.50 \mathrm{mmol}), 223 \mathrm{o}(1.50 \mathrm{mmol}), \mathrm{Co}(\mathrm{OAc})_{2} \cdot 4 \mathrm{H}_{2} \mathrm{O}(10 \mathrm{~mol} \%)$, $\mathrm{NaOPiv}$ (2.0 equiv), $n \mathrm{Bu}_{4} \mathrm{NPF}_{6}\left(0.50\right.$ equiv), GVL $(4.0 \mathrm{~mL}), 100{ }^{\circ} \mathrm{C}$, constant current at $4.0 \mathrm{~mA}, 14 \mathrm{~h}$, GF anode $(10 \mathrm{~mm} \times 15 \mathrm{~mm} \times 6 \mathrm{~mm})$, Pt-plate cathode $(10 \mathrm{~mm} \times 15 \mathrm{~mm} \times$ $0.25 \mathrm{~mm})$, undivided cell, isolated yields. [b] $\mathrm{Co}(\mathrm{OAc})_{2} \cdot 4 \mathrm{H}_{2} \mathrm{O}(20 \mathrm{~mol} \%)$. [c] Performed by Dr. C. Tian.

Next, we evaluated the viable substrate scope for unactivated alkenes $\mathbf{2 2 3}$ to demonstrate the synthetic utility of our transformation (Table 26). Interestingly, a variation in the extended alkyl chain length did not influence the efficacy of the electrocatalytic transformation. Under the optimized reaction conditions, both 1-decene 223q and 1-nonene 223r delivered the desired products $\mathbf{2 4 2 f q}$ and $\mathbf{2 4 2 f r}$, respectively, in good yields (entries 1-2). Likewise, allyl benzene 223a was exclusively transformed into the desired allylated product $\mathbf{2 4 2 f a}$ (entry 3). Gratifyingly, the cobaltaelectro-catalyzed $\mathrm{C}-\mathrm{H}$ allylation proved applicable to the chemoselective mono-functionalization of diene $223 \mathrm{~s}$ to deliver allylated benzamide product 242fs, demonstrating the unique selectivity features of this transformation without isomerization of the additional double bond (entry 4). Notably, various sensitive functional groups were fully tolerated by the versatile cobalt catalysis. Acetate-containing substrates $\mathbf{2 2 3 j}$ and $\mathbf{2 2 3 t}$ were efficiently converted to provide the corresponding allylated benzamides $\mathbf{2 4 2 f j}$ and 242ft in good yields (entries 5-6). It is noteworthy that chloro and epoxy groups were fully 
tolerated, albeit a higher catalyst loading was employed here (entries 7-8). More delightfully, challenging the free hydroxyl group $\mathbf{2 2 3 x}$ on the alkene was also well accepted (entry 9).

Table 26. Cobaltaelectro-catalyzed C-H allylation with unactivated alkenes 223 . ${ }^{\text {[a] }}$<smiles>Cc1ccccc1C(=O)NO</smiles>

$229 f$<smiles>C=CCc1ccccc1</smiles>

223

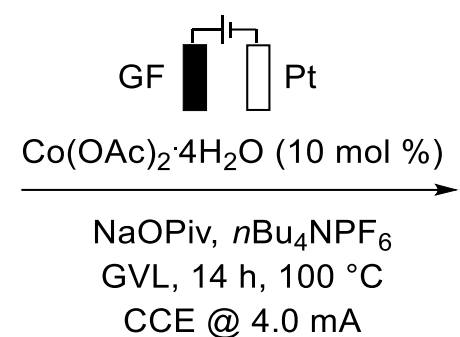

CCE @ $4.0 \mathrm{~mA}$

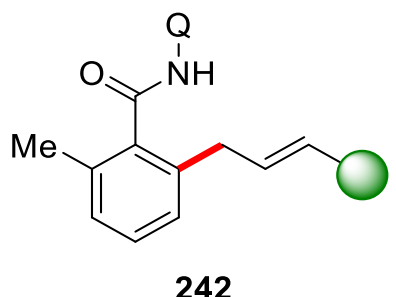

242

Entry


5<smiles>C=CCc1ccc(OC(C)=O)c(OC)c1</smiles>

223j<smiles>C=CCCCCOC(C)=O</smiles>

223t<smiles>C=CCCCCCl</smiles>

223u
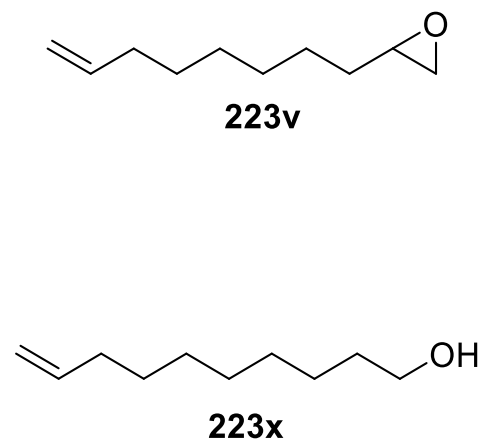<smiles>COc1cc(/C=C/Cc2cccc(C)c2C(=O)NO)ccc1OC(C)=O</smiles>

242fj 57 52

$63^{[b]}$<smiles>Cc1cccc(CC=C[Al]Cl)c1C(=O)NO</smiles>

242fu

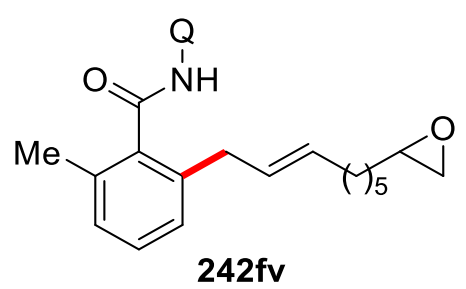<smiles>Cc1cccc(C/C=C/C(=O)O)c1C(=O)NO</smiles>

\section{2fx}

[a] Reaction conditions: $229 \mathrm{f}(0.50 \mathrm{mmol}), 223(1.50 \mathrm{mmol}), \mathrm{Co}(\mathrm{OAc})_{2} \cdot 4 \mathrm{H}_{2} \mathrm{O}(10 \mathrm{~mol} \%)$, $\mathrm{NaOPiv}$ (2.0 equiv), $n \mathrm{Bu}_{4} \mathrm{NPF}_{6}\left(0.50\right.$ equiv), GVL $(4.0 \mathrm{~mL}), 100{ }^{\circ} \mathrm{C}$, constant current at $4.0 \mathrm{~mA}, 14 \mathrm{~h}$, GF anode $(10 \mathrm{~mm} \times 15 \mathrm{~mm} \times 6 \mathrm{~mm})$, Pt-plate cathode $(10 \mathrm{~mm} \times 15 \mathrm{~mm} \times$ $0.25 \mathrm{~mm})$, undivided cell, isolated yields. [b] $\mathrm{Co}(\mathrm{OAc})_{2} \cdot 4 \mathrm{H}_{2} \mathrm{O}(20 \mathrm{~mol} \%)$.

\subsubsection{Mechanistic Studies}

After establishing the versatility of the first electrocatalytic $\mathrm{C}-\mathrm{H}$ allylation, we were intrigued to delineate the catalyst's mode of action. 


\subsubsection{Competition Experiments}

To this end, we carried out an intermolecular competition experiment with electronically distinct benzamides 229f and 229g, which clearly showed a preference for the electron-rich arene $\mathbf{2 4 2 f o}$ to react inherently faster than the electron-poor analogue $\mathbf{2 4 2 g o}$ (Scheme 120). This supports a BIES mechanism.

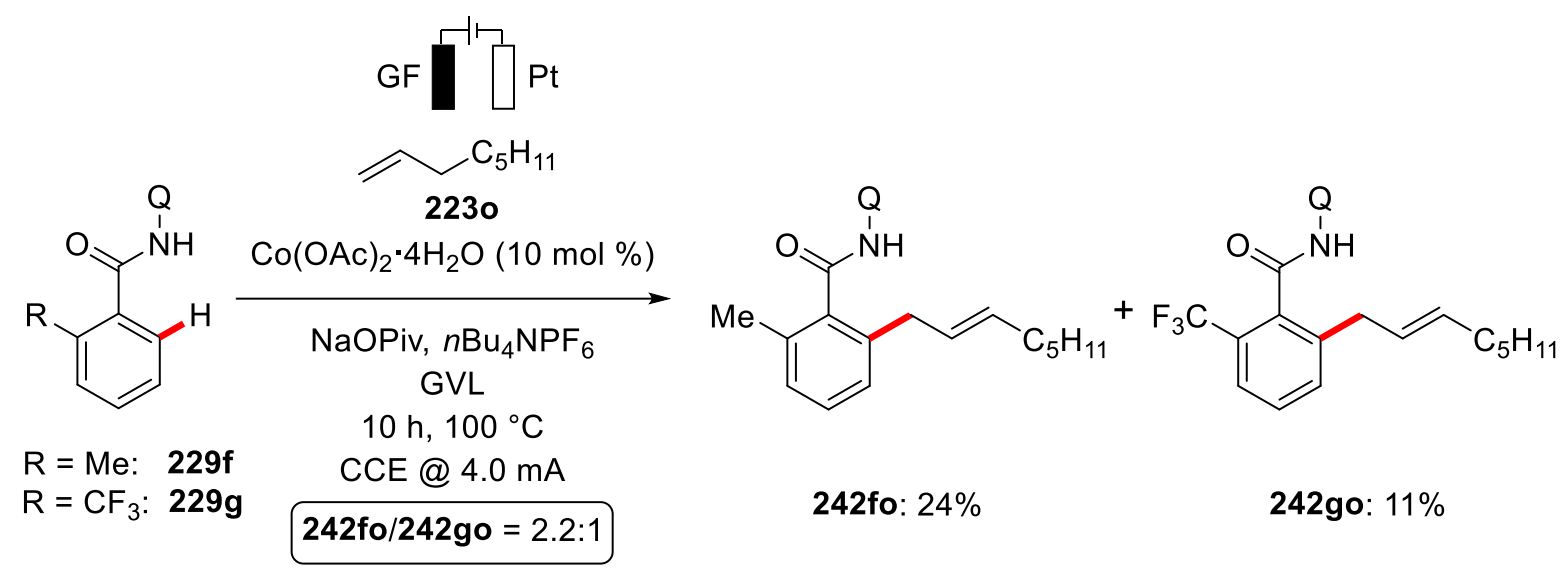

Scheme 120. Competition experiments for cobaltaelectro-catalyzed C-H allylation.

\subsubsection{H/D Exchange Experiment}

In addition, a $\mathrm{H} / \mathrm{D}$-exchange experiment was conducted using isotopically-labeled $\mathrm{CD}_{3} \mathrm{OD}$ as the deuterated co-solvent under the optimized reaction condition, which showed no H/D crossover either in the product $\mathbf{2 4 2 f o}$ or in the isolated starting material $229 f$ (Scheme 121). This observation suggests an irreversible $\mathrm{C}-\mathrm{H}$ activation event to be operative for the cobaltcatalyzed $\mathrm{C}-\mathrm{H}$ allylation.

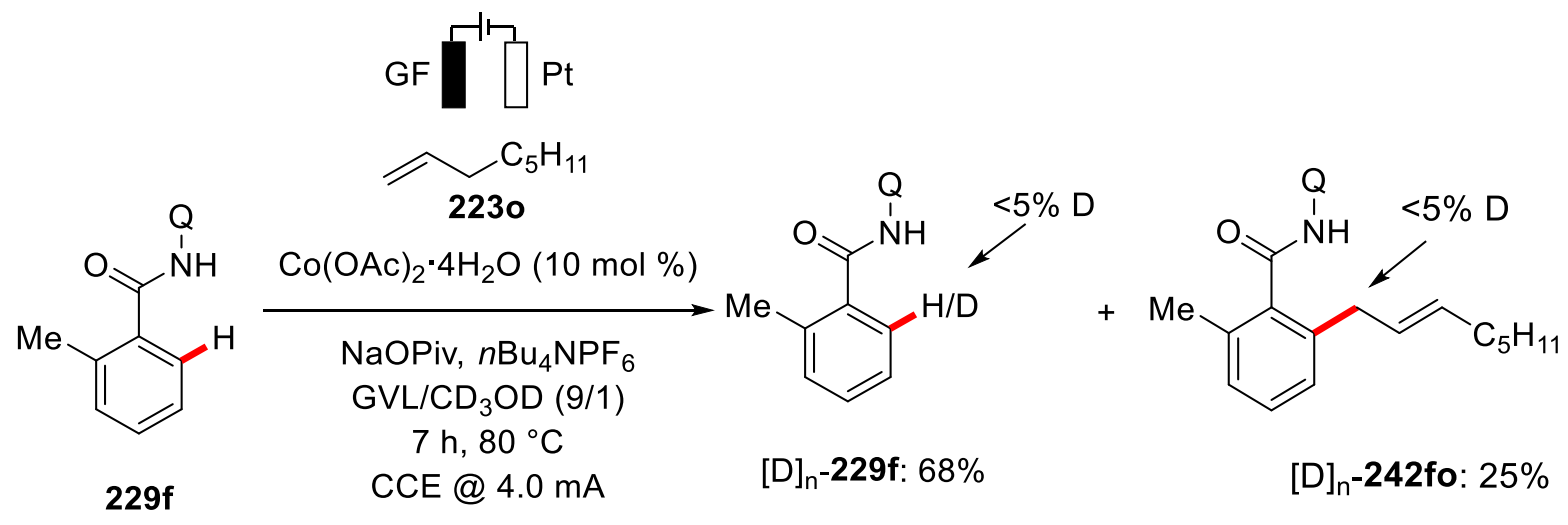

Scheme 121. H/D exchange experiment for cobaltaelectro-catalyzed C-H allylation. 


\subsubsection{Gas-Chromatographic Head-Space Analysis}

Finally, Dr. C. Tian observed the formation of molecular hydrogen by gas-chromatographic head-space analysis, highlighting molecular hydrogen as the sole by-product formed through cathodic reduction (Scheme 122).

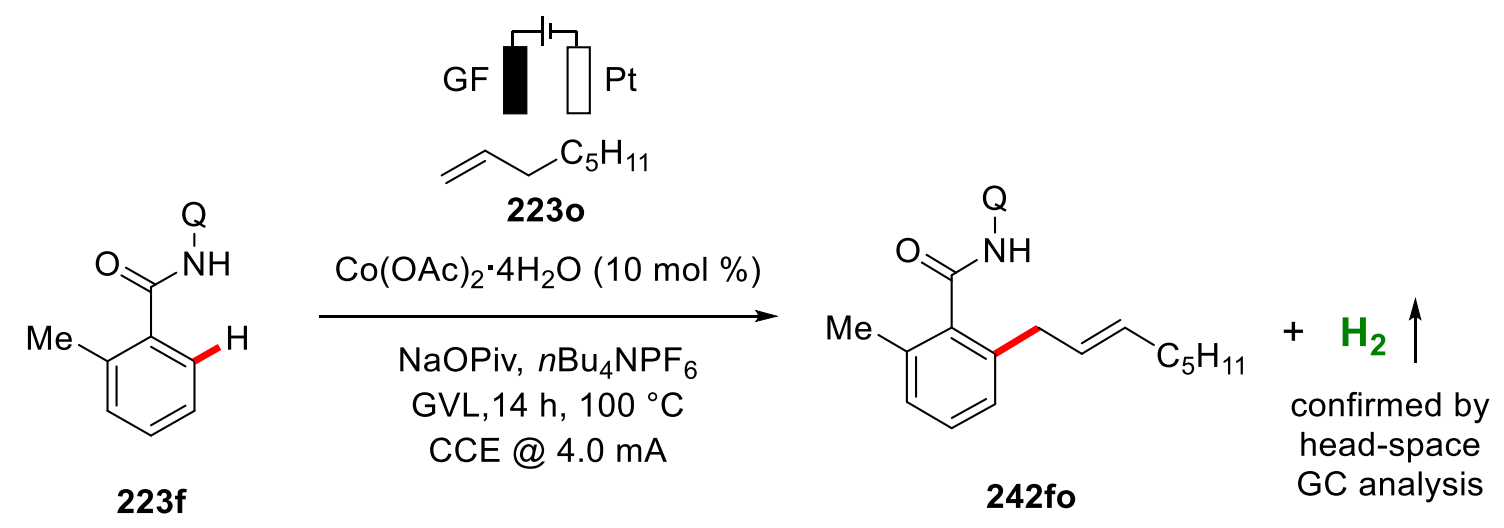

Scheme 122. Gas-chromatographic head-space analysis.

\subsubsection{Cyclic Voltammetry Studies}

Furthermore, detailed cyclic voltammetry studies were conducted by $\mathrm{Dr}$. C. Tian in acetonitrile on the electrochemical cobalt(II)-catalyzed $\mathrm{C}-\mathrm{H}$ allylation (Figure 3). While the amide substrate 229f was oxidized at $1.46 \mathrm{~V}_{\mathrm{SCE}}$, interestingly the alkene 223o did not show any relevant oxidation event. Finally, the in-situ generated cobalt catalyst showed a lower oxidation potential at $1.19 \mathrm{~V}_{\mathrm{SCE}}$. This observation strongly supports an initial anodic cobalt(II/III) singleelectron oxidation. 

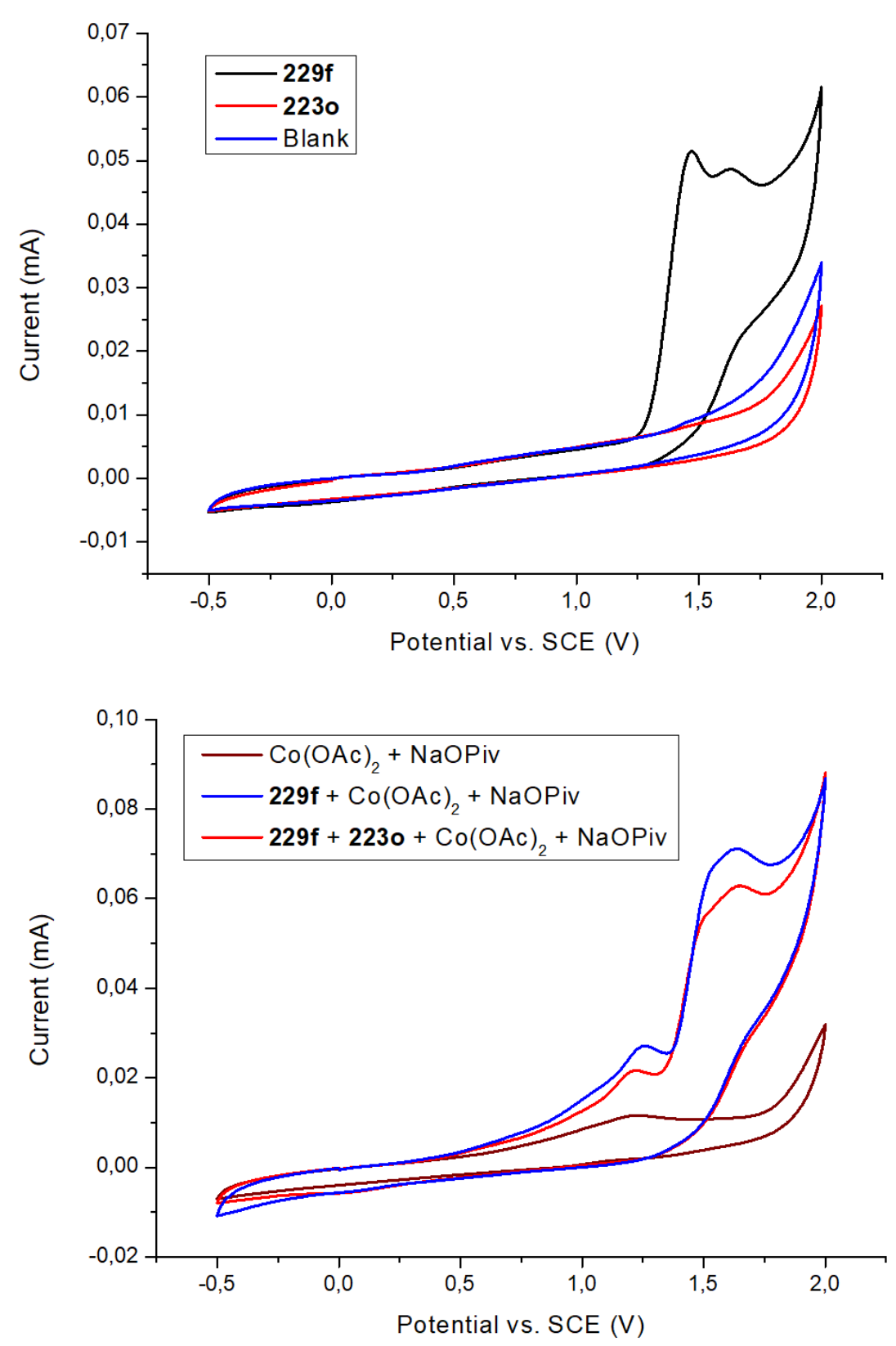

Figure 3. Cyclic voltammetry.

General condition: DMA, 0.1 M nBu4NPF6, $5 \mathrm{mM}$ HOAc, $5 \mathrm{mM}$ substrates, $100 \mathrm{mV} / \mathrm{s}$.

\subsubsection{Proposed Catalytic Cycle}

In accordance with recent findings ${ }^{[275]}$ and on the basis of our mechanistic findings, we have depicted a plausible catalytic cycle for the cobalt-catalyzed electrochemical $\mathrm{C}-\mathrm{H}$ allylation (Scheme 123). Here electrochemical cobalt(II)-catalyzed $\mathrm{C}-\mathrm{H}$ allylation is likely initiated by anodic cobalt oxidation to generate the cobalt(III) species 391. After generation of the active cobalt(III) species 391, the carboxylate-assisted C-H scission occurs by irreversible, BIES- 
type mechanistic pathways to form the 5-membered cobaltacycle 392 as supported by H/Dexchange experiment and competition experiment. Thus formed cyclometalated cobalt complex undergoes alkene co-ordination to afford 393 and subsequent 1,2-migratory insertion with the non-activated alkene $\mathbf{2 2 3}$ forms the conformationally strained 7-membered metallacycle 394. Next the 7-membered metallacycle 394 undergoes $\beta$-hydride elimination exclusively from the allylic proton, releasing the desired product $\mathbf{2 4 2}$ with allylic selectivity. Finally, the cobalt(I) species 395 is oxidized to the active cobalt(III) catalyst 391 by anodic oxidation to complete the catalytic cycle. Notably, the cathodic half-reaction formed $\mathrm{H}_{2}$ as the sole stoichiometric byproduct, showcasing the sustainability of the electrochemical oxidative allylation. 
<smiles>Cc1cccc(C)c1C(=O)Nc1cccc2cccnc12</smiles>

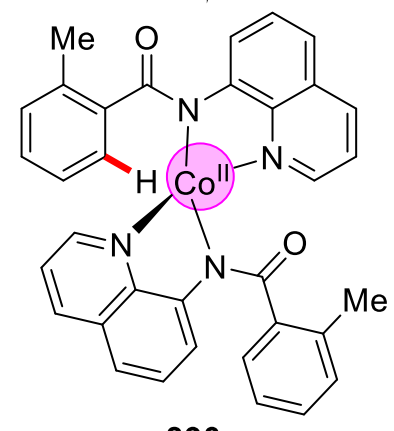

390
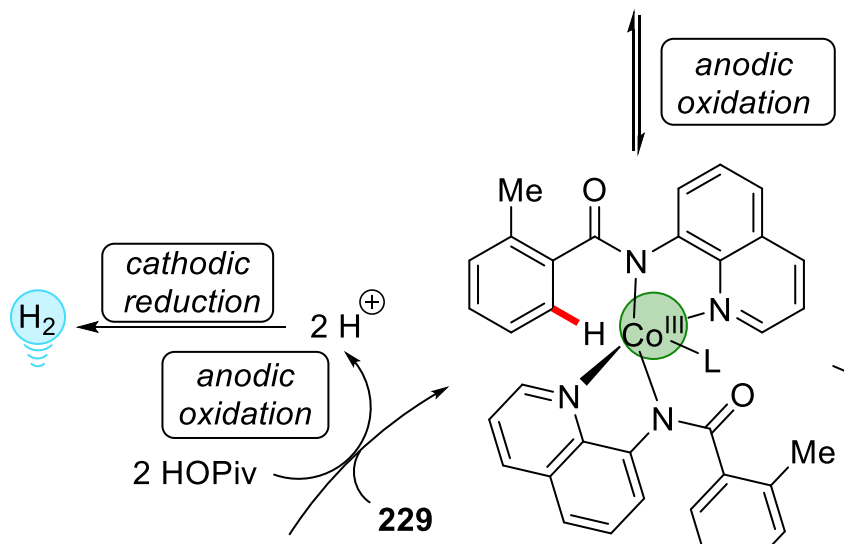

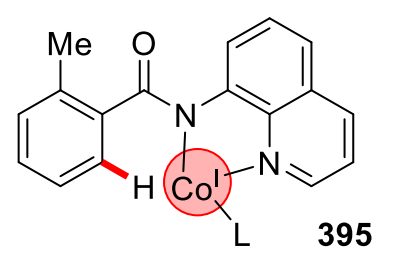

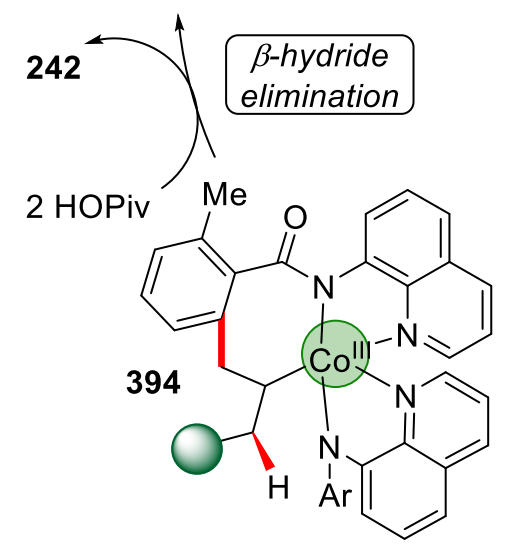

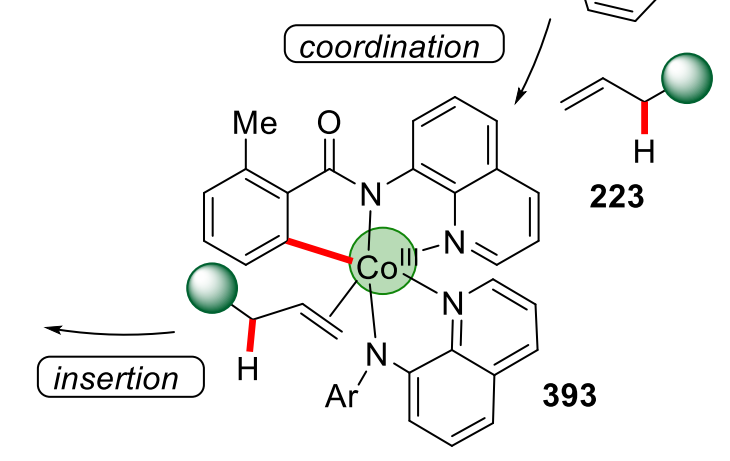

Scheme 123. Proposed catalytic cycle for cobaltaelectro-catalyzed C-H allylation. 


\section{Results and Discussion}

\subsection{Enantioselective Palladaelectro-Catalyzed C-H Activations}

Electrochemical oxidations have been well studied for the last few decades, since they offer an attractive approach by the utilization of electric current to obviate the use of toxic and expensive reagents. In recent years, significant advances have been realized by the merger of electrosynthesis with organometallic $\mathrm{C}-\mathrm{H}$ activations, using electrons as green redox equivalents. ${ }^{[232]}$ Major progresses in electrochemical palladium catalyzed $\mathrm{C}-\mathrm{H}$ activations have been realized by strong $N$-directing groups. ${ }^{[234-236,238-239,240 b, 241,276]}$ Despite these significant advances, electrochemical enantioselective $\mathrm{C}-\mathrm{H}$ activations are thus far unknown. ${ }^{[277]}$ Possibly cathodic catalyst reduction as well as electrochemical degradation of the chiral ligands make the asymmetric metallaelectro-catalysis an extremely challenging research area.

Considering the importance of axially-chiral biaryls as key structural motifs in various catalysts, ${ }^{[278]}$ ligands $^{[279]}$ and natural products, ${ }^{[280]}$ we were interested in the development of the first electrochemical enantioselective synthesis of axially chiral biaryls. It is noteworthy that since the early, albeit moderately selective report on rhodium(I)-catalyzed $\mathrm{C}-\mathrm{H}$ alkylations of arylpyridines, atroposelective syntheses of axially-chiral biaryls have become a major research area ( $c f$. chapter 1.3.1.). ${ }^{[281]}$ Notably, Shi employed chiral transient directing groups for the efficient synthesis of axially-chiral biaryls. ${ }^{[41 \mathrm{a}]}$ Despite these advances, these transformations are often limited to the use of toxic oxidants. Hence, we became interested in the development of an atroposelective synthesis of axially-chiral biaryls with the aid of transient directing groups, employing electricity as the redox agent. Furthermore, it should be duly noted that transient directing groups had never been used before in electrochemical $\mathrm{C}-\mathrm{H}$ activation reactions.

\subsubsection{Optimization Studies}

For the development of the first enantioselective electrochemical metal-catalyzed $\mathrm{C}-\mathrm{H}$ activation, we were interested in the advancement of atroposelective $\mathrm{C}-\mathrm{H}$ activation of biaryls under sustainable electrochemical conditions (Table 27). We began our investigations by evaluating a series of weakly-coordinating transient directing groups for the envisioned atroposelective electrocatalyzed $\mathrm{C}-\mathrm{H}$ olefination of biaryls 73a with $n$-butyl acrylate 38a. We started our optimization with several $\alpha$-amino acids to access highly enantioenriched axially chiral biaryls 74aa with synthetically useful formyl groups (entries 1-5). Thus, we found that L-tert-leucine was the best TDG for this atroposelective transformation, delivering the desired product with $53 \%$ yield and $97 \%$ ee (entry 5 ). Electrolytes always play a significant role in the 
outcome of electrochemical reactions. Thus, we tested other electrolyte additives, such as $\mathrm{NaOAc}, \mathrm{KOAc}, \mathrm{NaOPiv}$ and $n \mathrm{Bu}_{4} \mathrm{NPF}_{6}$, which provided inferior results as compared to LiOAc (entries 6-9). This finding suggested that the additive played an important role for the successful outcome of the reaction, thus operating both as an electrolyte and a base for the carboxylate-assisted $\mathrm{C}-\mathrm{H}$ bond cleavage (vide infra). It is noteworthy that $\mathrm{AcOH}$ has been found as a commonly used solvent for palladium-catalyzed electrochemical $\mathrm{C}-\mathrm{H}$ activation reactions. In line with previous literatures, we observed $\mathrm{AcOH}$ indeed to be the optimal solvent, possibly playing a crucial role in the in situ formation of the imine species. When we employed only TFE as the reaction medium, we did not observe any reactivity whereas a mixture of TFE and $\mathrm{AcOH}$ provided the product 74aa in moderate yield and with high enantioselectivity (entries 10-11). Prolonging the reaction time, delivered the $\mathrm{C}-\mathrm{H}$ olefinated product in $71 \%$ yield and $97 \%$ ee (entry 12). Notably, the enantioselective metallaelectro-catalysis also occurred under an inert atmosphere, albeit with reduced efficiency (entry 14). In stark contrast to the use of chemical oxidants, ${ }^{[89]}$ a redox mediator was not required for efficient metallaelectro-catalysis, as we observed that commonly used redox mediators such as benzoquinone, failed to improve the reactivity to a large extent. Control experiments confirmed the necessity of the TDG, the electricity and the palladium catalyst (entries 15-17).

Table 27. Optimization of the atroposelective electrocatalyzed $\mathrm{C}-\mathrm{H}$ olefination. ${ }^{[\mathrm{a}]}$

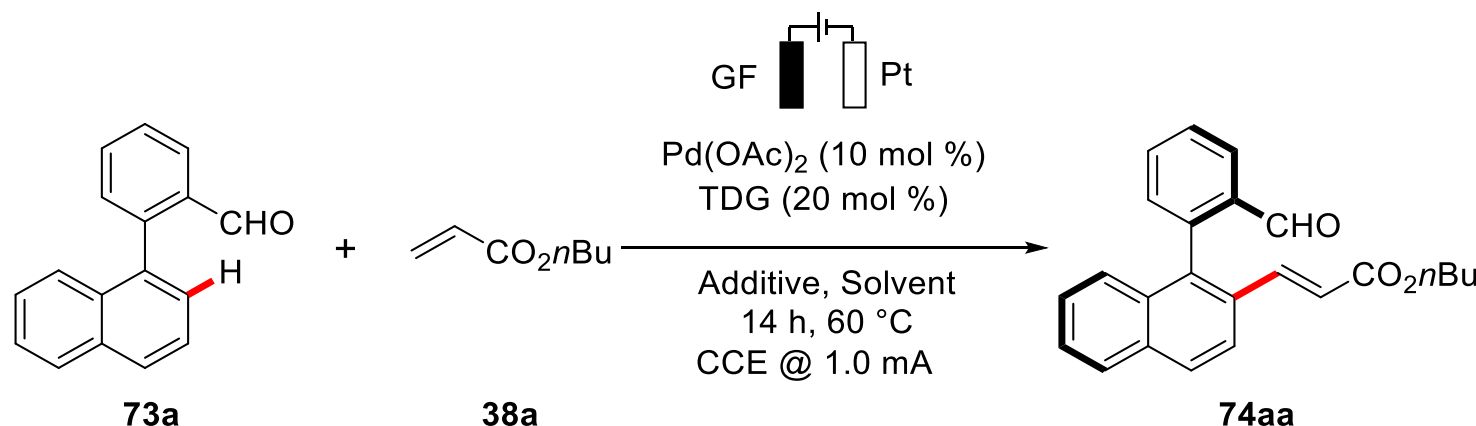

\begin{tabular}{cccccc}
\hline Entry & TDG & Additive & Solvent & Yield $[\%]$ & $\boldsymbol{e e ~}[\%]^{[\mathbf{b}]}$ \\
\hline 1 & L-valine & LiOAc & AcOH & 35 & $48^{[\mathrm{c}]}$ \\
2 & L-Phenylglycene & LiOAc & AcOH & 37 & 40 \\
3 & L-tryptophan & LiOAc & AcOH & 21 & $68^{[\mathrm{c}]}$ \\
4 & H-Asp $(\mathrm{O} t \mathrm{Bu})-\mathrm{OH}$ & LiOAc & $\mathrm{AcOH}$ & 55 & 20 \\
5 & L-tert-leucine & LiOAc & $\mathrm{AcOH}$ & 53 & 97 \\
6 & L-tert-leucine & NaOAc & $\mathrm{AcOH}$ & 47 & 99
\end{tabular}




\begin{tabular}{cccccc}
\hline 7 & L-tert-leucine & KOAc & AcOH & 45 & 98 \\
8 & L-tert-leucine & NaOPiv & AcOH & 50 & 96 \\
9 & L-tert-leucine & $n$ Bu$_{4} \mathrm{NPF}_{6}$ & AcOH & 48 & 99 \\
10 & L-tert-leucine & --- & TFE & --- & --- \\
11 & L-tert-leucine & --- & TFE/AcOH & 46 & 99 \\
12 & L-tert-leucine & LiOAc & AcOH & $\mathbf{7 1}$ & $9^{[\mathrm{d}]}$ \\
13 & L-tert-leucine & LiOAc & AcOH & 66 & $97^{[\mathrm{d}, \mathrm{e}]}$ \\
14 & L-tert-leucine & LiOAc & AcOH & 43 & $97^{[\mathrm{d}, \mathrm{f}]}$ \\
15 & ---- & LiOAc & AcOH & --- & --- \\
16 & L-tert-leucine & LiOAc & AcOH & 25 & $97^{[\mathrm{g}]}$ \\
17 & L-tert-leucine & LiOAc & AcOH & --- & $----^{[\mathrm{h}]}$ \\
\hline
\end{tabular}

[a] Reaction conditions: Undivided cell, 73a (0.20 mmol), 38a (0.60 mmol), [Pd] (10 mol \%), TDG (20 mol \%), additive (2.0 equiv), solvent $(4.5 \mathrm{~mL}), 60{ }^{\circ} \mathrm{C}$, constant current at $1.0 \mathrm{~mA}, 14$ $\mathrm{h}, \mathrm{GF}$ anode $(10 \mathrm{~mm} \times 15 \mathrm{~mm} \times 6 \mathrm{~mm})$, Pt-plate cathode $(10 \mathrm{~mm} \times 15 \mathrm{~mm} \times 0.25 \mathrm{~mm})$, isolated yields. [b] Enantioselectivities determined by chiral HPLC. [c] Performed by Dr. C. Tian. [d] 20 h. [e] 38a (2.0 equiv). [f] Under N2. [g] Without electricity. [h] No palladium.

\subsubsection{Substrate Scope of Atroposelective Electrocatalyzed C-H Olefination}

With the optimized reaction conditions in hand, we explored the generality of the enantioselective palladaelectro-catalysis (Table 28). First, electron-rich and electron-deficient racemic biaryls $\mathbf{7 3}$ were tested. To our delight, all the corresponding axially chiral compounds 74 were formed with good yields and in excellent enantioselectivities, reflecting very little effect of the electronic properties of the substituents on the outcome of the electrocatalysis (entries 1-7). 
Table 28. Atroposelective electro-catalyzed C-H olefination of biaryls 73. ${ }^{[a]}$

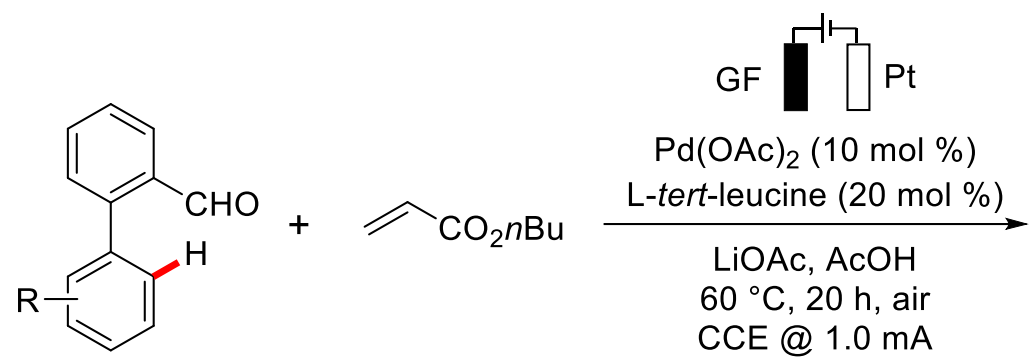

73

$38 a$

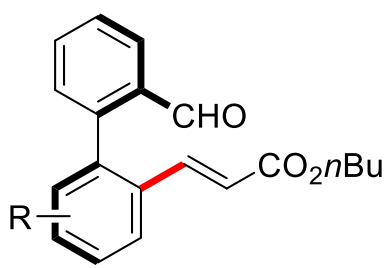

74

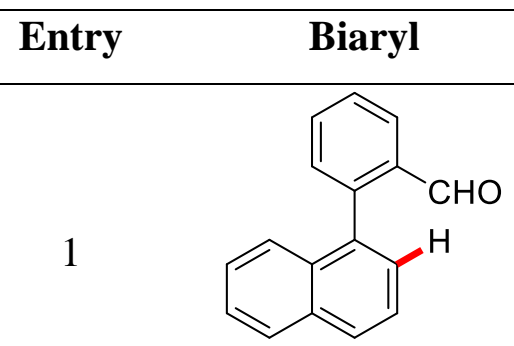

$73 a$

2<smiles>Cc1cccc(-c2ccccc2C=O)c1</smiles>

$73 b$

3<smiles>CCc1ccccc1-c1cc(F)ccc1C=O</smiles>

$73 c$<smiles>O=Cc1cc2c(cc1-c1cccc3ccccc13)OCO2</smiles>

73d
Product<smiles>CCCOC(=O)C=Cc1ccc2ccccc2c1-c1ccccc1C=O</smiles>

74aa<smiles>CCCOC(=O)C=Cc1cccc(C)c1-c1ccccc1C=O</smiles>

$74 \mathrm{ba}$<smiles>CCOC(=O)/C=C/c1cccc(CC)c1-c1cc(F)ccc1C=O</smiles>

71 95<smiles>CCOCC=Cc1ccc2ccccc2c1-c1cc2c(cc1C=O)OCO2</smiles>

54

99 
5<smiles>COc1cc(C=O)cc(-c2c(-c3ccccc3)ccc3ccccc23)c1</smiles>

$73 e$

6<smiles>O=Cc1cc(C(F)(F)F)ccc1-c1cccc2ccccc12</smiles>

$73 f$

7<smiles>O=Cc1ccc2ccccc2c1-c1ccccc1</smiles>

$73 \mathrm{~g}$<smiles>CCOC(=O)C=Cc1ccc2ccccc2c1-c1cc(OC)c(OC)cc1C=O</smiles>

60

98

$74 \mathrm{ea}$<smiles>CCc1cc(C(F)(F)F)ccc1-c1c(C=CC(=O)OC=O)ccc2ccccc12</smiles>

60

97

62

$95^{[\mathrm{cc}]}$

[a] Reaction conditions: Undivided cell, 73 (0.20 mmol), 38a (0.60 mmol), $\mathrm{Pd}(\mathrm{OAc})_{2}(10 \mathrm{~mol}$ $\%)$, L-tert-Leucine (20 mol \%), LiOAc (2.0 equiv), AcOH (4.5 mL), $60{ }^{\circ} \mathrm{C}$, constant current at $1.0 \mathrm{~mA}, 20 \mathrm{~h}, \mathrm{GF}$ anode $(10 \mathrm{~mm} \times 15 \mathrm{~mm} \times 6 \mathrm{~mm})$, Pt-plate cathode $(10 \mathrm{~mm} \times 15 \mathrm{~mm} \times$ $0.25 \mathrm{~mm}$ ), isolated yields. [b] Enantioselectivities determined by chiral HPLC. [c] Performed by J. Hao.

Second, a broad range of alkene coupling partners was investigated under our optimized electrochemical conditions (Table 29). $\alpha, \beta$-Unsaturated olefins 38 served as particularly effective coupling partners in this reaction conditions. Vinyl sulfone $\mathbf{3 8 b}$ and vinyl phosphonate 38c were efficiently installed through atroposelective $\mathrm{C}-\mathrm{H}$ activation in moderate to good yields and in excellent enantioselectivities (entries 1-2). Notably, methyl vinyl ketone 38d was also compatible, delivering the olefinated product 74bd in high enantioselectivity (entry 3). To our delight, various sensitive functional groups, like fluoro- (38f), bromo- (38g), nitro- (38h) and carbonyl (38i) substituents, on the arene were well tolerated, which should prove invaluable for further late stage modifications. In contrast, alkenes containing bromo(38j) or nitro- $(\mathbf{3 8 h})$ groups exhibited lower reactivity to deliver the corresponding products 
(entries 4-8). Remarkably, acrylamide (38j) was also compatible with our robust catalyst to furnish the axially-chiral biaryl 74bj with very high levels of enantio-induction (entry 9).

Table 29. Atroposelective palladaelectro-catalysis with alkenes 38. ${ }^{\text {[a] }}$
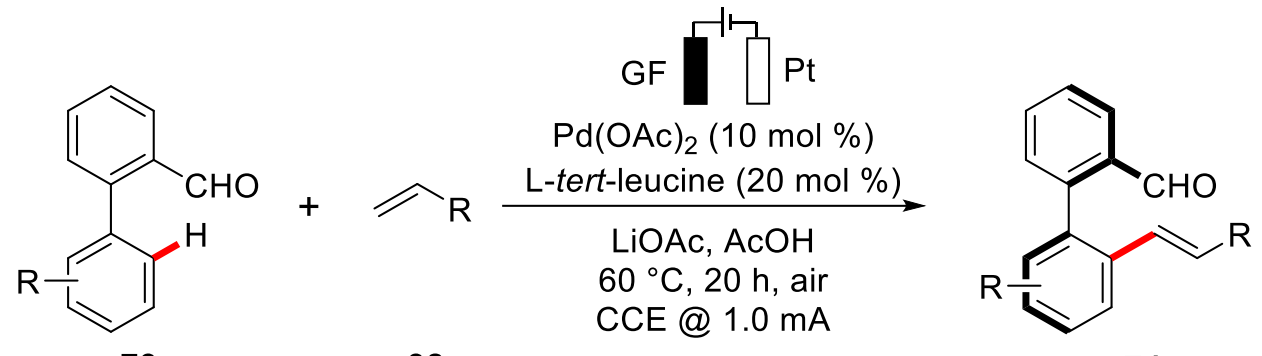

73

38

\begin{tabular}{lcccc}
\hline \multirow{2}{*}{ Entry } & Alkene & Product & Yield & $e e$ \\
& & {$[\%]$} & {$[\%]^{[\mathrm{b}]}$} \\
\hline
\end{tabular}

1

$\approx \mathrm{SO}_{2} \mathrm{Ph}$

$38 b$<smiles>O=Cc1ccccc1-c1c(/C=C/S(=O)(=O)Oc2ccccc2)ccc2ccccc12</smiles>

$74 a b$<smiles>C=CP(=O)(OCC)OCC</smiles>

$38 \mathrm{c}$<smiles>CCOP(=O)(/C=C/c1ccc2ccccc2c1-c1ccccc1C=O)OCC</smiles>

$$
74 a c
$$

3<smiles>C=CC(C)=O</smiles>

38d<smiles>CC(=O)/C=C/c1cccc(C)c1-c1ccccc1C=O</smiles>

$74 b d$<smiles>COc1ccc(OC(=O)/C=C/c2ccc3ccccc3c2-c2ccccc2C=O)cc1</smiles>

74ae 
5<smiles>C=CC(=O)OCc1ccc(F)cc1</smiles>

$38 f$<smiles>C=CC(=O)Oc1ccc(Br)cc1</smiles>

7<smiles>C=CC(=O)Oc1ccc([N+](=O)[O-])cc1</smiles>

$38 \mathrm{~h}$<smiles>C=CC(=O)Oc1ccc(C(C)=O)cc1</smiles>

$38 i$<smiles>C=CC(=O)NC(C)C</smiles>

38j<smiles>Cc1cccc(/C=C/C(=O)OCc2ccc(F)cc2)c1-c1ccccc1C=O</smiles>

$74 \mathrm{bf}$<smiles>O=Cc1ccccc1-c1c(/C=C/C(=O)Oc2ccc(Br)cc2)ccc2ccccc12</smiles>

74ag<smiles>O=Cc1ccccc1-c1c(/C=C/C(=O)Oc2ccc([N+](=O)[O-])cc2)ccc2ccccc12</smiles>

74ah<smiles>CC(=O)c1ccc(OC(=O)/C=C/c2ccc3ccccc3c2-c2ccccc2C=O)cc1</smiles>

74ai<smiles>Cc1ccccc1-c1c(C)cccc1/C=C/C(=O)NC(C)C</smiles>

74bj

[a] Reaction conditions: Undivided cell, 73 (0.20 mmol), 38 (0.60 mmol), Pd(OAc)2 (10 mol $\%)$, L-tert-Leucine (20 mol \%), LiOAc (2.0 equiv), AcOH (4.5 mL), $60{ }^{\circ} \mathrm{C}$, constant current at $1.0 \mathrm{~mA}, 20 \mathrm{~h}$, GF anode $(10 \mathrm{~mm} \times 15 \mathrm{~mm} \times 6 \mathrm{~mm})$, Pt-plate cathode $(10 \mathrm{~mm} \times 15 \mathrm{~mm} \times$ $0.25 \mathrm{~mm}$ ), isolated yields. [b] Enantioselectivities determined by chiral HPLC.

We were pleased to observe that the palladaelectro-catalysis was not only limited to the conversion of racemic biaryls 73. Indeed, the electrocatalysis also set the stage for the synthesis of N-C axially-chiral motifs ${ }^{[92 a, 93]}$ (Table 30). To improve the conversion, a slightly higher loading of TDG was employed for the synthesis of axially chiral N-C scaffold 397 and 398. 
To demonstrate the generality of our transformation, we tested the scope of olefin coupling partners with $\mathrm{N}$-aryl pyrrole 396 as the model substrate. Thus, $\mathrm{N}-\mathrm{C}$ axially-chiral $N$-aryl pyrroles 397 and 398 were obtained under the electrochemical conditions in a site- and highly enantio-selective fashion (entry 1). Other than $\alpha, \beta$-unsaturated olefins, perfluoroalkylalkenes 301a and 301c were also compatible to enable unprecedented $\mathrm{C}-\mathrm{H}$ perfluoroalkenylations (entries 2-3). Thus, this protocol provided a highly enantioselective strategy to deliver synthetically useful axially-chiral fluorinated heterobiaryls 398aa and 398ac in moderate to good yields. Similarly, vinyl phosphonate (38c), vinyl sulfone (38b) and cholesterol derivative (38k) were also identified as suitable coupling partners for the synthesis of versatile $\mathrm{N}-\mathrm{C}$ axially chiral scaffolds with high levels of enantio-induction (entries 4-6).

Table 30. Atroposelective palladaelectro-catalyzed C-H olefination of $N$-aryl pyrroles. ${ }^{\text {[a] }}$

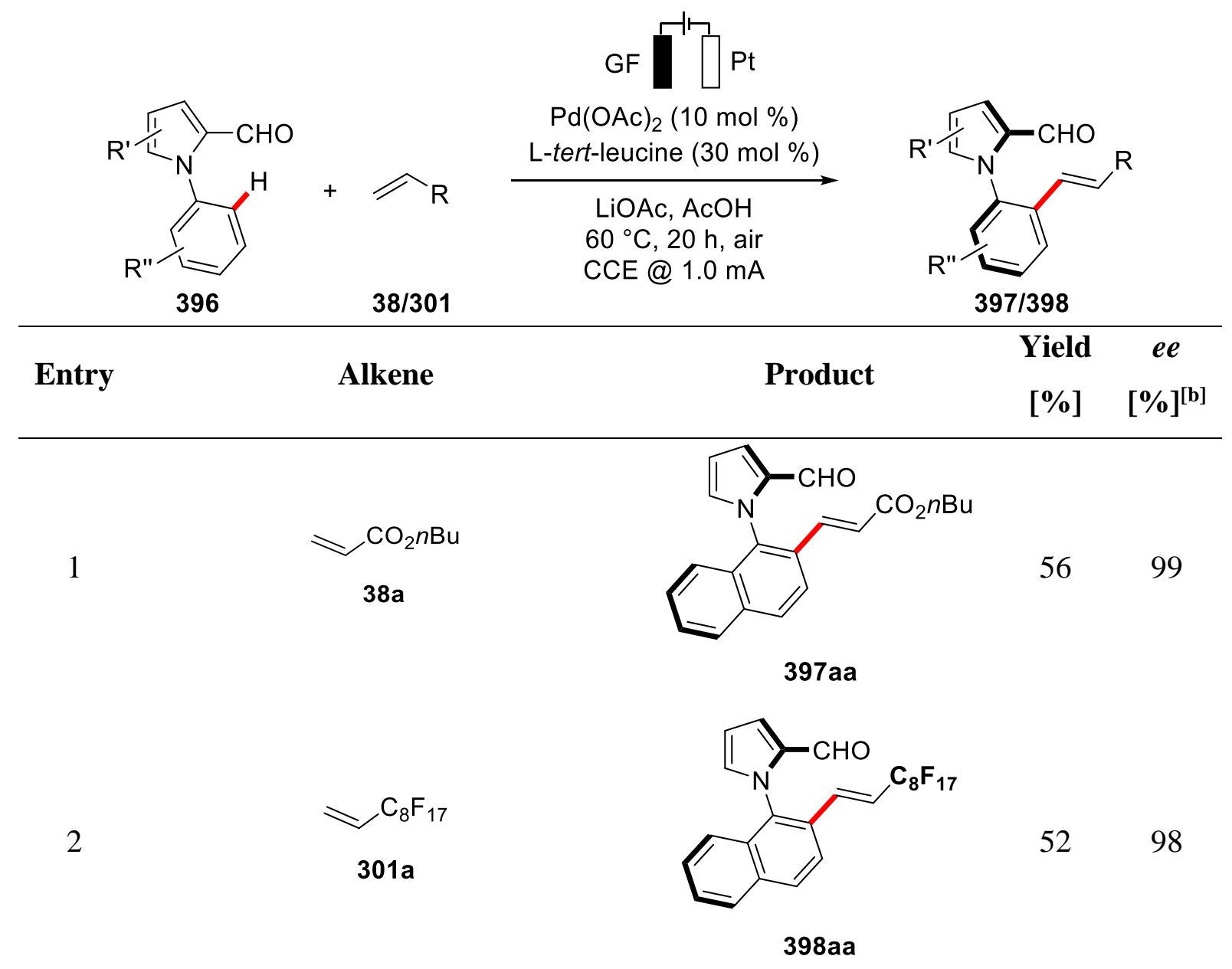


3

$$
\approx \mathrm{C}_{10} \mathrm{~F}_{21}
$$

$301 c$

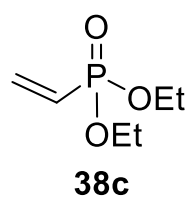

$\approx \mathrm{SO}_{2} \mathrm{Ph}$

5

$38 b$<smiles>O=Cc1cccn1-c1c(/C=C/C(F)F)ccc2ccccc12</smiles>

$398 a c$<smiles>CCOP(=O)(OC=Cc1ccc2ccccc2c1-n1cccc1C)OCC</smiles>

$397 a c$<smiles>O=Cc1cccn1-c1c(C=CS(=O)(=O)c2ccccc2)ccc2ccccc12</smiles>

$397 a b$<smiles>[R]OC(=O)/C=C/c1ccc2ccccc2c1-n1cccc1C=[18O]</smiles>

$38 \mathrm{k}$

[a] Reaction conditions: Undivided cell, $396(0.20 \mathrm{mmol}), \mathbf{3 8} / \mathbf{3 0 1}(0.60 \mathrm{mmol}), \mathrm{Pd}(\mathrm{OAc})_{2}(10$ mol \%), L-tert-Leucine (30 mol \%), LiOAc (2.0 equiv), AcOH (4.5 mL), $60{ }^{\circ} \mathrm{C}$, constant current at $1.0 \mathrm{~mA}, 20 \mathrm{~h}$, GF anode $(10 \mathrm{~mm} \times 15 \mathrm{~mm} \times 6 \mathrm{~mm})$, Pt-plate cathode $(10 \mathrm{~mm} \times$ $15 \mathrm{~mm} \times 0.25 \mathrm{~mm}$ ), isolated yields. [b] Enantioselectivities determined by chiral HPLC. [c] Performed by J. Hao.

\subsubsection{Mechanistic Studies}

After establishing a broad scope for the first atroposelective pallada-electrocatalyzed $\mathrm{C}-\mathrm{H}$ activation, detailed experimental and computational mechanistic studies were performed to gain insights into its mode of action. 


\subsubsection{H/D Scrambling and KIE Studies}

First, a H/D exchange experiment was conducted using AcOD as the solvent (Scheme 124a). We did not observe a H/D scrambling neither in the product 74aa nor in the recovered starting material 73a. Second, a KIE was studied by two independent reactions with isotopically labeled compound [D]5-73g, which showed a KIE of $k_{\mathrm{H}} / k_{\mathrm{D}} \approx 1.8$ (Scheme 124b). These findings from $\mathrm{H} / \mathrm{D}$ scrambling experiments and KIE experiments suggests the $\mathrm{C}-\mathrm{H}$ cleavage step is the ratedetermining step. 
(a) H/D scrambling<smiles>O=Cc1ccccc1-c1cccc2ccccc12</smiles>

$73 a$

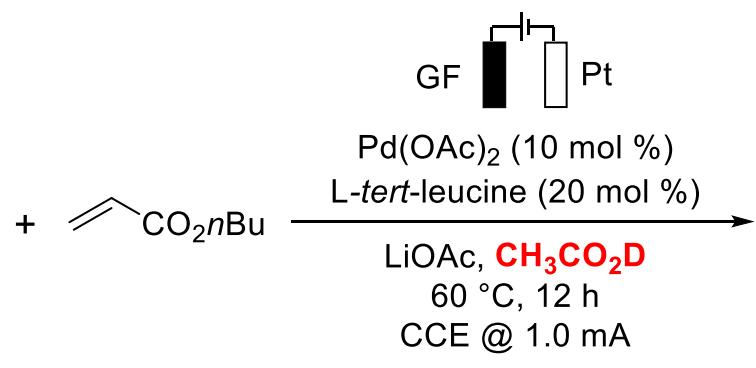

$38 a$

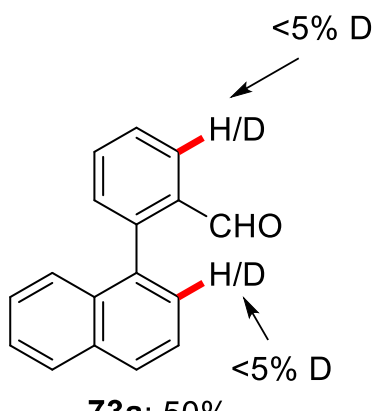

73a: $50 \%$

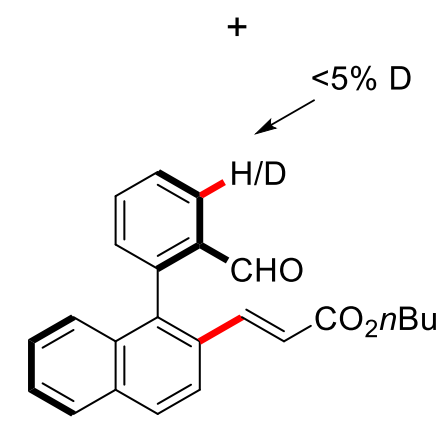

74aa: $47 \%$

(b) KIE Studies<smiles>O=Cc1ccc2ccccc2c1-c1ccccc1</smiles>

$\mathbf{7 3 g}$ or $[\mathrm{D}]_{5}-\mathbf{7 3 g}$

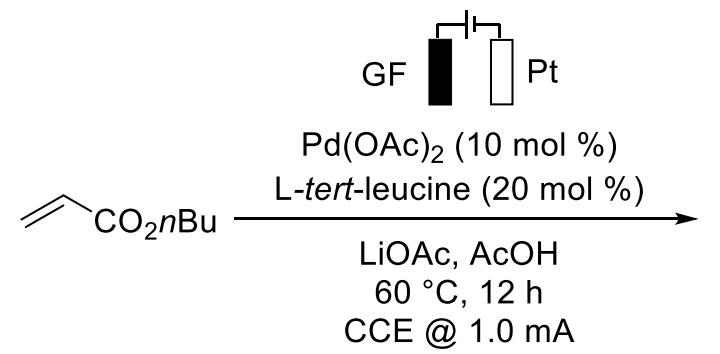

$38 a$

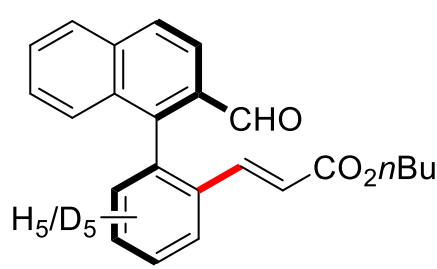

$74 g a$ or $[D]_{4}-74 g a$

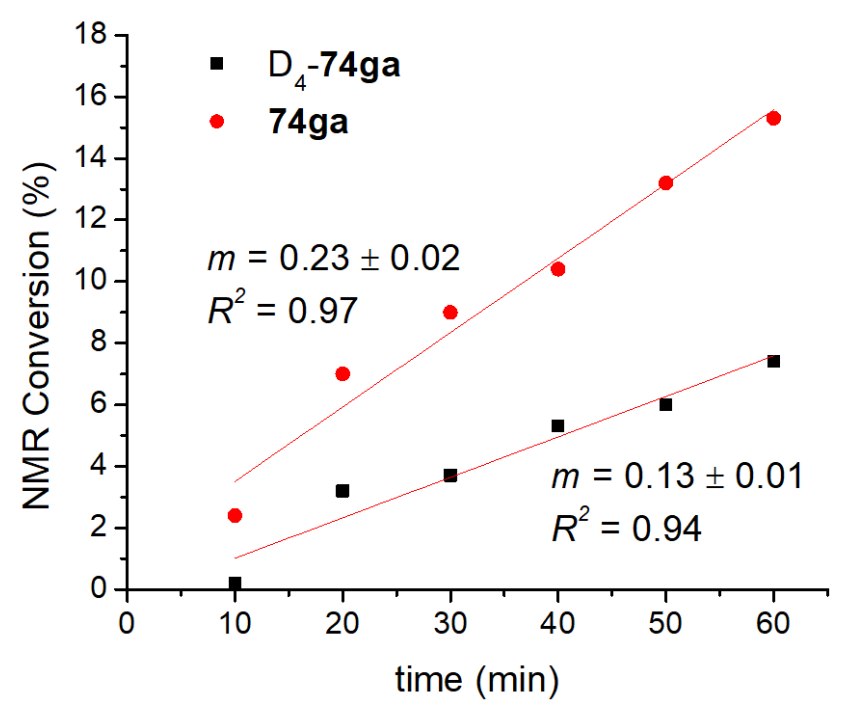

Scheme 124. H/D scrambling and KIE studies for the pallada-electrocatalysis. 


\subsubsection{Non-Linear Effect Studies}

To gain insights into the ligand-to-metal ratio in the atroposelective pallada-electrocatalysis, the effect of the enantiomeric excess of L-tert-Leucine on the enantiomeric induction of the electrochemical transformation was studied (Scheme 125). Here, we did not observe a nonlinear effect (NLE), which excludes a multi-ligand containing catalyst or oligomeric species, instead it is indicative of the enantio-determining step involving a metal to ligand ratio of 1:1.
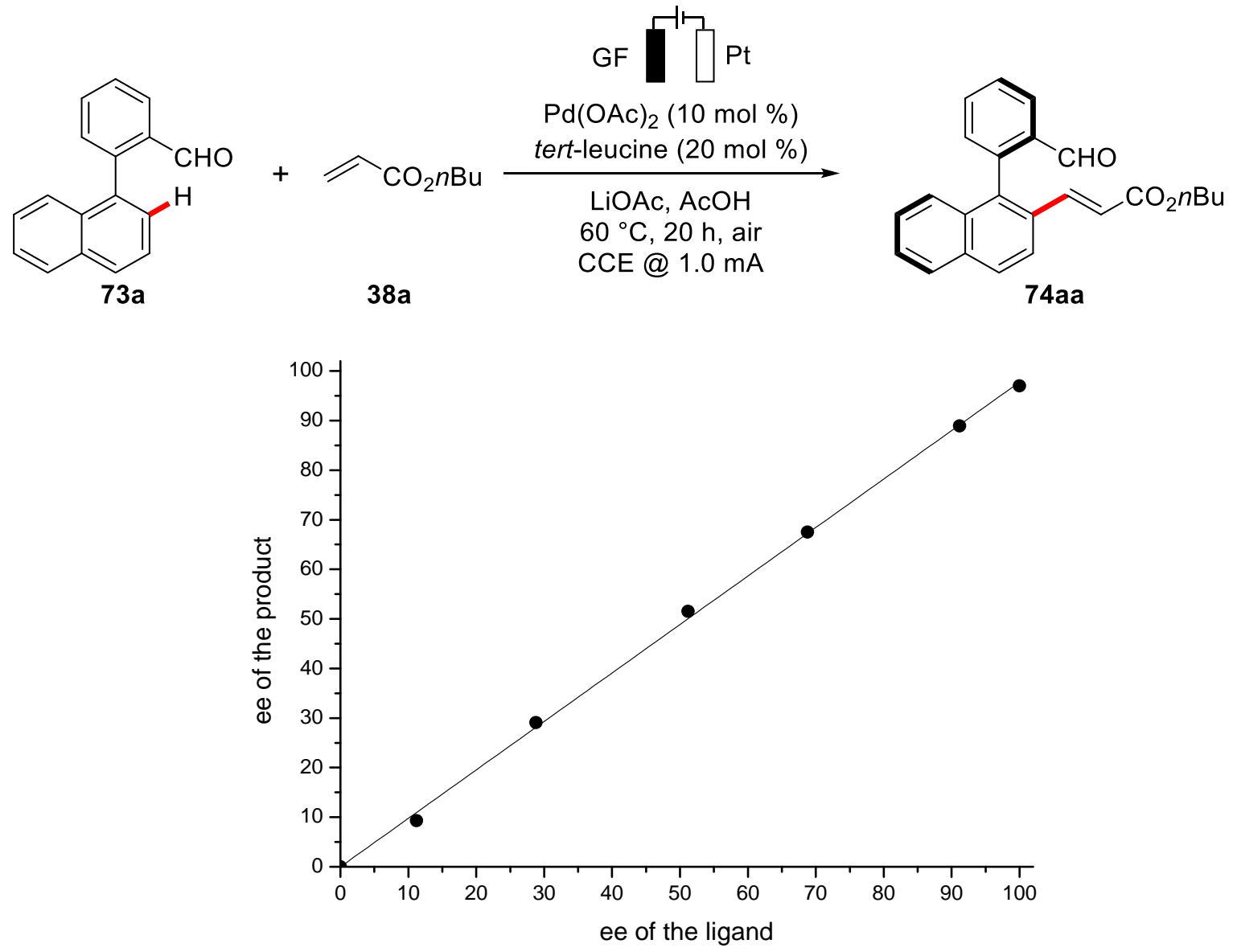

Scheme 125. Non-linear effect studies for the pallada-electrocatalysis.

\subsubsection{Product Diversification}

As previously described axially chiral compounds are very important building blocks, ${ }^{[278-280]}$ thus the synthetic value of the palladium-catalyzed electrochemical $\mathrm{C}-\mathrm{H}$ olefination was demonstrated by the late-stage diversification of thus-obtained highly enantiomericallyenriched biaryls (Scheme 126-128). In this context, straightforward asymmetric synthesis of enantiopure helicenes are in high demand. ${ }^{[282]}$ To this end, we performed a kinetic resolution on conformationally stable aldehyde $\mathbf{7 3 h}$ under otherwise optimal reaction conditions. The desired olefinated product 74 ha was obtained with $95 \%$ ee. Then, the addition of $\mathrm{K}_{2} \mathrm{OsO}_{4}$ and 
$\mathrm{NaIO}_{4}$ enabled the preparation of dialdeyde 399 in high yield by oxidative double bond cleavage. Subsequently, a Wittig reaction and a catalyzed olefin- metathesis provided the highly enantioenriched [5]-helicine $\mathbf{4 0 1}$ in overall good yield and in excellent optical yield (Scheme 126). Likewise, a similar strategy was followed for the synthesis of chiral [6]-helicine starting from conformationally stable aldehyde 73i. Here [6]-helicene $\mathbf{4 0 3}$ was obtained in overall high yield and enantioselectivity (Scheme 127). In addition, the recovered starting material 73i, after the kinetic resolution, was treated under the optimized reaction conditions using D-tert-Leucine as the TDG. Subsequently, the opposite enantiomer of the olefinated product 74ia was obtained which can be converted to the opposite enantiomer ent-[6]-helicine $\mathbf{4 0 3}$ following the same path. Furthermore, the synthetic utility of our method was reflected by the synthesis of chiral dicarboxylic acid 404 and chiral BINOL $\mathbf{4 0 5}$ (Scheme 128). Dialdehyde $\mathbf{4 0 2}$ was treated under Pinnick oxidation conditions, delivering the dicarboxylic acid $\mathbf{4 0 4}$ while Baeyer-Villiger-oxidation gave the chiral BINOL 405. These new chiral molecules should find various applications as ligands for asymmetric catalysis. 
<smiles>Cc1ccccc1-c1c(C=O)ccc2ccc3ccccc3c12</smiles>

$73 \mathrm{~h}$

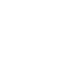
L-

$\mathrm{Pd}(\mathrm{OAc})_{2}(10 \mathrm{~mol} \%)$ L-tert-leucine (30 mol \%) $\mathrm{LiOAc}, \mathrm{AcOH}$ $60{ }^{\circ} \mathrm{C}, 20 \mathrm{~h}$, air CCE @ $1.0 \mathrm{~mA}$ $\widehat{\mathrm{CO}_{2} n \mathrm{Bu}}$

38a<smiles>C=Cc1cccc(C)c1-c1c(C=C)ccc2ccc3ccccc3c12</smiles>

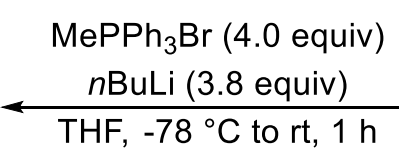

400: $99 \%, 95 \%$ ee

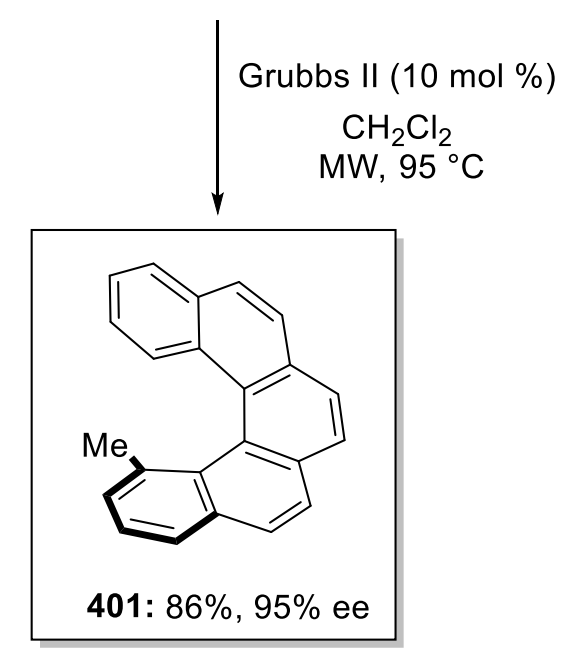<smiles>CCOC(=O)/C=C/c1cccc(C)c1-c1c(C=O)ccc2ccc3ccccc3c12</smiles>

(R)-74ha: $40 \%, 95 \%$ ee

$$
\begin{gathered}
\mathrm{K}_{2} \mathrm{OsO}_{4} \cdot 2 \mathrm{H}_{2} \mathrm{O} \\
(15 \mathrm{~mol} \%) \\
\mathrm{NaIO}_{4}(10 \text { equiv }) \\
\mathrm{THF}^{\mathrm{H}} \mathrm{H}_{2} \mathrm{O}(2 / 1) \\
50{ }^{\circ} \mathrm{C}, 24 \mathrm{~h}
\end{gathered}
$$

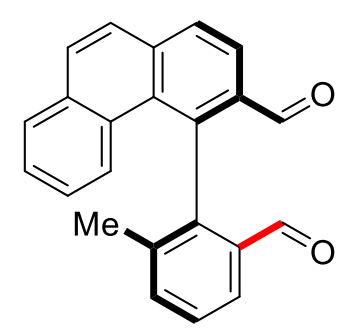

399: $85 \%, 95 \%$ ee

Scheme 126. Synthesis of enantioenriched [5]-helicine. 

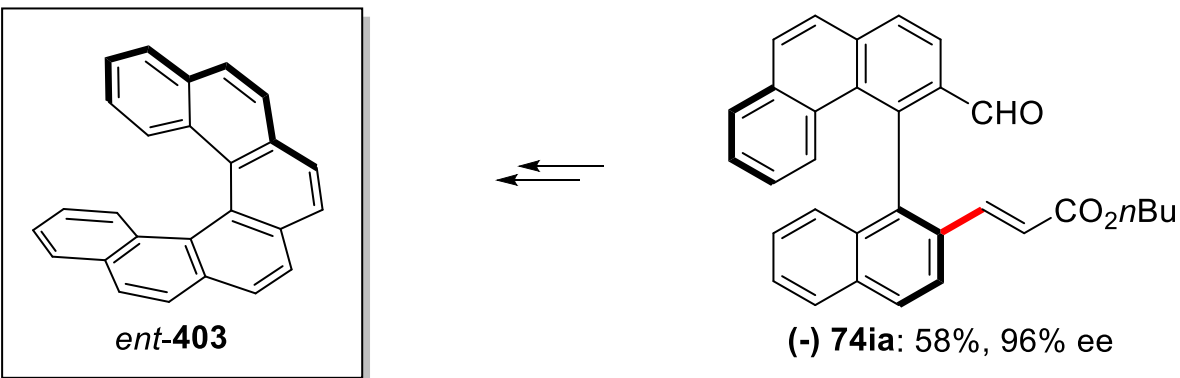

(-) 74ia: 58\%, 96\% ee

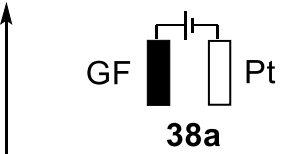

$\mathrm{Pd}(\mathrm{OAc})_{2}(10 \mathrm{~mol} \%)$

D-tert-leucine (30 mol \%)

$\mathrm{LiOAc}, \mathrm{AcOH}$

$60{ }^{\circ} \mathrm{C}, 20 \mathrm{~h}$, air

CCE@1.0 mA<smiles>O=Cc1ccc2ccc3ccccc3c2c1-c1cccc2ccccc12</smiles>

$73 i$

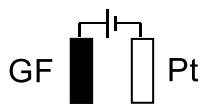

$38 a$

$\mathrm{Pd}(\mathrm{OAc})_{2}(10 \mathrm{~mol} \%)$ L-tert-leucine (30 mol \%)

$\mathrm{LiOAc}, \mathrm{AcOH}$

$60{ }^{\circ} \mathrm{C}, 20 \mathrm{~h}$, air

CCE @ 1.0 mA<smiles>O=Cc1ccc2ccc3ccccc3c2c1-c1cccc2ccccc12</smiles>

73i: $55 \%, 76 \%$ ee<smiles>CCOC(=O)/C=C/c1ccc2ccccc2c1-c1c(C=O)ccc2ccc3ccccc3c12</smiles>

(+) 74ia: $42 \%, 96 \%$ ee

$\mathrm{K}_{2} \mathrm{OsO}_{4} \cdot 2 \mathrm{H}_{2} \mathrm{O}$

(15 mol \%)

$\mathrm{NaIO}_{4}$ (10 equiv)

$\mathrm{THF} / \mathrm{H}_{2} \mathrm{O}(2 / 1)$

$50{ }^{\circ} \mathrm{C}, 24 \mathrm{~h}$

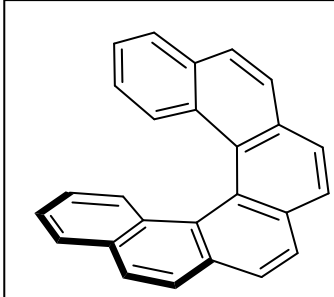

403: $87 \%, 96 \%$ ee

(a) $\mathrm{MePPh}_{3} \mathrm{Br}$ (4.0 equiv) $n$ BuLi (3.8 equiv) THF, $-78^{\circ} \mathrm{C}$ to $\mathrm{rt}, 1 \mathrm{~h}$

(b) Grubbs II (10 mol \%) $\mathrm{CH}_{2} \mathrm{Cl}_{2}$ $\mathrm{MW}, 95^{\circ} \mathrm{C}$<smiles>O=Cc1ccc2ccccc2c1-c1c(C=O)ccc2ccc3ccccc3c12</smiles>

402: $86 \%, 96 \%$ ee

Scheme 127. Synthesis of enantioenriched [6]-helicine. 


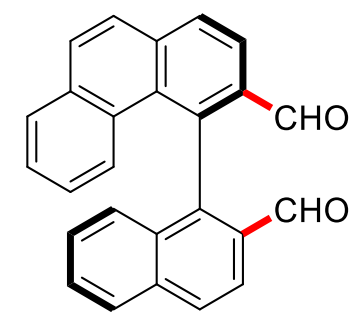

402

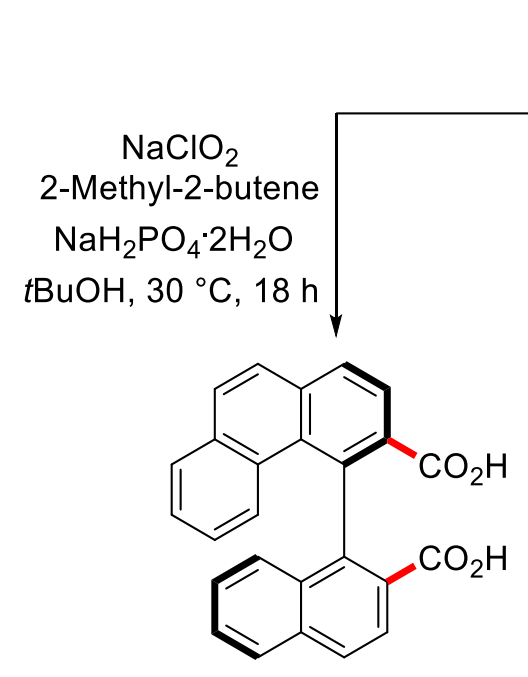

(R)-404: $82 \%, 96 \%$ ee (a) $m$ CPBA

$\mathrm{DCM}, 45^{\circ} \mathrm{C}, 48 \mathrm{~h}$

(b) $\mathrm{KOH}$

Scheme 128. Late-stage diversification to chiral diacid and substituted BINOL. 


\section{Summary and Outlook}

The advent of new synthetic strategies has enriched the synthetic organic chemistry to access molecules with tremendous complexity. In this context, transition metal-catalyzed $\mathrm{C}-\mathrm{H}$ activation has emerged as a powerful tool for highly step- and atom- economical synthesis that avoids laborious prefunctionalizations of starting materials. ${ }^{[27,56]}$ In this thesis, the primary focus was the development of novel and sustainable methods by direct $\mathrm{C}-\mathrm{H}$ activation to synthesize value-added synthetic targets of biological importance.

In the first project, the unprecedented use of a manganese(I) complex was demonstrated for challenging $\mathrm{C}-\mathrm{F} / \mathrm{C}-\mathrm{H}$ functionalizations (Scheme 129). ${ }^{[283]}$ Robust reaction conditions and ample substrate scope are some of the key characteristics of this approach. This method proved to be viable for synthetically meaningful ketimines. Thus, versatile manganese(I)-catalyzed $\mathrm{C}-\mathrm{F} / \mathrm{C}-\mathrm{H}$ functionalization allowed for the synthesis of diverse fluorinated scaffolds. In addition to allylations and alkenylations, we also identified the potential of manganese catalysis in $\mathrm{C}-\mathrm{H}$ perfluoroalkenylation using challenging perfluoroalkenes. It is noteworthy that even amino acids and peptides underwent $\mathrm{C}-\mathrm{F} / \mathrm{C}-\mathrm{H}$ functionalizations under racemization-free conditions.

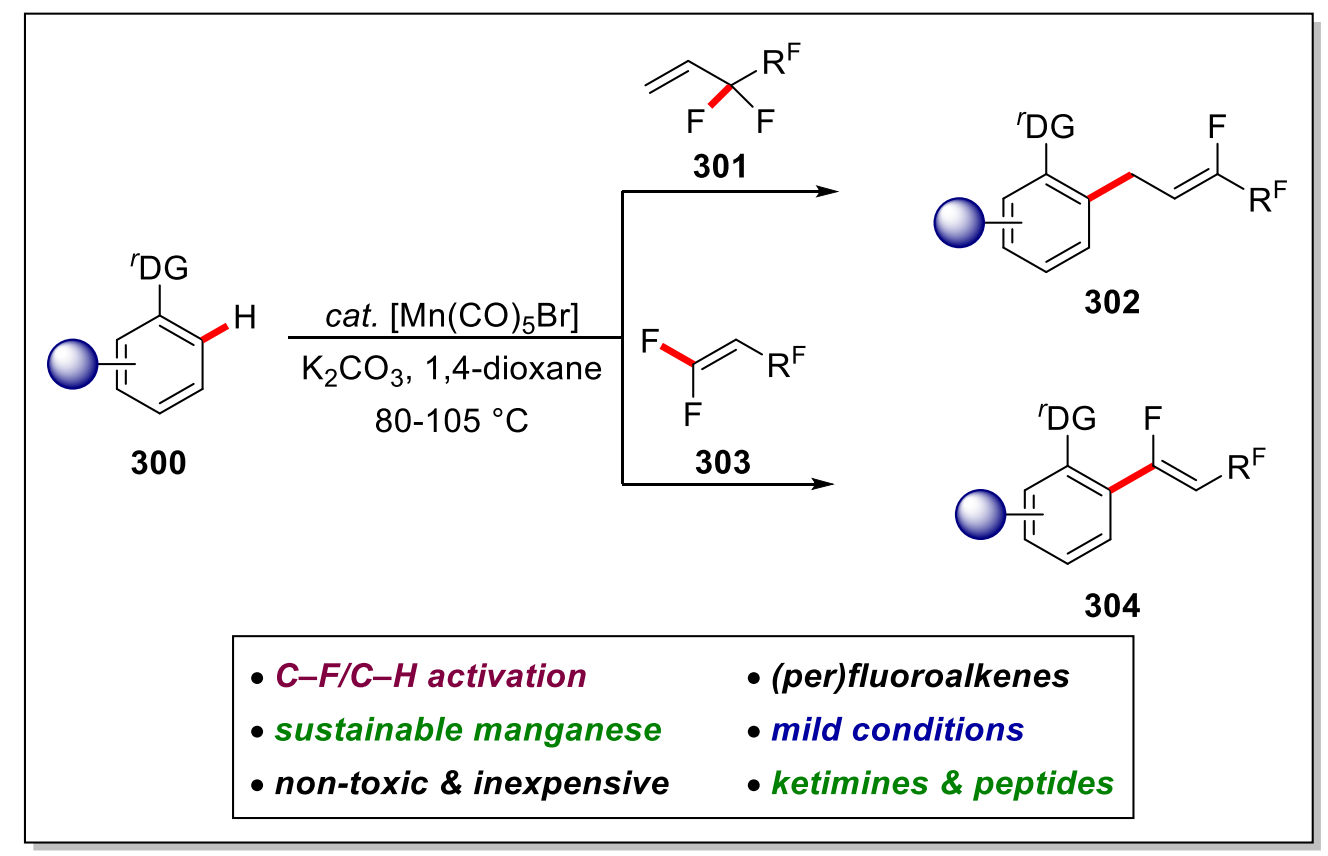

Scheme 129. Manganese(I)-catalyzed $\mathrm{C}-\mathrm{F} / \mathrm{C}-\mathrm{H}$ functionalizations.

In the second project, the versatility of ruthenium catalysis was shown towards $\mathrm{C}-\mathrm{F} / \mathrm{C}-\mathrm{H}$ functionalization (Scheme 130). ${ }^{[284]}$ Previously our group reported on the ruthenium-catalyzed $\mathrm{C}-\mathrm{H}$ hydroarylations with unactivated alkenes and perfluoroalkenes. In the present method, by 
the judicious choice of a tertiary phosphine ligand, a switch in chemoselectivity was observed towards challenging $\mathrm{C}-\mathrm{F}$ functionalization. More pleasingly, ketimines were found as amenable substrates for the envisioned $\mathrm{C}-\mathrm{F} / \mathrm{C}-\mathrm{H}$ functionalization to synthesis fluorinated ketones by a one-pot hydrolysis. This approach allowed for highly chemo- and positionselective $\beta$-fluorine eliminations with a broad range of substituted ketimines and perfluoroalkenes. Considering the importance of fluorinated building blocks, these studies are expected to inspire related developments in the field of transition metal catalysis.

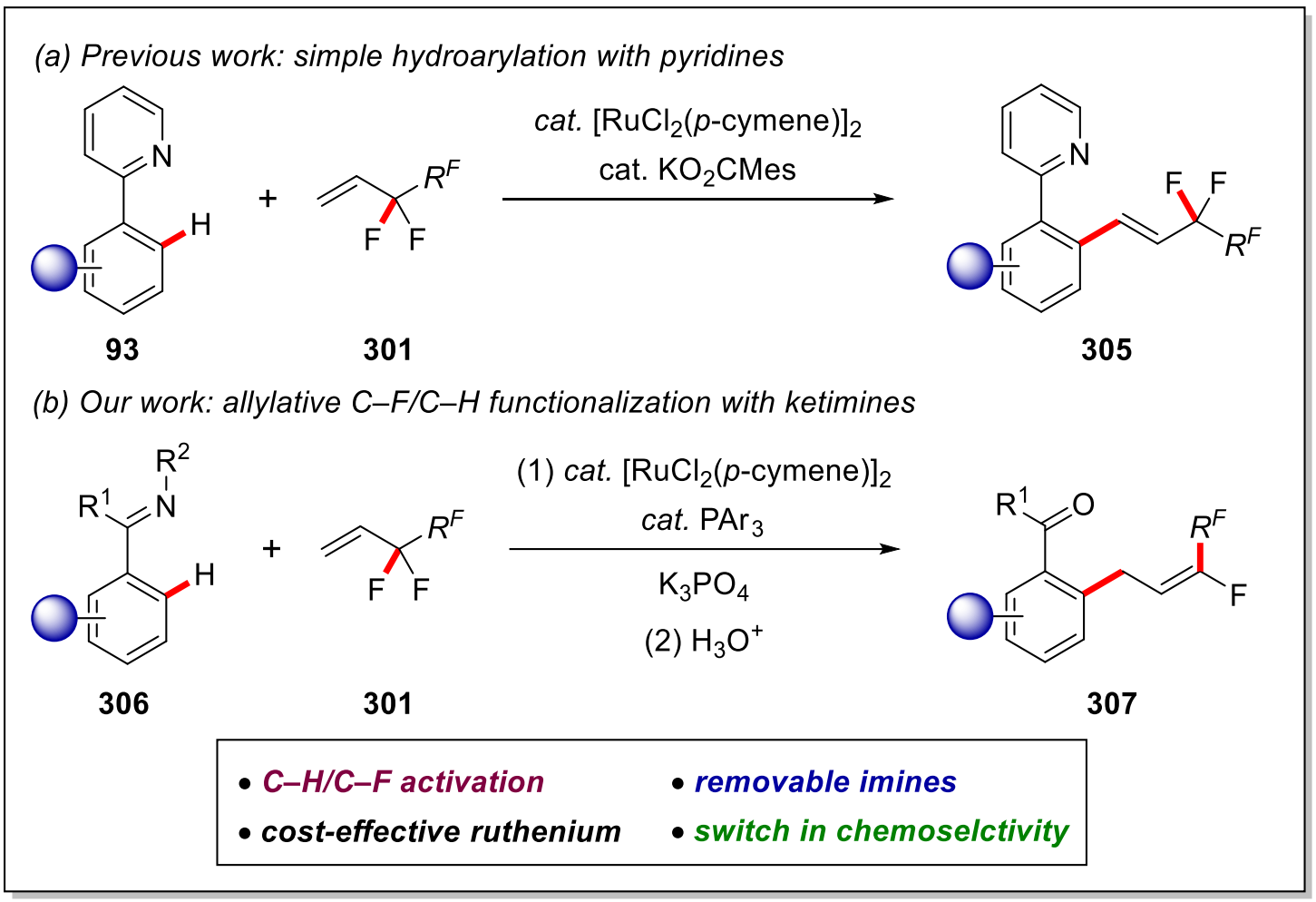

Scheme 130. E-selective C-H/C-F functionalization by ruthenium(II) catalysis.

As with fluorinated scaffolds, chiral molecules represent a class of highly desirable building blocks. Thus, the next part of the thesis focused on the development of sustainable enantioselective transformations using cost-effective transition metals. In the third project, we developed a novel chiral carboxylic acid CA5 to realize the first cobalt(III)-catalyzed enantioselective $\mathrm{C}-\mathrm{H}$ activation (Scheme 131). ${ }^{[270]}$ Initial studies with commonly used mono protected amino acids and chiral phosphoric acids failed to provide high levels of enantiocontrol. In contrast, the design of novel chiral carboxylic acid CA5 enabled the first highly enantioselective cobalt(III)-catalyzed C-H alkylation with unactivated alkenes $\mathbf{2 2 3}$ by organometallic chelation assisted $\mathrm{C}-\mathrm{H}$ activation. The mild Grignard-free reaction conditions tolerated a wide array of sensitive functional groups on the indoles $\mathbf{3 5 4}$ as well as on the alkene coupling partners 223. Moreover, the directing groups were removed in a traceless fashion 
under hydrogenation conditions without any erosion of the enantiomeric excess. Detailed mechanistic studies by kinetic experiments and non-linear effect studies provided evidence for dimeric hydrogen bond stabilized resting state of the chiral carboxylic acid. This study on cooperative cobalt(III)/chiral acid manifold set the stage for subsequent developments in the enantioselective cobalt(III)-catalyzed $\mathrm{C}-\mathrm{H}$ activation, as further reports were documented by Matsunaga ${ }^{[271 \mathrm{a}]}$ and Cramer. ${ }^{[285]}$

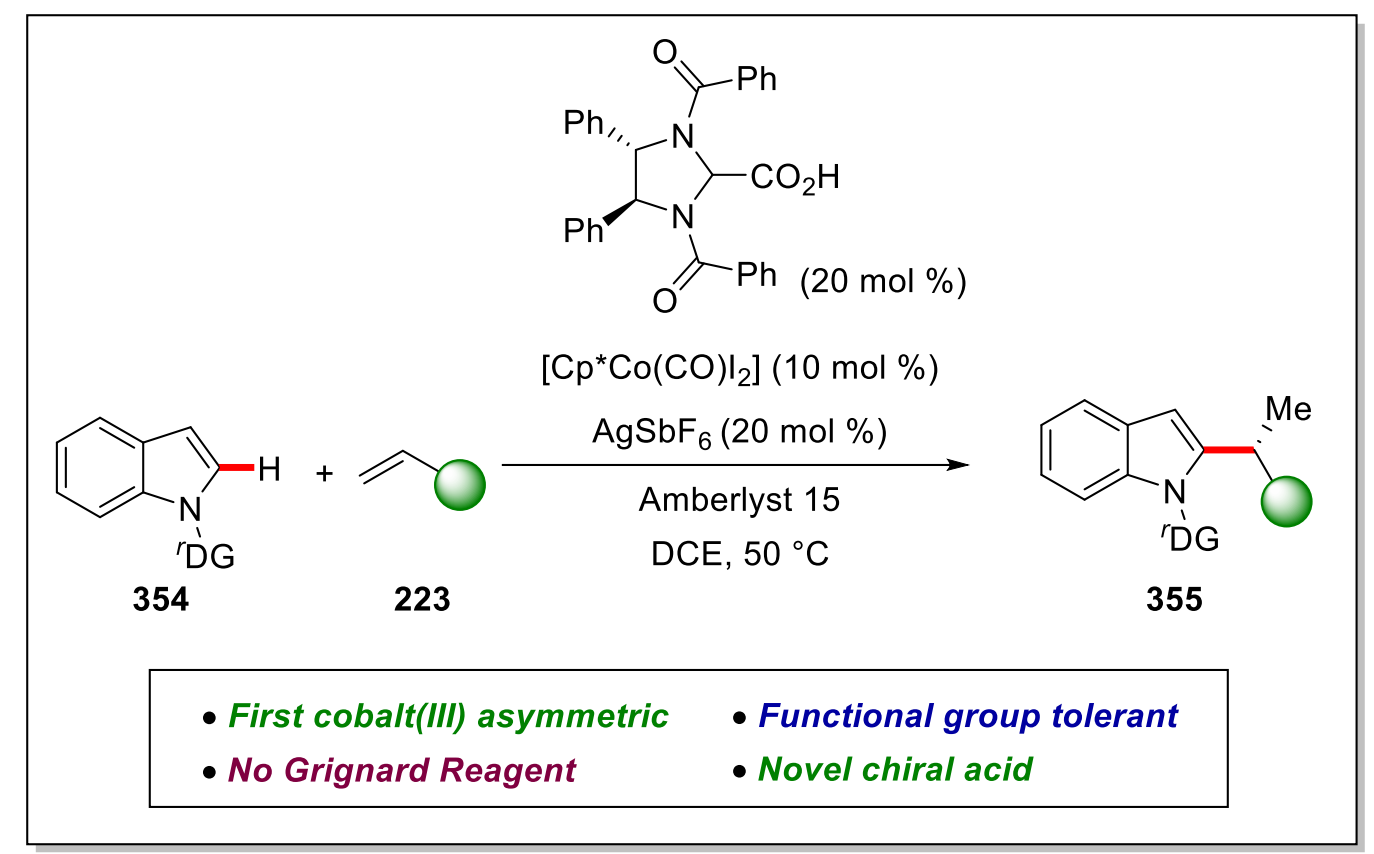

Scheme 131. Enantioselective cobalt(III)-catalyzed C-H alkylation by chiral carboxylic acid cooperation.

Thereafter, we became interested in the development of ruthenium-catalyzed enantioselective organometallic $\mathrm{C}-\mathrm{H}$ activation with the combination of a chiral acid. In contrast to the significant advances in the ruthenium catalyzed $\mathrm{C}-\mathrm{H}$ activation, organometallic enantioselective transformations remain largely underdeveloped. In this project we succeeded to achieve enantioselective ruthenium-catalyzed organometallic $\mathrm{C}-\mathrm{H}$ alkylation, employing a C2 symmetrical chiral acid CA14 to control the enantio-induction (Scheme 132). ${ }^{[286]}$ Costeffective and bench-stable $\left[\mathrm{RuCl}_{2}(p \text {-cymene) }]_{2}\right.$ was successfully employed with a chiral carboxylic acid to synthesis enantioenriched tetrahydrocarbazoles and cyclohepta[$[b]$ indoles derivatives by intramolecular cyclization at room temperature. $\mathrm{C} 2$-symmetric chiral acid was found to be crucial for enantioselective intramolecular $\mathrm{C}-\mathrm{H}$ alkylation while other commonly used chiral acids failed in this protocol. Detailed kinetic and DFT studies unraveled a reversible $\mathrm{C}-\mathrm{H}$ metalation step and an enantio-determining proto-demetalation step by the chiral acid. DFT studies provided support for the presence of weak secondary dispersive interactions to control enantio-induction. 


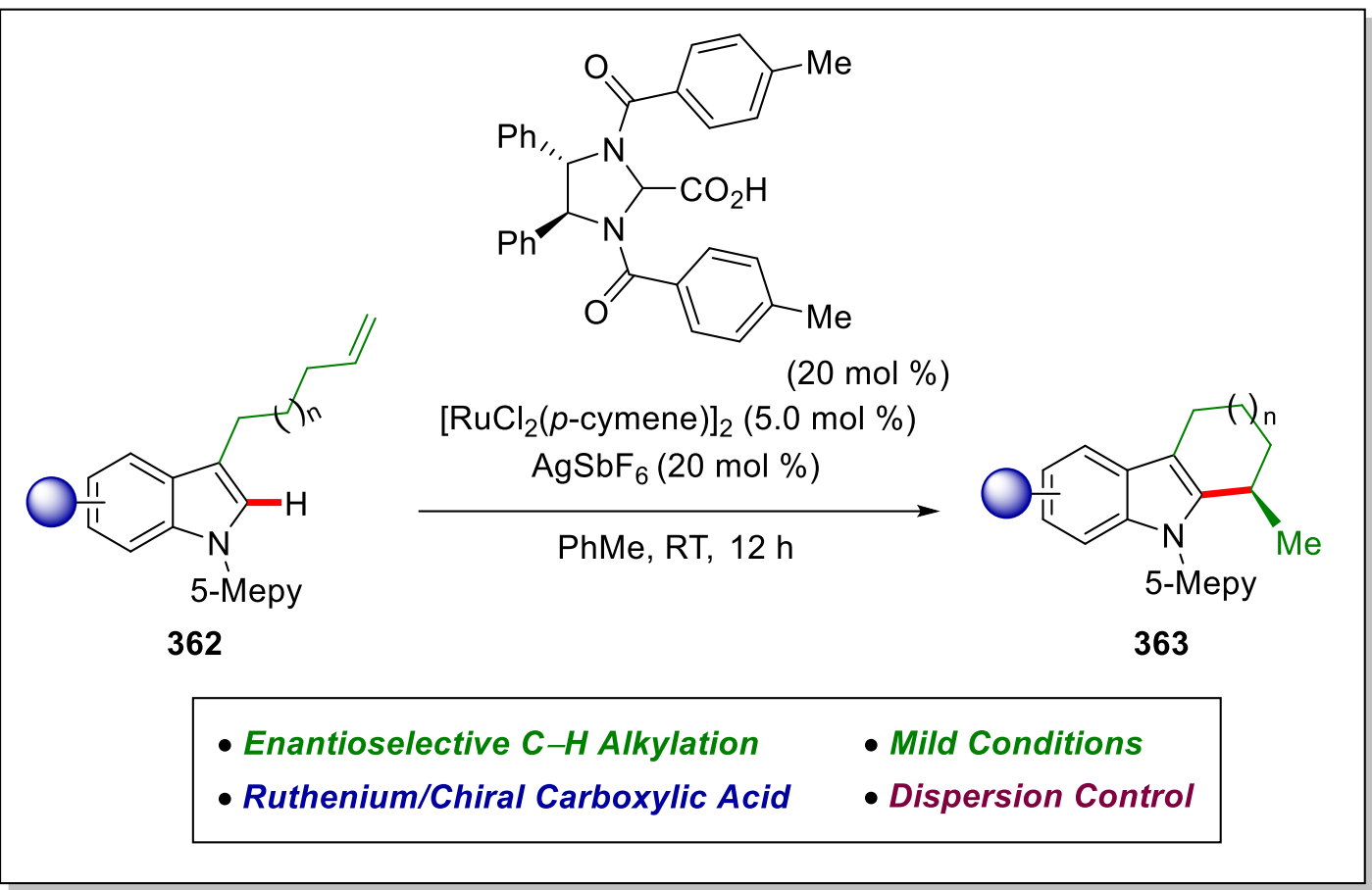

Scheme 132. Enantioselective ruthenium-catalyzed organometallic $\mathrm{C}-\mathrm{H}$ alkylation

Resource-economy is another important aspect in molecular syntheses. ${ }^{[224]}$ Consequently, a large portion of the doctoral thesis was focused on addressing improved sustainability and resource-economy for the activation of inert $\mathrm{C}-\mathrm{H}$ bonds. Over the past years, early examples of electrochemical $\mathrm{C}-\mathrm{H}$ activations were largely restricted to the use of palladium. In 2017, Ackermann realized the first electrochemical $3 \mathrm{~d}$ transition metal-catalyzed $\mathrm{C}-\mathrm{H}$ activation using inexpensive cobalt as a catalyst for oxygenation reactions, ${ }^{[246]}$ which has set the stage for the development of electrochemical transformations with Earth-abundant transition metals. ${ }^{\text {[232] }}$ In the fifth project, we realized electrochemical copper-catalyzed sequential alkyne annulations with benzamides to synthesis isoindolone motifs $\mathbf{2 5 6}$ in the absence of any chemical oxidants (Scheme 133). ${ }^{[287]}$ Inexpensive $\mathrm{Cu}(\mathrm{OAc})_{2}$ was employed as the catalyst for the electrooxidative alkynylation protocol by the assistance of 8 -aminoquinoline as the directing group. Furthermore, our reaction conditions were found to be suitable for the decarboxylative $\mathrm{C}-\mathrm{H} /$ C-C cleavage with alkynyl carboxylic acids. This study showed the unique potential of copper catalysts in electrochemical transformations, which is expected to inspire related developments in the near future. 


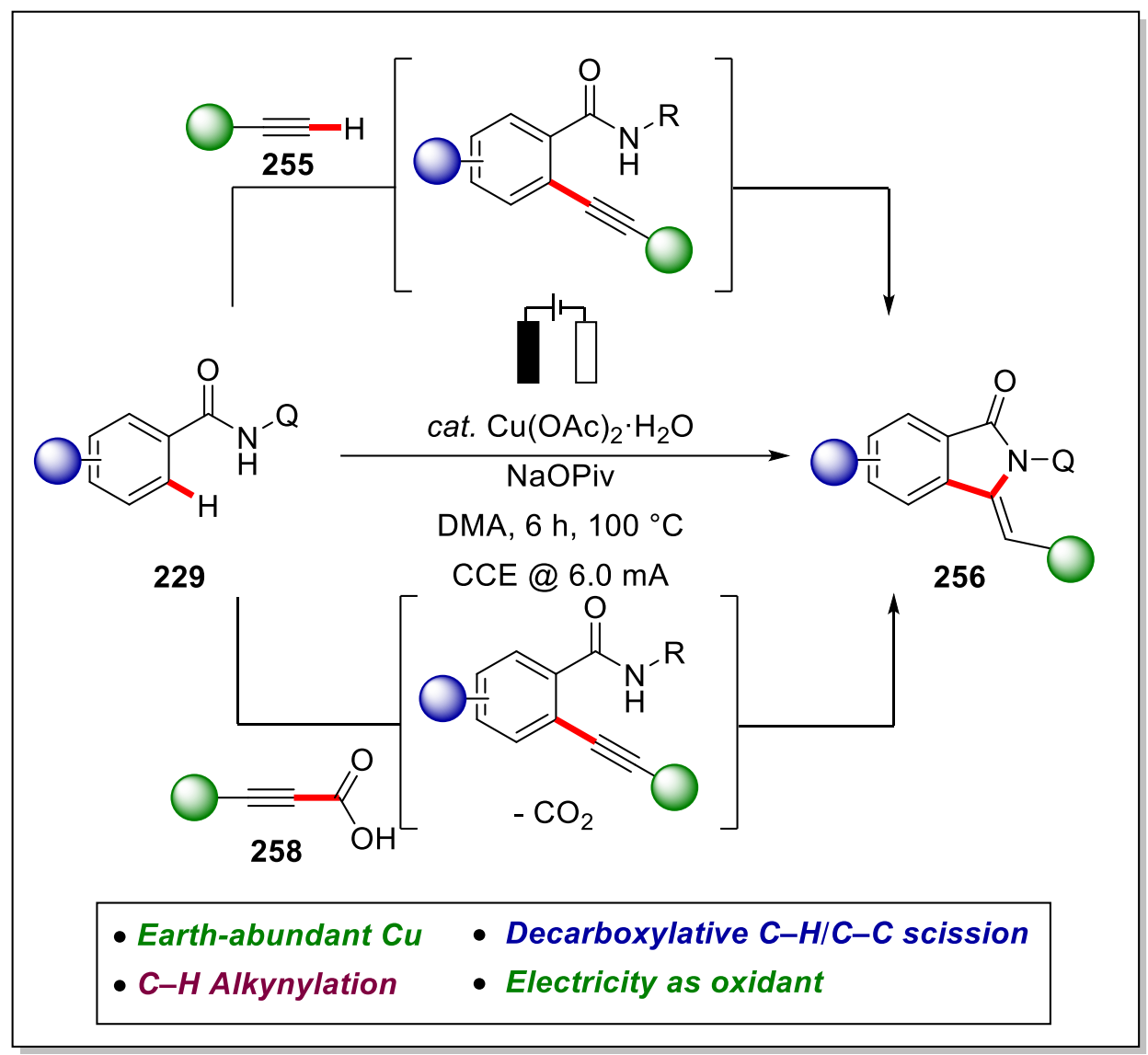

Scheme 133. Copper-catalyzed electrochemical alkyne annulation.

Thus far, all the reported electrochemical transformations with precious $4 \mathrm{~d}$ and $5 \mathrm{~d}$ transition metals were limited to activated alkenes, such as styrenes and acrylates. In the subsequent project, we showed the versatility of oxidative cobalt catalysis in electrocatalytic $\mathrm{C}-\mathrm{H}$ allylations with unbiased olefins (Scheme 134). ${ }^{[288]}$ A key characteristic of our strategy was the use of the biomass-derived solvent $\gamma$-valerolactone as the reaction media. Electro-oxidative cobalt catalysis provided the chelation-assisted ortho- $\mathrm{C}-\mathrm{H}$ allylation by the assistance of 8 aminoquinoline as the directing group, generating molecular hydrogen as the sole stoichiometric by-product. A plethora of sensitive functional groups were fully tolerated, providing exclusively the allylic selectivity. Competition experiment provided evidence for a base-assisted internal electrophilic-type substitution mechanism for the $\mathrm{C}-\mathrm{H}$ metalation event. This turns out to be one of the scarce example for the application of unactivated olefins in electrochemical $\mathrm{C}-\mathrm{H}$ activation reactions. 


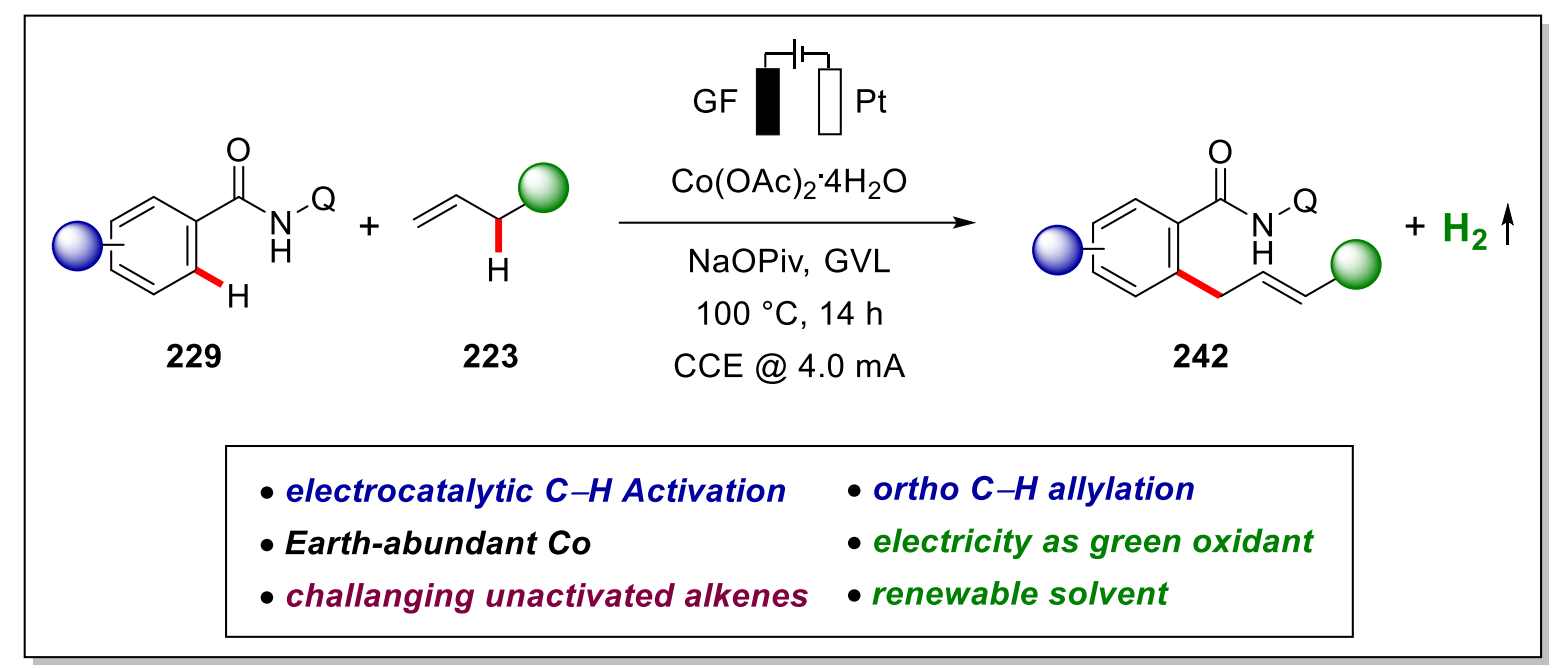

Scheme 134. Cobalt-catalyzed electrochemical C-H allylation

The merger of electrosynthesis with transition metal catalysis provides enormous potential towards perfect resource economy. Despite substantial progress, enantioselective metallaelectro-catalyzed $\mathrm{C}-\mathrm{H}$ activation was not realized before. To address the full potential of electrochemistry and considering practical importance of chiral building blocks, we achieved the first asymmetric metallaelectro-catalyzed $\mathrm{C}-\mathrm{H}$ activation under exceedingly mild reaction conditions (Scheme 135). ${ }^{[289]}$ We employed inexpensive L-tert-leucine as a transient directing group to enable electrochemical atroposelective organometallic $\mathrm{C}-\mathrm{H}$ activation. This was the unprecedented report for the application of transient directing group in electrochemical transformations. The combination of $\mathrm{Pd}(\mathrm{OAc})_{2}$ and L-tert-leucine provided excellent enantioselectivities for the atroposelective olefination reactions to furnish axially-chiral biaryls. On a pleasing note, similar reaction conditions were also effective for the synthesis of $\mathrm{N}-\mathrm{C}$ axially-chiral motifs in excellent enantioselectivities. Detailed kinetic studies shed light on the $\mathrm{C}-\mathrm{H}$ metalation step, being suggestive of the $\mathrm{C}-\mathrm{H}$ activation as the rate-determining step. In addition, DFT studies showed preference for the formation of seven membered ring over the five-membered metallacycle to enable the axial chirality. This metallaelectrocatalyzed enantioselective protocol provided a step-economical strategy to the synthesis of highly enantio-enriched BINOLs, dicarboxylic acids and helicenes. Given the topical interest in the development of new approach for enantioselective transformations, this sustainable protocol paves the path for further developments in this research area. 


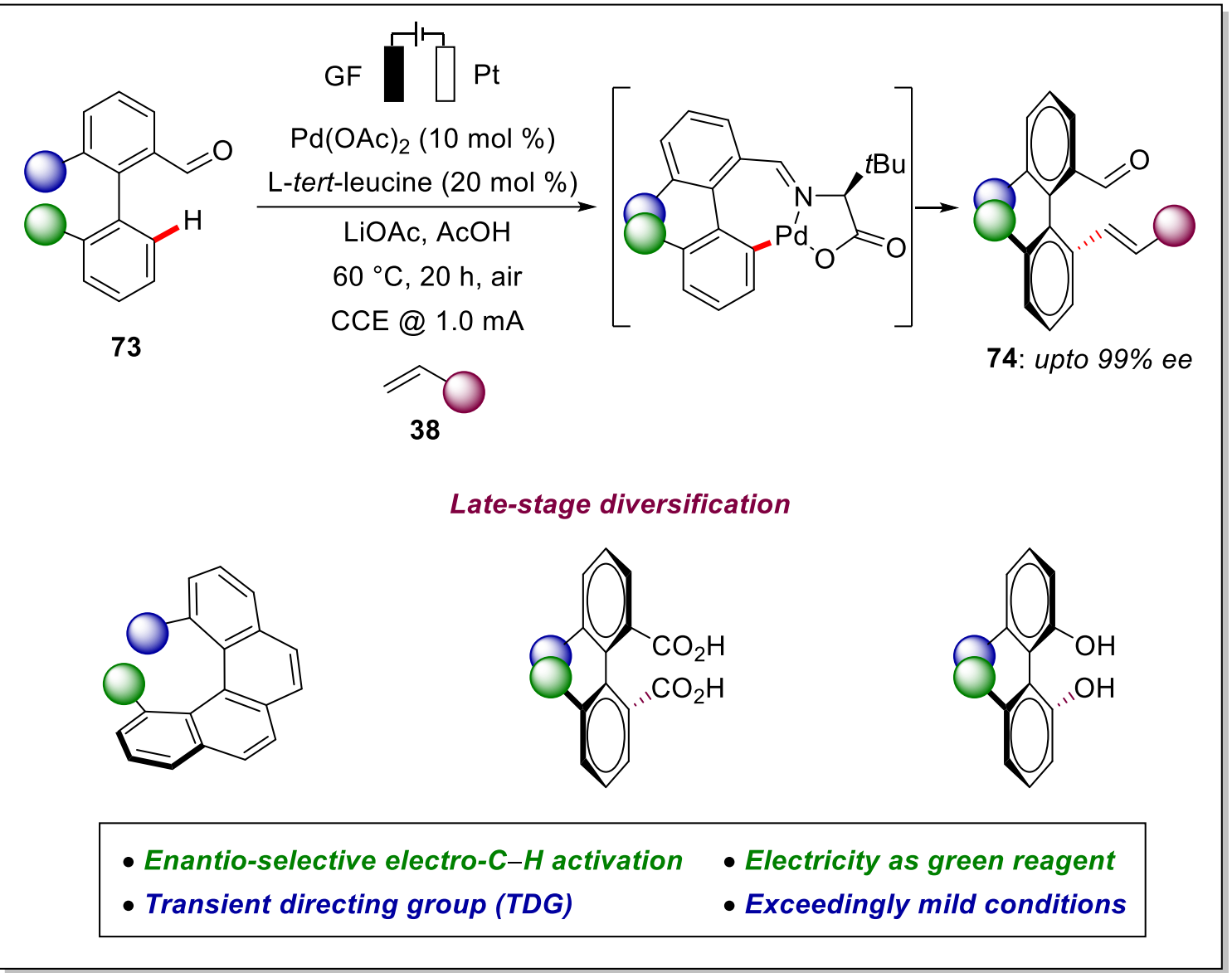

Scheme 135. Metallaelectro-catalyzed enantioselective $\mathrm{C}-\mathrm{H}$ activation. 


\section{Experimental Part}

\subsection{General Remarks}

All reactions involving air- and/or moisture-sensitive compounds were conducted under a dry nitrogen atmosphere using pre-dried glassware and standard Schlenk techniques. If not otherwise noted, yields refer to isolated compounds which were estimated to be $>95 \%$ pure based on ${ }^{1} \mathrm{H}-\mathrm{NMR}$.

\section{Vacuum}

The following average pressure was measured on the used rotary vane pump RD4 from Vacuubrand ${ }^{\circledR}: 0.8 \cdot 10-1$ mbar (uncorrected value).

\section{Melting Points}

Melting points were measured on a Stuart ${ }^{\circledR}$ Melting Point Apparatus SMP3 from Barloworld Scientific. Values are uncorrected.

\section{Chromatography}

Analytical thin layer chromatography (TLC) was performed on silica gel 60 F254 aluminium sheets from Merck. Plates were either visualized under irradiation at $254 \mathrm{~nm}$ or $365 \mathrm{~nm}$ or developed by treatment with a potassium permanganate solution followed by careful warming. Chromatographic purifications were accomplished by column chromatography on Merck Geduran ${ }^{\circledR}$ silica gel, grade 60 (40-63 $\mu \mathrm{m}, 70-230$ mesh ASTM).

\section{Gel permeation chromatography (GPC)}

GPC purifications were performed on a JAI system (JAI-LC-9260 II NEXT) equipped with two sequential columns (JAIGEL-2HR, gradient rate: 5.000; JAIGEL-2.5HR, gradient rate: 20.000; internal diameter $=20 \mathrm{~mm}$; length $=600 \mathrm{~mm}$; Flush rate $=10.0 \mathrm{~mL} / \mathrm{min}$ and chloroform (HPLC-quality with $0.6 \%$ ethanol as stabilizer) was used as the eluent.

\section{Infrared Spectroscopy}

IR spectra were recorded using a Bruker ${ }^{\circledR}$ Alpha-P ATR spectrometer. Liquid samples were measured as film and solid samples neat. Spectra were recorded in the range from 4000 to 400 $\mathrm{cm}^{-1}$. Analysis of the spectral data was carried out using Opus 6. Absorption is given in wave numbers $\left(\mathrm{cm}^{-1}\right)$. 


\section{Nuclear Magnetic Resonance Spectroscopy}

NMR spectra were recorded on Mercury Plus 300, VNMRS 300, Inova 500 and 600 from Varian®, or Avance 300, Avance III 300 and 400, Avance III HD 400 and 500 from Bruker®. Chemical shifts are reported in $\delta$-values in ppm relative to the residual proton peak or carbon peak of the deuterated solvent.

The coupling constants $J$ are reported in hertz $(\mathrm{Hz})$. Analysis of the recorded spectra was carried out using MestReNova 10.0 software.

$\begin{array}{ccc} & { }^{1} \mathrm{H}-\mathrm{NMR} & { }^{13} \mathrm{C}-\mathrm{NMR} \\ \mathrm{CDCl}_{3} & 7.26 & 77.16 \\ \mathrm{CD}_{3} \mathrm{CO}_{2} \mathrm{D} & 11.65 & 179.0\end{array}$

\section{Gas Chromatography}

Monitoring of reaction process via gas chromatography or coupled gas chromatography-mass spectrometry was performed using a 7890 GC-system with/without mass detector 5975C (Triple-Axis-Detector) or a 7890B GC-system coupled with a 5977A mass detector, both from Agilent Technologies ${ }^{\circledR}$.

\section{Mass Spectrometry}

Electron ionization (EI) and EI high resolution mass spectra (HR-MS) were measured on a time-of-flight mass spectrometer AccuTOF from JEOL. Electrospray ionization (ESI) mass spectra were recorded on an Io-Trap mass spectrometer LCQ from Finnigan, a quadrupole time-of-flight maXis from Bruker Daltonic or on a time-of-flight mass spectrometer microTOF from Bruker Daltonic. ESI-HR-MS spectra were recorded on a Bruker Apex IV or Bruker Daltonic 7T, Fourier transform ion cyclotron resonance (FTICR) mass spectrometer. The ratios of mass to charge $(\mathrm{m} / \mathrm{z})$ are indicated, intensities relative to the base peak $(\mathrm{I}=100)$ are written in parentheses.

\section{Chiral HPLC}

Chiral HPLC chromatograms were recorded on an Agilent 1290 Infinity using CHIRALPAK ${ }^{\circledR}$ IA-3, IB-3, IC-3, ID-3, IE-3 and IF-3 columns (3.0 $\mu \mathrm{m}$ particle size; ø: $4.6 \mathrm{~mm}$ and $250 \mathrm{~mm}$ length) at ambient temperature. 


\section{Specific Rotations}

Optical rotations were measured on an Anton Paar MCP 150 polarimeter using a $10 \mathrm{~cm}$ cell with a $\mathrm{Na} 589 \mathrm{~nm}$ filter. Concentrations are indicated in $\mathrm{g} / 100 \mathrm{~mL}$.

\section{Solvents}

All solvents for reactions involving air- and/or moisture-sensitive reagents were dried, distilled and stored under an inert atmosphere (dry nitrogen) according to the following standard procedures.

1,2-Dichloroethane (DCE) and toluene (PhMe) were dried over $\mathrm{CaH}_{2}$ for $8 \mathrm{~h}$, degassed and distilled under reduced pressure. 1,4-Dioxane and di- $n$-butylether $\left(n \mathrm{Bu}_{2} \mathrm{O}\right)$ were dried over $\mathrm{Na}$ for $8 \mathrm{~h}$, degassed and distilled under reduced pressure.

$\mathrm{CH}_{2} \mathrm{Cl}_{2}$, DMF, THF, Et $2 \mathrm{O}$ were obtained from a MBRAUN MB SPS-800 solvent purification system.

\section{Chemicals}

Chemicals obtained from commercial sources with a purity $>95 \%$ were used as received without further purification.

The following compounds were known from the literature and synthesized according to previously known methods: Indoles $\mathbf{3 1 5}$ and $\mathbf{3 5 4}^{[290]}$ and $\mathbf{3 6 2},{ }^{[291]}$, ketimines $\mathbf{3 4 0}^{[292]}$, Benzamides 229 ${ }^{[293]}$, Biaryl aldehydes 73. ${ }^{[89]}$

The following compounds were kindly synthesized and provided by the persons listed below: Karsten Rauch: IMes $\cdot \mathrm{HCl}, \mathrm{IPr} \cdot \mathrm{HCl},\left[\mathrm{RuCl}_{2}(p \text {-cymene) }]_{2},\left[\mathrm{Cp} * \mathrm{RhCl}_{2}\right]_{2}\right.$, dry and/or degassed solvents (DCE, $t \mathrm{AmOH}, 1,4-$ dioxane, $\mathrm{PhMe}$ ).

Dr. Daniel Zell: Indole 354e.

Valentine Müller: gem-Difluorostyrene 11a.

Dr. Fabio Pesciaioli: Chiral acid CA5.

Dr. Cong Tian: Benzamide 229d.

Nikolaos Kaplaneris: Indole 328a-328c, Alkene 38e-38j and 38k, 255m, Ligand CA2 and CA8.

Rongxin Yin: Indole 354b-354c, ketimine 340f.

Julia Struwe: 2-Phenyl pyridines $\mathbf{9 3 b}$.

Becky Bongsuiru Jei: Chiral acid CA13 and CA15. 


\subsection{General Procedures}

\subsubsection{General Procedure A: Manganese(I)-Catalyzed Allylative C-H/C-F Functionalization}

A suspension of heteroarene 315 ( $0.50 \mathrm{mmol}, 1.00$ equiv), $1 H, 1 H, 2 H$-perfluoroalkene 301 (0.60 mmol, 1.20 equiv), $\left[\mathrm{MnBr}(\mathrm{CO})_{5}\right] \quad(10.3 \mathrm{mg}, \quad 7.5 \mathrm{~mol} \%)$ and $\mathrm{K}_{2} \mathrm{CO}_{3} \quad(69.1 \mathrm{mg}$, $0.50 \mathrm{mmol}, 1.00$ equiv) in 1,4-dioxane $(0.50 \mathrm{~mL}, 1.00 \mathrm{M})$ was stirred at $80{ }^{\circ} \mathrm{C}$ for $20 \mathrm{~h}$. At ambient temperature, the mixture was diluted with EtOAc $(3.0 \mathrm{~mL})$ and the solvents were removed in vacuo and the remaining residue was purified by column chromatography on silica gel to afford the desired products $\mathbf{3 1 6}$.

\subsubsection{General Procedure B: Manganese(I)-Catalyzed $\mathrm{C}-\mathrm{H} / \mathrm{C}-\mathrm{F}$ Functionalization of} Heteroarenes with Perfluoroalkenes

A suspension of heteroarene $\mathbf{3 1 5 / 3 2 8 / 3 3 2}$ ( $0.50 \mathrm{mmol}$, 1.00 equiv), perfluoroalkene $\mathbf{3 0 3}$ (1.50 mmol, 3.00 equiv), $\left[\mathrm{MnBr}(\mathrm{CO})_{5}\right](13.7 \mathrm{mg}, 10.0 \mathrm{~mol} \%)$ and $\mathrm{K}_{2} \mathrm{CO}_{3} \quad(69.0 \mathrm{mg}$, $0.50 \mathrm{mmol}, 1.00$ equiv) in 1,4-dioxane $(0.50 \mathrm{~mL}, 1.00 \mathrm{M})$ was stirred at $100{ }^{\circ} \mathrm{C}$ for $20 \mathrm{~h}$. At ambient temperature, the solvent was removed in vacuo and the remaining residue was purified by column chromatography on silica gel to afford the desired products $\mathbf{3 2 8 / 3 3 1 / 3 3 3}$.

\subsubsection{General Procedure C: Ruthenium(II)-Catalyzed C-F/C-H Functionalization}

A suspension of ketimine 340 ( $0.50 \mathrm{mmol}, 1.0$ equiv), $1 \mathrm{H}, 1 \mathrm{H}, 2 \mathrm{H}$-perfluoroalkene 301 (1.50 mmol, 3.0 equiv), $\left[\mathrm{RuCl}_{2}(p \text {-cymene })\right]_{2}(15.3 \mathrm{mg}, 5.0 \mathrm{~mol} \%), \mathrm{P}\left(4-\mathrm{C}_{6} \mathrm{H}_{4} \mathrm{~F}\right)_{3}(31.6 \mathrm{mg}$, $20 \mathrm{~mol} \%$ ) and $\mathrm{K}_{3} \mathrm{PO}_{4}(212 \mathrm{mg}, 1.0 \mathrm{mmol}, 2.0$ equiv) in cyclohexane (1.0 mL) was stirred under $\mathrm{N}_{2}$ at $120{ }^{\circ} \mathrm{C}$ for $24 \mathrm{~h}$ in pressure tube. At ambient temperature, the reaction mixture was diluted with EtOAc $(5.0 \mathrm{~mL})$ and $\mathrm{HCl}(5.0 \mathrm{~mL}, 1 \mathrm{M})$ was added. The mixture was stirred for 3 $\mathrm{h}$ and extracted with EtOAc $(3 \times 10.0 \mathrm{~mL})$. After removal of the solvents in vacuo, the remaining residue was purified by column chromatography on silica gel to afford the desired products 307. 


\subsubsection{General Procedure D: Synthesis of the chiral acid CA5-CA7 and CA10-CA14.}

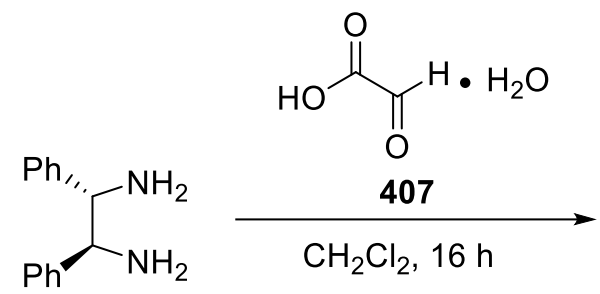

406

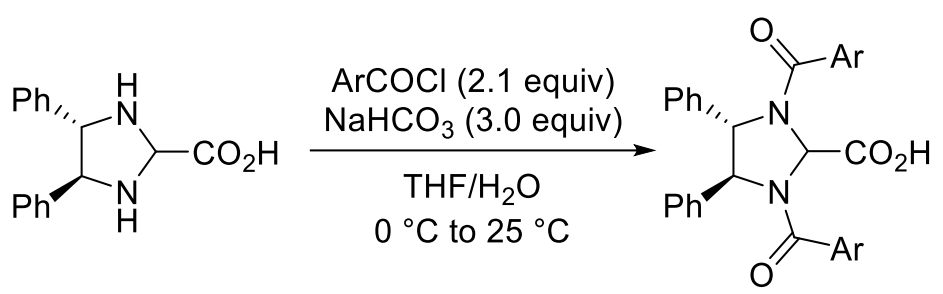

408
CA5-CA7 and

CA10-CA14

To a solution of $(S, S)$-diphenylethanediamine (212.3 mg, $1.00 \mathrm{mmol})$ in $\mathrm{CH}_{2} \mathrm{Cl}_{2}(4.0 \mathrm{~mL})$ was added an equimolar amount of glyoxylic acid monohydrate $(92.1 \mathrm{mg}, 1.00 \mathrm{mmol})$ under vigorous stirring. After $16 \mathrm{~h}$, the solvent was removed to afford $(4 S, 5 S)-4,5-$ diphenylimidazolidine-2- carboxylic acid 408 (265.3 mg, 99\% yield) as a yellow solid.

To a solution of 408 in $\mathrm{THF} / \mathrm{H}_{2} \mathrm{O}(5 \mathrm{~mL}, 1: 1)$ at $0{ }^{\circ} \mathrm{C}, \mathrm{NaHCO}_{3}(252 \mathrm{mg}, 3.00 \mathrm{mmol})$ and acyl chloride ( $2.10 \mathrm{mmol}, 2.1$ equiv) were added, and the reaction was allowed to reach ambient temperature. After $16 \mathrm{~h}$, the reaction mixture was diluted with $\mathrm{CH}_{2} \mathrm{Cl}_{2}(10 \mathrm{~mL})$ and washed with $\mathrm{HCl}(1 \mathrm{M}, 10 \mathrm{~mL})$ solution. The aqueous phase was extracted with $\mathrm{CH}_{2} \mathrm{Cl}_{2}(3 \times 10 \mathrm{~mL})$. The combined organic phase was washed with brine and dried over $\mathrm{Na}_{2} \mathrm{SO}_{4}$ and the solvent was removed under vacuum. The crude mixture was purified via flash chromatography $\left(\mathrm{CH}_{2} \mathrm{Cl}_{2}\right.$ $100 \%$ to $\left.\mathrm{CH}_{2} \mathrm{Cl}_{2}: \mathrm{CH}_{3} \mathrm{OH}=90: 10\right)$ to afford chiral acids CA5-CA7 and CA10-CA14.

\subsubsection{General Procedure E: Cobalt(III)-Catalyzed Asymmetric C-H Alkylation}

A suspension of indole 354 ( $0.50 \mathrm{mmol}, 1.00$ equiv), alkene 223 (1.50 mmol, 3.00 equiv), [Cp*Co(CO)I $\mathrm{I}_{2}$ ( $\left.23.8 \mathrm{mg}, 50.0 \mu \mathrm{mol}, 10.0 \mathrm{~mol} \%\right), \mathrm{AgSbF}_{6}(34.4 \mathrm{mg}, 100 \mu \mathrm{mol}, 20.0 \mathrm{~mol} \%)$, chiral acid CA5 (48.0 mg, $100 \mu \mathrm{mol}, 20.0 \mathrm{~mol} \%$ ) and Amberlyst 15 (160 mg, 1.50 equiv) in DCE $(0.5 \mathrm{~mL}, 1.0 \mathrm{M})$ were stirred at $50{ }^{\circ} \mathrm{C}$ for $65 \mathrm{~h}$. At ambient temperature, the reaction mixture was diluted with EtOAc $(2.0 \mathrm{~mL})$ and $\mathrm{Et}_{3} \mathrm{~N}(0.5 \mathrm{~mL})$ was added. The mixture was stirred for $0.5 \mathrm{~h}$ and filtered through a short pad of silica and the solvents were removed in vacuo. The crude mixture was purified by flash column chromatography on silica gel to afford the desired product 355.

\subsubsection{General Procedure F: Synthesis of Racemic Products for Cobalt(III)-Catalyzed} C-H Alkylation

A suspension of indole 354 ( $0.50 \mathrm{mmol}, 1.00$ equiv), alkene 223 (1.50 mmol, 3.00 equiv), [Cp*Co(CO)I $\mathrm{I}_{2}$ ( $\left.23.8 \mathrm{mg}, 50.0 \mu \mathrm{mol}, 10.0 \mathrm{~mol} \%\right), \mathrm{AgSbF}_{6}(34.4 \mathrm{mg}, 100 \mu \mathrm{mol}, 20.0 \mathrm{~mol} \%)$, $1-\mathrm{AdCO}_{2} \mathrm{H}(48.0 \mathrm{mg}, 100 \mu \mathrm{mol}, 20.0 \mathrm{~mol} \%)$ in $\mathrm{DCE}(0.5 \mathrm{~mL}, 1.0 \mathrm{M})$ were stirred at $50{ }^{\circ} \mathrm{C}$ for $20 \mathrm{~h}$. At ambient temperature, the reaction mixture was diluted with EtOAc (2.0 mL) and the 
solvents were removed in vacuo. The crude mixture was purified by flash column chromatography on silica gel to afford the racemic product 355 .

\subsubsection{General Procedure G: Traceless Removable of Directing Group for Cobalt(III)- Catalyzed C-H Alkylated Products}

To a solution of 355 (0.2 mmol, 1.00 equiv) in $\mathrm{CH}_{2} \mathrm{Cl}_{2}(0.5 \mathrm{~mL})$ was added MeOTf (36.1 mg, 1.10 equiv) dropwise at $0{ }^{\circ} \mathrm{C}$. After $30 \mathrm{~min}$, the mixture was allowed to warm up to $25^{\circ} \mathrm{C}$ and stirred for $6 \mathrm{~h}$. After removal of the solvent in vacuo, $\mathrm{Pd}(\mathrm{OH})_{2} / \mathrm{C}(7.7 \mathrm{mg}, 10$ wt.-\%) and ammonium formate (126 mg, $2.00 \mathrm{mmol}, 10.0$ equiv) were added. The mixture was diluted with $\mathrm{MeOH}(1.0 \mathrm{~mL})$ and stirred at $60{ }^{\circ} \mathrm{C}$ for $6 \mathrm{~h}$. After addition of EtOAc $(5.0 \mathrm{~mL})$ at ambient temperature, the mixture was filtered through a short pad of celite ${ }^{\circledR}$ and the solvents were removed in vacuo. The crude mixture was purified by flash column chromatography on silica gel to yield $\mathbf{3 5 7}$.

\subsubsection{General Procedure H: Ruthenium(II)-Catalyzed Asymmetric C-H Alkylation for the Synthesis of Tetrahydrocarbazoles}

A suspension of indole 362 (0.25 mmol, 1.00 equiv), [ $\mathrm{RuCl}_{2}$ (p-cymene) ]2 (7.7 mg, $5.0 \mathrm{~mol} \%$ ), $\mathrm{AgSbF}_{6}(17.2 \mathrm{mg}, 20 \mathrm{~mol} \%$ ), chiral acid CA14 (25.2 mg, $20 \mathrm{~mol} \%)$ in PhMe (0.50 mL) were stirred at $25{ }^{\circ} \mathrm{C}$ for $12 \mathrm{~h}$. The reaction mixture was diluted with EtOAc $(2.0 \mathrm{~mL})$ and the solvent was removed in vacuo. The crude mixture was purified by column chromatography on silica gel to afford the desired product $\mathbf{3 6 3}$.

\subsubsection{General Procedure I: Synthesis of Racemic Products for Ruthenium(II)-Catalyzed} C-H Alkylation

A suspension of indole 362 ( $0.10 \mathrm{mmol}, 1.00$ equiv), [ $\mathrm{RuCl}_{2}$ (p-cymene) $]_{2}(3.1 \mathrm{mg}, 5.0 \mathrm{~mol} \%)$, $\mathrm{AgSbF}_{6}(6.9 \mathrm{mg}, 100 \mu \mathrm{mol}, 20 \mathrm{~mol} \%), 1-\mathrm{AdCO}_{2} \mathrm{H}(18.0 \mathrm{mg}, 1$ equiv) in $\mathrm{PhMe}(0.50 \mathrm{~mL})$ were stirred at $50{ }^{\circ} \mathrm{C}$ for $12 \mathrm{~h}$. At ambient temperature, the reaction mixture was diluted with EtOAc $(2.0 \mathrm{~mL})$ and the solvents were removed in vacuo. The crude mixture was purified by column chromatography on silica gel to afford the racemic products rac-363.

\subsubsection{General Procedure J: Copper-catalyzed Alkyne Annulation by C-H Alkynylation}

The electrocatalysis was carried out in an undivided cell, with a RVC anode $(10 \mathrm{~mm} \times 15 \mathrm{~mm}$ $\times 6 \mathrm{~mm})$ and a platinum cathode $(10 \mathrm{~mm} \times 15 \mathrm{~mm} \times 0.25 \mathrm{~mm})$. Benzamide $229(0.25 \mathrm{mmol}$, 1.0 equiv), alkyne 255 ( $0.50 \mathrm{mmol}, 2.0$ equiv), NaOPiv ( $31 \mathrm{mg}, 0.25 \mathrm{mmol}, 1.0$ equiv) and 
$\mathrm{Cu}(\mathrm{OAc})_{2} \cdot \mathrm{H}_{2} \mathrm{O}(2.5 \mathrm{mg}, 5.0 \mathrm{~mol} \%)$ were placed in a $10 \mathrm{~mL}$ cell and dissolved in DMA (4.0 $\mathrm{mL}$ ). Electrocatalysis was performed at $100{ }^{\circ} \mathrm{C}$ with a constant current of $6.0 \mathrm{~mA}$ maintained for $6 \mathrm{~h}$. At ambient temperature, saturated aqueous $\mathrm{NaHCO}_{3}(4.0 \mathrm{~mL})$ was added. The RVC anode was washed with EtOAc $(3 \times 10 \mathrm{~mL})$ in an ultrasonic bath. The washings were added to the reaction mixture and the combined phases were extracted with EtOAc $(4 \times 10 \mathrm{~mL})$, then dried over $\mathrm{Na}_{2} \mathrm{SO}_{4}$. Evaporation of the solvent and subsequent column chromatography on silica gel afforded the corresponding products 256.

\subsubsection{General Procedure K: Cobaltaelectro-Catalyzed C-H Allylation}

The electrolysis was carried out in an undivided cell with a GF anode $(10 \mathrm{~mm} \times 15 \mathrm{~mm} \times 6$ $\mathrm{mm})$ and a platinum cathode $(10 \mathrm{~mm} \times 15 \mathrm{~mm} \times 0.25 \mathrm{~mm}) . \mathrm{Co}(\mathrm{OAc})_{2} \cdot 4 \mathrm{H}_{2} \mathrm{O}(12.7 \mathrm{mg}, 0.05$ mmol, $10 \mathrm{~mol} \%$ ), NaOPiv (124.0 mg, $1.0 \mathrm{mmol}, 2.0$ equiv), $n-\mathrm{Bu}_{4} \mathrm{NPF}_{6}$ (97.0 mg, $0.25 \mathrm{mmol}$, 0.50 equiv) and benzamide 229 ( $0.50 \mathrm{mmol}, 1.0$ equiv) were dissolved in GVL (4.0 mL) and the alkene 223 ( $1.5 \mathrm{mmol}, 3.0$ equiv) was added sequentially. At $100{ }^{\circ} \mathrm{C}$, electrolysis was conducted with a constant current of $4.0 \mathrm{~mA}$ for $14 \mathrm{~h}$. The mixture was transferred to a flask and the electrodes were rinsed with acetone $(3 \times 5.0 \mathrm{~mL})$. Then the combined solvent was removed under reduced pressure, the residue was diluted with EtOAc $(10 \mathrm{~mL})$ and stirred with $\mathrm{NaOH}(\mathrm{aq})(2 \mathrm{M}, 20 \mathrm{~mL})$ for $2 \mathrm{~h}$. The mixture was extracted with water $(3 \times 20 \mathrm{~mL})$ and successively with EtOAc $(3 \times 20 \mathrm{~mL})$, then the organic layer was dried over $\mathrm{Na}_{2} \mathrm{SO}_{4}$. After evaporation of the solvent under vacuo, subsequent column chromatography on silica gel ( $n$ hexane/EtOAc) yielded the desired product 242.

\subsubsection{General Procedure L: Atroposelective Palladaelectro-catalyzed C-H Olefination}

The electrocatalysis was carried out in an undivided cell, with a GF anode $(10 \mathrm{~mm} \times 15 \mathrm{~mm} \times$ $6 \mathrm{~mm})$ and a platinum cathode $(10 \mathrm{~mm} \times 15 \mathrm{~mm} \times 0.25 \mathrm{~mm})$. Biaryls 73 or $396(0.20 \mathrm{mmol}$, 1.0 equiv), acrylates 38 ( $0.60 \mathrm{mmol}, 3$ equiv), $\mathrm{Pd}(\mathrm{OAc}) 2$ (4.49 mg, $10 \mathrm{~mol} \%)$, L-tert-leucine (5.24 mg, $20 \%$ ) and LiOAc (26.4 mg, 2 equiv) were placed in a $10 \mathrm{~mL}$ cell and dissolved in $\mathrm{AcOH}(4.5 \mathrm{~mL})$. Electrocatalysis was performed at $60{ }^{\circ} \mathrm{C}$ with a constant current of $1.0 \mathrm{~mA}$ maintained for $20 \mathrm{~h}$. At ambient temperature, the reaction mixture was diluted with EtOAc. The GF anode was washed with EtOAc $(3 \times 10 \mathrm{~mL})$ in an ultrasonic bath. The combined washings were added to the reaction mixture and the solvents were removed in vacuo. The crude mixture was purified by column chromatography on silica gel to yield 74 or 397.

\subsubsection{General Procedure M: General Procedure for the Synthesis of Racemic Products}

The racemic compounds were prepared using $r a c$-D/L-valine as the transient directing groups instead of L-tert-leucine, following the general procedure $\mathbf{L}$. 


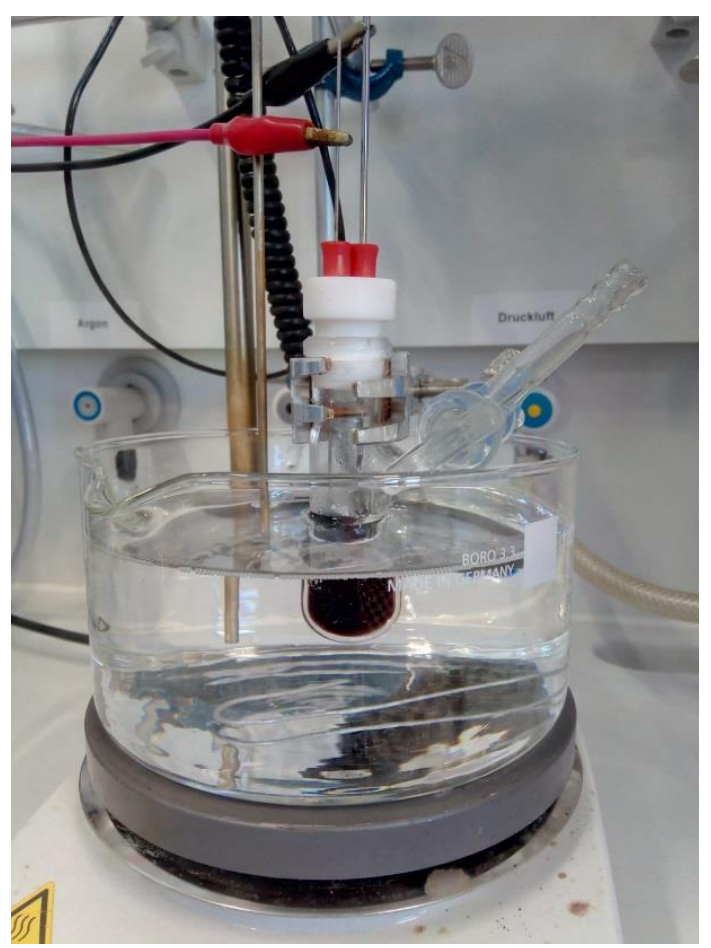

Figure 4. Electrochemical Reaction set up. 


\subsection{Manganese(I)-Catalyzed Allylative $\mathrm{C}-\mathrm{H} / \mathrm{C}-\mathrm{F}$ Functionalization}

\subsubsection{Characterization Data}<smiles>FC(=CCc1cc2ccccc2n1-c1ccccn1)C(F)F</smiles>

(Z)-2-(1H,1H,2H-Perfluorodec-2-en-1-yl)-1-(pyridin-2-yl)-1H-indole (316aa): The general procedure A was followed using 1-(pyridin-2-yl)-1H-indole (315a) $(97.1 \mathrm{mg}, 0.50 \mathrm{mmol})$ and $1 H, 1 H, 2 H$-perfluorodec-1-ene (301a) $\quad(268 \mathrm{mg}, \quad 0.60 \mathrm{mmol})$. Isolation by column chromatography ( $n$-hexane/EtOAc: $10: 1)$ yielded 316aa $(301 \mathrm{mg}, 97 \%, Z / E=90: 10)$ as a yellow oil.

${ }^{1} \mathrm{H}-\mathrm{NMR}\left(300 \mathrm{MHz}, \mathrm{CDCl}_{3}\right): \delta=8.64(\mathrm{ddd}, J=4.9,1.9,0.9 \mathrm{~Hz}, 1 \mathrm{H}), 7.88(\mathrm{ddd}, J=7.9,7.6$, $1.9 \mathrm{~Hz}, 1 \mathrm{H}), 7.61(\mathrm{ddd}, J=6.4,4.9,1.9 \mathrm{~Hz}, 1 \mathrm{H}), 7.41(\mathrm{ddd}, J=7.9,1.0,0.9 \mathrm{~Hz}, 1 \mathrm{H}), 7.38$ (ddd, $J=7.4,4.3,2.6 \mathrm{~Hz}, 1 \mathrm{H}), 7.31$ (ddd, $J=7.1,4.9,0.9 \mathrm{~Hz}, 1 \mathrm{H}), 7.25-7.12(\mathrm{~m}, 2 \mathrm{H}), 6.50$ $(\mathrm{dd}, J=0.9,0.9 \mathrm{~Hz}, 1 \mathrm{H}), 6.16(\mathrm{dt}, J=22.3,8.1 \mathrm{~Hz}, 0.10 \mathrm{H}, E), 5.82(\mathrm{dt}, J=33.0,7.5 \mathrm{~Hz}, 0.90 \mathrm{H}$, $Z$ ), 3.90 (ddt, $J=7.5,4.2,1.8 \mathrm{~Hz}, 1.80 \mathrm{H}, Z$ ), 3.84 (ddt, $J=8.1,4.5,1.8 \mathrm{~Hz}, 0.20 \mathrm{H}, E$ ).

${ }^{13} \mathrm{C}-\mathrm{NMR}\left(125 \mathrm{MHz}, \mathrm{CDCl}_{3}\right): \delta=150.8\left(\mathrm{C}_{\mathrm{q}}\right), 149.6(\mathrm{CH}), 146.1\left(\mathrm{dt},{ }^{1} J_{\mathrm{C}-\mathrm{F}}=261 \mathrm{~Hz},{ }^{2} J_{\mathrm{C}-\mathrm{F}}=\right.$ $\left.29.1 \mathrm{~Hz}, \mathrm{C}_{\mathrm{q}}\right), 138.3(\mathrm{CH}), 137.1\left(\mathrm{C}_{\mathrm{q}}\right), 136.1\left(\mathrm{C}_{\mathrm{q}}\right), 128.3\left(\mathrm{C}_{\mathrm{q}}\right), 122.4(\mathrm{CH}), 122.1(\mathrm{CH}), 121.0$ $(\mathrm{CH}), 120.5(\mathrm{CH}), 120.0(\mathrm{CH}), 117.0\left(\mathrm{dt},{ }^{1} J_{\mathrm{C}-\mathrm{F}}=288 \mathrm{~Hz},{ }^{2} J_{\mathrm{C}-\mathrm{F}}=31.3 \mathrm{~Hz}, \mathrm{C}_{\mathrm{q}}\right), 113.3\left(\mathrm{td},{ }^{2} J_{\mathrm{C}-\mathrm{F}}\right.$ $\left.=8.1 \mathrm{~Hz},{ }^{3} J_{\mathrm{C}-\mathrm{F}}=4.2 \mathrm{~Hz}, \mathrm{CH}\right), 112.4\left(\mathrm{~m}, \mathrm{C}_{\mathrm{q}}\right), 110.9\left(\mathrm{~m}, \mathrm{C}_{\mathrm{q}}\right), 110.7\left(\mathrm{~m}, \mathrm{C}_{\mathrm{q}}\right), 110.5\left(\mathrm{~m}, \mathrm{C}_{\mathrm{q}}\right), 108.6$ $\left(\mathrm{m}, \mathrm{C}_{\mathrm{q}}\right), 108.3\left(\mathrm{~m}, \mathrm{C}_{\mathrm{q}}\right), 110.1(\mathrm{CH}), 106.7(\mathrm{CH}), 22.7\left(\mathrm{~d},{ }^{3} \mathrm{~J}_{\mathrm{C}-\mathrm{F}}=4.3 \mathrm{~Hz}, \mathrm{CH}_{2}\right)$.

${ }^{19} \mathrm{~F}-\mathrm{NMR}\left(282 \mathrm{MHz}, \mathrm{CDCl}_{3}\right): \delta=-80.9(\mathrm{~m}),-115.0(\mathrm{~m}),-117.5(\mathrm{~m}),-122.0(\mathrm{~m}),-122.8(\mathrm{~m})$, $-123.0(\mathrm{~m}),-126.3(\mathrm{~m}),-130.8(\mathrm{~m})$.

IR (ATR): 3061, 1589, 1472, 1455, 1439, 1197, 1107, $736 \mathrm{~cm}^{-1}$.

MS (ESI) $m / z$ (relative intensity): $643\left(\left[\mathrm{M}+\mathrm{Na}^{+}\right], 20\right), 621\left([\mathrm{M}+\mathrm{H}]^{+}, 100\right)$.

HR-MS (ESI): $m / z$ calcd. for $\left[\mathrm{C}_{23} \mathrm{H}_{12} \mathrm{~F}_{16} \mathrm{~N}_{2}+\mathrm{H}\right]^{+}$621.0818, found 621.0809.<smiles>FC(=CCc1cc2cc(F)ccc2n1-c1ccccn1)C(F)F</smiles>

(Z)-2-(1H,1H,2H-Perfluorodec-2-en-1-yl)-5-fluoro-1-(pyridin-2-yl)-1H-indole (316ba):

The general procedure $\mathbf{A}$ was followed using 5-fluoro-1-(pyridin-2-yl)-1H-indole (315b) (106 mg, $0.50 \mathrm{mmol}$ ) and 1H,1H,2H-perfluoro-1-decene (301a) (268 mg, $0.60 \mathrm{mmol}$ ). 
Isolation by column chromatography $(n$-hexane/EtOAc $=10: 1)$ yielded 316ba $(271 \mathrm{mg}, 85 \%$, $Z / E=90: 10)$ as a white solid. M.p.: $95^{\circ} \mathrm{C}$.

${ }^{1} \mathrm{H}-\mathrm{NMR}\left(500 \mathrm{MHz}, \mathrm{CDCl}_{3}\right): \delta=8.63(\mathrm{ddd}, J=4.9,2.0,0.8 \mathrm{~Hz}, 1 \mathrm{H}), 7.88(\mathrm{ddd}, J=7.7,7.5$, $2.0 \mathrm{~Hz}, 1 \mathrm{H}), 7.43(\mathrm{ddd}, J=8.0,1.0,0.8 \mathrm{~Hz}, 1 \mathrm{H}), 7.32(\mathrm{ddd}, J=7.5,4.8,1.0 \mathrm{~Hz}, 1 \mathrm{H}), 7.27$ (dd, $J=8.9,4.4 \mathrm{~Hz}, 1 \mathrm{H}), 7.25-7.21(\mathrm{~m}, 1 \mathrm{H}), 6.90(\mathrm{dt}, J=9.1,2.6 \mathrm{~Hz}, 1 \mathrm{H}), 6.44(\mathrm{~d}, J=0.9 \mathrm{~Hz}, 1 \mathrm{H})$, $6.12(\mathrm{dt}, J=22.2,8.2 \mathrm{~Hz}, 0.10 \mathrm{H}, E), 5.78(\mathrm{dt}, J=32.6,7.5 \mathrm{~Hz}, 0.90 \mathrm{H}, Z), 3.85$ (ddt, $J=7.7$, 3.9, $2.0 \mathrm{~Hz}, 1.80 \mathrm{H}, Z$ ), 3.80 (ddt, 7.7, 4.1, $1.9 \mathrm{~Hz}, 0.20 \mathrm{H}, E$ ).

${ }^{13} \mathrm{C}-\mathrm{NMR}\left(125 \mathrm{MHz}, \mathrm{CDCl}_{3}\right): \delta=158.5\left(\mathrm{~d},{ }^{1} J_{\mathrm{C}-\mathrm{F}}=236 \mathrm{~Hz}, \mathrm{C}_{\mathrm{q}}\right), 150.7\left(\mathrm{C}_{\mathrm{q}}\right), 149.8(\mathrm{CH}), 146.2$ $\left(\mathrm{dt},{ }^{1} J_{\mathrm{C}-\mathrm{F}}=261,{ }^{2} J_{\mathrm{C}-\mathrm{F}}=29.0 \mathrm{~Hz}, \mathrm{C}_{\mathrm{q}}\right), 138.6(\mathrm{CH}), 137.7\left(\mathrm{C}_{\mathrm{q}}\right), 133.7\left(\mathrm{C}_{\mathrm{q}}\right), 128.8\left(\mathrm{~d},{ }^{3} J_{\mathrm{C}-\mathrm{F}}=10.3\right.$ $\left.\mathrm{Hz}, \mathrm{C}_{\mathrm{q}}\right), 122.4(\mathrm{CH}), 120.4(\mathrm{CH}), 117.2\left(\mathrm{dt},{ }^{1} J_{\mathrm{C}-\mathrm{F}}=285 \mathrm{~Hz},{ }^{2} J_{\mathrm{C}-\mathrm{F}}=33.3 \mathrm{~Hz}, \mathrm{C}_{\mathrm{q}}\right), 113.7\left(\mathrm{~m}, \mathrm{C}_{\mathrm{q}}\right)$, $113.0\left(\mathrm{dt},{ }^{2} J_{\mathrm{C}-\mathrm{F}}=8.5 \mathrm{~Hz},{ }^{3} J_{\mathrm{C}-\mathrm{F}}=4.4 \mathrm{~Hz}, \mathrm{CH}\right), 112.4\left(\mathrm{~m}, \mathrm{C}_{\mathrm{q}}\right), 110.9\left(\mathrm{~d},{ }^{2} J_{\mathrm{C}-\mathrm{F}}=9.5 \mathrm{~Hz}, \mathrm{CH}\right)$, $110.5\left(\mathrm{~d},{ }^{2} J_{\mathrm{C}-\mathrm{F}}=26.0 \mathrm{~Hz}, \mathrm{CH}\right), 110.4\left(\mathrm{~m}, \mathrm{C}_{\mathrm{q}}\right), 110.0\left(\mathrm{~m}, \mathrm{C}_{\mathrm{q}}\right), 108.6\left(\mathrm{~m}, \mathrm{C}_{\mathrm{q}}\right), 108.2\left(\mathrm{~m}, \mathrm{C}_{\mathrm{q}}\right)$, $105.4\left(\mathrm{~d},{ }^{2} J_{\mathrm{C}-\mathrm{F}}=23.7 \mathrm{~Hz}, \mathrm{CH}\right), 103.5\left(\mathrm{~d},{ }^{3} J_{\mathrm{C}-\mathrm{F}}=4.3 \mathrm{~Hz}, \mathrm{CH}\right), 22.7\left(\mathrm{~d},{ }^{3} J_{\mathrm{C}-\mathrm{F}}=4.3 \mathrm{~Hz}, \mathrm{CH}_{2}\right)$. ${ }^{19}$ F-NMR (470 MHz, $\left.\mathrm{CDCl}_{3}\right): \delta=-81.0(\mathrm{~m}),-117.6(\mathrm{~m}),-122.1(\mathrm{~m}),-122.9(\mathrm{~m}),-123.0(\mathrm{~m})$ $-123.4(\mathrm{~m}),-123.5(\mathrm{~m}),-126.3(\mathrm{~m}),-130.5(\mathrm{~m})$.

IR (ATR): 1473, 1450, 1439, 1235, 1143, 776, $663 \mathrm{~cm}^{-1}$.

MS (ESI) $m / z$ (relative intensity): $661\left([\mathrm{M}+\mathrm{Na}]^{+}, 15\right), 639\left([\mathrm{M}+\mathrm{H}]^{+}, 100\right)$.

HR-MS (ESI): $m / z$ calcd. for $\left[\mathrm{C}_{23} \mathrm{H}_{11} \mathrm{~F}_{17} \mathrm{~N}_{2}+\mathrm{H}\right]^{+}$639.0724, found 639.0731.

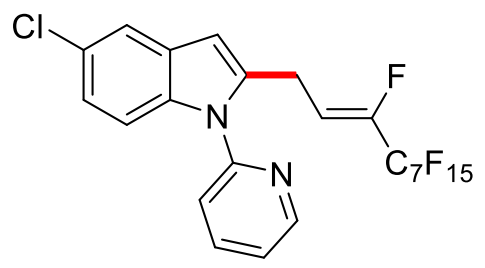

(Z)-2-(1H,1H,2H-Perfluorodec-2-en-1-yl)-5-chloro-1-(pyridin-2-yl)-1H-indole (316ca):

The general procedure A was followed using 5-chloro-1-(pyridin-2-yl)-1H-indole (315c) (114 mg, $0.50 \mathrm{mmol})$ and 1H,1H,2H-perfluoro-1-decene (301a) (268 mg, $0.60 \mathrm{mmol})$. Isolation by column chromatography ( $n$-hexane/EtOAc: 10:1) yielded 316ca (303 mg, 93\%, $Z / E=90: 10)$ as a white solid. M.p.: $95^{\circ} \mathrm{C}$.

${ }^{1} \mathrm{H}-\mathrm{NMR}\left(400 \mathrm{MHz}, \mathrm{CDCl}_{3}\right): \delta=8.63$ (ddd, $\left.J=4.8,2.0,0.8 \mathrm{~Hz}, 1 \mathrm{H}\right), 7.94-7.84(\mathrm{~m}, 1 \mathrm{H}), 7.54$ $(\mathrm{d}, J=2.0 \mathrm{~Hz}, 1 \mathrm{H}), 7.41(\mathrm{~d}, J=7.9 \mathrm{~Hz}, 1 \mathrm{H}), 7.33(\mathrm{dd}, J=7.7,4.8 \mathrm{~Hz}, 1 \mathrm{H}), 7.25(\mathrm{~d}, J=8.7$ $\mathrm{Hz}, 1 \mathrm{H}), 7.10(\mathrm{dd}, J=8.7,2.1 \mathrm{~Hz}, 1 \mathrm{H}), 6.41(\mathrm{~s}, 1 \mathrm{H}), 6.11(\mathrm{dt}, J=22.2,8.3 \mathrm{~Hz}, 0.10 \mathrm{H}, E), 5.77$ (dt, $J=32.6,7.1 \mathrm{~Hz}, 0.90 \mathrm{H}, Z$ ), 3.85 (ddt, $J=7.5,4.2,2.1 \mathrm{~Hz}, 1.80 \mathrm{H}, Z$ ), 3.80 (ddt, $J=7.5$, 4.2, $2.1 \mathrm{~Hz}, 0.20 \mathrm{H}, E)$.

${ }^{13} \mathrm{C}-\mathrm{NMR}\left(100 \mathrm{MHz}, \mathrm{CDCl}_{3}\right): \delta=150.5\left(\mathrm{C}_{\mathrm{q}}\right), 149.8(\mathrm{CH}), 146.4\left(\mathrm{dt},{ }^{1} J_{\mathrm{C}-\mathrm{F}}=261,{ }^{2} J_{\mathrm{C}-\mathrm{F}}=29.1\right.$ $\left.\mathrm{Hz}, \mathrm{C}_{\mathrm{q}}\right), 138.6(\mathrm{CH}), 137.6\left(\mathrm{C}_{\mathrm{q}}\right), 135.6\left(\mathrm{C}_{\mathrm{q}}\right), 129.3\left(\mathrm{C}_{\mathrm{q}}\right), 126.6\left(\mathrm{C}_{\mathrm{q}}\right), 122.6\left(\mathrm{~d},{ }^{2} J_{\mathrm{C}-\mathrm{F}}=13.5 \mathrm{~Hz}\right.$, 
$\mathrm{CH}), 120.6(\mathrm{CH}), 120.5(\mathrm{CH}), 119.8(\mathrm{CH}), 117.1\left(\mathrm{dt},{ }^{1} J_{\mathrm{C}-\mathrm{F}}=285 \mathrm{~Hz},{ }^{2} J_{\mathrm{C}-\mathrm{F}}=33.3 \mathrm{~Hz}, \mathrm{C}_{\mathrm{q}}\right), 113.4$ $\left(\mathrm{m}, \mathrm{C}_{\mathrm{q}}\right), 112.9\left(\mathrm{dt},{ }^{2} J_{\mathrm{C}-\mathrm{F}}=8.7 \mathrm{~Hz},{ }^{3} J_{\mathrm{C}-\mathrm{F}}=4.5 \mathrm{~Hz}, \mathrm{CH}\right), 111.2\left(\mathrm{~d},{ }^{4} J_{\mathrm{C}-\mathrm{F}}=2.8 \mathrm{~Hz}, \mathrm{CH}\right), 110.6$ $\left(\mathrm{m}, \mathrm{C}_{\mathrm{q}}\right), 110.2\left(\mathrm{~m}, \mathrm{C}_{\mathrm{q}}\right), 108.6\left(\mathrm{~m}, \mathrm{C}_{\mathrm{q}}\right), 108.2\left(\mathrm{~m}, \mathrm{C}_{\mathrm{q}}\right), 107.9\left(\mathrm{~m}, \mathrm{C}_{\mathrm{q}}\right), 103.1(\mathrm{CH}), 22.7\left(\mathrm{~d},{ }^{3} \mathrm{~J}_{\mathrm{C}-\mathrm{F}}\right.$ $\left.=4.4 \mathrm{~Hz}, \mathrm{CH}_{2}\right)$.

${ }^{19} \mathrm{~F}-\mathrm{NMR}\left(470 \mathrm{MHz}, \mathrm{CDCl}_{3}\right): \delta=-80.8(\mathrm{~m}),-117.5(\mathrm{~m}),-122.0(\mathrm{~m}),-122.8(\mathrm{~m}),-122.9(\mathrm{~m})$, $-123.4(\mathrm{~m}),-126.1(\mathrm{~m}),-130.2(\mathrm{~m})$.

IR (ATR): 3069, 1588, 1471, 1235, 1051, 781, 707, $528 \mathrm{~cm}^{-1}$.

MS (ESI) $m / z$ (relative intensity): $655\left([\mathrm{M}+\mathrm{H}]^{+}, 100\right), 621$ (15).

HR-MS (ESI): $m / z$ calcd. for $\left[\mathrm{C}_{23} \mathrm{H}_{11} \mathrm{ClF}_{16} \mathrm{~N}_{2}+\mathrm{H}\right]^{+}$655.0428, found 655.0436.

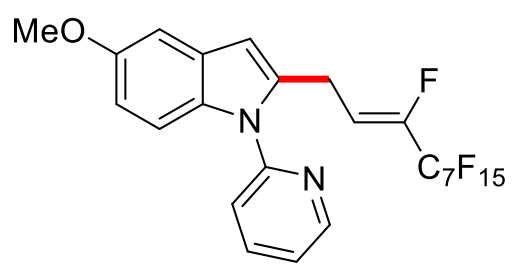

(Z)-2-(1H,1H,2H-Perfluorodec-2-en-1-yl)-5-methoxy-1-(pyridin-2-yl)-1H-indole (316da):

The general procedure A was followed using 5-methoxy-1-(pyridin-2-yl)-1H-indole (315d) (112 mg, $0.50 \mathrm{mmol}$ ), 1H,1H,2H-perfluoro-1-decene (301a) (268 mg, $0.60 \mathrm{mmol}$ ) and NaOAc $(12.3 \mathrm{mg}, 30 \mathrm{~mol} \%)$. Isolation by column chromatography ( $n$-hexane/EtOAc $=10: 1)$ yielded 316da $(292 \mathrm{mg}, 90 \%, Z / E=88: 12)$ as a colorless oil.

${ }^{1} \mathrm{H}-\mathrm{NMR}\left(400 \mathrm{MHz}, \mathrm{CDCl}_{3}\right): \delta=8.60(\mathrm{ddd}, J=4.8,2.0,0.9 \mathrm{~Hz}, 1 \mathrm{H}), 7.86(\mathrm{ddd}, J=7.7,7.5$, $2.0 \mathrm{~Hz}, 1 \mathrm{H}), 7.44(\mathrm{ddd}, J=8.0,1.0,0.9 \mathrm{~Hz}, 1 \mathrm{H}), 7.32-7.19(\mathrm{~m}, 2 \mathrm{H}), 7.05(\mathrm{~d}, J=2.5 \mathrm{~Hz}, 1 \mathrm{H})$, $6.81(\mathrm{dd}, J=9.0,2.5 \mathrm{~Hz}, 1 \mathrm{H}), 6.40(\mathrm{~d}, J=1.0 \mathrm{~Hz}, 1 \mathrm{H}), 6.13(\mathrm{dt}, J=22.3,8.2 \mathrm{~Hz}, 0.12 \mathrm{H}, E)$, $5.79(\mathrm{dt}, J=32.8,7.5 \mathrm{~Hz}, 0.88 \mathrm{H}, Z), 3.87$ (ddt, $J=7.5,4.0,2.3 \mathrm{~Hz}, 2 \mathrm{H}), 3.84$ (s, 3H).

${ }^{13} \mathrm{C}-\mathrm{NMR}\left(75 \mathrm{MHz}, \mathrm{CDCl}_{3}\right): \delta=155.1\left(\mathrm{C}_{\mathrm{q}}\right), 151.0\left(\mathrm{C}_{\mathrm{q}}\right), 149.8(\mathrm{CH}), 146.0\left(\mathrm{dt},{ }^{1} J_{\mathrm{C}-\mathrm{F}}=261 \mathrm{~Hz}\right.$, $\left.{ }^{2} J_{\mathrm{C}-\mathrm{F}}=29.0 \mathrm{~Hz}, \mathrm{C}_{\mathrm{q}}\right), 138.5(\mathrm{CH}), 136.6\left(\mathrm{C}_{\mathrm{q}}\right), 132.2\left(\mathrm{C}_{\mathrm{q}}\right), 128.9\left(\mathrm{C}_{\mathrm{q}}\right), 121.9(\mathrm{CH}), 120.2(\mathrm{CH})$, $116.7\left(\mathrm{dt},{ }^{1} J_{\mathrm{C}-\mathrm{F}}=285 \mathrm{~Hz},{ }^{2} J_{\mathrm{C}-\mathrm{F}}=33.3 \mathrm{~Hz}, \mathrm{C}_{\mathrm{q}}\right), 113.3\left(\mathrm{dt},{ }^{2} J_{\mathrm{C}-\mathrm{F}}=8.4 \mathrm{~Hz},{ }^{3} J_{\mathrm{C}-\mathrm{F}}=4.5 \mathrm{~Hz}, \mathrm{CH}\right)$, $112.1(\mathrm{CH}), 111.8\left(\mathrm{~m}, \mathrm{C}_{\mathrm{q}}\right), 111.0(\mathrm{CH}), 110.7\left(\mathrm{~m}, \mathrm{C}_{\mathrm{q}}\right), 110.2\left(\mathrm{~m}, \mathrm{C}_{\mathrm{q}}\right), 107.7\left(\mathrm{~m}, \mathrm{C}_{\mathrm{q}}\right), 107.2(\mathrm{~m}$, $\left.\mathrm{C}_{\mathrm{q}}\right), 106.6\left(\mathrm{~m}, \mathrm{C}_{\mathrm{q}}\right), 103.6(\mathrm{CH}), 102.4(\mathrm{CH}), 55.8\left(\mathrm{CH}_{3}\right), 22.8\left(\mathrm{~d}, J=4.3 \mathrm{~Hz}, \mathrm{CH}_{2}\right)$.

${ }^{19} \mathrm{~F}-\mathrm{NMR}\left(376 \mathrm{MHz}, \mathrm{CDCl}_{3}\right): \delta=-80.9(\mathrm{~m}),-117.5(\mathrm{~m}),-122.0(\mathrm{~m}),-122.8(\mathrm{~m}),-122.9(\mathrm{~m})$, $-123.4(\mathrm{~m}),-126.2(\mathrm{~m}),-130.9(\mathrm{~m})$.

IR (ATR): 1474, 1450, 1438, 1237, 1201, 1146, 907, 729, $649 \mathrm{~cm}^{-1}$. MS (ESI) $m / z$ (relative intensity): $673\left([\mathrm{M}+\mathrm{Na}]^{+}, 20\right), 651\left([\mathrm{M}+\mathrm{H}]^{+}, 100\right), 381(15)$. HR-MS (ESI): $m / z$ calcd. for $\left[\mathrm{C}_{24} \mathrm{H}_{14} \mathrm{~F}_{16} \mathrm{~N}_{2} \mathrm{O}+\mathrm{H}\right]^{+}$651.0923, found 651.0917 . 
<smiles>Cc1c(C/C=C(\F)C(F)F)n(-c2ccccn2)c2ccccc12</smiles>

(Z)-2-(1H,1H,2H-Perfluorodec-2-en-1-yl)-3-methyl-1-(pyridin-2-yl)-1H-indole (316ea): The general procedure $\mathbf{A}$ was followed using 3-methyl-1-(pyridin-2-yl)-1H-indole (315e) (104 mg, $0.50 \mathrm{mmol})$ and 1H,1H,2H-perfluoro-1-decene (301a) (268 mg, $0.60 \mathrm{mmol}$ ). Isolation by column chromatography $(n$-hexane/EtOAc $=10: 1)$ yielded 316ea $(285 \mathrm{mg}, 90 \%$, $Z / E=88: 12)$ as a white solid. M.p.: $65^{\circ} \mathrm{C}$.

${ }^{1} \mathrm{H}-\mathrm{NMR}\left(300 \mathrm{MHz}, \mathrm{CDCl}_{3}\right): \delta=8.60(\mathrm{ddd}, J=4.8,1.9,0.8 \mathrm{~Hz}, 1 \mathrm{H}), 7.86(\mathrm{ddd}, J=8.1,7.5$, $2.0 \mathrm{~Hz}, 1 \mathrm{H}), 7.58-7.53(\mathrm{~m}, 1 \mathrm{H}), 7.45$ (ddd, $J=8.0,1.0,0.8 \mathrm{~Hz}, 1 \mathrm{H}), 7.37-7.31(\mathrm{~m}, 1 \mathrm{H}), 7.28$ (ddd, $J=7.5,4.9,1.0 \mathrm{~Hz}, 1 \mathrm{H}), 7.19-7.14(\mathrm{~m}, 2 \mathrm{H}), 5.92$ (dt, $J=23.2,7.5 \mathrm{~Hz}, 0.12 \mathrm{H}, E), 5.69$ $(\mathrm{dt}, J=33.3,7.4 \mathrm{~Hz}, 0.88 \mathrm{H}, Z), 3.86$ (ddt, $J=7.5,3.9,2.3 \mathrm{~Hz}, 2 \mathrm{H}), 2.32$ (s, 3H).

${ }^{13} \mathrm{C}-\mathrm{NMR}\left(125 \mathrm{MHz}, \mathrm{CDCl}_{3}\right): \delta=151.2\left(\mathrm{C}_{\mathrm{q}}\right), 149.7(\mathrm{CH}), 145.3\left(\mathrm{dt},{ }^{1} J_{\mathrm{C}-\mathrm{F}}=261 \mathrm{~Hz},{ }^{2} J_{\mathrm{C}-\mathrm{F}}=\right.$ $\left.29.0 \mathrm{~Hz}, \mathrm{C}_{\mathrm{q}}\right), 138.3(\mathrm{CH}), 136.4\left(\mathrm{C}_{\mathrm{q}}\right), 131.2\left(\mathrm{C}_{\mathrm{q}}\right), 129.3\left(\mathrm{C}_{\mathrm{q}}\right), 122.7(\mathrm{CH}), 121.8(\mathrm{CH}), 120.6$ $(\mathrm{CH}), 120.4(\mathrm{CH}) 118.7(\mathrm{CH}), 116.6\left(\mathrm{dt},{ }^{1} J_{\mathrm{C}-\mathrm{F}}=285 \mathrm{~Hz},{ }^{2} J_{\mathrm{C}-\mathrm{F}}=33.3 \mathrm{~Hz}, \mathrm{C}_{\mathrm{q}}\right), 113.9\left(\mathrm{dt},{ }^{2} J_{\mathrm{C}-\mathrm{F}}\right.$ $\left.=8.2 \mathrm{~Hz},{ }^{3} J_{\mathrm{C}-\mathrm{F}}=4.5 \mathrm{~Hz}, \mathrm{CH}\right), 112.9\left(\mathrm{~m}, \mathrm{C}_{\mathrm{q}}\right), 111.7\left(\mathrm{C}_{\mathrm{q}}\right), 110.6\left(\mathrm{~m}, \mathrm{C}_{\mathrm{q}}\right), 110.5\left(\mathrm{~m}, \mathrm{C}_{\mathrm{q}}\right), 110.3$ $\left(\mathrm{m}, \mathrm{C}_{\mathrm{q}}\right), 109.9(\mathrm{CH}), 108.7\left(\mathrm{~m}, \mathrm{C}_{\mathrm{q}}\right), 108.2\left(\mathrm{~m}, \mathrm{C}_{\mathrm{q}}\right), 20.4\left(\mathrm{~d},{ }^{3} J_{\mathrm{C}-\mathrm{F}}=4.5 \mathrm{~Hz}, \mathrm{CH}_{2}\right), 8.6\left(\mathrm{CH}_{3}\right)$. ${ }^{19} \mathrm{~F}-\mathrm{NMR}\left(282 \mathrm{MHz}, \mathrm{CDCl}_{3}\right): \delta=-80.8(\mathrm{~m}),-117.4(\mathrm{~m}),-122.1(\mathrm{~m}),-122.8(\mathrm{~m}),-122.8(\mathrm{~m})$, $-123.3(\mathrm{~m}),-126.1(\mathrm{~m}),-131.7(\mathrm{~m})$.

IR (ATR): 3066, 1587, 1472, 1147, 906, $728 \mathrm{~cm}^{-1}$.

MS (ESI) $m / z$ (relative intensity): $657\left([\mathrm{M}+\mathrm{Na}]^{+}, 15\right), 635\left([\mathrm{M}+\mathrm{H}]^{+}, 100\right), 633(20)$.

HR-MS (ESI): $m / z$ calcd. for $\left[\mathrm{C}_{24} \mathrm{H}_{14} \mathrm{~F}_{16} \mathrm{~N}_{2}+\mathrm{H}\right]^{+}$635.0974, found 635.0973 .<smiles>CC(=O)Cc1c(C/C=C(\F)C(F)F)n(-c2ccccn2)c2ccccc12</smiles>

(Z)-Methyl-2-[(1H,1H,2H-Perfluorodec-2-en-1-yl)-1-(pyridin-2-yl)-1H-indole-3-

yl]acetate (316fa): The general procedure A was followed using methyl 2-(1-(pyridin-2-yl)$1 H$-indol-3-yl)acetate (315f) $(134 \mathrm{mg}, 0.50 \mathrm{mmol})$ and $1 H, 1 H, 2 H$-perfluoro-1-decene (301a) (268 mg, $0.60 \mathrm{mmol})$. Isolation by column chromatography ( $n$-hexane/EtOAc $=10: 1)$ yielded 316fa (214 mg, 62\%, $Z / E=90: 10)$ as a yellow solid. M.p.: $68{ }^{\circ} \mathrm{C}$. 
${ }^{1} \mathrm{H}-\mathrm{NMR}\left(500 \mathrm{MHz}, \mathrm{CDCl}_{3}\right): \delta=8.62(\mathrm{ddd}, J=4.9,1.9,0.8 \mathrm{~Hz}, 1 \mathrm{H}), 7.87$ (ddd, $J=7.7,7.5$, $1.9 \mathrm{~Hz}, 1 \mathrm{H}), 7.65(\mathrm{ddd}, J=8.1,3.2,1.7 \mathrm{~Hz}, 1 \mathrm{H}), 7.47$ (ddd, $J=7.9,1.0,0.8 \mathrm{~Hz}, 1 \mathrm{H}), 7.40$ $7.27(\mathrm{~m}, 2 \mathrm{H}), 7.26-7.15(\mathrm{~m}, 2 \mathrm{H}), 6.04(\mathrm{dt}, J=22.8,7.2 \mathrm{~Hz}, 0.10 \mathrm{H}, E), 5.77(\mathrm{dt}, J=33.4,7.4$ $\mathrm{Hz}, 0.90 \mathrm{H}, Z$ ), 3.94 (ddt, $J=7.4,4.4,2.2 \mathrm{~Hz}, 2 \mathrm{H}), 3.81$ (s, 2H), 3.69 (s, 3H).

${ }^{13} \mathrm{C}-\mathrm{NMR}\left(125 \mathrm{MHz}, \mathrm{CDCl}_{3}\right): \delta=171.7\left(\mathrm{C}_{\mathrm{q}}\right), 150.7\left(\mathrm{C}_{\mathrm{q}}\right), 149.7(\mathrm{CH}), 145.4\left(\mathrm{dt},{ }^{1} J_{\mathrm{C}-\mathrm{F}}=\right.$ $\left.260 \mathrm{~Hz},{ }^{2} J_{\mathrm{C}-\mathrm{F}}=29.1 \mathrm{~Hz}, \mathrm{C}_{\mathrm{q}}\right), 138.4(\mathrm{CH}), 136.4\left(\mathrm{C}_{\mathrm{q}}\right), 133.4\left(\mathrm{~d},{ }^{4} J_{\mathrm{C}-\mathrm{F}}=2.0 \mathrm{~Hz}, \mathrm{C}_{\mathrm{q}}\right), 128.1\left(\mathrm{C}_{\mathrm{q}}\right)$, $122.9(\mathrm{CH}), 122.2(\mathrm{CH}), 121.1(\mathrm{CH}), 120.7(\mathrm{CH}), 118.8(\mathrm{CH}), 116.7\left(\mathrm{dt},{ }^{1} J_{\mathrm{C}-\mathrm{F}}=282 \mathrm{~Hz},{ }^{2} J_{\mathrm{C}-\mathrm{F}}\right.$ $\left.=33.0 \mathrm{~Hz}, \mathrm{C}_{\mathrm{q}}\right), 113.7\left(\mathrm{dt},{ }^{2} J_{\mathrm{C}-\mathrm{F}}=8.1 \mathrm{~Hz},{ }^{3} J_{\mathrm{C}-\mathrm{F}}=4.3 \mathrm{~Hz}, \mathrm{CH}\right), 112.6\left(\mathrm{~m}, \mathrm{C}_{\mathrm{q}}\right), 112.3\left(\mathrm{~m}, \mathrm{C}_{\mathrm{q}}\right)$, $110.1(\mathrm{CH}), 110.7\left(\mathrm{~m}, \mathrm{C}_{\mathrm{q}}\right), 110.4\left(\mathrm{~m}, \mathrm{C}_{\mathrm{q}}\right), 108.7\left(\mathrm{C}_{\mathrm{q}}\right), 108.5\left(\mathrm{~m}, \mathrm{C}_{\mathrm{q}}\right), 108.2\left(\mathrm{~m}, \mathrm{C}_{\mathrm{q}}\right), 52.0\left(\mathrm{CH}_{3}\right)$, $30.1\left(\mathrm{CH}_{2}\right), 20.3\left(\mathrm{~d},{ }^{3} J_{\mathrm{C}-\mathrm{F}}=4.2 \mathrm{~Hz}, \mathrm{CH}_{2}\right)$.

${ }^{19} \mathrm{~F}-\mathrm{NMR}\left(376 \mathrm{MHz}, \mathrm{CDCl}_{3}\right): \delta=-80.9(\mathrm{~m}),-117.5(\mathrm{~m}),-122.1(\mathrm{~m}),-122.9(\mathrm{~m}),-123.4(\mathrm{~m})$, $-124.1(\mathrm{~m}),-126.2(\mathrm{~m}),-130.4(\mathrm{~m})$.

IR (ATR): 1740, 1472, 1439, 1200, 1108, 733, $663 \mathrm{~cm}^{-1}$.

MS (ESI) $m / z$ (relative intensity): $693\left[\mathrm{M}+\mathrm{H}^{+}\right],(100)$.

HR-MS (ESI): $m / z$ calcd. for $\left[\mathrm{C}_{26} \mathrm{H}_{16} \mathrm{~F}_{16} \mathrm{~N}_{2} \mathrm{O}_{2}+\mathrm{H}\right]^{+}$693.1029, found 693.1025 .<smiles>FC(=CCc1c(Br)c2ccccc2n1-c1ccccn1)C(F)F</smiles>

(Z)-2-(1H,1H,2H-Perfluorodec-2-en-1-yl)-3-bromo-1-(pyridin-2-yl)-1H-indole (319aa): A modified general procedure $\mathbf{A}$ was followed using 3-bromo-1-(pyrimidin-2-yl)- $1 \mathrm{H}$-indole (318a) (136 mg, $0.50 \mathrm{mmol}), 1 H, 1 H, 2 H$-perfluoro-1-decene (301a) (446 mg, $1.00 \mathrm{mmol}$ ), [MnBr(CO)5] (13.7 mg, $10 \mathrm{~mol} \%)$ and $\mathrm{NaOAc}(12.3 \mathrm{mg}, 30 \mathrm{~mol} \%)$. Isolation by column chromatography ( $n$-hexane/EtOAc $=10: 1)$ yielded 319aa $(310 \mathrm{mg}, 89 \%, Z / E=88: 12)$ as a colorless oil.

${ }^{1} \mathrm{H}-\mathrm{NMR}\left(500 \mathrm{MHz}, \mathrm{CDCl}_{3}\right): \delta=8.63(\mathrm{ddd}, J=4.9,2.0,0.8 \mathrm{~Hz}, 1 \mathrm{H}), 7.89$ (ddd, $J=7.7,7.7$, $2.0 \mathrm{~Hz}, 1 \mathrm{H}), 7.64-7.58(\mathrm{~m}, 1 \mathrm{H}), 7.48-7.42(\mathrm{~m}, 1 \mathrm{H}), 7.37-7.32(\mathrm{~m}, 2 \mathrm{H}), 7.27-7.23(\mathrm{~m}, 2 \mathrm{H})$, $5.96(\mathrm{dt}, J=22.4,7.3 \mathrm{~Hz}, 0.12 \mathrm{H}, E), 5.68(\mathrm{dt}, J=32.7,7.3 \mathrm{~Hz}, 0.88 \mathrm{H}, Z), 3.98(\mathrm{ddt}, J=7.5$, $3.9,2.0 \mathrm{~Hz}, 2 \mathrm{H})$.

${ }^{13} \mathrm{C}-\mathrm{NMR}\left(125 \mathrm{MHz}, \mathrm{CDCl}_{3}\right): \delta=150.2\left(\mathrm{~d},{ }^{4} J_{\mathrm{C}-\mathrm{F}}=2.5 \mathrm{~Hz}, \mathrm{C}_{\mathrm{q}}\right), 149.8(\mathrm{CH}), 145.7\left(\mathrm{dt},{ }^{1} J_{\mathrm{C}-\mathrm{F}}=\right.$ $\left.261 \mathrm{~Hz},{ }^{2} J_{\mathrm{C}-\mathrm{F}}=29.1 \mathrm{~Hz}, \mathrm{C}_{\mathrm{q}}\right), 138.4(\mathrm{CH}), 135.9\left(\mathrm{~d},{ }^{3} J_{\mathrm{C}-\mathrm{F}}=8.8 \mathrm{~Hz}, \mathrm{C}_{\mathrm{q}}\right), 132.8\left(\mathrm{~d},{ }^{4} J_{\mathrm{C}-\mathrm{F}}=\right.$ $\left.2.0 \mathrm{~Hz}, \mathrm{C}_{\mathrm{q}}\right), 127.2\left(\mathrm{C}_{\mathrm{q}}\right), 123.7\left(\mathrm{~d},{ }^{3} J_{\mathrm{C}-\mathrm{F}}=5.7 \mathrm{~Hz}, \mathrm{CH}\right), 122.5\left(\mathrm{~d},{ }^{2} J_{\mathrm{C}-\mathrm{F}}=10.1 \mathrm{~Hz}, \mathrm{CH}\right), 121.6$ $\left(\mathrm{d},{ }^{3} J_{\mathrm{C}-\mathrm{F}}=3.8 \mathrm{~Hz}, \mathrm{CH}\right), 120.4(\mathrm{CH}), 119.2(\mathrm{CH}), 117.2\left(\mathrm{dt},{ }^{1} J_{\mathrm{C}-\mathrm{F}}=283 \mathrm{~Hz},{ }^{2} J_{\mathrm{C}-\mathrm{F}}=33.0 \mathrm{~Hz}\right.$, 
$\left.\mathrm{C}_{\mathrm{q}}\right), 112.7\left(\mathrm{~m}, \mathrm{C}_{\mathrm{q}}\right), 112.5\left(\mathrm{dt},{ }^{2} J_{\mathrm{C}-\mathrm{F}}=8.5 \mathrm{~Hz},{ }^{3} J_{\mathrm{C}-\mathrm{F}}=4.4 \mathrm{~Hz}, \mathrm{CH}\right), 110.7\left(\mathrm{~m}, \mathrm{C}_{\mathrm{q}}\right), 110.6\left(\mathrm{~m}, \mathrm{C}_{\mathrm{q}}\right)$, $110.2(\mathrm{CH}), 110.1\left(\mathrm{~m}, \mathrm{C}_{\mathrm{q}}\right), 109.8\left(\mathrm{~m}, \mathrm{C}_{\mathrm{q}}\right), 108.4\left(\mathrm{~m}, \mathrm{C}_{\mathrm{q}}\right), 95.0\left(\mathrm{C}_{\mathrm{q}}\right), 21.1\left(\mathrm{~d},{ }^{3} J_{\mathrm{C}-\mathrm{F}}=4.3 \mathrm{~Hz}\right.$, $\left.\mathrm{CH}_{2}\right)$.

${ }^{19} \mathrm{~F}-\mathrm{NMR}\left(470 \mathrm{MHz}, \mathrm{CDCl}_{3}\right): \delta=-80.9(\mathrm{~m}),-117.5(\mathrm{~m}),-122.0(\mathrm{~m}),-122.8(\mathrm{~m}),-123.2(\mathrm{~m})$, $-123.4(\mathrm{~m}),-126.2(\mathrm{~m}),-130.1(\mathrm{~m})$.

IR (ATR): 1469, 1453, 1235, 1108, 738, $663 \mathrm{~cm}^{-1}$.

MS (ESI) $m / z$ (relative intensity): $699\left(\left[\mathrm{M}\left({ }^{79} \mathrm{Br}\right)+\mathrm{H}\right]^{+}, 100\right), 619(10)$.

HR-MS (ESI): $m / z$ calcd. for $\left[\mathrm{C}_{22} \mathrm{H}_{11}{ }^{79} \mathrm{BrF}_{16} \mathrm{~N}_{3}+\mathrm{H}\right]^{+} 699.9875$, found 699.9918 .<smiles>FC(=CCc1cc2cccnc2n1-c1ccccc1)C(F)F</smiles>

(Z)-2-(1H,1H,2H-Perfluorohex-2-en-1-yl)-1-(pyridin-2-yl)-1H-7-azaindole (316ga): A modified general procedure A was followed using 1-(pyridin-2-yl)- $1 H$-pyrrolo[2,3-b]pyridine (315g) (98.0 mg, $0.50 \mathrm{mmol}$ ), 1H,1H,2H-perfluoro-1-decene (301a) (446 mg, $1.00 \mathrm{mmol}$ ), $\left[\mathrm{MnBr}(\mathrm{CO})_{5}\right](13.7 \mathrm{mg}, 10 \mathrm{~mol} \%)$ and $\mathrm{NaOAc}(12.3 \mathrm{mg}, 30 \mathrm{~mol} \%)$. Isolation by column chromatography $(n$-hexane/EtOAc $=10: 1)$ yielded 316ga $(254 \mathrm{mg}, 82 \%, Z / E=80: 20)$ as a colorless oil.

${ }^{1} \mathrm{H}-\mathrm{NMR}\left(300 \mathrm{MHz}, \mathrm{CDCl}_{3}\right) \delta=8.58(\mathrm{ddd}, J=4.9,1.9,0.9 \mathrm{~Hz}, 1 \mathrm{H}), 8.28(\mathrm{dt}, J=4.8,1.8 \mathrm{~Hz}$, 1H), 7.95-7.82 (m, 3H), $7.30(\mathrm{ddd}, J=6.7,4.9,2.0 \mathrm{~Hz}, 1 \mathrm{H}), 7.12(\mathrm{ddd}, J=7.8,4.8,1.9 \mathrm{~Hz}$, $1 \mathrm{H}), 6.42(\mathrm{dt}, J=2.0,0.9 \mathrm{~Hz}, 1 \mathrm{H}), 6.17(\mathrm{dt}, J=22.3,8.2 \mathrm{~Hz}, 0.20 \mathrm{H}, E), 5.83(\mathrm{dt}, J=32.8$, $7.5 \mathrm{~Hz}, 0.80 \mathrm{H}, Z$ ), 4.00 (ddt, $J=7.5,3.6,2.0 \mathrm{~Hz}, 2 \mathrm{H}$ ).

${ }^{13} \mathrm{C}-\mathrm{NMR}\left(100 \mathrm{MHz}, \mathrm{CDCl}_{3}\right): \delta=149.8\left(\mathrm{C}_{\mathrm{q}}\right), 148.8(\mathrm{CH}, \mathrm{Z}), 148.7(\mathrm{CH}, E), 146.5\left(\mathrm{dt},{ }^{1} J_{\mathrm{C}-\mathrm{F}}=\right.$ $\left.262 \mathrm{~Hz},{ }^{2} J_{\mathrm{C}-\mathrm{F}}=29.6 \mathrm{~Hz}, \mathrm{C}_{\mathrm{q}}\right), 143.1(\mathrm{CH}), 138.1(\mathrm{CH}), 137.3\left(\mathrm{C}_{\mathrm{q}}\right), 128.1(\mathrm{CH}), 122.1(\mathrm{CH})$, 121.7 (CH), $119.0\left(\mathrm{C}_{\mathrm{q}}\right), 117.4(\mathrm{CH}), 116.5\left(\mathrm{dt},{ }^{1} J_{\mathrm{C}-\mathrm{F}}=286 \mathrm{~Hz},{ }^{2} J_{\mathrm{C}-\mathrm{F}}=32.7 \mathrm{~Hz}, \mathrm{C}_{\mathrm{q}}\right), 115.2\left(\mathrm{C}_{\mathrm{q}}\right)$, $113.0\left(\mathrm{dt},{ }^{2} J_{\mathrm{C}-\mathrm{F}}=8.7 \mathrm{~Hz},{ }^{3} J_{\mathrm{C}-\mathrm{F}}=4.5 \mathrm{~Hz}, \mathrm{CH}\right), 112.6\left(\mathrm{~m}, \mathrm{C}_{\mathrm{q}}\right), 111.5\left(\mathrm{~m}, \mathrm{C}_{\mathrm{q}}\right), 111.0\left(\mathrm{~m}, \mathrm{C}_{\mathrm{q}}\right)$, $110.4\left(\mathrm{~m}, \mathrm{C}_{\mathrm{q}}\right), 107.9\left(\mathrm{~m}, \mathrm{C}_{\mathrm{q}}\right), 106.7\left(\mathrm{~m}, \mathrm{C}_{\mathrm{q}}\right), 101.5(\mathrm{CH}), 23.3\left(\mathrm{~d},{ }^{3} J_{\mathrm{C}-\mathrm{F}}=4.4 \mathrm{~Hz}, \mathrm{CH}_{2}\right)$.

${ }^{19} \mathrm{~F}-\mathrm{NMR}\left(282 \mathrm{MHz}, \mathrm{CDCl}_{3}\right): \delta=-81.0(\mathrm{~m}),-117.6(\mathrm{~m}),-122.1(\mathrm{~m}),-122.1(\mathrm{~m}),-122.9(\mathrm{~m})$, $-123.0(\mathrm{~m}),-126.3(\mathrm{~m}),-130.4(\mathrm{~m})$.

IR (ATR): 3073, 2852, 1590, 1471, 1236, 805, $663 \mathrm{~cm}^{-1}$.

MS (ESI) $m / z$ (relative intensity): $622\left([\mathrm{M}+\mathrm{H}]^{+}, 100\right), 602(15)$.

HR-MS (ESI): $m / z$ calcd. for $\left[\mathrm{C}_{22} \mathrm{H}_{11} \mathrm{~F}_{16} \mathrm{~N}_{3}+\mathrm{H}\right]^{+}$622.0770, found 622.0769 . 
<smiles>FC(=CCc1cccn1-c1ccccn1)C(F)F</smiles>

(Z)-2-[2-(1H,1H,2H-Perfluorodec-2-en-1-yl)-1H-pyrrol-1-yl]pyridine (321aa): The general procedure A was followed using 2-(1H-pyrrol-1-yl)pyridine (320a) $(72.0 \mathrm{mg}$, $0.50 \mathrm{mmol}$ ) and $1 \mathrm{H}, 1 \mathrm{H}, 2 \mathrm{H}$-perfluoro-1-decene (301a) (268 $\mathrm{mg}, 0.60 \mathrm{mmol}$ ). Isolation by column chromatography $(n$-hexane/EtOAc $=10: 1)$ yielded 321aa $(177 \mathrm{mg}, 62 \%, Z / E=87: 13)$ and 321aa' (59.1 mg, 12\%, Z/E = 87:13) as yellow oils.

${ }^{1} \mathrm{H}-\mathrm{NMR}\left(400 \mathrm{MHz}, \mathrm{CDCl}_{3}\right): \delta=8.47$ (ddd, $\left.J=4.9,1.9,0.9 \mathrm{~Hz}, 1 \mathrm{H}\right), 7.77(\mathrm{ddd}, J=8.2,7.5$, $1.9 \mathrm{~Hz}, 1 \mathrm{H}), 7.28(\mathrm{dt}, J=8.2,0.9 \mathrm{~Hz}, 1 \mathrm{H}), 7.18(\mathrm{ddd}, J=7.5,4.9,0.9 \mathrm{~Hz}, 1 \mathrm{H}), 7.01(\mathrm{ddd}, J=$ $3.1,1.8,0.5 \mathrm{~Hz}, 1 \mathrm{H}), 6.24(\mathrm{ddd}, J=3.1,2.6,0.5 \mathrm{~Hz}, 1 \mathrm{H}), 6.16(\mathrm{dt}, J=22.7,8.2 \mathrm{~Hz}, 0.13 \mathrm{H}, E)$, 6.12-6.09 (m, 1H) $5.81(\mathrm{dt}, J=33.4,7.5 \mathrm{~Hz}, 0.87 \mathrm{H}, Z), 3.88(\mathrm{ddt}, J=7.5,3.9,2.0 \mathrm{~Hz}, 1.74 \mathrm{H}$, $Z$ ), 3.83 (ddt, $J=7.5,4.0,2.0 \mathrm{~Hz}, 0.26 \mathrm{H}, E$ ).

${ }^{13} \mathrm{C}-\mathrm{NMR}\left(100 \mathrm{MHz}, \mathrm{CDCl}_{3}\right): \delta=152.5\left(\mathrm{C}_{\mathrm{q}}\right), 148.6(\mathrm{CH}), 145.4\left(\mathrm{dt},{ }^{1} J_{\mathrm{C}-\mathrm{F}}=260 \mathrm{~Hz},{ }^{2} J_{\mathrm{C}-\mathrm{F}}=\right.$ $\left.30.1 \mathrm{~Hz}, \mathrm{C}_{\mathrm{q}}\right), 138.5(\mathrm{CH}), 129.1\left(\mathrm{C}_{\mathrm{q}}\right), 121.2(\mathrm{CH}), 121.0(\mathrm{CH}), 116.9\left(\mathrm{dt},{ }^{1} J_{\mathrm{C}-\mathrm{F}}=285 \mathrm{~Hz},{ }^{2} J_{\mathrm{C}-\mathrm{F}}\right.$ $\left.=33.3 \mathrm{~Hz}, \mathrm{C}_{\mathrm{q}}\right), 116.6(\mathrm{CH}), 114.6(\mathrm{dt}, J=8.3,4.3 \mathrm{~Hz}, \mathrm{CH}), 112.2\left(\mathrm{~m}, \mathrm{C}_{\mathrm{q}}\right), 111.3\left(\mathrm{~m}, \mathrm{C}_{\mathrm{q}}\right), 111.2$ $\left(\mathrm{m}, \mathrm{C}_{\mathrm{q}}\right), 110.9\left(\mathrm{~m}, \mathrm{C}_{\mathrm{q}}\right), 110.7(\mathrm{CH}), 109.7(\mathrm{CH}), 108.6\left(\mathrm{~m}, \mathrm{C}_{\mathrm{q}}\right), 107.8\left(\mathrm{C}_{\mathrm{q}}\right), 22.9\left(\mathrm{~d},{ }^{3} J_{\mathrm{C}-\mathrm{F}}=4.2\right.$ $\mathrm{Hz}, \mathrm{CH}_{2}$ ).

${ }^{19} \mathrm{~F}-\mathrm{NMR}\left(376 \mathrm{MHz}, \mathrm{CDCl}_{3}\right): \delta=-80.8(\mathrm{~m}),-117.5(\mathrm{~m}),-122.0(\mathrm{~m}),-122.8(\mathrm{~m}),-123.0(\mathrm{~m})$, $-123.5(\mathrm{~m}),-126.2(\mathrm{~m}),-132.3(\mathrm{~m})$.

IR (ATR): 1523, 1504, 1325, 1182, 992, $754 \mathrm{~cm}^{-1}$.

MS (ESI) $m / z$ (relative intensity): $593\left([\mathrm{M}+\mathrm{Na}]^{+}, 20\right), 571\left([\mathrm{M}+\mathrm{H}]^{+}, 100\right)$.

HR-MS (ESI): $m / z$ calcd. for $\left[\mathrm{C}_{19} \mathrm{H}_{10} \mathrm{~F}_{16} \mathrm{~N}_{2}+\mathrm{H}\right]^{+}$571.0661, found 571.0668.<smiles>FC(=CCc1ccc(CC=C(F)C(F)(F)F)n1-c1ccccn1)C(F)(F)F</smiles>

(Z)-2-[2,5-Di-(1H,1H,2H-perfluorodec-2-en-1-yl)-1H-pyrrol-1-yl]pyridine (321aa'):

${ }^{1} \mathrm{H}-\mathrm{NMR}\left(300 \mathrm{MHz}, \mathrm{CDCl}_{3}\right): \delta=8.58$ (ddd, $\left.J=4.9,1.9,0.9 \mathrm{~Hz}, 1 \mathrm{H}\right), 7.84$ (ddd, $J=8.2,7.5$, $2.0 \mathrm{~Hz}, 1 \mathrm{H}), 7.34(\mathrm{dt}, J=8.2,0.9 \mathrm{~Hz}, 1 \mathrm{H}), 7.23$ (ddd, $J=7.5,4.9,0.9 \mathrm{~Hz}, 1 \mathrm{H}), 6.03-5.92(\mathrm{~m}$, 2H), $5.80(\mathrm{dt}, J=22.7,8.2 \mathrm{~Hz}, 0.26 \mathrm{H}, E), 5.61(\mathrm{dt}, J=33.4,7.5 \mathrm{~Hz}, 1.74 \mathrm{H}, Z), 3.45$ (ddt, $J=$ $7.5,3.9,2.0 \mathrm{~Hz}, 4 \mathrm{H})$. 
${ }^{13} \mathrm{C}-\mathrm{NMR}\left(100 \mathrm{MHz}, \mathrm{CDCl}_{3}\right): \delta=150.7\left(\mathrm{C}_{\mathrm{q}}\right), 149.8(\mathrm{CH}), 145.7\left(\mathrm{dt},{ }^{1} J_{\mathrm{C}-\mathrm{F}}=259 \mathrm{~Hz},{ }^{2} J_{\mathrm{C}-\mathrm{F}}=\right.$ $\left.30.1 \mathrm{~Hz}, \mathrm{C}_{\mathrm{q}}\right), 138.4(\mathrm{CH}), 129.1\left(\mathrm{C}_{\mathrm{q}}\right), 123.1(\mathrm{CH}), 121.9(\mathrm{CH}), 117.4\left(\mathrm{dt},{ }^{1} J_{\mathrm{C}-\mathrm{F}}=288 \mathrm{~Hz},{ }^{2} J_{\mathrm{C}-\mathrm{F}}\right.$ $\left.=33.3 \mathrm{~Hz}, \mathrm{C}_{\mathrm{q}}\right), 112.6(\mathrm{dt}, J=8.3,4.3 \mathrm{~Hz}, \mathrm{CH}), 111.2\left(\mathrm{~m}, \mathrm{C}_{\mathrm{q}}\right), 110.8\left(\mathrm{~m}, \mathrm{C}_{\mathrm{q}}\right), 110.2\left(\mathrm{~m}, \mathrm{C}_{\mathrm{q}}\right)$, $109.7\left(\mathrm{~m}, \mathrm{C}_{\mathrm{q}}\right), 108.8\left(\mathrm{~m}, \mathrm{C}_{\mathrm{q}}\right), 108.2\left(\mathrm{~m}, \mathrm{C}_{\mathrm{q}}\right), 107.8(\mathrm{CH}), 21.3\left(\mathrm{~d},{ }^{3} J_{\mathrm{C}-\mathrm{F}}=4.1 \mathrm{~Hz}, \mathrm{CH}_{2}\right)$.

${ }^{19} \mathrm{~F}-\mathrm{NMR}\left(376 \mathrm{MHz}, \mathrm{CDCl}_{3}\right): \delta=-81.2(\mathrm{~m}),-117.7(\mathrm{~m}),-121.9(\mathrm{~m}),-122.2(\mathrm{~m}),-123.1(\mathrm{~m})$, $-123.1(\mathrm{~m}),-126.4(\mathrm{~m}),-131.8(\mathrm{~m})$.

IR (ATR): 2960, 2924, 1473, 1235, 1143, 1047, 735, $559 \mathrm{~cm}^{-1}$.

MS (ESI) $m / z$ (relative intensity): 997 ([M + H $\left.]^{+}, 100\right), 573$ (20), 545 (15).

HR-MS (ESI): $m / z$ calcd. for $\left[\mathrm{C}_{29} \mathrm{H}_{12} \mathrm{~F}_{32} \mathrm{~N}_{2}+\mathrm{H}\right]^{+}$997.0562, found: 997.0553<smiles>FC(=CCc1ccccc1-c1ccccn1)C(F)F</smiles>

(Z)-2-[2-(1H,1H,2H-Perfluorodec-2-en-1-yl)phenyl]pyridine (322aa): A modified procedure A was followed using 2-phenylpyridine (93a) $(78.0 \mathrm{mg}, 0.50 \mathrm{mmol}), 1 \mathrm{H}, 1 \mathrm{H}, 2 \mathrm{H}$ perfluoro-1-decene (301a) $(268 \mathrm{mg}, 0.60 \mathrm{mmol})$ and $\mathrm{NaOAc}(12.3 \mathrm{mg}, 30 \mathrm{~mol} \%)$ at $120{ }^{\circ} \mathrm{C}$. Isolation by column chromatography $(n$-hexane/EtOAc $=10: 1)$ yielded 322aa $(169 \mathrm{mg}, 58 \%$, $Z / E=86: 14)$ as a yellow oil.

${ }^{1} \mathrm{H}-\mathrm{NMR}\left(300 \mathrm{MHz}, \mathrm{CDCl}_{3}\right): \delta=8.67(\mathrm{ddd}, J=4.9,1.9,0.9 \mathrm{~Hz}, 1 \mathrm{H}), 7.74(\mathrm{dt}, J=7.7,1.8 \mathrm{~Hz}$, 1H), 7.48-7.17 (m, 6H), $6.05(\mathrm{dt}, J=23.1,8.2 \mathrm{~Hz}, 0.14 \mathrm{H}), 5.76(\mathrm{dt}, J=33.4,7.7 \mathrm{~Hz}, 0.86 \mathrm{H})$, 3.73 (ddt, $J=7.7,4.0,2.3 \mathrm{~Hz}, 2 \mathrm{H})$.

${ }^{13} \mathrm{C}-\mathrm{NMR}\left(125 \mathrm{MHz}, \mathrm{CDCl}_{3}\right): \delta=159.3\left(\mathrm{C}_{\mathrm{q}}\right), 149.0(\mathrm{CH}), 145.4\left(\mathrm{dt},{ }^{1} J_{\mathrm{C}-\mathrm{F}}=258 \mathrm{~Hz},{ }^{2} J_{\mathrm{C}-\mathrm{F}}=\right.$ $\left.29.0 \mathrm{~Hz}, \mathrm{C}_{\mathrm{q}}\right), 140.3\left(\mathrm{C}_{\mathrm{q}}\right), 136.4\left(\mathrm{~d},{ }^{2} J_{\mathrm{C}-\mathrm{F}}=7.4 \mathrm{~Hz}, \mathrm{CH}\right), 135.7\left(\mathrm{C}_{\mathrm{q}}\right), 130.0\left(\mathrm{~d},{ }^{2} J_{\mathrm{C}-\mathrm{F}}=7.8 \mathrm{~Hz}\right.$, $\mathrm{CH}), 128.7\left(\mathrm{~d},{ }^{3} J_{\mathrm{C}-\mathrm{F}}=3.2 \mathrm{~Hz}, \mathrm{CH}\right), 127.0\left(\mathrm{~d},{ }^{3} J_{\mathrm{C}-\mathrm{F}}=4.2 \mathrm{~Hz}, \mathrm{CH}\right), 123.9(\mathrm{CH}), 123.8\left(\mathrm{~d},{ }^{2} J_{\mathrm{C}-\mathrm{F}}\right.$ $=10.8 \mathrm{~Hz}, \mathrm{CH}), 121.9\left(\mathrm{~d},{ }^{4} J_{\mathrm{C}-\mathrm{F}}=2.2 \mathrm{~Hz}, \mathrm{CH}\right), 117.0\left(\mathrm{dt},{ }^{1} J_{\mathrm{C}-\mathrm{F}}=285 \mathrm{~Hz},{ }^{2} J_{\mathrm{C}-\mathrm{F}}=33.3 \mathrm{~Hz}, \mathrm{C}_{\mathrm{q}}\right)$, $115.7(\mathrm{~m}, \mathrm{CH}), 112.7\left(\mathrm{~m}, \mathrm{C}_{\mathrm{q}}\right), 112.4\left(\mathrm{~m}, \mathrm{C}_{\mathrm{q}}\right), 110.9\left(\mathrm{~m}, \mathrm{C}_{\mathrm{q}}\right), 110.7\left(\mathrm{~m}, \mathrm{C}_{\mathrm{q}}\right), 108.5\left(\mathrm{~m}, \mathrm{C}_{\mathrm{q}}\right), 108.3$ $\left(\mathrm{m}, \mathrm{C}_{\mathrm{q}}\right), 27.8\left(\mathrm{~d},{ }^{3} J_{\mathrm{C}-\mathrm{F}}=3.5 \mathrm{~Hz}, \mathrm{CH}_{2}\right)$.

${ }^{19} \mathrm{~F}-\mathrm{NMR}\left(282 \mathrm{MHz}, \mathrm{CDCl}_{3}\right): \delta=-81.0(\mathrm{~m}),-117.5(\mathrm{~m}),-122.2(\mathrm{~m}),-123.0(\mathrm{~m}),-123.5(\mathrm{~m})$, $-124.5(\mathrm{~m}),-126.3(\mathrm{~m}),-132.7(\mathrm{~m})$.

IR (ATR): 1235, 1198, 1105, 748, $663 \mathrm{~cm}^{-1}$.

MS (ESI) $m / z$ (relative intensity): $582[\mathrm{M}+\mathrm{H}]^{+},(100)$.

HR-MS (ESI): $m / z$ calcd. for $\left[\mathrm{C}_{21} \mathrm{H}_{11} \mathrm{~F}_{16} \mathrm{~N}+\mathrm{H}\right]^{+}$582.0709, found 582.0718. 
<smiles>FC(=CCc1cccc2ccc3cccnc3c12)C(F)F</smiles>

(Z)-10-(1H,1H,2H-Perfluorodec-2-en-1-yl)benzo[h]quinolone (324aa): A modified general procedure A was followed using benzo[ $h$ ]quinolone (323a) $(90.0 \mathrm{mg}, 0.50 \mathrm{mmol}), 1 \mathrm{H}, 1 \mathrm{H}, 2 \mathrm{H}$ perfluoro-1-decene (301a) (446 mg, $1.00 \mathrm{mmol})$, [MnBr(CO)5] (13.7 mg, $10 \mathrm{~mol} \%$ ) and $\mathrm{NaOAc}(12.3 \mathrm{mg}, \quad 30 \mathrm{~mol} \%)$ at $120^{\circ} \mathrm{C}$. Isolation by column chromatography ( $n$ hexane/EtOAc $=10: 1)$ yielded 324aa $(163 \mathrm{mg}, 54 \%, Z / E=96: 4)$ as a yellow oil.

${ }^{1} \mathrm{H}-\mathrm{NMR}\left(400 \mathrm{MHz}, \mathrm{CDCl}_{3}\right): \delta=8.97$ (ddd, $\left.J=4.3,1.9,0.9 \mathrm{~Hz}, 1 \mathrm{H}\right), 8.25-8.09$ (m, 1H), 7.85 $(\mathrm{dd}, J=7.3,1.9 \mathrm{~Hz}, 1 \mathrm{H}), 7.80(\mathrm{~d}, J=8.8 \mathrm{~Hz}, 1 \mathrm{H}), 7.67(\mathrm{~d}, J=8.8 \mathrm{~Hz}, 1 \mathrm{H}), 7.64-7.56(\mathrm{~m}, 2 \mathrm{H})$, 7.49 (ddd, $J=8.0,4.3,0.6 \mathrm{~Hz}, 1 \mathrm{H}), 6.50(\mathrm{dt}, J=24.3,8.0 \mathrm{~Hz}, 0.04 \mathrm{H}, E), 6.20(\mathrm{dt}, J=35.0$, $7.4 \mathrm{~Hz}, 0.96 \mathrm{H}, Z$ ), 4.80 (ddt, $J=7.4,3.8,2.3 \mathrm{~Hz}, 2 \mathrm{H}$ ).

${ }^{13} \mathrm{C}-\mathrm{NMR}\left(100 \mathrm{MHz}, \mathrm{CDCl}_{3}\right): \delta=147.8\left(\mathrm{C}_{\mathrm{q}}\right), 147.4(\mathrm{CH}), 145.0\left(\mathrm{dt},{ }^{1} J_{\mathrm{C}-\mathrm{F}}=261 \mathrm{~Hz},{ }^{2} J_{\mathrm{C}-\mathrm{F}}=\right.$ $\left.29.1 \mathrm{~Hz}, \mathrm{C}_{\mathrm{q}}\right), 137.4\left(\mathrm{C}_{\mathrm{q}}\right), 135.7(\mathrm{CH}), 135.5\left(\mathrm{C}_{\mathrm{q}}\right), 131.2(\mathrm{CH}), 129.2\left(\mathrm{C}_{\mathrm{q}}\right), 128.8(\mathrm{CH}), 128.2$ $(\mathrm{CH}), 127.7(\mathrm{CH}), 127.5\left(\mathrm{C}_{\mathrm{q}}\right), 125.8(\mathrm{CH}), 121.0(\mathrm{CH}), 117.6(\mathrm{CH}), 116.9\left(\mathrm{dt},{ }^{1} J_{\mathrm{C}-\mathrm{F}}=275 \mathrm{~Hz}\right.$, $\left.{ }^{2} J_{\mathrm{C}-\mathrm{F}}=32.3 \mathrm{~Hz}, \mathrm{C}_{\mathrm{q}}\right), 113.4\left(\mathrm{~m}, \mathrm{C}_{\mathrm{q}}\right), 111.3\left(\mathrm{~m}, \mathrm{C}_{\mathrm{q}}\right), 110.9\left(\mathrm{~m}, \mathrm{C}_{\mathrm{q}}\right), 110.7\left(\mathrm{~m}, \mathrm{C}_{\mathrm{q}}\right), 108.6\left(\mathrm{~m}, \mathrm{C}_{\mathrm{q}}\right)$, $108.0\left(\mathrm{~m}, \mathrm{C}_{\mathrm{q}}\right), 33.0\left(\mathrm{~d},{ }^{3} J_{\mathrm{C}-\mathrm{F}}=3.8 \mathrm{~Hz}, \mathrm{CH}_{2}\right)$.

${ }^{19} \mathrm{~F}-\mathrm{NMR}\left(376 \mathrm{MHz}, \mathrm{CDCl}_{3}\right): \delta=-80.8(\mathrm{~m}),-117.2(\mathrm{~m}),-122.0(\mathrm{~m}),-122.1(\mathrm{~m}),-122.8(\mathrm{~m})$, $-122.9(\mathrm{~m}),-126.2(\mathrm{~m}),-133.7(\mathrm{~m})$.

IR (ATR): 1235, 1200, 1146, 833, $663 \mathrm{~cm}^{-1}$.

MS (ESI) $m / z$ (relative intensity): $606\left([\mathrm{M}+\mathrm{H}]^{+}, 100\right), 582(20)$.

HR-MS (ESI): $m / z$ calcd. for $\left[\mathrm{C}_{23} \mathrm{H}_{11} \mathrm{~F}_{16} \mathrm{~N}+\mathrm{H}\right]^{+}$606.0709, found 606.0704.

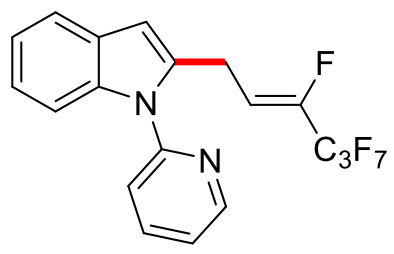

(Z)-2-(1H,1H,2H-Perfluorohex-2-en-1-yl)-1-(pyridin-2-yl)-1H-indole (316ab): The general procedure A was followed using 1-(pyridin-2-yl)-1H-indole (315a) $(97.1 \mathrm{mg}, 0.50 \mathrm{mmol})$ and 1H,1H,2H-perfluoro-1-hexene (301b) $\quad(148 \mathrm{mg}, \quad 0.60 \mathrm{mmol})$. Isolation by column chromatography $(n$-hexane/EtOAc $=10: 1)$ yielded 316ab $(160 \mathrm{mg}, 76 \%, Z / E=90: 10)$ as a colourless oil. 
${ }^{1} \mathrm{H}-\mathrm{NMR}\left(400 \mathrm{MHz}, \mathrm{CDCl}_{3}\right): \delta=8.68(\mathrm{ddd}, J=4.9,2.0,0.9 \mathrm{~Hz}, 1 \mathrm{H}), 7.93(\mathrm{ddd}, J=7.6,7.6$, $2.0 \mathrm{~Hz}, 1 \mathrm{H}), 7.72-7.60(\mathrm{~m}, 1 \mathrm{H}), 7.52(\mathrm{~d}, J=8.0 \mathrm{~Hz}, 1 \mathrm{H}), 7.45-7.32(\mathrm{~m}, 2 \mathrm{H}), 7.25-7.18(\mathrm{~m}$, $2 \mathrm{H}), 6.54(\mathrm{~d}, J=0.9 \mathrm{~Hz}, 1 \mathrm{H}), 6.20(\mathrm{dt}, J=22.5,8.3 \mathrm{~Hz}, 0.10 \mathrm{H}, E), 5.85(\mathrm{dt}, J=32.9,7.5 \mathrm{~Hz}$, $0.90 \mathrm{H}, Z$ ), 3.93 (ddt, $J=6.9,3.3,2.4 \mathrm{~Hz}, 2 \mathrm{H}$ ).

${ }^{13} \mathrm{C}-\mathrm{NMR}\left(100 \mathrm{MHz}, \mathrm{CDCl}_{3}\right): \delta=150.9\left(\mathrm{C}_{\mathrm{q}}\right), 149.7(\mathrm{CH}), 145.9\left(\mathrm{dt},{ }^{1} J_{\mathrm{C}-\mathrm{F}}=262 \mathrm{~Hz},{ }^{2} J_{\mathrm{C}-\mathrm{F}}=\right.$ $\left.29.8 \mathrm{~Hz}, \mathrm{C}_{\mathrm{q}}\right)$ 138.4 (CH), $137.1\left(\mathrm{C}_{\mathrm{q}}\right), 136.1\left(\mathrm{C}_{\mathrm{q}}\right), 128.3\left(\mathrm{C}_{\mathrm{q}}\right), 122.4(\mathrm{CH}), 122.2(\mathrm{CH}), 121.0$ $(\mathrm{CH}), 120.5(\mathrm{CH}), 120.4(\mathrm{CH}), 117.9\left(\mathrm{dt},{ }^{1} J_{\mathrm{C}-\mathrm{F}}=285 \mathrm{~Hz},{ }^{2} J_{\mathrm{C}-\mathrm{F}}=33.0 \mathrm{~Hz}, \mathrm{C}_{\mathrm{q}}\right), 113.3\left(\mathrm{dt},{ }^{2} J_{\mathrm{C}-\mathrm{F}}\right.$ $\left.=8.3 \mathrm{~Hz},{ }^{3} J_{\mathrm{C}-\mathrm{F}}=4.3 \mathrm{~Hz}, \mathrm{CH}\right), 110.1(\mathrm{CH}), 109.6\left(\mathrm{~m}, \mathrm{C}_{\mathrm{q}}\right), 107.7\left(\mathrm{~m}, \mathrm{C}_{\mathrm{q}}\right), 103.7(\mathrm{CH}), 22.7(\mathrm{~d}$, $\left.{ }^{3} J_{\mathrm{C}-\mathrm{F}}=4.3 \mathrm{~Hz}, \mathrm{CH}_{2}\right)$.

${ }^{19} \mathrm{~F}-\mathrm{NMR}\left(376 \mathrm{MHz}, \mathrm{CDCl}_{3}\right): \delta=-80.8(\mathrm{~m}),-115.9(\mathrm{~m}, E),-118.5(\mathrm{~m}, Z),-127.4(\mathrm{~m}, Z),-$ $127.9(\mathrm{~m}, E),-131.0(\mathrm{~m})$.

IR (ATR): 3059, 1587, 1119, 782, $737 \mathrm{~cm}^{-1}$.

MS (ESI) $m / z$ (relative intensity): $443\left([\mathrm{M}+\mathrm{Na}]^{+}, 10\right), 421(100)$.

HR-MS (ESI): $m / z$ calcd. for $\left[\mathrm{C}_{19} \mathrm{H}_{12} \mathrm{~F}_{8} \mathrm{~N}_{2}+\mathrm{H}\right]^{+} 421.0946$, found 421.0950 .<smiles>FC(=CCc1cc2ccccc2n1-c1ccccn1)C(F)(F)F</smiles>

(Z)-2-(1H,1H,2H-Perfluorododec-2-en-1-yl)-1-(pyridin-2-yl)-1H-indole $\quad$ (316ac): The general procedure A was followed using 1-(pyridin-2-yl)-1H-indole (315a) (97.1 mg, $0.50 \mathrm{mmol}$ ) and $1 \mathrm{H}, 1 \mathrm{H}, 2 \mathrm{H}$-perfluoro-1-dodecene (301c) (328 $\mathrm{mg}, 0.60 \mathrm{mmol}$ ). Isolation by column chromatography $(n$-hexane/EtOAc $=10: 1)$ yielded 316ac $(302 \mathrm{mg}, 84 \%, \mathrm{Z} / \mathrm{E}=89: 11)$ as a colorless oil.

${ }^{1} \mathrm{H}-\mathrm{NMR}\left(500 \mathrm{MHz}, \mathrm{CDCl}_{3}\right): \delta=8.64(\mathrm{ddd}, J=4.8,2.0,0.8 \mathrm{~Hz}, 1 \mathrm{H}), 7.87$ (ddd, $J=7.7,7.5$, $2.0 \mathrm{~Hz}, 1 \mathrm{H}), 7.63-7.58(\mathrm{~m}, 1 \mathrm{H}), 7.48$ (dt, $J=8.0,1.0 \mathrm{~Hz}, 1 \mathrm{H}), 7.40-7.36$ (m, 1H), 7.31 (ddd, $J=7.5,4.9,1.0 \mathrm{~Hz}, 1 \mathrm{H}), 7.20-7.15(\mathrm{~m}, 2 \mathrm{H}), 6.50(\mathrm{~d}, J=0.9 \mathrm{~Hz}, 1 \mathrm{H}), 6.15(\mathrm{dt}, J=22.4,8.2$ $\mathrm{Hz}, 0.11 \mathrm{H}, E), 5.81(\mathrm{dt}, J=32.8,7.5 \mathrm{~Hz}, 0.89 \mathrm{H}, Z$ ), 3.90 (ddt, $J=7.5,4.0,2.2 \mathrm{~Hz}, 1.78 \mathrm{H}, Z$ ), 3.85 (ddt, $J=7.5,4.0,2.2 \mathrm{~Hz}, 0.22 \mathrm{H}, E$ ).

${ }^{13} \mathrm{C}-\mathrm{NMR}\left(125 \mathrm{MHz}, \mathrm{CDCl}_{3}\right): \delta=150.8\left(\mathrm{C}_{\mathrm{q}}\right), 149.7(\mathrm{CH}), 146.2\left(\mathrm{dt},{ }^{1} J_{\mathrm{C}-\mathrm{F}}=261 \mathrm{~Hz},{ }^{2} J_{\mathrm{C}-\mathrm{F}}=\right.$ $\left.29.0 \mathrm{~Hz}, \mathrm{C}_{\mathrm{q}}\right), 138.4(\mathrm{CH}), 137.1\left(\mathrm{C}_{\mathrm{q}}\right), 136.1\left(\mathrm{~d},{ }^{4} J_{\mathrm{C}-\mathrm{F}}=2.0 \mathrm{~Hz}, \mathrm{C}_{\mathrm{q}}\right), 128.3\left(\mathrm{C}_{\mathrm{q}}\right), 122.4(\mathrm{CH})$, $122.2(\mathrm{CH}), 121.1(\mathrm{CH}), 120.6(\mathrm{CH}), 120.4(\mathrm{CH}), 117.2\left(\mathrm{dt},{ }^{1} J_{\mathrm{C}-\mathrm{F}}=290 \mathrm{~Hz},{ }^{2} J_{\mathrm{C}-\mathrm{F}}=33.1 \mathrm{~Hz}\right.$, $\left.\mathrm{C}_{\mathrm{q}}\right), 113.3\left(\mathrm{dt},{ }^{2} J_{\mathrm{C}-\mathrm{F}}=8.5 \mathrm{~Hz},{ }^{3} J_{\mathrm{C}-\mathrm{F}}=4.4 \mathrm{~Hz}, \mathrm{CH}\right), 112.7\left(\mathrm{~m}, \mathrm{C}_{\mathrm{q}}\right), 110.8\left(\mathrm{~m}, \mathrm{C}_{\mathrm{q}}\right), 110.6\left(\mathrm{~m}, \mathrm{C}_{\mathrm{q}}\right)$, 
$110.1(\mathrm{CH}), 108.8\left(\mathrm{~m}, \mathrm{C}_{\mathrm{q}}\right), 108.5\left(\mathrm{~m}, \mathrm{C}_{\mathrm{q}}\right), 108.2\left(\mathrm{~m}, \mathrm{C}_{\mathrm{q}}\right), 106.3\left(\mathrm{~m}, \mathrm{C}_{\mathrm{q}}\right), 106.1\left(\mathrm{~m}, \mathrm{C}_{\mathrm{q}}\right), 103.7$ $(\mathrm{CH}), 22.7\left(\mathrm{~d},{ }^{3} J_{\mathrm{C}-\mathrm{F}}=4.3 \mathrm{~Hz}, \mathrm{CH}_{2}\right)$.

${ }^{19} \mathrm{~F}-\mathrm{NMR}\left(470 \mathrm{MHz}, \mathrm{CDCl}_{3}\right): \delta=-81.0(\mathrm{~m}),-117.6(\mathrm{~m}),-121.8(\mathrm{~m}),-122.0(\mathrm{~m}),-122.0(\mathrm{~m})$, $-122.2(\mathrm{~m}),-122.9(\mathrm{~m}),-123.0(\mathrm{~m}),-126.3(\mathrm{~m}),-130.9(\mathrm{~m})$.

IR (ATR): 1471, 1438, 1200, 1105, 735, 556, $528 \mathrm{~cm}^{-1}$.

MS (ESI) $m / z$ (relative intensity): $721\left([\mathrm{M}+\mathrm{H}]^{+}, 100\right), 621$ (10).

HR-MS (ESI): $m / z$ calcd. for $\left[\mathrm{C}_{25} \mathrm{H}_{12} \mathrm{~F}_{20} \mathrm{~N}_{2}+\mathrm{H}\right]^{+} 721.0754$, found 721.0755 .<smiles>COc1ccc(-c2ccccn2)c(CC=C(F)C(F)(F)F)c1</smiles>

(Z)-4-Methoxy-2-[2-(1H,1H,2H-perfluorododec-2-en-1-yl)phenyl]pyridine (322bc): A modified general procedure $\mathbf{A}$ was followed using 2-(4-methoxyphenyl)pyridine (93b) (93.0 mg, $0.50 \mathrm{mmol}), 1 H, 1 H, 2 H$-perfluoro-1-dodecene (301c) $(546 \mathrm{mg}, 1.00 \mathrm{mmol})$ and $\left[\mathrm{MnBr}(\mathrm{CO})_{5}\right](13.7 \mathrm{mg}, 10 \mathrm{~mol} \%)$ at $120{ }^{\circ} \mathrm{C}$. Isolation by column chromatography $(n-$ hexane/EtOAc $=10: 1)$ yielded 322bc $(201 \mathrm{mg}, 57 \%, Z / E=92: 8)$ as a pale yellow solid. M.p.: $55^{\circ} \mathrm{C}$.

${ }^{1} \mathrm{H}-\mathrm{NMR}\left(300 \mathrm{MHz}, \mathrm{CDCl}_{3}\right): \delta=8.63(\mathrm{ddd}, J=4.9,1.9,0.9 \mathrm{~Hz}, 1 \mathrm{H}), 7.80-7.57(\mathrm{~m}, 1 \mathrm{H}), 7.37-$ $7.34(\mathrm{~m}, 1 \mathrm{H}), 7.34-7.31(\mathrm{~m}, 1 \mathrm{H}), 7.20(\mathrm{ddd}, J=7.6,4.9,1.2 \mathrm{~Hz}, 1 \mathrm{H}), 6.86(\mathrm{dd}, J=8.4,2.6 \mathrm{~Hz}$, $1 \mathrm{H}), 6.80(\mathrm{~d}, J=2.6 \mathrm{~Hz}, 1 \mathrm{H}), 6.05(\mathrm{dt}, J=23.0,8.2 \mathrm{~Hz}, 0.08 \mathrm{H}, E), 5.76(\mathrm{dt}, J=33.4,7.7 \mathrm{~Hz}$, $0.92 \mathrm{H}, Z), 3.82(\mathrm{~s}, 3 \mathrm{H}), 3.72(\mathrm{ddt}, J=7.4,3.8,2.3 \mathrm{~Hz}, 2 \mathrm{H})$.

${ }^{13} \mathrm{C}-\mathrm{NMR}\left(125 \mathrm{MHz}, \mathrm{CDCl}_{3}\right): \delta=159.8\left(\mathrm{C}_{\mathrm{q}}\right), 159.1\left(\mathrm{C}_{\mathrm{q}}\right), 149.0(\mathrm{CH}), 145.3\left(\mathrm{dt},{ }^{1} J_{\mathrm{C}-\mathrm{F}}=258 \mathrm{~Hz}\right.$, $\left.29.0 \mathrm{~Hz}, \mathrm{C}_{\mathrm{q}}\right), 137.2\left(\mathrm{C}_{\mathrm{q}}\right), 136.4(\mathrm{CH}), 132.9\left(\mathrm{C}_{\mathrm{q}}\right), 131.3(\mathrm{CH}), 123.7(\mathrm{CH}), 121.5(\mathrm{CH}), 117.1$ $\left(\mathrm{dt},{ }^{1} J_{\mathrm{C}-\mathrm{F}}=289 \mathrm{~Hz},{ }^{2} J_{\mathrm{C}-\mathrm{F}}=33.2 \mathrm{~Hz}, \mathrm{C}_{\mathrm{q}}\right), 115.7\left(\mathrm{C}_{\mathrm{q}}\right), 115.5(\mathrm{CH}), 112.4(\mathrm{CH}), 112.2\left(\mathrm{~m}, \mathrm{C}_{\mathrm{q}}\right)$, $110.7\left(\mathrm{~m}, \mathrm{C}_{\mathrm{q}}\right), 110.6\left(\mathrm{~m}, \mathrm{C}_{\mathrm{q}}\right), 110.5\left(\mathrm{~m}, \mathrm{C}_{\mathrm{q}}\right), 108.8\left(\mathrm{~m}, \mathrm{C}_{\mathrm{q}}\right), 108.5\left(\mathrm{~m}, \mathrm{C}_{\mathrm{q}}\right), 108.2\left(\mathrm{~m}, \mathrm{C}_{\mathrm{q}}\right), 55.3$ $\left(\mathrm{CH}_{3}\right), 28.1\left(\mathrm{~d},{ }^{4} \mathrm{~J}_{\mathrm{C}-\mathrm{F}}=3.4 \mathrm{~Hz}, \mathrm{CH}_{2}\right)$.

${ }^{19} \mathrm{~F}-\mathrm{NMR}\left(282 \mathrm{MHz}, \mathrm{CDCl}_{3}\right): \delta=-80.9(\mathrm{~m}),-117.5(\mathrm{~m}),-121.7(\mathrm{~m}),-121.8(\mathrm{~m}),-122.0(\mathrm{~m})$, $-122.2(\mathrm{~m}),-122.8(\mathrm{~m}),-123.0(\mathrm{~m}),-126.2(\mathrm{~m}),-132.7(\mathrm{~m})$.

IR (ATR): 1609, 1467, 1429, 1201, 1147, 1045, 786, $529 \mathrm{~cm}^{-1}$.

MS (ESI) $m / z$ (relative intensity): $712\left([\mathrm{M}+\mathrm{H}]^{+}, 100\right)$.

HR-MS (ESI): $m / z$ calcd. for $\left[\mathrm{C}_{24} \mathrm{H}_{13} \mathrm{~F}_{20} \mathrm{NO}+\mathrm{H}\right]^{+}$712.0751, found 712.0756. 
<smiles>CC(=O)NC(Cc1c(CC=C(F)C(F)F)n(-c2ccccn2)c2ccccc12)C(C)(F)F</smiles>

(Z)- Methyl acetyl-1-(pyridin-2-yl)-2-(1H,1H,2H-perfluorodec-2-en-1-yl)-L-tryptophanate (329aa): A modified general procedure $\mathbf{A}$ was followed using methyl acetyl-1-(pyridin-2yl)-L-tryptophanate (328a) (168 mg, $0.50 \mathrm{mmol}), \quad 1 H, 1 H, 2 H$-perfluoro-1-decene (301a) (446 mg, $1.00 \mathrm{mmol})$, [MnBr(CO)5] (13.7 mg, $10 \mathrm{~mol} \%$ ) and NaOAc (12.3 mg, $30 \mathrm{~mol} \%$ ). Isolation by column chromatography $(n$-hexane/EtOAc $=1: 1)$ yielded 329aa $(317 \mathrm{mg}, 83 \%$, $Z / E=98: 2)$ as a white solid. M.p.: $118^{\circ} \mathrm{C}$.

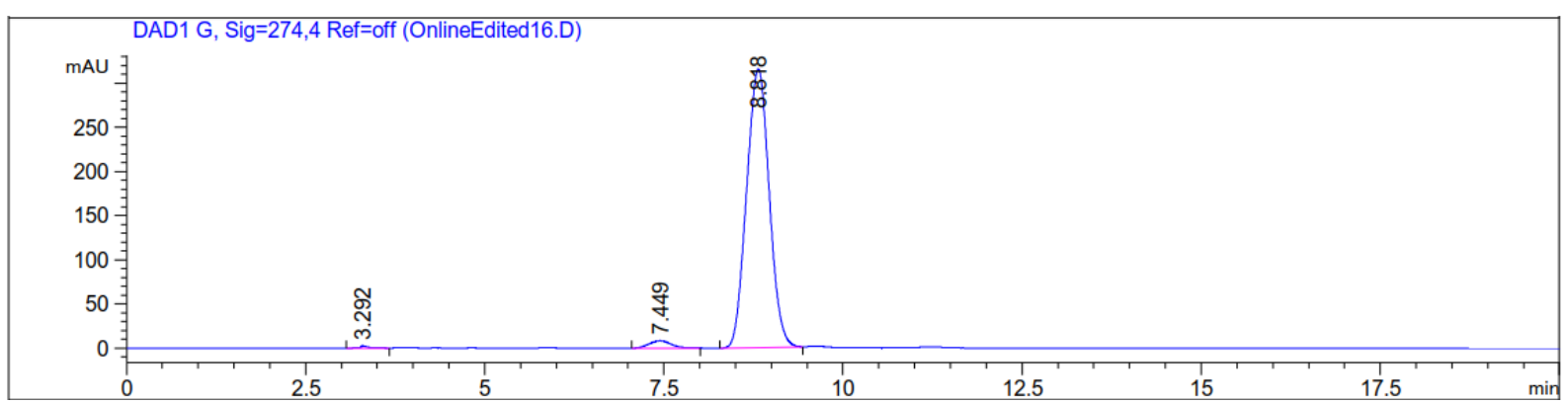

Reaction with 328a $(e e=35 \%)$ :

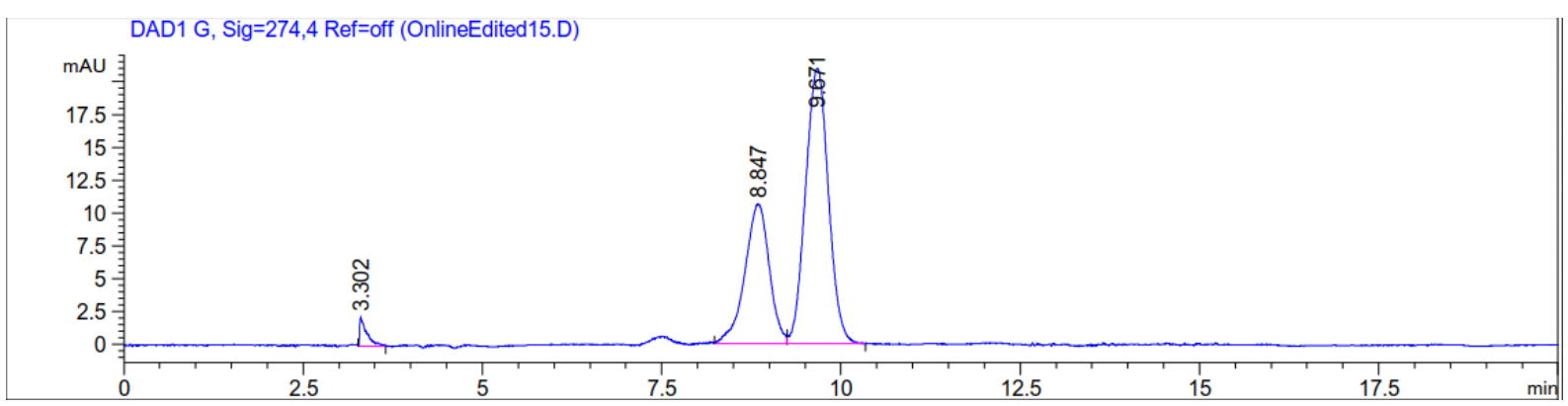

${ }^{1} \mathrm{H}-\mathrm{NMR}\left(500 \mathrm{MHz}, \mathrm{CDCl}_{3}\right): \delta=8.64-8.53(\mathrm{~m}, 1 \mathrm{H}), 7.85(\mathrm{ddd}, J=7.5,7.5,1.9 \mathrm{~Hz}, 1 \mathrm{H}), 7.58-$ $7.51(\mathrm{~m}, 1 \mathrm{H}), 7.42(\mathrm{dt}, J=8.0,1.0 \mathrm{~Hz}, 1 \mathrm{H}), 7.34-7.26(\mathrm{~m}, 2 \mathrm{H}), 7.19-7.11(\mathrm{~m}, 2 \mathrm{H}), 6.26(\mathrm{~d}, J$ $=8.0 \mathrm{~Hz}, 1 \mathrm{H}), 5.78(\mathrm{dt}, J=22.7,7.0 \mathrm{~Hz}, 0.02 \mathrm{H}, E), 5.47(\mathrm{dt}, J=33.1,7.2 \mathrm{~Hz}, 0.98 \mathrm{H}, Z), 4.96$ (ddd, $J=8.0,6.4,5.0 \mathrm{~Hz}, 1 \mathrm{H}), 4.01-3.77(\mathrm{~m}, 2 \mathrm{H}), 3.66(\mathrm{~s}, 3 \mathrm{H}), 3.42-3.25(\mathrm{~m}, 2 \mathrm{H}), 1.94$ (s, $3 \mathrm{H})$.

${ }^{13} \mathrm{C}-\mathrm{NMR}\left(125 \mathrm{MHz}, \mathrm{CDCl}_{3}\right): \delta=172.4\left(\mathrm{C}_{\mathrm{q}}\right), 169.8\left(\mathrm{C}_{\mathrm{q}}\right), 150.6\left(\mathrm{C}_{\mathrm{q}}\right), 149.7(\mathrm{CH}), 145.5(\mathrm{dt}$, $\left.{ }^{1} J_{\mathrm{C}-\mathrm{F}}=262 \mathrm{~Hz},{ }^{2} J_{\mathrm{C}-\mathrm{F}}=29.3 \mathrm{~Hz}, \mathrm{C}_{\mathrm{q}}\right), 138.4(\mathrm{CH}), 136.6\left(\mathrm{C}_{\mathrm{q}}\right), 133.6\left(\mathrm{C}_{\mathrm{q}}\right), 128.5\left(\mathrm{C}_{\mathrm{q}}\right), 122.9$ $(\mathrm{CH}), 122.3(\mathrm{CH}), 120.9(\mathrm{CH}), 120.6(\mathrm{CH}), 118.6(\mathrm{CH}), 116.9\left(\mathrm{dt},{ }^{1} J_{\mathrm{C}-\mathrm{F}}=292 \mathrm{~Hz},{ }^{2} J_{\mathrm{C}-\mathrm{F}}=\right.$ $\left.31.8 \mathrm{~Hz}, \mathrm{C}_{\mathrm{q}}\right), 113.6(\mathrm{CH}), 112.4\left(\mathrm{~m}, \mathrm{C}_{\mathrm{q}}\right), 112.1\left(\mathrm{~m}, \mathrm{C}_{\mathrm{q}}\right), 110.6\left(\mathrm{~m}, \mathrm{C}_{\mathrm{q}}\right), 110.3\left(\mathrm{~m}, \mathrm{C}_{\mathrm{q}}\right), 110.0$ 
$(\mathrm{CH}), 109.9\left(\mathrm{C}_{\mathrm{q}}\right), 108.5\left(\mathrm{~m}, \mathrm{C}_{\mathrm{q}}\right), 108.1\left(\mathrm{~m}, \mathrm{C}_{\mathrm{q}}\right), 52.8(\mathrm{CH}), 52.4\left(\mathrm{CH}_{3}\right), 26.9\left(\mathrm{~d},{ }^{4} J_{\mathrm{C}-\mathrm{F}}=4.1 \mathrm{~Hz}\right.$, $\left.\mathrm{CH}_{2}\right), 23.0\left(\mathrm{CH}_{3}\right), 20.1\left(\mathrm{CH}_{2}\right)$.

${ }^{19} \mathrm{~F}-\mathrm{NMR}\left(470 \mathrm{MHz}, \mathrm{CDCl}_{3}\right): \delta=-80.9(\mathrm{~m}),-117.4(\mathrm{~m}),-121.0(\mathrm{~m}),-121.1(\mathrm{~m}),-122.9(\mathrm{~m})$, $-123.0(\mathrm{~m}),-126.3(\mathrm{~m}),-130.2(\mathrm{~m})$.

IR (ATR): 1725, 1472, 1439, 1201, 1147, 1106, 908, $707 \mathrm{~cm}^{-1}$.

MS (ESI) $m / z$ (relative intensity): $786\left([\mathrm{M}+\mathrm{Na}]^{+}, 20\right), 764\left([\mathrm{M}+\mathrm{H}]^{+}, 100\right)$.

HR-MS (ESI): $m / z$ calcd. for $\left[\mathrm{C}_{29} \mathrm{H}_{21} \mathrm{~F}_{16} \mathrm{~N}_{3} \mathrm{O}_{3}+\mathrm{H}\right]^{+} 764.1400$, found 764.1392.

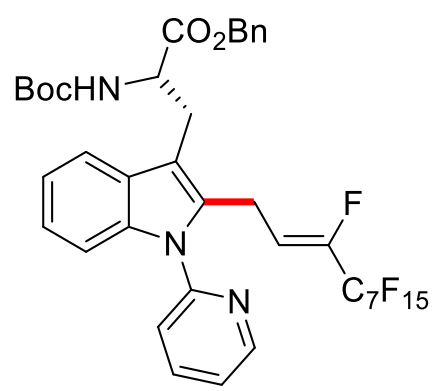

(Z)- Benzyl tert-butyloxycarbonyl-1-(pyridin-2-yl)-2-(1H,1H,2H-perfluorodec-2-en-1-yl)L-tryptophanate (329ba): A modified general procedure A was followed using benzyl tertbutyloxycarbonyl-1-(pyridin-2-yl)-L-tryptophanate (328b) (236 mg, $0.50 \mathrm{mmol}), 1 \mathrm{H}, 1 \mathrm{H}, 2 \mathrm{H}$ perfluoro-1-decene (301a) (446 mg, $1.00 \mathrm{mmol}$ ), [MnBr(CO)5] (13.7 mg, $10 \mathrm{~mol} \%$ ) and $\mathrm{NaOAc}(12.3 \mathrm{mg}, 30 \mathrm{~mol} \%)$. Isolation by column chromatography $(n$-hexane/EtOAc $=20: 1)$ yielded 329ba (381 mg, 85\%, $Z / E=90: 10)$ as a white solid. M.p.: $63{ }^{\circ} \mathrm{C}$.

${ }^{1} \mathrm{H}-\mathrm{NMR}\left(300 \mathrm{MHz}, \mathrm{CDCl}_{3}\right): \delta=8.60$ (ddd, $\left.J=4.8,1.9,0.9 \mathrm{~Hz}, 1 \mathrm{H}\right), 7.85$ (ddd, $J=7.7,7.6$, $1.9 \mathrm{~Hz}, 1 \mathrm{H}), 7.68-7.48(\mathrm{~m}, 1 \mathrm{H}), 7.41-7.26(\mathrm{~m}, 6 \mathrm{H}), 7.23-7.11(\mathrm{~m}, 4 \mathrm{H}), 5.84(\mathrm{dt}, J=23.1$, $8.4 \mathrm{~Hz}, 0.10 \mathrm{H}, E), 5.53(\mathrm{dt}, J=33.0,7.1 \mathrm{~Hz}, 0.90 \mathrm{H}, Z), 5.21$ (d, $J=8.3 \mathrm{~Hz}, 1 \mathrm{H}), 5.14-4.96$ (m, 2H), 4.80-4.68 (m, 1H), 3.95-3.78 (m, 2H), 3.34 (d, $J=6.0 \mathrm{~Hz}, 2 \mathrm{H}), 1.41$ (s, 9H).

${ }^{13} \mathrm{C}-\mathrm{NMR}\left(125 \mathrm{MHz}, \mathrm{CDCl}_{3}\right): \delta=171.8\left(\mathrm{C}_{\mathrm{q}}\right), 154.9\left(\mathrm{C}_{\mathrm{q}}\right), 150.6\left(\mathrm{C}_{\mathrm{q}}\right), 149.5(\mathrm{CH}), 145.7(\mathrm{dt}$, $\left.{ }^{1} J_{\mathrm{C}-\mathrm{F}}=261 \mathrm{~Hz},{ }^{2} J_{\mathrm{C}-\mathrm{F}}=29.0 \mathrm{~Hz}, \mathrm{C}_{\mathrm{q}}\right), 138.2(\mathrm{CH}), 136.6\left(\mathrm{C}_{\mathrm{q}}\right), 134.9\left(\mathrm{C}_{\mathrm{q}}\right), 133.6\left(\mathrm{C}_{\mathrm{q}}\right), 128.2$ $(\mathrm{CH}), 122.8(\mathrm{CH}), 122.1(\mathrm{CH}), 120.7\left(\mathrm{~d},{ }^{2} J_{\mathrm{C}-\mathrm{F}}=39.7 \mathrm{~Hz}, \mathrm{CH}\right), 118.8(\mathrm{CH}), 113.7(\mathrm{CH}), 110.1$ $\left(\mathrm{C}_{\mathrm{q}}\right), 110.0(\mathrm{CH}), 79.9\left(\mathrm{CH}_{2}\right), 67.3\left(\mathrm{C}_{\mathrm{q}}\right), 54.2(\mathrm{CH}), 28.2\left(\mathrm{CH}_{3}\right), 27.6\left(\mathrm{CH}_{2}\right), 20.3\left(\mathrm{~d},{ }^{3} J_{\mathrm{C}-\mathrm{F}}=\right.$ $4.0 \mathrm{~Hz}, \mathrm{CH}_{2}$ ).

${ }^{19} \mathrm{~F}-\mathrm{NMR}\left(282 \mathrm{MHz}, \mathrm{CDCl}_{3}\right): \delta=-80.9(\mathrm{~m}),-117.3(\mathrm{~m}),-122.1(\mathrm{~m}),-122.1(\mathrm{~m}),-122.8(\mathrm{~m})$, $-123.2(\mathrm{~m}),-126.2(\mathrm{~m}),-130.2(\mathrm{~m})$.

IR (ATR): 1707, 1472, 1238, 1149, 906, $649 \mathrm{~cm}^{-1}$.

MS (ESI) $m / z$ (relative intensity): $920\left([\mathrm{M}+\mathrm{Na}]^{+}, 20\right), 898\left([\mathrm{M}+\mathrm{H}]^{+}, 100\right)$.

HR-MS (ESI): $m / z$ calcd. for $\left[\mathrm{C}_{38} \mathrm{H}_{31} \mathrm{~F}_{16} \mathrm{~N}_{3} \mathrm{O}_{4}+\mathrm{H}\right]^{+}$898.2132, found: 898.2122. 


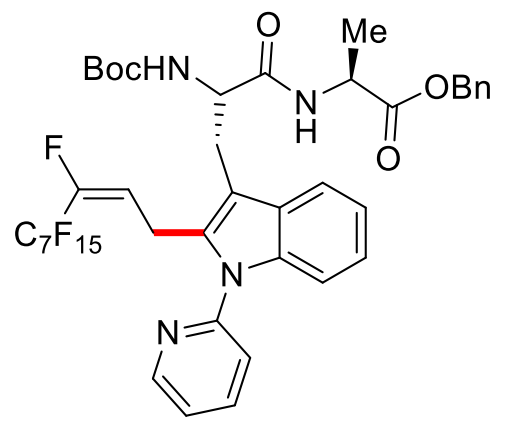

Benzyl [(S)-2-(tert-butoxycarbonyl)amino-3-\{2-((Z)-1H,1H,2H-perfluorodec-2-en-1-yl)1-(pyridin-2-yl)-1H-indol-3-yl\}propanoyl]-L-alaninate (329ca): A modified general procedure A was followed using benzyl $N$-(tert-butoxycarbonyl)-1-(pyridin-2-yl)-Ltryptophyl-L-alaninate $(\mathbf{3 2 8 c})(54.2 \mathrm{mg}, 0.10 \mathrm{mmol}), 1 \mathrm{H}, 1 \mathrm{H}, 2 \mathrm{H}$-perfluoro-1-decene (301a) (134 mg, $0.30 \mathrm{mmol}), \mathrm{NaOAc}(2.4 \mathrm{mg}, 30 \mathrm{~mol} \%)$ and $[\mathrm{MnBr}(\mathrm{CO}) 5](5.6 \mathrm{mg}, 20 \mathrm{~mol} \%)$. Isolation by column chromatography $(n$-hexane/EtOAc $=1: 1)$ yielded 329ca $(62.0 \mathrm{mg}, 64 \%$, $Z / E=90: 10)$ as a pale yellow solid. M.p.: $140{ }^{\circ} \mathrm{C}$.

${ }^{1} \mathrm{H}-\mathrm{NMR}\left(400 \mathrm{MHz}, \mathrm{CDCl}_{3}\right): \delta=8.63(\mathrm{ddd}, J=4.9,2.0,0.9 \mathrm{~Hz}, 1 \mathrm{H}), 7.90$ (ddd, $J=7.6,7.5$, $1.9 \mathrm{~Hz}, 1 \mathrm{H}), 7.77-7.64(\mathrm{~m}, 1 \mathrm{H}), 7.49(\mathrm{~d}, J=8.1 \mathrm{~Hz}, 1 \mathrm{H}), 7.39-7.31(\mathrm{~m}, 5 \mathrm{H}), 7.28(\mathrm{t}, J=3.8$ $\mathrm{Hz}, 2 \mathrm{H}), 7.19$ (dd, $J=6.1,3.1 \mathrm{~Hz}, 2 \mathrm{H}), 6.33$ (d, $J=7.1 \mathrm{~Hz}, 1 \mathrm{H}), 5.89$ (dt, $J=22.9,7.2 \mathrm{~Hz}$, $0.10 \mathrm{H}, E), 5.59$ (dt, $J=33.2,7.2 \mathrm{~Hz}, 0.90 \mathrm{H}, Z), 5.31$ (bs, $1 \mathrm{H}), 5.05$ (d, $J=2.8 \mathrm{~Hz}, 2 \mathrm{H}), 4.64$ $4.33(\mathrm{~m}, 2 \mathrm{H}), 3.93(\mathrm{ddt}, J=7.4,3.8,2.3 \mathrm{~Hz}, 2 \mathrm{H}), 3.47-3.13(\mathrm{~m}, 2 \mathrm{H}), 1.45(\mathrm{~s}, 9 \mathrm{H}), 1.33$ (d, $J=$ $7.1 \mathrm{~Hz}, 3 \mathrm{H})$.

${ }^{13} \mathrm{C}-\mathrm{NMR}\left(100 \mathrm{MHz}, \mathrm{CDCl}_{3}\right): \delta=172.0\left(\mathrm{C}_{\mathrm{q}}\right), 170.8\left(\mathrm{C}_{\mathrm{q}}\right), 155.1\left(\mathrm{C}_{\mathrm{q}}\right), 150.8\left(\mathrm{C}_{\mathrm{q}}\right), 149.7(\mathrm{CH})$, $145.2\left(\mathrm{dt},{ }^{1} J_{\mathrm{C}-\mathrm{F}}=260 \mathrm{~Hz},{ }^{2} J_{\mathrm{C}-\mathrm{F}}=29.1 \mathrm{~Hz}, \mathrm{C}_{\mathrm{q}}\right), 138.4(\mathrm{CH}), 136.8\left(\mathrm{C}_{\mathrm{q}}\right), 135.3\left(\mathrm{C}_{\mathrm{q}}\right), 133.8\left(\mathrm{C}_{\mathrm{q}}\right)$, $128.6(\mathrm{CH}), 128.4(\mathrm{CH}), 128.2\left(\mathrm{C}_{\mathrm{q}}\right), 128.0(\mathrm{CH}), 122.9(\mathrm{CH}), 122.3(\mathrm{CH}), 121.1(\mathrm{CH}), 120.9$ $(\mathrm{CH}), 118.9(\mathrm{CH}), 117.0\left(\mathrm{dt},{ }^{1} J_{\mathrm{C}-\mathrm{F}}=288 \mathrm{~Hz},{ }^{2} J_{\mathrm{C}-\mathrm{F}}=33.0 \mathrm{~Hz}, \mathrm{C}_{\mathrm{q}}\right), 113.7(\mathrm{dt}, J=8.3,4.3 \mathrm{~Hz}$, $\mathrm{CH}), 113.2\left(\mathrm{~m}, \mathrm{C}_{\mathrm{q}}\right), 112.7\left(\mathrm{~m}, \mathrm{C}_{\mathrm{q}}\right), 111.0\left(\mathrm{~m}, \mathrm{C}_{\mathrm{q}}\right), 110.9\left(\mathrm{~m}, \mathrm{C}_{\mathrm{q}}\right), 110.7\left(\mathrm{~m}, \mathrm{C}_{\mathrm{q}}\right), 110.4\left(\mathrm{C}_{\mathrm{q}}\right)$, $110.1(\mathrm{CH}), 107.9\left(\mathrm{~m}, \mathrm{C}_{\mathrm{q}}\right), 80.1\left(\mathrm{C}_{\mathrm{q}}\right), 67.0\left(\mathrm{CH}_{2}\right), 54.9(\mathrm{CH}), 48.3(\mathrm{CH}), 28.2\left(\mathrm{CH}_{3}\right), 27.7$ $\left(\mathrm{CH}_{2}\right), 20.2\left(\mathrm{~d},{ }^{3} \mathrm{~J}_{\mathrm{C}-\mathrm{F}}=4.6 \mathrm{~Hz}, \mathrm{CH}_{2}\right), 18.4\left(\mathrm{CH}_{3}\right)$.

${ }^{19} \mathrm{~F}-\mathrm{NMR}\left(375 \mathrm{MHz}, \mathrm{CDCl}_{3}\right): \delta=-80.8(\mathrm{~m}),-117.3(\mathrm{~m}),-122.0(\mathrm{~m}),-122.0(\mathrm{~m}),-122.8(\mathrm{~m})$, $-122.8(\mathrm{~m}),-126.1(\mathrm{~m}),-130.5(\mathrm{~m})$.

IR (ATR): 3303, 2982, 1658, 1472, 1458, 1238, 1202, $1148 \mathrm{~cm}^{-1}$.

MS (ESI) $m / z$ (relative intensity): $991\left([\mathrm{M}+\mathrm{Na}]^{+}, 30\right), 969\left([\mathrm{M}+\mathrm{H}]^{+}, 100\right)$.

HR-MS (ESI): $m / z$ calcd. for $\left[\mathrm{C}_{41} \mathrm{H}_{36} \mathrm{~F}_{16} \mathrm{~N}_{4} \mathrm{O}_{5}+\mathrm{H}\right]^{+}$969.2503, found: 969.2497. 
<smiles>FC(=C(F)C(F)F)c1cc2ccccc2n1-c1ccccn1</smiles>

(E)-1-(Pyridin-2-yl)-2-(perfluorodec-2-en-1-yl)-1H-indole (330aa): The general procedure B was followed using 1-(pyridin-2-yl)-1H-indole (315a) $(58.2 \mathrm{mg}, 0.30 \mathrm{mmol})$ and perfluorodec-1-ene (303a) (450 $\mathrm{mg}, 0.90 \mathrm{mmol}$ ). Isolation by column chromatography ( $n$ hexane/EtOAc $=20: 1)$ yielded 330aa $(172 \mathrm{mg}, 85 \%)$.

${ }^{1} \mathrm{H}-\mathrm{NMR}\left(500 \mathrm{MHz}, \mathrm{CDCl}_{3}\right): \delta=8.58(\mathrm{ddd}, J=4.9,1.9,0.9 \mathrm{~Hz}, 1 \mathrm{H}), 7.88$ (ddd, $J=7.7,5.9$, $1.9 \mathrm{~Hz}, 1 \mathrm{H}), 7.71(\mathrm{dt}, J=7.9,1.0 \mathrm{~Hz}, 1 \mathrm{H}), 7.58(\mathrm{dd}, J=8.5,0.9 \mathrm{~Hz}, 1 \mathrm{H}), 7.46(\mathrm{dt}, J=8.0,1.0$ $\mathrm{Hz}, 1 \mathrm{H}), 7.37-7.28(\mathrm{~m}, 2 \mathrm{H}), 7.24$ (dt, $J=7.4,1.0 \mathrm{~Hz}, 1 \mathrm{H}), 7.19$ (dd, $J=2.1,1.1 \mathrm{~Hz}, 1 \mathrm{H})$.

${ }^{13} \mathrm{C}-\mathrm{NMR}\left(125 \mathrm{MHz}, \mathrm{CDCl}_{3}\right): \delta=150.5\left(\mathrm{C}_{\mathrm{q}}\right), 149.4(\mathrm{CH}), 148.9\left(\mathrm{ddt},{ }^{1} J_{\mathrm{C}-\mathrm{F}}=255 \mathrm{~Hz},{ }^{2} J_{\mathrm{C}-\mathrm{F}}=\right.$ $\left.41.0 \mathrm{~Hz},{ }^{3} J_{\mathrm{C}-\mathrm{F}}=3.2 \mathrm{~Hz}, \mathrm{C}_{\mathrm{q}}\right), 138.3(\mathrm{CH}), 137.9\left(\mathrm{C}_{\mathrm{q}}\right), 137.2\left(\mathrm{dtd},{ }^{1} J_{\mathrm{C}-\mathrm{F}}=250 \mathrm{~Hz},{ }^{2} J_{\mathrm{C}-\mathrm{F}}=\right.$ $\left.46.0 \mathrm{~Hz},{ }^{2} J_{\mathrm{C}-\mathrm{F}}=29.7 \mathrm{~Hz}, \mathrm{C}_{\mathrm{q}}\right), 127.4\left(\mathrm{C}_{\mathrm{q}}\right), 125.5(\mathrm{CH}), 124.2\left(\mathrm{dd},{ }^{2} J_{\mathrm{C}-\mathrm{F}}=23.5 \mathrm{~Hz},{ }^{3} J_{\mathrm{C}-\mathrm{F}}=5.3\right.$ $\left.\mathrm{Hz}, \mathrm{C}_{\mathrm{q}}\right), 122.3(\mathrm{CH}), 122.0(\mathrm{CH}), 122.0(\mathrm{CH}), 120.7\left(\mathrm{~m}, \mathrm{C}_{\mathrm{q}}\right), 119.0(\mathrm{CH}), 116.9\left(\mathrm{~m}, \mathrm{C}_{\mathrm{q}}\right), 113.1$ $\left(\mathrm{m}, \mathrm{C}_{\mathrm{q}}\right), 112.7\left(\mathrm{~m}, \mathrm{C}_{\mathrm{q}}\right), 112.3\left(\mathrm{~m}, \mathrm{C}_{\mathrm{q}}\right), 111.4\left(\mathrm{dd},{ }^{3} J_{\mathrm{C}-\mathrm{F}}=7.7 \mathrm{~Hz},{ }^{4} J_{\mathrm{C}-\mathrm{F}}=5.3 \mathrm{~Hz}, \mathrm{CH}\right), 110.9$ $(\mathrm{CH}), 110.3\left(\mathrm{~m}, \mathrm{C}_{\mathrm{q}}\right), 108.5\left(\mathrm{~m}, \mathrm{C}_{\mathrm{q}}\right), 108.2\left(\mathrm{~m}, \mathrm{C}_{\mathrm{q}}\right)$.

${ }^{19} \mathrm{~F}-\mathrm{NMR}\left(282 \mathrm{MHz}, \mathrm{CDCl}_{3}\right): \delta=-80.9(\mathrm{~m}),-116.7(\mathrm{~m}),-122.1(\mathrm{~m}),-122.1(\mathrm{~m}),-122.2(\mathrm{~m})$, $-122.8(\mathrm{~m}),-123.7(\mathrm{~m}),-126.2(\mathrm{~m}),-135.0$ (dtt, $J=140,26.5,7.2 \mathrm{~Hz}),-162.9$ (dt, $J=140$, $12.6 \mathrm{~Hz})$.

IR (ATR): 1470, 1441, 1198, 1145, 737, $708 \mathrm{~cm}^{-1}$.

MS (ESI) $m / z$ (relative intensity): $675\left([\mathrm{M}+\mathrm{H}]^{+}, 100\right)$.

HR-MS (ESI): $m / z$ calcd. for $\left[\mathrm{C}_{23} \mathrm{H}_{9} \mathrm{~F}_{19} \mathrm{~N}_{2}+\mathrm{H}\right]^{+}$675.0535, found: 675.0539.<smiles>Cc1c(C(F)=C(F)C(F)(C(F)(F)F)C(F)(F)F)n(-c2ccccn2)c2ccccc12</smiles>

(E)-3-Methyl-1-(pyridin-2-yl)-2-(1,2,3,3-tetrafluoro-3-phenylprop-1-en-1-yl)-1H-indole

(330eb): The general procedure $\mathbf{B}$ was followed using 3-methyl-1-(pyridin-2-yl)- $H$-indole (315e) (62.4 mg, $0.30 \mathrm{mmol}$ ), 3-(pentafluorophenyl)pentafluoroprop-1-ene (303b) (286 mg, $0.90 \mathrm{mmol})$ and $\mathrm{NaOAc}(7.4 \mathrm{mg}, 30 \mathrm{~mol} \%)$. Isolation by column chromatography ( $n$ hexane/EtOAc $=15: 1)$ yielded 330eb $(126 \mathrm{mg}, 86 \%)$. 
${ }^{1} \mathrm{H}-\mathrm{NMR}\left(500 \mathrm{MHz}, \mathrm{CDCl}_{3}\right): \delta=8.53(\mathrm{ddd}, J=4.9,1.9,0.9 \mathrm{~Hz}, 1 \mathrm{H}), 7.84(\mathrm{ddd}, J=8.0,7.5$, $1.9 \mathrm{~Hz}, 1 \mathrm{H}), 7.68(\mathrm{~d}, J=8.1 \mathrm{~Hz}, 1 \mathrm{H}), 7.65(\mathrm{dt}, J=8.4,0.9 \mathrm{~Hz}, 1 \mathrm{H}), 7.41(\mathrm{dt}, J=8.1,0.9 \mathrm{~Hz}$, 1H), 7.34 (ddd, $J=8.4,7.2,1.1 \mathrm{~Hz}, 1 \mathrm{H}), 7.29-7.21(\mathrm{~m}, 2 \mathrm{H}), 2.41$ (dd, $J=3.1,2.2 \mathrm{~Hz}, 3 \mathrm{H})$. ${ }^{13} \mathrm{C}-\mathrm{NMR}\left(125 \mathrm{MHz} \mathrm{CDCl}_{3}\right): \delta=150.6\left(\mathrm{C}_{\mathrm{q}}\right), 149.3(\mathrm{CH}), 145.3\left(\mathrm{~m}, \mathrm{C}_{\mathrm{q}}\right), 145.2\left(\mathrm{dt},{ }^{1} J_{\mathrm{C}-\mathrm{F}}\right.$ $\left.=250 \mathrm{~Hz},{ }^{2} J_{\mathrm{C}-\mathrm{F}}=4.6 \mathrm{~Hz}, \mathrm{C}_{\mathrm{q}}\right), 141.9\left(\mathrm{~m}, \mathrm{C}_{\mathrm{q}}\right), 138.0\left(\mathrm{~m}, \mathrm{C}_{\mathrm{q}}\right), 138.3(\mathrm{CH}), 137.3\left(\mathrm{C}_{\mathrm{q}}\right), 136.8(\mathrm{~m}$, $\left.\mathrm{C}_{\mathrm{q}}\right), 128.5\left(\mathrm{C}_{\mathrm{q}}\right), 125.6(\mathrm{CH}), 121.7(\mathrm{CH}), 121.4(\mathrm{CH}), 121.1\left(\mathrm{dd},{ }^{2} J_{\mathrm{C}-\mathrm{F}}=22.8 \mathrm{~Hz},{ }^{3} J_{\mathrm{C}-\mathrm{F}}\right.$ $\left.=3.5 \mathrm{~Hz}, \mathrm{C}_{\mathrm{q}}\right), 120.9\left(\mathrm{C}_{\mathrm{q}}\right), 120.3(\mathrm{CH}), 118.3(\mathrm{CH}), 112.8\left(\mathrm{C}_{\mathrm{q}}\right), 111.1(\mathrm{CH}), 108.8\left(\mathrm{~m}, \mathrm{C}_{\mathrm{q}}\right), 9.4$ $\left(\mathrm{d},{ }^{4} J_{\mathrm{C}-\mathrm{F}}=3.2 \mathrm{~Hz}, \mathrm{CH}_{3}\right)$.

${ }^{19} \mathrm{~F}-\mathrm{NMR}\left(283 \mathrm{MHz}, \mathrm{CDCl}_{3}\right): \delta=-93.4(\mathrm{~m}),-130.3(\mathrm{dt}, J=146,15.4 \mathrm{~Hz}),-139.4(\mathrm{~m}),-148.5$ (m), $-159.4(\mathrm{~m}),-160.5(\mathrm{~m})$.

IR (ATR): 1592, 1580, 1528, 1506, 1282, 1187, 929, $745 \mathrm{~cm}^{-1}$.

MS (ESI) $m / z$ (relative intensity): $509\left([\mathrm{M}+\mathrm{Na}]^{+}, 10\right), 487\left([\mathrm{M}+\mathrm{H}]^{+}, 100\right), 467(15)$.

HR-MS (ESI): $m / z$ calcd. for $\left[\mathrm{C}_{23} \mathrm{H}_{11} \mathrm{~F}_{9} \mathrm{~N}_{2}+\mathrm{H}\right]^{+} 487.0851$, found: 487.0859 .

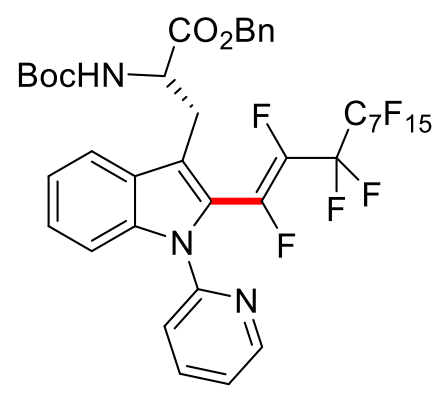

Benzyl ( $S, E)$-2-(tert-butoxycarbonyl)amino)-3-\{2-(perfluorodec-2-en-1-yl)-1-(pyridin-2yl)-1H-indol-3-yl $\}$ propanoate (331bc): A modified general procedure $\mathbf{B}$ was followed using benzyl tert-butyloxycarbonyl-1-(pyridin-2-yl)-L-tryptophanate (328b) (142 mg, $0.30 \mathrm{mmol}$ ), perfluorodec-1-ene (303c) (450 mg, $0.90 \mathrm{mmol}),\left[\mathrm{MnBr}(\mathrm{CO})_{5}\right](12.3 \mathrm{mg}, 15 \mathrm{~mol} \%)$ and $\mathrm{NaOAc}(7.4 \mathrm{mg}, 30 \mathrm{~mol} \%)$. Isolation by column chromatography $(n$-hexane/EtOAc $=10: 1)$ yielded 331bc (135 mg, 57\%).

${ }^{1} \mathrm{H}-\mathrm{NMR}\left(400 \mathrm{MHz}, \mathrm{CDCl}_{3}\right): \delta=8.53(\mathrm{ddd}, J=4.8,1.9,0.9 \mathrm{~Hz}, 1 \mathrm{H}), 7.83(\mathrm{~m}, 1 \mathrm{H}), 7.80-7.73$ (d, $J=8.0 \mathrm{~Hz}, 1 \mathrm{H}), 7.65-7.54(\mathrm{~d}, J=8.4 \mathrm{~Hz}, 1 \mathrm{H}), 7.39-7.33$ (t, $J=7.3 \mathrm{~Hz}, 2 \mathrm{H}), 7.31-7.22$ (m, 5H), 7.20-7.12 (m, 2H), 5.16-5.07 (dd, $J=11.3,5.1 \mathrm{~Hz}, 2 \mathrm{H}), 5.05-4.96$ (d, $J=12.4 \mathrm{~Hz}, 1 \mathrm{H})$, $4.83-4.73$ (q, $J=7.3 \mathrm{~Hz}, 1 \mathrm{H}), 3.52-3.13$ (d, $J=6.6 \mathrm{~Hz}, 2 \mathrm{H}), 1.54-1.15$ (s, 9H).

${ }^{13} \mathrm{C}-\mathrm{NMR}\left(125 \mathrm{MHz}, \mathrm{CDCl}_{3}\right): \delta=171.9\left(\mathrm{C}_{\mathrm{q}}\right), 155.0\left(\mathrm{C}_{\mathrm{q}}\right), 150.1\left(\mathrm{C}_{\mathrm{q}}\right), 149.5(\mathrm{CH}), 147.9(\mathrm{dd}$, $\left.{ }^{1} J_{\mathrm{C}-\mathrm{F}}=257 \mathrm{~Hz},{ }^{2} J_{\mathrm{C}-\mathrm{F}}=44.5 \mathrm{~Hz}, \mathrm{C}_{\mathrm{q}}\right), 138.4(\mathrm{CH}), 137.9\left(\mathrm{~m}, \mathrm{C}_{\mathrm{q}}\right), 137.4\left(\mathrm{C}_{\mathrm{q}}\right), 135.1(\mathrm{CH}), 128.5$ $(\mathrm{CH}), 128.2(\mathrm{CH}), 128.0(\mathrm{CH}), 127.7(\mathrm{CH}), 125.9(\mathrm{CH}), 122.2(\mathrm{CH}), 121.9\left(\mathrm{C}_{\mathrm{q}}\right), 120.7\left(\mathrm{C}_{\mathrm{q}}\right)$, $119.1\left(\mathrm{~m}, \mathrm{C}_{\mathrm{q}}\right), 118.7(\mathrm{CH}), 117.0\left(\mathrm{dt},{ }^{1} J_{\mathrm{C}-\mathrm{F}}=287 \mathrm{~Hz},{ }^{2} J_{\mathrm{C}-\mathrm{F}}=33.9 \mathrm{~Hz}, \mathrm{C}_{\mathrm{q}}\right), 113.4\left(\mathrm{~m}, \mathrm{C}_{\mathrm{q}}\right), 112.8$ 
$\left(\mathrm{m}, \mathrm{C}_{\mathrm{q}}\right), 111.2(\mathrm{CH}), 110.9\left(\mathrm{~m}, \mathrm{C}_{\mathrm{q}}\right), 110.7\left(\mathrm{~m}, \mathrm{C}_{\mathrm{q}}\right), 110.4\left(\mathrm{~m}, \mathrm{C}_{\mathrm{q}}\right), 108.8\left(\mathrm{~m}, \mathrm{C}_{\mathrm{q}}\right), 108.3\left(\mathrm{~m}, \mathrm{C}_{\mathrm{q}}\right)$, $79.9\left(\mathrm{CH}_{2}\right), 67.2\left(\mathrm{C}_{\mathrm{q}}\right), 53.8(\mathrm{CH}), 28.4\left(\mathrm{CH}_{2}\right), 27.6\left(\mathrm{CH}_{3}\right)$.

${ }^{19} \mathrm{~F}-\mathrm{NMR}\left(376 \mathrm{MHz}, \mathrm{CDCl}_{3}\right): \delta=-80.8(\mathrm{~m}),-116.7(\mathrm{~m}),-121.8(\mathrm{~m}),-121.9(\mathrm{~m}),-122.1(\mathrm{~m})$, $-122.7(\mathrm{~m}),-123.3(\mathrm{~m}),-121.1(\mathrm{~m}),-126.8(\mathrm{dt}, J=146,23.6 \mathrm{~Hz}),-160.3(\mathrm{dt}, J=146,12.3$ $\mathrm{Hz})$.

IR (ATR): 3362, 2957, 1587, 1569, 1450, 1383, 1212, $996 \mathrm{~cm}^{-1}$.

MS (ESI) $m / z$ (relative intensity): $974\left([\mathrm{M}+\mathrm{Na}]^{+}, 70\right), 952\left([\mathrm{M}+\mathrm{H}]^{+}, 100\right), 896(20)$.

HR-MS (ESI): $m / z$ calcd. for $\left[\mathrm{C}_{38} \mathrm{H}_{28} \mathrm{~F}_{19} \mathrm{~N}_{3} \mathrm{O}_{4}+\mathrm{H}\right]^{+} 952.1849$, found: 952.1833 .

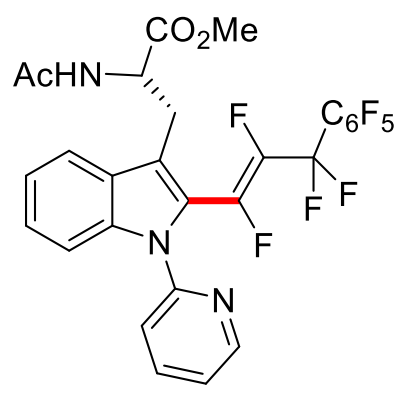

(E)-Methyl acetyl-1-(pyridin-2-yl)-2-[3-(pentafluorophenyl)tetrafluoroprop-1-en-1-yl]-Ltryptophanate (331ab): The general procedure B was followed using methyl acetyl-1(pyridin-2-yl)-L-tryptophanate (328a) (101 mg, $0.30 \mathrm{mmol})$, $3-$ (pentafluorophenyl)pentafluoroprop-1-ene (303b) $(178 \mathrm{mg}, 0.60 \mathrm{mmol})$ and $\mathrm{NaOAc}(7.4 \mathrm{mg}$, $30 \mathrm{~mol} \%)$. Isolation by column chromatography ( $n$-hexane/EtOAc $=1: 1)$ yielded 331ab $(148$ $\mathrm{mg}, 48 \%$ ) as a yellow solid. M.p.: $122^{\circ} \mathrm{C}$.

${ }^{1} \mathrm{H}-\mathrm{NMR}\left(400 \mathrm{MHz}, \mathrm{CDCl}_{3}\right): \delta=8.50$ (ddd, $\left.J=4.8,1.8,0.9 \mathrm{~Hz}, 1 \mathrm{H}\right), 7.85$ (ddd, $J=7.7,7.5$, $1.9 \mathrm{~Hz}, 1 \mathrm{H}), 7.75(\mathrm{~d}, J=8.0 \mathrm{~Hz}, 1 \mathrm{H}), 7.57(\mathrm{~d}, J=8.4 \mathrm{~Hz}, 1 \mathrm{H}), 7.41(\mathrm{~d}, J=8.0 \mathrm{~Hz}, 1 \mathrm{H}), 7.32$ $(\mathrm{d}, J=7.4 \mathrm{~Hz}, 1 \mathrm{H}), 7.30-7.27(\mathrm{~m}, 1 \mathrm{H}), 7.27-7.20(\mathrm{~m}, 1 \mathrm{H}), 6.11(\mathrm{~d}, J=8.0 \mathrm{~Hz}, 1 \mathrm{H}), 4.98(\mathrm{dt}$, $J=8.0,6.0 \mathrm{~Hz}, 1 \mathrm{H}), 3.62(\mathrm{~s}, 3 \mathrm{H}), 3.35(\mathrm{~d}, J=6.0 \mathrm{~Hz}, 2 \mathrm{H}), 1.92(\mathrm{~s}, 3 \mathrm{H})$.

${ }^{13} \mathrm{C}-\mathrm{NMR}\left(100 \mathrm{MHz}, \mathrm{CDCl}_{3}\right): \delta=171.9\left(\mathrm{C}_{\mathrm{q}}\right), 169.7\left(\mathrm{C}_{\mathrm{q}}\right), 150.2\left(\mathrm{C}_{\mathrm{q}}\right), 149.4(\mathrm{CH}), 146.2(\mathrm{~m}$, $\left.\mathrm{C}_{\mathrm{q}}\right), 143.7\left(\mathrm{~m}, \mathrm{C}_{\mathrm{q}}\right), 141.8\left(\mathrm{~m}, \mathrm{C}_{\mathrm{q}}\right), 139.1\left(\mathrm{~m}, \mathrm{C}_{\mathrm{q}}\right), 138.4(\mathrm{CH}), 137.3\left(\mathrm{~d},{ }^{4} \mathrm{~J}_{\mathrm{C}-\mathrm{F}}=2.0 \mathrm{~Hz}, \mathrm{C}_{\mathrm{q}}\right)$, $136.6\left(\mathrm{C}_{\mathrm{q}}\right), 127.7\left(\mathrm{~d},{ }^{4} J_{\mathrm{C}-\mathrm{F}}=1.7 \mathrm{~Hz}, \mathrm{C}_{\mathrm{q}}\right), 125.8(\mathrm{CH}), 122.5\left(\mathrm{C}_{\mathrm{q}}\right), 122.2(\mathrm{CH}), 121.9(\mathrm{CH})$, $120.5(\mathrm{CH}), 118.9(\mathrm{CH}), 118.7\left(\mathrm{~m}, \mathrm{C}_{\mathrm{q}}\right), 112.7\left(\mathrm{~m}, \mathrm{C}_{\mathrm{q}}\right), 111.3(\mathrm{CH}), 100.0\left(\mathrm{~m}, \mathrm{C}_{\mathrm{q}}\right), 52.4\left(\mathrm{CH}_{3}\right)$, $52.4(\mathrm{CH}), 27.7\left(\mathrm{CH}_{2}\right), 22.9\left(\mathrm{CH}_{3}\right)$.

${ }^{19} \mathrm{~F}-\mathrm{NMR}\left(375 \mathrm{MHz}, \mathrm{CDCl}_{3}\right): \delta=-94.0(\mathrm{~m}),-128.5(\mathrm{dt}, J=146,16.7 \mathrm{~Hz}),-139.4(\mathrm{~m}),-148.2$ (m), $-157.9(\mathrm{dt}, J=146,18.5 \mathrm{~Hz}),-160.1(\mathrm{~m})$.

IR (ATR): 3285, 2957, 1744, 1657, 1527, 1506, 1371, 993, $741 \mathrm{~cm}^{-1}$. MS (ESI) $m / z$ (relative intensity): $638\left([\mathrm{M}+\mathrm{Na}]^{+},(20), 616\left([\mathrm{M}+\mathrm{H}]^{+}, 100\right), 596(10)\right.$. HR-MS (ESI): $m / z$ calcd. for $\left[\mathrm{C}_{28} \mathrm{H}_{18} \mathrm{~F}_{9} \mathrm{~N}_{3} \mathrm{O}_{3}+\mathrm{H}\right]^{+}$616.1265, found 616.1277 . 
<smiles>COc1ccc(-n2cccn2)c(/C(F)=C(\F)C(F)(F)C(F)(F)F)c1</smiles>

\section{(E)-1-[4-methoxy-2-(1,2,3,3-tetrafluoro-3-phenylprop-1-en-1-yl)phenyl]-1H-pyrazole}

(333ab): A modified general procedure $\mathbf{B}$ was followed using 1-(4-methoxyphenyl)-1 $\mathrm{H}$ pyrazole (332a) $(52.2 \mathrm{mg}, 0.30 \mathrm{mmol})$, 3-(pentafluorophenyl)pentafluoroprop-1-ene (303b) (286 mg, $0.90 \mathrm{mmol}$ ) and NaOAc (7.4 mg, $30 \mathrm{~mol} \%$ ). Isolation by column chromatography $(n$-hexane/EtOAc $=15: 1)$ yielded 333ab $(96.3 \mathrm{mg}, 68 \%)$.

${ }^{1} \mathrm{H}-\mathrm{NMR}\left(400 \mathrm{MHz}, \mathrm{CDCl}_{3}\right): \delta=7.58(\mathrm{~d}, J=1.8 \mathrm{~Hz}, 1 \mathrm{H}), 7.56(\mathrm{~d}, J=2.4 \mathrm{~Hz}, 1 \mathrm{H}), 7.43(\mathrm{~d}, J$ $=8.5 \mathrm{~Hz}, 1 \mathrm{H}), 7.09(\mathrm{ddd}, J=8.5,2.8,2.4 \mathrm{~Hz}, 1 \mathrm{H}), 7.07(\mathrm{dd}, J=2.8,1.3 \mathrm{~Hz}, 1 \mathrm{H}), 6.35(\mathrm{dd}, J$ $=2.4,1.8 \mathrm{~Hz}, 1 \mathrm{H}), 3.86(\mathrm{~s}, 3 \mathrm{H})$.

${ }^{13} \mathrm{C}-\mathrm{NMR}\left(125 \mathrm{MHz} \mathrm{CDCl}_{3}\right): \delta=158.7\left(\mathrm{C}_{\mathrm{q}}\right), 149.4\left(\mathrm{dt},{ }^{1} J_{\mathrm{C}-\mathrm{F}}=255 \mathrm{~Hz},{ }^{2} J_{\mathrm{C}-\mathrm{F}}=45.0 \mathrm{~Hz},{ }^{3} J_{\mathrm{C}-\mathrm{F}}\right.$ $\left.=7.3 \mathrm{~Hz}, \mathrm{C}_{\mathrm{q}}\right), 146.0\left(\mathrm{~m}, \mathrm{C}_{\mathrm{q}}\right), 144.1\left(\mathrm{~m}, \mathrm{C}_{\mathrm{q}}\right), 142.9\left(\mathrm{~m}, \mathrm{C}_{\mathrm{q}}\right), 140.8(\mathrm{CH}), 138.1\left(\mathrm{~m}, \mathrm{C}_{\mathrm{q}}\right), 132.6$ $\left(\mathrm{C}_{\mathrm{q}}\right), 129.5(\mathrm{CH}), 126.9(\mathrm{CH}), 123.1\left(\mathrm{dd},{ }^{2} J_{\mathrm{C}-\mathrm{F}}=22.8 \mathrm{~Hz},{ }^{3} J_{\mathrm{C}-\mathrm{F}}=4.2 \mathrm{~Hz}, \mathrm{C}_{\mathrm{q}}\right), 117.8(\mathrm{CH}), 115.5$ $(\mathrm{CH}), 112.7\left(\mathrm{~m}, \mathrm{C}_{\mathrm{q}}\right), 108.5\left(\mathrm{~m}, \mathrm{C}_{\mathrm{q}}\right), 107.0(\mathrm{CH}), 55.8\left(\mathrm{CH}_{3}\right)$.

${ }^{19} \mathrm{~F}-\mathrm{NMR}\left(376 \mathrm{MHz}, \mathrm{CDCl}_{3}\right): \delta=-94.2(\mathrm{~m}),-132.8(\mathrm{dt}, J=141,16.3 \mathrm{~Hz}),-139.1(\mathrm{~m}),-148.6$ (m), $-160.3(\mathrm{~m}),-162.4(\mathrm{~m})$.

IR (ATR): 2946, 1524, 1505, 1326, 1182, 1043, 993, $755 \mathrm{~cm}^{-1}$. MS (ESI) $m / z$ (relative intensity): $475\left([\mathrm{M}+\mathrm{Na}]^{+}, 20\right), 453\left([\mathrm{M}+\mathrm{H}]^{+}, 100\right), 433(10)$.

HR-MS (ESI): $m / z$ calcd. for $\left[\mathrm{C}_{19} \mathrm{H}_{9} \mathrm{~F}_{9} \mathrm{~N}_{2} \mathrm{O}+\mathrm{H}\right]^{+} 453.0644$, found: 453.0646 . 


\subsubsection{Removal of Directing Group}

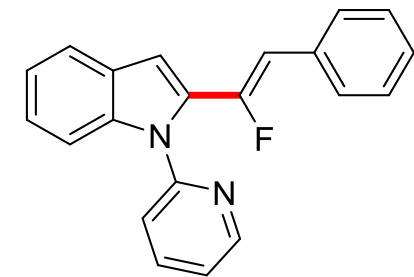

$317 \mathrm{ab}$

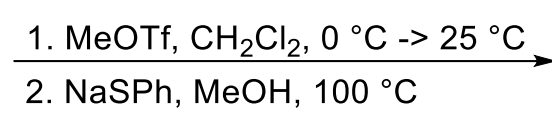

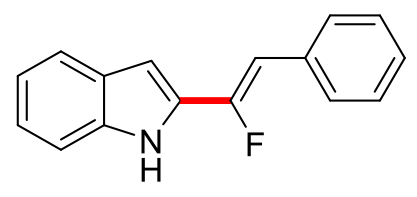

409

Methyl trifluoromethanesulfonate $(98.4 \mathrm{mg}, 66 \mu \mathrm{L}, 0.60 \mathrm{mmol}, 1.20$ equiv) was added dropwise to a solution of $\mathbf{3 1 7} \mathbf{a b}\left(157 \mathrm{mg}, 0.50 \mathrm{mmol}, 1.00\right.$ equiv) in $\mathrm{CH}_{2} \mathrm{Cl}_{2}(7.5 \mathrm{~mL})$ at $0{ }^{\circ} \mathrm{C}$, and the resulting solution was stirred for $12 \mathrm{~h}$ at $25^{\circ} \mathrm{C}$. After removal of the solvent, $\mathrm{PhSNa}$ (330 mg, $2.50 \mathrm{mmol}, 5.00$ equiv) and $\mathrm{MeOH}(5.0 \mathrm{~mL})$ were added and the resulting mixture was stirred at $100{ }^{\circ} \mathrm{C}$ for $24 \mathrm{~h}$ with a reflux condenser. The solvents were removed, and the resulting residue was neutralized using $\mathrm{HCl}(1.0 \mathrm{M})$ and extracted with $\mathrm{CH}_{2} \mathrm{Cl}_{2}(4 \times 20 \mathrm{~mL})$. The combined organic layers were washed with brine, dried over $\mathrm{Na}_{2} \mathrm{SO}_{4}$ and concentrated in vacuo. The remaining residue was purified by column chromatography on silica gel ( $n$ hexane/EtOAc: $20: 1)$ to afford the desired product $\mathbf{4 0 9}(71.4 \mathrm{mg}, 60 \%)$ as a white solid.<smiles>FC(=Cc1ccccc1)c1cc2ccccc2[nH]1</smiles>

(Z)-2-(1-Fluoro-2-phenylvinyl)-1H-indole (409): M.p.: $135{ }^{\circ} \mathrm{C}$.

${ }^{1} \mathrm{H}-\mathrm{NMR}\left(400 \mathrm{MHz}, \mathrm{CDCl}_{3}\right): \delta=8.31$ (bs, 1H), 7.63-7.58 (m, 3H), 7.40-7.34 (m, 3H), 7.29$7.21(\mathrm{~m}, 2 \mathrm{H}), 7.13(\mathrm{ddd}, J=7.9,7.5,0.9 \mathrm{~Hz}, 1 \mathrm{H}), 6.84(\mathrm{~d}, J=1.7 \mathrm{~Hz}, 1 \mathrm{H}), 6.50$ (d, $J=20.8$ $\mathrm{Hz}, 0.10 \mathrm{H}, E), 6.23$ (d, $J=39.9 \mathrm{~Hz}, 0.90 \mathrm{H}, Z$ ).

${ }^{13} \mathrm{C}-\mathrm{NMR}\left(100 \mathrm{MHz}, \mathrm{CDCl}_{3}\right): \delta=151.5\left(\mathrm{~d}, J=253 \mathrm{~Hz}, \mathrm{C}_{\mathrm{q}}\right), 136.5(\mathrm{CH}), 133.2\left(\mathrm{~d},{ }^{3} J_{\mathrm{C}-\mathrm{F}}=\right.$ $\left.3.3 \mathrm{~Hz}, \mathrm{C}_{\mathrm{q}}\right), 130.7\left(\mathrm{~d},{ }^{2} J_{\mathrm{C}-\mathrm{F}}=31.3 \mathrm{~Hz}, \mathrm{C}_{\mathrm{q}}\right), 128.8\left(\mathrm{~d},{ }^{4} J_{\mathrm{C}-\mathrm{F}}=7.5 \mathrm{~Hz}, \mathrm{CH}\right), 128.7(\mathrm{CH}), 128.5$ $\left(\mathrm{C}_{\mathrm{q}}\right), 127.5\left(\mathrm{C}_{\mathrm{q}}\right), 123.4(\mathrm{CH}), 121.0(\mathrm{CH}), 120.7(\mathrm{CH}), 111.1(\mathrm{CH}), 105.6\left(\mathrm{~d},{ }^{2} J_{\mathrm{C}-\mathrm{F}}=8.8 \mathrm{~Hz}\right.$, $\mathrm{CH}), 101.5\left(\mathrm{~d},{ }^{3} \mathrm{~J}_{\mathrm{C}-\mathrm{F}}=3.8 \mathrm{~Hz}, \mathrm{CH}\right)$.

${ }^{19} \mathrm{~F}-\mathrm{NMR}\left(376 \mathrm{MHz}, \mathrm{CDCl}_{3}\right): \delta=-109.4(\mathrm{~d}, J=20.8 \mathrm{~Hz}, E),-118.3(\mathrm{~d}, J=39.9 \mathrm{~Hz}, Z)$.

IR (ATR): 3425, 3052, 1653, 1446, 1024, 944, $589 \mathrm{~cm}^{-1}$.

MS (ESI) $m / z$ (relative intensity): $238\left([\mathrm{M}+\mathrm{H}]^{+}, 80\right), 163$ (100).

HR-MS (ESI): $m / z$ calcd. for $\left[\mathrm{C}_{16} \mathrm{H}_{12} \mathrm{FN}+\mathrm{H}\right]^{+} 238.1027$, found 238.1036. 


\subsection{Ruthenium(II)-catalyzed $\mathrm{C}-\mathrm{F} / \mathrm{C}-\mathrm{H}$ functionalization}

\subsubsection{Characterization Data}<smiles>CC(=O)c1ccccc1C/C=C(/F)C(F)(F)F</smiles>

(E)-1-[2-(1H,1H,2H-Perfluorodec-2-en-1-yl)phenyl]ethan-1-one (307aa): The general procedure $\mathbf{C}$ was followed using $N$-(3,4,5-trimethoxyphenyl)-1-phenylethan-1-imine (340a) (143 mg, $0.50 \mathrm{mmol})$ and $1 H, 1 H, 2 H$-perfluorodec-1-ene (301a) (669 mg, $1.50 \mathrm{mmol})$. Isolation by column chromatography ( $n$-hexane/EtOAc: $25 / 1$ ) yielded 307aa (199 mg, 73\%, $E / Z=78: 22, \mathbf{3 0 7} \mathbf{a a} / 339 \mathbf{a a}=98: 2)$ as a yellow oil.

${ }^{1} \mathrm{H}-\mathrm{NMR}\left(300 \mathrm{MHz}, \mathrm{CDCl}_{3}\right): \delta=7.84(\mathrm{dd}, J=7.4,1.4 \mathrm{~Hz}, 1 \mathrm{H}), 7.49$ (ddd, $J=7.6,7.4,1.4 \mathrm{~Hz}$, 1H), 7.39 (ddd, $J=7.6,7.5,1.4 \mathrm{~Hz}, 1 \mathrm{H}), 7.28$ (dd, $J=7.5,1.4 \mathrm{~Hz}, 1 \mathrm{H}), 6.18$ (dt, $J=23.1,8.4$ $\mathrm{Hz}, 0.78 \mathrm{H}, E), 5.95(\mathrm{dt}, J=33.7,7.8 \mathrm{~Hz}, 0.22 \mathrm{H}, Z$ ), 3.84 (ddt, $J=8.3,4.1,2.3 \mathrm{~Hz}, 2 \mathrm{H}), 3.20$ $3.10(\mathrm{~m}, 0.04 \mathrm{H}, 339 \mathrm{aa}), 2.64(\mathrm{~s}, 2.34 \mathrm{H}, E), 2.63$ (s, 0.66H, Z).

${ }^{13} \mathrm{C}-\mathrm{NMR}\left(75 \mathrm{MHz}, \mathrm{CDCl}_{3}\right): \delta=201.1\left(\mathrm{C}_{\mathrm{q}}\right), 144.4\left(\mathrm{dt},{ }^{1} J_{\mathrm{C}-\mathrm{F}}=257.1 \mathrm{~Hz},{ }^{2} J_{\mathrm{C}-\mathrm{F}}=29.1 \mathrm{~Hz}, \mathrm{C}_{\mathrm{q}}\right)$, $138.3\left(\mathrm{C}_{\mathrm{q}}\right), 136.6\left(\mathrm{C}_{\mathrm{q}}\right), 132.4(\mathrm{CH}), 131.2(\mathrm{CH}), 130.2(\mathrm{CH}), 127.1(\mathrm{CH}), 120.8\left(\mathrm{dt},{ }^{1} J_{\mathrm{C}-\mathrm{F}}=\right.$ $\left.288.3 \mathrm{~Hz},{ }^{2} J_{\mathrm{C}-\mathrm{F}}=34.2 \mathrm{~Hz}, \mathrm{C}_{\mathrm{q}}\right), 119.0\left(\mathrm{~d},{ }^{2} J_{\mathrm{C}-\mathrm{F}}=16.8 \mathrm{~Hz}, \mathrm{CH}\right), 115.2\left(\mathrm{~m}, \mathrm{C}_{\mathrm{q}}\right), 113.6\left(\mathrm{~m}, \mathrm{C}_{\mathrm{q}}\right)$, $111.1\left(\mathrm{~m}, \mathrm{C}_{\mathrm{q}}\right), 110.6\left(\mathrm{~m}, \mathrm{C}_{\mathrm{q}}\right), 108.2\left(\mathrm{~m}, \mathrm{C}_{\mathrm{q}}\right), 106.6\left(\mathrm{~m}, \mathrm{C}_{\mathrm{q}}\right), 29.2\left(\mathrm{CH}_{3}\right), 28.4\left(\mathrm{~m}, \mathrm{CH}_{2}\right)$.

${ }^{19} \mathrm{~F}-\mathrm{NMR}\left(282 \mathrm{MHz}, \mathrm{CDCl}_{3}\right): \delta=-80.9(\mathrm{~m}),-114.5(\mathrm{~m}, E),-117.5(\mathrm{~m}, Z),-122.1(\mathrm{~m}),-122.8$ (m), $-123.4(\mathrm{~m}),-124.0(\mathrm{~m}),-126.2(\mathrm{~m}),-132.4(\mathrm{~m})$.

IR (ATR): 1690, 1357, 1226, 1199, 1143, 1116, 759, $732 \mathrm{~cm}^{-1}$.

MS (ESI) $m / z$ (relative intensity): $569\left([\mathrm{M}+\mathrm{Na}]^{+}, 100\right), 547\left([\mathrm{M}+\mathrm{H}]^{+}, 45\right), 381(15)$.

HR-MS (ESI): $m / z$ calcd. for $\left[\mathrm{C}_{18} \mathrm{H}_{10} \mathrm{~F}_{16} \mathrm{O}+\mathrm{H}\right]^{+}$547.0549, found 547.0554.<smiles>CCC(=O)c1ccccc1C/C=C(/F)C(F)(F)F</smiles>

(E)-1-[2-(1H,1H,2H-perfluorodec-2-en-1-yl)phenyl]propan-1-one (307ba): The general procedure $\mathbf{C}$ was followed using $N$-(3,4,5-trimethoxyphenyl)-1-phenylpropan-1-imine (340b) (150 mg, $0.50 \mathrm{mmol})$ and $1 H, 1 H, 2 H$-perfluorodec-1-ene (301a) (669 mg, $1.50 \mathrm{mmol})$. Isolation by column chromatography ( $n$-hexane/EtOAc: $25 / 1$ ) yielded 307ba (176 mg, 63\%, $E / Z=75: 25, \mathbf{3 0 7} \mathbf{b a} / \mathbf{3 3 9} \mathbf{b a}=99: 1)$ as a yellow oil. 
${ }^{1} \mathrm{H}-\mathrm{NMR}\left(500 \mathrm{MHz}, \mathrm{CDCl}_{3}\right): \delta=7.72(\mathrm{dd}, J=8.0,1.4 \mathrm{~Hz}, 1 \mathrm{H}), 7.43(\mathrm{ddd}, J=7.7,7.5,1.4 \mathrm{~Hz}$, $1 \mathrm{H}), 7.33$ (ddd, $J=8.0,7.5,1.4 \mathrm{~Hz}, 1 \mathrm{H}), 7.22(\mathrm{dd}, J=7.7,1.4 \mathrm{~Hz}, 1 \mathrm{H}), 6.15(\mathrm{dt}, J=23.1,8.4$ $\mathrm{Hz}, 0.75 \mathrm{H}, E), 5.93(\mathrm{dt}, J=33.7,7.8 \mathrm{~Hz}, 0.25 \mathrm{H}, Z), 3.75(\mathrm{ddt}, J=7.4,4.1,2.0 \mathrm{~Hz}, 2 \mathrm{H}), 3.10$ $3.00(\mathrm{~m}, 0.02 \mathrm{H}, 339 \mathrm{ba}), 2.94(\mathrm{q}, J=7.2 \mathrm{~Hz}, 2 \mathrm{H}), 1.19(\mathrm{t}, J=7.3 \mathrm{~Hz}, 3 \mathrm{H})$.

${ }^{13} \mathrm{C}-\mathrm{NMR}\left(125 \mathrm{MHz}, \mathrm{CDCl}_{3}\right): \delta=204.4\left(\mathrm{C}_{\mathrm{q}}\right), 143.9\left(\mathrm{dt},{ }^{1} J_{\mathrm{C}-\mathrm{F}}=256.2 \mathrm{~Hz},{ }^{2} J_{\mathrm{C}-\mathrm{F}}=27.3 \mathrm{~Hz}, \mathrm{C}_{\mathrm{q}}\right)$, $137.8\left(\mathrm{C}_{\mathrm{q}}\right), 137.1\left(\mathrm{C}_{\mathrm{q}}\right), 131.9(\mathrm{CH}), 131.1(\mathrm{CH}), 129.0(\mathrm{CH}), 127.0(\mathrm{CH}), 119.0\left(\mathrm{~d},{ }^{2} J_{\mathrm{C}-\mathrm{F}}=\right.$ $8.2 \mathrm{~Hz}, \mathrm{CH}), 117.2\left(\mathrm{dt},{ }^{1} J_{\mathrm{C}-\mathrm{F}}=287.7 \mathrm{~Hz},{ }^{2} J_{\mathrm{C}-\mathrm{F}}=31.3 \mathrm{~Hz}, \mathrm{C}_{\mathrm{q}}\right), 113.4\left(\mathrm{~m}, \mathrm{C}_{\mathrm{q}}\right), 112.9\left(\mathrm{~m}, \mathrm{C}_{\mathrm{q}}\right)$, $112.0\left(\mathrm{~m}, \mathrm{C}_{\mathrm{q}}\right), 110.7\left(\mathrm{~m}, \mathrm{C}_{\mathrm{q}}\right), 110.4\left(\mathrm{~m}, \mathrm{C}_{\mathrm{q}}\right), 108.5\left(\mathrm{~m}, \mathrm{C}_{\mathrm{q}}\right), 34.4\left(\mathrm{CH}_{2}\right), 28.3\left(\mathrm{~m}, \mathrm{CH}_{2}\right), 8.2$ $\left(\mathrm{CH}_{3}\right)$.

${ }^{19} \mathrm{~F}-\mathrm{NMR}\left(471 \mathrm{MHz}, \mathrm{CDCl}_{3}\right): \delta=-80.9(\mathrm{~m}),-114.4(\mathrm{~m}, E),-117.4(\mathrm{~m}, Z),-122.0(\mathrm{~m}),-122.8$ (m), $-123.3(\mathrm{~m}),-123.9(\mathrm{~m}),-126.2(\mathrm{~m}),-132.5(\mathrm{~m})$.

IR (ATR): 1709, 1340, 1291, 1259, 1143, 1121, 721, $700 \mathrm{~cm}^{-1}$.

MS (ESI) $m / z$ (relative intensity): $583\left([\mathrm{M}+\mathrm{Na}]^{+}, 100\right), 561\left([\mathrm{M}+\mathrm{H}]^{+}, 10\right)$.

HR-MS (ESI): $m / z$ calcd. for $\left[\mathrm{C}_{19} \mathrm{H}_{12} \mathrm{~F}_{16} \mathrm{O}+\mathrm{H}\right]^{+}$561.0705, found 561.0708.<smiles>CC(=O)c1ccc(C)cc1C/C=C(/F)C(F)(F)F</smiles>

(E)-1-[4-Methyl-2-(1H,1H,2H-perfluorodec-2-en-1-yl)phenyl]ethan-1-one (307ca): The general procedure $\mathbf{C}$ was followed using 1-(4-methylphenyl)- $N$-(3,4,5-trimethoxyphenyl)-1phenylethan-1-imine (340c) (150 mg, $0.50 \mathrm{mmol})$ and $1 H, 1 H, 2 H$-perfluorodec-1-ene (301a) (669 mg, $1.50 \mathrm{mmol}$ ). Isolation by column chromatography ( $n$-hexane/EtOAc: $25 / 1$ ) yielded 307ca $(174 \mathrm{mg}, 62 \%, E / Z=84: 16, \mathbf{3 0 7} \mathbf{c a} / \mathbf{3 3 9} \mathbf{c a}=92: 8)$ as a yellow oil.

${ }^{1} \mathrm{H}-\mathrm{NMR}\left(500 \mathrm{MHz}, \mathrm{CDCl}_{3}\right): \delta=7.71(\mathrm{~d}, J=8.0 \mathrm{~Hz}, 1 \mathrm{H}), 7.15(\mathrm{dd}, J=8.0,1.4 \mathrm{~Hz}, 1 \mathrm{H}), 7.05$ $(\mathrm{d}, J=1.4 \mathrm{~Hz}, 1 \mathrm{H}), 6.14(\mathrm{dt}, J=23.3,8.3 \mathrm{~Hz}, 0.84 \mathrm{H}, E), 5.91(\mathrm{dt}, J=32.5,8.3 \mathrm{~Hz}, 0.16 \mathrm{H}, Z$ ), 3.80 (ddt, $J=7.5,4.0,2.2 \mathrm{~Hz}, 2 \mathrm{H}), 3.20-3.03$ (m, 0.16H, 339ca), 2.58 (s, 2.52H, E), 2.57 (s, $0.48 \mathrm{H}, \mathrm{Z}), 2.36(\mathrm{~s}, 3 \mathrm{H})$.

${ }^{13} \mathrm{C}-\mathrm{NMR}\left(125 \mathrm{MHz}, \mathrm{CDCl}_{3}\right): \delta=200.5\left(\mathrm{C}_{\mathrm{q}}\right), 143.9\left(\mathrm{dt},{ }^{1} J_{\mathrm{C}-\mathrm{F}}=260.3 \mathrm{~Hz},{ }^{2} J_{\mathrm{C}-\mathrm{F}}=27.5 \mathrm{~Hz}, \mathrm{C}_{\mathrm{q}}\right)$, $143.2\left(\mathrm{C}_{\mathrm{q}}\right), 138.6\left(\mathrm{C}_{\mathrm{q}}\right), 133.7\left(\mathrm{C}_{\mathrm{q}}\right), 132.1(\mathrm{CH}), 130.7(\mathrm{CH}), 127.6(\mathrm{CH}), 119.1\left(\mathrm{~d},{ }^{2} J_{\mathrm{C}-\mathrm{F}}=\right.$ $18.3 \mathrm{~Hz}, \mathrm{CH}), 117.1\left(\mathrm{dt},{ }^{1} J_{\mathrm{C}-\mathrm{F}}=289.1 \mathrm{~Hz},{ }^{2} J_{\mathrm{C}-\mathrm{F}}=33.8 \mathrm{~Hz}, \mathrm{C}_{\mathrm{q}}\right), 113.2\left(\mathrm{~m}, \mathrm{C}_{\mathrm{q}}\right), 112.1\left(\mathrm{~m}, \mathrm{C}_{\mathrm{q}}\right)$, $111.0\left(\mathrm{~m}, \mathrm{C}_{\mathrm{q}}\right), 110.7\left(\mathrm{~m}, \mathrm{C}_{\mathrm{q}}\right), 109.7\left(\mathrm{~m}, \mathrm{C}_{\mathrm{q}}\right), 108.6\left(\mathrm{~m}, \mathrm{C}_{\mathrm{q}}\right), 29.1\left(\mathrm{CH}_{3}\right), 28.5\left(\mathrm{~m}, \mathrm{CH}_{2}\right), 21.3$ $\left(\mathrm{CH}_{3}\right)$.

${ }^{19} \mathrm{~F}-\mathrm{NMR}\left(471 \mathrm{MHz}, \mathrm{CDCl}_{3}\right): \delta=-80.9(\mathrm{~m}),-114.5(\mathrm{~m}, E),-117.5(\mathrm{~m}, Z),-122.0(\mathrm{~m}),-122.8$ (m), $-123.4(\mathrm{~m}),-124.4(\mathrm{~m}),-126.3(\mathrm{~m}),-132.8(\mathrm{~m})$. 
IR (ATR): 1695, 1395, 1243, 1200, 1155, 1103, 749, $710 \mathrm{~cm}^{-1}$.

MS (ESI) $m / z$ (relative intensity): $583\left([\mathrm{M}+\mathrm{Na}]^{+}, 100\right), 561\left([\mathrm{M}+\mathrm{H}]^{+}, 20\right)$.

HR-MS (ESI): $m / z$ calcd. for $\left[\mathrm{C}_{19} \mathrm{H}_{12} \mathrm{~F}_{16} \mathrm{O}+\mathrm{H}\right]^{+} 561.0705$, found 561.0708 .<smiles>CC(=O)c1ccc(-c2ccccc2)cc1C/C=C(\F)C(F)F</smiles>

(E)-1-[4-Phenyl-2-(1H,1H,2H-perfluorodec-2-en-1-yl)phenyl]ethan-1-one (307da): The general procedure $\mathbf{C}$ was followed using 1-([1,1'-biphenyl]-4-yl)- $N-(3,4,5-$ trimethoxyphenyl)ethan-1-imine (340d) $(188 \mathrm{mg}, 0.50 \mathrm{mmol})$ and $1 \mathrm{H}, 1 \mathrm{H}, 2 \mathrm{H}$-perfluorodec-1ene (301a) (669 mg, $1.50 \mathrm{mmol}$ ). Isolation by column chromatography ( $n$-hexane/EtOAc: $25 / 1)$ yielded 307da $(165 \mathrm{mg}, 53 \%, E / Z=80: 20,307 \mathrm{da} / 339 \mathrm{da}=99: 1)$ as a yellow oil.

${ }^{1} \mathrm{H}-\mathrm{NMR}\left(300 \mathrm{MHz}, \mathrm{CDCl}_{3}\right): \delta=7.88(\mathrm{~d}, J=8.1 \mathrm{~Hz}, 1 \mathrm{H}), 7.72-7.52(\mathrm{~m}, 3 \mathrm{H}), 7.54-7.35(\mathrm{~m}$, $4 \mathrm{H}), 6.21(\mathrm{dt}, J=23.0,8.2,0.7 \mathrm{~Hz}, 0.80 \mathrm{H}, E), 5.98(\mathrm{dt}, J=33.7,10.5,1.2 \mathrm{~Hz}, 0.20 \mathrm{H}, Z), 3.91$ (ddt, $J=6.1,4.2,2.1 \mathrm{~Hz}, 2 \mathrm{H}), 3.41-3.06(\mathrm{~m}, 0.02 \mathrm{H}, 339 \mathrm{da}), 2.64(\mathrm{~s}, 2.40 \mathrm{H}, E), 2.63(\mathrm{~s}, 0.60 \mathrm{H}$, $Z)$.

${ }^{13} \mathrm{C}-\mathrm{NMR}\left(125 \mathrm{MHz}, \mathrm{CDCl}_{3}\right): \delta=200.1\left(\mathrm{C}_{\mathrm{q}}\right), 144.9\left(\mathrm{C}_{\mathrm{q}}\right), 144.3\left(\mathrm{dt},{ }^{1} J_{\mathrm{C}-\mathrm{F}}=251 \mathrm{~Hz},{ }^{2} J_{\mathrm{C}-\mathrm{F}}=\right.$ $\left.29.4 \mathrm{~Hz}, \mathrm{C}_{\mathrm{q}}\right), 139.1\left(\mathrm{C}_{\mathrm{q}}\right), 138.8\left(\mathrm{C}_{\mathrm{q}}\right), 134.8\left(\mathrm{C}_{\mathrm{q}}\right), 130.8(\mathrm{CH}), 129.9(\mathrm{CH}), 128.7(\mathrm{CH}), 128.1$ $(\mathrm{CH}), 129.0(\mathrm{CH}), 126.9(\mathrm{CH}), 125.3(\mathrm{CH}), 118.7\left(\mathrm{~d},{ }^{2} J_{\mathrm{C}-\mathrm{F}}=8.9 \mathrm{~Hz}, \mathrm{CH}\right), 116.8\left(\mathrm{dt},{ }^{1} J_{\mathrm{C}-\mathrm{F}}=\right.$ $\left.288.5 \mathrm{~Hz},{ }^{2} J_{\mathrm{C}-\mathrm{F}}=32.3 \mathrm{~Hz}, \mathrm{C}_{\mathrm{q}}\right), 112.7\left(\mathrm{~m}, \mathrm{C}_{\mathrm{q}}\right), 111.8\left(\mathrm{~m}, \mathrm{C}_{\mathrm{q}}\right), 110.8\left(\mathrm{~m}, \mathrm{C}_{\mathrm{q}}\right), 110.5\left(\mathrm{~m}, \mathrm{C}_{\mathrm{q}}\right)$, $110.5\left(\mathrm{~m}, \mathrm{C}_{\mathrm{q}}\right), 108.4\left(\mathrm{~m}, \mathrm{C}_{\mathrm{q}}\right), 29.0\left(\mathrm{CH}_{3}\right), 28.6\left(\mathrm{~m}, \mathrm{CH}_{2}\right)$.

${ }^{19} \mathrm{~F}-\mathrm{NMR}\left(282 \mathrm{MHz}, \mathrm{CDCl}_{3}\right): \delta=-80.8(\mathrm{~m}),-114.4(\mathrm{~m}, E),-117.4(\mathrm{~m}, Z),-121.9(\mathrm{~m}),-122.7$ (m), $-123.0(\mathrm{~m}),-123.3(\mathrm{~m}),-123.7(\mathrm{~m}),-126.1(\mathrm{~m}),-132.5(\mathrm{~m})$.

IR (ATR): 1693, 1452, 1257, 1233, 1143, 1057, 961, $749 \mathrm{~cm}^{-1}$.

MS (ESI) $m / z$ (relative intensity): $645\left([\mathrm{M}+\mathrm{Na}]^{+}, 100\right), 623\left([\mathrm{M}+\mathrm{H}]^{+}, 30\right)$.

HR-MS (ESI): $\mathrm{m} / z$ calcd. for $\left[\mathrm{C}_{24} \mathrm{H}_{14} \mathrm{~F}_{16} \mathrm{O}+\mathrm{H}\right]^{+}$623.0862, found 623.0867 .<smiles>COc1ccc(C(C)=O)c(C/C=C(\F)C(F)(F)F)c1</smiles>

(E)-1-[4-Methoxy-2-(1H,1H,2H-perfluorodec-2-en-1-yl)phenyl]ethan-1-one (307ea): The general procedure $\mathbf{C}$ was followed using 1-(4-methoxyphenyl)- $N$-(3,4,5-trimethoxyphenyl)-1phenylethan-1-imine (340e) (158 mg, $0.50 \mathrm{mmol})$ and $1 H, 1 H, 2 H$-perfluorodec-1-ene (301a) 
(669 mg, $1.50 \mathrm{mmol}$ ). Isolation by column chromatography ( $n$-hexane/EtOAc: $25 / 1$ ) yielded 307ea $(167 \mathrm{mg}, 58 \%, E / Z=75: 25, \mathbf{3 0 7} \mathbf{e a} / \mathbf{3 3 9} \mathbf{e a}=98: 2)$ as a yellow oil.

${ }^{1} \mathrm{H}-\mathrm{NMR}\left(500 \mathrm{MHz}, \mathrm{CDCl}_{3}\right): \delta=7.82(\mathrm{~d}, J=8.7 \mathrm{~Hz}, 1 \mathrm{H}), 6.82(\mathrm{dd}, J=8.7,2.7 \mathrm{~Hz}, 1 \mathrm{H}), 6.72$ $(\mathrm{d}, J=2.7 \mathrm{~Hz}, 1 \mathrm{H}), 6.17(\mathrm{dt}, J=23.5,8.8 \mathrm{~Hz}, 0.75 \mathrm{H}, E), 5.92(\mathrm{dt}, J=33.9,7.8 \mathrm{~Hz}, 0.25 \mathrm{H}, Z)$, 3.86 (ddt, $J=7.0,4.1,1.6 \mathrm{~Hz}, 2 \mathrm{H}), 3.83$ (s, 3H), 3.20-3.00 (m, 0.04H, 339ea) $2.56(\mathrm{~s}, 2.25 \mathrm{H}$, E), 2.55 (s, $0.75 \mathrm{H}, Z)$.

${ }^{13} \mathrm{C}-\mathrm{NMR}\left(125 \mathrm{MHz}, \mathrm{CDCl}_{3}\right): \delta=199.1\left(\mathrm{C}_{\mathrm{q}}\right), 162.5\left(\mathrm{C}_{\mathrm{q}}\right), 144.1\left(\mathrm{dt},{ }^{1} J_{\mathrm{C}-\mathrm{F}}=256.2 \mathrm{~Hz},{ }^{2} J_{\mathrm{C}-\mathrm{F}}=\right.$ $\left.27.3 \mathrm{~Hz}, \mathrm{C}_{\mathrm{q}}\right), 141.5\left(\mathrm{C}_{\mathrm{q}}\right), 133.1(\mathrm{CH}), 128.8\left(\mathrm{C}_{\mathrm{q}}\right), 118.8\left(\mathrm{~d},{ }^{2} J_{\mathrm{C}-\mathrm{F}}=8.9 \mathrm{~Hz}, \mathrm{CH}\right), 117.5\left(\mathrm{dt},{ }^{1} J_{\mathrm{C}-}\right.$ $\left.\mathrm{F}=287 \mathrm{~Hz},{ }^{2} J_{\mathrm{C}-\mathrm{F}}=31.3 \mathrm{~Hz}, \mathrm{C}_{\mathrm{q}}\right), 117.0(\mathrm{CH}), 116.5(\mathrm{CH}), 112.8\left(\mathrm{~m}, \mathrm{C}_{\mathrm{q}}\right), 112.6\left(\mathrm{~m}, \mathrm{C}_{\mathrm{q}}\right), 111.6$ $(\mathrm{CH}), 110.9\left(\mathrm{~m}, \mathrm{C}_{\mathrm{q}}\right), 110.7\left(\mathrm{~m}, \mathrm{C}_{\mathrm{q}}\right), 110.2\left(\mathrm{~m}, \mathrm{C}_{\mathrm{q}}\right), 55.3\left(\mathrm{CH}_{3}\right), 29.0\left(\mathrm{~m}, \mathrm{CH}_{2}\right), 28.8\left(\mathrm{CH}_{3}\right)$.

${ }^{19}$ F-NMR (471 MHz, $\left.\mathrm{CDCl}_{3}\right): \delta=-80.7(\mathrm{~m}),-114.3(\mathrm{~m}, E),-117.3(\mathrm{~m}, Z),-121.9(\mathrm{~m}),-122.9$ (m), $-123.3(\mathrm{~m}),-124.0(\mathrm{~m}),-126.1(\mathrm{~m}),-132.5(\mathrm{~m})$.

IR (ATR): 1686, 1604, 1585, 1235, 1199, 1144, 1106, 733, $706 \mathrm{~cm}^{-1}$.

MS (ESI) $m / z$ (relative intensity): $599\left([\mathrm{M}+\mathrm{Na}]^{+}, 100\right), 577\left([\mathrm{M}+\mathrm{H}]^{+}, 30\right)$.

HR-MS (ESI): $m / z$ calcd. for $\left[\mathrm{C}_{19} \mathrm{H}_{12} \mathrm{~F}_{16} \mathrm{O}_{2}+\mathrm{H}\right]^{+} 577.0655$, found 577.0653 .<smiles>CC(=O)c1ccc(C(F)(F)F)cc1C/C=C(\F)C(F)(F)F</smiles>

(E)-1-[4-Trifluoromethyl-2-(1H,1H,2H-perfluorodec-2-en-1-yl)phenyl]ethan-1-one

(307fa): The general procedure $\mathbf{C}$ was followed using 1-[4-trifluoromethyl- $N-(3,4,5-$ trimethoxyphenyl)-1-phenyl]ethan-1-one (340f) (177 mg, $0.50 \mathrm{mmol})$ and $1 \mathrm{H}, 1 \mathrm{H}, 2 \mathrm{H}$ perfluorodec-1-ene (301a) (669 $\mathrm{mg}, 1.50 \mathrm{mmol}$ ). Isolation by column chromatography ( $n$ hexane/EtOAc: $25 / 1)$ yielded 307fa $(166 \mathrm{mg}, 54 \%, E / Z=72: 28, \mathbf{3 0 7 f a} / \mathbf{3 3 9 f a}=97: 3)$ as a yellow oil.

${ }^{1} \mathrm{H}-\mathrm{NMR}\left(300 \mathrm{MHz}, \mathrm{CDCl}_{3}\right): \delta=7.88(\mathrm{~d}, J=8.1 \mathrm{~Hz}, 1 \mathrm{H}), 7.65(\mathrm{dd}, J=8.1,1.4 \mathrm{~Hz}, 1 \mathrm{H}), 7.53$ $(\mathrm{d}, 1.4 \mathrm{~Hz}, 1 \mathrm{H}), 6.10(\mathrm{dt}, J=22.6,8.5 \mathrm{~Hz}, 0.72 \mathrm{H}, E), 5.87(\mathrm{dt}, J=33.5,7.5 \mathrm{~Hz}, 0.28 \mathrm{H}, Z), 3.86$ (ddt, $J=7.0,4.0,2.0 \mathrm{~Hz}, 2 \mathrm{H}), 3.30-3.20$ (m, $0.06 \mathrm{H}, 339 \mathrm{fa}), 2.66$ (s, 2.16H, E), 2.65 (s, 0.84H, $Z)$.

${ }^{13} \mathrm{C}-\mathrm{NMR}\left(75 \mathrm{MHz}, \mathrm{CDCl}_{3}\right): \delta=200.4\left(\mathrm{C}_{\mathrm{q}}\right), 145.3\left(\mathrm{dt},{ }^{1} J_{\mathrm{C}-\mathrm{F}}=261.2 \mathrm{~Hz},{ }^{2} J_{\mathrm{C}-\mathrm{F}}=29.5 \mathrm{~Hz}, \mathrm{C}_{\mathrm{q}}\right)$, $139.7\left(\mathrm{C}_{\mathrm{q}}\right), 138.8\left(\mathrm{C}_{\mathrm{q}}\right), 133.7\left(\mathrm{q},{ }^{2} J_{\mathrm{C}-\mathrm{F}}=33.0 \mathrm{~Hz}, \mathrm{C}_{\mathrm{q}}\right), 130.0(\mathrm{CH}), 127.8\left(\mathrm{q},{ }^{3} J_{\mathrm{C}-\mathrm{F}}=3.8 \mathrm{~Hz}\right.$, $\mathrm{CH}), 125.0\left(\mathrm{~d},{ }^{1} J_{\mathrm{C}-\mathrm{F}}=273.3 \mathrm{~Hz}, \mathrm{C}_{\mathrm{q}}\right), 124.0\left(\mathrm{q},{ }^{3} J_{\mathrm{C}-\mathrm{F}}=3.7 \mathrm{~Hz}, \mathrm{CH}\right), 118.0\left(\mathrm{dt},{ }^{1} J_{\mathrm{C}-\mathrm{F}}=376.1 \mathrm{~Hz}\right.$, $\left.{ }^{2} J_{\mathrm{C}-\mathrm{F}}=22.3 \mathrm{~Hz}, \mathrm{C}_{\mathrm{q}}\right), 117.7\left(\mathrm{~d},{ }^{2} J_{\mathrm{C}-\mathrm{F}}=7.8 \mathrm{~Hz}, \mathrm{CH}\right), 114.0\left(\mathrm{~m}, \mathrm{C}_{\mathrm{q}}\right), 111.5\left(\mathrm{~m}, \mathrm{C}_{\mathrm{q}}\right), 110.8(\mathrm{~m}$, $\left.\mathrm{C}_{\mathrm{q}}\right), 110.2\left(\mathrm{~m}, \mathrm{C}_{\mathrm{q}}\right), 108.0\left(\mathrm{~m}, \mathrm{C}_{\mathrm{q}}\right), 107.5\left(\mathrm{~m}, \mathrm{C}_{\mathrm{q}}\right), 29.3\left(\mathrm{CH}_{3}\right), 28.1\left(\mathrm{~m}, \mathrm{CH}_{2}\right)$. 
${ }^{19} \mathrm{~F}-\mathrm{NMR}\left(282 \mathrm{MHz}, \mathrm{CDCl}_{3}\right): \delta=-63.6(\mathrm{~m}),-81.0(\mathrm{~m}),-114.7(\mathrm{~m}),-117.7(\mathrm{~m}),-122.1(\mathrm{~m})$, $-122.9(\mathrm{~m}),-123.2(\mathrm{~m}),-123.4(\mathrm{~m}),-126.4(\mathrm{~m}),-130.7(\mathrm{~m})$.

IR (ATR): 1719, 1311, 1263, 1223, 1140, 1100, 720, $700 \mathrm{~cm}^{-1}$.

MS (ESI) $m / z$ (relative intensity): $637\left([\mathrm{M}+\mathrm{Na}]^{+}, 100\right), 615\left([\mathrm{M}+\mathrm{H}]^{+}, 40\right)$.

HR-MS (ESI): $m / z$ calcd. for $\left[\mathrm{C}_{19} \mathrm{H}_{9} \mathrm{~F}_{19} \mathrm{O}+\mathrm{Na}\right]^{+}$637.0242, found 637.0241 .<smiles>CC(=O)c1ccc(C(C)=O)c(C/C=C(\F)C(F)(F)F)c1</smiles>

(E)-Methyl-4-acetyl-3-(1H,1H,2H-perfluorodec-2-en-1-yl)benzoate (307ga): The general procedure $\mathbf{C}$ was followed using methyl-4-(1-((3,4,5-trimethoxyphenyl)imino)ethyl)benzoate (340g) (172 mg, $0.50 \mathrm{mmol})$ and $1 \mathrm{H}, 1 \mathrm{H}, 2 \mathrm{H}$-perfluorodec-1-ene (301a) (669 mg, $1.50 \mathrm{mmol})$. Isolation by column chromatography ( $n$-hexane/EtOAc: $25 / 1$ ) yielded 307ga (145 mg, 48\%, $E / Z=70: 30$, 307ga/339ga $=99: 1)$ as a yellow oil.

${ }^{1} \mathrm{H}-\mathrm{NMR}\left(500 \mathrm{MHz}, \mathrm{CDCl}_{3}\right): \delta=8.00(\mathrm{~d}, J=7.7 \mathrm{~Hz}, 1 \mathrm{H}), 7.90(\mathrm{dd}, J=7.7,1.9 \mathrm{~Hz}, 1 \mathrm{H}), 7.79$ $(\mathrm{d}, J=1.9 \mathrm{~Hz}, 1 \mathrm{H}), 6.10(\mathrm{dt}, J=22.8,8.7,0.70 \mathrm{H}, E), 5.87(\mathrm{dt}, J=33.4,7.7 \mathrm{~Hz}, 0.30 \mathrm{H}, Z), 3.92$ (s, 3H), 3.81 (ddt, $J=7.4,4.5,2.1 \mathrm{~Hz}, 2 \mathrm{H}), 3.30-3.20$ (m, 0.02H, 339ga), $2.61(\mathrm{~s}, 2.10 \mathrm{H}, E)$, $2.60(\mathrm{~s}, 0.90 \mathrm{H}, Z)$.

${ }^{13} \mathrm{C}-\mathrm{NMR}\left(125 \mathrm{MHz}, \mathrm{CDCl}_{3}\right): \delta=200.9\left(\mathrm{C}_{\mathrm{q}}\right), 165.7\left(\mathrm{C}_{\mathrm{q}}\right), 144.5\left(\mathrm{dt},{ }^{1} J_{\mathrm{C}-\mathrm{F}}=256.2 \mathrm{~Hz},{ }^{2} J_{\mathrm{C}-\mathrm{F}}=\right.$ $\left.27.9 \mathrm{~Hz}, \mathrm{C}_{\mathrm{q}}\right), 140.3\left(\mathrm{C}_{\mathrm{q}}\right), 138.1\left(\mathrm{C}_{\mathrm{q}}\right), 133.1\left(\mathrm{C}_{\mathrm{q}}\right), 132.3(\mathrm{CH}), 129.6(\mathrm{CH}), 128.2(\mathrm{CH}), 118.0$ $\left(\mathrm{d},{ }^{2} J_{\mathrm{C}-\mathrm{F}}=8.1 \mathrm{~Hz}, \mathrm{CH}\right), 115.0\left(\mathrm{dt},{ }^{1} J_{\mathrm{C}-\mathrm{F}}=281 \mathrm{~Hz},{ }^{2} J_{\mathrm{C}-\mathrm{F}}=31.3 \mathrm{~Hz}, \mathrm{C}_{\mathrm{q}}\right), 112.6\left(\mathrm{~m}, \mathrm{C}_{\mathrm{q}}\right), 111.6$ $\left(\mathrm{m}, \mathrm{C}_{\mathrm{q}}\right), 110.9\left(\mathrm{~m}, \mathrm{C}_{\mathrm{q}}\right), 110.6\left(\mathrm{~m}, \mathrm{C}_{\mathrm{q}}\right), 110.4\left(\mathrm{~m}, \mathrm{C}_{\mathrm{q}}\right), 108.5\left(\mathrm{~m}, \mathrm{C}_{\mathrm{q}}\right), 52.4\left(\mathrm{CH}_{3}\right), 29.5\left(\mathrm{CH}_{3}\right)$, $28.1\left(\mathrm{~m}, \mathrm{CH}_{2}\right)$.

${ }^{19} \mathrm{~F}-\mathrm{NMR}\left(471 \mathrm{MHz}, \mathrm{CDCl}_{3}\right): \delta=-80.8(\mathrm{~m}),-114.5(\mathrm{~m}, E),-117.4(\mathrm{~m}, Z),-121.9(\mathrm{~m}),-122.7$ (m), $-122.9(\mathrm{~m}),-123.3(\mathrm{~m}),-126.1(\mathrm{~m}),-131.1(\mathrm{~m})$.

IR (ATR): 1725, 1663, 1222, 1205, 1156, 1100, $701 \mathrm{~cm}^{-1}$. MS (ESI) $m / z$ (relative intensity): $627\left([\mathrm{M}+\mathrm{Na}]^{+}, 100\right), 605\left([\mathrm{M}+\mathrm{H}]^{+}, 10\right)$. HR-MS (ESI): $m / z$ calcd. for $\left[\mathrm{C}_{20} \mathrm{H}_{12} \mathrm{~F}_{16} \mathrm{O}_{3}+\mathrm{H}\right]^{+}$605.0604, found 605.0601 . 
<smiles>CC(=O)c1ccc(Cl)cc1C/C=C(/F)C(F)F</smiles>

(E)-1-[4-Chloro-2-(1H,1H,2H-perfluorodec-2-en-1-yl)phenyl]ethan-1-one (307ha): The general procedure $\mathbf{C}$ was followed using 1-(4-chlorophenyl)- $N$-(3,4,5-trimethoxyphenyl)-1phenylethan-1-imine (340h) (160 mg, $0.50 \mathrm{mmol})$ and $1 H, 1 H, 2 H$-perfluorodec-1-ene (301a) (669 mg, $1.50 \mathrm{mmol}$ ). Isolation by column chromatography ( $n$-hexane/EtOAc: $25 / 1$ ) yielded 307ha $(171 \mathrm{mg}, 59 \%, E / Z=83: 17, \mathbf{3 0 7 h a / 3 3 9 h a}=98: 2)$ as a yellow oil.

${ }^{1} \mathrm{H}-\mathrm{NMR}\left(300 \mathrm{MHz}, \mathrm{CDCl}_{3}\right): \delta=7.76(\mathrm{dd}, J=8.4,1.9 \mathrm{~Hz}, 1 \mathrm{H}), 7.37(\mathrm{dd}, J=8.4,2.1 \mathrm{~Hz}, 1 \mathrm{H})$, $7.29(\mathrm{dd}, 2.1,1.9 \mathrm{~Hz}, 1 \mathrm{H}), 6.16(\mathrm{dt}, 22.3,8.7 \mathrm{~Hz}, 0.83 \mathrm{H}, E), 5.92(\mathrm{dt}, J=33.4,7.7 \mathrm{~Hz}, 0.17 \mathrm{H}$, Z), 3.80 (ddt, $J=7.8,4.1,2.0 \mathrm{~Hz}, 2 \mathrm{H}), 3.20-3.10$ (m, 0.04H, 339ha) 2.62 (s, 2.49H, E), 2.61 (s, $0.51 \mathrm{H}, Z)$.

${ }^{13} \mathrm{C}-\mathrm{NMR}\left(75 \mathrm{MHz}, \mathrm{CDCl}_{3}\right): \delta=199.8\left(\mathrm{C}_{\mathrm{q}}\right), 145.1\left(\mathrm{dt},{ }^{1} J_{\mathrm{C}-\mathrm{F}}=275 \mathrm{~Hz},{ }^{2} J_{\mathrm{C}-\mathrm{F}}=28.5 \mathrm{~Hz}, \mathrm{C}_{\mathrm{q}}\right)$, $140.4\left(\mathrm{C}_{\mathrm{q}}\right), 138.5\left(\mathrm{C}_{\mathrm{q}}\right), 134.7(\mathrm{CH}), 131.6(\mathrm{CH}), 131.2(\mathrm{CH}), 127.2\left(\mathrm{C}_{\mathrm{q}}\right), 118.2\left(\mathrm{dt},{ }^{1} J_{\mathrm{C}-\mathrm{F}}=\right.$ $\left.285.2 \mathrm{~Hz},{ }^{2} J_{\mathrm{C}-\mathrm{F}}=35.3 \mathrm{~Hz}, \mathrm{C}_{\mathrm{q}}\right), 118.0\left(\mathrm{~d},{ }^{2} J_{\mathrm{C}-\mathrm{F}}=7.2 \mathrm{~Hz}, \mathrm{CH}\right), 115.2\left(\mathrm{~m}, \mathrm{C}_{\mathrm{q}}\right), 114.5\left(\mathrm{~m}, \mathrm{C}_{\mathrm{q}}\right)$, $114.3\left(\mathrm{~m}, \mathrm{C}_{\mathrm{q}}\right), 112.4\left(\mathrm{~m}, \mathrm{C}_{\mathrm{q}}\right), 111.5\left(\mathrm{~m}, \mathrm{C}_{\mathrm{q}}\right), 111.1\left(\mathrm{~m}, \mathrm{C}_{\mathrm{q}}\right), 29.1\left(\mathrm{CH}_{3}\right), 28.2\left(\mathrm{~m}, \mathrm{CH}_{2}\right)$.

${ }^{19} \mathrm{~F}-\mathrm{NMR}\left(282 \mathrm{MHz}, \mathrm{CDCl}_{3}\right): \delta=-80.8(\mathrm{~m}),-114.5(\mathrm{~m}, E),-117.5(\mathrm{~m}, Z),-122.0(\mathrm{~m}),-122.7$ $(\mathrm{m}),-123.0(\mathrm{~m}),-123.3(\mathrm{~m}),-126.2(\mathrm{~m}),-131.2(\mathrm{~m})$.

IR (ATR): 1695, 1345, 1279, 1259, 1153, 1102, 741, $721 \mathrm{~cm}^{-1}$.

MS (ESI) $m / z$ (relative intensity): $603\left([\mathrm{M}+\mathrm{Na}]^{+}, 100\right), 581\left([\mathrm{M}+\mathrm{H}]^{+}, 55\right)$.

HR-MS (ESI): $m / z$ calcd. for $\left[\mathrm{C}_{18} \mathrm{H}_{9}{ }^{35} \mathrm{ClF}_{16} \mathrm{O}+\mathrm{H}\right]^{+} 581.0159$, found 581.0163 .<smiles>CC(=O)c1cc(C)ccc1CC=C(F)C(F)(F)C(F)(F)C(F)(F)F</smiles>

(E)-1-[5-Methyl-2-(1H,1H,2H-perfluorodec-2-en-1-yl)phenyl]ethan-1-one (307ia): The general procedure $\mathbf{C}$ was followed using 1-(3-methylphenyl)- $N$-(3,4,5-trimethoxyphenyl)-1phenylethan-1-imine (340i) (150 mg, $0.50 \mathrm{mmol})$ and $1 \mathrm{H}, 1 \mathrm{H}, 2 \mathrm{H}$-perfluorodec-1-ene (301a) (669 mg, $1.50 \mathrm{mmol}$ ). Isolation by column chromatography ( $n$-hexane/EtOAc: $25 / 1$ ) yielded 307ia $(176 \mathrm{mg}, 63 \%, E / Z=74: 26, \mathbf{3 0 7} \mathbf{i a / 3 3 9 i a}=91: 9)$ as a yellow oil.

${ }^{1} \mathrm{H}-\mathrm{NMR}\left(300 \mathrm{MHz}, \mathrm{CDCl}_{3}\right): \delta=7.61(\mathrm{~d}, J=2.7 \mathrm{~Hz}, 1 \mathrm{H}), 7.32(\mathrm{dd}, 8.4,2.7 \mathrm{~Hz}, 1 \mathrm{H}), 7.17(\mathrm{dd}$, $J=8.4 \mathrm{~Hz}, 2.7 \mathrm{~Hz}, 1 \mathrm{H}), 6.17(\mathrm{dt}, J=23.2,8.7 \mathrm{~Hz}, 0.74 \mathrm{H}, E), 5.94(\mathrm{dt}, J=33.8,7.8 \mathrm{~Hz}, 0.26 \mathrm{H}$, 
Z), 3.79 (ddt, $J=7.4,4.2,2.2 \mathrm{~Hz}, 2 \mathrm{H}), 3.22-2.97$ (m, 0.18H, 339ia), 2.62 (s, 2.22H, E), 2.61 (s, $0.78 \mathrm{H}, Z) 2.42(\mathrm{~s}, 3 \mathrm{H})$.

${ }^{13} \mathrm{C}-\mathrm{NMR}\left(75 \mathrm{MHz}, \mathrm{CDCl}_{3}\right): \delta=201.2\left(\mathrm{C}_{\mathrm{q}}\right), 144.1\left(\mathrm{dt},{ }^{1} J_{\mathrm{C}-\mathrm{F}}=258.1 \mathrm{~Hz},{ }^{2} J_{\mathrm{C}-\mathrm{F}}=28.3 \mathrm{~Hz}, \mathrm{C}_{\mathrm{q}}\right)$, $136.8\left(\mathrm{C}_{\mathrm{q}}\right), 136.5\left(\mathrm{C}_{\mathrm{q}}\right), 135.1\left(\mathrm{C}_{\mathrm{q}}\right), 133.0(\mathrm{CH}), 131.1(\mathrm{CH}), 130.7(\mathrm{CH}), 119.9\left(\mathrm{dt},{ }^{1} J_{\mathrm{C}-\mathrm{F}}=\right.$ $\left.288.2 \mathrm{~Hz},{ }^{2} J_{\mathrm{C}-\mathrm{F}}=34.1 \mathrm{~Hz}, \mathrm{C}_{\mathrm{q}}\right), 119.2\left(\mathrm{~d},{ }^{2} J_{\mathrm{C}-\mathrm{F}}=17.5 \mathrm{~Hz}, \mathrm{CH}\right), 115.2\left(\mathrm{~m}, \mathrm{C}_{\mathrm{q}}\right), 112.1\left(\mathrm{~m}, \mathrm{C}_{\mathrm{q}}\right)$, $111.6\left(\mathrm{~m}, \mathrm{C}_{\mathrm{q}}\right), 110.7\left(\mathrm{~m}, \mathrm{C}_{\mathrm{q}}\right), 108.6\left(\mathrm{~m}, \mathrm{C}_{\mathrm{q}}\right), 108.2\left(\mathrm{~m}, \mathrm{C}_{\mathrm{q}}\right), 29.1\left(\mathrm{CH}_{3}\right), 27.9\left(\mathrm{~m}, \mathrm{CH}_{2}\right), 20.8$ $\left(\mathrm{CH}_{3}\right)$.

${ }^{19} \mathrm{~F}-\mathrm{NMR}\left(282 \mathrm{MHz}, \mathrm{CDCl}_{3}\right): \delta=-80.9(\mathrm{~m}),-114.4(\mathrm{~m}, E),-117.5(\mathrm{~m}, Z),-122.0(\mathrm{~m}),-122.8$ (m), $-123.4(\mathrm{~m}),-124.3(\mathrm{~m}),-126.2(\mathrm{~m}),-132.7(\mathrm{~m})$.

IR (ATR): 1679, 1607, 1582, 1251, 1185, 1134, 1106, 733, $716 \mathrm{~cm}^{-1}$.

MS (ESI) $m / z$ (relative intensity): $583\left([\mathrm{M}+\mathrm{Na}]^{+}, 100\right), 561\left([\mathrm{M}+\mathrm{H}]^{+}, 40\right)$.

HR-MS (ESI): $m / z$ calcd. for $\left[\mathrm{C}_{19} \mathrm{H}_{12} \mathrm{~F}_{16} \mathrm{O}+\mathrm{H}\right]^{+} 561.0705$, found 561.0710 .<smiles></smiles>

(E)-1-[4-Methyl-2-(1H,1H,2H-perfluorododec-2-en-1-yl)phenyl]ethan-1-one (307ac): The general procedure $\mathbf{C}$ was followed using 1-(4-methylphenyl)- $N$-(3,4,5-trimethoxyphenyl)-1phenylethan-1-imine (340a) (150 mg, $0.50 \mathrm{mmol})$ and $1 \mathrm{H}, 1 \mathrm{H}, 2 \mathrm{H}$-perfluorododec-1-ene (301c) ( $820 \mathrm{mg}, 1.50 \mathrm{mmol}$ ). Isolation by column chromatography ( $n$-hexane/EtOAc: 25/1) yielded 307ac $(210 \mathrm{mg}, 64 \%, E / Z=83: 17,307 \mathbf{a c} / 339 \mathbf{a c}=94: 6)$ as a yellow oil .

${ }^{1} \mathrm{H}-\mathrm{NMR}\left(300 \mathrm{MHz}, \mathrm{CDCl}_{3}\right): \delta=7.75(\mathrm{~d}, J=8.0 \mathrm{~Hz}, 1 \mathrm{H}), 7.18(\mathrm{dd}, J=8.0,1.9 \mathrm{~Hz}, 1 \mathrm{H}), 7.08$ $(\mathrm{d}, J=1.9 \mathrm{~Hz}, 1 \mathrm{H}), 6.20(\mathrm{dt}, J=25.3,8.1 \mathrm{~Hz}, 0.83 \mathrm{H}, E), 5.95(\mathrm{dt}, J=33.9,4.4 \mathrm{~Hz}, 0.17 \mathrm{H}, Z$ ), 3.84 (ddt, $J=7.3,4.1,2.1 \mathrm{~Hz}, 2 \mathrm{H}$ ), 3.21-3.03 (m, 0.12H, 339ac), 2.61 (s, 2.49H, E), 2.60 (s, $0.51 \mathrm{H}, \mathrm{Z}), 2.40(\mathrm{~s}, 3 \mathrm{H})$.

${ }^{13} \mathrm{C}-\mathrm{NMR}\left(75 \mathrm{MHz}, \mathrm{CDCl}_{3}\right): \delta=200.4\left(\mathrm{C}_{\mathrm{q}}\right), 144.6\left(\mathrm{dt},{ }^{1} J_{\mathrm{C}-\mathrm{F}}=255.1 \mathrm{~Hz},{ }^{2} J_{\mathrm{C}-\mathrm{F}}=25.3 \mathrm{~Hz}, \mathrm{C}_{\mathrm{q}}\right)$, $143.2\left(\mathrm{C}_{\mathrm{q}}\right), 138.6\left(\mathrm{C}_{\mathrm{q}}\right), 133.6\left(\mathrm{C}_{\mathrm{q}}\right), 132.0(\mathrm{CH}), 130.7(\mathrm{CH}), 127.6(\mathrm{CH}), 119.7\left(\mathrm{dt},{ }^{1} J_{\mathrm{C}-\mathrm{F}}=\right.$ $\left.275.3 \mathrm{~Hz},{ }^{2} J_{\mathrm{C}-\mathrm{F}}=37.3 \mathrm{~Hz}, \mathrm{C}_{\mathrm{q}}\right), 119.1\left(\mathrm{~d},{ }^{2} J_{\mathrm{C}-\mathrm{F}}=9.8 \mathrm{~Hz}, \mathrm{CH}\right), 115.1\left(\mathrm{~m}, \mathrm{C}_{\mathrm{q}}\right), 111.6\left(\mathrm{~m}, \mathrm{C}_{\mathrm{q}}\right)$, $110.8\left(\mathrm{~m}, \mathrm{C}_{\mathrm{q}}\right), 110.7\left(\mathrm{~m}, \mathrm{C}_{\mathrm{q}}\right), 110.1\left(\mathrm{~m}, \mathrm{C}_{\mathrm{q}}\right), 108.6\left(\mathrm{~m}, \mathrm{C}_{\mathrm{q}}\right), 107.5\left(\mathrm{~m}, \mathrm{C}_{\mathrm{q}}\right), 107.1\left(\mathrm{~m}, \mathrm{C}_{\mathrm{q}}\right), 29.0$ $\left(\mathrm{CH}_{3}\right), 28.4\left(\mathrm{~m}, \mathrm{CH}_{2}\right), 21.2\left(\mathrm{CH}_{3}\right)$.

${ }^{19} \mathrm{~F}-\mathrm{NMR}\left(282 \mathrm{MHz}, \mathrm{CDCl}_{3}\right): \delta=-80.9(\mathrm{~m}),-114.5(\mathrm{~m}, E),-117.5(\mathrm{~m}, Z),-121.9(\mathrm{~m}),-122.8$ (m), $-123.0(\mathrm{~m}),-123.1(\mathrm{~m}),-123.4(\mathrm{~m}),-124.4(\mathrm{~m}),-126.3(\mathrm{~m}),-132.8(\mathrm{~m})$.

IR (ATR): 1700, 1355, 1249, 1210, 1195, 1100, 730, $695 \mathrm{~cm}^{-1}$.

MS (ESI) $m / z$ (relative intensity): $683\left([\mathrm{M}+\mathrm{Na}]^{+}, 100\right), 661\left([\mathrm{M}+\mathrm{H}]^{+}, 30\right)$. 
HR-MS (ESI): $m / z$ calcd. for $\left[\mathrm{C}_{21} \mathrm{H}_{12} \mathrm{~F}_{20} \mathrm{O}+\mathrm{H}\right]^{+} 661.0642$, found 661.0641 .<smiles>CC(=O)c1ccc(C)cc1C/C=C(/F)[C-]C(F)F</smiles>

(E)-1-[4-Methyl-2-(1H,1H,2H-perfluorododec-2-en-1-yl)phenyl]ethan-1-one (307cc): The general procedure $\mathbf{C}$ was followed using 1-(4-methylphenyl)- $N$-(3,4,5-trimethoxyphenyl)-1phenylethan-1-imine (340c) (150 mg, $0.50 \mathrm{mmol}$ ) and $1 \mathrm{H}, 1 \mathrm{H}, 2 \mathrm{H}$-perfluorododec-1-ene (301c) (820 mg, $1.50 \mathrm{mmol})$. Isolation by column chromatography ( $n$-hexane/EtOAc: $25 / 1)$ yielded 307cc $(210 \mathrm{mg}, 64 \%, E / Z=83: 17, \mathbf{3 0 7} \mathbf{c c / 3 3 9 c c}=94: 6)$ as a yellow oil.

${ }^{1} \mathrm{H}-\mathrm{NMR}\left(300 \mathrm{MHz}, \mathrm{CDCl}_{3}\right): \delta=7.75(\mathrm{~d}, J=8.0 \mathrm{~Hz}, 1 \mathrm{H}), 7.18(\mathrm{dd}, J=8.0,1.9 \mathrm{~Hz}, 1 \mathrm{H}), 7.08$ $(\mathrm{d}, J=1.9 \mathrm{~Hz}, 1 \mathrm{H}), 6.20(\mathrm{dt}, J=25.3,8.1 \mathrm{~Hz}, 0.83 \mathrm{H}, E), 5.95(\mathrm{dt}, J=33.9,4.4 \mathrm{~Hz}, 0.17 \mathrm{H}, Z)$, 3.84 (ddt, $J=7.3,4.1,2.1 \mathrm{~Hz}, 2 \mathrm{H}), 3.21-3.03$ (m, 0.12H, 339cc), 2.61 (s, 2.49H, E), 2.60 (s, $0.51 \mathrm{H}, \mathrm{Z}), 2.40$ (s, 3H).

${ }^{13} \mathrm{C}-\mathrm{NMR}\left(75 \mathrm{MHz}, \mathrm{CDCl}_{3}\right): \delta=200.4\left(\mathrm{C}_{\mathrm{q}}\right), 144.6\left(\mathrm{dt},{ }^{1} J_{\mathrm{C}-\mathrm{F}}=255.1 \mathrm{~Hz},{ }^{2} J_{\mathrm{C}-\mathrm{F}}=25.3 \mathrm{~Hz}, \mathrm{C}_{\mathrm{q}}\right)$, $143.2\left(\mathrm{C}_{\mathrm{q}}\right), 138.6\left(\mathrm{C}_{\mathrm{q}}\right), 133.6\left(\mathrm{C}_{\mathrm{q}}\right), 132.0(\mathrm{CH}), 130.7(\mathrm{CH}), 127.6(\mathrm{CH}), 119.7\left(\mathrm{dt},{ }^{1} J_{\mathrm{C}-\mathrm{F}}=\right.$ $\left.275.3 \mathrm{~Hz},{ }^{2} J_{\mathrm{C}-\mathrm{F}}=37.3 \mathrm{~Hz}, \mathrm{C}_{\mathrm{q}}\right), 119.1\left(\mathrm{~d},{ }^{2} J_{\mathrm{C}-\mathrm{F}}=9.8 \mathrm{~Hz}, \mathrm{CH}\right), 115.1\left(\mathrm{~m}, \mathrm{C}_{\mathrm{q}}\right), 111.6\left(\mathrm{~m}, \mathrm{C}_{\mathrm{q}}\right)$, $110.8\left(\mathrm{~m}, \mathrm{C}_{\mathrm{q}}\right), 110.7$ (m, $\left.\mathrm{C}_{\mathrm{q}}\right), 110.1$ (m, $\left.\mathrm{C}_{\mathrm{q}}\right), 108.6\left(\mathrm{~m}, \mathrm{C}_{\mathrm{q}}\right), 107.5\left(\mathrm{~m}, \mathrm{C}_{\mathrm{q}}\right), 107.1\left(\mathrm{~m}, \mathrm{C}_{\mathrm{q}}\right), 29.0$ $\left(\mathrm{CH}_{3}\right), 28.4\left(\mathrm{~m}, \mathrm{CH}_{2}\right), 21.2\left(\mathrm{CH}_{3}\right)$.

${ }^{19} \mathrm{~F}-\mathrm{NMR}\left(282 \mathrm{MHz}, \mathrm{CDCl}_{3}\right): \delta=-80.9(\mathrm{~m}),-114.5(\mathrm{~m}, E),-117.5(\mathrm{~m}, Z),-121.9(\mathrm{~m}),-122.8$ (m), $-123.0(\mathrm{~m}),-123.1(\mathrm{~m}),-123.4(\mathrm{~m}),-124.4(\mathrm{~m}),-126.3(\mathrm{~m}),-132.8(\mathrm{~m})$.

IR (ATR): 1700, 1355, 1249, 1210, 1195, 1100, 730, $695 \mathrm{~cm}^{-1}$.

MS (ESI) $m / z$ (relative intensity): $683\left([\mathrm{M}+\mathrm{Na}]^{+}, 100\right), 661\left([\mathrm{M}+\mathrm{H}]^{+}, 30\right)$.

HR-MS (ESI): $m / z$ calcd. for $\left[\mathrm{C}_{21} \mathrm{H}_{12} \mathrm{~F}_{20} \mathrm{O}+\mathrm{H}\right]^{+}$661.0642, found 661.0641 .<smiles>COc1ccc(C(C)=O)c(C/C=C(\F)C(F)(F)F)c1</smiles>

(E)-1-[4-Methoxy-2-(1H,1H,2H-perfluorododec-2-en-1-yl)phenyl]ethan-1-one $\quad(307 \mathrm{ec}):$ The general procedure $\mathbf{C}$ was followed using 1-[4-methoxy- $N$-(3,4,5-trimethoxyphenyl)-1phenylethan-1-imine (340e) (160 mg, $0.50 \mathrm{mmol}$ ) and 1H,1H,2H-perfluorododec-1-ene (301c) $(820 \mathrm{mg}, 1.50 \mathrm{mmol})$ Isolation by column chromatography ( $n$-hexane/EtOAc: $25 / 1)$ yielded 307ec $(203 \mathrm{mg}, 60 \%, E / Z=82: 18, \mathbf{3 0 7 e c / 3 3 9 e c}=98: 2)$ as a yellow solid. M.p.: $52{ }^{\circ} \mathrm{C}$. 
${ }^{1} \mathrm{H}-\mathrm{NMR}\left(500 \mathrm{MHz}, \mathrm{CDCl}_{3}\right): \delta=7.81(\mathrm{~d}, J=8.5 \mathrm{~Hz}, 1 \mathrm{H}), 6.81(\mathrm{dd}, J=8.5,2.7 \mathrm{~Hz}, 1 \mathrm{H}), 6.71$ $(\mathrm{d}, J=2.7 \mathrm{~Hz}, 1 \mathrm{H}), 6.16(\mathrm{dt}, J=27.5,7.8 \mathrm{~Hz}, 0.82 \mathrm{H}, E), 5.92(\mathrm{dt}, J=32.7,7.5 \mathrm{~Hz}, 0.18 \mathrm{H}, Z)$, 3.85 (ddt, $J=7.3,3.6,1.6 \mathrm{~Hz}, 2 \mathrm{H}), 3.82$ (s, 3H), 3.20-3.00 (m, 0.04H, 339ec), 2.55 (s, 2.46H, E), 2.54 (s, $0.54 \mathrm{H}, Z)$.

${ }^{13} \mathrm{C}-\mathrm{NMR}\left(125 \mathrm{MHz}, \mathrm{CDCl}_{3}\right): \delta=199.1\left(\mathrm{C}_{\mathrm{q}}\right), 162.4\left(\mathrm{C}_{\mathrm{q}}\right), 144.0\left(\mathrm{dt},{ }^{1} J_{\mathrm{C}-\mathrm{F}}=235.3 \mathrm{~Hz},{ }^{2} J_{\mathrm{C}-\mathrm{F}}=\right.$ $\left.28.1 \mathrm{~Hz}, \mathrm{C}_{\mathrm{q}}\right), 141.4\left(\mathrm{C}_{\mathrm{q}}\right), 133.0(\mathrm{CH}), 128.7\left(\mathrm{C}_{\mathrm{q}}\right), 118.7\left(\mathrm{~d},{ }^{2} J_{\mathrm{C}-\mathrm{F}}=8.5 \mathrm{~Hz}, \mathrm{CH}\right), 117.5\left(\mathrm{dt},{ }^{1} J_{\mathrm{C}-}\right.$ $\left.\mathrm{F}=273.2 \mathrm{~Hz},{ }^{2} J_{\mathrm{C}-\mathrm{F}}=30.9 \mathrm{~Hz}, \mathrm{C}_{\mathrm{q}}\right), 117.0(\mathrm{CH}), 112.7\left(\mathrm{~m}, \mathrm{C}_{\mathrm{q}}\right), 112.6\left(\mathrm{~m}, \mathrm{C}_{\mathrm{q}}\right), 112.5\left(\mathrm{~m}, \mathrm{C}_{\mathrm{q}}\right)$, $111.5(\mathrm{CH}), 111.4\left(\mathrm{~m}, \mathrm{C}_{\mathrm{q}}\right), 110.8\left(\mathrm{~m}, \mathrm{C}_{\mathrm{q}}\right), 110.6\left(\mathrm{~m}, \mathrm{C}_{\mathrm{q}}\right), 110.1\left(\mathrm{~m}, \mathrm{C}_{\mathrm{q}}\right), 108.4\left(\mathrm{~m}, \mathrm{C}_{\mathrm{q}}\right), 55.2$ $\left(\mathrm{CH}_{3}\right), 28.9\left(\mathrm{~m}, \mathrm{CH}_{2}\right), 28.7\left(\mathrm{CH}_{3}\right)$.

${ }^{19} \mathrm{~F}-\mathrm{NMR}\left(282 \mathrm{MHz}, \mathrm{CDCl}_{3}\right): \delta=-80.8(\mathrm{~m}),-114.3(\mathrm{~m}, E),-117.4(\mathrm{~m}, Z),-121.8(\mathrm{~m}),-122.7$ (m), $-123.0(\mathrm{~m}),-123.1(\mathrm{~m}),-123.3(\mathrm{~m}),-124.0(\mathrm{~m}),-126.1(\mathrm{~m}),-132.5(\mathrm{~m})$.

IR (ATR): 1720, 1450, 1335, 1229, 1209, 1104, 720, $607 \mathrm{~cm}^{-1}$.

MS (ESI) $m / z$ (relative intensity): $699\left([\mathrm{M}+\mathrm{Na}]^{+}, 100\right), 677(80)$.

HR-MS (ESI): $m / z$ calcd. for $\left[\mathrm{C}_{21} \mathrm{H}_{12} \mathrm{~F}_{20} \mathrm{O}_{2}+\mathrm{H}\right]^{+}$677.0591, found 677.0584.<smiles>CC(=O)c1cc(C)ccc1C/C=C(/F)C(F)(F)F</smiles>

(E)-1-[5-Methyl-2-(1H,1H,2H-perfluorododec-2-en-1-yl)phenyl]ethan-1-one (307ic): The general procedure $\mathbf{C}$ was followed using 1-(3-methylphenyl)- $N$-(3,4,5-trimethoxyphenyl)-1phenylethan-1-imine (340i) (150 mg, $0.50 \mathrm{mmol}$ ) and $1 \mathrm{H}, 1 \mathrm{H}, 2 \mathrm{H}$-perfluorododec-1-ene (301c) (820 mg, $1.50 \mathrm{mmol})$. Isolation by column chromatography ( $n$-hexane/EtOAc: $25 / 1$ ) yielded 307ic $(201 \mathrm{mg}, 61 \%, E / Z=73: 27, \mathbf{3 0 7 i c / 3 3 9 i c}=87: 13)$ as a yellow oil.

${ }^{1} \mathrm{H}-\mathrm{NMR}\left(300 \mathrm{MHz}, \mathrm{CDCl}_{3}\right): \delta=7.61(\mathrm{~d}, J=2.5 \mathrm{~Hz}, 1 \mathrm{H}), 7.31(\mathrm{dd}, 8.0,2.5 \mathrm{~Hz}, 1 \mathrm{H}), 7.16(\mathrm{~d}$, $J=8.0 \mathrm{~Hz}, 1 \mathrm{H}), 6.18(\mathrm{dt}, J=25.4,6.3,0.73 \mathrm{H}, E), 5.93(\mathrm{dt}, J=33.4,4.2 \mathrm{~Hz}, 0.27 \mathrm{H}, Z), 3.79$ (ddt, $J=7.7,4.2,2.2 \mathrm{~Hz}, 2 \mathrm{H}), 3.22-2.97$ (m, 0.27H, 339ic), 2.62 (s, 2.19H, E), $2.61(\mathrm{~s}, 0.81 \mathrm{H}$, Z), $2.42(\mathrm{~s}, 3 \mathrm{H})$.

${ }^{13} \mathrm{C}-\mathrm{NMR}\left(75 \mathrm{MHz}, \mathrm{CDCl}_{3}\right): \delta=201.2\left(\mathrm{C}_{\mathrm{q}}\right), 144.2\left(\mathrm{dt},{ }^{1} J_{\mathrm{C}-\mathrm{F}}=255.3 \mathrm{~Hz},{ }^{2} J_{\mathrm{C}-\mathrm{F}}=28.1 \mathrm{~Hz}, \mathrm{C}_{\mathrm{q}}\right)$, $136.8\left(\mathrm{C}_{\mathrm{q}}\right), 136.6\left(\mathrm{C}_{\mathrm{q}}\right), 135.1\left(\mathrm{C}_{\mathrm{q}}\right), 133.0(\mathrm{CH}), 131.1(\mathrm{CH}), 130.7(\mathrm{CH}), 119.6\left(\mathrm{dt},{ }^{1} J_{\mathrm{C}-\mathrm{F}}=\right.$ $\left.288.2 \mathrm{~Hz},{ }^{2} J_{\mathrm{C}-\mathrm{F}}=34.1 \mathrm{~Hz}, \mathrm{C}_{\mathrm{q}}\right), 119.2\left(\mathrm{~d},{ }^{2} J_{\mathrm{C}-\mathrm{F}}=7.5 \mathrm{~Hz}, \mathrm{CH}\right), 115.1\left(\mathrm{~m}, \mathrm{C}_{\mathrm{q}}\right), 112.1\left(\mathrm{~m}, \mathrm{C}_{\mathrm{q}}\right)$, $111.6\left(\mathrm{~m}, \mathrm{C}_{\mathrm{q}}\right), 111.2\left(\mathrm{~m}, \mathrm{C}_{\mathrm{q}}\right), 110.7\left(\mathrm{~m}, \mathrm{C}_{\mathrm{q}}\right), 110.1\left(\mathrm{~m}, \mathrm{C}_{\mathrm{q}}\right), 108.1\left(\mathrm{~m}, \mathrm{C}_{\mathrm{q}}\right), 107.5\left(\mathrm{~m}, \mathrm{C}_{\mathrm{q}}\right), 29.2$ $\left(\mathrm{CH}_{3}\right), 27.9\left(\mathrm{~m}, \mathrm{CH}_{2}\right), 20.9\left(\mathrm{CH}_{3}\right)$.

${ }^{19} \mathrm{~F}-\mathrm{NMR}\left(282 \mathrm{MHz}, \mathrm{CDCl}_{3}\right): \delta=-80.9(\mathrm{~m}),-114.5(\mathrm{~m}, E),-117.5(\mathrm{~m}, Z),-121.9(\mathrm{~m}),-122.8$ (m), $-123.0(\mathrm{~m}),-123.1(\mathrm{~m}),-123.4(\mathrm{~m}),-124.4(\mathrm{~m}),-126.3(\mathrm{~m}),-132.8(\mathrm{~m})$. 
IR (ATR): 1712, 1355, 1243, 1223, 1155, 1130, 725, $695 \mathrm{~cm}^{-1}$.

MS (ESI) $m / z$ (relative intensity): $683\left([\mathrm{M}+\mathrm{Na}]^{+}, 100\right), 661\left([\mathrm{M}+\mathrm{H}]^{+}, 20\right)$.

HR-MS (ESI): $m / z$ calcd. for $\left[\mathrm{C}_{21} \mathrm{H}_{12} \mathrm{~F}_{20} \mathrm{O}+\mathrm{H}\right]^{+} 661.0642$, found 661.0639 .<smiles>CC(=O)c1ccc(-c2ccccc2)cc1C/C=C(/F)C(F)(F)F</smiles>

(E)-1-[4-Phenyl-2-(1H,1H,2H-perfluorododec-2-en-1-yl)phenyl]ethan-1-one (307dc): The general procedure $\mathbf{C}$ was followed using 1-([1,1'-biphenyl]-4-yl)- $N$-(3,5-dimethoxy-4methylphenyl)ethan-1-imine (340d) (188 mg, $0.50 \mathrm{mmol})$ and $1 H, 1 H, 2 H$-perfluorododec-1ene (301c) ( $820 \mathrm{mg}, 1.50 \mathrm{mmol}$ ). Isolation by column chromatography ( $n$-hexane/EtOAc: 25/1) yielded 307dc $(202 \mathrm{mg}, 56 \%, E / Z=82: 18,307 \mathbf{d c} / 339 d \mathbf{d}=98: 2)$ as a yellow solid. M.p.: $67{ }^{\circ} \mathrm{C}$.

${ }^{1} \mathrm{H}-\mathrm{NMR}\left(300 \mathrm{MHz}, \mathrm{CDCl}_{3}\right): \delta=7.92(\mathrm{~d}, J=8.1 \mathrm{~Hz}, 1 \mathrm{H}), 7.66-7.58(\mathrm{~m}, 3 \mathrm{H}), 7.55-7.43(\mathrm{~m}$, $4 \mathrm{H}), 6.25(\mathrm{dt}, J=23.5,8.2 \mathrm{~Hz}, 0.82 \mathrm{H}, E), 6.02(\mathrm{dt}, J=33.7,7.8 \mathrm{~Hz}, 0.18 \mathrm{H}, Z), 3.90$ (ddt, $J=$ 8.5, 4.1, 2.0 Hz, 2H), 3.27-3.15 (m, 0.02H, 339dc), 2.68 (s, 2.46H, E), 2.67 (s, 0.54H, Z).

${ }^{13} \mathrm{C}-\mathrm{NMR}\left(75 \mathrm{MHz}, \mathrm{CDCl}_{3}\right): \delta=200.5\left(\mathrm{C}_{\mathrm{q}}\right), 145.2\left(\mathrm{dt},{ }^{1} J_{\mathrm{C}-\mathrm{F}}=251.3 \mathrm{~Hz},{ }^{2} J_{\mathrm{C}-\mathrm{F}}=29.4 \mathrm{~Hz}, \mathrm{C}_{\mathrm{q}}\right)$, $144.4\left(\mathrm{C}_{\mathrm{q}}\right), 139.4\left(\mathrm{C}_{\mathrm{q}}\right), 139.1\left(\mathrm{C}_{\mathrm{q}}\right), 134.9\left(\mathrm{C}_{\mathrm{q}}\right), 131.1(\mathrm{CH}), 130.2(\mathrm{CH}), 130.0(\mathrm{CH}), 128.9$ $(\mathrm{CH}), 128.3(\mathrm{CH}), 127.2(\mathrm{CH}), 125.6(\mathrm{CH}), 119.0\left(\mathrm{~d},{ }^{2} J_{\mathrm{C}-\mathrm{F}}=8.1 \mathrm{~Hz}, \mathrm{CH}\right), 118.1\left(\mathrm{dt},{ }^{1} J_{\mathrm{C}-\mathrm{F}}=\right.$ $\left.288.2 \mathrm{~Hz},{ }^{2} J_{\mathrm{C}-\mathrm{F}}=32.3 \mathrm{~Hz}, \mathrm{C}_{\mathrm{q}}\right), 115.2\left(\mathrm{~m}, \mathrm{C}_{\mathrm{q}}\right), 114.4\left(\mathrm{~m}, \mathrm{C}_{\mathrm{q}}\right), 114.1\left(\mathrm{~m}, \mathrm{C}_{\mathrm{q}}\right), 111.6\left(\mathrm{~m}, \mathrm{C}_{\mathrm{q}}\right)$, $110.8\left(\mathrm{~m}, \mathrm{C}_{\mathrm{q}}\right), 110.1\left(\mathrm{~m}, \mathrm{C}_{\mathrm{q}}\right), 107.6\left(\mathrm{~m}, \mathrm{C}_{\mathrm{q}}\right), 107.1\left(\mathrm{~m}, \mathrm{C}_{\mathrm{q}}\right), 29.1\left(\mathrm{CH}_{3}\right), 28.7\left(\mathrm{~m}, \mathrm{CH}_{2}\right)$.

${ }^{19} \mathrm{~F}-\mathrm{NMR}\left(282 \mathrm{MHz}, \mathrm{CDCl}_{3}\right): \delta=-80.8(\mathrm{~m}),-114.4(\mathrm{~m}, E),-117.4(\mathrm{~m}, Z),-121.9(\mathrm{~m}),-122.7$ (m), $-123.0(\mathrm{~m}),-123.3(\mathrm{~m}),-123.4(\mathrm{~m}),-123.7(\mathrm{~m}),-126.1(\mathrm{~m}),-132.5(\mathrm{~m})$.

IR (ATR): 1693, 1370, 1265, 1230, 1179, 1121, 710, $630 \mathrm{~cm}^{-1}$.

MS (ESI) $m / z$ (relative intensity): $745\left([\mathrm{M}+\mathrm{Na}]^{+}, 100\right), 740(30), 723\left([\mathrm{M}+\mathrm{H}]^{+}, 20\right)$.

HR-MS (ESI): $m / z$ calcd. for $\left[\mathrm{C}_{26} \mathrm{H}_{14} \mathrm{~F}_{20} \mathrm{O}+\mathrm{H}\right]^{+} 723.0798$, found 723.0786 .<smiles>CC(=O)c1ccc(C(F)(F)F)cc1C/C=C(/F)C(F)F</smiles>

(E)-1-[4-Trifluoromethyl-2-(1H,1H,2H-perfluorodec-2-en-1-yl)phenyl]ethan-1-one

(307fc): The general procedure $\mathbf{C}$ was followed using 1-[4-trifluoromethyl- $N-(3,4,5-$ trimethoxyphenyl)-1-phenyl]ethan-1-one (340f) (177 mg, $0.50 \mathrm{mmol})$ and $1 \mathrm{H}, 1 \mathrm{H}, 2 \mathrm{H}$ - 
perfluorododec-1-ene (301c) $(820 \mathrm{mg}, 1.50 \mathrm{mmol})$. Isolation by column chromatography ( $n$ hexane/EtOAc: 25/1) yielded $\mathbf{3 0 7 f c}(193 \mathrm{mg}, 54 \%, E / Z=73: 27)$ as a yellow oil.

${ }^{1} \mathrm{H}-\mathrm{NMR}\left(300 \mathrm{MHz}, \mathrm{CDCl}_{3}\right): \delta=7.87(\mathrm{~d}, J=8.0 \mathrm{~Hz}, 1 \mathrm{H}), 7.64(\mathrm{dd}, J=8.0,1.4 \mathrm{~Hz}, 1 \mathrm{H}), 7.52$ $(\mathrm{d}, J=1.4 \mathrm{~Hz}, 1 \mathrm{H}), 6.10(\mathrm{dt}, J=25.6,8.5 \mathrm{~Hz}, 0.73 \mathrm{H}, E), 5.87(\mathrm{dt}, J=33.4,7.8 \mathrm{~Hz}, 0.27 \mathrm{H}, Z)$, 3.86 (ddt, $J=7.5,4.0,2.0 \mathrm{~Hz}, 2 \mathrm{H}), 2.65$ (s, 2.19H, E), 2.64 (s, $0.81 \mathrm{H}, Z$ ).

${ }^{13} \mathrm{C}-\mathrm{NMR}\left(100 \mathrm{MHz}, \mathrm{CDCl}_{3}\right): \delta=200.4\left(\mathrm{C}_{\mathrm{q}}\right), 145.1\left(\mathrm{dt},{ }^{1} J_{\mathrm{C}-\mathrm{F}}=261.2 \mathrm{~Hz},{ }^{2} J_{\mathrm{C}-\mathrm{F}}=29.5 \mathrm{~Hz}, \mathrm{C}_{\mathrm{q}}\right)$, $139.9\left(\mathrm{C}_{\mathrm{q}}\right), 138.9(\mathrm{CH}), 133.9\left(\mathrm{q},{ }^{2} J_{\mathrm{C}-\mathrm{F}}=33.1 \mathrm{~Hz}, \mathrm{C}_{\mathrm{q}}\right), 130.0(\mathrm{CH}), 127.9\left(\mathrm{q},{ }^{3} J_{\mathrm{C}-\mathrm{F}}=3.8 \mathrm{~Hz}\right.$, $\mathrm{CH}), 125.0\left(\mathrm{~d},{ }^{1} J_{\mathrm{C}-\mathrm{F}}=273.5 \mathrm{~Hz}, \mathrm{C}_{\mathrm{q}}\right), 124.1\left(\mathrm{~d},{ }^{2} J_{\mathrm{C}-\mathrm{F}}=7.3 \mathrm{~Hz}, \mathrm{C}_{\mathrm{q}}\right), 117.5\left(\mathrm{dt},{ }^{1} J_{\mathrm{C}-\mathrm{F}}=275.2 \mathrm{~Hz}\right.$, $\left.{ }^{2} J_{\mathrm{C}-\mathrm{F}}=22.3 \mathrm{~Hz}, \mathrm{C}_{\mathrm{q}}\right), 116.9\left(\mathrm{~d},{ }^{2} J_{\mathrm{C}-\mathrm{F}}=7.8 \mathrm{~Hz}, \mathrm{CH}\right), 114.1\left(\mathrm{~m}, \mathrm{C}_{\mathrm{q}}\right), 113.2\left(\mathrm{~m}, \mathrm{C}_{\mathrm{q}}\right), 111.6(\mathrm{~m}$, $\left.\mathrm{C}_{\mathrm{q}}\right), 110.8\left(\mathrm{~m}, \mathrm{C}_{\mathrm{q}}\right), 110.5\left(\mathrm{~m}, \mathrm{C}_{\mathrm{q}}\right), 110.2\left(\mathrm{~m}, \mathrm{C}_{\mathrm{q}}\right), 108.7\left(\mathrm{~m}, \mathrm{C}_{\mathrm{q}}\right), 108.6\left(\mathrm{~m}, \mathrm{C}_{\mathrm{q}}\right), 29.4\left(\mathrm{CH}_{3}\right), 28.1$ (m, $\left.\mathrm{CH}_{2}\right)$.

${ }^{19} \mathrm{~F}-\mathrm{NMR}\left(376 \mathrm{MHz}, \mathrm{CDCl}_{3}\right): \delta=-63.6(\mathrm{~m}),-81.0(\mathrm{~m}),-114.6(\mathrm{~m}, E),-117.6(\mathrm{~m}, Z),-121.9$ (m), -122.0 (m), -122.3 (m), -122.5 (m), -123.2 (m), -123.4 (m), -126.3 (m), -130.7 (m). IR (ATR): 1712, 1412, 1238, 1212, 1155, 1114, 711, $601 \mathrm{~cm}^{-1}$. MS (ESI) $m / z$ (relative intensity): 737 ([M + Na $\left.]^{+}, 100\right), 722(20)$. HR-MS (ESI): $m / z$ calcd. for $\left[\mathrm{C}_{21} \mathrm{H}_{9} \mathrm{~F}_{23} \mathrm{O}+\mathrm{Na}\right]^{+} 737.0178$, found 737.0170 .<smiles>CC(=O)c1ccc(Cl)cc1C/C=C(/F)[18F]</smiles>

(E)-1-[4-Chloro-2-(1H,1H,2H-perfluorododec-2-en-1-yl)phenyl]ethan-1-one (307ha): The general procedure $\mathbf{C}$ was followed using 1-(4-chlorophenyl)- $N$-(3,4,5-trimethoxyphenyl)-1phenylethan-1-imine (340h) (160 mg, $0.50 \mathrm{mmol})$ and $1 \mathrm{H}, 1 \mathrm{H}, 2 \mathrm{H}$-perfluorododec-1-ene (301c) $(820 \mathrm{mg}, 1.50 \mathrm{mmol})$. Isolation by column chromatography ( $n$-hexane/EtOAc: $25 / 1$ ) yielded 307ha (204 mg, 60\%, $E / Z=76: 24$, 307ha/339ha $=99: 1)$ as a yellow oil.

${ }^{1} \mathrm{H}-\mathrm{NMR}\left(300 \mathrm{MHz}, \mathrm{CDCl}_{3}\right): \delta=7.76(\mathrm{~d}, J=8.4 \mathrm{~Hz}, 1 \mathrm{H}), 7.37(\mathrm{dd}, J=8.4,1.6 \mathrm{~Hz}, 1 \mathrm{H}), 7.22$ (d, 1.6 Hz, 1H), 6.14 (dt, $J=24.7,8.7 \mathrm{~Hz}, 0.76 \mathrm{H}, E), 5.92$ (dt, $J=35.4,7.8 \mathrm{~Hz}, 0.24 \mathrm{H}, Z$ ), 3.86 (ddt, $J=7.8,4.1,2.0 \mathrm{~Hz}, 2 \mathrm{H}), 3.26-3.03$ (m, 0.02H, 339ha), 2.62 (s, 2.28H, E), 2.61 (s, 0.72H, $Z)$.

${ }^{13} \mathrm{C}-\mathrm{NMR}\left(75 \mathrm{MHz}, \mathrm{CDCl}_{3}\right): \delta=199.7\left(\mathrm{C}_{\mathrm{q}}\right), 144.5\left(\mathrm{dt},{ }^{1} J_{\mathrm{C}-\mathrm{F}}=259.1 \mathrm{~Hz},{ }^{2} J_{\mathrm{C}-\mathrm{F}}=28.4 \mathrm{~Hz}, \mathrm{C}_{\mathrm{q}}\right)$, $140.1\left(\mathrm{C}_{\mathrm{q}}\right), 138.5\left(\mathrm{C}_{\mathrm{q}}\right), 134.7\left(\mathrm{C}_{\mathrm{q}}\right), 131.5(\mathrm{CH}), 131.2(\mathrm{CH}), 127.2(\mathrm{CH}), 118.3\left(\mathrm{dt},{ }^{1} J_{\mathrm{C}-\mathrm{F}}=\right.$ $\left.288.3 \mathrm{~Hz},{ }^{2} J_{\mathrm{C}-\mathrm{F}}=32.3 \mathrm{~Hz}, \mathrm{C}_{\mathrm{q}}\right), 118.0\left(\mathrm{~d},{ }^{2} J_{\mathrm{C}-\mathrm{F}}=8.9 \mathrm{~Hz}, \mathrm{CH}\right), 114.5\left(\mathrm{C}_{\mathrm{q}}\right), 113.3\left(\mathrm{C}_{\mathrm{q}}\right), 112.1$ $\left(\mathrm{C}_{\mathrm{q}}\right), 111.5\left(\mathrm{C}_{\mathrm{q}}\right), 111.1\left(\mathrm{C}_{\mathrm{q}}\right), 110.5\left(\mathrm{C}_{\mathrm{q}}\right), 108.0\left(\mathrm{C}_{\mathrm{q}}\right), 107.1\left(\mathrm{C}_{\mathrm{q}}\right), 29.1\left(\mathrm{CH}_{3}\right), 28.1\left(\mathrm{~m}, \mathrm{CH}_{2}\right)$. 
${ }^{19} \mathrm{~F}-\mathrm{NMR}\left(282 \mathrm{MHz}, \mathrm{CDCl}_{3}\right): \delta=-80.9(\mathrm{~m}),-114.5(\mathrm{~m}, E),-117.5(\mathrm{~m}, Z),-122.0(\mathrm{~m}),-122.8$ (m), -123.1 (m), -123.3 (m), -123.4 (m), -123.8 (m), -126.2 (m), -132.4 (m).

IR (ATR): 1699, 1379, 1269, 1232, 1181, 1123, 711, $630 \mathrm{~cm}^{-1}$.

MS (ESI) $m / z$ (relative intensity): 703 ([M + Na $\left.]^{+}, 100\right), 698$ (10), 685 (20).

HR-MS (ESI): $m / z$ calcd. for $\left[\mathrm{C}_{20} \mathrm{H}_{9} \mathrm{ClF}_{20} \mathrm{O}+\mathrm{Na}\right]^{+} 702.9915$, found 702.9905 .<smiles>CC(=O)c1ccccc1C/C=C(/F)C(F)F</smiles>

(E)-1-[2-(1H,1H,2H-Perfluorohex-2-en-1-yl)phenyl]ethan-1-one (307ab): The general procedure $\mathbf{C}$ was followed using $N$-(3,4,5-trimethoxyphenyl)-1-phenylethan-1-imine (340a) (143 mg, $0.50 \mathrm{mmol})$ and 1H,1H,2H-perfluorohex-2-en-1-yl (301b) (370 mg, $1.50 \mathrm{mmol})$. Isolation by column chromatography ( $n$-hexane/EtOAc: $25 / 1$ ) yielded 307ab ( $83 \mathrm{mg}, 48 \%, E / Z$ $=89: 11, \mathbf{3 0 7} \mathbf{a b} / \mathbf{3 3 9} \mathbf{a b}=91: 9)$ as a yellow oil.

${ }^{1} \mathrm{H}-\mathrm{NMR}\left(300 \mathrm{MHz}, \mathrm{CDCl}_{3}\right): \delta=7.82(\mathrm{dd}, J=7.5,1.6 \mathrm{~Hz}, 1 \mathrm{H}), 7.50(\mathrm{ddd}, J=7.7,7.5,1.6 \mathrm{~Hz}$, $1 \mathrm{H}), 7.39$ (ddd, $J=7.7,7.6,1.6 \mathrm{~Hz}, 1 \mathrm{H}), 7.27$ (dd, 7.6, 1.6 Hz, 1H), 6.18 (dt, $J=23.1,8.3 \mathrm{~Hz}$, $0.89 \mathrm{H}, E), 5.95(\mathrm{dt}, J=33.8,7.8 \mathrm{~Hz}, 0.11 \mathrm{H}, Z), 3.80(\mathrm{ddt}, J=7.8,4.0,2.0 \mathrm{~Hz}, 2 \mathrm{H}), 3.20-3.10$ (m, 0.18H, 339ab), 2.64 (s, 2.67H, E), 2.64 (s, 0.33H, Z).

${ }^{13} \mathrm{C}-\mathrm{NMR}\left(75 \mathrm{MHz}, \mathrm{CDCl}_{3}\right): \delta=201.1\left(\mathrm{C}_{\mathrm{q}}\right), 141.5\left(\mathrm{dt},{ }^{1} J_{\mathrm{C}-\mathrm{F}}=259.2 \mathrm{~Hz},{ }^{2} J_{\mathrm{C}-\mathrm{F}}=28.4 \mathrm{~Hz}, \mathrm{C}_{\mathrm{q}}\right)$, $138.2\left(\mathrm{C}_{\mathrm{q}}\right), 136.6\left(\mathrm{C}_{\mathrm{q}}\right), 132.4(\mathrm{CH}), 131.2(\mathrm{CH}), 130.2(\mathrm{CH}), 127.1(\mathrm{CH}), 119.3\left(\mathrm{dt},{ }^{1} J_{\mathrm{C}-\mathrm{F}}=\right.$ $\left.288.1 \mathrm{~Hz},{ }^{2} J_{\mathrm{C}-\mathrm{F}}=32.3 \mathrm{~Hz}, \mathrm{C}_{\mathrm{q}}\right), 118.3\left(\mathrm{~d},{ }^{2} J_{\mathrm{C}-\mathrm{F}}=8.9 \mathrm{~Hz}, \mathrm{CH}\right), 115.8\left(\mathrm{~m}, \mathrm{C}_{\mathrm{q}}\right), 111.1\left(\mathrm{~m}, \mathrm{C}_{\mathrm{q}}\right)$, $29.3\left(\mathrm{CH}_{3}\right), 28.3\left(\mathrm{~m}, \mathrm{CH}_{2}\right)$.

${ }^{19} \mathrm{~F}-\mathrm{NMR}\left(282 \mathrm{MHz}, \mathrm{CDCl}_{3}\right): \delta=-80.7(\mathrm{~m}),-115.4(\mathrm{~m}, E),-118.5(\mathrm{~m}, Z),-124.1(\mathrm{~m}, E),-$ $127.8(\mathrm{~m}, Z),-132.6(\mathrm{~m})$.

IR (ATR): 1709, 1425, 1255, 1232, 1189, 1104, 781, $651 \mathrm{~cm}^{-1}$.

MS (ESI) $m / z$ (relative intensity): $381\left([\mathrm{M}+\mathrm{Na}]^{+}, 100\right), 369(80)$.

HR-MS (ESI): $m / z$ calcd. for $\left[\mathrm{C}_{14} \mathrm{H}_{10} \mathrm{~F}_{8} \mathrm{O}+\mathrm{Na}\right]^{+} 369.0496$, found 369.0497 .<smiles>CC(=O)c1ccc(C)cc1CC=C(F)C(F)(F)C(F)(F)C(F)(F)F</smiles>

(E)-1-[4-Methyl-2-(1H,1H,2H-perfluorohex-2-en-1-yl)phenyl]ethan-1-one (307cb): The general procedure $\mathbf{C}$ was followed using 1-(4-methylphenyl)- $N$-(3,4,5-trimethoxyphenyl)-1phenylethan-1-imine (340c) $(150 \mathrm{mg}, 0.50 \mathrm{mmol})$ and $1 H, 1 H, 2 H$-perfluorohex-2-en-1-yl 
(301b) (370 mg, $1.50 \mathrm{mmol}$ ). Isolation by column chromatography ( $n$-hexane/EtOAc: 25/1) yielded 307cb $(88 \mathrm{mg}, 49 \%, E / Z=81: 19, \mathbf{3 0 7} \mathbf{c b} / \mathbf{3 3 9} \mathbf{c b}=99: 1)$ as a yellow oil.

${ }^{1} \mathrm{H}-\mathrm{NMR}\left(300 \mathrm{MHz}, \mathrm{CDCl}_{3}\right): \delta=7.75(\mathrm{dd}, J=1.8 \mathrm{~Hz}, 0.8 \mathrm{~Hz}, 1 \mathrm{H}), 7.19$ (dd, $J=8.0,1.8 \mathrm{~Hz}$, 1H), 7.17 (dd, 8.0, 0.8 Hz, 1H), 6.18 (dt, $J=23.3,8.3 \mathrm{~Hz}, 0.81 \mathrm{H}, E), 5.95$ (dt, $J=32.9,7.8 \mathrm{~Hz}$, $0.19 \mathrm{H}, Z$ ), 3.83 (ddt, $J=8.4,4.8,2.2 \mathrm{~Hz}, 2 \mathrm{H}), 3.30-3.15$ (m, 0.02H, 339cb), 2.62 (s, 2.43H, E), $2.61(\mathrm{~s}, 0.57 \mathrm{H}, Z), 2.40(\mathrm{~s}, 3 \mathrm{H})$.

${ }^{13} \mathrm{C}-\mathrm{NMR}\left(75 \mathrm{MHz}, \mathrm{CDCl}_{3}\right): \delta=200.5\left(\mathrm{C}_{\mathrm{q}}\right), 144.2\left(\mathrm{dt},{ }^{1} J_{\mathrm{C}-\mathrm{F}}=259.1 \mathrm{~Hz},{ }^{2} J_{\mathrm{C}-\mathrm{F}}=28.4 \mathrm{~Hz}, \mathrm{C}_{\mathrm{q}}\right)$, $143.2\left(\mathrm{C}_{\mathrm{q}}\right), 138.6\left(\mathrm{C}_{\mathrm{q}}\right), 133.6\left(\mathrm{C}_{\mathrm{q}}\right), 132.1(\mathrm{CH}), 130.7(\mathrm{CH}), 127.6(\mathrm{CH}), 119.1\left(\mathrm{dt},{ }^{1} J_{\mathrm{C}-\mathrm{F}}=\right.$ $\left.288.3 \mathrm{~Hz},{ }^{2} J_{\mathrm{C}-\mathrm{F}}=32.3 \mathrm{~Hz}, \mathrm{C}_{\mathrm{q}}\right), 118.3\left(\mathrm{~d},{ }^{2} J_{\mathrm{C}-\mathrm{F}}=8.7 \mathrm{~Hz}, \mathrm{CH}\right), 112.8\left(\mathrm{~m}, \mathrm{C}_{\mathrm{q}}\right), 108.3\left(\mathrm{~m}, \mathrm{C}_{\mathrm{q}}\right)$, $29.0\left(\mathrm{CH}_{3}\right), 28.4\left(\mathrm{~m}, \mathrm{CH}_{2}\right), 21.3\left(\mathrm{CH}_{3}\right)$.

${ }^{19} \mathrm{~F}-\mathrm{NMR}\left(282 \mathrm{MHz}, \mathrm{CDCl}_{3}\right): \delta=-80.7(\mathrm{~m}),-115.4(\mathrm{~m}, E),-118.4(\mathrm{~m}, Z),-124.5(\mathrm{~m}, E),-$ $127.8(\mathrm{~m}, Z),-133.0(\mathrm{~m})$.

IR (ATR): 1720, 1470, 1267, 1232, 1189, 1131, 711, $630 \mathrm{~cm}^{-1}$.

MS (ESI) $m / z$ (relative intensity): $383\left([\mathrm{M}+\mathrm{Na}]^{+}, 100\right), 333(10)$.

HR-MS (ESI): $m / z$ calcd. for $\left[\mathrm{C}_{15} \mathrm{H}_{12} \mathrm{~F}_{8} \mathrm{O}+\mathrm{H}\right]^{+} 361.0833$, found 361.0828 .<smiles>CC(=O)c1ccc(-c2ccccc2)cc1C/C=C(\F)C(F)F</smiles>

(E)-1-[4-Phenyl-2-(1H,1H,2H-perfluorohex-2-en-1-yl)phenyl]ethan-1-one (307db): The general procedure $\mathbf{C}$ was followed using 1-([1,1'-biphenyl]-4-yl)- $N$-(3,5-dimethoxy-4methylphenyl)ethan-1-imine (340d) (188 mg, $0.50 \mathrm{mmol})$ and $1 \mathrm{H}, 1 \mathrm{H}, 2 \mathrm{H}$-Perfluorohex-2-en1-yl (301b) (370 mg, $1.50 \mathrm{mmol}$ ). Isolation by column chromatography ( $n$-hexane/EtOAc: 25/1) yielded 307db (110 mg, 52\%, $E / Z=84: 16,307 \mathbf{d b} / 339 d b=99: 1)$ as a yellow oil.

${ }^{1} \mathrm{H}-\mathrm{NMR}\left(300 \mathrm{MHz}, \mathrm{CDCl}_{3}\right): \delta=7.90(\mathrm{~d}, J=8.1 \mathrm{~Hz}, 1 \mathrm{H}), 7.60-7.55(\mathrm{~m}, 3 \mathrm{H}), 7.52-7.40(\mathrm{~m}$, 4H), $6.23(\mathrm{dt}, J=23.1,8.4 \mathrm{~Hz}, 0.84 \mathrm{H}, E), 6.00$ (dt, $J=33.7,7.8 \mathrm{~Hz}, 0.16 \mathrm{H}, Z), 3.87$ (ddt, $J=$ 8.3, 4.2, 2.1 Hz, 2H), 3.23-3.12 (m, 0.02H, 339db), 2.65 (s, 2.52H, E), 2.66 (s, 0.48H, Z).

${ }^{13} \mathrm{C}-\mathrm{NMR}\left(75 \mathrm{MHz}, \mathrm{CDCl}_{3}\right): \delta=200.5\left(\mathrm{C}_{\mathrm{q}}\right), 145.2\left(\mathrm{dt},{ }^{1} J_{\mathrm{C}-\mathrm{F}}=259.9 \mathrm{~Hz},{ }^{2} J_{\mathrm{C}-\mathrm{F}}=28.4 \mathrm{~Hz}, \mathrm{C}_{\mathrm{q}}\right)$, $144.5\left(\mathrm{C}_{\mathrm{q}}\right), 139.4\left(\mathrm{C}_{\mathrm{q}}\right), 139.0\left(\mathrm{C}_{\mathrm{q}}\right), 134.9\left(\mathrm{C}_{\mathrm{q}}\right), 131.1(\mathrm{CH}), 130.2(\mathrm{CH}), 129.9(\mathrm{CH}), 129.0$ 
$(\mathrm{CH}), 128.4(\mathrm{CH}), 127.1(\mathrm{CH}), 125.6(\mathrm{CH}), 119.0\left(\mathrm{~d},{ }^{2} J_{\mathrm{C}-\mathrm{F}}=7.8 \mathrm{~Hz}, \mathrm{CH}\right), 117.4\left(\mathrm{dt},{ }^{1} J_{\mathrm{C}-\mathrm{F}}=\right.$ $\left.288.1 \mathrm{~Hz},{ }^{2} J_{\mathrm{C}-\mathrm{F}}=32.3 \mathrm{~Hz}, \mathrm{C}_{\mathrm{q}}\right), 111.5\left(\mathrm{~m}, \mathrm{C}_{\mathrm{q}}\right), 108.8\left(\mathrm{~m}, \mathrm{C}_{\mathrm{q}}\right), 29.2\left(\mathrm{CH}_{3}\right), 28.6\left(\mathrm{~m}, \mathrm{CH}_{2}\right)$.

${ }^{19} \mathrm{~F}-\mathrm{NMR}\left(282 \mathrm{MHz}, \mathrm{CDCl}_{3}\right): \delta=-80.6(\mathrm{~m}),-115.3(\mathrm{~m}, E),-118.4(\mathrm{~m}, Z),-124.0(\mathrm{~m}, E),-$ $127.7(\mathrm{~m}, Z),-132.4(\mathrm{~m})$.

IR (ATR): 1711, 1410, 1237, 1212, 1199, 1111, 701, $600 \mathrm{~cm}^{-1}$.

MS (ESI) $m / z$ (relative intensity): $445\left([\mathrm{M}+\mathrm{Na}]^{+}, 100\right), 423\left([\mathrm{M}+\mathrm{H}]^{+}, 20\right)$.

HR-MS (ESI): $m / z$ calcd. for $\left[\mathrm{C}_{20} \mathrm{H}_{14} \mathrm{~F}_{8} \mathrm{O}+\mathrm{H}\right]^{+} 423.0990$, found 423.0996 .<smiles>CC(=O)c1ccccc1CCC(F)F</smiles>

\section{1-(2-(3,3,4,4,5,5,6,6,7,7,8,8,9,9,10,10,10-heptadecafluorodecyl)phenyl)ethan-1-one} (339aa):

A suspension of ketimine $\mathbf{3 4 0 a}(0.50 \mathrm{mmol}, 1.0$ equiv), $1 H, 1 H, 2 H$-perfluoroalkene $301 \mathrm{a}$ (1.50 mmol, 3.0 equiv), [RuCl 2 (p-cymene) $]_{2} \quad(15.3 \mathrm{mg}, 5.0 \mathrm{~mol} \%), \mathrm{NaOAc}$ (12.3 mg, $30 \mathrm{~mol} \%)$ and $\mathrm{K}_{2} \mathrm{CO}_{3}(104 \mathrm{mg}, 0.75 \mathrm{mmol}, 1.50$ equiv) in 1,4-dioxane $(0.50 \mathrm{~mL}, 1 \mathrm{M})$ was stirred under nitrogen at $120^{\circ} \mathrm{C}$ for $16 \mathrm{~h}$. At ambient temperature, the reaction mixture was diluted with EtOAc $(5.0 \mathrm{~mL})$ and $\mathrm{HCl}(5.0 \mathrm{~mL}, 1 \mathrm{M})$ was added. The mixture was stirred for 3 $\mathrm{h}$ and extracted with EtOAc $(3 \times 10 \mathrm{~mL})$. After removal of the solvents in vacuo, the remaining residue was purified by column chromatography on silica gel to afford the desired product 339aa.

${ }^{1} \mathrm{H}-\mathrm{NMR}\left(300 \mathrm{MHz}, \mathrm{CDCl}_{3}\right): \delta=7.76(\mathrm{dd}, J=7.8,1.6 \mathrm{~Hz}, 1 \mathrm{H}), 7.44(\mathrm{ddd}, J=7.7,7.5,1.6 \mathrm{~Hz}$, $1 \mathrm{H}), 7.33(\mathrm{ddd}, J=7.8,7.5,1.6 \mathrm{~Hz}, 1 \mathrm{H}), 7.28(\mathrm{dd}, J=7.7,1.6 \mathrm{~Hz}, 1 \mathrm{H}), 3.38-2.77(\mathrm{~m}, 2 \mathrm{H})$, 2.59 (s, 3H), 2.56-2.24 (m, 2H).

${ }^{13} \mathrm{C}-\mathrm{NMR}\left(125 \mathrm{MHz}, \mathrm{CDCl}_{3}\right): \delta=201.0\left(\mathrm{C}_{\mathrm{q}}\right), 140.0\left(\mathrm{C}_{\mathrm{q}}\right), 137.0\left(\mathrm{C}_{\mathrm{q}}\right), 132.2(\mathrm{CH}), 131.8(\mathrm{CH})$, 130.1 (CH), $126.8(\mathrm{CH}), 121.0-108.2\left(\mathrm{~m},-\mathrm{C}_{8} \mathrm{~F}_{17}\right), 32.7\left(\mathrm{t},{ }^{2} J_{\mathrm{C}-\mathrm{F}}=22 \mathrm{~Hz}, \mathrm{CH}_{2}\right), 29.2\left(\mathrm{CH}_{3}\right)$, $25.7\left(\mathrm{t},{ }^{3} J_{\mathrm{C}-\mathrm{F}}=5 \mathrm{~Hz}, \mathrm{CH}_{2}\right)$.

${ }^{19} \mathrm{~F}-\mathrm{NMR}\left(282 \mathrm{MHz}, \mathrm{CDCl}_{3}\right): \delta=-80.9(\mathrm{~m}),-114.6(\mathrm{~m}),-121.7(\mathrm{~m}),-122.0(\mathrm{~m}),-122.8(\mathrm{~m})$, $-123.5(\mathrm{~m}),-126.1(\mathrm{~m}),-126.3(\mathrm{~m})$.

IR (ATR): 1701, 1419, 1257, 1233, 1155, 1121, 711, $610 \mathrm{~cm}^{-1}$.

MS (ESI) m/z (relative intensity): $589\left([\mathrm{M}+\mathrm{Na}]^{+}, 100\right), 584$ (10), 569 (40).

HR-MS (ESI): m/z calcd. for $\left[\mathrm{C}_{18} \mathrm{H}_{11} \mathrm{~F}_{17} \mathrm{O}+\mathrm{Na}\right]+589.0431$, found 589.0432 . 


\subsubsection{Mechanistic Studies}

\subsubsection{Intermolecular competition experiment}

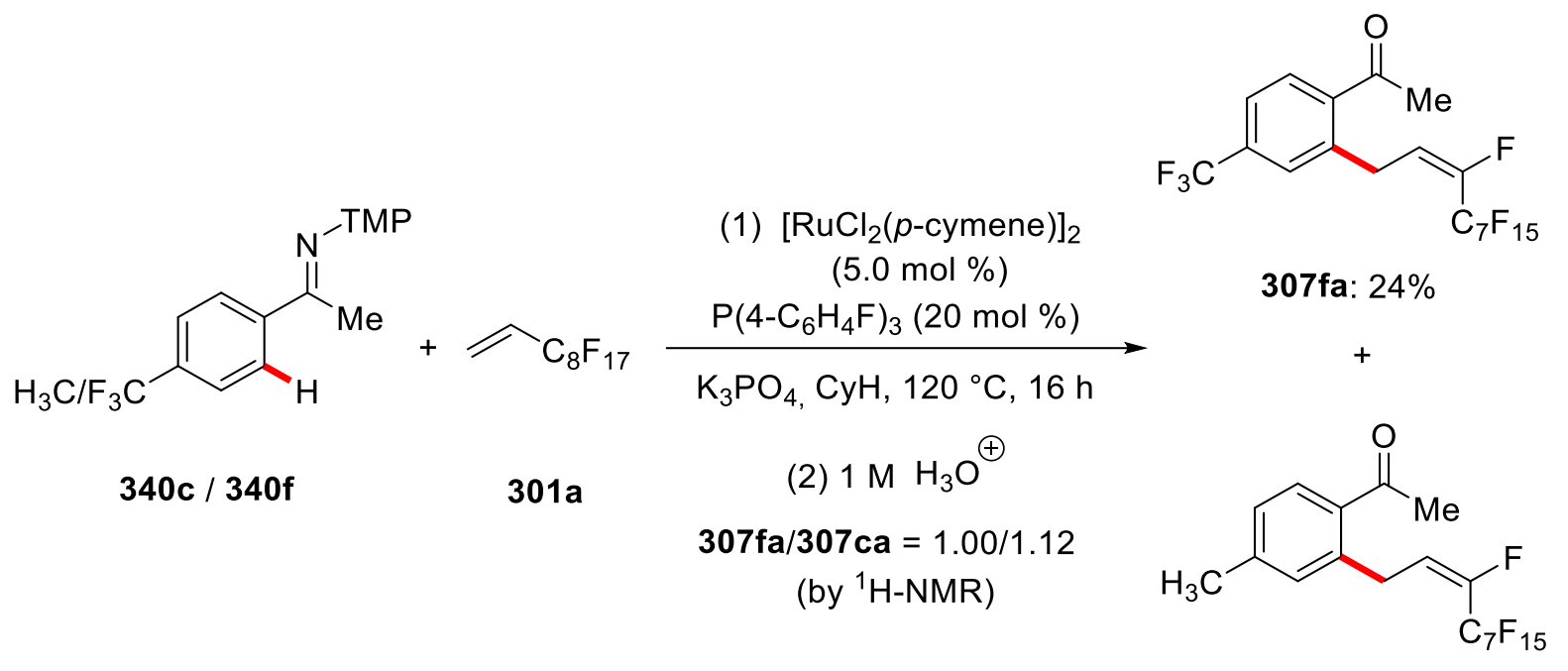

307ca: $28 \%$

1-(4-methylphenyl)- $N$-(3,4,5-trimethoxyphenyl)-1-phenylethan-1-imine (340c) $(150 \mathrm{mg}, 0.50$ mmol), 1-[4-trifluoromethyl- $N$-(3,4,5-trimethoxyphenyl)-1-phenyl]ethan-1-one (340f) (177 $\mathrm{mg}, 0.50 \mathrm{mmol}), 1 H, 1 H, 2 H$-perfluoroalkene (301a) $(446 \mathrm{mg}, 1.0 \mathrm{mmol}),\left[\mathrm{RuCl}_{2}(p \text {-cymene) }]_{2}\right.$ (15.3 mg, $5.0 \mathrm{~mol} \%), \mathrm{P}\left(4-\mathrm{C}_{6} \mathrm{H}_{4} \mathrm{~F}\right)_{3}(31.6 \mathrm{mg}, 20 \mathrm{~mol} \%)$ and $\mathrm{K}_{3} \mathrm{PO}_{4}(212 \mathrm{mg}, 1.0 \mathrm{mmol})$ were stirred in cyclohexane $(1.0 \mathrm{~mL})$ at $120{ }^{\circ} \mathrm{C}$ for $16 \mathrm{~h}$. At ambient temperature, the reaction mixture was diluted with EtOAc $(10.0 \mathrm{~mL})$, and $\mathrm{HCl}(5 \mathrm{~mL}, 1 \mathrm{M})$ was added. The mixture was stirred for $3 \mathrm{~h}$ and extracted with EtOAc $(3 \times 10.0 \mathrm{~mL})$. After removal of the solvents in vacuo, 307fa and 307ca were isolated together by column chromatography on silica gel. The ratio of 307fa and 307ca was determined by means of ${ }^{1} \mathrm{H}-\mathrm{NMR}$ spectroscopy which corresponds to 307fa $24 \%$ and 307ca $28 \%$. 


\subsubsection{H/D Exchange Experiments}<smiles>CC(=NN)c1ccccc1</smiles>

$340 a$
1) $\left[\mathrm{RuCl}_{2}(p \text {-cymene })\right]_{2}(5.0 \mathrm{~mol} \%)$<smiles>C=C[Se-]</smiles>

$301 a$

$$
\underset{\mathrm{K}_{3} \mathrm{PO}_{4}, \mathrm{CyH}, 120{ }^{\circ} \mathrm{C}, 16 \mathrm{~h}}{\mathrm{P}\left(4-\mathrm{C}_{6} \mathrm{H}_{4} \mathrm{~F}\right)_{3}(20 \mathrm{~mol} \%)}
$$$$
\mathrm{D}_{2} \mathrm{O} \text { (5 equiv) }
$$

2) $1 \mathrm{M} \mathrm{H}_{3} \mathrm{O}^{\oplus}$
$38 \%$<smiles>CC(=O)c1c([18OH])cccc1C/C=C(\F)C(F)(F)F</smiles>

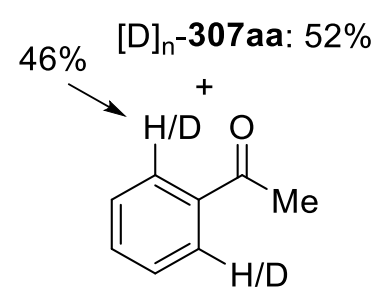

$[D]_{n}-340 a^{\prime}: 21 \%$

Ketimine 340a (143 mg, $0.50 \mathrm{mmol}$ ), 1H,1H,2H-perfluoroalkene (301a) (669 mg, $1.50 \mathrm{mmol}$ ), $\left[\mathrm{RuCl}_{2}(p \text {-cymene })\right]_{2}(15.3 \mathrm{mg}, 5.0 \mathrm{~mol} \%), \mathrm{P}\left(4-\mathrm{C}_{6} \mathrm{H}_{4} \mathrm{~F}\right)_{3}(31.6 \mathrm{mg}, 20.0 \mathrm{~mol} \%)$ and $\mathrm{K}_{3} \mathrm{PO}_{4}$ $(212 \mathrm{mg}, 1.0 \mathrm{mmol})$ were stirred in cyclohexane $(1.0 \mathrm{~mL})$ and $\mathrm{D}_{2} \mathrm{O}\left(5\right.$ equiv) at $120{ }^{\circ} \mathrm{C}$ for $16 \mathrm{~h}$. At ambient temperature, the reaction mixture was diluted with EtOAc $(5.0 \mathrm{~mL})$ and $\mathrm{HCl}$ $(5.0 \mathrm{~mL}, 1 \mathrm{M})$ was added. The mixture was stirred for $3 \mathrm{~h}$ and extracted with EtOAc $(3 \mathrm{x}$ $10.0 \mathrm{~mL}$ ). After removal of the solvents in vacuo, purification by flash column chromatography on silica gel yielded $[\mathrm{D}]_{\mathrm{n}}-\mathbf{3 4 0 a}(21 \%)$ and $[\mathrm{D}]_{\mathrm{n}}-\mathbf{3 0 7 a a}(52 \%)$.

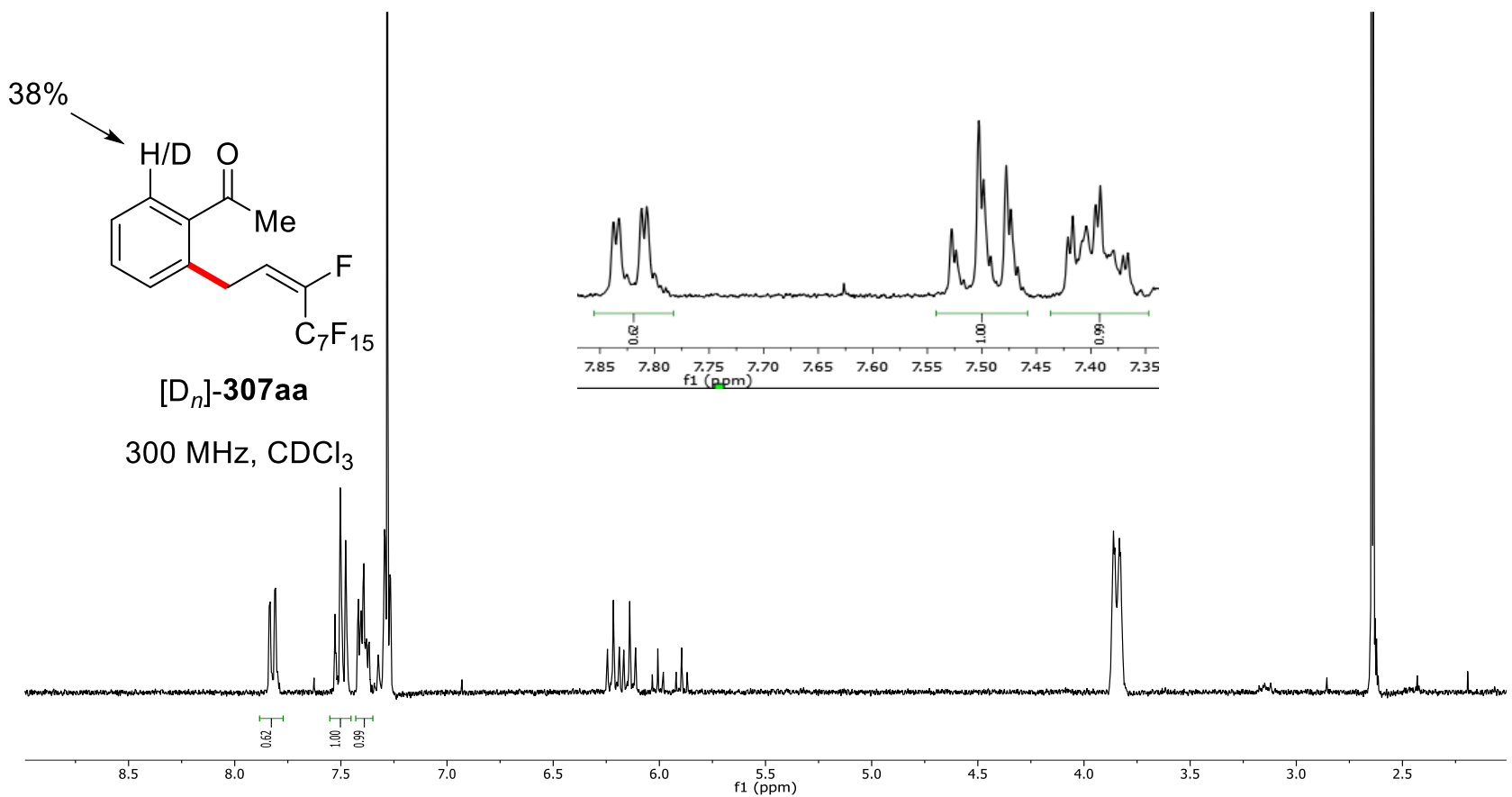




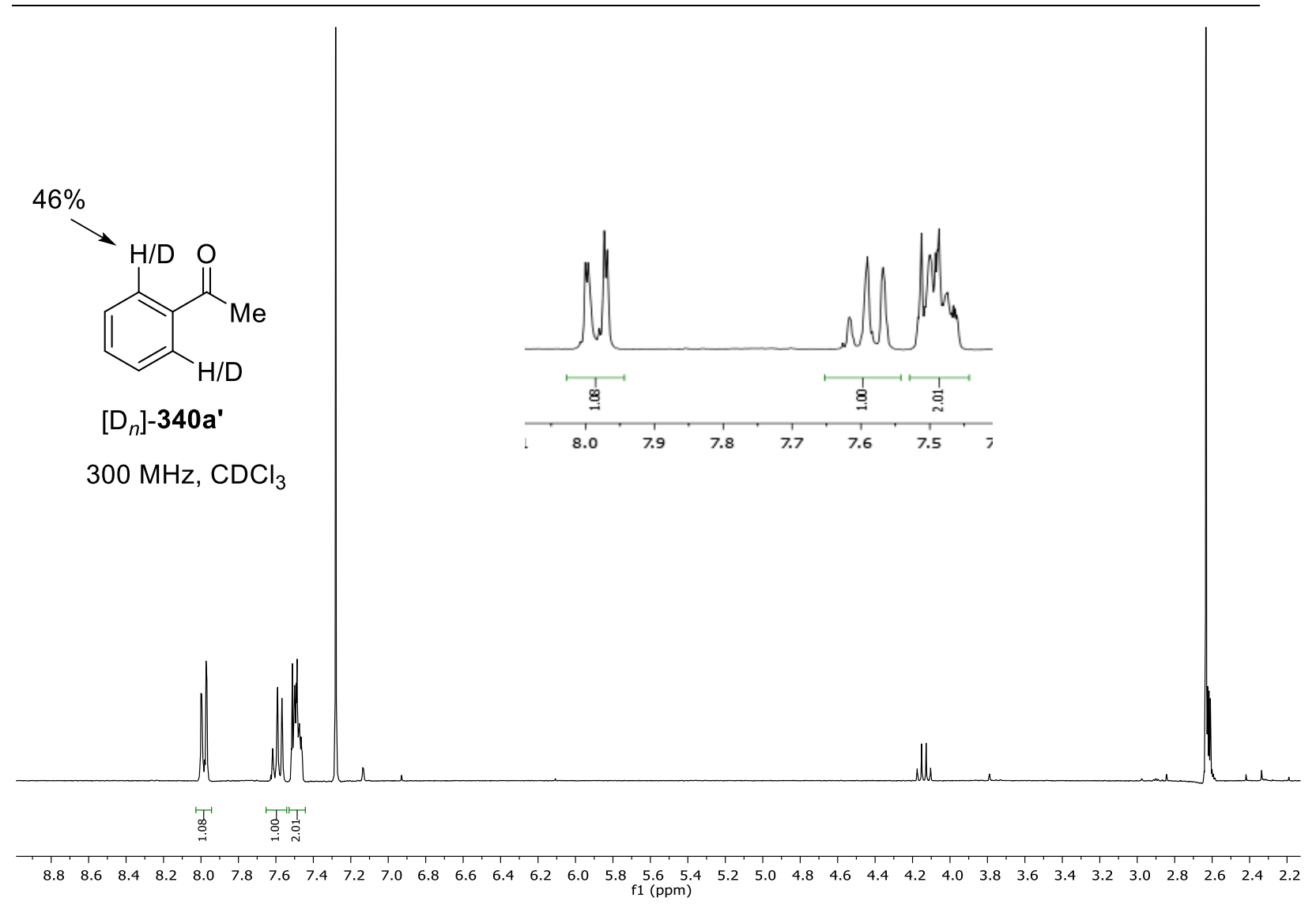

\subsubsection{Intermolecular KIE by Independent Experiments}

Two parallel reactions with $\mathbf{3 4 0 a}$ and $[\mathrm{D}]_{5}-\mathbf{3 4 0 a}$ were performed to determine the corresponding KIE value. 340a $(143 \mathrm{mg}, 0.50 \mathrm{mmol})$ or $[\mathrm{D}] 5-340 \mathrm{a}(145 \mathrm{mg}, 0.50 \mathrm{mmol})$, $\left[\mathrm{RuCl}_{2}(p \text {-cymene })\right]_{2} \quad(15.3 \mathrm{mg}, 5.0 \mathrm{~mol} \%), \mathrm{P}\left(4-\mathrm{C}_{6} \mathrm{H}_{4} \mathrm{~F}\right)_{3} \quad(31.6 \mathrm{mg}, 20.0 \mathrm{~mol} \%), \quad 1,3,5-$ trimethoxybenzene $(84 \mathrm{mg}, 0.50 \mathrm{mmol})$ and $\mathrm{K}_{3} \mathrm{PO}_{4}(212 \mathrm{mg}, 1.0 \mathrm{mmol})$ were stirred in cyclohexane $(1.0 \mathrm{~mL})$ at $120{ }^{\circ} \mathrm{C}$. A periodic aliquot $(0.02 \mathrm{~mL})$ was removed by syringe and analyzed by ${ }^{1} \mathrm{H}-\mathrm{NMR}$ spectroscopy to provide the following conversions: 
<smiles>C=CC(F)C(F)F</smiles>

$301 \mathrm{a}$

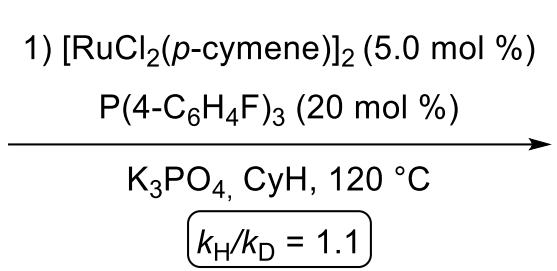

$k_{\mathrm{H}} / k_{\mathrm{D}}=1.1$

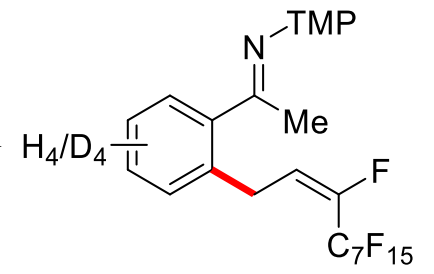

$307 a a /\left[D_{4}\right]-307 a a$

Table 31. Conversion-time table for determination of the KIE.

\begin{tabular}{cccccc}
\hline Time $(\min )$ & 70 & 85 & 100 & 115 & 130 \\
\hline 307aa & 1.2 & 3.1 & 5.3 & 7.5 & 10.4 \\
{$[\mathrm{D}]_{5-307 a a}$} & 0.1 & 2.4 & 4.3 & 6.6 & 8.3 \\
\hline
\end{tabular}




\subsection{Enantioselective Cobalt(III)-catalyzed $\mathrm{C}-\mathrm{H}$ activation}

\subsubsection{Analytical Data of Novel Chiral Acids}<smiles>O=C(O)C1N(C(=O)c2ccccc2)C(c2ccccc2)[C@H](c2ccccc2)N1C(=O)c1ccccc1</smiles>

\section{(4S,5S)-1,3-Dibenzoyl-4,5-diphenylimidazolidine-2-carboxylic acid (CA5): General} procedure $\mathbf{D}$ was followed using benzoyl chloride (295 $\mathrm{mg}, 2.10 \mathrm{mmol})$ to afford $(4 S, 5 S)-1,3-$ dibenzoyl-4,5-diphenylimidazolidine-2-carboxylic acid CA5 (309.4 mg, 65\% yield) as a white solid.

${ }^{1} \mathrm{H}-\mathrm{NMR}\left(600 \mathrm{MHz}, \mathrm{CD}_{3} \mathrm{CO}_{2} \mathrm{D}\right): \delta=7.74-7.06(\mathrm{~m}, 19 \mathrm{H}), 7.15-6.84(\mathrm{~m}, 2 \mathrm{H}), 5.50(\mathrm{~s}, 1 \mathrm{H})$, $5.24(\mathrm{~s}, 1 \mathrm{H})$.

${ }^{13} \mathrm{C}-\mathrm{NMR}$ (125 MHz, $\mathrm{CD}_{3} \mathrm{CO}_{2} \mathrm{D}$ ): (one carbon resonance is missing due to overlap): $\delta=173.2$ $\left(\mathrm{C}_{\mathrm{q}}\right), 172.6\left(\mathrm{C}_{\mathrm{q}}\right), 171.5\left(\mathrm{C}_{\mathrm{q}}\right), 141.0\left(\mathrm{C}_{\mathrm{q}}\right), 139.1\left(\mathrm{C}_{\mathrm{q}}\right), 135.7\left(\mathrm{C}_{\mathrm{q}}\right), 134.7\left(\mathrm{C}_{\mathrm{q}}\right), 131.7(\mathrm{CH}), 131.5$ $(\mathrm{CH}), 129.9(\mathrm{CH}), 129.7(\mathrm{CH}), 129.2(\mathrm{CH}), 129.1(\mathrm{CH}), 129.1(\mathrm{CH}), 127.8(\mathrm{CH}), 127.7(\mathrm{CH})$, $127.2(\mathrm{CH}), 126.7(\mathrm{CH}), 73.9(\mathrm{CH}), 72.8(\mathrm{CH}), 71.0(\mathrm{CH})$.

IR (ATR): 3060, 1645, 1602, 1495, 1447, 1388, 867, 754, 698, $551 \mathrm{~cm}^{-1}$. $[\alpha]_{\mathrm{D}}^{20}:-76.0\left(\mathrm{c}=1.00, \mathrm{CHCl}_{3}\right)$.

MS (ESI) $m / z$ (relative intensity): $499(80)[\mathrm{M}+\mathrm{Na}]^{+}, 477(100)[\mathrm{M}+\mathrm{H}]^{+}, 425(20)$.

HR-MS (ESI): $m / z$ calcd. for $\left[\mathrm{C}_{30} \mathrm{H}_{24} \mathrm{~N}_{2} \mathrm{O}_{4}+\mathrm{H}\right]^{+} 477.1807$ found 477.1809 .<smiles>Cc1cccc(C(=O)N2C(c3ccccc3)[C@@H](c3ccccc3)N(C(=O)c3cccc(C)c3)C2C(=O)O)c1</smiles>

(4S,5S)-1,3-Bis(3-methylbenzoyl)-4,5-diphenylimidazolidine-2-carboxylic acid (CA6): General procedure $\mathbf{D}$ was followed using $m$-tolouyl chloride (323 $\mathrm{mg}, 2.10 \mathrm{mmol}$ ) to afford (4S,5S)-1,3-bis(3-methylbenzoyl)-4,5-diphenylimidazolidine-2-carboxylic acid CA6 (352.8 $\mathrm{mg}, 70 \%$ yield) as a white solid.

${ }^{1} \mathrm{H}-\mathrm{NMR}\left(500 \mathrm{MHz}, \mathrm{CD}_{3} \mathrm{CO}_{2} \mathrm{D}\right): \delta=7.49-7.19$ (m, 9H), 7.18-7.03 (m, 8H), 7.02-6.88 (m, $2 \mathrm{H}), 5.49(\mathrm{~s}, 1 \mathrm{H}), 5.22(\mathrm{~s}, 1 \mathrm{H}), 2.20(\mathrm{~s}, 3 \mathrm{H}), 2.13$ (s, 3H). 
${ }^{13} \mathrm{C}-\mathrm{NMR}$ (125 MHz, $\mathrm{CD}_{3} \mathrm{CO}_{2} \mathrm{D}$ ): (one carbon resonance is missing due to overlap): $\delta=173.7$ $\left(\mathrm{C}_{\mathrm{q}}\right), 172.9\left(\mathrm{C}_{\mathrm{q}}\right), 171.6\left(\mathrm{C}_{\mathrm{q}}\right), 141.3\left(\mathrm{C}_{\mathrm{q}}\right), 139.5\left(\mathrm{C}_{\mathrm{q}}\right), 139.4\left(\mathrm{C}_{\mathrm{q}}\right), 139.3\left(\mathrm{C}_{\mathrm{q}}\right), 139.2\left(\mathrm{C}_{\mathrm{q}}\right), 135.8$ $\left(\mathrm{C}_{\mathrm{q}}\right), 135.4(\mathrm{CH}), 134.8(\mathrm{CH}), 132.5(\mathrm{CH}), 132.3(\mathrm{CH}), 131.4(\mathrm{CH}), 130.0(\mathrm{CH}), 129.8(\mathrm{CH})$, 129.4 (CH), $129.3(\mathrm{CH}), 129.2(\mathrm{CH}), 129.1(\mathrm{CH}), 128.5(\mathrm{CH}), 128.2(\mathrm{CH}), 127.4(\mathrm{CH}), 126.9$ $(\mathrm{CH}), 125.0(\mathrm{CH}), 124.8(\mathrm{CH}), 73.8(\mathrm{CH}), 72.8(\mathrm{CH}), 70.8(\mathrm{CH}), 21.2\left(\mathrm{CH}_{3}\right), 21.1\left(\mathrm{CH}_{3}\right)$. IR (ATR): 3030, 1642, 1585, 1495, 1384, 1211, 1092, 749, 698, $663 \mathrm{~cm}^{-1}$. $[\alpha]_{\mathrm{D}}^{20}:-67.8\left(\mathrm{c}=1.10, \mathrm{CHCl}_{3}\right)$.

MS (ESI) $m / z$ (relative intensity): $527(80)[\mathrm{M}+\mathrm{Na}]^{+}, 505(100)[\mathrm{M}+\mathrm{H}]^{+}, 341(20)$. HR-MS (ESI): $m / z$ calcd. for $\left[\mathrm{C}_{32} \mathrm{H}_{28} \mathrm{~N}_{2} \mathrm{O}_{4}+\mathrm{H}\right]^{+} 505.2122$ found 505.2119.<smiles>O=C(O)C1N(C(=O)c2cccc3ccccc23)C([PH](=O)c2ccccc2)[C@@H](c2ccccc2)N1C(=O)c1cccc2ccccc12</smiles>

(4S,5S)-1,3-Di(1-naphthoyl)-4,5-diphenylimidazolidine-2-carboxylic acid (CA7): General procedure D was followed using 1-naphthoyl chloride (399 $\mathrm{mg}, 2.10 \mathrm{mmol}$ ) to afford $(4 S, 5 S)$ 1,3-bis(3-methylbenzoyl)-4,5-diphenylimidazolidine-2-carboxylic acid CA7 (392.1 mg, 68\% yield) as a white solid.

${ }^{1} \mathrm{H}-\mathrm{NMR}$ (400 MHz, CDCl3+ 1\% TFA): $\delta=9.00-8.40(\mathrm{~m}, 5 \mathrm{H}), 8.00-7.53(\mathrm{~m}, 3 \mathrm{H}), 7.52-7.40$ (m, 1H), 7.39-7.26 (m, 3H), 7.20-6.89 (m, 9H), 6.76-6.57 (m, 2H), 6.56-6.24 (m, 2H), 4.91 $(\mathrm{s}, 1 \mathrm{H}), 4.71(\mathrm{~s}, 1 \mathrm{H})$.

${ }^{13} \mathrm{C}-\mathrm{NMR}$ (125 MHz, $\mathrm{CD}_{3} \mathrm{CO}_{2} \mathrm{D}$ ): (four carbon resonance is missing due to overlap): $\delta=172.6$ $\left(\mathrm{C}_{\mathrm{q}}\right), 172.3\left(\mathrm{C}_{\mathrm{q}}\right), 172.1\left(\mathrm{C}_{\mathrm{q}}\right), 140.5(\mathrm{CH}), 139.0\left(\mathrm{C}_{\mathrm{q}}\right), 138.9\left(\mathrm{C}_{\mathrm{q}}\right), 135.1(\mathrm{CH}), 134.9\left(\mathrm{C}_{\mathrm{q}}\right), 134.0$ $\left(\mathrm{C}_{\mathrm{q}}\right), 133.9\left(\mathrm{C}_{\mathrm{q}}\right), 133.1\left(\mathrm{C}_{\mathrm{q}}\right), 132.6\left(\mathrm{C}_{\mathrm{q}}\right), 132.6\left(\mathrm{C}_{\mathrm{q}}\right), 132.3(\mathrm{CH}), 131.0(\mathrm{CH}), 129.6(\mathrm{CH}), 129.2$ 
$(\mathrm{CH}), 129.0(\mathrm{CH}), 128.8(\mathrm{CH}), 127.9(\mathrm{CH}), 127.5(\mathrm{CH}), 127.3(\mathrm{CH}), 127.2(\mathrm{CH}), 126.7(\mathrm{CH})$, $126.7(\mathrm{CH}), 125.6(\mathrm{CH}), 125.4(\mathrm{CH}), 75.3(\mathrm{CH}), 73.9(\mathrm{CH}), 71.9(\mathrm{CH})$.

IR (ATR): 3054, 1637, 1508, 1457, 1299, 778, 750, 697, $655 \mathrm{~cm}^{-1}$.

$[\alpha]_{\mathrm{D}}^{20}:-94.9\left(\mathrm{c}=1.18, \mathrm{CHCl}_{3}\right)$.

MS (ESI) m/z: $599[\mathrm{M}+\mathrm{Na}]^{+}$.

HR-MS (ESI): $m / z$ calcd. for $\left[\mathrm{C}_{38} \mathrm{H}_{28} \mathrm{~N}_{2} \mathrm{O}_{4}+\mathrm{H}\right]^{+} 577.2122$ found 577.2112.<smiles>O=C(O)C1[C@H](c2cccc(C(F)(F)F)c2)[C@H](c2ccccc2)[C@@H](c2ccccc2)N1C(=O)c1cccc(C(F)(F)F)c1</smiles>

(4S,5S)-4,5-Diphenyl-1,3-bis[3-(trifluoromethyl)benzoyl]imidazolidine-2-carboxylic acid (CA11): General procedure D was followed using 3-(trifluoromethyl)benzoyl chloride (436.8 mg, $2.10 \mathrm{mmol}$ ) to afford CA11 (367.1 mg, 60\% yield) as a white solid. M.p.: >200 ${ }^{\circ} \mathrm{C}$. ${ }^{1} \mathrm{H}-\mathrm{NMR}\left(600 \mathrm{MHz}, \mathrm{CD}_{3} \mathrm{CO}_{2} \mathrm{D}\right): \delta=7.62-7.48(\mathrm{~m}, 5 \mathrm{H}), 7.42-7.34(\mathrm{~m}, 2 \mathrm{H}), 7.29-7.13(\mathrm{~m}$, 9H), 7.11-6.99 (m, 2H), 6.98-6.83 (m, 1H), 5.35 (s, 1H), 5.17 (bs, 1H).

${ }^{13} \mathrm{C}-\mathrm{NMR}\left(100 \mathrm{MHz}, \mathrm{CD}_{3} \mathrm{CO}_{2} \mathrm{D}\right.$ ) (one carbon resonances are missing due to overlap): $\delta=171.7$ $\left(\mathrm{C}_{\mathrm{q}}\right), 171.6\left(\mathrm{C}_{\mathrm{q}}\right), 170.9\left(\mathrm{C}_{\mathrm{q}}\right), 140.0\left(\mathrm{C}_{\mathrm{q}}\right), 138.7\left(\mathrm{C}_{\mathrm{q}}\right), 137.0\left(\mathrm{C}_{\mathrm{q}}\right), 136.1\left(\mathrm{C}_{\mathrm{q}}\right), 131.5\left(\mathrm{q},{ }^{2} J_{\mathrm{C}-\mathrm{F}}=\right.$ $\left.32.4 \mathrm{~Hz}, \mathrm{C}_{\mathrm{q}}\right), 131.4\left(\mathrm{q},{ }^{2} J_{\mathrm{C}-\mathrm{F}}=32.4 \mathrm{~Hz}, \mathrm{C}_{\mathrm{q}}\right), 131.4(\mathrm{CH}), 130.3(\mathrm{CH}), 130.2(\mathrm{CH}), 130.1(\mathrm{CH})$, $129.9(\mathrm{CH}), 129.5(\mathrm{CH}), 128.2(\mathrm{CH}), 128.2(\mathrm{CH}), 128.0(\mathrm{CH}), 127.6(\mathrm{CH}), 127.4(\mathrm{CH}), 124.9$ $(\mathrm{CH}), 124.9(\mathrm{CH}), 124.7\left(\mathrm{q},{ }^{1} J_{\mathrm{C}-\mathrm{F}}=271.8 \mathrm{~Hz}, \mathrm{C}_{\mathrm{q}}\right), 124.6\left(\mathrm{q},{ }^{1} J_{\mathrm{C}-\mathrm{F}}=271.8 \mathrm{~Hz}, \mathrm{C}_{\mathrm{q}}\right), 74.5(\mathrm{CH})$, $73.3(\mathrm{CH}), 71.6(\mathrm{CH})$.

${ }^{19} \mathrm{~F}-\mathrm{NMR}\left(377 \mathrm{MHz}, \mathrm{CD}_{3} \mathrm{CO}_{2} \mathrm{D}\right): \delta=-63.7(\mathrm{~m}),-63.8(\mathrm{~m})$.

IR (ATR): 3066, 3033, 1651, 1456, 1386, 1326, 1280, 1121, 1072, 750, $699 \mathrm{~cm}^{-1}$. $[\alpha]_{\mathrm{D}}^{20}:-49.2\left(\mathrm{c}=1.00, \mathrm{CHCl}_{3}\right)$. MS (ESI) $\mathrm{m} / z$ (relative intensity): $1247(20)[2 \mathrm{M}+\mathrm{Na}]^{+}, 635$ (100) $[\mathrm{M}+\mathrm{Na}]^{+}, 613(15)[\mathrm{M}+\mathrm{H}]^{+}$.

HR-MS (ESI): $m / z$ calcd. for $\left[\mathrm{C}_{32} \mathrm{H}_{22}{ }^{19} \mathrm{~F}_{6} \mathrm{~N}_{2} \mathrm{O}_{4}+\mathrm{Na}\right]^{+} 635.1376$ found 635.1361 . 


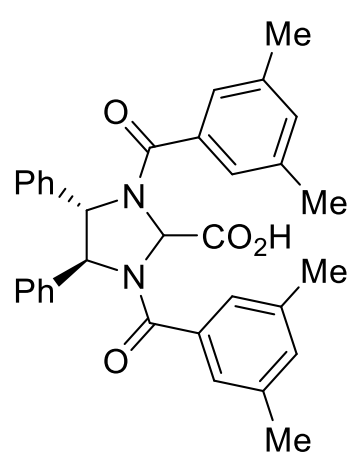

\section{(4S,5S)-1,3-Bis(3,5-dimethylbenzoyl)-4,5-diphenylimidazolidine-2-carboxylic}

acid

(CA12): General procedure D was followed using 3,5-dimethylbenzoyl chloride (352.8 $\mathrm{mg}$, $2.10 \mathrm{mmol}$ ) to afford CA12 (329.0 mg, 62\% yield) as a white solid. M.p.: $180-186{ }^{\circ} \mathrm{C}$.

${ }^{1} \mathrm{H}-\mathrm{NMR}\left(400 \mathrm{MHz}, \mathrm{CD}_{3} \mathrm{CO}_{2} \mathrm{D}\right): \delta=7.46-7.27$ (m, 8H), 7.25-7.08 (m, 2H), 7.04-6.67 (m, $7 \mathrm{H}), 5.51(\mathrm{~s}, 1 \mathrm{H}), 5.24(\mathrm{bs}, 1 \mathrm{H}), 2.19(\mathrm{~s}, 6 \mathrm{H}), 2.14$ (s, 6H).

${ }^{13} \mathrm{C}-\mathrm{NMR}$ (100 MHz, $\mathrm{CD}_{3} \mathrm{CO}_{2} \mathrm{D}$ ) (two carbon resonances are missing due to overlap): $\delta=172.9$ $\left(\mathrm{C}_{\mathrm{q}}\right), 171.9\left(\mathrm{C}_{\mathrm{q}}\right), 170.3\left(\mathrm{C}_{\mathrm{q}}\right), 140.2\left(\mathrm{C}_{\mathrm{q}}\right), 138.5\left(\mathrm{C}_{\mathrm{q}}\right), 138.1\left(\mathrm{C}_{\mathrm{q}}\right), 138.1\left(\mathrm{C}_{\mathrm{q}}\right), 134.6\left(\mathrm{C}_{\mathrm{q}}\right), 133.7$ $\left(\mathrm{C}_{\mathrm{q}}\right), 132.2(\mathrm{CH}), 132.0(\mathrm{CH}), 128.9(\mathrm{CH}), 128.6(\mathrm{CH}), 128.1(\mathrm{CH}), 128.0(\mathrm{CH}), 126.4(\mathrm{CH})$, $125.8(\mathrm{CH}), 124.6(\mathrm{CH}), 124.5(\mathrm{CH}), 72.6(\mathrm{CH}), 71.7(\mathrm{CH}), 69.6(\mathrm{CH}), 20.0\left(\mathrm{CH}_{3}\right), 20.0\left(\mathrm{CH}_{3}\right)$. IR (ATR): 3030, 2920, 1651, 1602, 1455, 1390, 1345, 858, 753, 698, $664 \mathrm{~cm}^{-1}$. $[\alpha]_{\mathrm{D}}^{20}:-97.7\left(\mathrm{c}=1.00, \mathrm{CHCl}_{3}\right)$.

MS (ESI) $m / z$ (relative intensity): $1087(10)[2 \mathrm{M}+\mathrm{Na}]^{+}, 533(100)[\mathrm{M}+\mathrm{H}]^{+}$.

HR-MS (ESI): $m / z$ calcd. for $\left[\mathrm{C}_{34} \mathrm{H}_{32} \mathrm{~N}_{2} \mathrm{O}_{4}+\mathrm{H}\right]^{+} 533.2435$ found 533.2436.<smiles>Cc1ccc(C(=O)N2C(C(=O)O)N(C(=O)c3ccc(C)cc3)[C@H](c3ccccc3)[C@H]2c2ccccc2)cc1</smiles>

(4S,5S)-1,3-Bis(4-methylbenzoyl)-4,5-diphenylimidazolidine-2-carboxylic acid (CA14):

General procedure $\mathbf{D}$ was followed using 4-methylbenzoyl chloride (323.0 $\mathrm{mg}, 2.10 \mathrm{mmol}$ ) to afford (4S,5S)-1,3-dibenzoyl-4,5-diphenylimidazolidine-2-carboxylic acid CA14 (352.0 mg, $70 \%$ yield) as a white solid. M.p.: $168-175^{\circ} \mathrm{C}$.

${ }^{1} \mathrm{H}-\mathrm{NMR}\left(400 \mathrm{MHz}, \mathrm{CD}_{3} \mathrm{CO}_{2} \mathrm{D}\right): \delta=7.49$ (d, $\left.J=7.4 \mathrm{~Hz}, 2 \mathrm{H}\right), 7.45-7.40$ (m, 2H), 7.39-7.35 (m, 1H), 7.35-7.21 (m, 7H), 7.21-7.12 (m, 2H), 7.13-6.91 (m, 5H), $5.59(\mathrm{~s}, 1 \mathrm{H}), 5.32(\mathrm{bs}, 1 \mathrm{H})$, $2.30(\mathrm{~s}, 3 \mathrm{H}), 2.27(\mathrm{~s}, 3 \mathrm{H})$.

${ }^{13} \mathrm{C}-\mathrm{NMR}\left(100 \mathrm{MHz}, \mathrm{CD}_{3} \mathrm{CO}_{2} \mathrm{D}\right): \delta=173.8\left(\mathrm{C}_{\mathrm{q}}\right), 173.0\left(\mathrm{C}_{\mathrm{q}}\right), 171.4\left(\mathrm{C}_{\mathrm{q}}\right), 142.8\left(\mathrm{C}_{\mathrm{q}}\right), 142.4$ $\left(\mathrm{C}_{\mathrm{q}}\right), 141.4\left(\mathrm{C}_{\mathrm{q}}\right), 139.3\left(\mathrm{C}_{\mathrm{q}}\right), 132.9\left(\mathrm{C}_{\mathrm{q}}\right), 131.8\left(\mathrm{C}_{\mathrm{q}}\right), 130.1(\mathrm{CH}), 130.0(\mathrm{CH}), 129.9(\mathrm{CH}), 129.9$ 
$(\mathrm{CH}), 129.3(\mathrm{CH}), 129.2(\mathrm{CH}), 128.2(\mathrm{CH}), 128.1(\mathrm{CH}), 127.3(\mathrm{CH}), 126.7(\mathrm{CH}), 73.4(\mathrm{CH})$, $72.7(\mathrm{CH}), 70.9(\mathrm{CH}), 21.4\left(\mathrm{CH}_{3}\right), 21.4\left(\mathrm{CH}_{3}\right)$.

IR (ATR): 3061, 3008, 1635, 1455, 1377, 1388, 1211, 1182, 828, 752, $697 \mathrm{~cm}^{-1}$. $[\alpha]_{\mathrm{D}}^{20}:-57.4\left(\mathrm{c}=1.00, \mathrm{CHCl}_{3}\right)$.

MS (ESI) $m / z$ (relative intensity): $1031(10)[2 \mathrm{M}+\mathrm{Na}]^{+}, 527(100)[\mathrm{M}+\mathrm{Na}]^{+}, 505(20)[\mathrm{M}+\mathrm{H}]^{+}$. HR-MS (ESI): $m / z$ calcd. for $\left[\mathrm{C}_{32} \mathrm{H}_{28} \mathrm{~N}_{2} \mathrm{O}_{4}+\mathrm{Na}\right]^{+} 527.1941$ found 527.1929 .

\subsubsection{Characterization Data of the Alkylated Products}<smiles>CC(Cc1ccccc1)c1cc2ccccc2n1-c1ccccn1</smiles>

(R)-2-(1-Phenylpropan-2-yl)-1-(pyridin-2-yl)-1H-indole (357aa): The general procedure $\mathbf{E}$ was followed using 1-(pyridin-2-yl)-1H-indole (315a) $(97.1 \mathrm{mg}, 0.50 \mathrm{mmol})$ and allylbenzene (223a) $(177 \mathrm{mg}, 1.50 \mathrm{mmol})$. Isolation by column chromatography $(n$-hexane/EtOAc $=30: 1)$ yielded 357aa (92 mg, 59\%, M/AM = 82:18) as a yellow oil.

${ }^{1} \mathrm{H}-\mathrm{NMR}\left(300 \mathrm{MHz}, \mathrm{CDCl}_{3}\right.$ ): $\delta=8.74$ (ddd, $\left.J=4.9,2.0,0.8 \mathrm{~Hz}, 1 \mathrm{H}\right), 7.89$ (ddd, $J=7.7,2.0$ $\mathrm{Hz}, 1 \mathrm{H}), 7.70-7.60(\mathrm{~m}, 1 \mathrm{H}), 7.38(\mathrm{ddd}, J=7.5,4.9,1.1 \mathrm{~Hz}, 1 \mathrm{H}), 7.33(\mathrm{dd}, J=8.4,1.2 \mathrm{~Hz}, 1 \mathrm{H})$, $7.28(\mathrm{~d}, J=3.2 \mathrm{~Hz}, 1 \mathrm{H}), 7.24-7.12(\mathrm{~m}, 5 \mathrm{H}), 6.99-6.92(\mathrm{~m}, 2 \mathrm{H}), 6.58(\mathrm{~d}, J=0.9 \mathrm{~Hz}, 1 \mathrm{H}), 3.68-$ $3.49(\mathrm{~m}, 0.82 \mathrm{H}, \mathrm{M}), 3.05(\mathrm{dd}, J=13.3,5.3 \mathrm{~Hz}, 1 \mathrm{H}), 2.95(\mathrm{t}, J=7.7 \mathrm{~Hz}, 0.36 \mathrm{H}, \mathrm{AM}), 2.60$ (dd, $J=13.3,7.5 \mathrm{~Hz}, 1 \mathrm{H}), 1.28(\mathrm{~d}, J=6.9 \mathrm{~Hz}, 3 \mathrm{H})$.

${ }^{13} \mathrm{C}-\mathrm{NMR}\left(75 \mathrm{MHz}, \mathrm{CDCl}_{3}\right): \delta=151.6\left(\mathrm{C}_{\mathrm{q}}\right), 149.7(\mathrm{CH}), 146.5\left(\mathrm{C}_{\mathrm{q}}\right), 140.3\left(\mathrm{C}_{\mathrm{q}}\right), 138.4(\mathrm{CH})$, $137.3\left(\mathrm{C}_{\mathrm{q}}\right), 129.1(\mathrm{CH}), 128.3\left(\mathrm{C}_{\mathrm{q}}\right), 128.1(\mathrm{CH}), 125.9(\mathrm{CH}), 122.3(\mathrm{CH}), 121.8(\mathrm{CH}), 121.7$ $(\mathrm{CH}), 120.6(\mathrm{CH}), 120.1(\mathrm{CH}), 109.9(\mathrm{CH}), 100.5(\mathrm{CH}), 43.9\left(\mathrm{CH}_{2}\right), 32.9(\mathrm{CH}), 19.4\left(\mathrm{CH}_{3}\right)$.

IR (ATR): 3025, 2965, 1595, 1585, 1468, 1452, $741 \mathrm{~cm}^{-1}$.

MS (EI) $m / z$ (relative intensity): $312(20)[\mathrm{M}]^{+}, 221$ (35), 207 (100).

HR-MS $\left(\mathrm{EI}^{+}\right): m / z$ calcd. For $\left[\mathrm{C}_{22} \mathrm{H}_{20} \mathrm{~N}_{2}\right]^{+} 312.1626$, found 312.1621 .

$[\alpha]_{\mathrm{D}}^{20}:+16.0\left(\mathrm{c}=1.00, \mathrm{CHCl}_{3}\right)$.

HPLC separation (Chiralpak ${ }^{\circledR}$ IB-3, $n$-hexane/EtOAc 90:10, $1.0 \mathrm{~mL} / \mathrm{min}$, detection at 280 $\mathrm{nm}): t_{r}($ major $)=7.9 \mathrm{~min}, t_{r}(\operatorname{minor})=9.5 \mathrm{~min}, t_{r}(\mathrm{AM})=10.2 \mathrm{~min}, 88: 12$ e.r. 
<smiles>Cc1ccc(-n2c(CCc3ccccc3)cc3ccccc32)cc1</smiles>

(R)-1-(5-Methylpyridin-2-yl)-2-(1-phenylpropan-2-yl)-1H-indole (355aa): The general procedure E was followed using 1-(5-methylpyridin-2-yl)-1H-indole (354a) (104.1 mg, $0.50 \mathrm{mmol})$ and allylbenzene (223a) $(177 \mathrm{mg}, 1.50 \mathrm{mmol})$. Isolation by column chromatography $(n$-hexane/EtOAc $=30: 1)$ yielded 355aa $(99.4 \mathrm{mg}, 61 \%, \mathrm{M} / \mathrm{AM}=92: 8)$ as a yellow oil.

${ }^{1} \mathrm{H}-\mathrm{NMR}\left(300 \mathrm{MHz}, \mathrm{CDCl}_{3}\right): \delta=8.54(\mathrm{dd}, J=2.4,0.8 \mathrm{~Hz}, 1 \mathrm{H}), 7.69-7.60(\mathrm{~m}, 2 \mathrm{H}), 7.28-7.20$ (m, 3H), 7.20-7.09 (m, 4H), 7.04-6.89 (m, 2H), 6.54 (d, J = 0.8 Hz, 1H), 3.72-3.43 (m, 0.92H, M), $3.07(\mathrm{dd}, J=13.3,5.2 \mathrm{~Hz}, 1 \mathrm{H}), 2.90(\mathrm{t}, J=7.5 \mathrm{~Hz}, 0.16 \mathrm{H}, \mathrm{AM}), 2.61(\mathrm{dd}, J=13.4,9.0$ $\mathrm{Hz}, 1 \mathrm{H}), 2.46(\mathrm{~s}, 3 \mathrm{H}), 1.26(\mathrm{~d}, J=6.8 \mathrm{~Hz}, 3 \mathrm{H})$.

${ }^{13} \mathrm{C}-\mathrm{NMR}\left(125 \mathrm{MHz}, \mathrm{CDCl}_{3}\right): \delta=149.7(\mathrm{CH}), 149.0\left(\mathrm{C}_{\mathrm{q}}\right), 146.3\left(\mathrm{C}_{\mathrm{q}}\right), 140.2\left(\mathrm{C}_{\mathrm{q}}\right), 138.7(\mathrm{CH})$, $137.3\left(\mathrm{C}_{\mathrm{q}}\right), 131.9\left(\mathrm{C}_{\mathrm{q}}\right), 128.9(\mathrm{CH}), 128.3\left(\mathrm{C}_{\mathrm{q}}\right), 127.9(\mathrm{CH}), 125.8(\mathrm{CH}), 121.4(\mathrm{CH}), 121.1$ $(\mathrm{CH}), 120.3(\mathrm{CH}), 119.9(\mathrm{CH}), 109.9(\mathrm{CH}), 99.9(\mathrm{CH}), 43.7\left(\mathrm{CH}_{2}\right), 32.9(\mathrm{CH}), 19.5\left(\mathrm{CH}_{3}\right)$, $18.1\left(\mathrm{CH}_{3}\right)$.

IR (ATR): 2925, 1596, 1482, 1455, 1396, 1346, 1314, 785, 748, $699 \mathrm{~cm}^{-1}$. MS (ESI) $m / z$ (relative intensity): $349(20)[\mathrm{M}+\mathrm{Na}]^{+}, 327(100)[\mathrm{M}+\mathrm{H}]^{+}$.

HR-MS (ESI): $m / z$ calcd. for $\left[\mathrm{C}_{23} \mathrm{H}_{22} \mathrm{~N}_{2}+\mathrm{H}\right]^{+} 327.1859$ found 327.1856 .

$[\alpha]_{\mathrm{D}}^{20}:+9.2\left(\mathrm{c}=0.90, \mathrm{CHCl}_{3}\right)$.

HPLC separation (Chiralpak ${ }^{\circledR}$ IB-3, $n$-hexane/i-PrOH 95:5, $0.75 \mathrm{~mL} / \mathrm{min}$, detection at $273 \mathrm{~nm}$ ): $t_{r}($ major $)=8.9 \mathrm{~min}, t_{r}($ minor $)=10.0 \mathrm{~min}, t_{r}(\mathrm{AM})=10.7 \mathrm{~min}, 92: 8$ e.r.<smiles>Cc1ccc(-n2c(CCc3ccccc3)cc3cc(Br)ccc32)cc1</smiles>

(R)-5-Bromo-1-(5-methylpyridin-2-yl)-2-(1-phenylpropan-2-yl)-1H-indole (355ba): The general procedure $\mathbf{E}$ was followed using 5-bromo-1-(5-methylpyridin-2-yl)-1H-indole (354b) $(143 \mathrm{mg}, 0.50 \mathrm{mmol})$ and allylbenzene $(\mathbf{2 2 3 a})(177 \mathrm{mg}, 1.50 \mathrm{mmol})$. Isolation by column chromatography $(n$-hexane/EtOAc $=30: 1)$ yielded 355ba $(133.3 \mathrm{mg}, 66 \%, \mathrm{M} / \mathrm{AM}=94: 6)$ as a yellow oil. 
${ }^{1} \mathrm{H}-\mathrm{NMR}\left(300 \mathrm{MHz}, \mathrm{CDCl}_{3}\right): \delta=8.50(\mathrm{dd}, J=2.5,0.8 \mathrm{~Hz}, 1 \mathrm{H}), 7.71(\mathrm{ddd}, J=7.5,7.2,2.5 \mathrm{~Hz}$, 1H), 7.64 (ddd, $J=7.2,2.5,0.8 \mathrm{~Hz}, 1 \mathrm{H}), 7.21-7.12(\mathrm{~m}, 4 \mathrm{H}), 7.10-7.00(\mathrm{~m}, 2 \mathrm{H}), 6.95-6.88$ (m, $2 \mathrm{H}), 6.44(\mathrm{~d}, J=0.8 \mathrm{~Hz}, 1 \mathrm{H}), 3.53-3.36(\mathrm{~m}, 0.94 \mathrm{H}, \mathrm{M}), 3.00(\mathrm{dd}, J=13.3,5.5 \mathrm{~Hz}, 1 \mathrm{H}), 2.83$ (t, $J=7.7 \mathrm{~Hz}, 0.12 \mathrm{H}, \mathrm{AM}), 2.59$ (dd, $J=13.3,8.7 \mathrm{~Hz}, 1 \mathrm{H}), 2.44(\mathrm{~s}, 3 \mathrm{H}), 1.23$ (d, $J=6.9 \mathrm{~Hz}$, $3 \mathrm{H})$.

${ }^{13} \mathrm{C}-\mathrm{NMR}\left(125 \mathrm{MHz}, \mathrm{CDCl}_{3}\right): \delta=149.8(\mathrm{CH}), 148.5\left(\mathrm{C}_{\mathrm{q}}\right), 147.6\left(\mathrm{C}_{\mathrm{q}}\right), 139.9\left(\mathrm{C}_{\mathrm{q}}\right), 138.9(\mathrm{CH})$, $136.0\left(\mathrm{C}_{\mathrm{q}}\right), 132.3\left(\mathrm{C}_{\mathrm{q}}\right), 130.0\left(\mathrm{C}_{\mathrm{q}}\right), 128.9(\mathrm{CH}), 128.0(\mathrm{CH}), 125.9(\mathrm{CH}), 124.1(\mathrm{CH}), 122.3$ $(\mathrm{CH}), 121.0(\mathrm{CH}), 113.4\left(\mathrm{C}_{\mathrm{q}}\right), 111.4(\mathrm{CH}), 99.4(\mathrm{CH}), 43.6\left(\mathrm{CH}_{2}\right), 32.9(\mathrm{CH}), 19.6\left(\mathrm{CH}_{3}\right), 18.1$ $\left(\mathrm{CH}_{3}\right)$.

IR (ATR): 2964, 1595, 1575, 1481, 1450, $747 \mathrm{~cm}^{-1}$.

MS (ESI) $m / z$ (relative intensity): 405 (100) $\left[\mathrm{M}+\mathrm{H},{ }^{79} \mathrm{Br}\right]^{+}, 327$ (20), 289 (10).

HR-MS (ESI): $m / z$ calcd. for $\left[\mathrm{C}_{23} \mathrm{H}_{21}{ }^{79} \mathrm{BrN}_{2}+\mathrm{H}\right]^{+} 405.0957$, found 405.0961 .

$[\alpha]_{\mathrm{D}}^{20}:-12.0\left(\mathrm{c}=1.00, \mathrm{CHCl}_{3}\right)$.

HPLC separation (Chiralpak ${ }^{\circledR}$ ID-3, $n$-hexane/i-PrOH 99:1, $1.00 \mathrm{~mL} / \mathrm{min}$, detection at 273 $\mathrm{nm}): t_{r}($ major $)=17.3 \mathrm{~min}, t_{r}($ minor $)=20.2 \mathrm{~min}, t_{r}(\mathrm{AM})=24.0 \mathrm{~min}, 93: 7$ e.r.<smiles>Cc1ccc(-n2c(CCc3ccccc3)cc3cc(I)ccc32)cc1</smiles>

(R)-5-Iodo-1-(5-methylpyridin-2-yl)-2-(1-phenylpropan-2-yl)-1H-indole $\quad$ (355ca): The general procedure $\mathbf{E}$ was followed using 5-iodo-1-(5-methylpyridin-2-yl)-1H-indole (354c) (167.1 $\mathrm{mg}, 0.50 \mathrm{mmol})$ and allylbenzene (223a) $(177 \mathrm{mg}, 1.50 \mathrm{mmol})$. Isolation by column chromatography $(n$-hexane/EtOAc $=30: 1)$ yielded 355ca $(146.9 \mathrm{mg}, 65 \%, \mathrm{M} / \mathrm{AM}=96: 4)$ as a yellow oil.

${ }^{1} \mathrm{H}-\mathrm{NMR}\left(500 \mathrm{MHz}, \mathrm{CDCl}_{3}\right): \delta=8.49(\mathrm{dd}, J=2.4,0.9 \mathrm{~Hz}, 1 \mathrm{H}), 7.91(\mathrm{dd}, J=1.6,0.9 \mathrm{~Hz}, 1 \mathrm{H})$, $7.63(\mathrm{ddd}, J=8.0,2.4,0.9 \mathrm{~Hz}, 1 \mathrm{H}), 7.34$ (dd, $J=8.6,1.6 \mathrm{~Hz}, 1 \mathrm{H}), 7.21-7.11(\mathrm{~m}, 3 \mathrm{H}), 7.06$ (d, $J=8.0 \mathrm{~Hz}, 1 \mathrm{H}), 6.94(\mathrm{~d}, J=8.6 \mathrm{~Hz}, 1 \mathrm{H}), 6.92-6.86(\mathrm{~m}, 2 \mathrm{H}), 6.41(\mathrm{~d}, J=0.8 \mathrm{~Hz}, 1 \mathrm{H}), 3.50-$ $3.36(\mathrm{~m}, 0.96 \mathrm{H}, \mathrm{M}), 2.98(\mathrm{dd}, J=13.4,5.5 \mathrm{~Hz}, 1 \mathrm{H}), 2.80(\mathrm{t}, J=7.9 \mathrm{~Hz}, 0.08 \mathrm{H}, \mathrm{AM}), 2.58$ (dd, $J=13.4,8.6 \mathrm{~Hz}, 1 \mathrm{H}), 2.44(\mathrm{~s}, 3 \mathrm{H}), 1.21$ (d, $J=6.8 \mathrm{~Hz}, 3 \mathrm{H})$.

${ }^{13} \mathrm{C}-\mathrm{NMR}\left(125 \mathrm{MHz}, \mathrm{CDCl}_{3}\right): \delta=149.9(\mathrm{CH}), 148.5\left(\mathrm{C}_{\mathrm{q}}\right), 147.3\left(\mathrm{C}_{\mathrm{q}}\right), 139.9\left(\mathrm{C}_{\mathrm{q}}\right), 139.0(\mathrm{CH})$, $136.5\left(\mathrm{C}_{\mathrm{q}}\right), 132.4\left(\mathrm{C}_{\mathrm{q}}\right), 130.8\left(\mathrm{C}_{\mathrm{q}}\right), 129.7(\mathrm{CH}), 129.0(\mathrm{CH}), 128.7(\mathrm{CH}), 128.1(\mathrm{CH}), 125.9$ $(\mathrm{CH}), 121.1(\mathrm{CH}), 112.0(\mathrm{CH}), 99.1(\mathrm{CH}), 83.8\left(\mathrm{C}_{\mathrm{q}}\right), 43.6\left(\mathrm{CH}_{2}\right), 32.8(\mathrm{CH}), 19.5\left(\mathrm{CH}_{3}\right), 18.1$ $\left(\mathrm{CH}_{3}\right)$. 
IR (ATR): 3024, 1594, 1495, 1481, 1453, 790, $748 \mathrm{~cm}^{-1}$.

MS (ESI) $m / z$ (relative intensity): $475(100)[\mathrm{M}+\mathrm{Na}]^{+}, 453(70)[\mathrm{M}+\mathrm{H}]^{+}, 397(10)$.

HR-MS (ESI): $m / z$ calcd. for $\left[\mathrm{C}_{23} \mathrm{H}_{21} \mathrm{IN}_{2}+\mathrm{Na}\right]^{+} 475.0646$, found 475.0642 .

$[\alpha]_{\mathrm{D}^{20}}:-23.3\left(\mathrm{c}=1.03, \mathrm{CHCl}_{3}\right)$.

HPLC separation (Chiralpak ${ }^{\circledR}$ ID-3, $n$-hexane $/ i$-PrOH 98:2, $0.75 \mathrm{~mL} / \mathrm{min}$, detection at 273 $\mathrm{nm}): t_{r}($ major $)=16.6 \mathrm{~min}, t_{r}(\operatorname{minor})=19.4 \mathrm{~min}, t_{r}(\mathrm{AM})=23.3 \mathrm{~min}, 92: 8$ e.r.<smiles>CC(=O)c1ccc2cc(CCc3ccccc3)n(-c3ccc(C)cn3)c2c1</smiles>

(R)-Methyl 1-(5-methylpyridin-2-yl)-2-(1-phenylpropan-2-yl)-1H-indole-6-carboxylate (355da): The general procedure $\mathbf{E}$ was followed using methyl 1-(5-methylpyridin-2-yl)-1Hindole-5-carboxylate (354d) $(192.1 \mathrm{mg}, 0.50 \mathrm{mmol})$ and allylbenzene (223a) (177 mg, $1.50 \mathrm{mmol})$. Isolation by column chromatography $(n$-hexane/EtOAc $=10: 1)$ yielded 355da (140.2 $\mathrm{mg}, 73 \%, \mathrm{M} / \mathrm{AM}=94: 6)$ as a yellow oil.

${ }^{1} \mathrm{H}-\mathrm{NMR}\left(400 \mathrm{MHz}, \mathrm{CDCl}_{3}\right): \delta=8.51(\mathrm{dd}, J=2.4,0.7 \mathrm{~Hz}, 1 \mathrm{H}), 7.88(\mathrm{dd}, J=1.5,0.7 \mathrm{~Hz}, 1 \mathrm{H})$, 7.85-7.77 (m, 1H), 7.67 (ddd, $J=8.0,2.4,0.7 \mathrm{~Hz}, 1 \mathrm{H}), 7.59$ (dd, $J=8.0,0.7 \mathrm{~Hz}, 1 \mathrm{H}), 7.20$ $7.06(\mathrm{~m}, 4 \mathrm{H}), 6.97-6.84(\mathrm{~m}, 2 \mathrm{H}), 6.54(\mathrm{~d}, J=0.7 \mathrm{~Hz}, 1 \mathrm{H}), 3.86(\mathrm{~s}, 3 \mathrm{H}), 3.52-3.35(\mathrm{~m}, 0.94 \mathrm{H}$, M), $3.02(\mathrm{dd}, J=13.3,5.5 \mathrm{~Hz}, 1 \mathrm{H}), 2.85$ (t, $J=7.7 \mathrm{~Hz}, 0.12 \mathrm{H}, \mathrm{AM}), 2.61$ (dd, $J=13.3,8.7$ $\mathrm{Hz}, 1 \mathrm{H}), 2.45$ (s, 3H), $1.24(\mathrm{~d}, J=6.8 \mathrm{~Hz}, 3 \mathrm{H})$.

${ }^{13} \mathrm{C}-\mathrm{NMR}\left(100 \mathrm{MHz}, \mathrm{CDCl}_{3}\right): \delta=168.1\left(\mathrm{C}_{\mathrm{q}}\right), 150.1\left(\mathrm{C}_{\mathrm{q}}\right), 150.0(\mathrm{CH}), 148.4\left(\mathrm{C}_{\mathrm{q}}\right), 139.9\left(\mathrm{C}_{\mathrm{q}}\right)$, $139.1(\mathrm{CH}), 136.8\left(\mathrm{C}_{\mathrm{q}}\right), 132.7\left(\mathrm{C}_{\mathrm{q}}\right), 132.1\left(\mathrm{C}_{\mathrm{q}}\right), 129.0(\mathrm{CH}), 128.1(\mathrm{CH}), 126.1(\mathrm{CH}), 123.1$ $\left(\mathrm{C}_{\mathrm{q}}\right), 121.6(\mathrm{CH}), 121.4(\mathrm{CH}), 119.5(\mathrm{CH}), 112.2(\mathrm{CH}), 100.2(\mathrm{CH}), 51.8\left(\mathrm{CH}_{3}\right), 43.6\left(\mathrm{CH}_{2}\right)$, $33.0(\mathrm{CH}), 19.5\left(\mathrm{CH}_{3}\right), 18.1\left(\mathrm{CH}_{3}\right)$.

IR (ATR): 3026, 1710, 1614, 1534, 1444, 1288, $743 \mathrm{~cm}^{-1}$.

MS (ESI) $m / z$ (relative intensity): 407 (30) $[\mathrm{M}+\mathrm{Na}]^{+}, 385(100)[\mathrm{M}+\mathrm{H}]^{+}, 269$ (10).

HR-MS (ESI): $m / z$ calcd. for $\left[\mathrm{C}_{25} \mathrm{H}_{24} \mathrm{~N}_{2} \mathrm{O}_{2}+\mathrm{Na}\right]^{+} 407.1729$, found 407.1730.

$[\alpha]_{\mathrm{D}}^{20}:+12.0\left(\mathrm{c}=0.67, \mathrm{CHCl}_{3}\right)$.

HPLC separation (Chiralpak ${ }^{\circledR}$ IA-3, $n$-hexane $/ i$-PrOH 99:1, $1.0 \mathrm{~mL} / \mathrm{min}$, detection at $273 \mathrm{~nm}$ ): $t_{r}($ major $)=25.1 \mathrm{~min}, t_{r}(\operatorname{minor})=27.5 \mathrm{~min}, t_{r}(\mathrm{AM})=42.9 \mathrm{~min}, 92: 8$ e.r. 


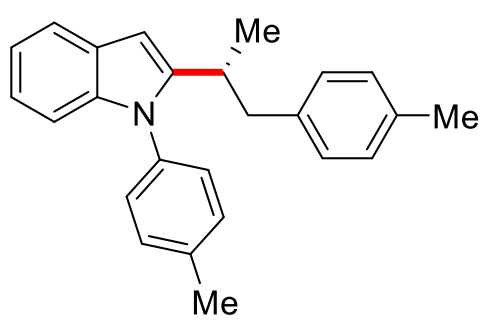

(R)-1-(5-Methylpyridin-2-yl)-2-[1-(p-tolyl)propan-2-yl]-1H-indole (355ab): The general procedure E was followed using 1-(5-methylpyridin-2-yl)-1H-indole (354a) (104.1 mg, $0.50 \mathrm{mmol})$ and 1-allyl-4-methylbenzene (223b) $(198.3 \mathrm{mg}, 1.50 \mathrm{mmol})$. Isolation by column chromatography $(n$-hexane/EtOAc $=30: 1)$ yielded 355ab $(78.2 \mathrm{mg}, 46 \%, \mathrm{M} / \mathrm{AM}=97: 3)$ as a yellow oil.

${ }^{1} \mathrm{H}-\mathrm{NMR}\left(400 \mathrm{MHz}, \mathrm{CDCl}_{3}\right): \delta=8.51(\mathrm{dd}, J=2.5,0.8 \mathrm{~Hz}, 1 \mathrm{H}), 7.65(\mathrm{ddd}, J=8.0,2.5,0.8 \mathrm{~Hz}$, 1H), 7.61-7.57 (m, 1H), 7.23-7.17 (m, 2H), 7.14-7.09 (m, 2H), 6.99 (d, J = 7.8 Hz, 2H), 6.83 $(\mathrm{d}, J=7.8 \mathrm{~Hz}, 2 \mathrm{H}), 6.50(\mathrm{~d}, J=0.8 \mathrm{~Hz}, 1 \mathrm{H}), 3.58-3.38(\mathrm{~m}, 0.97 \mathrm{H}, \mathrm{M}), 2.99(\mathrm{dd}, J=13.4,5.1$ Hz, 1H), 2.86 (t, $J=7.6 \mathrm{~Hz}, 0.06 \mathrm{H}, \mathrm{AM}), 2.60$ (dd, $J=13.4,7.8 \mathrm{~Hz}, 1 \mathrm{H}), 2.44$ (s, 3H), 2.28 (s, $3 \mathrm{H}), 1.21(\mathrm{~d}, J=6.8 \mathrm{~Hz}, 3 \mathrm{H})$.

${ }^{13} \mathrm{C}-\mathrm{NMR}\left(100 \mathrm{MHz}, \mathrm{CDCl}_{3}\right): \delta=149.8(\mathrm{CH}), 149.2\left(\mathrm{C}_{\mathrm{q}}\right), 146.6\left(\mathrm{C}_{\mathrm{q}}\right), 138.8(\mathrm{CH}), 137.4\left(\mathrm{C}_{\mathrm{q}}\right)$, $137.2\left(\mathrm{C}_{\mathrm{q}}\right), 135.2\left(\mathrm{C}_{\mathrm{q}}\right), 132.0\left(\mathrm{C}_{\mathrm{q}}\right), 128.9(\mathrm{CH}), 128.7(\mathrm{CH}), 128.4\left(\mathrm{C}_{\mathrm{q}}\right), 121.4(\mathrm{CH}), 121.2$ $(\mathrm{CH}), 120.3(\mathrm{CH}), 120.0(\mathrm{CH}), 109.9(\mathrm{CH}), 99.9(\mathrm{CH}), 43.2\left(\mathrm{CH}_{2}\right), 32.8(\mathrm{CH}), 20.9\left(\mathrm{CH}_{3}\right)$, $19.3\left(\mathrm{CH}_{3}\right), 18.1\left(\mathrm{CH}_{3}\right)$.

IR (ATR): 3014, 1596, 1482, 1456, 899, 802, $737 \mathrm{~cm}^{-1}$.

MS (ESI) $m / z$ (relative intensity): $363(20)[\mathrm{M}+\mathrm{Na}]^{+}, 341(100)[\mathrm{M}+\mathrm{H}]^{+}, 251(10)$.

HR-MS (ESI): $m / z$ calcd. for $\left[\mathrm{C}_{24} \mathrm{H}_{24} \mathrm{~N}_{2}+\mathrm{Na}\right]^{+} 363.1830$, found 363.1832.

$[\alpha]_{\mathrm{D}}^{20}:+11.5\left(\mathrm{c}=1.04, \mathrm{CHCl}_{3}\right)$.

HPLC separation (Chiralpak ${ }^{\circledR}$ ID-3, $n$-hexane/i-PrOH 99:1, $0.50 \mathrm{~mL} / \mathrm{min}$, detection at 273 $\mathrm{nm}): t_{r}($ major $)=31.6 \mathrm{~min}, t_{r}(\operatorname{minor})=34.0 \mathrm{~min}, t_{r}(\mathrm{AM})=38.9 \mathrm{~min}, 90: 10$ e.r.<smiles>COc1ccc(CCc2cc3ccccc3n2-c2ccc(C)cn2)cc1</smiles>

(R)-2-[1-(4-Methoxyphenyl)propan-2-yl]-1-(5-methylpyridin-2-yl)-1H-indole (355ac):

The general procedure $\mathbf{E}$ was followed using 1-(5-methylpyridin-2-yl)-1H-indole (354a) (104.1 mg, $0.50 \mathrm{mmol}), 1$-allyl-4-methoxybenzene (223c) (222 mg, $1.50 \mathrm{mmol})$. Isolation by 
column chromatography $(n$-hexane/EtOAc $=10: 1)$ yielded 355ac $(108.6 \mathrm{mg}, 61 \%, \mathrm{M} / \mathrm{AM}=$ 92:8) as a yellow oil.

${ }^{1} \mathrm{H}-\mathrm{NMR}\left(300 \mathrm{MHz}, \mathrm{CDCl}_{3}\right): \delta=8.51(\mathrm{dd}, J=2.5,0.8 \mathrm{~Hz}, 1 \mathrm{H}), 7.68(\mathrm{ddd}, J=7.9,7.5,2.1 \mathrm{~Hz}$, 1H) 7.66-7.55 (m, 1H), 7.23-7.09 (m, 4H), $6.85(\mathrm{~d}, J=8.6 \mathrm{~Hz}, 2 \mathrm{H}), 6.72(\mathrm{~d}, J=8.7 \mathrm{~Hz}, 2 \mathrm{H})$, $6.49(\mathrm{~d}, J=0.8 \mathrm{~Hz}, 1 \mathrm{H}), 3.75(\mathrm{~s}, 3 \mathrm{H}), 3.55-3.35(\mathrm{~m}, 0.92 \mathrm{H}, \mathrm{M}), 2.96(\mathrm{dd}, J=13.5,5.2 \mathrm{~Hz}$, 1H), $2.84(\mathrm{t}, J=7.6 \mathrm{~Hz}, 0.16 \mathrm{H}, \mathrm{AM}), 2.53(\mathrm{dd}, J=13.5,8.8 \mathrm{~Hz}, 1 \mathrm{H}), 2.45(\mathrm{~s}, 3 \mathrm{H}), 1.22(\mathrm{~d}, J$ $=6.9 \mathrm{~Hz}, 3 \mathrm{H})$.

${ }^{13} \mathrm{C}-\mathrm{NMR}\left(125 \mathrm{MHz}, \mathrm{CDCl}_{3}\right): \delta=157.7\left(\mathrm{C}_{\mathrm{q}}\right), 149.7(\mathrm{CH}), 149.1\left(\mathrm{C}_{\mathrm{q}}\right), 146.4\left(\mathrm{C}_{\mathrm{q}}\right), 138.7(\mathrm{CH})$, $137.3\left(\mathrm{C}_{\mathrm{q}}\right), 132.3\left(\mathrm{C}_{\mathrm{q}}\right), 131.9\left(\mathrm{C}_{\mathrm{q}}\right), 129.8(\mathrm{CH}), 128.3\left(\mathrm{C}_{\mathrm{q}}\right), 121.4(\mathrm{CH}), 121.1(\mathrm{CH}), 120.2$ $(\mathrm{CH}), 120.0(\mathrm{CH}), 113.4(\mathrm{CH}), 109.9(\mathrm{CH}), 99.9(\mathrm{CH}), 55.2\left(\mathrm{CH}_{3}\right), 42.8\left(\mathrm{CH}_{2}\right), 33.0(\mathrm{CH})$, $19.5\left(\mathrm{CH}_{3}\right), 18.1\left(\mathrm{CH}_{3}\right)$.

IR (ATR): 2961, 1688, 1511, 1483, 1456, 811, $747 \mathrm{~cm}^{-1}$.

MS (ESI) $m / z$ (relative intensity): $379(20)[\mathrm{M}+\mathrm{Na}]^{+}, 357(100)[\mathrm{M}+\mathrm{H}]^{+}, 211(10)$.

HR-MS (ESI): $m / z$ calcd. for $\left[\mathrm{C}_{24} \mathrm{H}_{24} \mathrm{~N}_{2} \mathrm{O}+\mathrm{Na}\right]^{+} 357.1959$, found 357.1961 .

$[\alpha]_{\mathrm{D}^{20}}^{20}+5.0\left(\mathrm{c}=0.80, \mathrm{CHCl}_{3}\right)$.

HPLC separation (Chiralpak ${ }^{\circledR}$ ID-3, $n$-hexane/i-PrOH 98:2, $0.75 \mathrm{~mL} / \mathrm{min}$, detection at 273 $\mathrm{nm}): t_{r}($ major $)=25.6 \min , t_{r}($ minor $)=29.7 \min , t_{r}(\mathrm{AM})=35.4 \mathrm{~min}, 91: 9$ e.r.

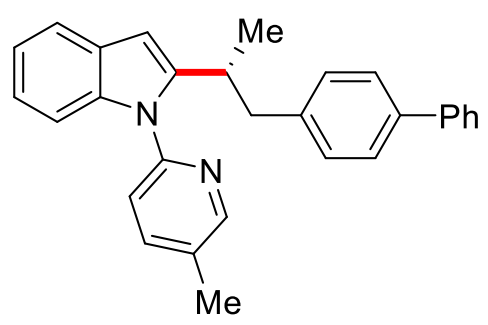

(R)-2-[1-\{(1,1'-Biphenyl)-4-yl\}propan-2-yl]-1-(5-methylpyridin-2-yl)-1H-indole (355ad): The general procedure $\mathbf{E}$ was followed using 1-(5-methylpyridin-2-yl)-1H-indole (354a) (104.1 mg, $0.50 \mathrm{mmol}$ ), 4-allyl-1,1'-biphenyl (223d) (291.2 mg, $1.50 \mathrm{mmol})$. Isolation by column chromatography ( $n$-hexane/EtOAc $=20: 1)$ yielded 355ad $(102.6 \mathrm{mg}, 51 \%, \mathrm{M} / \mathrm{AM}=$ 92:8) as a yellow oil.

${ }^{1} \mathrm{H}-\mathrm{NMR}\left(500 \mathrm{MHz}, \mathrm{CDCl}_{3}\right): \delta=8.53(\mathrm{dd}, J=2.2,0.9 \mathrm{~Hz}, 1 \mathrm{H}), 7.69-7.60(\mathrm{~m}, 2 \mathrm{H}), 7.59-7.54$ $(\mathrm{m}, 2 \mathrm{H}), 7.45-7.40(\mathrm{~m}, 4 \mathrm{H}), 7.36-7.30(\mathrm{~m}, 1 \mathrm{H}), 7.24-7.21(\mathrm{~m}, 1 \mathrm{H}), 7.18(\mathrm{~d}, J=8.1 \mathrm{~Hz}, 1 \mathrm{H})$, 7.14 (ddd, $J=7.2,5.0,1.7 \mathrm{~Hz}, 2 \mathrm{H}), 7.03-6.98(\mathrm{~m}, 2 \mathrm{H}), 6.55(\mathrm{~d}, J=0.8 \mathrm{~Hz}, 1 \mathrm{H}), 3.63-3.50$ (m, $0.92 \mathrm{H}, \mathrm{M}), 3.07$ (dd, $J=13.4,5.4 \mathrm{~Hz}, 1 \mathrm{H}), 2.90(\mathrm{t}, J=7.9 \mathrm{~Hz}, 0.16 \mathrm{H}, \mathrm{AM}), 2.65$ (dd, $J=13.4$, $8.7 \mathrm{~Hz}, 1 \mathrm{H}), 2.45$ (s, 3H), 1.29 (d, $J=6.8 \mathrm{~Hz}, 3 \mathrm{H})$.

${ }^{13} \mathrm{C}-\mathrm{NMR}\left(125 \mathrm{MHz}, \mathrm{CDCl}_{3}\right): \delta=149.8(\mathrm{CH}), 149.1\left(\mathrm{C}_{\mathrm{q}}\right), 146.4\left(\mathrm{C}_{\mathrm{q}}\right), 140.9\left(\mathrm{C}_{\mathrm{q}}\right), 139.4\left(\mathrm{C}_{\mathrm{q}}\right)$, $138.8(\mathrm{CH}), 138.7\left(\mathrm{C}_{\mathrm{q}}\right), 137.4\left(\mathrm{C}_{\mathrm{q}}\right), 132.0\left(\mathrm{C}_{\mathrm{q}}\right), 129.4(\mathrm{CH}), 128.7(\mathrm{CH}), 128.4\left(\mathrm{C}_{\mathrm{q}}\right), 127.0$ 
$(\mathrm{CH}), 126.8(\mathrm{CH}), 126.7(\mathrm{CH}), 121.5(\mathrm{CH}), 121.2(\mathrm{CH}), 120.4(\mathrm{CH}), 120.0(\mathrm{CH}), 109.9(\mathrm{CH})$, $100.0(\mathrm{CH}), 43.4\left(\mathrm{CH}_{2}\right), 32.8(\mathrm{CH}), 19.5\left(\mathrm{CH}_{3}\right), 18.1\left(\mathrm{CH}_{3}\right)$.

IR (ATR): 3025, 1596, 1482, 1470, 1455, 748, $697 \mathrm{~cm}^{-1}$.

MS (ESI) $m / z$ (relative intensity): $425(15)[\mathrm{M}+\mathrm{Na}]^{+}, 403(100)[\mathrm{M}+\mathrm{H}]^{+}, 381$ (10).

HR-MS (ESI): $m / z$ calcd. for $\left[\mathrm{C}_{29} \mathrm{H}_{26} \mathrm{~N}_{2}+\mathrm{Na}\right]^{+} 425.1987$, found 425.1988 .

$[\alpha]_{\mathrm{D}}^{20}:+20.0\left(\mathrm{c}=0.80, \mathrm{CHCl}_{3}\right)$.

HPLC separation (Chiralpak ${ }^{\circledR}$ ID-3, $n$-hexane $/ i$-PrOH 98:2, $1.0 \mathrm{~mL} / \mathrm{min}$, detection at $273 \mathrm{~nm}$ ): $t_{r}($ major $)=16.1 \mathrm{~min}, t_{r}($ minor $)=17.7 \mathrm{~min}, t_{r}(\mathrm{AM})=22.0 \mathrm{~min}, 89: 11$ e.r.

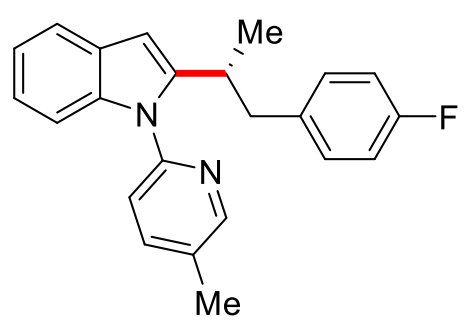

(R)-2-[1-(4-Fluorophenyl)propan-2-yl]-1-(5-methylpyridin-2-yl)-1H-indole (355ae): The general procedure A was followed using 1-(5-methylpyridin-2-yl)-1H-indole (354a) (104.1 mg, $0.50 \mathrm{mmol}$ ) and 1-allyl-4-fluorobenzene (223e) (204.2 mg, $1.50 \mathrm{mmol})$. Isolation by column chromatography ( $n$-hexane/EtOAc $=20: 1)$ yielded 355ae $(89.5 \mathrm{mg}, 52 \%, \mathrm{M} / \mathrm{AM}=$ 94:6) as a yellow oil.

${ }^{1} \mathrm{H}-\mathrm{NMR}\left(400 \mathrm{MHz}, \mathrm{CDCl}_{3}\right): \delta=8.51(\mathrm{dd}, J=2.4,0.8 \mathrm{~Hz}, 1 \mathrm{H}), 7.65(\mathrm{ddd}, J=8.0,7.4,2.4 \mathrm{~Hz}$, $1 \mathrm{H}), 7.62-7.58(\mathrm{~m}, 1 \mathrm{H}), 7.22(\mathrm{dd}, J=2.6,0.8 \mathrm{~Hz}, 1 \mathrm{H}), 7.18(\mathrm{dd}, J=8.0,0.7 \mathrm{~Hz}, 1 \mathrm{H}), 7.15-$ $7.10(\mathrm{~m}, 2 \mathrm{H}), 6.88(\mathrm{~d}, J=3.8 \mathrm{~Hz}, 2 \mathrm{H}), 6.86(\mathrm{~d}, J=3.8 \mathrm{~Hz}, 2 \mathrm{H}), 6.49$ (d, $J=0.9 \mathrm{~Hz}, 1 \mathrm{H}), 3.54-$ $3.44(\mathrm{~m}, 0.94 \mathrm{H}, \mathrm{M}), 2.99(\mathrm{dd}, J=13.5,5.5 \mathrm{~Hz}, 1 \mathrm{H}), 2.89-2.80(\mathrm{t}, J=7.9 \mathrm{~Hz}, 0.12 \mathrm{H}, \mathrm{AM})$, $2.59(\mathrm{dd}, J=13.5,8.5 \mathrm{~Hz}, 1 \mathrm{H}), 2.44(\mathrm{~s}, 3 \mathrm{H}), 1.24(\mathrm{~d}, J=6.9 \mathrm{~Hz}, 3 \mathrm{H})$.

${ }^{13} \mathrm{C}-\mathrm{NMR}\left(100 \mathrm{MHz}, \mathrm{CDCl}_{3}\right): \delta=161.4\left(\mathrm{~d},{ }^{1} J_{\mathrm{C}-\mathrm{F}}=244.2 \mathrm{~Hz}, \mathrm{C}_{\mathrm{q}}\right), 149.8(\mathrm{CH}), 149.1\left(\mathrm{C}_{\mathrm{q}}\right)$, $146.1\left(\mathrm{C}_{\mathrm{q}}\right), 138.8(\mathrm{CH}), 137.3\left(\mathrm{C}_{\mathrm{q}}\right), 135.8\left(\mathrm{C}_{\mathrm{q}}\right), 132.0\left(\mathrm{C}_{\mathrm{q}}\right), 130.4\left(\mathrm{~d},{ }^{3} J_{\mathrm{C}-\mathrm{F}}=8.2 \mathrm{~Hz}, \mathrm{CH}\right), 128.3$ $\left(\mathrm{C}_{\mathrm{q}}\right), 121.5(\mathrm{CH}), 121.1(\mathrm{CH}), 120.4(\mathrm{CH}), 120.0(\mathrm{CH}), 114.7\left(\mathrm{~d},{ }^{2} J_{\mathrm{C}-\mathrm{F}}=24.2 \mathrm{~Hz}, \mathrm{CH}\right), 109.9$ $(\mathrm{CH}), 100.1(\mathrm{CH}), 42.8\left(\mathrm{CH}_{2}\right), 32.8(\mathrm{CH}), 19.4\left(\mathrm{CH}_{3}\right), 18.0\left(\mathrm{CH}_{3}\right)$.

${ }^{19} \mathrm{~F}-\mathrm{NMR}\left(375 \mathrm{MHz}, \mathrm{CDCl}_{3}\right): \delta=-117.5(\mathrm{~m}, 1 \mathrm{~F})$.

IR (ATR): 2965, 1597, 1508, 1482, 1456, 1218, $747 \mathrm{~cm}^{-1}$.

MS (ESI) $m / z$ (relative intensity): $367(15)[\mathrm{M}+\mathrm{Na}]^{+}, 345(100)[\mathrm{M}+\mathrm{H}]^{+}, 211$ (10).

HR-MS (ESI): $m / z$ calcd. for $\left[\mathrm{C}_{23} \mathrm{H}_{21} \mathrm{FN}_{2}+\mathrm{Na}\right]^{+} 367.1578$, found 367.1581 .

$[\alpha]_{\mathrm{D}}^{20}:+11.2\left(\mathrm{c}=1.07, \mathrm{CHCl}_{3}\right)$.

HPLC separation (Chiralpak ${ }^{\circledR}$ IA-3, $n$-hexane $i$-PrOH 99:1, $1.0 \mathrm{~mL} / \mathrm{min}$, detection at $273 \mathrm{~nm}$ ): $t_{r}(\operatorname{minor})=13.3 \mathrm{~min}, t_{r}($ major $)=14.4 \mathrm{~min}, t_{r}(\mathrm{AM})=18.3 \mathrm{~min}, 8: 92$ e.r. 
<smiles>COc1ccc(CCc2cc3ccccc3n2-c2ccc(C)cn2)cc1OC</smiles>

(R)-2-[1-(3,4-Dimethoxyphenyl)propan-2-yl]-1-(5-methylpyridin-2-yl)-1H-indole

(355af): The general procedure $\mathbf{E}$ was followed using 1-(5-methylpyridin-2-yl)-1H-indole (354a) (104.1 mg, $0.50 \mathrm{mmol}$ ), 4-allyl-1,2-dimethoxybenzene (223f) (267.2 mg, $1.50 \mathrm{mmol}$ ). Isolation by column chromatography $(n$-hexane/EtOAc $=5: 1)$ yielded 355af $(121.7 \mathrm{mg}, 63 \%$, $\mathrm{M} / \mathrm{AM}=91: 9)$ as a yellow oil.

${ }^{1} \mathrm{H}-\mathrm{NMR}\left(500 \mathrm{MHz}, \mathrm{CDCl}_{3}\right): \delta=8.48(\mathrm{dd}, J=2.6,0.8 \mathrm{~Hz}, 0.91 \mathrm{H}, \mathrm{M}), 8.46(\mathrm{dd}, J=2.6,0.8$ $\mathrm{Hz}, 0.09 \mathrm{H}, \mathrm{AM}), 7.62$ (ddd, $J=8.0,2.6,0.8 \mathrm{~Hz}, 1 \mathrm{H}), 7.60-7.54(\mathrm{~m}, 1 \mathrm{H}), 7.21-7.15(\mathrm{~m}, 1 \mathrm{H})$, 7.14-7.06 (m, 3H), $6.65(\mathrm{~d}, J=8.0 \mathrm{~Hz}, 1 \mathrm{H}), 6.51-6.43(\mathrm{~m}, 2 \mathrm{H}), 6.29(\mathrm{~d}, J=1.9 \mathrm{~Hz}, 1 \mathrm{H}), 3.81$ $(\mathrm{s}, 3 \mathrm{H}), 3.62(\mathrm{~s}, 3 \mathrm{H}), 3.53-3.43(\mathrm{~m}, 1 \mathrm{H}), 2.87(\mathrm{dd}, J=13.4,5.7 \mathrm{~Hz}, 1 \mathrm{H}), 2.53(\mathrm{dd}, J=13.4,6.9$ $\mathrm{Hz}, 1 \mathrm{H}), 2.42(\mathrm{~s}, 3 \mathrm{H}), 1.27$ (d, $J=6.9 \mathrm{~Hz}, 3 \mathrm{H})$.

${ }^{13} \mathrm{C}-\mathrm{NMR}\left(125 \mathrm{MHz}, \mathrm{CDCl}_{3}\right): \delta=149.6(\mathrm{CH}), 149.1\left(\mathrm{C}_{\mathrm{q}}\right), 148.3\left(\mathrm{C}_{\mathrm{q}}\right), 147.1\left(\mathrm{C}_{\mathrm{q}}\right), 146.2\left(\mathrm{C}_{\mathrm{q}}\right)$, $138.7(\mathrm{CH}), 137.3\left(\mathrm{C}_{\mathrm{q}}\right), 132.7\left(\mathrm{C}_{\mathrm{q}}\right), 131.9\left(\mathrm{C}_{\mathrm{q}}\right), 128.3\left(\mathrm{C}_{\mathrm{q}}\right), 121.4(\mathrm{CH}), 121.2(\mathrm{CH}), 120.9$ $(\mathrm{CH}), 120.3(\mathrm{CH}), 119.9(\mathrm{CH}), 111.9(\mathrm{CH}), 110.7(\mathrm{CH}), 109.8(\mathrm{CH}), 100.1(\mathrm{CH}), 55.8\left(\mathrm{CH}_{3}\right)$, $55.4\left(\mathrm{CH}_{3}\right), 43.5\left(\mathrm{CH}_{2}\right), 32.9(\mathrm{CH}), 19.3\left(\mathrm{CH}_{3}\right), 18.0\left(\mathrm{CH}_{3}\right)$.

IR (ATR): 2933, 1590, 1515, 1442, 1410, 817, $787 \mathrm{~cm}^{-1}$.

MS (ESI) $m / z$ (relative intensity): 409 (15) $[\mathrm{M}+\mathrm{Na}]^{+}, 387$ (100) $[\mathrm{M}+\mathrm{H}]^{+}, 211$ (10). HR-MS (ESI): $m / z$ calcd. for $\left[\mathrm{C}_{25} \mathrm{H}_{26} \mathrm{~N}_{2} \mathrm{O}_{2}+\mathrm{Na}\right]^{+} 409.1888$, found 409.1886 .

$[\alpha]_{\mathrm{D}}^{20}:+20.0\left(\mathrm{c}=1.00, \mathrm{CHCl}_{3}\right)$.

HPLC separation (Chiralpak ${ }^{\circledR}$ IA-3, $n$-hexane $/ i$-PrOH 90:10, $1.00 \mathrm{~mL} / \mathrm{min}$, detection at 273 $\mathrm{nm}): t_{r}($ major $)=10.4 \min , t_{r}(\operatorname{minor})=11.4 \min , t_{r}(\mathrm{AM})=14.4 \mathrm{~min}, 92: 8$ e.r.

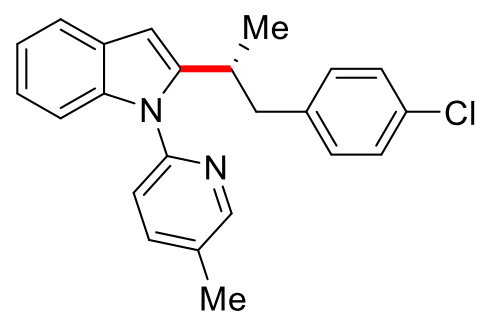

(R)-2-[1-(4-Chlorophenyl)propan-2-yl]-1-(5-methylpyridin-2-yl)-1H-indole (355ag): The general procedure $\mathbf{E}$ was followed using 1-(5-methylpyridin-2-yl)-1H-indole (354a) (104.1 mg, $0.50 \mathrm{mmol})$, 1-allyl-4-chlorobenzene (223g) (228 mg, $1.50 \mathrm{mmol})$. Isolation by 
column chromatography $(n$-hexane/EtOAc $=20: 1)$ yielded 355ag $(73.8 \mathrm{mg}, 41 \%, \mathrm{M} / \mathrm{AM}=$ 93:7) as a yellow oil.

${ }^{1} \mathrm{H}-\mathrm{NMR}\left(400 \mathrm{MHz}, \mathrm{CDCl}_{3}\right): \delta=8.49(\mathrm{dd}, J=2.4,0.8 \mathrm{~Hz}, 1 \mathrm{H}), 7.65(\mathrm{ddd}, J=8.0,2.4,0.7 \mathrm{~Hz}$, 1H), 7.60-7.57 (m, 1H), 7.22-7.18 (m, 1H), 7.18-7.14 (m, 1H), 7.14-7.09 (m, 4H), 6.83 (d, J $=8.1 \mathrm{~Hz}, 2 \mathrm{H}), 6.48(\mathrm{~d}, J=0.8 \mathrm{~Hz}, 1 \mathrm{H}), 3.57-3.41(\mathrm{~m}, 0.93 \mathrm{H}, \mathrm{M}), 2.96(\mathrm{dd}, J=13.4,5.7 \mathrm{~Hz}$, 1H), $2.80(\mathrm{t}, J=8.4 \mathrm{~Hz}, 0.14 \mathrm{H}, \mathrm{AM}), 2.58(\mathrm{dd}, J=13.4,8.3 \mathrm{~Hz}, 1 \mathrm{H}), 2.44(\mathrm{~s}, 3 \mathrm{H}), 1.23(\mathrm{~d}, J$ $=6.9 \mathrm{~Hz}, 3 \mathrm{H})$.

${ }^{13} \mathrm{C}-\mathrm{NMR}\left(100 \mathrm{MHz}, \mathrm{CDCl}_{3}\right): \delta=149.8(\mathrm{CH}), 149.1\left(\mathrm{C}_{\mathrm{q}}\right), 145.9\left(\mathrm{C}_{\mathrm{q}}\right), 138.8(\mathrm{CH}), 138.6\left(\mathrm{C}_{\mathrm{q}}\right)$, $137.3\left(\mathrm{C}_{\mathrm{q}}\right), 132.0\left(\mathrm{C}_{\mathrm{q}}\right), 131.6\left(\mathrm{C}_{\mathrm{q}}\right), 130.3(\mathrm{CH}), 128.3\left(\mathrm{C}_{\mathrm{q}}\right), 128.1(\mathrm{CH}), 121.6(\mathrm{CH}), 121.1$ $(\mathrm{CH}), 120.4(\mathrm{CH}), 120.0(\mathrm{CH}), 110.0(\mathrm{CH}), 100.2(\mathrm{CH}), 43.1\left(\mathrm{CH}_{2}\right), 32.7(\mathrm{CH}), 19.5\left(\mathrm{CH}_{3}\right)$, $18.1\left(\mathrm{CH}_{3}\right)$.

IR (ATR): 2965, 1687, 1483, 1456, 1216, 839, $738 \mathrm{~cm}^{-1}$.

MS (ESI) $m / z$ (relative intensity): $383(15)\left[\mathrm{M}+\mathrm{Na},{ }^{35} \mathrm{Cl}\right]^{+}, 361(100)\left[\mathrm{M}+\mathrm{H},{ }^{35} \mathrm{Cl}\right]^{+}, 211(10)$, $173(5)$.

HR-MS (ESI): $m / z$ calcd. for $\left[\mathrm{C}_{23} \mathrm{H}_{21}{ }^{35} \mathrm{ClN}_{2}+\mathrm{Na}\right]^{+} 383.1284$, found 383.1285 .

$[\alpha]_{\mathrm{D}}^{20}:+8.0\left(\mathrm{c}=1.0, \mathrm{CHCl}_{3}\right)$.

HPLC separation (Chiralpak ${ }^{\circledR}$ IA-3, $n$-hexane/i-PrOH 95:5, $0.75 \mathrm{~mL} / \mathrm{min}$, detection at $273 \mathrm{~nm}$ ): $t_{r}($ minor $)=11.6 \mathrm{~min}, t_{r}($ major $)=12.3 \mathrm{~min}, t_{r}(\mathrm{AM})=14.4 \mathrm{~min}, 12: 88$ e.r.

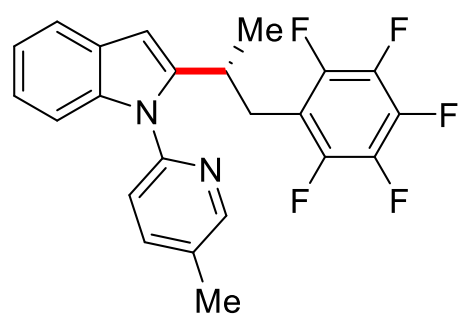

(R)-1-(5-methylpyridin-2-yl)-2-[1-(perfluorophenyl)propan-2-yl]-1H-indole (355ah): The general procedure $\mathbf{E}$ was followed using 1-(5-methylpyridin-2-yl)-1H-indole (354a) (104.1 mg, $0.50 \mathrm{mmol})$, 1-allyl-2,3,4,5,6-pentafluorobenzene (223h) (312.2 mg, $1.50 \mathrm{mmol})$. Isolation by column chromatography $(n$-hexane/EtOAc $=20: 1)$ yielded 355ah $(114.4 \mathrm{mg}, 55 \%$, $\mathrm{M} / \mathrm{AM}=96: 4)$ as a yellow oil.

${ }^{1} \mathrm{H}-\mathrm{NMR}\left(400 \mathrm{MHz}, \mathrm{CDCl}_{3}\right): \delta=8.47(\mathrm{dd}, J=2.4,0.8 \mathrm{~Hz}, 1 \mathrm{H}), 7.68(\mathrm{ddd}, J=8.0,7.5,2.4 \mathrm{~Hz}$, 1H), 7.62-7.55 (m, 1H), 7.27-7.22 (m, 1H), 7.22-7.17 (m, 1H), 7.14-7.07 (m, 2H), 6.54 (d, $J$ $=0.8 \mathrm{~Hz}, 1 \mathrm{H}), 3.68-3.50(\mathrm{~m}, 0.96 \mathrm{H}, \mathrm{M}), 3.03(\mathrm{dd}, J=13.6,6.1 \mathrm{~Hz}, 1 \mathrm{H}), 2.88(\mathrm{t}, J=7.9 \mathrm{~Hz}$, 0.08H, AM), $2.78(\mathrm{dd}, J=13.6,8.8 \mathrm{~Hz}, 1 \mathrm{H}), 2.45(\mathrm{~s}, 3 \mathrm{H}), 1.28(\mathrm{~d}, J=7.0 \mathrm{~Hz}, 3 \mathrm{H})$.

${ }^{13} \mathrm{C}-\mathrm{NMR}\left(100 \mathrm{MHz}, \mathrm{CDCl}_{3}\right): \delta=150.0(\mathrm{CH}), 148.8\left(\mathrm{C}_{\mathrm{q}}\right), 145.2\left(\mathrm{dm},{ }^{1} J_{\mathrm{C}-\mathrm{F}}=243.2 \mathrm{~Hz}, \mathrm{C}_{\mathrm{q}}\right)$, $144.8\left(\mathrm{C}_{\mathrm{q}}\right), 139.9\left(\mathrm{dm},{ }^{1} J_{\mathrm{C}-\mathrm{F}}=253.2 \mathrm{~Hz}, \mathrm{C}_{\mathrm{q}}\right), 138.8(\mathrm{CH}), 137.4\left(\mathrm{C}_{\mathrm{q}}\right), 137.2\left(\mathrm{dm},{ }^{1} J_{\mathrm{C}-\mathrm{F}}=251.2\right.$ 
$\left.\mathrm{Hz}, \mathrm{C}_{\mathrm{q}}\right), 132.2\left(\mathrm{C}_{\mathrm{q}}\right), 128.2\left(\mathrm{C}_{\mathrm{q}}\right), 121.9(\mathrm{CH}), 120.8(\mathrm{CH}), 120.5(\mathrm{CH}), 120.2(\mathrm{CH}), 113.2\left(\mathrm{t},{ }^{2} J_{\mathrm{C}-}\right.$ $\left.\mathrm{F}=24.2, \mathrm{C}_{\mathrm{q}}\right), 110.0(\mathrm{CH}), 100.2(\mathrm{CH}), 30.6(\mathrm{CH}), 30.1\left(\mathrm{CH}_{2}\right), 19.5\left(\mathrm{CH}_{3}\right), 18.0\left(\mathrm{CH}_{3}\right)$.

${ }^{19} \mathrm{~F}-\mathrm{NMR}\left(375 \mathrm{MHz}, \mathrm{CDCl}_{3}\right): \delta=-142.7$ (m, 2F), -157.4 (m, 1F), -163.0 (m, 2F).

IR (ATR): 2974, 1596, 1519, 1502, 1146, 971, $789 \mathrm{~cm}^{-1}$.

MS (ESI) $m / z$ (relative intensity): $439(15)[\mathrm{M}+\mathrm{Na}]^{+}, 417(100)[\mathrm{M}+\mathrm{H}]^{+}, 211(10)$.

HR-MS (ESI): $m / z$ calcd. for $\left[\mathrm{C}_{23} \mathrm{H}_{17} \mathrm{~F}_{5} \mathrm{~N}_{2}+\mathrm{H}\right]^{+} 417.1380$, found 417.1385 .

$[\alpha]_{\mathrm{D}}^{20}:+4.0\left(\mathrm{c}=1.00, \mathrm{CHCl}_{3}\right)$.

HPLC separation (Chiralpak ${ }^{\circledR}$ IA-3, $n$-hexane $/ i$-PrOH 95:5, $1.0 \mathrm{~mL} / \mathrm{min}$, detection at $273 \mathrm{~nm}$ ): $t_{r}($ major $)=6.5 \mathrm{~min}, t_{r}($ minor $)=7.9 \min , t_{r}(\mathrm{AM})=17.6 \mathrm{~min}, 83: 17$ e.r.

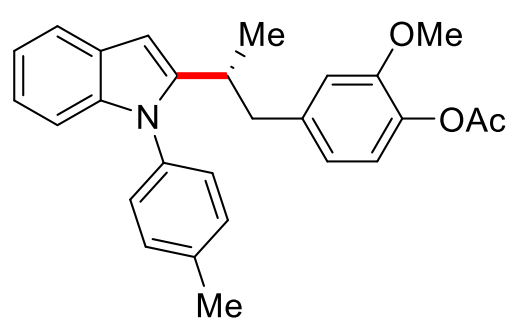

(R)-2-Methoxy-5-(2-(1-(5-methylpyridin-2-yl)-1H-indol-2-yl)propyl)phenyl

acetate

(355aj): A modified general procedure $\mathbf{E}$ was followed using 5-bromo-1-(5-methylpyridin-2yl)-1H-indole (354a) $(104.1 \mathrm{mg}, \quad 0.50 \mathrm{mmol}), \quad 5$-allyl-2-methoxyphenyl acetate (223j) $(309.2 \mathrm{mg}, 1.50 \mathrm{mmol})$ at $60{ }^{\circ} \mathrm{C}$. Isolation by column chromatography ( $n$-hexane/EtOAc $\left.=5: 1\right)$ yielded 355aj (113.9 $\mathrm{mg}, 55 \%, \mathrm{M} / \mathrm{AM}=75: 25)$ as a yellow oil.

Major isomer (M): ${ }^{1} \mathrm{H}-\mathrm{NMR}\left(500 \mathrm{MHz}, \mathrm{CDCl}_{3}\right): \delta=8.46(\mathrm{dd}, J=2.4,0.8 \mathrm{~Hz}, 1 \mathrm{H}), 7.64-7.60$ (m, 1H), 7.60-7.55 (m, 1H), 7.15 (dd, $J=7.2,0.8 \mathrm{~Hz}, 1 \mathrm{H}), 7.13-7.10(\mathrm{~m}, 1 \mathrm{H}), 7.09-7.08$ (m, $1 \mathrm{H}), 7.03(\mathrm{~d}, J=8.0 \mathrm{~Hz}, 1 \mathrm{H}), 6.77(\mathrm{~d}, J=8.0 \mathrm{~Hz}, 1 \mathrm{H}), 6.52(\mathrm{~d}, J=0.8 \mathrm{~Hz}, 1 \mathrm{H}), 6.45-6.41(\mathrm{~m}$, $1 \mathrm{H}), 6.34(\mathrm{~d}, J=1.9 \mathrm{~Hz}, 1 \mathrm{H}), 3.51(\mathrm{~s}, 3 \mathrm{H}), 3.49-3.41(\mathrm{~m}, 1 \mathrm{H}), 2.91-2.80(\mathrm{~m}, 1 \mathrm{H}), 2.72-2.54$ (m, 1H), 2.40 (s, 3H), 2.27 (s, 3H), 1.31 (d, $J=6.8 \mathrm{~Hz}, 3 \mathrm{H})$.

${ }^{13} \mathrm{C}-\mathrm{NMR}\left(125 \mathrm{MHz}, \mathrm{CDCl}_{3}\right): \delta=169.2\left(\mathrm{C}_{\mathrm{q}}\right), 150.4(\mathrm{CH}), 149.6(\mathrm{CH}), 148.9\left(\mathrm{C}_{\mathrm{q}}\right), 146.0\left(\mathrm{C}_{\mathrm{q}}\right)$, $140.9\left(\mathrm{C}_{\mathrm{q}}\right), 139.1\left(\mathrm{C}_{\mathrm{q}}\right), 138.9(\mathrm{CH}), 137.8\left(\mathrm{C}_{\mathrm{q}}\right), 137.2\left(\mathrm{C}_{\mathrm{q}}\right), 131.9\left(\mathrm{C}_{\mathrm{q}}\right), 128.3\left(\mathrm{C}_{\mathrm{q}}\right), 122.0(\mathrm{CH})$, $121.5(\mathrm{CH}), 121.1(\mathrm{CH}), 120.3(\mathrm{CH}), 119.9(\mathrm{CH}), 112.9(\mathrm{CH}), 109.9(\mathrm{CH}), 99.9(\mathrm{CH}), 55.4$ $\left(\mathrm{CH}_{3}\right), 44.2\left(\mathrm{CH}_{2}\right), 32.9(\mathrm{CH}), 20.6\left(\mathrm{CH}_{3}\right), 19.7\left(\mathrm{CH}_{3}\right), 18.0\left(\mathrm{CH}_{3}\right)$.

Minor isomer (AM): (one carbon signal less due to overlapping with major isomer) ${ }^{1} \mathrm{H}-\mathrm{NMR}$ $\left(500 \mathrm{MHz}, \mathrm{CDCl}_{3}\right): \delta=8.43(\mathrm{dd}, J=2.4,0.8 \mathrm{~Hz}, 1 \mathrm{H}), 7.65(\mathrm{dd}, J=2.4,0.8 \mathrm{~Hz}, 1 \mathrm{H}), 7.56-$ $7.55(\mathrm{~m}, 1 \mathrm{H}), 7.28-7.25(\mathrm{~m}, 1 \mathrm{H}), 7.25-7.24(\mathrm{~m}, 1 \mathrm{H}), 7.08-7.06(\mathrm{~m}, 2 \mathrm{H}), 6.88(\mathrm{~d}, J=8.0 \mathrm{~Hz}$, $1 \mathrm{H}), 6.68(\mathrm{~d}, J=1.9 \mathrm{~Hz}, 1 \mathrm{H}), 6.65(\mathrm{dd}, J=8.0,1.9 \mathrm{~Hz}, 1 \mathrm{H}), 6.46(\mathrm{~d}, J=1.9 \mathrm{~Hz}, 1 \mathrm{H}), 3.76(\mathrm{~s}$, $3 \mathrm{H}), 2.93-2.82(\mathrm{~m}, 2 \mathrm{H}), 2.68-2.55(\mathrm{~m}, 2 \mathrm{H}), 2.41$ (s, 3H), 2.29 (s, 3H), 1.86 (ddd, $J=15.3,8.3$, $7.0 \mathrm{~Hz}, 2 \mathrm{H})$. 
${ }^{13} \mathrm{C}-\mathrm{NMR}\left(125 \mathrm{MHz}, \mathrm{CDCl}_{3}\right): \delta=169.2\left(\mathrm{C}_{\mathrm{q}}\right), 150.6\left(\mathrm{C}_{\mathrm{q}}\right), 149.8(\mathrm{CH}), 148.9\left(\mathrm{C}_{\mathrm{q}}\right), 146.0\left(\mathrm{C}_{\mathrm{q}}\right)$, $141.0\left(\mathrm{C}_{\mathrm{q}}\right), 138.8(\mathrm{CH}), 137.6\left(\mathrm{C}_{\mathrm{q}}\right), 137.3\left(\mathrm{C}_{\mathrm{q}}\right), 131.8\left(\mathrm{C}_{\mathrm{q}}\right), 128.4\left(\mathrm{C}_{\mathrm{q}}\right), 122.3(\mathrm{CH}), 120.5(\mathrm{CH})$, $120.4(\mathrm{CH}), 120.4(\mathrm{CH}), 119.8(\mathrm{CH}), 112.5(\mathrm{CH}), 110.0(\mathrm{CH}), 101.9(\mathrm{CH}), 99.9(\mathrm{CH}), 55.7$ $\left(\mathrm{CH}_{3}\right), 35.2\left(\mathrm{CH}_{2}\right), 30.1\left(\mathrm{CH}_{2}\right), 26.8\left(\mathrm{CH}_{2}\right), 17.8\left(\mathrm{CH}_{3}\right)$.

IR (ATR): 3011, 1762, 1598, 1482, 1456, 1197, 1034, $749 \mathrm{~cm}^{-1}$.

MS (ESI) $m / z$ (relative intensity): $437(10)[\mathrm{M}+\mathrm{Na}]^{+}, 415(100)[\mathrm{M}+\mathrm{H}]^{+}, 275(10)$.

HR-MS (ESI): $m / z$ calcd. for $\left[\mathrm{C}_{26} \mathrm{H}_{26} \mathrm{~N}_{2} \mathrm{O}_{3}+\mathrm{H}\right]^{+} 415.2010$, found 415.2016.

$[\alpha]_{\mathrm{D}}^{20}:+3.9\left(\mathrm{c}=1.02, \mathrm{CHCl}_{3}\right)$.

HPLC separation (Chiralpak ${ }^{\circledR}$ ID-3, $n$-hexane/i-PrOH 90:10, $1.0 \mathrm{~mL} / \mathrm{min}$, detection at 273 $\mathrm{nm}): t_{r}($ minor $)=15.5 \mathrm{~min}, t_{r}($ major $)=16.5 \mathrm{~min}, t_{r}(\mathrm{AM})=32.8 \mathrm{~min}, 12: 88$ e.r.

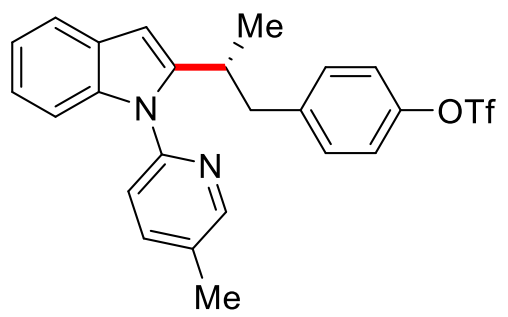

\section{(R)-4-[2-\{1-(5-Methylpyridin-2-yl)-1H-indol-2-yl\}propyl]phenyl}

trifluoromethanesulfonate (355ak): The general procedure $\mathbf{E}$ was followed using 1-(5methylpyridin-2-yl)-1H-indole $\quad(\mathbf{3 5 4 a}) \quad(104.1 \mathrm{mg}, \quad 0.50 \mathrm{mmol}), \quad$ ethyl 4-allylphenyl trifluoromethanesulfonate $\mathbf{( 2 2 3 k}) \quad(399.2 \mathrm{mg}, \quad 1.50 \mathrm{mmol})$. Isolation by column chromatography $(n$-hexane/EtOAc $=30: 1)$ yielded 355ak $(99.5 \mathrm{mg}, 42 \%, \mathrm{M} / \mathrm{AM}=96: 4)$ as a yellow oil.

${ }^{1} \mathrm{H}-\mathrm{NMR}\left(400 \mathrm{MHz}, \mathrm{CDCl}_{3}\right): \delta=8.48(\mathrm{dd}, J=2.4,0.8 \mathrm{~Hz}, 1 \mathrm{H}), 7.65(\mathrm{ddd}, J=8.0,2.4,0.8 \mathrm{~Hz}$, 1H), 7.60-7.57 (m, 1H), 7.21-7.16 (m, 1H), 7.14-7.09 (m, 3H), 7.05 (d, J=8.7 Hz, 2H), 6.97 $(\mathrm{d}, J=8.7 \mathrm{~Hz}, 2 \mathrm{H}), 6.48(\mathrm{~d}, J=0.8 \mathrm{~Hz}, 1 \mathrm{H}), 3.59-3.40(\mathrm{~m}, 0.96 \mathrm{H}, \mathrm{M}), 3.02(\mathrm{dd}, J=13.4,5.9$ Hz, 1H), 2.85 (t, $J=7.5 \mathrm{~Hz}, 0.08 \mathrm{H}, \mathrm{AM}), 2.65$ (dd, $J=13.4,8.2 \mathrm{~Hz}, 1 \mathrm{H}), 2.44(\mathrm{~s}, 3 \mathrm{H}), 1.25$ $(\mathrm{d}, J=7.0 \mathrm{~Hz}, 3 \mathrm{H})$.

${ }^{13} \mathrm{C}-\mathrm{NMR}\left(100 \mathrm{MHz}, \mathrm{CDCl}_{3}\right): \delta=149.8(\mathrm{CH}), 148.9\left(\mathrm{C}_{\mathrm{q}}\right), 147.8\left(\mathrm{C}_{\mathrm{q}}\right), 145.6\left(\mathrm{C}_{\mathrm{q}}\right), 140.9\left(\mathrm{C}_{\mathrm{q}}\right)$, $138.9(\mathrm{CH}), 137.3\left(\mathrm{C}_{\mathrm{q}}\right), 132.1\left(\mathrm{C}_{\mathrm{q}}\right), 130.7(\mathrm{CH}), 128.3\left(\mathrm{C}_{\mathrm{q}}\right), 121.7(\mathrm{CH}), 121.0(\mathrm{CH}), 120.8$ $(\mathrm{CH}), 120.5(\mathrm{CH}), 120.1(\mathrm{CH}), 119.2\left(\mathrm{q},{ }^{1} J_{\mathrm{C}-\mathrm{F}}=319.1 \mathrm{~Hz}, \mathrm{C}_{\mathrm{q}}\right), 109.9(\mathrm{CH}), 100.3(\mathrm{CH}), 43.2$ $\left(\mathrm{CH}_{2}\right), 32.7(\mathrm{CH}), 19.6\left(\mathrm{CH}_{3}\right), 18.0\left(\mathrm{CH}_{3}\right)$.

${ }^{19} \mathrm{~F}-\mathrm{NMR}\left(375 \mathrm{MHz}, \mathrm{CDCl}_{3}\right): \delta=-73.0(\mathrm{~m}, 1 \mathrm{~F})$.

IR (ATR): 2967, 1596, 1483, 1456, 1208, 888, $710 \mathrm{~cm}^{-1}$.

MS (ESI) $m / z$ (relative intensity): $497(10)[\mathrm{M}+\mathrm{Na}]^{+}, 475(100)[\mathrm{M}+\mathrm{H}]^{+}$.

HR-MS (ESI): $m / z$ calcd. for $\left[\mathrm{C}_{24} \mathrm{H}_{21} \mathrm{~F}_{3} \mathrm{~N}_{2} \mathrm{O}_{3} \mathrm{~S}+\mathrm{Na}\right]^{+} 497.1119$, found 497.1117 . 
$[\alpha]_{\mathrm{D}}^{20}:+4.4\left(\mathrm{c}=0.90, \mathrm{CHCl}_{3}\right)$.

HPLC separation (Chiralpak ${ }^{\circledR}$ ID-3, $n$-hexane/i-PrOH 99:1, $0.75 \mathrm{~mL} / \mathrm{min}$, detection at 273 $\mathrm{nm}): t_{r}($ minor $)=21.0 \mathrm{~min}, t_{r}($ major $)=23.2 \mathrm{~min}, t_{r}(\mathrm{AM})=32.6 \mathrm{~min}, 13: 87$ e.r.

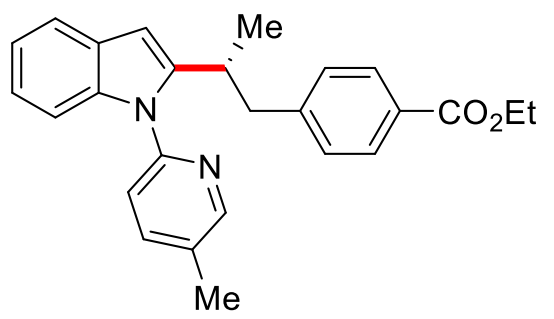

(R)-Ethyl 4-[2-\{1-(5-methylpyridin-2-yl)-1H-indol-2-yl\}propyl]benzoate (355al): The general procedure $\mathbf{E}$ was followed using 1-(5-methylpyridin-2-yl)-1H-indole (354a) (104.1 mg, $0.50 \mathrm{mmol}$ ), ethyl 4-allylbenzoate (2231) (286.5 mg, $1.50 \mathrm{mmol})$. Isolation by column chromatography $(n$-hexane/EtOAc $=10: 1)$ yielded 355al $(111.7 \mathrm{mg}, 56 \%, \mathrm{M} / \mathrm{AM}=$ 86:14) as a yellow oil.

${ }^{1} \mathrm{H}-\mathrm{NMR}\left(300 \mathrm{MHz}, \mathrm{CDCl}_{3}\right): \delta=8.54(\mathrm{dd}, J=2.4,0.8 \mathrm{~Hz}, 1 \mathrm{H}), 7.93-7.84(\mathrm{~m}, 2 \mathrm{H}), 7.74-7.55$ $(\mathrm{m}, 2 \mathrm{H}), 7.27-7.12(\mathrm{~m}, 4 \mathrm{H}), 7.08-6.98(\mathrm{~m}, 2 \mathrm{H}), 6.53(\mathrm{~d}, J=0.8 \mathrm{~Hz}, 1 \mathrm{H}), 4.39(\mathrm{q}, J=7.1 \mathrm{~Hz}$, 2H), 3.66-3.49 (m, 0.86H, M), 3.10 (dd, $J=13.4,5.5 \mathrm{~Hz}, 1 \mathrm{H}), 2.89$ (t, $J=7.6 \mathrm{~Hz}, 0.28 \mathrm{H}, \mathrm{AM})$, $2.70(\mathrm{dd}, J=13.4,6.5 \mathrm{~Hz}, 1 \mathrm{H}), 2.48(\mathrm{~s}, 3 \mathrm{H}), 1.41(\mathrm{t}, J=7.1 \mathrm{~Hz}, 3 \mathrm{H}), 1.27$ (d, $J=6.8 \mathrm{~Hz}, 3 \mathrm{H})$. ${ }^{13} \mathrm{C}-\mathrm{NMR}\left(75 \mathrm{MHz}, \mathrm{CDCl}_{3}\right): \delta=166.7\left(\mathrm{C}_{\mathrm{q}}\right), 149.9(\mathrm{CH}), 149.1\left(\mathrm{C}_{\mathrm{q}}\right), 145.9\left(\mathrm{C}_{\mathrm{q}}\right), 145.7\left(\mathrm{C}_{\mathrm{q}}\right)$, $138.9(\mathrm{CH}), 137.4\left(\mathrm{C}_{\mathrm{q}}\right), 132.2\left(\mathrm{C}_{\mathrm{q}}\right), 129.4(\mathrm{CH}), 129.1(\mathrm{CH}), 128.4\left(\mathrm{C}_{\mathrm{q}}\right), 128.3\left(\mathrm{C}_{\mathrm{q}}\right), 121.7$ $(\mathrm{CH}), 121.1(\mathrm{CH}), 120.5(\mathrm{CH}), 120.1(\mathrm{CH}), 110.0(\mathrm{CH}), 100.3(\mathrm{CH}), 60.8\left(\mathrm{CH}_{2}\right), 43.8\left(\mathrm{CH}_{2}\right)$, $32.7(\mathrm{CH}), 19.5\left(\mathrm{CH}_{3}\right), 18.1\left(\mathrm{CH}_{3}\right), 14.4\left(\mathrm{CH}_{3}\right)$.

IR (ATR): 2976, 1722, 1609, 1483, 1275, $844 \mathrm{~cm}^{-1}$.

MS (ESI) $m / z$ (relative intensity): $421(30)[\mathrm{M}+\mathrm{Na}]^{+}, 399(100)[\mathrm{M}+\mathrm{H}]^{+}, 381(5), 211(10)$. HR-MS (ESI): $m / z$ calcd. for $\left[\mathrm{C}_{26} \mathrm{H}_{26} \mathrm{~N}_{2} \mathrm{O}_{2}+\mathrm{Na}\right]^{+} 421.1887$, found 421.1886 .

$[\alpha]_{\mathrm{D}}^{20}:+3.6\left(\mathrm{c}=1.10, \mathrm{CHCl}_{3}\right)$.

HPLC separation (Chiralpak ${ }^{\circledR}$ IB-3, $n$-hexane/EtOAc 90:10, $1.0 \mathrm{~mL} / \mathrm{min}$, detection at 280 $\mathrm{nm}): t_{r}($ major $)=9.9 \mathrm{~min}, t_{r}($ minor $)=12.1 \mathrm{~min}, t_{r}(\mathrm{AM})=17.3 \mathrm{~min}, 86: 14$ e.r.<smiles>Cc1ccc(-n2c(CCc3ccc(-c4ccccc4)cc3)cc3cc(Br)ccc32)nc1</smiles>

(R)-2-(1-([1,1'-Biphenyl]-4-yl)propan-2-yl)-5-bromo-1-(5-methylpyridin-2-yl)-1H-indole (355bm): The general procedure $\mathbf{E}$ was followed using 5-bromo-1-(5-methylpyridin-2-yl)-1H- 
indole (354b) (143 mg, 0.50 mmol), 4-allyl-1,1'-biphenyl (223m) (291.2 mg, $1.50 \mathrm{mmol})$. Isolation by column chromatography $(n$-hexane/EtOAc $=20: 1)$ yielded 355bm $(127.2 \mathrm{mg}$, $53 \%, \mathrm{M} / \mathrm{AM}=92: 8)$ as a yellow oil.

${ }^{1} \mathrm{H}-\mathrm{NMR}\left(300 \mathrm{MHz}, \mathrm{CDCl}_{3}\right): \delta=8.54(\mathrm{dd}, J=2.4,0.9 \mathrm{~Hz}, 1 \mathrm{H}), 7.74(\mathrm{~d}, J=1.9 \mathrm{~Hz}, 1 \mathrm{H}), 7.66$ (ddd, $J=8.31,2.4,0.9 \mathrm{~Hz}, 1 \mathrm{H}), 7.60-7.54(\mathrm{~m}, 2 \mathrm{H}), 7.50-7.45(\mathrm{~m}, 4 \mathrm{H}), 7.40-7.35(\mathrm{~m}, 1 \mathrm{H})$, $7.21(\mathrm{dd}, J=8.7,1.9 \mathrm{~Hz}, 1 \mathrm{H}), 7.15-7.04(\mathrm{~m}, 2 \mathrm{H}), 7.03-6.95(\mathrm{~m}, 2 \mathrm{H}), 6.49$ (s, 1H), 3.61-3.44 (m, 0.92H, M), $3.04(\mathrm{dd}, J=13.3,5.7 \mathrm{~Hz}, 1 \mathrm{H}), 2.89$ (t, $J=7.9 \mathrm{~Hz}, 0.16 \mathrm{H}, \mathrm{AM}) 2.68$ (dd, $J=$ $13.3,8.4 \mathrm{~Hz}, 1 \mathrm{H}), 2.48$ (s, 3H), 1.30 (d, $J=6.9 \mathrm{~Hz}, 3 \mathrm{H})$.

${ }^{13} \mathrm{C}-\mathrm{NMR}\left(75 \mathrm{MHz}, \mathrm{CDCl}_{3}\right): \delta=145.0(\mathrm{CH}), 148.7\left(\mathrm{C}_{\mathrm{q}}\right), 147.7\left(\mathrm{C}_{\mathrm{q}}\right), 141.0\left(\mathrm{C}_{\mathrm{q}}\right), 139.2\left(\mathrm{C}_{\mathrm{q}}\right)$, $139.0(\mathrm{CH}), 138.9\left(\mathrm{C}_{\mathrm{q}}\right), 136.1\left(\mathrm{C}_{\mathrm{q}}\right), 132.5\left(\mathrm{C}_{\mathrm{q}}\right), 130.1(\mathrm{CH}), 129.5(\mathrm{CH}), 128.8(\mathrm{CH}), 127.1$ $\left(\mathrm{C}_{\mathrm{q}}\right), 126.9(\mathrm{CH}), 126.8(\mathrm{CH}), 124.3(\mathrm{CH}), 122.5(\mathrm{CH}), 121.2(\mathrm{CH}), 113.6\left(\mathrm{C}_{\mathrm{q}}\right), 111.5(\mathrm{CH})$, 99.6 (CH), $43.4\left(\mathrm{CH}_{2}\right), 32.9(\mathrm{CH}), 19.7\left(\mathrm{CH}_{3}\right), 18.1\left(\mathrm{CH}_{3}\right)$.

IR (ATR): 3026, 1595, 1482, 1207, 1034, 791, $697 \mathrm{~cm}^{-1}$.

MS (ESI) $m / z$ (relative intensity): $503(10)\left[\mathrm{M}+\mathrm{Na},{ }^{79} \mathrm{Br}\right]^{+}, 481(100)\left[\mathrm{M}+\mathrm{H},{ }^{79} \mathrm{Br}\right]^{+}, 403(10)$. HR-MS (ESI): $m / z$ calcd. for $\left[\mathrm{C}_{29} \mathrm{H}_{25}{ }^{79} \mathrm{BrN}_{2}+\mathrm{Na}\right]^{+} 503.1098$, found 503.1093.

$[\alpha]_{\mathrm{D}}^{20}:-8.9\left(\mathrm{c}=0.90, \mathrm{CHCl}_{3}\right)$.

HPLC separation (Chiralpak ${ }^{\circledR}$ ID-3, $n$-hexane $/ i$-PrOH 98:2, $1.0 \mathrm{~mL} / \mathrm{min}$, detection at $273 \mathrm{~nm}$ ): $t_{r}($ major $)=17.1 \mathrm{~min}, t_{r}($ minor $)=19.5 \mathrm{~min}, t_{r}(\mathrm{AM})=25.8 \mathrm{~min}, 89: 11$ e.r.

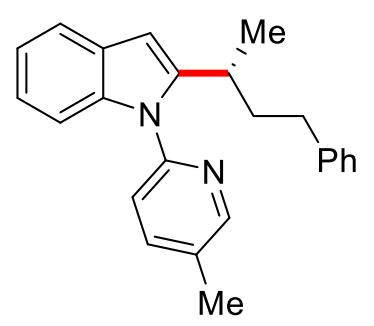

(R)-1-(5-Methylpyridin-2-yl)-2-(4-phenylbutan-2-yl)-1H-indole (355an): The general procedure $\mathbf{E}$ was followed using 1-(5-methylpyridin-2-yl)- $1 H$-indole (354a) (104.1 mg, $0.50 \mathrm{mmol})$, 4-Phenyl-1-butene $\mathbf{( 2 2 3 n}) \quad(198 \mathrm{mg}, 1.50 \mathrm{mmol})$. Isolation by column chromatography $(n$-hexane/EtOAc $=30: 1)$ yielded 355an $(57.8 \mathrm{mg}, 34 \%, \mathrm{M} / \mathrm{AM}=80: 20)$ as a yellow oil.

${ }^{1} \mathrm{H}-\mathrm{NMR}\left(300 \mathrm{MHz}, \mathrm{CDCl}_{3}\right): \delta=8.45(\mathrm{~d}, J=2.4 \mathrm{~Hz}, 1 \mathrm{H}), 7.71-7.64(\mathrm{~m}, 1 \mathrm{H}), 7.64-7.59(\mathrm{~m}$, $1 \mathrm{H}), 7.28(\mathrm{~d}, J=3.3 \mathrm{~Hz}, 1 \mathrm{H}), 7.27-7.23(\mathrm{~m}, 2 \mathrm{H}), 7.23-7.20(\mathrm{~m}, 1 \mathrm{H}), 7.20-7.16(\mathrm{~m}, 1 \mathrm{H}), 7.16-$ $7.11(\mathrm{~m}, 2 \mathrm{H}), 7.09-7.04(\mathrm{~m}, 2 \mathrm{H}), 6.52(\mathrm{~s}, 1 \mathrm{H}), 3.31-3.11(\mathrm{~m}, 0.90 \mathrm{H}, \mathrm{M}), 2.87(\mathrm{t}, J=4.0 \mathrm{~Hz}$, $0.10 \mathrm{H}, \mathrm{AM}), 2.59$ (t, $J=7.6 \mathrm{~Hz}, 2 \mathrm{H}), 2.47(\mathrm{~s}, 3 \mathrm{H}), 2.10-1.94(\mathrm{~m}, 1 \mathrm{H}), 1.83-1.70(\mathrm{~m}, 1 \mathrm{H}), 1.33$ $(\mathrm{d}, J=6.9 \mathrm{~Hz}, 3 \mathrm{H})$. 
${ }^{13} \mathrm{C}-\mathrm{NMR}\left(100 \mathrm{MHz}, \mathrm{CDCl}_{3}\right): \delta=150.0(\mathrm{CH}), 149.1\left(\mathrm{C}_{\mathrm{q}}\right), 146.9\left(\mathrm{C}_{\mathrm{q}}\right), 142.3\left(\mathrm{C}_{\mathrm{q}}\right), 138.8(\mathrm{CH})$, $137.5\left(\mathrm{C}_{\mathrm{q}}\right), 132.0\left(\mathrm{C}_{\mathrm{q}}\right), 128.5\left(\mathrm{C}_{\mathrm{q}}\right), 128.4(\mathrm{CH}), 128.2(\mathrm{CH}), 125.5(\mathrm{CH}), 121.4(\mathrm{CH}), 121.2$ $(\mathrm{CH}), 120.4(\mathrm{CH}), 120.0(\mathrm{CH}), 110.1(\mathrm{CH}), 99.7(\mathrm{CH}), 38.8(\mathrm{CH}), 33.4\left(\mathrm{CH}_{2}\right), 30.3\left(\mathrm{CH}_{2}\right)$, $20.6\left(\mathrm{CH}_{3}\right), 18.1\left(\mathrm{CH}_{3}\right)$.

IR (ATR): 2955, 1593, 1481, 1435, 1399, 1366, 1324, 765, 758, $670 \mathrm{~cm}^{-1}$. MS (ESI) $m / z$ (relative intensity): $363(80)[\mathrm{M}+\mathrm{H}]^{+}, 341(15)[\mathrm{M}+\mathrm{H}]^{+}$. HR-MS (ESI): $m / z$ calcd. for $\left[\mathrm{C}_{24} \mathrm{H}_{24} \mathrm{~N}_{2}+\mathrm{H}\right]^{+} 341.2012$ found 341.2011 . $[\alpha]_{\mathrm{D}^{20}}:+16.0\left(\mathrm{c}=1.25, \mathrm{CHCl}_{3}\right)$

HPLC separation (Chiralpak® IF-3, $n$-hexane/EtOAc 95:5, $1.00 \mathrm{~mL} / \mathrm{min}$, detection at $273 \mathrm{~nm}$ ): $t_{r}($ major $)=8.1 \mathrm{~min}, t_{r}($ minor $)=7.5 \mathrm{~min}, t_{r}(\mathrm{AM})=7.8 \mathrm{~min}, 68: 32$ e.r.<smiles>CCCCCCCCCCCCCCc1cc2ccccc2n1-c1ccc(C)cn1</smiles>

(R)-1-(5-Methylpyridin-2-yl)-2-(octan-2-yl)-1H-indole (355ao): The general procedure $\mathbf{E}$ was followed using 1-(5-methylpyridin-2-yl)-1H-indole (354a) (104.1 mg, $0.50 \mathrm{mmol}), 1$ octene (223o) $(168 \mathrm{mg}, 1.50 \mathrm{mmol})$. Isolation by column chromatography ( $n$-hexane/EtOAc $=$ 30:1) yielded 355ao (59.2 $\mathrm{mg}, 37 \%, \mathrm{M} / \mathrm{AM}=90: 10)$ as a yellow oil.

${ }^{1} \mathrm{H}-\mathrm{NMR}\left(300 \mathrm{MHz}, \mathrm{CDCl}_{3}\right): \delta=8.52(\mathrm{~d}, J=2.5 \mathrm{~Hz}, 1 \mathrm{H}), 7.72(\mathrm{dd}, J=8.1,2.5,1 \mathrm{H}), 7.64$ $7.56(\mathrm{~m}, 1 \mathrm{H}), 7.33(\mathrm{~d}, J=8.1 \mathrm{~Hz}, 1 \mathrm{H}), 7.26-7.18(\mathrm{~m}, 1 \mathrm{H}), 7.18-7.04(\mathrm{~m}, 2 \mathrm{H}), 6.46(\mathrm{~s}, 1 \mathrm{H})$, 3.23-3.08 (m, 0.90H, M), $2.82(\mathrm{t}, J=7.6 \mathrm{~Hz}, 0.10 \mathrm{H}, \mathrm{AM}) 2.47(\mathrm{~s}, 3 \mathrm{H}), 1.73-1.52(\mathrm{~m}, 1 \mathrm{H})$, $1.50-1.06(\mathrm{~m}, 12 \mathrm{H}), 0.87(\mathrm{t}, J=6.9 \mathrm{~Hz}, 3 \mathrm{H})$.

${ }^{13} \mathrm{C} \mathrm{NMR}\left(125 \mathrm{MHz}, \mathrm{CDCl}_{3}\right) \delta=149.9(\mathrm{CH}), 149.2\left(\mathrm{C}_{\mathrm{q}}\right), 147.5\left(\mathrm{C}_{\mathrm{q}}\right), 138.7(\mathrm{CH}), 137.4\left(\mathrm{C}_{\mathrm{q}}\right)$, $131.9\left(\mathrm{C}_{\mathrm{q}}\right), 128.4\left(\mathrm{C}_{\mathrm{q}}\right), 121.3(\mathrm{CH}), 121.2(\mathrm{CH}), 120.2(\mathrm{CH}), 119.8(\mathrm{CH}), 109.9(\mathrm{CH}), 99.3$ $(\mathrm{CH}), 37.0\left(\mathrm{CH}_{2}\right), 31.6\left(\mathrm{CH}_{2}\right), 30.7(\mathrm{CH}), 29.2\left(\mathrm{CH}_{2}\right), 27.0\left(\mathrm{CH}_{2}\right), 22.6\left(\mathrm{CH}_{2}\right), 20.5\left(\mathrm{CH}_{3}\right), 18.0$ $\left(\mathrm{CH}_{3}\right), 14.0\left(\mathrm{CH}_{3}\right)$.

IR (ATR): 2935, 1591, 1472, 1465, 1366, 1321, 1310, 787, 741, $689 \mathrm{~cm}^{-1}$. MS (ESI) $m / z$ (relative intensity): $321(100)[\mathrm{M}+\mathrm{H}]^{+}, 342(15)[\mathrm{M}+\mathrm{Na}]^{+}$. HR-MS (ESI): $m / z$ calcd. for $\left[\mathrm{C}_{22} \mathrm{H}_{28} \mathrm{~N}_{2}+\mathrm{H}\right]^{+} 321.2325$ found 321.2328 . $[\alpha]_{\mathrm{D}}^{20}:+25.0\left(\mathrm{c}=0.8, \mathrm{CHCl}_{3}\right)$.

HPLC separation (Chiralpak® IF-3, $n$-hexane/EtOAc 90:10, $1.00 \mathrm{~mL} / \mathrm{min}$, detection at 280 $\mathrm{nm}): t_{r}($ major $)=6.3 \mathrm{~min}, t_{r}($ minor $)=5.5 \mathrm{~min}, t_{r}(\mathrm{AM})=7.8 \mathrm{~min}, 72: 28$ e.r. 


\subsubsection{Removable of the Directing Group}<smiles>CC(Cc1ccccc1)c1cc2ccccc2[nH]1</smiles>

(R)-2-(1-Phenylpropan-2-yl)-1H-indole (357aa): The general procedure $\mathbf{G}$ was followed using (R)-1-(5-Methylpyridin-2-yl)-2-(1-phenylpropan-2-yl)-1H-indole (355aa) (65.2 mg, $0.20 \mathrm{mmol}$, e.r. 92:8). Isolation by column chromatography ( $n$-hexane/EtOAc $=10: 1)$ yielded 357aa $(40.4 \mathrm{mg}, 86 \%, \mathrm{M} / \mathrm{AM}=92: 8)$ as a brown solid. M. P.: $75-78^{\circ} \mathrm{C}$.

${ }^{1} \mathrm{H}-\mathrm{NMR}\left(600 \mathrm{MHz}, \mathrm{CDCl}_{3}\right): \delta=7.65$ (s, 1H), 7.60 (dd, $\left.J=7.7,1.2 \mathrm{~Hz}, 1 \mathrm{H}\right), 7.34-7.29$ (m, 2H), 7.27 (dd, $J=7.8,1.7 \mathrm{~Hz}, 2 \mathrm{H}), 7.19-7.15(\mathrm{~m}, 3 \mathrm{H}), 7.16-7.10(\mathrm{~m}, 1 \mathrm{H}), 6.25$ (d, $J=0.8 \mathrm{~Hz}$, $0.92 \mathrm{H}, \mathrm{M}), 6.23(\mathrm{~d}, J=0.8 \mathrm{~Hz}, 0.08 \mathrm{H}, \mathrm{M}), 3.21(\mathrm{~m}, 1 \mathrm{H}), 3.06(\mathrm{dd}, J=13.3,6.6 \mathrm{~Hz}, 1 \mathrm{H}), 2.90$ $(\mathrm{dd}, J=13.3,7.6 \mathrm{~Hz}, 1 \mathrm{H}), 1.38(\mathrm{~d}, J=6.9 \mathrm{~Hz}, 3 \mathrm{H})$.

${ }^{13} \mathrm{C}-\mathrm{NMR}\left(125 \mathrm{MHz}, \mathrm{CDCl}_{3}\right): \delta=143.9\left(\mathrm{C}_{\mathrm{q}}\right), 139.9\left(\mathrm{C}_{\mathrm{q}}\right), 135.5\left(\mathrm{C}_{\mathrm{q}}\right), 128.9(\mathrm{CH}), 128.4\left(\mathrm{C}_{\mathrm{q}}\right)$, $128.2(\mathrm{CH}), 126.1(\mathrm{CH}), 120.9(\mathrm{CH}), 119.9(\mathrm{CH}), 119.5(\mathrm{CH}), 110.3(\mathrm{CH}), 98.2(\mathrm{CH}), 43.8$ $\left(\mathrm{CH}_{2}\right), 35.2(\mathrm{CH}), 19.9\left(\mathrm{CH}_{3}\right)$.

IR (ATR): 3399, 3025, 1676, 1454, 1301, 1029, $748 \mathrm{~cm}^{-1}$.

MS (ESI) $m / z$ (relative intensity): $258(30)[\mathrm{M}+\mathrm{Na}]^{+}, 236(100)[\mathrm{M}+\mathrm{H}]^{+}, 209$ (5), 201 (10).

HR-MS (ESI): $m / z$ calcd. for $\left[\mathrm{C}_{17} \mathrm{H}_{17} \mathrm{~N}+\mathrm{H}\right]^{+} 236.1430$, found 236.1434 .

$[\alpha]_{\mathrm{D}}^{20}:-30.0\left(\mathrm{c}=0.80, \mathrm{CHCl}_{3}\right)$.

HPLC separation (Chiralpak ${ }^{\circledR}$ IA-3, $n$-hexane/i-PrOH 99:1, $0.75 \mathrm{~mL} / \mathrm{min}$, detection at 273 $\mathrm{nm}): t_{r}($ major $)=23.9 \mathrm{~min}, t_{r}($ minor $)=26.2 \mathrm{~min}, t_{r}(\mathrm{AM})=36.9 \mathrm{~min}, 92: 8$ e.r.<smiles>CC(=O)c1ccc2cc(C(C)Cc3ccccc3)[nH]c2c1</smiles>

(R)-Methyl 2-(1-phenylpropan-2-yl)-1H-indole-6-carboxylate (357da): The general procedure $\mathbf{G}$ was followed using $(R)$-methyl 1-(5-methylpyridin-2-yl)-2-(1-phenylpropan-2yl)-1H-indole-6-carboxylate (355da) $(76.8 \mathrm{mg}, 0.20 \mathrm{mmol}$, e.r. 92:8). Isolation by column chromatography $(n$-hexane/EtOAc $=10: 1)$ yielded 357da $(46.5 \mathrm{mg}, 79 \%, \mathrm{M} / \mathrm{AM}=94: 6)$ as a yellow solid. M. P.: $145-149^{\circ} \mathrm{C}$.

${ }^{1} \mathrm{H}-\mathrm{NMR}\left(500 \mathrm{MHz}, \mathrm{CDCl}_{3}\right): \delta=8.24(\mathrm{~s}, 1 \mathrm{H}), 8.04(\mathrm{dd}, J=1.6,0.8 \mathrm{~Hz}, 1 \mathrm{H}), 7.77$ (dd, $J=8.4$, $1.6 \mathrm{~Hz}, 1 \mathrm{H}), 7.53$ (d, $J=8.4 \mathrm{~Hz}, 1 \mathrm{H}), 7.30-7.16(\mathrm{~m}, 3 \mathrm{H}), 7.12-7.02(\mathrm{~m}, 2 \mathrm{H}), 6.31$ (dd, $J=2.1$, $1.0 \mathrm{~Hz}, 1 \mathrm{H}), 3.91(\mathrm{~s}, 3 \mathrm{H}), 3.23(\mathrm{~m}, 0.94 \mathrm{H}, \mathrm{M}), 3.03(\mathrm{dd}, J=13.4,7.1 \mathrm{~Hz}, 1 \mathrm{H}), 2.89$ (dd, $J=$ 13.4, 7.5 Hz, 1H), 2.79 (t, $J=7.6 \mathrm{~Hz}, 0.12 \mathrm{H}, \mathrm{AM}), 1.37$ (d, $J=6.9 \mathrm{~Hz}, 3 \mathrm{H})$. 
${ }^{13} \mathrm{C}-\mathrm{NMR}\left(125 \mathrm{MHz}, \mathrm{CDCl}_{3}\right): \delta=168.5\left(\mathrm{C}_{\mathrm{q}}\right), 148.1\left(\mathrm{C}_{\mathrm{q}}\right), 139.8\left(\mathrm{C}_{\mathrm{q}}\right), 134.9\left(\mathrm{C}_{\mathrm{q}}\right), 132.4\left(\mathrm{C}_{\mathrm{q}}\right)$, $129.1(\mathrm{CH}), 128.4(\mathrm{CH}), 126.4(\mathrm{CH}), 122.5\left(\mathrm{C}_{\mathrm{q}}\right), 120.8(\mathrm{CH}), 119.4(\mathrm{CH}), 112.9(\mathrm{CH}), 98.9$ $(\mathrm{CH}), 52.0\left(\mathrm{CH}_{3}\right), 43.7\left(\mathrm{CH}_{2}\right), 35.4(\mathrm{CH}), 19.7\left(\mathrm{CH}_{3}\right)$.

IR (ATR): 3342, 3025, 1687, 1619, 1546, 1314, $743 \mathrm{~cm}^{-1}$. MS (ESI) $m / z$ (relative intensity): $316(30)[\mathrm{M}+\mathrm{Na}]^{+}, 294(100)[\mathrm{M}+\mathrm{H}]^{+}, 117$ (5).

HR-MS (ESI): $m / z$ calcd. for $\left[\mathrm{C}_{19} \mathrm{H}_{19} \mathrm{NO}_{2}+\mathrm{H}\right]^{+} 294.1484$, found 294.1489. $[\alpha]_{\mathrm{D}}^{20}:-72.9\left(\mathrm{c}=0.93, \mathrm{CHCl}_{3}\right)$.

HPLC separation (Chiralpak ${ }^{\circledR}$ IF-3, $n$-hexane/i-PrOH 95:5, $1.0 \mathrm{~mL} / \mathrm{min}$, detection at $273 \mathrm{~nm}$ ): $t_{r}($ major $)=14.1 \mathrm{~min}, t_{r}($ minor $)=16.0 \mathrm{~min}, t_{r}(\mathrm{AM})=23.9 \mathrm{~min}, 92: 8$ e.r.<smiles>COc1ccc(CC(C)c2cc3ccccc3[nH]2)cc1OC</smiles>

(R)-2-(1-(3,4-Dimethoxyphenyl)propan-2-yl)-1H-indole (357af): The general procedure $\mathbf{G}$ was followed using (R)-2-(1-(3,4-dimethoxyphenyl)propan-2-yl)-1-(5-methylpyridin-2-yl)$1 H$-indole (355af) $(77.2 \mathrm{mg}, 0.20 \mathrm{mmol})$. Isolation by column chromatography ( $n$ hexane/EtOAc $=5: 1)$ yielded 357af $(48.4 \mathrm{mg}, 82 \%, \mathrm{M} / \mathrm{AM}=92: 8)$ as a yellow oil.

${ }^{1} \mathrm{H}-\mathrm{NMR}\left(500 \mathrm{MHz}, \mathrm{CDCl}_{3}\right): \delta=7.73(\mathrm{~s}, 1 \mathrm{H}), 7.57-7.47(\mathrm{~m}, 1 \mathrm{H}), 7.27-7.18(\mathrm{~m}, 1 \mathrm{H}), 7.08$ $(\mathrm{dd}, J=8.1,1.4 \mathrm{~Hz}, 2 \mathrm{H}), 6.76(\mathrm{~d}, J=8.1 \mathrm{~Hz}, 1 \mathrm{H}), 6.66(\mathrm{dd}, J=8.1,2.0 \mathrm{~Hz}, 1 \mathrm{H}), 6.49(\mathrm{~d}, J=$ $2.0 \mathrm{~Hz}, 1 \mathrm{H}), 6.26(\mathrm{dd}, J=2.1,0.9 \mathrm{~Hz}, 1 \mathrm{H}), 3.85(\mathrm{~s}, 3 \mathrm{H}), 3.65$ (s, 3H), 3.15 (m, 0.91H, M), 2.93 $(\mathrm{dd}, J=13.5,7.2 \mathrm{~Hz}, 1 \mathrm{H}), 2.83(\mathrm{dd}, J=13.5,7.0 \mathrm{~Hz}, 1 \mathrm{H}), 2.76(\mathrm{t}, J=7.5 \mathrm{~Hz}, 0.18 \mathrm{H}, \mathrm{AM})$, $1.36(\mathrm{~d}, J=6.9 \mathrm{~Hz}, 3 \mathrm{H}) .{ }^{13} \mathrm{C}-\mathrm{NMR}\left(125 \mathrm{MHz}, \mathrm{CDCl}_{3}\right): \delta=148.6\left(\mathrm{C}_{\mathrm{q}}\right), 147.4\left(\mathrm{C}_{\mathrm{q}}\right), 144.0\left(\mathrm{C}_{\mathrm{q}}\right)$, $135.5\left(\mathrm{C}_{\mathrm{q}}\right), 132.5\left(\mathrm{C}_{\mathrm{q}}\right), 128.4\left(\mathrm{C}_{\mathrm{q}}\right), 121.0(\mathrm{CH}), 121.0(\mathrm{CH}), 119.8(\mathrm{CH}), 119.5(\mathrm{CH}), 112.1$ $(\mathrm{CH}), 110.9(\mathrm{CH}), 110.3(\mathrm{CH}), 98.3(\mathrm{CH}), 55.8\left(\mathrm{CH}_{3}\right), 55.6\left(\mathrm{CH}_{3}\right), 43.5\left(\mathrm{CH}_{2}\right), 35.3(\mathrm{CH}), 19.7$ $\left(\mathrm{CH}_{3}\right)$.

IR (ATR): 3368, 3004, 1589, 1305, 1140, 1026, $784 \mathrm{~cm}^{-1}$.

MS (ESI) $m / z$ (relative intensity): $318(100)[\mathrm{M}+\mathrm{Na}]^{+}, 295(30)[\mathrm{M}+\mathrm{H}]^{+}, 209$ (5).

HR-MS (ESI): $m / z$ calcd. for $\left[\mathrm{C}_{19} \mathrm{H}_{21} \mathrm{NO}_{2}+\mathrm{H}\right]^{+} 296.1641$, found 296.1645.

$[\alpha] \mathrm{D}^{20}:-88.4\left(\mathrm{c}=0.95, \mathrm{CHCl}_{3}\right)$.

HPLC separation (Chiralpak ${ }^{\circledR}$ IF-3, $n$-hexane/i-PrOH 98:2, $1.0 \mathrm{~mL} / \mathrm{min}$, detection at $273 \mathrm{~nm}$ ): $t_{r}($ major $)=19.5 \mathrm{~min}, t_{r}($ minor $)=21.8 \mathrm{~min}, t_{r}(\mathrm{AM})=23.0 \mathrm{~min}, 92: 8$ e.r. 


\subsubsection{Mechanistic Studies}

\subsubsection{H/D-exchange for the asymmetric $\mathrm{C}-\mathrm{H}$ alkylation}

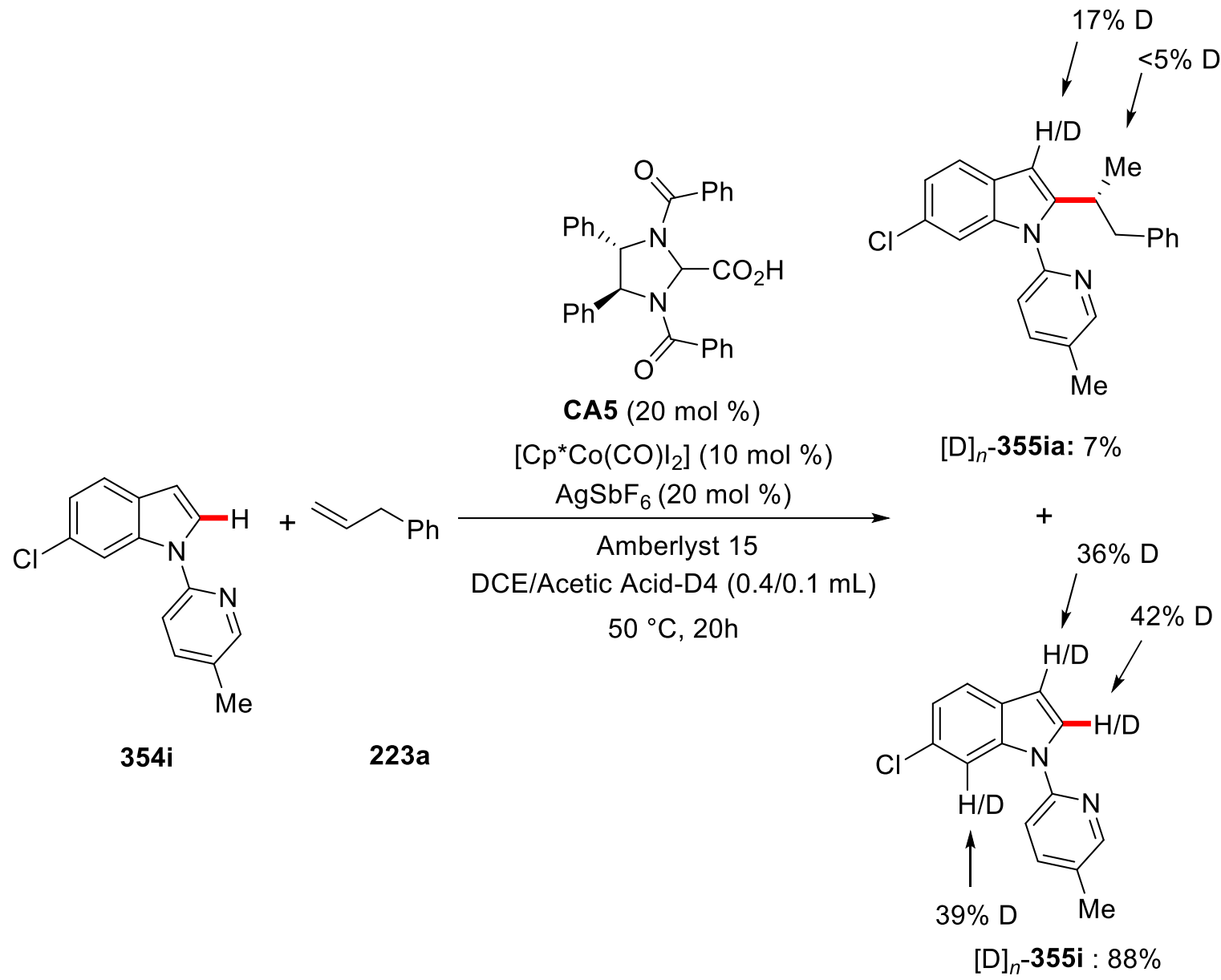

The representative procedure $\mathbf{E}$ was followed using 354i (121 mg, $0.50 \mathrm{mmol}, 1$ equiv), allylbenzene (223a) (177 mg, $1.50 \mathrm{mmol}, 1.50$ equiv), [Cp*Co(CO)I 2$]$ (23.8 mg, $10.0 \mathrm{~mol} \%$ ) and $\mathrm{AgSbF}_{6}(34.4 \mathrm{mg}, 20.0 \mathrm{~mol} \%)$ in $\mathrm{DCE}(0.4 \mathrm{~mL})$ and $\mathrm{CD}_{3} \mathrm{CO}_{2} \mathrm{D}(0.1 \mathrm{~mL})$ for $20 \mathrm{~h}$. At ambient temperature, the reaction mixture was diluted with EtOAc $(2.0 \mathrm{~mL})$ and $\mathrm{Et}_{3} \mathrm{~N}(0.5 \mathrm{~mL})$ was added. The mixture was stirred for $0.5 \mathrm{~h}$ and filtered through a short pad of silica and the solvents were removed in vасио. The crude mixture was purified by flash column chromatography on silica gel to afford the desired product $[\mathrm{D}]_{n} \mathbf{- 3 5 5 i a}(12 \mathrm{mg}, 7 \%)$ and $[\mathrm{D}]_{n}$ 355i (106 mg, 88\% reis.) as yellow oils. 

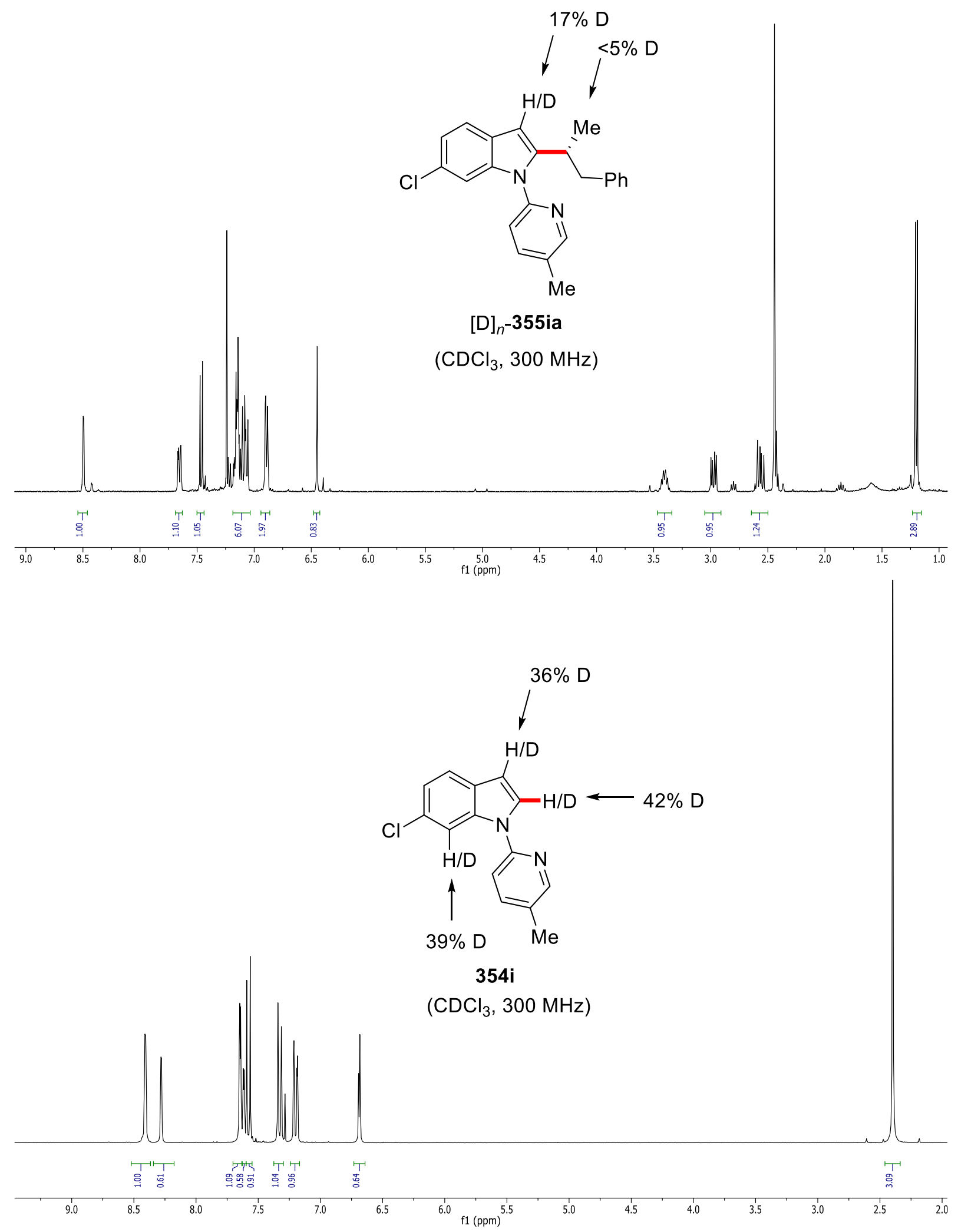


\subsubsection{Kinetic Studies}

\subsection{Determination of the reaction order with respect to the concentration of CA5:}

The reaction order was examined using the initial rate method. Five parallel independent reactions of 354h $(56.6 \mathrm{mg}, 0.25 \mathrm{mmol}), \mathbf{2 2 3 a}(88.5 \mathrm{mg}, 0.75 \mathrm{mmol}),\left[\mathrm{Cp} * \mathrm{Co}(\mathrm{CO}) \mathrm{I}_{2}\right](11.9$ mg, $25.0 \mu \mathrm{mol}), \operatorname{AgSbF}_{6}(17.2 \mathrm{mg}, 50 \mu \mathrm{mol})$, Amberlyst 15 (80 mg, $\left.0.38 \mathrm{mmol}\right)$ and CA5 $(0.0375,0.0435,0.05,0.05625,0.0625 \mathrm{mmol})$ were heated at $50^{\circ} \mathrm{C}$ in DCE $(0.50 \mathrm{~mL})$. After cooling to ambient temperature, ${ }^{19} \mathrm{~F}-\mathrm{NMR}$ conversions were measured by using 1 fluorononane as the internal standard.

Table 32. Reaction order in CA5 for the asymmetric $\mathrm{C}-\mathrm{H}$ alkylation

\begin{tabular}{|c|c|c|c|c|}
\hline Entry & $c / \mathbf{m o l ~ L}^{-1}$ & $k / \operatorname{mol~L}^{-1} \min ^{-1}$ & $\ln \left(c / \mathrm{mol} \mathrm{L}^{-1}\right)$ & $\ln \left(k / \mathrm{mol} \mathrm{L}^{-1} \min ^{-1}\right)$ \\
\hline 1 & 0.075 & 0.0357 & -2.59027 & -3.3326 \\
\hline 2 & 0.0875 & 0.0404 & -2.43612 & -3.20893 \\
\hline 3 & 0.10 & 0.0468 & -2.30259 & -3.06187 \\
\hline 4 & 0.1125 & 0.0512 & -2.1848 & -2.97202 \\
\hline 5 & 0.125 & 0.0483 & -2.07944 & -2.88062 \\
\hline
\end{tabular}

5.5.4.2.2. Determination of the reaction order with respect to the concentration of CA5 without Amberlyst 15:

The reaction order was examined using the change of the vibration between the range of 1497$1478 \mathrm{~cm}^{-1}$ with the React-IR. A solution of 354a (104.1 mg, $\left.0.50 \mathrm{mmol}\right)$, 223a (177 mg, 1.50 mmol), [Cp*Co(CO)I $\left.\mathrm{I}_{2}\right](23.8 \mathrm{mg}, 50.0 \mu \mathrm{mol}), \mathrm{AgSbF}_{6}(34.5 \mathrm{mg}, 100 \mu \mathrm{mol})$ and CA5 (0.0875, $0.1,0.1125,0.125,0.15 \mathrm{mmol})$ were heated at $50{ }^{\circ} \mathrm{C}$ in DCE $(0.50 \mathrm{~mL})$ and a diamond probe connected to a Mettler Toledo ReactIR. Every three minutes during $2 \mathrm{~h}$ an IR spectrum was recorded. The slope for the vibration between the range of $1497-1478 \mathrm{~cm}^{-1}$ was determined during the interval between $3 \mathrm{~min}$ and $30 \mathrm{~min}$.

Table 33. Reaction order in CA5 for the asymmetric C-H alkylation without Amberlyst 15.

\begin{tabular}{ccccc}
\hline Entry & $\boldsymbol{c} / \mathbf{~ m o l ~ L}^{-\mathbf{1}}$ & $\boldsymbol{k} / \mathbf{~ m o l ~ L}^{-\mathbf{1}} \mathbf{~ m i n}^{-\mathbf{1}}$ & $\ln \left(\boldsymbol{c} / \mathbf{~ m o l ~ \mathbf { L } ^ { - 1 } )}\right.$ & $\ln \left(\boldsymbol{k} / \mathbf{~ m o l ~ L}^{-\mathbf{1}} \mathbf{~ m i n}^{-\mathbf{1}}\right)$ \\
\hline 1 & 0.058 & 0.045 & -2.84158 & $-3,10109$ \\
2 & 0.067 & 0.0633 & -2.70805 & $-2,75987$ \\
3 & 0.075 & 0.0722 & -2.59026 & $-2,62832$ \\
4 & 0.083 & 0.0909 & -2.48490 & $-2,398$
\end{tabular}




$\begin{array}{llllr}5 & 0.1 & 0.1431 & -2.30258 & -1,94421\end{array}$

\subsubsection{Nonlinear Effect Study}

\subsection{Nonlinear effect study in presence of Amberlyst 15}

Six parallel independent reactions of $\mathbf{3 5 4 a}(56.6 \mathrm{mg}, 0.25 \mathrm{mmol}), \mathbf{2 2 3 a}(88.6 \mathrm{mg}, 0.75 \mathrm{mmol})$, [Cp*Co(CO)I2] (11.9 mg, $25.0 \mu \mathrm{mol}), \mathrm{AgSbF}_{6}(17.2 \mathrm{mg}, 50 \mu \mathrm{mol})$, Amberlyst 15 (80 mg, 0.38 $\mathrm{mmol})$ and CA5 $(10-100 \%$ ee, $24.0 \mathrm{mg}, 50.0 \mu \mathrm{mol})$ were heated at $50{ }^{\circ} \mathrm{C}$ in DCE $(0.50 \mathrm{~mL})$ for $65 \mathrm{~h}$. At ambient temperature, the reaction mixture was diluted with EtOAc $(2 \mathrm{~mL})$ and $\mathrm{Et}_{3} \mathrm{~N}(0.50 \mathrm{~mL})$ was added. The mixture was stirred for $0.5 \mathrm{~h}$ and filtered through a short pad of silica and the solvents were removed in vacuo. The crude mixture was purified by flash column chromatography on silica gel to afford the desired product 355aa. The enantiomeric excess was determined by HPLC with chiral stationary phase.

Table 34. Nonlinear effect study for the asymmetric C-H alkylation.

\begin{tabular}{ccc}
\hline Entry & $e e$ of the chiral acid [CA5] & $e e$ of the product [355aa] \\
\hline 1 & 0 & 0 \\
2 & 10 & 9.3 \\
3 & 30 & 25.7 \\
4 & 50 & 41.4 \\
5 & 70 & 56.1 \\
6 & 90 & 74.4 \\
7 & 100 & 84.0 \\
\hline
\end{tabular}

\subsection{Nonlinear effect study in absence of Amberlyst 15}

Six parallel independent reactions of $\mathbf{3 5 4 a}(56.6 \mathrm{mg}, 0.25 \mathrm{mmol})$, 223a $(88.6 \mathrm{mg}, 0.75 \mathrm{mmol})$, [Cp*Co(CO)I $\left.\mathrm{I}_{2}\right](11.9 \mathrm{mg}, 25.0 \mu \mathrm{mol}), \mathrm{AgSbF}_{6}(17.2 \mathrm{mg}, 50.0 \mu \mathrm{mol})$ and CA5 (10-100\% ee, $24.0 \mathrm{mg}, 50.0 \mu \mathrm{mol})$ were heated at $50^{\circ} \mathrm{C}$ in DCE $(0.50 \mathrm{~mL})$ for $65 \mathrm{~h}$. At ambient temperature, the reaction mixture was diluted with EtOAc $(2 \mathrm{~mL})$ and the solvents were removed in vacuo. The crude mixture was purified by flash column chromatography on silica gel to afford the desired product 355aa. The enantiomeric excess was determined by HPLC with chiral stationary phase. 
Table 35. Nonlinear effect study for the asymmetric C-H alkylation without Amberlyst 15.

\begin{tabular}{ccc}
\hline Entry & $e e$ of the chiral acid [CA5] & $e e$ of the product [355aa] \\
\hline 1 & 0 & 0 \\
2 & 10 & 2.5 \\
3 & 30 & 14.7 \\
4 & 50 & 26.8 \\
5 & 70 & 44.1 \\
6 & 90 & 68.6 \\
7 & 100 & 84.0 \\
\hline
\end{tabular}

\subsubsection{DOSY Experiment:}

Comparison of two NMR Samples:

1) $8 \mathrm{mg}$ chiral acid $\mathbf{C A 5}$ in $700 \mu \mathrm{L}$ of $\mathrm{CDCl}_{3}+1 \mu \mathrm{L}$ of $n$-hexane.

2) $8 \mathrm{mg}$ chiral acid $\mathbf{C A 5}$ in $700 \mu \mathrm{L}$ of $\mathrm{CDCl}_{3}+5 \mu \mathrm{L}$ of TFA $+1 \mu \mathrm{L}$ of $n$-hexane. 


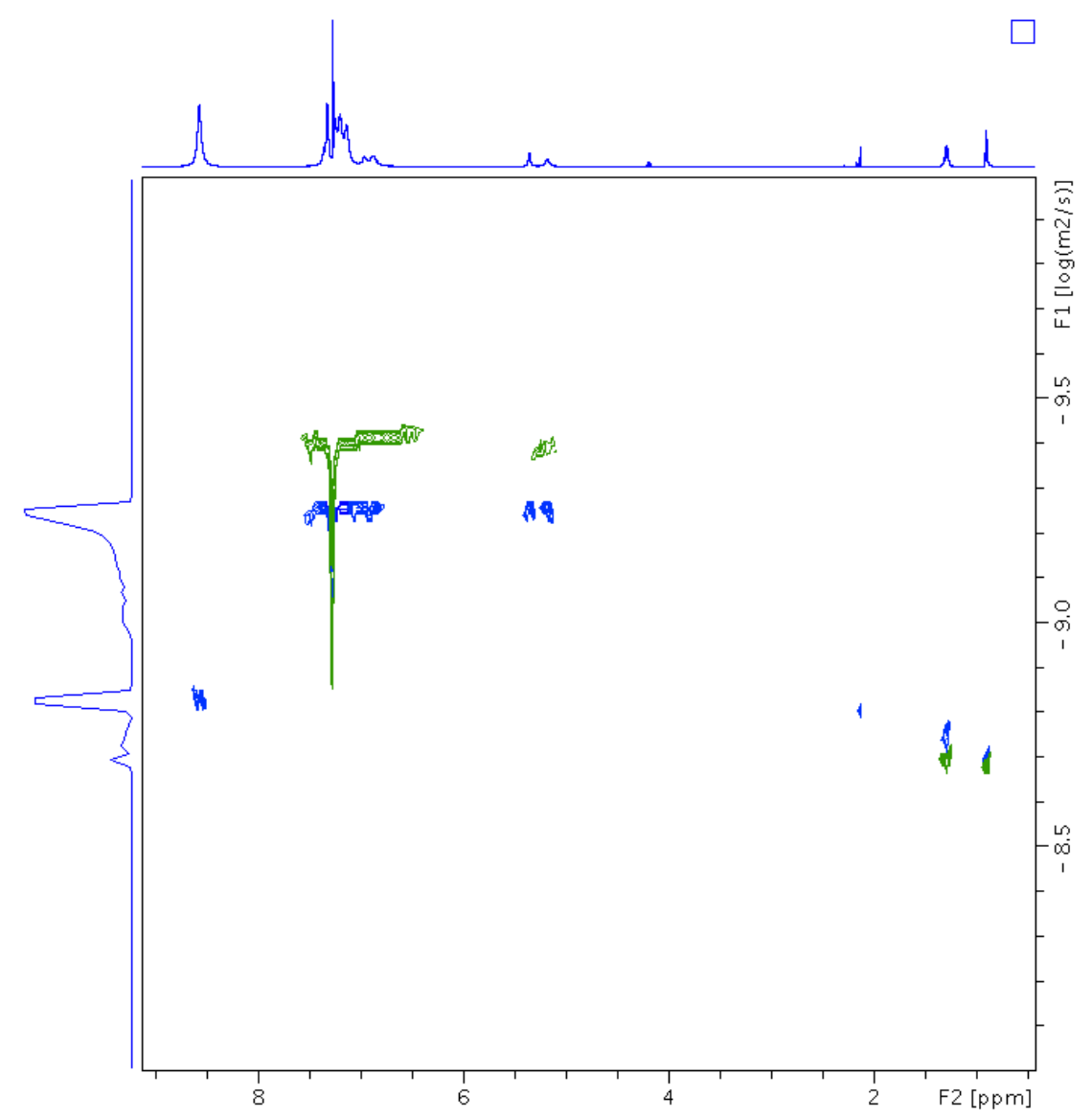

Figure 4. Overlay of DOSY spectra $\left(500 \mathrm{MHz}, 25^{\circ} \mathrm{C}, \mathrm{CDCl}_{3}\right)$ of $\mathbf{C A 5}(8 \mathrm{mg}, 0.017 \mathrm{mmol}$, in $700 \mathrm{~mL}$ of $\mathrm{CDCl}_{3}$ ) in the presence (blue) and absence (green) of $0.063 \mathrm{mmol}$ of TFA. The ratio of diffusion coefficients $\left(5.5 \times 10^{-10} \pm 0.2 \times 10^{-10} \mathrm{~m}^{2} \mathrm{~s}^{-1} / 4.0 \times 10^{-10} \pm 0.2 \times 10^{-10} \mathrm{~m}^{2} \mathrm{~s}^{-1}=1.375\right)$ indicates formation of dimers in the absence of TFA. DOSY spectra were recorded on a Bruker Avance III HD $500 \mathrm{MHz}$ instrument equipped with a Cryoprobe Prodigy. The pulse sequence dstebpgp3s was used, and the diffusion delay (d20) and gradient duration (p30) were set to 150 and $1 \mathrm{~ms}$, respectively. $n$ Hexane was used as internal standard.

\subsection{Ruthenium(II)-Catalyzed Enantioselective C-H Activation}

\subsubsection{Characterization Data}<smiles>CC1CCCc2c1n(-c1ccccn1)c1ccccc21</smiles>

(R)-1-Methyl-9-(pyridin-2-yl)-2,3,4,9-tetrahydro-1H-carbazole $\quad$ (365a): The general procedure $\mathbf{H}$ was followed using 3-(pent-4-en-1-yl)-1-(pyridin-2-yl)-1H-indole (364a) 
(65.5 mg, $0.25 \mathrm{mmol})$. Isolation by column chromatography $(n$-hexane/EtOAc $=20: 1)$ yielded 365a (57.7 mg, 88\%) as a yellow solid. M.p.: $77-82{ }^{\circ} \mathrm{C}$.

${ }^{1} \mathrm{H}-\mathrm{NMR}\left(400 \mathrm{MHz}, \mathrm{CDCl}_{3}\right): \delta=8.62(\mathrm{ddd}, J=4.9,2.0,0.9 \mathrm{~Hz}, 1 \mathrm{H}), 7.85(\mathrm{ddd}, J=8.0,7.4$, $2.0 \mathrm{~Hz}, 1 \mathrm{H}), 7.52-7.49$ (m, 1H), 7.45 (dd, $J=8.0,0.9 \mathrm{~Hz}, 1 \mathrm{H}), 7.40-7.37$ (m, 1H), 7.26 (ddd, $J=7.4,4.9,0.9 \mathrm{~Hz}, 1 \mathrm{H}), 7.16-7.10(\mathrm{~m}, 2 \mathrm{H}), 3.57-3.47$ (m, 1H), 2.84-2.67 (m, 2H), 2.16-2.05 (m, 1H), 1.98-1.81 (m, 2H), 1.69-1.58 (m, 1H), $0.83(\mathrm{~d}, J=6.9 \mathrm{~Hz}, 3 \mathrm{H})$.

${ }^{13} \mathrm{C}-\mathrm{NMR}\left(100 \mathrm{MHz}, \mathrm{CDCl}_{3}\right): \delta=152.1\left(\mathrm{C}_{\mathrm{q}}\right), 149.5(\mathrm{CH}), 140.2\left(\mathrm{C}_{\mathrm{q}}\right), 138.2(\mathrm{CH}), 136.8\left(\mathrm{C}_{\mathrm{q}}\right)$, $128.3\left(\mathrm{C}_{\mathrm{q}}\right), 121.8(\mathrm{CH}), 121.4(\mathrm{CH}), 120.2(\mathrm{CH}), 120.2(\mathrm{CH}), 118.1(\mathrm{CH}), 112.6\left(\mathrm{C}_{\mathrm{q}}\right), 109.8$ $(\mathrm{CH}), 31.9\left(\mathrm{CH}_{2}\right), 27.2(\mathrm{CH}), 21.5\left(\mathrm{CH}_{2}\right), 20.3\left(\mathrm{CH}_{3}\right), 19.9\left(\mathrm{CH}_{2}\right)$.

IR (ATR): 2959, 2929, 1584, 1471, 1437, 1372, $738 \mathrm{~cm}^{-1}$.

MS (ESI) $m / z$ (relative intensity): $285(25)[\mathrm{M}+\mathrm{Na}]^{+}, 263(100)[\mathrm{M}+\mathrm{H}]^{+}$.

HR-MS (ESI): $m / z$ calcd. for $\left[\mathrm{C}_{18} \mathrm{H}_{18} \mathrm{~N}_{2}+\mathrm{H}\right]^{+} 263.1543$ found 263.1542 .

$[\alpha]_{\mathrm{D}}^{20}:-70.5\left(\mathrm{c}=1.0, \mathrm{CHCl}_{3}\right)$.

HPLC separation (Chiralpak ${ }^{\circledR}$ IF-3, $n$-hexane/EtOAc 95:5, $1.0 \mathrm{~mL} / \mathrm{min}$, detection at $273 \mathrm{~nm}$ ): $t_{r}($ major $)=11.7 \mathrm{~min}, t_{r}($ minor $)=10.5 \mathrm{~min}, 76: 24$ e.r.

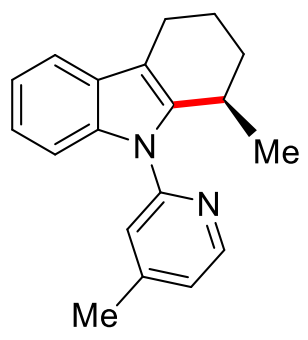

(R)-1-Methyl-9-(4-methylpyridin-2-yl)-2,3,4,9-tetrahydro-1H-carbazole $\quad(367 a): \quad$ The general procedure $\mathbf{H}$ was followed using 1-(4-methylpyridin-2-yl)-3-(pent-4-en-1-yl)-1Hindole (366a) $(69.0 \mathrm{mg}, 0.25 \mathrm{mmol})$. Isolation by column chromatography ( $n$-hexane/EtOAc $=$ 20:1) yielded 367a (62.0 $\mathrm{mg}, 90 \%)$ as a colourless oil.

${ }^{1} \mathrm{H}-\mathrm{NMR}\left(400 \mathrm{MHz}, \mathrm{CDCl}_{3}\right): \delta=8.47(\mathrm{~d}, J=5.1 \mathrm{~Hz}, 1 \mathrm{H}), 7.53-7.46(\mathrm{~m}, 1 \mathrm{H}), 7.40-7.34(\mathrm{~m}$, $1 \mathrm{H}), 7.27(\mathrm{~d}, J=1.5 \mathrm{~Hz}, 1 \mathrm{H}), 7.16-7.09(\mathrm{~m}, 3 \mathrm{H}), 3.59-3.45(\mathrm{~m}, 1 \mathrm{H}), 2.86-2.67(\mathrm{~m}, 2 \mathrm{H}), 2.47$ (s, 3H), 2.17-2.05 (m, 1H), 1.98-1.80 (m, 2H), 1.68-1.58 (m, 1H), 0.84 (d, J=6.9 Hz, 3H).

${ }^{13} \mathrm{C}-\mathrm{NMR}\left(100 \mathrm{MHz}, \mathrm{CDCl}_{3}\right): \delta=152.0\left(\mathrm{C}_{\mathrm{q}}\right), 149.9\left(\mathrm{C}_{\mathrm{q}}\right), 149.0(\mathrm{CH}), 140.2\left(\mathrm{C}_{\mathrm{q}}\right), 136.9\left(\mathrm{C}_{\mathrm{q}}\right)$, $128.3\left(\mathrm{C}_{\mathrm{q}}\right), 122.6(\mathrm{CH}), 121.7(\mathrm{CH}), 120.9(\mathrm{CH}), 120.1(\mathrm{CH}), 118.1(\mathrm{CH}), 112.5\left(\mathrm{C}_{\mathrm{q}}\right), 109.8$ $(\mathrm{CH}), 31.8\left(\mathrm{CH}_{2}\right), 27.2(\mathrm{CH}), 21.5\left(\mathrm{CH}_{2}\right), 21.2\left(\mathrm{CH}_{3}\right), 20.3\left(\mathrm{CH}_{3}\right), 19.9\left(\mathrm{CH}_{2}\right)$.

IR (ATR): 2930, 1601, 1478, 1454, 1224, 824, $736 \mathrm{~cm}^{-1}$.

MS (ESI) $m / z$ (relative intensity): $299(10)[\mathrm{M}+\mathrm{Na}]^{+}, 277(100)[\mathrm{M}+\mathrm{H}]^{+}$.

HR-MS (ESI): $m / z$ calcd. for $\left[\mathrm{C}_{19} \mathrm{H}_{20} \mathrm{~N}_{2}+\mathrm{Na}\right]^{+} 299.1519$ found 299.1519 .

$[\alpha]_{\mathrm{D}}^{20}:-82.2\left(\mathrm{c}=1.0, \mathrm{CHCl}_{3}\right)$. 
HPLC separation (Chiralpak ${ }^{\circledR}$ IB-3, $n$-hexane/EtOAc 95:5, $1.0 \mathrm{~mL} / \mathrm{min}$, detection at $273 \mathrm{~nm}$ ): $t_{r}($ major $)=13.9 \min , t_{r}($ minor $)=9.5 \min , 81: 19$ e.r.<smiles>Cc1ccc(-n2c3c(c4ccccc42)CCCC3C)nc1</smiles>

(R)-1-Methyl-9-(5-methylpyridin-2-yl)-2,3,4,9-tetrahydro-1H-carbazole $\quad$ (363a): The general procedure $\mathbf{H}$ was followed using 1-(5-methylpyridin-2-yl)-3-(pent-4-en-1-yl)-1Hindole (362a) $(69.0 \mathrm{mg}, 0.25 \mathrm{mmol})$. Isolation by column chromatography ( $n$-hexane/EtOAc $=$ 20:1) yielded 363a $(65.7 \mathrm{mg}, 95 \%)$ as a colourless oil.

${ }^{1} \mathrm{H}-\mathrm{NMR}\left(400 \mathrm{MHz}, \mathrm{CDCl}_{3}\right): \delta=8.45$ (d, $\left.J=2.4,0.8 \mathrm{~Hz}, 1 \mathrm{H}\right), 7.68(\mathrm{ddd}, J=8.1,2.4,0.8 \mathrm{~Hz}$, 1H), 7.54-7.47 (m, 1H), 7.38-7.32 (m, 2H), 7.16-7.09 (m, 2H), 3.60-3.40 (m, 1H), 2.86-2.66 $(\mathrm{m}, 2 \mathrm{H}), 2.43(\mathrm{~s}, 3 \mathrm{H}), 2.17-2.05(\mathrm{~m}, 1 \mathrm{H}), 2.00-1.80(\mathrm{~m}, 2 \mathrm{H}), 1.71-1.59(\mathrm{~m}, 1 \mathrm{H}), 0.85(\mathrm{~d}, J=$ $6.8 \mathrm{~Hz}, 3 \mathrm{H})$.

${ }^{13} \mathrm{C}-\mathrm{NMR}\left(100 \mathrm{MHz}, \mathrm{CDCl}_{3}\right): \delta=149.7(\mathrm{CH}), 149.7\left(\mathrm{C}_{\mathrm{q}}\right), 140.2\left(\mathrm{C}_{\mathrm{q}}\right), 138.8(\mathrm{CH}), 137.0\left(\mathrm{C}_{\mathrm{q}}\right)$, $131.1\left(\mathrm{C}_{\mathrm{q}}\right), 128.1\left(\mathrm{C}_{\mathrm{q}}\right), 121.7(\mathrm{CH}), 120.0(\mathrm{CH}), 119.8(\mathrm{CH}), 118.0(\mathrm{CH}), 112.1\left(\mathrm{C}_{\mathrm{q}}\right), 109.7$ $(\mathrm{CH}), 31.8\left(\mathrm{CH}_{2}\right), 27.1(\mathrm{CH}), 21.5\left(\mathrm{CH}_{2}\right), 20.3\left(\mathrm{CH}_{3}\right), 19.9\left(\mathrm{CH}_{2}\right), 18.0\left(\mathrm{CH}_{3}\right)$.

IR (ATR): 2928, 1570, 1483, 1385, 1224, 1028, 833, $737 \mathrm{~cm}^{-1}$.

MS (ESI) $m / z$ (relative intensity): $299(10)[\mathrm{M}+\mathrm{Na}]^{+}, 277(100)[\mathrm{M}+\mathrm{H}]^{+}$.

HR-MS (ESI): $m / z$ calcd. for $\left[\mathrm{C}_{19} \mathrm{H}_{20} \mathrm{~N}_{2}+\mathrm{H}\right]^{+} 277.1699$ found 277.1700 .

$[\alpha]_{\mathrm{D}}^{20}:-95.3\left(\mathrm{c}=1.0, \mathrm{CHCl}_{3}\right)$. HPLC separation (Chiralpak ${ }^{\circledR}$ ID-3, $n$-hexane/EtOAc 90:10, 1.0 $\mathrm{mL} / \mathrm{min}$, detection at $273 \mathrm{~nm}): t_{r}($ major $)=7.5 \mathrm{~min}, t_{r}($ minor $)=5.8 \mathrm{~min}, 85: 15$ e.r.<smiles>[M]C1CCCc2c1n(-c1ccc(C)cn1)c1ccc(OC)cc21</smiles>

(R)-6-Methoxy-1-methyl-9-(5-methylpyridin-2-yl)-2,3,4,9-tetrahydro-1H-carbazole

(363b): The general procedure $\mathbf{H}$ was followed using 5-methoxy-1-(5-methylpyridin-2-yl)-3(pent-4-en-1-yl)-1H-indole (362b) $\quad(76.5 \mathrm{mg}, \quad 0.25 \mathrm{mmol}) . \quad$ Isolation by column chromatography $(n$-hexane/EtOAc $=10: 1)$ yielded $\mathbf{3 6 3 b}(68.0 \mathrm{mg}, 89 \%)$ as a yellow oil. 
${ }^{1} \mathrm{H}-\mathrm{NMR}\left(400 \mathrm{MHz}, \mathrm{CDCl}_{3}\right): \delta=8.43(\mathrm{~d}, J=2.3 \mathrm{~Hz}, 1 \mathrm{H}), 7.65(\mathrm{dd}, J=8.1,2.3 \mathrm{~Hz}, 1 \mathrm{H}), 7.31$ $(\mathrm{d}, J=8.1 \mathrm{~Hz}, 1 \mathrm{H}), 7.26(\mathrm{~d}, J=8.8 \mathrm{~Hz}, 1 \mathrm{H}), 6.96(\mathrm{~d}, J=2.5 \mathrm{~Hz}, 1 \mathrm{H}), 6.77(\mathrm{dd}, J=8.8,2.5$ $\mathrm{Hz}, 1 \mathrm{H}), 3.87$ (s, 3H), 3.55-3.40 (m, 1H), 2.80-2.64 (m, 2H), $2.41(\mathrm{~s}, 3 \mathrm{H}), 2.20-2.02(\mathrm{~m}, 1 \mathrm{H})$, 2.01-1.80 (m, 2H), 1.68-1.56 (m, 1H), $0.84(\mathrm{~d}, J=6.9 \mathrm{~Hz}, 3 \mathrm{H})$.

${ }^{13} \mathrm{C}-\mathrm{NMR}\left(100 \mathrm{MHz}, \mathrm{CDCl}_{3}\right): \delta=154.5\left(\mathrm{C}_{\mathrm{q}}\right), 149.8\left(\mathrm{C}_{\mathrm{q}}\right), 149.6(\mathrm{CH}), 140.9\left(\mathrm{C}_{\mathrm{q}}\right), 138.8(\mathrm{CH})$, $132.1\left(\mathrm{C}_{\mathrm{q}}\right), 130.9\left(\mathrm{C}_{\mathrm{q}}\right), 128.6\left(\mathrm{C}_{\mathrm{q}}\right), 119.5(\mathrm{CH}), 111.9\left(\mathrm{C}_{\mathrm{q}}\right), 111.0(\mathrm{CH}), 110.6(\mathrm{CH}), 100.6$ $(\mathrm{CH}), 56.0\left(\mathrm{CH}_{3}\right), 31.8\left(\mathrm{CH}_{2}\right), 27.2(\mathrm{CH}), 21.5\left(\mathrm{CH}_{2}\right), 20.3\left(\mathrm{CH}_{3}\right), 19.9\left(\mathrm{CH}_{2}\right), 18.0\left(\mathrm{CH}_{3}\right)$.

IR (ATR): 2930, 1596, 1483, 1440, 1388, 1156, $820 \mathrm{~cm}^{-1}$.

MS (ESI) $m / z$ (relative intensity): $329(25)[\mathrm{M}+\mathrm{Na}]^{+}, 307(100)[\mathrm{M}+\mathrm{H}]^{+}$.

HR-MS (ESI): $m / z$ calcd. for $\left[\mathrm{C}_{20} \mathrm{H}_{22} \mathrm{~N}_{2} \mathrm{O}+\mathrm{H}\right]^{+} 307.1805$ found 307.1808 .

$[\alpha]_{\mathrm{D}}^{20}:-51.6\left(\mathrm{c}=1.0, \mathrm{CHCl}_{3}\right)$.

HPLC separation (Chiralpak ${ }^{\circledR}$ ID-3, $n$-hexane/EtOAc 90:10, $1.0 \mathrm{~mL} / \mathrm{min}$, detection at $273 \mathrm{~nm}$ ): $t_{r}($ major $)=13.6 \mathrm{~min}, t_{r}(\operatorname{minor})=8.6 \mathrm{~min}, 85: 15$ e.r.

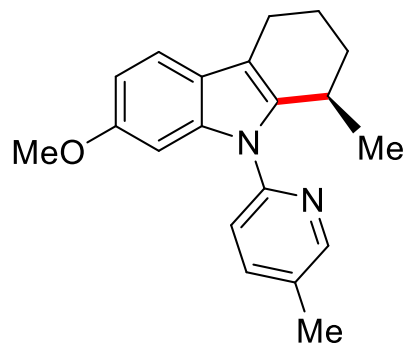

(R)-7-Methoxy-1-methyl-9-(5-methylpyridin-2-yl)-2,3,4,9-tetrahydro-1H-carbazole

(363c): The general procedure $\mathbf{H}$ was followed using 6-methoxy-1-(5-methylpyridin-2-yl)-3(pent-4-en-1-yl)-1H-indole (362c) $(76.5 \mathrm{mg}, 0.25 \mathrm{mmol})$. Isolation by column chromatography $(n$-hexane/EtOAc $=10: 1)$ yielded 363c $(72.0 \mathrm{mg}, 95 \%)$ as a yellow oil.

${ }^{1} \mathrm{H}-\mathrm{NMR}\left(300 \mathrm{MHz}, \mathrm{CDCl}_{3}\right): \delta=8.46(\mathrm{~d}, J=2.4 \mathrm{~Hz}, 1 \mathrm{H}), 7.67(\mathrm{dd}, J=8.1,2.4 \mathrm{~Hz}, 1 \mathrm{H}), 7.37$ $(\mathrm{d}, J=8.5 \mathrm{~Hz}, 1 \mathrm{H}), 7.32(\mathrm{~d}, J=8.1 \mathrm{~Hz}, 1 \mathrm{H}), 6.90(\mathrm{~d}, J=2.3 \mathrm{~Hz}, 1 \mathrm{H}), 6.79(\mathrm{dd}, J=8.5,2.3$ $\mathrm{Hz}, 1 \mathrm{H}), 3.79$ (s, 3H), 3.46-3.34 (m, 1H), 2.83-2.60 (m, 2H), 2.43 (s, 3H), 2.15-2.00 (m, 1H), $1.95-1.80(\mathrm{~m}, 2 \mathrm{H}), 1.69-1.56(\mathrm{~m}, 1 \mathrm{H}), 0.82(\mathrm{~d}, J=6.8 \mathrm{~Hz}, 3 \mathrm{H})$.

${ }^{13} \mathrm{C}-\mathrm{NMR}\left(100 \mathrm{MHz}, \mathrm{CDCl}_{3}\right): \delta=156.4\left(\mathrm{C}_{\mathrm{q}}\right), 149.8\left(\mathrm{C}_{\mathrm{q}}\right), 149.8(\mathrm{CH}), 139.0\left(\mathrm{C}_{\mathrm{q}}\right), 138.9(\mathrm{CH})$, $137.8\left(\mathrm{C}_{\mathrm{q}}\right), 131.1\left(\mathrm{C}_{\mathrm{q}}\right), 122.6\left(\mathrm{C}_{\mathrm{q}}\right), 119.7(\mathrm{CH}), 118.5(\mathrm{CH}), 112.1\left(\mathrm{C}_{\mathrm{q}}\right), 109.0(\mathrm{CH}), 94.7(\mathrm{CH})$, $55.9\left(\mathrm{CH}_{3}\right), 31.8\left(\mathrm{CH}_{2}\right), 27.2(\mathrm{CH}), 21.5\left(\mathrm{CH}_{2}\right), 20.4\left(\mathrm{CH}_{3}\right), 20.0\left(\mathrm{CH}_{2}\right), 18.1\left(\mathrm{CH}_{3}\right)$.

IR (ATR): 2930, 1596, 1475, 1406, 1227, 1203, 1025, $796 \mathrm{~cm}^{-1}$.

MS (ESI) $m / z$ (relative intensity): $329(10)[\mathrm{M}+\mathrm{Na}]^{+}, 307(100)[\mathrm{M}+\mathrm{H}]^{+}$.

HR-MS (ESI): $m / z$ calcd. for $\left[\mathrm{C}_{20} \mathrm{H}_{22} \mathrm{~N}_{2} \mathrm{O}+\mathrm{Na}\right]^{+} 329.1624$ found 329.1622 .

$[\alpha]_{\mathrm{D}}^{20}:-65.1\left(\mathrm{c}=1.0, \mathrm{CHCl}_{3}\right)$. 
HPLC separation (Chiralpak ${ }^{\circledR}$ ID-3, $n$-hexane/EtOAc 90:10, $1.0 \mathrm{~mL} / \mathrm{min}$, detection at $273 \mathrm{~nm}$ ): $t_{r}($ major $)=13.8 \mathrm{~min}, t_{r}($ minor $)=9.6 \min , 84: 16$ e.r.<smiles>[CH]C1CCCc2c1n(-c1ccc(C)cn1)c1cc(F)ccc21</smiles>

(R)-7-Fluoro-1-methyl-9-(5-methylpyridin-2-yl)-2,3,4,9-tetrahydro-1H-carbazole (363d): The general procedure $\mathbf{H}$ was followed using 6-fluoro-1-(5-methylpyridin-2-yl)-3-(pent-4-en1-yl)-1H-indole (362d) $(73.5 \mathrm{mg}, 0.25 \mathrm{mmol})$. Isolation by column chromatography ( $n$ hexane/EtOAc $=30: 1)$ yielded 363d $(49 \mathrm{mg}, 66 \%)$ as a yellow oil.

${ }^{1} \mathrm{H}-\mathrm{NMR}\left(400 \mathrm{MHz}, \mathrm{CDCl}_{3}\right): \delta=8.47(\mathrm{~d}, J=2.3 \mathrm{~Hz}, 1 \mathrm{H}), 7.71(\mathrm{dd}, J=8.1,2.3 \mathrm{~Hz}, 1 \mathrm{H}), 7.41$ $(\mathrm{dd}, J=8.5,5.4 \mathrm{~Hz}, 1 \mathrm{H}), 7.33(\mathrm{~d}, J=8.0 \mathrm{~Hz}, 1 \mathrm{H}), 7.07$ (dd, $J=9.5,2.3 \mathrm{~Hz}, 1 \mathrm{H}), 6.90$ (ddd, $J$ = 9.5, 8.5, 2.3 Hz, 1H), 3.55-3.38 (m, 1H), 2.84-2.66 (m, 2H), $2.45(\mathrm{~s}, 3 \mathrm{H}), 2.16-2.05(\mathrm{~m}, 1 \mathrm{H})$, 2.00-1.81 (m, 2H), 1.69-1.59 (m, 1H), $0.85(\mathrm{~d}, J=6.8 \mathrm{~Hz}, 3 \mathrm{H})$.

${ }^{13} \mathrm{C}-\mathrm{NMR}\left(75 \mathrm{MHz}, \mathrm{CDCl}_{3}\right): \delta=160.1\left(\mathrm{~d},{ }^{1} J_{\mathrm{C}-\mathrm{F}}=234.1 \mathrm{~Hz}, \mathrm{C}_{\mathrm{q}}\right), 149.9(\mathrm{CH}), 149.4\left(\mathrm{C}_{\mathrm{q}}\right), 140.5$ $\left(\mathrm{d},{ }^{4} J_{\mathrm{C}-\mathrm{F}}=3.4 \mathrm{~Hz}, \mathrm{C}_{\mathrm{q}}\right), 139.0(\mathrm{CH}), 137.1\left(\mathrm{~d},{ }^{3} J_{\mathrm{C}-\mathrm{F}}=12.2 \mathrm{~Hz}, \mathrm{C}_{\mathrm{q}}\right), 131.5\left(\mathrm{C}_{\mathrm{q}}\right), 124.6\left(\mathrm{C}_{\mathrm{q}}\right), 119.6$ $(\mathrm{CH}), 118.5\left(\mathrm{~d},{ }^{3} J_{\mathrm{C}-\mathrm{F}}=9.9 \mathrm{~Hz}, \mathrm{CH}\right), 112.1\left(\mathrm{C}_{\mathrm{q}}\right), 108.1\left(\mathrm{~d},{ }^{2} J_{\mathrm{C}-\mathrm{F}}=24.1 \mathrm{~Hz}, \mathrm{CH}\right), 97.0\left(\mathrm{~d},{ }^{2} J_{\mathrm{C}-\mathrm{F}}\right.$ $=27.2 \mathrm{~Hz}, \mathrm{CH}), 31.7\left(\mathrm{CH}_{2}\right), 27.2(\mathrm{CH}), 21.4\left(\mathrm{CH}_{2}\right), 20.3\left(\mathrm{CH}_{3}\right), 19.9\left(\mathrm{CH}_{2}\right), 18.1\left(\mathrm{CH}_{3}\right)$.

${ }^{19} \mathrm{~F}-\mathrm{NMR}\left(377 \mathrm{MHz}, \mathrm{CDCl}_{3}\right): \delta=-121.5$.

IR (ATR): 2929, 1596, 1473, 1484, 1387, 1142, 825, $797 \mathrm{~cm}^{-1}$.

MS (ESI) $\mathrm{m} / z$ (relative intensity): 295 (100) $[\mathrm{M}+\mathrm{H}]^{+}$.

HR-MS (ESI): $m / z$ calcd. for $\left[\mathrm{C}_{19} \mathrm{H}_{19}{ }^{19} \mathrm{FN}_{2}+\mathrm{H}\right]^{+} 295.1605$ found 295.1612 .

$[\alpha]_{\mathrm{D}}^{20}:-78.6\left(\mathrm{c}=1.0, \mathrm{CHCl}_{3}\right)$.

HPLC separation (Chiralpak ${ }^{\circledR}$ ID-3, $n$-hexane/EtOAc 90:10, $1.0 \mathrm{~mL} / \mathrm{min}$, detection at $273 \mathrm{~nm}$ ): $t_{r}($ major $)=7.2 \mathrm{~min}, t_{r}($ minor $)=5.3 \mathrm{~min}, 86: 14$ e.r.<smiles>Cc1ccc(-n2c3c(c4cc(Br)ccc42)CCCC3C)nc1</smiles>

(R)-6-Bromo-1-methyl-9-(5-methylpyridin-2-yl)-2,3,4,9-tetrahydro-1H-carbazole (363e):

The general procedure $\mathbf{H}$ was followed using 5-bromo-1-(5-methylpyridin-2-yl)-3-(pent-4-en- 
1-yl)-1H-indole (362e) $(88.5 \mathrm{mg}, 0.25 \mathrm{mmol})$. Isolation by column chromatography ( $n$ hexane/EtOAc $=15: 1)$ yielded 363e $(78.0 \mathrm{mg}, 88 \%)$ as a yellow solid. M.p.: $110-115{ }^{\circ} \mathrm{C}$.

${ }^{1} \mathrm{H}-\mathrm{NMR}\left(300 \mathrm{MHz}, \mathrm{CDCl}_{3}\right): \delta=8.44(\mathrm{~d}, J=2.4 \mathrm{~Hz}, 1 \mathrm{H}), 7.68(\mathrm{dd}, J=8.2,2.4 \mathrm{~Hz}, 1 \mathrm{H}), 7.60$ $(\mathrm{d}, J=1.3 \mathrm{~Hz}, 1 \mathrm{H}), 7.29$ (d, $J=8.2 \mathrm{~Hz}, 1 \mathrm{H}), 7.23-7.10(\mathrm{~m}, 2 \mathrm{H}), 3.52-3.34(\mathrm{~m}, 1 \mathrm{H}), 2.81-2.59$ $(\mathrm{m}, 2 \mathrm{H}), 2.43(\mathrm{~s}, 3 \mathrm{H}), 2.15-2.01(\mathrm{~m}, 1 \mathrm{H}), 1.97-1.80(\mathrm{~m}, 2 \mathrm{H}), 1.74-1.55(\mathrm{~m}, 1 \mathrm{H}), 0.83(\mathrm{~d}, J=$ $6.8 \mathrm{~Hz}, 3 \mathrm{H})$.

${ }^{13} \mathrm{C}-\mathrm{NMR}\left(100 \mathrm{MHz}, \mathrm{CDCl}_{3}\right): \delta=149.9(\mathrm{CH}), 149.3\left(\mathrm{C}_{\mathrm{q}}\right), 141.6\left(\mathrm{C}_{\mathrm{q}}\right), 139.0(\mathrm{CH}), 135.7\left(\mathrm{C}_{\mathrm{q}}\right)$, $131.7\left(\mathrm{C}_{\mathrm{q}}\right), 129.9\left(\mathrm{C}_{\mathrm{q}}\right), 124.3(\mathrm{CH}), 120.7(\mathrm{CH}), 119.8(\mathrm{CH}), 113.2\left(\mathrm{C}_{\mathrm{q}}\right), 111.7\left(\mathrm{C}_{\mathrm{q}}\right), 111.3$ $(\mathrm{CH}), 31.6\left(\mathrm{CH}_{2}\right), 27.1(\mathrm{CH}), 21.3\left(\mathrm{CH}_{2}\right), 20.2\left(\mathrm{CH}_{3}\right), 19.8\left(\mathrm{CH}_{2}\right), 18.1\left(\mathrm{CH}_{3}\right)$.

IR (ATR): 2929, 1572, 1483, 1455, 1402, 1027, $792 \mathrm{~cm}^{-1}$. MS (ESI) $m / z$ (relative intensity): $377(25)[\mathrm{M}+\mathrm{Na}]^{+}, 355(100)[\mathrm{M}+\mathrm{H}]^{+}$. HR-MS (ESI): $m / z$ calcd. for $\left[\mathrm{C}_{19} \mathrm{H}_{19}{ }^{79} \mathrm{BrN}_{2}+\mathrm{Na}\right]^{+} 377.0624$ found 377.0620 . $[\alpha]_{\mathrm{D}}^{20}:-50.5\left(\mathrm{c}=1.0, \mathrm{CHCl}_{3}\right)$.

HPLC separation (Chiralpak ${ }^{\circledR}$ ID-3, $n$-hexane/EtOAc 90:10, $1.0 \mathrm{~mL} / \mathrm{min}$, detection at $273 \mathrm{~nm}$ ): $t_{r}($ major $)=8.6 \mathrm{~min}, t_{r}($ minor $)=5.7 \mathrm{~min}, 82: 18$ e.r.

1 mmol scale reaction: A modified procedure $\mathbf{H}$ was followed using 5-bromo-1-(5methylpyridin-2-yl)-3-(pent-4-en-1-yl)-1H-indole (362e) $(354.0 \mathrm{mg}, 1.0 \mathrm{mmol}),\left[\mathrm{RuCl}_{2}(p\right.$ cymene)] 2 (30.6 mg, $5.0 \mathrm{~mol} \%$ ), AgSbF6 (68.8 mg, $20 \mathrm{~mol} \%$ ) and chiral acid CA14 (100.4 $\mathrm{mg}, 20 \mathrm{~mol} \%)$ in $\mathrm{PhMe}(2.0 \mathrm{~mL})$ at $25{ }^{\circ} \mathrm{C}$ for $36 \mathrm{~h}$. The reaction mixture was diluted with EtOAc $(5.0 \mathrm{~mL})$ and the solvent was removed in vacuo. The crude mixture was purified by flash column chromatography $(n$-hexane/EtOAc $=15: 1)$ on silica gel to afford the desired product 363e. (304.2 $\mathrm{mg}, 86 \%$ ) as a yellow soild. HPLC separation (Chiralpak ${ }^{\circledR}$ ID-3, $n$ hexane/EtOAc 90:10, $1.0 \mathrm{~mL} / \mathrm{min}$, detection at $273 \mathrm{~nm}): t_{r}$ (major $)=8.5 \mathrm{~min}, t_{r}($ minor $)=5.7$ $\min , 83: 17$ e.r.<smiles>Cc1ccc(-n2c3c(c4ccccc42)CCCCC3C)nc1</smiles>

(R)-6-Methyl-5-(5-methylpyridin-2-yl)-5,6,7,8,9,10-hexahydrocyclohepta[b]indole

(369a): The general procedure $\mathbf{H}$ was followed using 3-(hex-5-en-1-yl)-1-(5-methylpyridin-2yl)-1H-indole (368a) $(29.0 \mathrm{mg}, 0.10 \mathrm{mmol})$. Isolation by column chromatography ( $n$ hexane/EtOAc $=30: 1)$ yielded 369a $(5.0 \mathrm{mg}, 17 \%)$ as a yellow oil. 
${ }^{1} \mathrm{H}-\mathrm{NMR}\left(600 \mathrm{MHz}, \mathrm{CDCl}_{3}\right): \delta=8.45(\mathrm{dd}, J=2.5,0.8 \mathrm{~Hz}, 1 \mathrm{H}), 7.67-7.61(\mathrm{~m}, 1 \mathrm{H}), 7.51-7.44$ $(\mathrm{m}, 1 \mathrm{H}), 7.22(\mathrm{~d}, J=7.0 \mathrm{~Hz}, 1 \mathrm{H}), 7.10(\mathrm{dd}, J=8.0,0.8 \mathrm{~Hz}, 1 \mathrm{H}), 7.07(\mathrm{ddd}, J=8.0,7.0,1.2$ $\mathrm{Hz}, 1 \mathrm{H}), 7.03$ (ddd, $J=8.0,7.0,1.2 \mathrm{~Hz}, 1 \mathrm{H}), 3.26-3.18(\mathrm{~m}, 1 \mathrm{H}), 3.06(\mathrm{ddd}, J=15.4,5.8,2.6$ Hz, 1H), 2.67 (ddd, $J=15.4,12.4,2.6 \mathrm{~Hz}, 1 \mathrm{H}), 2.40$ (s, 3H), 2.06-1.99 (m, 1H), 1.96-1.87 (m, 2H), 1.84-1.74 (m, 2H), 1.56-1.50 (m, 1H), 1.17 (d, J = 7.2 Hz, 3H).

${ }^{13} \mathrm{C}-\mathrm{NMR}\left(100 \mathrm{MHz}, \mathrm{CDCl}_{3}\right): \delta=150.0(\mathrm{CH}), 149.5\left(\mathrm{C}_{\mathrm{q}}\right), 143.1\left(\mathrm{C}_{\mathrm{q}}\right), 138.7(\mathrm{CH}), 136.3\left(\mathrm{C}_{\mathrm{q}}\right)$, $131.8\left(\mathrm{C}_{\mathrm{q}}\right), 128.8\left(\mathrm{C}_{\mathrm{q}}\right), 121.6(\mathrm{CH}), 121.2(\mathrm{CH}), 119.8(\mathrm{CH}), 117.7(\mathrm{CH}), 114.6\left(\mathrm{C}_{\mathrm{q}}\right), 110.0$ $(\mathrm{CH}), 33.2\left(\mathrm{CH}_{2}\right), 30.5(\mathrm{CH}), 28.7\left(\mathrm{CH}_{2}\right), 25.4\left(\mathrm{CH}_{2}\right), 24.1\left(\mathrm{CH}_{2}\right), 18.4\left(\mathrm{CH}_{3}\right), 18.1\left(\mathrm{CH}_{3}\right)$.

IR (ATR): 2920, 1596, 1570, 1483, 1459, 1384, 1201, $738 \mathrm{~cm}^{-1}$.

MS (ESI) $m / z$ (relative intensity): $313(10)[\mathrm{M}+\mathrm{Na}]^{+}, 291(100)[\mathrm{M}+\mathrm{H}]^{+}$.

HR-MS (ESI): $m / z$ calcd. for $\left[\mathrm{C}_{20} \mathrm{H}_{22} \mathrm{~N}_{2}+\mathrm{H}\right]^{+} 291.1856$ found 291.1858 .

$[\alpha]_{\mathrm{D}}^{20}:-7.4\left(\mathrm{c}=1.0, \mathrm{CHCl}_{3}\right)$.

HPLC separation (Chiralpak ${ }^{\circledR}$ ID-3, $n$-hexane/EtOAc 90:10, $1.0 \mathrm{~mL} / \mathrm{min}$, detection at $273 \mathrm{~nm}$ ): $t_{r}($ major $)=7.6 \mathrm{~min}, t_{r}($ minor $)=6.0 \mathrm{~min}, 82: 18$ e.r.

\subsubsection{Mechanistic Studies}

\subsubsection{H/D Exchange Experiment}

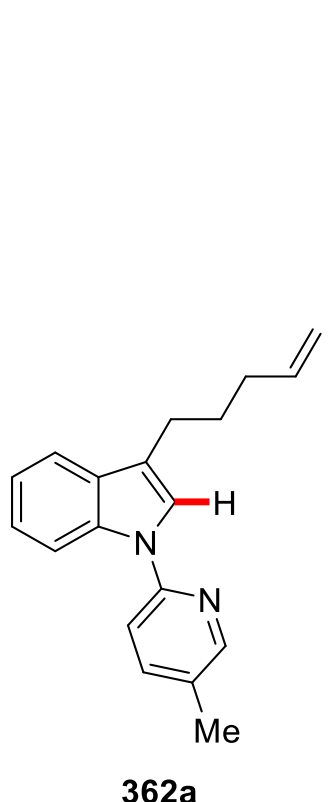

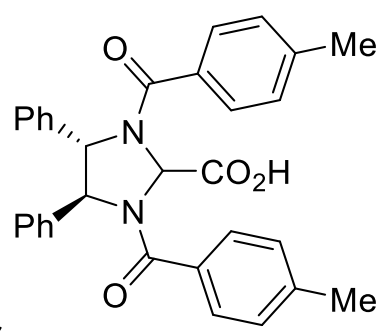

CA14 $(20 \mathrm{~mol} \%)$

$\left[\mathrm{RuCl}_{2}(p \text {-cymene })\right]_{2}$ $(5.0 \mathrm{~mol} \%)$

$\mathrm{AgSbF}_{6}(20 \mathrm{~mol} \%)$

$\mathrm{PhMe} / \mathrm{D}_{2} \mathrm{O}(5: 1)$

$\mathrm{RT}, 12 \mathrm{~h}$

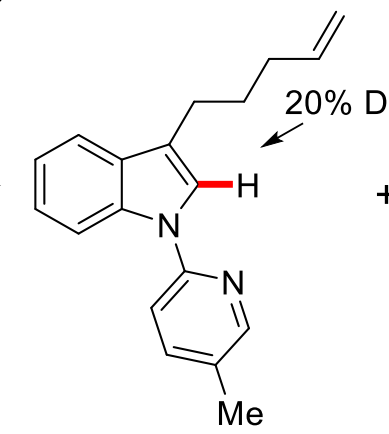

$[D]_{n}-362 \mathrm{a}: 24 \%$

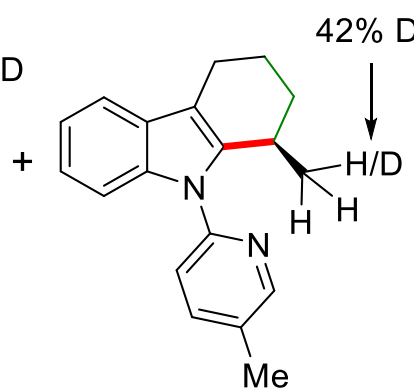

$[\mathrm{D}]_{n}-\mathbf{3 6 3 a :} 71 \%$

The representative procedure $\mathbf{H}$ was followed using 362a $(69.0 \mathrm{mg}, 0.25 \mathrm{mmol}, 1$ equiv), $\left[\mathrm{RuCl}_{2}(p \text {-cymene) }]_{2}(7.7 \mathrm{mg}, 5.0 \mathrm{~mol} \%), \operatorname{AgSbF}_{6}(17.2 \mathrm{mg}, 20 \mathrm{~mol} \%), \mathbf{C A 1 4}(25.2 \mathrm{mg}, 20\right.$ $\mathrm{mol} \%)$ in $\mathrm{PhMe}(0.50 \mathrm{~mL})$ and $\mathrm{D}_{2} \mathrm{O}(0.10 \mathrm{~mL})$ at $25{ }^{\circ} \mathrm{C}$ for $12 \mathrm{~h}$. At ambient temperature, the reaction mixture was diluted with EtOAc $(2.0 \mathrm{~mL})$ and the solvents was removed in vacuo. 
The crude mixture was purified by flash column chromatography on silica gel to afford the desired product $[\mathrm{D}]_{n} \mathbf{- 3 6 3 a}(48.0 \mathrm{mg}, 71 \%)$ and $[\mathrm{D}]_{n} \mathbf{- 3 6 2 a}(17.0 \mathrm{mg}, 24 \%)$ as yellow oils.

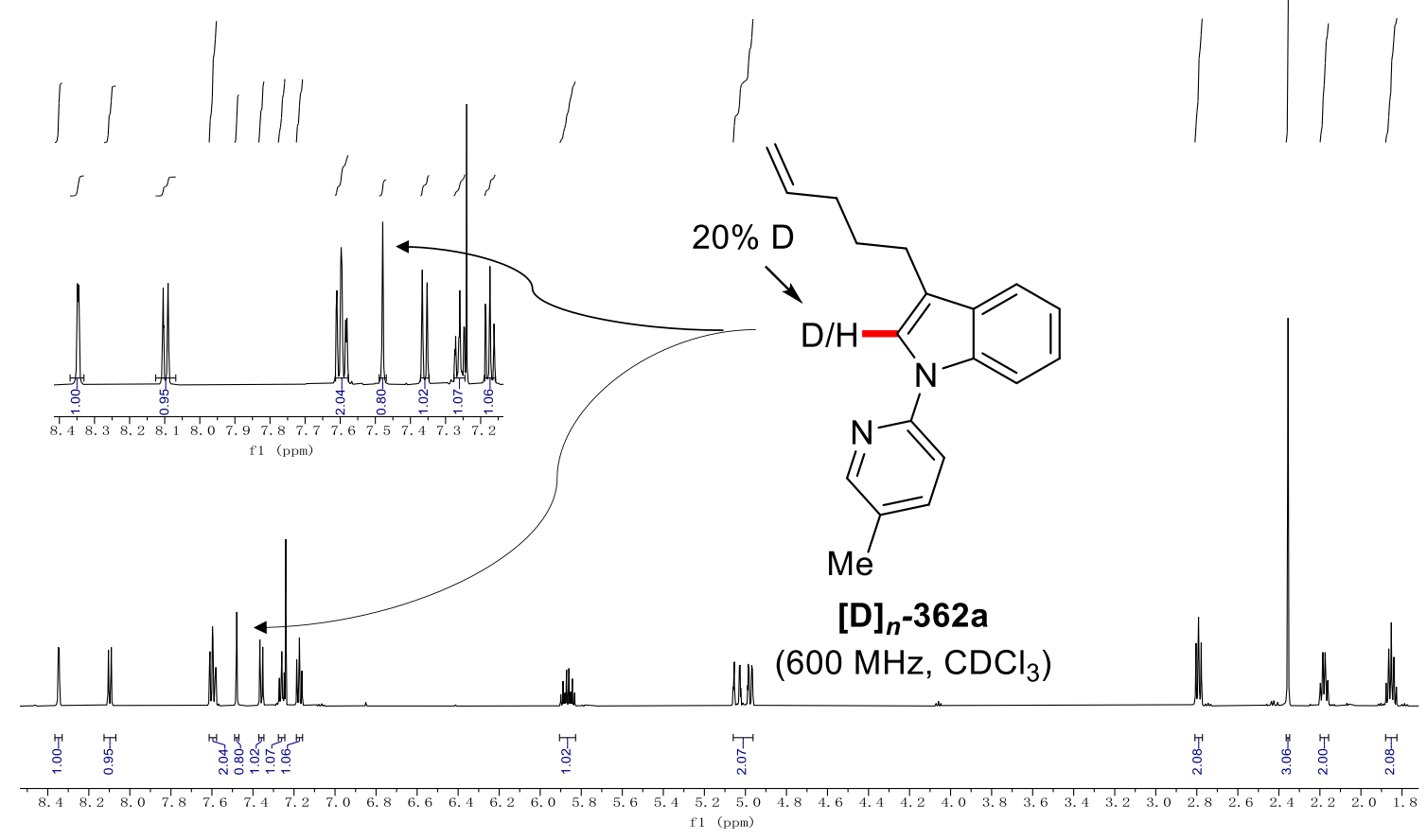

Figure 5. ${ }^{1} \mathrm{H}-\mathrm{NMR}$ of reisolated $[\mathrm{D}]_{n}-\mathbf{3 6 2}$ from the deuteration study.

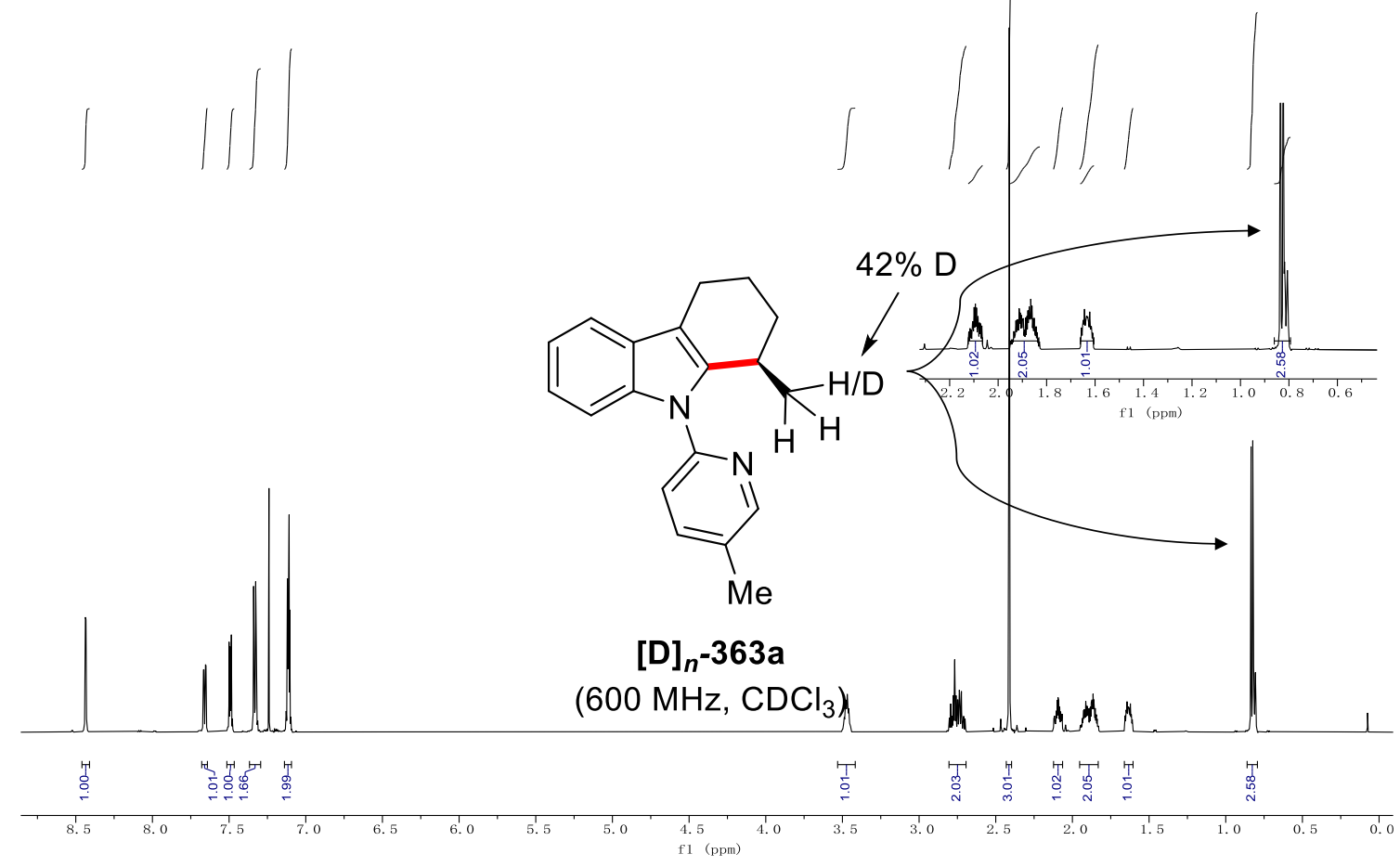

Figure 6. ${ }^{1} \mathrm{H}-\mathrm{NMR}$ of $[\mathrm{D}]_{n}-363$ from the deuteration study. 


\subsubsection{Intramolecular Competition KIE Experiment}

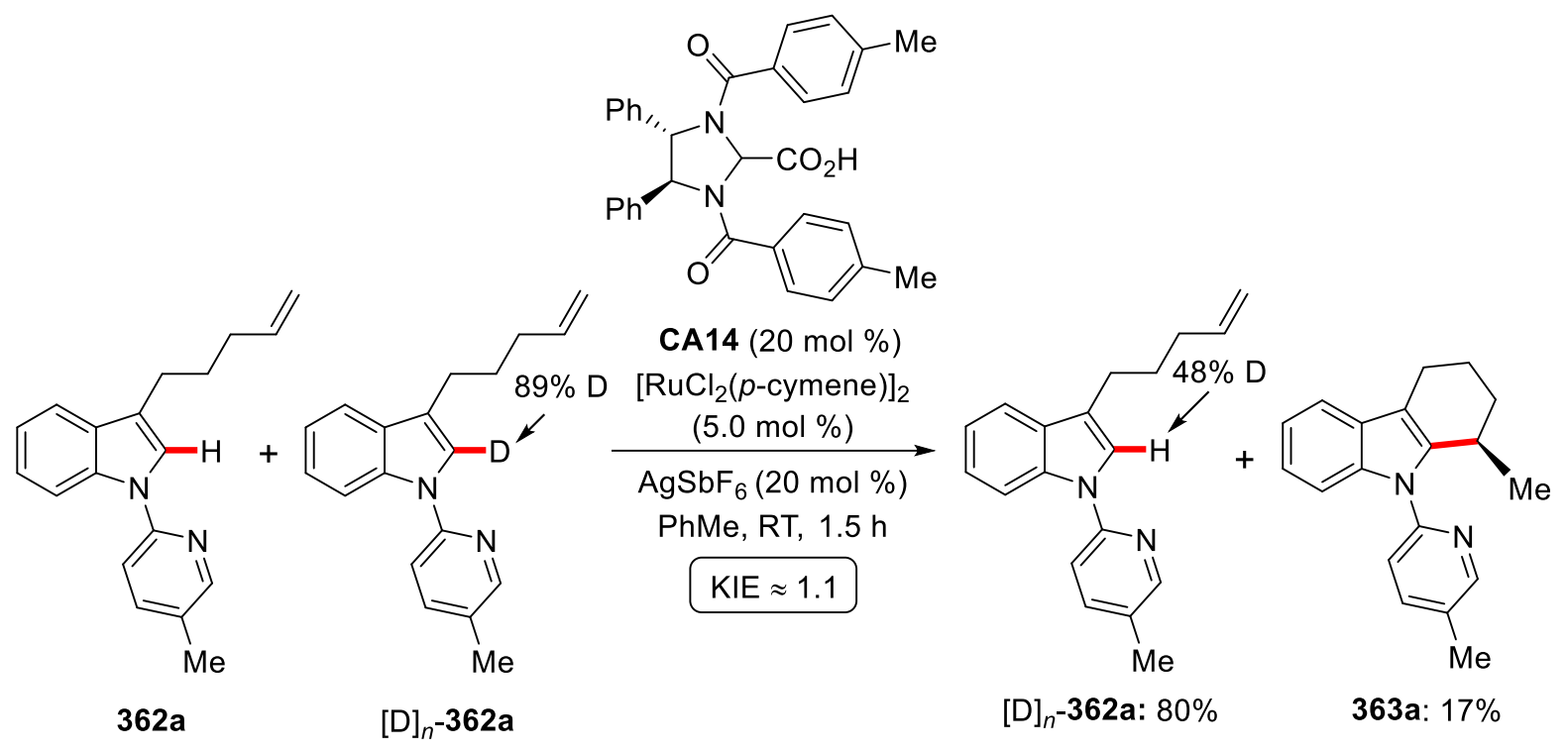

The representative procedure A was followed using 362a (53.8 $\mathrm{mg}, 0.195 \mathrm{mmol}, 1$ equiv), $[\mathrm{D}]_{n}$-362a (69.3 mg, $0.25 \mathrm{mmol}, 1$ equiv)], $\left[\mathrm{RuCl}_{2} \text { (p-cymene) }\right]_{2}(13.7 \mathrm{mg}, 10 \mathrm{~mol} \%), \mathrm{AgSbF}_{6}$ (30.5 mg, $20 \mathrm{~mol} \%$ ) and CA14 (44.8 mg, $20 \mathrm{~mol} \%$ ) in PhMe (1.5 mL) at $25^{\circ} \mathrm{C}$ for $1.5 \mathrm{~h}$. The reaction mixture was diluted with EtOAc $(5.0 \mathrm{~mL})$ and the solvent was removed in vacuo. The crude mixture was purified by flash column chromatography on silica gel to afford the desired product 363a $(21.0 \mathrm{mg}, 17 \%)$ and $[\mathrm{D}]_{n}-\mathbf{3 6 2 a}(98.0 \mathrm{mg}, 80 \%)$ as yellow oils. The kinetic isotope effect of this reaction was determined to be $k_{\mathrm{H}} / k_{\mathrm{D}} \approx 52 / 48 \approx 1.1$ as estimated by ${ }^{1} \mathrm{H}-\mathrm{NMR}$ spectroscopy, based on the recovered starting material. 


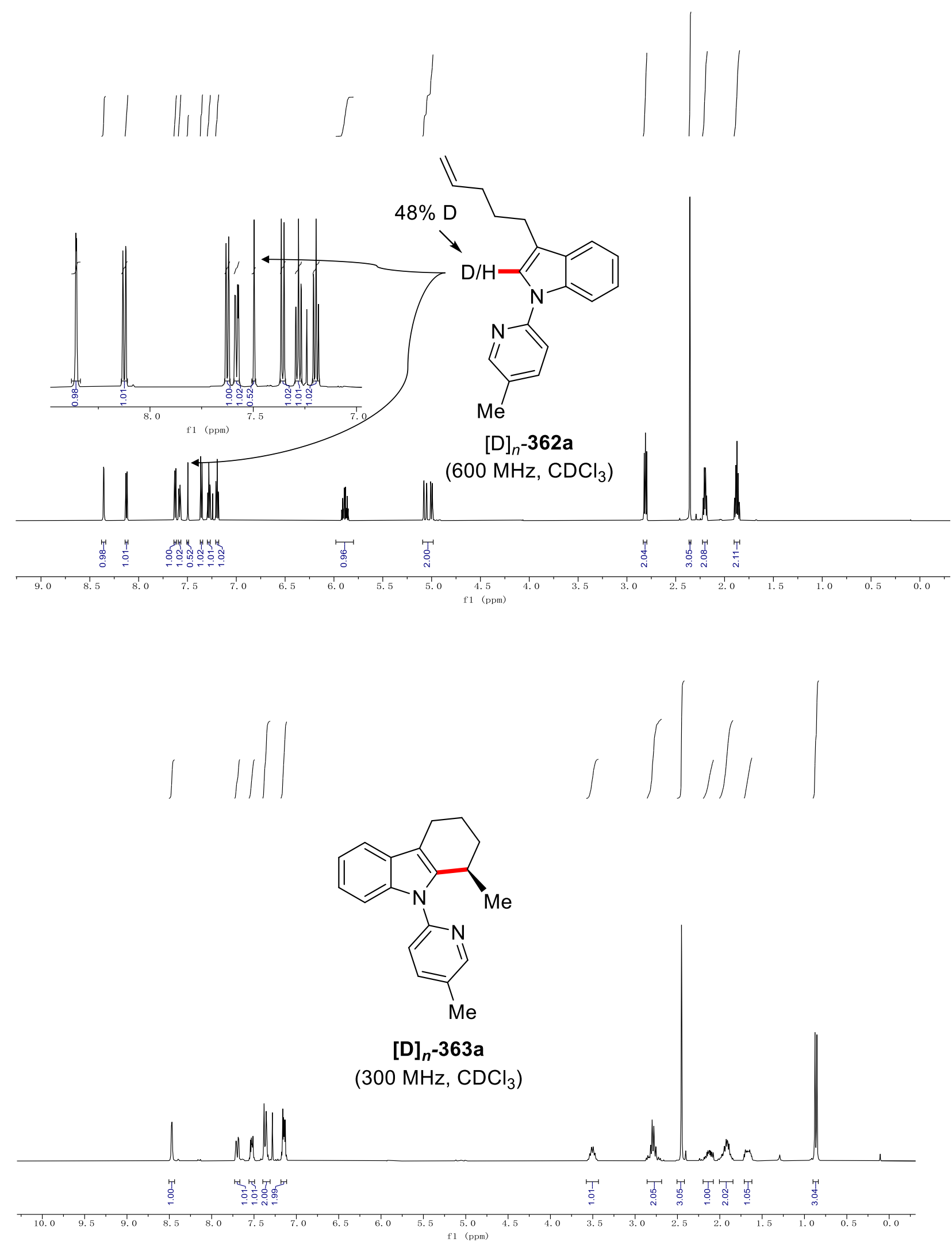




\subsection{Copper-catalyzed Alkyne Annulation by C-H Alkynylation}

\subsubsection{Characterization Data}<smiles>O=C1c2ccccc2/C(=C/c2ccccc2)N1c1cccc2cccnc12</smiles>

(Z)-3-Benzylidene-2-(quinolin-8-yl) isoindolin-1-one (256aa): The general procedure $\mathbf{J}$ was followed using benzamide 229a (62 $\mathrm{mg}, 0.25 \mathrm{mmol}$ ) and alkyne 255a (51 mg, $0.50 \mathrm{mmol}$ ). Purification by column chromatography on silica gel ( $n$-hexane/EtOAc: $5 / 1)$ yielded 256aa (78.7 mg, 90\%, $E / Z=1: 13$ ) as a white solid. M. p.: $210-215^{\circ} \mathrm{C}$.

Resonances are reported for (Z)-256aa. ${ }^{1} \mathrm{H}-\mathrm{NMR}\left(300 \mathrm{MHz}, \mathrm{CDCl}_{3}\right): \delta=8.85(\mathrm{dd}, J=4.2,1.7$ $\mathrm{Hz}, 1 \mathrm{H}), 8.02-7.94(\mathrm{~m}, 2 \mathrm{H}), 7.88(\mathrm{~d}, J=7.7 \mathrm{~Hz}, 1 \mathrm{H}), 7.68(\mathrm{td}, J=7.5,1.2 \mathrm{~Hz}, 1 \mathrm{H}), 7.61-7.53$ (m, 2H), 7.48 (dd, $J=7.4,1.5 \mathrm{~Hz}, 1 \mathrm{H}), 7.34-7.27$ (m, 2H), 6.81 (s, 0.93H, Z), 6.71-6.64 (m, $1 \mathrm{H}), 6.60-6.48(\mathrm{~m}, 4 \mathrm{H}), 6.02(\mathrm{~s}, 0.07 \mathrm{H}, E)$.

${ }^{13} \mathrm{C}-\mathrm{NMR}\left(125 \mathrm{MHz}, \mathrm{CDCl}_{3}\right): \delta=167.9\left(\mathrm{C}_{\mathrm{q}}\right), 150.2(\mathrm{CH}), 144.3\left(\mathrm{C}_{\mathrm{q}}\right), 138.6\left(\mathrm{C}_{\mathrm{q}}\right), 136.0\left(\mathrm{C}_{\mathrm{q}}\right)$, $135.6(\mathrm{CH}), 134.1\left(\mathrm{C}_{\mathrm{q}}\right), 133.4\left(\mathrm{C}_{\mathrm{q}}\right), 132.1(\mathrm{CH}), 129.9(\mathrm{CH}), 128.9(\mathrm{CH}), 128.7\left(\mathrm{C}_{\mathrm{q}}\right), 128.2$ $\left(\mathrm{C}_{\mathrm{q}}\right), 128.2(\mathrm{CH}), 128.0(\mathrm{CH}), 126.2(\mathrm{CH}), 125.9(\mathrm{CH}), 125.5(\mathrm{CH}), 123.8(\mathrm{CH}), 121.1(\mathrm{CH})$, $119.5(\mathrm{CH}), 107.2(\mathrm{CH})$.

IR (ATR): 3061, 1704, 1596, 1472, 1377, 1221, 1024, $716 \mathrm{~cm}^{-1}$. MS (ESI) $\mathrm{m} / z$ (relative intensity): $371(10)[\mathrm{M}+\mathrm{Na}]^{+}, 349(60)[\mathrm{M}+\mathrm{H}]^{+}$.

HR-MS (ESI) $m / z$ calcd for $\mathrm{C}_{24} \mathrm{H}_{17} \mathrm{~N}_{2} \mathrm{O}[\mathrm{M}+\mathrm{H}]^{+}: 349.1335$, found: 349.1324 . The analytical data correspond with those reported in the literature. ${ }^{[208]}$<smiles>O=C1c2c(Br)cccc2/C(=C/c2ccccc2)N1c1cccc2cccnc12</smiles>

(Z)-3-Benzylidene-7-bromo-2-(quinolin-8-yl)isoindolin-1-one (256ba): The general procedure $\mathbf{J}$ was followed using benzamide $229 \mathbf{b}$ ( $82 \mathrm{mg}, 0.25 \mathrm{mmol})$ and alkyne $\mathbf{2 5 5 \mathbf { a }}(51 \mathrm{mg}$, $0.50 \mathrm{mmol}$ ). Purification by column chromatography on silica gel ( $n$-hexane/EtOAc: $2 / 1)$ yielded 256ba $(69.2 \mathrm{mg}, 65 \%, E / Z=1: 10)$ as a yellow solid. M. p.: 200-205 ${ }^{\circ} \mathrm{C}$.

Resonances are reported for $(Z)-\mathbf{2 5 6 b a}$.

${ }^{1} \mathrm{H}-\mathrm{NMR}\left(400 \mathrm{MHz}, \mathrm{CDCl}_{3}\right): \delta=8.83(\mathrm{dd}, J=4.2,1.7 \mathrm{~Hz}, 1 \mathrm{H}), 8.02-7.93$ (m, 2H), 7.90-7.85 $(\mathrm{m}, 1 \mathrm{H}), 7.67(\mathrm{dd}, J=7.8,1.2 \mathrm{~Hz}, 1 \mathrm{H}), 7.56(\mathrm{dd}, J=7.5,1.2 \mathrm{~Hz}, 2 \mathrm{H}), 7.46(\mathrm{dd}, J=7.4,1.4$ 
$\mathrm{Hz}, 1 \mathrm{H}), 7.31-7.26(\mathrm{~m}, 2 \mathrm{H}), 6.79(\mathrm{~s}, 0.90 \mathrm{H}, \mathrm{Z}), 6.70-6.61(\mathrm{~m}, 1 \mathrm{H}), 6.60-6.43(\mathrm{~m}, 3 \mathrm{H}), 6.00$ (s, $0.10 \mathrm{H}, E)$.

${ }^{13} \mathrm{C}-\mathrm{NMR}\left(100 \mathrm{MHz}, \mathrm{CDCl}_{3}\right): \delta=168.1\left(\mathrm{C}_{\mathrm{q}}\right), 150.3(\mathrm{CH}), 144.4\left(\mathrm{C}_{\mathrm{q}}\right), 138.7\left(\mathrm{C}_{\mathrm{q}}\right), 136.1\left(\mathrm{C}_{\mathrm{q}}\right)$, $135.7(\mathrm{CH}), 135.5\left(\mathrm{C}_{\mathrm{q}}\right), 135.3\left(\mathrm{C}_{\mathrm{q}}\right), 134.2\left(\mathrm{C}_{\mathrm{q}}\right), 133.6\left(\mathrm{C}_{\mathrm{q}}\right), 132.2(\mathrm{CH}), 130.0(\mathrm{CH}), 129.1$ $(\mathrm{CH}), 128.8\left(\mathrm{C}_{\mathrm{q}}\right), 128.1(\mathrm{CH}), 126.3(\mathrm{CH}), 126.0(\mathrm{CH}), 125.6(\mathrm{CH}), 123.9(\mathrm{CH}), 121.2(\mathrm{CH})$, $119.6(\mathrm{CH}), 107.3(\mathrm{CH})$.

IR (ATR): 3048, 1714, 1650, 1500, 1473, 1070, 757, $693 \mathrm{~cm}^{-1}$.

MS (ESI) $m / z$ (relative intensity): $449(30)\left[\mathrm{M}\left({ }^{79} \mathrm{Br}\right)+\mathrm{Na}\right]^{+}, 427(100)\left[\mathrm{M}\left({ }^{79} \mathrm{Br}\right)+\mathrm{H}\right]^{+}$.

HR-MS (ESI): $m / z$ calcd for $\mathrm{C}_{24} \mathrm{H}_{16}{ }^{79} \mathrm{BrN}_{2} \mathrm{O}[\mathrm{M}+\mathrm{H}]^{+}: 427.0441$, found: 427.0448 .<smiles>O=C1/C(=C\c2ccccc2)c2cccc(-c3ccccc3)c21</smiles>

(Z)-3-Benzylidene-7-phenyl-2-(quinolin-8-yl)isoindolin-1-one (256ca): The general procedure $\mathbf{J}$ was followed using benzamide $229 \mathrm{c}$ ( $81 \mathrm{mg}, 0.25 \mathrm{mmol})$ and alkyne $255 \mathbf{a}(51 \mathrm{mg}$, $0.50 \mathrm{mmol})$ with $\mathrm{Cu}(\mathrm{OAc})_{2} \cdot \mathrm{H}_{2} \mathrm{O}(5.0 \mathrm{mg}, 10 \mathrm{~mol} \%)$. Purification by column chromatography on silica gel ( $n$-hexane/EtOAc: $2 / 1)$ yielded 256ca $(54.3 \mathrm{mg}, 51 \%, E / Z=1: 3)$ as a yellow oil. Resonances reported for (Z)-256ca: ${ }^{1} \mathrm{H}-\mathrm{NMR}\left(400 \mathrm{MHz}, \mathrm{CDCl}_{3}\right)$ : $\delta=8.82$ (dd, $J=4.2,1.6 \mathrm{~Hz}$, 1H), 7.95-7.86 (m, 2H), $7.71(\mathrm{~d}, J=7.7 \mathrm{~Hz}, 1 \mathrm{H}), 7.63(\mathrm{~d}, J=1.7 \mathrm{~Hz}, 1 \mathrm{H}), 7.61(\mathrm{~d}, J=1.2 \mathrm{~Hz}$, $1 \mathrm{H}), 7.54(\mathrm{~d}, J=1.3 \mathrm{~Hz}, 1 \mathrm{H}), 7.48(\mathrm{dd}, J=7.5,1.0 \mathrm{~Hz}, 2 \mathrm{H}), 7.43-7.39$ (m, 2H), 7.38-7.35 (m, 2H), $7.26(\mathrm{~d}, J=1.7 \mathrm{~Hz}, 1 \mathrm{H}), 6.83(\mathrm{~s}, 1 \mathrm{H}), 6.64(\mathrm{t}, J=7.3 \mathrm{~Hz}, 1 \mathrm{H}), 6.60-6.55(\mathrm{~m}, 2 \mathrm{H}), 6.51$ $(\mathrm{d}, J=7.5 \mathrm{~Hz}, 2 \mathrm{H})$.

${ }^{13} \mathrm{C}-\mathrm{NMR}\left(125 \mathrm{MHz}, \mathrm{CDCl}_{3}\right): \delta=167.2\left(\mathrm{C}_{\mathrm{q}}\right), 150.2(\mathrm{CH}), 144.3\left(\mathrm{C}_{\mathrm{q}}\right), 141.1\left(\mathrm{C}_{\mathrm{q}}\right), 139.7\left(\mathrm{C}_{\mathrm{q}}\right)$, $137.2\left(\mathrm{C}_{\mathrm{q}}\right), 135.6\left(\mathrm{C}_{\mathrm{q}}\right), 135.6(\mathrm{CH}), 134.2\left(\mathrm{C}_{\mathrm{q}}\right), 133.6\left(\mathrm{C}_{\mathrm{q}}\right), 131.7(\mathrm{CH}), 131.1(\mathrm{CH}), 130.2$ $(\mathrm{CH}), 129.7(\mathrm{CH}), 129.4(\mathrm{CH}), 128.7\left(\mathrm{C}_{\mathrm{q}}\right), 128.4(\mathrm{CH}), 128.1(\mathrm{CH}), 127.5(\mathrm{CH}), 126.1(\mathrm{CH})$, $125.8(\mathrm{CH}), 125.5(\mathrm{CH}), 124.0\left(\mathrm{C}_{\mathrm{q}}\right), 121.0(\mathrm{CH}), 118.6(\mathrm{CH}), 106.7(\mathrm{CH})$.

Resonances reported for $(E)-256 \mathrm{ca}:{ }^{1} \mathrm{H}-\mathrm{NMR}\left(400 \mathrm{MHz}, \mathrm{CDCl}_{3}\right): \delta=8.92$ (dd, $J=4.2,1.6 \mathrm{~Hz}$, $1 \mathrm{H}), 8.20(\mathrm{dd}, J=8.3,1.6 \mathrm{~Hz}, 1 \mathrm{H}), 7.95-7.89(\mathrm{~m}, 1 \mathrm{H}), 7.81(\mathrm{dd}, J=7.3,1.4 \mathrm{~Hz}, 1 \mathrm{H}), 7.66$ (d, $J=7.8 \mathrm{~Hz}, 1 \mathrm{H}), 7.60(\mathrm{~d}, J=1.6 \mathrm{~Hz}, 1 \mathrm{H}), 7.58(\mathrm{t}, J=1.4 \mathrm{~Hz}, 1 \mathrm{H}), 7.51-7.45(\mathrm{~m}, 1 \mathrm{H}), 7.43-$ $7.38(\mathrm{~m}, 1 \mathrm{H}), 7.38-7.35(\mathrm{~m}, 2 \mathrm{H}), 7.35-7.32(\mathrm{~m}, 4 \mathrm{H}), 7.32-7.27(\mathrm{~m}, 3 \mathrm{H}), 7.24(\mathrm{~s}, 1 \mathrm{H}), 6.01(\mathrm{~s}$, $1 \mathrm{H})$.

${ }^{13} \mathrm{C}-\mathrm{NMR}$ (125 MHz, $\mathrm{CDCl}_{3}$ ) (two carbon peak less due to overlap): $\delta=166.1\left(\mathrm{C}_{\mathrm{q}}\right), 151.1$ $(\mathrm{CH}), 144.9\left(\mathrm{C}_{\mathrm{q}}\right), 141.0\left(\mathrm{C}_{\mathrm{q}}\right), 138.1\left(\mathrm{C}_{\mathrm{q}}\right), 137.4\left(\mathrm{C}_{\mathrm{q}}\right), 136.6\left(\mathrm{C}_{\mathrm{q}}\right), 136.1(\mathrm{CH}), 135.5\left(\mathrm{C}_{\mathrm{q}}\right), 132.8$ 
$\left(\mathrm{C}_{\mathrm{q}}\right), 131.5(\mathrm{CH}), 131.3(\mathrm{CH}), 129.7(\mathrm{CH}), 129.4\left(\mathrm{C}_{\mathrm{q}}\right), 129.2(\mathrm{CH}), 128.1(\mathrm{CH}), 127.7(\mathrm{CH})$, 127.6 (CH), $127.5(\mathrm{CH}), 127.4(\mathrm{CH}), 126.2(\mathrm{CH}), 122.2(\mathrm{CH}), 121.7(\mathrm{CH}), 111.5(\mathrm{CH})$.

IR (ATR): 3055, 1719, 1595, 1473, 1377, 825, $759 \mathrm{~cm}^{-1}$.

MS (ESI) $m / z$ (relative intensity): $447(10)[\mathrm{M}+\mathrm{Na}]^{+}, 425(100)[\mathrm{M}+\mathrm{H}]^{+}$.

HR-MS (ESI): $m / z$ calcd for $\mathrm{C}_{30} \mathrm{H}_{20} \mathrm{~N}_{2} \mathrm{ONa}[\mathrm{M}+\mathrm{Na}]^{+}$: 447.1468, found: 447.1473.

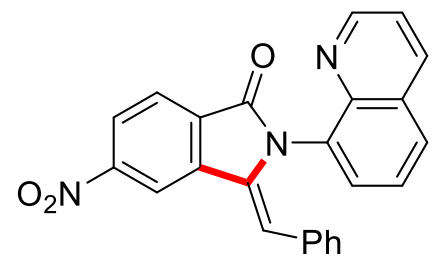

(Z)-3-Benzylidene-5-nitro-2-(quinolin-8-yl) isoindolin-1-one (256da): The general procedure $\mathbf{J}$ was followed using benzamide $229 \mathbf{d}$ (73 $\mathrm{mg}, 0.25 \mathrm{mmol}$ ) and alkyne $\mathbf{2 5 5 \mathbf { a }}(51 \mathrm{mg}$, $0.50 \mathrm{mmol})$ with $\mathrm{Cu}(\mathrm{OAc})_{2} \cdot \mathrm{H}_{2} \mathrm{O}(5.0 \mathrm{mg}, 10 \mathrm{~mol} \%)$. Purification by column chromatography on silica gel ( $n$-hexane/EtOAc: $1 / 1)$ yielded 256da (57 mg, 58\%, E/Z = 1:3) as a yellow oil.

Resonances reported for (Z)-256da. ${ }^{1} \mathrm{H}-\mathrm{NMR}\left(400 \mathrm{MHz}, \mathrm{CDCl}_{3}\right.$ ): $\delta=8.84$ (dd, $J=4.2,1.6$ $\mathrm{Hz}, 1 \mathrm{H}), 8.78(\mathrm{~d}, J=1.8 \mathrm{~Hz}, 1 \mathrm{H}), 8.44(\mathrm{dd}, J=8.3,1.9 \mathrm{~Hz}, 1 \mathrm{H}), 8.17(\mathrm{~d}, J=8.3 \mathrm{~Hz}, 1 \mathrm{H}), 8.01$ $(\mathrm{dd}, J=8.3,1.6 \mathrm{~Hz}, 1 \mathrm{H}), 7.65(\mathrm{dd}, J=8.2,1.4 \mathrm{~Hz}, 1 \mathrm{H}), 7.53(\mathrm{dd}, J=7.4,1.3 \mathrm{~Hz}, 1 \mathrm{H}), 7.38-$ $7.31(\mathrm{~m}, 2 \mathrm{H}), 6.99(\mathrm{~s}, 1 \mathrm{H}), 6.74(\mathrm{dd}, J=8.9,5.3 \mathrm{~Hz}, 1 \mathrm{H}), 6.59(\mathrm{dd}, J=7.1,6.4 \mathrm{~Hz}, 4 \mathrm{H})$.

${ }^{13} \mathrm{C}-\mathrm{NMR}\left(100 \mathrm{MHz}, \mathrm{CDCl}_{3}\right): \delta=166.0\left(\mathrm{C}_{\mathrm{q}}\right), 150.8\left(\mathrm{C}_{\mathrm{q}}\right), 150.5(\mathrm{CH}), 144.0\left(\mathrm{C}_{\mathrm{q}}\right), 139.5\left(\mathrm{C}_{\mathrm{q}}\right)$, $135.9(\mathrm{CH}), 134.6\left(\mathrm{C}_{\mathrm{q}}\right), 133.5\left(\mathrm{C}_{\mathrm{q}}\right), 132.7\left(\mathrm{C}_{\mathrm{q}}\right), 132.5\left(\mathrm{C}_{\mathrm{q}}\right), 130.0(\mathrm{CH}), 129.9(\mathrm{CH}), 129.7\left(\mathrm{C}_{\mathrm{q}}\right)$, $128.1(\mathrm{CH}), 126.7(\mathrm{CH}), 126.5(\mathrm{CH}), 125.7(\mathrm{CH}), 125.2(\mathrm{CH}), 124.0(\mathrm{CH}), 121.5(\mathrm{CH}), 115.6$ $(\mathrm{CH}), 110.4(\mathrm{CH})$.

Resonances reported for (E)-256da. ${ }^{1} \mathrm{H}-\mathrm{NMR}\left(400 \mathrm{MHz}, \mathrm{CDCl}_{3}\right): \delta=8.94$ (dd, $J=4.2,1.6$ $\mathrm{Hz}, 1 \mathrm{H}), 8.41-8.34(\mathrm{~m}, 2 \mathrm{H}), 8.30$ (dd, $J=8.3,1.7 \mathrm{~Hz}, 1 \mathrm{H}), 8.15$ (d, $J=8.1 \mathrm{~Hz}, 2 \mathrm{H}), 8.05$ (dd, $J=8.3,1.4 \mathrm{~Hz}, 1 \mathrm{H}), 7.90(\mathrm{dd}, J=7.3,1.4 \mathrm{~Hz}, 1 \mathrm{H}), 7.76(\mathrm{dd}, J=8.2,7.3 \mathrm{~Hz}, 1 \mathrm{H}), 7.50(\mathrm{dd}, J$ $=8.4,4.3 \mathrm{~Hz}, 1 \mathrm{H}), 7.42(\mathrm{dd}, J=6.6,2.5 \mathrm{~Hz}, 4 \mathrm{H}), 6.23(\mathrm{~s}, 1 \mathrm{H})$.

${ }^{13} \mathrm{C}-\mathrm{NMR}\left(100 \mathrm{MHz}, \mathrm{CDCl}_{3}\right)$ (two peaks overlap): $\delta=164.9\left(\mathrm{C}_{\mathrm{q}}\right), 151.4(\mathrm{CH}), 150.3\left(\mathrm{C}_{\mathrm{q}}\right)$, 144.6 $\left(\mathrm{C}_{\mathrm{q}}\right), 137.3\left(\mathrm{C}_{\mathrm{q}}\right), 136.4(\mathrm{CH}), 136.2\left(\mathrm{C}_{\mathrm{q}}\right), 134.8\left(\mathrm{C}_{\mathrm{q}}\right), 134.1\left(\mathrm{C}_{\mathrm{q}}\right), 132.1\left(\mathrm{C}_{\mathrm{q}}\right), 131.2(\mathrm{CH})$, $129.3(\mathrm{CH}), 128.9(\mathrm{CH}), 128.7(\mathrm{CH}), 126.4(\mathrm{CH}), 124.8(\mathrm{CH}), 124.3(\mathrm{CH}), 122.1(\mathrm{CH}), 119.0$ $(\mathrm{CH}), 115.0(\mathrm{CH})$.

IR (ATR): 2955, 1712, 1645, 1596, 1342, 1180, 827, $790 \mathrm{~cm}^{-1}$.

MS (ESI) $m / z$ (relative intensity): $416(20)[\mathrm{M}+\mathrm{Na}]^{+}, 394(100)[\mathrm{M}+\mathrm{H}]^{+}$.

HR-MS (ESI): $m / z$ calcd for $\mathrm{C}_{24} \mathrm{H}_{16} \mathrm{~N}_{3} \mathrm{O}_{3}[\mathrm{M}+\mathrm{H}]^{+}:$394.1186, found: 394.1188 . 


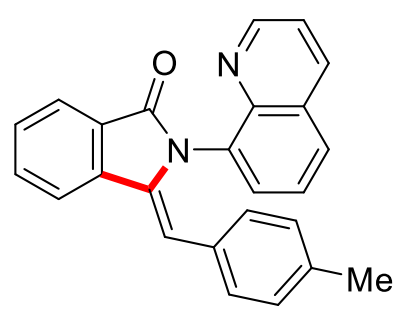

(Z)-3-(4-Methybenzylidene)-2-(quinolin-8-yl) isoindolin-1-one (256ab): The general procedure $\mathbf{J}$ was followed using benzamide $229 \mathbf{a}$ (62 $\mathrm{mg}, 0.25 \mathrm{mmol}$ ) and alkyne $255 \mathbf{b}$ (58 $\mathrm{mg}$, $0.50 \mathrm{mmol}$ ). Purification by column chromatography on silica gel ( $n$-hexane/EtOAc: $2 / 1$ ) yielded 256ab $(69.7 \mathrm{mg}, 77 \%, E / Z=1: 6)$ as a yellow oil.

Resonances reported for (Z)-256ab. ${ }^{1} \mathrm{H}-\mathrm{NMR}\left(400 \mathrm{MHz}, \mathrm{CDCl}_{3}\right): \delta=8.82(\mathrm{~d}, J=3.2 \mathrm{~Hz}, 1 \mathrm{H})$, $7.97(\mathrm{~d}, J=7.2 \mathrm{~Hz}, 2 \mathrm{H}), 7.86$ (d, $J=7.8 \mathrm{~Hz}, 1 \mathrm{H}), 7.66$ (t, $J=7.6 \mathrm{~Hz}, 1 \mathrm{H}), 7.61-7.55(\mathrm{~m}, 1 \mathrm{H})$, $7.52(\mathrm{dd}, J=7.5,0.8 \mathrm{~Hz}, 1 \mathrm{H}), 7.45$ (dd, $J=7.4,1.2 \mathrm{~Hz}, 1 \mathrm{H}), 7.33-7.24(\mathrm{~m}, 2 \mathrm{H}), 6.77$ (s, 1H), $6.41(\mathrm{~d}, J=7.8 \mathrm{~Hz}, 2 \mathrm{H}), 6.30(\mathrm{~d}, J=7.8 \mathrm{~Hz}, 2 \mathrm{H}), 2.00(\mathrm{~s}, 3 \mathrm{H})$.

${ }^{13} \mathrm{C}-\mathrm{NMR}\left(100 \mathrm{MHz}, \mathrm{CDCl}_{3}\right): \delta=168.1\left(\mathrm{C}_{\mathrm{q}}\right), 150.3(\mathrm{CH}), 144.4\left(\mathrm{C}_{\mathrm{q}}\right), 138.7\left(\mathrm{C}_{\mathrm{q}}\right), 135.8\left(\mathrm{C}_{\mathrm{q}}\right)$, $135.8(\mathrm{CH}), 135.6\left(\mathrm{C}_{\mathrm{q}}\right), 134.3\left(\mathrm{C}_{\mathrm{q}}\right), 132.1(\mathrm{CH}), 130.5\left(\mathrm{C}_{\mathrm{q}}\right), 130.0(\mathrm{CH}), 129.1(\mathrm{CH}), 128.9$ $(\mathrm{CH}), 128.8\left(\mathrm{C}_{\mathrm{q}}\right), 128.2\left(\mathrm{C}_{\mathrm{q}}\right), 128.0(\mathrm{CH}), 126.9(\mathrm{CH}), 125.6(\mathrm{CH}), 123.9(\mathrm{CH}), 121.2(\mathrm{CH})$, $119.6(\mathrm{CH}), 107.5(\mathrm{CH}), 20.8\left(\mathrm{CH}_{3}\right)$.

Resonances reported for (E)-256ab. ${ }^{1} \mathrm{H}-\mathrm{NMR}\left(400 \mathrm{MHz}, \mathrm{CDCl}_{3}\right): \delta=8.91(\mathrm{dd}, J=4.2,1.5$ $\mathrm{Hz}, 1 \mathrm{H}), 8.22$ (dd, $J=8.1,1.3 \mathrm{~Hz}, 1 \mathrm{H}), 7.99-7.93$ (m, 2H), 7.82 (dd, $J=7.3,1.2 \mathrm{~Hz}, 1 \mathrm{H})$, 7.71-7.68 (m, 1H), 7.52-7.51 (m, 1H), 7.50-7.47 (m, 1H), 7.43-7.36 (m, 2H), $7.25(\mathrm{~d}, J=3.7$ $\mathrm{Hz}, 2 \mathrm{H}), 7.14$ (d, J=7.9 Hz, 2H), 5.98 (s, 1H), 2.35 (s, 3H).

${ }^{13} \mathrm{C}-\mathrm{NMR}\left(100 \mathrm{MHz}, \mathrm{CDCl}_{3}\right): \delta=167.0\left(\mathrm{C}_{\mathrm{q}}\right), 151.2(\mathrm{CH}), 145.0\left(\mathrm{C}_{\mathrm{q}}\right), 138.5\left(\mathrm{C}_{\mathrm{q}}\right), 137.4\left(\mathrm{C}_{\mathrm{q}}\right)$, $136.2(\mathrm{CH}), 135.6\left(\mathrm{C}_{\mathrm{q}}\right), 132.9\left(\mathrm{C}_{\mathrm{q}}\right), 132.2\left(\mathrm{C}_{\mathrm{q}}\right), 131.6(\mathrm{CH}), 131.4(\mathrm{CH}), 130.4\left(\mathrm{C}_{\mathrm{q}}\right), 129.6\left(\mathrm{C}_{\mathrm{q}}\right)$, 129.4 (CH), $129.2(\mathrm{CH}), 128.0(\mathrm{CH}), 126.9(\mathrm{CH}), 126.3(\mathrm{CH}), 123.7(\mathrm{CH}), 123.3(\mathrm{CH}), 121.8$ $(\mathrm{CH}), 112.3(\mathrm{CH}), 21.3\left(\mathrm{CH}_{3}\right)$.

IR (ATR): 2922, 1718, 1630, 1565, 1255, 1203, 891, $724 \mathrm{~cm}^{-1}$.

MS (ESI) $\mathrm{m} / z$ (relative intensity): $385(10)[\mathrm{M}+\mathrm{Na}]^{+}, 363(100)[\mathrm{M}+\mathrm{H}]^{+}$.

HR-MS (ESI): $m / z$ calcd for $\mathrm{C}_{25} \mathrm{H}_{19} \mathrm{~N}_{2} \mathrm{O}[\mathrm{M}+\mathrm{H}]^{+}: 363.1495$, found: 363.1492 . The analytical data correspond with those reported in the literature. ${ }^{[208]}$ 


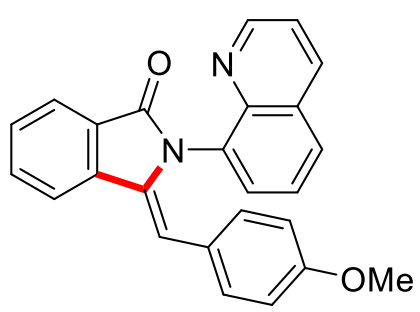

(Z)-3-(4-Methoxybenzylidene)-2-(quinolin-8-yl) isoindolin-1-one (256ac): The general procedure $\mathbf{J}$ was followed using benzamide $229 \mathbf{a}(62 \mathrm{mg}, 0.25 \mathrm{mmol})$ and alkyne $\mathbf{2 5 5} \mathbf{c}(66 \mathrm{mg}$, $0.50 \mathrm{mmol}$ ). Purification by column chromatography on silica gel ( $n$-hexane/EtOAc: 1/1) yielded 256ac $(68.1 \mathrm{mg}, 72 \%, E / Z=1: 1.4)$ as a white solid. M. p.: $185-190{ }^{\circ} \mathrm{C}$.

Resonances reported for (Z)-256ac. ${ }^{1} \mathrm{H}-\mathrm{NMR}\left(400 \mathrm{MHz}, \mathrm{CDCl}_{3}\right): \delta=8.83$ (dd, $J=4.2,1.7 \mathrm{~Hz}$, $1 \mathrm{H}), 8.00-7.92(\mathrm{~m}, 2 \mathrm{H}), 7.85(\mathrm{dd}, J=7.8,1.5 \mathrm{~Hz}, 1 \mathrm{H}), 7.72-7.58(\mathrm{~m}, 2 \mathrm{H}), 7.57-7.49(\mathrm{~m}, 1 \mathrm{H})$, 7.49-7.43 (m, 1H), 7.34-7.26 (m, 2H), $6.75(\mathrm{~s}, 1 \mathrm{H}), 6.50-6.43(\mathrm{~m}, 2 \mathrm{H}), 6.10-6.02(\mathrm{~m}, 2 \mathrm{H})$, $3.81(\mathrm{~s}, 3 \mathrm{H})$.

${ }^{13} \mathrm{C}-\mathrm{NMR}\left(100 \mathrm{MHz}, \mathrm{CDCl}_{3}\right): \delta=168.1\left(\mathrm{C}_{\mathrm{q}}\right), 157.7\left(\mathrm{C}_{\mathrm{q}}\right), 150.3(\mathrm{CH}), 144.5\left(\mathrm{C}_{\mathrm{q}}\right), 138.8\left(\mathrm{C}_{\mathrm{q}}\right)$, $135.7(\mathrm{CH}), 135.5\left(\mathrm{C}_{\mathrm{q}}\right), 134.4\left(\mathrm{C}_{\mathrm{q}}\right), 132.1(\mathrm{CH}), 130.7(\mathrm{CH}), 129.6\left(\mathrm{C}_{\mathrm{q}}\right), 129.4(\mathrm{CH}), 128.9$ $\left(\mathrm{C}_{\mathrm{q}}\right), 128.8(\mathrm{CH}), 128.2(\mathrm{CH}), 126.0\left(\mathrm{C}_{\mathrm{q}}\right), 125.7(\mathrm{CH}), 123.9(\mathrm{CH}), 121.2(\mathrm{CH}), 119.5(\mathrm{CH})$, $111.9(\mathrm{CH}), 107.2(\mathrm{CH}), 55.1\left(\mathrm{CH}_{3}\right)$.

Resonances reported for (E)-256ac. ${ }^{1} \mathrm{H}-\mathrm{NMR}\left(400 \mathrm{MHz}, \mathrm{CDCl}_{3}\right): \delta=8.90$ (dd, $J=4.2,1.7$ $\mathrm{Hz}, 1 \mathrm{H}), 8.22$ (dd, $J=8.2,1.7 \mathrm{~Hz}, 1 \mathrm{H}), 8.00-7.92(\mathrm{~m}, 2 \mathrm{H}), 7.82(\mathrm{dd}, J=7.3,1.5 \mathrm{~Hz}, 1 \mathrm{H})$, 7.72-7.58 (m, 1H), 7.57-7.49 (m, 1H), 7.49-7.43 (m, 1H), 7.43-7.36 (m, 2H), 7.34-7.26 (m, $2 \mathrm{H}), 6.91-6.84(\mathrm{~m}, 2 \mathrm{H}), 5.96(\mathrm{~s}, 1 \mathrm{H}), 3.54(\mathrm{~s}, 3 \mathrm{H})$.

${ }^{13} \mathrm{C}-\mathrm{NMR}\left(100 \mathrm{MHz}, \mathrm{CDCl}_{3}\right): \delta=166.9\left(\mathrm{C}_{\mathrm{q}}\right), 159.1\left(\mathrm{C}_{\mathrm{q}}\right), 151.2(\mathrm{CH}), 145.0\left(\mathrm{C}_{\mathrm{q}}\right), 138.3\left(\mathrm{C}_{\mathrm{q}}\right)$, $136.2(\mathrm{CH}), 135.6\left(\mathrm{C}_{\mathrm{q}}\right), 133.0\left(\mathrm{C}_{\mathrm{q}}\right), 131.6(\mathrm{CH}), 131.4(\mathrm{CH}), 129.9(\mathrm{CH}), 129.2(\mathrm{CH}), 128.2$ $(\mathrm{CH}), 128.2\left(\mathrm{C}_{\mathrm{q}}\right), 127.5\left(\mathrm{C}_{\mathrm{q}}\right), 123.7(\mathrm{CH}), 123.1(\mathrm{CH}), 121.8(\mathrm{CH}), 127.5\left(\mathrm{C}_{\mathrm{q}}\right), 126.3(\mathrm{CH})$, $113.9(\mathrm{CH}), 112.0(\mathrm{CH}), 55.3\left(\mathrm{CH}_{3}\right)$.

IR (ATR): 3022, 1712, 1610, 1555, 1243, 1103, 791, $754 \mathrm{~cm}^{-1}$.

MS (ESI) $\mathrm{m} / z$ (relative intensity): $401(10)[\mathrm{M}+\mathrm{Na}]^{+}, 379(100)[\mathrm{M}+\mathrm{H}]^{+}$.

HR-MS (ESI): $m / z$ calcd for $\mathrm{C}_{25} \mathrm{H}_{19} \mathrm{~N}_{2} \mathrm{O}_{2}[\mathrm{M}+\mathrm{H}]^{+}: 379.1441$, found: 379.1458 . The analytical data correspond with those reported in the literature. ${ }^{[208]}$ 


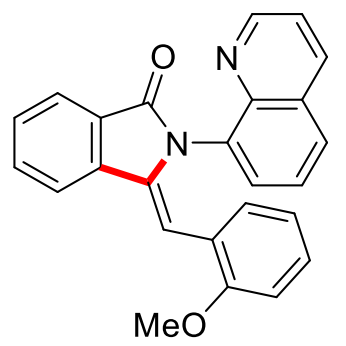

(Z)-3-(2-Methoxybenzylidene)-2-(quinolin-8-yl) isoindolin-1-one (256ad): The general procedure $\mathbf{J}$ was followed using benzamide 229a (62 $\mathrm{mg}, 0.25 \mathrm{mmol}$ ) and alkyne $255 \mathbf{d}$ (66 mg, $0.50 \mathrm{mmol}$ ). Purification by column chromatography on silica gel ( $n$-hexane/EtOAc: 1/1) yielded 256ad $(62.0 \mathrm{mg}, 66 \%, E / Z=1: 4)$ as a white solid. M. p.: $172-180{ }^{\circ} \mathrm{C}$.

Resonances are reported for (Z)-256ad. ${ }^{1} \mathrm{H}-\mathrm{NMR}\left(300 \mathrm{MHz}, \mathrm{CDCl}_{3}\right): \delta=8.88(\mathrm{dd}, J=4.1,1.5$ $\mathrm{Hz}, 1 \mathrm{H}), 8.06-7.96(\mathrm{~m}, 2 \mathrm{H}), 7.94(\mathrm{~d}, J=8.0 \mathrm{~Hz}, 1 \mathrm{H}), 7.70$ (t, $J=7.5 \mathrm{~Hz}, 1 \mathrm{H}), 7.58$ (d, $J=7.4$ $\mathrm{Hz}, 2 \mathrm{H}), 7.51(\mathrm{dd}, J=7.4,1.3 \mathrm{~Hz}, 1 \mathrm{H}), 7.34-7.28(\mathrm{~m}, 2 \mathrm{H}), 6.79(\mathrm{~s}, 1 \mathrm{H}), 6.70(\mathrm{dd}, J=7.8,1.8$ $\mathrm{Hz}, 1 \mathrm{H}), 6.33$ (t, $J=7.6 \mathrm{~Hz}, 2 \mathrm{H}), 5.95(\mathrm{t}, J=7.6 \mathrm{~Hz}, 1 \mathrm{H}), 3.61(\mathrm{~s}, 3 \mathrm{H})$.

${ }^{13} \mathrm{C}-\mathrm{NMR}\left(125 \mathrm{MHz}, \mathrm{CDCl}_{3}\right): \delta=167.9\left(\mathrm{C}_{\mathrm{q}}\right), 155.9\left(\mathrm{C}_{\mathrm{q}}\right), 150.0(\mathrm{CH}), 144.4\left(\mathrm{C}_{\mathrm{q}}\right), 138.5\left(\mathrm{C}_{\mathrm{q}}\right)$, $136.1\left(\mathrm{C}_{\mathrm{q}}\right), 135.6(\mathrm{CH}), 133.9\left(\mathrm{C}_{\mathrm{q}}\right), 131.9(\mathrm{CH}), 129.8(\mathrm{CH}), 129.7(\mathrm{CH}), 128.7(\mathrm{CH}), 128.5$ $\left(\mathrm{C}_{\mathrm{q}}\right), 128.21\left(\mathrm{C}_{\mathrm{q}}\right), 128.1(\mathrm{CH}), 127.7(\mathrm{CH}), 125.2(\mathrm{CH}), 123.6(\mathrm{CH}), 122.3\left(\mathrm{C}_{\mathrm{q}}\right), 120.8(\mathrm{CH})$, $119.8(\mathrm{CH}), 118.3(\mathrm{CH}), 108.6(\mathrm{CH}), 103.6(\mathrm{CH}), 54.9\left(\mathrm{CH}_{3}\right)$.

Resonances are reported for $(E)$-256ad. ${ }^{1} \mathrm{H}-\mathrm{NMR}\left(300 \mathrm{MHz}, \mathrm{CDCl}_{3}\right): \delta=8.95(\mathrm{dd}, J=4.2,1.5$ $\mathrm{Hz}, 1 \mathrm{H}), 8.25$ (dd, $J=8.4,1.6 \mathrm{~Hz}, 1 \mathrm{H}), 8.00(\mathrm{dd}, J=8.4,1.2 \mathrm{~Hz}, 2 \mathrm{H}), 7.96-7.88$ (m, 1H), 7.69 $(\mathrm{dd}, J=7.6,1.1 \mathrm{~Hz}, 1 \mathrm{H}), 7.61-7.55(\mathrm{~m}, 1 \mathrm{H}), 7.54-7.49(\mathrm{~m}, 1 \mathrm{H}), 7.44(\mathrm{dd}, J=7.5,1.2 \mathrm{~Hz}, 2 \mathrm{H})$, 7.37-7.28 (m, 2H), 7.03-6.94 (m, 1H), $6.89(\mathrm{~d}, J=8.2 \mathrm{~Hz}, 1 \mathrm{H}), 6.02(\mathrm{~s}, 1 \mathrm{H}), 3.72(\mathrm{~s}, 3 \mathrm{H})$.

${ }^{13} \mathrm{C}-\mathrm{NMR}\left(125 \mathrm{MHz}, \mathrm{CDCl}_{3}\right): \delta=166.8\left(\mathrm{C}_{\mathrm{q}}\right), 157.3\left(\mathrm{C}_{\mathrm{q}}\right), 150.9(\mathrm{CH}), 144.9\left(\mathrm{C}_{\mathrm{q}}\right), 138.2\left(\mathrm{C}_{\mathrm{q}}\right)$, $136.0(\mathrm{CH}), 132.9\left(\mathrm{C}_{\mathrm{q}}\right), 131.5(\mathrm{CH}), 131.2(\mathrm{CH}), 131.1(\mathrm{CH}), 130.3\left(\mathrm{C}_{\mathrm{q}}\right), 129.4\left(\mathrm{C}_{\mathrm{q}}\right), 129.3$ $(\mathrm{CH}), 129.1(\mathrm{CH}), 129.0(\mathrm{CH}), 126.2(\mathrm{CH}), 123.9\left(\mathrm{C}_{\mathrm{q}}\right), 123.5(\mathrm{CH}), 123.1(\mathrm{CH}), 122.3\left(\mathrm{C}_{\mathrm{q}}\right)$, 121.6 (CH), $120.1(\mathrm{CH}), 110.6(\mathrm{CH}), 108.7(\mathrm{CH}), 55.4\left(\mathrm{CH}_{3}\right)$.

IR (ATR): 3048, 1709, 1595, 1398, 1243, $791 \mathrm{~cm}^{-1}$.

MS (ESI) $m / z$ (relative intensity): $401(25)[\mathrm{M}+\mathrm{Na}]^{+}, 379(100)[\mathrm{M}+\mathrm{H}]^{+}$.

HR-MS (ESI): $\mathrm{m} / z$ calcd for $\mathrm{C}_{25} \mathrm{H}_{18} \mathrm{~N}_{2} \mathrm{O}_{2} \mathrm{Na}[\mathrm{M}+\mathrm{Na}]^{+}:$401.1260, found: 401.1262. The analytical data correspond with those reported in the literature. ${ }^{[208]}$ 


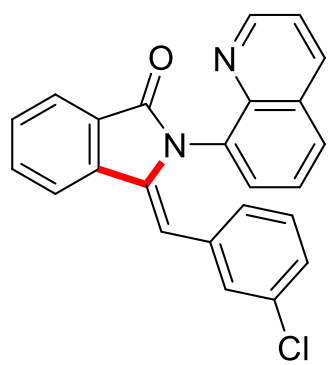

(Z)-3-(3-Chlorobenzylidene)-2-(quinolin-8-yl) isoindolin-1-one (256ae): The general procedure $\mathbf{J}$ was followed using benzamide $229 \mathbf{a}(62 \mathrm{mg}, 0.25 \mathrm{mmol})$ and alkyne $255 \mathbf{e}$ (68 $\mathrm{mg}$, $0.50 \mathrm{mmol}$ ). Purification by column chromatography on silica gel ( $n$-hexane/EtOAc: $2 / 1$ ) yielded 256ae (66.6 mg, $70 \%, E / Z=1: 4)$ as a white solid. M. p.: $170-177{ }^{\circ} \mathrm{C}$.

Resonances are reported for $(Z)$-256ae. ${ }^{1} \mathrm{H}-\mathrm{NMR}\left(400 \mathrm{MHz}, \mathrm{CDCl}_{3}\right): \delta=8.84$ (dd, $J=4.2$, $1.7 \mathrm{~Hz}, 1 \mathrm{H}), 7.99-7.95$ (m, 2H), 7.84 (dd, $J=7.6,1.2 \mathrm{~Hz}, 1 \mathrm{H}), 7.69-7.64$ (m, 1H), 7.60 (dd, $J$ $=8.3,1.4 \mathrm{~Hz}, 1 \mathrm{H}), 7.56(\mathrm{dd}, J=7.5,0.9 \mathrm{~Hz}, 1 \mathrm{H}), 7.46(\mathrm{dd}, J=7.5,1.4 \mathrm{~Hz}, 1 \mathrm{H}), 7.35-7.29(\mathrm{~m}$, 2H), 7.26 (dd, $J=1.4,0.4 \mathrm{~Hz}, 1 \mathrm{H}), 6.66(\mathrm{~s}, 1 \mathrm{H}), 6.63$ (dd, $J=7.6,1.6 \mathrm{~Hz}, 1 \mathrm{H}), 6.50-6.47$ (m, $1 \mathrm{H}), 6.46-6.44(\mathrm{~m}, 1 \mathrm{H})$.

${ }^{13} \mathrm{C}-\mathrm{NMR}\left(100 \mathrm{MHz}, \mathrm{CDCl}_{3}\right): \delta=168.0\left(\mathrm{C}_{\mathrm{q}}\right), 150.5(\mathrm{CH}), 144.2\left(\mathrm{C}_{\mathrm{q}}\right), 138.4\left(\mathrm{C}_{\mathrm{q}}\right), 137.0\left(\mathrm{C}_{\mathrm{q}}\right)$, $135.9(\mathrm{CH}), 135.4\left(\mathrm{C}_{\mathrm{q}}\right), 133.9\left(\mathrm{C}_{\mathrm{q}}\right), 132.4\left(\mathrm{C}_{\mathrm{q}}\right), 132.3(\mathrm{CH}), 129.2(\mathrm{CH}), 129.3(\mathrm{CH}), 129.0$ $\left(\mathrm{C}_{\mathrm{q}}\right), 128.6(\mathrm{CH}), 128.4(\mathrm{CH}), 128.3\left(\mathrm{C}_{\mathrm{q}}\right), 127.4(\mathrm{CH}), 126.3(\mathrm{CH}), 126.0(\mathrm{CH}), 125.7(\mathrm{CH})$, 124.0 (CH), $121.4(\mathrm{CH}), 119.7(\mathrm{CH}), 105.3(\mathrm{CH})$.

Resonances are reported for $(E)$-256ae. ${ }^{1} \mathrm{H}-\mathrm{NMR}\left(400 \mathrm{MHz}, \mathrm{CDCl}_{3}\right): \delta=8.90$ (dd, $J=4.2$, $1.7 \mathrm{~Hz}, 1 \mathrm{H}), 8.22(\mathrm{dd}, J=8.3,1.7 \mathrm{~Hz}, 1 \mathrm{H}), 8.01(\mathrm{~d}, J=1.7 \mathrm{~Hz}, 2 \mathrm{H}), 7.81(\mathrm{dd}, J=7.3,1.4 \mathrm{~Hz}$, $1 \mathrm{H}), 7.71-7.64(\mathrm{~m}, 1 \mathrm{H}), 7.51(\mathrm{dd}, J=7.5,1.4 \mathrm{~Hz}, 1 \mathrm{H}), 7.43-7.39(\mathrm{~m}, 1 \mathrm{H}), 7.35(\mathrm{dd}, J=2.3$, $1.8 \mathrm{~Hz}, 2 \mathrm{H}), 6.52(\mathrm{~d}, J=7.6 \mathrm{~Hz}, 1 \mathrm{H}), 6.55-6.50(\mathrm{~m}, 3 \mathrm{H}), 5.89(\mathrm{~s}, 1 \mathrm{H})$.

${ }^{13} \mathrm{C}-\mathrm{NMR}\left(100 \mathrm{MHz}, \mathrm{CDCl}_{3}\right): \delta=166.9\left(\mathrm{C}_{\mathrm{q}}\right), 151.2(\mathrm{CH}), 144.9\left(\mathrm{C}_{\mathrm{q}}\right), 139.6\left(\mathrm{C}_{\mathrm{q}}\right), 137.2\left(\mathrm{C}_{\mathrm{q}}\right)$, $136.2(\mathrm{CH}), 135.2\left(\mathrm{C}_{\mathrm{q}}\right), 134.3\left(\mathrm{C}_{\mathrm{q}}\right), 132.6\left(\mathrm{C}_{\mathrm{q}}\right), 131.9(\mathrm{CH}), 131.3(\mathrm{CH}), 130.5\left(\mathrm{C}_{\mathrm{q}}\right), 129.8$ $(\mathrm{CH}), 129.7(\mathrm{CH}), 129.7(\mathrm{CH}), 129.5\left(\mathrm{C}_{\mathrm{q}}\right), 129.4(\mathrm{CH}), 127.6(\mathrm{CH}), 127.6(\mathrm{CH}), 126.3(\mathrm{CH})$, $123.9(\mathrm{CH}), 123.1(\mathrm{CH}), 121.9(\mathrm{CH}), 110.1(\mathrm{CH})$.

IR (ATR): 3058, 1716, 1652, 1593, 1500, 1397, 827, $757 \mathrm{~cm}^{-1}$.

MS (ESI) $m / z$ (relative intensity): $405(10)[\mathrm{M}+\mathrm{Na}]^{+}, 383(100)[\mathrm{M}+\mathrm{H}]^{+}$.

HR-MS (ESI): $m / z$ calcd for $\mathrm{C}_{24} \mathrm{H}_{15}{ }^{35} \mathrm{ClN}_{2} \mathrm{ONa}[\mathrm{M}+\mathrm{Na}]^{+}: 405.0765$, found: 405.0762 . 


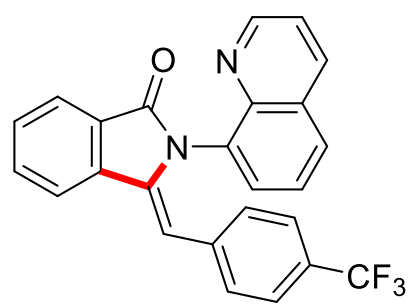

(Z)-2-(Quinolin-8-yl)-3-(4-(trifluoromethyl) benzylidene) isoindolin-1-one (256af)

The general procedure $\mathbf{J}$ was followed using benzamide 229a (73 mg, $0.25 \mathrm{mmol}$ ) and alkyne $255 f(85 \mathrm{mg}, 0.50 \mathrm{mmol})$. Purification by column chromatography on silica gel ( $n$ hexane/EtOAc: 2/1) yielded 256af (62.6 mg, 60\%, $E / Z=1: 20)$ as a yellow oil.

Resonances are reported for (Z)-256af: ${ }^{1} \mathrm{H}-\mathrm{NMR}\left(400 \mathrm{MHz}, \mathrm{CDCl}_{3}\right): \delta=8.82(\mathrm{dd}, J=4.2,1.7$ $\mathrm{Hz}, 1 \mathrm{H}), 8.03$ (dd, $J=7.6,1.0 \mathrm{~Hz}, 1 \mathrm{H}), 7.95$ (dd, $J=8.3,1.7 \mathrm{~Hz}, 1 \mathrm{H}), 7.91(\mathrm{dd}, J=7.8,1.0$ $\mathrm{Hz}, 1 \mathrm{H}), 7.73(\mathrm{dd}, J=7.6,1.2 \mathrm{~Hz}, 1 \mathrm{H}), 7.62(\mathrm{dd}, J=7.8,1.2 \mathrm{~Hz}, 2 \mathrm{H}), 7.56(\mathrm{dd}, J=7.6,1.4$ $\mathrm{Hz}, 1 \mathrm{H}), 7.37$ (dd, $J=8.3,7.6 \mathrm{~Hz}, 1 \mathrm{H}), 7.31$ (dd, $J=8.3,4.2 \mathrm{~Hz}, 1 \mathrm{H}), 6.80-6.72(\mathrm{~m}, 3 \mathrm{H})$, 6.68-6.61 (m, 2H).

${ }^{13} \mathrm{C}-\mathrm{NMR}\left(100 \mathrm{MHz}, \mathrm{CDCl}_{3}\right): \delta=167.9\left(\mathrm{C}_{\mathrm{q}}\right), 150.4(\mathrm{CH}), 144.1\left(\mathrm{C}_{\mathrm{q}}\right), 138.3\left(\mathrm{C}_{\mathrm{q}}\right), 137.5\left(\mathrm{C}_{\mathrm{q}}\right)$, $137.4\left(\mathrm{C}_{\mathrm{q}}\right), 135.9(\mathrm{CH}), 133.9\left(\mathrm{C}_{\mathrm{q}}\right), 132.5(\mathrm{CH}), 130.2(\mathrm{CH}), 129.5(\mathrm{CH}), 128.9\left(\mathrm{C}_{\mathrm{q}}\right), 128.7$ $(\mathrm{CH}), 128.4\left(\mathrm{C}_{\mathrm{q}}\right), 128.2(\mathrm{CH}), 127.7\left(\mathrm{q},{ }^{2} J_{\mathrm{C}-\mathrm{F}}=34.2 \mathrm{~Hz}, \mathrm{C}_{\mathrm{q}}\right), 125.8(\mathrm{CH}), 124.1(\mathrm{CH}), 123.4$ $\left(\mathrm{q},{ }^{1} J_{\mathrm{C}-\mathrm{F}}=270 \mathrm{~Hz}, \mathrm{C}_{\mathrm{q}}\right), 122.8\left(\mathrm{q},{ }^{3} J_{\mathrm{C}-\mathrm{F}}=3.4 \mathrm{~Hz}, \mathrm{CH}\right), 121.4(\mathrm{CH}), 119.8(\mathrm{CH}), 105.2(\mathrm{CH})$. ${ }^{19} \mathrm{~F}-\mathrm{NMR}\left(375 \mathrm{MHz}, \mathrm{CDCl}_{3}\right): \delta=-63.1(\mathrm{~m})$.

IR (ATR): 3022, 1711, 1609, 1511, 1221, 827, 798, $728 \mathrm{~cm}^{-1}$.

MS (ESI) $m / z$ (relative intensity): $417(100)[\mathrm{M}+\mathrm{H}]^{+}$.

HR-MS (ESI): $m / z$ calcd for $\mathrm{C}_{25} \mathrm{H}_{16} \mathrm{~F}_{3} \mathrm{~N}_{2} \mathrm{O}[\mathrm{M}+\mathrm{H}]^{+}: 417.1209$, found: 417.1218.<smiles>O=C1c2ccccc2/C(=C/c2ccc(F)cc2)N1c1cccc2cccnc12</smiles>

(Z)-3-(4-Fluorobenzylidene)-2-(quinolin-8-yl) isoindolin-1-one (256ag): The general procedure $\mathbf{J}$ was followed using benzamide $229 \mathbf{a}(62 \mathrm{mg}, 0.25 \mathrm{mmol})$ and alkyne $\mathbf{2 5 5} \mathbf{g}(60 \mathrm{mg}$, $0.50 \mathrm{mmol}$ ). Purification by column chromatography on silica gel ( $n$-hexane/EtOAc: $2 / 1$ ) yielded 256ag (66.9 mg, 73\%, $E / Z=1: 6)$ as a yellow oil.

Resonances are reported for (Z)-256ag: ${ }^{1} \mathrm{H}-\mathrm{NMR}\left(400 \mathrm{MHz}, \mathrm{CDCl}_{3}\right): \delta=8.83(\mathrm{dd}, J=4.2,1.7$ $\mathrm{Hz}, 1 \mathrm{H}), 8.03-7.97(\mathrm{~m}, 2 \mathrm{H}), 7.87$ (dd, $J=7.8,0.9 \mathrm{~Hz}, 1 \mathrm{H}), 7.68(\mathrm{t}, J=7.8 \mathrm{~Hz}, 1 \mathrm{H}), 7.64(\mathrm{dd}$, $J=8.3,1.4 \mathrm{~Hz}, 1 \mathrm{H}), 7.56(\mathrm{dd}, J=7.4,0.9 \mathrm{~Hz}, 1 \mathrm{H}), 7.49(\mathrm{dd}, J=7.4,1.4 \mathrm{~Hz}, 1 \mathrm{H}), 7.38-7.28$ $(\mathrm{m}, 2 \mathrm{H}), 6.71(\mathrm{~s}, 1 \mathrm{H}), 6.57-6.47(\mathrm{~m}, 2 \mathrm{H}), 6.26-6.18(\mathrm{~m}, 2 \mathrm{H})$. 
${ }^{13} \mathrm{C}-\mathrm{NMR}\left(100 \mathrm{MHz}, \mathrm{CDCl}_{3}\right): \delta=168.0\left(\mathrm{C}_{\mathrm{q}}\right), 161.0\left(\mathrm{~d},{ }^{1} J_{\mathrm{C}-\mathrm{F}}=240 \mathrm{~Hz}, \mathrm{C}_{\mathrm{q}}\right), 150.4(\mathrm{CH}), 144.3$ $\left(\mathrm{C}_{\mathrm{q}}\right), 138.5\left(\mathrm{C}_{\mathrm{q}}\right), 136.4\left(\mathrm{C}_{\mathrm{q}}\right), 135.8(\mathrm{CH}), 134.1\left(\mathrm{C}_{\mathrm{q}}\right), 132.3(\mathrm{CH}), 130.1(\mathrm{CH}), 129.7\left(\mathrm{~d},{ }^{3} J_{\mathrm{C}-\mathrm{F}}=\right.$ $8.1 \mathrm{~Hz}, \mathrm{CH}), 129.5\left(\mathrm{~d},{ }^{4} J_{\mathrm{C}-\mathrm{F}}=2.9 \mathrm{~Hz}, \mathrm{C}_{\mathrm{q}}\right), 129.2(\mathrm{CH}), 128.8\left(\mathrm{C}_{\mathrm{q}}\right), 128.4(\mathrm{CH}), 128.3\left(\mathrm{C}_{\mathrm{q}}\right)$, $125.7(\mathrm{CH}), 123.9(\mathrm{CH}), 121.3(\mathrm{CH}), 119.6(\mathrm{CH}), 113.1\left(\mathrm{~d},{ }^{2} J_{\mathrm{C}-\mathrm{F}}=22.9 \mathrm{~Hz}, \mathrm{CH}\right), 106.0(\mathrm{CH})$. ${ }^{19} \mathrm{~F}-\mathrm{NMR}\left(375 \mathrm{MHz}, \mathrm{CDCl}_{3}\right): \delta=-115.6(\mathrm{~m})$.

Resonances are reported for $(E)$-256ag: ${ }^{1} \mathrm{H}-\mathrm{NMR}\left(400 \mathrm{MHz}, \mathrm{CDCl}_{3}\right): \delta=8.90(\mathrm{dd}, J=4.2,1.7$ $\mathrm{Hz}, 1 \mathrm{H}), 8.22(\mathrm{dd}, J=8.4,1.7 \mathrm{~Hz}, 1 \mathrm{H}), 7.96-7.94(\mathrm{~m}, 2 \mathrm{H}), 7.82(\mathrm{dd}, J=7.4,1.5 \mathrm{~Hz}, 1 \mathrm{H})$, 7.51-7.49 (m, 1H), 7.44-7.42 (m, 1H), 7.42-7.39 (m, 3H), 7.38-7.28 (m, 2H), 7.08-6.98 (m, 2H), $5.92(\mathrm{~s}, 1 \mathrm{H})$.

${ }^{13} \mathrm{C}-\mathrm{NMR}\left(100 \mathrm{MHz}, \mathrm{CDCl}_{3}\right): \delta=167.0\left(\mathrm{C}_{\mathrm{q}}\right), 161.5\left(\mathrm{~d},{ }^{1} J_{\mathrm{C}-\mathrm{F}}=247.5 \mathrm{~Hz}, \mathrm{C}_{\mathrm{q}}\right), 151.2(\mathrm{CH})$, $144.9\left(\mathrm{C}_{\mathrm{q}}\right), 139.1\left(\mathrm{C}_{\mathrm{q}}\right), 136.2(\mathrm{CH}), 135.3\left(\mathrm{C}_{\mathrm{q}}\right), 132.8\left(\mathrm{C}_{\mathrm{q}}\right), 131.8(\mathrm{CH}), 131.4(\mathrm{CH}), 131.2(\mathrm{~d}$, $\left.{ }^{3} J_{\mathrm{C}-\mathrm{F}}=8.0 \mathrm{~Hz}, \mathrm{CH}\right), 131.2\left(\mathrm{C}_{\mathrm{q}}\right), 130.5\left(\mathrm{C}_{\mathrm{q}}\right), 129.5\left(\mathrm{~d},{ }^{4} J_{\mathrm{C}-\mathrm{F}}=2.9 \mathrm{~Hz}, \mathrm{C}_{\mathrm{q}}\right), 129.6(\mathrm{CH}), 126.3$ $(\mathrm{CH}), 123.9(\mathrm{CH}), 123.8(\mathrm{CH}), 123.1(\mathrm{CH}), 121.8(\mathrm{CH}), 115.5\left(\mathrm{~d},{ }^{2} J_{\mathrm{C}-\mathrm{F}}=21.5 \mathrm{~Hz}, \mathrm{CH}\right), 1107$ $(\mathrm{CH})$.

${ }^{19} \mathrm{~F}-\mathrm{NMR}\left(375 \mathrm{MHz}, \mathrm{CDCl}_{3}\right): \delta=-113.9(\mathrm{~m})$.

IR (ATR): 3048, 1715, 1655, 1596, 1397, 1227, $829 \mathrm{~cm}^{-1}$.

MS (ESI) $m / z$ (relative intensity): $389(15)[\mathrm{M}+\mathrm{Na}]^{+}, 367(100)[\mathrm{M}+\mathrm{H}]^{+}$.

HR-MS (ESI): $m / z$ calcd for $\mathrm{C}_{24} \mathrm{H}_{16} \mathrm{~N}_{2} \mathrm{O}[\mathrm{M}+\mathrm{H}]^{+}: 367.1241$, found: 367.1253 . The analytical data correspond with those reported in the literature. ${ }^{[210]}$

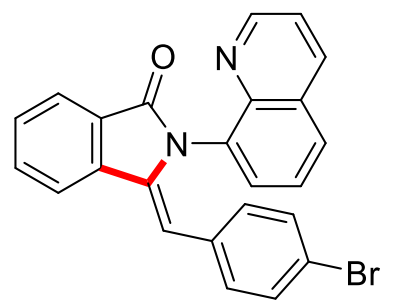

(Z)-3-(4-Bromobenzylidene)-2-(quinolin-8-yl) isoindolin-1-one (256ah): The general procedure $\mathbf{J}$ was followed using benzamide $229 \mathbf{a}(62 \mathrm{mg}, 0.25 \mathrm{mmol})$ and alkyne $\mathbf{2 5 5 h}(91 \mathrm{mg}$, $0.50 \mathrm{mmol}$ ). Purification by column chromatography on silica gel ( $n$-hexane/EtOAc: $2 / 1$ ) yielded 256ah $(76.7 \mathrm{mg}, 72 \%, E / Z=1: 4)$ as a yellow oil.

Resonances are reported for (Z)-256ah: ${ }^{1} \mathrm{H}-\mathrm{NMR}\left(400 \mathrm{MHz}, \mathrm{CDCl}_{3}\right): \delta=8.80(\mathrm{dd}, J=4.2,1.7$ $\mathrm{Hz}, 1 \mathrm{H}), 8.05-7.97$ (m, 2H), $7.84(\mathrm{~d}, J=7.8 \mathrm{~Hz}, 1 \mathrm{H}), 7.70-7.63(\mathrm{~m}, 2 \mathrm{H}), 7.55$ (dd, $J=7.4,0.9$ $\mathrm{Hz}, 1 \mathrm{H}), 7.49$ (dd, $J=7.4,1.4 \mathrm{~Hz}, 1 \mathrm{H}), 7.37-7.27$ (m, 2H), $6.66(\mathrm{~s}, 1 \mathrm{H}), 6.59$ (d, $J=8.3 \mathrm{~Hz}$, $2 \mathrm{H}), 6.37(\mathrm{~d}, J=8.3 \mathrm{~Hz}, 2 \mathrm{H})$.

${ }^{13} \mathrm{C}-\mathrm{NMR}\left(100 \mathrm{MHz}, \mathrm{CDCl}_{3}\right): \delta=167.9\left(\mathrm{C}_{\mathrm{q}}\right), 150.4(\mathrm{CH}), 144.3\left(\mathrm{C}_{\mathrm{q}}\right), 138.4\left(\mathrm{C}_{\mathrm{q}}\right), 136.8\left(\mathrm{C}_{\mathrm{q}}\right)$, $135.8(\mathrm{CH}), 134.1\left(\mathrm{C}_{\mathrm{q}}\right), 132.4\left(\mathrm{C}_{\mathrm{q}}\right), 132.3(\mathrm{CH}), 131.6(\mathrm{CH}), 131.2(\mathrm{CH}), 130.1(\mathrm{CH}), 129.5$ 
$(\mathrm{CH}), 129.1(\mathrm{CH}), 128.9\left(\mathrm{C}_{\mathrm{q}}\right), 128.5(\mathrm{CH}), 128.3\left(\mathrm{C}_{\mathrm{q}}\right), 124.0(\mathrm{CH}), 121.4(\mathrm{CH}), 120.0\left(\mathrm{C}_{\mathrm{q}}\right)$, $119.7(\mathrm{CH}), 105.7(\mathrm{CH})$.

Resonances are reported for (E)-256ah: ${ }^{1} \mathrm{H}-\mathrm{NMR}\left(400 \mathrm{MHz}, \mathrm{CDCl}_{3}\right): \delta=8.95(\mathrm{~d}, J=4.3 \mathrm{~Hz}$, $1 \mathrm{H}), 8.27(\mathrm{dd}, J=8.4,1.6 \mathrm{~Hz}, 1 \mathrm{H}), 8.06(\mathrm{~d}, J=1.6 \mathrm{~Hz}, 1 \mathrm{H}), 7.91-7.83(\mathrm{~m}, 1 \mathrm{H}), 7.73(\mathrm{~d}, J=$ $1.3 \mathrm{~Hz}, 2 \mathrm{H}), 7.51-7.49$ (m, 2H), 7.48-7.44 (m, 2H), 7.30-7.26 (m, 4H), 5.87 (s, 1H).

${ }^{13} \mathrm{C}-\mathrm{NMR}\left(100 \mathrm{MHz}, \mathrm{CDCl}_{3}\right): \delta=166.9\left(\mathrm{C}_{\mathrm{q}}\right), 151.2(\mathrm{CH}), 144.9\left(\mathrm{C}_{\mathrm{q}}\right), 139.2\left(\mathrm{C}_{\mathrm{q}}\right), 136.3(\mathrm{CH})$, $135.2\left(\mathrm{C}_{\mathrm{q}}\right), 134.3\left(\mathrm{C}_{\mathrm{q}}\right), 134.2(\mathrm{CH}), 132.7\left(\mathrm{C}_{\mathrm{q}}\right), 131.9(\mathrm{CH}), 131.4(\mathrm{CH}), 130.5\left(\mathrm{C}_{\mathrm{q}}\right), 129.6$ $(\mathrm{CH}), 129.6\left(\mathrm{C}_{\mathrm{q}}\right), 129.5(\mathrm{CH}), 129.3(\mathrm{CH}), 126.3(\mathrm{CH}), 123.9(\mathrm{CH}), 123.1(\mathrm{CH}), 121.9(\mathrm{CH})$, $121.6\left(\mathrm{C}_{\mathrm{q}}\right), 110.4(\mathrm{CH})$.

IR (ATR): 3049, 1713, 1595, 1472, 1302, 827, 759, $718 \mathrm{~cm}^{-1}$.

MS (ESI) $m / z$ (relative intensity): $449(10)\left[\mathrm{M}\left({ }^{79} \mathrm{Br}\right)+\mathrm{Na}\right]^{+}, 427(100)\left[\mathrm{M}\left({ }^{79} \mathrm{Br}\right)+\mathrm{H}\right]^{+}$.

HR-MS (ESI): $m / z$ calcd for $\mathrm{C}_{24} \mathrm{H}_{15}{ }^{79} \mathrm{BrN}_{2} \mathrm{ONa}[\mathrm{M}+\mathrm{Na}]^{+}:$449.0260, found: 449.0270 .

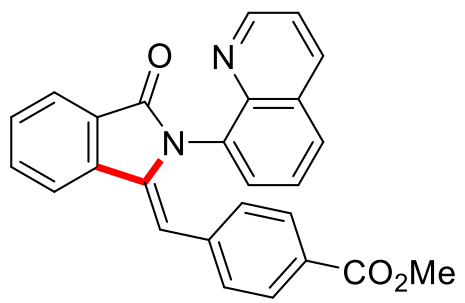

(Z)-Methyl 4-[\{3-oxo-2-(quinolin-8-yl)isoindolin-1-ylidene\} methyl)benzoate (256ai): The general procedure $\mathbf{J}$ was followed using benzamide $229 \mathbf{a}(62 \mathrm{mg}, 0.25 \mathrm{mmol}$ ) and alkyne $\mathbf{2 5 5 \mathbf { i }}$ (80 mg, $0.50 \mathrm{mmol})$. Purification by column chromatography on silica gel ( $n$-hexane/EtOAc: 2/1) yielded 256ai (71.7 mg, 70\%, E/Z = 1:7) as a yellow solid. M. p.: $185-190{ }^{\circ} \mathrm{C}$.

Resonances are reported for (Z)-256ai. ${ }^{1} \mathrm{H}-\mathrm{NMR}\left(400 \mathrm{MHz}, \mathrm{CDCl}_{3}\right): \delta=8.81(\mathrm{dd}, J=4.2,1.7$ $\mathrm{Hz}, 1 \mathrm{H}), 7.97(\mathrm{dd}, J=7.6,1.2 \mathrm{~Hz}, 1 \mathrm{H}), 7.93(\mathrm{~d}, J=8.2 \mathrm{~Hz}, 1 \mathrm{H}), 7.86(\mathrm{~d}, J=7.8 \mathrm{~Hz}, 1 \mathrm{H}), 7.67$ (t, $J=7.4 \mathrm{~Hz}, 1 \mathrm{H}), 7.59-7.53(\mathrm{~m}, 2 \mathrm{H}), 7.48(\mathrm{~d}, J=7.4,1 \mathrm{H}), 7.31-7.25(\mathrm{~m}, 2 \mathrm{H}), 7.21-7.15$ (m, $2 \mathrm{H}), 6.73(\mathrm{~s}, 1 \mathrm{H}), 6.62-6.54(\mathrm{~m}, 2 \mathrm{H}), 3.79(3 \mathrm{H})$.

${ }^{13} \mathrm{C}-\mathrm{NMR}\left(100 \mathrm{MHz}, \mathrm{CDCl}_{3}\right): \delta=168.0\left(\mathrm{C}_{\mathrm{q}}\right), 166.6\left(\mathrm{C}_{\mathrm{q}}\right), 150.4(\mathrm{CH}), 144.2\left(\mathrm{C}_{\mathrm{q}}\right), 138.6\left(\mathrm{C}_{\mathrm{q}}\right)$, $138.4\left(\mathrm{C}_{\mathrm{q}}\right), 137.2\left(\mathrm{C}_{\mathrm{q}}\right), 135.8(\mathrm{CH}), 134.0\left(\mathrm{C}_{\mathrm{q}}\right), 132.4(\mathrm{CH}), 130.0(\mathrm{CH}), 129.4(\mathrm{CH}), 128.8$ $\left(\mathrm{C}_{\mathrm{q}}\right), 128.5(\mathrm{CH}), 128.3\left(\mathrm{C}_{\mathrm{q}}\right), 128.1(\mathrm{CH}), 127.4(\mathrm{CH}), 127.3\left(\mathrm{C}_{\mathrm{q}}\right), 125.7(\mathrm{CH}), 124.0(\mathrm{CH})$, $121.4(\mathrm{CH}), 119.7(\mathrm{CH}), 105.7(\mathrm{CH}), 51.9\left(\mathrm{CH}_{3}\right)$.

Resonances are reported for $(E)$-256ai: ${ }^{1} \mathrm{H}-\mathrm{NMR}\left(400 \mathrm{MHz}, \mathrm{CDCl}_{3}\right): \delta=8.90$ (dd, $J=4.2,1.7$ $\mathrm{Hz}, 1 \mathrm{H}), 8.23(\mathrm{dd}, J=8.3,1.7 \mathrm{~Hz}, 1 \mathrm{H}), 8.02-7.99(\mathrm{~m}, 2 \mathrm{H}), 7.82(\mathrm{dd}, J=7.3,1.4 \mathrm{~Hz}, 1 \mathrm{H}), 7.67$ $(\mathrm{t}, J=7.4 \mathrm{~Hz}, 1 \mathrm{H}), 7.51(\mathrm{dd}, J=7.4,1.0 \mathrm{~Hz}, 1 \mathrm{H}), 7.46-7.42(\mathrm{~m}, 3 \mathrm{H}), 7.41-7.37$ (m, 1H), 7.31$7.25(\mathrm{~m}, 2 \mathrm{H}), 7.21-7.15(\mathrm{~m}, 2 \mathrm{H}), 5.96(\mathrm{~s}, 1 \mathrm{H}), 3.81(3 \mathrm{H})$. 
${ }^{13} \mathrm{C}-\mathrm{NMR}\left(100 \mathrm{MHz}, \mathrm{CDCl}_{3}\right): \delta=167.0\left(\mathrm{C}_{\mathrm{q}}\right), 166.7\left(\mathrm{C}_{\mathrm{q}}\right), 151.3(\mathrm{CH}), 144.9\left(\mathrm{C}_{\mathrm{q}}\right), 140.4\left(\mathrm{C}_{\mathrm{q}}\right)$, $139.8\left(\mathrm{C}_{\mathrm{q}}\right), 136.3(\mathrm{CH}), 135.2\left(\mathrm{C}_{\mathrm{q}}\right), 132.6\left(\mathrm{C}_{\mathrm{q}}\right), 131.9(\mathrm{CH}), 131.4(\mathrm{CH}), 130.5\left(\mathrm{C}_{\mathrm{q}}\right), 129.8$ $(\mathrm{CH}), 129.7(\mathrm{CH}), 129.6(\mathrm{CH}), 129.5(\mathrm{CH}), 129.1\left(\mathrm{C}_{\mathrm{q}}\right), 127.3\left(\mathrm{C}_{\mathrm{q}}\right), 126.3(\mathrm{CH}), 123.9(\mathrm{CH})$, $123.2(\mathrm{CH}), 121.9(\mathrm{CH}), 110.6(\mathrm{CH}), 52.1\left(\mathrm{CH}_{3}\right)$.

IR (ATR): 3050, 1712, 1604, 1472, 1276, 1107, 791, $732 \mathrm{~cm}^{-1}$.

MS (ESI) $m / z$ (relative intensity): $429(10)[\mathrm{M}+\mathrm{Na}]^{+}, 407(100)[\mathrm{M}+\mathrm{H}]^{+}$.

HR-MS (ESI): $m / z$ calcd for $\mathrm{C}_{26} \mathrm{H}_{19} \mathrm{~N}_{2} \mathrm{O}_{3}[\mathrm{M}+\mathrm{H}]^{+}: 407.1390$, found: 407.1397.

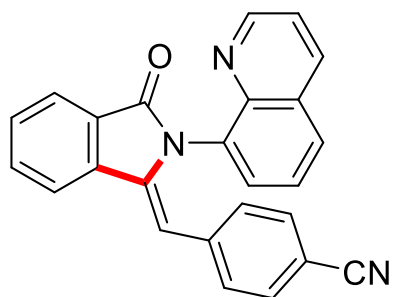

(Z)-4-[\{3-Oxo-2-(quinolin-8-yl) isoindolin-1-ylidene $\}$ methyl] benzonitrile (256aj): The general procedure $\mathbf{J}$ was followed using benzamide 229a (62 mg, $0.25 \mathrm{mmol}$ ) and alkyne 255j (64 mg, $0.50 \mathrm{mmol}$ ). Purification by column chromatography on silica gel ( $n$-hexane/EtOAc: 1/1) yielded 256aj (61.5 mg, 66\%, E/Z =1:6) as a white solid. M. p.: 235-242 ${ }^{\circ} \mathrm{C}$.

Resonances are reported for (Z)-256aj. ${ }^{1} \mathrm{H}-\mathrm{NMR}\left(400 \mathrm{MHz}, \mathrm{CDCl}_{3}\right): \delta=8.83(\mathrm{dd}, J=4.2,1.7$ Hz, 1H), 8.06-7.97 (m, 2H), 7.89 (d, $J=7.7 \mathrm{~Hz}, 1 \mathrm{H}), 7.72$ (t, $J=7.6 \mathrm{~Hz}, 1 \mathrm{H}), 7.67$ (dd, $J=$ 8.2, 1.4 Hz, 1H), 7.65-7.59 (m, 1H), 7.54 (d, $J=6.5 \mathrm{~Hz}, 1 \mathrm{H}), 7.41-7.30(\mathrm{~m}, 2 \mathrm{H}), 6.80(\mathrm{~d}, J=$ $8.2 \mathrm{~Hz}, 2 \mathrm{H}), 6.71(\mathrm{~s}, 1 \mathrm{H}), 6.66(\mathrm{~d}, J=8.2 \mathrm{~Hz}, 2 \mathrm{H})$.

${ }^{13} \mathrm{C}-\mathrm{NMR}\left(100 \mathrm{MHz}, \mathrm{CDCl}_{3}\right): \delta=167.9\left(\mathrm{C}_{\mathrm{q}}\right), 150.5(\mathrm{CH}), 144.1\left(\mathrm{C}_{\mathrm{q}}\right), 138.8\left(\mathrm{C}_{\mathrm{q}}\right), 138.2\left(\mathrm{C}_{\mathrm{q}}\right)$, $138.0\left(\mathrm{C}_{\mathrm{q}}\right), 136.0(\mathrm{CH}), 133.9\left(\mathrm{C}_{\mathrm{q}}\right), 132.6(\mathrm{CH}), 130.1(\mathrm{CH}), 129.8(\mathrm{CH}), 128.9\left(\mathrm{C}_{\mathrm{q}}\right), 128.8$ $(\mathrm{CH}), 128.7(\mathrm{CH}), 128.3\left(\mathrm{C}_{\mathrm{q}}\right), 125.8(\mathrm{CH}), 124.1(\mathrm{CH}), 121.6(\mathrm{CH}), 119.9(\mathrm{CH}), 118.7\left(\mathrm{C}_{\mathrm{q}}\right)$, $109.5(\mathrm{CH}), 109.2\left(\mathrm{C}_{\mathrm{q}}\right), 104.6(\mathrm{CH})$.

Resonances are reported for $(E)-256 a j . ~{ }^{1} \mathrm{H}-\mathrm{NMR}\left(400 \mathrm{MHz}, \mathrm{CDCl}_{3}\right): \delta=8.93(\mathrm{dd}, J=4.2,1.7$ $\mathrm{Hz}, 1 \mathrm{H}), 8.27(\mathrm{dd}, J=8.3,1.7 \mathrm{~Hz}, 1 \mathrm{H}), 8.05-8.02(\mathrm{~m}, 2 \mathrm{H}), 7.85(\mathrm{dd}, J=7.3,1.4 \mathrm{~Hz}, 1 \mathrm{H}), 7.72$ $(\mathrm{dd}, J=7.5,1.1 \mathrm{~Hz}, 1 \mathrm{H}), 7.66-7.59(\mathrm{~m}, 2 \mathrm{H}), 7.58-7.55(\mathrm{~m}, 1 \mathrm{H}), 7.52-7.42(\mathrm{~m}, 5 \mathrm{H}), 5.93(\mathrm{~s}$, $1 \mathrm{H})$.

${ }^{13} \mathrm{C}-\mathrm{NMR}\left(100 \mathrm{MHz}, \mathrm{CDCl}_{3}\right): \delta=166.9\left(\mathrm{C}_{\mathrm{q}}\right), 151.3(\mathrm{CH}), 144.9\left(\mathrm{C}_{\mathrm{q}}\right), 140.6\left(\mathrm{C}_{\mathrm{q}}\right), 140.4\left(\mathrm{C}_{\mathrm{q}}\right)$, $138.8\left(\mathrm{C}_{\mathrm{q}}\right), 136.4(\mathrm{CH}), 136.0(\mathrm{CH}), 134.9\left(\mathrm{C}_{\mathrm{q}}\right), 132.5\left(\mathrm{C}_{\mathrm{q}}\right), 132.2(\mathrm{CH}), 132.1(\mathrm{CH}), 131.4$ $(\mathrm{CH}), 130.6\left(\mathrm{C}_{\mathrm{q}}\right), 130.3(\mathrm{CH}), 130.2(\mathrm{CH}), 129.8(\mathrm{CH}), 129.6\left(\mathrm{C}_{\mathrm{q}}\right), 126.4(\mathrm{CH}), 123.0(\mathrm{CH})$, $122.0(\mathrm{CH}), 118.8(\mathrm{CH}), 111.0\left(\mathrm{C}_{\mathrm{q}}\right)$.

IR (ATR): 3047, 1704, 1650, 1597, 1470, 1144, $754 \mathrm{~cm}^{-1}$. MS (ESI) $m / z$ (relative intensity): $396(20)[\mathrm{M}+\mathrm{Na}]^{+}, 374(100)[\mathrm{M}+\mathrm{H}]^{+}$. 
HR-MS (ESI): $m / z$ calcd for $\mathrm{C}_{25} \mathrm{H}_{16} \mathrm{~N}_{3} \mathrm{O}[\mathrm{M}+\mathrm{H}]^{+}: 374.1288$, found: 374.1295 . The analytical data correspond with those reported in the literature. ${ }^{[208]}$<smiles>O=C1/C(=C\c2ccsc2)c2ccccc21</smiles>

(Z)-2-(Quinolin-8-yl)-3-(thiophen-3-ylmethylene) isoindolin-1-one (256ak): The general procedure $\mathbf{J}$ was followed using benzamide $229 \mathbf{a}(73 \mathrm{mg}, 0.25 \mathrm{mmol})$ and alkyne $255 \mathbf{k}$ (54 $\mathrm{mg}$, $0.50 \mathrm{mmol})$ with $\mathrm{Cu}(\mathrm{OAc})_{2} \cdot \mathrm{H}_{2} \mathrm{O}(5.0 \mathrm{mg}, 10 \mathrm{~mol} \%)$. Purification by column chromatography on silica gel ( $n$-hexane/EtOAc: $2 / 1)$ yielded 256ak (66 mg, 75\%, E/Z = 1:3) as a yellow solid. M. p.: $170-175^{\circ} \mathrm{C}$.

Resonances reported for (Z)-256ak: ${ }^{1} \mathrm{H}-\mathrm{NMR}\left(300 \mathrm{MHz}, \mathrm{CDCl}_{3}\right): \delta=8.83(\mathrm{dd}, J=4.1,1.8$ Hz, 1H), $8.04(\mathrm{dd}, J=8.4,1.7 \mathrm{~Hz}, 1 \mathrm{H}), 7.96(\mathrm{~d}, J=7.7 \mathrm{~Hz}, 1 \mathrm{H}), 7.84(\mathrm{~d}, J=7.9 \mathrm{~Hz}, 1 \mathrm{H}), 7.68$ $(\mathrm{dd}, J=8.0,5.8 \mathrm{~Hz}, 2 \mathrm{H}), 7.56-7.52(\mathrm{~m}, 2 \mathrm{H}), 7.39(\mathrm{~d}, J=7.9 \mathrm{~Hz}, 1 \mathrm{H}), 7.37-7.28(\mathrm{~m}, 1 \mathrm{H}), 6.65$ $(\mathrm{s}, 1 \mathrm{H}), 6.54(\mathrm{dd}, J=5.0,3.0 \mathrm{~Hz}, 1 \mathrm{H}), 6.20(\mathrm{~d}, J=4.3 \mathrm{~Hz}, 2 \mathrm{H})$.

${ }^{13} \mathrm{C}-\mathrm{NMR}\left(100 \mathrm{MHz}, \mathrm{CDCl}_{3}\right): \delta=168.0\left(\mathrm{C}_{\mathrm{q}}\right), 150.5(\mathrm{CH}), 144.6\left(\mathrm{C}_{\mathrm{q}}\right), 138.6\left(\mathrm{C}_{\mathrm{q}}\right), 136.2\left(\mathrm{C}_{\mathrm{q}}\right)$, $135.9(\mathrm{CH}), 134.2\left(\mathrm{C}_{\mathrm{q}}\right), 133.8\left(\mathrm{C}_{\mathrm{q}}\right), 132.2(\mathrm{CH}), 129.8(\mathrm{CH}), 129.0(\mathrm{CH}), 128.9\left(\mathrm{C}_{\mathrm{q}}\right), 128.5$ $(\mathrm{CH}), 128.2\left(\mathrm{C}_{\mathrm{q}}\right), 127.9(\mathrm{CH}), 125.8(\mathrm{CH}), 123.9(\mathrm{CH}), 123.0(\mathrm{CH}), 122.8(\mathrm{CH}), 121.4(\mathrm{CH})$, $119.5(\mathrm{CH}), 101.8(\mathrm{CH})$.

Resonances reported for (E)-256ak: ${ }^{1} \mathrm{H}-\mathrm{NMR}\left(300 \mathrm{MHz}, \mathrm{CDCl}_{3}\right): \delta=8.91(\mathrm{dd}, J=4.1,1.8$ Hz, 1H), 8.23 (dd, $J=8.4,1.7 \mathrm{~Hz}, 1 \mathrm{H}), 7.96(\mathrm{~d}, J=7.7 \mathrm{~Hz}, 2 \mathrm{H}), 7.84$ (d, $J=7.9 \mathrm{~Hz}, 1 \mathrm{H}), 7.73-$ $7.61(\mathrm{~m}, 2 \mathrm{H}), 7.54(\mathrm{t}, J=7.4 \mathrm{~Hz}, 1 \mathrm{H}), 7.49-7.42(\mathrm{~m}, 2 \mathrm{H}), 7.37-7.27(\mathrm{~m}, 2 \mathrm{H}), 7.07$ (d, $J=5.0$ $\mathrm{Hz}, 1 \mathrm{H}), 5.85(\mathrm{~s}, 1 \mathrm{H})$.

${ }^{13} \mathrm{C}-\mathrm{NMR}\left(100 \mathrm{MHz}, \mathrm{CDCl}_{3}\right): \delta=166.9\left(\mathrm{C}_{\mathrm{q}}\right), 151.3(\mathrm{CH}), 145.0\left(\mathrm{C}_{\mathrm{q}}\right), 139.2\left(\mathrm{C}_{\mathrm{q}}\right), 136.3(\mathrm{CH})$, $135.5\left(\mathrm{C}_{\mathrm{q}}\right), 134.2\left(\mathrm{C}_{\mathrm{q}}\right), 132.8\left(\mathrm{C}_{\mathrm{q}}\right), 131.8(\mathrm{CH}), 131.4(\mathrm{CH}), 130.3\left(\mathrm{C}_{\mathrm{q}}\right), 129.6\left(\mathrm{C}_{\mathrm{q}}\right) .129 .5(\mathrm{CH})$, 129.4 (CH), $128.9(\mathrm{CH}), 126.3(\mathrm{CH}), 125.7(\mathrm{CH}), 124.0(\mathrm{CH}), 123.8(\mathrm{CH}), 123.2(\mathrm{CH}), 121.8$ $(\mathrm{CH}), 106.2(\mathrm{CH})$.

IR (ATR): 3021, 1709, 1501, 1473, 1397, 827, $789 \mathrm{~cm}^{-1}$.

MS (ESI) $\mathrm{m} / z$ (relative intensity): $377(10)[\mathrm{M}+\mathrm{Na}]^{+}, 355(100)[\mathrm{M}+\mathrm{H}]^{+}$.

HR-MS (ESI): $m / z$ calcd for $\mathrm{C}_{22} \mathrm{H}_{15} \mathrm{~N}_{2} \mathrm{OS}[\mathrm{M}+\mathrm{H}]^{+}: 355.0900$, found: 355.0902 . 
<smiles>CCOC(=O)/C=C1/c2ccccc2C(=O)N1c1cccc2cccnc12</smiles>

(Z)-Ethyl 2-(3-oxo-2-(quinolin-8-yl) isoindolin-1-ylidene)acetate (256al): The general procedure $\mathbf{J}$ was followed using benzamide 229a (73 mg, $0.25 \mathrm{mmol}$ ) and alkyne $255 \mathbf{l}$ (49 $\mathrm{mg}$, $0.50 \mathrm{mmol})$ with $\mathrm{Cu}(\mathrm{OAc})_{2} \cdot \mathrm{H}_{2} \mathrm{O}(10.0 \mathrm{mg}, 20 \mathrm{~mol} \%)$. Purification by column chromatography on silica gel ( $n$-hexane/EtOAc: $1 / 3)$ yielded 256al $(36.2 \mathrm{mg}, 42 \%, E / Z=1: 5)$ as a yellow oil.

Resonances are reported for (Z)-256al: ${ }^{1} \mathrm{H}-\mathrm{NMR}\left(400 \mathrm{MHz}, \mathrm{CDCl}_{3}\right): \delta=8.88(\mathrm{dd}, J=4.4,1.7$ $\mathrm{Hz}, 1 \mathrm{H}), 8.24$ (dd, $J=8.3,1.7 \mathrm{~Hz}, 1 \mathrm{H}), 7.99$ (dd, $J=7.5,1.0 \mathrm{~Hz}, 1 \mathrm{H}), 7.94$ (dd, $J=8.3,1.4$ $\mathrm{Hz}, 1 \mathrm{H}), 7.83(\mathrm{dd}, J=7.3,1.0 \mathrm{~Hz}, 1 \mathrm{H}), 7.78(\mathrm{dd}, J=7.3,1.4 \mathrm{~Hz}, 1 \mathrm{H}), 7.74-7.64(\mathrm{~m}, 3 \mathrm{H}), 7.43$ $(\mathrm{dd}, J=8.3,4.2 \mathrm{~Hz}, 1 \mathrm{H}), 5.98(\mathrm{~s}, 1 \mathrm{H}), 3.45(\mathrm{dq}, J=10.9,7.1 \mathrm{~Hz}, 1 \mathrm{H}), 3.26(\mathrm{dq}, J=10.9,7.1$ $\mathrm{Hz}, 1 \mathrm{H}), 0.72(\mathrm{t}, \mathrm{J}=7.1,0.7 \mathrm{~Hz}, 3 \mathrm{H})$.

${ }^{13} \mathrm{C}-\mathrm{NMR}\left(100 \mathrm{MHz}, \mathrm{CDCl}_{3}\right): \delta=168.4\left(\mathrm{C}_{\mathrm{q}}\right), 164.3\left(\mathrm{C}_{\mathrm{q}}\right), 150.6(\mathrm{CH}), 144.9\left(\mathrm{C}_{\mathrm{q}}\right), 144.0\left(\mathrm{C}_{\mathrm{q}}\right)$, $138.0\left(\mathrm{C}_{\mathrm{q}}\right), 136.2(\mathrm{CH}), 134.5\left(\mathrm{C}_{\mathrm{q}}\right), 132.9(\mathrm{CH}), 130.9(\mathrm{CH}), 129.4(\mathrm{CH}), 128.9\left(\mathrm{C}_{\mathrm{q}}\right), 128.7$ $(\mathrm{CH}), 128.2\left(\mathrm{C}_{\mathrm{q}}\right), 126.1(\mathrm{CH}), 124.3(\mathrm{CH}), 121.5(\mathrm{CH}), 120.4(\mathrm{CH}), 95.5(\mathrm{CH}), 60.1\left(\mathrm{CH}_{2}\right)$, $13.6\left(\mathrm{CH}_{3}\right)$.

Resonances are reported for (E)-256al: ${ }^{1} \mathrm{H}-\mathrm{NMR}\left(400 \mathrm{MHz}, \mathrm{CDCl}_{3}\right): \delta=9.23$ (dd, $J=7.9,0.9$ $\mathrm{Hz}, 1 \mathrm{H}), 8.90(\mathrm{~d}, J=1.6 \mathrm{~Hz}, 1 \mathrm{H}), 8.30-8.26(\mathrm{~m}, 1 \mathrm{H}), 8.07-8.00(\mathrm{~m}, 2 \mathrm{H}), 7.75(\mathrm{dd}, J=6.5,1.1$ $\mathrm{Hz}, 3 \mathrm{H}), 7.73-7.62(\mathrm{~m}, 1 \mathrm{H}), 7.48(\mathrm{dd}, J=8.3,4.2 \mathrm{~Hz}, 1 \mathrm{H}), 5.25(\mathrm{~s}, 1 \mathrm{H}), 4.18(\mathrm{qd}, J=7.1,3.8$ $\mathrm{Hz}, 2 \mathrm{H}), 1.24(\mathrm{t}, J=7.0 \mathrm{~Hz}, 3 \mathrm{H})$.

${ }^{13} \mathrm{C}-\mathrm{NMR}\left(100 \mathrm{MHz}, \mathrm{CDCl}_{3}\right): \delta=167.6\left(\mathrm{C}_{\mathrm{q}}\right), 166.1\left(\mathrm{C}_{\mathrm{q}}\right), 151.5(\mathrm{CH}), 150.8\left(\mathrm{C}_{\mathrm{q}}\right), 144.7\left(\mathrm{C}_{\mathrm{q}}\right)$, $136.3(\mathrm{CH}), 134.3\left(\mathrm{C}_{\mathrm{q}}\right), 133.3(\mathrm{CH}), 131.9\left(\mathrm{C}_{\mathrm{q}}\right), 131.4(\mathrm{CH}), 131.3(\mathrm{CH}), 130.3\left(\mathrm{C}_{\mathrm{q}}\right), 130.0$ $(\mathrm{CH}), 129.6\left(\mathrm{C}_{\mathrm{q}}\right), 128.4(\mathrm{CH}), 126.4(\mathrm{CH}), 123.7(\mathrm{CH}), 122.1(\mathrm{CH}), 100.2(\mathrm{CH}), 60.3\left(\mathrm{CH}_{2}\right)$, $14.2\left(\mathrm{CH}_{3}\right)$.

IR (ATR): 3010, 1705, 1601, 1533, 1290, 855, 770, $728 \mathrm{~cm}^{-1}$. MS (ESI) $m / z$ (relative intensity): $345(100)[\mathrm{M}+\mathrm{H}]^{+}$.

HR-MS (ESI): $m / z$ calcd for $\mathrm{C}_{21} \mathrm{H}_{17} \mathrm{~N}_{2} \mathrm{O}_{3}[\mathrm{M}+\mathrm{H}]^{+}: 345.1234$, found: 345.1232 . 


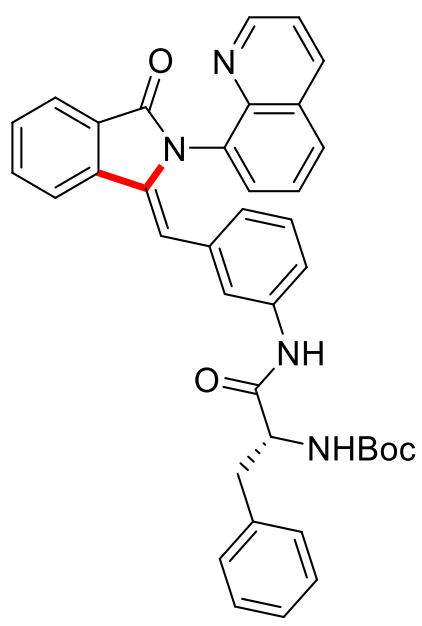

(S,Z)-tert-Butyl-(1-oxo-1-((3-((3-oxo-2-(quinolin-8-yl) isoindolin-1-ylidene) methyl) phenyl) amino)-3-phenylpropan-2-yl) carbamate (256am): The general procedure $\mathbf{J}$ was followed using benzamide 229a (73 mg, $0.25 \mathrm{mmol}$ ) and alkyne $255 \mathrm{~m}$ (182 mg, $0.50 \mathrm{mmol}$ ) with $\mathrm{Cu}(\mathrm{OAc})_{2} \cdot \mathrm{H}_{2} \mathrm{O}(5.0 \mathrm{mg}, 10 \mathrm{~mol} \%)$. Purification by column chromatography on silica gel ( $n$-hexane/EtOAc: $2 / 1)$ yielded 256am (106.7 mg, 70\%, E/Z = 1:6) as a yellow oil.

Resonances are reported for (Z)-256am: ${ }^{1} \mathrm{H}-\mathrm{NMR}\left(400 \mathrm{MHz}, \mathrm{CDCl}_{3}\right): \delta=8.78$ (dd, $J=4.0$, $1.1 \mathrm{~Hz}, 1 \mathrm{H}), 7.95(\mathrm{~d}, J=7.5 \mathrm{~Hz}, 1 \mathrm{H}), 7.86-7.78(\mathrm{~m}, 2 \mathrm{H}), 7.69-7.61(\mathrm{~m}, 1 \mathrm{H}), 7.54(\mathrm{t}, J=7.5$ $\mathrm{Hz}, 1 \mathrm{H}), 7.48-7.43(\mathrm{~m}, 1 \mathrm{H}), 7.38(\mathrm{~d}, J=7.1 \mathrm{~Hz}, 1 \mathrm{H}), 7.32-7.27(\mathrm{~m}, 3 \mathrm{H}), 7.24-7.14(\mathrm{~m}, 5 \mathrm{H})$, $6.85(\mathrm{~d}, J=8.0 \mathrm{~Hz}, 1 \mathrm{H}), 6.68(\mathrm{~s}, 1 \mathrm{H}), 6.52-6.40(\mathrm{~m}, 2 \mathrm{H}), 6.26(\mathrm{dd}, J=12.6,7.6 \mathrm{~Hz}, 1 \mathrm{H}), 5.06$ (s, 1H), 4.31 (s, 1H), 3.14-2.92 (m, 2H), 1.43 (s, 9H).

${ }^{13} \mathrm{C}-\mathrm{NMR}\left(100 \mathrm{MHz}, \mathrm{CDCl}_{3}\right): \delta=167.9\left(\mathrm{C}_{\mathrm{q}}\right), 167.8\left(\mathrm{C}_{\mathrm{q}}\right), 167.1\left(\mathrm{C}_{\mathrm{q}}\right), 149.4(\mathrm{CH}), 143.3\left(\mathrm{C}_{\mathrm{q}}\right)$, $137.6\left(\mathrm{C}_{\mathrm{q}}\right), 135.5(\mathrm{CH}), 135.5\left(\mathrm{C}_{\mathrm{q}}\right), 134.9(\mathrm{CH}), 134.8(\mathrm{CH}), 134.7\left(\mathrm{C}_{\mathrm{q}}\right), 133.3\left(\mathrm{C}_{\mathrm{q}}\right), 133.1\left(\mathrm{C}_{\mathrm{q}}\right)$, $131.3(\mathrm{CH}), 129.0\left(\mathrm{C}_{\mathrm{q}}\right), 128.4\left(\mathrm{C}_{\mathrm{q}}\right), 128.3(\mathrm{CH}), 128.2(\mathrm{CH}), 128.0(\mathrm{CH}), 127.4(\mathrm{CH}), 127.3$ $\left(\mathrm{C}_{\mathrm{q}}\right), 126.0(\mathrm{CH}), 124.8(\mathrm{CH}), 124.7(\mathrm{CH}), 123.4(\mathrm{CH}), 123.0(\mathrm{CH}), 120.3(\mathrm{CH}), 120.2(\mathrm{CH})$, $118.9(\mathrm{CH}), 118.7(\mathrm{CH}), 105.6(\mathrm{CH}), 79.7\left(\mathrm{C}_{\mathrm{q}}\right), 55.5(\mathrm{CH}), 37.1\left(\mathrm{CH}_{2}\right), 27.3\left(\mathrm{CH}_{3}\right)$.

Resonances are reported for $(E)$-256am: ${ }^{1} \mathrm{H}-\mathrm{NMR}$ (400 $\left.\mathrm{MHz}, \mathrm{CDCl}_{3}\right): \delta=8.88(\mathrm{dd}, J=4.0$, $1.1 \mathrm{~Hz}, 1 \mathrm{H}), 8.21(\mathrm{~d}, J=7.9 \mathrm{~Hz}, 1 \mathrm{H}), 7.95(\mathrm{~d}, J=7.4 \mathrm{~Hz}, 2 \mathrm{H}), 7.89-7.75(\mathrm{~m}, 2 \mathrm{H}), 7.65(\mathrm{t}, J=$ $7.4 \mathrm{~Hz}, 1 \mathrm{H}), 7.50(\mathrm{~d}, J=1.1 \mathrm{~Hz}, 1 \mathrm{H}), 7.43-7.36(\mathrm{~m}, 3 \mathrm{H}), 7.35-7.24(\mathrm{~m}, 2 \mathrm{H}), 7.22-7.14(\mathrm{~m}$, 2H), $7.11(\mathrm{~d}, J=6.9 \mathrm{~Hz}, 2 \mathrm{H}), 7.07-6.98(\mathrm{~m}, 3 \mathrm{H}), 5.90(\mathrm{~s}, 1 \mathrm{H}), 5.13(\mathrm{~s}, 1 \mathrm{H}), 4.42(\mathrm{~s}, 1 \mathrm{H}), 3.15-$ $2.91(\mathrm{~m}, 2 \mathrm{H}), 1.36(\mathrm{~s}, 9 \mathrm{H})$.

${ }^{13} \mathrm{C}-\mathrm{NMR}\left(100 \mathrm{MHz}, \mathrm{CDCl}_{3}\right): \delta=168.7\left(\mathrm{C}_{\mathrm{q}}\right), 166.1\left(\mathrm{C}_{\mathrm{q}}\right), 154.8(\mathrm{CH}), 150.3(\mathrm{CH}), 144.0\left(\mathrm{C}_{\mathrm{q}}\right)$, $138.1\left(\mathrm{C}_{\mathrm{q}}\right), 136.6\left(\mathrm{C}_{\mathrm{q}}\right), 135.7(\mathrm{CH}), 135.6(\mathrm{CH}), 135.3\left(\mathrm{C}_{\mathrm{q}}\right), 135.1\left(\mathrm{C}_{\mathrm{q}}\right), 134.3\left(\mathrm{C}_{\mathrm{q}}\right), 133.3\left(\mathrm{C}_{\mathrm{q}}\right)$, $131.8(\mathrm{CH}), 130.9(\mathrm{CH}), 130.4\left(\mathrm{C}_{\mathrm{q}}\right), 129.4(\mathrm{CH}), 128.5(\mathrm{CH}), 128.5\left(\mathrm{C}_{\mathrm{q}}\right), 127.8(\mathrm{CH}), 126.2$ $\left(\mathrm{C}_{\mathrm{q}}\right), 125.9(\mathrm{CH}), 125.4(\mathrm{CH}), 124.6(\mathrm{CH}), 122.8(\mathrm{CH}), 122.5(\mathrm{CH}), 120.9(\mathrm{CH}), 119.9(\mathrm{CH})$, $118.2(\mathrm{CH}), 116.9(\mathrm{CH}), 116.8(\mathrm{CH}), 110.6(\mathrm{CH}), 79.7\left(\mathrm{C}_{\mathrm{q}}\right), 55.5(\mathrm{CH}), 37.3\left(\mathrm{CH}_{2}\right), 27.3\left(\mathrm{CH}_{3}\right)$. 
IR (ATR): 3022, 1721, 1652, 1542, 1244, 872, 791, $711 \mathrm{~cm}^{-1}$.

MS (ESI) $m / z$ (relative intensity): $633(10)[\mathrm{M}+\mathrm{Na}]^{+}, 611(100)[\mathrm{M}+\mathrm{H}]^{+}$.

HR-MS (ESI): $m / z$ calcd for $\mathrm{C}_{38} \mathrm{H}_{34} \mathrm{~N}_{4} \mathrm{O}_{4} \mathrm{Na}[\mathrm{M}+\mathrm{Na}]^{+}: 633.2472$, found: 633.2475 .

\subsection{Electrochemical Cobalt-catalyzed C-H Allylation}

\subsubsection{Characterization Data}<smiles>CCCCC/C=C/Cc1cccc(C)c1C(=O)Nc1cccc2cccnc12</smiles>

(E)-2-Methyl-6-(oct-2-en-1-yl)- $N$-(quinolin-8-yl)benzamide (242fo): The general procedure $\mathbf{K}$ was followed using 2-methyl- $N$-(quinolin-8-yl)benzamide (229f) (131.1 mg, $0.50 \mathrm{mmol}$ ) and $n$-octene (223o) $(168.0 \mathrm{mg}, 1.5 \mathrm{mmol})$. Isolation by column chromatography ( $n$ hexane/EtOAc $=10: 1)$ yielded $\mathbf{2 4 2 f o}(112.0 \mathrm{mg}, 60 \%)$ as a colourless oil.

${ }^{1} \mathrm{H}-\mathrm{NMR}\left(400 \mathrm{MHz}, \mathrm{CDCl}_{3}\right): \delta=9.90(\mathrm{~s}, 1 \mathrm{H}), 8.98$ (dd, $\left.J=7.4,1.7 \mathrm{~Hz}, 1 \mathrm{H}\right), 8.72(\mathrm{dd}, J=4.2$, $1.7 \mathrm{~Hz}, 1 \mathrm{H}), 8.15$ (dd, $J=8.3,1.7 \mathrm{~Hz}, 1 \mathrm{H}), 7.61-7.57$ (m, 1H), $7.54(\mathrm{dd}, J=8.3,1.7 \mathrm{~Hz}, 1 \mathrm{H})$, 7.42 (dd, $J=8.3,4.2 \mathrm{~Hz}, 1 \mathrm{H}), 7.26$ (dd, $J=7.4,1.7 \mathrm{~Hz}, 1 \mathrm{H}), 7.16-7.07$ (m, 2H), 5.54 (dtt, $J=$ 14.7, 6.6, 1.4 Hz, 1H), 5.40 (dtt, $J=14.7,6.6,1.4 \mathrm{~Hz}, 1 \mathrm{H}), 3.43$ (d, $J=6.6 \mathrm{~Hz}, 2 \mathrm{H}), 2.42$ (s, $3 \mathrm{H}), 1.88-1.73(\mathrm{~m}, 2 \mathrm{H}), 1.18-1.06(\mathrm{~m}, 6 \mathrm{H}), 0.77$ (t, $J=6.2 \mathrm{~Hz}, 3 \mathrm{H})$.

${ }^{13} \mathrm{C}-\mathrm{NMR}\left(100 \mathrm{MHz}, \mathrm{CDCl}_{3}\right): \delta=168.7\left(\mathrm{C}_{\mathrm{q}}\right), 148.2(\mathrm{CH}), 138.5\left(\mathrm{C}_{\mathrm{q}}\right), 137.8\left(\mathrm{C}_{\mathrm{q}}\right), 137.7\left(\mathrm{C}_{\mathrm{q}}\right)$, $136.3(\mathrm{CH}), 134.7\left(\mathrm{C}_{\mathrm{q}}\right), 134.4\left(\mathrm{C}_{\mathrm{q}}\right), 132.5(\mathrm{CH}), 129.1(\mathrm{CH}), 128.1(\mathrm{CH}), 128.1(\mathrm{CH}), 128.0$ $\left(\mathrm{C}_{\mathrm{q}}\right), 127.4(\mathrm{CH}), 127.0(\mathrm{CH}), 121.9(\mathrm{CH}), 121.6(\mathrm{CH}), 116.8(\mathrm{CH}), 36.7\left(\mathrm{CH}_{2}\right), 32.4\left(\mathrm{CH}_{2}\right)$, $31.4\left(\mathrm{CH}_{2}\right), 28.9\left(\mathrm{CH}_{2}\right), 22.4\left(\mathrm{CH}_{2}\right), 19.5\left(\mathrm{CH}_{3}\right), 14.0\left(\mathrm{CH}_{3}\right)$.

IR (ATR): 2947, 1675, 1582, 1429, 1296, 970, 800, $710 \mathrm{~cm}^{-1}$.

MS (ESI) $m / z$ (relative intensity): $395(20)[\mathrm{M}+\mathrm{Na}]^{+}, 373(100)[\mathrm{M}+\mathrm{H}]^{+}$.

HR-MS (ESI): $m / z$ calcd. for $\left[\mathrm{C}_{25} \mathrm{H}_{28} \mathrm{~N}_{2} \mathrm{O}+\mathrm{Na}\right]^{+} 395.2094$ found 395.2087.

The analytical data correspond with those reported in the literature. ${ }^{[193]}$ 
<smiles>CCCCC/C=C/Cc1cccc(OC)c1C(=O)Nc1cccc2cccnc12</smiles>

(E)-2-Methoxy-6-(oct-2-en-1-yl)-N-(quinolin-8-yl)benzamide (242eo): A modified general procedure K was followed using 2-methoxy- $N$-(quinolin-8-yl)benzamide (229e) (140.0 mg, $0.50 \mathrm{mmol})$ and $n$-octene (223o) $(168.0 \mathrm{mg}, 1.5 \mathrm{mmol})$ with $\mathrm{Co}(\mathrm{OAc})_{2} \cdot 4 \mathrm{H}_{2} \mathrm{O}(25.4 \mathrm{mg}, 0.1$ mmol, $20 \mathrm{~mol} \%)$. Isolation by column chromatography $(n$-hexane/EtOAc $=5: 1)$ yielded 242eo (106.5 $\mathrm{mg}, 55 \%)$ as a yellow oil.

${ }^{1} \mathrm{H}-\mathrm{NMR}\left(400 \mathrm{MHz}, \mathrm{CDCl}_{3}\right): \delta=10.04$ (s, 1H), 8.99 (dd, $\left.J=7.5,1.5 \mathrm{~Hz}, 1 \mathrm{H}\right), 8.72$ (dd, $J=$ $4.2,1.5 \mathrm{~Hz}, 1 \mathrm{H}), 8.14(\mathrm{dd}, J=8.3,1.5 \mathrm{~Hz}, 1 \mathrm{H}), 7.58(\mathrm{dd}, J=8.3,7.5 \mathrm{~Hz}, 1 \mathrm{H}), 7.51(\mathrm{dd}, J=$ $8.3,1.5 \mathrm{~Hz}, 1 \mathrm{H}), 7.41(\mathrm{dd}, J=8.3,4.2 \mathrm{~Hz}, 1 \mathrm{H}), 7.32(\mathrm{dd}, J=8.3,7.5 \mathrm{~Hz}, 1 \mathrm{H}), 6.90(\mathrm{dd}, J=$ 7.7, $1.0 \mathrm{~Hz}, 1 \mathrm{H}), 6.84(\mathrm{dd}, J=8.4,0.9 \mathrm{~Hz}, 1 \mathrm{H}), 5.55$ (dtt, $J=15.2,6.6,1.2 \mathrm{~Hz}, 1 \mathrm{H}), 5.42$ (dtt, $J=15.2,6.6,1.2 \mathrm{~Hz}, 1 \mathrm{H}), 3.82(\mathrm{~s}, 3 \mathrm{H}), 3.49-3.41$ (m, 2H), 1.87-1.76 (m, 2H), 1.18-1.04 (m, $6 \mathrm{H}), 0.76(\mathrm{t}, J=6.4 \mathrm{~Hz}, 3 \mathrm{H})$.

${ }^{13} \mathrm{C}-\mathrm{NMR}\left(100 \mathrm{MHz}, \mathrm{CDCl}_{3}\right): \delta=166.3\left(\mathrm{C}_{\mathrm{q}}\right), 156.4\left(\mathrm{C}_{\mathrm{q}}\right), 148.0(\mathrm{CH}), 140.3\left(\mathrm{C}_{\mathrm{q}}\right), 138.5\left(\mathrm{C}_{\mathrm{q}}\right)$, $136.2(\mathrm{CH}), 134.8\left(\mathrm{C}_{\mathrm{q}}\right), 132.5(\mathrm{CH}), 130.2(\mathrm{CH}), 128.0\left(\mathrm{C}_{\mathrm{q}}\right), 127.9(\mathrm{CH}), 127.4(\mathrm{CH}), 126.9$ $\left(\mathrm{C}_{\mathrm{q}}\right), 122.0(\mathrm{CH}), 121.6(\mathrm{CH}), 121.5(\mathrm{CH}), 116.7(\mathrm{CH}), 108.8(\mathrm{CH}), 55.8\left(\mathrm{CH}_{3}\right), 36.4\left(\mathrm{CH}_{2}\right)$, $32.3\left(\mathrm{CH}_{2}\right), 31.3\left(\mathrm{CH}_{2}\right), 28.8\left(\mathrm{CH}_{2}\right), 22.4\left(\mathrm{CH}_{2}\right), 14.0\left(\mathrm{CH}_{3}\right)$.

IR (ATR): 2922, 1656, 1590, 1492, 1322, 998, 850, $730 \mathrm{~cm}^{-1}$.

MS (ESI) $m / z$ (relative intensity): $411(80)[\mathrm{M}+\mathrm{Na}]^{+}, 389(100)[\mathrm{M}+\mathrm{H}]^{+}$.

HR-MS (ESI): $m / z$ calcd. for $\left[\mathrm{C}_{25} \mathrm{H}_{28} \mathrm{~N}_{2} \mathrm{O}_{2}+\mathrm{Na}\right]^{+} 411.2043$ found 411.2040 .

The analytical data correspond with those reported in the literature. ${ }^{[193]}$<smiles>CCCCC/C=C/Cc1cccc(C(F)(F)F)c1C(=O)Nc1cccc2cccnc12</smiles>

(E)-2-(Oct-2-en-1-yl)- $N$-(quinolin-8-yl)-6-(trifluoromethyl)benzamide $\quad$ (242go): $\quad$ The general procedure $\mathbf{K}$ was followed using $N$-(quinolin-8-yl)-2-(trifluoromethyl)benzamide (229g) (158.4 mg, $0.50 \mathrm{mmol})$ and $n$-octene (223o) (168.0 $\mathrm{mg}, 1.5 \mathrm{mmol})$. Isolation by column chromatography $(n$-hexane/EtOAc $=20: 1)$ yielded 242 go $(110.3 \mathrm{mg}, 52 \%)$ as a yellow oil. 
${ }^{1} \mathrm{H}-\mathrm{NMR}\left(400 \mathrm{MHz}, \mathrm{CDCl}_{3}\right): \delta=9.98(\mathrm{~s}, 1 \mathrm{H}), 8.95(\mathrm{dd}, J=7.1,1.7 \mathrm{~Hz}, 1 \mathrm{H}), 8.71(\mathrm{dd}, J=4.2$, $1.7 \mathrm{~Hz}, 1 \mathrm{H}), 8.15(\mathrm{dd}, J=8.3,1.7 \mathrm{~Hz}, 1 \mathrm{H}), 7.64-7.56$ (m, 3H), 7.55-7.48 (m, 2H), 7.42 (dd, $J$ $=8.3,4.2 \mathrm{~Hz}, 1 \mathrm{H}), 5.59-5.49(\mathrm{~m}, 1 \mathrm{H}), 5.48-5.38(\mathrm{~m}, 1 \mathrm{H}), 3.49(\mathrm{~d}, J=6.8 \mathrm{~Hz}, 2 \mathrm{H}), 1.86-1.78$ $(\mathrm{m}, 2 \mathrm{H}), 1.20-1.07(\mathrm{~m}, 6 \mathrm{H}), 0.79(\mathrm{t}, J=6.2 \mathrm{~Hz}, 3 \mathrm{H})$.

${ }^{13} \mathrm{C}-\mathrm{NMR}\left(100 \mathrm{MHz}, \mathrm{CDCl}_{3}\right.$ ) (one resonance is missing due to overlap): $\delta=165.5\left(\mathrm{C}_{\mathrm{q}}\right), 148.3$ $(\mathrm{CH}), 139.9\left(\mathrm{C}_{\mathrm{q}}\right), 138.4\left(\mathrm{C}_{\mathrm{q}}\right), 136.3(\mathrm{CH}), 135.1\left(\mathrm{q},{ }^{3} J_{\mathrm{C}-\mathrm{F}}=1.9 \mathrm{~Hz}, \mathrm{C}_{\mathrm{q}}\right), 134.1\left(\mathrm{C}_{\mathrm{q}}\right), 133.4(\mathrm{CH})$, $129.3(\mathrm{CH}), 128.0\left(\mathrm{C}_{\mathrm{q}}\right), 127.4(\mathrm{CH}), 127.4\left(\mathrm{q},{ }^{2} J_{\mathrm{C}-\mathrm{F}}=30.1 \mathrm{~Hz}, \mathrm{C}_{\mathrm{q}}\right), 127.1(\mathrm{CH}), 124.0\left(\mathrm{q},{ }^{3} J_{\mathrm{C}-}\right.$ $\mathrm{F}=4.7 \mathrm{~Hz}, \mathrm{CH}), 123.8\left(\mathrm{q},{ }^{1} J_{\mathrm{C}-\mathrm{F}}=270.4, \mathrm{C}_{\mathrm{q}}\right), 122.2(\mathrm{CH}), 121.7(\mathrm{CH}), 116.9(\mathrm{CH}), 36.3\left(\mathrm{CH}_{2}\right)$, $32.3\left(\mathrm{CH}_{2}\right), 31.3\left(\mathrm{CH}_{2}\right), 28.7\left(\mathrm{CH}_{2}\right), 22.4\left(\mathrm{CH}_{2}\right), 14.0\left(\mathrm{CH}_{3}\right)$.

${ }^{19} \mathrm{~F}-\mathrm{NMR}\left(375 \mathrm{MHz}, \mathrm{CDCl}_{3}\right): \delta=-58.8$.

IR (ATR): 3328, 1720, 1670, 1532, 1422, 1350, 980, 720, $\mathrm{cm}^{-1}$. MS (ESI) $m / z$ (relative intensity): 449 (70) $[\mathrm{M}+\mathrm{Na}]^{+}, 427(100)[\mathrm{M}+\mathrm{H}]^{+}$.

HR-MS (ESI): $m / z$ calcd. for $\left[\mathrm{C}_{25} \mathrm{H}_{25} \mathrm{~N}_{2} \mathrm{OF}_{3}+\mathrm{Na}\right]^{+} 449.1811$ found 449.1804 .

The analytical data correspond with those reported in the literature. ${ }^{[192]}$<smiles>CCCCC/C=C/Cc1cccc(-c2ccccc2)c1C(=O)Nc1cccc2cccnc12</smiles>

(E)-3-(Oct-2-en-1-yl)- $N$-(quinolin-8-yl)-[1,1'-biphenyl]-2-carboxamide $\quad$ (242co): $\quad$ The general procedure $\mathbf{K}$ was followed using $N$-(quinolin-8-yl)-[1,1'-biphenyl]-2-carboxamide (229c) (162.0 mg, $0.50 \mathrm{mmol})$ and $n$-octene (223o) (168.0 mg, $1.5 \mathrm{mmol})$. Isolation by column chromatography ( $n$-hexane/EtOAc $=10: 1)$ yielded 242co $(119.1 \mathrm{mg}, 55 \%)$ as a yellow oil . ${ }^{1} \mathrm{H}-\mathrm{NMR}\left(400 \mathrm{MHz}, \mathrm{CDCl}_{3}\right): \delta=9.66(\mathrm{~s}, 1 \mathrm{H}), 8.80$ (dd, $\left.J=7.4,1.8 \mathrm{~Hz}, 1 \mathrm{H}\right), 8.63$ (dd, $J=4.2$, $1.8 \mathrm{~Hz}, 1 \mathrm{H}), 8.09$ (dd, $J=8.3,1.8 \mathrm{~Hz}, 1 \mathrm{H}), 7.59-7.45(\mathrm{~m}, 5 \mathrm{H}), 7.40-7.34(\mathrm{~m}, 3 \mathrm{H}), 7.24$ (d, $J$ $=7.7 \mathrm{~Hz}, 2 \mathrm{H}), 7.18-7.07(\mathrm{~m}, 1 \mathrm{H}), 5.73-5.58(\mathrm{~m}, 1 \mathrm{H}), 5.56-5.40(\mathrm{~m}, 1 \mathrm{H}), 3.61(\mathrm{~d}, J=6.7 \mathrm{~Hz}$, 2H), 1.95-1.75 (m, 2H), 1.27-1.05 (m, 6H), 0.80 (t, $J=6.6 \mathrm{~Hz}, 3 \mathrm{H})$.

${ }^{13} \mathrm{C}-\mathrm{NMR}\left(100 \mathrm{MHz}, \mathrm{CDCl}_{3}\right): \delta=168.1\left(\mathrm{C}_{\mathrm{q}}\right), 147.9(\mathrm{CH}), 140.4\left(\mathrm{C}_{\mathrm{q}}\right), 139.8\left(\mathrm{C}_{\mathrm{q}}\right), 139.0\left(\mathrm{C}_{\mathrm{q}}\right)$, $138.4\left(\mathrm{C}_{\mathrm{q}}\right), 136.6\left(\mathrm{C}_{\mathrm{q}}\right), 136.0(\mathrm{CH}), 134.4\left(\mathrm{C}_{\mathrm{q}}\right), 132.6(\mathrm{CH}), 129.3(\mathrm{CH}), 128.8(\mathrm{CH}), 128.7$ $(\mathrm{CH}), 128.2(\mathrm{CH}), 128.0(\mathrm{CH}), 128.0(\mathrm{CH}), 127.8\left(\mathrm{C}_{\mathrm{q}}\right), 127.3(\mathrm{CH}), 127.3(\mathrm{CH}), 121.6(\mathrm{CH})$, $121.4(\mathrm{CH}), 116.5(\mathrm{CH}), 36.8\left(\mathrm{CH}_{2}\right), 32.4\left(\mathrm{CH}_{2}\right), 31.4\left(\mathrm{CH}_{2}\right), 28.9\left(\mathrm{CH}_{2}\right), 22.4\left(\mathrm{CH}_{2}\right), 14.0$ $\left(\mathrm{CH}_{3}\right)$.

IR (ATR): 2955, 1678, 1522, 1502, 1472, 1290, 932, $\mathrm{cm}^{-1}$.

MS (ESI) $m / z$ (relative intensity): $457(30)[\mathrm{M}+\mathrm{Na}]^{+}, 435(100)[\mathrm{M}+\mathrm{H}]^{+}$. 
HR-MS (ESI): $m / z$ calcd. for $\left[\mathrm{C}_{30} \mathrm{H}_{30} \mathrm{~N}_{2} \mathrm{O}+\mathrm{Na}\right]^{+} 457.2256$ found 457.2252.

The analytical data correspond with those reported in the literature. ${ }^{[192]}$<smiles>CCCCC/C=C/Cc1ccc(C)c(C)c1C(=O)Nc1cccc2cccnc12</smiles>

(E)-2,3-Dimethyl-6-(oct-2-en-1-yl)- $N$-(quinolin-8-yl)benzamide (242ho): The general procedure K was followed using 2,3-dimethyl- $N$-(quinolin-8-yl)benzamide (229h) (138.1 mg, $0.50 \mathrm{mmol})$ and $n$-octene $(\mathbf{2 2 3 0})(168.0 \mathrm{mg}, 1.5 \mathrm{mmol})$. Isolation by column chromatography ( $n$-hexane/EtOAc $=30: 1)$ yielded $242 \mathrm{ho}(114.0 \mathrm{mg}, 59 \%)$ as a yellow oil.

${ }^{1} \mathrm{H}-\mathrm{NMR}\left(300 \mathrm{MHz}, \mathrm{CDCl}_{3}\right): \delta=9.90(\mathrm{~s}, 1 \mathrm{H}), 9.00(\mathrm{dd}, J=7.3,1.7 \mathrm{~Hz}, 1 \mathrm{H}), 8.70(\mathrm{dd}, J=4.2$, $1.7 \mathrm{~Hz}, 1 \mathrm{H}), 8.15(\mathrm{dd}, J=8.3,1.7 \mathrm{~Hz}, 1 \mathrm{H}), 7.60(\mathrm{dd}, J=8.3,7.2 \mathrm{~Hz}, 1 \mathrm{H}), 7.54(\mathrm{dd}, J=8.3$, $1.7 \mathrm{~Hz}, 1 \mathrm{H}), 7.42(\mathrm{dd}, J=8.3,4.2 \mathrm{~Hz}, 1 \mathrm{H}), 7.16(\mathrm{~d}, J=7.8 \mathrm{~Hz}, 1 \mathrm{H}), 7.04(\mathrm{~d}, J=7.8 \mathrm{~Hz}, 1 \mathrm{H})$, $5.53(\mathrm{dtt}, J=15.2,6.2,1.2 \mathrm{~Hz}, 1 \mathrm{H}), 5.38$ (dtt, $J=15.2,6.2,1.2 \mathrm{~Hz}, 1 \mathrm{H}), 3.40(\mathrm{~d}, J=6.2 \mathrm{~Hz}$, 2H), $2.31(\mathrm{~s}, 3 \mathrm{H}), 2.29(\mathrm{~s}, 3 \mathrm{H}), 1.85-1.72(\mathrm{~m}, 2 \mathrm{H}), 1.20-1.06(\mathrm{~m}, 6 \mathrm{H}), 0.78(\mathrm{t}, J=6.8 \mathrm{~Hz}, 3 \mathrm{H})$. ${ }^{13} \mathrm{C}-\mathrm{NMR}\left(125 \mathrm{MHz}, \mathrm{CDCl}_{3}\right): \delta=169.1\left(\mathrm{C}_{\mathrm{q}}\right), 148.0(\mathrm{CH}), 138.4\left(\mathrm{C}_{\mathrm{q}}\right), 137.9\left(\mathrm{C}_{\mathrm{q}}\right), 136.2(\mathrm{CH})$, $135.1\left(\mathrm{C}_{\mathrm{q}}\right), 134.8\left(\mathrm{C}_{\mathrm{q}}\right), 134.4\left(\mathrm{C}_{\mathrm{q}}\right), 132.8\left(\mathrm{C}_{\mathrm{q}}\right), 132.1(\mathrm{CH}), 130.4(\mathrm{CH}), 128.2(\mathrm{CH}), 128.0\left(\mathrm{C}_{\mathrm{q}}\right)$, $127.3(\mathrm{CH}), 126.7(\mathrm{CH}), 121.7(\mathrm{CH}), 121.5(\mathrm{CH}), 116.7(\mathrm{CH}), 36.6\left(\mathrm{CH}_{2}\right), 32.4\left(\mathrm{CH}_{2}\right), 31.4$ $\left(\mathrm{CH}_{2}\right), 28.9\left(\mathrm{CH}_{2}\right), 22.5\left(\mathrm{CH}_{2}\right), 20.0\left(\mathrm{CH}_{3}\right), 16.7\left(\mathrm{CH}_{3}\right), 14.1\left(\mathrm{CH}_{3}\right)$.

IR (ATR): 2045, 1710, 1668, 1552, 1473, 1224, 1175, 865, $\mathrm{cm}^{-1}$. MS (ESI) $m / z$ (relative intensity): 409 (90) $[\mathrm{M}+\mathrm{Na}]^{+}, 387(100)[\mathrm{M}+\mathrm{H}]^{+}$. HR-MS (ESI): $m / z$ calcd. for $\left[\mathrm{C}_{26} \mathrm{H}_{30} \mathrm{~N}_{2} \mathrm{O}+\mathrm{Na}\right]^{+} 409.2250$ found 409.2251.

The analytical data correspond with those reported in the literature. ${ }^{[192]}$<smiles>CCCCCCC/C=C/Cc1cccc(C)c1C(=O)Nc1cccc2cccnc12</smiles>

(E)-2-(Dec-2-en-1-yl)-6-methyl- $N$-(quinolin-8-yl)benzamide (242fq): The general procedure $\mathbf{K}$ was followed using 2-methyl- $N$-(quinolin-8-yl)benzamide (229f) (131.1 mg, $0.50 \mathrm{mmol})$ and $n$-decene (223q) $(210.1 \mathrm{mg}, 1.5 \mathrm{mmol})$. Isolation by column chromatography $(n$-hexane/EtOAc $=10: 1)$ yielded $\mathbf{2 4 2 f q}(124.0 \mathrm{mg}, 62 \%)$ as a yellow oil. 
${ }^{1} \mathrm{H}-\mathrm{NMR}\left(600 \mathrm{MHz}, \mathrm{CDCl}_{3}\right): \delta=9.92(\mathrm{~s}, 1 \mathrm{H}), 8.99(\mathrm{dd}, J=7.5,1.3 \mathrm{~Hz}, 1 \mathrm{H}), 8.71(\mathrm{dd}, J=4.2$, $1.7 \mathrm{~Hz}, 1 \mathrm{H}), 8.15(\mathrm{dd}, J=8.3,1.7 \mathrm{~Hz}, 1 \mathrm{H}), 7.61-7.58(\mathrm{~m}, 1 \mathrm{H}), 7.54(\mathrm{dd}, J=8.3,1.4 \mathrm{~Hz}, 1 \mathrm{H})$, 7.42 (dd, $J=8.3,4.2 \mathrm{~Hz}, 1 \mathrm{H}), 7.27$ (dd, $J=7.7,1.4 \mathrm{~Hz}, 1 \mathrm{H}), 7.17-7.10$ (m, 2H), 5.56 (dtt, $J=$ 16.5, 6.7, $1.3 \mathrm{~Hz}, 1 \mathrm{H}), 5.41(\mathrm{dtt}, J=16.5,6.7,1.3 \mathrm{~Hz}, 1 \mathrm{H}), 3.45$ (d, $J=6.7 \mathrm{~Hz}, 2 \mathrm{H}), 2.43$ (s, $3 \mathrm{H}), 1.87-1.77(\mathrm{~m}, 2 \mathrm{H}), 1.25-1.20(\mathrm{~m}, 2 \mathrm{H}), 1.17-1.07(\mathrm{~m}, 8 \mathrm{H}), 0.84(\mathrm{t}, J=7.3 \mathrm{~Hz}, 3 \mathrm{H})$.

${ }^{13} \mathrm{C}-\mathrm{NMR}\left(125 \mathrm{MHz}, \mathrm{CDCl}_{3}\right): \delta=168.5\left(\mathrm{C}_{\mathrm{q}}\right), 148.1(\mathrm{CH}), 138.4\left(\mathrm{C}_{\mathrm{q}}\right), 137.6\left(\mathrm{C}_{\mathrm{q}}\right), 137.6\left(\mathrm{C}_{\mathrm{q}}\right)$, $136.2(\mathrm{CH}), 134.5\left(\mathrm{C}_{\mathrm{q}}\right), 134.3\left(\mathrm{C}_{\mathrm{q}}\right), 132.3(\mathrm{CH}), 129.0(\mathrm{CH}), 128.0(\mathrm{CH}), 127.9(\mathrm{CH}), 127.9$ $\left(\mathrm{C}_{\mathrm{q}}\right), 127.3(\mathrm{CH}), 126.9(\mathrm{CH}), 121.8(\mathrm{CH}), 121.5(\mathrm{CH}), 116.7(\mathrm{CH}), 36.7\left(\mathrm{CH}_{2}\right), 32.4\left(\mathrm{CH}_{2}\right)$, $31.8\left(\mathrm{CH}_{2}\right), 29.2\left(\mathrm{CH}_{2}\right), 29.1\left(\mathrm{CH}_{2}\right), 29.1\left(\mathrm{CH}_{2}\right), 22.7\left(\mathrm{CH}_{2}\right), 19.5\left(\mathrm{CH}_{3}\right), 14.1\left(\mathrm{CH}_{3}\right)$.

IR (ATR): 2977, 1688, 1533, 1405, 1299, 973, 850, $719 \mathrm{~cm}^{-1}$.

MS (ESI) $m / z$ (relative intensity): $423(40)[\mathrm{M}+\mathrm{Na}]^{+}, 401(100)[\mathrm{M}+\mathrm{H}]^{+}$.

HR-MS (ESI): $\mathrm{m} / z$ calcd. for $\left[\mathrm{C}_{27} \mathrm{H}_{32} \mathrm{~N}_{2} \mathrm{O}+\mathrm{H}\right]^{+} 401.2587$ found 401.2589 .

The analytical data correspond with those reported in the literature. ${ }^{[193]}$<smiles>CCCCCC/C=C/Cc1cccc(C)c1C(=O)Nc1cccc2cccnc12</smiles>

(E)-2-Methyl-6-(non-2-en-1-yl)- $N$-(quinolin-8-yl)benzamide (242fr): The general procedure $\mathbf{K}$ was followed using 2-methyl- $N$-(quinolin-8-yl)benzamide (229f) (131.1 mg, 0.50 $\mathrm{mmol}$ ) and $n$-nonene (223r) (189.0 $\mathrm{mg}, 1.5 \mathrm{mmol})$. Isolation by column chromatography ( $n$ hexane/EtOAc $=10: 1)$ yielded $242 f r(124.1 \mathrm{mg}, 64 \%)$ as a yellow oil.

${ }^{1} \mathrm{H}-\mathrm{NMR}\left(600 \mathrm{MHz}, \mathrm{CDCl}_{3}\right): \delta=9.93(\mathrm{~s}, 1 \mathrm{H}), 9.01(\mathrm{dd}, J=7.6,1.4 \mathrm{~Hz}, 1 \mathrm{H}), 8.72(\mathrm{dd}, J=4.2$, $1.7 \mathrm{~Hz}, 1 \mathrm{H}), 8.15(\mathrm{dd}, J=8.3,1.7 \mathrm{~Hz}, 1 \mathrm{H}), 7.60(\mathrm{dd}, J=7.9 \mathrm{~Hz}, 1.7 \mathrm{~Hz}, 1 \mathrm{H}), 7.55$ (dd, $J=8.3$, $1.4 \mathrm{~Hz}, 1 \mathrm{H}), 7.42(\mathrm{dd}, J=8.3,4.2 \mathrm{~Hz}, 1 \mathrm{H}), 7.28(\mathrm{dd}, J=7.7,1.4 \mathrm{~Hz}, 1 \mathrm{H}), 7.15(\mathrm{dd}, J=7.8$, $1.2 \mathrm{~Hz}, 1 \mathrm{H}), 7.13(\mathrm{~d}, J=7.7 \mathrm{~Hz}, 1 \mathrm{H}), 5.57$ (dtt, $J=14.9,6.7,1.5 \mathrm{~Hz}, 1 \mathrm{H}), 5.41$ (dtt, $J=14.9$, $6.6,1.5 \mathrm{~Hz}, 1 \mathrm{H}), 3.46(\mathrm{dd}, J=6.8,1.5 \mathrm{~Hz}, 2 \mathrm{H}), 2.44$ (s, 3H), 1.88-1.79 (m, 2H), 1.22-1.07 (m, $8 \mathrm{H}), 0.82(\mathrm{t}, J=7.3 \mathrm{~Hz}, 3 \mathrm{H})$.

${ }^{13} \mathrm{C}-\mathrm{NMR}\left(125 \mathrm{MHz}, \mathrm{CDCl}_{3}\right): \delta=168.5\left(\mathrm{C}_{\mathrm{q}}\right), 148.0(\mathrm{CH}), 138.4\left(\mathrm{C}_{\mathrm{q}}\right), 137.6\left(\mathrm{C}_{\mathrm{q}}\right), 137.6\left(\mathrm{C}_{\mathrm{q}}\right)$, $136.1(\mathrm{CH}), 134.5\left(\mathrm{C}_{\mathrm{q}}\right), 134.3\left(\mathrm{C}_{\mathrm{q}}\right), 132.3(\mathrm{CH}), 128.9(\mathrm{CH}), 128.0(\mathrm{CH}), 127.9(\mathrm{CH}), 127.9$ $\left(\mathrm{C}_{\mathrm{q}}\right), 127.3(\mathrm{CH}), 126.9(\mathrm{CH}), 121.8(\mathrm{CH}), 121.5(\mathrm{CH}), 116.7(\mathrm{CH}), 36.7\left(\mathrm{CH}_{2}\right), 32.4\left(\mathrm{CH}_{2}\right)$, $31.6\left(\mathrm{CH}_{2}\right), 29.1\left(\mathrm{CH}_{2}\right), 28.8\left(\mathrm{CH}_{2}\right), 22.6\left(\mathrm{CH}_{2}\right), 19.5\left(\mathrm{CH}_{3}\right), 14.1\left(\mathrm{CH}_{3}\right)$.

IR (ATR): 2912, 1666, 1545, 1492, 1287, 890, 811, $765 \mathrm{~cm}^{-1}$.

MS (ESI) $m / z$ (relative intensity): $409(20)[\mathrm{M}+\mathrm{Na}]^{+}, 387(100)[\mathrm{M}+\mathrm{H}]^{+}$. 
HR-MS (ESI): $m / z$ calcd. for $\left[\mathrm{C}_{26} \mathrm{H}_{30} \mathrm{~N}_{2} \mathrm{O}+\mathrm{Na}\right]^{+} 409.2250$ found 409.2248 .

The analytical data correspond with those reported in the literature. ${ }^{[193]}$<smiles>COc1cccc(C/C=C/c2ccccc2)c1C(=O)Nc1cccc2cccnc12</smiles>

(E)-2-Cinnamyl-6-methyl- $N$-(quinolin-8-yl)benzamide (242fa): The general procedure K was followed using 2-methyl- $N$-(quinolin-8-yl)benzamide (229f) $(131.1 \mathrm{mg}, 0.50 \mathrm{mmol}$ ) and allylbenzene (223a) $(177.0 \mathrm{mg}, 1.5 \mathrm{mmol})$. Isolation by column chromatography ( $n$ hexane/EtOAc $=10: 1)$ yielded $\mathbf{2 4 2 f a}(100.1 \mathrm{mg}, 53 \%)$ as a yellow oil.

${ }^{1} \mathrm{H}-\mathrm{NMR}\left(600 \mathrm{MHz}, \mathrm{CDCl}_{3}\right): \delta=9.98(\mathrm{~s}, 1 \mathrm{H}), 9.02(\mathrm{dd}, J=7.9,1.3 \mathrm{~Hz}, 1 \mathrm{H}), 8.48(\mathrm{dd}, J=4.3$, $1.7 \mathrm{~Hz}, 1 \mathrm{H}), 8.10(\mathrm{dd}, J=8.3,1.7 \mathrm{~Hz}, 1 \mathrm{H}), 7.60(\mathrm{dd}, J=7.9,1.3 \mathrm{~Hz}, 1 \mathrm{H}), 7.53(\mathrm{dd}, J=8.3$, $1.3 \mathrm{~Hz}, 1 \mathrm{H}), 7.34-7.29(\mathrm{~m}, 2 \mathrm{H}), 7.22-7.20(\mathrm{~m}, 1 \mathrm{H}), 7.17$ (d, J = 7.6 Hz, 1H), 7.14-7.10 (m, 2H), 7.10-7.07 (m, 3H), 6.41-6.27 (m, 2H), 3.66 (d, J=6.5 Hz, 2H), 2.47 (s, 3H).

${ }^{13} \mathrm{C}-\mathrm{NMR}\left(125 \mathrm{MHz}, \mathrm{CDCl}_{3}\right): \delta=168.4\left(\mathrm{C}_{\mathrm{q}}\right), 148.0(\mathrm{CH}), 138.2\left(\mathrm{C}_{\mathrm{q}}\right), 137.8\left(\mathrm{C}_{\mathrm{q}}\right), 137.1\left(\mathrm{C}_{\mathrm{q}}\right)$, $136.6\left(\mathrm{C}_{\mathrm{q}}\right), 136.0(\mathrm{CH}), 134.8\left(\mathrm{C}_{\mathrm{q}}\right), 134.2\left(\mathrm{C}_{\mathrm{q}}\right), 131.2(\mathrm{CH}), 129.1(\mathrm{CH}), 128.5(\mathrm{CH}), 128.3$ $(\mathrm{CH}), 128.0(\mathrm{CH}), 127.8\left(\mathrm{C}_{\mathrm{q}}\right), 127.2(\mathrm{CH}), 127.2(\mathrm{CH}), 126.7(\mathrm{CH}), 125.9(\mathrm{CH}), 121.9(\mathrm{CH})$, $121.5(\mathrm{CH}), 116.6(\mathrm{CH}), 37.1\left(\mathrm{CH}_{2}\right), 19.5\left(\mathrm{CH}_{3}\right)$.

IR (ATR): 2952, 1671, 1570, 1477, 1223, 899, 801, $734 \mathrm{~cm}^{-1}$.

MS (ESI) $m / z$ (relative intensity): $401(30)[\mathrm{M}+\mathrm{Na}]^{+}, 379(100)[\mathrm{M}+\mathrm{H}]^{+}$.

HR-MS (ESI): $m / z$ calcd. for $\left[\mathrm{C}_{26} \mathrm{H}_{22} \mathrm{~N}_{2} \mathrm{O}+\mathrm{H}\right]^{+} 379.1805$ found 379.1804 .

The analytical data correspond with those reported in the literature. ${ }^{[192]}$<smiles>C=CCCC/C=C/Cc1cccc(C)c1C(=O)Nc1cccc2cccnc12</smiles>

(E)-2-Methyl-6-(octa-2,7-dien-1-yl)- $N$-(quinolin-8-yl)benzamide (242fs): A modified procedure $\mathbf{K}$ was followed using 2-methyl- $N$-(quinolin-8-yl)benzamide (229f) (131.1 mg, $0.50 \mathrm{mmol})$ and 1,7 -octadiene (223s) $(167.0 \mathrm{mg}, 1.5 \mathrm{mmol})$ with $\mathrm{Co}(\mathrm{OAc})_{2} \cdot 4 \mathrm{H}_{2} \mathrm{O}(25.4 \mathrm{mg}$, 
$0.1 \mathrm{mmol}, 20 \mathrm{~mol} \%)$. Isolation by column chromatography ( $n$-hexane/EtOAc $=10: 1)$ yielded 242fs $(98.0 \mathrm{mg}, 53 \%)$ as a yellow oil.

${ }^{1} \mathrm{H}-\mathrm{NMR}\left(600 \mathrm{MHz}, \mathrm{CDCl}_{3}\right): \delta=9.92(\mathrm{~s}, 1 \mathrm{H}), 8.99$ (dd, $\left.J=7.6,1.4 \mathrm{~Hz}, 1 \mathrm{H}\right), 8.71(\mathrm{dd}, J=4.2$, $1.7 \mathrm{~Hz}, 1 \mathrm{H}), 8.15(\mathrm{dd}, J=8.3,1.7 \mathrm{~Hz}, 1 \mathrm{H}), 7.62-7.58(\mathrm{~m}, 1 \mathrm{H}), 7.55(\mathrm{dd}, J=8.3,1.4 \mathrm{~Hz}, 1 \mathrm{H})$, $7.42(\mathrm{dd}, J=8.3,4.2 \mathrm{~Hz}, 1 \mathrm{H}), 7.28(\mathrm{t}, J=7.6 \mathrm{~Hz}, 1 \mathrm{H}), 7.15-7.11(\mathrm{~m}, 2 \mathrm{H}), 5.65(\mathrm{dtt}, J=16.9$, $10.2,6.7 \mathrm{~Hz}, 1 \mathrm{H}), 5.58(\mathrm{dtt}, J=15.0,6.7,1.4 \mathrm{~Hz}, 1 \mathrm{H}), 5.40(\mathrm{dtt}, J=15.0,6.7,1.4 \mathrm{~Hz}, 1 \mathrm{H})$, 5.03-4.74 (m, 2H), $3.45(\mathrm{dd}, J=6.7,1.4 \mathrm{~Hz}, 2 \mathrm{H}), 2.43$ (s, 3H), 1.95-1.77 (m, 4H), 1.30-1.24 $(\mathrm{m}, 2 \mathrm{H})$.

${ }^{13} \mathrm{C}-\mathrm{NMR}\left(125 \mathrm{MHz}, \mathrm{CDCl}_{3}\right): \delta=168.5\left(\mathrm{C}_{\mathrm{q}}\right), 148.1(\mathrm{CH}), 138.6(\mathrm{CH}), 138.4\left(\mathrm{C}_{\mathrm{q}}\right), 137.6\left(\mathrm{C}_{\mathrm{q}}\right)$, $137.5\left(\mathrm{C}_{\mathrm{q}}\right), 136.2(\mathrm{CH}), 134.6\left(\mathrm{C}_{\mathrm{q}}\right), 134.3\left(\mathrm{C}_{\mathrm{q}}\right), 131.8(\mathrm{CH}), 129.0(\mathrm{CH}), 128.4(\mathrm{CH}), 128.0$ $(\mathrm{CH}), 127.9\left(\mathrm{C}_{\mathrm{q}}\right), 127.3(\mathrm{CH}), 126.9(\mathrm{CH}), 121.8(\mathrm{CH}), 121.5(\mathrm{CH}), 116.7(\mathrm{CH}), 114.2\left(\mathrm{CH}_{2}\right)$, $36.7\left(\mathrm{CH}_{2}\right), 33.2\left(\mathrm{CH}_{2}\right), 31.8\left(\mathrm{CH}_{2}\right), 28.4\left(\mathrm{CH}_{2}\right), 19.5\left(\mathrm{CH}_{3}\right)$.

IR (ATR): 2910, 1651, 1561, 1432, 1297, 907, 809, $720 \mathrm{~cm}^{-1}$.

MS (ESI) $m / z$ (relative intensity): $393(25)[\mathrm{M}+\mathrm{Na}]^{+}, 371(100)[\mathrm{M}+\mathrm{H}]^{+}$.

HR-MS (ESI): $m / z$ calcd. for $\left[\mathrm{C}_{25} \mathrm{H}_{26} \mathrm{~N}_{2} \mathrm{O}+\mathrm{Na}\right]^{+} 393.1937$ found 393.1931 .

The analytical data correspond with those reported in the literature. ${ }^{[193]}$<smiles>COc1ccc(/C=C/Cc2cccc(OC(C)=O)c2C(=O)Nc2cccc3cccnc23)cc1OC</smiles>

(E)-2-Methoxy-4-\{3-[3-methyl-2-(quinolin-8-ylcarbamoyl)phenyl]prop-1-en-1-yl $\}$ phenyl acetate (242fj): A modified general procedure $\mathbf{K}$ was used with 2-methyl- $N$-(quinolin-8yl)benzamide (229f) (131.1 mg, $0.50 \mathrm{mmol}$ ) and eugenol acetate (223j) (309.1 mg, $1.5 \mathrm{mmol})$. After electrolysis, the mixture was transferred to a flask and the electrodes were rinsed with acetone $(3 \times 5.0 \mathrm{~mL})$. Then the combined solvent was removed under reduced pressure and subsequent column chromatography on silica gel $(n$-hexane/EtOAc $=5: 1)$ yielded $242 f \mathbf{j}(132.1$ $\mathrm{mg}, 57 \%)$ as a yellow oil.

${ }^{1} \mathrm{H}-\mathrm{NMR}\left(400 \mathrm{MHz}, \mathrm{CDCl}_{3}\right): \delta=9.93(\mathrm{~s}, 1 \mathrm{H}), 8.97$ (dd, $\left.J=7.5,1.5 \mathrm{~Hz}, 1 \mathrm{H}\right), 8.39$ (dd, $J=4.2$, $1.7 \mathrm{~Hz}, 1 \mathrm{H}), 8.08(\mathrm{dd}, J=8.3,1.7 \mathrm{~Hz}, 1 \mathrm{H}), 7.58(\mathrm{dd}, J=8.3,7.5 \mathrm{~Hz}, 1 \mathrm{H}), 7.52(\mathrm{dd}, J=8.3$, $1.5 \mathrm{~Hz}, 1 \mathrm{H}), 7.37-7.32(\mathrm{~m}, 1 \mathrm{H}), 7.32-7.28(\mathrm{~m}, 1 \mathrm{H}), 7.20-7.14(\mathrm{~m}, 2 \mathrm{H}), 6.74(\mathrm{~d}, J=8.0 \mathrm{~Hz}$, $1 \mathrm{H}), 6.63-6.55(\mathrm{~m}, 2 \mathrm{H}), 6.34-6.15(\mathrm{~m}, 2 \mathrm{H}), 3.65(\mathrm{~s}, 3 \mathrm{H}), 3.62(\mathrm{~d}, J=5.6 \mathrm{~Hz}, 2 \mathrm{H}), 2.44(\mathrm{~s}, 3 \mathrm{H})$, $2.27(\mathrm{~s}, 3 \mathrm{H})$. 
${ }^{13} \mathrm{C}-\mathrm{NMR}\left(100 \mathrm{MHz}, \mathrm{CDCl}_{3}\right): \delta=169.0\left(\mathrm{C}_{\mathrm{q}}\right), 168.5\left(\mathrm{C}_{\mathrm{q}}\right), 150.7\left(\mathrm{C}_{\mathrm{q}}\right), 148.3(\mathrm{CH}), 138.6\left(\mathrm{C}_{\mathrm{q}}\right)$, $138.3\left(\mathrm{C}_{\mathrm{q}}\right), 138.0\left(\mathrm{C}_{\mathrm{q}}\right), 136.5\left(\mathrm{C}_{\mathrm{q}}\right), 136.3\left(\mathrm{C}_{\mathrm{q}}\right), 136.0(\mathrm{CH}), 135.0\left(\mathrm{C}_{\mathrm{q}}\right), 134.3\left(\mathrm{C}_{\mathrm{q}}\right), 130.6(\mathrm{CH})$, $129.2(\mathrm{CH}), 128.9(\mathrm{CH}), 128.5(\mathrm{CH}), 127.9\left(\mathrm{C}_{\mathrm{q}}\right), 127.4(\mathrm{CH}), 127.2(\mathrm{CH}), 122.3(\mathrm{CH}), 122.0$ $(\mathrm{CH}), 121.7(\mathrm{CH}), 118.5(\mathrm{CH}), 116.7(\mathrm{CH}), 109.6(\mathrm{CH}), 55.6\left(\mathrm{CH}_{3}\right), 37.1\left(\mathrm{CH}_{2}\right), 20.7\left(\mathrm{CH}_{3}\right)$, $19.5\left(\mathrm{CH}_{3}\right)$.

IR (ATR): 2940, 1682, 1577, 1321, 1277, 960, 808, $659 \mathrm{~cm}^{-1}$.

MS (ESI) $m / z$ (relative intensity): $489(100)[\mathrm{M}+\mathrm{Na}]^{+}, 467(90)[\mathrm{M}+\mathrm{H}]^{+}$.

HR-MS (ESI): $m / z$ calcd. for $\left[\mathrm{C}_{29} \mathrm{H}_{26} \mathrm{~N}_{2} \mathrm{O}_{4}+\mathrm{Na}\right]^{+} 489.1785$ found 489.1777 .<smiles>CC(=O)OCCC/C=C/Cc1cccc(C)c1C(=O)Nc1cccc2cccnc12</smiles>

(E)-6-[3-Methyl-2-(quinolin-8-ylcarbamoyl)phenyl]hex-4-en-1-yl acetate (242ft): A modified general procedure $\mathbf{K}$ was used with 2-methyl- $N$-(quinolin-8-yl)benzamide (229f) (131.1 mg, $0.50 \mathrm{mmol})$ and hex-5-en-1-yl acetate (223t) (177.0 mg, $1.5 \mathrm{mmol})$. After electrolysis, the mixture was transferred to a flask and the electrodes were rinsed with acetone $(3 \times 5.0 \mathrm{~mL})$. Then the combined solvent was removed under reduced pressure and subsequent column chromatography on silica gel $(n$-hexane/EtOAc $=3: 1)$ yielded $\mathbf{2 4 2 f t}(104.0 \mathrm{mg}, 52 \%)$ as a yellow oil.

${ }^{1} \mathrm{H}-\mathrm{NMR}\left(600 \mathrm{MHz}, \mathrm{CDCl}_{3}\right): \delta=9.90(\mathrm{~s}, 1 \mathrm{H}), 8.97$ (dd, $\left.J=7.5,1.4 \mathrm{~Hz}, 1 \mathrm{H}\right), 8.71(\mathrm{dd}, J=4.2$, $1.7 \mathrm{~Hz}, 1 \mathrm{H}), 8.15(\mathrm{dd}, J=8.3,1.7 \mathrm{~Hz}, 1 \mathrm{H}), 7.60-7.57(\mathrm{~m}, 1 \mathrm{H}), 7.54(\mathrm{dd}, J=8.3,1.4 \mathrm{~Hz}, 1 \mathrm{H})$, $7.42(\mathrm{dd}, J=8.3,4.2 \mathrm{~Hz}, 1 \mathrm{H}), 7.27(\mathrm{t}, J=7.5 \mathrm{~Hz}, 1 \mathrm{H}), 7.13-7.10(\mathrm{~m}, 2 \mathrm{H}), 5.60$ (dtt, $J=15.0$, 6.7, $1.5 \mathrm{~Hz}, 1 \mathrm{H}), 5.37(\mathrm{dtt}, J=15.0,6.7,1.5 \mathrm{~Hz}, 1 \mathrm{H}), 3.89$ (t, $J=6.7 \mathrm{~Hz}, 2 \mathrm{H}), 3.47-3.41(\mathrm{~m}$, 2H), 2.42 (s, 3H), 1.96 (s, 3H), 1.92-1.87 (m, 2H), 1.53-1.47 (m, 2H).

${ }^{13} \mathrm{C}-\mathrm{NMR}\left(125 \mathrm{MHz}, \mathrm{CDCl}_{3}\right): \delta=170.8\left(\mathrm{C}_{\mathrm{q}}\right), 168.4\left(\mathrm{C}_{\mathrm{q}}\right), 148.1(\mathrm{CH}), 138.4\left(\mathrm{C}_{\mathrm{q}}\right), 137.6\left(\mathrm{C}_{\mathrm{q}}\right)$, $137.2\left(\mathrm{C}_{\mathrm{q}}\right), 136.2(\mathrm{CH}), 134.6\left(\mathrm{C}_{\mathrm{q}}\right), 134.2\left(\mathrm{C}_{\mathrm{q}}\right), 130.5(\mathrm{CH}), 129.2(\mathrm{CH}), 129.0(\mathrm{CH}), 128.0$ $(\mathrm{CH}), 127.9\left(\mathrm{C}_{\mathrm{q}}\right), 127.3(\mathrm{CH}), 126.9(\mathrm{CH}), 121.8(\mathrm{CH}), 121.5(\mathrm{CH}), 116.7(\mathrm{CH}), 63.9\left(\mathrm{CH}_{2}\right)$, $36.6\left(\mathrm{CH}_{2}\right), 28.7\left(\mathrm{CH}_{2}\right), 28.1\left(\mathrm{CH}_{2}\right), 21.0\left(\mathrm{CH}_{3}\right), 19.5\left(\mathrm{CH}_{3}\right)$.

IR (ATR): 3011, 1650, 1555, 1423, 1276, 903, 801, $689 \mathrm{~cm}^{-1}$. MS (ESI) $m / z$ (relative intensity): $425(70)[\mathrm{M}+\mathrm{Na}]^{+}, 403(90)[\mathrm{M}+\mathrm{H}]^{+}$. HR-MS (ESI): $m / z$ calcd. for $\left[\mathrm{C}_{25} \mathrm{H}_{26} \mathrm{~N}_{2} \mathrm{O}_{3}+\mathrm{Na}\right]^{+} 425.1836$ found 425.1829 .

The analytical data correspond with those reported in the literature. ${ }^{[192]}$ 
<smiles>COc1cccc(C/C=C/CCCCl)c1C(=O)Nc1cccc2cccnc12</smiles>

(E)-2-(6-Chlorohex-2-en-1-yl)-6-methyl-N-(quinolin-8-yl)benzamide (242fu): A modified general procedure $\mathbf{K}$ was used with 2-methyl- $N$-(quinolin-8-yl)benzamide (229f) (131.1 mg, $0.50 \mathrm{mmol})$ and 6-chlorohexene (223u) $(177.0 \mathrm{mg}, 1.5 \mathrm{mmol})$ with $\mathrm{Co}(\mathrm{OAc})_{2} \cdot 4 \mathrm{H}_{2} \mathrm{O}(25.4 \mathrm{mg}$, $0.1 \mathrm{mmol}, 20 \mathrm{~mol} \%)$. After electrolysis, the mixture was transferred to a flask and the electrodes were rinsed with acetone $(3 \times 5.0 \mathrm{~mL})$. Then the combined solvent was removed under reduced pressure and subsequent column chromatography on silica gel ( $n$-hexane/EtOAc $=5: 1)$ yielded $242 f u(119.0 \mathrm{mg}, 63 \%)$ as a yellow oil.

${ }^{1} \mathrm{H}-\mathrm{NMR}\left(400 \mathrm{MHz}, \mathrm{CDCl}_{3}\right): \delta=9.94(\mathrm{~s}, 1 \mathrm{H}), 9.02$ (dd, $\left.J=7.4,1.7 \mathrm{~Hz}, 1 \mathrm{H}\right), 8.77$ (dd, $J=4.2$, $1.7 \mathrm{~Hz}, 1 \mathrm{H}), 8.21(\mathrm{dd}, J=8.3,1.7 \mathrm{~Hz}, 1 \mathrm{H}), 7.64(\mathrm{dd}, J=7.4,1.6 \mathrm{~Hz}, 1 \mathrm{H}), 7.60(\mathrm{dd}, J=8.3$, $1.6 \mathrm{~Hz}, 1 \mathrm{H}), 7.47$ (dd, $J=8.3,4.2 \mathrm{~Hz}, 1 \mathrm{H}), 7.34-7.30$ (m, 1H), 7.20-7.10 (m, 2H), 5.67 (dtt, $J$ $=15.0,6.7,1.5 \mathrm{~Hz}, 1 \mathrm{H}), 5.38(\mathrm{dtt}, J=15.0,6.7,1.5 \mathrm{~Hz}, 1 \mathrm{H}), 3.48(\mathrm{~d}, J=6.7 \mathrm{~Hz}, 2 \mathrm{H}), 3.42-$ $3.33(\mathrm{~m}, 2 \mathrm{H}), 2.47$ (s, 3H), 2.07-1.97 (m, 2H), 1.70-1.62 (m, 2H).

${ }^{13} \mathrm{C}-\mathrm{NMR}\left(100 \mathrm{MHz}, \mathrm{CDCl}_{3}\right): \delta=168.6\left(\mathrm{C}_{\mathrm{q}}\right), 148.3(\mathrm{CH}), 138.5\left(\mathrm{C}_{\mathrm{q}}\right), 137.7\left(\mathrm{C}_{\mathrm{q}}\right), 137.3\left(\mathrm{C}_{\mathrm{q}}\right)$, $136.4(\mathrm{CH}), 134.8\left(\mathrm{C}_{\mathrm{q}}\right), 134.4\left(\mathrm{C}_{\mathrm{q}}\right), 130.0(\mathrm{CH}), 129.9(\mathrm{CH}), 129.2(\mathrm{CH}), 128.2(\mathrm{CH}), 128.0$ $\left(\mathrm{C}_{\mathrm{q}}\right), 127.4(\mathrm{CH}), 127.1(\mathrm{CH}), 122.0(\mathrm{CH}), 121.7(\mathrm{CH}), 116.8(\mathrm{CH}), 44.4\left(\mathrm{CH}_{2}\right), 36.7\left(\mathrm{CH}_{2}\right)$, $31.9\left(\mathrm{CH}_{2}\right), 29.5\left(\mathrm{CH}_{2}\right), 19.5\left(\mathrm{CH}_{3}\right)$.

IR (ATR): 2937, 1645, 1502, 1444, 1238, $780 \mathrm{~cm}^{-1}$.

MS (ESI) $m / z$ (relative intensity): $401(100)[\mathrm{M}+\mathrm{Na}]^{+}, 379(90)[\mathrm{M}+\mathrm{H}]^{+}$.

HR-MS (ESI): $m / z$ calcd. for $\left[\mathrm{C}_{23} \mathrm{H}_{23} \mathrm{~N}_{2} \mathrm{O}^{35} \mathrm{Cl}+\mathrm{Na}\right]^{+} 401.1391$ found 401.1394 .<smiles>Cc1cccc(C/C=C/CCCCCC2CO2)c1C(=O)Nc1cccc2cccnc12</smiles>

(E)-2-Methyl-6-[8-(oxiran-2-yl)oct-2-en-1-yl]- $N$-(quinolin-8-yl)benzamide $\quad(242 \mathrm{fv}): \quad$ A modified general procedure $\mathbf{K}$ was used with 2-methyl- $N$-(quinolin-8-yl)benzamide (229f) $(131.1 \mathrm{mg}, \quad 0.50 \mathrm{mmol})$ and 1,2-epoxy-9-decene $(\mathbf{2 2 3 v}) \quad(232.0 \mathrm{mg}, \quad 1.5 \mathrm{mmol})$ with $\mathrm{Co}(\mathrm{OAc})_{2} \cdot 4 \mathrm{H}_{2} \mathrm{O}(25.4 \mathrm{mg}, 0.1 \mathrm{mmol}, 20 \mathrm{~mol} \%)$. After electrolysis, the mixture was transferred 
to a flask and the electrodes were rinsed with acetone $(3 \times 5.0 \mathrm{~mL})$. Then the combined solvent was removed under reduced pressure and subsequent column chromatography on silica gel ( $n$ hexane/EtOAc $=4: 1)$ yielded $242 f \mathbf{f}(118.0 \mathrm{mg}, 57 \%)$ as a yellow oil.

${ }^{1} \mathrm{H}-\mathrm{NMR}\left(600 \mathrm{MHz}, \mathrm{CDCl}_{3}\right): \delta=9.89$ (s, $\left.1 \mathrm{H}\right), 8.97$ (dd, $\left.J=7.5,1.4 \mathrm{~Hz}, 1 \mathrm{H}\right), 8.71$ (dd, $J=4.2$, $1.7 \mathrm{~Hz}, 1 \mathrm{H}), 8.16(\mathrm{dd}, J=8.3,1.7 \mathrm{~Hz}, 1 \mathrm{H}), 7.61-7.57(\mathrm{~m}, 1 \mathrm{H}), 7.55(\mathrm{dd}, J=8.3,1.4 \mathrm{~Hz}, 1 \mathrm{H})$, $7.43(\mathrm{dd}, J=8.3,4.2 \mathrm{~Hz}, 1 \mathrm{H}), 7.26(\mathrm{t}, J=7.7 \mathrm{~Hz}, 1 \mathrm{H}), 7.13-7.08(\mathrm{~m}, 2 \mathrm{H}), 5.55(\mathrm{dtt}, J=15.0$, 6.7, $1.4 \mathrm{~Hz}, 1 \mathrm{H}), 5.38(\mathrm{dtt}, J=15.0,6.7,1.4 \mathrm{~Hz}, 1 \mathrm{H}), 3.46-3.41(\mathrm{~m}, 2 \mathrm{H}), 2.82(\mathrm{tdd}, J=5.7$, 4.0, 2.7 Hz, 1H), 2.69 (dd, $J=5.1,4.0 \mathrm{~Hz}, 1 \mathrm{H}), 2.42$ (s, 3H), 2.40 (dd, $J=5.1,2.7 \mathrm{~Hz}, 1 \mathrm{H})$, $1.82(\mathrm{~d}, J=6.5 \mathrm{~Hz}, 2 \mathrm{H}), 1.43-1.38(\mathrm{~m}, 2 \mathrm{H}), 1.34-1.22(\mathrm{~m}, 2 \mathrm{H}), 1.20-1.14(\mathrm{~m}, 4 \mathrm{H})$.

${ }^{13} \mathrm{C}-\mathrm{NMR}\left(150 \mathrm{MHz}, \mathrm{CDCl}_{3}\right): \delta=168.6\left(\mathrm{C}_{\mathrm{q}}\right), 148.2(\mathrm{CH}), 138.5\left(\mathrm{C}_{\mathrm{q}}\right), 137.7\left(\mathrm{C}_{\mathrm{q}}\right), 136.3(\mathrm{CH})$, $134.7\left(\mathrm{C}_{\mathrm{q}}\right), 134.4\left(\mathrm{C}_{\mathrm{q}}\right), 132.1(\mathrm{CH}), 129.1(\mathrm{CH}), 128.4(\mathrm{CH}), 128.1(\mathrm{CH}), 128.0\left(\mathrm{C}_{\mathrm{q}}\right), 127.4$ $(\mathrm{CH}), 127.0(\mathrm{CH}), 121.9(\mathrm{CH}), 121.6(\mathrm{CH}), 116.8(\mathrm{CH}), 52.3(\mathrm{CH}), 47.1\left(\mathrm{CH}_{2}\right), 36.7\left(\mathrm{CH}_{2}\right)$, $32.4\left(\mathrm{CH}_{2}\right), 32.2\left(\mathrm{CH}_{2}\right), 29.0\left(\mathrm{CH}_{2}\right), 28.9\left(\mathrm{CH}_{2}\right), 25.7\left(\mathrm{CH}_{2}\right), 19.5\left(\mathrm{CH}_{3}\right)$.

IR (ATR): 2921, 1688, 1566, 1430, 1154, 903, 810, $737 \mathrm{~cm}^{-1}$.

MS (ESI) $m / z$ (relative intensity): $437(50)[\mathrm{M}+\mathrm{Na}]^{+}, 415(100)[\mathrm{M}+\mathrm{H}]^{+}$.

HR-MS (ESI): $m / z$ calcd. for $\left[\mathrm{C}_{27} \mathrm{H}_{30} \mathrm{~N}_{2} \mathrm{O}_{2}+\mathrm{Na}\right]^{+} 437.2199$ found 437.2196.

The analytical data correspond with those reported in the literature. ${ }^{[193]}$<smiles>Cc1cccc(C/C=C/CCCCCCCO)c1C(=O)Nc1cccc2cccnc12</smiles>

(E)-2-(10-Hydroxydec-2-en-1-yl)-6-methyl- $N$-(quinolin-8-yl)benzamide $\quad(242 \mathrm{fx}): \quad$ A modified general procedure $\mathbf{K}$ was used with 2-methyl- $N$-(quinolin-8-yl)benzamide (229f) $(131.1 \mathrm{mg}, 0.50 \mathrm{mmol})$ and 9-decenol (223x) $(234.0 \mathrm{mg}, 1.5 \mathrm{mmol})$. After electrolysis, the mixture was transferred to a flask and the electrodes were rinsed with acetone $(3 \times 5.0 \mathrm{~mL})$. Then the combined solvent was removed under reduced pressure and subsequent column chromatography on silica gel ( $n$-hexane/EtOAc $=2: 1)$ yielded $\mathbf{2 4 2 f \mathbf { x }}(114.0 \mathrm{mg}, 55 \%)$ as a yellow oil.

${ }^{1} \mathrm{H}-\mathrm{NMR}\left(600 \mathrm{MHz}, \mathrm{CDCl}_{3}\right): \delta=9.92(\mathrm{~s}, 1 \mathrm{H}), 8.98(\mathrm{dd}, J=7.5,1.4 \mathrm{~Hz}, 1 \mathrm{H}), 8.70$ (dd, $J=4.2$, $1.7 \mathrm{~Hz}, 1 \mathrm{H}), 8.14$ (dd, $J=8.3,1.7 \mathrm{~Hz}, 1 \mathrm{H}), 7.61-7.56(\mathrm{~m}, 1 \mathrm{H}), 7.53(\mathrm{dd}, J=8.3,1.4 \mathrm{~Hz}, 1 \mathrm{H})$, $7.41(\mathrm{dd}, J=8.3,4.2 \mathrm{~Hz}, 1 \mathrm{H}), 7.26(\mathrm{t}, 1 \mathrm{H}), 7.14-7.08(\mathrm{~m}, 2 \mathrm{H}), 5.58-5.51(\mathrm{~m}, 1 \mathrm{H}), 5.43-5.33$ 
(m, 1H), 3.58-3.50 (m, 2H), $3.43(\mathrm{~d}, J=6.9 \mathrm{~Hz}, 2 \mathrm{H}), 2.42(\mathrm{~s}, 3 \mathrm{H}), 1.83-1.78(\mathrm{~m}, 2 \mathrm{H}), 1.49$ $1.42(\mathrm{~m}, 2 \mathrm{H}), 1.24-1.18(\mathrm{~m}, 2 \mathrm{H}), 1.16-1.07$ (m, 6H).

${ }^{13} \mathrm{C}-\mathrm{NMR}\left(125 \mathrm{MHz}, \mathrm{CDCl}_{3}\right): \delta=168.5\left(\mathrm{C}_{\mathrm{q}}\right), 148.0(\mathrm{CH}), 138.3\left(\mathrm{C}_{\mathrm{q}}\right), 137.6\left(\mathrm{C}_{\mathrm{q}}\right), 137.5\left(\mathrm{C}_{\mathrm{q}}\right)$, $136.1(\mathrm{CH}), 134.5\left(\mathrm{C}_{\mathrm{q}}\right), 134.2\left(\mathrm{C}_{\mathrm{q}}\right), 132.2(\mathrm{CH}), 128.9(\mathrm{CH}), 128.0(\mathrm{CH}), 127.9(\mathrm{CH}), 127.9$ $(\mathrm{CH}), 127.2(\mathrm{CH}), 126.9\left(\mathrm{C}_{\mathrm{q}}\right), 121.8(\mathrm{CH}), 121.5(\mathrm{CH}), 116.7(\mathrm{CH}), 62.8\left(\mathrm{CH}_{2}\right), 36.7\left(\mathrm{CH}_{2}\right)$, $32.7\left(\mathrm{CH}_{2}\right), 32.3\left(\mathrm{CH}_{2}\right), 29.1\left(\mathrm{CH}_{2}\right), 29.1\left(\mathrm{CH}_{2}\right), 29.0\left(\mathrm{CH}_{2}\right), 25.6\left(\mathrm{CH}_{2}\right), 19.5\left(\mathrm{CH}_{3}\right)$.

IR (ATR): 2923, 1670, 1535, 1437, 1255, 987, 850, $719 \mathrm{~cm}^{-1}$.

MS (ESI) $m / z$ (relative intensity): $439(70)[\mathrm{M}+\mathrm{Na}]^{+}, 417(100)[\mathrm{M}+\mathrm{H}]^{+}$.

HR-MS (ESI): $m / z$ calcd. for $\left[\mathrm{C}_{27} \mathrm{H}_{32} \mathrm{~N}_{2} \mathrm{O}_{2}+\mathrm{H}\right]^{+} 417.2537$ found 417.2535.

\subsubsection{Mechanistic Studies}

\subsubsection{Competition Experiments}

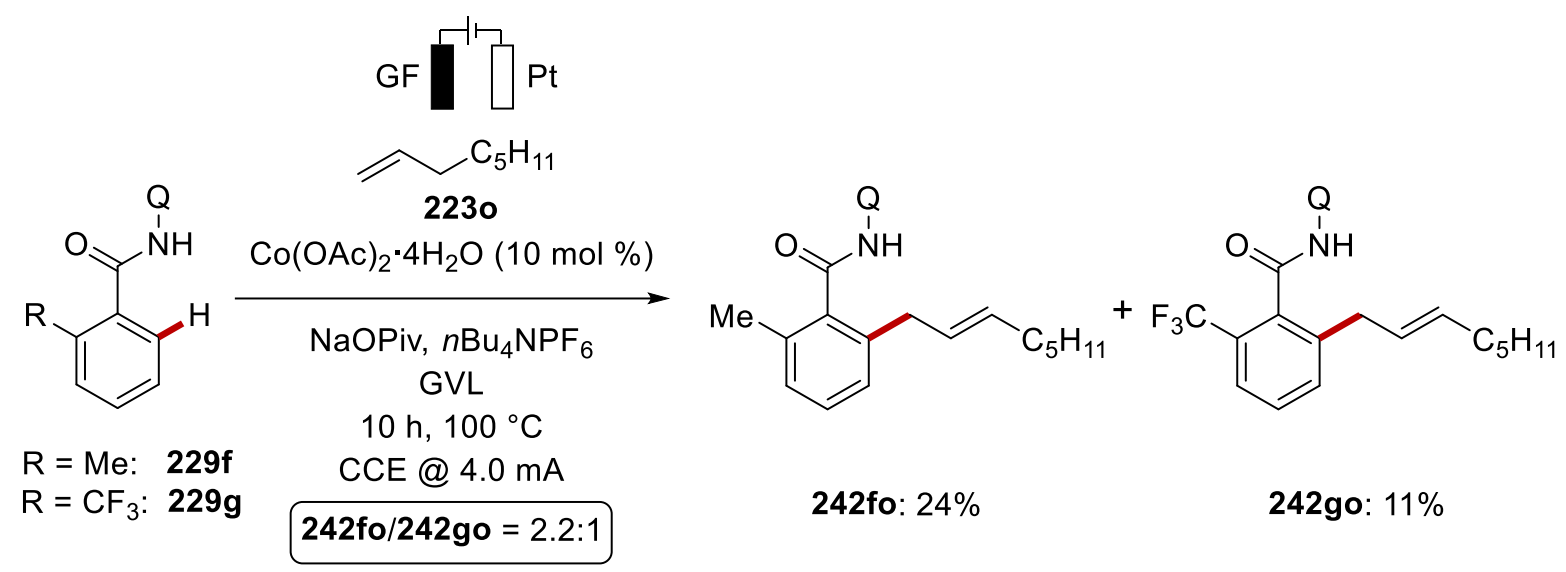

The electrocatalysis was carried out in an undivided cell with a GF anode $(10 \mathrm{~mm} \times 15 \mathrm{~mm} \times$ $6 \mathrm{~mm})$ and a Pt cathode $(10 \mathrm{~mm} \times 15 \mathrm{~mm} \times 0.25 \mathrm{~mm})$. Benzamide 229f $(157.2 \mathrm{mg}$, $0.60 \mathrm{mmol}$ ), and benzamide $229 \mathrm{~g}$ (189.6 mg, $0.60 \mathrm{mmol}$ ), $n$-octene $223 \mathrm{o}$ (22.4 $\mathrm{mg}$, $0.20 \mathrm{mmol}$ ), NaOPiv (49.6 mg, $0.40 \mathrm{mmol}$ ), $n \mathrm{Bu}_{4} \mathrm{NPF}_{6}(97.0 \mathrm{mg}, 0.25 \mathrm{mmol}$ ), and $\mathrm{Co}(\mathrm{OAc})_{2} \cdot 4 \mathrm{H}_{2} \mathrm{O}(5.0 \mathrm{mg}, 10 \mathrm{~mol} \%)$ were placed in a $10 \mathrm{~mL}$ cell and dissolved in GVL (4.0 $\mathrm{mL}$ ). Electrocatalysis was proformed at $100{ }^{\circ} \mathrm{C}$ with a constant current of $4.0 \mathrm{~mA}$ maintained for $10 \mathrm{~h}$. At ambient temperature, the mixture was transferred to a flask and the electrodes were rinsed with acetone $(3 \times 5.0 \mathrm{~mL})$. Then, the solvent was removed under reduced pressure and the residue was stirred with $\mathrm{NaOH}(\mathrm{aq})(2 \mathrm{M}, 15 \mathrm{~mL})$ for $2 \mathrm{~h}$. The mixture was extracted with $\mathrm{H}_{2} \mathrm{O}(3 \times 20 \mathrm{~mL})$ and successively with EtOAc $(3 \times 20 \mathrm{~mL})$ then the organic layer was dried over $\mathrm{Na}_{2} \mathrm{SO}_{4}$. After evaporation of the solvent under vacuo, the crude mixture was filtered through very short silica column. After evaporation of the solvent, dibromomethane $(43.5 \mathrm{mg}$, 
0.25 mmol, 1.25 equiv) was added as an internal standard. The ratio of $\mathbf{2 4 2 f o}$ and $\mathbf{2 4 2 g o}$ was determined by means of ${ }^{1} \mathrm{H}-\mathrm{NMR}$ which corresponds to $\mathbf{2 4 2 f o}(24 \%)$ and $\mathbf{2 4 2 g o}(11 \%)$.

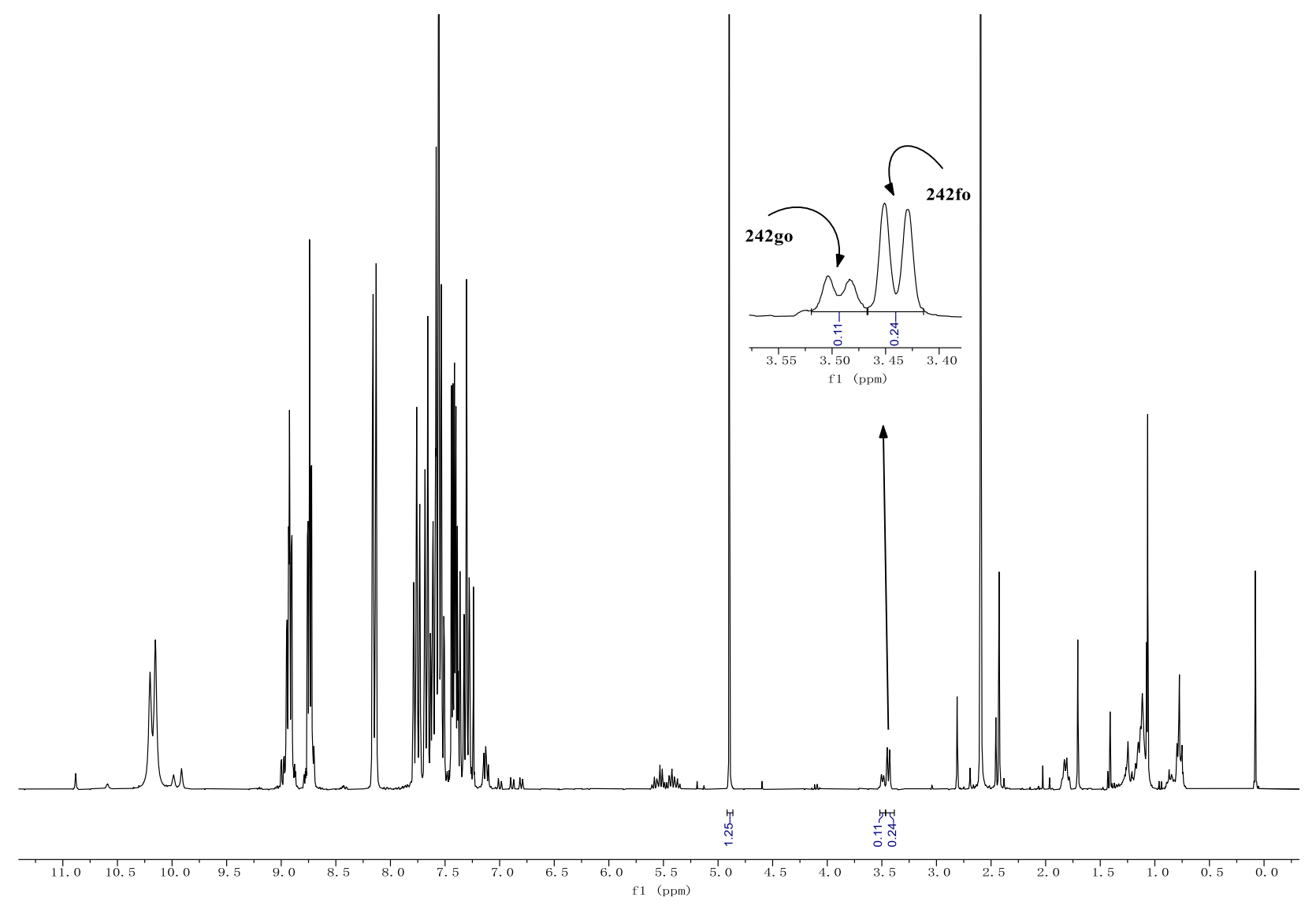

\subsubsection{H/D Exchange Experiment}




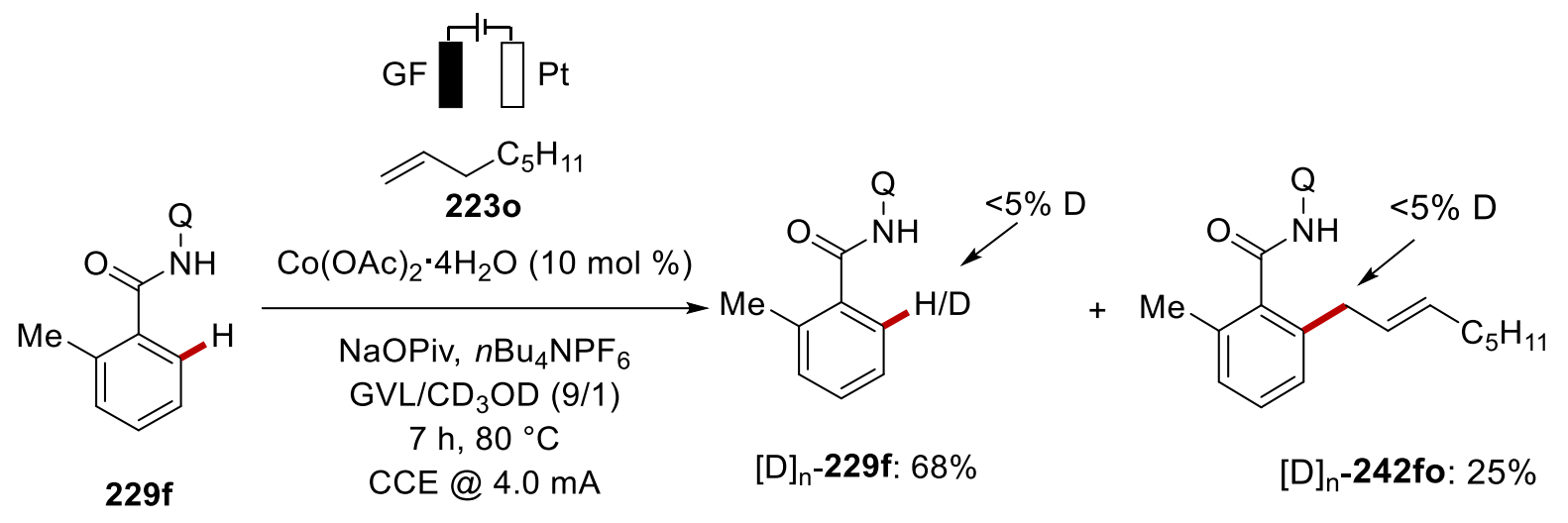

The electrocatalysis was carried out in an undivided cell with a GF anode $(10 \mathrm{~mm} \times 15 \mathrm{~mm} \times$ $6 \mathrm{~mm})$ and a Pt cathode $(10 \mathrm{~mm} \times 15 \mathrm{~mm} \times 0.25 \mathrm{~mm})$. Benzamide 229f $(131.1 \mathrm{mg}$, $0.50 \mathrm{mmol}$ ), $n$-octene $223 \mathrm{o}$ (168.4 mg, $1.5 \mathrm{mmol}$ ), NaOPiv (124.0 mg, $1.0 \mathrm{mmol}$ ), $n \mathrm{Bu}_{4} \mathrm{NPF}_{6}$ $(97.0 \mathrm{mg}, 0.25 \mathrm{mmol})$ and $\mathrm{Co}(\mathrm{OAc})_{2} \cdot 4 \mathrm{H}_{2} \mathrm{O}(12.7 \mathrm{mg}, 10 \mathrm{~mol} \%)$ were placed in a $10 \mathrm{~mL}$ cell and dissolved in GVL $(3.6 \mathrm{~mL})$ and $\mathrm{CD}_{3} \mathrm{OD}(0.40 \mathrm{~mL})$. Electrocatalysis was performed at 80 ${ }^{\circ} \mathrm{C}$ with a constant current of $4.0 \mathrm{~mA}$ maintained for $7 \mathrm{~h}$. At ambient temperature, the mixture was transferred to a flask and the electrodes were rinsed with acetone $(3 \times 5.0 \mathrm{~mL})$. Then, the combined solvent was removed under reduced pressure, the residue diluted with EtOAc (10 $\mathrm{mL})$ and stirred with $\mathrm{NaOH}(\mathrm{aq})(2 \mathrm{M}, 20 \mathrm{~mL})$. The mixture was extracted with $\mathrm{H}_{2} \mathrm{O}(3 \times 20$ $\mathrm{mL})$ and successively with EtOAc $(3 \times 20 \mathrm{~mL})$ then the organic layer was dried over $\mathrm{Na}_{2} \mathrm{SO}_{4}$. After evaporation of the solvent under vacuo subsequently column chromatography on silica gel $(n$-hexane/EtOAc $=10: 1)$ yielded $[\mathrm{D}]_{\mathrm{n}}-\mathbf{2 2 9 f}(89.0 \mathrm{mg}, 68 \%)$ as a yellow solid and $[\mathrm{D}]_{\mathrm{n}}$ 242fo $\left(46.6 \mathrm{mg}, 25 \%\right.$ ) as a colorless oil. The D-incorporation was estimated by ${ }^{1} \mathrm{H}-\mathrm{NMR}$ spectroscopy. 

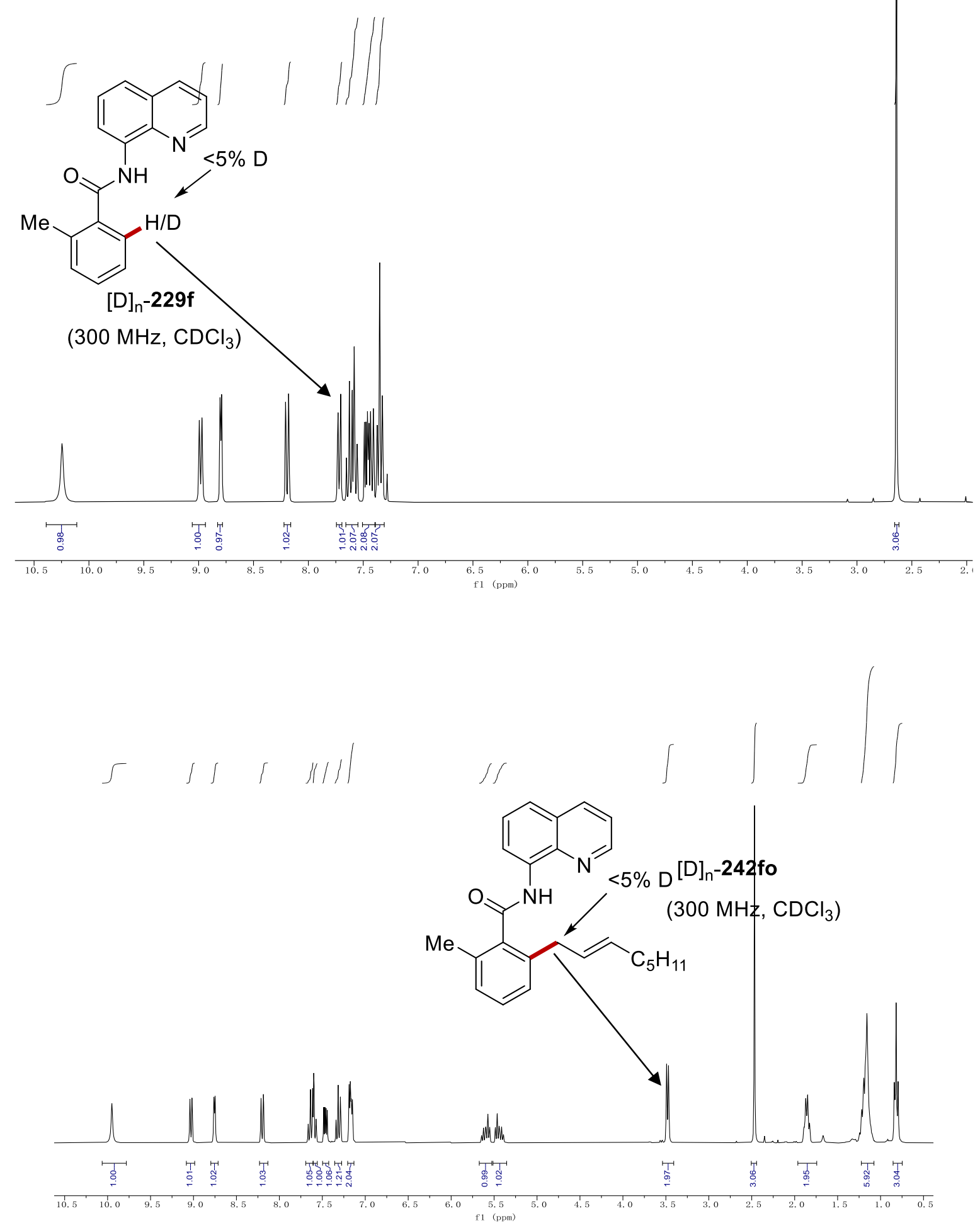
5.9 Enantioselective Palladaelectro-Catalyzed C-H Activations by Transient Directing Groups

\subsubsection{Characterization Data}<smiles>CCOC(=O)/C=C/c1ccc2ccccc2c1-c1ccccc1C=O</smiles>

(E)-Butyl 3-(1-(2-formylphenyl)naphthalen-2-yl)acrylate (74aa): The general procedure $\mathbf{L}$ was followed using 2-(naphthalen-1-yl)benzaldehyde (73a) $(46.4 \mathrm{mg}, 0.20 \mathrm{mmol})$ and $n$-butyl acrylate (38a) $(76.9 \mathrm{mg}, 0.60 \mathrm{mmol})$. Isolation by column chromatography ( $n$-hexane/EtOAc $=5: 1)$ yielded 74aa $(51.1 \mathrm{mg}, 71 \%)$ as a yellow oil.

${ }^{1} \mathrm{H}-\mathrm{NMR}\left(300 \mathrm{MHz}, \mathrm{CDCl}_{3}\right): \delta=9.49(\mathrm{~s}, 1 \mathrm{H}), 8.19(\mathrm{dd}, J=7.6,0.8 \mathrm{~Hz}, 1 \mathrm{H}), 7.97(\mathrm{~d}, J=8.8$ $\mathrm{Hz}, 1 \mathrm{H}), 7.93(\mathrm{~d}, J=8.1 \mathrm{~Hz}, 1 \mathrm{H}), 7.86(\mathrm{~d}, J=8.8 \mathrm{~Hz}, 1 \mathrm{H}), 7.78(\mathrm{td}, J=8.8,1.5 \mathrm{~Hz}, 1 \mathrm{H}), 7.69$ $(\mathrm{t}, J=7.4 \mathrm{~Hz}, 1 \mathrm{H}), 7.55(\mathrm{~d}, J=8.1 \mathrm{~Hz}, 1 \mathrm{H}), 7.48-7.34(\mathrm{~m}, 3 \mathrm{H}), 7.28(\mathrm{~d}, J=8.4 \mathrm{~Hz}, 1 \mathrm{H}), 6.50$ $(\mathrm{d}, J=16.0 \mathrm{~Hz}, 1 \mathrm{H}), 4.13(\mathrm{t}, J=6.5 \mathrm{~Hz}, 2 \mathrm{H}), 1.64-1.60(\mathrm{~m}, 2 \mathrm{H}), 1.38-1.33(\mathrm{~m}, 2 \mathrm{H}), 0.93(\mathrm{t}$, $J=7.3 \mathrm{~Hz}, 3 \mathrm{H})$.

${ }^{13} \mathrm{C}-\mathrm{NMR}\left(75 \mathrm{MHz}, \mathrm{CDCl}_{3}\right): \delta=191.3(\mathrm{CH}), 166.6\left(\mathrm{C}_{\mathrm{q}}\right), 142.0(\mathrm{CH}), 141.3\left(\mathrm{C}_{\mathrm{q}}\right), 136.7\left(\mathrm{C}_{\mathrm{q}}\right)$, $135.3\left(\mathrm{C}_{\mathrm{q}}\right), 134.1(\mathrm{CH}), 133.8\left(\mathrm{C}_{\mathrm{q}}\right), 133.3\left(\mathrm{C}_{\mathrm{q}}\right), 132.0(\mathrm{CH}), 131.2\left(\mathrm{C}_{\mathrm{q}}\right), 129.1(\mathrm{CH}), 128.9$ $(\mathrm{CH}), 128.2(\mathrm{CH}), 127.8(\mathrm{CH}), 127.3(\mathrm{CH}), 127.3(\mathrm{CH}), 127.0(\mathrm{CH}), 122.7(\mathrm{CH}), 120.2(\mathrm{CH})$, $64.4\left(\mathrm{CH}_{2}\right), 30.6\left(\mathrm{CH}_{2}\right), 19.2\left(\mathrm{CH}_{2}\right), 13.7\left(\mathrm{CH}_{3}\right)$.

IR (ATR): 2959, 1697, 1630, 1597, 1389, 1297, 1269, 1176, $818 \mathrm{~cm}^{-1}$.

MS (ESI) $m / z$ (relative intensity): $381(100)[\mathrm{M}+\mathrm{Na}]^{+}, 359(30)[\mathrm{M}+\mathrm{H}]^{+}$.

HR-MS (ESI): $m / z$ calcd. for $\left[\mathrm{C}_{24} \mathrm{H}_{22} \mathrm{O}_{3}+\mathrm{Na}\right]^{+} 381.1461$ found 381.1468.

$[\alpha]_{\mathrm{D}}^{20}:-35.9\left(\mathrm{c}=1.1, \mathrm{CHCl}_{3}\right)$.

HPLC separation (Chiralpak ${ }^{\circledR}$ IA-3, $n$-hexane $/ i$-PrOH 95:5, $1.0 \mathrm{~mL} / \mathrm{min}$, detection at $273 \mathrm{~nm}$ ): $t_{r}($ major $)=17.1 \mathrm{~min}, t_{r}($ minor $)=11.2 \mathrm{~min}, 97 \%$ ee .

The analytical data correspond with those reported in the literature. ${ }^{[89]}$<smiles>CCOC(=O)/C=C/c1cccc(C)c1-c1ccccc1C</smiles>

(E)-Butyl 3-(2'-formyl-6-methyl-[1,1'-biphenyl]-2-yl)acrylate (74ba) 
The general procedure $\mathbf{L}$ was followed using 2'-methyl-[1,1'-biphenyl]-2-carbaldehyde (73b) $(39.3 \mathrm{mg}, 0.20 \mathrm{mmol})$ and and $n$-butyl acrylate (38a) $(76.9 \mathrm{mg}, 0.60 \mathrm{mmol})$. Isolation by column chromatography ( $n$-hexane/EtOAc $=6: 1)$ yielded 74ba $(42.6 \mathrm{mg}, 66 \%)$ as a yellow oil. ${ }^{1} \mathrm{H}-\mathrm{NMR}\left(400 \mathrm{MHz}, \mathrm{CDCl}_{3}\right): \delta=9.61(\mathrm{~s}, 1 \mathrm{H}), 8.06$ (dd, $\left.J=7.8,1.4 \mathrm{~Hz}, 1 \mathrm{H}\right), 7.69(\mathrm{td}, J=7.5$, $1.4 \mathrm{~Hz}, 1 \mathrm{H}), 7.64-7.52(\mathrm{~m}, 2 \mathrm{H}), 7.41-7.29(\mathrm{~m}, 2 \mathrm{H}), 7.25-7.17(\mathrm{~m}, 2 \mathrm{H}), 6.27(\mathrm{~d}, J=15.9 \mathrm{~Hz}$, $1 \mathrm{H}), 4.06(\mathrm{t}, J=6.6 \mathrm{~Hz}, 2 \mathrm{H}), 2.00(\mathrm{~s}, 3 \mathrm{H}), 1.64-1.46(\mathrm{~m}, 2 \mathrm{H}), 1.39-1.20(\mathrm{~m}, 2 \mathrm{H}), 0.89$ (t, $J=$ $7.4 \mathrm{~Hz}, 3 \mathrm{H})$.

${ }^{13} \mathrm{C}-\mathrm{NMR}\left(100 \mathrm{MHz}, \mathrm{CDCl}_{3}\right): \delta=191.5(\mathrm{CH}), 166.5\left(\mathrm{C}_{\mathrm{q}}\right), 142.7\left(\mathrm{C}_{\mathrm{q}}\right), 142.4(\mathrm{CH}), 138.1\left(\mathrm{C}_{\mathrm{q}}\right)$, $137.3\left(\mathrm{C}_{\mathrm{q}}\right), 134.3(\mathrm{CH}), 134.1\left(\mathrm{C}_{\mathrm{q}}\right), 134.0\left(\mathrm{C}_{\mathrm{q}}\right), 131.5(\mathrm{CH}), 130.9(\mathrm{CH}), 128.5(\mathrm{CH}), 128.5$ $(\mathrm{CH}), 128.0(\mathrm{CH}), 123.9(\mathrm{CH}), 119.9(\mathrm{CH}), 64.3\left(\mathrm{CH}_{2}\right), 30.6\left(\mathrm{CH}_{2}\right), 20.8\left(\mathrm{CH}_{3}\right), 19.1\left(\mathrm{CH}_{2}\right)$, $13.7\left(\mathrm{CH}_{3}\right)$.

IR (ATR): 2959, 1596, 1711, 1695, 1311, 1245, 1014, 785, 748, $699 \mathrm{~cm}^{-1}$. MS (ESI) $m / z$ (relative intensity): $345(100)[\mathrm{M}+\mathrm{Na}]^{+}, 323(5)[\mathrm{M}+\mathrm{H}]^{+}$.

HR-MS (ESI): $m / z$ calcd. for $\left[\mathrm{C}_{21} \mathrm{H}_{22} \mathrm{O}_{3}+\mathrm{Na}\right]^{+} 345.1461$ found 345.1466.

$[\alpha]_{\mathrm{D}}^{20}:-35.9\left(\mathrm{c}=1.1, \mathrm{CHCl}_{3}\right)$.

HPLC separation (Chiralpak ${ }^{\circledR}$ IA-3, $n$-hexane $/ i$-PrOH 98:2, $1.0 \mathrm{~mL} / \mathrm{min}$, detection at $273 \mathrm{~nm}$ ): $t_{r}($ major $)=11.3 \mathrm{~min}, t_{r}($ minor $)=10.2 \mathrm{~min}, 95 \%$ ee .

The analytical data correspond with those reported in the literature. ${ }^{[89]}$<smiles>CCOC(=O)/C=C/c1cccc(CC)c1-c1cc(F)ccc1C=O</smiles>

(E)-Butyl 3-(6-ethyl-5'-fluoro-2'-formyl-[1,1'-biphenyl]-2-yl)acrylate (74ca): The general procedure $\mathbf{L}$ was followed using 2'-ethyl-5-fluoro-[1,1'-biphenyl]-2-carbaldehyde (73c) $(45.4 \mathrm{mg}, 0.20 \mathrm{mmol})$ and $n$-butyl acrylate $(\mathbf{3 8 a})(76.9 \mathrm{mg}, 0.60 \mathrm{mmol})$. Isolation by column chromatography $(n$-hexane/EtOAc $=5: 1)$ yielded $74 \mathbf{c a}(50.3 \mathrm{mg}, 71 \%, E / Z=98: 2)$ as a yellow oil.

${ }^{1} \mathrm{H}-\mathrm{NMR}\left(400 \mathrm{MHz}, \mathrm{CDCl}_{3}\right): \delta=9.53(\mathrm{~s}, 1 \mathrm{H}), 8.12(\mathrm{dd}, J=8.7,5.9 \mathrm{~Hz}, 1 \mathrm{H}), 7.61(\mathrm{dd}, J=7.7$, $1.4 \mathrm{~Hz}, 1 \mathrm{H}), 7.50-7.35(\mathrm{~m}, 2 \mathrm{H}), 7.34-7.23(\mathrm{~m}, 1 \mathrm{H}), 7.19$ (d, $J=16.0 \mathrm{~Hz}, 1 \mathrm{H}), 6.98(\mathrm{dd}, J=$ 8.8, 2.6 Hz, 1H), $6.31(\mathrm{~d}, J=16.0 \mathrm{~Hz}, 0.98 \mathrm{H}, E), 5.78(\mathrm{~d}, J=12.0 \mathrm{~Hz}, 0.02 \mathrm{H}, Z), 4.10(\mathrm{t}, J=$ $6.6 \mathrm{~Hz}, 2 \mathrm{H}), 2.35(\mathrm{qd}, J=7.4,3.5 \mathrm{~Hz}, 2 \mathrm{H}), 1.66-1.52(\mathrm{~m}, 2 \mathrm{H}), 1.41-1.25(\mathrm{~m}, 2 \mathrm{H}), 1.06(\mathrm{t}, J=$ $7.5 \mathrm{~Hz}, 3 \mathrm{H}), 0.92(\mathrm{t}, J=7.4 \mathrm{~Hz}, 3 \mathrm{H})$. 
${ }^{13} \mathrm{C}-\mathrm{NMR}\left(100 \mathrm{MHz}, \mathrm{CDCl}_{3}\right): \delta=189.8(\mathrm{CH}), 166.4\left(\mathrm{C}_{\mathrm{q}}\right), 166.0\left(\mathrm{~d},{ }^{1} J_{\mathrm{C}-\mathrm{F}}=260.1 \mathrm{~Hz}, \mathrm{Cq}\right)$, $145.3\left(\mathrm{~d},{ }^{3} J_{\mathrm{C}-\mathrm{F}}=8.5 \mathrm{~Hz}, \mathrm{C}_{\mathrm{q}}\right), 143.1\left(\mathrm{C}_{\mathrm{q}}\right), 142.0(\mathrm{CH}), 136.0\left(\mathrm{C}_{\mathrm{q}}\right), 133.9\left(\mathrm{C}_{\mathrm{q}}\right), 131.1\left(\mathrm{~d},{ }^{4} J_{\mathrm{C}-\mathrm{F}}=\right.$ $\left.2.7 \mathrm{~Hz}, \mathrm{C}_{\mathrm{q}}\right), 130.7\left(\mathrm{~d},{ }^{2} J_{\mathrm{C}-\mathrm{F}}=10.2 \mathrm{~Hz}, \mathrm{CH}\right) 130.1(\mathrm{CH}), 129.1(\mathrm{CH}), 123.9(\mathrm{CH}), 120.4(\mathrm{CH})$, $118.2\left(\mathrm{~d},{ }^{2} J_{\mathrm{C}-\mathrm{F}}=20.2 \mathrm{~Hz}, \mathrm{CH}\right), 116.2(\mathrm{CH}), 64.4\left(\mathrm{CH}_{2}\right), 30.6\left(\mathrm{CH}_{2}\right), 26.6\left(\mathrm{CH}_{2}\right), 19.1\left(\mathrm{CH}_{2}\right)$, $14.9\left(\mathrm{CH}_{3}\right), 13.7\left(\mathrm{CH}_{3}\right)$.

${ }^{19} \mathrm{~F}-\mathrm{NMR}\left(375 \mathrm{MHz}, \mathrm{CDCl}_{3}\right): \delta=-102.4$.

IR (ATR): 2963, 1713, 1635, 1604, 1580, 1272, 1222, 1183, $799 \mathrm{~cm}^{-1}$.

MS (ESI) $m / z$ (relative intensity): $377(100)[\mathrm{M}+\mathrm{Na}]^{+}, 355(5)[\mathrm{M}+\mathrm{H}]^{+}$.

HR-MS (ESI): $\mathrm{m} / \mathrm{z}$ calcd. for $\left[\mathrm{C}_{22} \mathrm{H}_{23} \mathrm{FO}_{3}+\mathrm{Na}\right]^{+} 377.1523$ found 377.1528 .

$[\alpha]_{\mathrm{D}}^{20}:-1.2\left(\mathrm{c}=1.2, \mathrm{CHCl}_{3}\right)$.

HPLC separation (Chiralpak® IA-3, $n$-hexane $/ i$-PrOH 98:2, $1 \mathrm{~mL} / \mathrm{min}$, detection at $273 \mathrm{~nm}$ ): $t_{r}($ major $)=10.0 \mathrm{~min}, t_{r}($ minor $)=8.8 \mathrm{~min}, 95 \%$ ee.<smiles>CCOC(=O)C=Cc1ccc2ccccc2c1-c1cc2c(cc1C=O)OCO2</smiles>

(E)-Butyl 3-(1-(6-formylbenzo[d][1,3]dioxol-5-yl)naphthalen-2-yl)acrylate (74da): The general procedure $\mathbf{L}$ was followed using 6-(naphthalen-1-yl)benzo[ $d][1,3]$ dioxole-5carbaldehyde (73d) $(55.2 \mathrm{mg}, 0.20 \mathrm{mmol})$ and $n$-butyl acrylate (38a) $(76.9 \mathrm{mg}, 0.60 \mathrm{mmol})$. Isolation by column chromatography $(n$-hexane/EtOAc $=4: 1)$ yielded 74da $(43.4 \mathrm{mg}, 54 \%$, $E / Z=97: 3)$ as a yellow oil.

${ }^{1} \mathrm{H}-\mathrm{NMR}\left(400 \mathrm{MHz}, \mathrm{CDCl}_{3}\right): \delta=9.34(\mathrm{~s}, 0.03 \mathrm{H}, Z), 9.23(\mathrm{~s}, 0.97 \mathrm{H}, E), 7.95$ (d, J = $8.7 \mathrm{~Hz}$, $1 \mathrm{H}), 7.91(\mathrm{~d}, J=8.1 \mathrm{~Hz}, 1 \mathrm{H}), 7.84(\mathrm{~d}, J=8.7 \mathrm{~Hz}, 1 \mathrm{H}), 7.59(\mathrm{~s}, 1 \mathrm{H}), 7.58-7.50(\mathrm{~m}, 2 \mathrm{H}), 7.47-$ $7.41(\mathrm{~m}, 1 \mathrm{H}), 7.38(\mathrm{~d}, J=8.5 \mathrm{~Hz}, 1 \mathrm{H}), 6.77(\mathrm{~s}, 1 \mathrm{H}), 6.51(\mathrm{~d}, J=16.0 \mathrm{~Hz}, 1 \mathrm{H}), 6.20(\mathrm{~d}, J=3.3$ $\mathrm{Hz}, 2 \mathrm{H}), 4.16(\mathrm{t}, J=6.6 \mathrm{~Hz}, 2 \mathrm{H}), 1.76-1.57(\mathrm{~m}, 2 \mathrm{H}), 1.46-1.34(\mathrm{~m}, 2 \mathrm{H}), 0.96(\mathrm{t}, J=7.4 \mathrm{~Hz}$, $3 \mathrm{H})$.

${ }^{13} \mathrm{C}-\mathrm{NMR}\left(100 \mathrm{MHz}, \mathrm{CDCl}_{3}\right): \delta=189.6(\mathrm{CH}), 166.7\left(\mathrm{C}_{\mathrm{q}}\right), 152.7\left(\mathrm{C}_{\mathrm{q}}\right), 148.7\left(\mathrm{C}_{\mathrm{q}}\right), 142.0(\mathrm{CH})$, $138.5(\mathrm{CH}), 136.2\left(\mathrm{C}_{\mathrm{q}}\right), 133.8\left(\mathrm{C}_{\mathrm{q}}\right), 133.5\left(\mathrm{C}_{\mathrm{q}}\right), 131.5\left(\mathrm{C}_{\mathrm{q}}\right), 130.5\left(\mathrm{C}_{\mathrm{q}}\right), 129.2\left(\mathrm{C}_{\mathrm{q}}\right), 128.2(\mathrm{CH})$, 127.4 (CH), $127.4(\mathrm{CH}), 127.0(\mathrm{CH}), 122.6(\mathrm{CH}), 120.3(\mathrm{CH}), 111.3(\mathrm{CH}), 106.4(\mathrm{CH}), 102.4$ $\left(\mathrm{CH}_{2}\right), 64.5\left(\mathrm{CH}_{2}\right), 30.7\left(\mathrm{CH}_{2}\right), 19.2\left(\mathrm{CH}_{2}\right), 13.7\left(\mathrm{CH}_{3}\right)$.

IR (ATR): 2927, 1712, 1683, 1480, 1259, 1177, 1036, $819 \mathrm{~cm}^{-1}$. MS (ESI) $m / z$ (relative intensity): $425(100)[\mathrm{M}+\mathrm{Na}]^{+}, 403(30)[\mathrm{M}+\mathrm{H}]^{+}$. 
HR-MS (ESI): $m / z$ calcd. for $\left[\mathrm{C}_{25} \mathrm{H}_{22} \mathrm{O}_{5}+\mathrm{Na}\right]^{+} 425.1359$ found 425.1363 .

$[\alpha]_{\mathrm{D}}^{20}:+4.0\left(\mathrm{c}=0.35, \mathrm{CHCl}_{3}\right)$.

HPLC separation (Chiralpak ${ }^{\circledR}$ IA-3, $n$-hexane $/ i$-PrOH 90:10, $1.0 \mathrm{~mL} / \mathrm{min}$, detection at $273 \mathrm{~nm}$ ): $t_{r}($ major $)=16.4 \mathrm{~min}, t_{r}($ minor $)=11.7 \mathrm{~min}, 99 \%$ ee .<smiles>CCOC(=O)C=Cc1ccc2ccccc2c1-c1cc(OC)c(OC)cc1C=O</smiles>

(E)-Butyl 3-(1-(2-formyl-4,5-dimethoxyphenyl)naphthalen-2-yl)acrylate (74ea): The general procedure $\mathbf{L}$ was followed using 4,5-dimethoxy-2-(naphthalen-1-yl)benzaldehyde (73e) $(58.4 \mathrm{mg}, 0.20 \mathrm{mmol})$ and $n$-butyl acrylate (38a) $(76.9 \mathrm{mg}, 0.60 \mathrm{mmol})$. Isolation by column chromatography ( $n$-hexane/EtOAc $=3: 1)$ yielded 74ea $(50.3 \mathrm{mg}, 60 \%)$ as a yellow oil. ${ }^{1} \mathrm{H}-\mathrm{NMR}\left(400 \mathrm{MHz}, \mathrm{CDCl}_{3}\right): \delta=9.30(\mathrm{~s}, 1 \mathrm{H}), 7.96(\mathrm{~d}, J=8.7 \mathrm{~Hz}, 1 \mathrm{H}), 7.92(\mathrm{~d}, J=8.1 \mathrm{~Hz}$, $1 \mathrm{H}), 7.85(\mathrm{~d}, J=8.7 \mathrm{~Hz}, 1 \mathrm{H}), 7.65(\mathrm{~s}, 1 \mathrm{H}), 7.57-7.47(\mathrm{~m}, 2 \mathrm{H}), 7.43(\mathrm{dd}, J=8.1,6.6 \mathrm{~Hz}, 1 \mathrm{H})$, $7.36(\mathrm{~d}, J=8.4 \mathrm{~Hz}, 1 \mathrm{H}), 6.77(\mathrm{~s}, 1 \mathrm{H}), 6.50(\mathrm{~d}, J=15.9 \mathrm{~Hz}, 1 \mathrm{H}), 4.14(\mathrm{t}, J=6.6 \mathrm{~Hz}, 2 \mathrm{H}), 4.07$ (s, 3H), 3.93 (s, 3H), 1.69-1.57 (m, 2H), 1.40-1.33 (h, $J=7.4 \mathrm{~Hz}, 2 \mathrm{H}), 0.94$ (t, $J=7.4 \mathrm{~Hz}$, $3 \mathrm{H})$.

${ }^{13} \mathrm{C}-\mathrm{NMR}\left(100 \mathrm{MHz}, \mathrm{CDCl}_{3}\right): \delta=190.1(\mathrm{CH}), 166.6\left(\mathrm{C}_{\mathrm{q}}\right), 153.9\left(\mathrm{C}_{\mathrm{q}}\right), 149.4\left(\mathrm{C}_{\mathrm{q}}\right), 142.1(\mathrm{CH})$, $136.4\left(\mathrm{C}_{\mathrm{q}}\right), 136.4\left(\mathrm{C}_{\mathrm{q}}\right), 133.8\left(\mathrm{C}_{\mathrm{q}}\right), 133.65\left(\mathrm{C}_{\mathrm{q}}\right), 131.5\left(\mathrm{C}_{\mathrm{q}}\right), 129.1(\mathrm{CH}), 128.8\left(\mathrm{C}_{\mathrm{q}}\right), 128.1(\mathrm{CH})$, $127.4(\mathrm{CH}), 127.3(\mathrm{CH}), 127.1(\mathrm{CH}), 122.6(\mathrm{CH}), 120.2(\mathrm{CH}), 113.5(\mathrm{CH}), 108.5(\mathrm{CH}), 64.4$ $\left(\mathrm{CH}_{2}\right), 56.4\left(\mathrm{CH}_{3}\right), 56.2\left(\mathrm{CH}_{3}\right), 30.7\left(\mathrm{CH}_{2}\right), 19.2\left(\mathrm{CH}_{2}\right), 13.7\left(\mathrm{CH}_{3}\right)$.

IR (ATR): 2958, 1708, 1680, 1595, 1272, 1092, $752 \mathrm{~cm}^{-1}$. MS (ESI) $m / z$ (relative intensity): $441(100)[\mathrm{M}+\mathrm{Na}]^{+}, 419(5)[\mathrm{M}+\mathrm{H}]^{+}$. HR-MS (ESI): $m / z$ calcd. for $\left[\mathrm{C}_{26} \mathrm{H}_{26} \mathrm{O}_{5}+\mathrm{Na}\right]^{+} 441.1672$ found 441.1676 . $[\alpha]_{\mathrm{D}}^{20}:+23.7\left(\mathrm{c}=1.0, \mathrm{CHCl}_{3}\right)$.

HPLC separation (Chiralpak ${ }^{\circledR}$ IA-3, $n$-hexane $/ i$-PrOH 95:5, $1 \mathrm{~mL} / \mathrm{min}$, detection at $273 \mathrm{~nm}$ ): $t_{r}$ $($ major $)=24.1 \mathrm{~min}, t_{r}($ minor $)=21.9 \mathrm{~min}, 98 \%$ ee

The analytical data correspond with those reported in the literature. ${ }^{[89]}$ 
<smiles>CCOC(=O)C=Cc1ccc2ccccc2c1-c1ccc(C(F)(F)F)cc1C=O</smiles>

(E)-Butyl 3-(1-(2-formyl-4-(trifluoromethyl)phenyl)naphthalen-2-yl)acrylate (74fa): The general procedure $\mathbf{L}$ was followed using 2-(naphthalen-1-yl)-5-(trifluoromethyl)benzaldehyde (73f) $(60.2 \mathrm{mg}, 0.20 \mathrm{mmol})$ and $n$-butyl acrylate (38a) $(76.9 \mathrm{mg}, 0.60 \mathrm{mmol})$. Isolation by column chromatography ( $n$-hexane/EtOAc $=5: 1)$ yielded $74 f a(51.4 \mathrm{mg}, 60 \%)$ as a yellow oil. ${ }^{1} \mathrm{H}-\mathrm{NMR}\left(400 \mathrm{MHz}, \mathrm{CDCl}_{3}\right): \delta=9.45$ (s, 1H), 8.45-8.37 (m, 1H), 8.02-7.95 (m, 2H), 7.94$7.89(\mathrm{~m}, 1 \mathrm{H}), 7.84$ (d, $J=8.8 \mathrm{~Hz}, 1 \mathrm{H}), 7.58-7.47$ (m, 2H), 7.41 (ddd, $J=8.3,6.9,1.3 \mathrm{~Hz}, 1 \mathrm{H})$, $7.33(\mathrm{~d}, J=15.9 \mathrm{~Hz}, 1 \mathrm{H}), 7.16(\mathrm{dd}, J=8.5,0.9 \mathrm{~Hz}, 1 \mathrm{H}), 6.48(\mathrm{~d}, J=15.9 \mathrm{~Hz}, 1 \mathrm{H}), 4.09$ (t, $J=$ $6.9 \mathrm{~Hz}, 2 \mathrm{H}), 1.65-1.51(\mathrm{~m}, 2 \mathrm{H}), 1.39-1.25(\mathrm{~m}, 2 \mathrm{H}), 0.89$ (t, $J=7.4 \mathrm{~Hz}, 3 \mathrm{H})$.

${ }^{13} \mathrm{C}-\mathrm{NMR}\left(100 \mathrm{MHz}, \mathrm{CDCl}_{3}\right): \delta=189.7(\mathrm{CH}), 166.3\left(\mathrm{C}_{\mathrm{q}}\right), 144.7\left(\mathrm{C}_{\mathrm{q}}\right), 141.1(\mathrm{CH}), 135.6\left(\mathrm{C}_{\mathrm{q}}\right)$, $134.8\left(\mathrm{C}_{\mathrm{q}}\right), 133.7\left(\mathrm{C}_{\mathrm{q}}\right), 132.9(\mathrm{CH}), 131.7\left(\mathrm{C}_{\mathrm{q}}\right), 131.4\left(\mathrm{~d},{ }^{2} J_{\mathrm{C}-\mathrm{F}}=33.8 \mathrm{~Hz}, \mathrm{C}_{\mathrm{q}}\right), 131.2\left(\mathrm{C}_{\mathrm{q}}\right), 130.3$ $\left(\mathrm{q},{ }^{3} J_{\mathrm{C}-\mathrm{F}}=3.2 \mathrm{~Hz}, \mathrm{CH}\right), 129.7(\mathrm{CH}), 128.4(\mathrm{CH}), 127.8(\mathrm{CH}), 127.6(\mathrm{CH}), 126.4(\mathrm{CH}), 124.9$ $\left(\mathrm{q},{ }^{3} J_{\mathrm{C}-\mathrm{F}}=3.7 \mathrm{~Hz}, \mathrm{CH}\right), 123.9\left(\mathrm{q},{ }^{1} J_{\mathrm{C}-\mathrm{F}}=278.2 \mathrm{~Hz}, \mathrm{C}_{\mathrm{q}}\right) 122.7(\mathrm{CH}), 121.0(\mathrm{CH}), 64.5\left(\mathrm{CH}_{2}\right)$, $30.6\left(\mathrm{CH}_{2}\right), 19.1\left(\mathrm{CH}_{2}\right), 13.6\left(\mathrm{CH}_{3}\right)$.

${ }^{19} \mathrm{~F}-\mathrm{NMR}\left(375 \mathrm{MHz}, \mathrm{CDCl}_{3}\right): \delta=-62.9$.

IR (ATR): 2961, 1701, 1615, 1330, 1173, 1131, 750, $710 \mathrm{~cm}^{-1}$.

MS (ESI) $m / z$ (relative intensity): $449(100)[\mathrm{M}+\mathrm{Na}]^{+}, 427(10)[\mathrm{M}+\mathrm{H}]^{+}$.

HR-MS (ESI): $m / z$ calcd. for $\left[\mathrm{C}_{25} \mathrm{H}_{21} \mathrm{~F}_{3} \mathrm{O}_{3}+\mathrm{Na}\right]^{+} 449.1335$ found 449.1336 .

$[\alpha]_{\mathrm{D}}^{20}:-8.1\left(\mathrm{c}=1.0, \mathrm{CHCl}_{3}\right)$.

HPLC separation (Chiralpak ${ }^{\circledR}$ IA-3, $n$-hexane $/ i$-PrOH 95:5, $1 \mathrm{~mL} / \mathrm{min}$, detection at $273 \mathrm{~nm}$ ): $t_{r}$ $($ major $)=11.5 \mathrm{~min}, t_{r}($ minor $)=8.0 \mathrm{~min}, 97 \%$ ee .

The analytical data correspond with those reported in the literature. ${ }^{1}$<smiles>O=Cc1ccccc1-c1c(/C=C/S(=O)(=O)c2ccccc2)ccc2ccccc12</smiles>

(E)-2-(2-(2-(Phenylsulfonyl)vinyl)naphthalen-1-yl)benzaldehyde (74ab): The general procedure $\mathbf{L}$ was followed using 2-(naphthalen-1-yl)benzaldehyde (73a) (46.4 mg, $0.20 \mathrm{mmol}$ ) and (vinylsulfonyl)benzene $\mathbf{( 3 8 b )} \quad(100.8 \mathrm{mg}, \quad 0.60 \mathrm{mmol})$. Isolation by column chromatography ( $n$-hexane/EtOAc $=1: 1)$ yielded 74ab $(41.4 \mathrm{mg}, 52 \%)$ as a yellow oil. 
${ }^{1} \mathrm{H}-\mathrm{NMR}\left(400 \mathrm{MHz}, \mathrm{CDCl}_{3}\right): \delta=9.44(\mathrm{~s}, 1 \mathrm{H}), 8.18$ (dd, $\left.J=7.7,1.4 \mathrm{~Hz}, 1 \mathrm{H}\right), 7.96-7.88(\mathrm{~m}$, 2H), 7.84-7.76 (m, 3H), $7.73(\mathrm{~d}, J=7.6,1.0 \mathrm{~Hz}, 1 \mathrm{H}), 7.70(\mathrm{~d}, J=8.5 \mathrm{~Hz}, 1 \mathrm{H}), 7.65-7.60(\mathrm{~m}$, 1H), 7.59-7.52 (m, 3H), $7.44(\mathrm{dd}, J=8.2,6.8,1.2 \mathrm{~Hz}, 1 \mathrm{H}), 7.41-7.33(\mathrm{~m}, 2 \mathrm{H}), 7.31(\mathrm{~d}, J=8.5$ $\mathrm{Hz}, 1 \mathrm{H}), 6.86(\mathrm{~d}, J=15.6 \mathrm{~Hz}, 1 \mathrm{H})$.

${ }^{13} \mathrm{C}-\mathrm{NMR}\left(100 \mathrm{MHz}, \mathrm{CDCl}_{3}\right)$ : (two carbon less due to overlap) $\delta=190.9(\mathrm{CH}), 140.4\left(\mathrm{C}_{\mathrm{q}}\right)$, $140.2\left(\mathrm{C}_{\mathrm{q}}\right), 140.1(\mathrm{CH}), 137.7\left(\mathrm{C}_{\mathrm{q}}\right), 135.2\left(\mathrm{C}_{\mathrm{q}}\right), 134.2(\mathrm{CH}), 134.1\left(\mathrm{C}_{\mathrm{q}}\right), 133.5(\mathrm{CH}), 133.1\left(\mathrm{C}_{\mathrm{q}}\right)$, $131.9(\mathrm{CH}), 129.6(\mathrm{CH}), 129.4(\mathrm{CH}), 129.3\left(\mathrm{C}_{\mathrm{q}}\right), 128.3(\mathrm{CH}), 128.2(\mathrm{CH}), 127.8(\mathrm{CH}), 127.7$ $(\mathrm{CH}), 127.6(\mathrm{CH}), 127.1(\mathrm{CH}), 122.8(\mathrm{CH})$.

IR (ATR): 2924, 1696, 1607, 1303, 1084, 786, 742, $680 \mathrm{~cm}^{-1}$.

MS (ESI) $m / z$ (relative intensity): $421(100)[\mathrm{M}+\mathrm{Na}]^{+}, 399(10)[\mathrm{M}+\mathrm{H}]^{+}$.

HR-MS (ESI): $m / z$ calcd. for $\left[\mathrm{C}_{25} \mathrm{H}_{18} \mathrm{O}_{3} \mathrm{~S}+\mathrm{Na}\right]^{+} 421.0869$ found 421.0870 .

$[\alpha]_{\mathrm{D}}^{20}:+20.1\left(\mathrm{c}=1.0, \mathrm{CHCl}_{3}\right)$.

HPLC separation (Chiralpak ${ }^{\circledR}$ IB-3, $n$-hexane $/ i$-PrOH 80:20, $1 \mathrm{~mL} / \mathrm{min}$, detection at $273 \mathrm{~nm}$ ): $t_{r}($ major $)=20.0 \mathrm{~min}, t_{r}($ minor $)=12.9 \mathrm{~min}, 98 \%$ ee .<smiles>CCOP(=O)(O)/C=C/c1ccc2ccccc2c1-c1ccccc1C</smiles>

(E)-Diethyl (2-(1-(2-formylphenyl)naphthalen-2-yl)vinyl)phosphonate (74ac): The general procedure $\mathbf{L}$ was followed using 2-(naphthalen-1-yl)benzaldehyde (73a) (46.4 mg, 0.20 mmol) and diethyl vinylphosphonate (38c) $(98.4 \mathrm{mg}, 0.60 \mathrm{mmol})$. Isolation by column chromatography $(n$-hexane/EtOAc $=1: 9)$ yielded 74ac $(53.6 \mathrm{mg}, 68 \%)$ as a yellow oil. ${ }^{1} \mathrm{H}-\mathrm{NMR}\left(400 \mathrm{MHz}, \mathrm{CDCl}_{3}\right): \delta=9.43(\mathrm{~s}, 1 \mathrm{H}), 8.12(\mathrm{dd}, J=7.8,1.5 \mathrm{~Hz}, 1 \mathrm{H}), 7.93(\mathrm{~d}, J=8.7$ $\mathrm{Hz}, 1 \mathrm{H}), 7.88(\mathrm{dd}, J=8.2,1.2 \mathrm{~Hz}, 1 \mathrm{H}), 7.78(\mathrm{~d}, J=8.7 \mathrm{~Hz}, 1 \mathrm{H}), 7.75-7.69(\mathrm{~m}, 1 \mathrm{H}), 7.66-7.59$ (m, 1H), 7.50 (ddd, $J=8.2,6.8,1.2 \mathrm{~Hz}, 1 \mathrm{H}), 7.37$ (ddd, $J=8.2,6.8,1.2 \mathrm{~Hz}, 1 \mathrm{H}), 7.31$ (ddd, $J$ $=7.5,1.2,0.6 \mathrm{~Hz}, 1 \mathrm{H}), 7.25-7.21(\mathrm{~m}, 1 \mathrm{H}), 7.20-7.05(\mathrm{~m}, 1 \mathrm{H}), 6.29(\mathrm{t}, J=17.7 \mathrm{~Hz}, 1 \mathrm{H}), 4.04-$ $3.86(\mathrm{~m}, 4 \mathrm{H}), 1.20(\mathrm{dt}, J=15.2,7.1 \mathrm{~Hz}, 6 \mathrm{H})$.

${ }^{13} \mathrm{C}-\mathrm{NMR}\left(100 \mathrm{MHz}, \mathrm{CDCl}_{3}\right): \delta=191.2(\mathrm{CH}), 145.4(\mathrm{~d}, J=7.1 \mathrm{~Hz}, \mathrm{CH}), 141.2\left(\mathrm{C}_{\mathrm{q}}\right), 136.0$ $\left(\mathrm{C}_{\mathrm{q}}\right), 135.2\left(\mathrm{C}_{\mathrm{q}}\right), 134.0(\mathrm{CH}), 133.7\left(\mathrm{C}_{\mathrm{q}}\right), 133.2\left(\mathrm{C}_{\mathrm{q}}\right), 131.9(\mathrm{CH}), 131.6\left(\mathrm{~d}, J=1.8 \mathrm{~Hz}, \mathrm{C}_{\mathrm{q}}\right)$, $129.1(\mathrm{CH}), 128.9(\mathrm{CH}), 128.1(\mathrm{CH}), 127.7(\mathrm{CH}), 127.3(\mathrm{CH}), 126.9(\mathrm{CH}), 122.5(\mathrm{CH}), 117.7$ $(\mathrm{CH}), 115.8(\mathrm{CH}), 61.9\left(\mathrm{~d}, J=5.4 \mathrm{~Hz}, \mathrm{CH}_{2}\right), 61.8\left(\mathrm{~d}, J=5.4 \mathrm{~Hz}, \mathrm{CH}_{2}\right), 16.3(\mathrm{~d}, J=4.1 \mathrm{~Hz}$, $\left.\mathrm{CH}_{3}\right), 16.2\left(\mathrm{~d}, J=4.1 \mathrm{~Hz}, \mathrm{CH}_{3}\right)$.

${ }^{31} \mathrm{P}-\mathrm{NMR}\left(160 \mathrm{MHz}, \mathrm{CDCl}_{3}\right): \delta=18.2$. 
IR (ATR): 2981, 1697, 1595, 1247, 1049, 1023, 965, $770 \mathrm{~cm}^{-1}$.

MS (ESI) $m / z$ (relative intensity): $417(100)[\mathrm{M}+\mathrm{Na}]^{+}, 395(10)[\mathrm{M}+\mathrm{H}]^{+}$.

HR-MS (ESI): $m / z$ calcd. for $\left[\mathrm{C}_{23} \mathrm{H}_{23} \mathrm{O}_{4} \mathrm{P}+\mathrm{Na}\right]^{+} 417.1226$ found 417.1232 .

$[\alpha]_{\mathrm{D}}^{20}:-6.8\left(\mathrm{c}=1.2, \mathrm{CHCl}_{3}\right)$.

HPLC separation (Chiralpak ${ }^{\circledR}$ IB-3, $n$-hexane $/ i$-PrOH 95:5, $1 \mathrm{~mL} / \mathrm{min}$, detection at $273 \mathrm{~nm}$ ): $t_{r}$ $($ major $)=31.0 \mathrm{~min}, t_{r}($ minor $)=28.7 \mathrm{~min}, 99 \%$ ee .<smiles>CC(=O)/C=C/c1cccc(C)c1-c1ccccc1C</smiles>

(E)-2'-methyl-6'-(3-oxobut-1-en-1-yl)-[1,1'-biphenyl]-2-carbaldehyde (74bd): The general procedure $\mathbf{L}$ was followed using 2'-methyl-[1,1'-biphenyl]-2-carbaldehyde (73b) (39.3 mg, $0.20 \mathrm{mmol})$ and but-3-en-2-one (38d) (42.1 $\mathrm{mg}, 0.60 \mathrm{mmol})$. Isolation by column chromatography $(n$-hexane/EtOAc $=7: 1)$ yielded 74bd $(33.8 \mathrm{mg}, 64 \%, E / Z=96: 4)$ as a colourless oil.

${ }^{1} \mathrm{H}-\mathrm{NMR}\left(400 \mathrm{MHz}, \mathrm{CDCl}_{3}\right): \delta=9.63(\mathrm{~s}, 1 \mathrm{H}), 8.08(\mathrm{dd}, J=7.8,1.5,1 \mathrm{H}), 7.71(\mathrm{td}, J=7.5,1.5$ $\mathrm{Hz}, 1 \mathrm{H}), 7.65-7.55$ (m, 2H), 7.41-7.32 (m, 2H), 7.23 (ddd, $J=7.6,1.3,0.6 \mathrm{~Hz}, 1 \mathrm{H}), 7.03$ (d, $J=16.2 \mathrm{~Hz}, 1 \mathrm{H}), 6.53(\mathrm{~d}, J=16.0 \mathrm{~Hz}, 0.96 \mathrm{H}, E), 6.44(\mathrm{~d}, J=12.0 \mathrm{~Hz}, 0.04 \mathrm{H}, Z), 2.07(\mathrm{~s}, 3 \mathrm{H})$, $2.02(\mathrm{~s}, 3 \mathrm{H})$.

${ }^{13} \mathrm{C}-\mathrm{NMR}\left(100 \mathrm{MHz}, \mathrm{CDCl}_{3}\right): \delta=198.0\left(\mathrm{C}_{\mathrm{q}}\right), 191.4(\mathrm{CH}), 142.6\left(\mathrm{C}_{\mathrm{q}}\right), 141.3(\mathrm{CH}), 138.3\left(\mathrm{C}_{\mathrm{q}}\right)$, $137.3\left(\mathrm{C}_{\mathrm{q}}\right), 134.2(\mathrm{CH}), 134.2\left(\mathrm{C}_{\mathrm{q}}\right), 134.0\left(\mathrm{C}_{\mathrm{q}}\right), 131.8(\mathrm{CH}), 130.9(\mathrm{CH}), 128.8(\mathrm{CH}), 128.6$ $(\mathrm{CH}), 128.6(\mathrm{CH}), 128.0(\mathrm{CH}), 124.0(\mathrm{CH}), 27.1\left(\mathrm{CH}_{3}\right), 20.8\left(\mathrm{CH}_{3}\right)$.

IR (ATR): 2945, 1696, 1632, 1445, 1376, 1316, 750, $701 \mathrm{~cm}^{-1}$.

MS (ESI) $m / z$ (relative intensity): $287(100)[\mathrm{M}+\mathrm{Na}]^{+}, 265(30)[\mathrm{M}+\mathrm{H}]^{+}$.

HR-MS (ESI): $m / z$ calcd. for $\left[\mathrm{C}_{18} \mathrm{H}_{16} \mathrm{O}_{2}+\mathrm{Na}\right]^{+} 287.1043$ found 287.1045 .

$[\alpha]_{\mathrm{D}}^{20}:-26.7\left(\mathrm{c}=1.1, \mathrm{CHCl}_{3}\right)$.

HPLC separation (Chiralpak ${ }^{\circledR} \mathrm{IB}-3, n$-hexane/i-PrOH 95:5, $1 \mathrm{~mL} / \mathrm{min}$, detection at $273 \mathrm{~nm}$ ): $t_{r}$ $($ major $)=15.8 \mathrm{~min}, t_{r}($ minor $)=11.6 \mathrm{~min}, 98 \%$ ee.

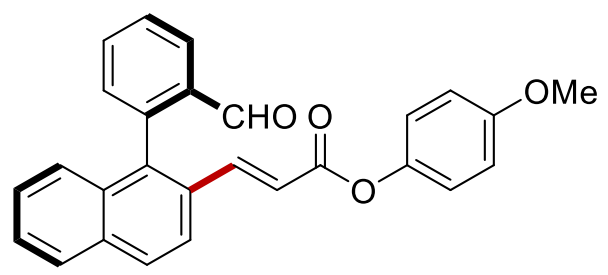

(E)-4-methoxyphenyl -3-(1-(2-formylphenyl)naphthalen-2-yl)acrylate (74ae): The general procedure $\mathbf{L}$ was followed using 2-(naphthalen-1-yl)benzaldehyde (73a) (46.4 mg, $0.20 \mathrm{mmol}$ ) 
and 4-methoxyphenyl acrylate (38e) $(106.9 \mathrm{mg}, 0.60 \mathrm{mmol})$. Isolation by column chromatography $(n$-hexane/EtOAc $=4: 1)$ yielded 74ae $(55.5 \mathrm{mg}, 68 \%, E / Z=97: 3)$ as a yellow oil.

${ }^{1} \mathrm{H}-\mathrm{NMR}\left(400 \mathrm{MHz}, \mathrm{CDCl}_{3}\right): \delta=9.55(\mathrm{~s}, 0.03 \mathrm{H}, Z), 9.53$ (s, 0.97H, E), 8.19 (dd, J = 7.9, 1.4 $\mathrm{Hz}, 1 \mathrm{H}), 8.02(\mathrm{~d}, J=8.8 \mathrm{~Hz}, 1 \mathrm{H}), 7.99-7.89(\mathrm{~m}, 2 \mathrm{H}), 7.83-7.73(\mathrm{~m}, 1 \mathrm{H}), 7.73-7.51(\mathrm{~m}, 3 \mathrm{H})$, 7.51-7.40 (m, 2H), 7.34-7.22 (m, 2H), $6.80(\mathrm{dd}, J=8.3,2.5 \mathrm{~Hz}, 1 \mathrm{H}), 6.75-6.65(\mathrm{~m}, 3 \mathrm{H}), 3.81$ $(\mathrm{s}, 3 \mathrm{H})$.

${ }^{13} \mathrm{C}-\mathrm{NMR}\left(100 \mathrm{MHz}, \mathrm{CDCl}_{3}\right): \delta=191.2(\mathrm{CH}), 164.8\left(\mathrm{C}_{\mathrm{q}}\right), 160.4\left(\mathrm{C}_{\mathrm{q}}\right), 151.6\left(\mathrm{C}_{\mathrm{q}}\right), 144.0(\mathrm{CH})$, $141.0\left(\mathrm{C}_{\mathrm{q}}\right), 137.3\left(\mathrm{C}_{\mathrm{q}}\right), 135.3\left(\mathrm{C}_{\mathrm{q}}\right), 134.1(\mathrm{CH}), 133.9\left(\mathrm{C}_{\mathrm{q}}\right), 133.3\left(\mathrm{C}_{\mathrm{q}}\right), 131.9(\mathrm{CH}), 130.8\left(\mathrm{C}_{\mathrm{q}}\right)$, $129.7(\mathrm{CH}), 129.2(\mathrm{CH}), 129.1(\mathrm{CH}), 128.2(\mathrm{CH}), 128.0(\mathrm{CH}), 127.5(\mathrm{CH}), 127.4(\mathrm{CH}), 127.1$ $(\mathrm{CH}), 122.7(\mathrm{CH}), 119.1(\mathrm{CH}), 113.7(\mathrm{CH}), 111.7(\mathrm{CH}), 107.4(\mathrm{CH}), 55.4\left(\mathrm{CH}_{3}\right)$.

IR (ATR): 2920, 1724, 1695, 1594, 1489, 1146, $757 \mathrm{~cm}^{-1}$.

MS (ESI) $m / z$ (relative intensity): $431(100)[\mathrm{M}+\mathrm{Na}]^{+}, 409(20)[\mathrm{M}+\mathrm{H}]^{+}$.

HR-MS (ESI): $m / z$ calcd. for $\left[\mathrm{C}_{27} \mathrm{H}_{20} \mathrm{O}_{4}+\mathrm{Na}\right]^{+} 431.1254$ found 431.1253 .

$[\alpha]_{\mathrm{D}}^{20}:-31.9\left(\mathrm{c}=1.0, \mathrm{CHCl}_{3}\right)$.

HPLC separation (Chiralpak ${ }^{\circledR}$ IA-3, $n$-hexane $/ i$-PrOH 95:5, $1 \mathrm{~mL} / \mathrm{min}$, detection at $273 \mathrm{~nm}$ ): $t_{r}$ $($ major $)=15.1 \mathrm{~min}, t_{r}($ minor $)=13.6 \mathrm{~min}, 98 \%$ ee.<smiles>Cc1ccccc1-c1c(C)cccc1/C=C/C(=O)OCc1ccc(F)cc1</smiles>

4-Fluorobenzyl $\quad(E)-3-(2 '-f o r m y l-6-m e t h y l-[1,1 '-b i p h e n y l]-2-y l) a c r y l a t e \quad(74 b f): \quad$ The general procedure $\mathbf{L}$ was followed using 2'-methyl-[1,1'-biphenyl]-2-carbaldehyde (73b) (40 $\mathrm{mg}, 0.20 \mathrm{mmol}$ ) and 4-fluorobenzyl acrylate (38f) (108 $\mathrm{mg}, 0.60 \mathrm{mmol})$. Isolation by column chromatography ( $n$-hexane/EtOAc $=5: 1)$ yielded 74bf $(53 \mathrm{mg}, 70 \%)$.

${ }^{1} \mathrm{H}-\mathrm{NMR}\left(400 \mathrm{MHz}, \mathrm{CDCl}_{3}\right): \delta=9.61(\mathrm{~s}, 1 \mathrm{H}), 8.06(\mathrm{dd}, J=7.8,1.4 \mathrm{~Hz}, 1 \mathrm{H}), 7.69$ (dd, $J=7.5$, $1.5 \mathrm{~Hz}, 1 \mathrm{H}), 7.62-7.54(\mathrm{~m}, 2 \mathrm{H}), 7.39-7.31(\mathrm{~m}, 2 \mathrm{H}), 7.31-7.19(\mathrm{~m}, 4 \mathrm{H}), 7.06-6.99(\mathrm{~m}, 2 \mathrm{H})$, $6.31(\mathrm{~d}, J=16.0 \mathrm{~Hz}, 1 \mathrm{H}), 5.07(\mathrm{~s}, 2 \mathrm{H}), 2.00(\mathrm{~s}, 3 \mathrm{H})$.

${ }^{13} \mathrm{C}-\mathrm{NMR}\left(100 \mathrm{MHz}, \mathrm{CDCl}_{3}\right): \delta=191.4(\mathrm{CH}), 166.1\left(\mathrm{C}_{\mathrm{q}}\right), 162.5\left(\mathrm{~d},{ }^{1} \mathrm{~J}_{\mathrm{C}-\mathrm{F}}=246.8 \mathrm{~Hz}, \mathrm{C}_{\mathrm{q}}\right)$, $143.2(\mathrm{CH}), 142.5\left(\mathrm{C}_{\mathrm{q}}\right), 138.2\left(\mathrm{C}_{\mathrm{q}}\right), 137.3\left(\mathrm{C}_{\mathrm{q}}\right), 134.2(\mathrm{CH}), 134.1\left(\mathrm{C}_{\mathrm{q}}\right), 133.7\left(\mathrm{C}_{\mathrm{q}}\right), 131.8(\mathrm{~d}$, $\left.{ }^{4} J_{\mathrm{C}-\mathrm{F}}=3.2 \mathrm{~Hz}, \mathrm{C}_{\mathrm{q}}\right), 131.7(\mathrm{CH}), 130.9(\mathrm{CH}), 129.9\left(\mathrm{~d},{ }^{3} J_{\mathrm{C}-\mathrm{F}}=8.2 \mathrm{~Hz}, \mathrm{CH}\right), 128.5(\mathrm{CH}), 128.5$ $(\mathrm{CH}), 128.0(\mathrm{CH}), 123.9(\mathrm{CH}), 119.2(\mathrm{CH}), 115.4\left(\mathrm{~d},{ }^{2} J_{\mathrm{C}-\mathrm{F}}=21.6 \mathrm{~Hz}, \mathrm{CH}\right), 65.4\left(\mathrm{CH}_{2}\right), 20.8$ $\left(\mathrm{CH}_{3}\right)$. 
${ }^{19} \mathrm{~F}-\mathrm{NMR}\left(375 \mathrm{MHz}, \mathrm{CDCl}_{3}\right): \delta=-113.8$.

IR (ATR): 2955, 1730, 1682, 1485, 1376, 1320, $744 \mathrm{~cm}^{-1}$.

MS (ESI) $m / z$ (relative intensity): $397(100)[\mathrm{M}+\mathrm{Na}]^{+}, 375(20)[\mathrm{M}+\mathrm{H}]^{+}$.

HR-MS (ESI): $m / z$ calcd. for $\left[\mathrm{C}_{24} \mathrm{H}_{19} \mathrm{FO}_{3}+\mathrm{Na}\right]^{+} 397.1210$ found 397.1215 .

$[\alpha]_{\mathrm{D}}^{20}:-7.0\left(\mathrm{c}=1.0, \mathrm{CHCl}_{3}\right)$.

HPLC separation (Chiralpak ${ }^{\circledR}$ IA-3, $n$-hexane $/ i$-PrOH 95:5, $1 \mathrm{~mL} / \mathrm{min}$, detection at $273 \mathrm{~nm}$ ): $t_{r}$ $($ major $)=12.6 \mathrm{~min}, t_{r}($ minor $)=16.3 \mathrm{~min}, 98 \%$ ee<smiles>Cc1ccccc1-c1c(/C=C/C(=O)Oc2ccc(Br)cc2)ccc2ccccc12</smiles>

(E)-4-Bromophenyl -3-(1-(2-formylphenyl)naphthalen-2-yl)acrylate (74ag): The general procedure $\mathbf{L}$ was followed using 2-(naphthalen-1-yl)benzaldehyde (73a) (46 mg, $0.20 \mathrm{mmol}$ ) and 4-bromophenyl acrylate (38g) (135.6 $\mathrm{mg}, 0.60 \mathrm{mmol})$. Isolation by column chromatography $(n$-hexane/EtOAc $=5: 1)$ yielded 74ag $(45.6 \mathrm{mg}, 50 \%)$ as yellow oil.

${ }^{1} \mathrm{H}-\mathrm{NMR}\left(400 \mathrm{MHz}, \mathrm{CDCl}_{3}\right): \delta=9.50(\mathrm{~s}, 1 \mathrm{H}), 8.16(\mathrm{~d}, J=7.7 \mathrm{~Hz}, 1 \mathrm{H}), 7.99(\mathrm{~d}, J=8.7 \mathrm{~Hz}$, 1H), 7.95-7.88 (m, 2H), 7.82-7.62 (m, 2H), 7.63-7.52 (m, 2H), 7.50-7.45 (m, 2H), 7.42 (t, $J$ $=8.5 \mathrm{~Hz}, 1 \mathrm{H}), 7.37(\mathrm{~d}, J=7.6 \mathrm{~Hz}, 1 \mathrm{H}), 7.31-7.25(\mathrm{~m}, 1 \mathrm{H}), 7.02-6.93(\mathrm{~m}, 2 \mathrm{H}), 6.64(\mathrm{~d}, J=$ $16.6 \mathrm{~Hz}, 1 \mathrm{H})$.

${ }^{13} \mathrm{C}-\mathrm{NMR}\left(100 \mathrm{MHz}, \mathrm{CDCl}_{3}\right): \delta=191.2(\mathrm{CH}), 164.6\left(\mathrm{C}_{\mathrm{q}}\right), 149.7\left(\mathrm{C}_{\mathrm{q}}\right), 144.4(\mathrm{CH}), 140.9\left(\mathrm{C}_{\mathrm{q}}\right)$, $137.5\left(\mathrm{C}_{\mathrm{q}}\right), 135.3\left(\mathrm{C}_{\mathrm{q}}\right), 134.1(\mathrm{CH}), 134.0\left(\mathrm{C}_{\mathrm{q}}\right), 133.3\left(\mathrm{C}_{\mathrm{q}}\right), 132.4(\mathrm{CH}), 132.0(\mathrm{CH}), 130.7\left(\mathrm{C}_{\mathrm{q}}\right)$, $129.3(\mathrm{CH}), 129.1(\mathrm{CH}), 128.2(\mathrm{CH}), 128.1(\mathrm{CH}), 127.7(\mathrm{CH}), 127.5(\mathrm{CH}), 127.1(\mathrm{CH}), 123.3$ $(\mathrm{CH}), 122.6(\mathrm{CH}), 118.8\left(\mathrm{C}_{\mathrm{q}}\right), 118.7(\mathrm{CH})$.

IR (ATR): 2935, 1712, 1682, 1355, 1250, 1146, 1014, $920 \mathrm{~cm}^{-1}$.

MS (ESI) $m / z$ (relative intensity): $479(100)[\mathrm{M}+\mathrm{Na}]^{+}, 457(10)[\mathrm{M}+\mathrm{H}]^{+}$.

HR-MS (ESI): $m / z$ calcd. for $\left[\mathrm{C}_{26} \mathrm{H}_{17}{ }^{79} \mathrm{BrO}_{3}+\mathrm{Na}\right]^{+} 479.0253$ found 479.0245 .

$[\alpha]_{\mathrm{D}}^{20}:-34.0\left(\mathrm{c}=1.5, \mathrm{CHCl}_{3}\right)$.

HPLC separation (Chiralpak ${ }^{\circledR}$ IA-3, $n$-hexane $/ i$-PrOH 95:5, $1 \mathrm{~mL} / \mathrm{min}$, detection at $273 \mathrm{~nm}$ ): $t_{r}$ $($ major $)=20.4 \mathrm{~min}, t_{r}($ minor $)=23.1 \mathrm{~min}, 97 \%$ ee . 
<smiles>O=C/C=C/c1ccc2ccccc2c1-c1ccccc1COC(=O)Oc1ccc([N+](=O)[O-])cc1</smiles>

(E)-4-nitrophenyl-3-(1-(2-formylphenyl)naphthalen-2-yl)acrylate (74ah): The general procedure $\mathbf{L}$ was followed using 2-(naphthalen-1-yl)benzaldehyde (73a) (46.4 mg, $0.20 \mathrm{mmol}$ ) and 4-nitrophenyl acrylate $(\mathbf{3 8 h})(115.9 \mathrm{mg}, 0.60 \mathrm{mmol})$. Isolation by column chromatography $(n$-hexane/EtOAc $=1: 1)$ yielded 74ah $(40.6 \mathrm{mg}, 48 \%)$ as a yellow oil.

${ }^{1} \mathrm{H}-\mathrm{NMR}\left(400 \mathrm{MHz}, \mathrm{CDCl}_{3}\right): \delta=9.53(\mathrm{~s}, 1 \mathrm{H}), 8.28(\mathrm{~d}, J=9.1 \mathrm{~Hz}, 2 \mathrm{H}), 8.19(\mathrm{~d}, J=7.7 \mathrm{~Hz}$, $1 \mathrm{H}), 8.03(\mathrm{~d}, J=8.8 \mathrm{~Hz}, 1 \mathrm{H}), 7.99-7.89(\mathrm{~m}, 2 \mathrm{H}), 7.80(\mathrm{td}, J=7.5,1.5 \mathrm{~Hz}, 1 \mathrm{H}), 7.76-7.54(\mathrm{~m}$, 3H), 7.51-7.37 (m, 2H), 7.36-7.25 (m, 3H), $6.68(\mathrm{~d}, J=15.9 \mathrm{~Hz}, 1 \mathrm{H})$.

${ }^{13} \mathrm{C}-\mathrm{NMR}\left(100 \mathrm{MHz}, \mathrm{CDCl}_{3}\right): \delta=191.2(\mathrm{CH}), 163.9\left(\mathrm{C}_{\mathrm{q}}\right), 155.5\left(\mathrm{C}_{\mathrm{q}}\right), 145.4(\mathrm{CH}), 145.3\left(\mathrm{C}_{\mathrm{q}}\right)$, $140.8\left(\mathrm{C}_{\mathrm{q}}\right), 137.9\left(\mathrm{C}_{\mathrm{q}}\right), 135.3\left(\mathrm{C}_{\mathrm{q}}\right), 134.2\left(\mathrm{C}_{\mathrm{q}}\right), 134.1(\mathrm{CH}), 133.3\left(\mathrm{C}_{\mathrm{q}}\right), 132.0(\mathrm{CH}), 130.5\left(\mathrm{C}_{\mathrm{q}}\right)$, 129.4 (CH), $129.2(\mathrm{CH}), 128.3(\mathrm{CH}), 128.2(\mathrm{CH}), 127.9(\mathrm{CH}), 127.6(\mathrm{CH}), 127.2(\mathrm{CH}), 125.2$ $(\mathrm{CH}), 122.5(\mathrm{CH}), 122.4(\mathrm{CH}), 117.9(\mathrm{CH})$.

IR (ATR): 3018, 1696, 1661, 1215, 751, 720, $683 \mathrm{~cm}^{-1}$.

MS (ESI) $m / z$ (relative intensity): $446(100)[\mathrm{M}+\mathrm{Na}]^{+}, 424(20)[\mathrm{M}+\mathrm{H}]^{+}$.

HR-MS (ESI): $m / z$ calcd. for $\left[\mathrm{C}_{26} \mathrm{H}_{17} \mathrm{NO}_{5}+\mathrm{Na}\right]^{+} 446.0999$ found 446.0998 .

$[\alpha]_{\mathrm{D}}^{20}:-10.6\left(\mathrm{c}=0.2, \mathrm{CHCl}_{3}\right)$.

HPLC separation (Chiralpak ${ }^{\circledR}$ IA-3, $n$-hexane $/ i$-PrOH 90:10, $1 \mathrm{~mL} / \mathrm{min}$, detection at $273 \mathrm{~nm}$ ): $t_{r}($ major $)=27.0 \mathrm{~min}, t_{r}($ minor $)=42.4 \mathrm{~min}, 96 \%$ ee .<smiles>CC(=O)c1ccc(OC(=O)/C=C/c2ccc3ccccc3c2-c2ccccc2C)cc1</smiles>

4-Acetylphenyl (E)-3-(1-(2-formylphenyl)naphthalen-2-yl)acrylate (74ai): The general procedure $\mathbf{L}$ was followed using 2-(naphthalen-1-yl)benzaldehyde (73a) (46 mg, $0.20 \mathrm{mmol}$ ) and 4-acetylphenyl acrylate (38i) (114 $\mathrm{mg}, 0.60 \mathrm{mmol})$. Isolation by column chromatography $(n$-hexane/EtOAc $=4: 1)$ yielded 74ai $(54 \mathrm{mg}, 64 \%)$ as colourless oil.

${ }^{1} \mathrm{H}-\mathrm{NMR}\left(400 \mathrm{MHz}, \mathrm{CDCl}_{3}\right): \delta=9.51(\mathrm{~s}, 1 \mathrm{H}), 8.16(\mathrm{ddd}, J=7.9,1.5,0.6 \mathrm{~Hz}, 1 \mathrm{H}), 8.02-7.96$ $(\mathrm{m}, 3 \mathrm{H}), 7.95-7.92(\mathrm{~m}, 1 \mathrm{H}), 7.91(\mathrm{~d}, J=8.8 \mathrm{~Hz}, 1 \mathrm{H}), 7.77(\mathrm{td}, J=7.5,1.5 \mathrm{~Hz}, 1 \mathrm{H}), 7.70-7.54$ (m, 3H), 7.46-7.34 (m, 2H), 7.32-7.24 (m, 1H), 7.23-7.17 (m, 2H), $6.66(\mathrm{~d}, J=15.9 \mathrm{~Hz}, 1 \mathrm{H})$, $2.59(\mathrm{~s}, 3 \mathrm{H})$. 
${ }^{13} \mathrm{C}-\mathrm{NMR}\left(100 \mathrm{MHz}, \mathrm{CDCl}_{3}\right): \delta=196.8\left(\mathrm{C}_{\mathrm{q}}\right), 191.2(\mathrm{CH}), 164.3\left(\mathrm{C}_{\mathrm{q}}\right), 154.4\left(\mathrm{C}_{\mathrm{q}}\right), 144.7(\mathrm{CH})$, $140.9\left(\mathrm{C}_{\mathrm{q}}\right), 137.6\left(\mathrm{C}_{\mathrm{q}}\right), 135.3\left(\mathrm{C}_{\mathrm{q}}\right), 134.6\left(\mathrm{C}_{\mathrm{q}}\right), 134.1(\mathrm{CH}), 134.0\left(\mathrm{C}_{\mathrm{q}}\right), 133.3\left(\mathrm{C}_{\mathrm{q}}\right), 131.9(\mathrm{CH})$, $130.7\left(\mathrm{C}_{\mathrm{q}}\right), 129.8(\mathrm{CH}), 129.3(\mathrm{CH}), 129.1(\mathrm{CH}), 128.2(\mathrm{CH}), 128.1(\mathrm{CH}), 127.7(\mathrm{CH}), 127.5$ $(\mathrm{CH}), 127.1(\mathrm{CH}), 122.6(\mathrm{CH}), 121.7(\mathrm{CH}), 118.5(\mathrm{CH}), 26.6\left(\mathrm{CH}_{3}\right)$.

IR (ATR): 2925, 1733, 1682, 1596, 1201, 1130, 753, $658 \mathrm{~cm}^{-1}$.

MS (ESI) $m / z$ (relative intensity): $443(100)[\mathrm{M}+\mathrm{Na}]^{+}, 421(5)[\mathrm{M}+\mathrm{H}]^{+}$.

HR-MS (ESI): $m / z$ calcd. for $\left[\mathrm{C}_{28} \mathrm{H}_{20} \mathrm{O}_{4}+\mathrm{Na}\right]^{+} 443.1254$ found 443.1258 .

$[\alpha]_{\mathrm{D}}^{20}:-29.9\left(\mathrm{c}=1.0, \mathrm{CHCl}_{3}\right)$.

HPLC separation (Chiralpak ${ }^{\circledR}$ IA-3, $n$-hexane/i-PrOH 70:30, $0.75 \mathrm{~mL} / \mathrm{min}$, detection at 273 $\mathrm{nm}): t_{r}($ major $)=17.2 \mathrm{~min}, t_{r}($ minor $)=21.4 \mathrm{~min}, 98 \%$ ee.<smiles>Cc1ccccc1-c1c(C)cccc1/C=C/C(=O)NC(C)C</smiles>

$(R, E)-3-(2 '-f o r m y l-6-m e t h y l-[1,1 '-b i p h e n y l]-2-y l)-N$-isopropylacrylamide $\quad(74 b j): \quad$ The general procedure $\mathbf{L}$ was followed using 2'-methyl-[1,1'-biphenyl]-2-carbaldehyde (73b) (39.3 $\mathrm{mg}, 0.20 \mathrm{mmol})$ and $N$-isopropylacrylamide (38j) $(67.9 \mathrm{mg}, 0.60 \mathrm{mmol})$. Isolation by column chromatography ( $n$-hexane/EtOAc $=1: 2)$ yielded 74bj $(33.8 \mathrm{mg}, 55 \%)$ as a white solid. M.P. $145-150{ }^{\circ} \mathrm{C}$.

${ }^{1} \mathrm{H}-\mathrm{NMR}\left(400 \mathrm{MHz}, \mathrm{CDCl}_{3}\right): \delta=9.59(\mathrm{~s}, 1 \mathrm{H}), 8.02(\mathrm{~d}, J=7.8 \mathrm{~Hz}, 1 \mathrm{H}), 7.66(\mathrm{td}, J=7.5,1.5$ $\mathrm{Hz}, 1 \mathrm{H}), 7.58-7.48(\mathrm{~m}, 2 \mathrm{H}), 7.38-7.24(\mathrm{~m}, 2 \mathrm{H}), 7.24-7.12(\mathrm{~m}, 2 \mathrm{H}), 6.16(\mathrm{~d}, J=15.4 \mathrm{~Hz}, 1 \mathrm{H})$, $5.40(\mathrm{~d}, J=7.9 \mathrm{~Hz}, 1 \mathrm{H}), 4.13-4.00(\mathrm{~m}, 1 \mathrm{H}), 1.97(\mathrm{~s}, 3 \mathrm{H}), 1.18-1.08(\mathrm{~m}, 6 \mathrm{H})$.

${ }^{13} \mathrm{C}-\mathrm{NMR}\left(100 \mathrm{MHz}, \mathrm{CDCl}_{3}\right): \delta=191.7(\mathrm{CH}), 164.4\left(\mathrm{C}_{\mathrm{q}}\right), 142.8\left(\mathrm{C}_{\mathrm{q}}\right), 138.7(\mathrm{CH}), 137.9\left(\mathrm{C}_{\mathrm{q}}\right)$, $137.3\left(\mathrm{C}_{\mathrm{q}}\right), 134.5\left(\mathrm{C}_{\mathrm{q}}\right), 134.4\left(\mathrm{C}_{\mathrm{q}}\right), 134.1(\mathrm{CH}), 130.9(\mathrm{CH}), 130.8(\mathrm{CH}), 128.5(\mathrm{CH}), 128.3$ $(\mathrm{CH}), 128.0(\mathrm{CH}), 123.7(\mathrm{CH}), 122.8(\mathrm{CH}), 41.5(\mathrm{CH}), 22.8\left(\mathrm{CH}_{3}\right), 22.7\left(\mathrm{CH}_{3}\right), 20.8\left(\mathrm{CH}_{3}\right)$. IR (ATR): 2924, 1694, 1652, 1541, 1456, 1225, 1195, $755 \mathrm{~cm}^{-1}$. MS (ESI) $m / z$ (relative intensity): $330(100)[\mathrm{M}+\mathrm{Na}]^{+}, 308(20)[\mathrm{M}+\mathrm{H}]^{+}$. HR-MS (ESI): $m / z$ calcd. for $\left[\mathrm{C}_{20} \mathrm{H}_{21} \mathrm{NO}_{2}+\mathrm{Na}\right]^{+} 330.1465$ found 330.1470 . $[\alpha]_{\mathrm{D}}^{20}:+9.2\left(\mathrm{c}=0.25, \mathrm{CHCl}_{3}\right)$.

HPLC separation (Chiralpak ${ }^{\circledR}$ IA-3, $n$-hexane $/ i$-PrOH 90:10, $1 \mathrm{~mL} / \mathrm{min}$, detection at $273 \mathrm{~nm}$ ): $t_{r}($ major $)=13.2 \mathrm{~min}, t_{r}($ minor $)=12.0 \mathrm{~min}, 96 \%$ ee. 


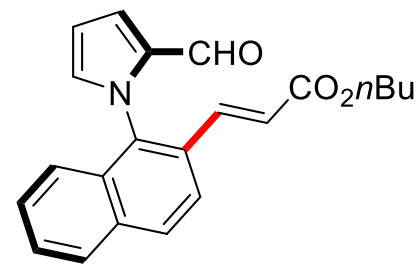

(E)-Butyl -3-(1-(2-formyl-1H-pyrrol-1-yl)naphthalen-2-yl)acrylate (397aa): A modified procedure A was followed using 1-(naphthalen-1-yl)-1H-pyrrole-2-carbaldehyde (396a) (44.3 $\mathrm{mg}, 0.20 \mathrm{mmol})$ and $n$-butyl acrylate (38a) $(76.9 \mathrm{mg}, 0.60 \mathrm{mmol})$ with L-tert-leucine $(7.9 \mathrm{mg}$, $30 \mathrm{~mol} \%)$. Isolation by column chromatography $(n$-hexane/EtOAc $=5: 1)$ yielded 397aa $(38.9$ $\mathrm{mg}, 56 \%)$ as a yellow oil.

${ }^{1} \mathrm{H}-\mathrm{NMR}\left(400 \mathrm{MHz}, \mathrm{CDCl}_{3}\right): \delta=9.46(\mathrm{~s}, 1 \mathrm{H}), 8.02(\mathrm{~d}, J=8.8 \mathrm{~Hz}, 1 \mathrm{H}), 7.96(\mathrm{~d}, J=8.2 \mathrm{~Hz}$, $1 \mathrm{H}), 7.86(\mathrm{~d}, J=8.8 \mathrm{~Hz}, 1 \mathrm{H}), 7.65-7.56(\mathrm{~m}, 1 \mathrm{H}), 7.56-7.46(\mathrm{~m}, 1 \mathrm{H}), 7.37-7.28(\mathrm{~m}, 2 \mathrm{H}), 7.18$ (d, $J=8.5 \mathrm{~Hz}, 1 \mathrm{H}), 7.09$ (s, 1H), 6.69-6.62 (m, 1H), 6.52 (d, $J=16.0 \mathrm{~Hz}, 1 \mathrm{H}), 4.20$ (t, $J=6.6$ $\mathrm{Hz}, 2 \mathrm{H}), 1.75-1.62(\mathrm{~m}, 2 \mathrm{H}), 1.50-1.38(\mathrm{~m}, 2 \mathrm{H}), 0.99$ (t, $J=7.3 \mathrm{~Hz}, 3 \mathrm{H})$.

${ }^{13} \mathrm{C}-\mathrm{NMR}\left(100 \mathrm{MHz}, \mathrm{CDCl}_{3}\right): \delta=178.5(\mathrm{CH}), 166.4\left(\mathrm{C}_{\mathrm{q}}\right), 139.1\left(\mathrm{C}_{\mathrm{q}}\right), 138.3(\mathrm{CH}), 135.6(\mathrm{CH})$, $134.5\left(\mathrm{C}_{\mathrm{q}}\right), 134.4\left(\mathrm{C}_{\mathrm{q}}\right), 132.2(\mathrm{CH}), 131.5\left(\mathrm{C}_{\mathrm{q}}\right), 129.7\left(\mathrm{C}_{\mathrm{q}}\right), 129.5(\mathrm{CH}), 128.1(\mathrm{CH}), 128.0$ $(\mathrm{CH}), 127.8(\mathrm{CH}), 123.2(\mathrm{CH}), 122.6(\mathrm{CH}), 121.6(\mathrm{CH}), 111.5(\mathrm{CH}), 64.5\left(\mathrm{CH}_{2}\right), 30.6\left(\mathrm{CH}_{2}\right)$, $19.1\left(\mathrm{CH}_{2}\right), 13.7\left(\mathrm{CH}_{3}\right)$.

IR (ATR): 2957, 1712, 1671, 1305, 1196, 1150, 787, $741 \mathrm{~cm}^{-1}$.

MS (ESI) $m / z$ (relative intensity): $370(100)[\mathrm{M}+\mathrm{Na}]^{+}, 348(20)[\mathrm{M}+\mathrm{H}]^{+}$.

HR-MS (ESI): $m / z$ calcd. for $\left[\mathrm{C}_{22} \mathrm{H}_{21} \mathrm{NO}_{3}+\mathrm{Na}\right]^{+} 370.1414$ found 370.1419 .

$[\alpha]_{\mathrm{D}}^{20}:-43.1\left(\mathrm{c}=0.4, \mathrm{CHCl}_{3}\right)$.

HPLC separation (Chiralpak ${ }^{\circledR}$ ID-3, $n$-hexane $/ i$-PrOH 80:20, $1 \mathrm{~mL} / \mathrm{min}$, detection at $273 \mathrm{~nm}$ ): $t_{r}($ major $)=15.2 \mathrm{~min}, t_{r}($ minor $)=16.6 \mathrm{~min}, 99 \%$ ee. The analytical data correspond with those reported in the literature. ${ }^{[276]}$

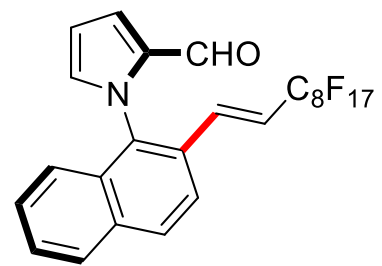

(E)-1-(2-(3,3,4,4,5,5,6,6,7,7,8,8,9,9,10,10,10-heptadecafluorodec-1-en-1-yl)naphthalen-1yl)-1H-pyrrole-2-carbaldehyde (398aa): A modified procedure A was followed using 1(naphthalen-1-yl)-1H-pyrrole-2-carbaldehyde $\quad$ (396a) $\quad(44.3 \quad \mathrm{mg}, \quad 0.20 \mathrm{mmol}) \quad$ and 3,3,4,4,5,5,6,6,7,7,8,8,9,9,10,10,10-heptadecafluorodec-1-ene (301a) (267.7 mg, 0.60 mmol) with L-tert-leucine $(7.9 \mathrm{mg}, 30 \mathrm{~mol} \%)$. Isolation by column chromatography ( $n$-hexane/DCM $=1: 1)$ yielded 398aa $(69.2 \mathrm{mg}, 52 \%)$ as a yellow oil. 
${ }^{1} \mathrm{H}-\mathrm{NMR}\left(400 \mathrm{MHz}, \mathrm{CDCl}_{3}\right): \delta=9.43(\mathrm{~s}, 1 \mathrm{H}), 7.99$ (d, $\left.J=8.7 \mathrm{~Hz}, 1 \mathrm{H}\right), 7.92$ (d, $J=8.2 \mathrm{~Hz}$, $1 \mathrm{H}), 7.72(\mathrm{~d}, J=8.7 \mathrm{~Hz}, 1 \mathrm{H}), 7.61-7.50(\mathrm{~m}, 1 \mathrm{H}), 7.52-7.43(\mathrm{~m}, 1 \mathrm{H}), 7.27(\mathrm{dd}, J=4.0,1.6 \mathrm{~Hz}$, $1 \mathrm{H}), 7.15(\mathrm{~d}, J=7.5 \mathrm{~Hz}, 1 \mathrm{H}), 7.06-6.97(\mathrm{~m}, 1 \mathrm{H}), 6.72(\mathrm{dt}, J=16.1,2.4 \mathrm{~Hz}, 1 \mathrm{H}), 6.60(\mathrm{dd}, J=$ 4.0, $2.5 \mathrm{~Hz}, 1 \mathrm{H}), 6.17(\mathrm{dt}, J=16.2,11.8 \mathrm{~Hz}, 1 \mathrm{H})$.

${ }^{13} \mathrm{C}-\mathrm{NMR}\left(100 \mathrm{MHz}, \mathrm{CDCl}_{3}\right): \delta=178.3(\mathrm{CH}), 135.4\left(\mathrm{C}_{\mathrm{q}}\right), 134.6-134.3\left(\mathrm{~m}, \mathrm{CH}+\mathrm{C}_{\mathrm{q}}\right), 134.3$ $\left(\mathrm{C}_{\mathrm{q}}\right), 131.9(\mathrm{CH}), 131.3\left(\mathrm{C}_{\mathrm{q}}\right), 129.7(\mathrm{CH}), 128.7\left(\mathrm{C}_{\mathrm{q}}\right), 128.3(\mathrm{CH}), 128.1(\mathrm{CH}), 127.9(\mathrm{CH})$, $123.1(\mathrm{CH}), 122.6(\mathrm{CH}), 122.1(\mathrm{CH}), 117.8\left(\mathrm{t}, J=23.1 \mathrm{~Hz}, \mathrm{CH}-\mathrm{CF}_{2}\right), 111.6(\mathrm{CH})$.

${ }^{19}$ F-NMR (375 MHz, $\left.\mathrm{CDCl}_{3}\right): \delta=-80.7(\mathrm{~m}),-111.5(\mathrm{~m}),-121.3(\mathrm{~m}),-121.9(\mathrm{~m}),-122.7(\mathrm{~m})$, $-123.1(\mathrm{~m}),-126.1(\mathrm{~m})$.

IR (ATR): 2925, 1671, 1239, 1201, 1146, 1113, 762, 746, $\mathrm{cm}^{-1}$.

MS (ESI) $m / z$ (relative intensity): $688(100)[\mathrm{M}+\mathrm{Na}]^{+}, 666(20)[\mathrm{M}+\mathrm{H}]^{+}$.

HR-MS (ESI): $m / z$ calcd. for $\left[\mathrm{C}_{25} \mathrm{H}_{12} \mathrm{~F}_{17} \mathrm{NO}+\mathrm{Na}\right]^{+} 688.0540$ found 688.0535 .

$[\alpha]_{\mathrm{D}}^{20}:-38.3\left(\mathrm{c}=0.75, \mathrm{CHCl}_{3}\right)$.

HPLC separation (Chiralpak® ID-3, $n$-hexane/i-PrOH 99:1, $1 \mathrm{~mL} / \mathrm{min}$, detection at $273 \mathrm{~nm}$ ): $t_{r}($ major $)=6.1 \mathrm{~min}, t_{r}($ minor $)=6.7 \mathrm{~min}, 98 \%$ ee.

\subsubsection{Late stage Diversification}<smiles>CCOC(=O)/C=C/c1cccc(C)c1-c1c(C=O)ccc2ccc3ccccc3c12</smiles>

$(R, \quad E)$-Butyl 3-(2-(3-formylphenanthren-4-yl)-3-methylphenyl)acrylate (74ha): A modified procedure $\mathbf{L}$ was followed using 4-(o-tolyl)phenanthrene-3-carbaldehyde (73h) (59.2 $\mathrm{mg}, 0.20 \mathrm{mmol})$ and $n$-butyl acrylate (38a) $(76.9 \mathrm{mg}, 0.60 \mathrm{mmol})$ with L-tert-leucine (7.9 $\mathrm{mg}, 30 \mathrm{~mol} \%)$. Isolation by column chromatography $(n$-hexane/EtOAc $=5: 1)$ yielded 74ha (33.8 $\mathrm{mg}, 40 \%)$ as a yellow oil and $\mathbf{7 3 h}(32.0 \mathrm{mg}, 54 \%)$ as yellow oil.

${ }^{1} \mathrm{H}-\mathrm{NMR}\left(400 \mathrm{MHz}, \mathrm{CDCl}_{3}\right): \delta=9.59(\mathrm{~s}, 1 \mathrm{H}), 8.28(\mathrm{~d}, J=8.2 \mathrm{~Hz}, 1 \mathrm{H}), 8.09(\mathrm{~d}, J=8.2 \mathrm{~Hz}$, 1H), 7.95-7.82 (m, 3H), 7.77 (d, $J=7.9 \mathrm{~Hz}, 1 \mathrm{H}), 7.63-7.40(\mathrm{~m}, 4 \mathrm{H}), 7.24-7.05(\mathrm{~m}, 2 \mathrm{H}), 6.26$ $(\mathrm{d}, J=15.8 \mathrm{~Hz}, 1 \mathrm{H}), 3.94(\mathrm{t}, J=6.5 \mathrm{~Hz}, 2 \mathrm{H}), 1.86(\mathrm{~s}, 3 \mathrm{H}), 1.52-1.38(\mathrm{~m}, 2 \mathrm{H}), 1.24-1.10$ (m, $2 \mathrm{H}), 0.83(\mathrm{t}, J=7.4 \mathrm{~Hz}, 3 \mathrm{H})$.

${ }^{13} \mathrm{C}-\mathrm{NMR}\left(100 \mathrm{MHz}, \mathrm{CDCl}_{3}\right): \delta=192.3(\mathrm{CH}), 166.2\left(\mathrm{C}_{\mathrm{q}}\right), 141.9(\mathrm{CH}), 141.7\left(\mathrm{C}_{\mathrm{q}}\right), 139.4\left(\mathrm{C}_{\mathrm{q}}\right)$, $137.8\left(\mathrm{C}_{\mathrm{q}}\right), 137.4\left(\mathrm{C}_{\mathrm{q}}\right), 134.6\left(\mathrm{C}_{\mathrm{q}}\right), 133.7\left(\mathrm{C}_{\mathrm{q}}\right), 133.0\left(\mathrm{C}_{\mathrm{q}}\right), 132.4(\mathrm{CH}), 131.3\left(\mathrm{C}_{\mathrm{q}}\right), 131.2(\mathrm{CH})$, 130.0 (CH), $129.4(\mathrm{CH}), 129.2(\mathrm{CH}), 128.4\left(\mathrm{C}_{\mathrm{q}}\right), 127.5(\mathrm{CH}), 127.0(\mathrm{CH}), 126.7(\mathrm{CH}), 125.6$ 
$(\mathrm{CH}), 124.9(\mathrm{CH}), 124.4(\mathrm{CH}), 120.5(\mathrm{CH}), 64.2\left(\mathrm{CH}_{2}\right), 30.5\left(\mathrm{CH}_{2}\right), 20.4\left(\mathrm{CH}_{3}\right), 19.0\left(\mathrm{CH}_{2}\right)$, $13.6\left(\mathrm{CH}_{3}\right)$.

IR (ATR): 2933, 1701, 1650, 1590, 1410, 1251, 1115, 1045, $795 \mathrm{~cm}^{-1}$.

MS (ESI) $m / z$ (relative intensity): $445(100)[\mathrm{M}+\mathrm{Na}]^{+}, 423(20)[\mathrm{M}+\mathrm{H}]^{+}$.

HR-MS (ESI): $m / z$ calcd. for $\left[\mathrm{C}_{29} \mathrm{H}_{26} \mathrm{O}_{3}+\mathrm{H}\right]^{+} 423.1955$ found 423.1959 .

$[\alpha]_{\mathrm{D}}^{20}:+238.1\left(\mathrm{c}=0.8, \mathrm{CHCl}_{3}\right)$.

HPLC separation (Chiralpak ${ }^{\circledR}$ IA-3, $n$-hexane $/ i$-PrOH 99:1, $1 \mathrm{~mL} / \mathrm{min}$, detection at $273 \mathrm{~nm}$ ): $t_{r}$ $($ major $)=23.7 \min , t_{r}(\operatorname{minor})=22.7 \mathrm{~min}, 95 \%$ ee .<smiles>Cc1ccccc1-c1c(C=O)ccc2ccc3ccccc3c12</smiles>

(R)-4-(o-Tolyl)phenanthrene-3-carbaldehyde (73h):

${ }^{1} \mathrm{H}-\mathrm{NMR}\left(600 \mathrm{MHz}, \mathrm{CDCl}_{3}\right): \delta=9.69(\mathrm{~s}, 1 \mathrm{H}), 8.21(\mathrm{~d}, J=8.3 \mathrm{~Hz}, 1 \mathrm{H}), 7.99(\mathrm{dd}, J=8.3,0.9$ Hz, 1H), 7.90-7.82 (m, 2H), $7.80(\mathrm{~d}, J=8.8 \mathrm{~Hz}, 1 \mathrm{H}), 7.51-7.44(\mathrm{~m}, 3 \mathrm{H}), 7.41(\mathrm{dd}, J=7.7,1.4$, $1 \mathrm{H}), 7.38(\mathrm{dd}, J=7.5,1.4 \mathrm{~Hz}, 1 \mathrm{H}), 7.27(\mathrm{dd}, J=7.5,1.4 \mathrm{~Hz}, 1 \mathrm{H}), 7.16-7.12(\mathrm{~m}, 1 \mathrm{H}), 1.93$ (s, $3 \mathrm{H})$.

${ }^{13} \mathrm{C}-\mathrm{NMR}\left(150 \mathrm{MHz}, \mathrm{CDCl}_{3}\right): \delta=193.1(\mathrm{CH}), 144.6\left(\mathrm{C}_{\mathrm{q}}\right), 138.7\left(\mathrm{C}_{\mathrm{q}}\right), 137.2\left(\mathrm{C}_{\mathrm{q}}\right), 136.8\left(\mathrm{C}_{\mathrm{q}}\right)$, $133.6\left(\mathrm{C}_{\mathrm{q}}\right), 133.0\left(\mathrm{C}_{\mathrm{q}}\right), 131.4\left(\mathrm{C}_{\mathrm{q}}\right), 130.9(\mathrm{CH}), 130.8(\mathrm{CH}), 130.3(\mathrm{CH}), 129.3(\mathrm{CH}), 129.1$ $(\mathrm{CH}), 128.8(\mathrm{CH}), 128.4\left(\mathrm{C}_{\mathrm{q}}\right), 127.4(\mathrm{CH}), 126.9(\mathrm{CH}), 126.5(\mathrm{CH}), 126.5(\mathrm{CH}), 126.4(\mathrm{CH})$, $123.9(\mathrm{CH}), 20.1\left(\mathrm{CH}_{3}\right)$.

IR (ATR): 2937, 1710, 1599, 1432, 1211, 1105, 1020, $710 \mathrm{~cm}^{-1}$.

MS (ESI) $m / z$ (relative intensity): $319(100)[\mathrm{M}+\mathrm{Na}]^{+}, 297(20)[\mathrm{M}+\mathrm{H}]^{+}$.

HR-MS (ESI): $m / z$ calcd. for $\left[\mathrm{C}_{22} \mathrm{H}_{16} \mathrm{O}+\mathrm{Na}\right]^{+} 319.1093$ found 319.1098 .

$[\alpha]_{\mathrm{D}}^{20}:+21.2\left(\mathrm{c}=1.0, \mathrm{CHCl}_{3}\right)$.

HPLC separation (Chiralpak ${ }^{\circledR}$ IB-3, $n$-hexane/EtOAc 99:1, $1 \mathrm{~mL} / \mathrm{min}$, detection at $273 \mathrm{~nm}$ ): $t_{r}$ $($ major $)=7.3 \mathrm{~min}, t_{r}(\operatorname{minor})=7.1 \mathrm{~min}, 77 \%$ ee<smiles>Cc1cccc(C=O)c1-c1c(C=O)ccc2ccc3ccccc3c12</smiles> 
(S)-4-(2-Formyl-6-methylphenyl)phenanthrene-3-carbaldehyde (399): To a solution of 74ha (30 mg, $0.07 \mathrm{mmol}, 1$ equiv) in THF (1.8 mL) and $\mathrm{H}_{2} \mathrm{O}(0.9 \mathrm{~mL}), \mathrm{K}_{2} \mathrm{OsO}_{4} \cdot 2 \mathrm{H}_{2} \mathrm{O}(4 \mathrm{mg}$, $0.011 \mathrm{mmol}, 15 \mathrm{~mol} \%)$ and $\mathrm{NaIO}_{4}\left(149 \mathrm{mg}, 0.7 \mathrm{mmol}, 10\right.$ equiv) were added at $25{ }^{\circ} \mathrm{C}$, the reaction mixture was stirred at $50{ }^{\circ} \mathrm{C}$ for $16 \mathrm{~h}$. The reaction mixture was then stopped by the addition with sat. aqueous $\mathrm{Na}_{2} \mathrm{~S}_{2} \mathrm{O}_{3}(5 \mathrm{~mL})$ and stirred vigorously for $30 \mathrm{~min}$. The biphasic reaction mixture was extracted with EtOAc $(3 \times 20 \mathrm{~mL})$ and then the combined organic layers were washed with brine $(20 \mathrm{~mL})$, dried over $\mathrm{Na}_{2} \mathrm{SO}_{4}$, and concentrated. The crude product was purified by flash column chromatography ( $n$-hexane/EtOAc $=3: 1)$ to provide $399(19.3 \mathrm{mg}$, $85 \%)$ as a yellow oil.

${ }^{1} \mathrm{H}-\mathrm{NMR}\left(400 \mathrm{MHz}, \mathrm{CDCl}_{3}\right): \delta=9.63(\mathrm{~s}, 1 \mathrm{H}), 9.49$ (s, 1H), 8.30 (dd, $\left.J=8.3,1.2 \mathrm{~Hz}, 1 \mathrm{H}\right)$, 8.16-8.11 (m, 1H), 8.10-8.05 (m, 1H), 7.99-7.84 (m, 3H), 7.80-7.68 (m, 2H), 7.52 (ddd, $J=$ 8.3, 6.9, 1.2 Hz, 1H), 7.34 (d, $J=9.2 \mathrm{~Hz}, 1 \mathrm{H}), 7.17$ (ddd, $J=8.7,7.0,1.4 \mathrm{~Hz}, 1 \mathrm{H}), 2.01$ (s, $3 \mathrm{H})$.

${ }^{13} \mathrm{C}-\mathrm{NMR}\left(100 \mathrm{MHz}, \mathrm{CDCl}_{3}\right): \delta=191.5(\mathrm{CH}), 190.9(\mathrm{CH}), 142.2\left(\mathrm{C}_{\mathrm{q}}\right), 139.6\left(\mathrm{C}_{\mathrm{q}}\right), 138.4\left(\mathrm{C}_{\mathrm{q}}\right)$, $137.3\left(\mathrm{C}_{\mathrm{q}}\right), 136.4(\mathrm{CH}), 135.2\left(\mathrm{C}_{\mathrm{q}}\right), 133.8\left(\mathrm{C}_{\mathrm{q}}\right), 133.4\left(\mathrm{C}_{\mathrm{q}}\right), 131.5(\mathrm{CH}), 131.0\left(\mathrm{C}_{\mathrm{q}}\right), 130.3(\mathrm{CH})$, 129.6 (CH), $129.4(\mathrm{CH}), 128.8\left(\mathrm{C}_{\mathrm{q}}\right), 127.5(\mathrm{CH}), 127.1(\mathrm{CH}), 126.9(\mathrm{CH}), 126.9(\mathrm{CH}), 125.7$ $(\mathrm{CH}), 124.5(\mathrm{CH}), 19.9\left(\mathrm{CH}_{3}\right)$.

IR (ATR): 2925, 1710, 1643, 1555, 1400, 1320, 1290, $850 \mathrm{~cm}^{-1}$. MS (ESI) $m / z$ (relative intensity): $347(100)[\mathrm{M}+\mathrm{Na}]^{+}, 325(20)[\mathrm{M}+\mathrm{H}]^{+}$. HR-MS (ESI): $m / z$ calcd. for $\left[\mathrm{C}_{23} \mathrm{H}_{16} \mathrm{O}_{2}+\mathrm{Na}\right]^{+} 347.1043$ found 347.1038 . $[\alpha]_{\mathrm{D}}^{20}:+42.8\left(\mathrm{c}=1.0, \mathrm{CHCl}_{3}\right)$.<smiles>C=Cc1cccc(C)c1-c1c(C=C)ccc2ccc3ccccc3c12</smiles>

(S)-4-(2-Methyl-6-vinylphenyl)-3-vinylphenanthrene (400): A flame dried round bottom flask was charged with 399 (16 mg, $0.05 \mathrm{mmol}, 1$ equiv). THF (1.5 mL) was added and the mixture is stirred until dissolution of the substrate. The solution was cooled to $-78{ }^{\circ} \mathrm{C}$. A second flame dried round bottom flask was charged with methyltriphenylphosphonium bromide $(71.5$ $\mathrm{mg}, 0.2 \mathrm{mmol}, 4$ equiv). THF (1.5 mL) was added and the suspension was cooled to $-78^{\circ} \mathrm{C} . n$ Butyllithium ( 3.8 equiv, $0.19 \mathrm{mmol}$ ) was added to the suspension of the phosphonium salt. The orange solution was warmed to $\mathrm{rt}$ for $10 \mathrm{~min}$, and then cooled to $-78^{\circ} \mathrm{C}$. The orange solution 
of the phosphorus ylide was slowly transferred via canula to the solution of 399 . The reaction mixture was warmed to rt and stirred for 1 hour. Silica gel was directly added to the reaction mixture and the solvent was evaporated under vacuum. The crude product was purified by flash column chromatography ( $n$-hexane/EtOAc $=15: 1)$ to provide $\mathbf{4 0 0}(15.9 \mathrm{mg}, 99 \%)$ as a yellow oil.

${ }^{1} \mathrm{H}-\mathrm{NMR}\left(400 \mathrm{MHz}, \mathrm{CDCl}_{3}\right): \delta=7.97(\mathrm{~d}, J=1.6 \mathrm{~Hz}, 2 \mathrm{H}), 7.89-7.73(\mathrm{~m}, 3 \mathrm{H}), 7.68(\mathrm{~d}, J=7.8$ $\mathrm{Hz}, 1 \mathrm{H}), 7.53(\mathrm{~d}, J=8.8 \mathrm{~Hz}, 1 \mathrm{H}), 7.50-7.42(\mathrm{~m}, 2 \mathrm{H}), 7.34(\mathrm{~d}, J=7.5 \mathrm{~Hz}, 1 \mathrm{H}), 7.13(\mathrm{ddd}, J=$ $8.7,6.9,1.6 \mathrm{~Hz}, 1 \mathrm{H}), 6.45-6.31(\mathrm{~m}, 1 \mathrm{H}), 6.27-6.15(\mathrm{~m}, 1 \mathrm{H}), 5.76(\mathrm{dd}, J=17.4,1.4 \mathrm{~Hz}, 1 \mathrm{H})$, $5.58(\mathrm{dd}, J=17.4,1.4 \mathrm{~Hz}, 1 \mathrm{H}), 5.16(\mathrm{dd}, J=11.0,1.5 \mathrm{~Hz}, 1 \mathrm{H}), 4.89(\mathrm{dd}, J=11.0,1.5 \mathrm{~Hz}, 1 \mathrm{H})$, $1.80(\mathrm{~s}, 3 \mathrm{H})$.

${ }^{13} \mathrm{C}-\mathrm{NMR}\left(100 \mathrm{MHz}, \mathrm{CDCl}_{3}\right): \delta=140.6\left(\mathrm{C}_{\mathrm{q}}\right), 136.8\left(\mathrm{C}_{\mathrm{q}}\right), 136.6\left(\mathrm{C}_{\mathrm{q}}\right), 135.8\left(\mathrm{C}_{\mathrm{q}}\right), 135.6\left(\mathrm{C}_{\mathrm{q}}\right)$, $135.5(\mathrm{CH}), 135.0(\mathrm{CH}), 133.6\left(\mathrm{C}_{\mathrm{q}}\right), 133.3\left(\mathrm{C}_{\mathrm{q}}\right), 131.4\left(\mathrm{C}_{\mathrm{q}}\right), 130.2(\mathrm{CH}), 129.1(\mathrm{CH}), 128.8$ $\left(\mathrm{C}_{\mathrm{q}}\right), 128.8(\mathrm{CH}), 128.0(\mathrm{CH}), 127.9(\mathrm{CH}), 127.7(\mathrm{CH}), 126.2(\mathrm{CH}), 126.0(\mathrm{CH}), 126.0(\mathrm{CH})$, 124.0 (CH), $123.4(\mathrm{CH}), 115.5\left(\mathrm{CH}_{2}\right), 114.9\left(\mathrm{CH}_{2}\right), 20.1\left(\mathrm{CH}_{3}\right)$.

IR (ATR): 2932, 1550, 1472, 1355, 1259, 1231, 980, $720 \mathrm{~cm}^{-1}$.

MS (EI) $m / z$ (relative intensity): 320 (20), 305 (20), 276 (100), 263 (10), 228 (30).

HR-MS (EI): $m / z$ calcd. for $\left[\mathrm{C}_{25} \mathrm{H}_{20}\right][\mathrm{M}]^{+} 320.1560$ found 320.1558 .

$[\alpha]_{\mathrm{D}}^{20}:+10.8\left(\mathrm{c}=1.0, \mathrm{CHCl}_{3}\right)$.

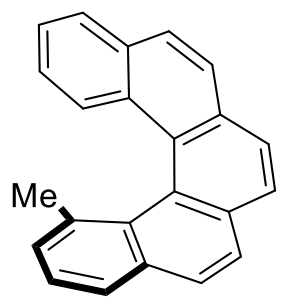

10-Methyldibenzo[c,g]phenanthrene (401): A flame-dried microwave vessel, equipped with a magnetic stirrer was charged with $400(9.6 \mathrm{mg}, 0.03 \mathrm{mmol})$ under $\mathrm{N}_{2}$. Anhydrous $\mathrm{CH}_{2} \mathrm{Cl}_{2}$ $(1.5 \mathrm{~mL})$ was added and the mixture was stirred until dissolution of all the substrates. The Grubbs II catalyst ( $2.5 \mathrm{mg}, 0.003 \mathrm{mmol}, 10 \mathrm{~mol} \%$ ) was added, the tube was sealed. The reaction vessel was irradiated in a microwave at $95{ }^{\circ} \mathrm{C}$ for $1 \mathrm{~h}$. The reaction mixture is concentrated in vacuo and purified by flash column silica gel chromatography ( $n$ hexane/EtOAc $=30: 1)$ to afford [5]-helicene $401(7.4 \mathrm{mg}, 86 \%)$ as a colourless oil.

${ }^{1} \mathrm{H}-\mathrm{NMR}\left(600 \mathrm{MHz}, \mathrm{CDCl}_{3}\right): \delta=7.96-7.90(\mathrm{~m}, 5 \mathrm{H}), 7.89$ (d, $\left.J=8.4 \mathrm{~Hz}, 1 \mathrm{H}\right), 7.88-7.86$ (m, 1H), $7.84(\mathrm{dd}, J=8.4,0.7 \mathrm{~Hz}, 1 \mathrm{H}), 7.80(\mathrm{~d}, J=8.4 \mathrm{~Hz}, 1 \mathrm{H}), 7.54$ (d, $J=7.5 \mathrm{~Hz}, 1 \mathrm{H}), 7.45$ (ddd, $J=8.0,6.8,1.2 \mathrm{~Hz}, 1 \mathrm{H}), 7.21-7.17(\mathrm{~m}, 1 \mathrm{H}), 7.12(\mathrm{ddd}, J=8.4,6.8,1.4 \mathrm{~Hz}, 1 \mathrm{H}), 1.54$ (s, $3 \mathrm{H})$. 
${ }^{13} \mathrm{C}-\mathrm{NMR}\left(150 \mathrm{MHz}, \mathrm{CDCl}_{3}\right): \delta=136.0\left(\mathrm{C}_{\mathrm{q}}\right), 133.2\left(\mathrm{C}_{\mathrm{q}}\right), 132.9\left(\mathrm{C}_{\mathrm{q}}\right), 131.9\left(\mathrm{C}_{\mathrm{q}}\right), 131.5\left(\mathrm{C}_{\mathrm{q}}\right)$, $131.2\left(\mathrm{C}_{\mathrm{q}}\right), 130.4\left(\mathrm{C}_{\mathrm{q}}\right), 128.6(\mathrm{CH}), 128.5\left(\mathrm{C}_{\mathrm{q}}\right), 127.8(\mathrm{CH}), 127.8(\mathrm{CH}), 127.1(\mathrm{CH}), 127.1$ $(\mathrm{CH}), 126.3(\mathrm{CH}), 126.2(\mathrm{CH}), 126.1(\mathrm{CH}), 126.0(\mathrm{CH}), 125.6(\mathrm{CH}), 125.5(\mathrm{CH}), 125.2(\mathrm{CH})$, $125.1(\mathrm{CH}), 124.9\left(\mathrm{C}_{\mathrm{q}}\right), 23.2\left(\mathrm{CH}_{3}\right)$.

IR (ATR): 2922, 1532, 1452, 1260, 1096, 1018, 798, $695 \mathrm{~cm}^{-1}$.

MS (EI) $m / z$ (relative intensity): 292 (30), 277 (100), 261 (10), 228 (10), 138 (30).

HR-MS (EI): $m / z$ calcd. for $\mathrm{C}_{23} \mathrm{H}_{16}$ [M] ${ }^{+}: 292.1252$, found 292.1246 .

$[\alpha]_{\mathrm{D}}^{20}:-20.4\left(\mathrm{c}=0.25, \mathrm{CHCl}_{3}\right)$.

HPLC separation (Chiralpak ${ }^{\circledR} \mathrm{IB}-3, n$-hexane $/ i$-PrOH 98:2, $1 \mathrm{~mL} / \mathrm{min}$, detection at $273 \mathrm{~nm}$ ): $t_{r}$ $($ major $)=3.6 \mathrm{~min}, t_{r}($ minor $)=3.9 \mathrm{~min}, 95 \%$ ee.

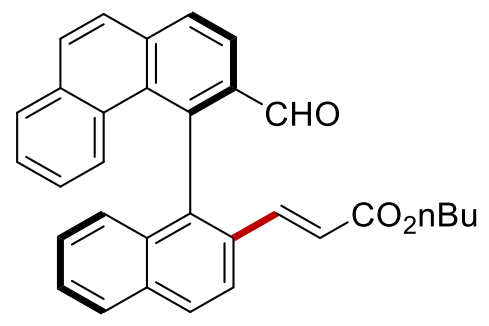

(+)(E)-n-Butyl-3-(1-(3-formylphenanthren-4-yl)naphthalen-2-yl)acrylate $\quad$ (74ia): A modified procedure $\mathbf{L}$ was followed using 4-(naphthalen-1-yl)phenanthrene-3-carbaldehyde (73i) $(66.4 \mathrm{mg}, 0.20 \mathrm{mmol})$ and $n$-butyl acrylate (38a) $(76.9 \mathrm{mg}, 0.60 \mathrm{mmol})$ with L-tertleucine $(7.9 \mathrm{mg}, 30 \mathrm{~mol} \%)$. Isolation by column chromatography $(n$-hexane/EtOAc $=5: 1)$ yielded 74ia $(35.5 \mathrm{mg}, 42 \%, E / Z=96: 4)$ as a yellow oil and $\mathbf{7 3 i}(38.0 \mathrm{mg}, 55 \%)$ as yellow solid. M.P.: $130-132{ }^{\circ} \mathrm{C}$.

${ }^{1} \mathrm{H}-\mathrm{NMR}\left(400 \mathrm{MHz}, \mathrm{CDCl}_{3}\right): \delta=9.38(\mathrm{~s}, 1 \mathrm{H}), 8.35(\mathrm{dd}, J=8.2,1.7 \mathrm{~Hz}, 1 \mathrm{H}), 8.22-8.10(\mathrm{~m}$, 2H), 8.03-7.89 (m, 4H), $7.85(\mathrm{dd}, J=7.9,1.6 \mathrm{~Hz}, 1 \mathrm{H}), 7.54(\mathrm{dd}, J=8.2,1.5 \mathrm{~Hz}, 1 \mathrm{H}), 7.40$ (dd, $J=7.5,6.9,1.2 \mathrm{~Hz}, 1 \mathrm{H}), 7.32-7.17(\mathrm{~m}, 4 \mathrm{H}), 6.94$ (dd, $J=8.6,1.6 \mathrm{~Hz}, 1 \mathrm{H}), 6.41$ (d, $J=15.8$ $\mathrm{Hz}, 0.96 \mathrm{H}, E), 5.67(\mathrm{~d}, J=12.3 \mathrm{~Hz}, 0.04 \mathrm{H}, Z), 3.97(\mathrm{t}, J=6.5 \mathrm{~Hz}, 2 \mathrm{H}), 1.54-1.40(\mathrm{~m}, 2 \mathrm{H})$, $1.29-1.14(\mathrm{~m}, 2 \mathrm{H}), 0.84(\mathrm{t}, J=6.5 \mathrm{~Hz}, 3 \mathrm{H})$.

${ }^{13} \mathrm{C}-\mathrm{NMR}\left(100 \mathrm{MHz}, \mathrm{CDCl}_{3}\right): \delta=192.1(\mathrm{CH}), 166.2\left(\mathrm{C}_{\mathrm{q}}\right), 141.3(\mathrm{CH}), 140.2\left(\mathrm{C}_{\mathrm{q}}\right), 138.1\left(\mathrm{C}_{\mathrm{q}}\right)$, $137.3\left(\mathrm{C}_{\mathrm{q}}\right), 134.2\left(\mathrm{C}_{\mathrm{q}}\right), 134.1\left(\mathrm{C}_{\mathrm{q}}\right), 133.7\left(\mathrm{C}_{\mathrm{q}}\right), 133.4\left(\mathrm{C}_{\mathrm{q}}\right), 131.8\left(\mathrm{C}_{\mathrm{q}}\right), 131.4(\mathrm{CH}), 130.7\left(\mathrm{C}_{\mathrm{q}}\right)$, $130.4(\mathrm{CH}), 129.6(\mathrm{CH}), 129.5\left(\mathrm{C}_{\mathrm{q}}\right), 129.3(\mathrm{CH}), 128.3(\mathrm{CH}), 127.9(\mathrm{CH}), 127.8(\mathrm{CH}), 127.5$ $(\mathrm{CH}), 127.0(\mathrm{CH}), 126.8(\mathrm{CH}), 126.6(\mathrm{CH}), 126.3(\mathrm{CH}), 124.4(\mathrm{CH}), 123.3(\mathrm{CH}), 120.7(\mathrm{CH})$, $64.2\left(\mathrm{CH}_{2}\right), 30.5\left(\mathrm{CH}_{2}\right), 19.0\left(\mathrm{CH}_{2}\right), 13.7\left(\mathrm{CH}_{3}\right)$.

IR (ATR): 2933, 1698, 1652, 1559, 1421, 1222, $885 \mathrm{~cm}^{-1}$.

MS (ESI) $m / z$ (relative intensity): $481(100)[\mathrm{M}+\mathrm{Na}]^{+}, 459(10)[\mathrm{M}+\mathrm{H}]^{+}$.

HR-MS (ESI): $m / z$ calcd. for $\left[\mathrm{C}_{32} \mathrm{H}_{26} \mathrm{O}_{3}+\mathrm{Na}\right]^{+} 481.1774$ found 481.1773. 
$[\alpha]_{\mathrm{D}}^{20}:+178.2\left(\mathrm{c}=1.0, \mathrm{CHCl}_{3}\right)$.

HPLC separation (Chiralpak ${ }^{\circledR}$ IA-3, $n$-hexane $/ i$-PrOH 95:5, $1.0 \mathrm{~mL} / \mathrm{min}$, detection at $273 \mathrm{~nm}$ ): $t_{r}($ major $)=15.4 \mathrm{~min}, t_{r}($ minor $)=12.1 \mathrm{~min}, 96 \%$ ee .<smiles>O=Cc1ccc2ccc3ccccc3c2c1-c1cccc2ccccc12</smiles>

(R)-4-(Naphthalen-1-yl)phenanthrene-3-carbaldehyde (73i): ${ }^{1} \mathrm{H}$ NMR $\left(600 \mathrm{MHz}, \mathrm{CDCl}_{3}\right)$ : $\delta=9.45(\mathrm{~s}, 1 \mathrm{H}), 8.27(\mathrm{~d}, J=8.3 \mathrm{~Hz}, 1 \mathrm{H}), 8.11-8.06(\mathrm{~m}, 2 \mathrm{H}), 7.99(\mathrm{dd}, J=8.3,0.9 \mathrm{~Hz}, 1 \mathrm{H})$, $7.88(\mathrm{~d}, J=8.8 \mathrm{~Hz}, 1 \mathrm{H}), 7.85(\mathrm{~d}, J=8.8 \mathrm{~Hz}, 1 \mathrm{H}), 7.81(\mathrm{dd}, J=7.8,1.5 \mathrm{~Hz}, 1 \mathrm{H}), 7.62(\mathrm{dd}, J=$ 8.3, $6.9 \mathrm{~Hz}, 1 \mathrm{H}), 7.52-7.48(\mathrm{~m}, 1 \mathrm{H}), 7.47(\mathrm{dd}, J=6.9,1.2 \mathrm{~Hz}, 1 \mathrm{H}), 7.38-7.33(\mathrm{~m}, 2 \mathrm{H}), 7.27$ (ddd, $J=8.3,6.7,1.0 \mathrm{~Hz}, 1 \mathrm{H}), 7.20$ (dd, $J=8.7,1.0 \mathrm{~Hz}, 1 \mathrm{H}), 6.86$ (ddd, $J=8.7,6.9,1.5 \mathrm{~Hz}$, $1 \mathrm{H})$.

${ }^{13} \mathrm{C}-\mathrm{NMR}\left(150 \mathrm{MHz}, \mathrm{CDCl}_{3}\right): \delta=192.9(\mathrm{CH}), 143.1\left(\mathrm{C}_{\mathrm{q}}\right), 137.2\left(\mathrm{C}_{\mathrm{q}}\right), 136.9\left(\mathrm{C}_{\mathrm{q}}\right), 134.2\left(\mathrm{C}_{\mathrm{q}}\right)$, $133.7\left(\mathrm{C}_{\mathrm{q}}\right), 133.6\left(\mathrm{C}_{\mathrm{q}}\right), 133.2\left(\mathrm{C}_{\mathrm{q}}\right), 131.0(\mathrm{CH}), 130.8\left(\mathrm{C}_{\mathrm{q}}\right), 129.7(\mathrm{CH}), 129.4\left(\mathrm{C}_{\mathrm{q}}\right), 129.0(\mathrm{CH})$, $128.9(\mathrm{CH}), 128.5(\mathrm{CH}), 128.3(\mathrm{CH}), 127.3(\mathrm{CH}), 127.2(\mathrm{CH}), 127.2(\mathrm{CH}), 126.7(\mathrm{CH}), 126.4$ $(\mathrm{CH}), 126.2(\mathrm{CH}), 126.0(\mathrm{CH}), 125.9(\mathrm{CH}), 123.9(\mathrm{CH})$.

IR (ATR): 2955, 1678, 1569, 1417, 1232, $685 \mathrm{~cm}^{-1}$.

MS (ESI) $m / z$ (relative intensity): $355(100)[\mathrm{M}+\mathrm{Na}]^{+}, 333(20)[\mathrm{M}+\mathrm{H}]^{+}$.

HR-MS (ESI): $m / z$ calcd. for $\left[\mathrm{C}_{25} \mathrm{H}_{16} \mathrm{O}+\mathrm{Na}\right]^{+} 355.1093$ found 355.1095 .

$[\alpha]_{\mathrm{D}}^{20}:-4.5\left(\mathrm{c}=1.2, \mathrm{CHCl}_{3}\right)$. HPLC separation (Chiralpak ${ }^{\circledR}$ ID-3, $n$-hexane/i-PrOH 99:1, 1.0 $\mathrm{mL} / \mathrm{min}$, detection at $273 \mathrm{~nm}): t_{r}($ major $)=15.3 \mathrm{~min}, t_{r}($ minor $)=16.2 \mathrm{~min}, 76 \%$ ee.<smiles>CCOC(=O)/C=C/c1ccc2ccccc2c1-c1c(C=O)ccc2ccc3ccccc3c12</smiles>

(-)(E)-n-Butyl-3-(1-(3-formylphenanthren-4-yl)naphthalen-2-yl)acrylate $\quad$ (74ia): A modified procedure $\mathbf{L}$ was followed using recovered 4-(naphthalen-1-yl)phenanthrene-3carbaldehyde 73i (30 mg, $0.09 \mathrm{mmol}, 76 \%$ ee) and $n$-butyl acrylate (38a) (34.6 mg, 
$0.27 \mathrm{mmol}$ ) with D-tert-leucine (3.6 mg, $30 \mathrm{~mol} \%)$. Isolation by column chromatography ( $n$ hexane/EtOAc $=5: 1)$ yielded ent-74ia $(23.9 \mathrm{mg}, 58 \%, E / Z=96: 4,96 \%$ ee $)$.

$[\alpha]_{\mathrm{D}}^{20}:-30.2(\mathrm{c}=0.4)$.

HPLC separation (Chiralpak ${ }^{\circledR}$ IA-3, $n$-hexane $/ i$-PrOH 95:5, $1.0 \mathrm{~mL} / \mathrm{min}$, detection at $273 \mathrm{~nm}$ ): $t_{r}($ major $)=11.9 \mathrm{~min}, t_{r}($ minor $)=14.9 \mathrm{~min}, 96 \%$ ee<smiles>O=Cc1ccc2ccccc2c1-c1c(C=O)ccc2ccc3ccccc3c12</smiles>

4-(2-Formylnaphthalen-1-yl)phenanthrene-3-carbaldehyde (402): To a solution of 74ia (32.1 mg, $0.07 \mathrm{mmol}, 1$ equiv) in THF (1.8 mL) and $\mathrm{H}_{2} \mathrm{O}(0.9 \mathrm{~mL}), \mathrm{K}_{2} \mathrm{OsO}_{4} \cdot 2 \mathrm{H}_{2} \mathrm{O}(4 \mathrm{mg}, 0.011$ mmol, $15 \mathrm{~mol} \%)$ and $\mathrm{NaIO}_{4}\left(149 \mathrm{mg}, 0.7 \mathrm{mmol}, 10\right.$ equiv) were added at $25{ }^{\circ} \mathrm{C}$, the reaction mixture was stirred at $50{ }^{\circ} \mathrm{C}$ for $16 \mathrm{~h}$. The reaction mixture was then quenched with sat. aqueous $\mathrm{Na}_{2} \mathrm{~S}_{2} \mathrm{O}_{3}(5 \mathrm{~mL})$ and stirred vigorously for $30 \mathrm{~min}$. The biphasic reaction mixture was extracted with EtOAc $(3 \times 20 \mathrm{~mL})$ and then the combined organic layers were washed with brine $(20$ $\mathrm{mL}$ ), dried over $\mathrm{Na}_{2} \mathrm{SO}_{4}$, and concentrated. The crude product was purified by column chromatography ( $n$-hexane/EtOAc $=3: 1)$ to provide $402(22.3 \mathrm{mg}, 86 \%)$ as a yellow oil. ${ }^{1} \mathrm{H}-\mathrm{NMR}\left(400 \mathrm{MHz}, \mathrm{CDCl}_{3}\right): \delta=9.60(\mathrm{~s}, 1 \mathrm{H}), 9.42(\mathrm{~s}, 1 \mathrm{H}), 8.38(\mathrm{dd}, J=8.3,1.5 \mathrm{~Hz}, 1 \mathrm{H})$, $8.27-8.18(\mathrm{~m}, 3 \mathrm{H}), 8.09(\mathrm{~d}, J=8.2 \mathrm{~Hz}, 1 \mathrm{H}), 8.00-7.91(\mathrm{~m}, 2 \mathrm{H}), 7.88(\mathrm{dd}, J=7.9,1.5 \mathrm{~Hz}, 1 \mathrm{H})$, 7.69 (ddd, $J=8.3,6.7,1.5 \mathrm{~Hz}, 1 \mathrm{H}), 7.53-7.47(\mathrm{~m}, 1 \mathrm{H}), 7.46-7.37(\mathrm{~m}, 2 \mathrm{H}), 7.06$ (d, $J=8.8 \mathrm{~Hz}$, $1 \mathrm{H}), 6.94$ (ddd, $J=8.8,7.0,1.2 \mathrm{~Hz}, 1 \mathrm{H})$.

${ }^{13} \mathrm{C}-\mathrm{NMR}\left(100 \mathrm{MHz}, \mathrm{CDCl}_{3}\right): \delta=191.3(\mathrm{CH}), 190.9(\mathrm{CH}), 143.5\left(\mathrm{C}_{\mathrm{q}}\right), 137.8\left(\mathrm{C}_{\mathrm{q}}\right), 137.1\left(\mathrm{C}_{\mathrm{q}}\right)$, $136.1\left(\mathrm{C}_{\mathrm{q}}\right), 134.8\left(\mathrm{C}_{\mathrm{q}}\right), 133.9\left(\mathrm{C}_{\mathrm{q}}\right), 133.3\left(\mathrm{C}_{\mathrm{q}}\right), 132.4\left(\mathrm{C}_{\mathrm{q}}\right), 131.7(\mathrm{CH}), 130.8(\mathrm{CH}), 130.2\left(\mathrm{C}_{\mathrm{q}}\right)$, $130.1\left(\mathrm{C}_{\mathrm{q}}\right), 129.9(\mathrm{CH}), 129.9(\mathrm{CH}), 129.5(\mathrm{CH}), 128.7(\mathrm{CH}), 128.4(\mathrm{CH}), 127.3(\mathrm{CH}), 127.2$ $(\mathrm{CH}), 126.9(\mathrm{CH}), 126.8(\mathrm{CH}), 126.6(\mathrm{CH}), 124.3(\mathrm{CH}), 123.0(\mathrm{CH})$.

IR (ATR): 2935, 1712, 1695, 1555, 1496, 1246, 1114, $795 \mathrm{~cm}^{-1}$.

MS (ESI) $m / z$ (relative intensity): $383(100)[\mathrm{M}+\mathrm{Na}]^{+}, 361(30)[\mathrm{M}+\mathrm{H}]^{+}$.

HR-MS (ESI): $m / z$ calcd. for $\left[\mathrm{C}_{26} \mathrm{H}_{16} \mathrm{O}_{2}+\mathrm{Na}\right]^{+} 383.1043$ found 383.1044 .

$[\alpha]_{\mathrm{D}}^{20}:-11.4\left(\mathrm{c}=0.9, \mathrm{CHCl}_{3}\right)$.

HPLC separation (Chiralpak ${ }^{\circledR}$ IA-3, $n$-hexane/i-PrOH 90:10, $1.0 \mathrm{~mL} / \mathrm{min}$, detection at $273 \mathrm{~nm}$ ): $t_{r}($ major $)=30.8 \mathrm{~min}, t_{r}($ minor $)=12.7 \mathrm{~min}, 96 \%$ ee . 
<smiles>C=Cc1ccc2ccccc2c1-c1c(C=C)ccc2ccc3ccccc3c12</smiles>

3-Vinyl-4-(2-vinylnaphthalen-1-yl)phenanthrene (402'): A flame dried round bottom flask was charged with 403 (17.8 mg, $0.05 \mathrm{mmol}, 1$ equiv). THF (1.5 mL) was added and the mixture was stirred until dissolution of the substrate. The solution was cooled to $-78{ }^{\circ} \mathrm{C}$. A second flame-dried round bottom flask was charged with methyltriphenylphosphonium bromide (71.5 $\mathrm{mg}, 0.2 \mathrm{mmol}, 4$ equiv). THF (1.5 mL) was added and the suspension was cooled to $-78^{\circ} \mathrm{C} . n$ Butyllithium ( 3.8 equiv, $0.19 \mathrm{mmol}$ ) was added to the suspension of the phosphonium salt. The orange solution was warmed to $\mathrm{rt}$ for $10 \mathrm{~min}$, and then cooled back to $-78{ }^{\circ} \mathrm{C}$. The orange solution of phosphorus ylide was slowly transferred via canula to the solution of $\mathbf{4 0 2}$. The reaction mixture was warmed to $\mathrm{rt}$ and stirred for 1 hour. Silica gel was directly added to the reaction mixture and the solvent is evaporated under vacuum. The crude product was purified by column chromatography ( $n$-hexane/EtOAc $=15: 1)$ to provide $\mathbf{4 0 2},(17.7 \mathrm{mg}, 99 \%)$ as yellow oil.

${ }^{1} \mathrm{H}-\mathrm{NMR}\left(400 \mathrm{MHz}, \mathrm{CDCl}_{3}\right): \delta=8.12-8.00(\mathrm{~m}, 3 \mathrm{H}), 8.01-7.92(\mathrm{~m}, 2 \mathrm{H}), 7.87(\mathrm{~d}, J=8.8 \mathrm{~Hz}$, 1H), 7.83-7.75 (m, 2H), 7.45 (ddd, $J=8.8,5.5,2.4 \mathrm{~Hz}, 1 \mathrm{H}), 7.40-7.29(\mathrm{~m}, 2 \mathrm{H}), 7.23-7.15$ (m, 2H), 6.89 (ddd, $J=8.8,6.9,1.6 \mathrm{~Hz}, 1 \mathrm{H}), 6.38(\mathrm{dd}, J=17.5,11.0 \mathrm{~Hz}, 1 \mathrm{H}), 6.21(\mathrm{dd}, J=17.5$, $11.0 \mathrm{~Hz}, 1 \mathrm{H}), 5.80-5.68$ (m, 2H), 5.07-4.98 (m, 2H).

${ }^{13} \mathrm{C}-\mathrm{NMR}\left(100 \mathrm{MHz}, \mathrm{CDCl}_{3}\right): \delta=138.0\left(\mathrm{C}_{\mathrm{q}}\right), 137.0\left(\mathrm{C}_{\mathrm{q}}\right), 135.6(\mathrm{CH}), 134.7(\mathrm{CH}), 134.1\left(\mathrm{C}_{\mathrm{q}}\right)$, $133.7\left(\mathrm{C}_{\mathrm{q}}\right), 133.6\left(\mathrm{C}_{\mathrm{q}}\right), 133.5\left(\mathrm{C}_{\mathrm{q}}\right), 133.3\left(\mathrm{C}_{\mathrm{q}}\right), 132.7\left(\mathrm{C}_{\mathrm{q}}\right), 131.0\left(\mathrm{C}_{\mathrm{q}}\right), 129.9\left(\mathrm{C}_{\mathrm{q}}\right), 129.5(\mathrm{CH})$, $128.7(\mathrm{CH}), 128.3(\mathrm{CH}), 128.1(\mathrm{CH}), 128.0(\mathrm{CH}), 127.6(\mathrm{CH}), 126.8(\mathrm{CH}), 126.6(\mathrm{CH}), 126.4$ $(\mathrm{CH}), 126.3(\mathrm{CH}), 126.0(\mathrm{CH}), 125.9(\mathrm{CH}), 123.9(\mathrm{CH}), 123.1(\mathrm{CH}), 115.5\left(\mathrm{CH}_{2}\right), 115.4\left(\mathrm{CH}_{2}\right)$. IR (ATR): 2925, 1596, 1482, 1455, 1396, 1346, 1314, 785, 748, $699 \mathrm{~cm}^{-1}$. MS (EI) $m / z$ (relative intensity): 356 (70), 328 (80), 313 (100), 298 (70), 215 (10).

HR-MS (EI): $\mathrm{m} / z$ calcd. for $\mathrm{C}_{28} \mathrm{H}_{20}[\mathrm{M}]^{+}: 356.1560$, found 356.1559 .

$[\alpha]_{\mathrm{D}}^{20}:+130.5\left(\mathrm{c}=1.0, \mathrm{CHCl}_{3}\right)$.

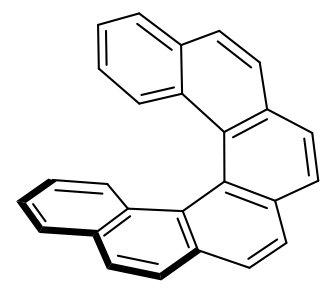


[6]-helicene (403): A flame-dried microwave vessel, equipped with a magnetic stirrer, was charged with 402' (10.7 $\mathrm{mg}, 0.03 \mathrm{mmol}) . \mathrm{CH}_{2} \mathrm{Cl}_{2}(1.5 \mathrm{~mL})$ was added and the mixture was stirred until dissolution of all the substrate. Grubbs II (2.5 mg, $0.003 \mathrm{mmol}, 10 \mathrm{~mol} \%)$ was added, and the tube was sealed. The reaction vessel was irradiated in a microwave at $95{ }^{\circ} \mathrm{C}$ for $1 \mathrm{~h}$. The reaction mixture was concentrated in vacuo and purified by column silica gel chromatography ( $n$-hexane/EtOAc $=30: 1)$ to afford [6]-helicene $403(8.6 \mathrm{mg}, 88 \%)$ as a colourless oil.

${ }^{1} \mathrm{H}-\mathrm{NMR}\left(600 \mathrm{MHz}, \mathrm{CDCl}_{3}\right): \delta=8.02-7.94(\mathrm{~m}, 4 \mathrm{H}), 7.94-7.88(\mathrm{~m}, 4 \mathrm{H}), 7.83-7.79(\mathrm{~m}, 2 \mathrm{H})$, $7.58(\mathrm{ddt}, J=8.6,1.2,0.6 \mathrm{~Hz}, 2 \mathrm{H}), 7.20(\mathrm{ddd}, J=8.0,6.8,1.1 \mathrm{~Hz}, 2 \mathrm{H}), 6.67$ (ddd, $J=8.4,6.8$, $1.4 \mathrm{~Hz}, 2 \mathrm{H})$.

${ }^{13} \mathrm{C}-\mathrm{NMR}\left(150 \mathrm{MHz}, \mathrm{CDCl}_{3}\right): \delta=133.1\left(\mathrm{C}_{\mathrm{q}}\right), 131.7\left(\mathrm{C}_{\mathrm{q}}\right), 131.2\left(\mathrm{C}_{\mathrm{q}}\right), 129.9\left(\mathrm{C}_{\mathrm{q}}\right), 128.0\left(\mathrm{C}_{\mathrm{q}}\right)$, $127.9(\mathrm{CH}), 127.7(\mathrm{CH}), 127.5(\mathrm{CH}), 127.2(\mathrm{CH}), 126.9(\mathrm{CH}), 126.2(\mathrm{CH}), 125.5(\mathrm{CH}), 124.6$ $(\mathrm{CH}), 124.1\left(\mathrm{C}_{\mathrm{q}}\right)$.

IR (ATR): 2922, 1496, 1259, 1095, 1070, 795, 749, $610 \mathrm{~cm}^{-1}$.

MS (EI) $m / z$ (relative intensity): 328 (80), 313 (90), 300 (100), 162 (20).

HR-MS (EI): $m / z$ calcd. for $\mathrm{C}_{26} \mathrm{H}_{16}[\mathrm{M}]^{+}: 328.1247$, found 328.1242 .

$[\alpha]_{\mathrm{D}}^{20}:-350.1\left(\mathrm{c}=1.0, \mathrm{CHCl}_{3}\right)$.

HPLC separation (Chiralpak ${ }^{\circledR}$ IB-3, $n$-hexane/i-PrOH 99:1, $1 \mathrm{~mL} / \mathrm{min}$, detection at $273 \mathrm{~nm}$ ): $t_{r}$ $($ major $)=7.3 \mathrm{~min}, t_{r}($ minor $)=8.5 \min , 96 \%$ ee.<smiles>Oc1ccc2ccccc2c1-c1c(O)ccc2ccc3ccccc3c12</smiles>

(R)-4-(2-Hydroxynaphthalen-1-yl)phenanthren-3-ol (405): 402 (15 mg, 0.04 mmol) and $m$ chloroperbenzoic acid (mCPBA) $(75 \%, 23 \mathrm{mg}, 0.1 \mathrm{mmol})$ were refluxed in $\mathrm{CH}_{2} \mathrm{Cl}_{2}(1.5 \mathrm{~mL})$ for $48 \mathrm{~h}$. The reaction mixture was allowed to cool and then aqueous $\mathrm{Na}_{2} \mathrm{~S}_{2} \mathrm{O}_{3}$ was added to destroy the excess of $m$ CPBA. The suspension mixture was neutralized with aqueous $\mathrm{NaHCO}_{3}$. The solution was extracted with $\mathrm{CH}_{2} \mathrm{Cl}_{2}(3 \times 50 \mathrm{~mL})$. The combined extracts were washed with brine $(4 \times 100 \mathrm{~mL})$ and dried with anhydrous magnesium sulfate. Removal of the solvent gave a brown solid, which was dissolved in $\mathrm{MeOH}(3 \mathrm{~mL})$ and hydrolyzed under nitrogen with aqueous $\mathrm{KOH}$ (2.5 equiv). After $2 \mathrm{~h} \mathrm{MeOH}$ was evaporated and the solution was acidified to pH2 with a concentrated $\mathrm{HCl}$ solution. The product was finally extracted with $\mathrm{CH}_{2} \mathrm{Cl}_{2}$ and 
chromatography on silica gel $(n$-hexane/EtOAc $=1: 2)$ provided the desired product $405(7.0$ $\mathrm{mg}, 51 \%)$ as a white solid.

${ }^{1} \mathrm{H}-\mathrm{NMR}\left(600 \mathrm{MHz}, \mathrm{CDCl}_{3}\right): \delta=8.07-7.99(\mathrm{~m}, 2 \mathrm{H}), 7.93(\mathrm{dd}, J=8.1,1.0 \mathrm{~Hz}, 1 \mathrm{H}), 7.81-7.74$ $(\mathrm{m}, 2 \mathrm{H}), 7.66(\mathrm{~d}, J=8.8 \mathrm{~Hz}, 1 \mathrm{H}), 7.51-7.48(\mathrm{~m}, 1 \mathrm{H}), 7.46(\mathrm{~d}, J=8.6 \mathrm{~Hz}, 1 \mathrm{H}), 7.40-7.36$ (m, 2H), 7.34 (ddd, $J=7.9,6.9,1.1 \mathrm{~Hz}, 1 \mathrm{H}), 7.30-7.28(\mathrm{~m}, 2 \mathrm{H}), 6.90$ (ddd, $J=8.6,7.0,1.6 \mathrm{~Hz}$, $1 \mathrm{H}), 5.11(\mathrm{~s}, 1 \mathrm{H}), 5.04(\mathrm{~s}, 1 \mathrm{H})$.

${ }^{13} \mathrm{C}-\mathrm{NMR}\left(150 \mathrm{MHz}, \mathrm{CDCl}_{3}\right): \delta=154.0\left(\mathrm{C}_{\mathrm{q}}\right), 151.9\left(\mathrm{C}_{\mathrm{q}}\right), 133.7\left(\mathrm{C}_{\mathrm{q}}\right), 132.6\left(\mathrm{C}_{\mathrm{q}}\right), 132.5(\mathrm{CH})$, $131.7(\mathrm{CH}), 130.7\left(\mathrm{C}_{\mathrm{q}}\right), 12989\left(\mathrm{C}_{\mathrm{q}}\right), 129.5\left(\mathrm{C}_{\mathrm{q}}\right), 128.6(\mathrm{CH}), 128.6\left(\mathrm{C}_{\mathrm{q}}\right), 128.6(\mathrm{CH}), 127.9$ $(\mathrm{CH}), 127.5(\mathrm{CH}), 126.6(\mathrm{CH}), 126.1(\mathrm{CH}), 125.8(\mathrm{CH}), 125.2(\mathrm{CH}), 124.6(\mathrm{CH}), 123.9(\mathrm{CH})$, $118.2(\mathrm{CH}), 116.9(\mathrm{CH}), 114.5\left(\mathrm{C}_{\mathrm{q}}\right), 112.4\left(\mathrm{C}_{\mathrm{q}}\right)$.

IR (ATR): 2912, 1680, 1540, 1420, 1260, 846, $755 \mathrm{~cm}^{-1}$.

MS (ESI) $m / z$ (relative intensity): $359(100)[\mathrm{M}+\mathrm{Na}]^{+}, 337(10)[\mathrm{M}+\mathrm{H}]^{+}$.

HR-MS (ESI): $m / z$ calcd. for $\left[\mathrm{C}_{24} \mathrm{H}_{16} \mathrm{O}_{2}+\mathrm{Na}\right]^{+} 359.1043$ found 359.1044 .

$[\alpha]_{\mathrm{D}}^{20}:-4.9\left(\mathrm{c}=0.35, \mathrm{CHCl}_{3}\right)$.

HPLC separation (Chiralpak ${ }^{\circledR}$ IA-3, $n$-hexane/i-PrOH 90:10, $1.0 \mathrm{~mL} / \mathrm{min}$, detection at $273 \mathrm{~nm}$ ): $t_{r}($ major $)=36.8 \mathrm{~min}, t_{r}($ minor $)=27.8 \mathrm{~min}, 96 \%$ ee .<smiles>O=C(O)c1ccc2ccccc2c1-c1c(C(=O)O)ccc2ccc3ccccc3c12</smiles>

(R)-4-(2-Carboxynaphthalen-1-yl)phenanthrene-3-carboxylic acid (404): To a stirred solution of compound $\mathbf{4 0 2}$ (15 mg, $0.04 \mathrm{mmol})$ and 2-methylbut-2-ene (36.4 mg, $0.52 \mathrm{mmol})$ in $t \mathrm{BuOH}(1.5 \mathrm{~mL})$ were added a saturated solution of $\mathrm{NaClO}_{2}(14.4 \mathrm{mg}, 0.16 \mathrm{mmol})$ and $\mathrm{NaH}_{2} \mathrm{PO}_{4} \cdot 2 \mathrm{H}_{2} \mathrm{O}(31.2 \mathrm{mg}, 0.20 \mathrm{mmol})$. The mixture was stirred at $30{ }^{\circ} \mathrm{C}$ for 18 hours. The mixture was treated with saturated $\mathrm{NH}_{4} \mathrm{Cl}$ and extracted with EtOAc. The combined organic layers were washed with brine, dried over $\mathrm{Na}_{2} \mathrm{SO}_{4}$, filtered, concentrated, and purified by chromatography on silica gel ( $n$-hexane/EtOAc/AcOH = 1:1:0.1) to give compound 404 (12.4 mg, $82 \%)$ M.p. $>200{ }^{\circ} \mathrm{C}$.

${ }^{1} \mathrm{H}-\mathrm{NMR}\left(400 \mathrm{MHz}, \mathrm{CD}_{3} \mathrm{CO}_{2} \mathrm{D}\right): \delta=8.32(\mathrm{~d}, J=8.8 \mathrm{~Hz}, 1 \mathrm{H}), 8.25(\mathrm{~d}, J=8.3 \mathrm{~Hz}, 1 \mathrm{H}), 8.22-$ $8.19(\mathrm{~m}, 2 \mathrm{H}), 8.02(\mathrm{~d}, J=8.3 \mathrm{~Hz}, 1 \mathrm{H}), 7.91(\mathrm{~d}, J=8.8 \mathrm{~Hz}, 2 \mathrm{H}), 7.83(\mathrm{dd}, J=8.1,1.5 \mathrm{~Hz}, 1 \mathrm{H})$, 7.53 (ddd, $J=8.1,6.2,1.7 \mathrm{~Hz}, 1 \mathrm{H}), 7.37-7.31$ (m, 1H), 7.26-7.17 (m, 2H), 7.14 (d, $J=8.8 \mathrm{~Hz}$, $1 \mathrm{H}), 6.87$ (ddd, $J=8.7,7.0,1.7 \mathrm{~Hz}, 1 \mathrm{H})$. 
${ }^{13} \mathrm{C}-\mathrm{NMR}\left(150 \mathrm{MHz}, \mathrm{CD}_{3} \mathrm{CO}_{2} \mathrm{D}\right): \delta=173.4\left(\mathrm{C}_{\mathrm{q}}\right), 172.5\left(\mathrm{C}_{\mathrm{q}}\right), 144.5\left(\mathrm{C}_{\mathrm{q}}\right), 139.6\left(\mathrm{C}_{\mathrm{q}}\right), 136.9$ $\left(\mathrm{C}_{\mathrm{q}}\right), 136.8\left(\mathrm{C}_{\mathrm{q}}\right), 134.1\left(\mathrm{C}_{\mathrm{q}}\right), 133.9\left(\mathrm{C}_{\mathrm{q}}\right), 131.8\left(\mathrm{C}_{\mathrm{q}}\right), 131.0(\mathrm{CH}), 130.9\left(\mathrm{C}_{\mathrm{q}}\right), 130.7\left(\mathrm{C}_{\mathrm{q}}\right), 130.1$ $(\mathrm{CH}), 129.5(\mathrm{CH}), 129.3(\mathrm{CH}), 129.1(\mathrm{CH}), 128.4(\mathrm{CH}), 128.1(\mathrm{CH}), 128.1(\mathrm{CH}), 128.0\left(\mathrm{C}_{\mathrm{q}}\right)$, $127.8(\mathrm{CH}), 127.7(\mathrm{CH}), 127.5(\mathrm{CH}), 127.3(\mathrm{CH}), 127.1(\mathrm{CH})$.

IR (ATR): 2922, 1719, 1595, 1455, 1168, 1142, 748, $699 \mathrm{~cm}^{-1}$. MS (ESI) $m / z$ (relative intensity): $415(100)[\mathrm{M}+\mathrm{Na}]^{+}, 393(10)[\mathrm{M}+\mathrm{H}]^{+}$.

HR-MS (ESI): $m / z$ calcd. for $\left[\mathrm{C}_{26} \mathrm{H}_{16} \mathrm{O}_{4}+\mathrm{Na}\right]^{+} 415.0941$ found 415.0940 . $[\alpha]_{\mathrm{D}}^{20}:-19.9\left(\mathrm{c}=0.8, \mathrm{CHCl}_{3}\right)$.

HPLC separation (Chiralpak ${ }^{\circledR}$ IB-3, $n$-hexane/i-PrOH/TFA 92:8:.0.08, $1.0 \mathrm{~mL} / \mathrm{min}$, detection at $273 \mathrm{~nm}): t_{r}($ major $)=18.7 \mathrm{~min}, t_{r}($ minor $)=25.9 \mathrm{~min}, 96 \%$ ee.

\subsubsection{Mechanistic Studies for the Atroposelective C-H Activation}

\subsubsection{H/D-exchange experiment}

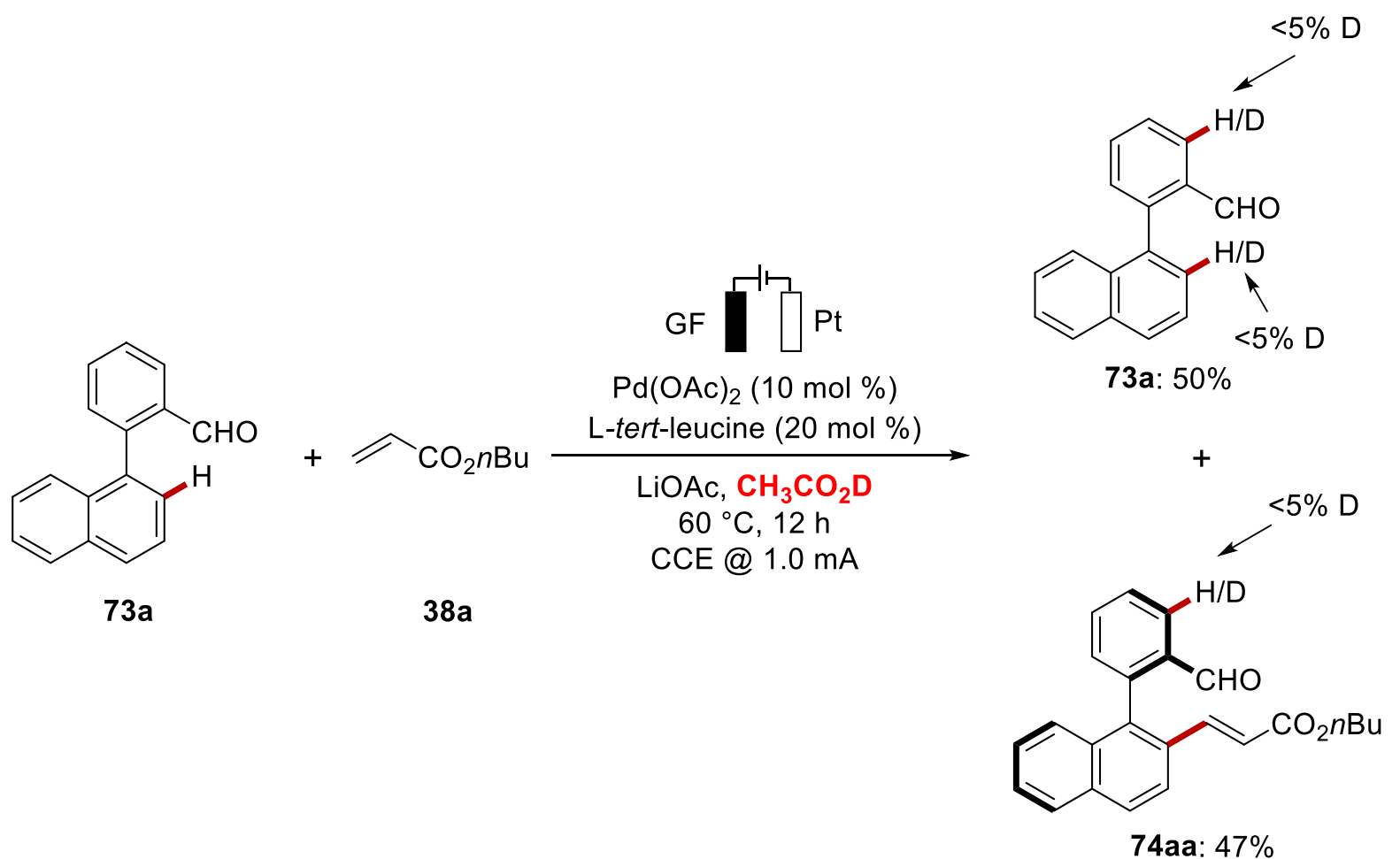

The representative procedure $\mathbf{L}$ was followed using 73a (46.4 mg, $0.20 \mathrm{mmol}, 1$ equiv), $n$-butyl acrylate (38a) (76.9 mg, 0.6 mmol, 3 equiv), $\mathrm{Pd}(\mathrm{OAc})_{2}$ (4.49 mg, $10 \mathrm{~mol} \%$ ), L-tert-leucine (5.24 mg, $20 \mathrm{~mol} \%)$ and LiOAc (26.4 mg, 2 equiv) in AcOD $(4.5 \mathrm{~mL})$ at $60{ }^{\circ} \mathrm{C}$ for $12 \mathrm{~h}$. At ambient temperature, the reaction mixture was diluted with EtOAc $(3.0 \mathrm{~mL})$ and the solvents were removed in vacuo. The crude mixture was purified by flash column chromatography on silica gel to afford the desired product 74aa (34 mg, 47\%) and 73a (23.2 mg, 50\% reisolated). 


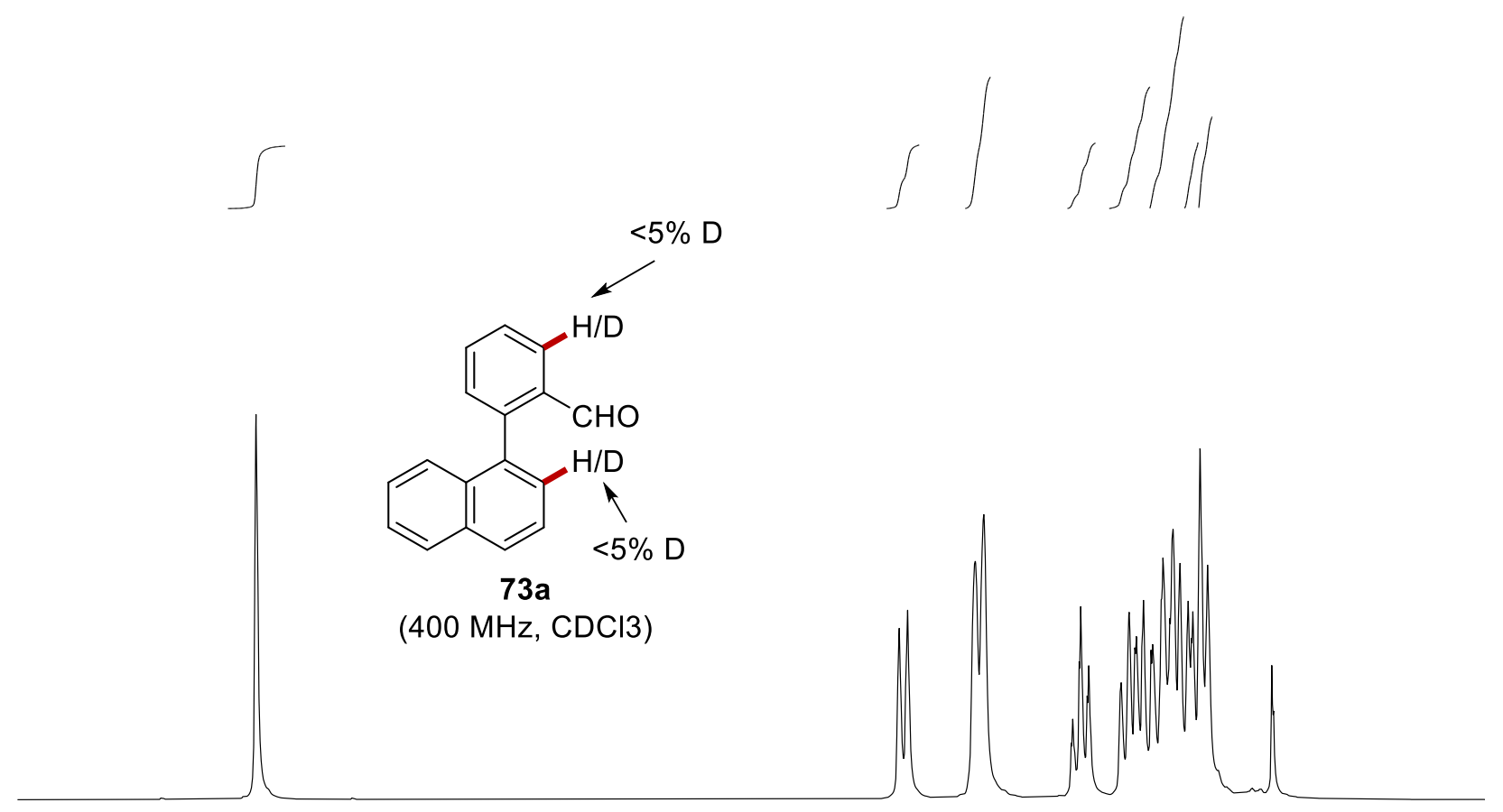

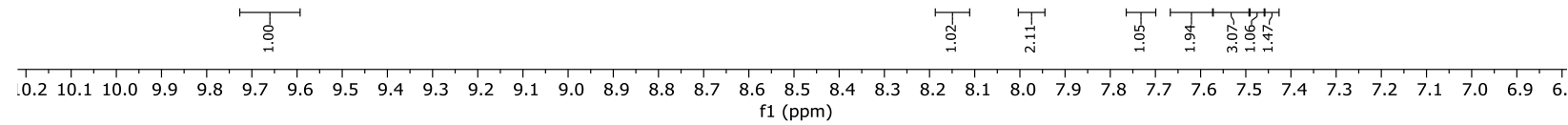
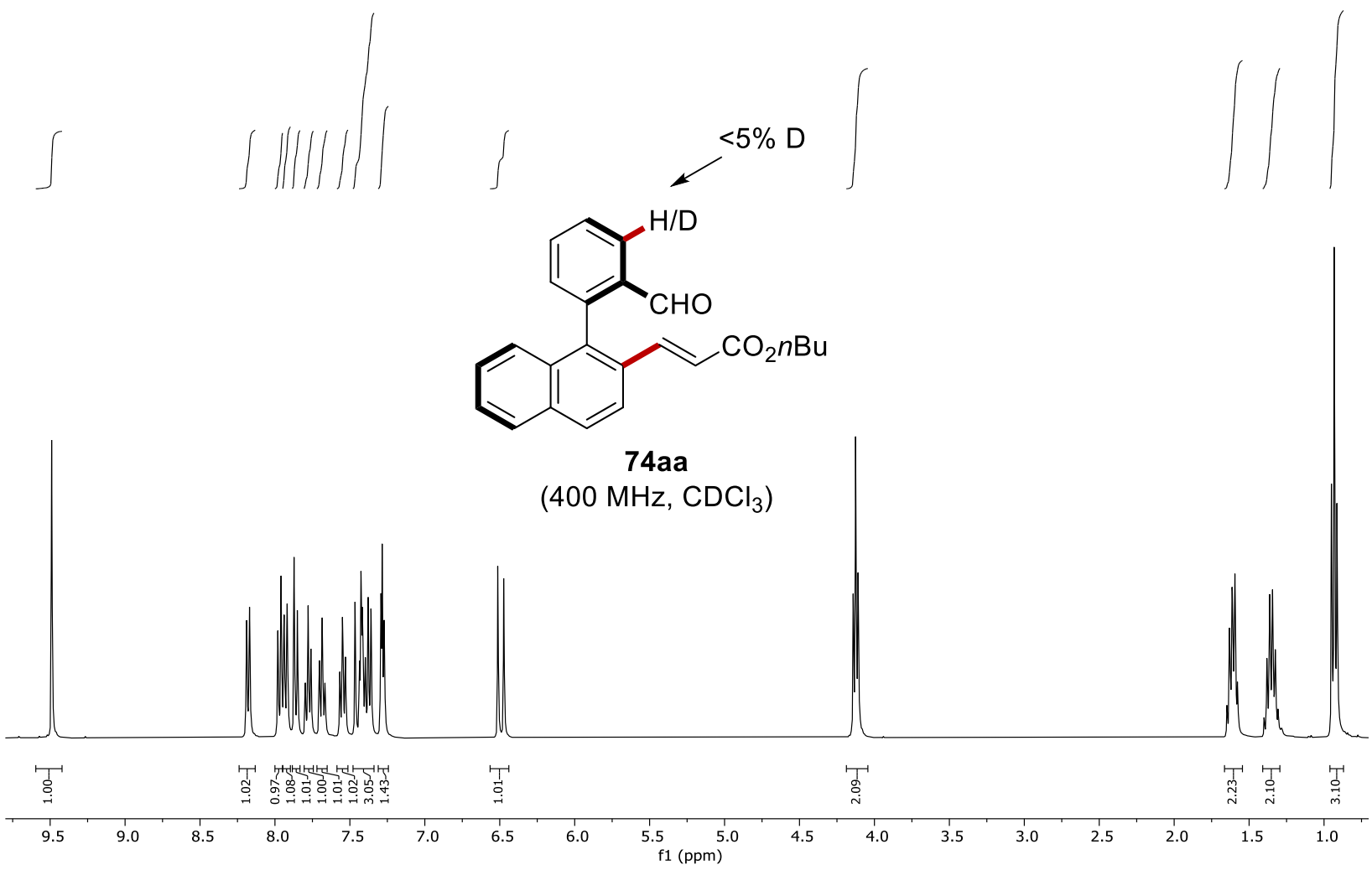

5.7.3.2. KIE Studies 


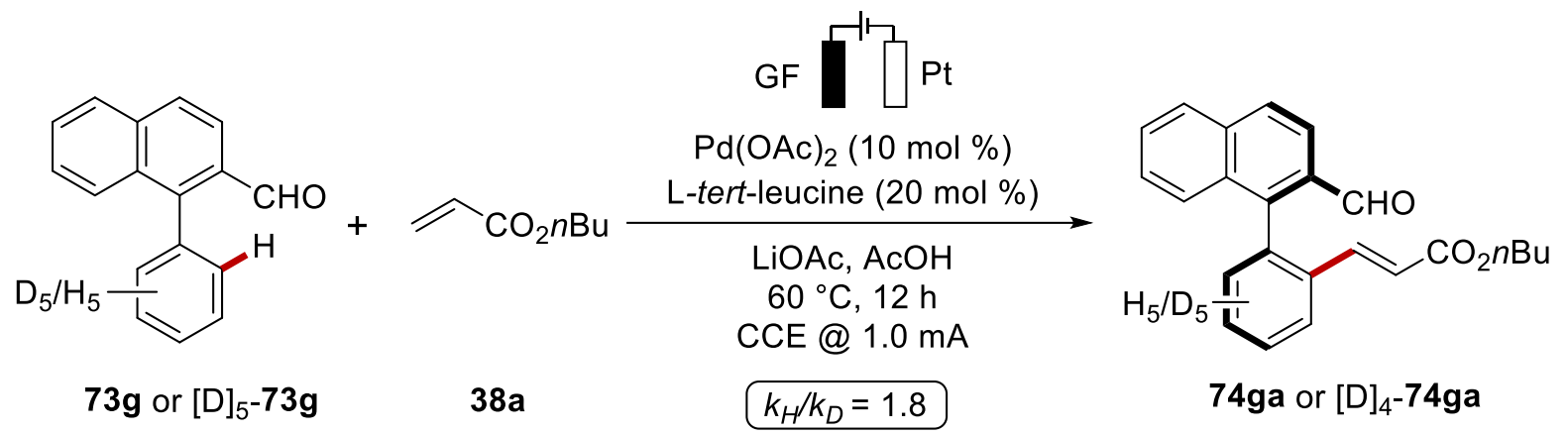

Two parallel reactions of $\mathbf{7 3 g}$ and $[\mathrm{D}] 5-\mathbf{7 3 g}$ with $\mathbf{3 8 a}$ were performed to determine the KIE by comparison of the initial reaction rates through ${ }^{1} \mathrm{H}-\mathrm{NMR}$-analysis with triphenylmethane as the the internal standard. A suspension of $\mathbf{7 3 g}$ (46.4 mg, $0.20 \mathrm{mmol}, 1.00$ equiv) or [D]5-73g (47.4 $\mathrm{mg}, 0.50 \mathrm{mmol}, 1.00$ equiv), 38a (76.9 mg, $1.50 \mathrm{mmol}, 3$ equiv), $\mathrm{Pd}(\mathrm{OAc})_{2}$ (4.49 mg, $10 \mathrm{~mol}$ $\%$ ), L-tert-leucine (5.24 mg, $20 \mathrm{~mol} \%$ ) and LiOAc (26.4 mg, 2 equiv) and triphenylmethane $(48.9 \mathrm{mg}, 0.20 \mathrm{mmol})$ in $\mathrm{AcOH}(5.6 \mathrm{~mL})$ was stirred at $60{ }^{\circ} \mathrm{C}$. Aliquots $(30 \mu \mathrm{L})$ were periodically removed to provide the following conversions as determined by ${ }^{1} \mathrm{H}-\mathrm{NMR}$ :

Table 36. Conversion-time table

\begin{tabular}{ccccccc}
\hline $\boldsymbol{t} / \mathbf{m i n}$ & $\mathbf{1 0}$ & $\mathbf{2 0}$ & $\mathbf{3 0}$ & $\mathbf{4 0}$ & $\mathbf{5 0}$ & $\mathbf{6 0}$ \\
\hline $\mathbf{7 4 g a} / \%$ & 2.41 & 7.11 & 9.02 & 10.38 & 13.18 & 15.2 \\
$\begin{array}{c}{[\mathrm{D}]_{n-74} / \%} \\
/ \%\end{array}$ & 0.2 & 3.21 & 3.71 & 5.31 & 6.05 & 7.43 \\
\hline
\end{tabular}

\subsubsection{Nonlinear Effect Study}

Six parallel independent reactions of 73a $(46.4 \mathrm{mg}, 0.20 \mathrm{mmol}), 38 \mathbf{a}(76.9 \mathrm{mg}, 0.60 \mathrm{mmol})$, $\mathrm{Pd}(\mathrm{OAc})_{2}(4.49 \mathrm{mg}, 10 \mathrm{~mol} \%)$, L-tert-leucine (10-100\% ee, $\left.5.24 \mathrm{mg}, 20 \mathrm{~mol} \%\right)$ and LiOAc (26.4 mg, 2 equiv) were heated at $60{ }^{\circ} \mathrm{C}$ in $\mathrm{AcOH}(4.5 \mathrm{~mL})$ for $20 \mathrm{~h}$. At ambient temperature, the reaction mixture was diluted with EtOAc $(3.0 \mathrm{~mL})$ and the solvents were removed in vacuo. The crude mixture was purified by flash column chromatography on silica gel to afford the desired product 74aa. The enantiomeric excess was determined by HPLC on chiral stationary phase. 
Table 37. Nonlinear effect study for the asymmetric C-H olefination.

\begin{tabular}{ccc}
\hline Entry & $\boldsymbol{e}$ of L-tert-leucine & $\boldsymbol{e}$ of the product [74aa] \\
\hline 1 & 0 & 0 \\
2 & 11.2 & 9.3 \\
3 & 28.8 & 29.1 \\
4 & 51.2 & 51.5 \\
5 & 68.8 & 67.5 \\
6 & 91.2 & 88.9 \\
7 & 100 & 97.3 \\
\hline
\end{tabular}

\subsection{Crystallographic Data}

The crystal structures of 357da, 363e and 256aj were measured and solved by Dr. Christopher Golz.

\subsubsection{Determination of Absolute Stereochemistry of 357da}

357da (40 mg, $0.14 \mathrm{mmol}$, e.r. 92:8) was recrystallized from $n$-hexane/ $\mathrm{CH}_{2} \mathrm{Cl}_{2}$ to furnish optically pure product (15 mg, $0.05 \mathrm{mmol}$, e.r. 99:1) as mother liquor. HPLC separation (Chiralpak ${ }^{\circledR}$ IF-3, $n$-hexane $/ i$-PrOH 95:5, $1.0 \mathrm{~mL} / \mathrm{min}$, detection at $273 \mathrm{~nm}$ ): $t_{r}$ (major) $=14.1$ $\min , t_{r}(\operatorname{minor})=16.1 \mathrm{~min}, 99.4: 0.6$ e.r.

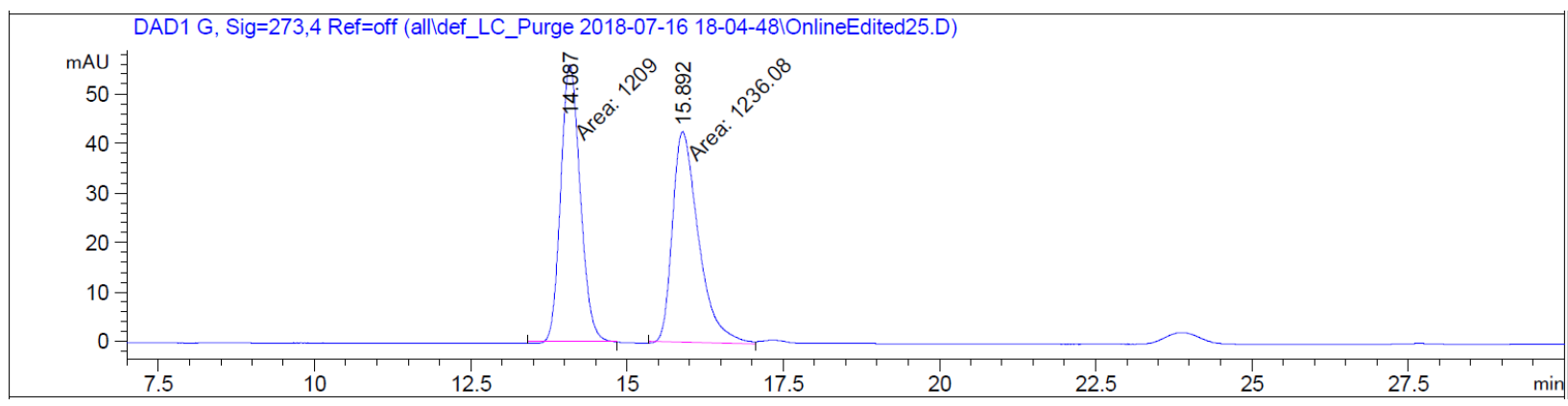




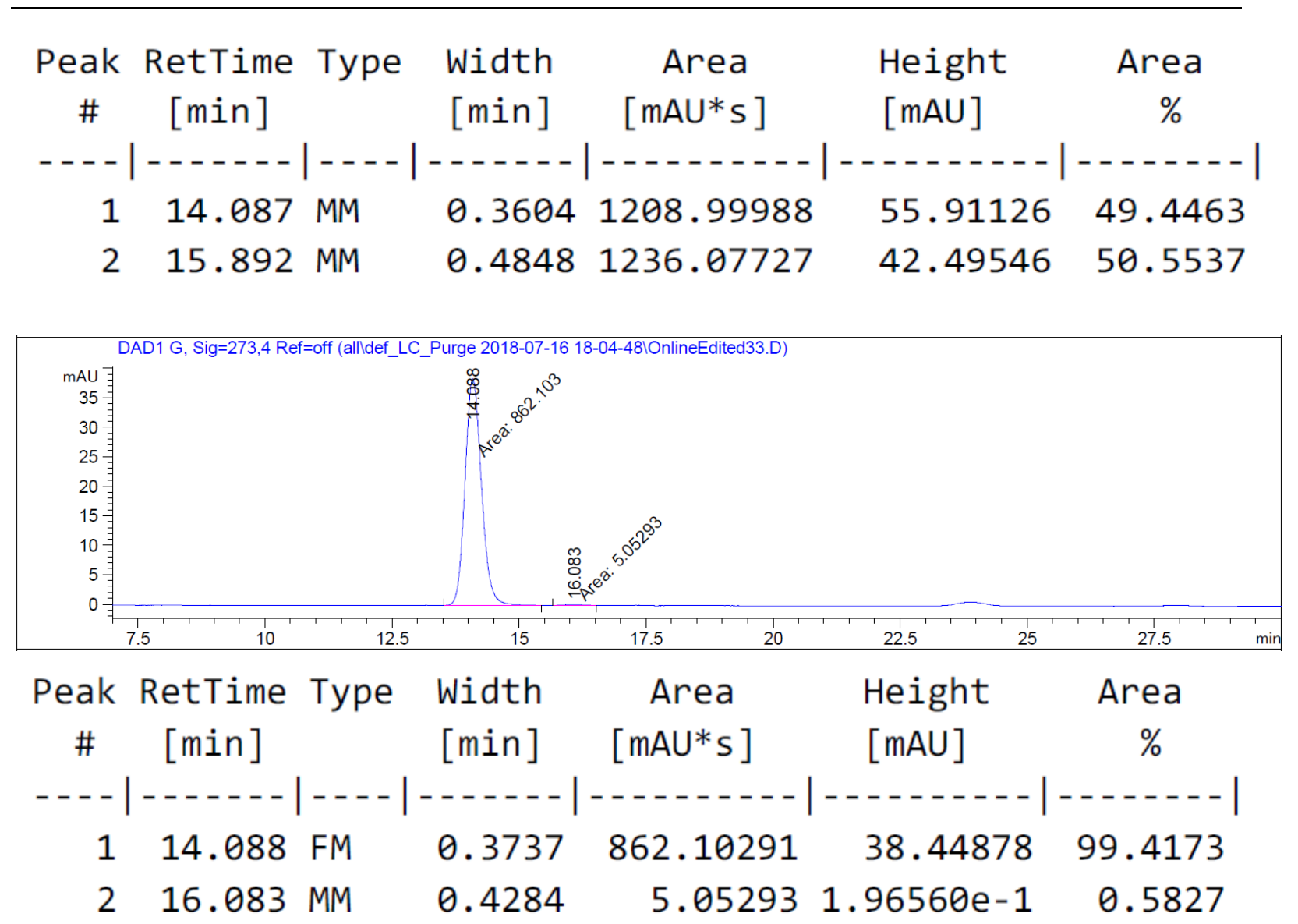

Crystals suitable for X-Ray crystallography were grown by slow evaporation from $n$-hexane/ $\mathrm{CH}_{2} \mathrm{Cl}_{2}$.

\subsubsection{X-Ray Crystallographic Analysis of 357da}

Table 38. Crystal data of 357da

\begin{tabular}{|l|c|}
\hline Compound & 357da \\
\hline CCDC Number & $\mathrm{CCDC} 1857899$ \\
\hline Empirical formula & $\mathrm{C}_{19} \mathrm{H}_{19} \mathrm{NO}_{2}$ \\
\hline Formula Weight & 293.35 \\
\hline Temperature & 100.03 \\
\hline Crystal System & monoclinic \\
\hline Space group & $\mathrm{P} 2{ }_{1}$ \\
\hline $\mathrm{a} / \AA$ & $8.3652(5)$ \\
\hline $\mathrm{b} / \AA$ & $12.7119(8)$ \\
\hline $\mathrm{c} / \AA$ & $14.4909(9)$ \\
\hline$\alpha /^{\circ}$ & 90 \\
\hline$\beta /{ }^{\circ}$ & $91.7540(10)$ \\
\hline$\gamma /{ }^{\circ}$ & 90 \\
\hline
\end{tabular}




\begin{tabular}{|c|c|}
\hline Volume $/ \AA^{3}$ & $1540.21(16)$ \\
\hline $\mathrm{Z}$ & 4 \\
\hline$\rho_{\text {calc }} / \mathrm{cm}^{3}$ & 1.265 \\
\hline$\mu / \mathrm{mm}^{-1}$ & 0.650 \\
\hline $\mathrm{F}(000)$ & 624.0 \\
\hline Crystal size $/ \mathrm{mm}^{3}$ & $0.525 \times 0.462 \times 0.094$ \\
\hline Radiation & $\operatorname{CuK} \alpha(\lambda=1.54178)$ \\
\hline $2 \Theta$ range for data collection $/^{\circ}$ & 6.102 to 155.35 \\
\hline Index ranges & $-10 \leq \mathrm{h} \leq 10,-16 \leq \mathrm{k} \leq 16,-18 \leq 1 \leq 18$ \\
\hline Reflections collected & 6284 \\
\hline Independent reflections & $6284\left[\mathrm{R}_{\text {int }}=0.0300, \mathrm{R}_{\text {sigma }}=0.0301\right]$ \\
\hline Data/restraints/parameters & $6284 / 136 / 540$ \\
\hline Goodness-of-fit on $\mathrm{F}^{2}$ & 1.064 \\
\hline Final $R$ indexes $[I>=2 \sigma(I)]$ & $\mathrm{R}_{1}=0.0300, \mathrm{wR}_{2}=0.0827$ \\
\hline Final $\mathrm{R}$ indexes [all data] & $\mathrm{R}_{1}=0.0301, \mathrm{wR}_{2}=0.0827$ \\
\hline Largest diff. peak/hole / e $\AA^{-3}$ & $0.26 /-0.13$ \\
\hline Flack parameter & $0.00(9)$ \\
\hline
\end{tabular}

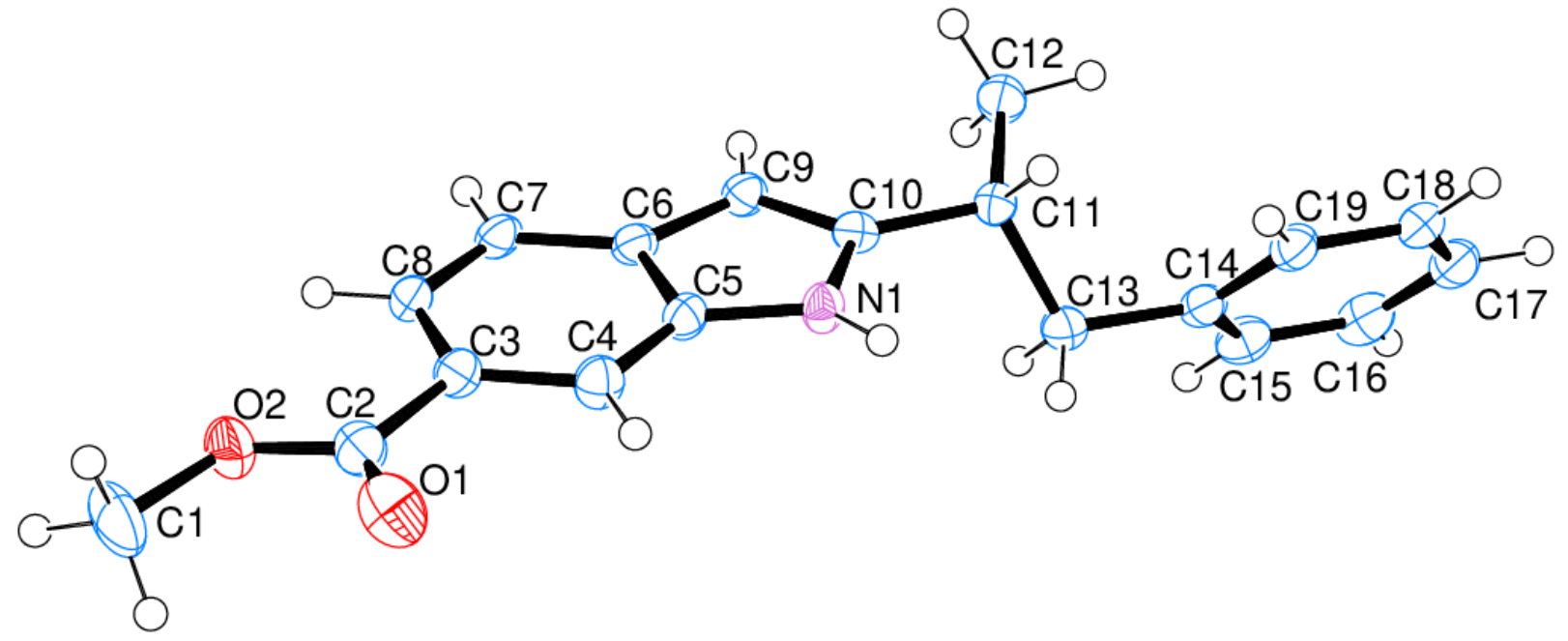

Table 39. Selected bond lengths $[\AA]$ and angles $\left[{ }^{\circ}\right]$ for $357 \mathbf{d a}$

$\begin{array}{cccc}\text { O1-C2 } & 1.215(3) & \mathrm{C} 2-\mathrm{O} 2-\mathrm{C} 1 & 117.2(2) \\ \mathrm{O} 2-\mathrm{C} 1 & 1.448(3) & \mathrm{C} 10-\mathrm{N} 1-\mathrm{C} 5 & 109.00(17) \\ \mathrm{O} 2-\mathrm{C} 2 & 1.338(3) & \mathrm{O} 1-\mathrm{C} 2-\mathrm{O} 2 & 123.1(2) \\ \mathrm{N} 1-\mathrm{C} 5 & 1.379(3) & \mathrm{O} 1-\mathrm{C} 2-\mathrm{C} 3 & 125.1(2) \\ \mathrm{N} 1-\mathrm{C} 10 & 1.377(3) & \mathrm{O} 2-\mathrm{C} 2-\mathrm{C} 3 & 111.8(2)\end{array}$




\begin{tabular}{|c|c|c|c|}
\hline $\mathrm{C} 2-\mathrm{C} 3$ & $1.482(3)$ & $\mathrm{C} 4-\mathrm{C} 3-\mathrm{C} 2$ & $117.3(2)$ \\
\hline $\mathrm{C} 3-\mathrm{C} 4$ & $1.398(3)$ & $\mathrm{C} 4-\mathrm{C} 3-\mathrm{C} 8$ & $120.8(2)$ \\
\hline $\mathrm{C} 3-\mathrm{C} 8$ & $1.409(3)$ & $\mathrm{C} 8-\mathrm{C} 3-\mathrm{C} 2$ & $121.8(2)$ \\
\hline $\mathrm{C} 4-\mathrm{C} 5$ & $1.391(3)$ & $\mathrm{C} 5-\mathrm{C} 4-\mathrm{C} 3$ & $117.7(2)$ \\
\hline C5-C6 & $1.419(3)$ & $\mathrm{N} 1-\mathrm{C} 5-\mathrm{C} 4$ & $130.3(2)$ \\
\hline C6-C7 & $1.403(3)$ & N1-C5-C6 & $107.56(18)$ \\
\hline C6-C9 & $1.425(3)$ & $\mathrm{C} 4-\mathrm{C} 5-\mathrm{C} 6$ & $122.2(2)$ \\
\hline $\mathrm{C} 7-\mathrm{C} 8$ & $1.381(3)$ & C5-C6-C9 & $106.59(18)$ \\
\hline C9-C10 & $1.372(3)$ & C7-C6-C5 & $118.9(2)$ \\
\hline C10-C11 & $1.503(3)$ & C7-C6-C9 & $134.5(2)$ \\
\hline C11-C12 & $1.528(3)$ & C8-C7-C6 & 119.41(19) \\
\hline C11-C13 & $1.547(3)$ & $\mathrm{C} 7-\mathrm{C} 8-\mathrm{C} 3$ & 120.99(19) \\
\hline C13-C14 & $1.515(3)$ & C10-C9-C6 & $107.54(19)$ \\
\hline C14-C15 & $1.397(3)$ & N1-C10-C11 & $120.88(18)$ \\
\hline C14-C19 & $1.395(3)$ & C9-C10-N1 & 109.32(19) \\
\hline C15-C16 & $1.386(3)$ & C9-C10-C11 & $129.80(19)$ \\
\hline C16-C17 & $1.379(4)$ & C10-C11-C12 & $111.03(17)$ \\
\hline C17-C18 & $1.388(3)$ & C10-C11-C13 & $110.73(16)$ \\
\hline \multirow[t]{10}{*}{ C18-C19 } & $1.390(3)$ & $\mathrm{C} 12-\mathrm{C} 11-\mathrm{C} 13$ & $111.86(17)$ \\
\hline & & C14-C13-C11 & $113.08(16)$ \\
\hline & & C15-C14-C13 & 120.61(19) \\
\hline & & C19-C14-C13 & $121.46(18)$ \\
\hline & & C19-C14-C15 & $117.9(2)$ \\
\hline & & C16-C15-C14 & $120.8(2)$ \\
\hline & & C17-C16-C15 & $120.7(2)$ \\
\hline & & C16-C17-C18 & $119.5(2)$ \\
\hline & & C17-C18-C19 & $120.0(2)$ \\
\hline & & C18-C19-C14 & $121.16(19)$ \\
\hline
\end{tabular}

\subsubsection{Determination of Absolute Stereochemistry of $363 \mathrm{e}$}

363e (70 mg, $0.20 \mathrm{mmol}, 82: 18$ e.r.) was recrystallized from $\mathrm{CH}_{2} \mathrm{Cl}_{2}$ at $\mathrm{RT}$ by slow evaporation to obtain suitable crystals for X-Ray crystallography. HPLC separation of crystal 363e 
(Chiralpak® ID-3, $n$-hexane/EtOAc 90:10, $1.0 \mathrm{~mL} / \mathrm{min}$, detection at $273 \mathrm{~nm}): t_{r}$ (major) $=8.6$ $\min , t_{r}$ (minor) $=5.7 \min , 99.4: 0.6$ e.r.
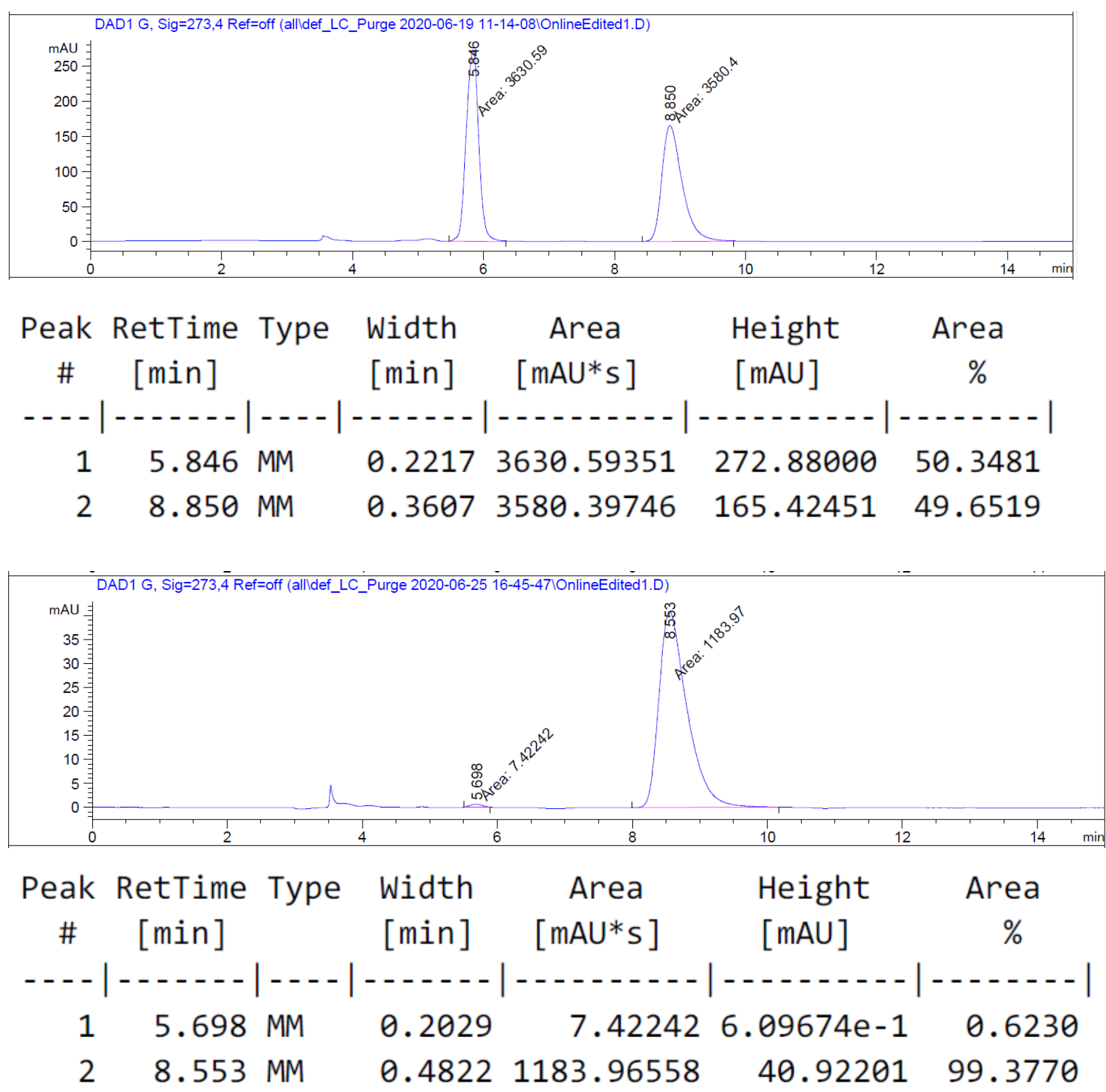

\subsubsection{X-Ray Crystallographic Analysis of 363e}




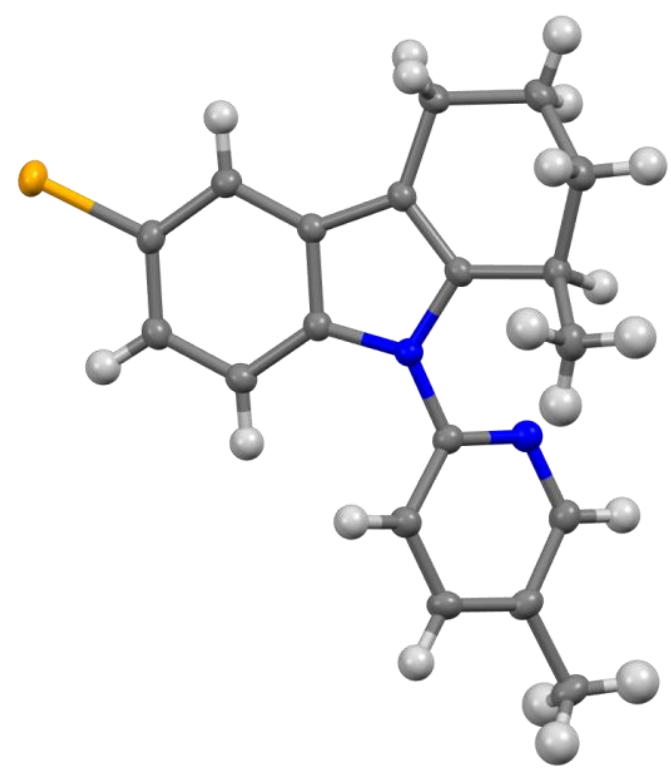

Table 40. Crystal data of 256aj

\begin{tabular}{|c|c|}
\hline Compound & $363 e$ \\
\hline CCDC Number & CCDC 2012314 \\
\hline Empirical formula & $\mathrm{C}_{19} \mathrm{H}_{19} \mathrm{BrN}_{2}$ \\
\hline Formula Weight & 355.27 \\
\hline Temperature & 100.0 \\
\hline Crystal System & orthorhombic \\
\hline Space group & $\mathrm{P} 2{ }_{12} 2_{1}$ \\
\hline $\mathrm{a} / \AA$ & $9.0448(5)$ \\
\hline $\mathrm{b} / \AA$ & $12.6834(6)$ \\
\hline $\mathrm{c} / \AA$ & $13.7386(5)$ \\
\hline$\alpha /^{\circ}$ & 90 \\
\hline$\beta /^{\circ}$ & 90 \\
\hline$\gamma /{ }^{\circ}$ & 90 \\
\hline Volume $/ \AA^{3}$ & $1576.08(13)$ \\
\hline $\mathrm{Z}$ & 4 \\
\hline$\rho_{\text {calc }} \mathrm{g} / \mathrm{cm}^{3}$ & 1.497 \\
\hline$\mu / \mathrm{mm}^{-1}$ & 2.606 \\
\hline $\mathrm{F}(000)$ & 728.0 \\
\hline Crystal size $/ \mathrm{mm}^{3}$ & $0.344 \times 0.172 \times 0.155$ \\
\hline Radiation & $\operatorname{MoK} \alpha(\lambda=0.71073)$ \\
\hline $2 \Theta$ range for data collection ${ }^{\circ}$ & 4.37 to 61.036 \\
\hline
\end{tabular}




\begin{tabular}{|l|c|}
\hline Index ranges & $-12 \leq \mathrm{h} \leq 12,-18 \leq \mathrm{k} \leq 18,-19 \leq 1 \leq 18$ \\
\hline Reflections collected & 54097 \\
\hline Independent reflections & $4808\left[\mathrm{R}_{\text {int }}=0.0218, \mathrm{R}_{\text {sigma }}=0.0107\right]$ \\
\hline Data/restraints/parameters & $4808 / 0 / 201$ \\
\hline Goodness-of-fit on $\mathrm{F}^{2}$ & 1.067 \\
\hline Final R indexes [I $>=2 \sigma(\mathrm{I})]$ & $\mathrm{R}_{1}=0.0188, \mathrm{wR}_{2}=0.0501$ \\
\hline Final R indexes [all data] & $\mathrm{R}_{1}=0.0194, \mathrm{wR}_{2}=0.0509$ \\
\hline Largest diff. peak/hole / e $\AA^{-3}$ & $0.55 /-0.19$ \\
\hline Flack parameter & $0.0083(14)$ \\
\hline
\end{tabular}

Table 41. Selected bond lengths $[\AA]$ and angles $\left[{ }^{\circ}\right]$ for $363 \mathbf{e}$

\begin{tabular}{|c|c|c|c|}
\hline Br1-C1 & $1.9134(16)$ & C6-C1-Br1 & $118.57(12)$ \\
\hline N1-C4 & $1.397(2)$ & C6-C1-C2 & $123.22(15)$ \\
\hline $\mathrm{N} 1-\mathrm{C} 8$ & $1.410(2)$ & $\mathrm{C} 3-\mathrm{C} 2-\mathrm{C} 1$ & $119.93(15)$ \\
\hline N1-C14 & $1.416(2)$ & $\mathrm{C} 2-\mathrm{C} 3-\mathrm{C} 4$ & $118.00(15)$ \\
\hline $\mathrm{N} 2-\mathrm{C} 14$ & $1.336(2)$ & N1-C4-C5 & $107.50(14)$ \\
\hline N2-C18 & $1.335(2)$ & C3-C4-N1 & $130.62(15)$ \\
\hline $\mathrm{C} 1-\mathrm{C} 2$ & $1.397(2)$ & C3-C4-C5 & $121.88(15)$ \\
\hline C1-C6 & $1.383(2)$ & C4-C5-C7 & $107.48(14)$ \\
\hline $\mathrm{C} 2-\mathrm{C} 3$ & $1.388(2)$ & C6-C5-C4 & $119.67(15)$ \\
\hline $\mathrm{C} 3-\mathrm{C} 4$ & $1.393(2)$ & C6-C5-C7 & $132.84(15)$ \\
\hline C4-C5 & $1.416(2)$ & C1-C6-C5 & $117.24(15)$ \\
\hline C5-C6 & $1.406(2)$ & C5-C7-C12 & $128.90(14)$ \\
\hline $\mathrm{C} 5-\mathrm{C} 7$ & $1.430(2)$ & $\mathrm{C} 8-\mathrm{C} 7-\mathrm{C} 5$ & $107.64(14)$ \\
\hline $\mathrm{C} 7-\mathrm{C} 8$ & $1.366(2)$ & $\mathrm{C} 8-\mathrm{C} 7-\mathrm{C} 12$ & $123.39(14)$ \\
\hline C7-C12 & $1.501(2)$ & N1-C8-C9 & $124.30(14)$ \\
\hline C8-C9 & $1.499(2)$ & C7-C8-N1 & $109.45(14)$ \\
\hline C9-C10 & $1.558(2)$ & C7-C8-C9 & $125.96(15)$ \\
\hline C9-C13 & $1.530(2)$ & C8-C9-C10 & $107.93(14)$ \\
\hline $\mathrm{C} 10-\mathrm{C} 11$ & $1.526(2)$ & C8-C9-C13 & $111.97(14)$ \\
\hline C11-C12 & $1.528(2)$ & C13-C9-C10 & $108.24(14)$ \\
\hline C14-C15 & $1.392(2)$ & C11-C10-C9 & $112.86(15)$ \\
\hline $\mathrm{C} 15-\mathrm{C} 16$ & $1.390(2)$ & $\mathrm{C} 10-\mathrm{C} 11-\mathrm{C} 12$ & $110.35(15)$ \\
\hline C16-C17 & $1.393(2)$ & C7-C12-C11 & $109.53(14)$ \\
\hline
\end{tabular}




$\begin{array}{cccc}\text { C17-C18 } & 1.397(2) & \mathrm{N} 2-\mathrm{C} 14-\mathrm{N} 1 & 115.55(14) \\ \mathrm{C} 17-\mathrm{C} 19 & 1.505(2) & \mathrm{N} 2-\mathrm{C} 14-\mathrm{C} 15 & 123.07(16) \\ \mathrm{C} 4-\mathrm{N} 1-\mathrm{C} 8 & 107.92(13) & \mathrm{C} 15-\mathrm{C} 14-\mathrm{N} 1 & 121.38(15) \\ \mathrm{C} 4-\mathrm{N} 1-\mathrm{C} 14 & 124.61(14) & \mathrm{C} 16-\mathrm{C} 15-\mathrm{C} 14 & 118.31(16) \\ \mathrm{C} 8-\mathrm{N} 1-\mathrm{C} 14 & 125.71(14) & \mathrm{C} 15-\mathrm{C} 16-\mathrm{C} 17 & 119.87(16) \\ \mathrm{C} 18-\mathrm{N} 2-\mathrm{C} 14 & 117.42(15) & \mathrm{C} 16-\mathrm{C} 17-\mathrm{C} 18 & 116.58(16) \\ \mathrm{C} 2-\mathrm{C} 1-\mathrm{Br} 1 & 118.21(12) & \mathrm{C} 16-\mathrm{C} 17-\mathrm{C} 19 & 122.65(17) \\ & & \mathrm{C} 18-\mathrm{C} 17-\mathrm{C} 19 & 120.76(16) \\ & & \mathrm{N} 2-\mathrm{C} 18-\mathrm{C} 17 & 124.62(16)\end{array}$

\subsubsection{X-Ray Crystallographic Analysis of 256aj}

Table 42. Crystal data of 256aj

\begin{tabular}{|c|c|}
\hline Compound & 256aj \\
\hline CCDC Number & CCDC 1910199 \\
\hline Empirical formula & $\mathrm{C}_{25} \mathrm{H}_{15} \mathrm{~N}_{3} \mathrm{O}$ \\
\hline Formula Weight & 373.40 \\
\hline Temperature & 99.95 \\
\hline Crystal System & monoclinic \\
\hline Space group & $\mathrm{C} 2 / \mathrm{c}$ \\
\hline $\mathrm{a} / \AA$ & $39.582(3)$ \\
\hline $\mathrm{b} / \AA$ & $6.6842(5)$ \\
\hline $\mathrm{c} / \AA$ & $13.9095(8)$ \\
\hline$\alpha /^{\circ}$ & 90 \\
\hline$\beta /{ }^{\circ}$ & $97.656(2)$ \\
\hline$\gamma /{ }^{\circ}$ & 90 \\
\hline Volume $/ \AA^{3}$ & $3647.2(4)$ \\
\hline $\bar{Z}$ & 8 \\
\hline$\rho_{\text {calc }} g / \mathrm{cm}^{3}$ & 1.360 \\
\hline$\mu / \mathrm{mm}^{-1}$ & 0.085 \\
\hline $\mathrm{F}(000)$ & 1552.0 \\
\hline Crystal size $/ \mathrm{mm}^{3}$ & $0.379 \times 0.351 \times 0.052$ \\
\hline Radiation & $\operatorname{MoK} \alpha(\lambda=0.71073)$ \\
\hline $2 \Theta$ range for data collection $/{ }^{\circ}$ & 5.91 to 59.128 \\
\hline Index ranges & $-54 \leq \mathrm{h} \leq 54,-9 \leq \mathrm{k} \leq 9,-19 \leq 1 \leq 17$ \\
\hline
\end{tabular}




\begin{tabular}{|l|c|}
\hline Reflections collected & 31821 \\
\hline Independent reflections & $5081\left[\mathrm{R}_{\text {int }}=0.0295, \mathrm{R}_{\text {sigma }}=0.0196\right]$ \\
\hline Data/restraints/parameters & $5081 / 0 / 262$ \\
\hline Goodness-of-fit on $\mathrm{F}^{2}$ & 1.042 \\
\hline Final R indexes [I $>=2 \sigma(\mathrm{I})]$ & $\mathrm{R}_{1}=0.0410, \mathrm{wR}_{2}=0.1015$ \\
\hline Final R indexes [all data] & $\mathrm{R}_{1}=0.0479, \mathrm{wR}_{2}=0.1090$ \\
\hline Largest diff. peak/hole $/ \mathrm{e} \AA^{-3}$ & $0.30 /-0.25$ \\
\hline
\end{tabular}

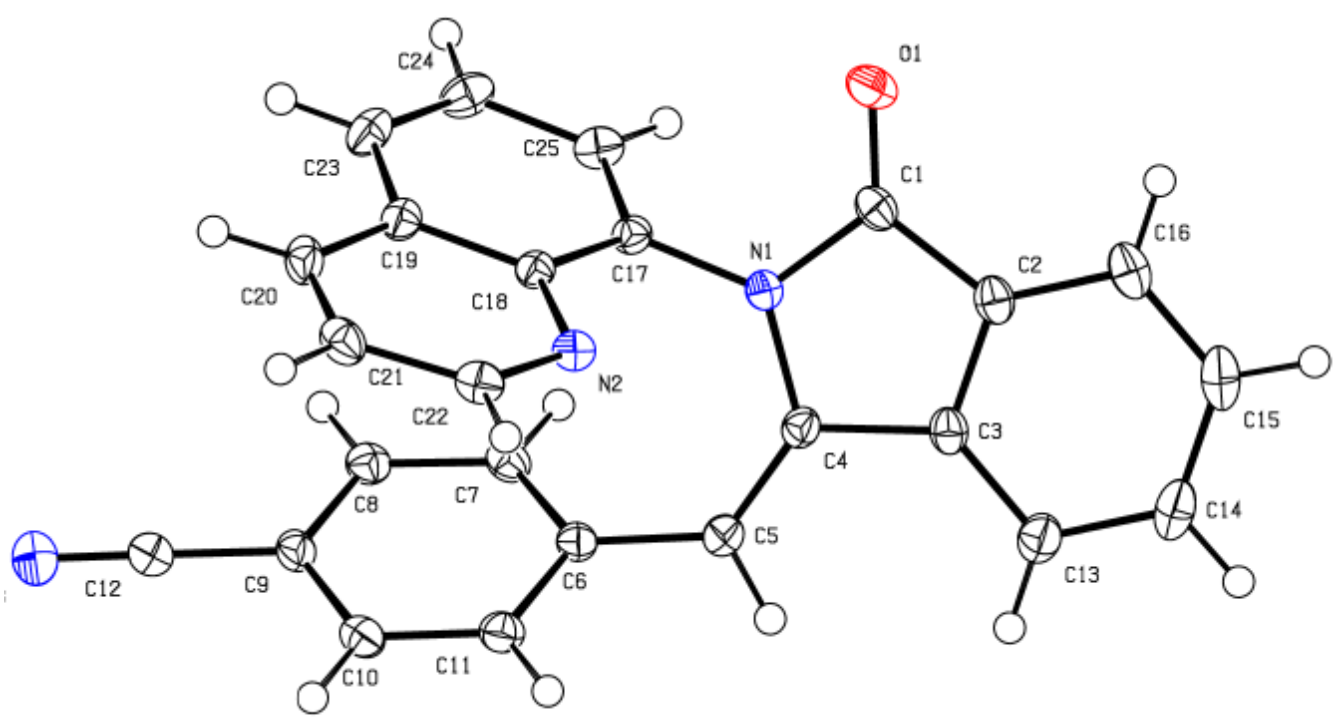

Table 43. Selected bond lengths $[\AA \AA]$ and angles $\left[^{\circ}\right]$ for $\mathbf{2 5 6 a j}$

$\begin{array}{cccc}\text { O1-C1 } & 1.2182(13) & \mathrm{C} 9-\mathrm{C} 10 & 1.3996(16) \\ \mathrm{N} 1-\mathrm{C} 1 & 1.3978(13) & \mathrm{C} 9-\mathrm{C} 12 & 1.4425(15) \\ \mathrm{N} 1-\mathrm{C} 4 & 1.4170(13) & \mathrm{C} 10-\mathrm{C} 11 & 1.3817(15) \\ \mathrm{N} 1-\mathrm{C} 17 & 1.4260(13) & \mathrm{C} 13-\mathrm{C} 14 & 1.3925(16) \\ \mathrm{N} 2-\mathrm{C} 18 & 1.3686(13) & \mathrm{C} 14-\mathrm{C} 15 & 1.3961(19) \\ \mathrm{N} 2-\mathrm{C} 22 & 1.3206(14) & \mathrm{C} 15-\mathrm{C} 16 & 1.3907(18) \\ \mathrm{N} 3-\mathrm{C} 12 & 1.1448(16) & \mathrm{C} 17-\mathrm{C} 18 & 1.4228(14) \\ \mathrm{C} 1-\mathrm{C} 2 & 1.4766(15) & \mathrm{C} 17-\mathrm{C} 25 & 1.3735(15) \\ \mathrm{C} 2-\mathrm{C} 3 & 1.3933(15) & \mathrm{C} 18-\mathrm{C} 19 & 1.4227(14) \\ \mathrm{C} 2-\mathrm{C} 16 & 1.3898(15) & \mathrm{C} 19-\mathrm{C} 20 & 1.4185(15) \\ \mathrm{C} 3-\mathrm{C} 4 & 1.4729(14) & \mathrm{C} 19-\mathrm{C} 23 & 1.4182(15) \\ \mathrm{C} 3-\mathrm{C} 13 & 1.3912(15) & \mathrm{C} 20-\mathrm{C} 21 & 1.3652(17) \\ \mathrm{C} 4-\mathrm{C} 5 & 1.3433(14) & \mathrm{C} 21-\mathrm{C} 22 & 1.4141(16) \\ \mathrm{C} 5-\mathrm{C} 6 & 1.4741(14) & \mathrm{C} 23-\mathrm{C} 24 & 1.3673(17)\end{array}$


5. Experimental Part

\begin{tabular}{|c|c|c|c|}
\hline C6-C7 & $1.4025(15)$ & $\mathrm{C} 24-\mathrm{C} 25$ & $1.4092(16)$ \\
\hline C6-C11 & $1.4020(14)$ & $\mathrm{C} 1-\mathrm{N} 1-\mathrm{C} 4$ & 112.09(9) \\
\hline $\mathrm{C} 7-\mathrm{C} 8$ & $1.3859(15)$ & $\mathrm{C} 1-\mathrm{N} 1-\mathrm{C} 17$ & 121.05(9) \\
\hline C8-C9 & $1.515(3)$ & C4-N1-C17 & $126.86(8)$ \\
\hline C22-N2-C18 & 116.81(9) & $\mathrm{C} 11-\mathrm{C} 10-\mathrm{C} 9$ & $119.29(10)$ \\
\hline $\mathrm{O} 1-\mathrm{C} 1-\mathrm{N} 1$ & $124.93(10)$ & C10-C11-C6 & $120.96(10)$ \\
\hline $\mathrm{O} 1-\mathrm{C} 1-\mathrm{C} 2$ & $129.39(10)$ & N3-C12-C9 & $179.31(14)$ \\
\hline $\mathrm{N} 1-\mathrm{C} 1-\mathrm{C} 2$ & 105.67(9) & C3-C13-C14 & $117.70(11)$ \\
\hline $\mathrm{C} 3-\mathrm{C} 2-\mathrm{C} 1$ & 108.35(9) & C13-C14-C15 & $121.68(11)$ \\
\hline $\mathrm{C} 16-\mathrm{C} 2-\mathrm{C} 1$ & $129.61(10)$ & C16-C15-C14 & $120.58(11)$ \\
\hline $\mathrm{C} 16-\mathrm{C} 2-\mathrm{C} 3$ & $122.04(10)$ & C2-C16-C15 & $117.56(11)$ \\
\hline $\mathrm{C} 2-\mathrm{C} 3-\mathrm{C} 4$ & $108.88(9)$ & C18-C17-N1 & 120.31(9) \\
\hline $\mathrm{C} 13-\mathrm{C} 3-\mathrm{C} 2$ & $120.42(10)$ & $\mathrm{C} 25-\mathrm{C} 17-\mathrm{N} 1$ & $118.85(9)$ \\
\hline C13-C3-C4 & $130.70(10)$ & C25-C17-C18 & $120.84(10)$ \\
\hline $\mathrm{N} 1-\mathrm{C} 4-\mathrm{C} 3$ & 104.99(8) & $\mathrm{N} 2-\mathrm{C} 18-\mathrm{C} 17$ & 119.19(9) \\
\hline $\mathrm{C} 5-\mathrm{C} 4-\mathrm{N} 1$ & $129.95(10)$ & N2-C18-C19 & 122.97(9) \\
\hline $\mathrm{C} 5-\mathrm{C} 4-\mathrm{C} 3$ & $125.06(10)$ & C19-C18-C17 & $117.83(9)$ \\
\hline C4-C5-C6 & $128.86(10)$ & C20-C19-C18 & $117.51(10)$ \\
\hline C7-C6-C5 & $122.87(9)$ & C23-C19-C18 & $119.92(10)$ \\
\hline C11-C6-C5 & $118.35(10)$ & C23-C19-C20 & $122.57(10)$ \\
\hline C11-C6-C7 & $118.78(10)$ & C21-C20-C19 & $119.20(10)$ \\
\hline C8-C7-C6 & $120.96(10)$ & $\mathrm{C} 20-\mathrm{C} 21-\mathrm{C} 22$ & $118.80(10)$ \\
\hline $\mathrm{C} 7-\mathrm{C} 8-\mathrm{C} 9$ & $119.06(10)$ & $\mathrm{N} 2-\mathrm{C} 22-\mathrm{C} 21$ & $124.66(10)$ \\
\hline C8-C9-C12 & $120.08(10)$ & C24-C23-C19 & $120.51(10)$ \\
\hline $\mathrm{C} 10-\mathrm{C} 9-\mathrm{C} 8$ & $120.78(10)$ & $\mathrm{C} 23-\mathrm{C} 24-\mathrm{C} 25$ & $120.07(10)$ \\
\hline C10-C9-C12 & $119.13(10)$ & C17-C25-C24 & $120.68(10)$ \\
\hline
\end{tabular}




\section{References}

[1] F. Wöhler, Ann. Phys. 1828, 88, 253-256.

[2] a) K. C. Nicolaou, S. Rigol, Angew. Chem. Int. Ed. 2019, 58, 11206-11241; b) K. C. Nicolaou, Isr. J. Chem. 2018, 58, 104-113; c) L. F. Tietze, T. Eicher, U. Diederichsen, A. Speicher, N. Schützenmeister, Reactions and Syntheses: In the Organic Chemistry Laboratory, Second, Completely Revised and Updated Edition, Wiley-VCH, Weinheim, 2015; d) K. C. Nicolaou, Proc. R. Soc. London Ser. A 2014, 470, 20130690; e) K. C. Nicolaou, J. S. Chen, Classics in total synthesis III: Further targets, strategies, methods, Wiley-VCH, Weinheim, 2011; f) E.-i. Negishi, A. de Meijere, Handbook of Organopalladium Chemistry for Organic Synthesis, Wiley, New York, 2002.

[3] a) S. A. Matlin, G. Mehta, H. Hopf, A. Krief, Nat. Chem. 2016, 8, 393-398; b) B. H. Lipshutz, N. A. Isley, J. C. Fennewald, E. D. Slack, Angew. Chem. Int. Ed. 2013, 52, 10952-10958.

[4] a) B. M. Trost, Angew. Chem. Int. Ed. 1995, 34, 259-281; b) B. M. Trost, Science 1991, $254,1471-1477$.

[5] a) P. T. Anastas, M. M. Kirchhoff, Acc. Chem. Res. 2002, 35, 686-694; b) P. T. Anastas, J. C. Warner, Green chemistry: theory and practice, Oxford University Press, Oxford, 1998.

[6] P. Gandeepan, N. Kaplaneris, S. Santoro, L. Vaccaro, L. Ackermann, ACS Sustainable Chem. Eng. 2019, 7, 8023-8040.

[7] L. Ackermann, Modern Arylation Methods, Wiley-VCH, Weinheim, 2009.

[8] a) C. Glaser, Justus Liebigs Ann. Chem. 1870, 154, 137-171; b) C. Glaser, Ber. Dtsch. Chem. Ges. 1869, 2, 422-424.

[9] F. Ullmann, J. Bielecki, Ber. Dtsch. Chem. Ges. 1901, 34, 2174-2185.

[10] C. C. C. Johansson Seechurn, M. O. Kitching, T. J. Colacot, V. Snieckus, Angew. Chem. Int. Ed. 2012, 51, 5062-5085.

[11] R. Mozingo, Org. Synth. 1946, 26, 77-82.

[12] H. Lindlar, Helv. Chim. Acta 1952, 35, 446-450.

[13] J. Smidt, W. Hafner, R. Jira, J. Sedlmeier, R. Sieber, H. Kojer, R. Rüttinger, Angew. Chem. 1959, 71, 176-182.

[14] a) R. F. Heck, J. Am. Chem. Soc. 1968, 90, 5546-5548; b) R. F. Heck, J. Am. Chem. Soc. 1968, 90, 5542-5546; c) R. F. Heck, J. Am. Chem. Soc. 1968, 90, 5538-5542; d) 
R. F. Heck, J. Am. Chem. Soc. 1968, 90, 5531-5534; e) R. F. Heck, J. Am. Chem. Soc. 1968, 90, 5526-5531; f) R. F. Heck, J. Am. Chem. Soc. 1968, 90, 5518-5526.

[15] a) K. Mori, T. Mizoroki, A. Ozaki, Bull. Chem. Soc. Jpn. 1973, 46, 1505-1508; b) T. Mizoroki, K. Mori, A. Ozaki, Bull. Chem. Soc. Jpn. 1971, 44, 581-581.

[16] a) H. A. Dieck, R. F. Heck, J. Am. Chem. Soc. 1974, 96, 1133-1136; b) R. F. Heck, J. P. Nolley, J. Org. Chem. 1972, 37, 2320-2322.

[17] a) N. Miyaura, A. Suzuki, Chem. Rev. 1995, 95, 2457-2483; b) N. Miyaura, K. Yamada, A. Suzuki, Tetrahedron Lett. 1979, 20, 3437-3440; c) N. Miyaura, A. Suzuki, J. Chem. Soc., Chem. Commun. 1979, 866-867.

[18] a) E. Negishi, A. O. King, N. Okukado, J. Org. Chem. 1977, 42, 1821-1823; b) A. O. King, N. Okukado, E.-i. Negishi, J. Chem. Soc., Chem. Commun. 1977, 683-684.

[19] a) K. Tamao, K. Sumitani, M. Kumada, J. Am. Chem. Soc. 1972, 94, 4374-4376; b) R. J. P. Corriu, J. P. Masse, J. Chem. Soc., Chem. Commun. 1972, 144a-144a.

[20] a) T. Hiyama, J. Organomet. Chem. 2002, 653, 58-61; b) Y. Hatanaka, T. Hiyama, J. Org. Chem. 1988, 53, 918-920.

[21] a) J. K. Stille, Angew. Chem. Int. Ed. 1986, 25, 508-524; b) D. Milstein, J. K. Stille, J. Am. Chem. Soc. 1979, 101, 4992-4998; c) D. Milstein, J. K. Stille, J. Am. Chem. Soc. 1978, 100, 3636-3638.

[22] a) R. Chinchilla, C. Nájera, Chem. Soc. Rev. 2011, 40, 5084-5121; b) R. Chinchilla, C. Nájera, Chem. Rev. 2007, 107, 874-922; c) K. Sonogashira, J. Organomet. Chem. 2002, 653, 46-49; d) K. Sonogashira, Y. Tohda, N. Hagihara, Tetrahedron Lett. 1975, 16, 4467-4470.

[23] a) B. M. Trost, D. L. Van Vranken, Chem. Rev. 1996, 96, 395-422; b) B. M. Trost, P. E. Strege, J. Am. Chem. Soc. 1977, 99, 1649-1651; c) B. M. Trost, T. J. Fullerton, J. Am. Chem. Soc. 1973, 95, 292-294; d) J. Tsuji, H. Takahashi, M. Morikawa, Tetrahedron Lett. 1965, 6, 4387-4388.

[24] a) F. Paul, J. Patt, J. F. Hartwig, J. Am. Chem. Soc. 1994, 116, 5969-5970; b) A. S. Guram, S. L. Buchwald, J. Am. Chem. Soc. 1994, 116, 7901-7902.

[25] The nobel prize in chemistry 2010 - press release: https://www.nobelprize.org/nobel_prizes/chemistry/laureates/2010/press.html (accessed on 07.02.2021).

[26] A. de Meijere, S. Bräse, M. Oestreich, Metal-Catalyzed Cross-Coupling Reactions and More, Wiley-VCH, Weinheim, 2014. 
[27] a) S. Rej, Y. Ano, N. Chatani, Chem. Rev. 2020, 120, 1788-1887; b) A. Dey, S. K. Sinha, T. K. Achar, D. Maiti, Angew. Chem. Int. Ed. 2019, 58, 10820-10843; c) Y. Xu, G. Dong, Chem. Sci. 2018, 9, 1424-1432; d) C. Sambiagio, D. Schönbauer, R. Blieck, T. Dao-Huy, G. Pototschnig, P. Schaaf, T. Wiesinger, M. F. Zia, J. Wencel-Delord, T. Besset, B. U. W. Maes, M. Schnürch, Chem. Soc. Rev. 2018, 47, 6603-6743; e) Y. Park, Y. Kim, S. Chang, Chem. Rev. 2017, 117, 9247-9301; f) J. R. Hummel, J. A. Boerth, J. A. Ellman, Chem. Rev. 2017, 117, 9163-9227; g) J. He, M. Wasa, K. S. L. Chan, Q. Shao, J.-Q. Yu, Chem. Rev. 2017, 117, 8754-8786; h) H. M. L. Davies, D. Morton, ACS Cent. Sci. 2017, 3, 936-943; i) T. Gensch, M. N. Hopkinson, F. Glorius, J. WencelDelord, Chem. Soc. Rev. 2016, 45, 2900-2936; j) P. Gandeepan, C.-H. Cheng, Chem. Asian J. 2015, 10, 824-838; k) O. Daugulis, J. Roane, L. D. Tran, Acc. Chem. Res. 2015, 48, 1053-1064; 1) J. Wencel-Delord, F. Glorius, Nat. Chem. 2013, 5, 369-375; m) C. S. Yeung, V. M. Dong, Chem. Rev. 2011, 111, 1215-1292; n) I. A. I. Mkhalid, J. H. Barnard, T. B. Marder, J. M. Murphy, J. F. Hartwig, Chem. Rev. 2010, 110, 890-931; o) T. W. Lyons, M. S. Sanford, Chem. Rev. 2010, 110, 1147-1169; p) A. Gunay, K. H. Theopold, Chem. Rev. 2010, 110, 1060-1081; q) D. A. Colby, R. G. Bergman, J. A. Ellman, Chem. Rev. 2010, 110, 624-655; r) L. Ackermann, R. Vicente, A. R. Kapdi, Angew. Chem. Int. Ed. 2009, 48, 9792-9826; s) R. G. Bergman, Nature 2007, 446, 391393; t) L. Ackermann, Synlett 2007, 507-526.

[28] a) J. Börgel, T. Ritter, Chem 2020, 6, 1877-1887; b) W. Wang, M. M. Lorion, J. Shah, A. R. Kapdi, L. Ackermann, Angew. Chem. Int. Ed. 2018, 57, 14700-14717; c) A. F. M. Noisier, M. A. Brimble, Chem. Rev. 2014, 114, 8775-8806.

[29] a) J.-R. Pouliot, F. Grenier, J. T. Blaskovits, S. Beaupré, M. Leclerc, Chem. Rev. 2016, 116, 14225-14274; b) D. J. Schipper, K. Fagnou, Chem. Mater. 2011, 23, 1594-1600.

[30] a) S. D. Friis, M. J. Johansson, L. Ackermann, Nat. Chem. 2020, 12, 511-519; b) D. C. Blakemore, L. Castro, I. Churcher, D. C. Rees, A. W. Thomas, D. M. Wilson, A. Wood, Nat. Chem. 2018, 10, 383-394; c) M. Seki, Org. Process Res. Dev. 2016, 20, 867-877; d) T. Cernak, K. D. Dykstra, S. Tyagarajan, P. Vachal, S. W. Krska, Chem. Soc. Rev. 2016, 45, 546-576; e) L. Ackermann, Org. Process Res. Dev. 2015, 19, 260-269.

[31] P. Gandeepan, T. Müller, D. Zell, G. Cera, S. Warratz, L. Ackermann, Chem. Rev. 2019, $119,2192-2452$.

[32] a) R. Mei, U. Dhawa, R. C. Samanta, W. Ma, J. Wencel-Delord, L. Ackermann, ChemSusChem 2020, 13, 3306-3356; b) S. M. Khake, N. Chatani, Chem 2020, 6, 10561081; c) S. M. Khake, N. Chatani, Trends Chem. 2019, 1, 524-539; d) A. Baccalini, S. 
Vergura, P. Dolui, G. Zanoni, D. Maiti, Org. Biomol. Chem. 2019, 17, 10119-10141; e) P. M. Edwards, L. L. Schafer, Chem. Commun. 2018, 54, 12543-12560; f) T. Yoshino, S. Matsunaga, Adv. Synth. Catal. 2017, 359, 1245-1262; g) W. Liu, L. Ackermann, ACS Catal. 2016, 6, 3743-3752; h) G. Cera, L. Ackermann, Top. Curr. Chem. 2016, 374, 57; i) K. Gao, N. Yoshikai, Acc. Chem. Res. 2014, 47, 1208-1219; j) C.-L. Sun, B.-J. Li, Z.-J. Shi, Chem. Rev. 2011, 111, 1293-1314; k) A. A. Kulkarni, O. Daugulis, Synthesis 2009, 4087-4109.

[33] S. J. Blanksby, G. B. Ellison, Acc. Chem. Res. 2003, 36, 255-263.

[34] a) L. Ackermann, Chem. Rev. 2011, 111, 1315-1345; b) D. Balcells, E. Clot, O. Eisenstein, Chem. Rev. 2010, 110, 749-823.

[35] a) D. Lapointe, K. Fagnou, Chem. Lett. 2010, 39, 1118-1126; b) S. I. Gorelsky, D. Lapointe, K. Fagnou, J. Am. Chem. Soc. 2008, 130, 10848-10849; c) L.-C. Campeau, M. Parisien, A. Jean, K. Fagnou, J. Am. Chem. Soc. 2006, 128, 581-590.

[36] a) Y. Boutadla, D. L. Davies, S. A. Macgregor, A. I. Poblador-Bahamonde, Dalton Trans. 2009, 5887-5893; b) D. L. Davies, S. M. A. Donald, S. A. Macgregor, J. Am. Chem. Soc. 2005, 127, 13754-13755.

[37] a) K. Naksomboon, J. Poater, F. M. Bickelhaupt, M. Á. Fernández-Ibáñez, J. Am. Chem. Soc. 2019, 141, 6719-6725; b) E. Tan, O. Quinonero, M. Elena de Orbe, A. M. Echavarren, ACS Catal. 2018, 8, 2166-2172; c) H. Wang, M. Moselage, M. J. González, L. Ackermann, ACS Catal. 2016, 6, 2705-2709; d) D. Santrač, S. Cella, W. Wang, L. Ackermann, Eur. J. Org. Chem. 2016, 5429-5436; e) W. Ma, R. Mei, G. Tenti, L. Ackermann, Chem. Eur. J. 2014, 20, 15248-15251.

[38] Z. Chen, B. Wang, J. Zhang, W. Yu, Z. Liu, Y. Zhang, Org. Chem. Front. 2015, 2, 1107-1295.

[39] S. De Sarkar, W. Liu, S. I. Kozhushkov, L. Ackermann, Adv. Synth. Catal. 2014, 356, 1461-1479.

[40] a) W. Ma, P. Gandeepan, J. Li, L. Ackermann, Org. Chem. Front. 2017, 4, 1435-1467; b) F. Zhang, D. R. Spring, Chem. Soc. Rev. 2014, 43, 6906-6919.

[41] a) G. Liao, T. Zhang, Z.-K. Lin, B.-F. Shi, Angew. Chem. Int. Ed. 2020, 59, 1977319786; b) M. I. Lapuh, S. Mazeh, T. Besset, ACS Catal. 2020, 10, 12898-12919; c) P. Gandeepan, L. Ackermann, Chem 2018, 4, 199-222.

[42] a) T. Ahrens, J. Kohlmann, M. Ahrens, T. Braun, Chem. Rev. 2015, 115, 931-972; b) H. Amii, K. Uneyama, Chem. Rev. 2009, 109, 2119-2183; c) W. K. Hagmann, J. Med. Chem. 2008, 51, 4359-4369. 
[43] a) T. Furuya, A. S. Kamlet, T. Ritter, Nature 2011, 473, 470-477; b) K. Müller, C. Faeh, F. Diederich, Science 2007, 317, 1881-1886.

[44] a) G. Landelle, M. Bergeron, M.-O. Turcotte-Savard, J.-F. Paquin, Chem. Soc. Rev. 2011, 40, 2867-2908; b) C. E. Jakobsche, G. Peris, S. J. Miller, Angew. Chem. Int. Ed. 2008, 47, 6707-6711.

[45] a) Y. Ye, S. D. Schimler, P. S. Hanley, M. S. Sanford, J. Am. Chem. Soc. 2013, 135, 16292-16295; b) P. S. Fier, J. F. Hartwig, J. Am. Chem. Soc. 2012, 134, 10795-10798; c) X. Wang, L. Truesdale, J.-Q. Yu, J. Am. Chem. Soc. 2010, 132, 3648-3649; d) E. J. Cho, T. D. Senecal, T. Kinzel, Y. Zhang, D. A. Watson, S. L. Buchwald, Science 2010, 328, 1679-1681; e) D. A. Watson, M. Su, G. Teverovskiy, Y. Zhang, J. García-Fortanet, T. Kinzel, S. L. Buchwald, Science 2009, 325, 1661-1664.

[46] T. Fujita, K. Fuchibe, J. Ichikawa, Angew. Chem. Int. Ed. 2019, 58, 390-402.

[47] W. Heitz, A. Knebelkamp, Makromol. Chem. Rapid Commun. 1991, 12, 69-75.

[48] K. Sakoda, J. Mihara, J. Ichikawa, Chem. Commun. 2005, 4684-4686.

[49] J. Ichikawa, R. Nadano, N. Ito, Chem. Commun. 2006, 4425-4427.

[50] T. Miura, Y. Ito, M. Murakami, Chem. Lett. 2008, 37, 1006-1007.

[51] R. T. Thornbury, F. D. Toste, Angew. Chem. Int. Ed. 2016, 55, 11629-11632.

[52] P. Tian, C. Feng, T.-P. Loh, Nat. Commun. 2015, 6, 7472.

[53] J.-Q. Wu, S.-S. Zhang, H. Gao, Z. Qi, C.-J. Zhou, W.-W. Ji, Y. Liu, Y. Chen, Q. Li, X. Li, H. Wang, J. Am. Chem. Soc. 2017, 139, 3537-3545.

[54] C.-Q. Wang, L. Ye, C. Feng, T.-P. Loh, J. Am. Chem. Soc. 2017, 139, 1762-1765.

[55] F. Romanov-Michailidis, B. D. Ravetz, D. W. Paley, T. Rovis, J. Am. Chem. Soc. 2018, 140, 5370-5374.

[56] a) H. Yi, G. Zhang, H. Wang, Z. Huang, J. Wang, A. K. Singh, A. Lei, Chem. Rev. 2017, 117, 9016-9085; b) Z. Dong, Z. Ren, S. J. Thompson, Y. Xu, G. Dong, Chem. Rev. 2017, 117, 9333-9403; c) G. Rouquet, N. Chatani, Angew. Chem. Int. Ed. 2013, 52, 11726-11743.

[57] C. G. Newton, S.-G. Wang, C. C. Oliveira, N. Cramer, Chem. Rev. 2017, 117, 89088976.

[58] a) T. Yoshino, S. Satake, S. Matsunaga, Chem. Eur. J. 2020, 26, 7346; b) T. K. Achar, S. Maiti, S. Jana, D. Maiti, ACS Catal. 2020, 13748-13793; c) C. Zheng, S.-L. You, RSC Adv. 2014, 4, 6173-6214; d) J. Wencel-Delord, F. Colobert, Chem. Eur. J. 2013, 19, 14010-14017; e) R. Giri, B.-F. Shi, K. M. Engle, N. Maugel, J.-Q. Yu, Chem. Soc. Rev. 2009, 38, 3242-3272. 
[59] a) Ł. Woźniak, N. Cramer, Trends Chem. 2019, 1, 471-484; b) J. Loup, U. Dhawa, F. Pesciaioli, J. Wencel-Delord, L. Ackermann, Angew. Chem. Int. Ed. 2019, 58, $12803-$ 12818.

[60] A. R. Dick, M. S. Sanford, Tetrahedron 2006, 62, 2439-2463.

[61] a) H. M. L. Davies, J. R. Manning, Nature 2008, 451, 417-424; b) J. T. Groves, P. Viski, J. Am. Chem. Soc. 1989, 111, 8537-8538.

[62] V. I. Sokolov, L. L. Troitskaya, O. A. Reutov, J. Organomet. Chem. 1977, 133, C28C30.

[63] a) Q. Shao, K. Wu, Z. Zhuang, S. Qian, J.-Q. Yu, Acc. Chem. Res. 2020, 53, 833-851;

b) K. M. Engle, J.-Q. Yu, J. Org. Chem. 2013, 78, 8927-8955.

[64] M. R. Albicker, N. Cramer, Angew. Chem. Int. Ed. 2009, 48, 9139-9142.

[65] T. Saget, N. Cramer, Angew. Chem. Int. Ed. 2013, 52, 7865-7868.

[66] Z.-Q. Lin, W.-Z. Wang, S.-B. Yan, W.-L. Duan, Angew. Chem. Int. Ed. 2015, 54, 62656269.

[67] L. Liu, A.-A. Zhang, Y. Wang, F. Zhang, Z. Zuo, W.-X. Zhao, C.-L. Feng, W. Ma, Org. Lett. 2015, 17, 2046-2049.

[68] C. He, M. Hou, Z. Zhu, Z. Gu, ACS Catal. 2017, 7, 5316-5320.

[69] J. Luo, T. Zhang, L. Wang, G. Liao, Q.-J. Yao, Y.-J. Wu, B.-B. Zhan, Y. Lan, X.-F. Lin, B.-F. Shi, Angew. Chem. Int. Ed. 2019, 58, 6708-6712.

[70] B.-B. Zhan, L. Wang, J. Luo, X.-F. Lin, B.-F. Shi, Angew. Chem. Int. Ed. 2020, 59, 3568-3572.

[71] R. Shintani, H. Otomo, K. Ota, T. Hayashi, J. Am. Chem. Soc. 2012, 134, 7305-7308.

[72] L. Yang, M. Neuburger, O. Baudoin, Angew. Chem. Int. Ed. 2018, 57, 1394-1398.

[73] D. Grosheva, N. Cramer, ACS Catal. 2017, 7, 7417-7420.

[74] B.-F. Shi, N. Maugel, Y.-H. Zhang, J.-Q. Yu, Angew. Chem. Int. Ed. 2008, 47, 48824886.

[75] B.-F. Shi, Y.-H. Zhang, J. K. Lam, D.-H. Wang, J.-Q. Yu, J. Am. Chem. Soc. 2010, 132, 460-461.

[76] L. Chu, X.-C. Wang, C. E. Moore, A. L. Rheingold, J.-Q. Yu, J. Am. Chem. Soc. 2013, $135,16344-16347$.

[77] B. N. Laforteza, K. S. L. Chan, J.-Q. Yu, Angew. Chem. Int. Ed. 2015, 54, 11143-11146.

[78] Z.-J. Du, J. Guan, G.-J. Wu, P. Xu, L.-X. Gao, F.-S. Han, J. Am. Chem. Soc. 2015, 137, 632-635. 
[79] D.-W. Gao, Y.-C. Shi, Q. Gu, Z.-L. Zhao, S.-L. You, J. Am. Chem. Soc. 2013, 135, 8689.

[80] C. Pi, Y. Li, X. Cui, H. Zhang, Y. Han, Y. Wu, Chem. Sci. 2013, 4, 2675-2679.

[81] D.-W. Gao, Q. Gu, S.-L. You, J. Am. Chem. Soc. 2016, 138, 2544-2547.

[82] L. Chu, K.-J. Xiao, J.-Q. Yu, Science 2014, 346, 451-455.

[83] K.-J. Xiao, L. Chu, J.-Q. Yu, Angew. Chem. Int. Ed. 2016, 55, 2856-2860.

[84] K.-J. Xiao, L. Chu, G. Chen, J.-Q. Yu, J. Am. Chem. Soc. 2016, 138, 7796-7800.

[85] D.-W. Gao, Q. Gu, S.-L. You, ACS Catal. 2014, 4, 2741-2745.

[86] S.-X. Li, Y.-N. Ma, S.-D. Yang, Org. Lett. 2017, 19, 1842-1845.

[87] L. Jin, Q.-J. Yao, P.-P. Xie, Y. Li, B.-B. Zhan, Y.-Q. Han, X. Hong, B.-F. Shi, Chem 2020, 6, 497-511.

[88] F.-L. Zhang, K. Hong, T.-J. Li, H. Park, J.-Q. Yu, Science 2016, 351, 252-256.

[89] Q.-J. Yao, S. Zhang, B.-B. Zhan, B.-F. Shi, Angew. Chem. Int. Ed. 2017, 56, 66176621.

[90] G. Liao, Q.-J. Yao, Z.-Z. Zhang, Y.-J. Wu, D.-Y. Huang, B.-F. Shi, Angew. Chem. Int. Ed. 2018, 57, 3661-3665.

[91] G. Liao, B. Li, H.-M. Chen, Q.-J. Yao, Y.-N. Xia, J. Luo, B.-F. Shi, Angew. Chem. Int. Ed. 2018, 57, 17151-17155.

[92] a) S. Zhang, Q.-J. Yao, G. Liao, X. Li, H. Li, H.-M. Chen, X. Hong, B.-F. Shi, ACS Catal. 2019, 9, 1956-1961; b) H.-M. Chen, S. Zhang, G. Liao, Q.-J. Yao, X.-T. Xu, K. Zhang, B.-F. Shi, Organometallics 2019, 38, 4022-4028.

[93] J. Zhang, Q. Xu, J. Wu, J. Fan, M. Xie, Org. Lett. 2019, 21, 6361-6365.

[94] T. Wesch, F. R. Leroux, F. Colobert, Adv. Synth. Catal. 2013, 355, 2139-2144.

[95] C. K. Hazra, Q. Dherbassy, J. Wencel-Delord, F. Colobert, Angew. Chem. Int. Ed. 2014, $53,13871-13875$.

[96] a) Q. Dherbassy, J. P. Djukic, J. Wencel-Delord, F. Colobert, Angew. Chem. Int. Ed. 2018, 57, 4668-4672; b) Q. Dherbassy, J. Wencel-Delord, F. Colobert, Tetrahedron 2018, 74, 6205-6212.

[97] H. Shi, A. N. Herron, Y. Shao, Q. Shao, J.-Q. Yu, Nature 2018, 558, 581-585.

[98] Z.-S. Liu, Y. Hua, Q. Gao, Y. Ma, H. Tang, Y. Shang, H.-G. Cheng, Q. Zhou, Nat. Catal. 2020, 3, 727-733.

[99] N. Fujii, F. Kakiuchi, A. Yamada, N. Chatani, S. Murai, Chem. Lett. 1997, 26, 425-426.

[100] a) H. Harada, R. K. Thalji, R. G. Bergman, J. A. Ellman, J. Org. Chem. 2008, 73, 67726779; b) A. Watzke, R. M. Wilson, S. J. O’Malley, R. G. Bergman, J. A. Ellman, Synlett 
2007, 2383-2389; c) R. K. Thalji, J. A. Ellman, R. G. Bergman, J. Am. Chem. Soc. 2004, 126, 7192-7193.

[101] a) D. N. Tran, N. Cramer, Angew. Chem. Int. Ed. 2013, 52, 10630-10634; b) D. N. Tran, N. Cramer, Angew. Chem. Int. Ed. 2011, 50, 11098-11102.

[102] S. Satake, T. Kurihara, K. Nishikawa, T. Mochizuki, M. Hatano, K. Ishihara, T. Yoshino, S. Matsunaga, Nat. Catal. 2018, 1, 585-591.

[103] L. Lin, S. Fukagawa, D. Sekine, E. Tomita, T. Yoshino, S. Matsunaga, Angew. Chem. Int. Ed. 2018, 57, 12048-12052.

[104] Z.-J. Cai, C.-X. Liu, Q. Wang, Q. Gu, S.-L. You, Nat. Commun. 2019, 10, 4168.

[105] Q. Wang, Z.-J. Cai, C.-X. Liu, Q. Gu, S.-L. You, J. Am. Chem. Soc. 2019, 141, 95049510.

[106] J. Mas-Roselló, A. G. Herraiz, B. Audic, A. Laverny, N. Cramer, Angew. Chem. Int. Ed. 2021, DOI: 10.1002/anie.202008166.

[107] B. Ye, N. Cramer, Science 2012, 338, 504-506.

[108] B. Ye, N. Cramer, J. Am. Chem. Soc. 2013, 135, 636-639.

[109] a) B. Ye, P. A. Donets, N. Cramer, Angew. Chem. Int. Ed. 2014, 53, 507-511; b) B. Ye, N. Cramer, Synlett 2015, 26, 1490-1495.

[110] B. Ye, N. Cramer, Angew. Chem. Int. Ed. 2014, 53, 7896-7899.

[111] J. Zheng, S.-B. Wang, C. Zheng, S.-L. You, J. Am. Chem. Soc. 2015, 137, 4880-4883.

[112] T. J. Potter, D. N. Kamber, B. Q. Mercado, J. A. Ellman, ACS Catal. 2017, 7, 150-153.

[113] S. Maity, T. J. Potter, J. A. Ellman, Nat. Catal. 2019, 2, 756-762.

[114] J. Zheng, S.-L. You, Angew. Chem. Int. Ed. 2014, 53, 13244-13247.

[115] J. Zheng, W.-J. Cui, C. Zheng, S.-L. You, J. Am. Chem. Soc. 2016, 138, 5242-5245.

[116] H. Li, X. Yan, J. Zhang, W. Guo, J. Jiang, J. Wang, Angew. Chem. Int. Ed. 2019, 58, 6732-6736.

[117] a) F. Wang, Z. Qi, Y. Zhao, S. Zhai, G. Zheng, R. Mi, Z. Huang, X. Zhu, X. He, X. Li, Angew. Chem. Int. Ed. 2020, 59, 13288-13294; b) M. Tian, D. Bai, G. Zheng, J. Chang, X. Li, J. Am. Chem. Soc. 2019, 141, 9527-9532.

[118] Z.-J. Jia, C. Merten, R. Gontla, C. G. Daniliuc, A. P. Antonchick, H. Waldmann, Angew Chem Int Edit 2017, 56, 2429-2434.

[119] T. K. Hyster, L. Knorr, T. R. Ward, T. Rovis, Science 2012, 338, 500-503.

[120] I. S. Hassan, A. N. Ta, M. W. Danneman, N. Semakul, M. Burns, C. H. Basch, V. N. Dippon, B. R. McNaughton, T. Rovis, J. Am. Chem. Soc. 2019, 141, 4815-4819.

[121] G. Li, J. Jiang, H. Xie, J. Wang, Chem. Eur. J. 2019, 25, 4688-4694. 
[122] Ł. Woźniak, J.-F. Tan, Q.-H. Nguyen, A. Madron du Vigné, V. Smal, Y.-X. Cao, N. Cramer, Chem. Rev. 2020, 120, 10516-10543.

[123] R. Aufdenblatten, S. Diezi, A. Togni, Monatsh. Chem. 2000, 131, 1345-1350.

[124] K. Tsuchikama, M. Kasagawa, Y.-K. Hashimoto, K. Endo, T. Shibata, J. Organomet. Chem. 2008, 693, 3939-3942.

[125] C. S. Sevov, J. F. Hartwig, J. Am. Chem. Soc. 2013, 135, 2116-2119.

[126] T. Shirai, Y. Yamamoto, Angew. Chem. Int. Ed. 2015, 54, 9894-9897.

[127] M. Nagamoto, J.-i. Fukuda, M. Hatano, H. Yorimitsu, T. Nishimura, Org. Lett. 2017, $19,5952-5955$.

[128] S. Pan, N. Ryu, T. Shibata, J. Am. Chem. Soc. 2012, 134, 17474-17477.

[129] T. Shibata, N. Ryu, H. Takano, Adv. Synth. Catal. 2015, 357, 1131-1135.

[130] T. Shibata, T. Shizuno, Angew. Chem. Int. Ed. 2014, 53, 5410-5413.

[131] E. M. Carreira, L. Kvaerno, Classics in Stereoselective Synthesis, John Wiley \& Sons, New York, 2009.

[132] S. Grélaud, P. Cooper, L. J. Feron, J. F. Bower, J. Am. Chem. Soc. 2018, 140, 93519356.

[133] V. S. Shinde, M. V. Mane, L. Cavallo, M. Rueping, Chem. Eur. J. 2020, 26, 8308-8313.

[134] a) A. Romero-Arenas, V. Hornillos, J. Iglesias-Sigüenza, R. Fernández, J. LópezSerrano, A. Ros, J. M. Lassaletta, J. Am. Chem. Soc. 2020, 142, 2628-2639; b) D. Yamauchi, T. Nishimura, H. Yorimitsu, Chem. Commun. 2017, 53, 2760-2763; c) Y. Ebe, M. Onoda, T. Nishimura, H. Yorimitsu, Angew. Chem. Int. Ed. 2017, 56, 56075611; d) M. Hatano, Y. Ebe, T. Nishimura, H. Yorimitsu, J. Am. Chem. Soc. 2016, 138, 4010-4013; e) Y. Ebe, T. Nishimura, J. Am. Chem. Soc. 2015, 137, 5899-5902.

[135] K. Tsuchikama, Y.-k. Hashimoto, K. Endo, T. Shibata, Adv. Synth. Catal. 2009, 351, 2850-2854.

[136] T. Shirai, H. Ito, Y. Yamamoto, Angew. Chem. Int. Ed. 2014, 53, 2658-2661.

[137] L. Ackermann, Acc. Chem. Res. 2014, 47, 281-295.

[138] a) P. Nareddy, F. Jordan, M. Szostak, ACS Catal. 2017, 7, 5721-5745; b) B. Li, P. H. Dixneuf, Chem. Soc. Rev. 2013, 42, 5744-5767; c) P. B. Arockiam, C. Bruneau, P. H. Dixneuf, Chem. Rev. 2012, 112, 5879-5918.

[139] Z.-Y. Li, H. H. C. Lakmal, X. Qian, Z. Zhu, B. Donnadieu, S. J. McClain, X. Xu, X. Cui, J. Am. Chem. Soc. 2019, 141, 15730-15736.

[140] G. Li, Q. Liu, L. Vasamsetty, W. Guo, J. Wang, Angew. Chem. Int. Ed. 2020, 59, 34753479. 
[141] a) S. Z. Tasker, E. A. Standley, T. F. Jamison, Nature 2014, 509, 299-309; b) Y. Nakao, Chem. Rec. 2011, 11, 242-251.

[142] L. Ackermann, T. B. Gunnoe, L. G. Habgood, Catalytic hydroarylation of carboncarbon multiple bonds, Wiley-VCH, Weinheim, 2018.

[143] Y. Nakao, H. Idei, K. S. Kanyiva, T. Hiyama, J. Am. Chem. Soc. 2009, 131, 1599615997.

[144] D. Hirsch-Weil, K. A. Abboud, S. Hong, Chem. Commun. 2010, 46, 7525-7527.

[145] P. A. Donets, N. Cramer, Angew. Chem. Int. Ed. 2015, 54, 633-637.

[146] a) A. Albright, R. E. Gawley, J. Am. Chem. Soc. 2011, 133, 19680-19683; b) A. Albright, D. Eddings, R. Black, C. J. Welch, N. N. Gerasimchuk, R. E. Gawley, J. Org. Chem. 2011, 76, 7341-7351.

[147] J. Diesel, A. M. Finogenova, N. Cramer, J. Am. Chem. Soc. 2018, 140, 4489-4493.

[148] Y.-X. Wang, S.-L. Qi, Y.-X. Luan, X.-W. Han, S. Wang, H. Chen, M. Ye, J. Am. Chem. Soc. 2018, 140, 5360-5364.

[149] Y.-X. Wang, M. Ye, Sci. China Chem. 2018, 61, 1004-1013.

[150] H. Landert, F. Spindler, A. Wyss, H.-U. Blaser, B. Pugin, Y. Ribourduoille, B. Gschwend, B. Ramalingam, A. Pfaltz, Angew. Chem. Int. Ed. 2010, 49, 6873-6876.

[151] J. Loup, V. Müller, D. Ghorai, L. Ackermann, Angew. Chem. Int. Ed. 2019, 58, 17491753.

[152] J. Diesel, D. Grosheva, S. Kodama, N. Cramer, Angew. Chem. Int. Ed. 2019, 58, 1104411048.

[153] W.-B. Zhang, X.-T. Yang, J.-B. Ma, Z.-M. Su, S.-L. Shi, J. Am. Chem. Soc. 2019, 141, $5628-5634$.

[154] Y. Cai, X. Ye, S. Liu, S.-L. Shi, Angew. Chem. Int. Ed. 2019, 58, 13433-13437.

[155] K. Ogata, Y. Atsuumi, D. Shimada, S.-i. Fukuzawa, Angew. Chem. Int. Ed. 2011, 50, 5896-5899.

[156] J. S. E. Ahlin, N. Cramer, Org. Lett. 2016, 18, 3242-3245.

[157] T. J. Seiders, D. W. Ward, R. H. Grubbs, Org. Lett. 2001, 3, 3225-3228.

[158] J. Yang, N. Yoshikai, J. Am. Chem. Soc. 2014, 136, 16748-16751.

[159] J. Yang, A. Rérat, Y. J. Lim, C. Gosmini, N. Yoshikai, Angew. Chem. Int. Ed. 2017, $56,2449-2453$.

[160] D. K. Kim, J. Riedel, R. S. Kim, V. M. Dong, J. Am. Chem. Soc. 2017, 139, 1020810211.

[161] P.-S. Lee, N. Yoshikai, Org. Lett. 2015, 17, 22-25. 
[162] a) A. Fürstner, ACS Cent. Sci. 2016, 2, 778-789; b) I. Bauer, H.-J. Knölker, Chem. Rev. 2015, 115, 3170-3387.

[163] J. Loup, D. Zell, J. C. A. Oliveira, H. Keil, D. Stalke, L. Ackermann, Angew. Chem. Int. Ed. 2017, 56, 14197-14201.

[164] a) S. Warratz, C. Kornhaaß, A. Cajaraville, B. Niepötter, D. Stalke, L. Ackermann, Angew. Chem. Int. Ed. 2015, 54, 5513-5517; b) J. Piera, J.-E. Bäckvall, Angew. Chem. Int. Ed. 2008, 47, 3506-3523; c) S. S. Stahl, Angew. Chem. Int. Ed. 2004, 43, 34003420; d) R. Mei, H. Wang, S. Warratz, S. A. Macgregor, L. Ackermann, Chem. Eur. J. 2016, 22, 6759-6763.

[165] P. M. Osterberg, J. K. Niemeier, C. J. Welch, J. M. Hawkins, J. R. Martinelli, T. E. Johnson, T. W. Root, S. S. Stahl, Org. Process Res. Dev. 2015, 19, 1537-1543.

[166] a) J. Le Bras, J. Muzart, Chem. Rev. 2011, 111, 1170-1214; b) K. C. Nicolaou, P. G. Bulger, D. Sarlah, Angew. Chem. Int. Ed. 2005, 44, 4442-4489; c) A. B. Dounay, L. E. Overman, Chem. Rev. 2003, 103, 2945-2964; d) I. P. Beletskaya, A. V. Cheprakov, Chem. Rev. 2000, 100, 3009-3066; e) R. F. Heck, Acc. Chem. Res. 1979, 12, 146-151.

[167] a) Y. Fujiwara, I. Moritani, S. Danno, R. Asano, S. Teranishi, J. Am. Chem. Soc. 1969, 91, 7166-7169; b) Y. Fujiwara, I. Moritani, M. Matsuda, S. Teranishi, Tetrahedron Lett. 1968, 9, 633-636; c) I. Moritani, Y. Fujiwara, Tetrahedron Lett. 1967, 8, 1119-1122.

[168] M. D. K. Boele, G. P. F. van Strijdonck, A. H. M. de Vries, P. C. J. Kamer, J. G. de Vries, P. W. N. M. van Leeuwen, J. Am. Chem. Soc. 2002, 124, 1586-1587.

[169] G. Cai, Y. Fu, Y. Li, X. Wan, Z. Shi, J. Am. Chem. Soc. 2007, 129, 7666-7673.

[170] S. H. Cho, S. J. Hwang, S. Chang, J. Am. Chem. Soc. 2008, 130, 9254-9256.

[171] K. M. Engle, D.-H. Wang, J.-Q. Yu, Angew. Chem. Int. Ed. 2010, 49, 6169-6173.

[172] M. Wasa, K. M. Engle, J.-Q. Yu, J. Am. Chem. Soc. 2010, 132, 3680-3681.

[173] C. Huang, B. Chattopadhyay, V. Gevorgyan, J. Am. Chem. Soc. 2011, 133, 1240612409.

[174] B. Liu, H.-Z. Jiang, B.-F. Shi, J. Org. Chem. 2014, 79, 1521-1526.

[175] G. Li, D. Leow, L. Wan, J.-Q. Yu, Angew. Chem. Int. Ed. 2013, 52, 1245-1247.

[176] A. Deb, S. Bag, R. Kancherla, D. Maiti, J. Am. Chem. Soc. 2014, 136, 13602-13605.

[177] S. Kancherla, K. B. Jørgensen, M. Á. Fernández-Ibáñez, Synthesis 2019, 51, 643-663.

[178] a) C. Jia, T. Kitamura, Y. Fujiwara, Acc. Chem. Res. 2001, 34, 633-639; b) C. Jia, W. Lu, T. Kitamura, Y. Fujiwara, Org. Lett. 1999, 1, 2097-2100; c) I. Moritanl, Y. Fujiwara, Tetrahedron Lett. 1967, 8, 1119-1122. 
[179] a) L.-Y. Liu, K.-S. Yeung, J.-Q. Yu, Chem. Eur. J. 2019, 25, 2199-2202; b) P. Wang, P. Verma, G. Xia, J. Shi, J. X. Qiao, S. Tao, P. T. W. Cheng, M. A. Poss, M. E. Farmer, K.-S. Yeung, J.-Q. Yu, Nature 2017, 551, 489-493; c) P. Wang, M. E. Farmer, J.-Q. Yu, Angew. Chem. Int. Ed. 2017, 56, 5125-5129; d) Y.-H. Zhang, B.-F. Shi, J.-Q. Yu, J. Am. Chem. Soc. 2009, 131, 5072-5074.

[180] a) A. K. Cook, M. S. Sanford, J. Am. Chem. Soc. 2015, 137, 3109-3118; b) J. B. Gary, A. K. Cook, M. S. Sanford, ACS Catal. 2013, 3, 700-703; c) A. K. Cook, M. H. Emmert, M. S. Sanford, Org. Lett. 2013, 15, 5428-5431; d) A. Kubota, M. H. Emmert, M. S. Sanford, Org. Lett. 2012, 14, 1760-1763; e) M. H. Emmert, A. K. Cook, Y. J. Xie, M. S. Sanford, Angew. Chem. Int. Ed. 2011, 50, 9409-9412.

[181] Y. Izawa, S. S. Stahl, Adv. Synth. Catal. 2010, 352, 3223-3229.

[182] a) W.-L. Jia, N. Westerveld, K. M. Wong, T. Morsch, M. Hakkennes, K. Naksomboon, M. Á. Fernández-Ibáñez, Org. Lett. 2019, 21, 9339-9342; b) Y. Álvarez-Casao, M. Á. Fernández-Ibáñez, Eur. J. Org. Chem. 2019, 1842-1845.

[183] K. Naksomboon, C. Valderas, M. Gómez-Martínez, Y. Álvarez-Casao, M. Á. Fernández-Ibáñez, ACS Catal. 2017, 7, 6342-6346.

[184] L. Grigorjeva, O. Daugulis, Angew. Chem. Int. Ed. 2014, 53, 10209-10212.

[185] a) S. Zhai, S. Qiu, X. Chen, J. Wu, H. Zhao, C. Tao, Y. Li, B. Cheng, H. Wang, H. Zhai, Chem. Commun. 2018, 54, 98-101; b) T. T. Nguyen, L. Grigorjeva, O. Daugulis, Angew. Chem. Int. Ed. 2018, 57, 1688-1691; c) Á. M. Martínez, N. Rodríguez, R. Gómez-Arrayás, J. C. Carretero, Chem. Eur. J. 2017, 23, 11669-11676; d) T. T. Nguyen, L. Grigorjeva, O. Daugulis, ACS Catal. 2016, 6, 551-554; e) L.-B. Zhang, X.Q. Hao, Z.-J. Liu, X.-X. Zheng, S.-K. Zhang, J.-L. Niu, M.-P. Song, Angew. Chem. Int. Ed. 2015, 54, 10012-10015; f) W. Ma, L. Ackermann, ACS Catal. 2015, 5, 2822-2825.

[186] L. Grigorjeva, O. Daugulis, Org. Lett. 2014, 16, 4684-4687.

[187] R. Boobalan, R. Kuppusamy, R. Santhoshkumar, P. Gandeepan, C.-H. Cheng, ChemCatChem 2017, 9, 273-277.

[188] a) A. Dey, N. Thrimurtulu, C. M. R. Volla, Org. Lett. 2019, 21, 3871-3875; b) R. Nallagonda, N. Thrimurtulu, C. M. R. Volla, Adv. Synth. Catal. 2018, 360, 255-260; c) N. Thrimurtulu, A. Dey, D. Maiti, C. M. R. Volla, Angew. Chem. Int. Ed. 2016, 55, 12361-12365.

[189] V. G. Landge, G. Jaiswal, E. Balaraman, Org. Lett. 2016, 18, 812-815.

[190] Z.-Z. Zhang, Y.-Q. Han, B.-B. Zhan, S. Wang, B.-F. Shi, Angew. Chem. Int. Ed. 2017, $56,13145-13149$. 
[191] R. Manoharan, G. Sivakumar, M. Jeganmohan, Chem. Commun. 2016, 52, 1053310536.

[192] T. Yamaguchi, Y. Kommagalla, Y. Aihara, N. Chatani, Chem. Commun. 2016, 52, 10129-10132.

[193] a) A. Baccalini, S. Vergura, P. Dolui, S. Maiti, S. Dutta, S. Maity, F. F. Khan, G. K. Lahiri, G. Zanoni, D. Maiti, Org. Lett. 2019, 21, 8842-8846; b) S. Maity, P. Dolui, R. Kancherla, D. Maiti, Chem. Sci. 2017, 8, 5181-5185; c) S. Maity, R. Kancherla, U. Dhawa, E. Hoque, S. Pimparkar, D. Maiti, ACS Catal. 2016, 6, 5493-5499.

[194] L.-B. Zhang, X.-Q. Hao, S.-K. Zhang, Z.-J. Liu, X.-X. Zheng, J.-F. Gong, J.-L. Niu, M.-P. Song, Angew. Chem. Int. Ed. 2015, 54, 272-275.

[195] X. Wu, K. Yang, Y. Zhao, H. Sun, G. Li, H. Ge, Nat. Commun. 2015, 6, 6462.

[196] L.-B. Zhang, S.-K. Zhang, D. Wei, X. Zhu, X.-Q. Hao, J.-H. Su, J.-L. Niu, M.-P. Song, Org. Lett. 2016, 18, 1318-1321.

[197] a) J. Hassan, M. Sévignon, C. Gozzi, E. Schulz, M. Lemaire, Chem. Rev. 2002, 102, 1359-1470; b) P. E. Fanta, Chem. Rev. 1964, 64, 613-632; c) I. Goldberg, Ber. Dtsch. Chem. Ges. 1906, 39, 1691-1692.

[198] a) H.-Q. Do, R. M. K. Khan, O. Daugulis, J. Am. Chem. Soc. 2008, 130, 15185-15192;

b) H.-Q. Do, O. Daugulis, J. Am. Chem. Soc. 2008, 130, 1128-1129; c) H.-Q. Do, O. Daugulis, J. Am. Chem. Soc. 2007, 129, 12404-12405.

[199] a) T. Yoshizumi, T. Satoh, K. Hirano, D. Matsuo, A. Orita, J. Otera, M. Miura, Tetrahedron Lett. 2009, 50, 3273-3276; b) T. Yoshizumi, H. Tsurugi, T. Satoh, M. Miura, Tetrahedron Lett. 2008, 49, 1598-1600.

[200] a) I. Choi, V. Müller, G. Lole, R. Köhler, V. Karius, W. Viöl, C. Jooss, L. Ackermann, Chem. Eur. J. 2020, 26, 3509-3514; b) F. Yang, J. Koeller, L. Ackermann, Angew. Chem. Int. Ed. 2016, 55, 4759-4762; c) R. Jeyachandran, H. K. Potukuchi, L. Ackermann, Beilstein J. Org. Chem. 2012, 8, 1771-1777; d) L. Ackermann, H. K. Potukuchi, D. Landsberg, R. Vicente, Org. Lett. 2008, 10, 3081-3084.

[201] a) H. A. Duong, R. E. Gilligan, M. L. Cooke, R. J. Phipps, M. J. Gaunt, Angew. Chem. Int. Ed. 2011, 50, 463-466; b) C.-L. Ciana, R. J. Phipps, J. R. Brandt, F.-M. Meyer, M. J. Gaunt, Angew. Chem. Int. Ed. 2011, 50, 458-462; c) R. J. Phipps, M. J. Gaunt, Science 2009, 323, 1593-1597; d) R. J. Phipps, N. P. Grimster, M. J. Gaunt, J. Am. Chem. Soc. 2008, 130, 8172-8174.

[202] S. Vásquez-Céspedes, K. M. Chepiga, N. Möller, A. H. Schäfer, F. Glorius, ACS Catal. 2016, 6, 5954-5961. 
[203] Y. Yang, R. Li, Y. Zhao, D. Zhao, Z. Shi, J. Am. Chem. Soc. 2016, 138, 8734-8737.

[204] a) L.-H. Zou, J. Mottweiler, D. L. Priebbenow, J. Wang, J. A. Stubenrauch, C. Bolm, Chem. Eur. J. 2013, 19, 3302-3305; b) S. Fan, Z. Chen, X. Zhang, Org. Lett. 2012, 14, 4950-4953; c) H.-Q. Do, O. Daugulis, J. Am. Chem. Soc. 2011, 133, 13577-13586.

[205] S. Zhao, J. Yuan, Y.-C. Li, B.-F. Shi, Chem. Commun. 2015, 51, 12823-12826.

[206] W. Zeng, W. Wu, H. Jiang, L. Huang, Y. Sun, Z. Chen, X. Li, Chem. Commun. 2013, 49, 6611-6613.

[207] Y.-J. Liu, Y.-H. Liu, X.-S. Yin, W.-J. Gu, B.-F. Shi, Chem. Eur. J. 2015, 21, 205-209.

[208] J. Dong, F. Wang, J. You, Org. Lett. 2014, 16, 2884-2887.

[209] Y. Zhang, Q. Wang, H. Yu, Y. Huang, Org. Biomol. Chem. 2014, 12, 8844-8850.

[210] J. Zhang, D. Li, H. Chen, B. Wang, Z. Liu, Y. Zhang, Adv. Synth. Catal. 2016, 358, 792-807.

[211] a) A. John, K. M. Nicholas, J. Org. Chem. 2011, 76, 4158-4162; b) Q. Shuai, G. Deng, Z. Chua, D. S. Bohle, C.-J. Li, Adv. Synth. Catal. 2010, 352, 632-636; c) T. Uemura, S. Imoto, N. Chatani, Chem. Lett. 2006, 35, 842-843; d) X. Chen, X.-S. Hao, C. E. Goodhue, J.-Q. Yu, J. Am. Chem. Soc. 2006, 128, 6790-6791.

[212] G. Li, C. Jia, K. Sun, Org. Lett. 2013, 15, 5198-5201.

[213] L. D. Tran, J. Roane, O. Daugulis, Angew. Chem. Int. Ed. 2013, 52, 6043-6046.

[214] Q. Li, S.-Y. Zhang, G. He, Z. Ai, W. A. Nack, G. Chen, Org. Lett. 2014, 16, 17641767.

[215] Z. Wang, J. Ni, Y. Kuninobu, M. Kanai, Angew. Chem. Int. Ed. 2014, 53, 3496-3499.

[216] X. Wu, Y. Zhao, G. Zhang, H. Ge, Angew. Chem. Int. Ed. 2014, 53, 3706-3710.

[217] C. Wang, Y. Yang, D. Qin, Z. He, J. You, J. Org. Chem. 2015, 80, 8424-8429.

[218] S. Bhadra, C. Matheis, D. Katayev, L. J. Gooßen, Angew. Chem. Int. Ed. 2013, 52, 9279-9283.

[219] W. Lu, H. Xu, Z. Shen, Org. Biomol. Chem. 2017, 15, 1261-1267.

[220] X. Wu, Y. Zhao, H. Ge, Chem. Asian J. 2014, 9, 2736-2739.

[221] a) P. Lanzafame, S. Abate, C. Ampelli, C. Genovese, R. Passalacqua, G. Centi, S. Perathoner, ChemSusChem 2017, 10, 4409-4419; b) R. Schlögl, Angew. Chem. Int. Ed. 2011, 50, 6424-6426; c) R. Schlögl, ChemSusChem 2010, 3, 209-222.

[222] W. Leitner, E. A. Quadrelli, R. Schlögl, Green Chem. 2017, 19, 2307-2308.

[223] N. Sauermann, T. H. Meyer, Y. Qiu, L. Ackermann, ACS Catal. 2018, 8, 7086-7103.

[224] T. H. Meyer, I. Choi, C. Tian, L. Ackermann, Chem 2020, 6, 2484-2496. 
[225] a) H. Kolbe, E. Lautemann, Justus Liebigs Ann. Chem. 1860, 115, 157-206; b) M. Faraday, Philos. Trans. R. Soc. London 1825, 115, 440-466.

[226] T. Shono, Tetrahedron 1984, 40, 811-850.

[227] a) D. Pollok, S. R. Waldvogel, Chem. Sci. 2020, 11, 12386-12400; b) J. Liu, L. Lu, D. Wood, S. Lin, ACS Cent. Sci. 2020, 6, 1317-1340; c) A. Wiebe, T. Gieshoff, S. Möhle, E. Rodrigo, M. Zirbes, S. R. Waldvogel, Angew. Chem. Int. Ed. 2018, 57, 5594-5619; d) S. Tang, Y. Liu, A. Lei, Chem 2018, 4, 27-45; e) G. S. Sauer, S. Lin, ACS Catal. 2018, 8, 5175-5187; f) K. D. Moeller, Chem. Rev. 2018, 118, 4817-4833; g) M. D. Kärkäs, Chem. Soc. Rev. 2018, 47, 5786-5865; h) M. Yan, Y. Kawamata, P. S. Baran, Chem. Rev. 2017, 117, 13230-13319; i) H. Kolbe, Justus Liebigs Ann. Chem. 1849, 69, 257-294; j) M. Faraday, Ann. Phys. 1834, 109, 149-189.

[228] a) A. Wiebe, S. Lips, D. Schollmeyer, R. Franke, S. R. Waldvogel, Angew. Chem. Int. Ed. 2017, 56, 14727-14731; b) L. J. Wesenberg, S. Herold, A. Shimizu, J.-i. Yoshida, S. R. Waldvogel, Chem. Eur. J. 2017, 23, 12096-12099; c) T. Gieshoff, A. Kehl, D. Schollmeyer, K. D. Moeller, S. R. Waldvogel, J. Am. Chem. Soc. 2017, 139, $12317-$ 12324; d) A. Wiebe, D. Schollmeyer, K. M. Dyballa, R. Franke, S. R. Waldvogel, Angew. Chem. Int. Ed. 2016, 55, 11801-11805; e) S. Lips, A. Wiebe, B. Elsler, D. Schollmeyer, K. M. Dyballa, R. Franke, S. R. Waldvogel, Angew. Chem. Int. Ed. 2016, 55, 10872-10876; f) B. Elsler, A. Wiebe, D. Schollmeyer, K. M. Dyballa, R. Franke, S. R. Waldvogel, Chem. Eur. J. 2015, 21, 12321-12325; g) A. Kirste, B. Elsler, G. Schnakenburg, S. R. Waldvogel, J. Am. Chem. Soc. 2012, 134, 3571-3576.

[229] a) C. Li, Y. Kawamata, H. Nakamura, J. C. Vantourout, Z. Liu, Q. Hou, D. Bao, J. T. Starr, J. Chen, M. Yan, P. S. Baran, Angew. Chem. Int. Ed. 2017, 56, 13088-13093; b) Y. Kawamata, M. Yan, Z. Liu, D.-H. Bao, J. Chen, J. T. Starr, P. S. Baran, J. Am. Chem. Soc. 2017, 139, 7448-7451; c) E. J. Horn, B. R. Rosen, Y. Chen, J. Tang, K. Chen, M. D. Eastgate, P. S. Baran, Nature 2016, 533, 77-81; d) B. R. Rosen, E. W. Werner, A. G. O’Brien, P. S. Baran, J. Am. Chem. Soc. 2014, 136, 5571-5574; e) A. G. O'Brien, A. Maruyama, Y. Inokuma, M. Fujita, P. S. Baran, D. G. Blackmond, Angew. Chem. Int. Ed. 2014, 53, 11868-11871.

[230] a) R. Hayashi, A. Shimizu, J.-i. Yoshida, J. Am. Chem. Soc. 2016, 138, 8400-8403; b) T. Morofuji, A. Shimizu, J.-i. Yoshida, J. Am. Chem. Soc. 2015, 137, 9816-9819; c) T. Morofuji, A. Shimizu, J.-i. Yoshida, J. Am. Chem. Soc. 2014, 136, 4496-4499; d) T. Morofuji, A. Shimizu, J.-i. Yoshida, J. Am. Chem. Soc. 2013, 135, 5000-5003; e) Y. Ashikari, A. Shimizu, T. Nokami, J.-i. Yoshida, J. Am. Chem. Soc. 2013, 135, 16070- 
16073; f) T. Morofuji, A. Shimizu, J.-i. Yoshida, Angew. Chem. Int. Ed. 2012, 51, 72597262; g) Y. Ashikari, T. Nokami, J.-i. Yoshida, J. Am. Chem. Soc. 2011, 133, 1184011843.

[231] a) P. Xiong, H.-H. Xu, J. Song, H.-C. Xu, J. Am. Chem. Soc. 2018, 140, 2460-2464; b) H.-B. Zhao, Z.-J. Liu, J. Song, H.-C. Xu, Angew. Chem. Int. Ed. 2017, 56, 1273212735; c) P. Xiong, H.-H. Xu, H.-C. Xu, J. Am. Chem. Soc. 2017, 139, 2956-2959; d) Z.-J. Wu, H.-C. Xu, Angew. Chem. Int. Ed. 2017, 56, 4734-4738; e) A. A. FolgueirasAmador, X.-Y. Qian, H.-C. Xu, T. Wirth, Chem. Eur. J. 2017, 24, 487-491; f) H.-B. Zhao, Z.-W. Hou, Z.-J. Liu, Z.-F. Zhou, J. Song, H.-C. Xu, Angew. Chem. Int. Ed. 2016, 56, 587-590; g) Z.-W. Hou, Z.-Y. Mao, H.-B. Zhao, Y. Y. Melcamu, X. Lu, J. Song, H.-C. Xu, Angew. Chem. Int. Ed. 2016, 55, 9168-9172.

[232] a) R. C. Samanta, T. H. Meyer, I. Siewert, L. Ackermann, Chem. Sci. 2020, 11, 86578670; b) K.-J. Jiao, Y.-K. Xing, Q.-L. Yang, H. Qiu, T.-S. Mei, Acc. Chem. Res. 2020, 53, 300-310; c) P. Gandeepan, L. H. Finger, T. H. Meyer, L. Ackermann, Chem. Soc. Rev. 2020, 49, 4254-4272; d) L. Ackermann, Acc. Chem. Res. 2020, 53, 84-104; e) T. H. Meyer, L. H. Finger, P. Gandeepan, L. Ackermann, Trends Chem. 2019, 1, 63-76; f) Q.-L. Yang, P. Fang, T.-S. Mei, Chin. J. Chem . 2018, 36, 338-352; g) C. Ma, P. Fang, T.-S. Mei, ACS Catal. 2018, 8, 7179-7189; h) A. Jutand, Chem. Rev. 2008, 108, 2300-2347.

[233] C. Amatore, C. Cammoun, A. Jutand, Adv. Synth. Catal. 2007, 349, 292-296.

[234] F. Kakiuchi, T. Kochi, H. Mutsutani, N. Kobayashi, S. Urano, M. Sato, S. Nishiyama, T. Tanabe, J. Am. Chem. Soc. 2009, 131, 11310-11311.

[235] H. Aiso, T. Kochi, H. Mutsutani, T. Tanabe, S. Nishiyama, F. Kakiuchi, J. Org. Chem. 2012, 77, 7718-7724.

[236] Y. B. Dudkina, D. Y. Mikhaylov, T. V. Gryaznova, A. I. Tufatullin, O. N. Kataeva, D. A. Vicic, Y. H. Budnikova, Organometallics 2013, 32, 4785-4792.

[237] V. S. Thirunavukkarasu, S. I. Kozhushkov, L. Ackermann, Chem. Commun. 2014, 50, 29-39.

[238] M. Konishi, K. Tsuchida, K. Sano, T. Kochi, F. Kakiuchi, J. Org. Chem. 2017, 82, 8716-8724.

[239] Q.-L. Yang, Y.-Q. Li, C. Ma, P. Fang, X.-J. Zhang, T.-S. Mei, J. Am. Chem. Soc. 2017, 139, 3293-3298. 
[240] a) Q.-L. Yang, C.-Z. Li, L.-W. Zhang, Y.-Y. Li, X. Tong, X.-Y. Wu, T.-S. Mei, Organometallics 2019, 38, 1208-1212; b) C. Ma, C.-Q. Zhao, Y.-Q. Li, L.-P. Zhang, X.-T. Xu, K. Zhang, T.-S. Mei, Chem. Commun. 2017, 53, 12189-12192.

[241] A. Shrestha, M. Lee, A. L. Dunn, M. S. Sanford, Org. Lett. 2018, 20, 204-207.

[242] a) W.-J. Kong, Z. Shen, L. H. Finger, L. Ackermann, Angew. Chem. Int. Ed. 2020, 59, 5551-5556; b) Z.-J. Wu, F. Su, W. Lin, J. Song, T.-B. Wen, H.-J. Zhang, H.-C. Xu, Angew. Chem. Int. Ed. 2019, 58, 16770-16774; c) W.-J. Kong, L. H. Finger, J. C. A. Oliveira, L. Ackermann, Angew. Chem. Int. Ed. 2019, 58, 6342-6346; d) W.-J. Kong, L. H. Finger, A. M. Messinis, R. Kuniyil, J. C. A. Oliveira, L. Ackermann, J. Am. Chem. Soc. 2019, 141, 17198-17206; e) Y. Qiu, A. Scheremetjew, L. Ackermann, J. Am. Chem. Soc. 2019, 141, 2731-2738; f) Y. Qiu, W.-J. Kong, J. Struwe, N. Sauermann, T. Rogge, A. Scheremetjew, L. Ackermann, Angew. Chem. Int. Ed. 2018, 57, 5828-5832.

[243] a) Q.-L. Yang, Y.-K. Xing, X.-Y. Wang, H.-X. Ma, X.-J. Weng, X. Yang, H.-M. Guo, T.-S. Mei, J. Am. Chem. Soc. 2019, 141, 18970-18976; b) Y. Qiu, M. Stangier, T. H. Meyer, J. C. A. Oliveira, L. Ackermann, Angew. Chem. Int. Ed. 2018, 57, 14179-14183.

[244] a) X. Tan, X. Hou, T. Rogge, L. Ackermann, Angew. Chem. Int. Ed. 2021, DOI: 10.1002/anie.202014289; b) L. Yang, R. Steinbock, A. Scheremetjew, R. Kuniyil, L. H. Finger, A. M. Messinis, L. Ackermann, Angew. Chem. Int. Ed. 2020, 59, 1113011135; c) L. Massignan, X. Tan, T. H. Meyer, R. Kuniyil, A. M. Messinis, L. Ackermann, Angew. Chem. Int. Ed. 2020, 59, 3184-3189; d) Z.-Q. Wang, C. Hou, Y.F. Zhong, Y.-X. Lu, Z.-Y. Mo, Y.-M. Pan, H.-T. Tang, Org. Lett. 2019, 21, 9841-9845; e) M.-J. Luo, T.-T. Zhang, F.-J. Cai, J.-H. Li, D.-L. He, Chem. Commun. 2019, 55, 7251-7254; f) M.-J. Luo, M. Hu, R.-J. Song, D.-L. He, J.-H. Li, Chem. Commun. 2019, 55, 1124-1127; g) F. Xu, Y.-J. Li, C. Huang, H.-C. Xu, ACS Catal. 2018, 8, 3820-3824; h) Y. Qiu, C. Tian, L. Massignan, T. Rogge, L. Ackermann, Angew. Chem. Int. Ed. 2018, 57, 5818-5822; i) R. Mei, J. Koeller, L. Ackermann, Chem. Commun. 2018, 54, 12879-12882.

[245] N. Sauermann, T. H. Meyer, L. Ackermann, Chem. Eur. J. 2018, 24, 16209-16217.

[246] N. Sauermann, T. H. Meyer, C. Tian, L. Ackermann, J. Am. Chem. Soc. 2017, 139, 18452-18455.

[247] N. Sauermann, R. Mei, L. Ackermann, Angew. Chem. Int. Ed. 2018, 57, 5090-5094.

[248] T. Dalton, T. Faber, F. Glorius, ACS Cent. Sci. 2021, DOI: 10.1021/acscentsci.1020c01413.

[249] X. Gao, P. Wang, L. Zeng, S. Tang, A. Lei, J. Am. Chem. Soc. 2018, 140, 4195-4199. 
[250] C. Tian, L. Massignan, T. H. Meyer, L. Ackermann, Angew. Chem. Int. Ed. 2018, 57, 2383-2387.

[251] S. Tang, D. Wang, Y. Liu, L. Zeng, A. Lei, Nature Commun. 2018, 9, 798.

[252] R. Mei, N. Sauermann, J. C. A. Oliveira, L. Ackermann, J. Am. Chem. Soc. 2018, 140, 7913-7921.

[253] a) R. Mei, X. Fang, L. He, J. Sun, L. Zou, W. Ma, L. Ackermann, Chem. Commun. 2020, 56, 1393-1396; b) T. H. Meyer, J. C. A. Oliveira, S. C. Sau, N. W. J. Ang, L. Ackermann, ACS Catal. 2018, 8, 9140-9147.

[254] L. Zeng, H. Li, S. Tang, X. Gao, Y. Deng, G. Zhang, C.-W. Pao, J.-L. Chen, J.-F. Lee, A. Lei, ACS Catal. 2018, 8, 5448-5453.

[255] S. C. Sau, R. Mei, J. Struwe, L. Ackermann, ChemSusChem 2019, 12, 3023-3027.

[256] Q.-L. Yang, X.-Y. Wang, J.-Y. Lu, L.-P. Zhang, P. Fang, T.-S. Mei, J. Am. Chem. Soc. 2018, 140, 11487-11494.

[257] S. Kathiravan, S. Suriyanarayanan, I. A. Nicholls, Org. Lett. 2019, 21, 1968-1972.

[258] M. Schinkel, I. Marek, L. Ackermann, Angew. Chem. Int. Ed. 2013, 52, 3977-3980.

[259] a) T. Aneeja, M. Neetha, C. M. A. Afsina, G. Anilkumar, Catal. Sci. Technol. 2021, 11, 444-458; b) R. Cano, K. Mackey, G. P. McGlacken, Catal. Sci. Technol. 2018, 8, 12511266; c) C. Wang, Synlett 2013, 24, 1606-1613.

[260] a) C. Zhu, J. C. A. Oliveira, Z. Shen, H. Huang, L. Ackermann, ACS Catal. 2018, 8, 4402-4407; b) Y.-F. Liang, R. Steinbock, L. Yang, L. Ackermann, Angew. Chem. Int. Ed. 2018, 57, 10625-10629; c) Y. Hu, B. Zhou, H. Chen, C. Wang, Angew. Chem. Int. Ed. 2018, 57, 12071-12075; d) H. Wang, F. Pesciaioli, J. C. A. Oliveira, S. Warratz, L. Ackermann, Angew. Chem. Int. Ed. 2017, 56, 15063-15067; e) Y.-F. Liang, V. Müller, W. Liu, A. Münch, D. Stalke, L. Ackermann, Angew. Chem. Int. Ed. 2017, 56, 94159419; f) S. Sueki, Z. Wang, Y. Kuninobu, Org. Lett. 2016, 18, 304-307; g) W. Liu, S. C. Richter, Y. Zhang, L. Ackermann, Angew. Chem. Int. Ed. 2016, 55, 7747-7750; h) B. Zhou, Y. Hu, C. Wang, Angew. Chem. Int. Ed. 2015, 54, 13659-13663; i) B. Zhou, P. Ma, H. Chen, C. Wang, Chem. Commun. 2014, 50, 14558-14561; j) B. Zhou, H. Chen, C. Wang, J. Am. Chem. Soc. 2013, 135, 1264-1267; k) Y. Kuninobu, Y. Nishina, T. Takeuchi, K. Takai, Angew. Chem. Int. Ed. 2007, 46, 6518-6520.

[261] K. Fuchibe, H. Hatta, K. Oh, R. Oki, J. Ichikawa, Angew. Chem. Int. Ed. 2017, 56, 5890-5893.

[262] a) M. Schinkel, J. Wallbaum, S. I. Kozhushkov, I. Marek, L. Ackermann, Org. Lett. 2013, 15, 4482-4484; b) U. Helmstedt, E. Clot, Chem. Eur. J. 2012, 18, 11449-11458; 
c) N. M. Neisius, B. Plietker, Angew. Chem. Int. Ed. 2009, 48, 5752-5755; d) K. Cheng, B. Yao, J. Zhao, Y. Zhang, Org. Lett. 2008, 10, 5309-5312; e) F. Kakiuchi, H. Ohtaki, M. Sonoda, N. Chatani, S. Murai, Chem. Lett. 2001, 30, 918-919; f) S. Busch, W. Leitner, Adv. Synth. Catal. 2001, 343, 192-195.

[263] a) S. I. Kozhushkov, L. Ackermann, Chem. Sci. 2013, 4, 886-896; b) L. Ackermann, Isr. J. Chem. 2010, 50, 652-663.

[264] M. Moselage, J. Li, L. Ackermann, ACS Catal. 2015, 6, 498-525.

[265] D. Zell, M. Bursch, V. Müller, S. Grimme, L. Ackermann, Angew. Chem. Int. Ed. 2017, 56, 10378-10382.

[266] a) S.-Y. Yan, Y.-Q. Han, Q.-J. Yao, X.-L. Nie, L. Liu, B.-F. Shi, Angew. Chem. Int. Ed. 2018, 57, 9093-9097; b) H. Wang, H.-R. Tong, G. He, G. Chen, Angew. Chem. Int. Ed. 2016, 55, 15387-15391; c) L. Ackermann, R. Vicente, A. Althammer, Org. Lett. 2008, $10,2299-2302$.

[267] a) A. I. Gerasyuto, R. P. Hsung, N. Sydorenko, B. Slafer, J. Org. Chem. 2005, 70, 42484256; b) N. Halland, P. S. Aburel, K. A. Jørgensen, Angew. Chem. Int. Ed. 2004, 43, 1272-1277; c) N. Halland, T. Hansen, K. A. Jørgensen, Angew. Chem. Int. Ed. 2003, 42, 4955-4957; d) N. Halland, R. G. Hazell, K. A. Jørgensen, J. Org. Chem. 2002, 67, 8331-8338; e) A. Alexakis, J.-P. Tranchier, N. Lensen, P. Mangeney, J. Am. Chem. Soc. 1995, 117, 10767-10768.

[268] a) Q. Xing, C.-M. Chan, Y.-W. Yeung, W.-Y. Yu, J. Am. Chem. Soc. 2019, 141, 38493853; b) Y. Nishioka, T. Uchida, T. Katsuki, Angew. Chem. Int. Ed. 2013, 52, 17391742; c) E. Milczek, N. Boudet, S. Blakey, Angew. Chem. Int. Ed. 2008, 47, 6825-6828; d) F. Kakiuchi, P. Le Gendre, A. Yamada, H. Ohtaki, S. Murai, Tetrahedron: Asymmetry 2000, 11, 2647-2651.

[269] a) S. H. Park, S.-G. Wang, N. Cramer, ACS Catal. 2019, 9, 10226-10231; b) D. Kossler, F. G. Perrin, A. A. Suleymanov, G. Kiefer, R. Scopelliti, K. Severin, N. Cramer, Angew. Chem. Int. Ed. 2017, 56, 11490-11493; c) D. Kossler, N. Cramer, Chem. Sci. 2017, 8, 1862-1866; d) D. Kossler, N. Cramer, J. Am. Chem. Soc. 2015, 137, 12478-12481.

[270] F. Pesciaioli, U. Dhawa, J. C. A. Oliveira, R. Yin, M. John, L. Ackermann, Angew. Chem. Int. Ed. 2018, 57, 15425-15429.

[271] a) S. Fukagawa, Y. Kato, R. Tanaka, M. Kojima, T. Yoshino, S. Matsunaga, Angew. Chem. Int. Ed. 2019, 58, 1153-1157; b) L. Lin, S. Fukagawa, D. Sekine, E. Tomita, T. Yoshino, S. Matsunaga, Angew. Chem. Int. Ed. 2018, 57, 12048-12052; c) D. Gwon, S. Park, S. Chang, Tetrahedron 2015, 71, 4504-4511. 
[272] a) W.-C. C. Lee, W. Wang, J. J. Li, J. Org. Chem. 2018, 83, 2382-2388; b) X.-X. Zheng, C. Du, X.-M. Zhao, X. Zhu, J.-F. Suo, X.-Q. Hao, J.-L. Niu, M.-P. Song, J. Org. Chem. 2016, 81, 4002-4011; c) X.-Q. Hao, C. Du, X. Zhu, P.-X. Li, J.-H. Zhang, J.-L. Niu, M.-P. Song, Org. Lett. 2016, 18, 3610-3613; d) J. Zhang, H. Chen, C. Lin, Z. Liu, C. Wang, Y. Zhang, J. Am. Chem. Soc. 2015, 137, 12990-12996; e) W. Miura, K. Hirano, M. Miura, Org. Lett. 2015, 17, 4034-4037; f) M. Shang, H.-L. Wang, S.-Z. Sun, H.-X. Dai, J.-Q. Yu, J. Am. Chem. Soc. 2014, 136, 11590-11593; g) A. E. Wendlandt, A. M. Suess, S. S. Stahl, Angew. Chem. Int. Ed. 2011, 50, 11062-11087.

[273] a) H. Jo, S. Han, J. Park, M. Choi, S. H. Han, T. Jeong, S.-Y. Lee, J. H. Kwak, Y. H. Jung, I. S. Kim, Tetrahedron 2016, 72, 571-578; b) G. Cera, T. Haven, L. Ackermann, Angew. Chem. Int. Ed. 2016, 55, 1484-1488; c) Y. Suzuki, B. Sun, K. Sakata, T. Yoshino, S. Matsunaga, M. Kanai, Angew. Chem. Int. Ed. 2015, 54, 9944-9947; d) T. Gensch, S. Vásquez-Céspedes, D.-G. Yu, F. Glorius, Org. Lett. 2015, 17, 3714-3717; e) D.-G. Yu, T. Gensch, F. de Azambuja, S. Vásquez-Céspedes, F. Glorius, J. Am. Chem. Soc. 2014, 136, 17722-17725; f) X. Cong, Y. Li, Y. Wei, X. Zeng, Org. Lett. 2014, 16, 3926-3929.

[274] Y. Cao, Y. Yuan, Y. Lin, X. Jiang, Y. Weng, T. Wang, F. Bu, L. Zeng, A. Lei, Green Chem. 2020, 22, 1548-1552.

[275] T. H. Meyer, J. C. A. de Oliveira, D. Ghorai, L. Ackermann, Angew. Chem. Int. Ed. 2020, 59, 10955-10960.

[276] a) F. Saito, H. Aiso, T. Kochi, F. Kakiuchi, Organometallics 2014, 33, 6704-6707; b) Y.-Q. Li, Q.-L. Yang, P. Fang, T.-S. Mei, D. Zhang, Org. Lett. 2017, 19, 2905-2908; c) Q.-L. Yang, X.-Y. Wang, T.-L. Wang, X. Yang, D. Liu, X. Tong, X.-Y. Wu, T.-S. Mei, Org. Lett. 2019, 21, 2645-2649.

[277] a) K. E. Poremba, S. E. Dibrell, S. E. Reisman, ACS Catal. 2020, 10, 8237-8246; b) X. Chang, Q. Zhang, C. Guo, Angew. Chem. Int. Ed. 2020, 59, 12612-12622; c) Q. Lin, L. Li, S. Luo, Chem. Eur. J. 2019, 25, 10033-10044; d) M. Ghosh, V. S. Shinde, M. Rueping, Beilstein J. Org. Chem. 2019, 15, 2710-2746.

[278] a) Q. Wang, Q. Gu, S.-L. You, Angew. Chem. Int. Ed. 2019, 58, 6818-6825; b) D. Parmar, E. Sugiono, S. Raja, M. Rueping, Chem. Rev. 2014, 114, 9047-9153; c) J. Yu, F. Shi, L.-Z. Gong, Acc. Chem. Res. 2011, 44, 1156-1171; d) J. M. Brunel, Chem. Rev. 2008, 108, 1170-1170; e) T. Akiyama, J. Itoh, K. Fuchibe, Adv. Synth. Catal. 2006, $348,999-1010$. 
[279] a) J. F. Teichert, B. L. Feringa, Angew. Chem. Int. Ed. 2010, 49, 2486-2528; b) Y. Chen, S. Yekta, A. K. Yudin, Chem. Rev. 2003, 103, 3155-3212; c) R. Noyori, H. Takaya, Acc. Chem. Res. 1990, 23, 345-350.

[280] a) G. Bringmann, T. Gulder, T. A. M. Gulder, M. Breuning, Chem. Rev. 2011, 111, 563-639; b) M. C. Kozlowski, B. J. Morgan, E. C. Linton, Chem. Soc. Rev. 2009, 38, 3193-3207.

[281] G. Liao, T. Zhou, Q.-J. Yao, B.-F. Shi, Chem. Commun. 2019, 55, 8514-8523.

[282] a) I. G. Stará, I. Starý, Acc. Chem. Res. 2020, 53, 144-158; b) P. Redero, T. Hartung, J. Zhang, L. D. M. Nicholls, G. Zichen, M. Simon, C. Golz, M. Alcarazo, Angew. Chem. Int. Ed. 2020, 59, 23527-23531; c) J. Nejedlý, M. Šámal, J. Rybáček, I. G. Sánchez, V. Houska, T. Warzecha, J. Vacek, L. Sieger, M. Buděšínský, L. Bednárová, P. Fiedler, I. Císařová, I. Starý, I. G. Stará, J. Org. Chem. 2020, 85, 248-276; d) T. Hartung, R. Machleid, M. Simon, C. Golz, M. Alcarazo, Angew. Chem. Int. Ed. 2020, 59, 56605664; e) K. Dhbaibi, L. Favereau, J. Crassous, Chem. Rev. 2019, 119, 8846-8953; f) M. Gingras, Chem. Soc. Rev. 2013, 42, 1051-1095; g) Y. Shen, C.-F. Chen, Chem. Rev. 2012, 112, 1463-1535.

[283] D. Zell, U. Dhawa, V. Müller, M. Bursch, S. Grimme, L. Ackermann, ACS Catal. 2017, 7, 4209-4213.

[284] U. Dhawa, D. Zell, R. Yin, S. Okumura, M. Murakami, L. Ackermann, J. Catal. 2018, 364, 14-18.

[285] K. Ozols, Y.-S. Jang, N. Cramer, J. Am. Chem. Soc. 2019, 141, 5675-5680.

[286] U. Dhawa, R. Connon, J. C. A. Oliveira, R. Steinbock, L. Ackermann, Org. Lett. 2021, DOI: 10.1021/acs.orglett.1c00615.

[287] C. Tian, U. Dhawa, A. Scheremetjew, L. Ackermann, ACS Catal. 2019, 9, 7690-7696.

[288] U. Dhawa, C. Tian, W. Li, L. Ackermann, ACS Catal. 2020, 6457-6462.

[289] U. Dhawa, C. Tian, T. Wdowik, J. C. A. Oliveira, J. Hao, L. Ackermann, Angew. Chem. Int. Ed. 2020, 59, 13451-13457.

[290] L. Liang, S. Fu, D. Lin, X.-Q. Zhang, Y. Deng, H. Jiang, W. Zeng, J. Org. Chem. 2014, $79,9472-9480$.

[291] a) A. Whyte, A. Torelli, B. Mirabi, L. Prieto, J. F. Rodríguez, M. Lautens, J. Am. Chem. Soc. 2020, 142, 9510-9517; b) R. K. Nandi, R. Guillot, C. Kouklovsky, G. Vincent, Org. Lett. 2016, 18, 1716-1719.

[292] L. Ackermann, Org. Lett. 2005, 7, 3123-3125.

[293] R. Ueno, S. Natsui, N. Chatani, Org. Lett. 2018, 20, 1062-1065. 


\section{Acknowledgements}

First, I would like to express my sincere gratitude to my supervisor Prof. Dr. Lutz Ackermann for giving me the opportunity to carry out my $\mathrm{PhD}$ under his supervision, and for constant encouragement and support. His insightful suggestions, in many ways, have shaped my research career and greatly influenced the overall development as a research scholar. His unmistakable devotion, patience and strong work ethics would surely have a lasting impression on my professional career. Honestly, I could not have imagined having a better advisor and mentor for my $\mathrm{PhD}$ study. Thank you for all your support and guidance.

Besides my advisor, I would like to thank Prof. Dr. Manuel Alcarazo for accepting to be my second supervisor. Valuable suggestions from him has helped significantly to assess my work and improve further.

I also would like to thank Prof. Dr. Dr. h.c.mult. Lutz F. Tietze, Prof. Dr. Ricardo Mata, Dr. Michael John, Dr. Daniel Janßen-Müller for agreeing to take part in my defense.

I am thankful to Institut für Organische und Biomolekulare Chemie, Georg-August-Universität Göttingen for the work space and the instrumental facilities.

Financial assistance from DAAD, University of Göttingen and Prof. Dr. Lutz Ackermann is gratefully acknowledged.

I gratefully acknowledge Ms. Gabriele Keil-Knepel and Bianca Spitalieri for their kind assistance for the administrative works. I sincerely thank Mr. Stefan Beußhausen for taking care of all the instruments in our research group, especially the chiral HPLC, the glovebox and the GPC, which I used very often during my stay in the last fours years. Also I thank him for technical assistance with computers. I sincerely thank Mr. Karsten Rauch for his kind support and guidance to maintain safety in the lab.

My sincere thanks also goes to my fellow labmates, and all the members of our lab, past and present, for great work atmosphere, teamwork and companionship. I sincerely thank Dr. Daniel Zell, Dr. Fabio Pesciaioli, Dr. Cong Tian, Dr. Joachim Loup, Dr. Ramesh Chandra Samanta, Dr. Joao Carlos Agostinho de Oliveira, Dr. Tomasz Wdowik, Dr. Robert Connon, Dr. Ruhuai Mei, Dr. Wenbo Ma, Dr. Lars H. Finger, Nikolaos Kaplaneris, Valentin Müller, Tjark Meyer, Ralf Alexander Steinbock, Isaac Choi, Maximilian Stangier, Julia Struwe, Alexej Scheremetjew, Becky Bongsuiru Jei, Zhipeng Lin, Xiaoyan Hou, Binbin Yuan, Shintaro 
Okumura, Masoom Nasiha Hussain, Weizhao Li, Rongxin Yin for their help on my PhD projects.

I would like to thank whole Ackermann family and special thank to all members in 309: Dr. Daniel Zell, Dr. Fabio Pesciaioli, Dr. Yu-Feng Liang, Dr. Debasish Ghorai, Dr. Weiping Liu, Dr. Tomasz Wdowik, Dr. Robert Connon, Dr. Cong Tian, Dr. Elżbieta Gońka, Valentin Müller, Ralf Alexander Steinbock, Long Yang, Becky Bongsuiru Jei, Isaac Maksso, Binbin Yuan Masoom Nasiha Hussain, Weizhao Li, Rongxin Yin.

Many thanks to Dr. Robert Connon, Dr. Joao Carlos Agostinho de Oliveira, Nikolaos Kaplaneris, Dr. Tomasz Wdowik, Dr. Ramesh Chandra Samanta, Leonardo Massignan, Maximilian Stangier, Nate Ang for their time to correct this thesis. I sincerely would like to thank all the people who previously corrected manuscripts, supporting information, posters, abstracts and proposals in very short time: Nikolaos Kaplaneris, Dr. Ramesh Chandra Samanta, Dr. Joao Carlos Agostinho de Oliveira, Dr. Tomasz Wdowik, Dr. Robert Connon, Valentin Müller, Tjark Meyer, Isaac Choi, Maximilian Stangier, Dr. Yu-Feng Liang, Dr. Debasish Ghorai, Dr. Joachim Loup, Dr. Wei Wang, Dr. Gandeepan Parthasarathy, Dr. Santhi Vardhana Yetra, Dr. Mélanie Lorion, Dr. Parthasarathi Subramanian. Thank you all for your time and patience.

Moreover, I deeply thank to Dr. Michael John for helping me in DOSY experiment as well as in analyzing some NMR spectroscopic data. I am thankful to Dr. Christopher Golz for his assistance with X-ray diffraction analysis. I am thankful to the instrument operators, and staffs (NMR and mass spectrometry) at the IOBC for their continuous support to our research work.

I also would like to express my gratitude to my former supervisors Prof. Dr. Debabrata Maiti and Prof. Dr. Yashwant D. Vankar for teaching me chemistry and giving me the opportunity to conduct research within their laboratories.

Last but not the least, I would like to express my deepest gratitude to my parents and my friends. Their unconditional support and encouragement made it possible to come this far. 
NMR Spectra and HPLC Chromatograms
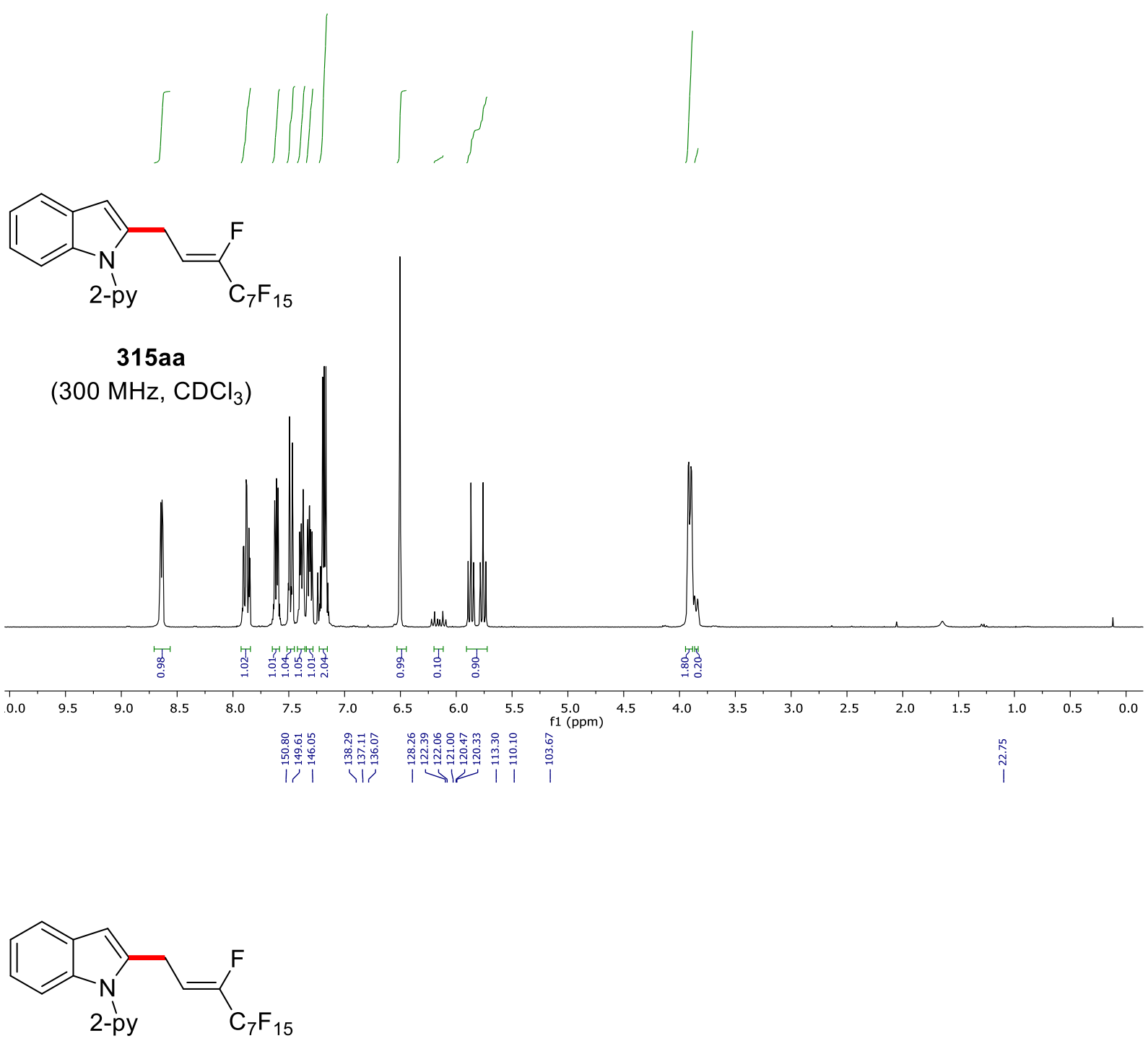

315aa

(125 $\mathrm{MHz} \mathrm{CDCl}_{3}$ )

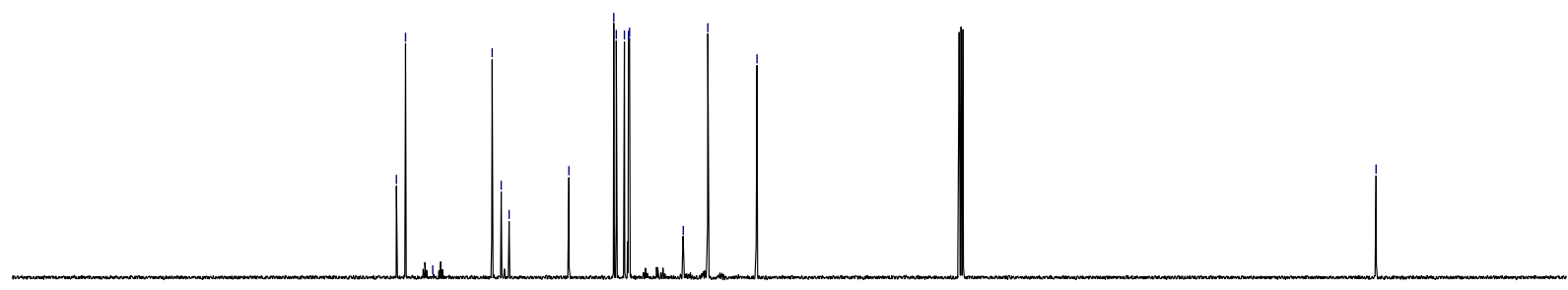




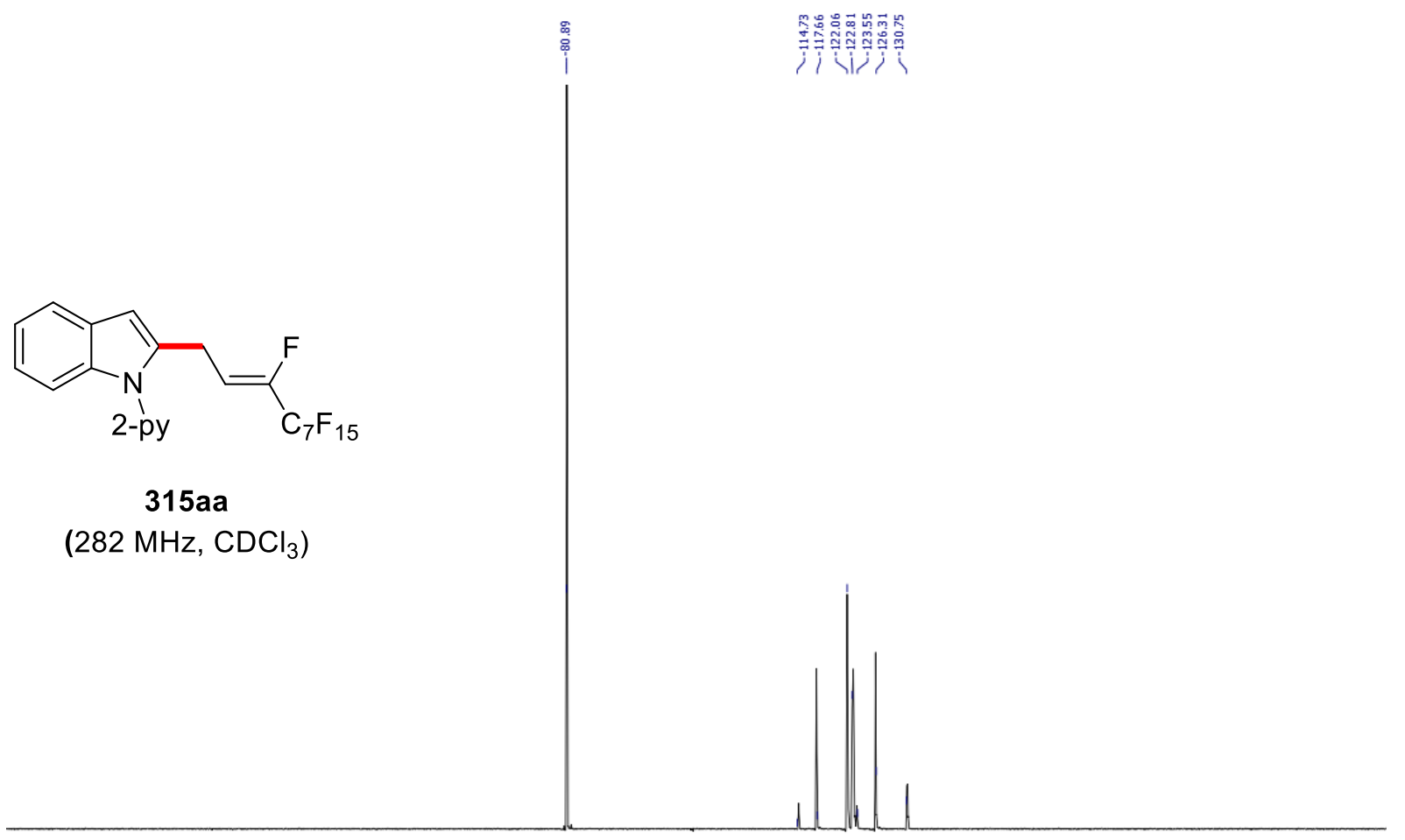

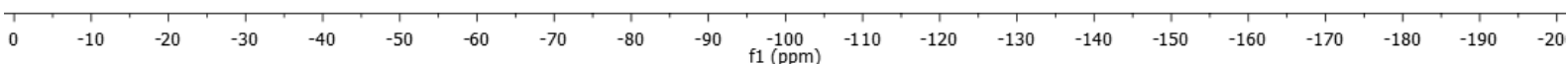




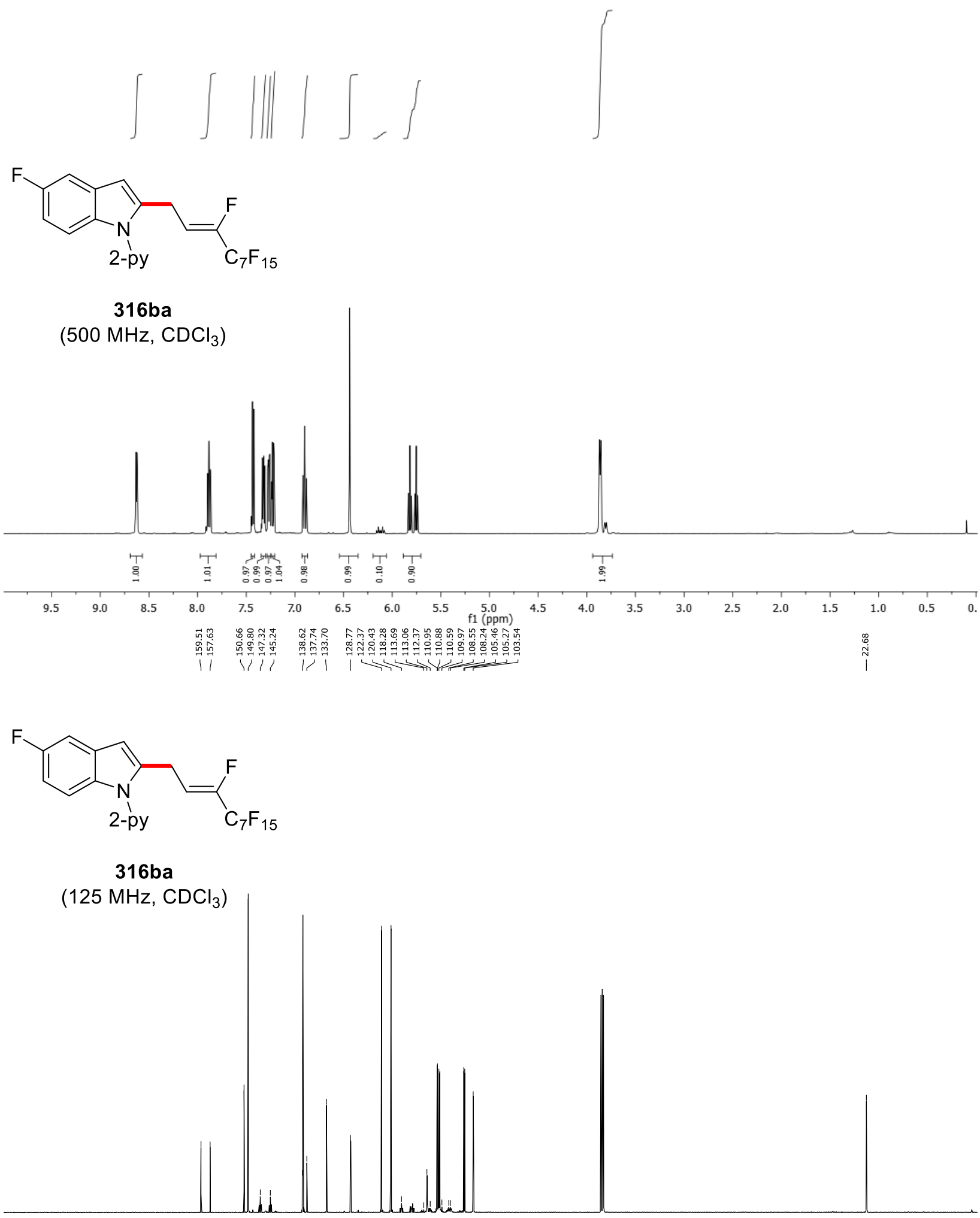

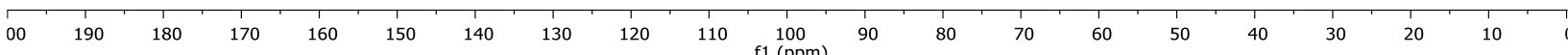




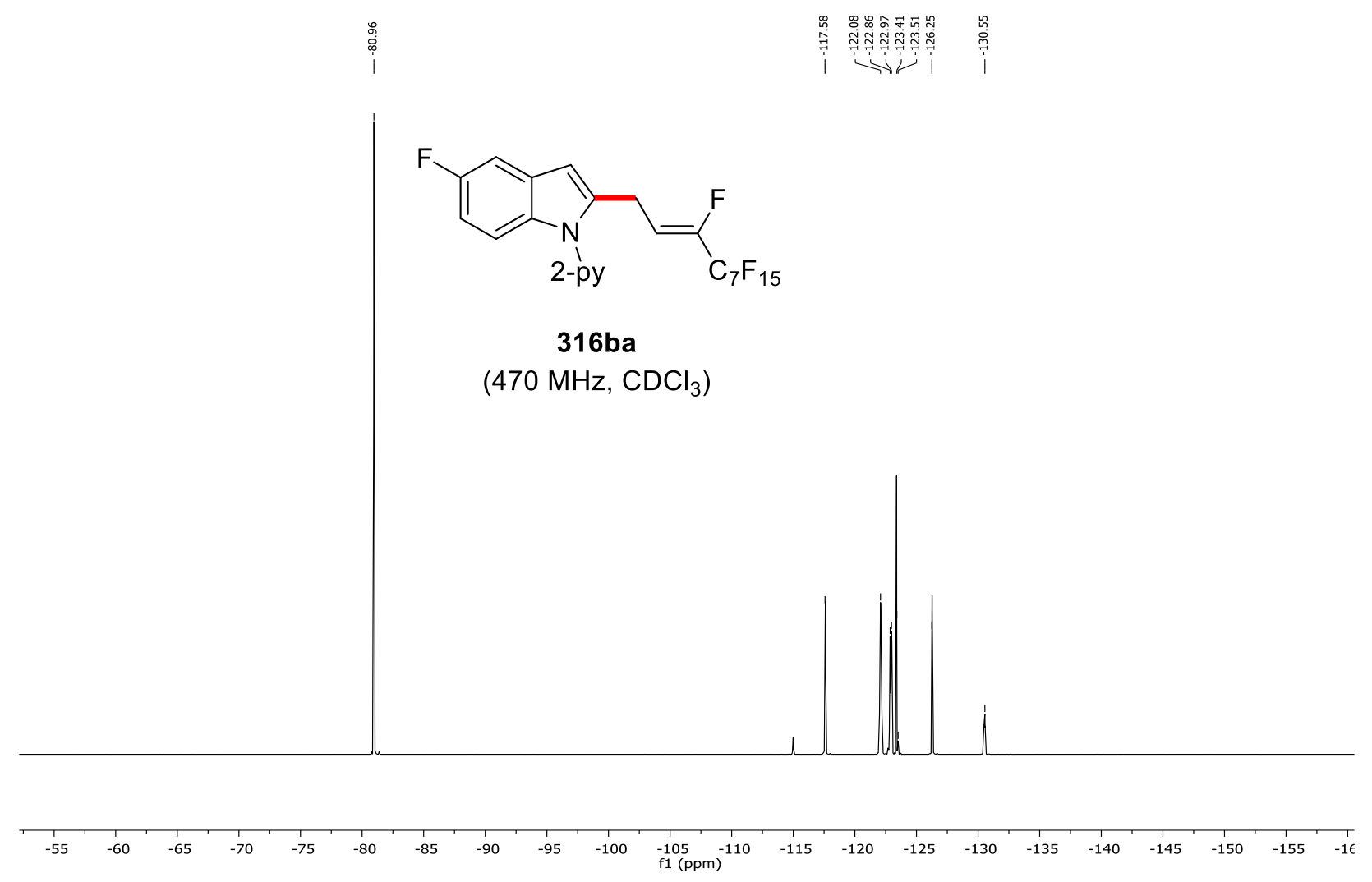




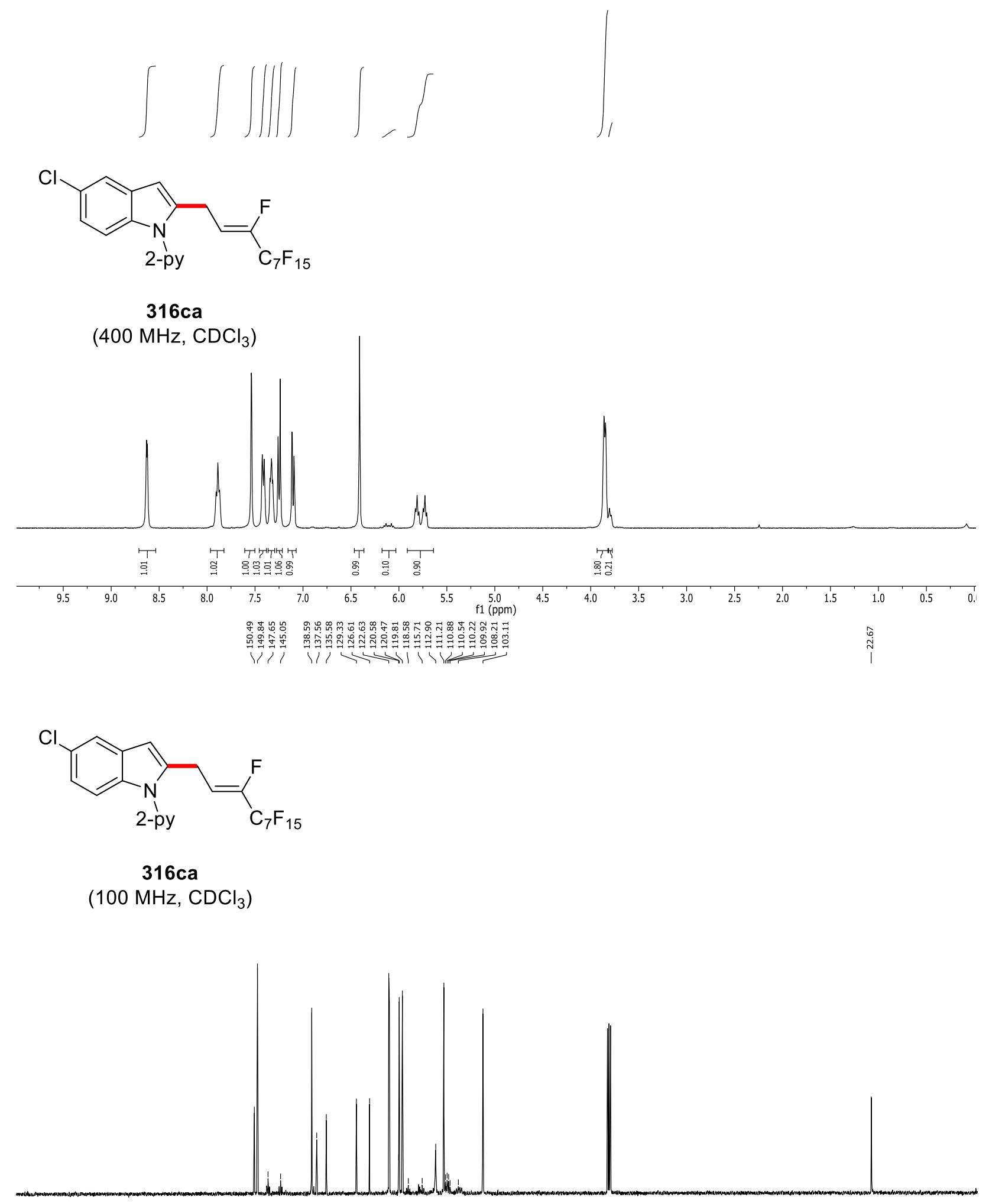

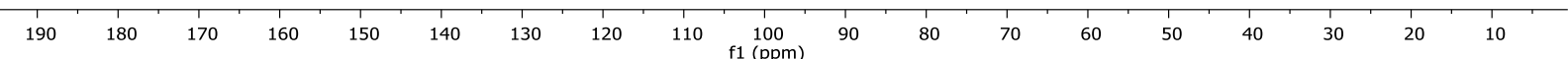




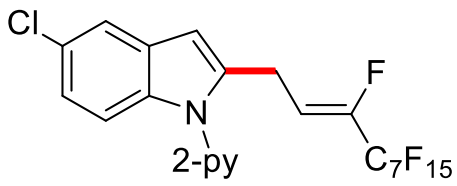

316ca

(470 $\mathrm{MHz} \mathrm{CDCl}_{3}$ )

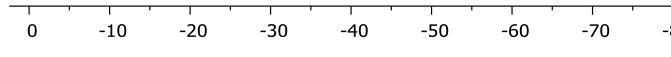




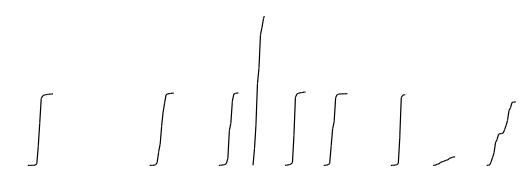

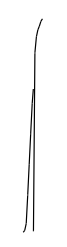<smiles>[Y7]P(O)n1c(C/C=C(\F)C(F)F)cc2cc(OC)ccc21</smiles>

316da

(400 MHz, $\mathrm{CDCl}_{3}$ )

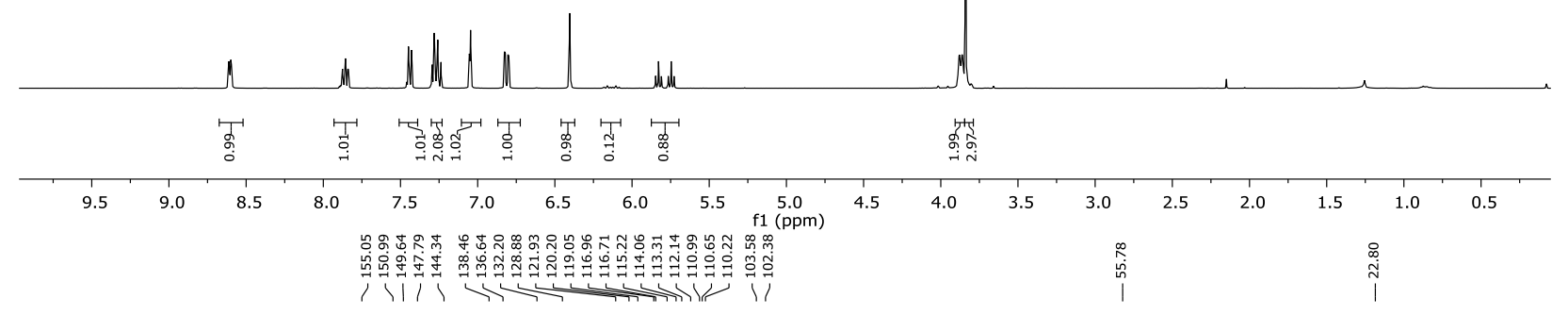

2-py

316da

(75 MHz, $\mathrm{CDCl}_{3}$ )

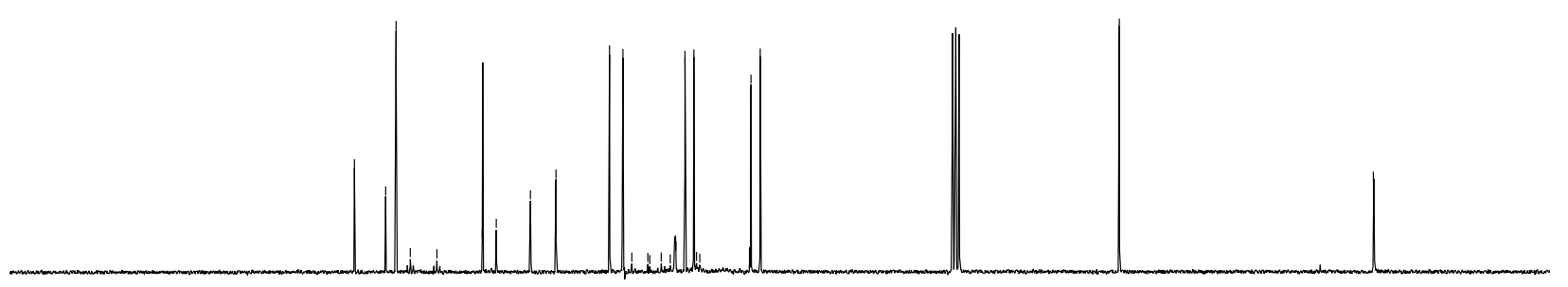



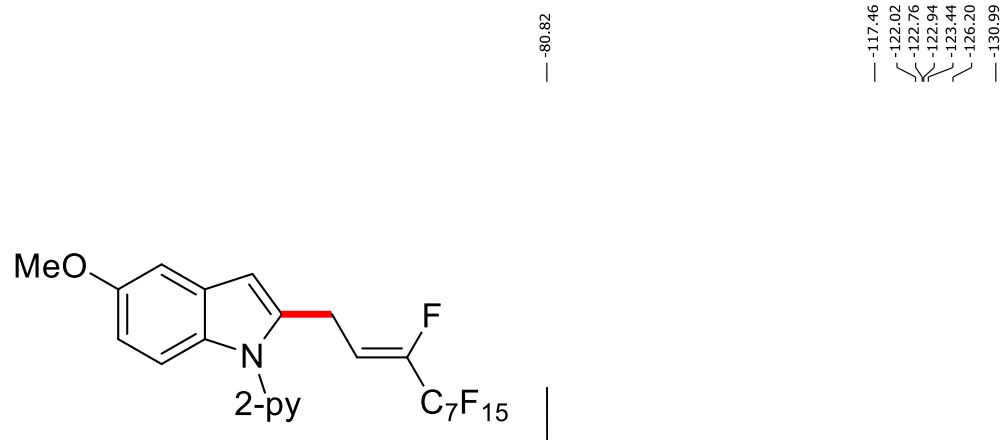

316da

(376 MHz, $\mathrm{CDCl}_{3}$ )

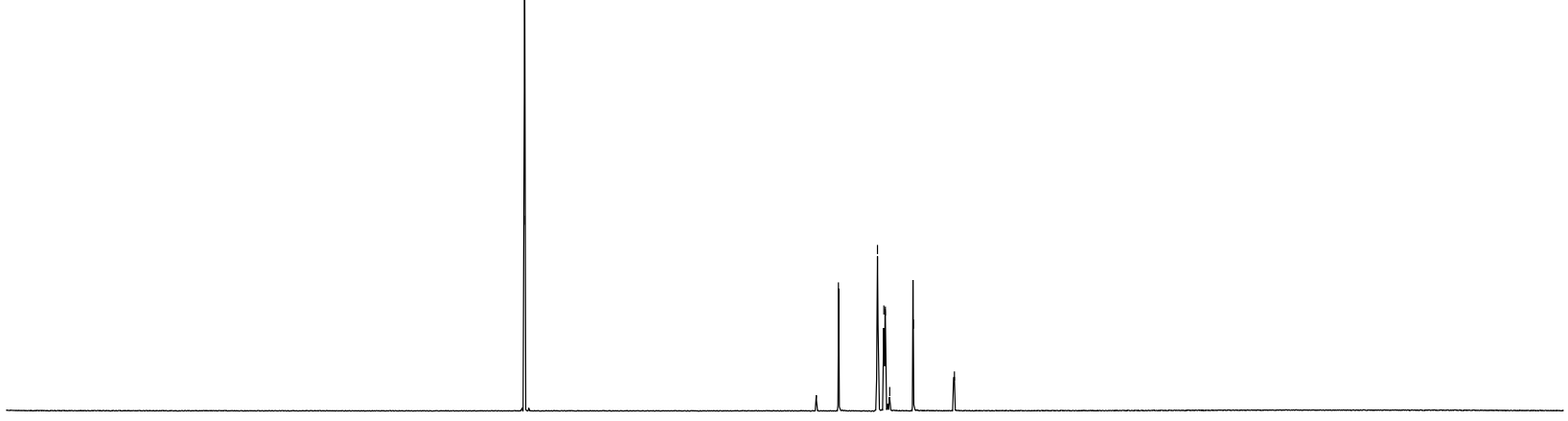

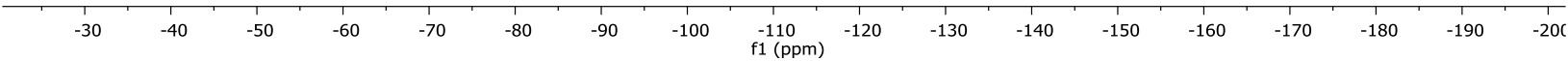



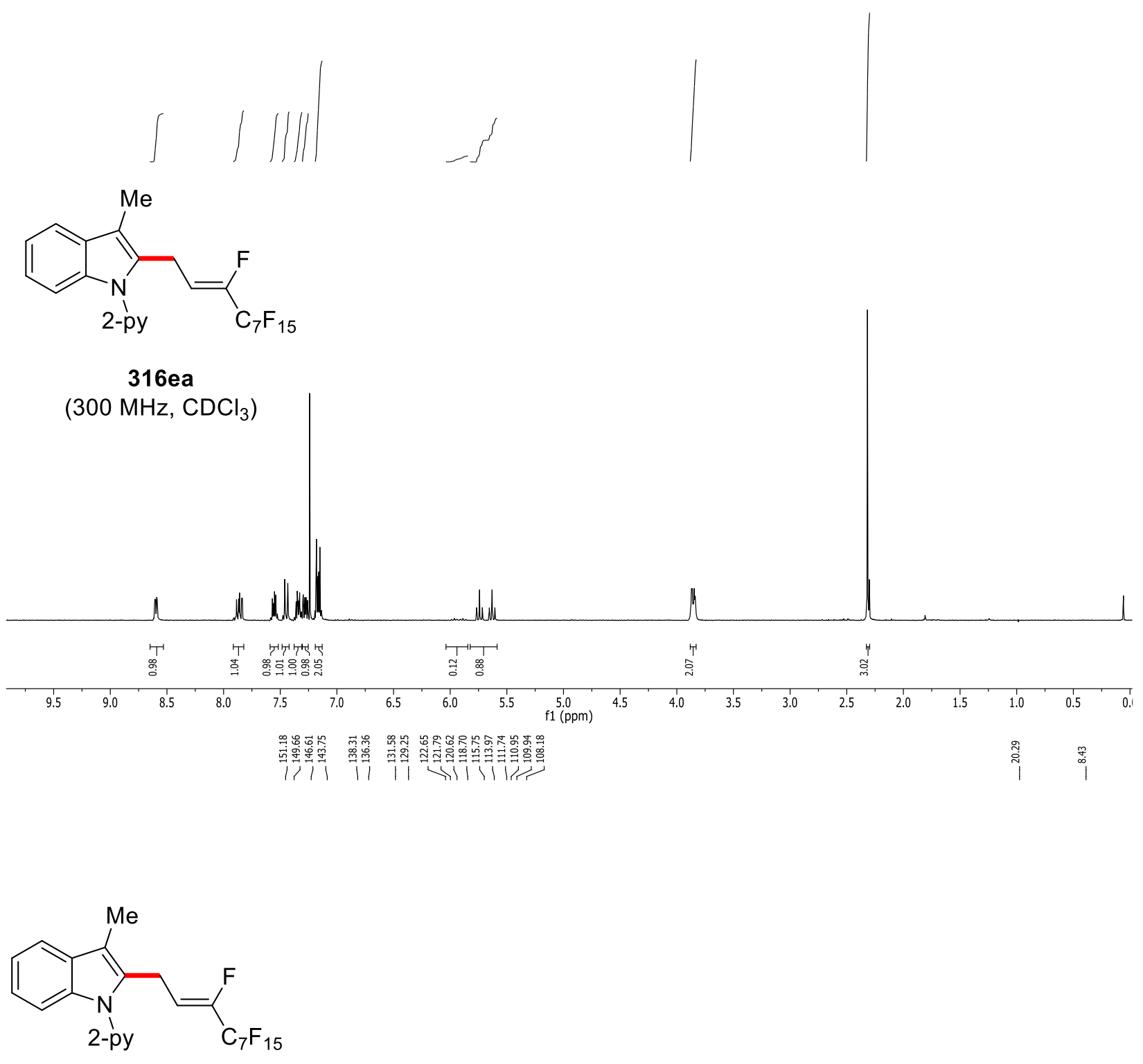

316 ea

$\left(100 \mathrm{MHz}, \mathrm{CDCl}_{3}\right.$ )

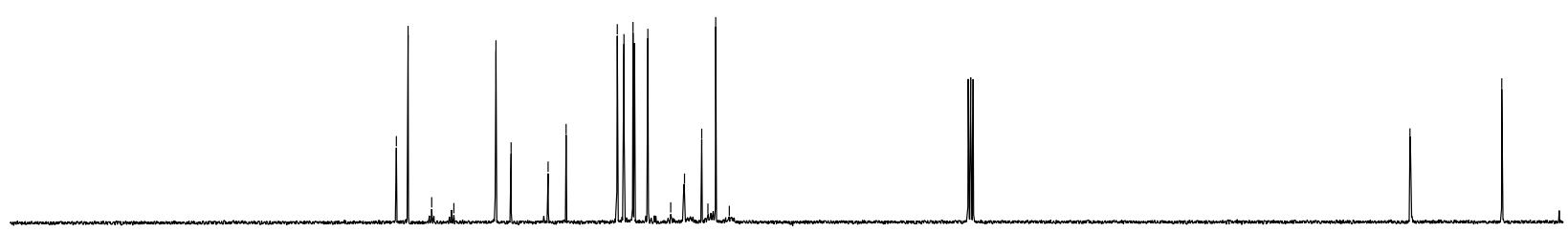

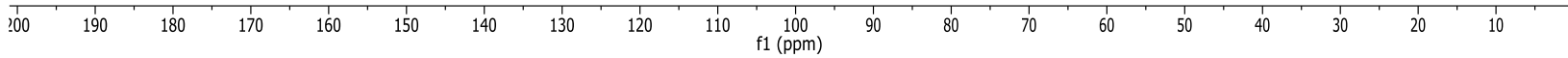



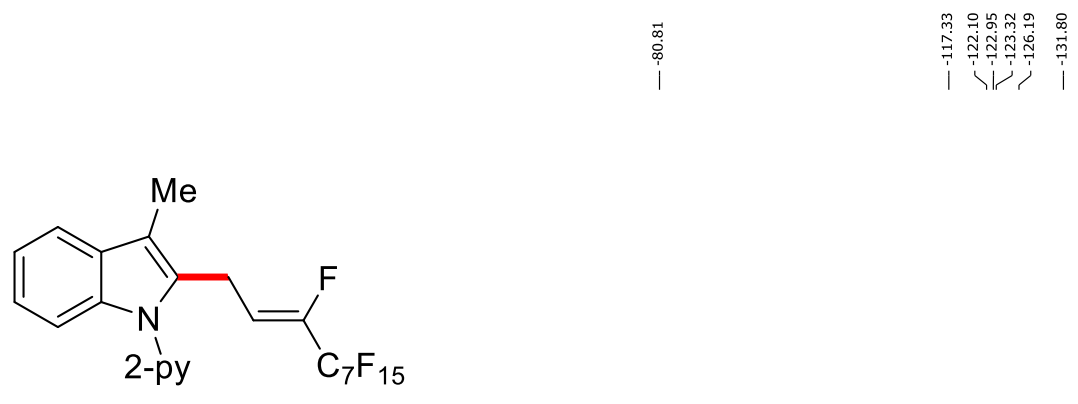

316ea

(375 MHz, $\mathrm{CDCl}_{3}$ )

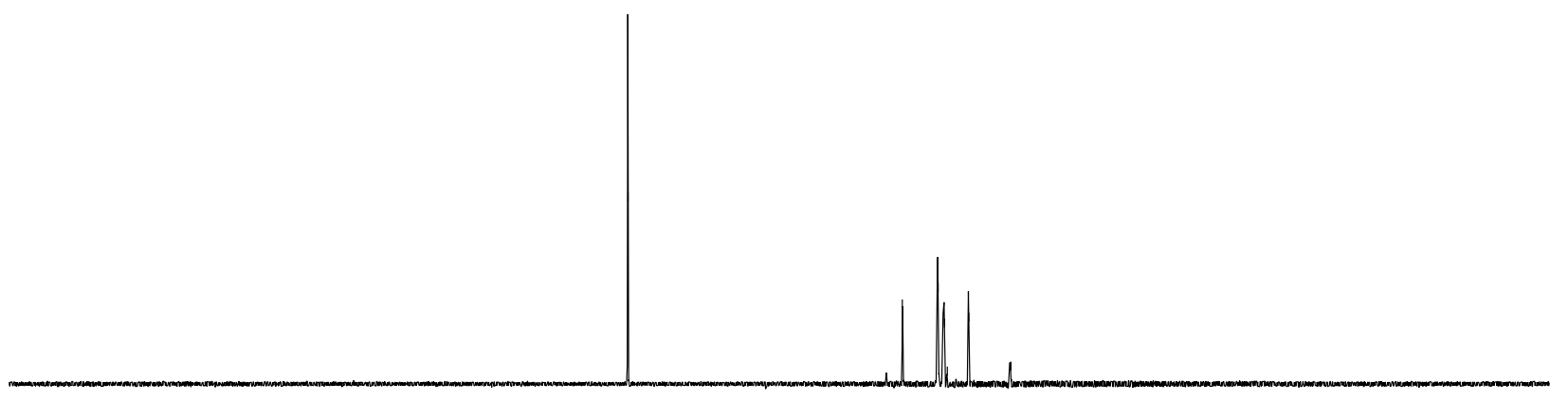

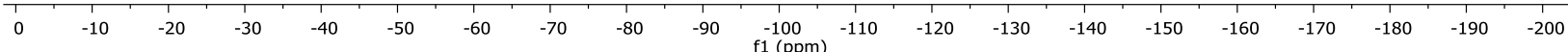




$$
1|1|
$$
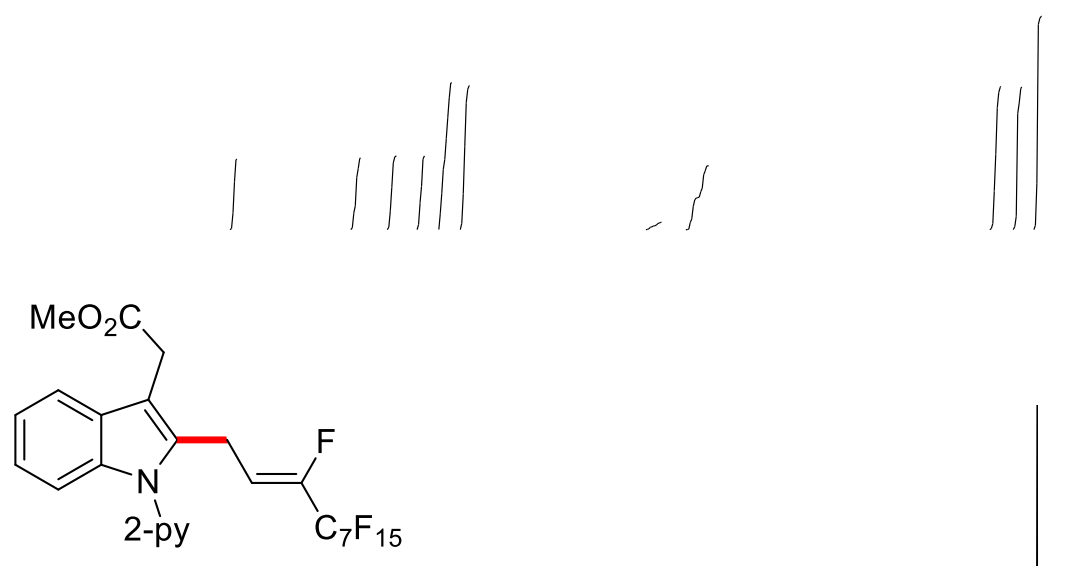

$316 f a$

$\left(500 \mathrm{MHz}^{\mathrm{CDCl}} \mathrm{CDC}_{3}\right.$
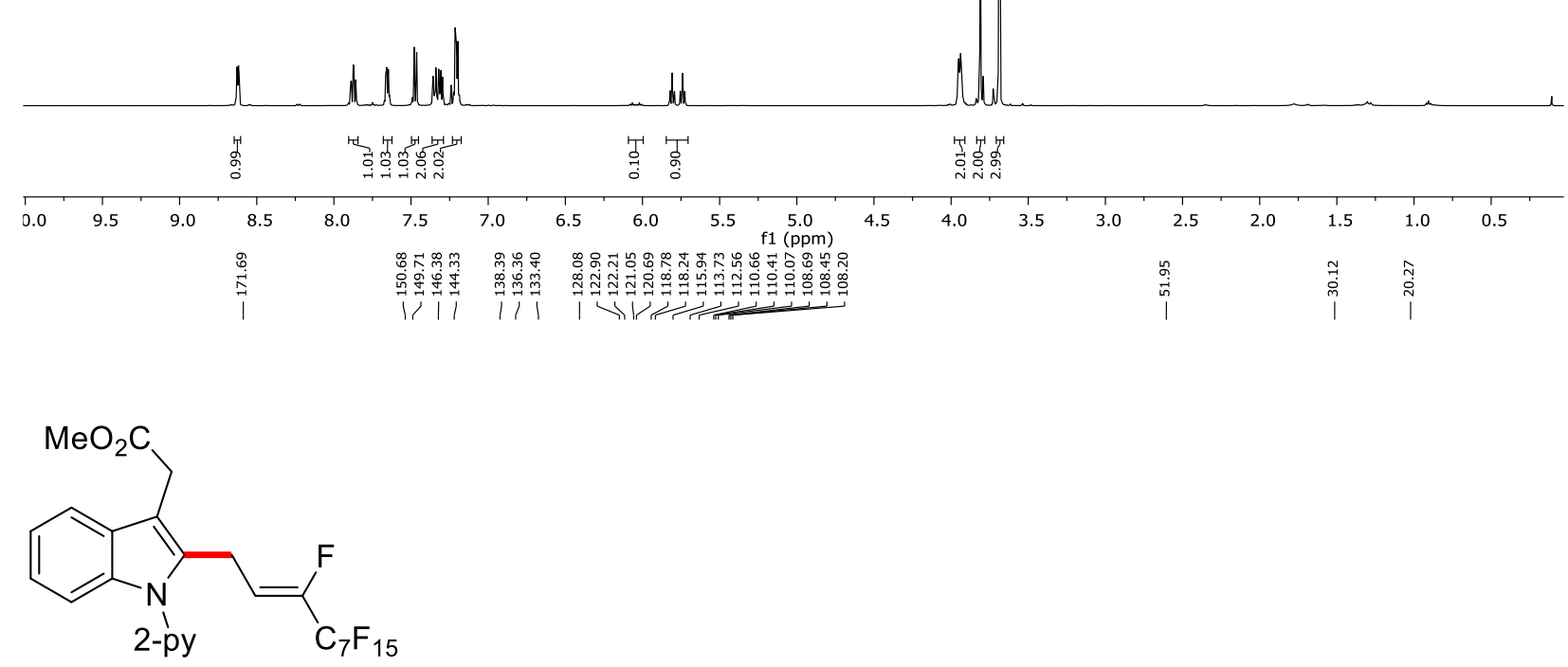

$316 f a$

$\left(125 \mathrm{MHz} \mathrm{CDCl}_{3}\right)$

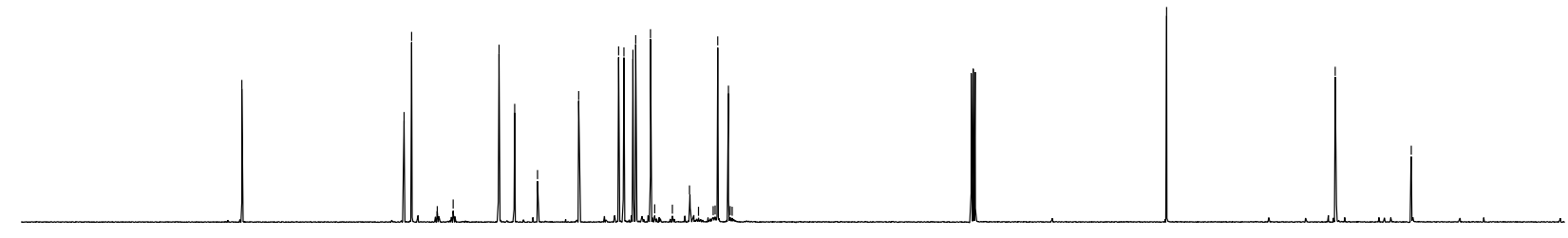

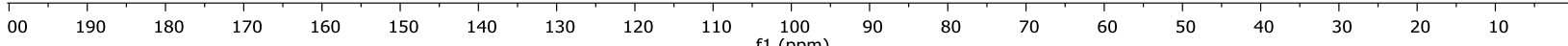




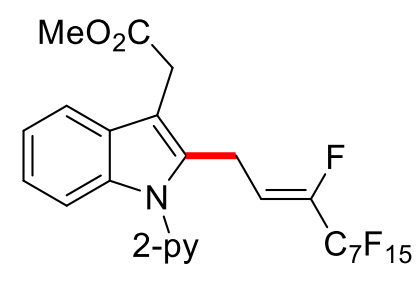

$316 f a$

(375 MHz, $\mathrm{CDCl}_{3}$ )

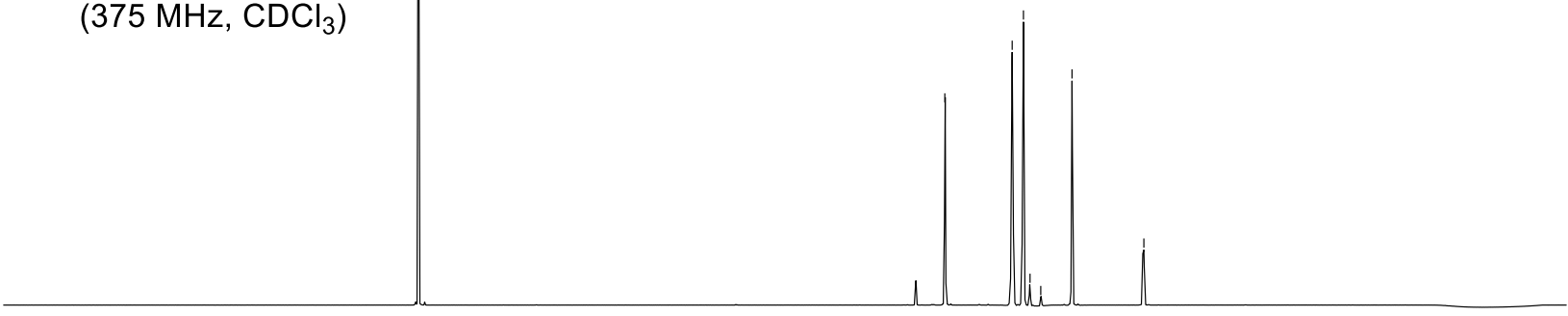

$\begin{array}{llllllllllllllllllllllll}-55 & -60 & -65 & -70 & -75 & -80 & -85 & -90 & -95 & -100 & -105 & -110 & -115 & -120 & -125 & -130 & -135 & -140 & -145 & -150 & -155 & -1 \epsilon\end{array}$ 

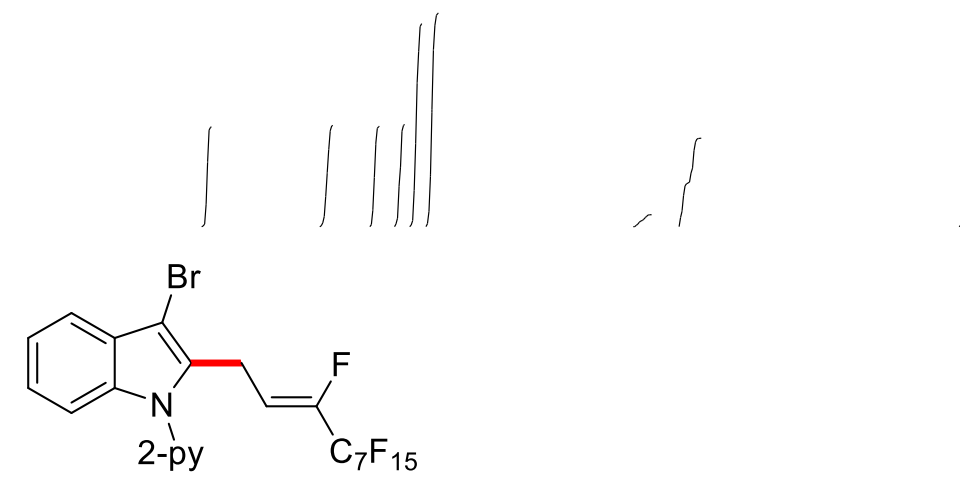

319aa

$\left(500 \mathrm{MHz}, \mathrm{CDCl}_{3}\right)$
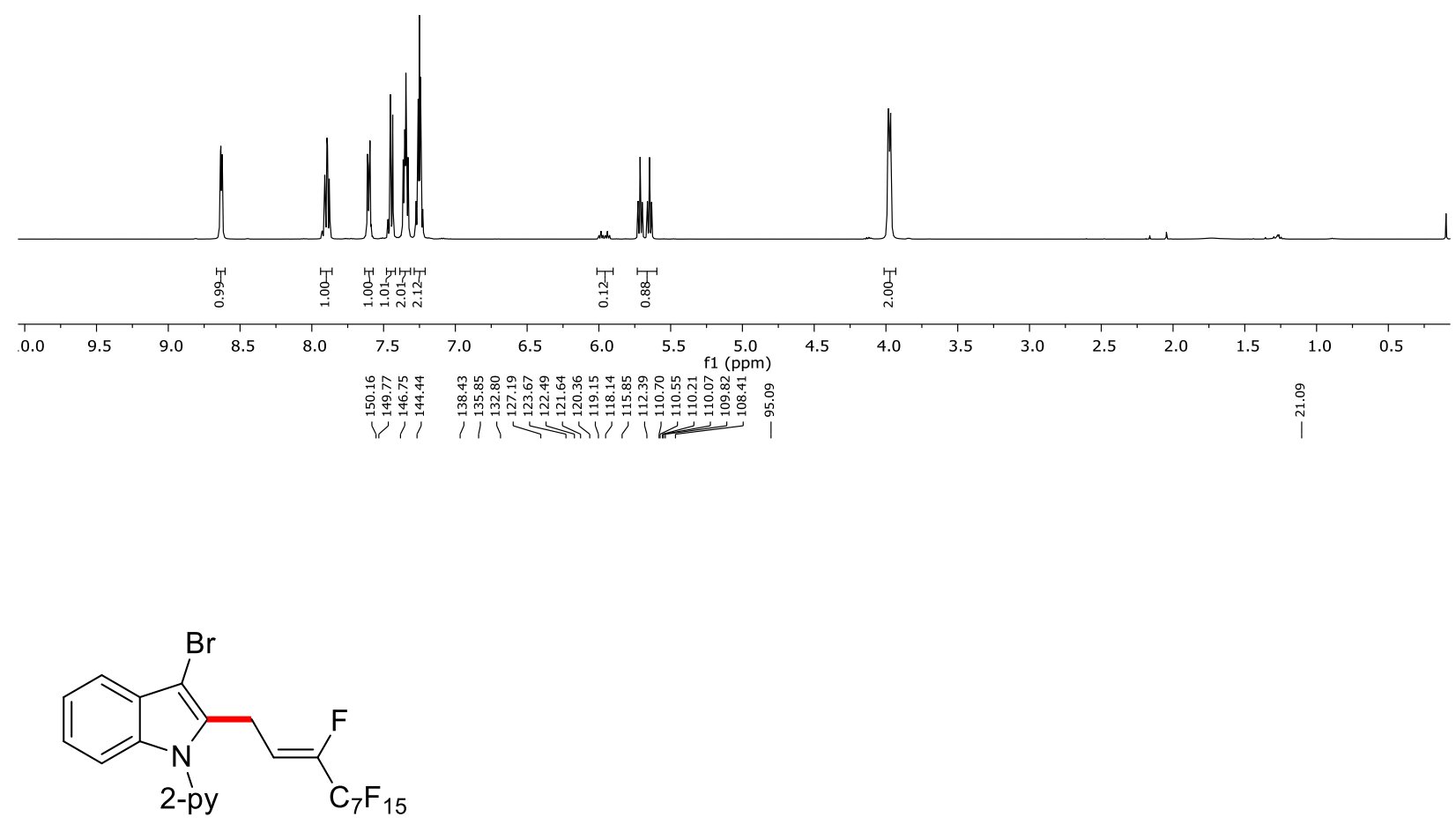

319aa

(125 MHz, $\mathrm{CDCl}_{3}$ )

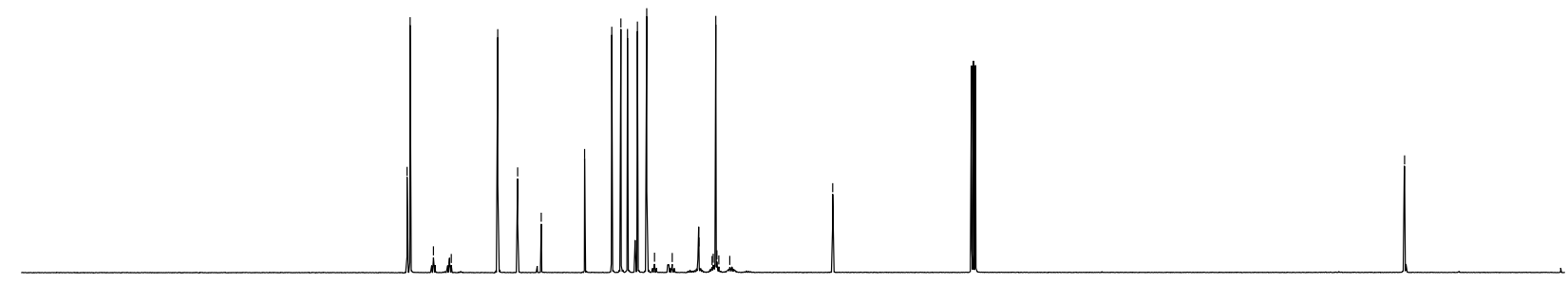

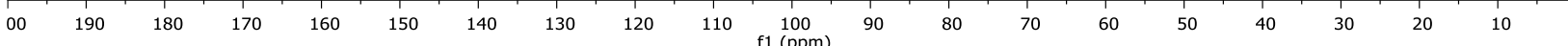




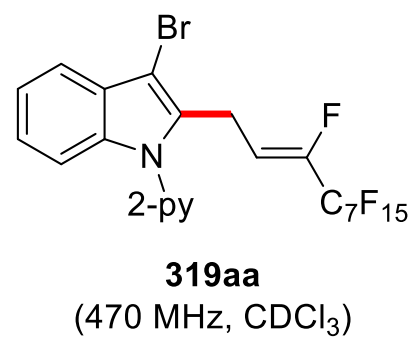

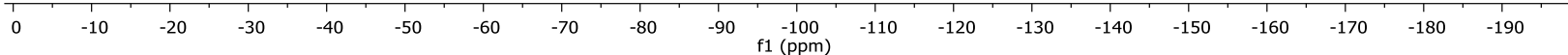



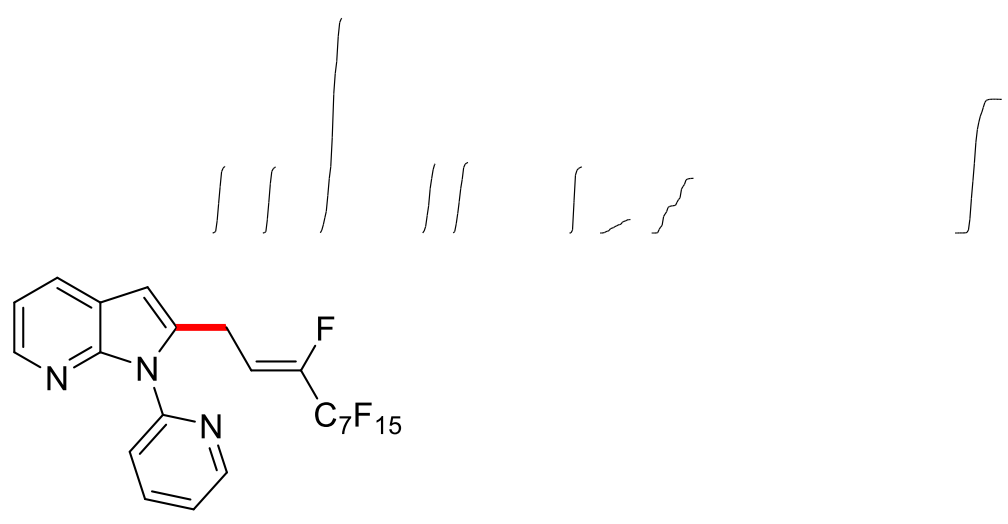

316ga

(300 MHz, $\mathrm{CDCl}_{3}$ )
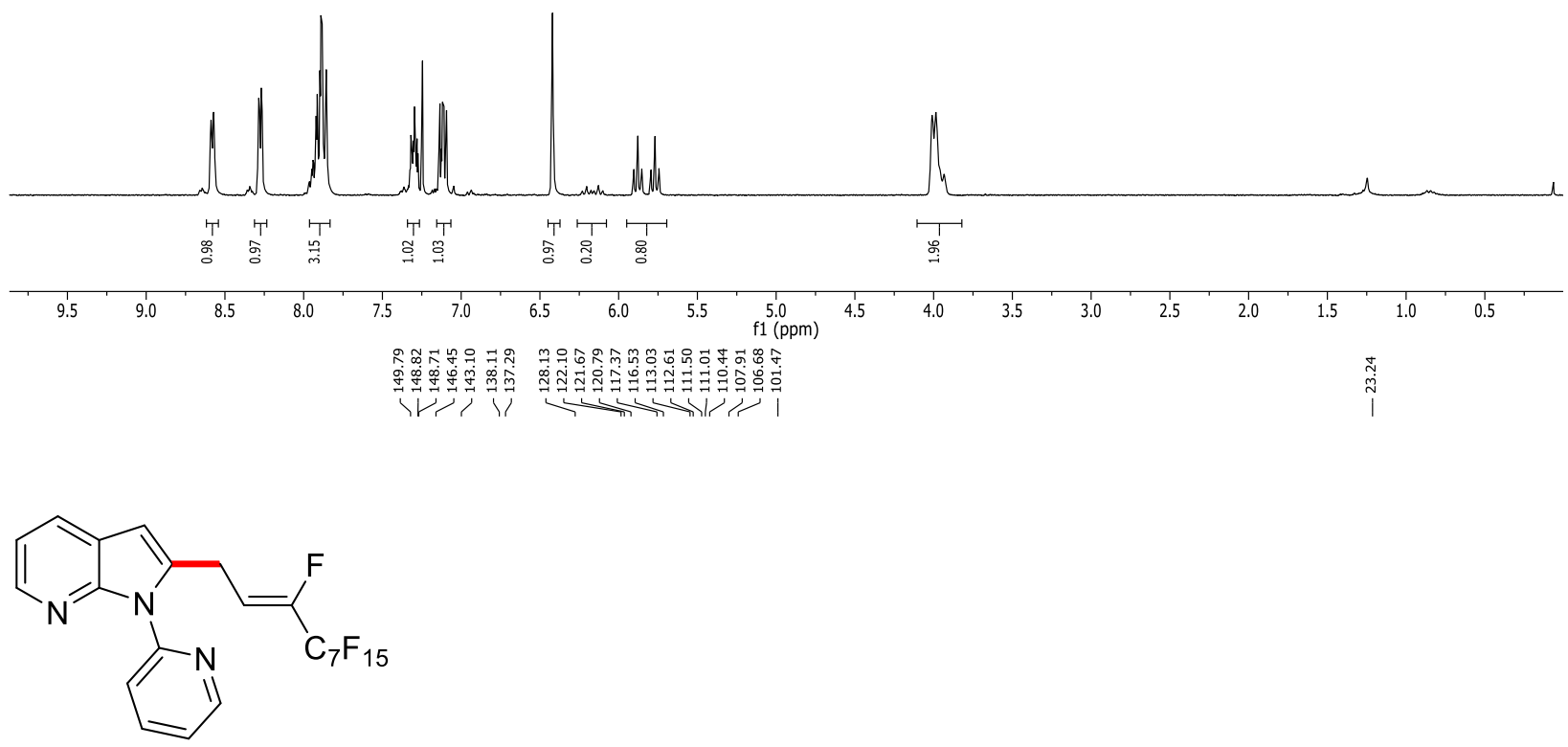

316ga

$\left(100 \mathrm{MHz} \mathrm{CDCl}_{3}\right)$

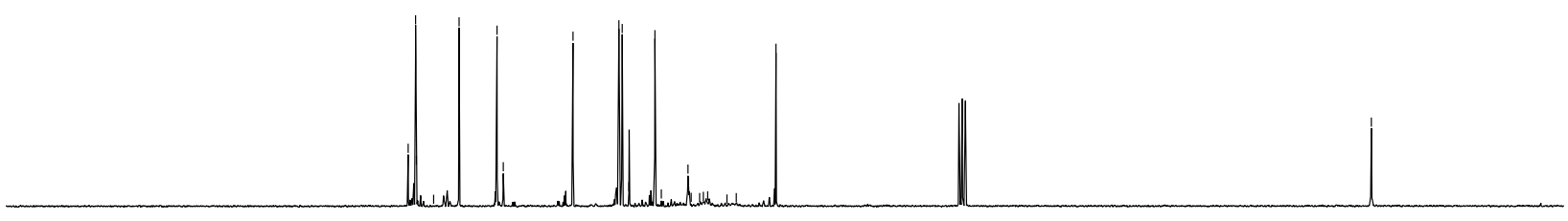

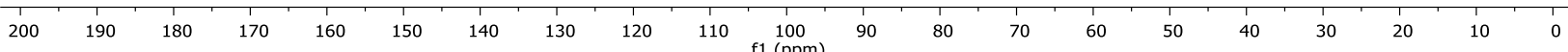




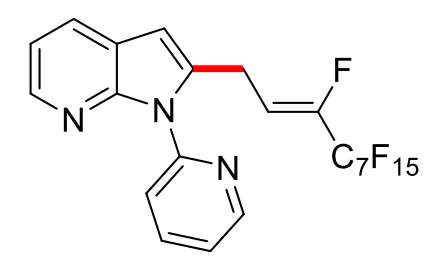

316ga

(282 $\mathrm{MHz} \mathrm{CDCl}_{3}$ )

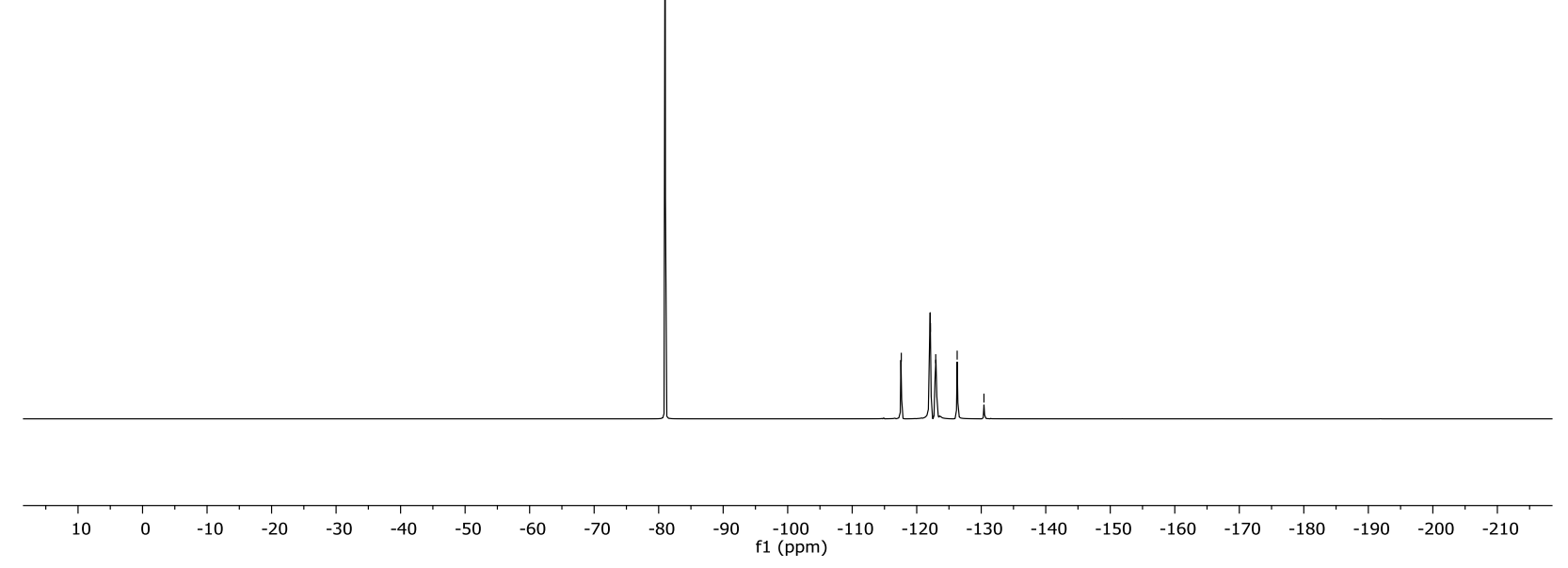



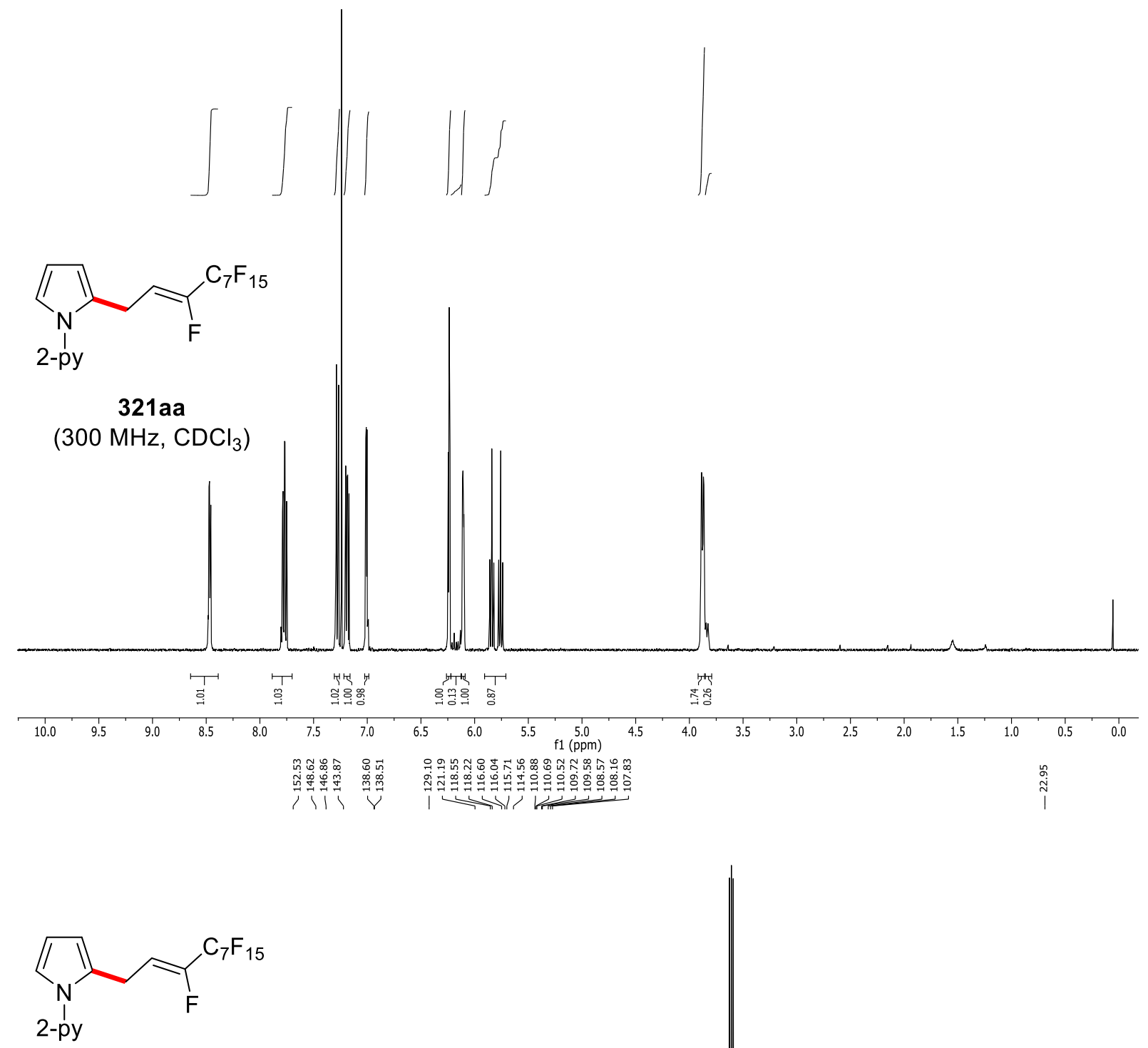

321 aa

$\left(100 \mathrm{MHz}, \mathrm{CDCl}_{3}\right)$

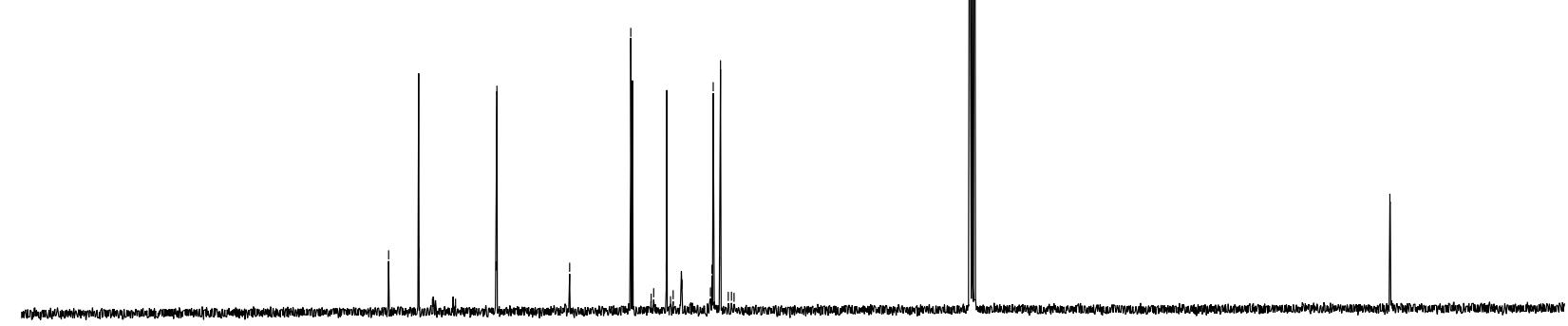

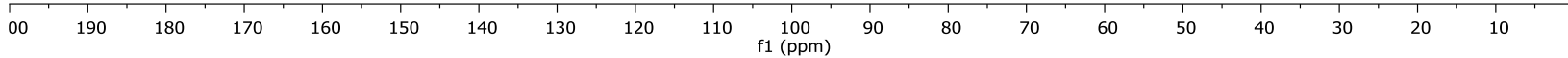




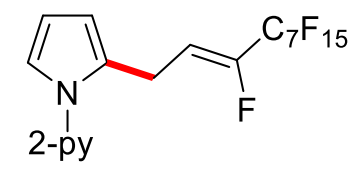

321 aa

(375 MHz, CDCl ${ }_{3}$ )

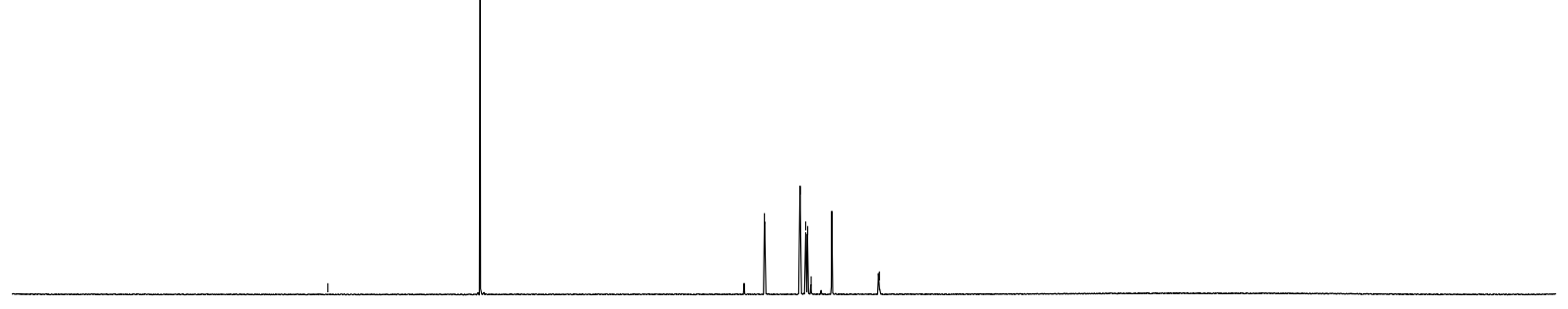

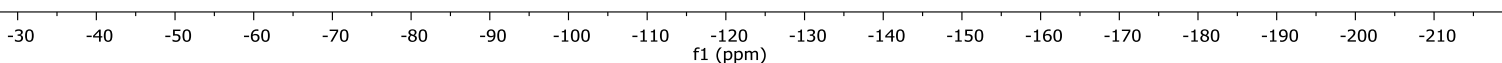




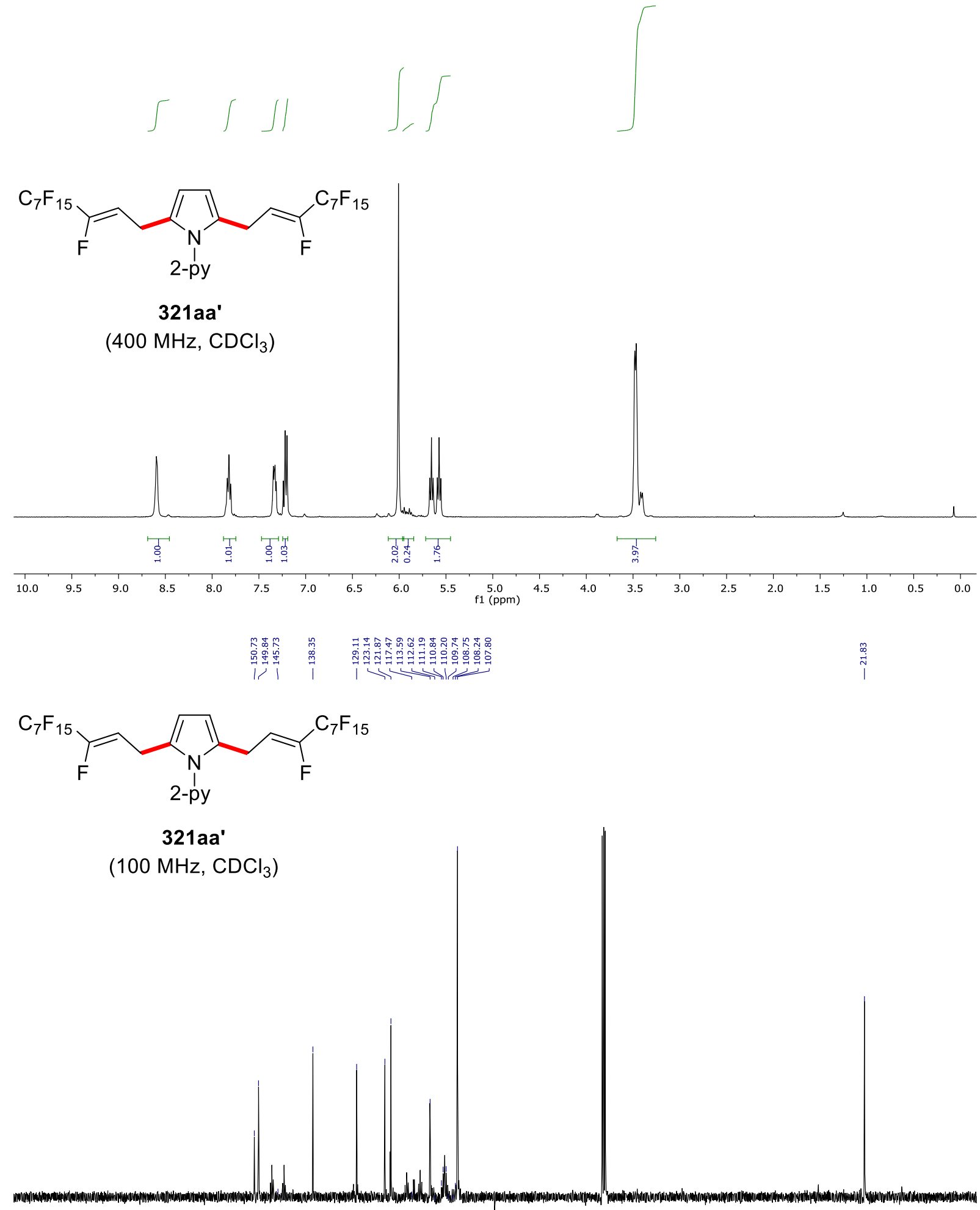

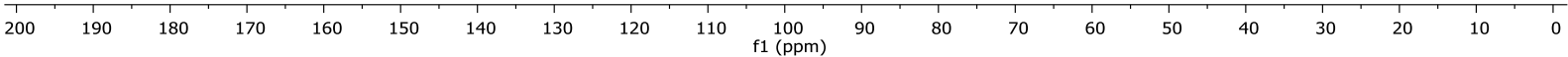




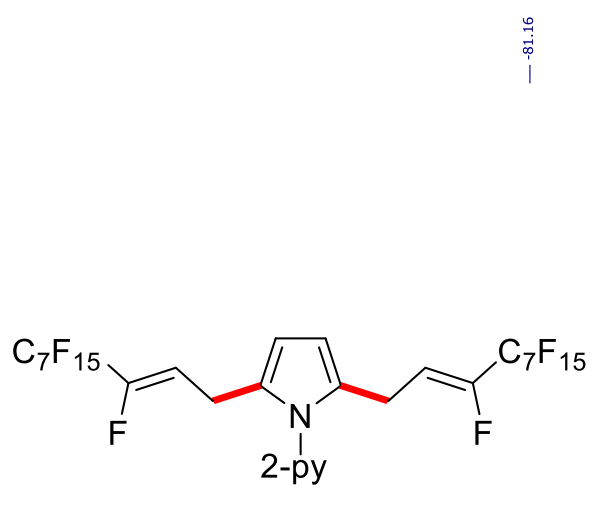

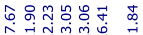

조줘ำ

i نंi

321aa'

(375 MHz, $\mathrm{CDCl}_{3}$ )
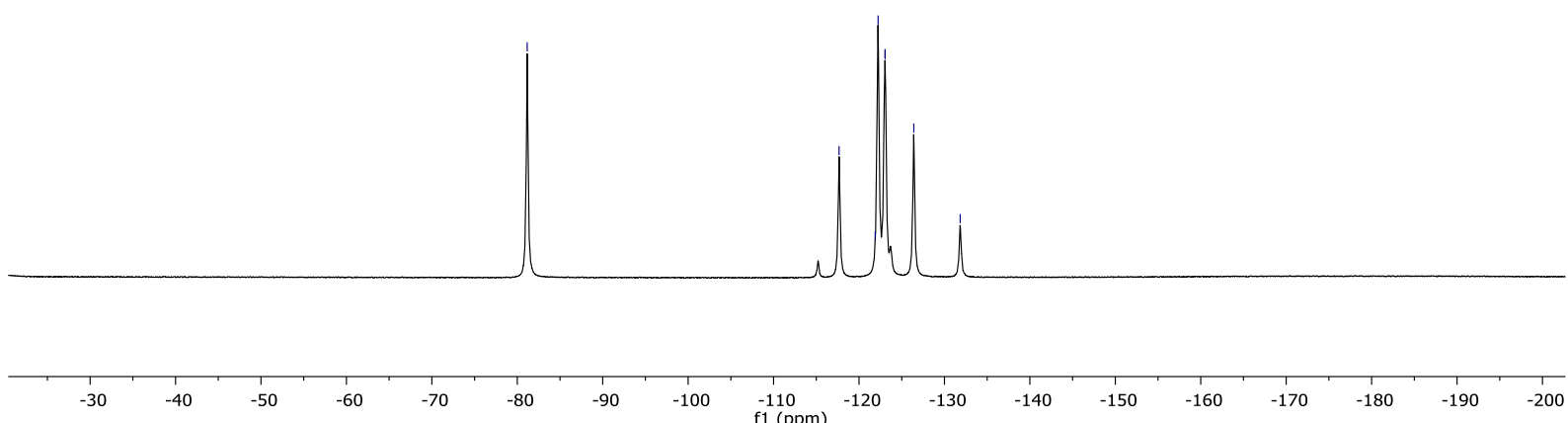

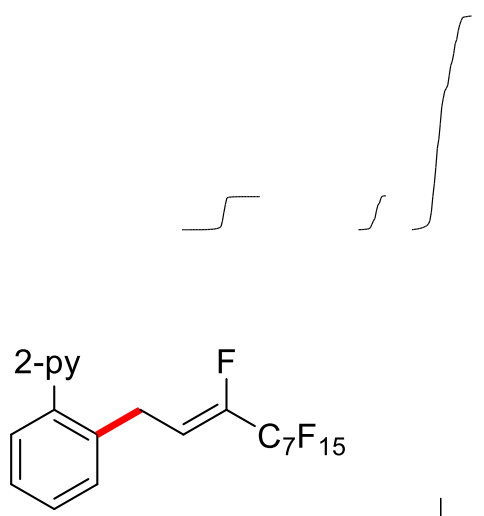

322aa

(300 MHz, $\mathrm{CDCl}_{3}$ )
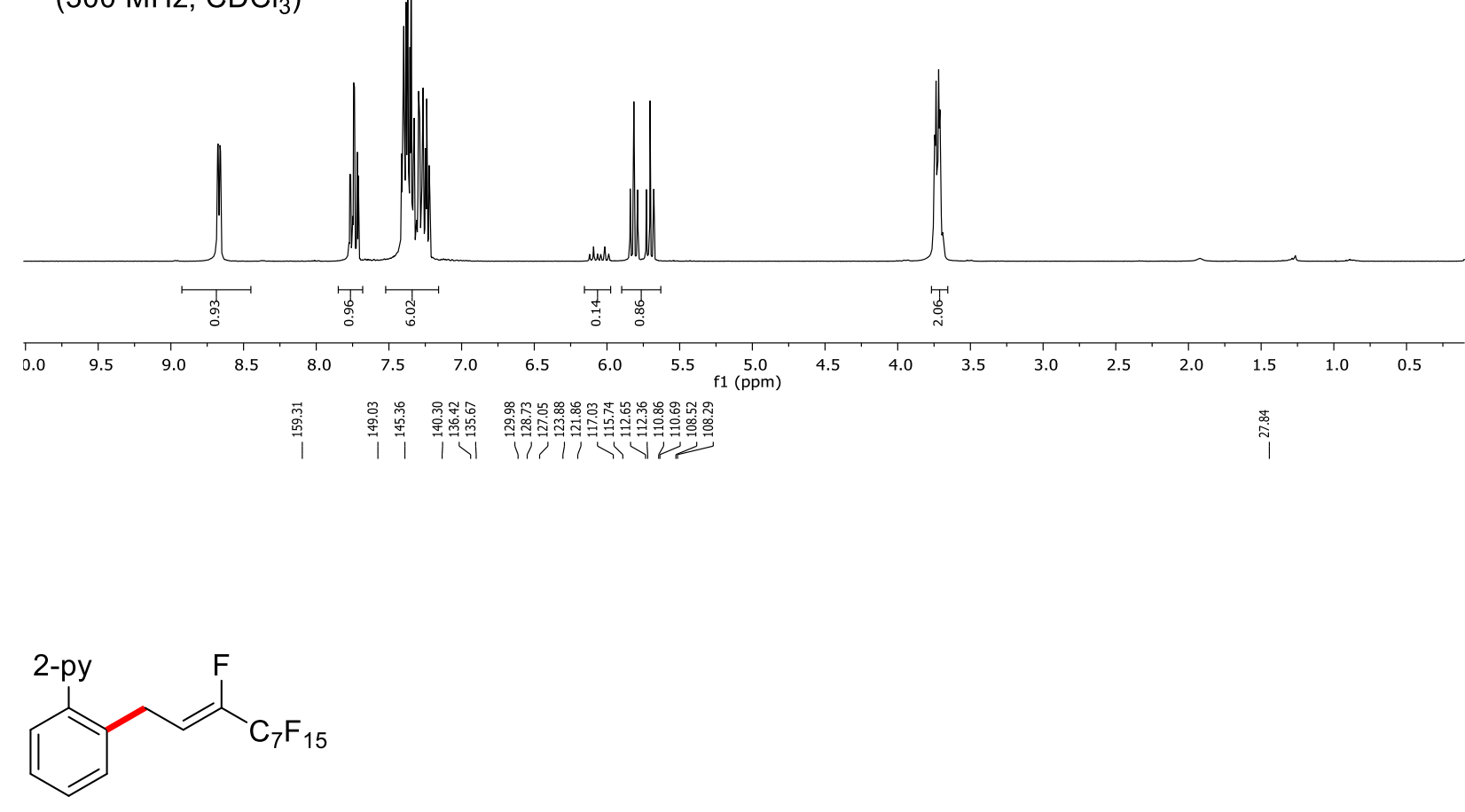

322aa

(125 MHz, $\mathrm{CDCl}_{3}$ )

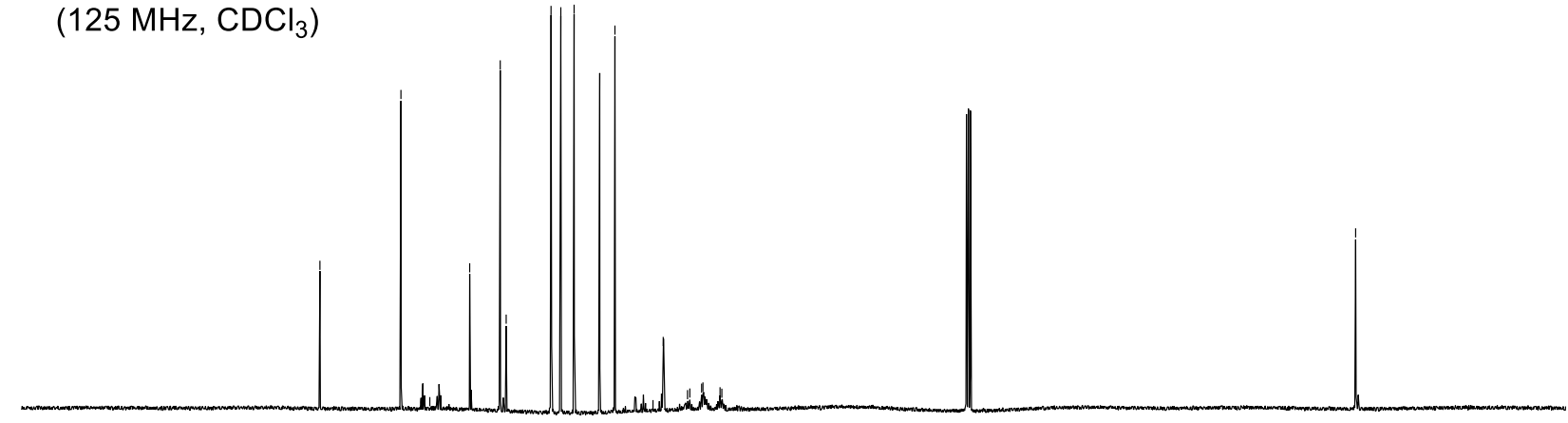

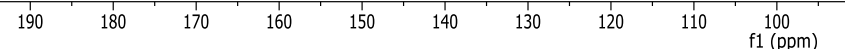




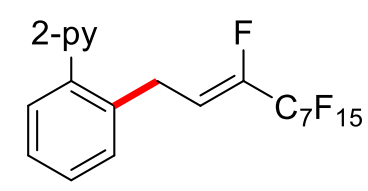

322aa

(282 MHz, $\mathrm{CDCl}_{3}$ )

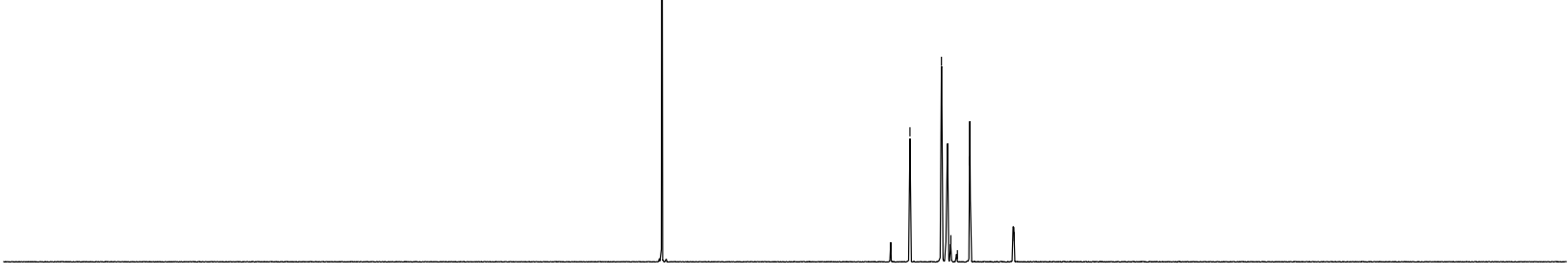

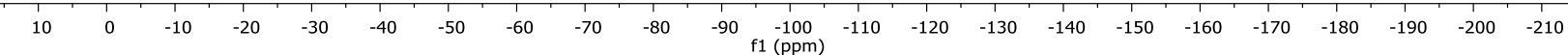




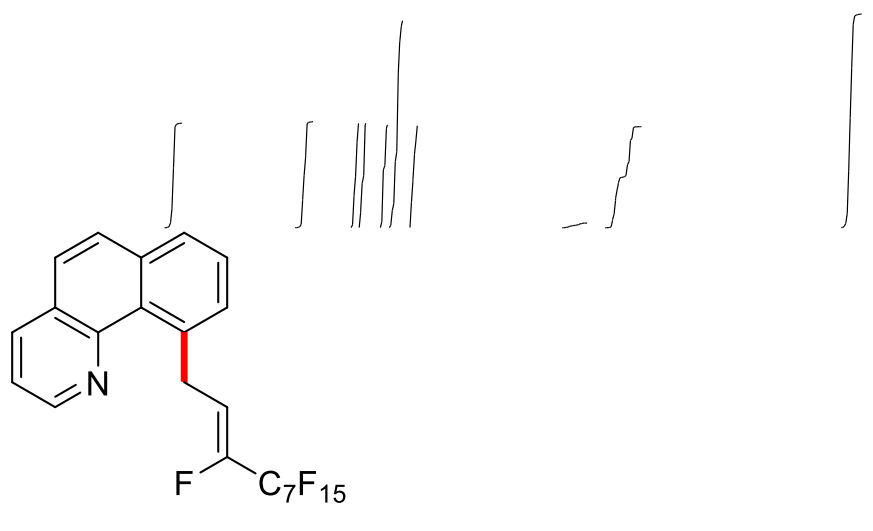

324aa

$\left(400 \mathrm{MHz}, \mathrm{CDCl}_{3}\right)$

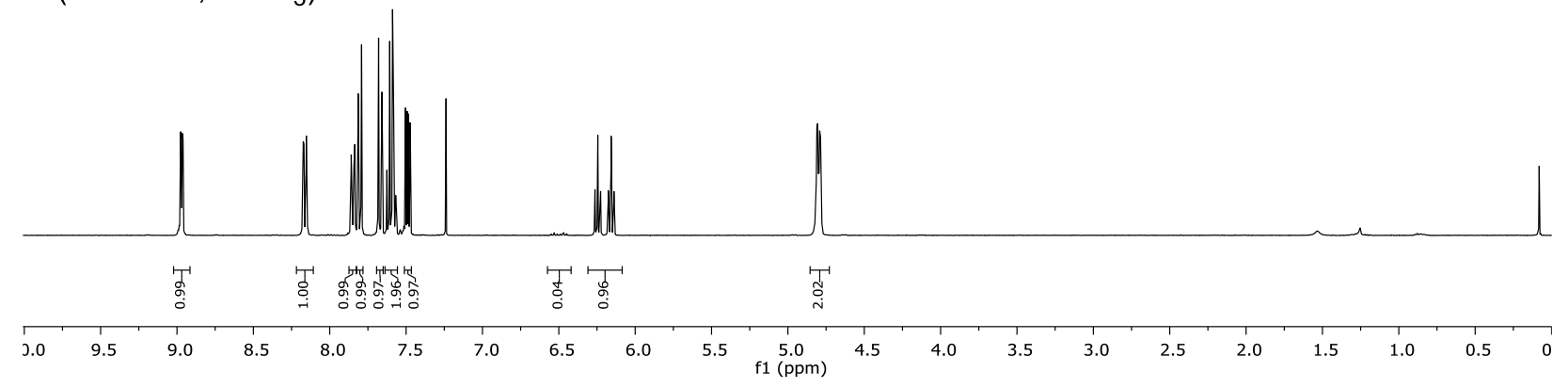

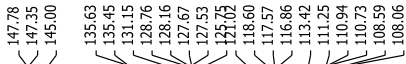<smiles>FC(F)=C(F)CCc1cccc2ccc3cccnc3c12</smiles>

324aa

(100 MHz, $\mathrm{CDCl}_{3}$ )

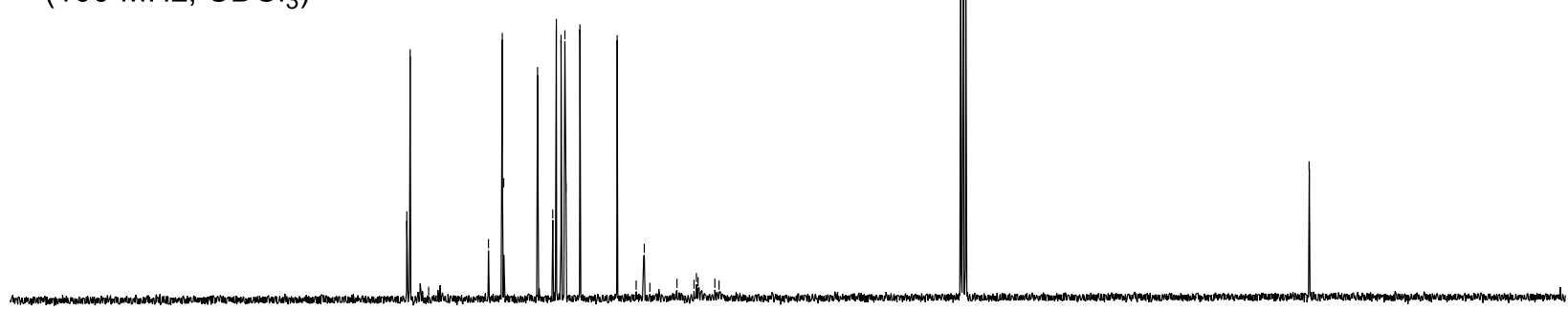

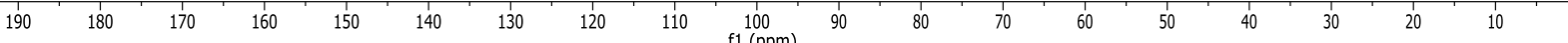



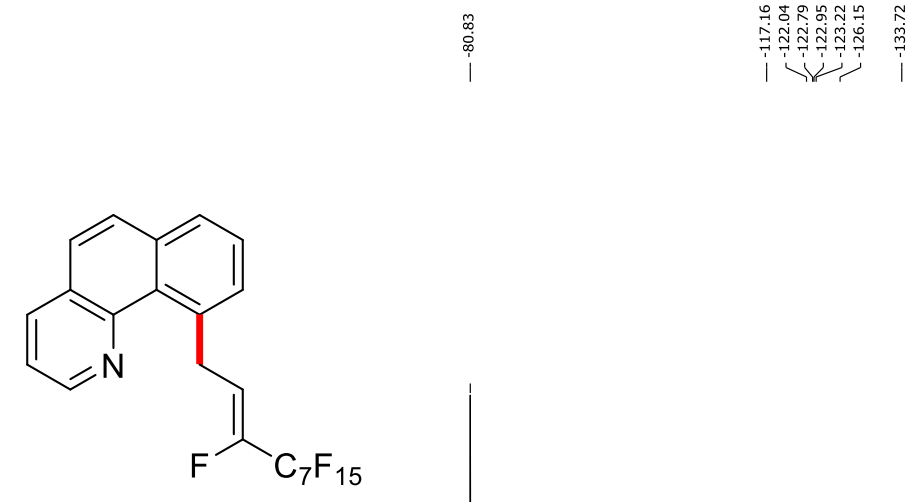

324aa

$\left(375 \mathrm{MHz} \mathrm{CDCl}_{3}\right)$

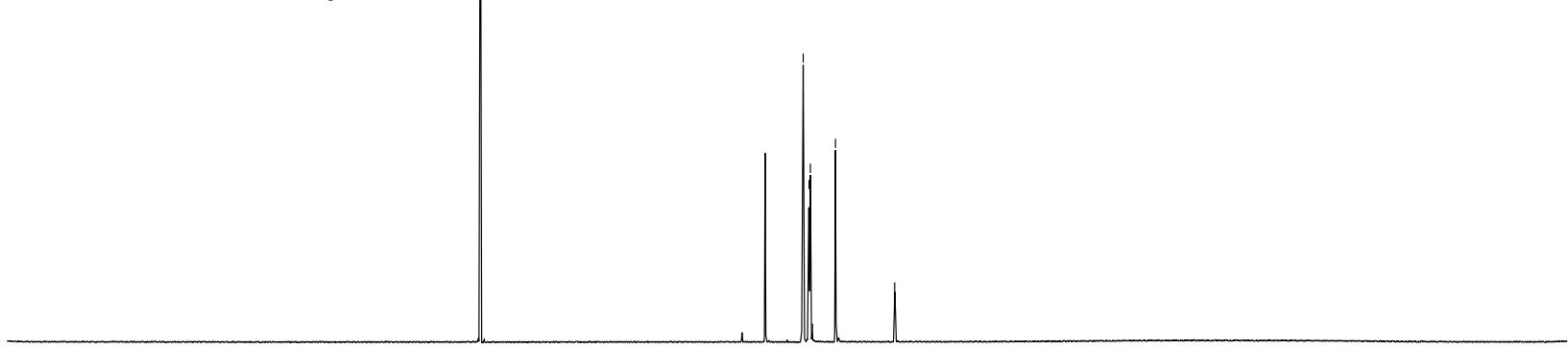

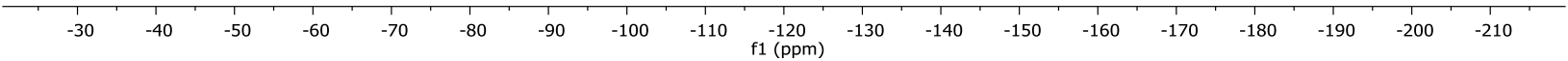



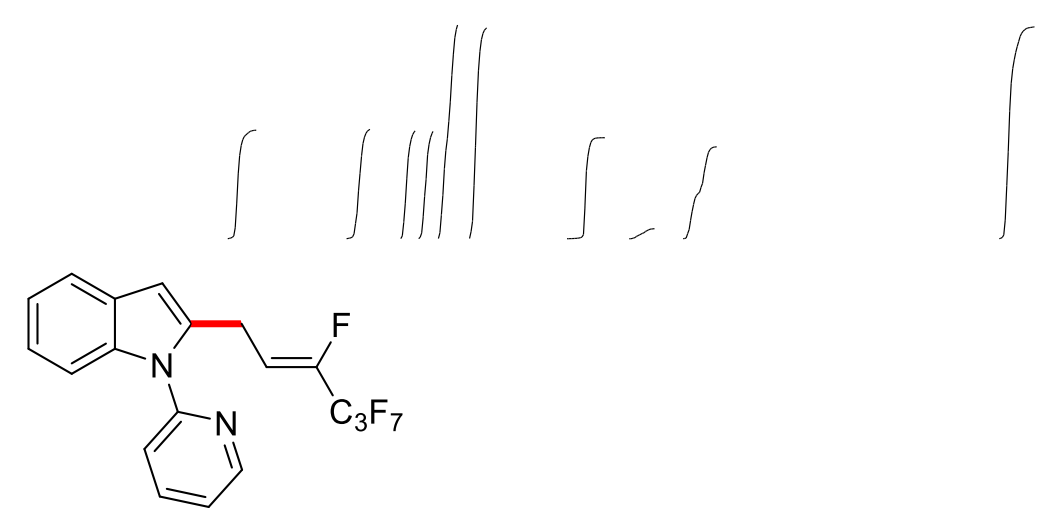

316ab

(400 MHz, $\mathrm{CDCl}_{3}$ )
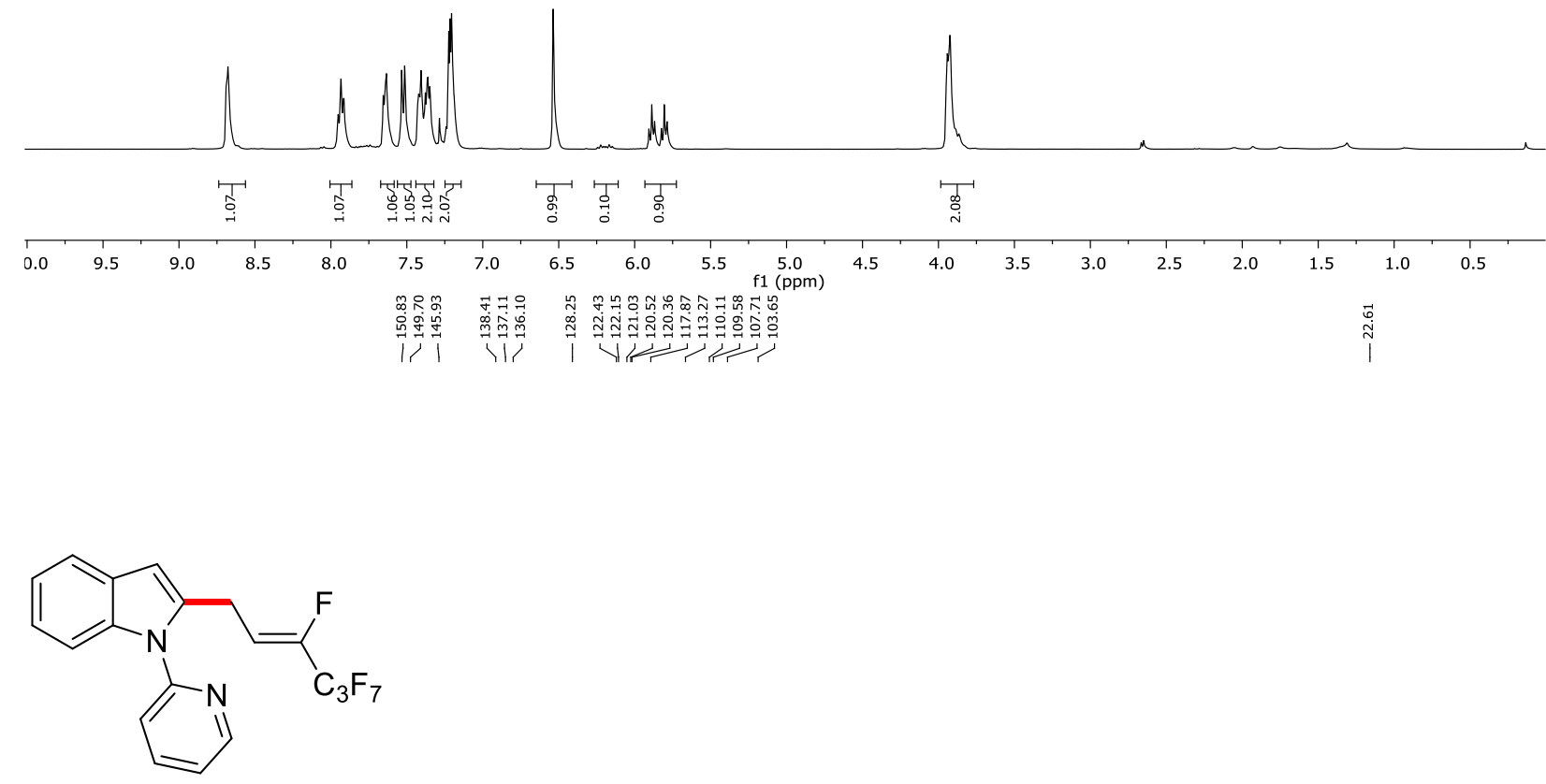

316ab

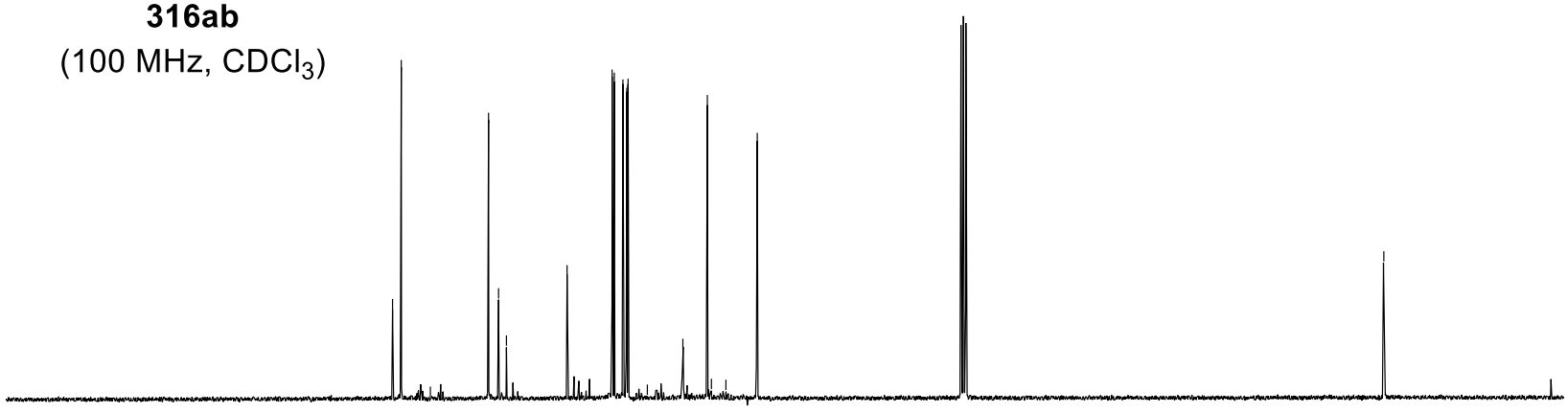

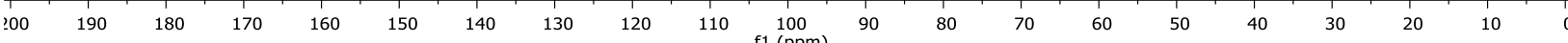




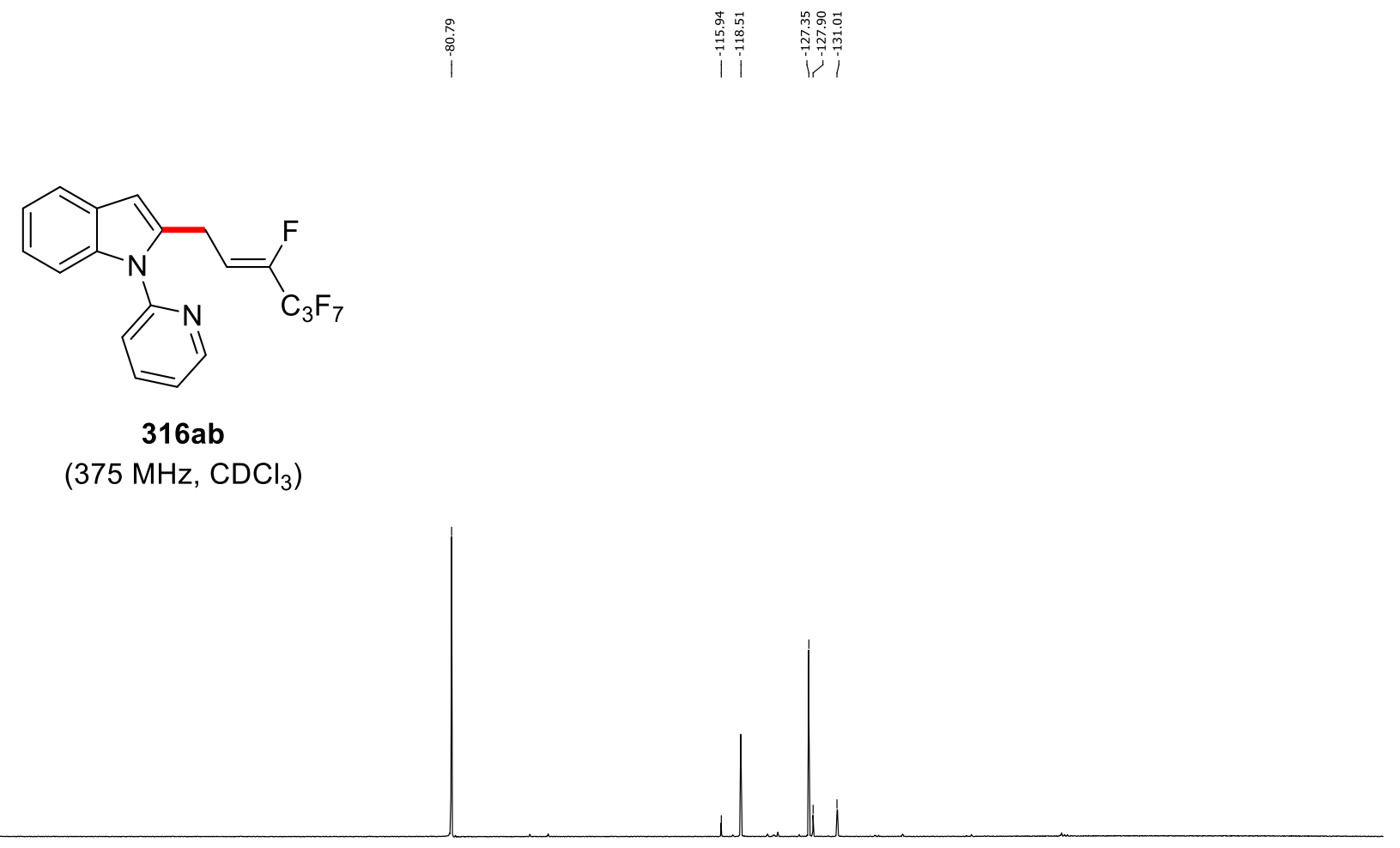

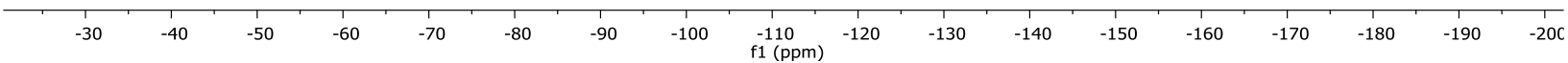




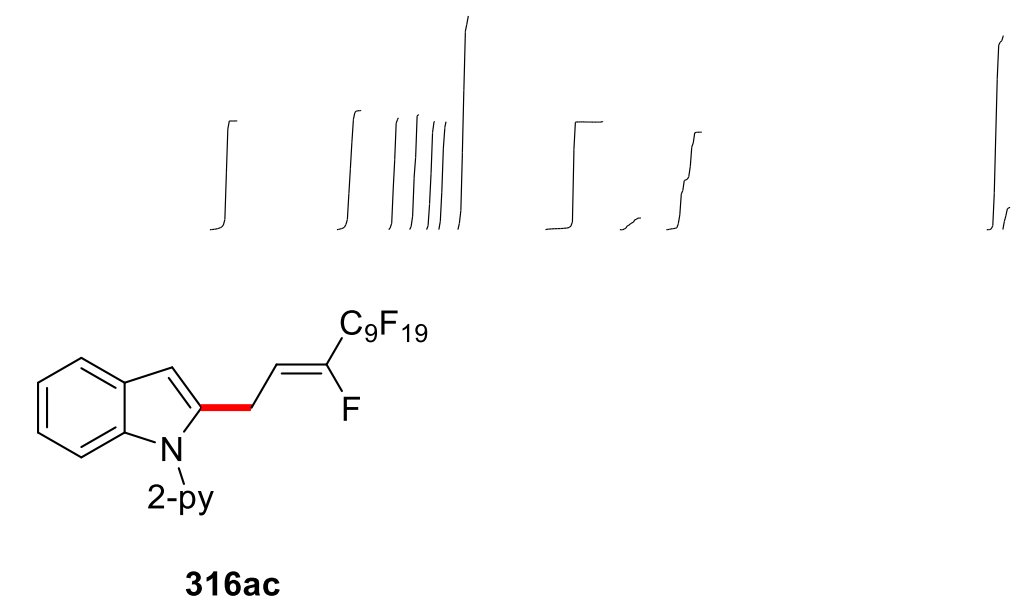

(500 MHz, $\mathrm{CDCl}_{3}$ )
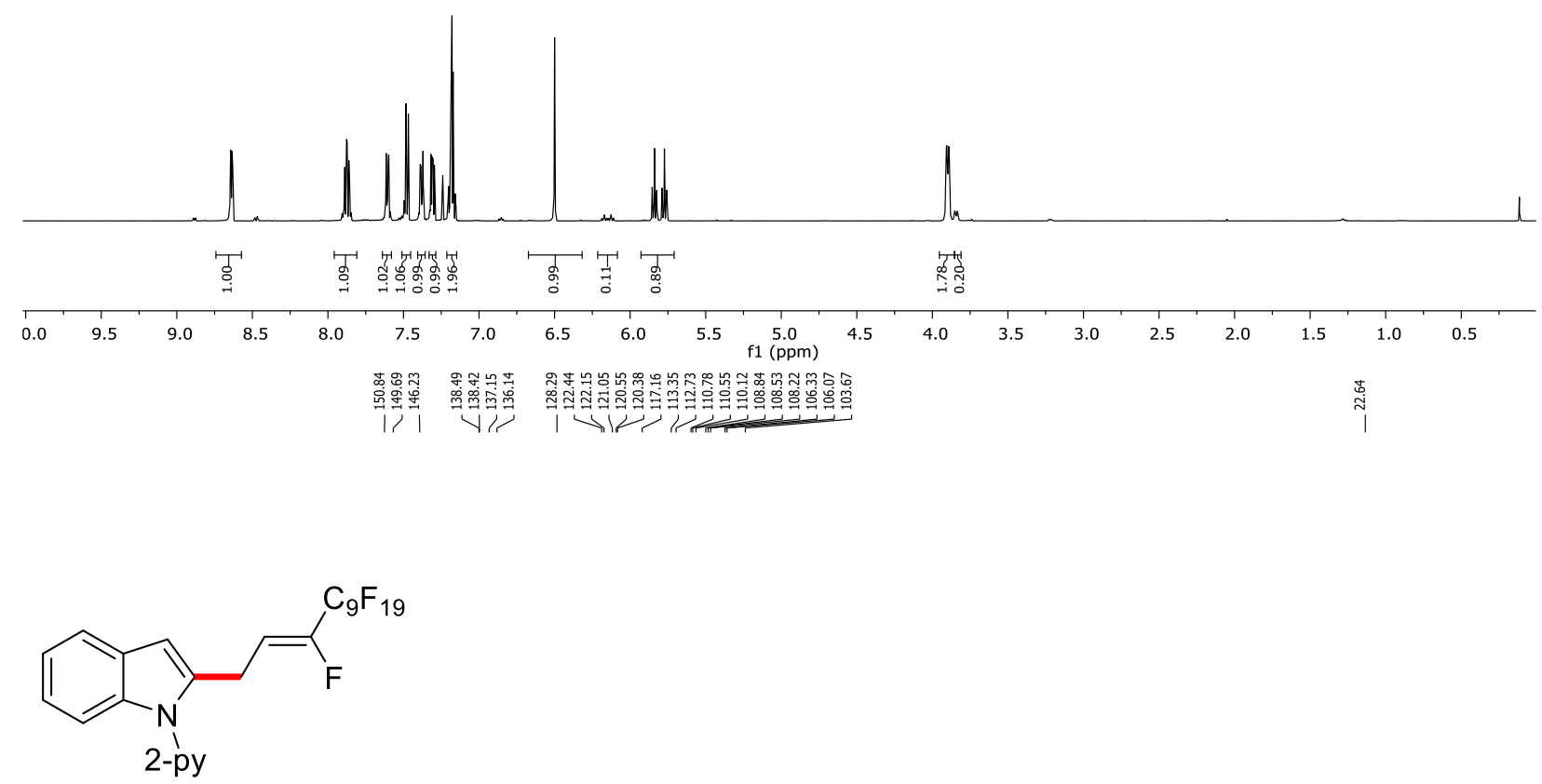

$316 a c$

(125 MHz, $\mathrm{CDCl}_{3}$ )

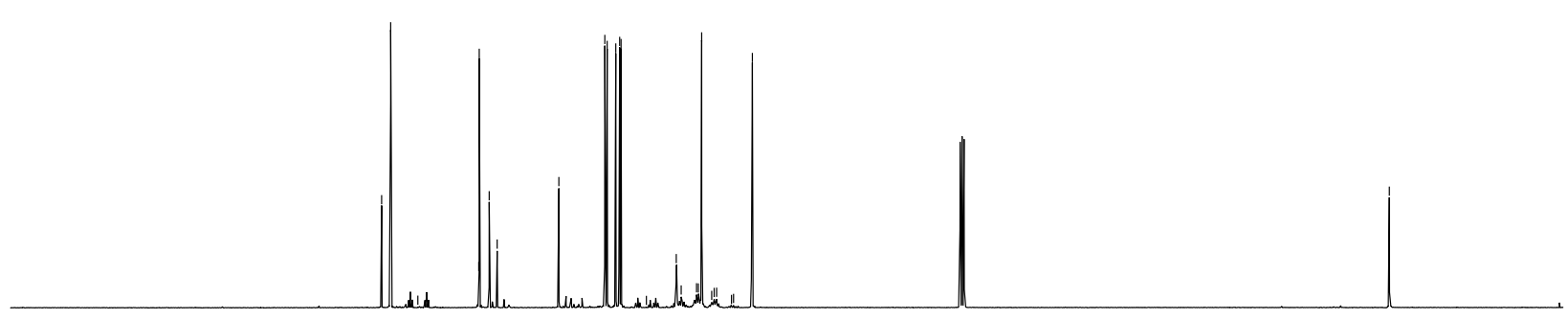

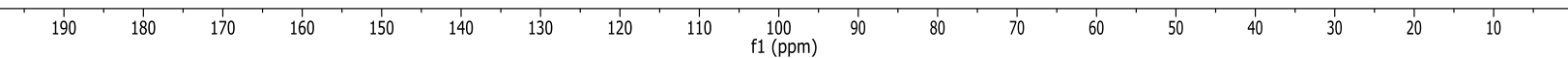




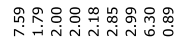

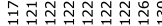

2-py

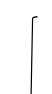

1

$316 a c$

$\left(470 \mathrm{MHz}, \mathrm{CDCl}_{3}\right.$ )

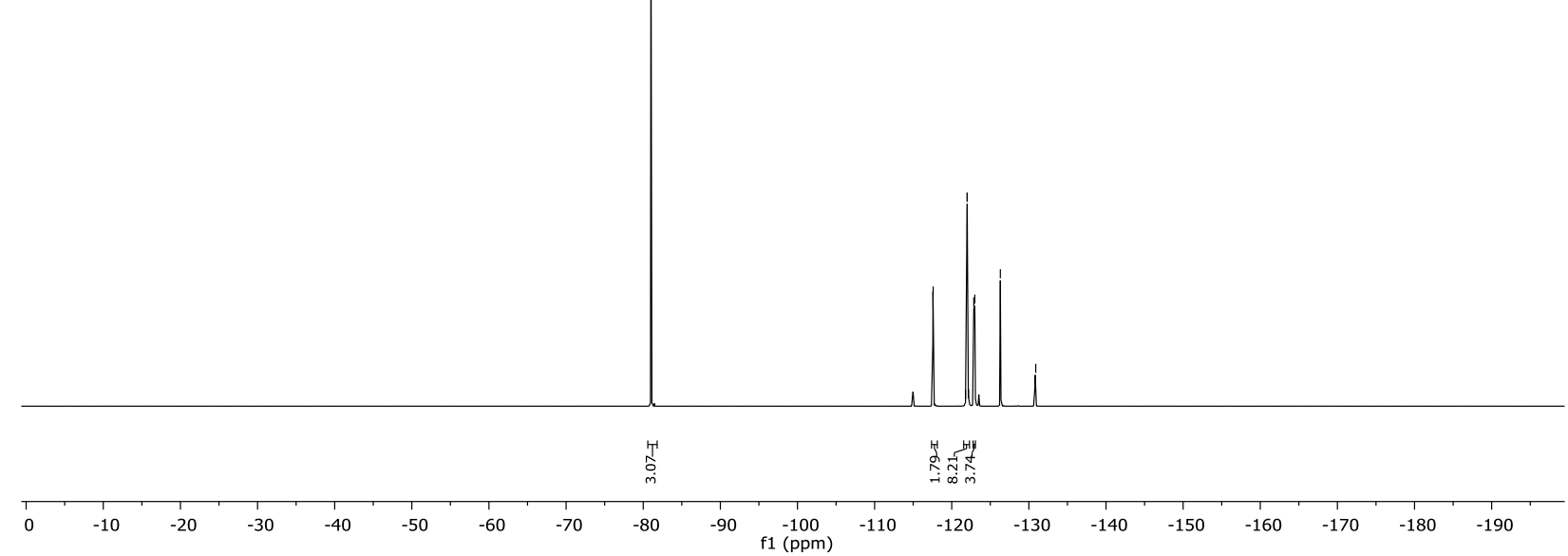



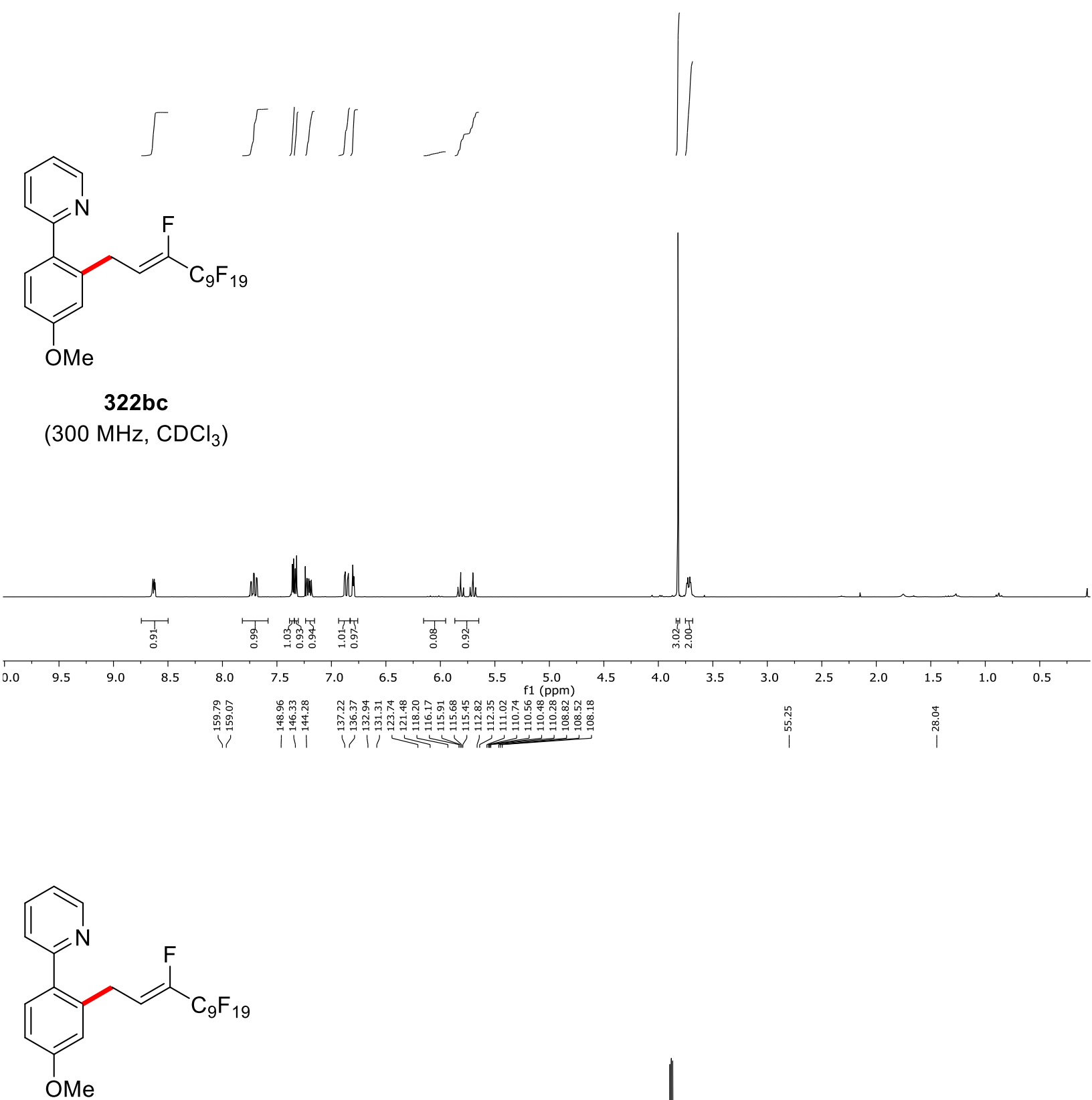

$322 \mathrm{bc}$

(125 MHz, $\mathrm{CDCl}_{3}$ )

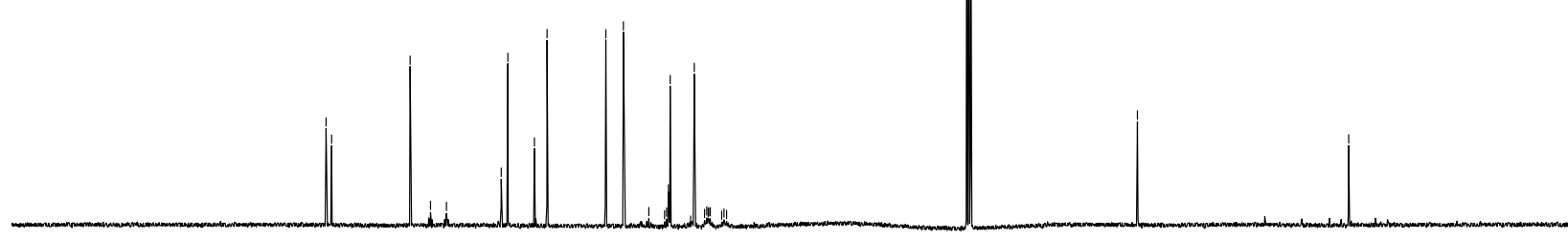

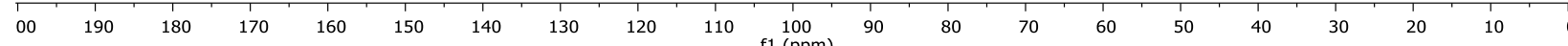




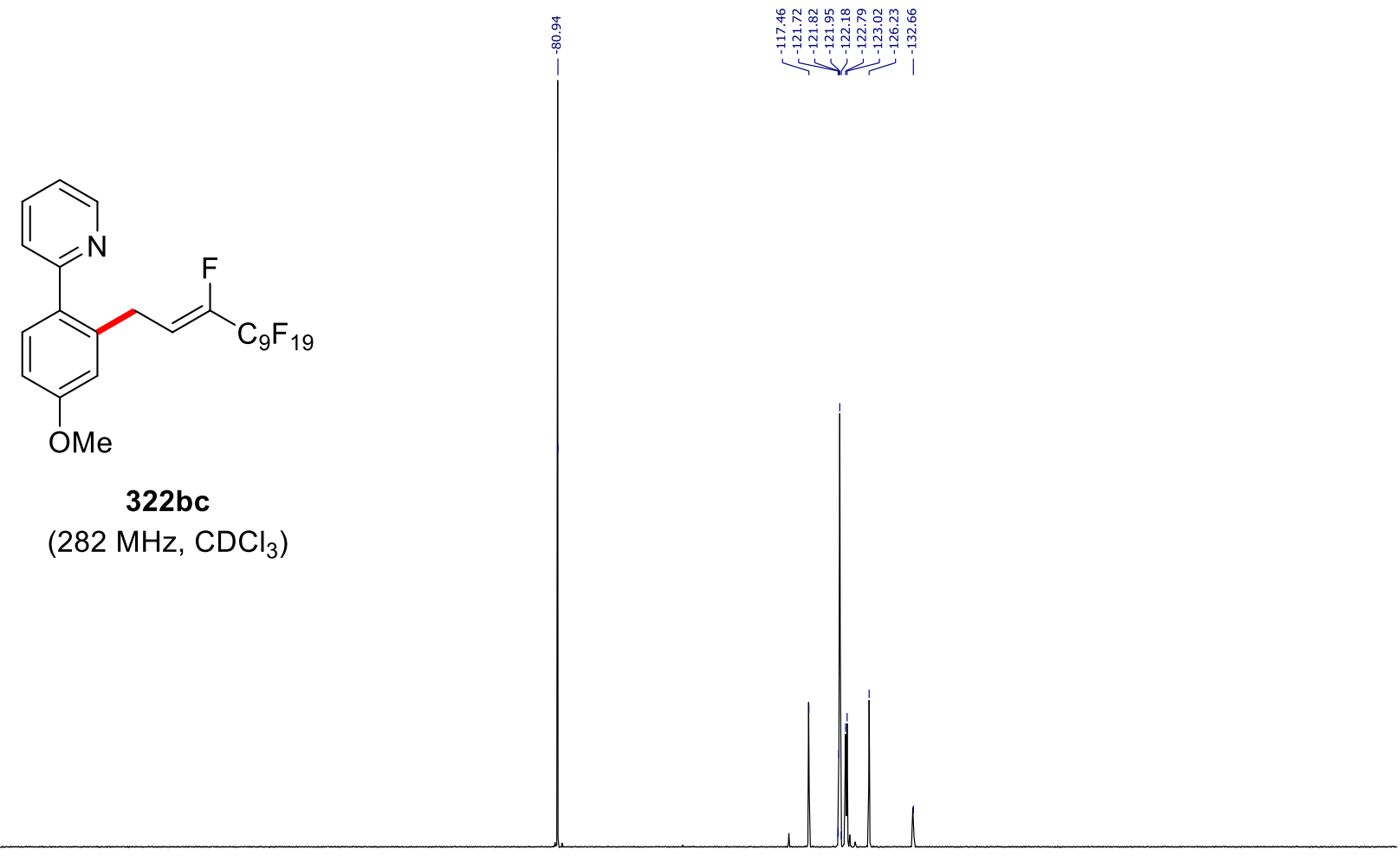

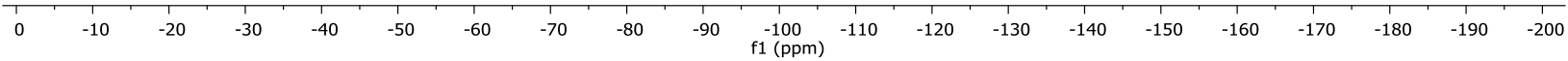




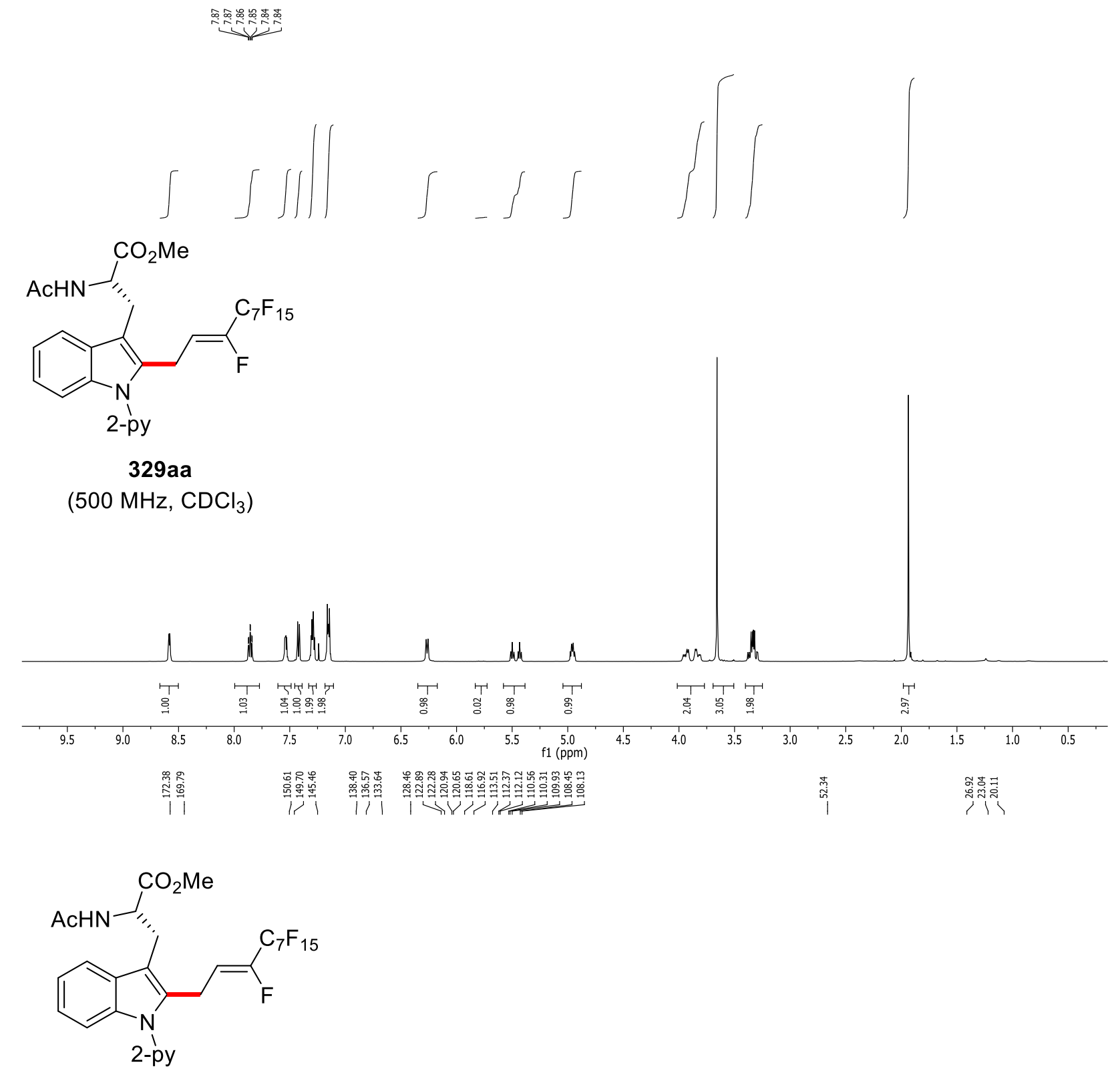

$329 a a$

(125 MHz, $\mathrm{CDCl}_{3}$ )

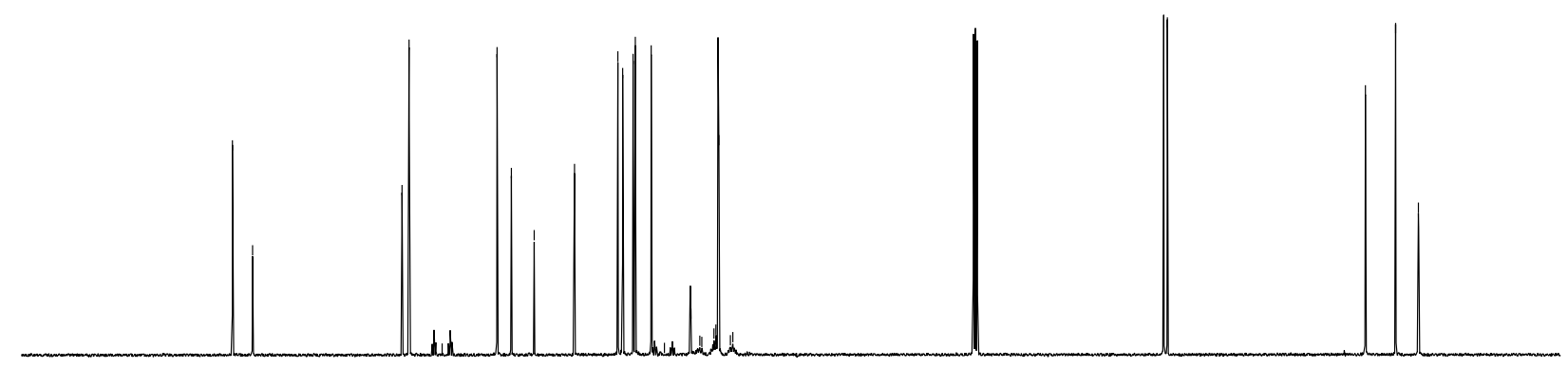

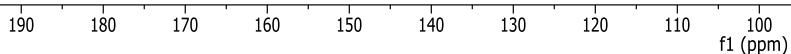




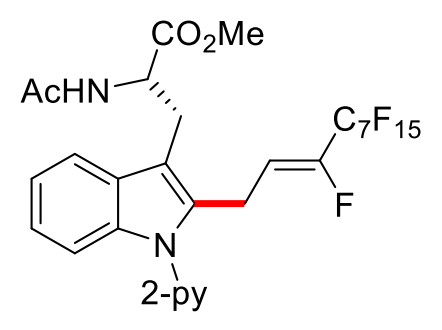

i

329aa

$\left(470 \mathrm{MHz}, \mathrm{CDCl}_{3}\right)$

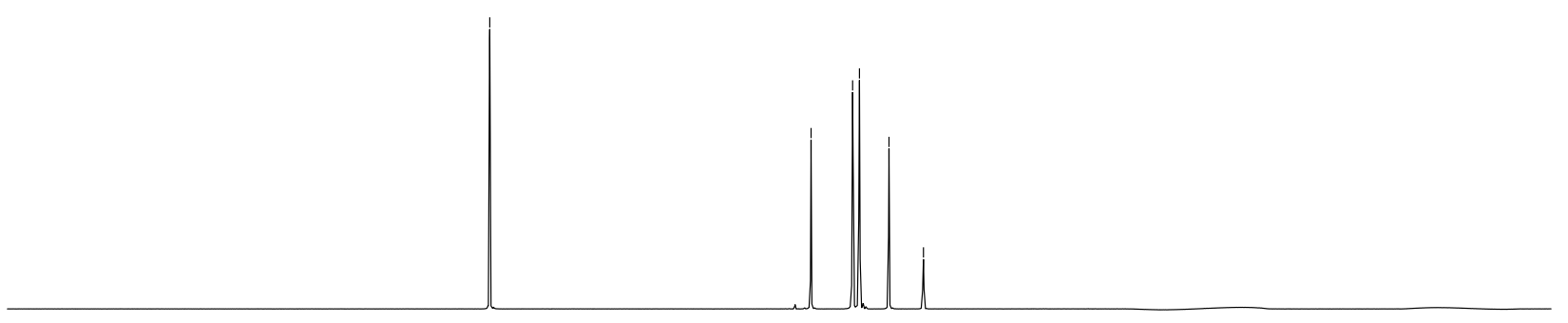

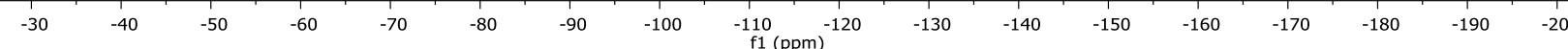


S S, $\int$<smiles>O=C(OCc1ccccc1)C(Cc1c(CC=C(F)C(F)F)n([Ga])c2ccccc12)C(F)(F)F</smiles>

329ba

$\left(300 \mathrm{MHz}, \mathrm{CDCl}_{3}\right)$
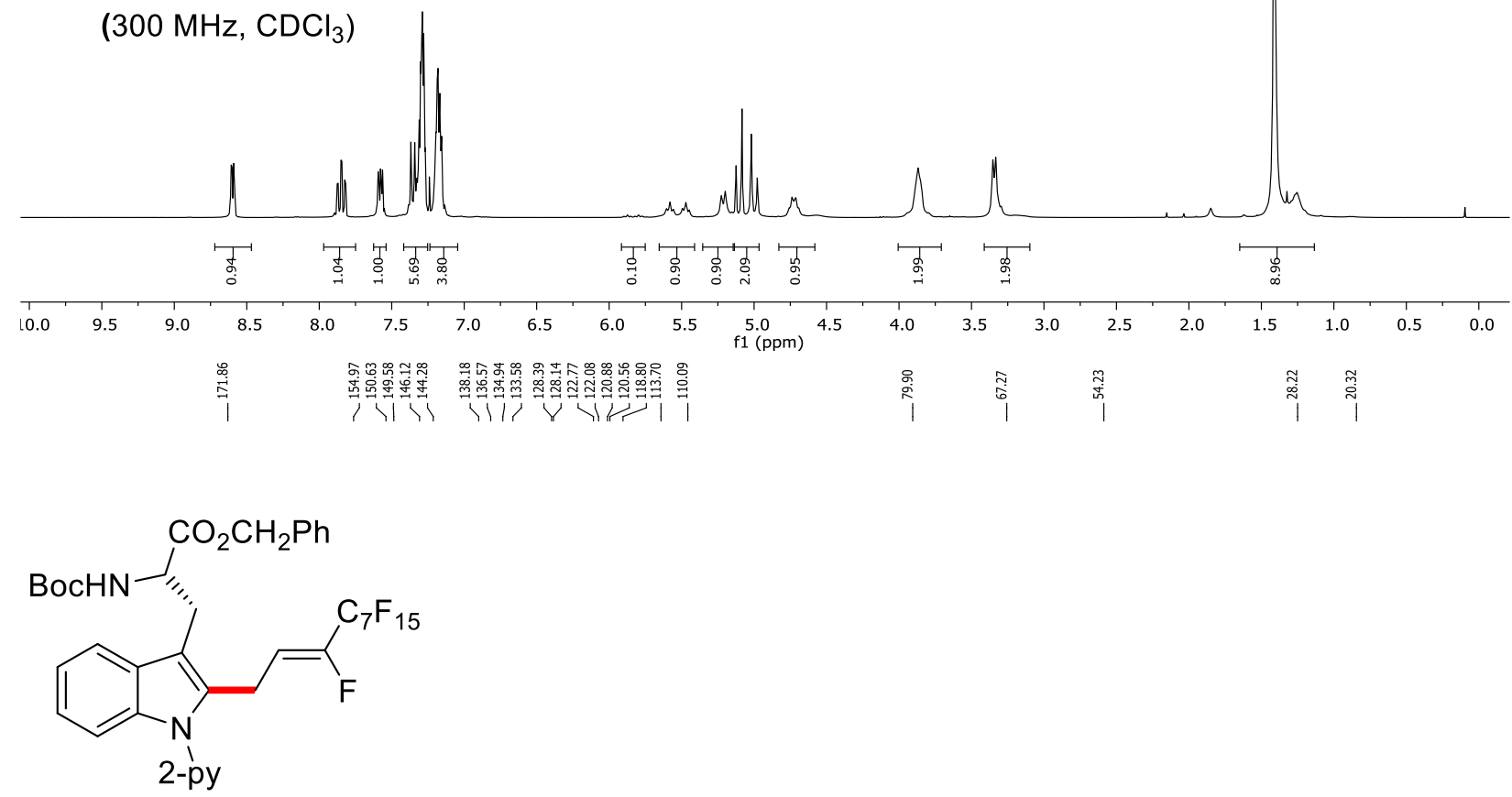

$329 \mathrm{ba}$

(125 MHz, $\mathrm{CDCl}_{3}$ )

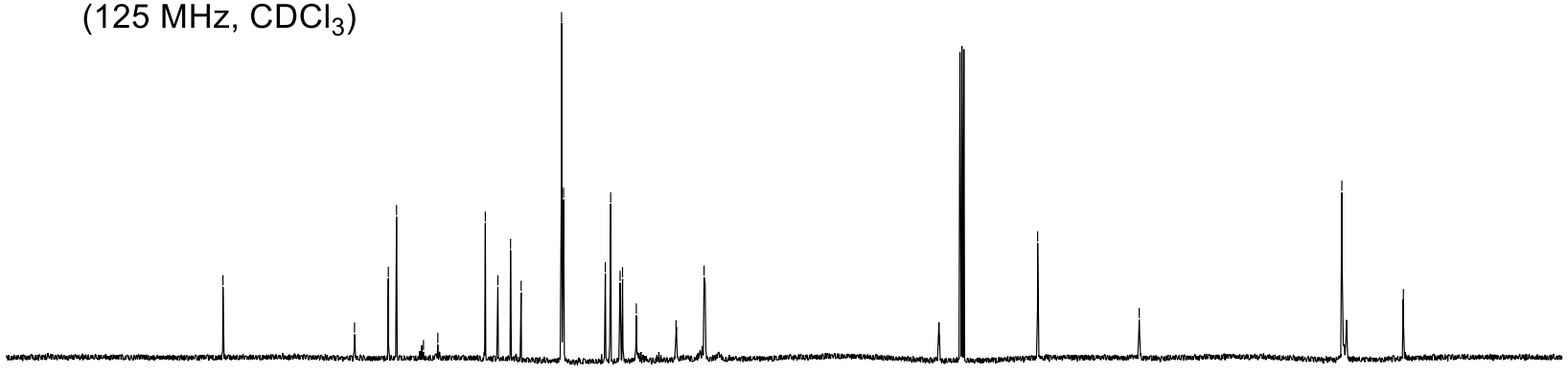

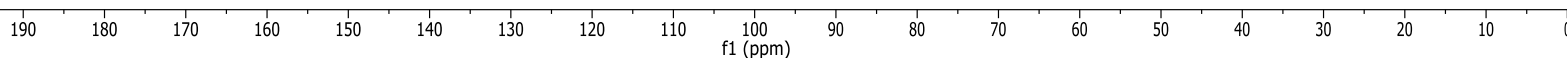



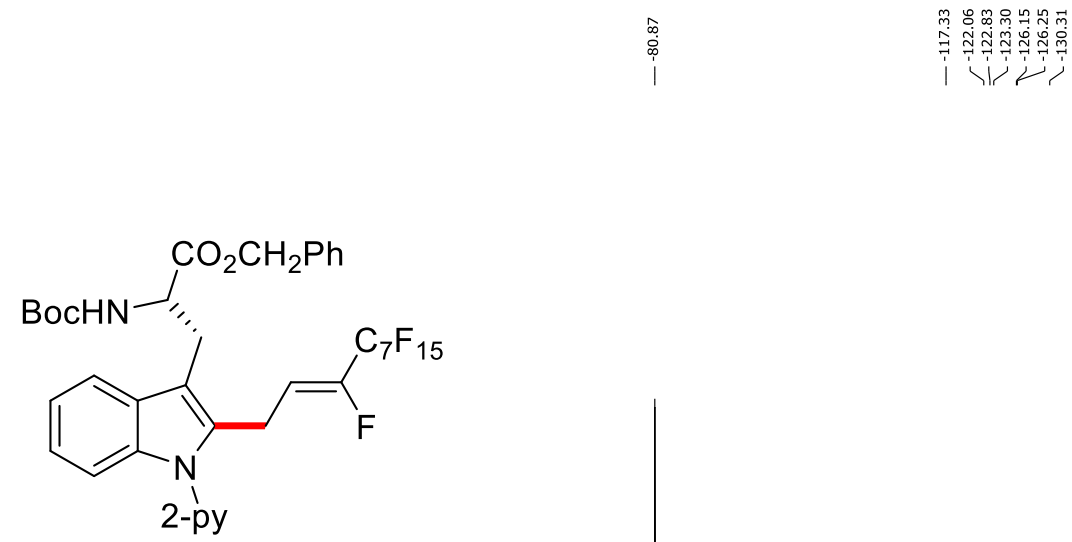

329ba

(470 MHz, $\mathrm{CDCl}_{3}$ )

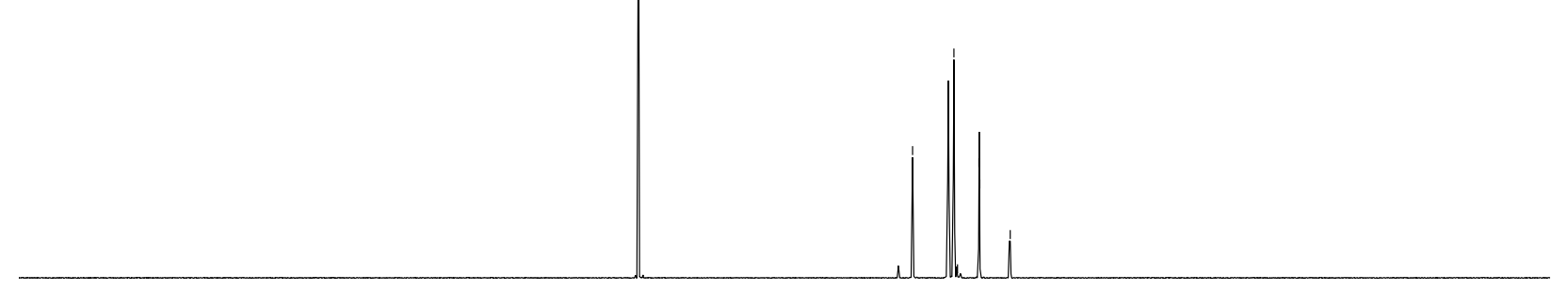

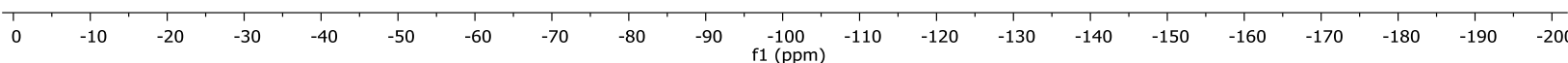




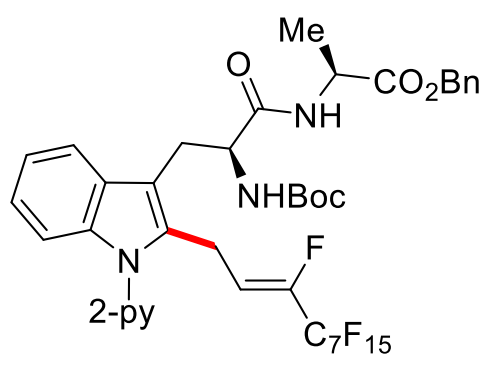

$329 \mathrm{ca}$

$\left(400 \mathrm{MHz}, \mathrm{CDCl}_{3}\right)$
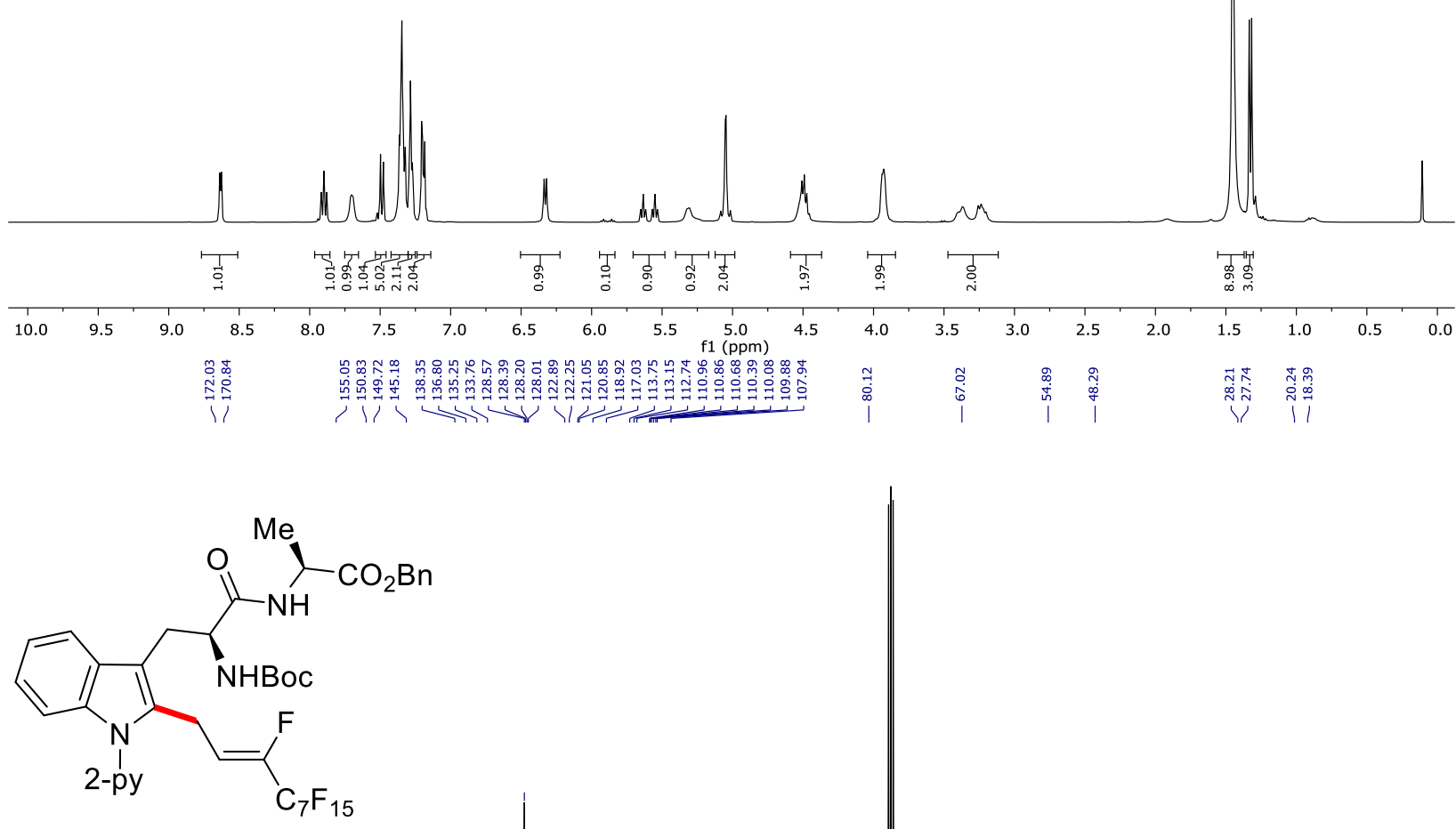

329ca

$\left(100 \mathrm{MHz}^{\mathrm{CDCl}}\right)_{3}$

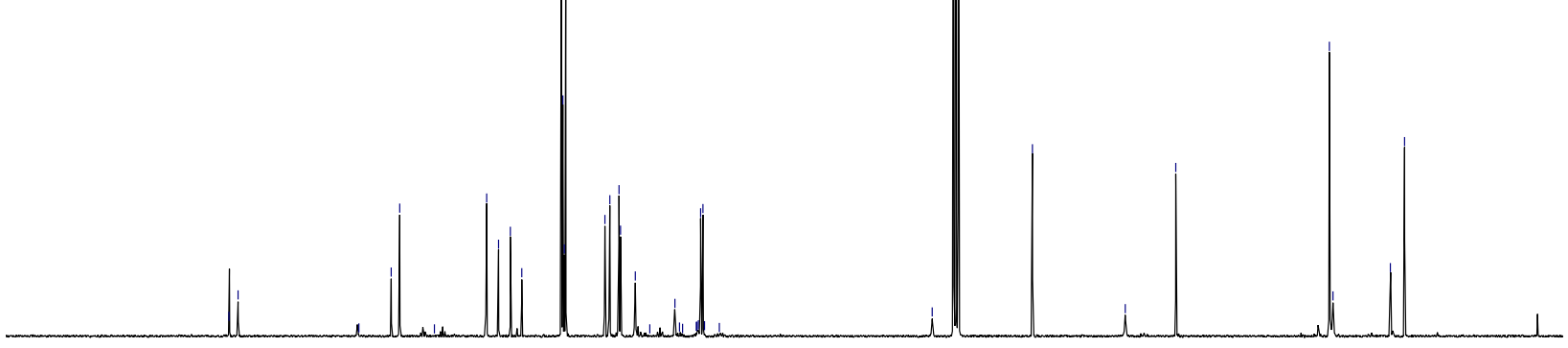

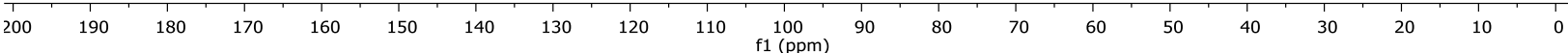



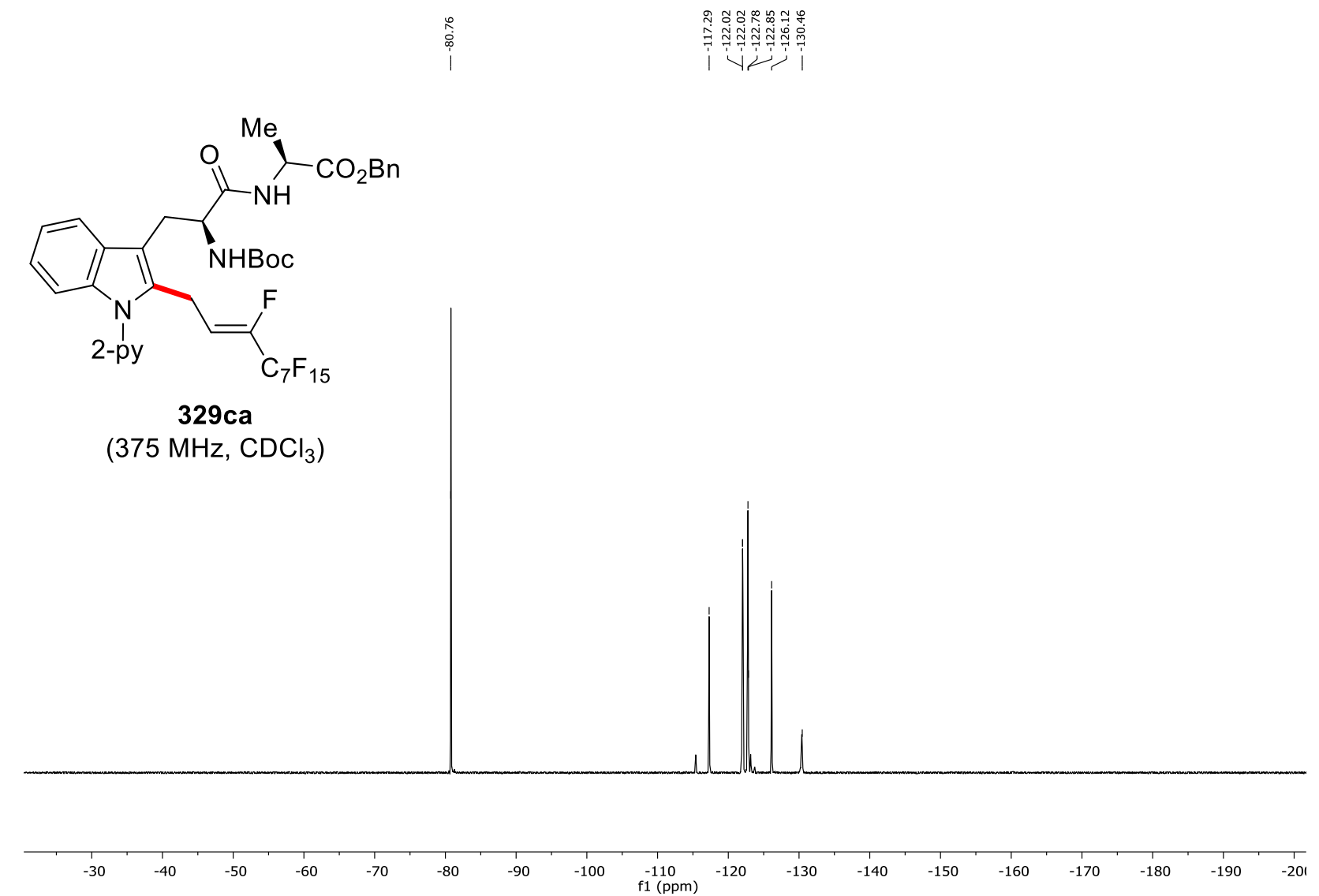


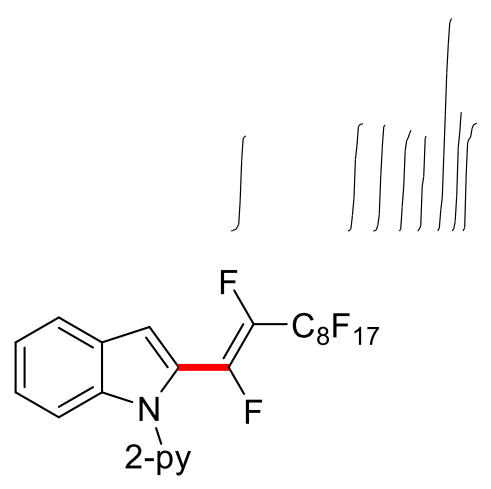

$330 a a$

$\left(500 \mathrm{MHz} \mathrm{CDCl}_{3}\right)$
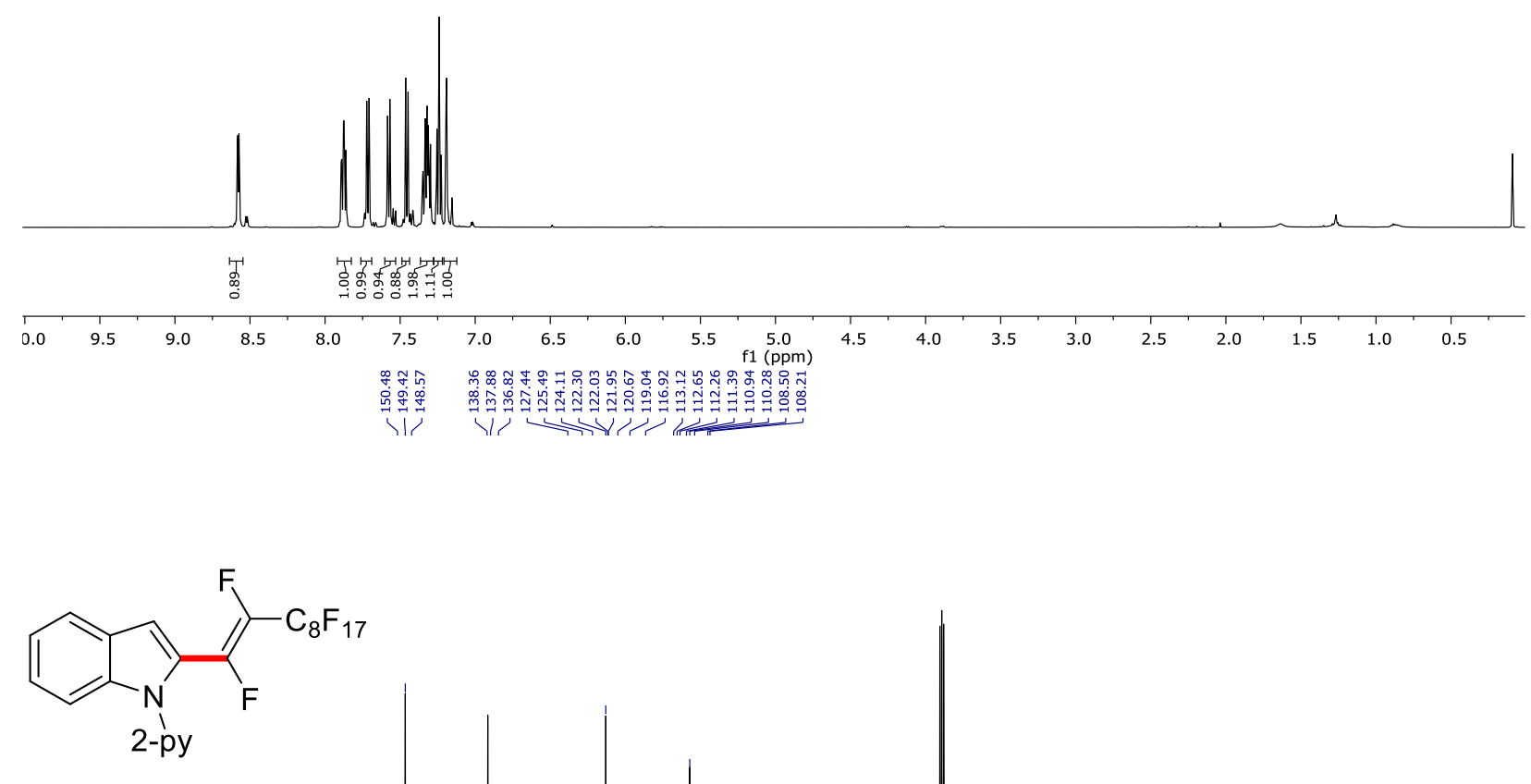

330aa

$\left(125 \mathrm{MHz}^{\mathrm{CDCl}}\right)_{3}$

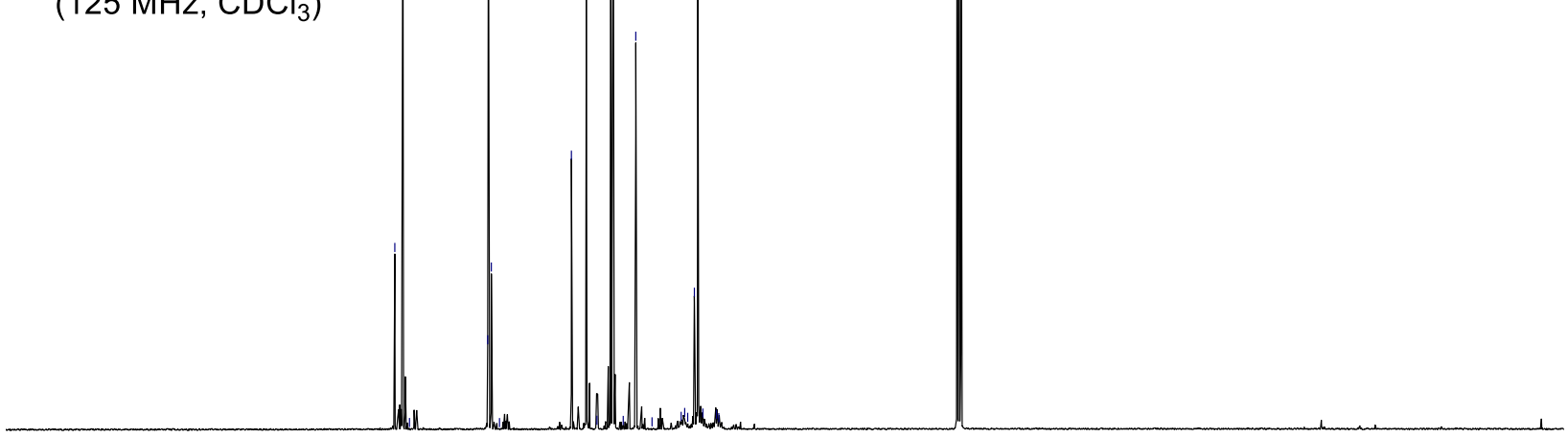

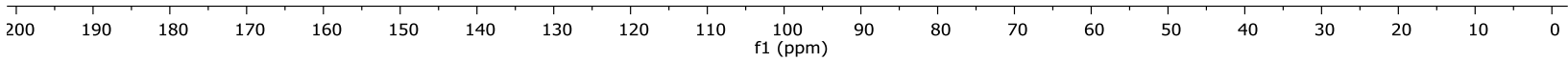



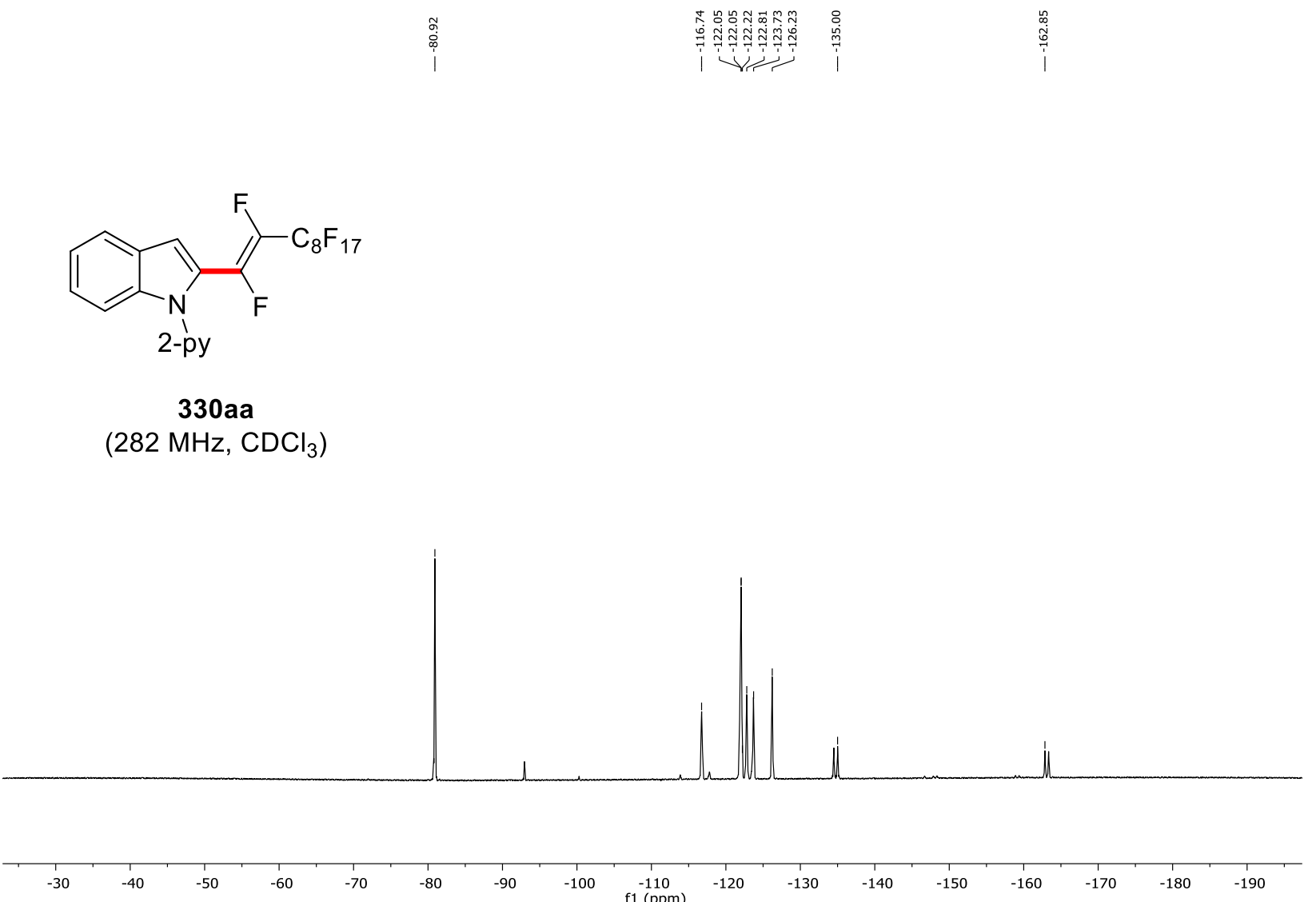


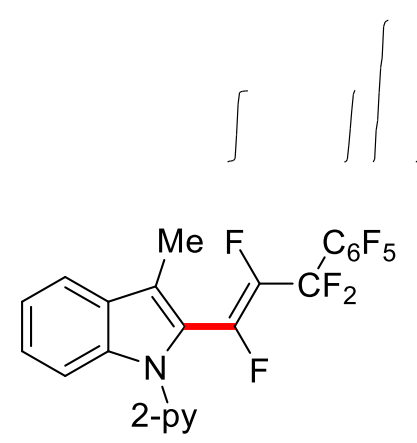

$330 \mathrm{eb}$

(500 MHz, $\mathrm{CDCl}_{3}$ )
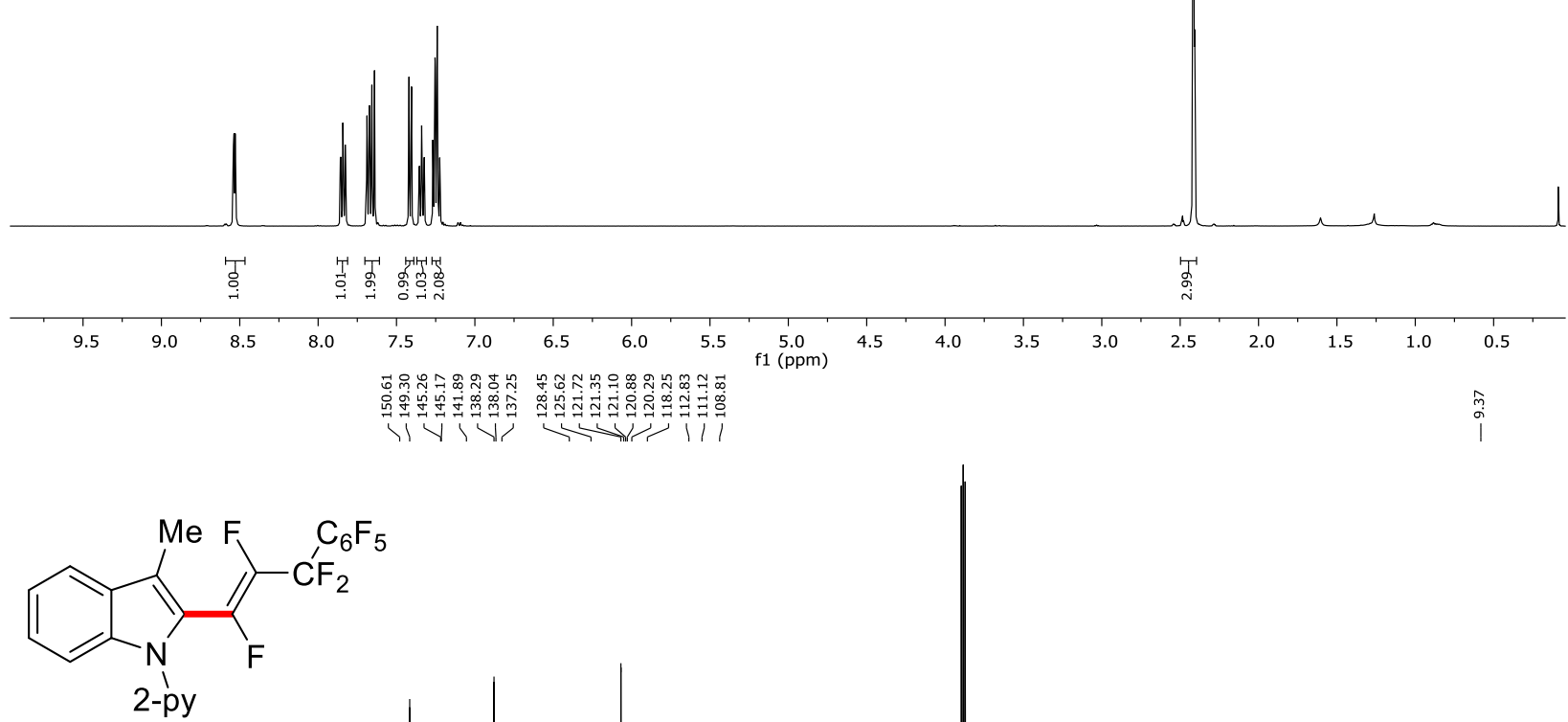

$330 \mathrm{eb}$

$\left(125 \mathrm{MHz} \mathrm{CDCl}_{3}\right)$

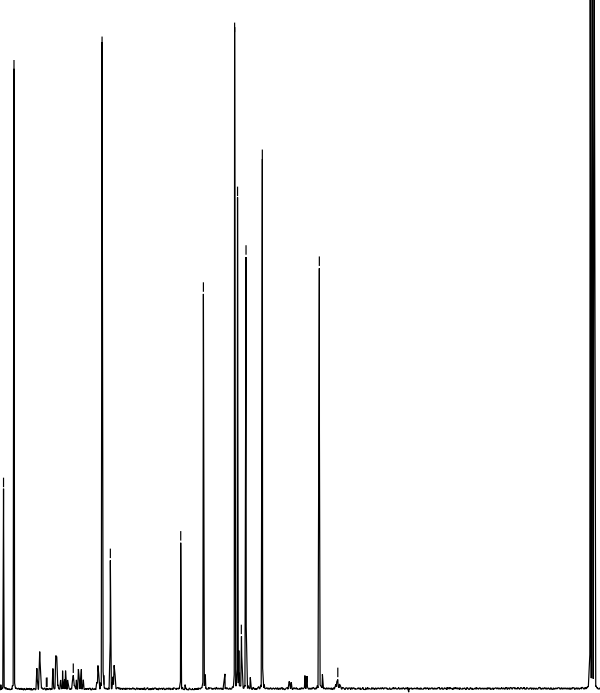

200

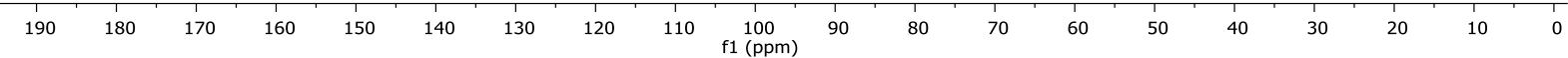



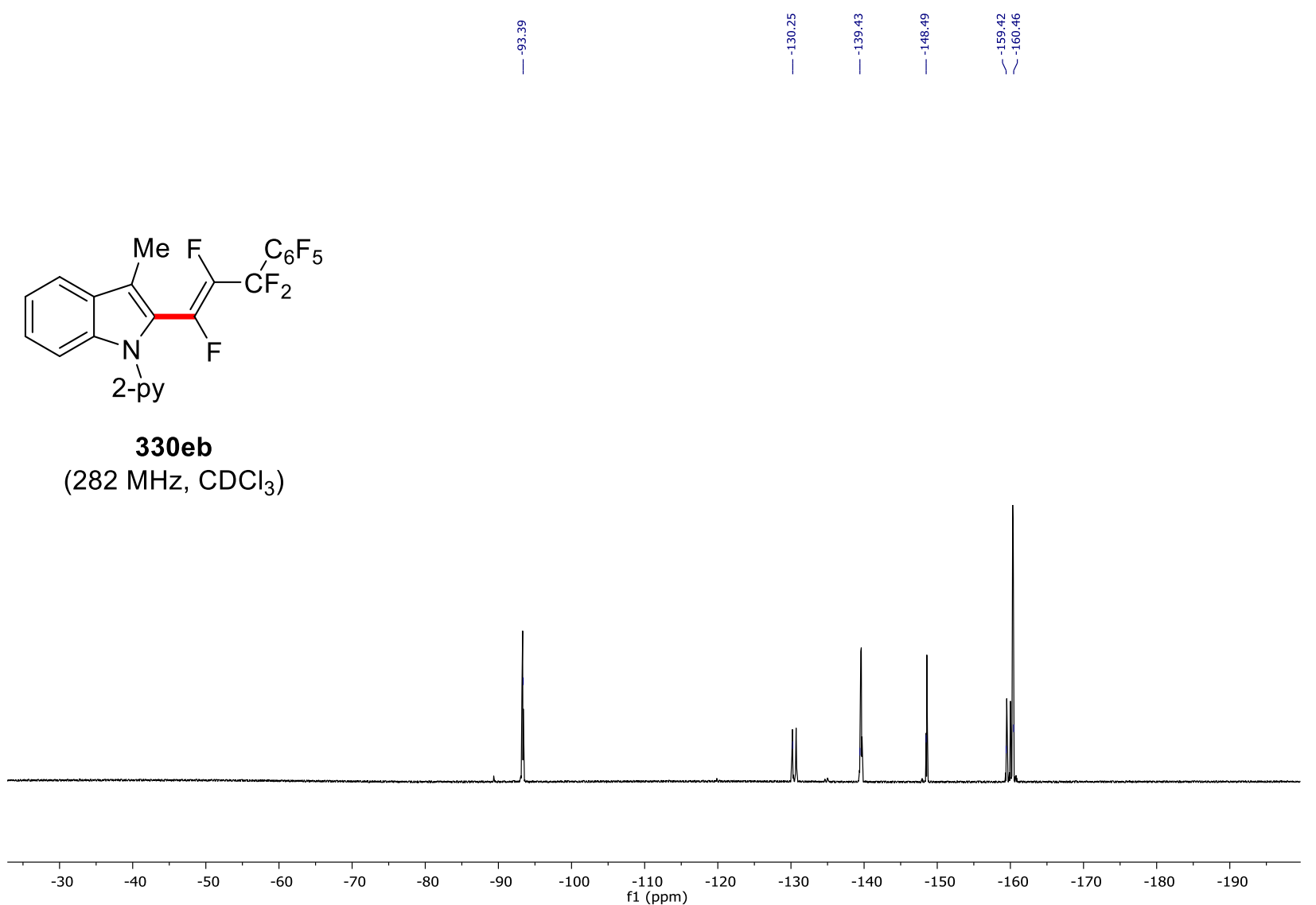


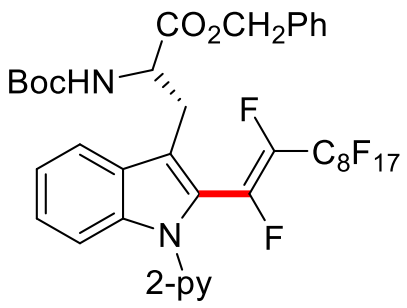

$331 \mathrm{bc}$

(400 $\mathrm{MHz}, \mathrm{CDCl}_{3}$ )

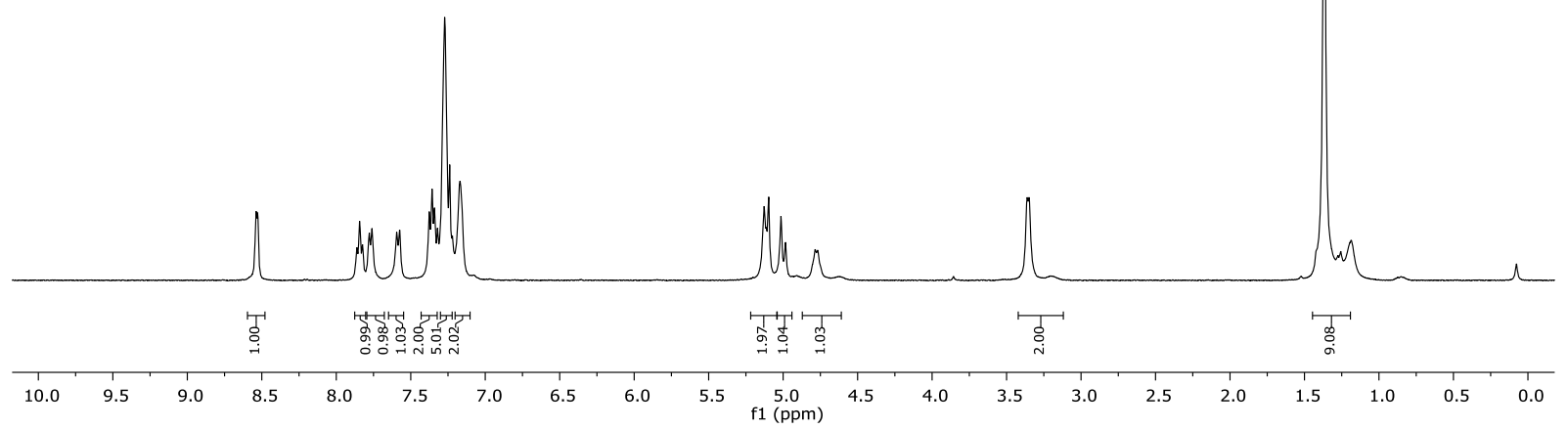

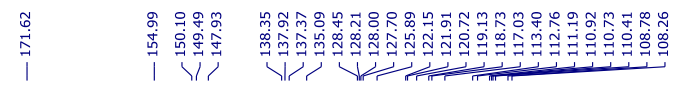
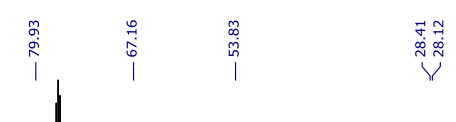

(-py)
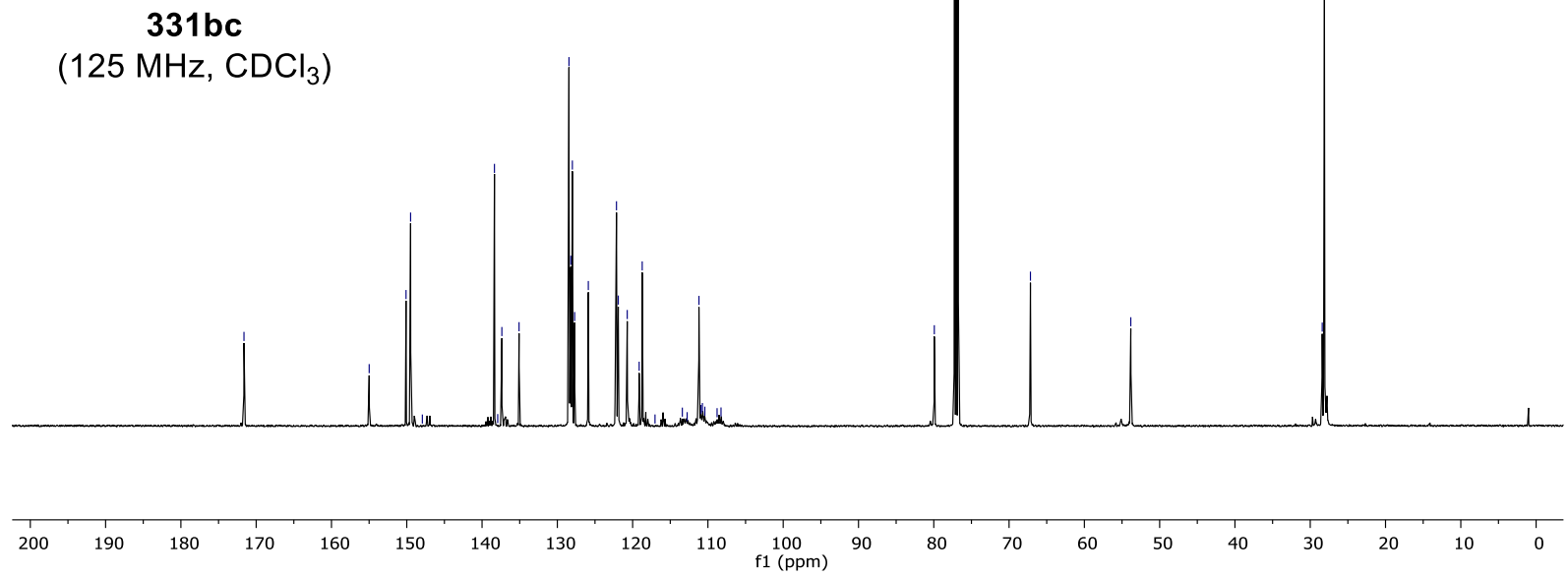

375 

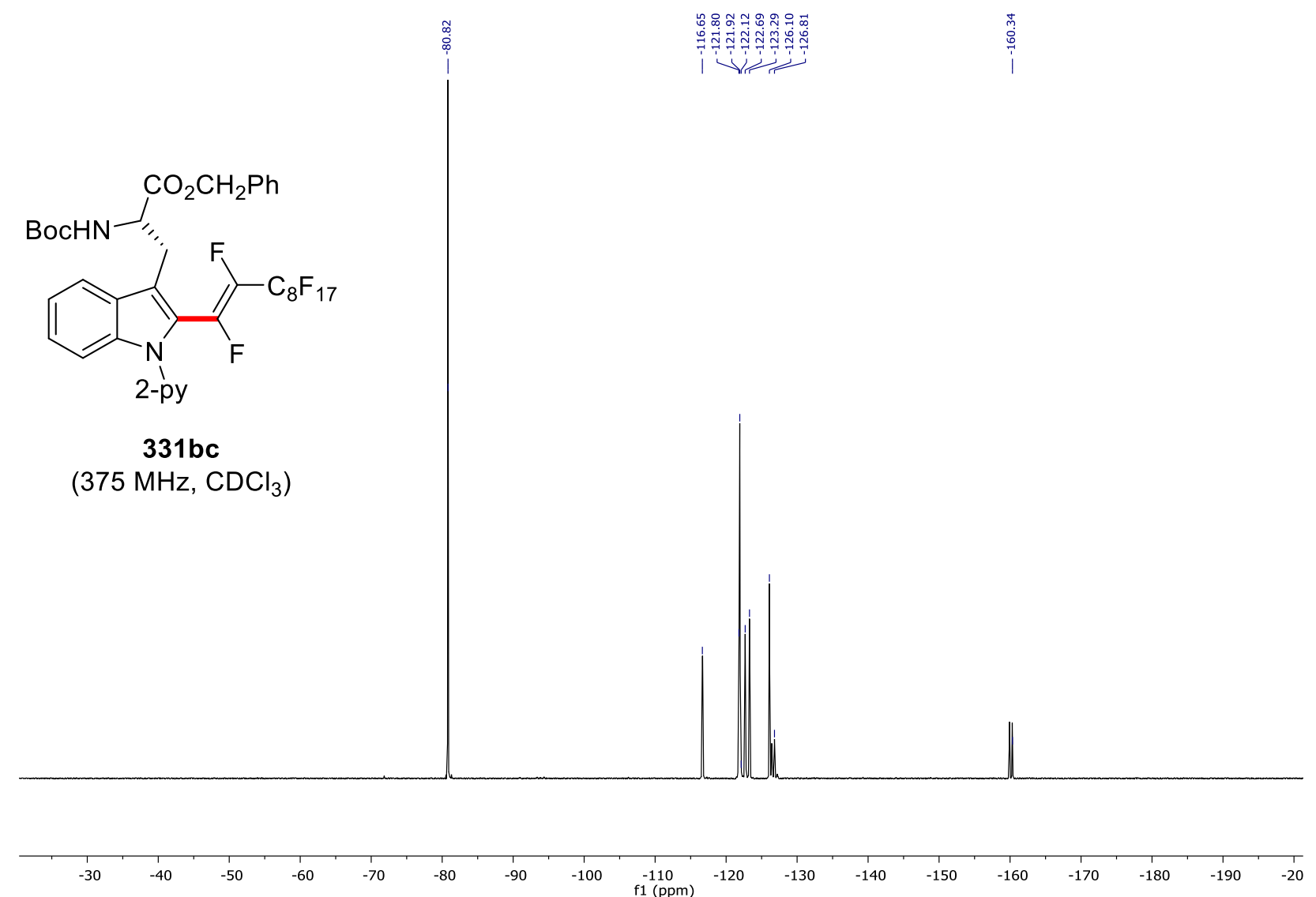

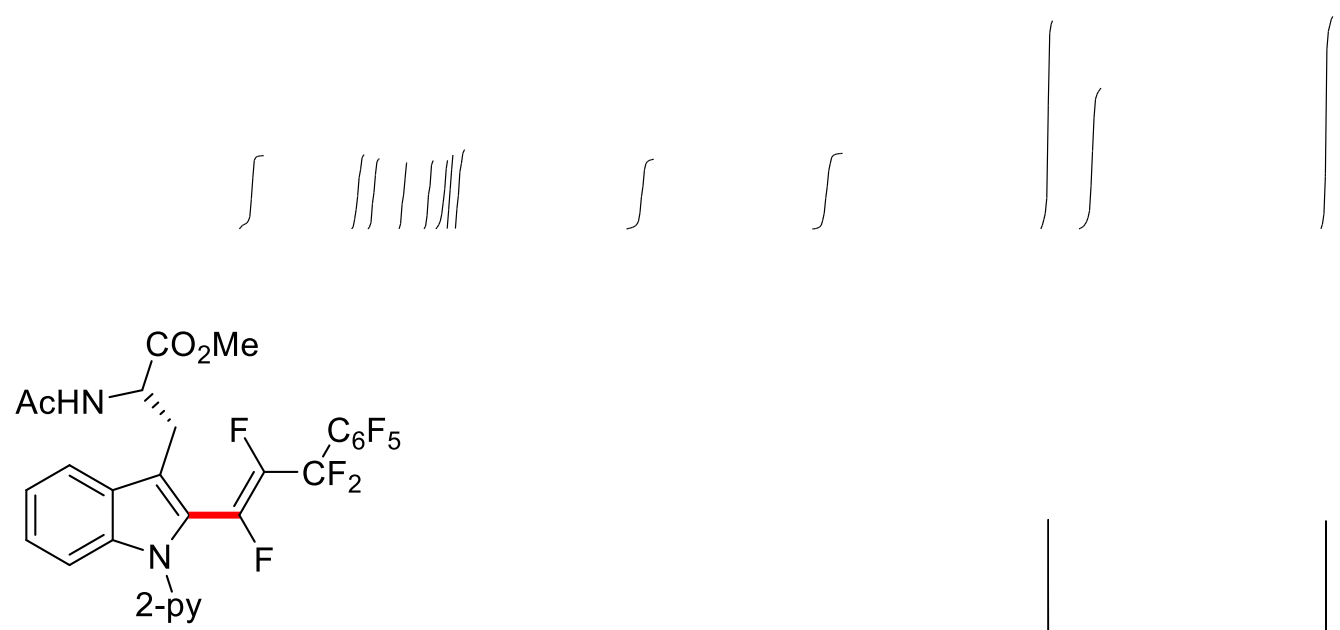

$331 \mathrm{ab}$

$\left(400 \mathrm{MHz}, \mathrm{CDCl}_{3}\right)$

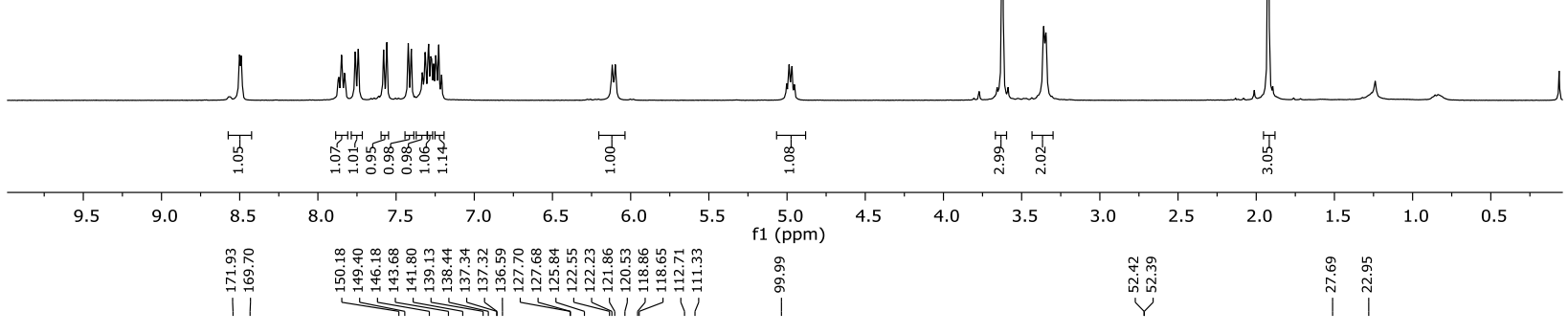

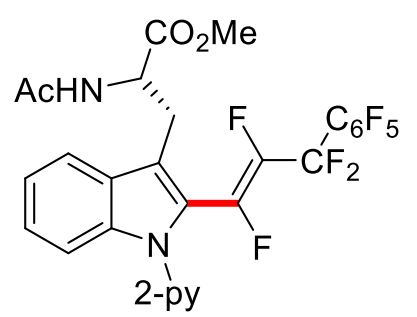

$331 \mathrm{ab}$

$\left(100 \mathrm{MHz}, \mathrm{CDCl}_{3}\right)$

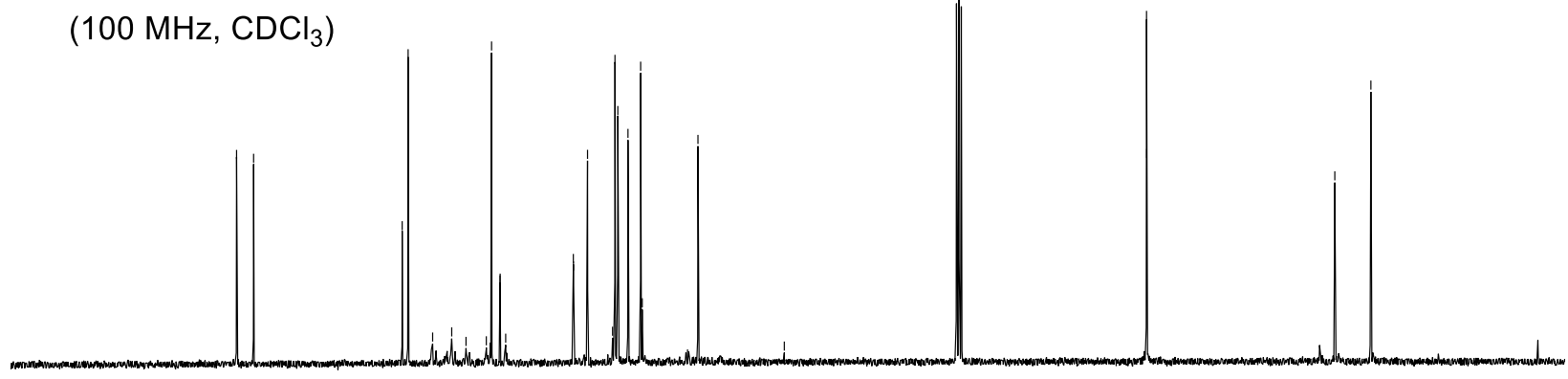

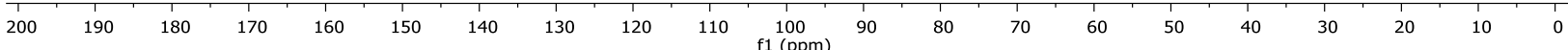




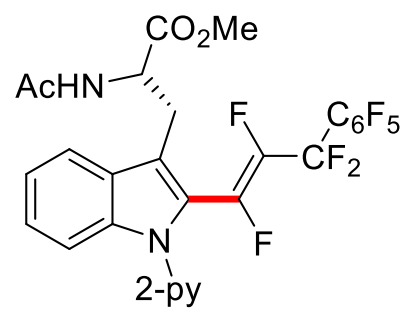

$331 \mathrm{ab}$

(375 MHz, $\mathrm{CDCl}_{3}$ )

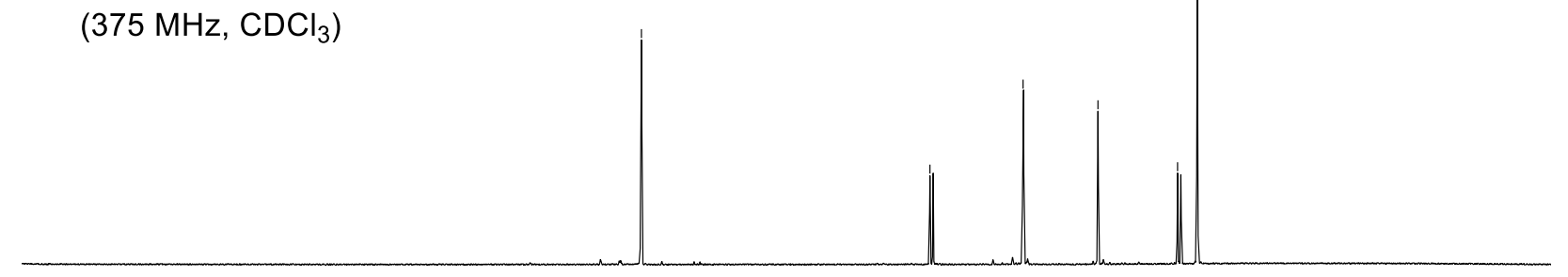



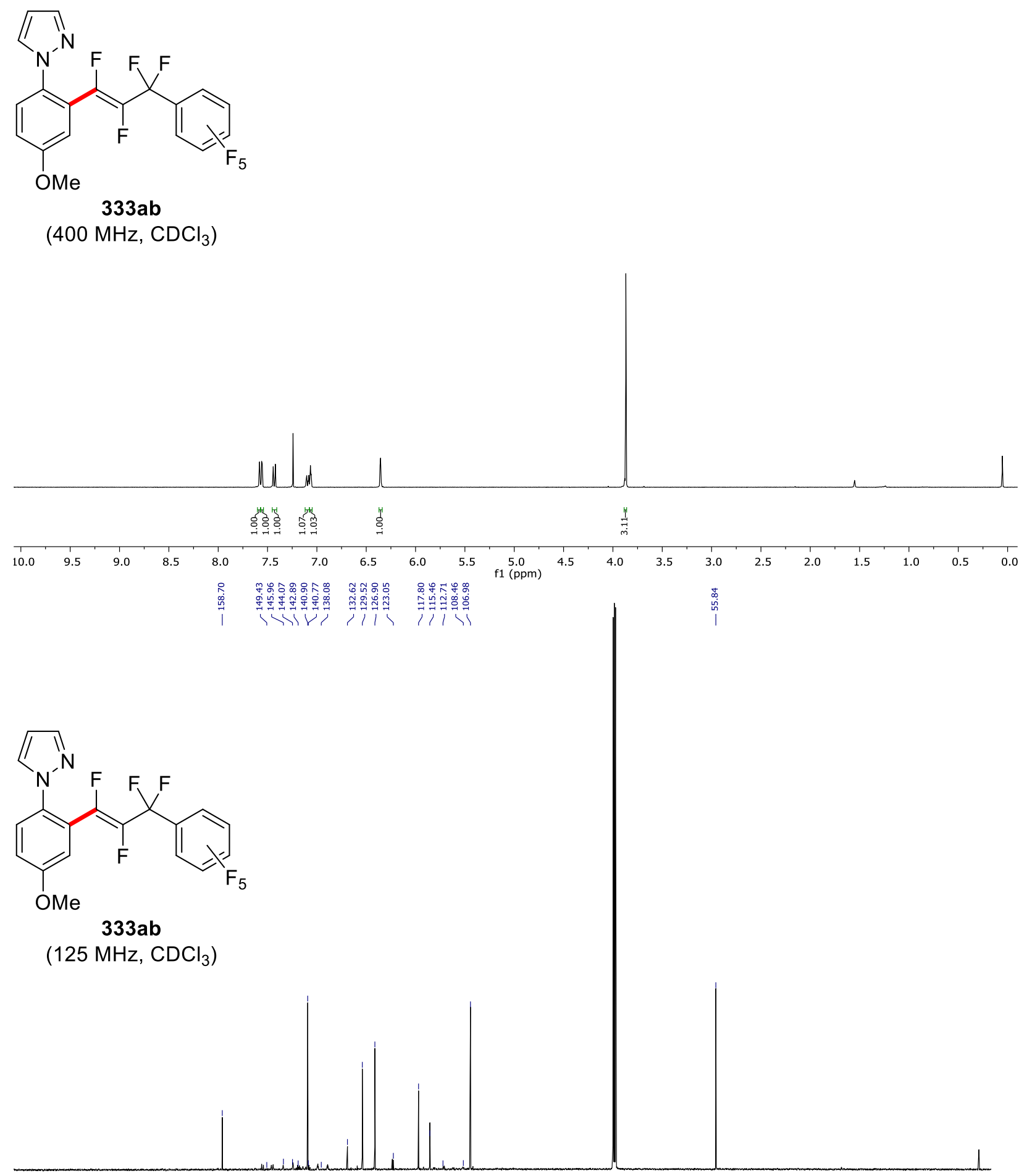

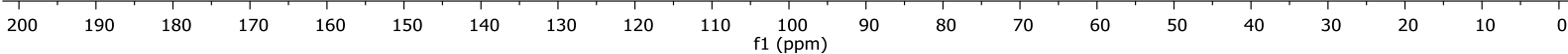




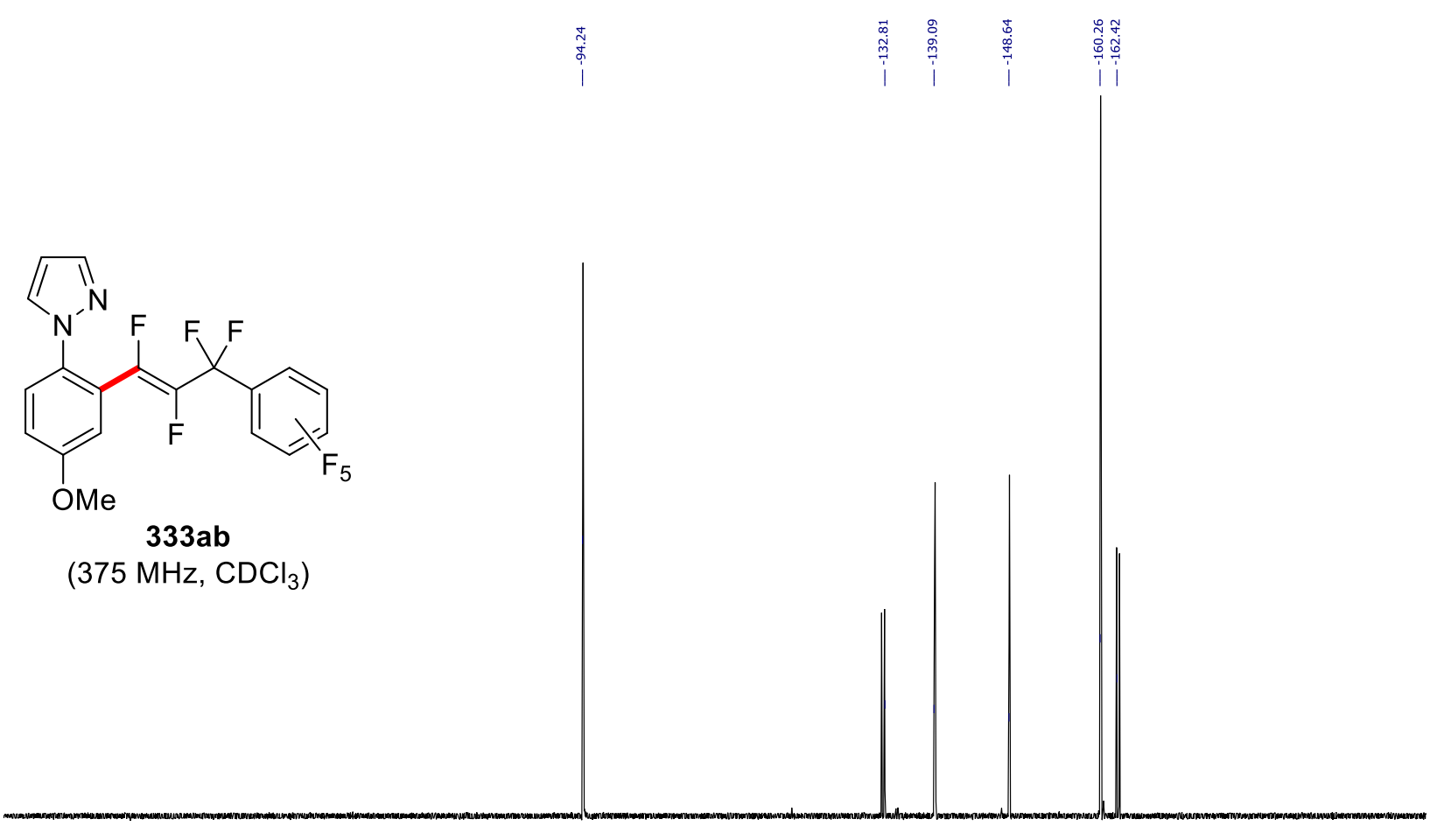




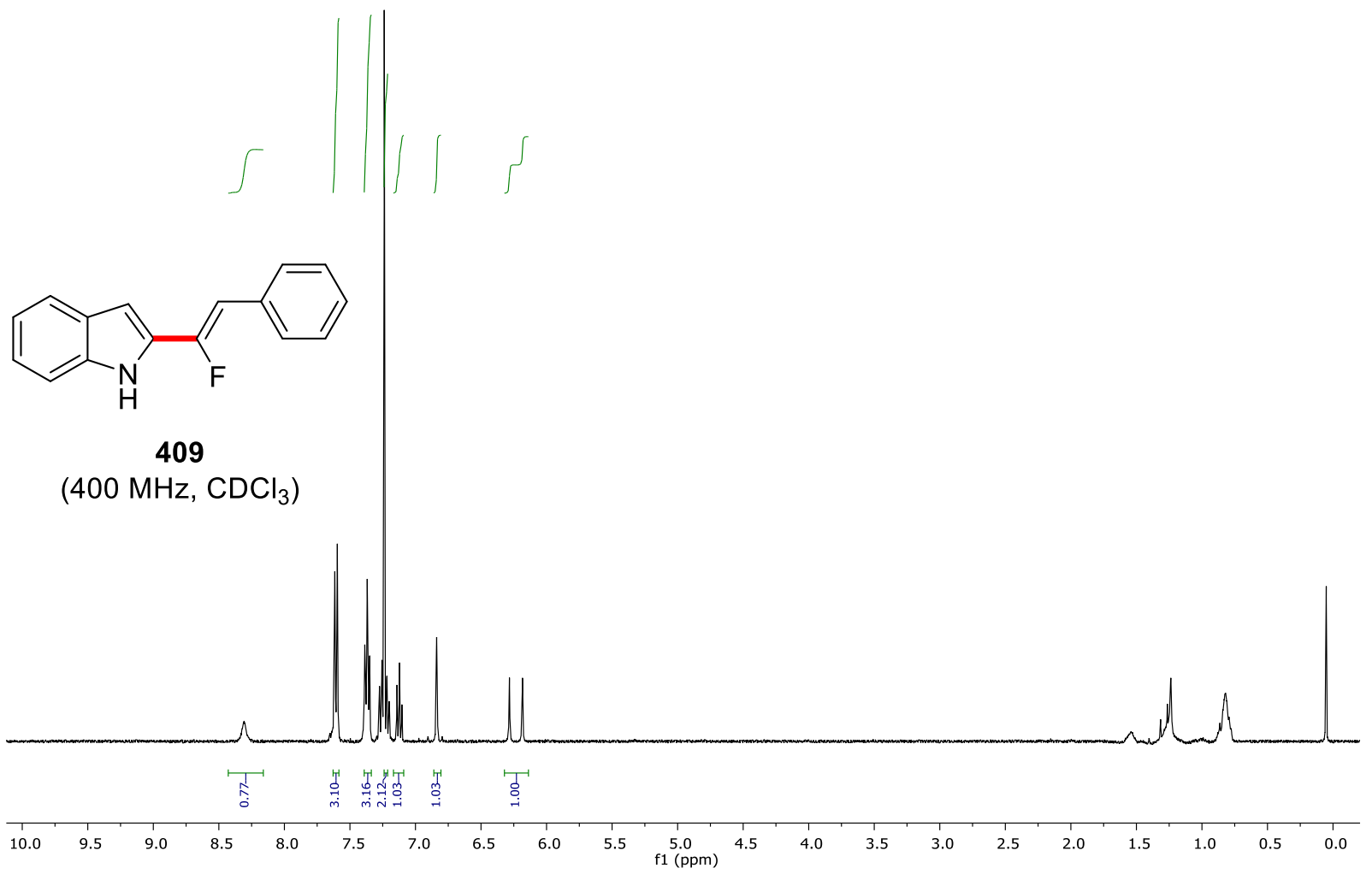

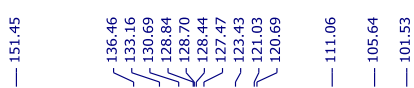

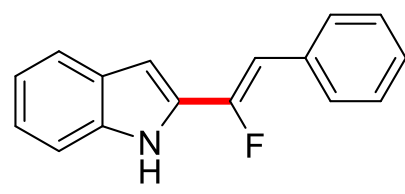

409

$\left(100 \mathrm{MHz}, \mathrm{CDCl}_{3}\right.$ )
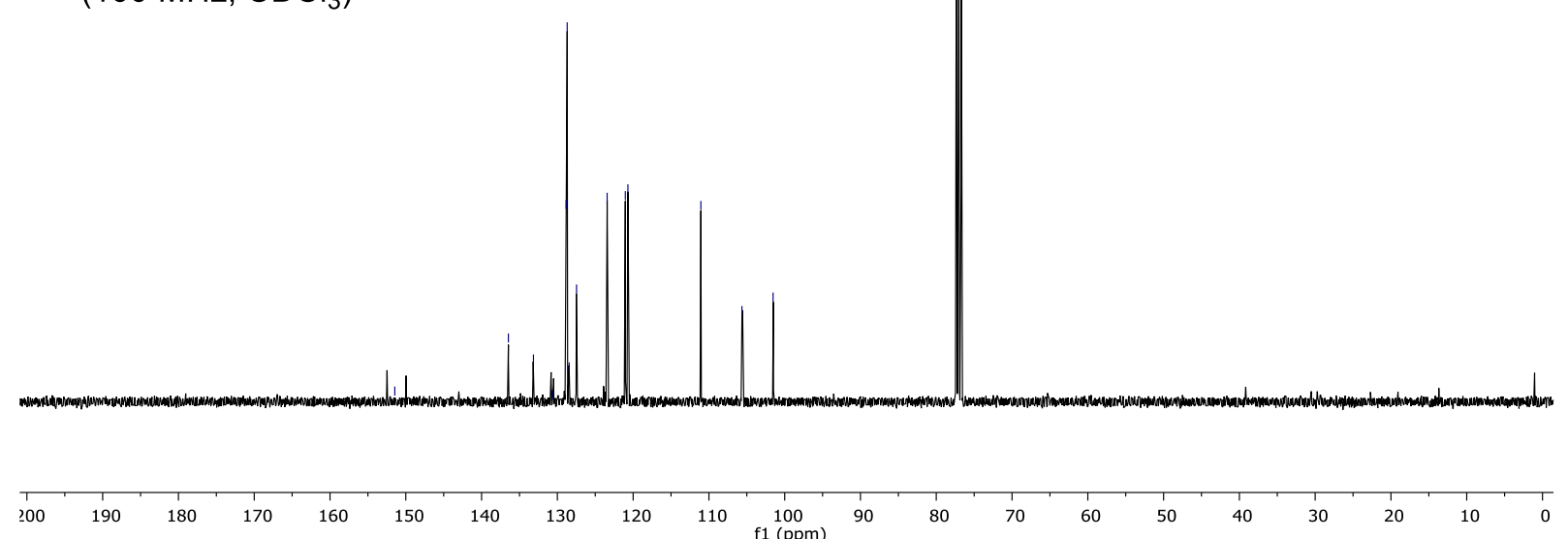


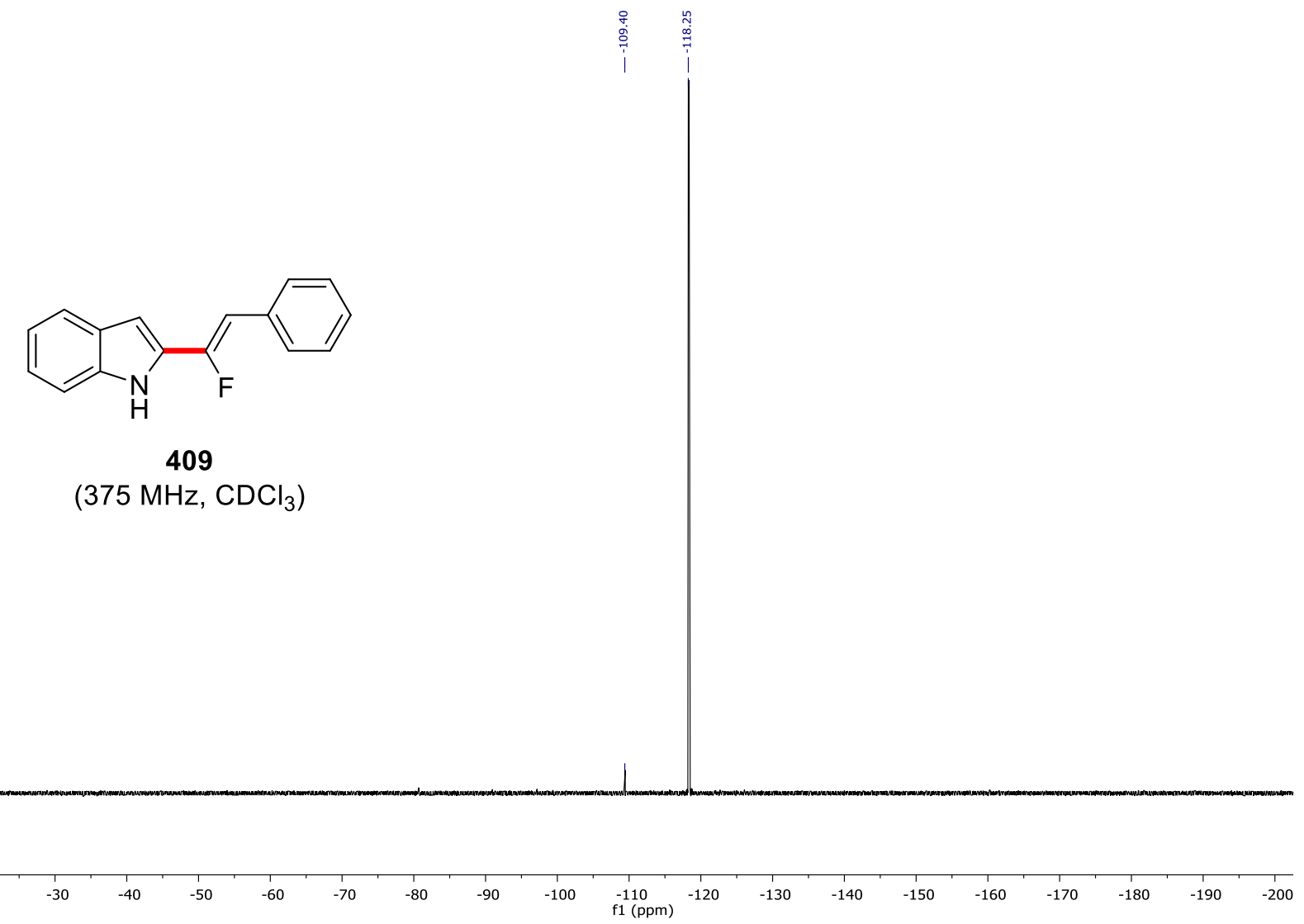




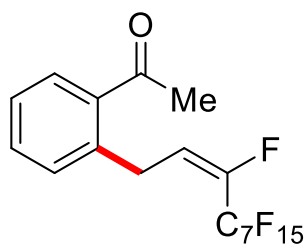

307 aa

(300 MHz, $\mathrm{CDCl}_{3}$ )
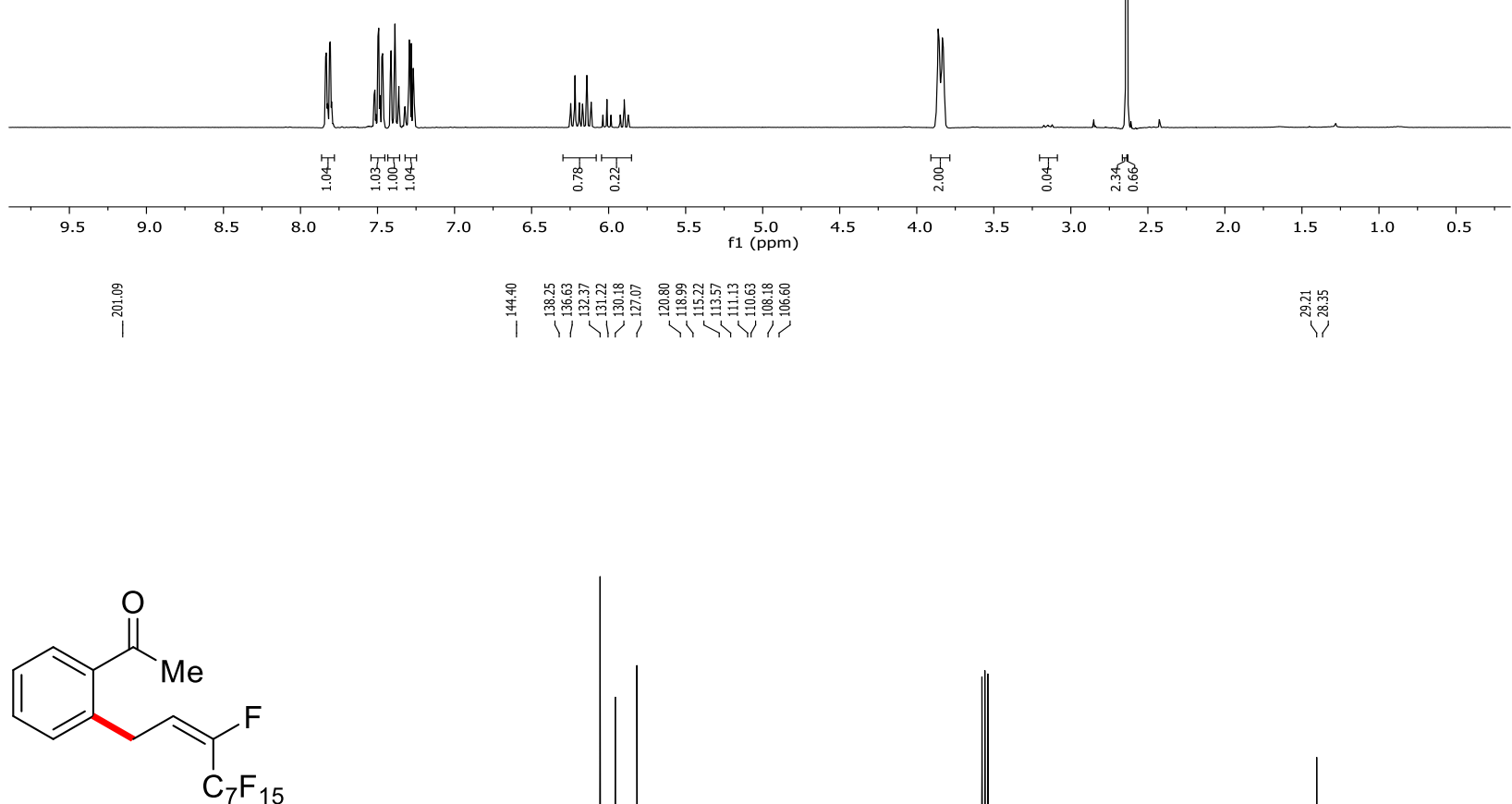

307 aa

$\left(75 \mathrm{MHz}, \mathrm{CDCl}_{3}\right.$ )

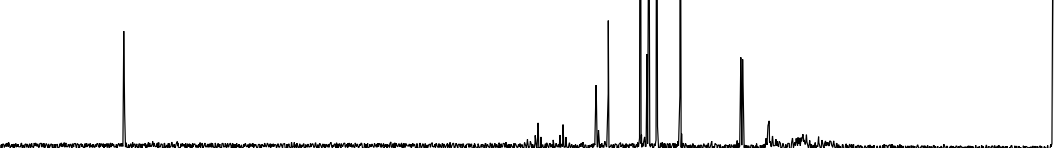

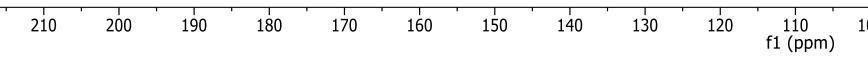




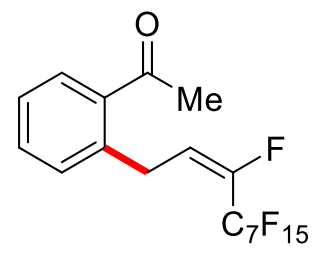

$307 a a$

(282 MHz, $\mathrm{CDCl}_{3}$ )

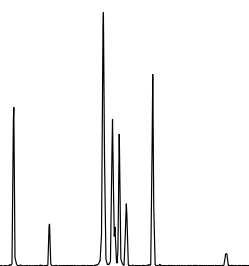


<smiles>CCC(=O)c1ccccc1C/C=C(/F)C(F)(F)C(F)(F)C(F)(F)C(F)(F)C(F)(F)C(F)(F)F</smiles>

$307 \mathrm{ba}$

$\left(300 \mathrm{MHz}, \mathrm{CDCl}_{3}\right)$

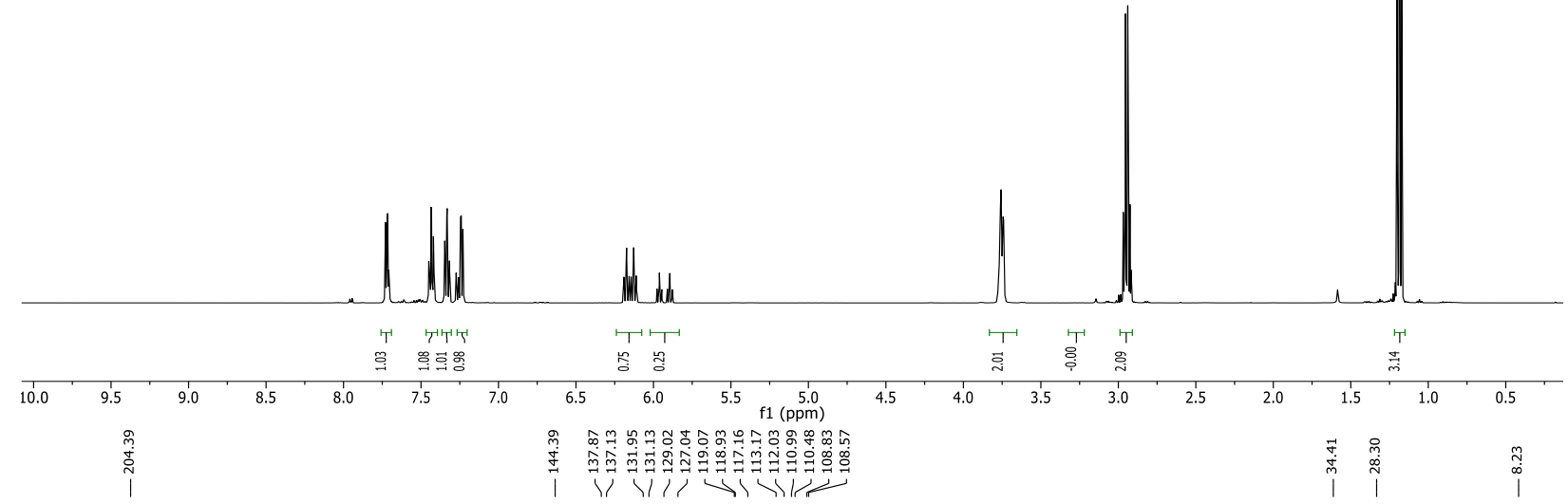<smiles>CCC(=O)c1ccccc1C/C=C(/F)C(F)(F)C(F)(F)F</smiles>

$307 \mathrm{ba}$

(125 MHz, $\mathrm{CDCl}_{3}$ )
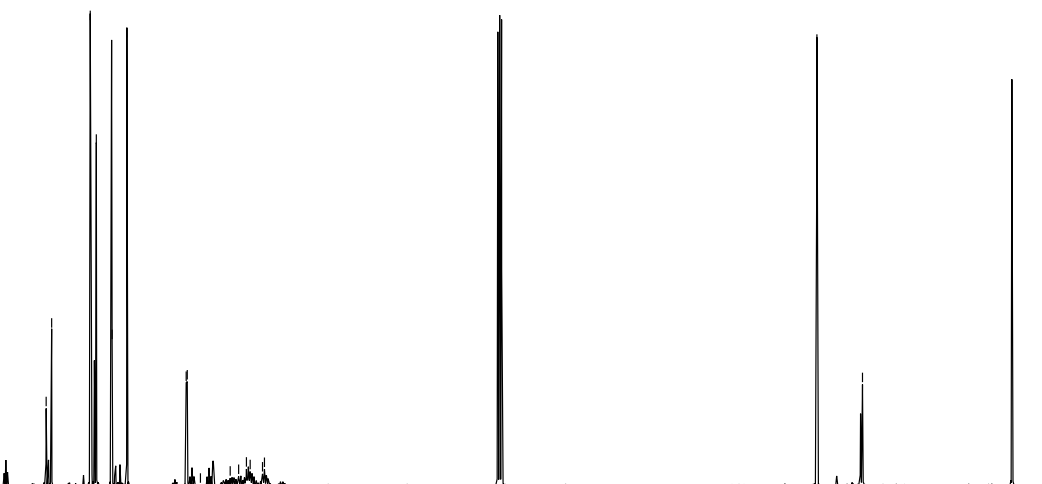

$\begin{array}{llllllllllllllllllllll}210 & 200 & 190 & 180 & 170 & 160 & 150 & 140 & 130 & 120 & 110 & 100 & 90 & 80 & 70 & 60 & 50 & 40 & 30 & 20 & 10\end{array}$ 

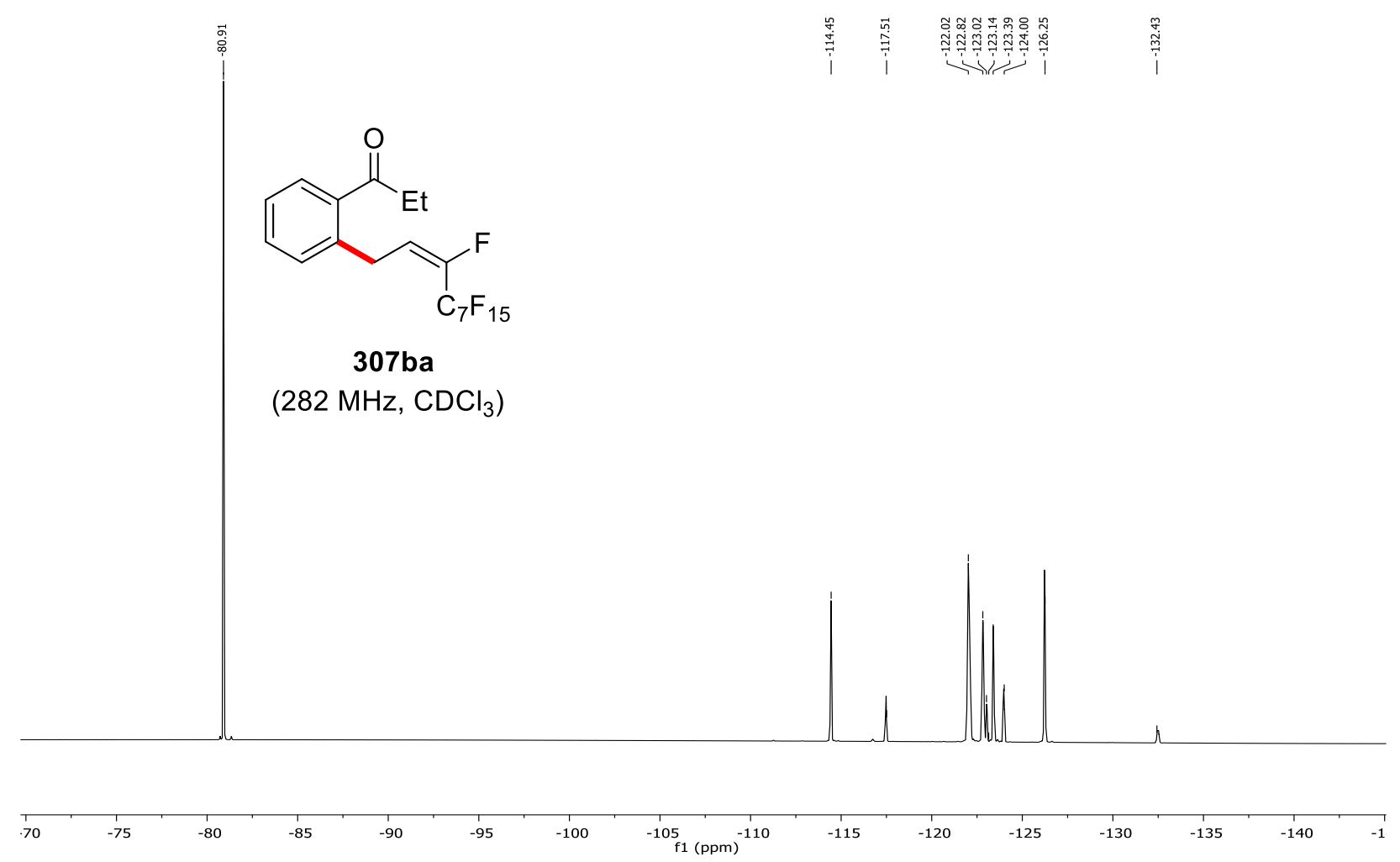
<smiles>CC(=O)c1ccc(C)cc1C/C=C(/F)C(F)(F)C(F)(F)C(F)(F)C(F)(F)C(F)(F)F</smiles>

$307 \mathrm{ca}$

(500 MHz, $\mathrm{CDCl}_{3}$ )

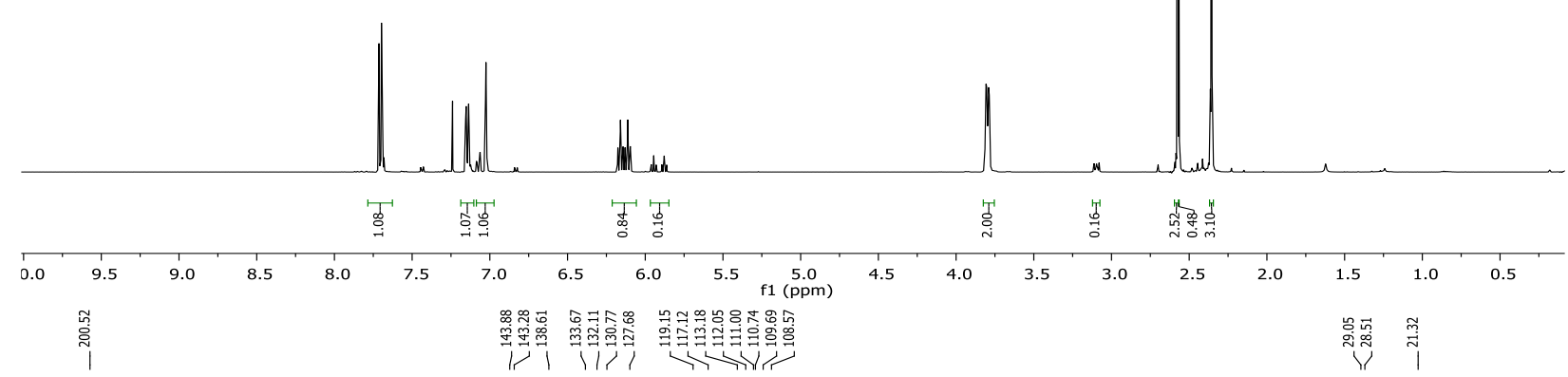<smiles>CC(=O)c1ccc(C)cc1C/C=C(\F)C(F)F</smiles>

$307 \mathrm{ca}$

(125 MHz, $\mathrm{CDCl}_{3}$ )

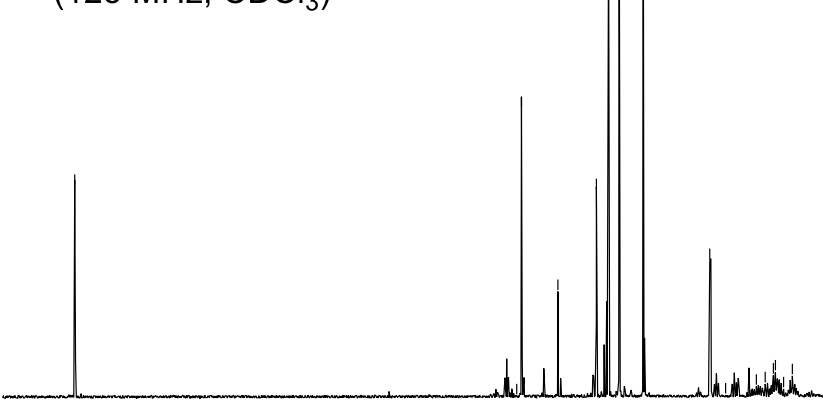

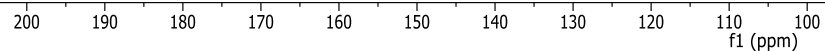




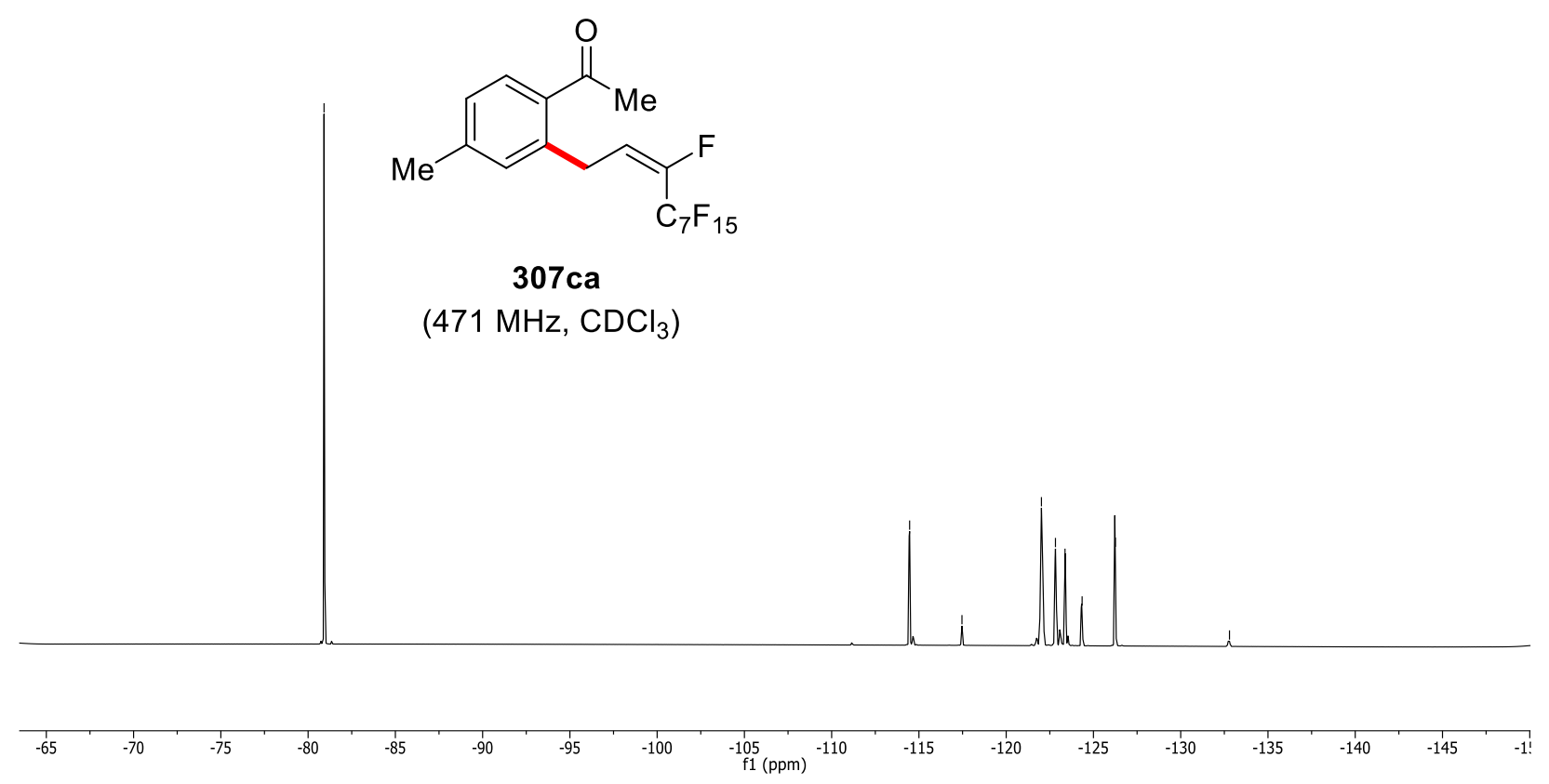


<smiles>CC(=O)c1ccc(-c2ccccc2)cc1C/C=C(/F)C(F)(F)C(F)(F)F</smiles>

307da

(300 MHz, $\mathrm{CDCl}_{3}$ )

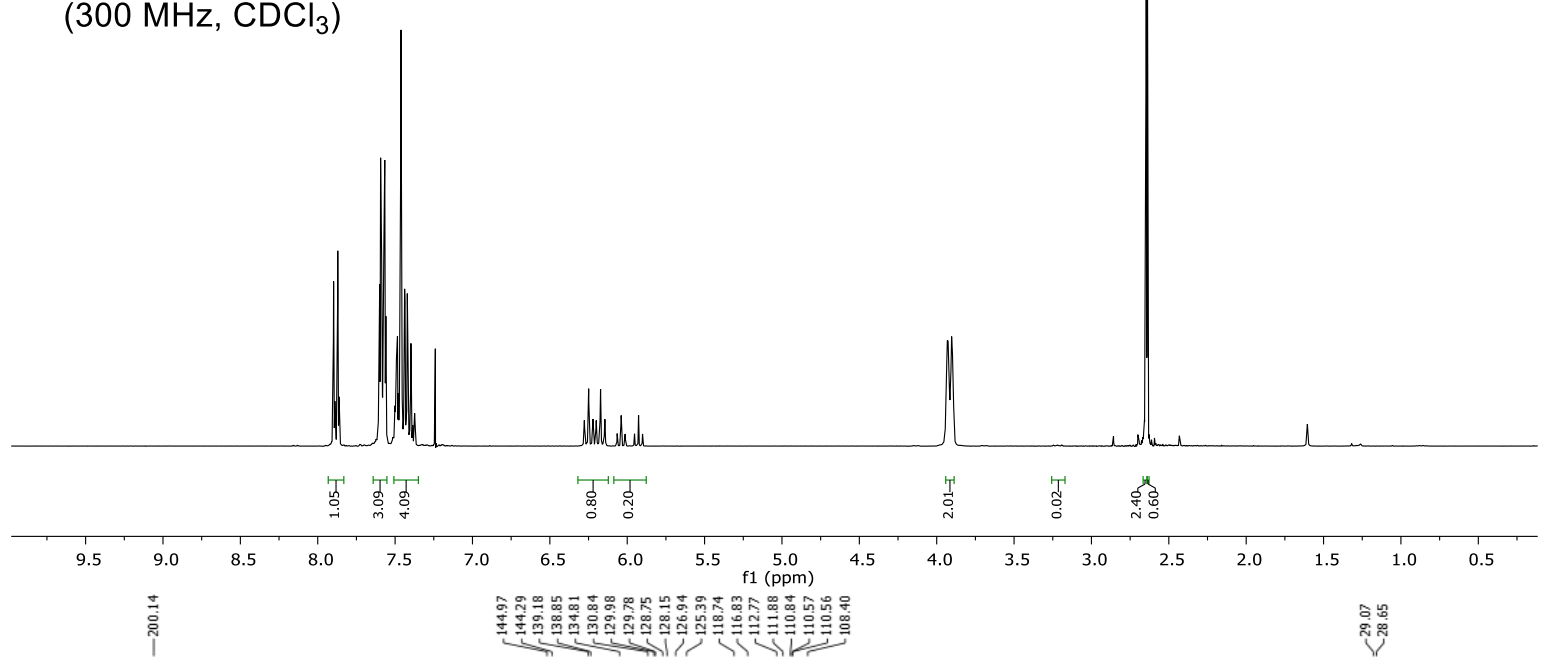<smiles>CC(=O)c1ccc(-c2ccccc2)cc1C/C=C(/F)C(F)(F)C(F)(F)F</smiles>

307da

(125 MHz, $\mathrm{CDCl}_{3}$ )

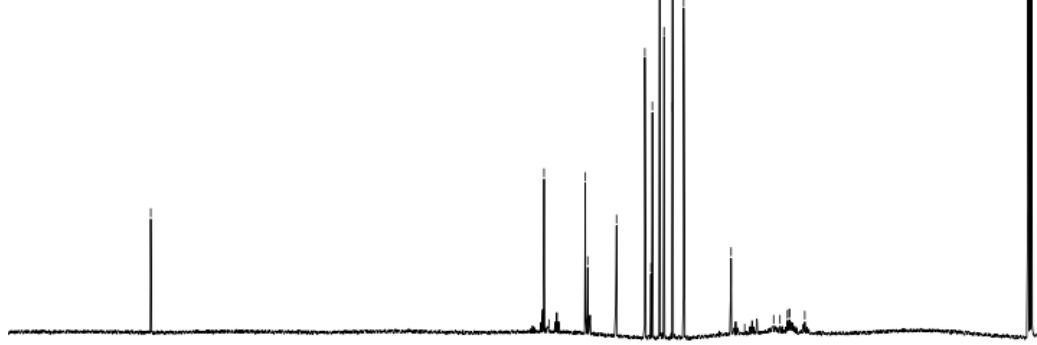

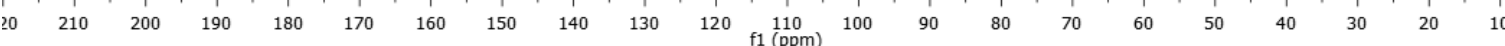


1 1

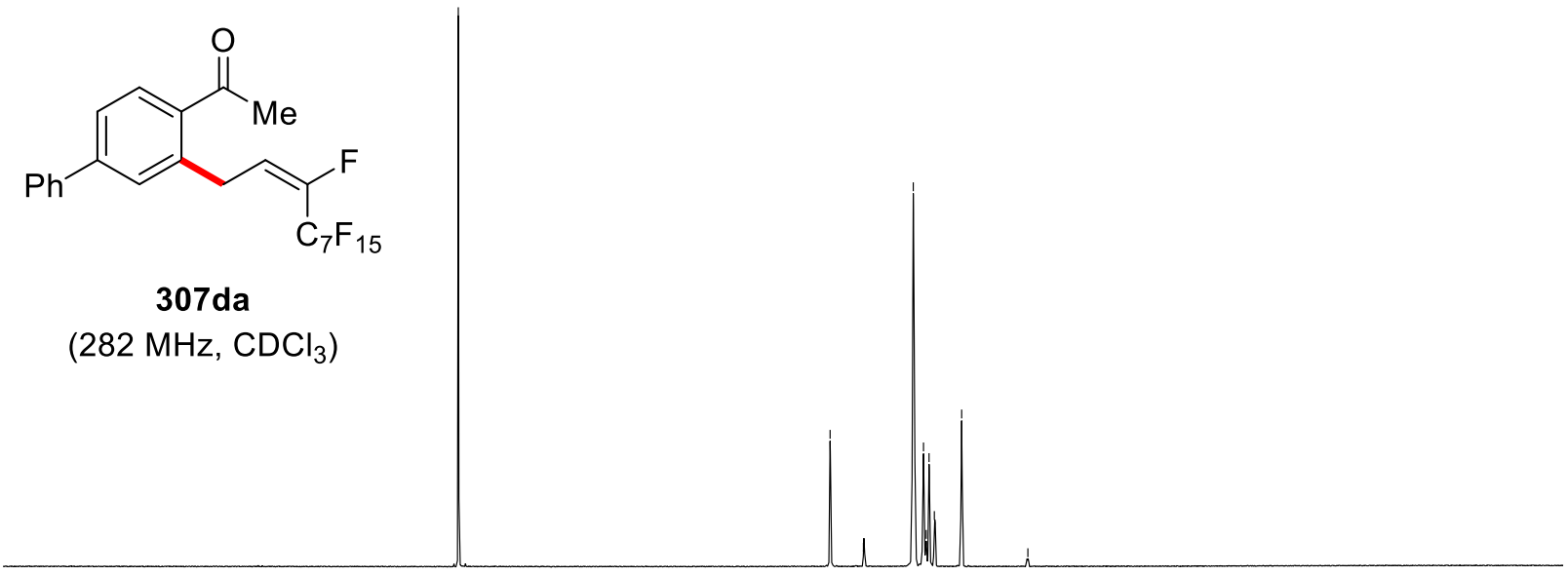

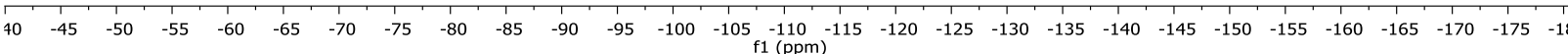




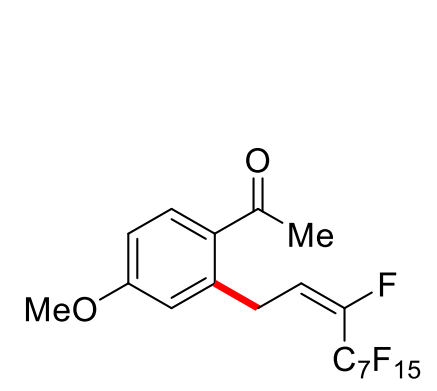

307 ea

$\left(500 \mathrm{MHz}, \mathrm{CDCl}_{3}\right)$
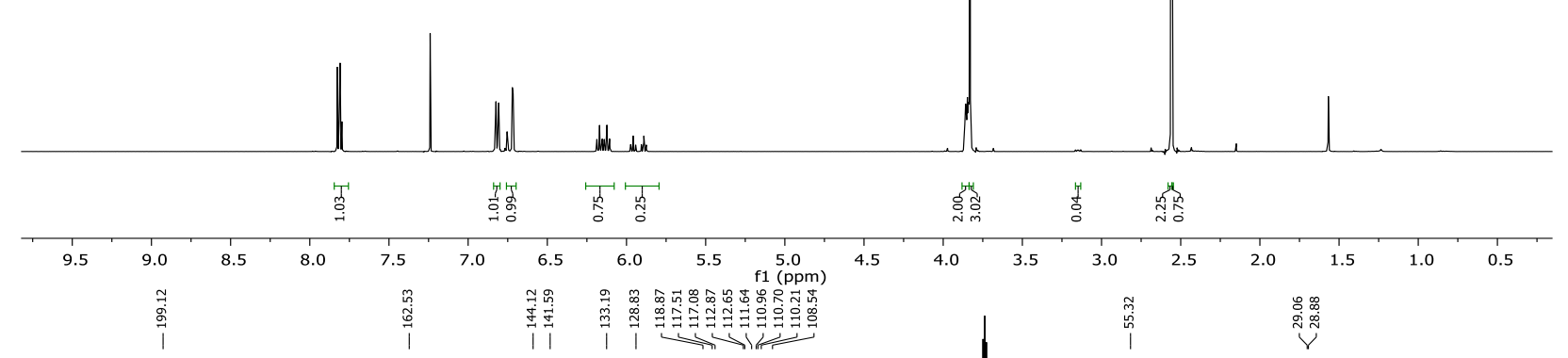<smiles>COc1ccc(C(C)=O)c(C/C=C(\F)C(F)(F)C(F)(F)F)c1</smiles>

307ea

$\left(125 \mathrm{MHz} \mathrm{CDCl}_{3}\right)$

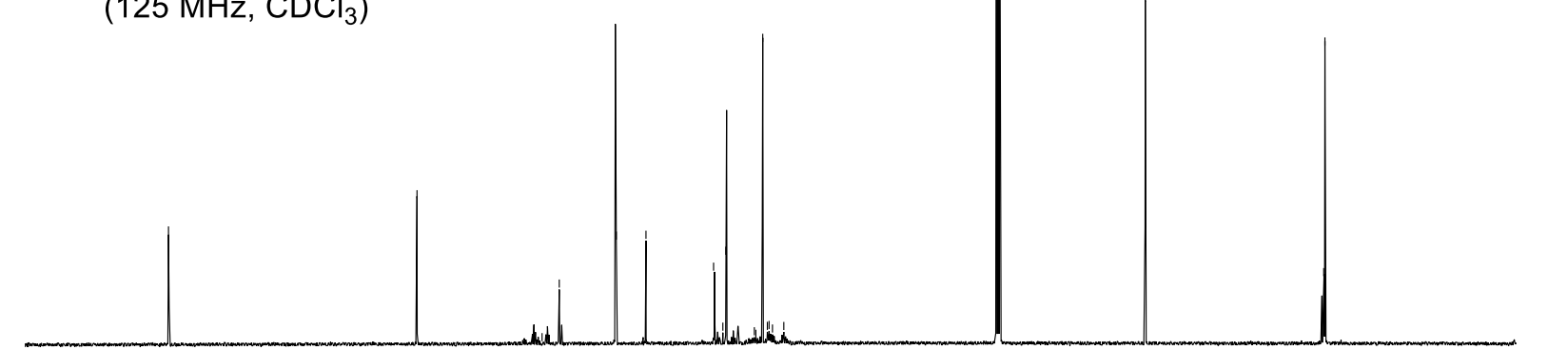

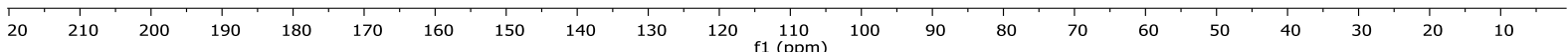




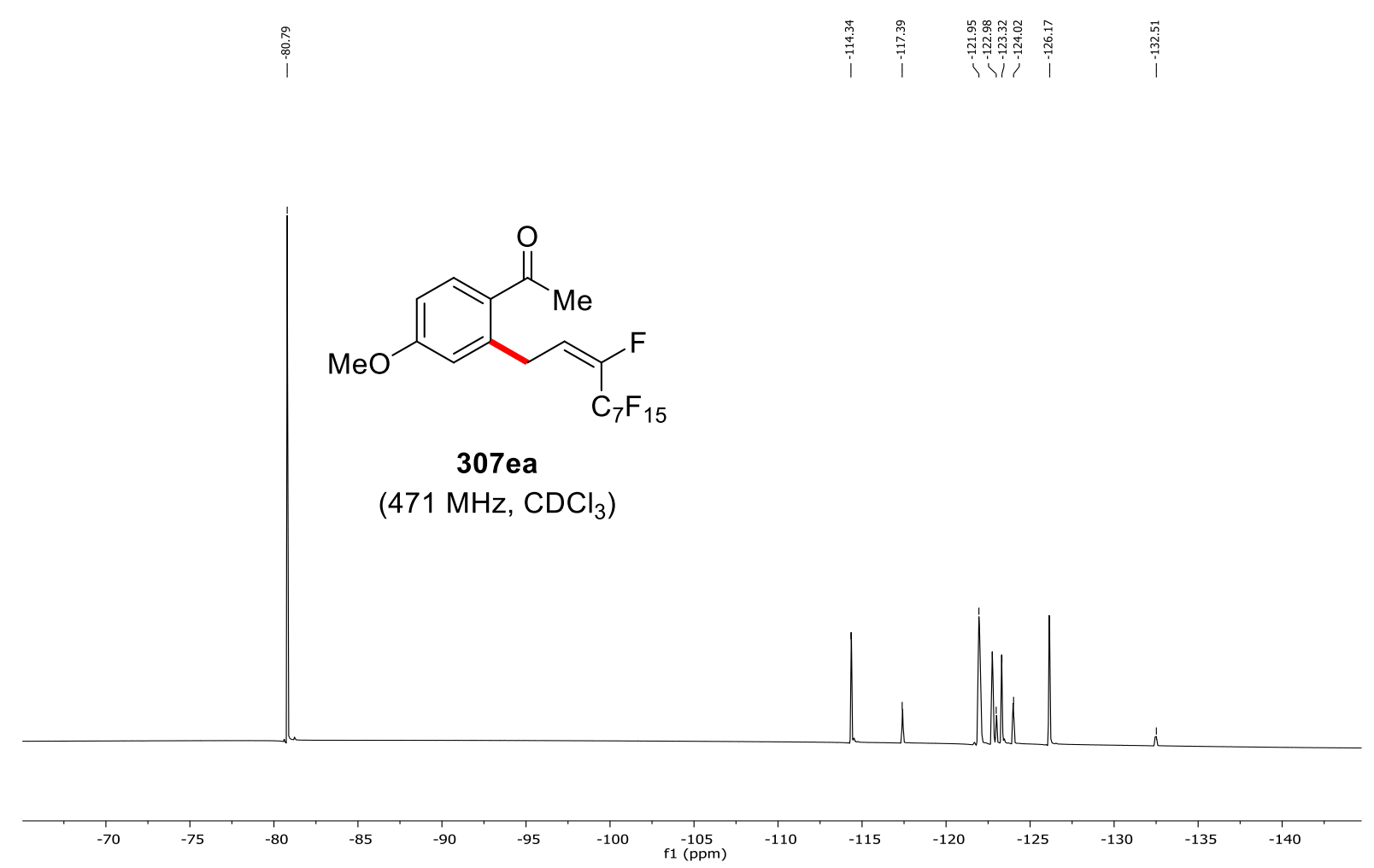


<smiles>CC(=O)c1ccc(C(F)(F)F)cc1C/C=C(\F)C(F)(F)C(F)(F)F</smiles>

$307 \mathrm{fa}$

(300 MHz, $\mathrm{CDCl}_{3}$ )

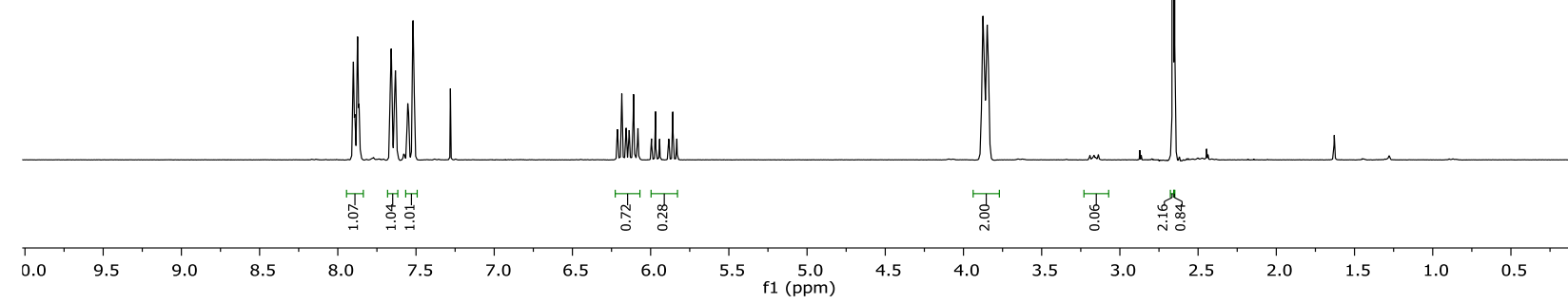

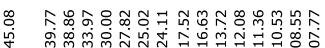

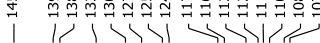<smiles>CC(=O)c1ccc(C(F)(F)F)cc1C/C=C(\F)C(F)(F)C(F)(F)F</smiles>

$307 \mathrm{fa}$

(75 MHz, $\mathrm{CDCl}_{3}$ )

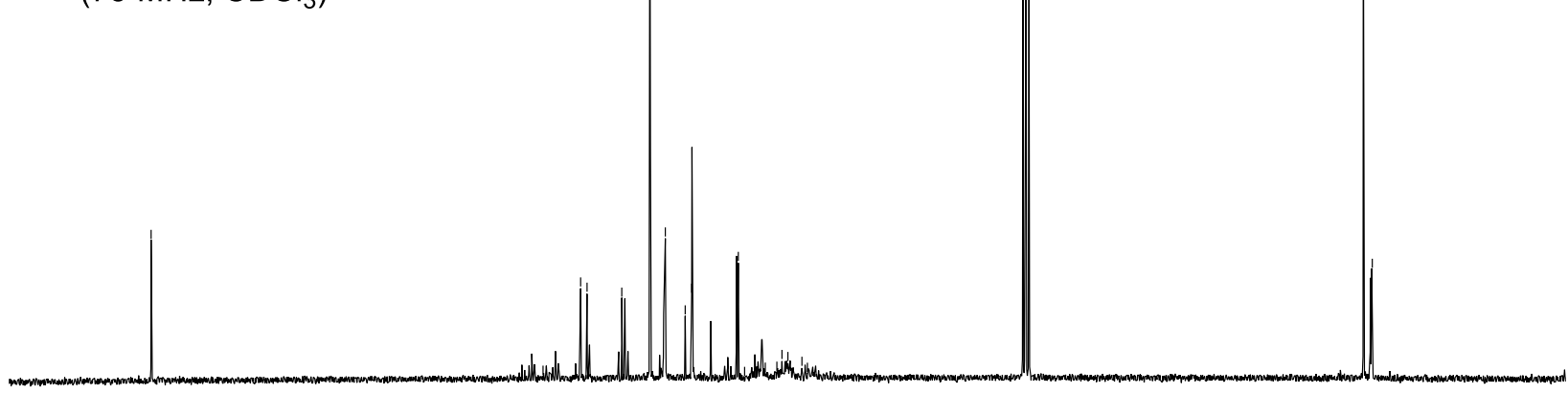

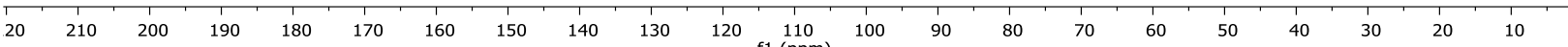




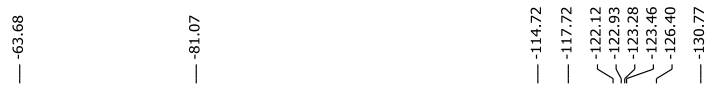

$\overbrace{C_{C_{7} F_{15}}}^{C}$

$307 \mathrm{fa}$

(282 MHz, $\mathrm{CDCl}_{3}$ )

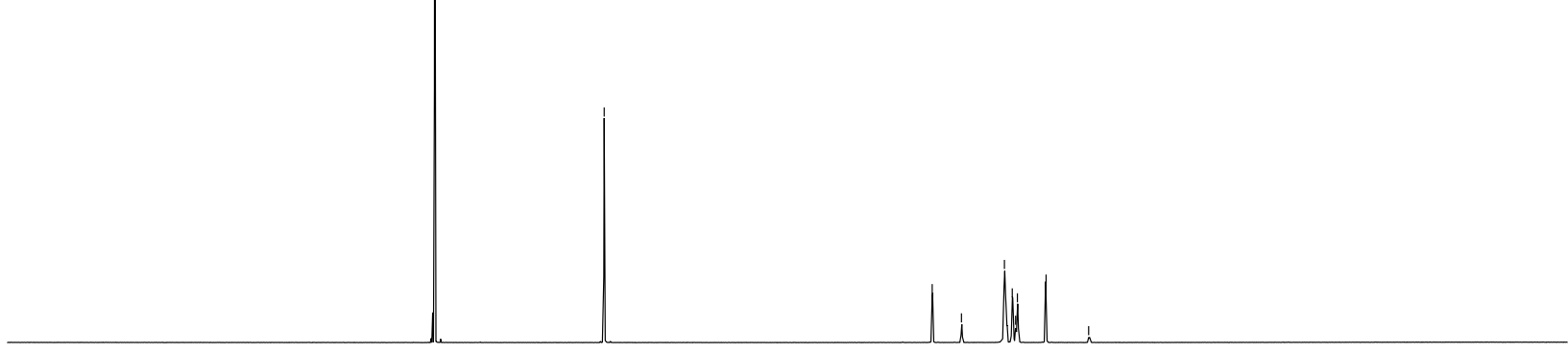

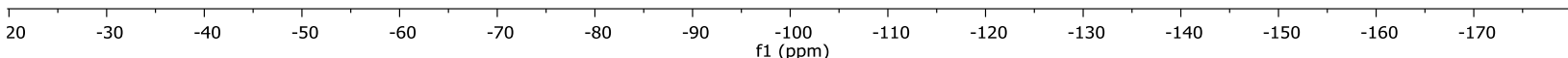




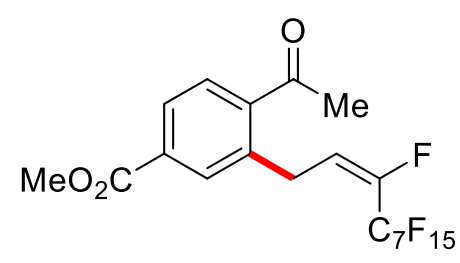

$307 g a$

$\left(500 \mathrm{MHz}, \mathrm{CDCl}_{3}\right)$

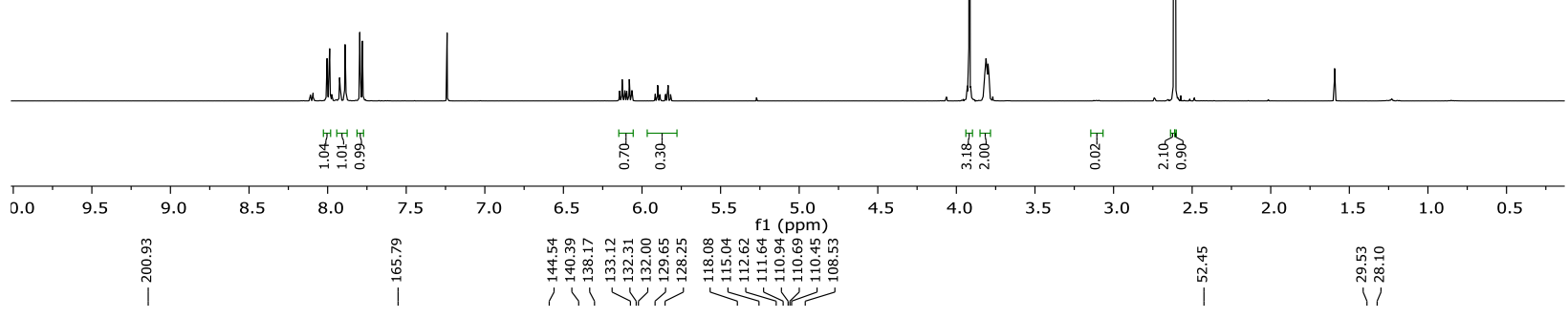<smiles>CC(=O)c1ccc(C(C)=O)c(C/C=C(/F)C(F)(F)C(F)(F)C(F)(F)F)c1</smiles>

307ga

(125 MHz, $\mathrm{CDCl}_{3}$ )

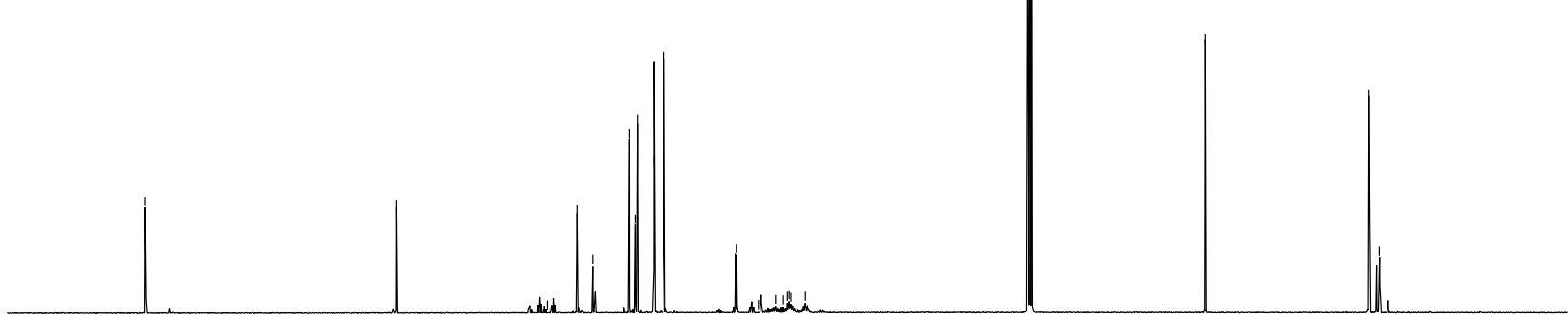

$\begin{array}{lllllllllllllllllllllllllll} & 210 & 200 & 190 & 180 & 170 & 160 & 150 & 140 & 130 & 120 & 110 & 100 & 90 & 80 & 70 & 60 & 50 & 40 & 30 & 20 & 10\end{array}$ 


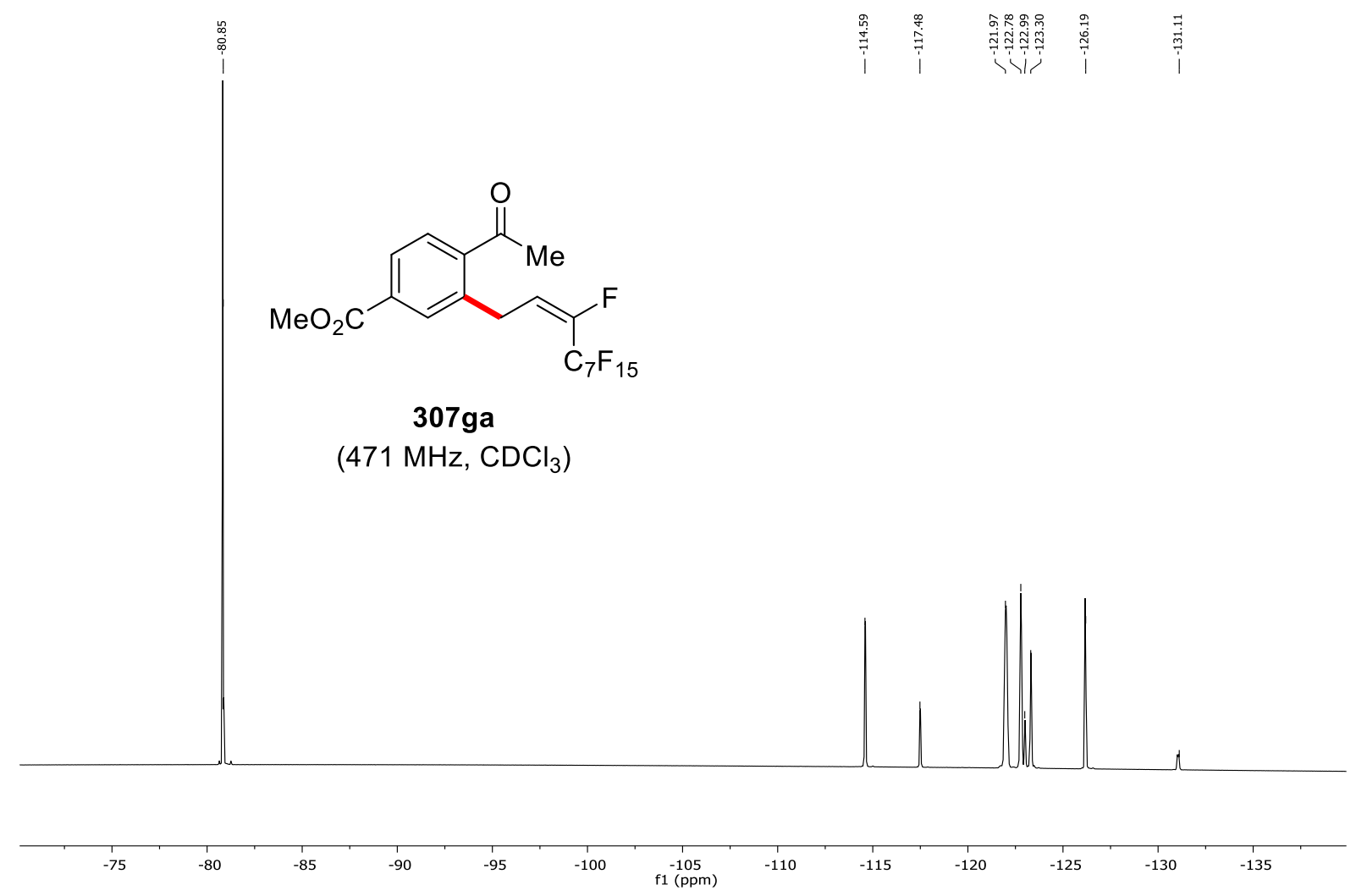


<smiles>CC(=O)c1ccc(Cl)cc1C/C=C(/F)C(F)(F)C(F)(F)C(F)(F)F</smiles>

307ha

(300 MHz, $\mathrm{CDCl}_{3}$ )

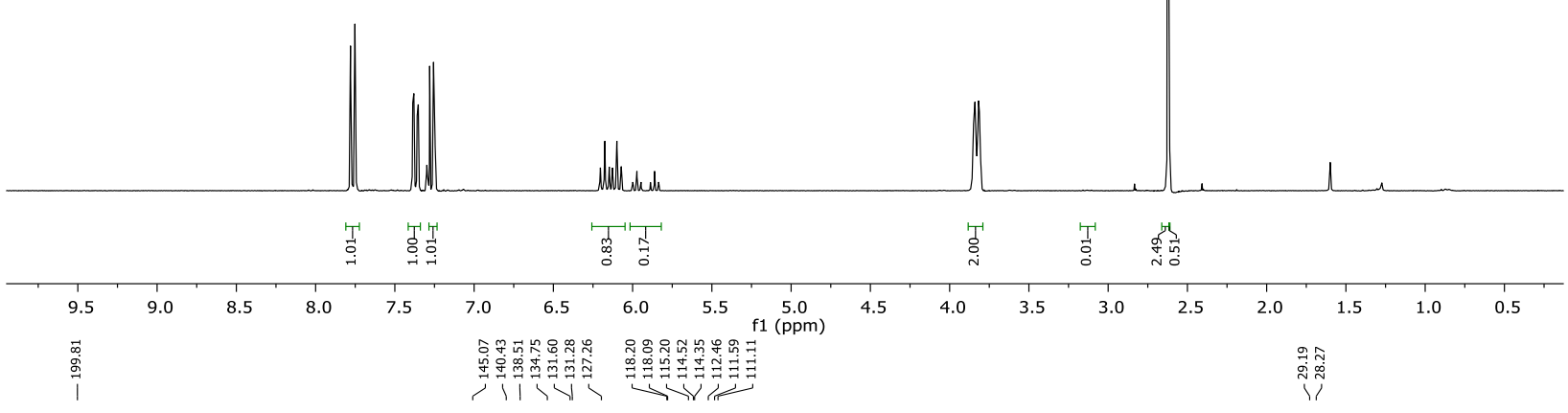<smiles>CC(=O)c1ccc(Cl)cc1C/C=C(/F)C(F)(F)C(F)(F)F</smiles>

307ha

(75 MHz, $\mathrm{CDCl}_{3}$ )

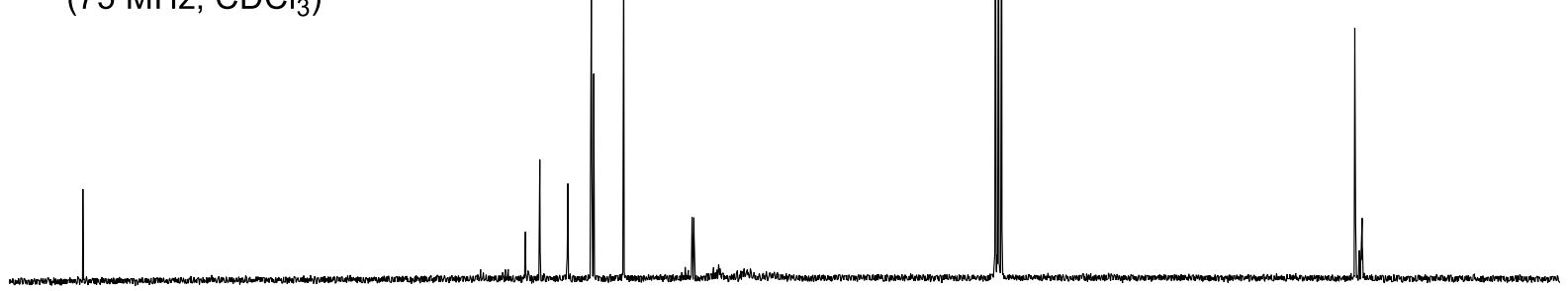

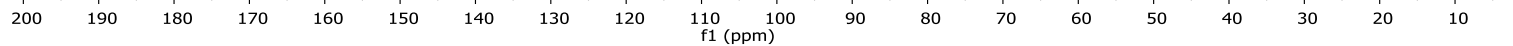


崖

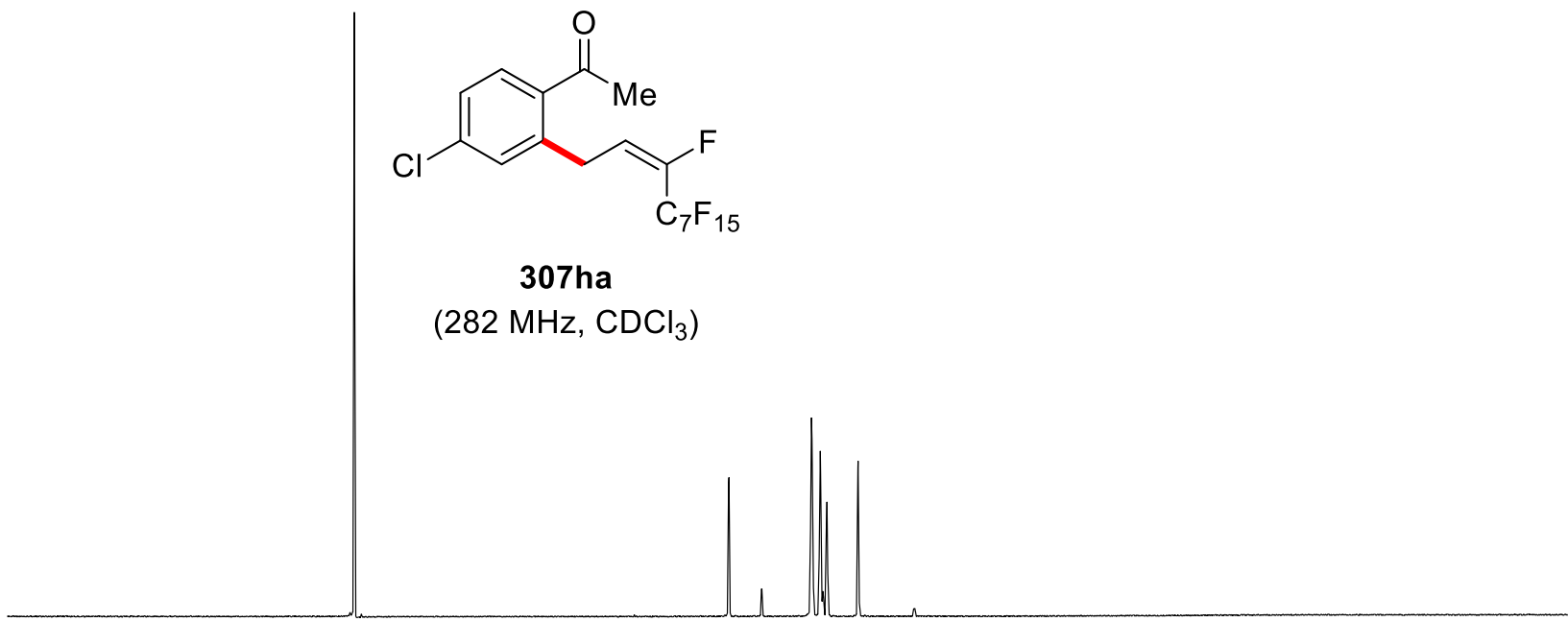

$\begin{array}{llllllllllllllllllllllllllllllllllllllllllllllllllllll}50 & -55 & -60 & -65 & -70 & -75 & -80 & -85 & -90 & -95 & -100 & -105 & -110 & -115 & -120 & -125 & -130 & -135 & -140 & -145 & -150 & -155 & -160 & -165 & -170 & -175 & -180 & -185 & -1\end{array}$ 


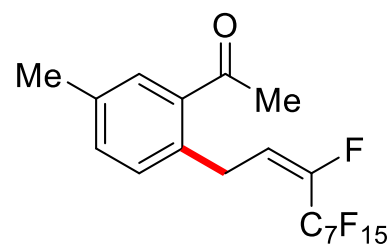

307 ia

$\left(300 \mathrm{MHz}^{\mathrm{CDCl}} \mathrm{CDC}_{3}\right)$

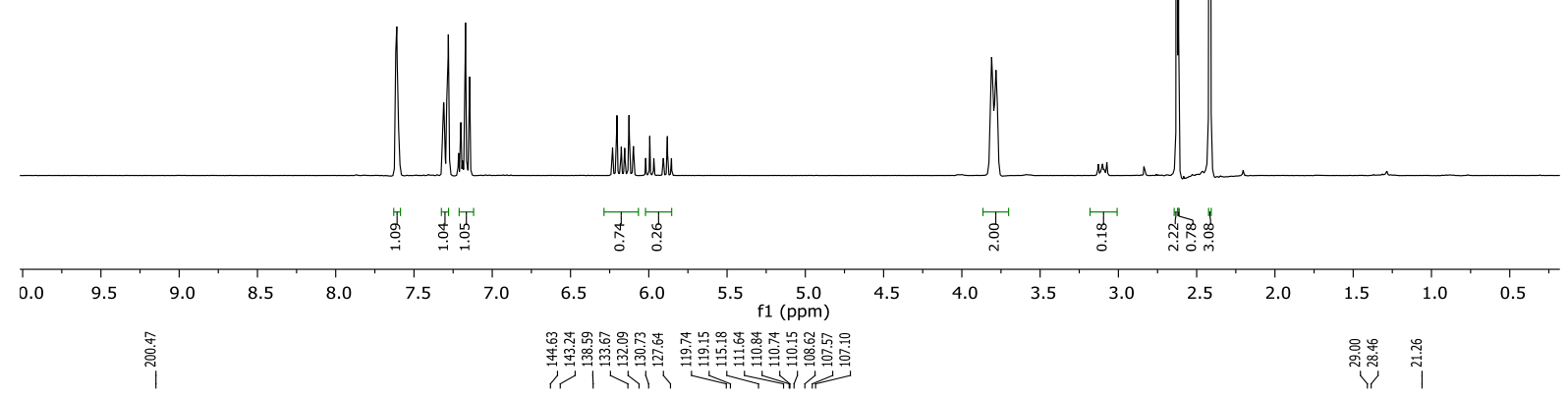

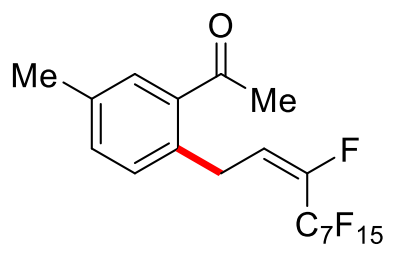

307 ia

(75 MHz, $\mathrm{CDCl}_{3}$ )

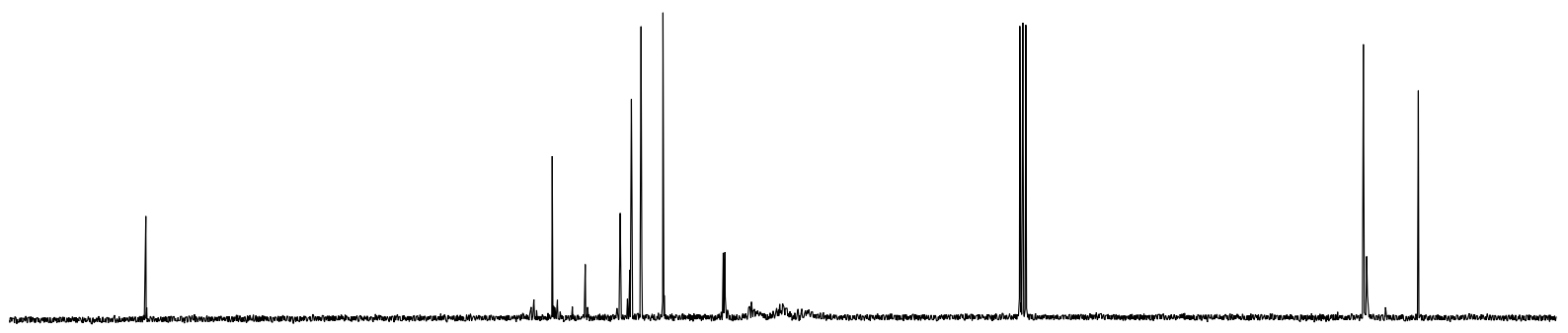

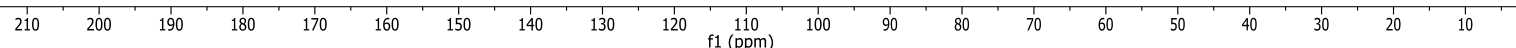




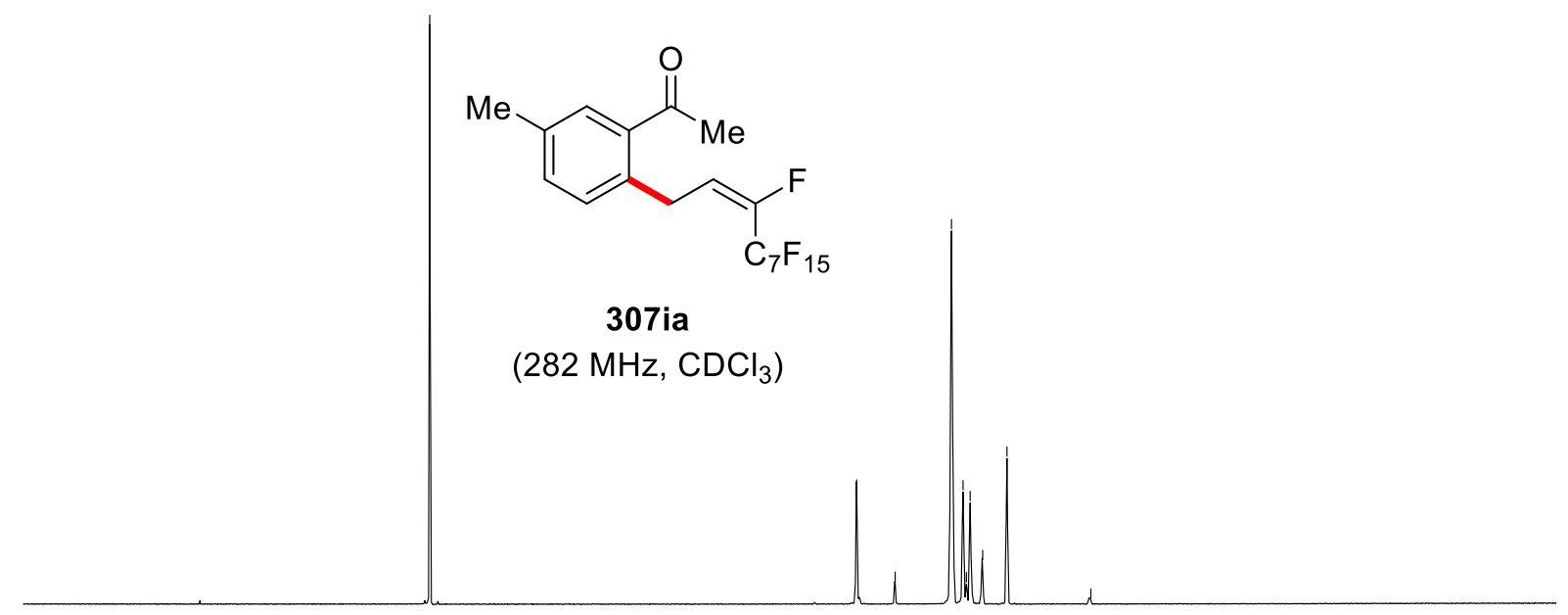

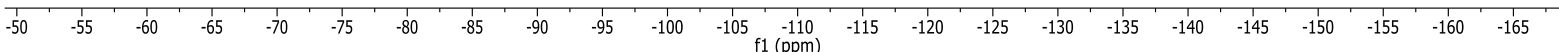


<smiles>CC(=O)c1ccccc1C/C=C(/F)C(F)(F)F</smiles>

307 ac

(300 MHz, $\mathrm{CDCl}_{3}$ )

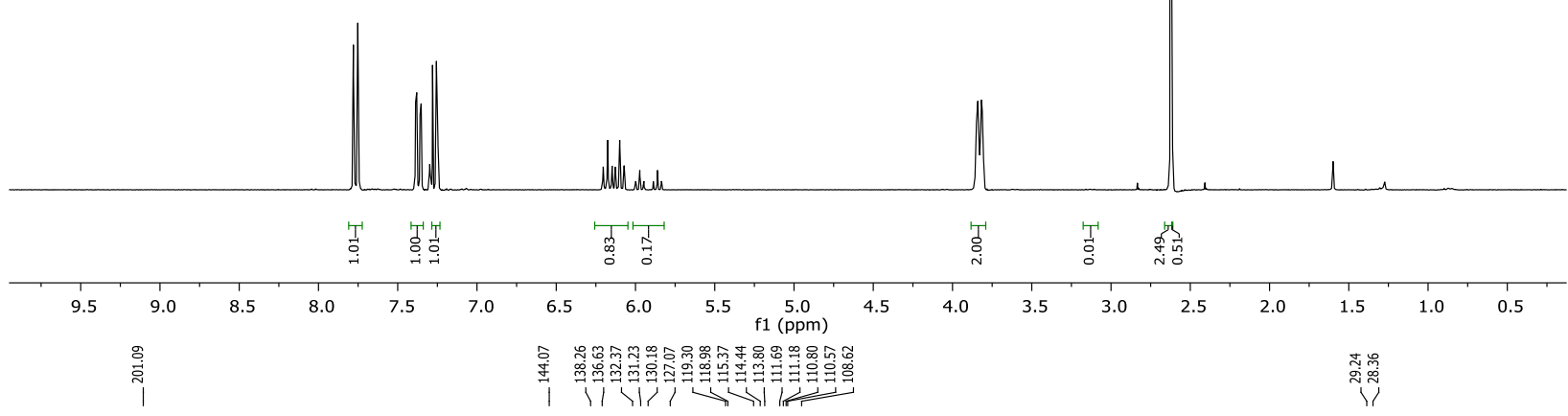<smiles>CC(=O)c1ccccc1C/C=C(/F)C(F)(F)F</smiles>

307 ac

(75 MHz, $\mathrm{CDCl}_{3}$ )

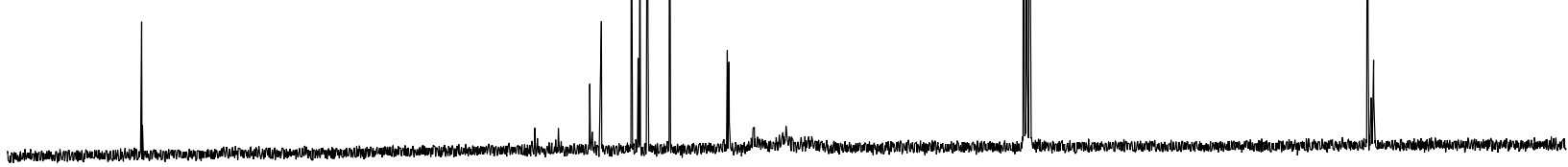

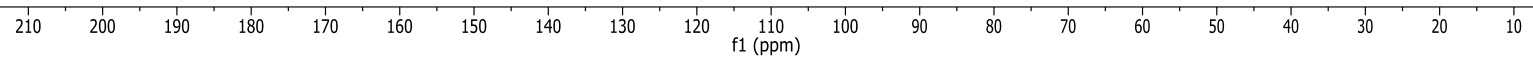




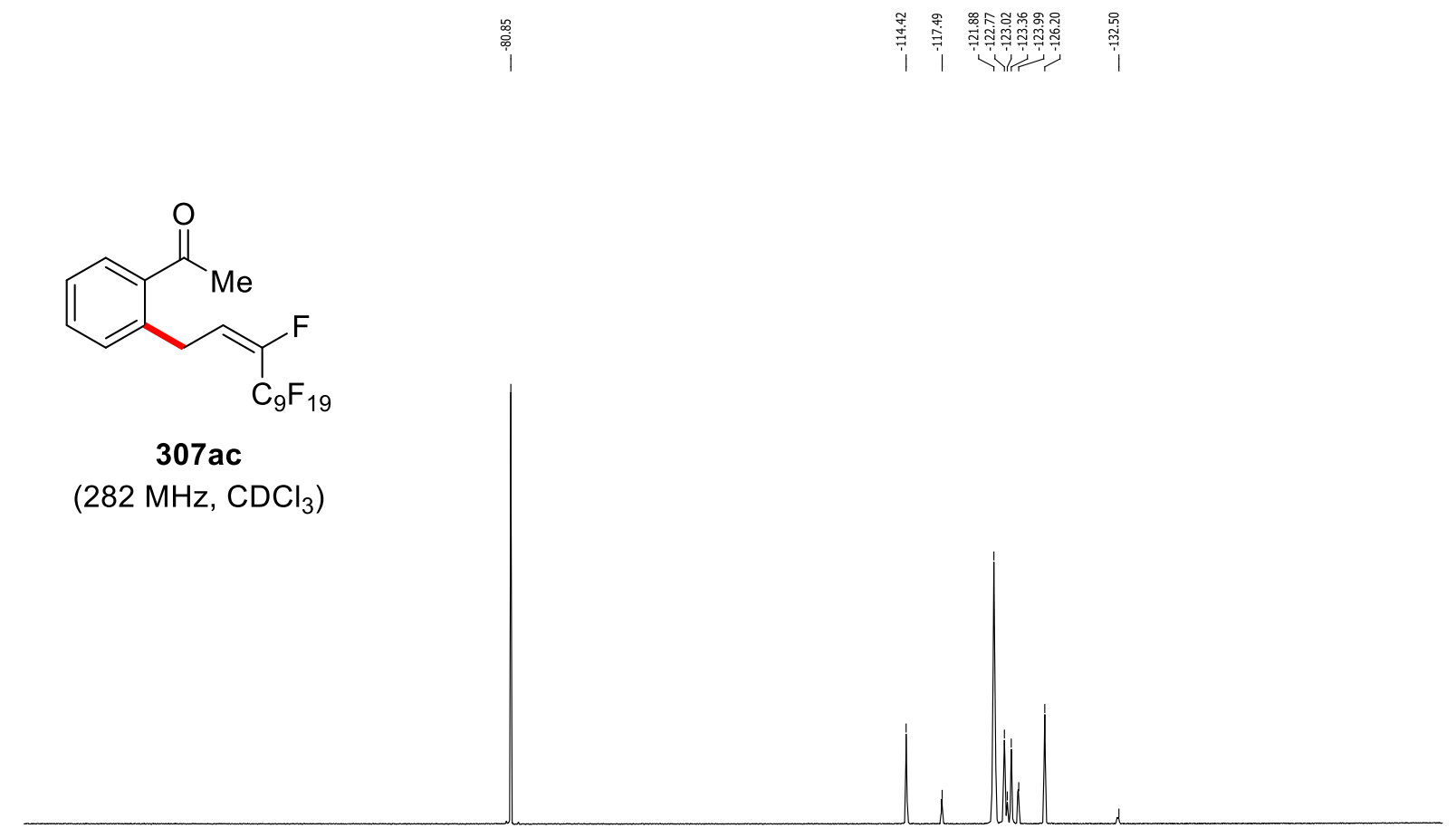

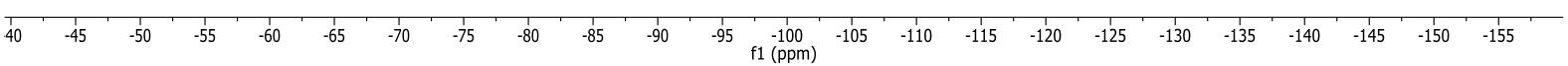




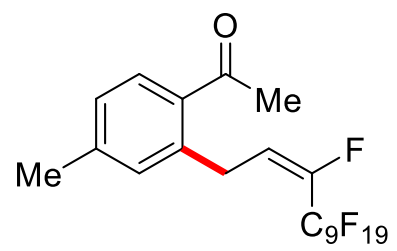

$307 \mathrm{cc}$

$\left(300 \mathrm{MHz}, \mathrm{CDCl}_{3}\right)$

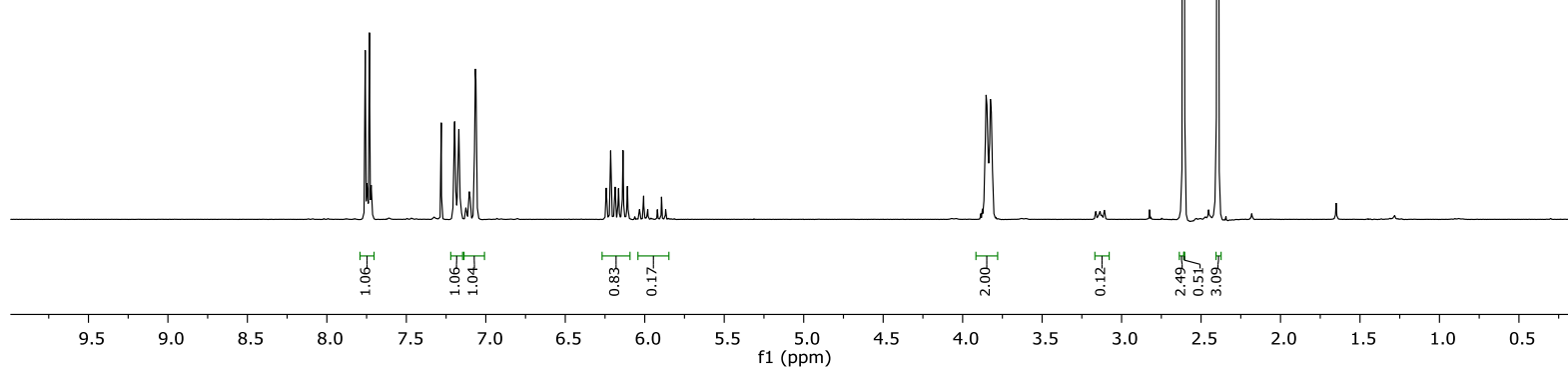<smiles></smiles>

$307 \mathrm{cc}$

$\left(75 \mathrm{MHz}, \mathrm{CDCl}_{3}\right)$

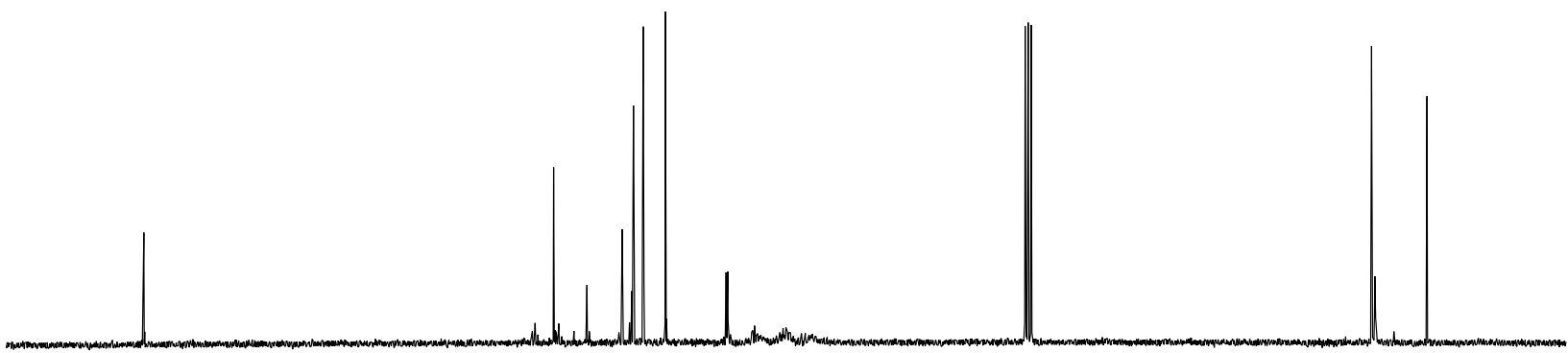

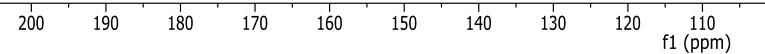




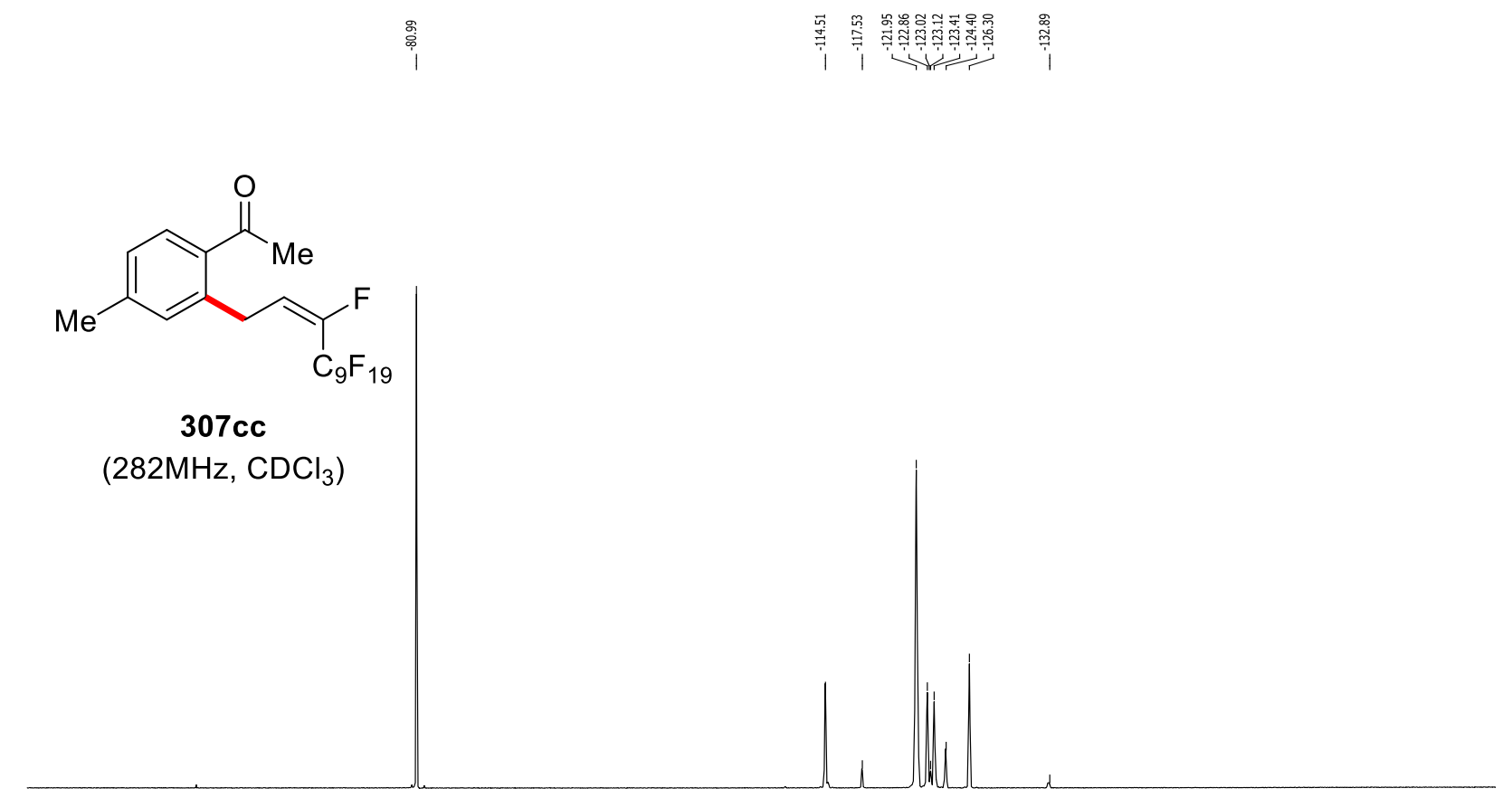

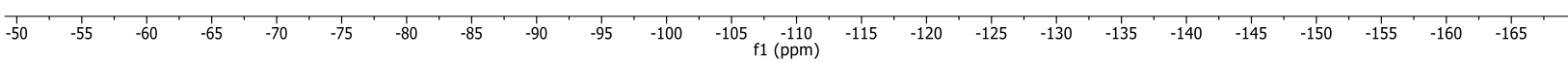




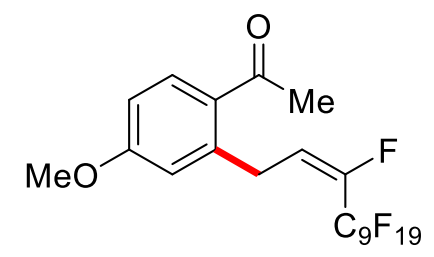

307 ec

$\left(500 \mathrm{MHz}, \mathrm{CDCl}_{3}\right)$
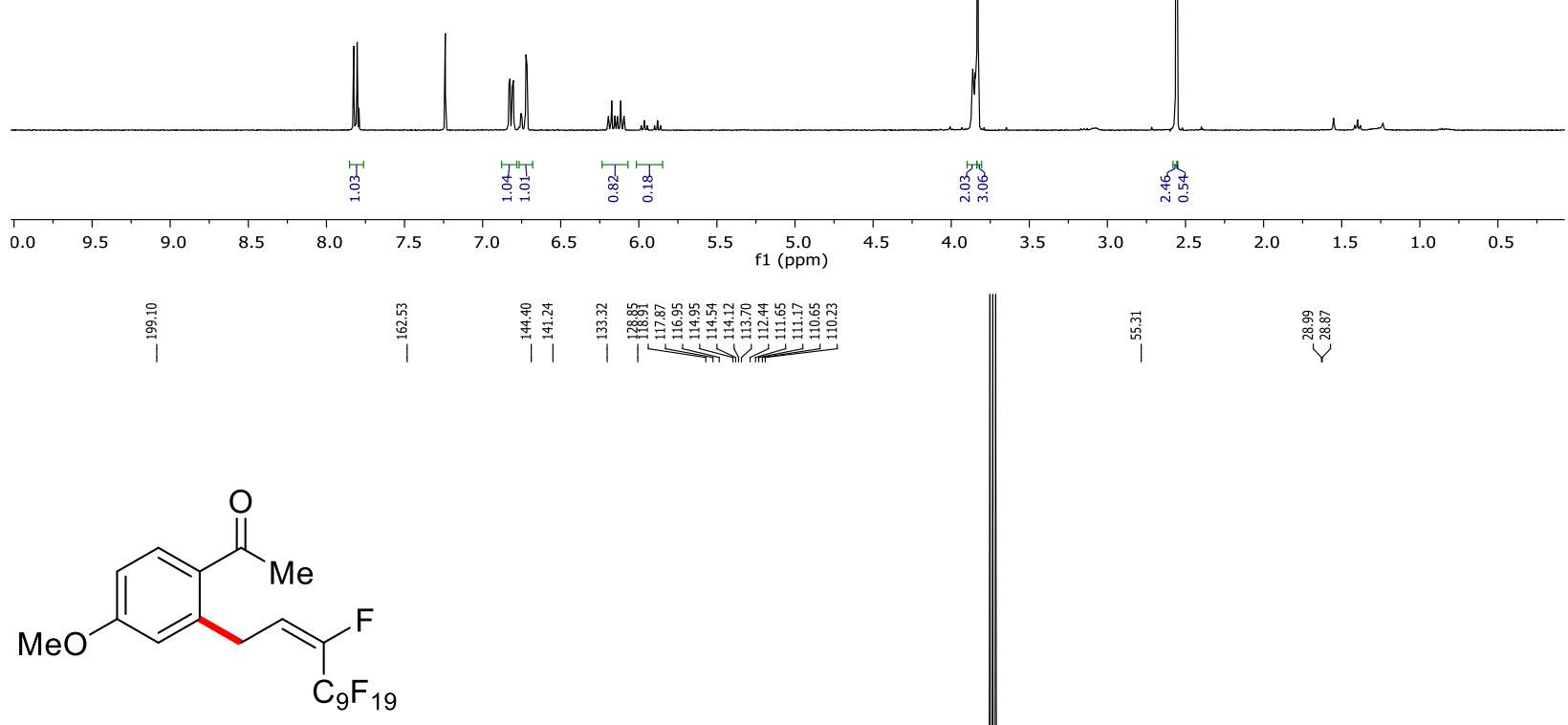

307 ec

$\left(125 \mathrm{MHz}, \mathrm{CDCl}_{3}\right)$

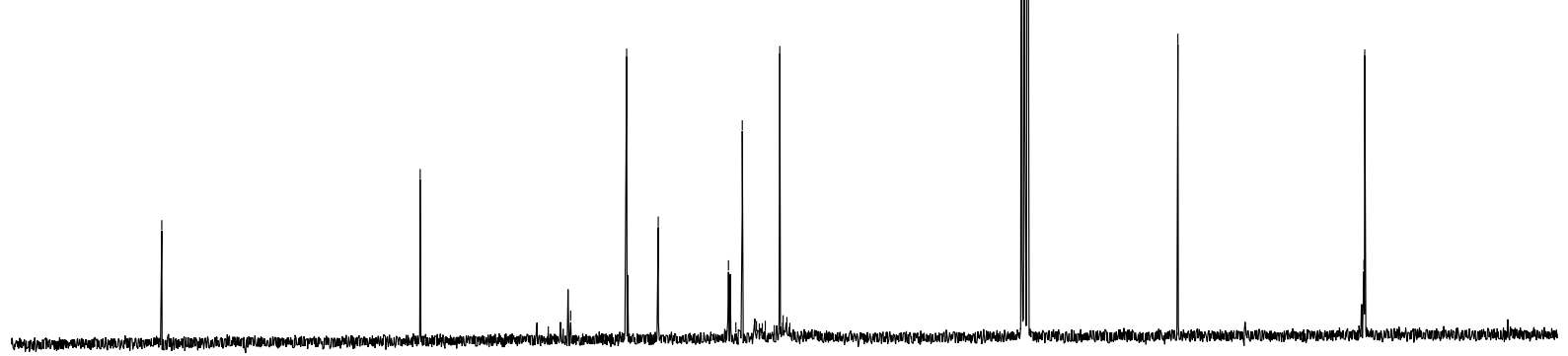

$20 \quad 210$

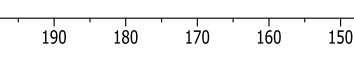

$\frac{1}{140} \quad 130$

110
$\mathrm{f} 1(\mathrm{ppm})$ 


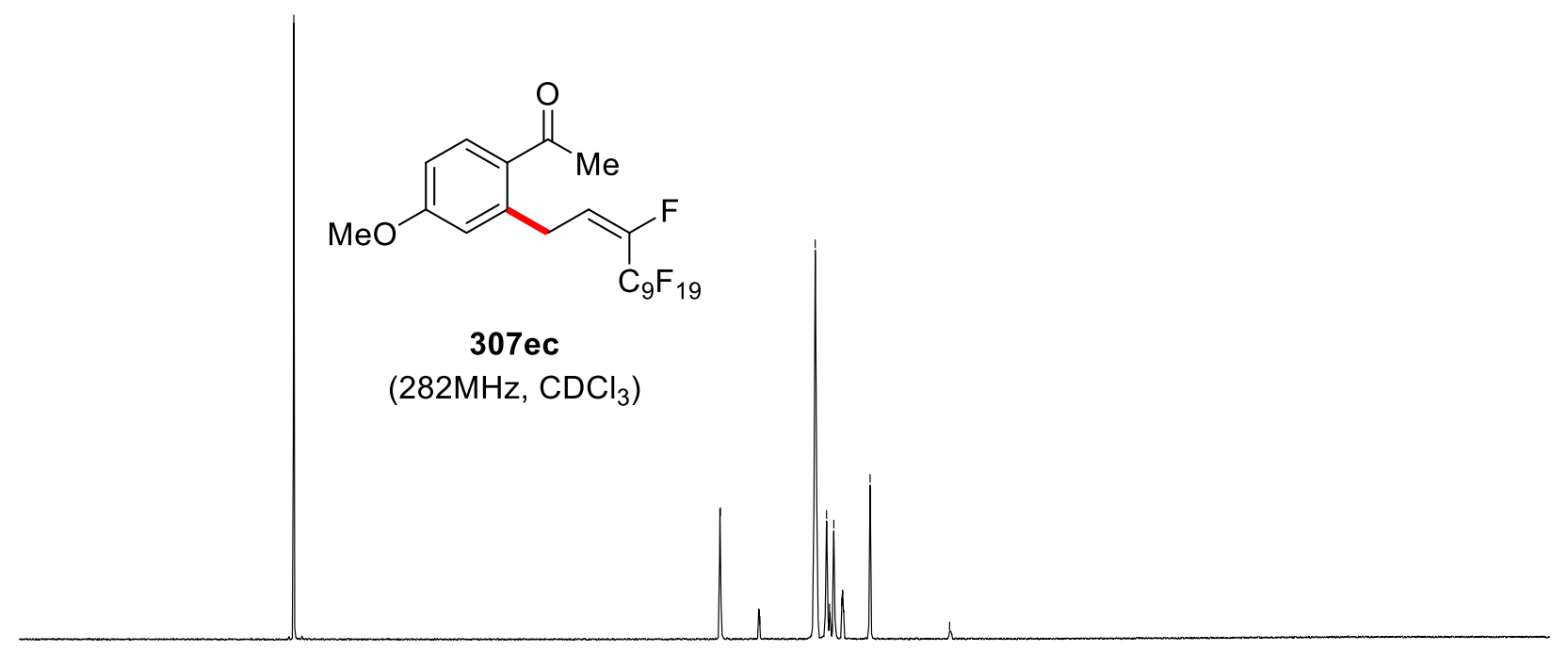

\begin{tabular}{lllllllllllllllllllllllllllllllll}
\hline-60 & -65 & -70 & -75 & -80 & -85 & -90 & -95 & -100 & -105 & -110 & -115 & -120 & -125 & -130 & -135 & -140 & -145 & -150 & -155 & -160 & -165 & -170 & -175
\end{tabular} 


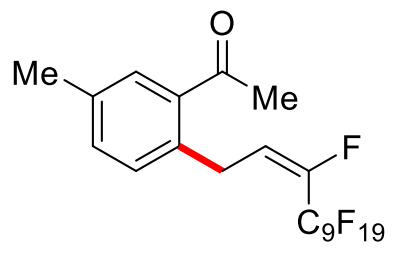

307 ic

$\left(300 \mathrm{MHz}, \mathrm{CDCl}_{3}\right)$
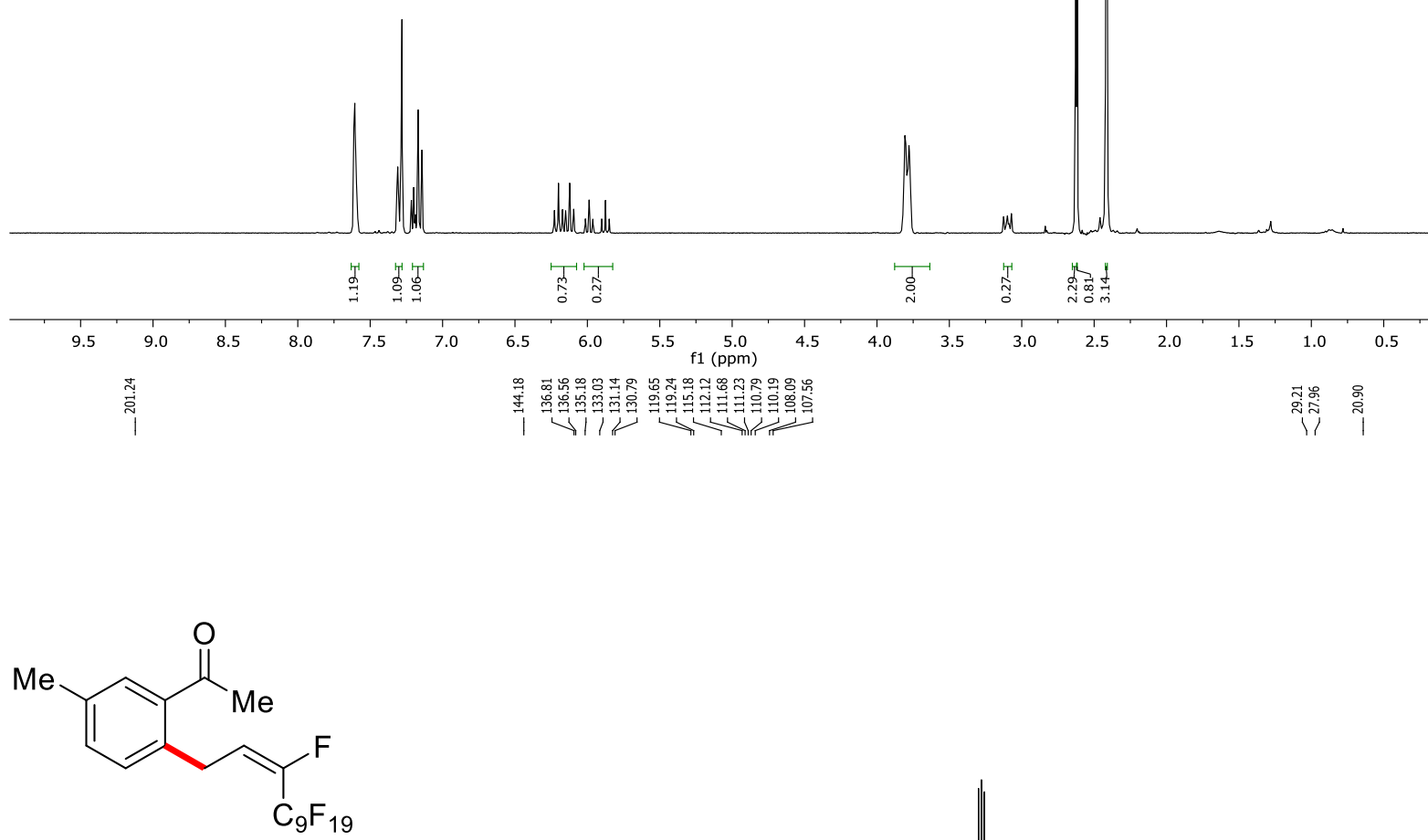

$307 i c$

$\left(75 \mathrm{MHz}, \mathrm{CDCl}_{3}\right)$

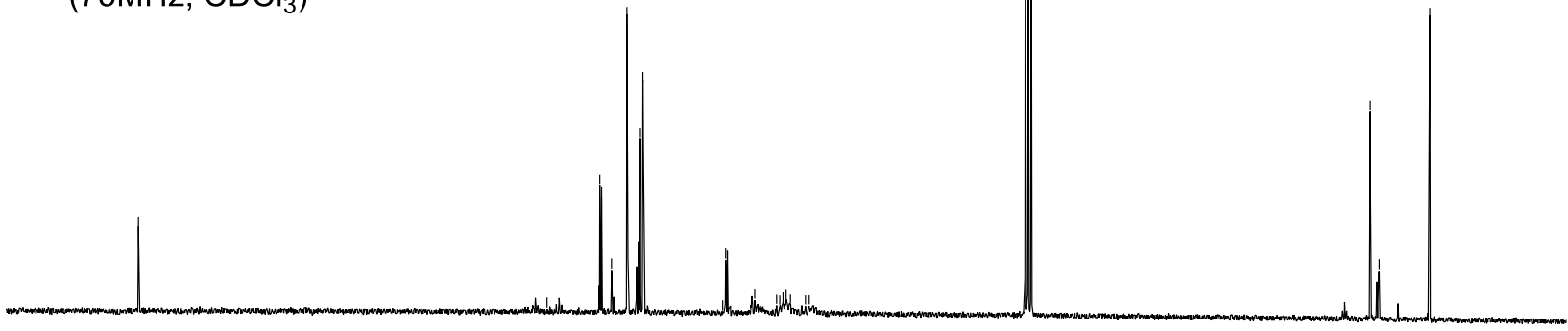




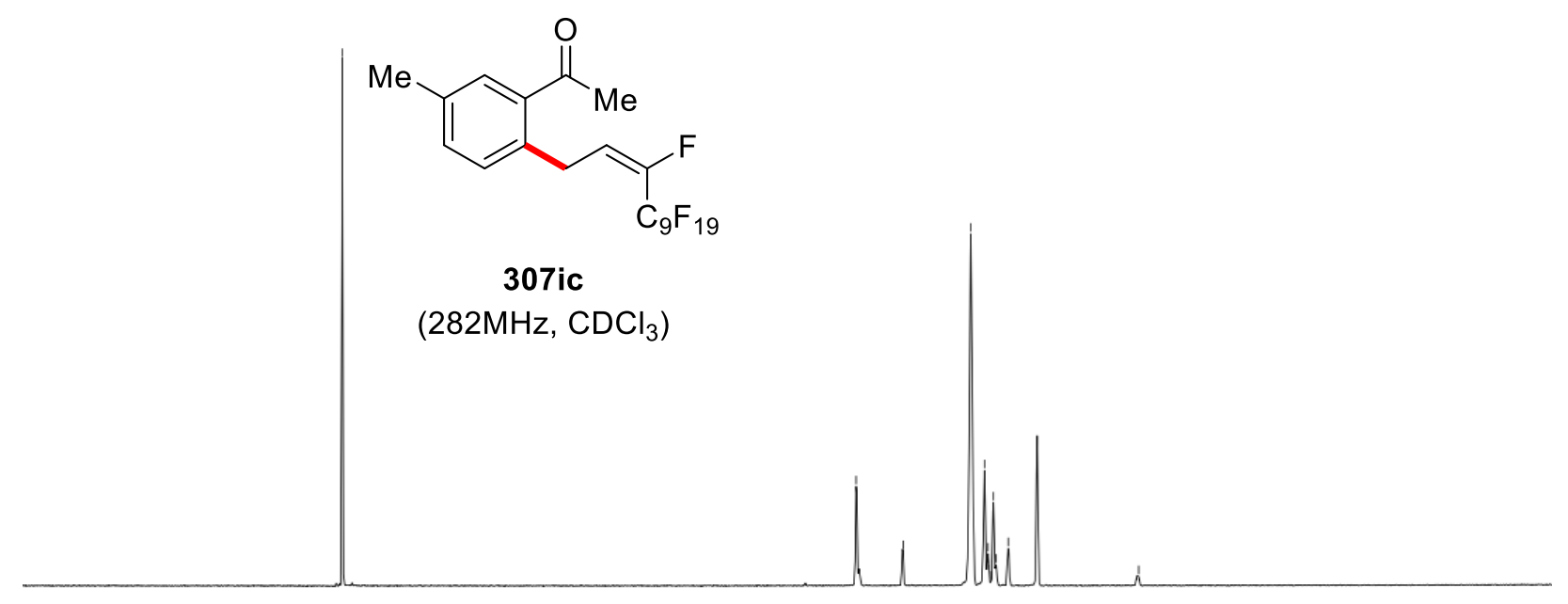


<smiles>CC(=O)c1ccc(-c2ccccc2)cc1C/C=C(/F)C(F)F</smiles>

307dc

(300MHz, $\mathrm{CDCl}_{3}$ )

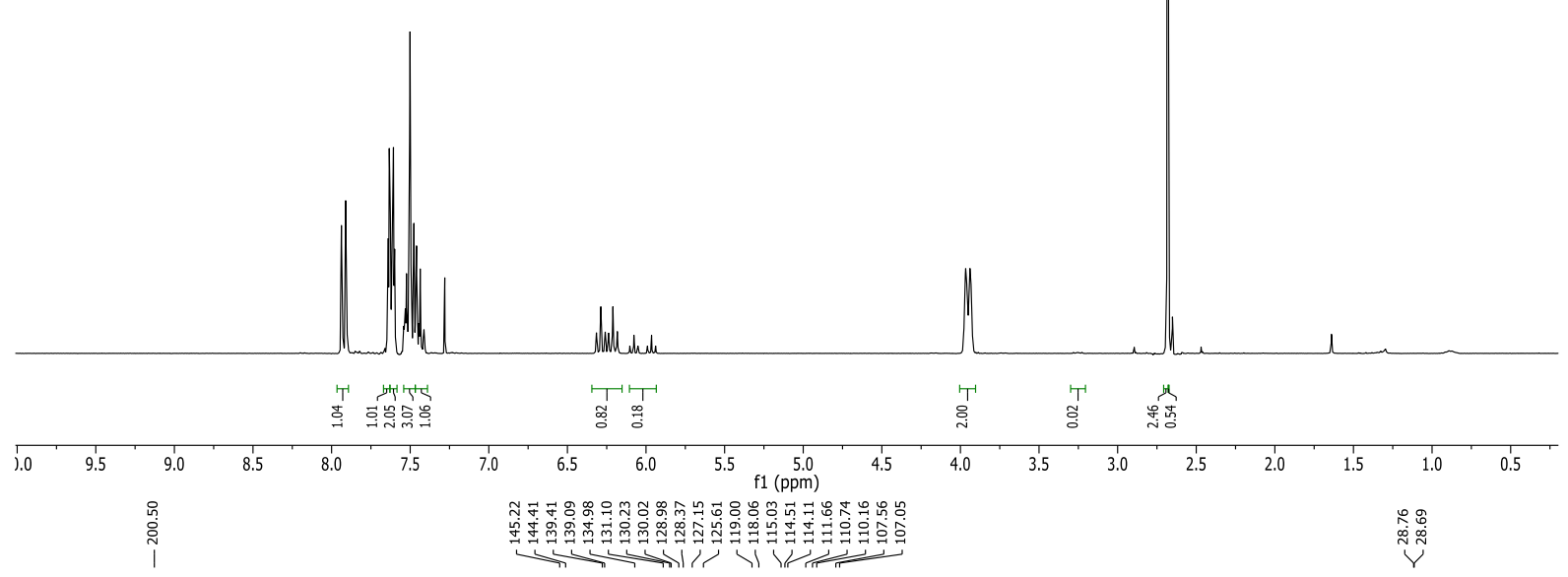<smiles>CC(=O)c1ccc(-c2ccccc2)cc1C/C=C(/F)C(F)(F)F</smiles>

307dc

(75MHz, $\mathrm{CDCl}_{3}$ )

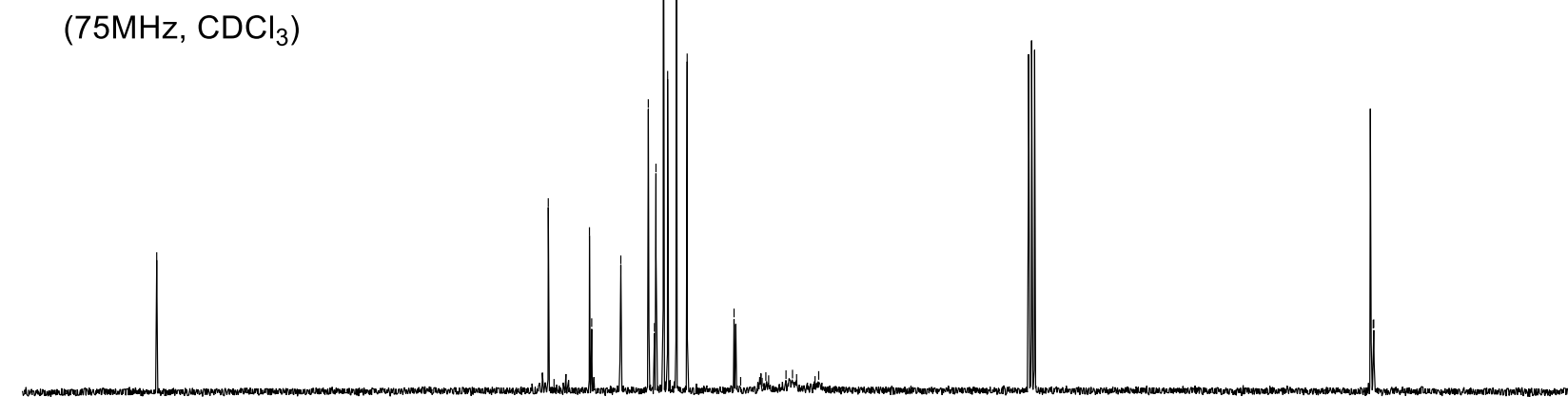

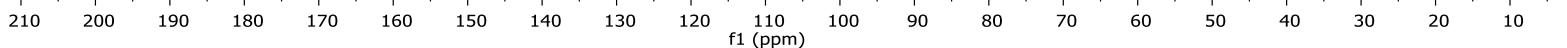




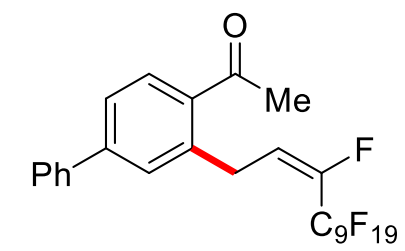

$307 \mathrm{dc}$

$\left(282 \mathrm{MHz}, \mathrm{CDCl}_{3}\right)$

$\begin{array}{llllllllllllllllllllllllllllllll} & 40 & -45 & -50 & -55 & -60 & -65 & -70 & -75 & -80 & -85 & -90 & -95 & -100 & -105 & -110 & -115 & -120 & -125 & -130 & -135 & -140 & -145 & -150 & -155 & -160 & -165 & -170 & -175 & -1\end{array}$ 
<smiles>CC[CH-]/C(F)=C\Cc1cc(C(F)(F)F)ccc1C(C)=O</smiles>

$307 \mathrm{fc}$

$\left(300 \mathrm{MHz}, \mathrm{CDCl}_{3}\right.$ )

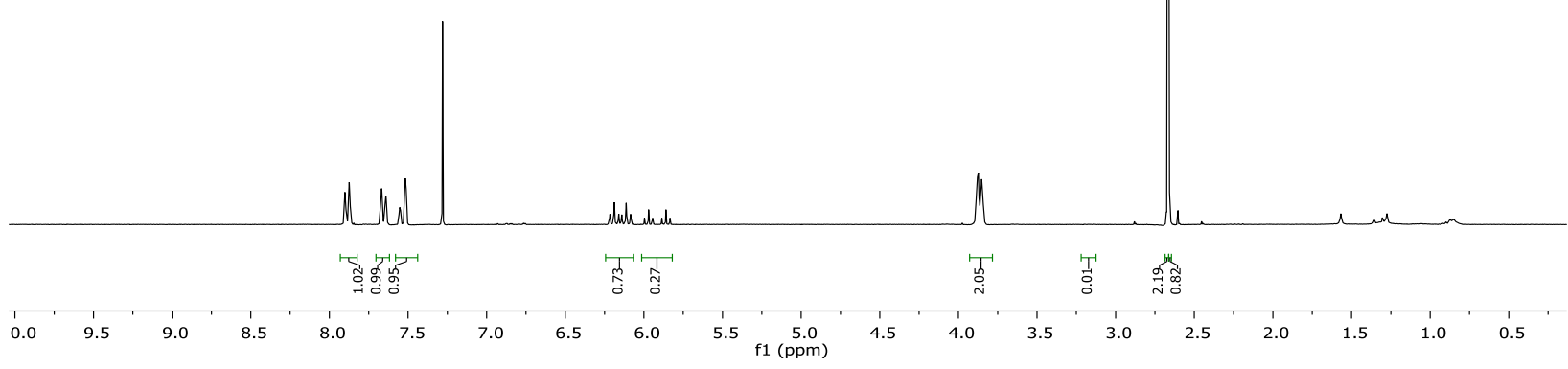<smiles>CC[CH-]/C(F)=C\Cc1cc(C(F)(F)F)ccc1C(C)=O</smiles>

$307 \mathrm{fc}$

$\left(100 \mathrm{MHz}, \mathrm{CDCl}_{3}\right.$ )

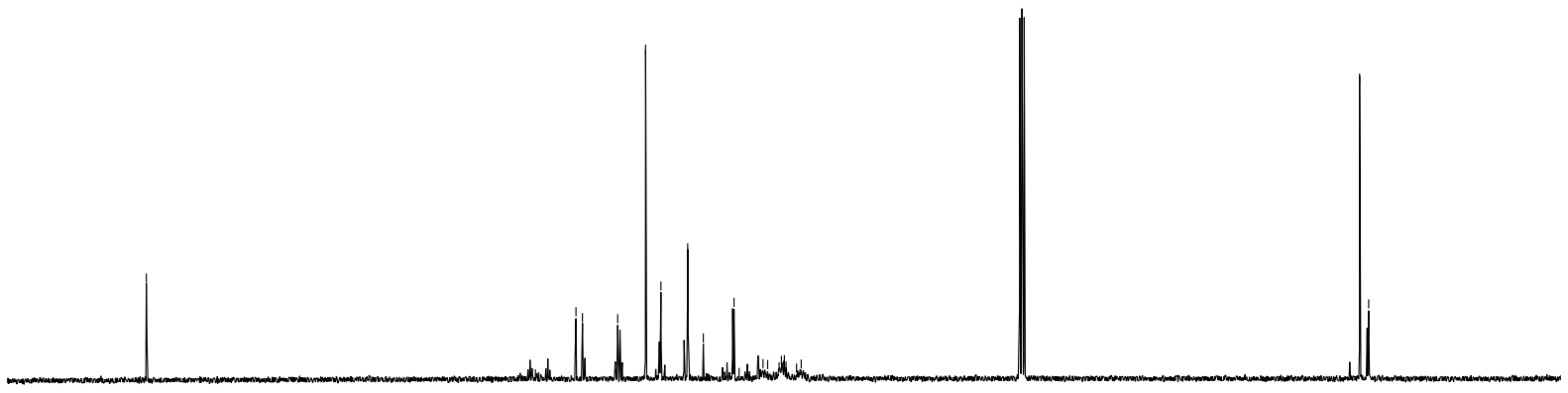

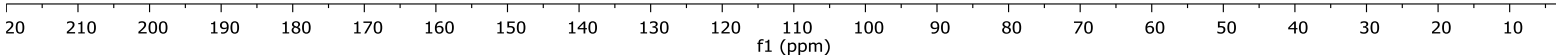




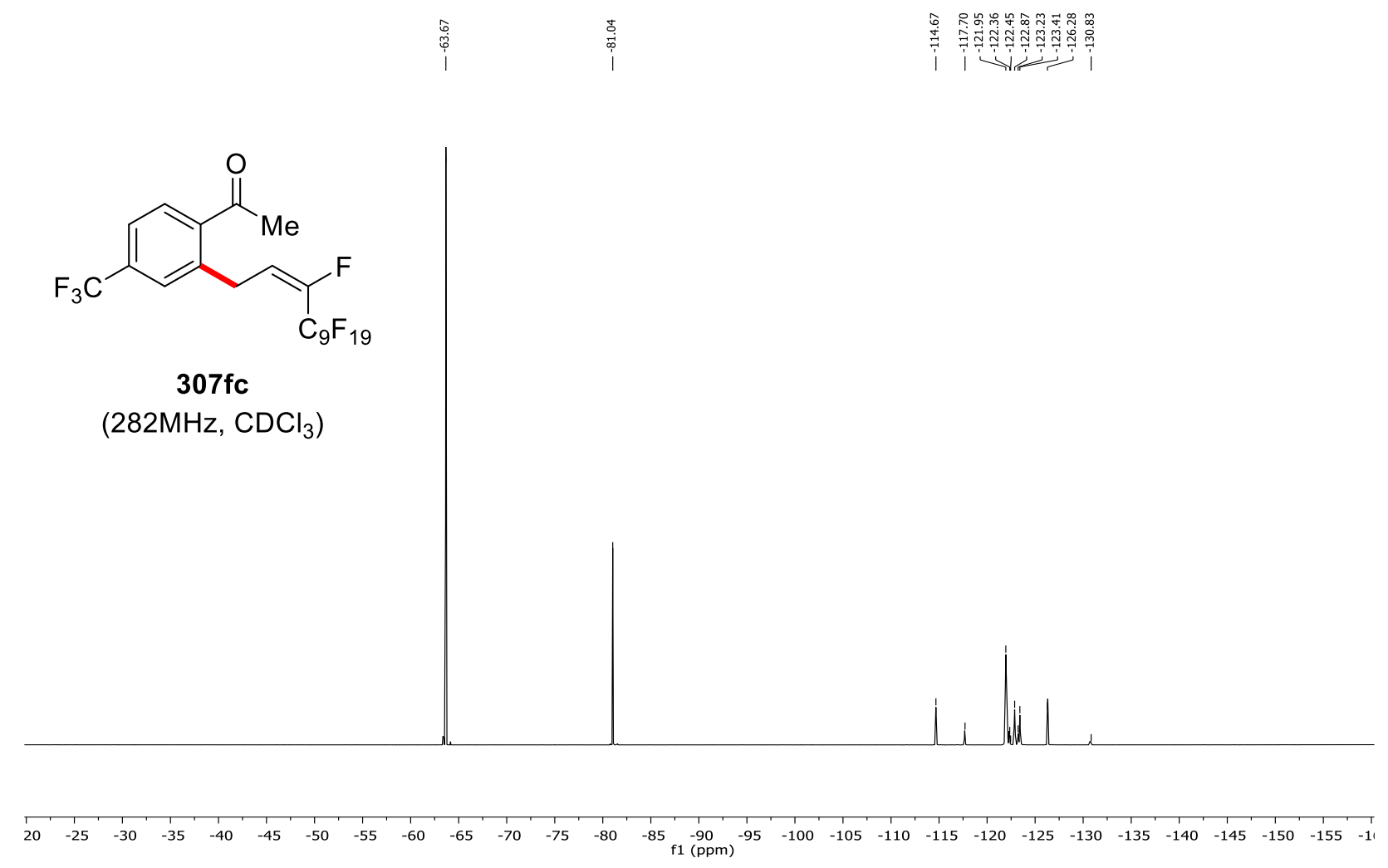


<smiles>CC(=O)c1ccc(Cl)cc1C/C=C(/F)C(F)(F)F</smiles>

307ha

$\left(300 \mathrm{MHz}, \mathrm{CDCl}_{3}\right)$

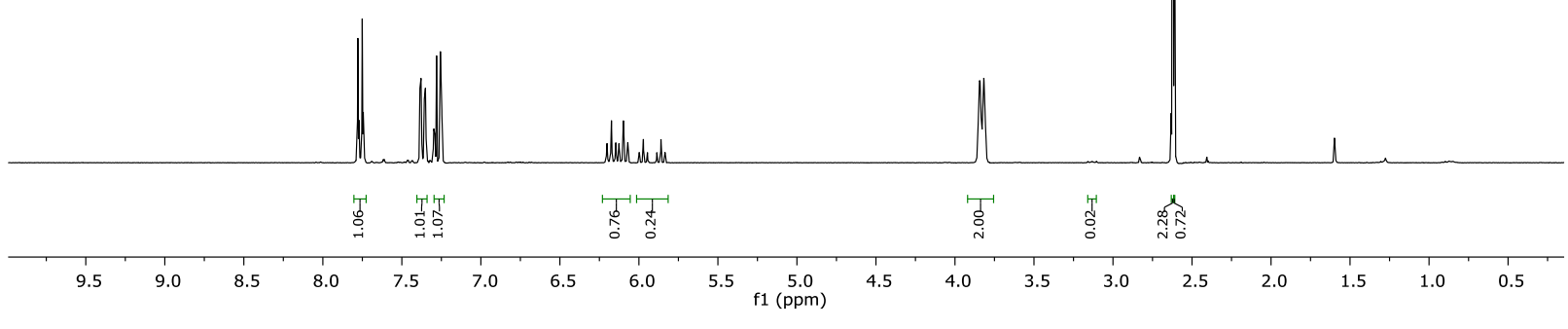

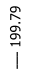

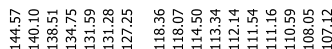

This<smiles>CC(=O)c1ccc(Cl)cc1C/C=C(/F)C(F)(F)F</smiles>

307ha

$\left(75 \mathrm{MHz}, \mathrm{CDCl}_{3}\right)$

$\begin{array}{lllllllllllllllllllllll} & 200 & 190 & 180 & 170 & 160 & 150 & 140 & 130 & 120 & 110 & 100 & 90 & 80 & 70 & 60 & 50 & 40 & 30 & 20 & 10\end{array}$ 


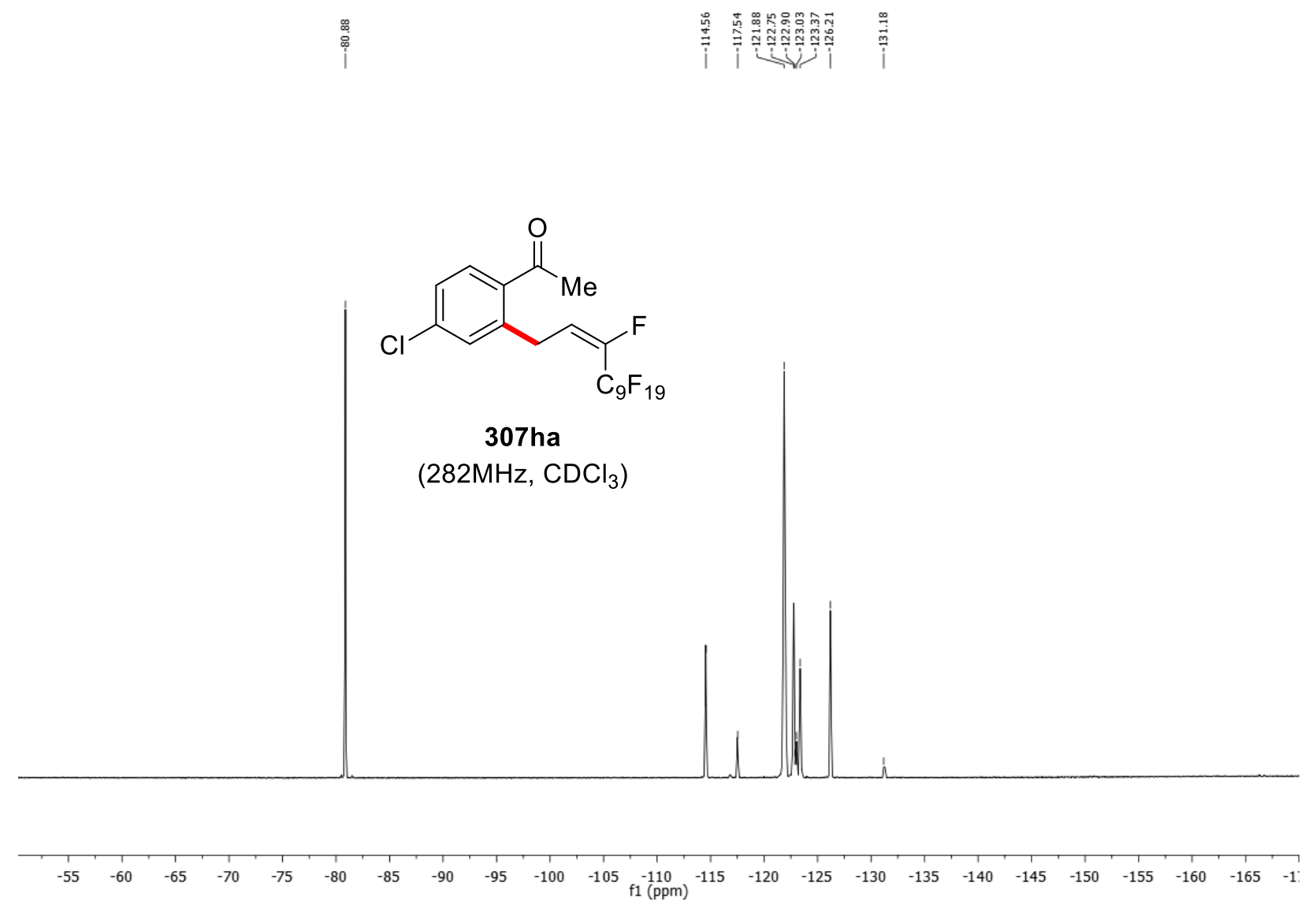


<smiles>CC(=O)c1ccccc1C/C=C(\F)C(F)(F)F</smiles>

$307 a b$

(300MHz, $\mathrm{CDCl}_{3}$ )
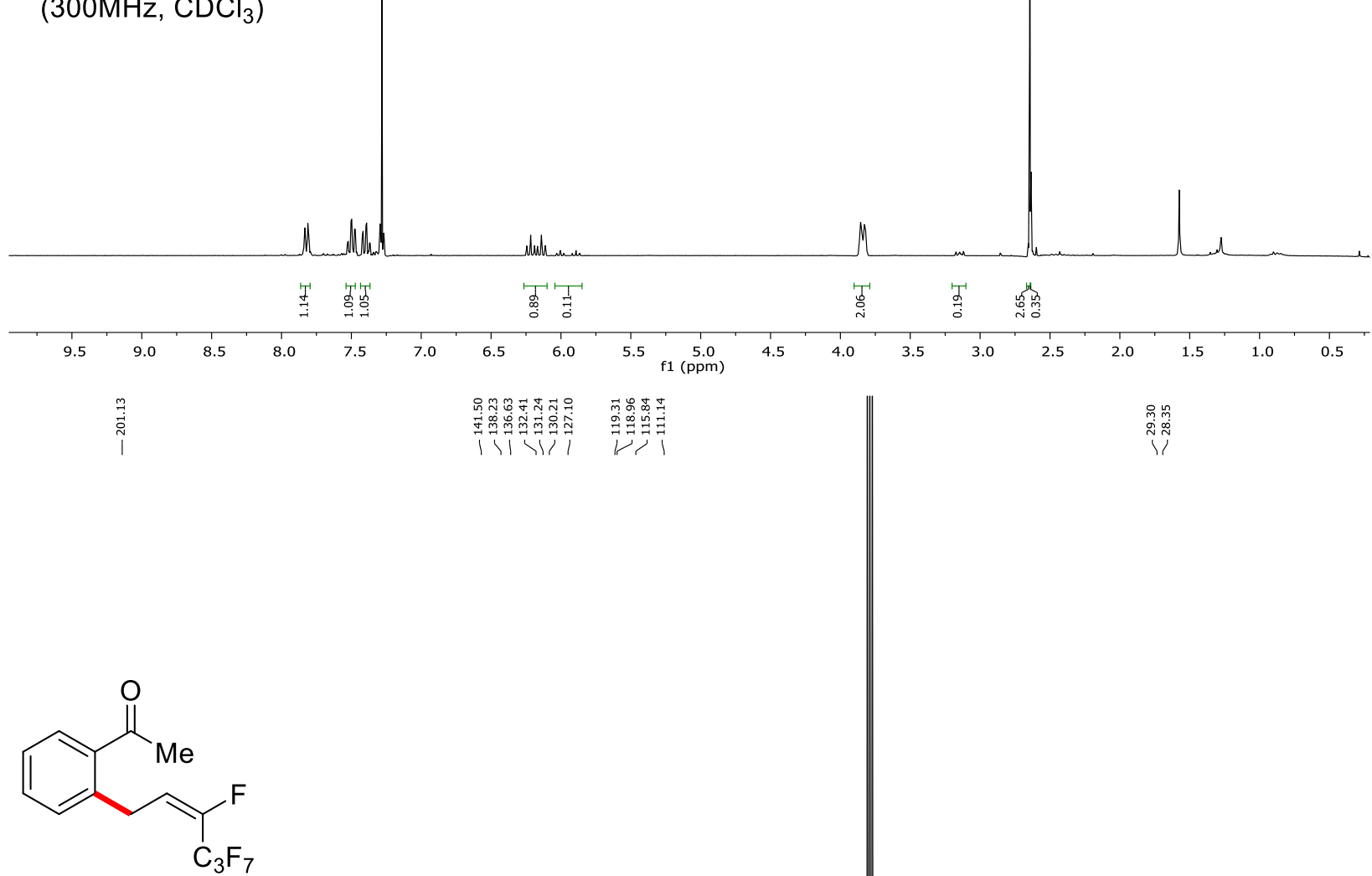

$307 a b$

$\left(75 \mathrm{MHz}, \mathrm{CDCl}_{3}\right)$

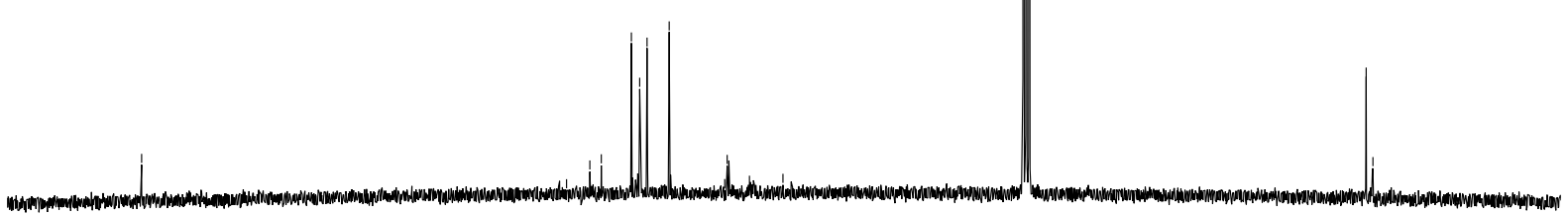

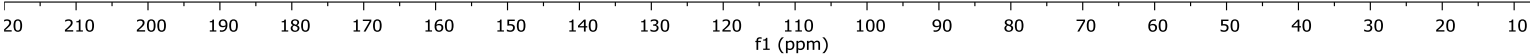




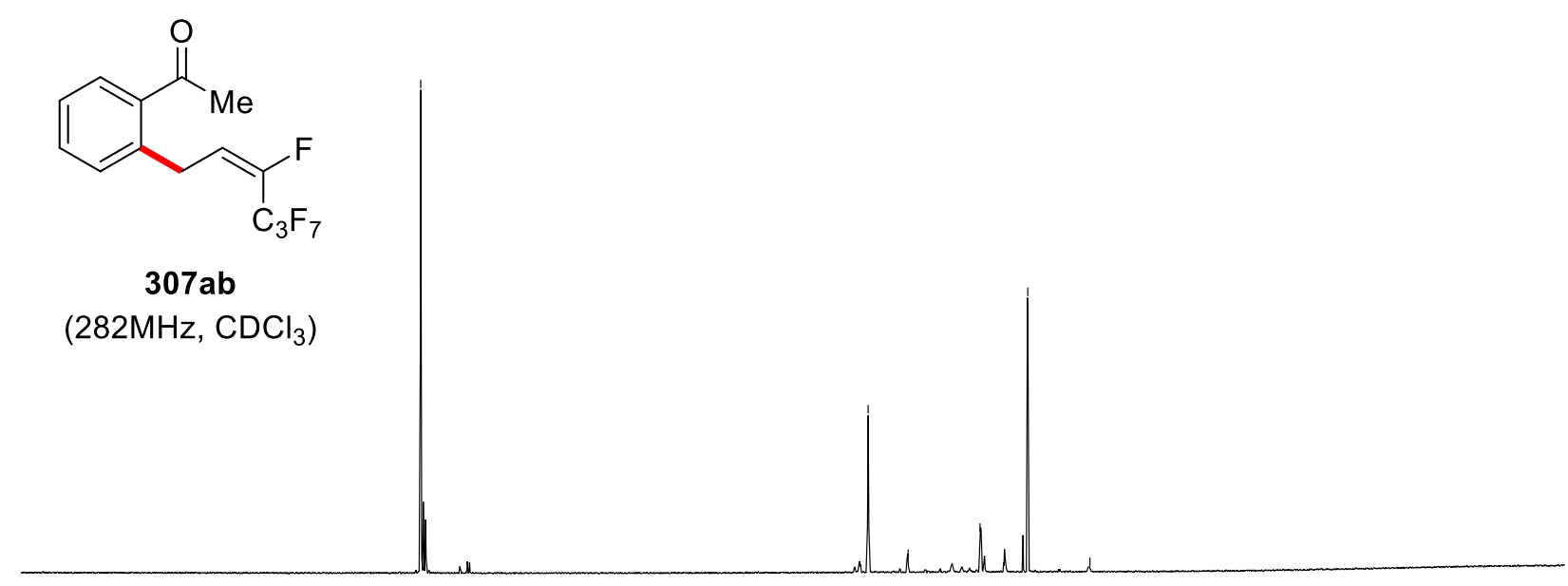

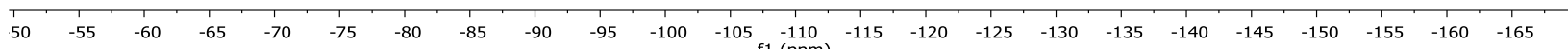


<smiles>CC(=O)c1ccc(C)cc1CC=C(F)C(F)F</smiles>

$307 \mathrm{cb}$

$\left(300 \mathrm{MHz}, \mathrm{CDCl}_{3}\right)$

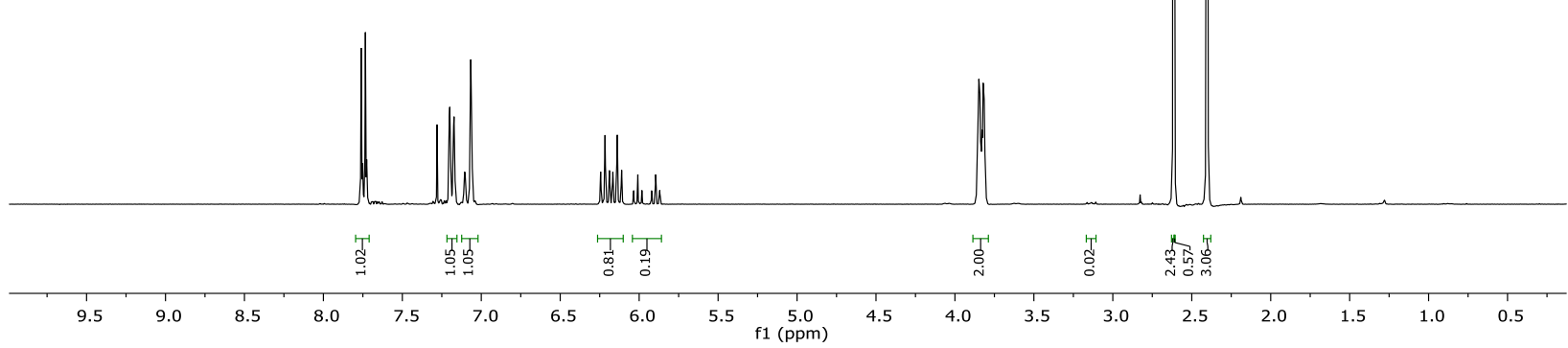<smiles>CC(=O)c1ccc(C)cc1CC=C(F)C(F)(F)C(F)(F)F</smiles>

$307 \mathrm{cb}$

$\left(75 \mathrm{MHz}, \mathrm{CDCl}_{3}\right)$

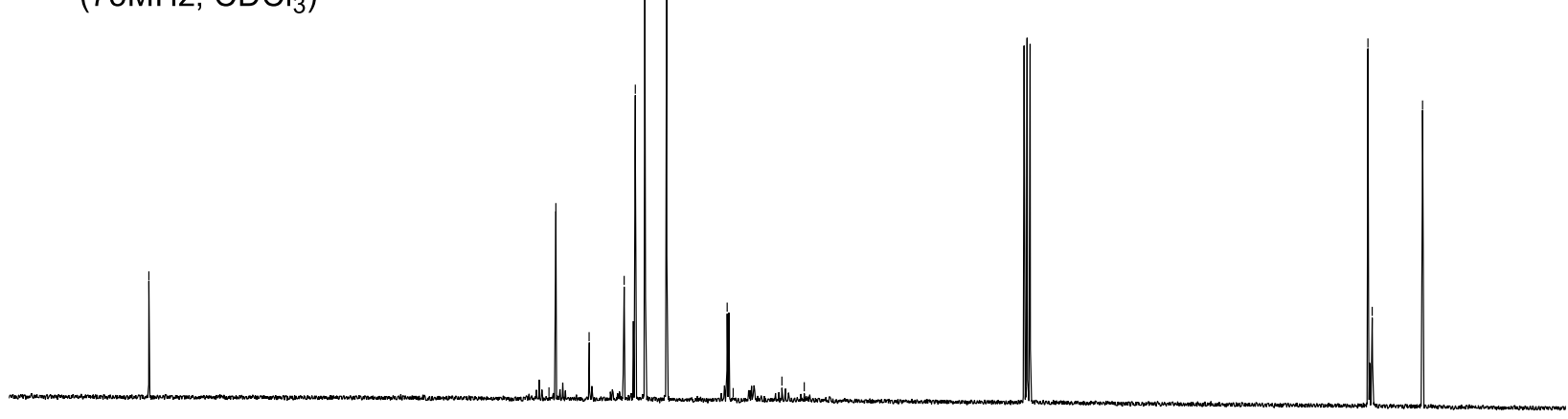

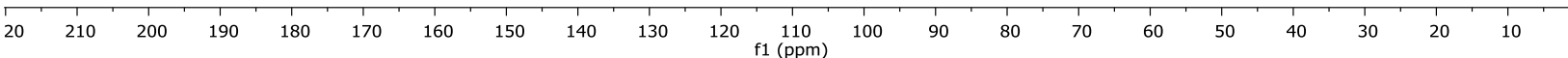




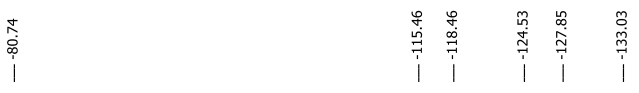

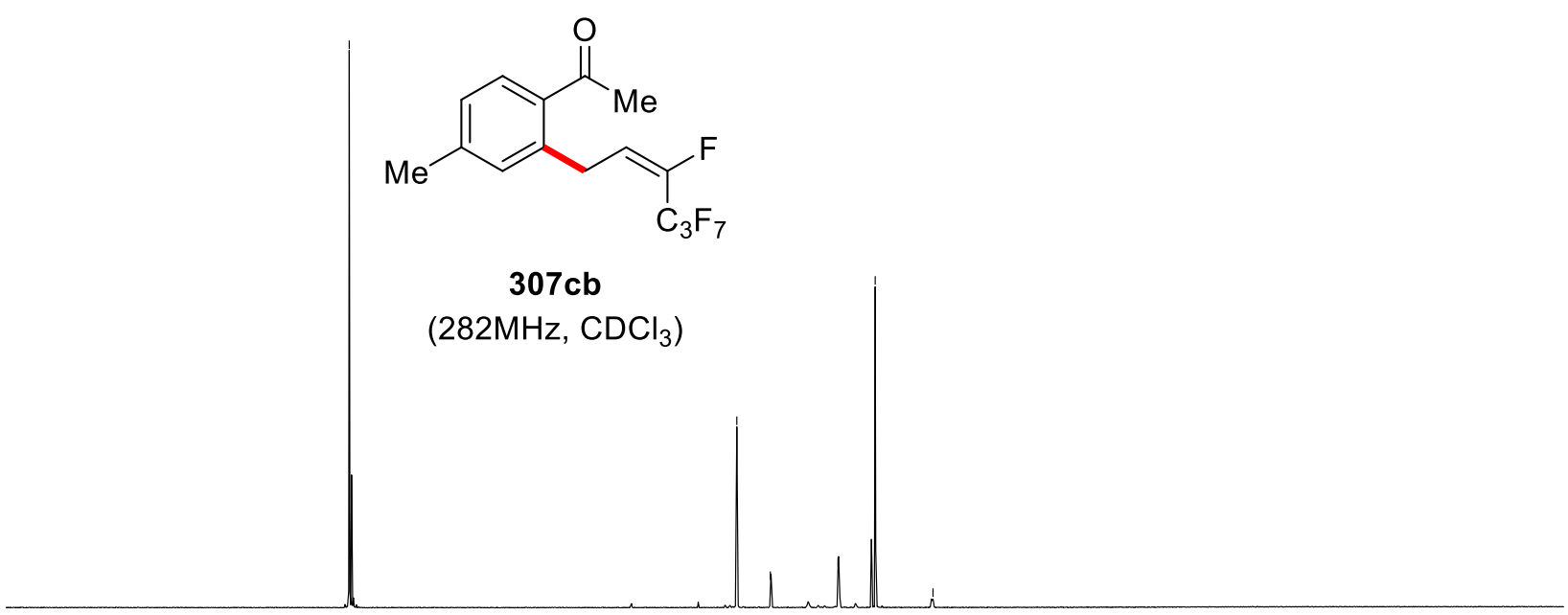

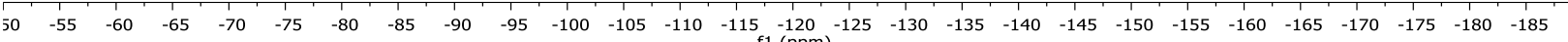


<smiles>CC(=O)c1ccc(-c2ccccc2)cc1C/C=C(\F)C(F)(F)C(F)(F)F</smiles>

$307 \mathrm{db}$

$\left(300 \mathrm{MHz}, \mathrm{CDCl}_{3}\right)$

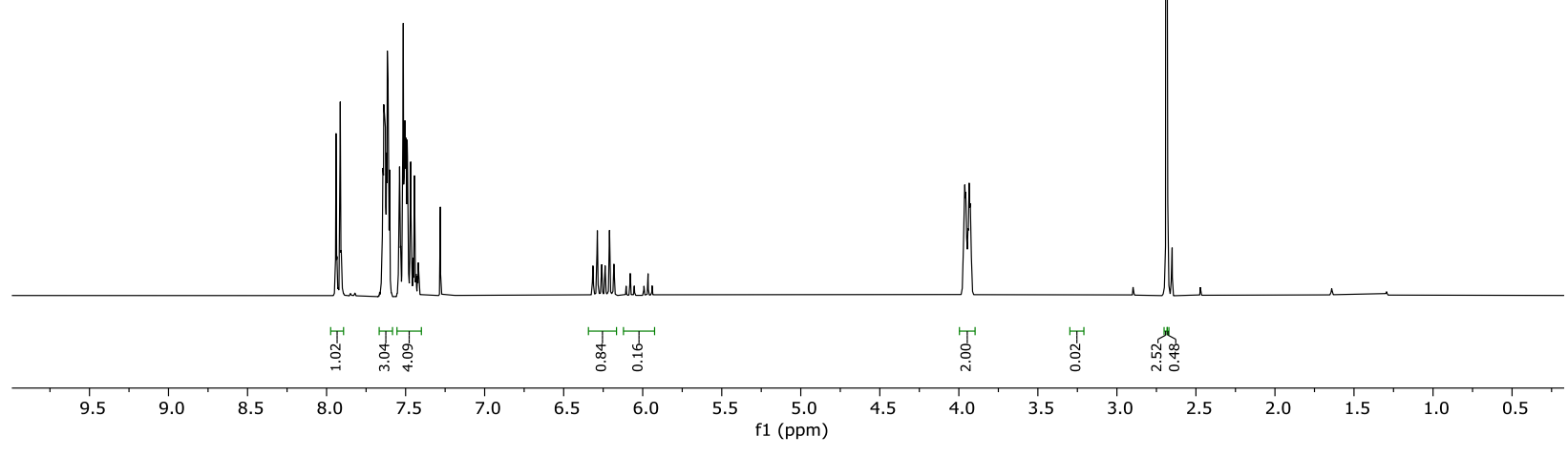

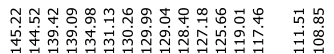

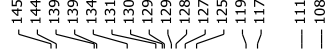

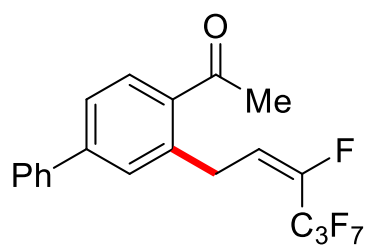

$307 \mathrm{db}$

$\left(75 \mathrm{MHz}, \mathrm{CDCl}_{3}\right)$

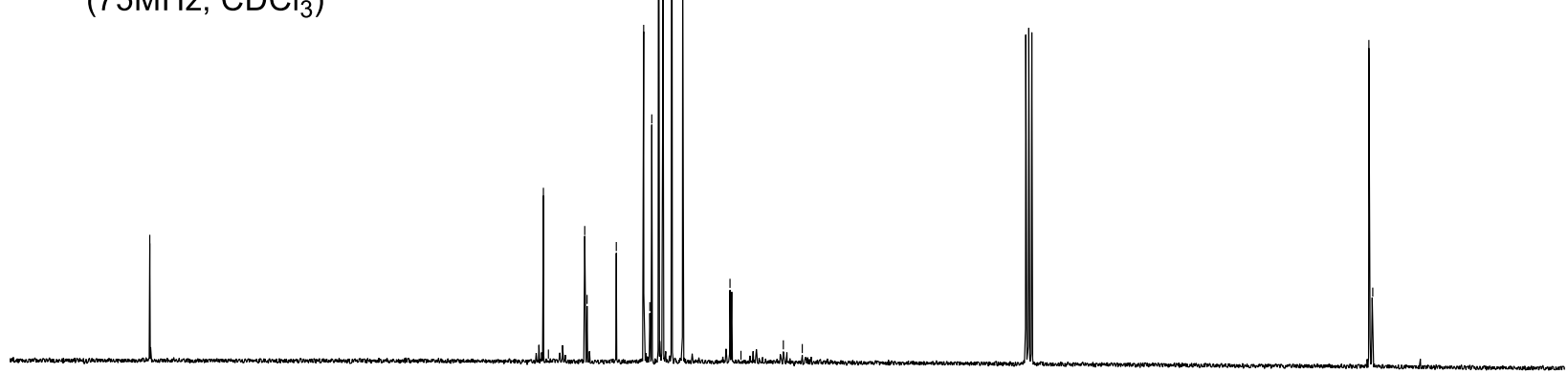

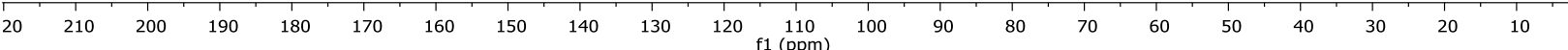




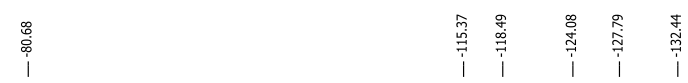

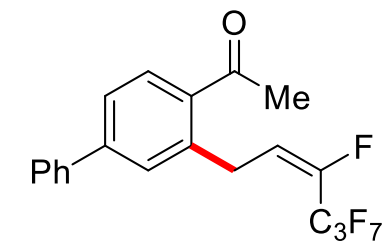

$307 \mathrm{db}$

(282MHz, $\mathrm{CDCl}_{3}$ )

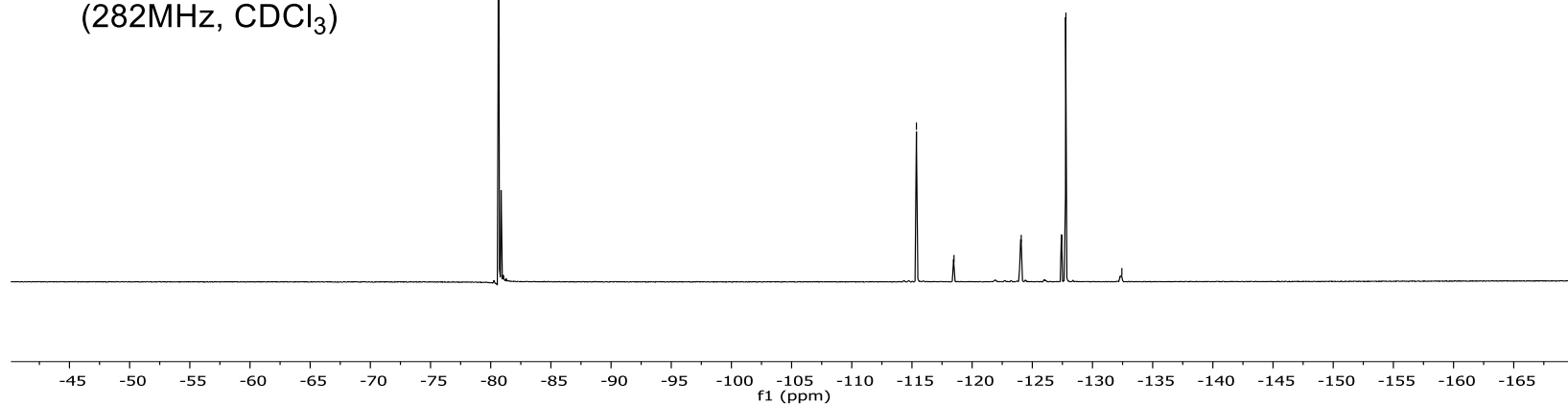


<smiles>CC(=O)c1ccccc1CCC(F)F</smiles>

339aa

(300 MHz, $\mathrm{CDCl}_{3}$ )
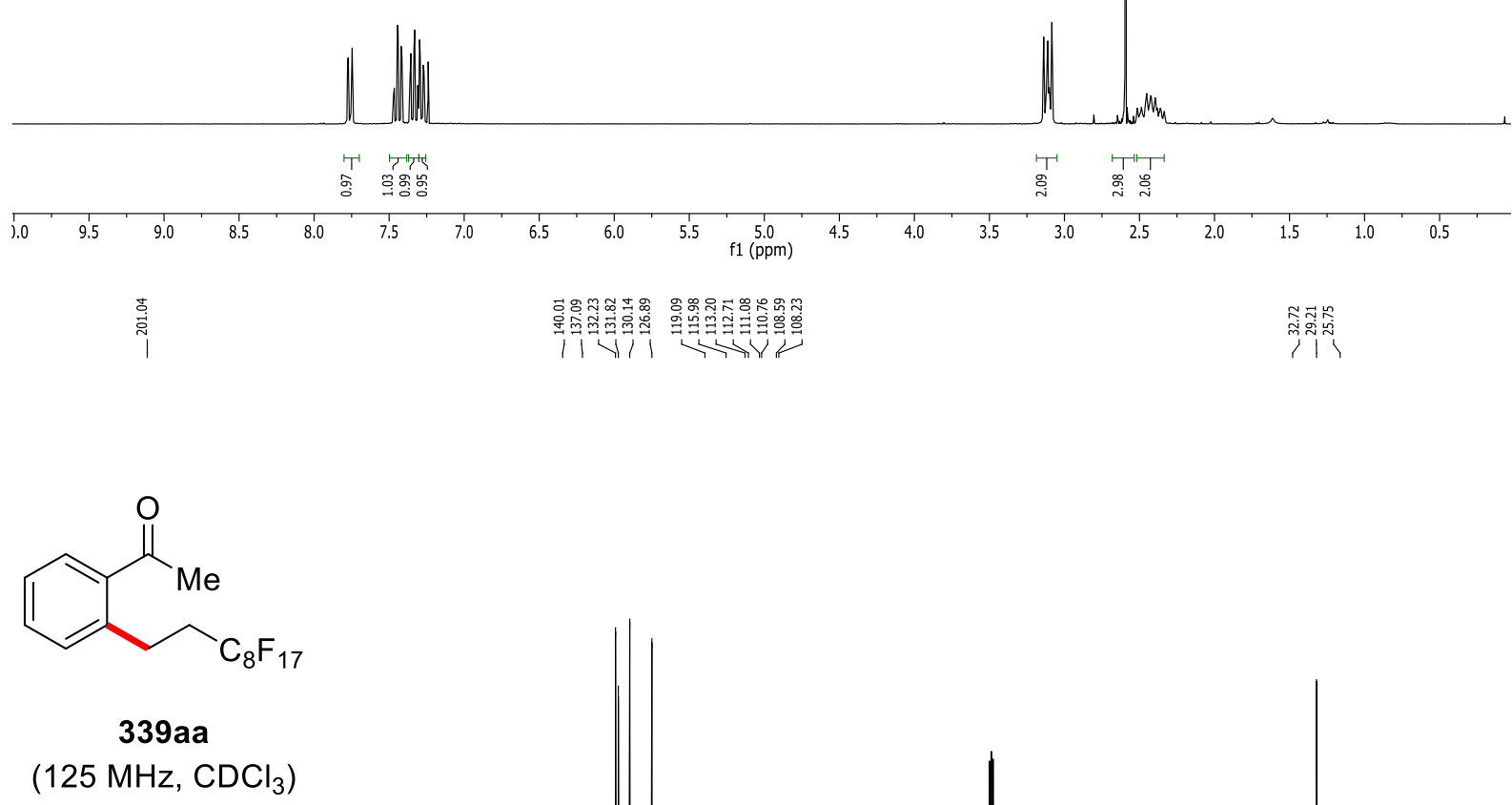

$$
\text { (125 MHz, } \mathrm{CDCl}_{3} \text { ) }
$$

$20 \quad 2$
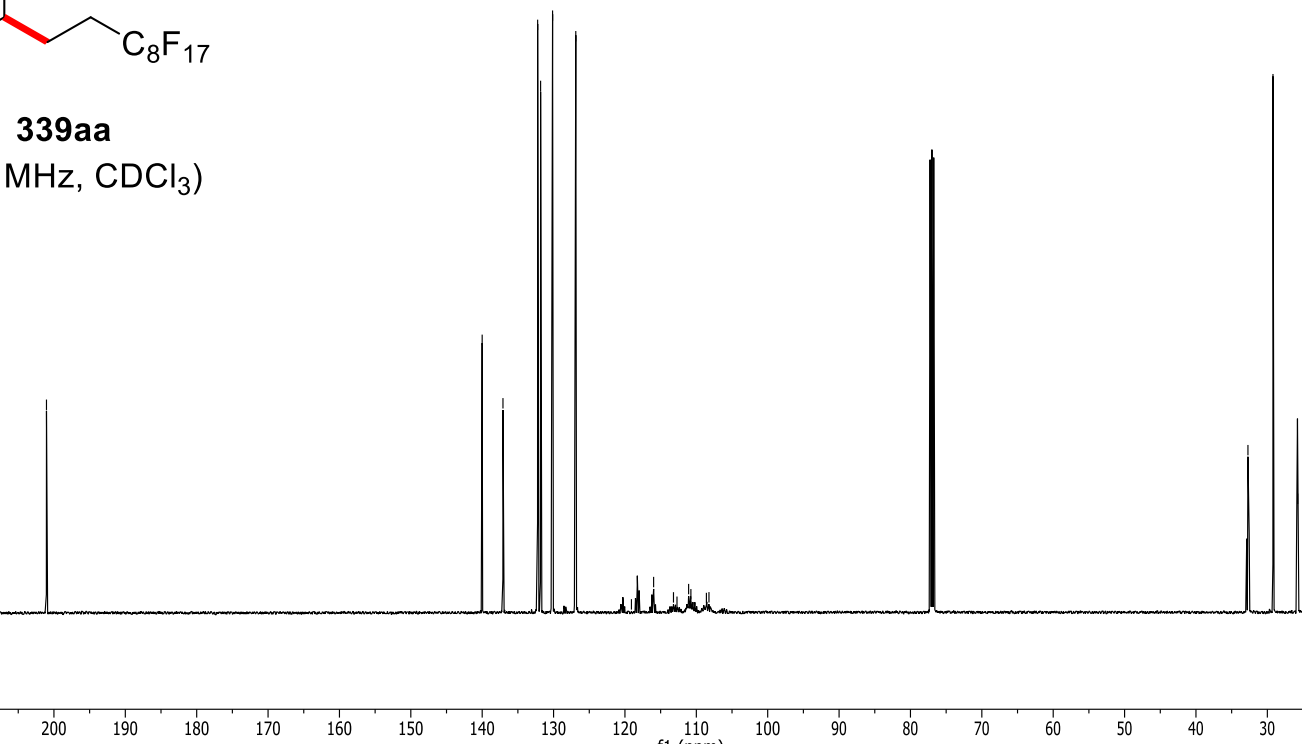


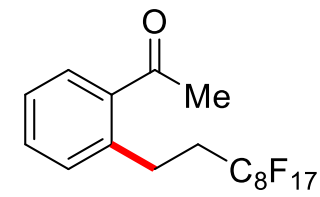

339aa

(282 MHz, $\mathrm{CDCl}_{3}$ )

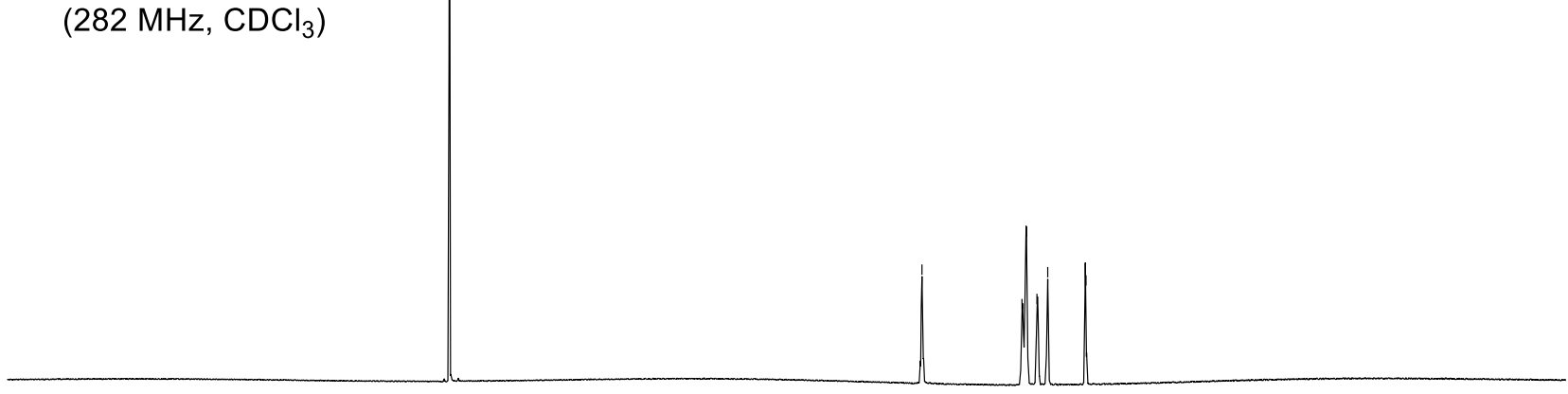

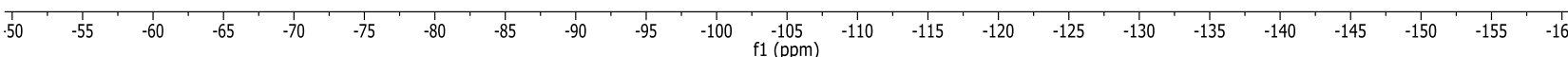



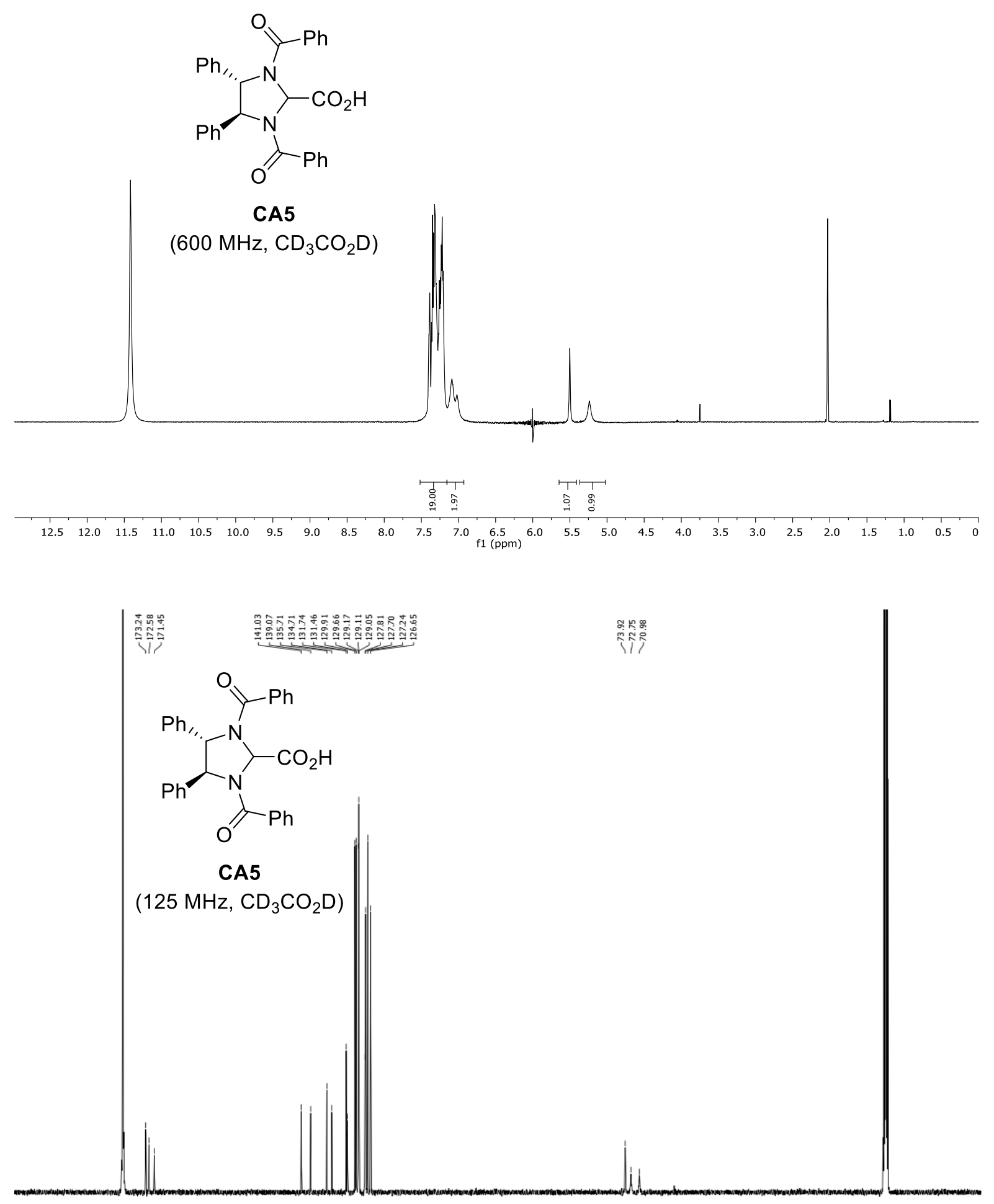

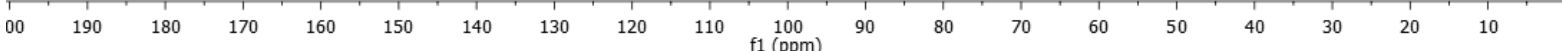




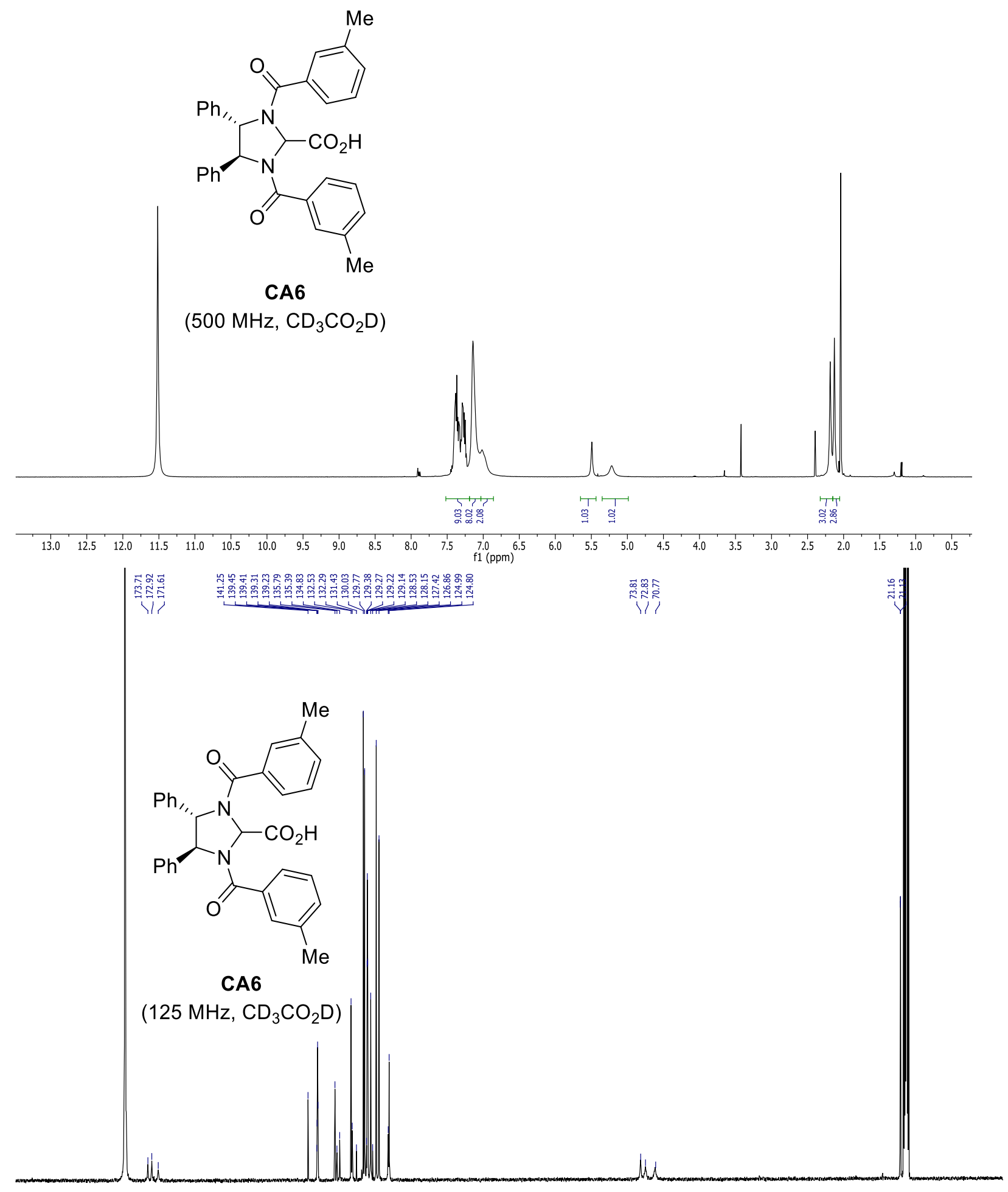

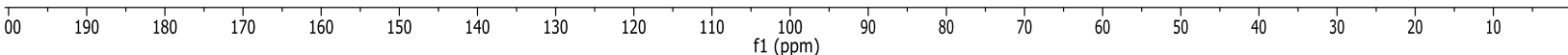




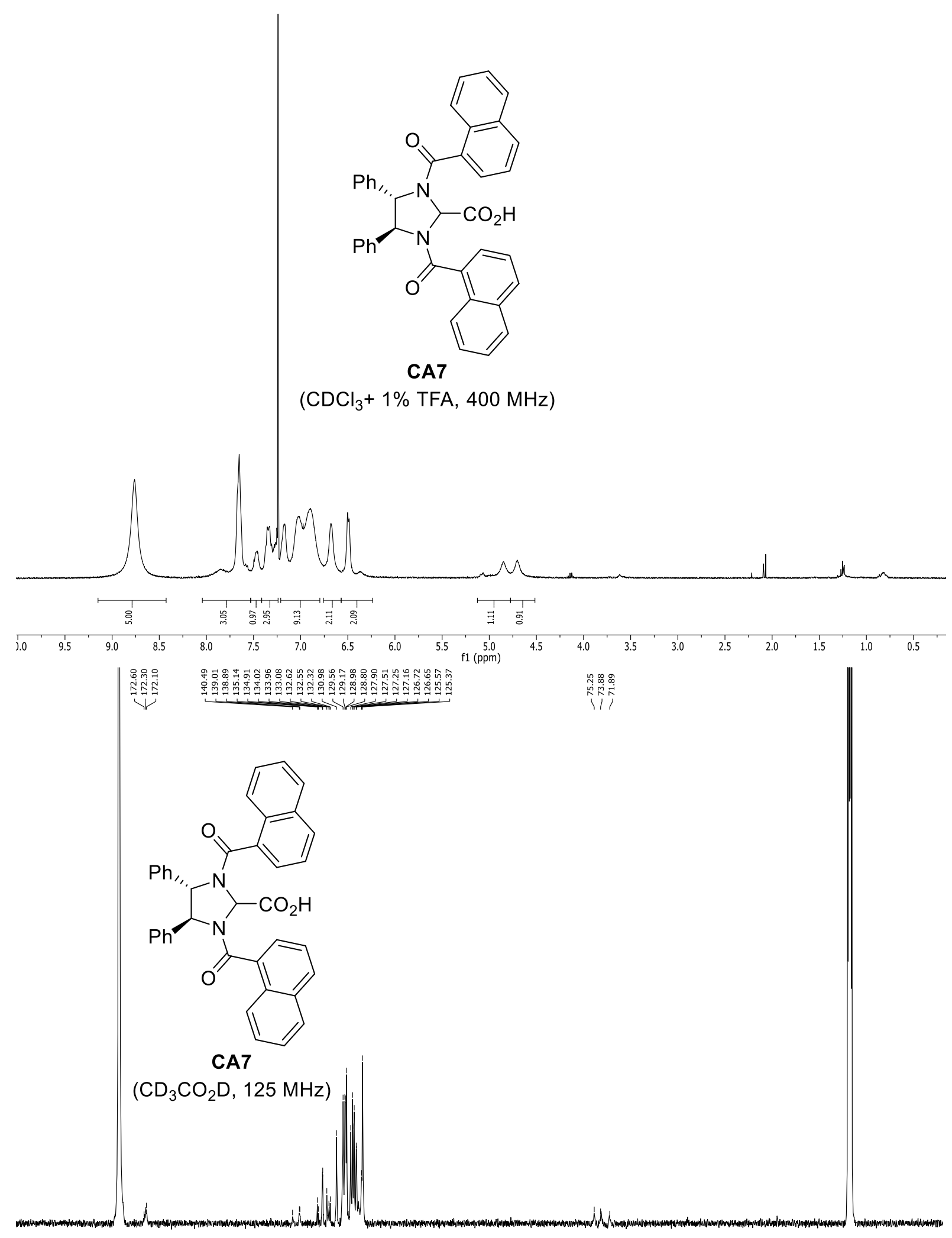

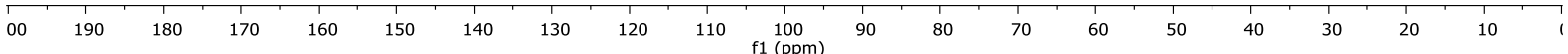




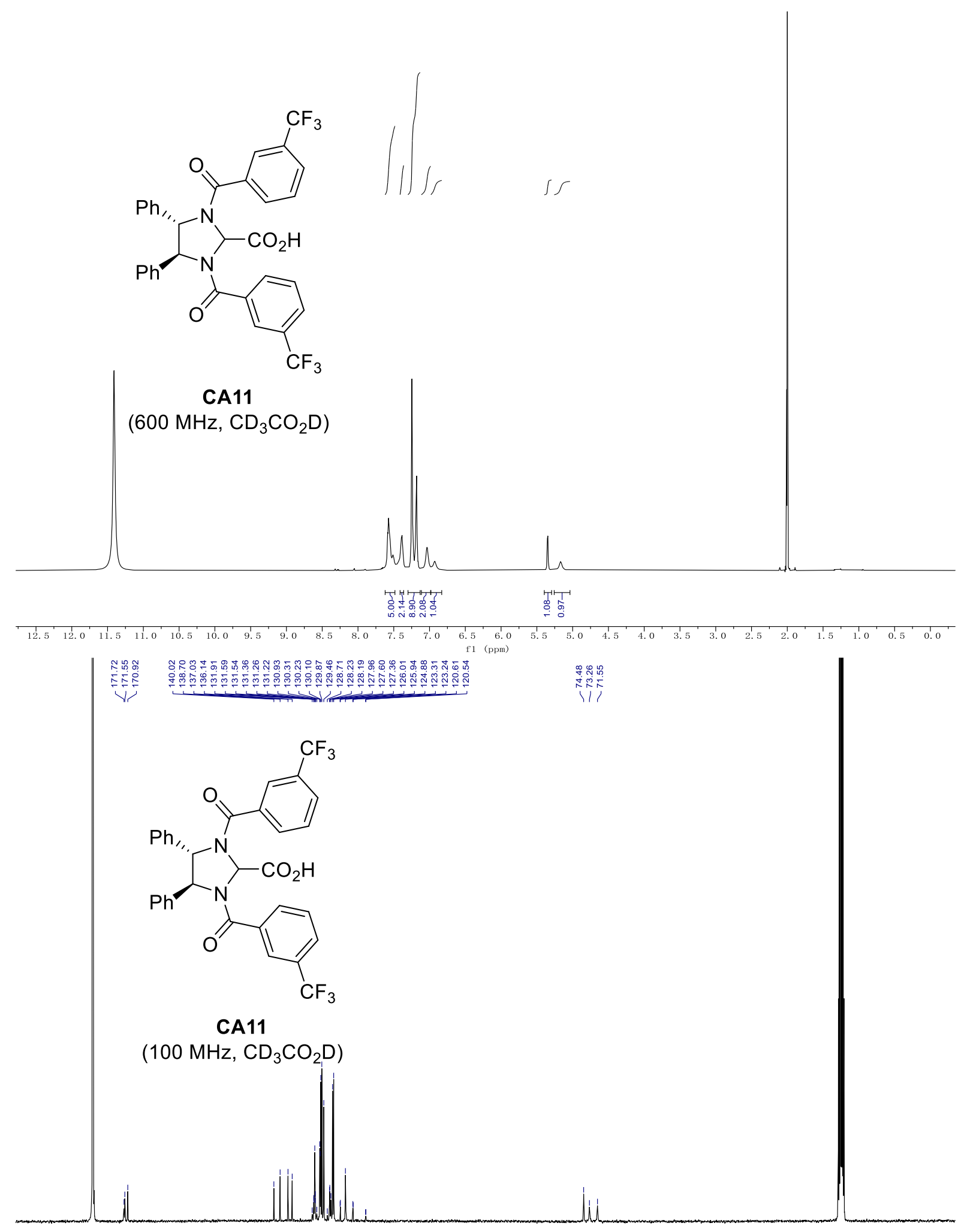


<smiles>O=C(O)C1N(C(=O)c2cccc(C(F)(F)F)c2)[C@H](c2ccccc2)[C@@H](c2ccccc2)N1C(=O)c1cccc(C(F)(F)F)c1</smiles>

CA11

(377 MHz, $\mathrm{CD}_{3} \mathrm{CO}_{2} \mathrm{D}$ ) 


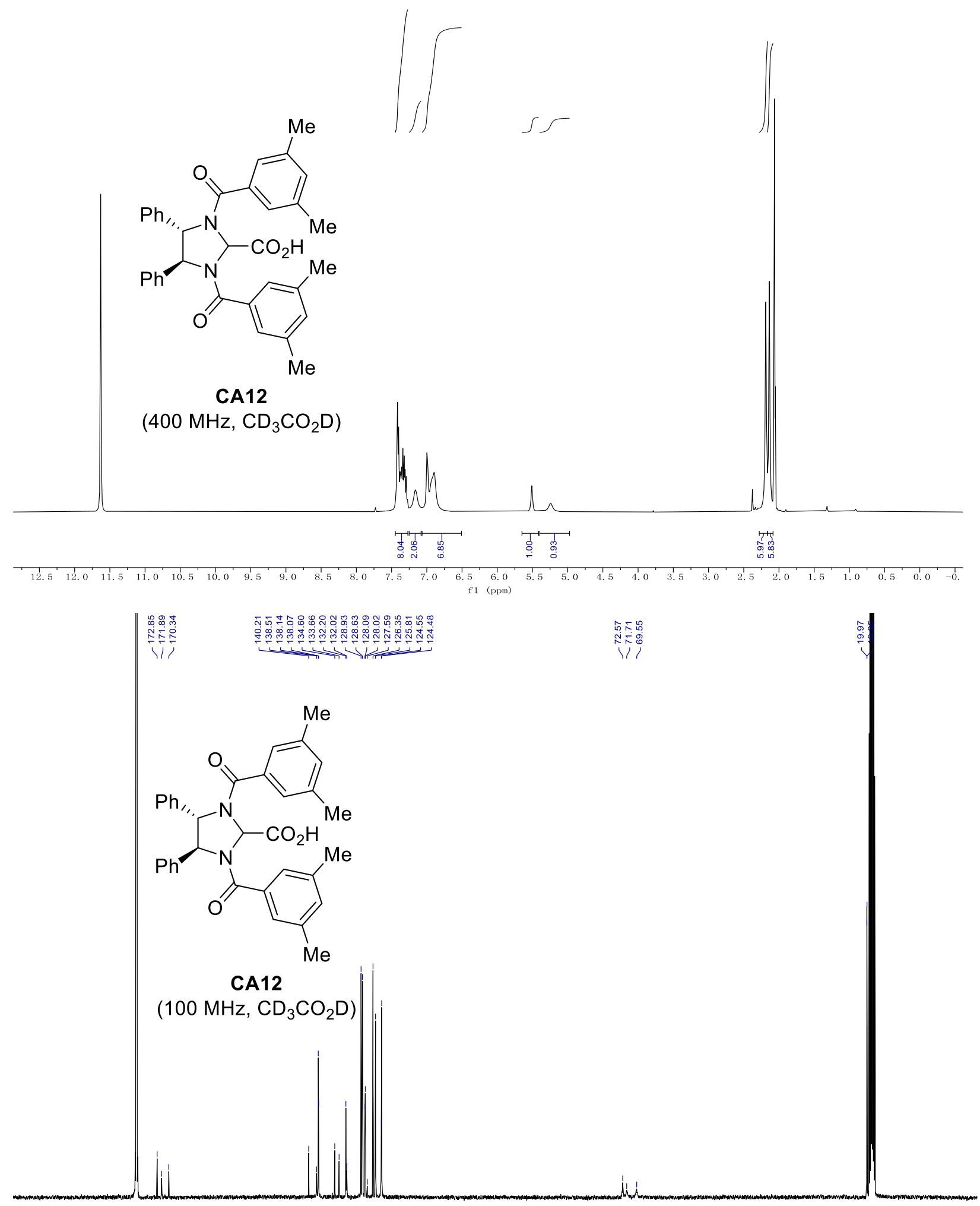




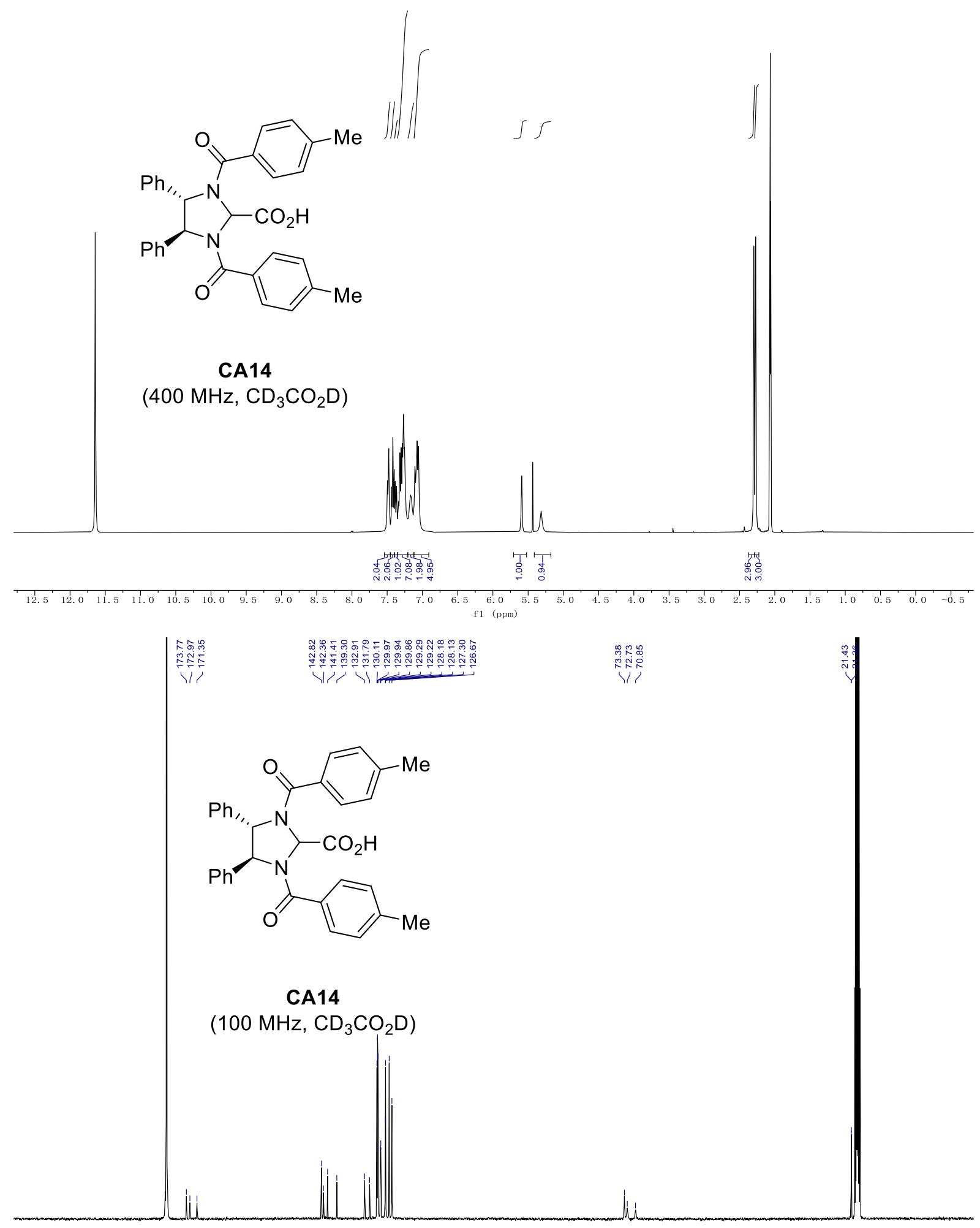

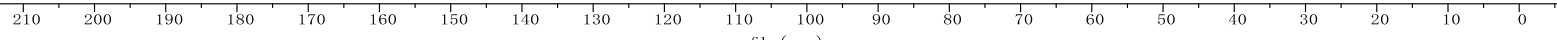



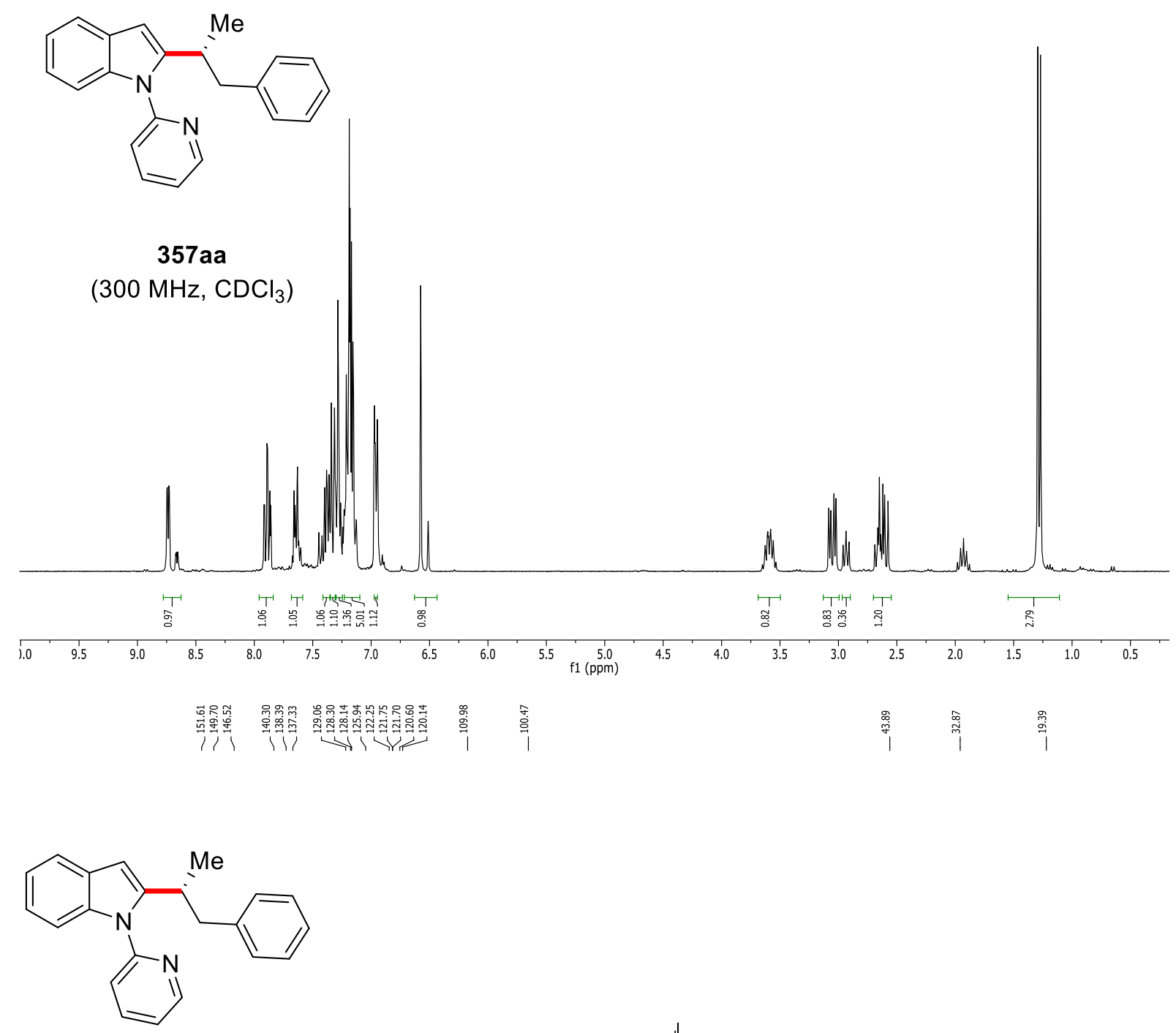

357 aa

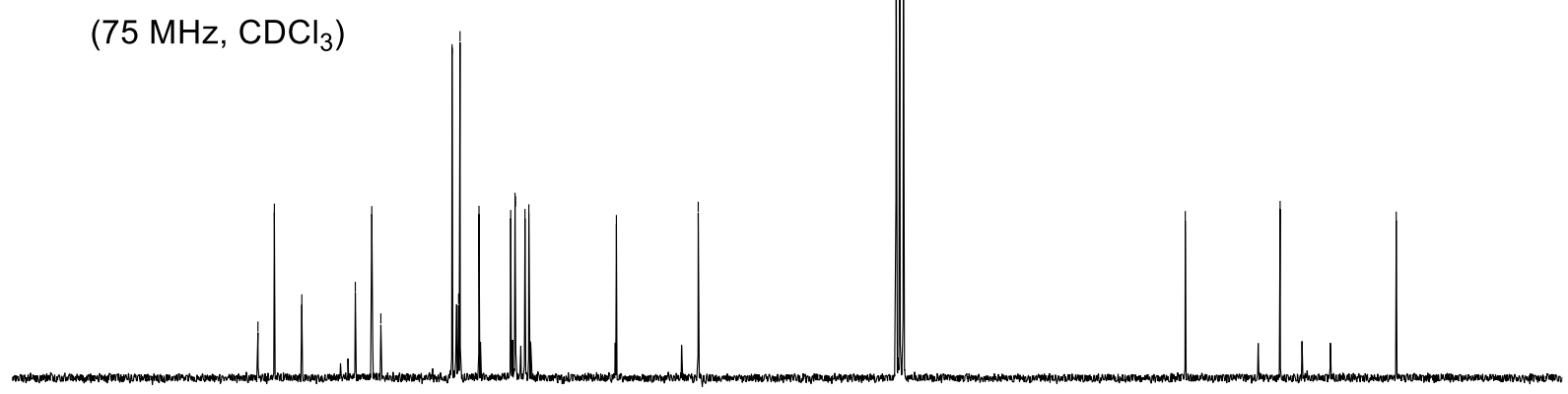

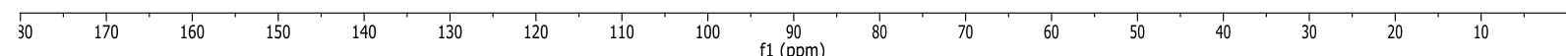


Chiral HPLC of 357aa:
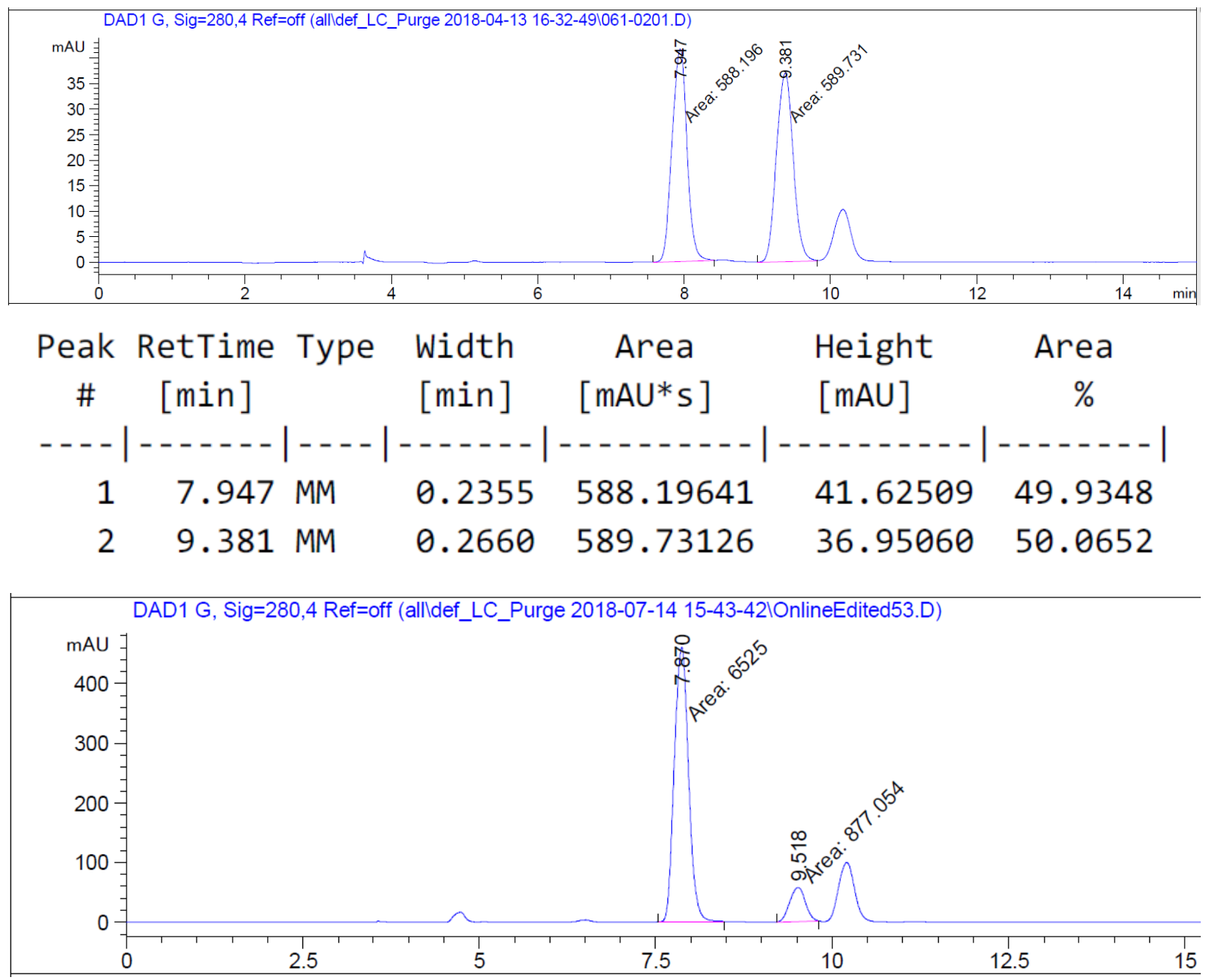

Peak RetTime Type Width Area Height Area

\# [min] [min] [mAU*s $] \quad[\mathrm{mAU}] \quad \%$

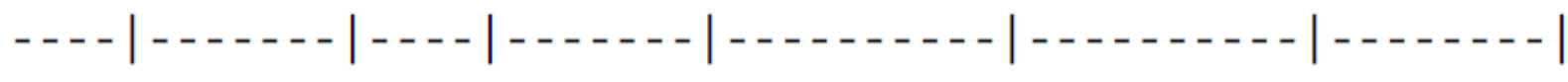

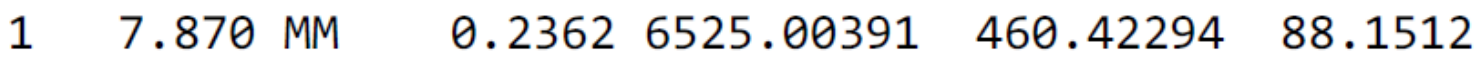

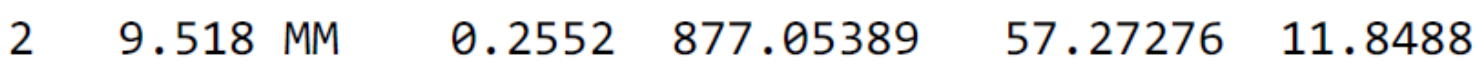



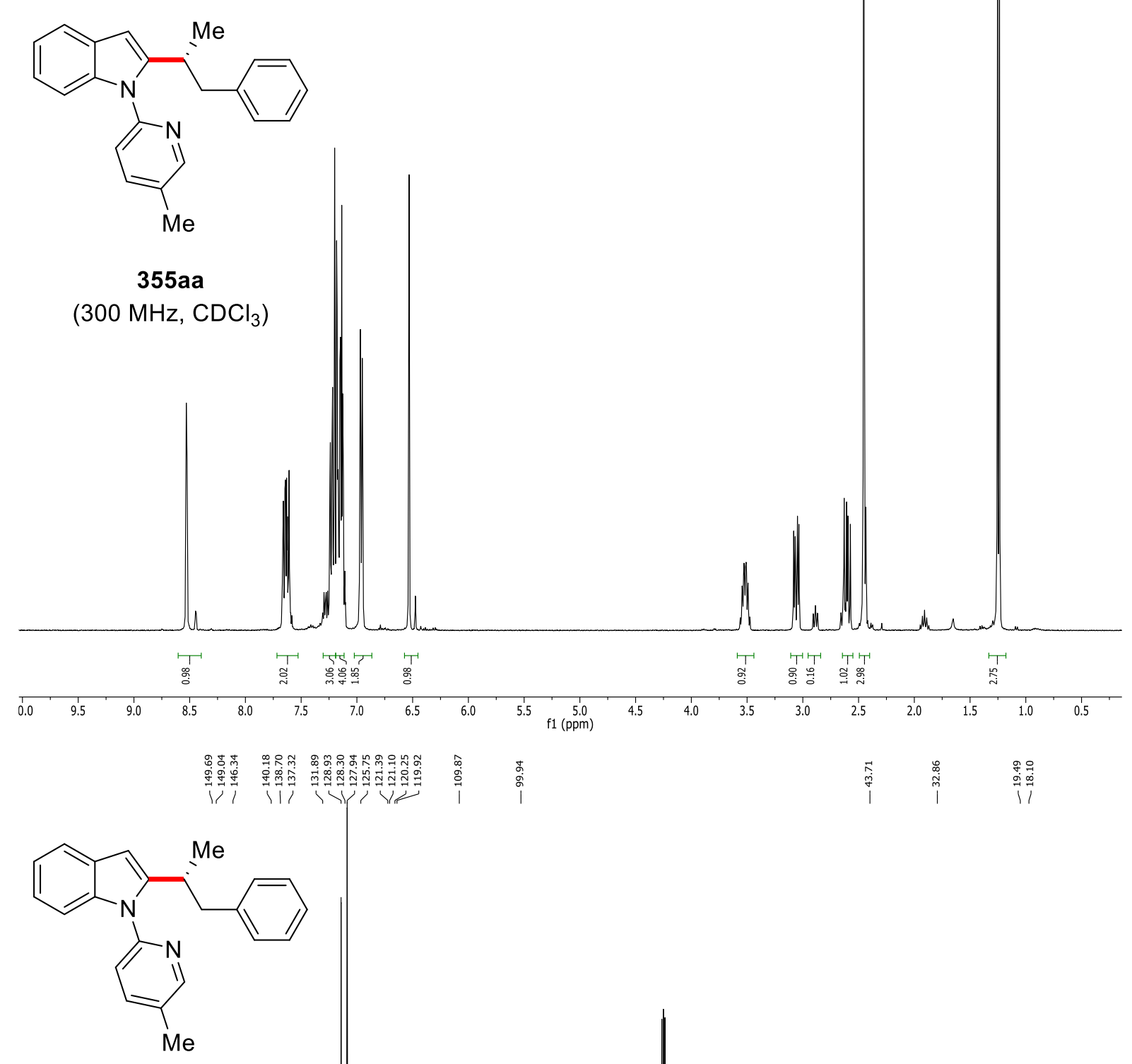

355aa

(125 MHz, $\mathrm{CDCl}_{3}$ )

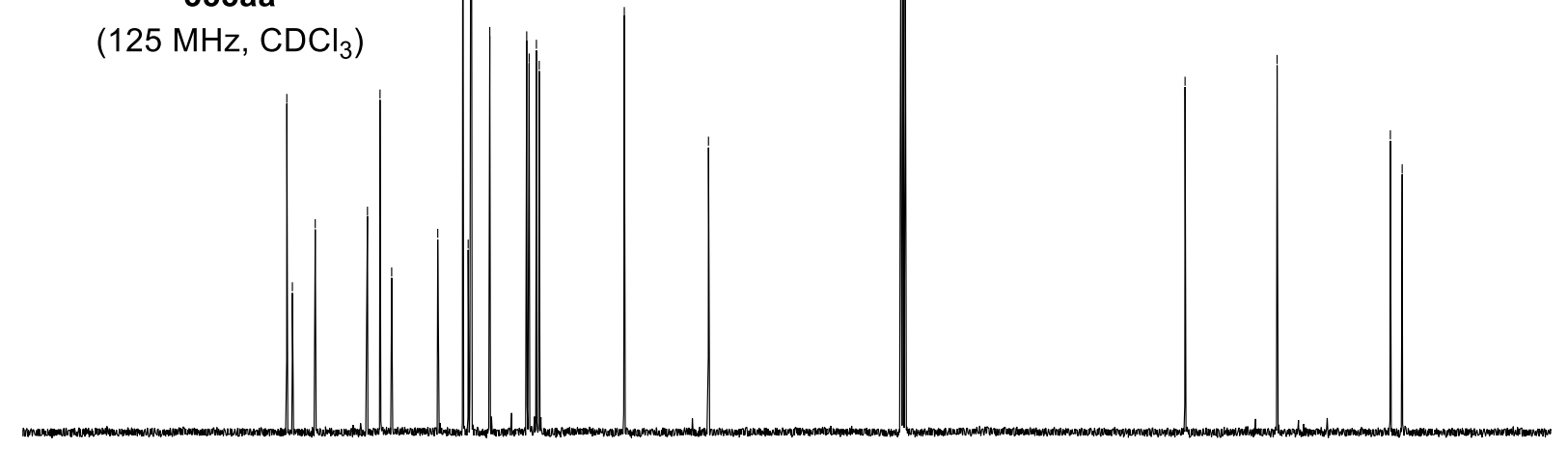


Chiral HPLC of 355aa:

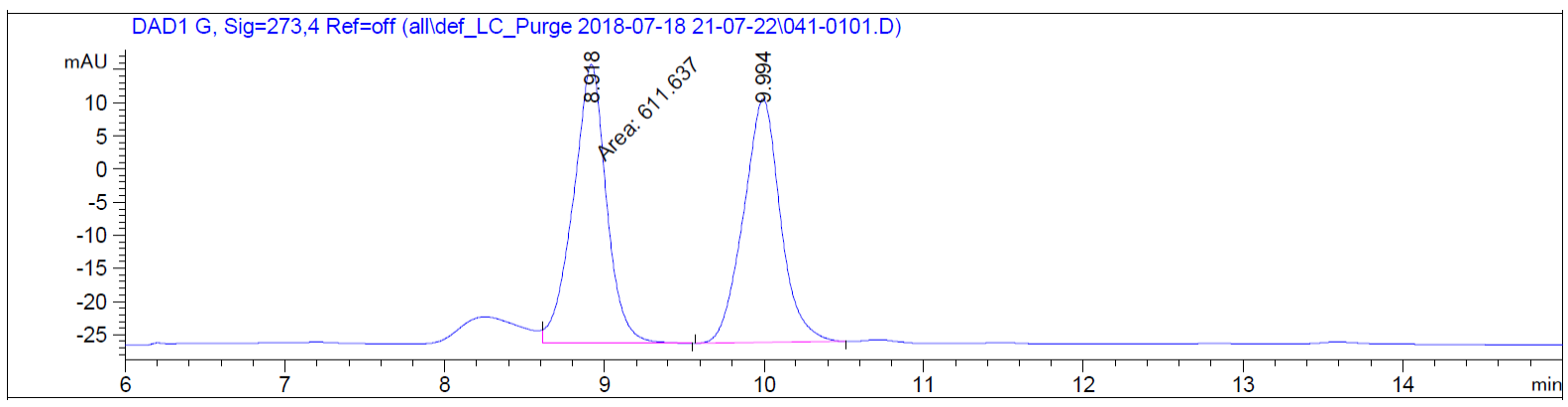

$\begin{array}{cccccc}\text { Peak } & \text { RetTime Type } & \text { Width } & \text { Area } & \text { Height } & \text { Area } \\ \# & {[\text { min }]} & {[\text { min }]} & {[\text { mAU*s }]} & {[\text { mAU }]} & \%\end{array}$

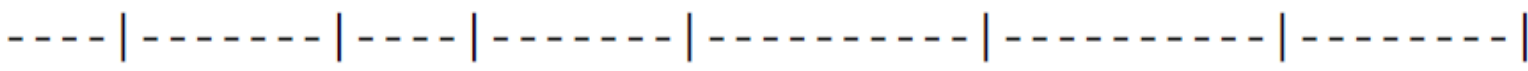
18.918 FM
$0.2419 \quad 611.63660$
$42.14855 \quad 50.7977$
29.994 BB
$0.2372 \quad 592.42639$
36.71786
49.2023

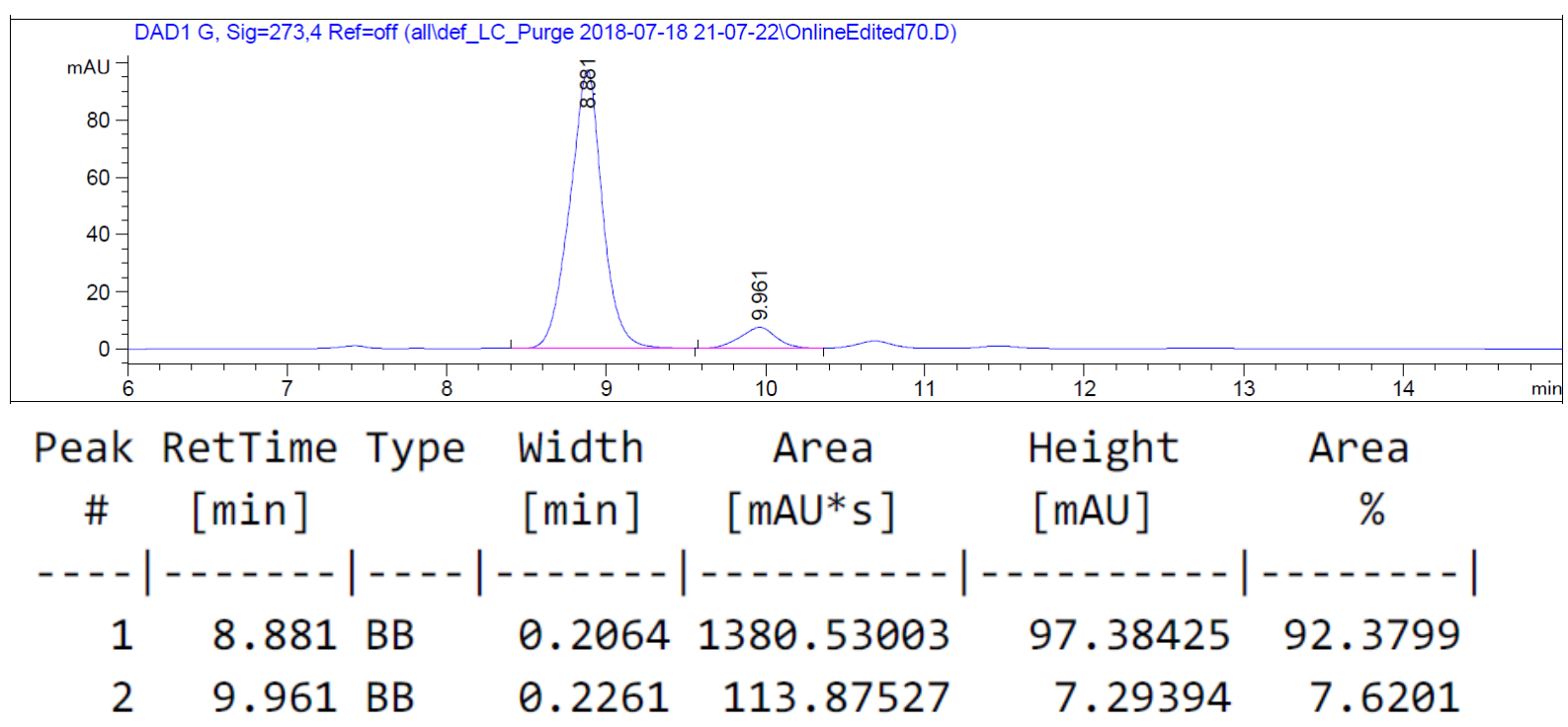



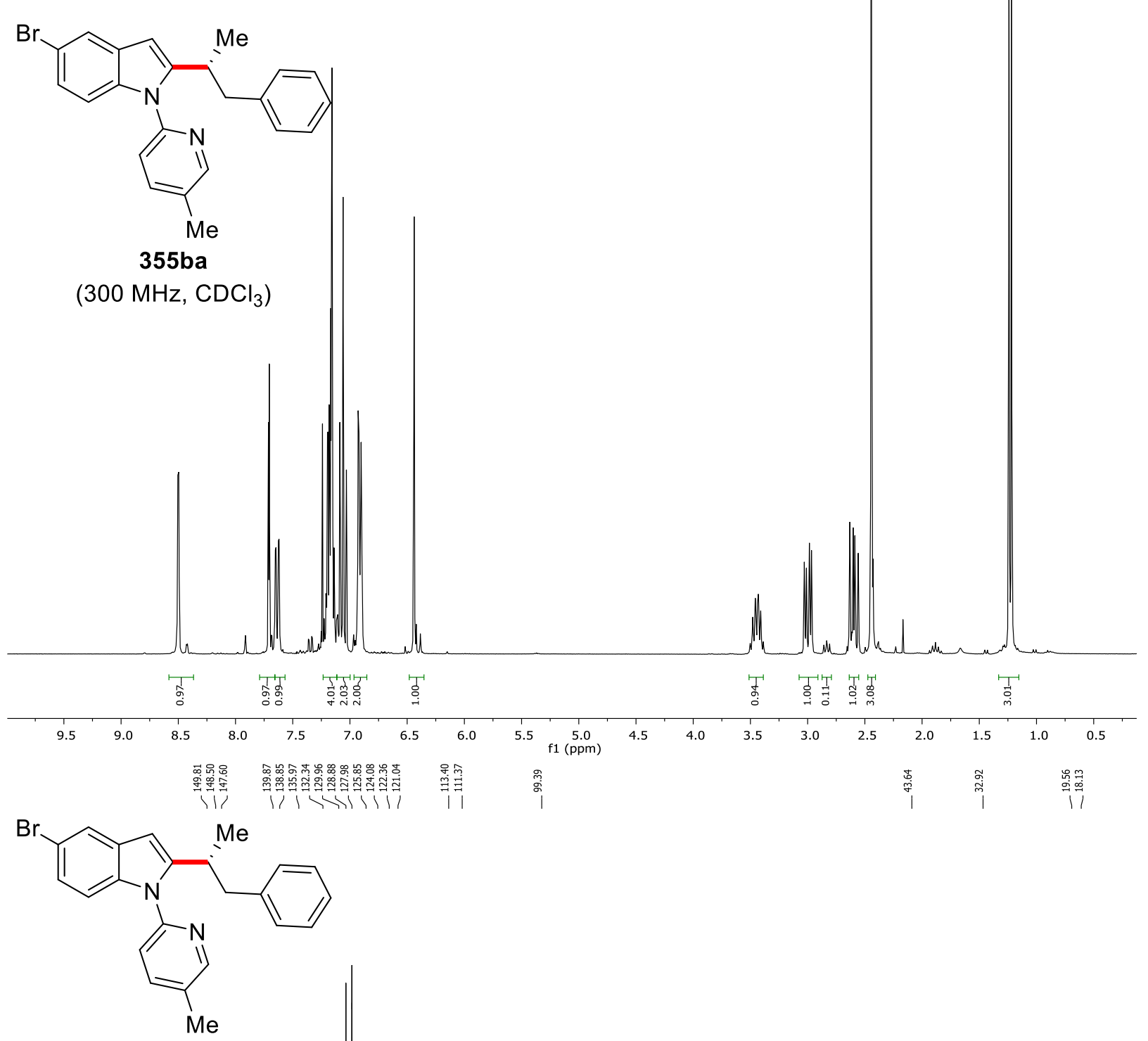

$355 \mathrm{ba}$

(125 MHz, $\mathrm{CDCl}_{3}$ )

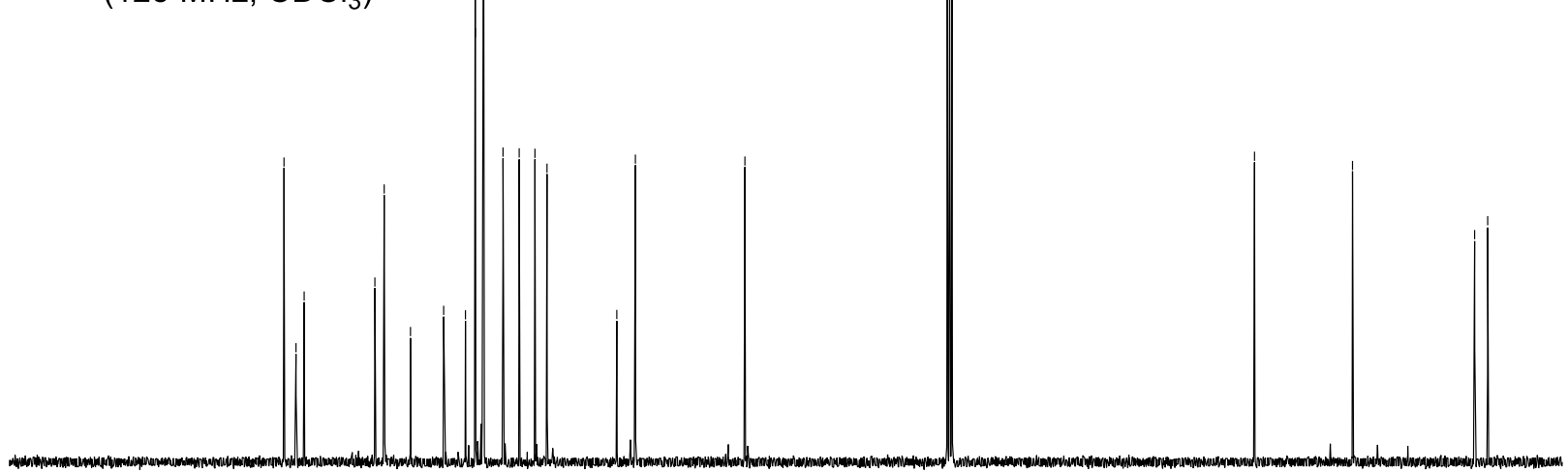


Chiral HPLC of 355ba:

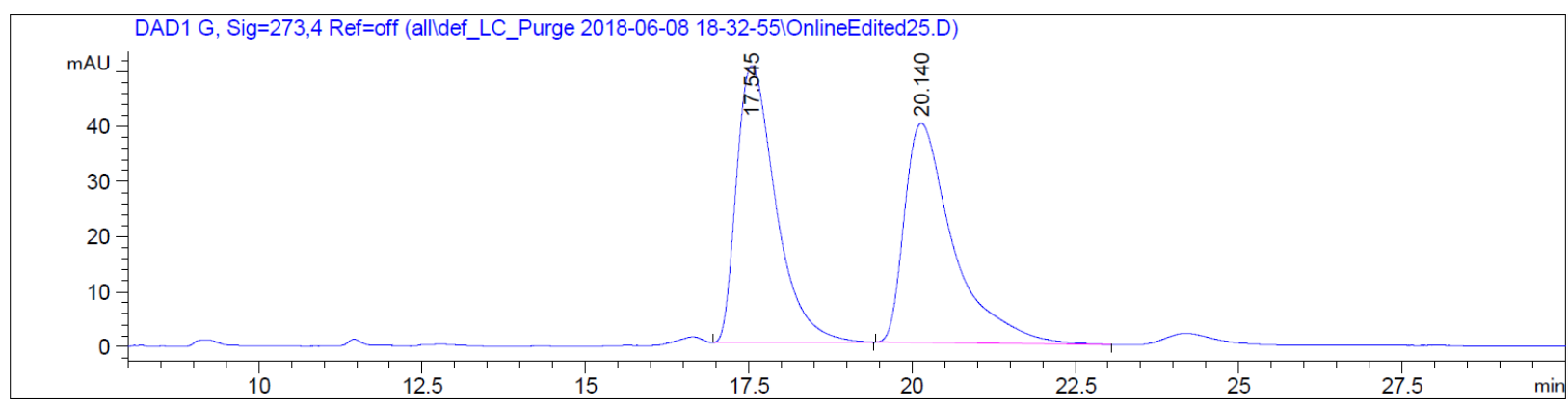

Peak RetTime Type Width Area Height Area

$\begin{array}{lllll}\text { \# } & {[\mathrm{min}]} & \mathrm{min}] & {[\mathrm{mAU} * \mathrm{~s}]} & {[\mathrm{mAU}]}\end{array}$

-- - - | - - - - - |-- - | - - - - - | - - - - - - | - - - - - - | - - - - - | |

$\begin{array}{lllllll}1 & 17.545 & \text { BB } & 0.6281 & 2103.89453 & 50.28347 & 50.3633\end{array}$

$2 \quad 20.140$ BB $\quad 0.73872073 .53882 \quad 39.87462 \quad 49.6367$

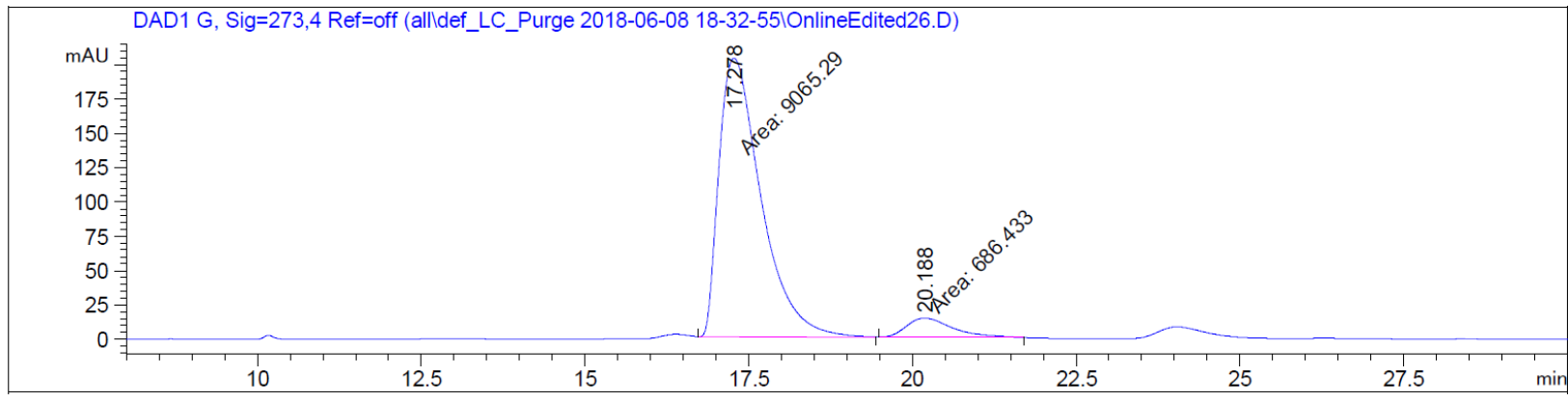

Peak RetTime Type width Area Height Area

\# [min] $[\mathrm{min}] \quad\left[\mathrm{mAU} \mathrm{H}^{*} \mathrm{~m}\right] \quad[\mathrm{mAU}] \quad \%$

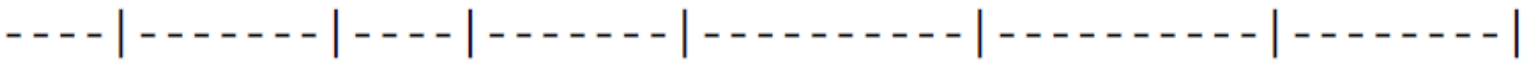

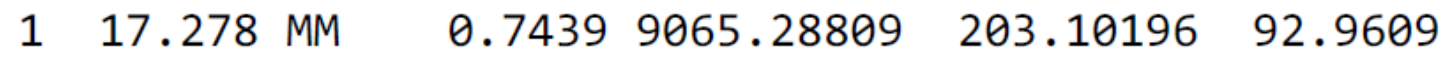

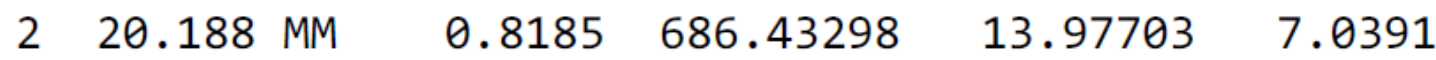




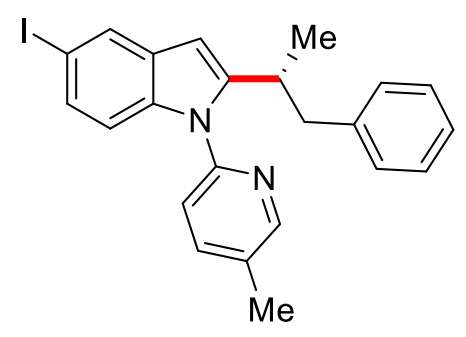

355ca

$\left(500 \mathrm{MHz}, \mathrm{CDCl}_{3}\right)$
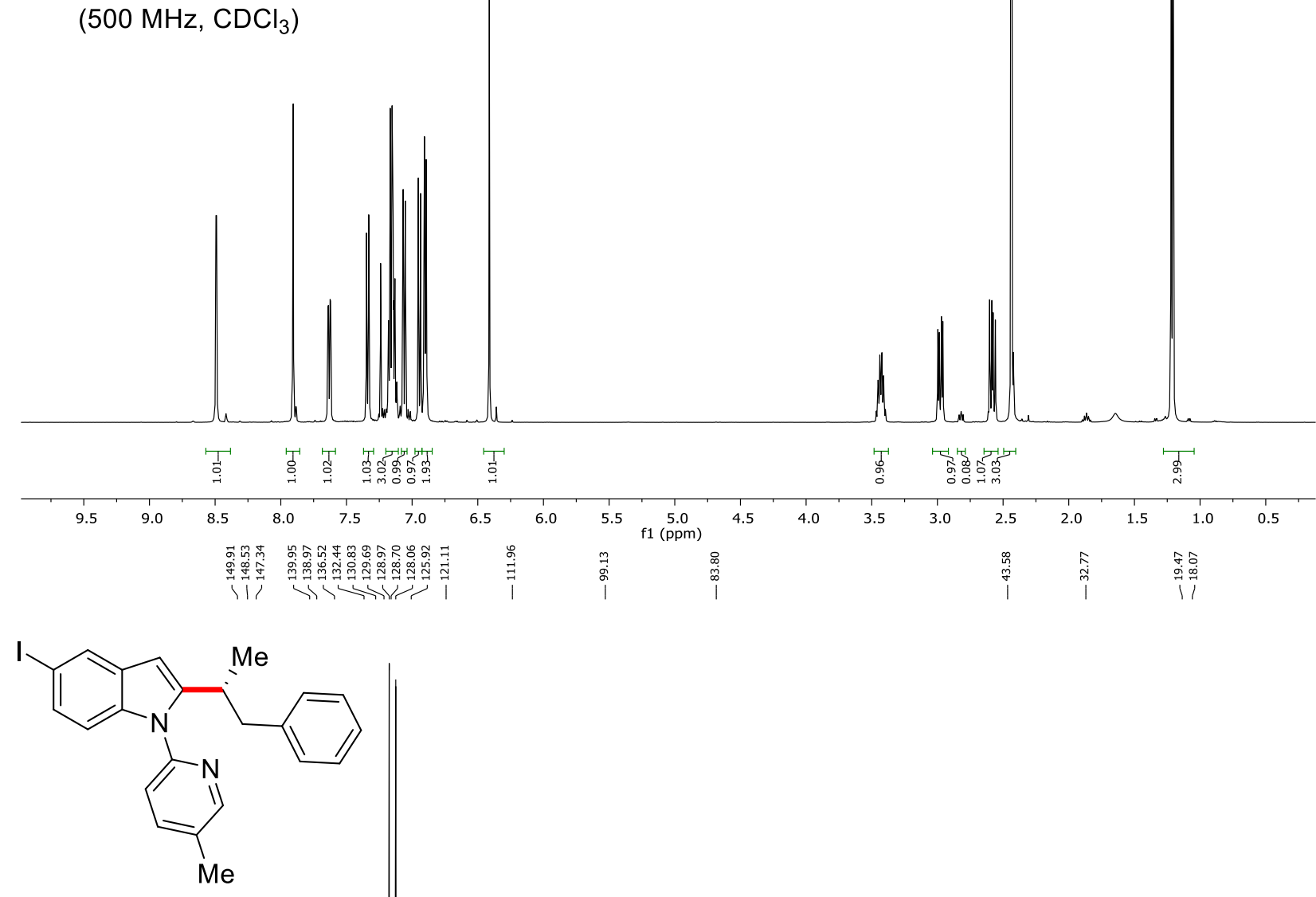

$355 \mathrm{ca}$

$\left(125 \mathrm{MHz} \mathrm{CDCl}_{3}\right)$

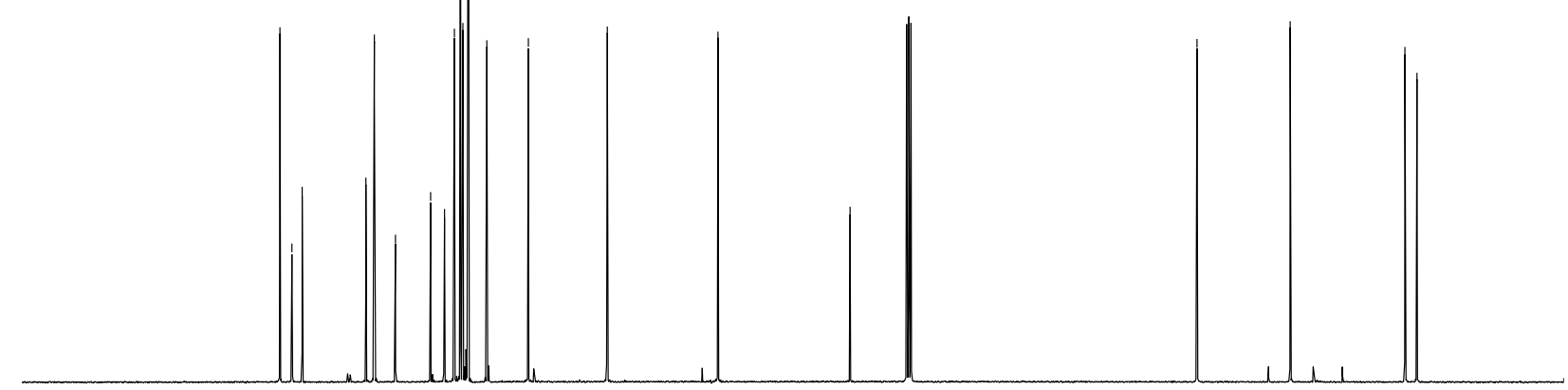

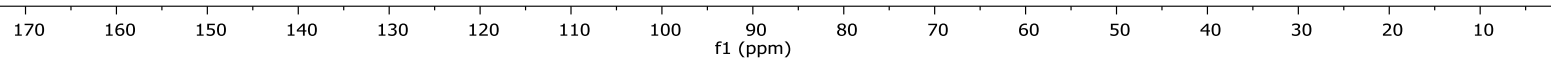


Chiral HPLC of 355ca:

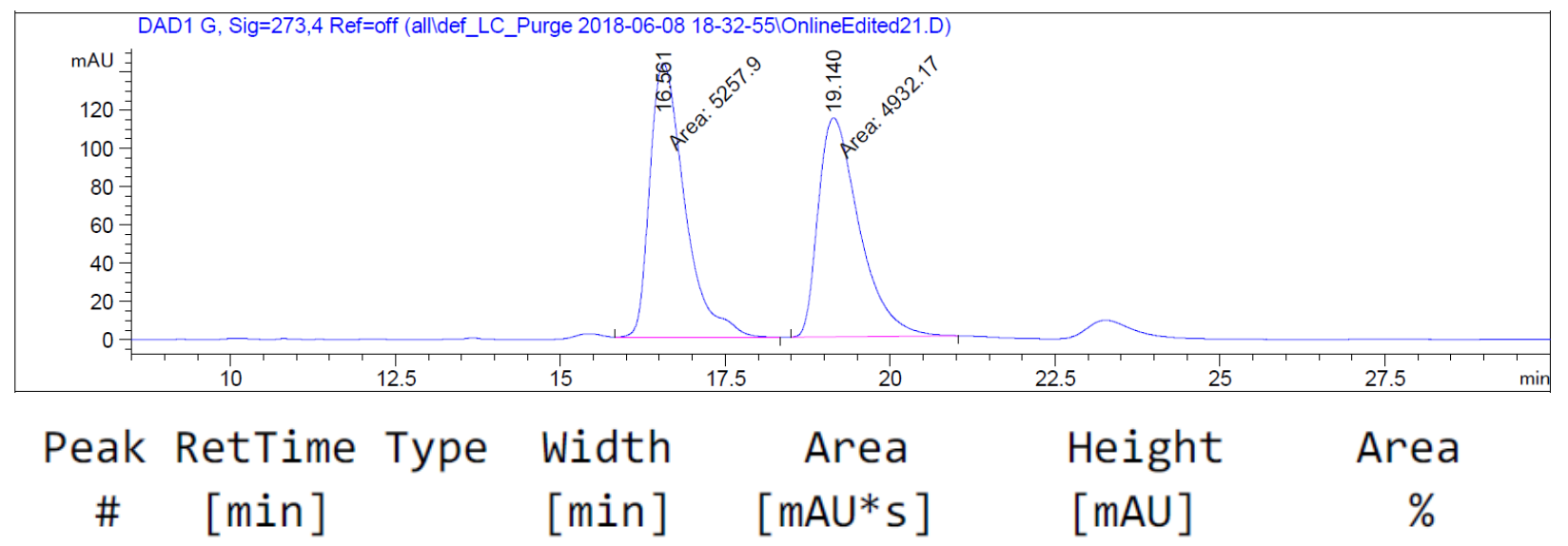

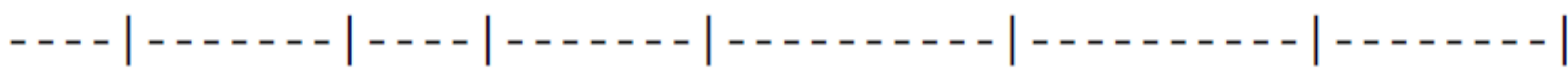

$1 \quad 16.561$ MM $\quad 0.61215257 .89502 \quad 143.15543 \quad 51.5982$

$\begin{array}{lllllll}2 & 19.140 \text { MM } & 0.7197 & 4932.17480 & 114.21161 & 48.4018\end{array}$

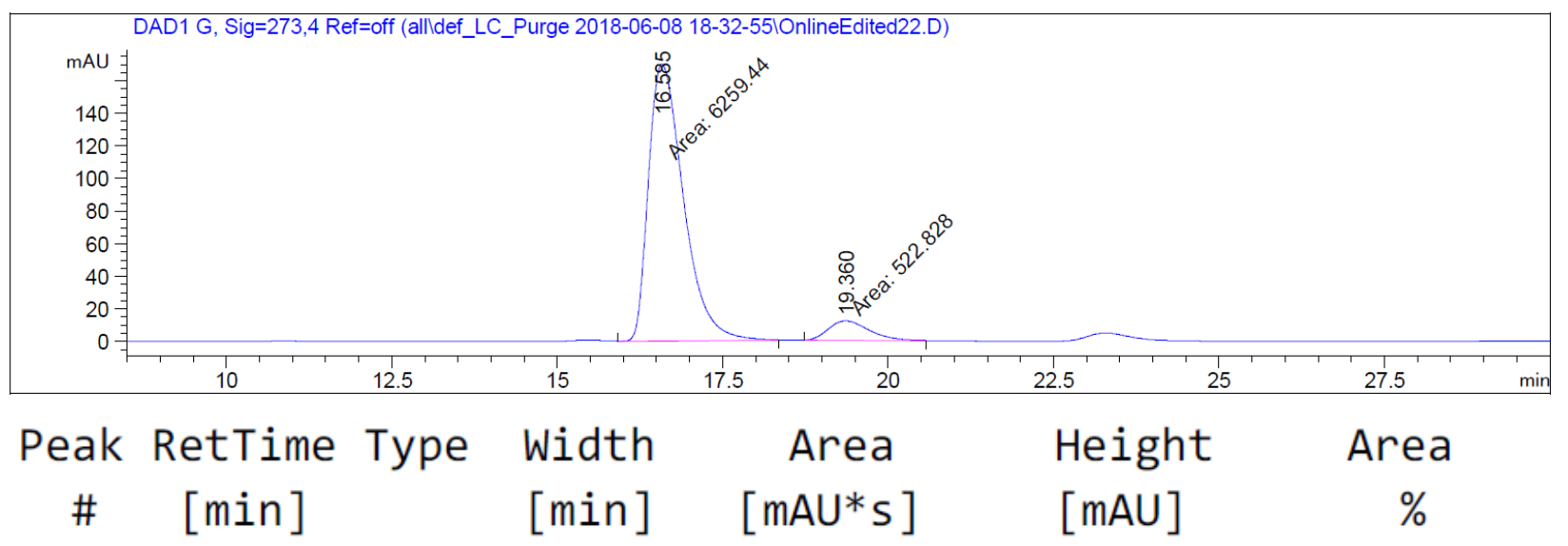

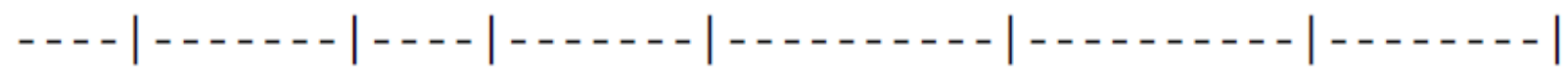

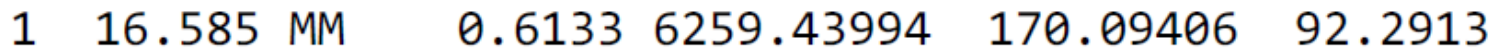

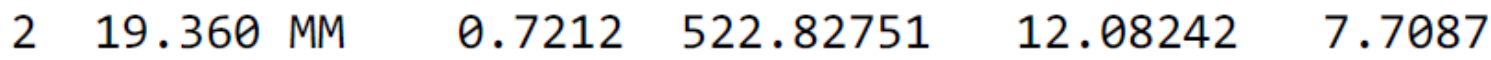


<smiles>COC(=O)c1ccc2cc(C(C)Cc3ccccc3)n(-c3ccc(C)cn3)c2c1</smiles>

355da

$\left(400 \mathrm{MHz}, \mathrm{CDCl}_{3}\right)$
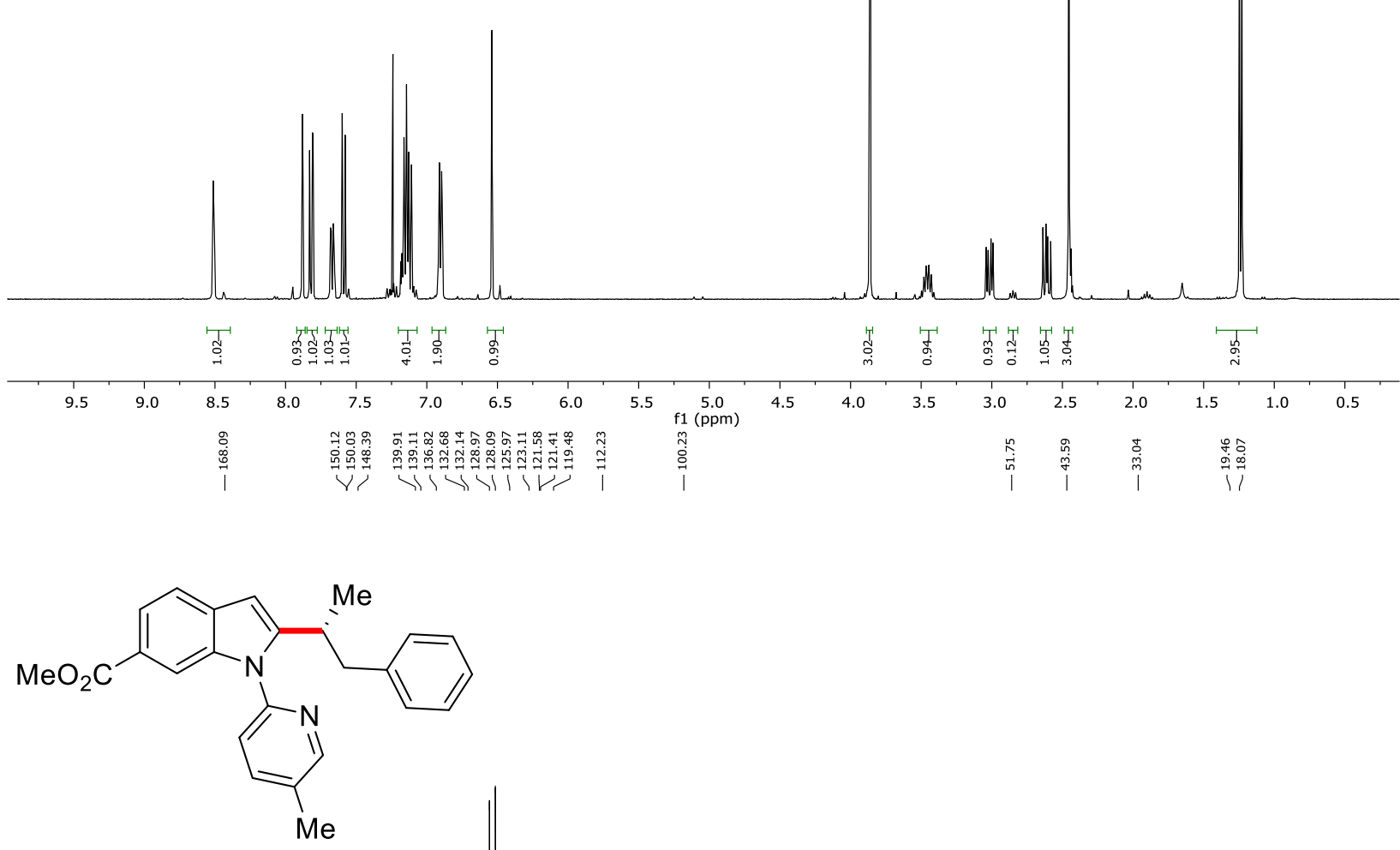

355da

$\left(100 \mathrm{MHz} \mathrm{CDCl}_{3}\right)$

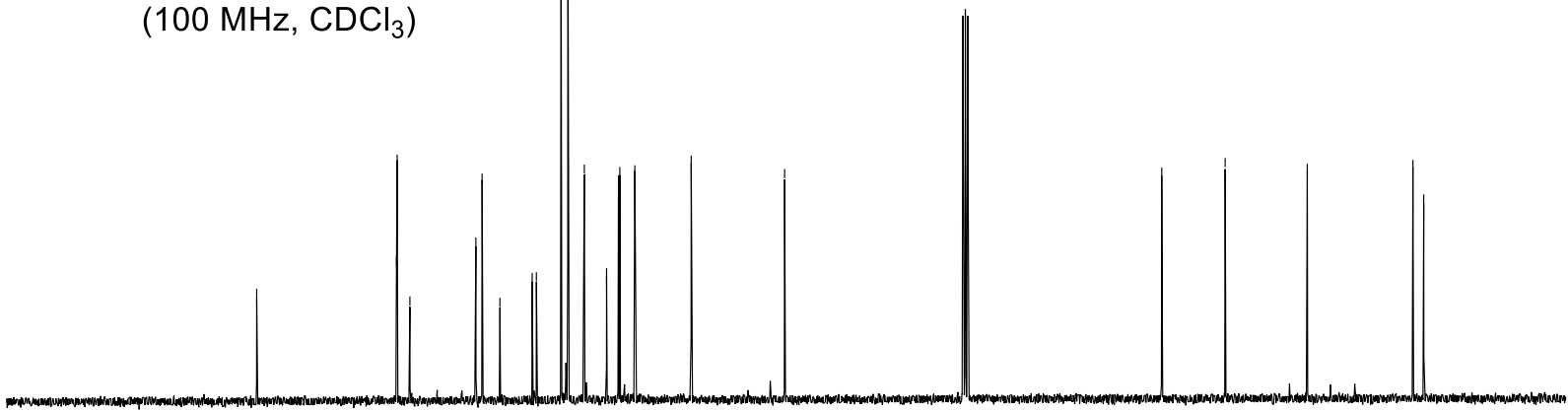

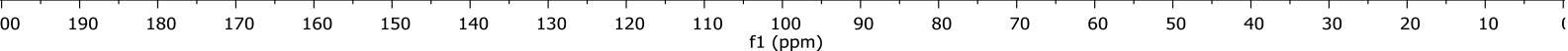


Chiral HPLC of 355da:
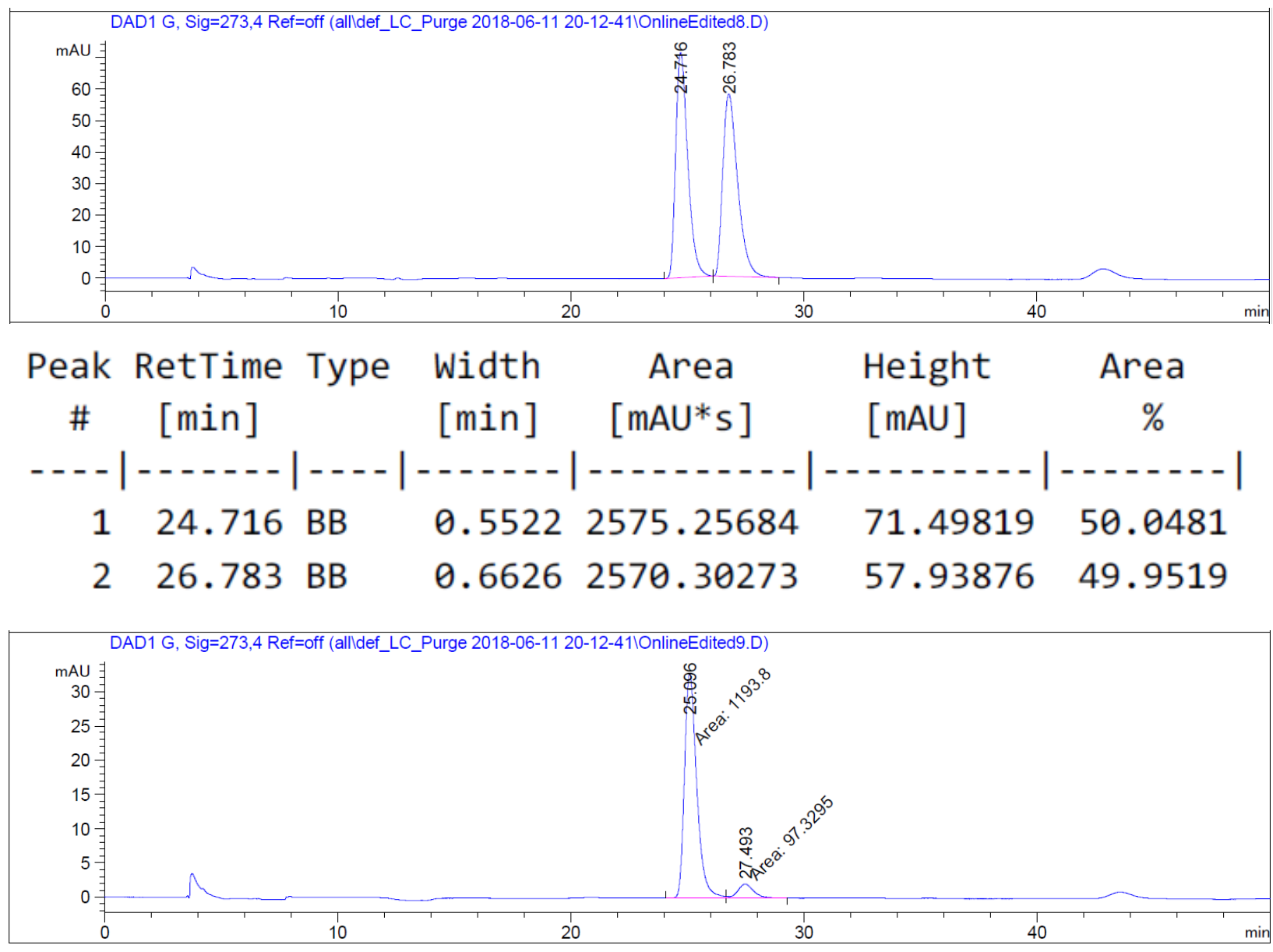

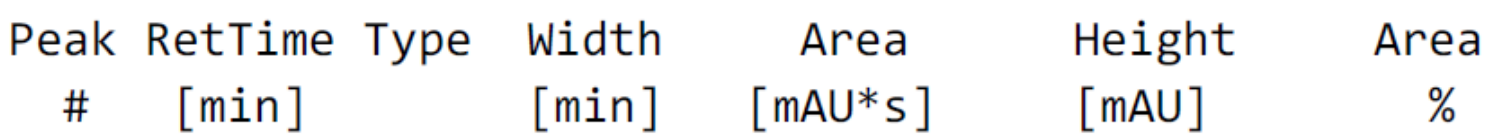

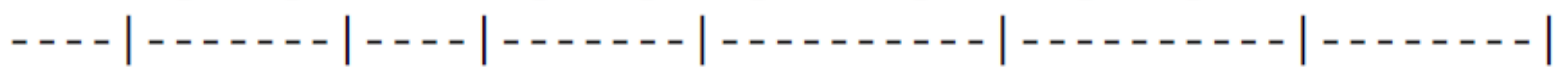
$125.096 \mathrm{MF}$
0.60661193 .79517
$32.80224 \quad 92.4617$
$227.493 \mathrm{FM}$
0.7956
97.32949
2.03891
7.5383 


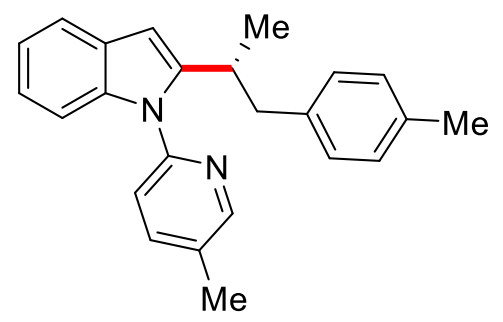

$355 a b$

(400 MHz, $\mathrm{CDCl}_{3}$ )
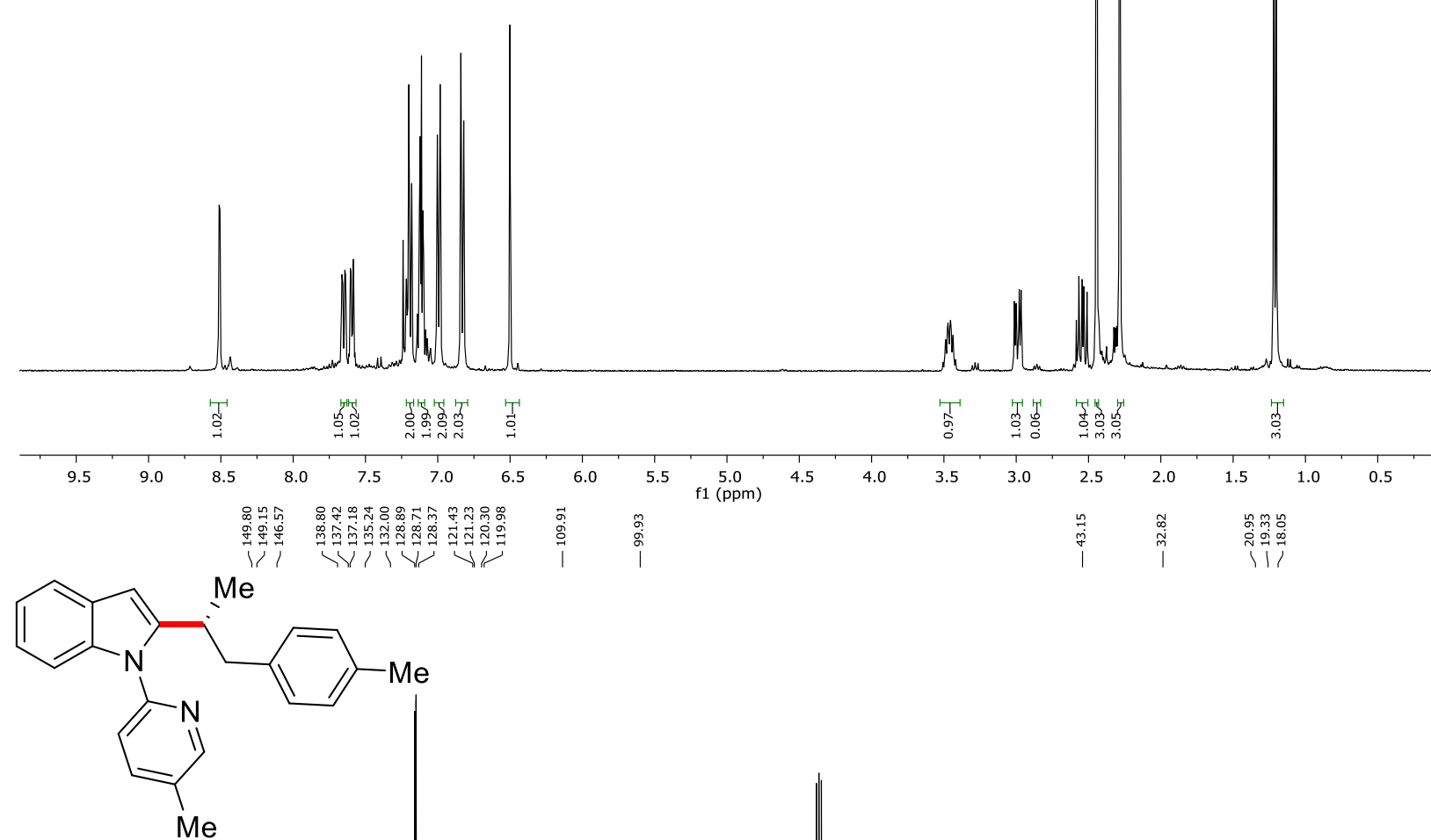

$355 \mathrm{ab}$

$\left(100 \mathrm{MHz}, \mathrm{CDCl}_{3}\right.$ )

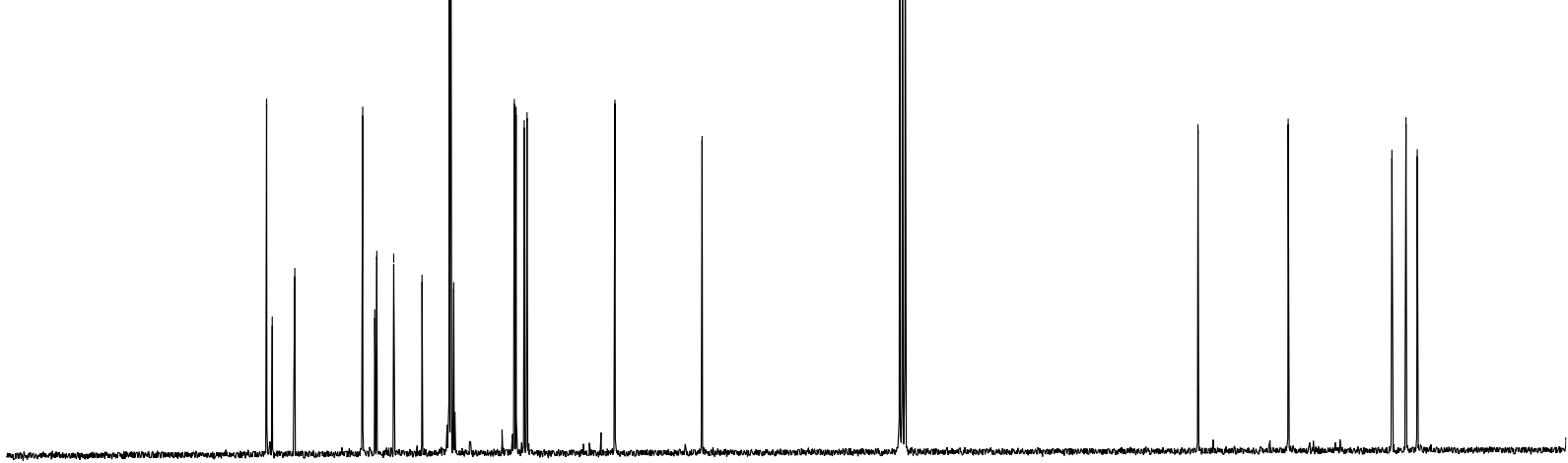

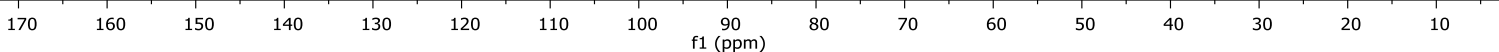


Chiral HPLC of 355ab:

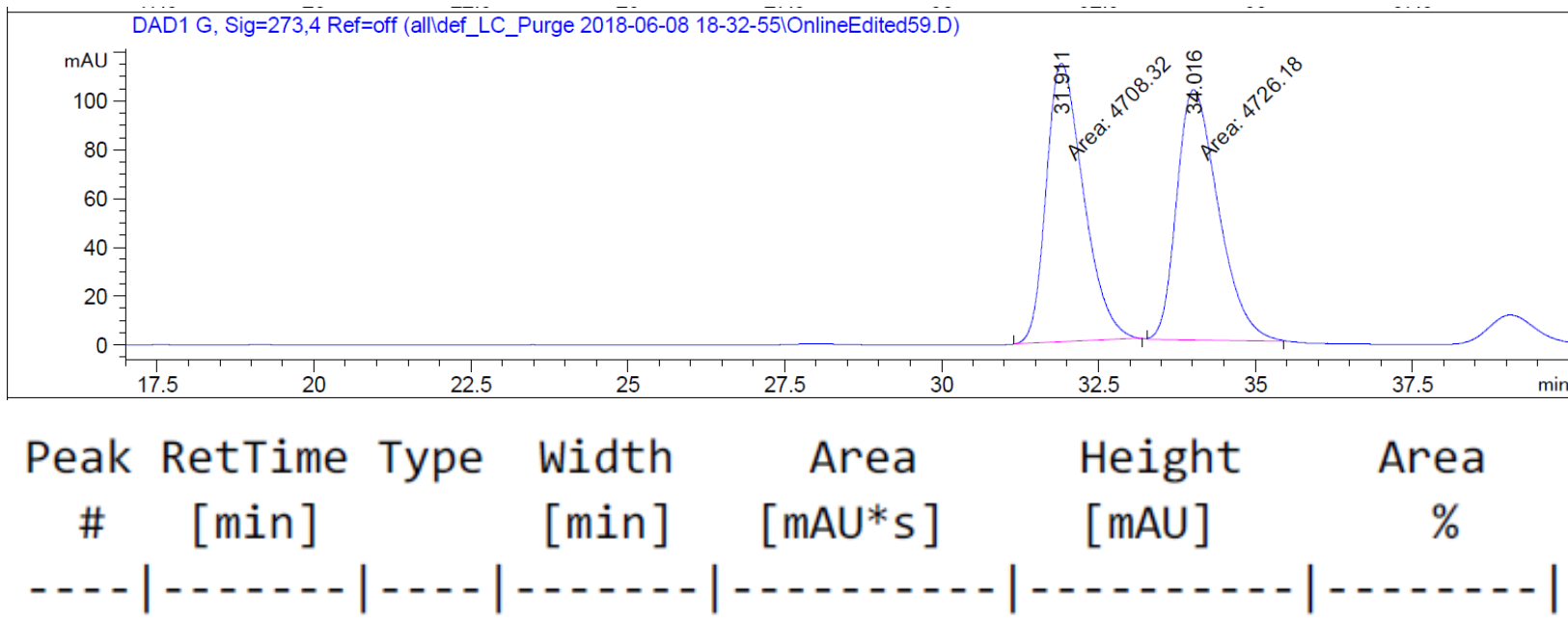

$\begin{array}{lllllll}1 & 31.911 & \text { BB } & 0.6290 & 4741.79736 & 114.54191 & 49.9170\end{array}$

$2 \quad 34.016$ BB $\quad 0.7005 \quad 4757.56152 \quad 102.69714 \quad 50.0830$

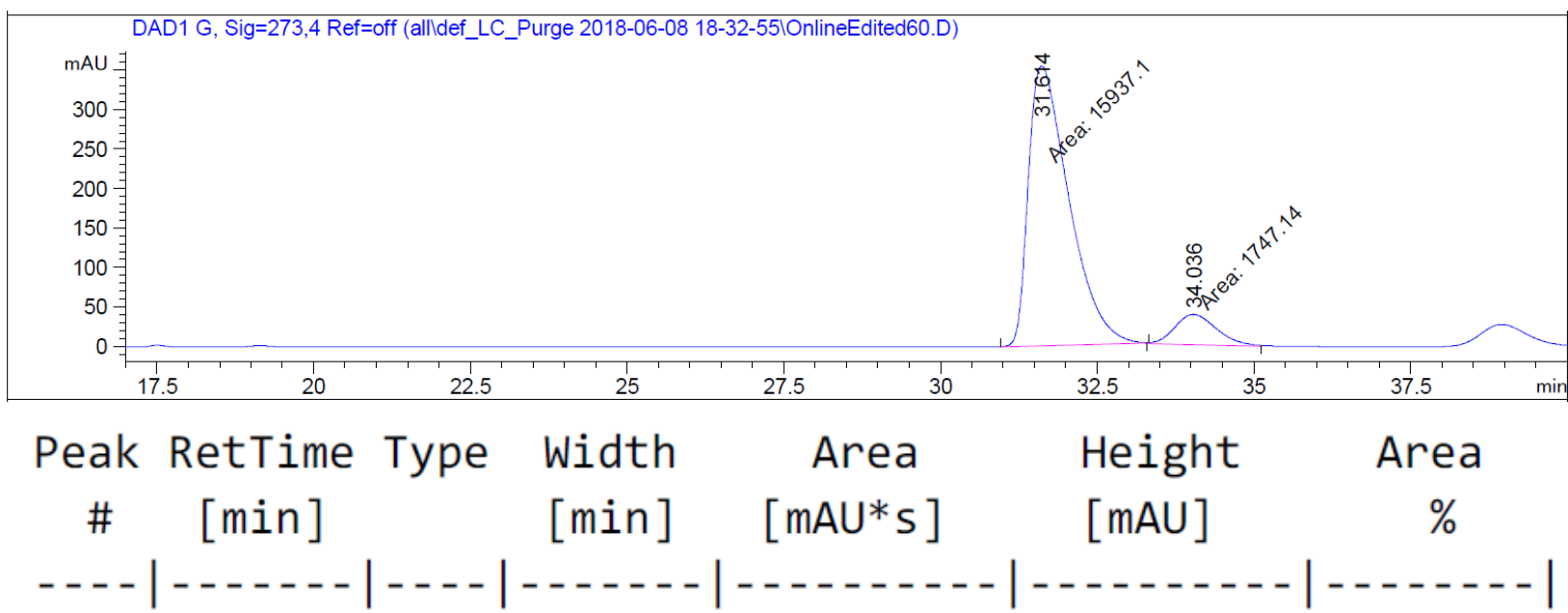

$\begin{array}{llllll}1 & 31.614 \mathrm{MM} & 0.7493 & 1.59371 \mathrm{e} 4 & 354.50583 & 90.1203\end{array}$

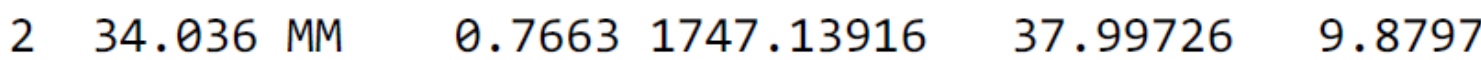




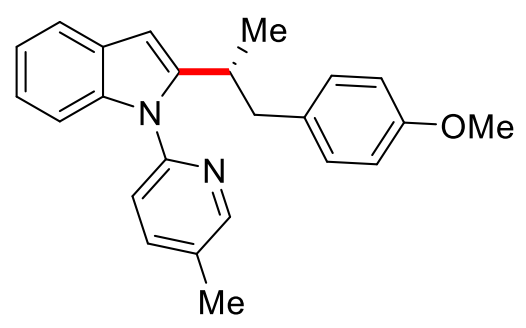

$355 \mathrm{ac}$

(300 MHz, CDCl ${ }_{3}$ )

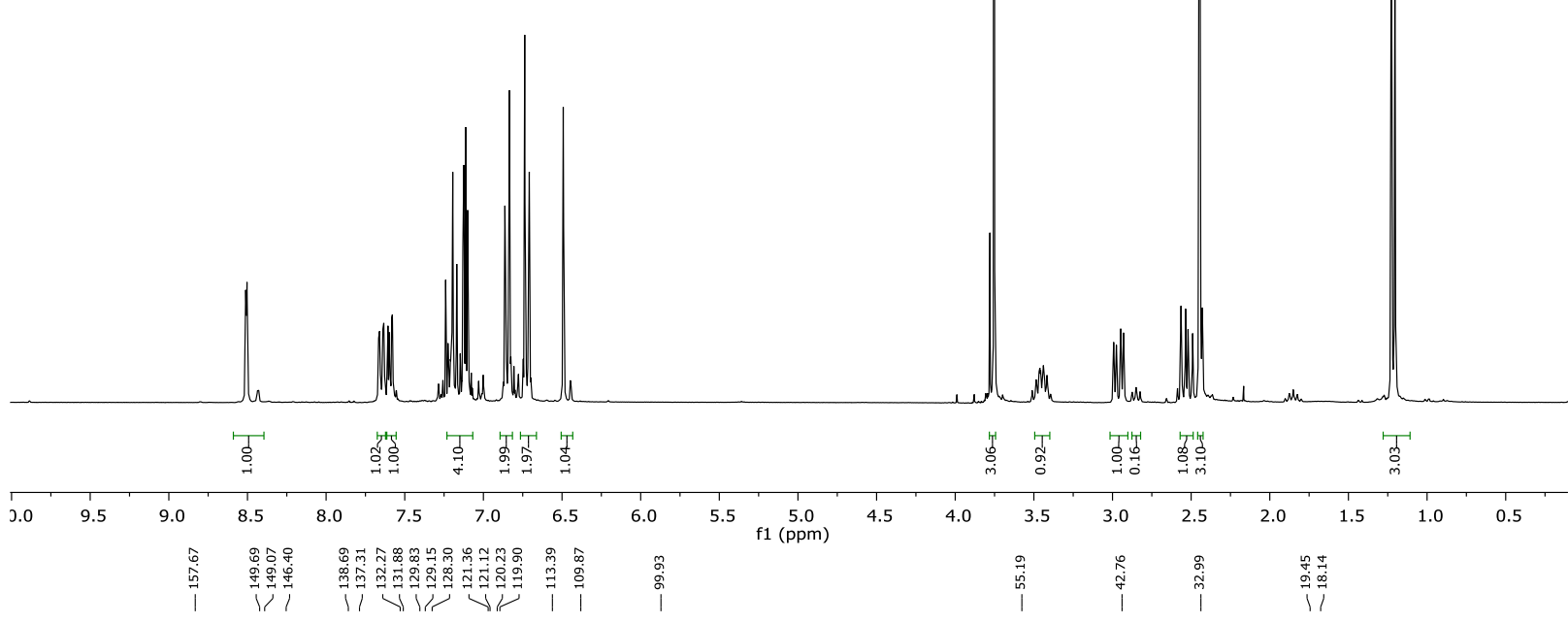<smiles>[M]C(C#N)CCc1cc2ccccc2n1-c1ccc(C)cn1</smiles>

355ac

(125 $\mathrm{MHz} \mathrm{CDCl}_{3}$ )
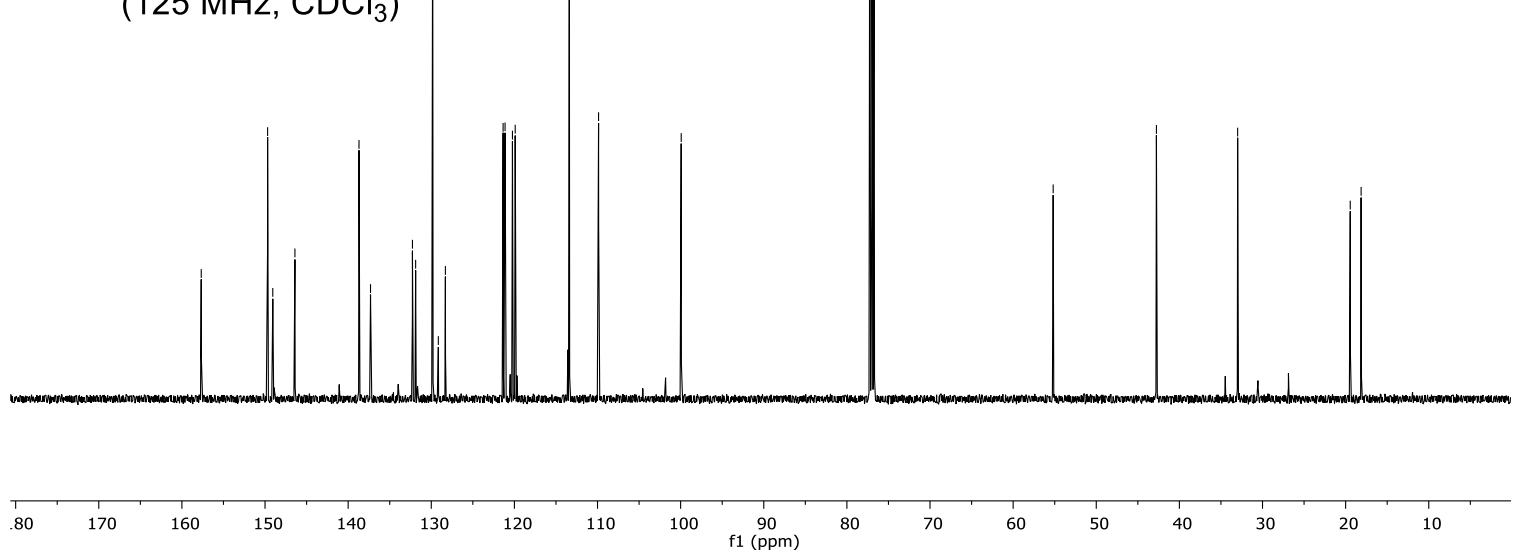

$50 \quad 40$

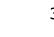

$20 \quad 10$ 
Chiral HPLC of 355ac:
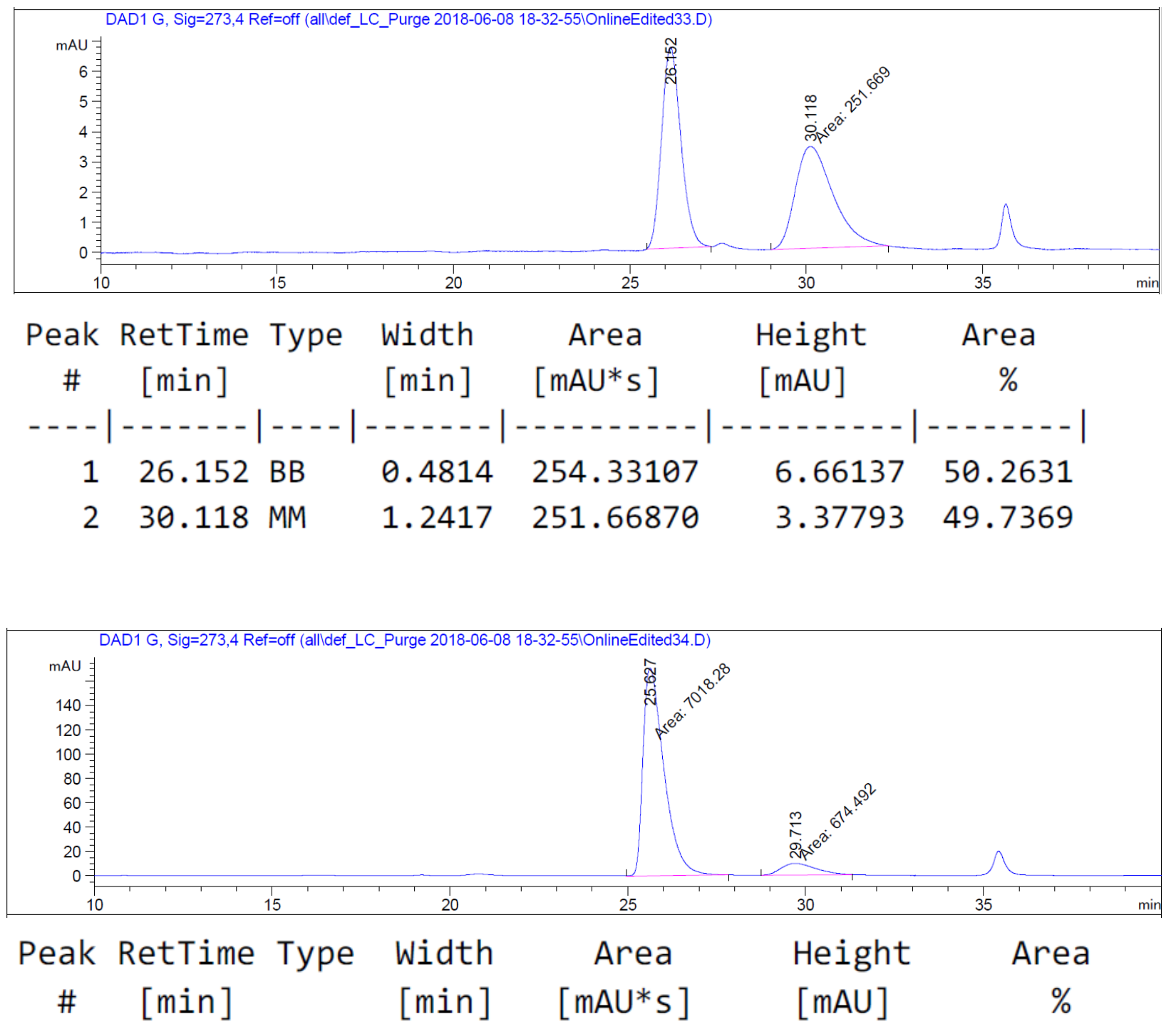

--- - | - - - - - | - - - | - - - - - | - - - - - - - | - - - - - - - | - - - - - - |

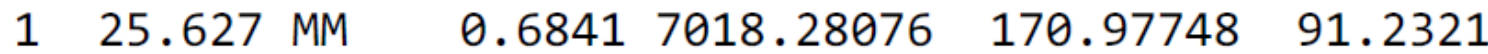

$\begin{array}{llllll}2 & 29.713 \text { MM } & 1.1670 & 674.49158 & 9.63254 & 8.7679\end{array}$ 


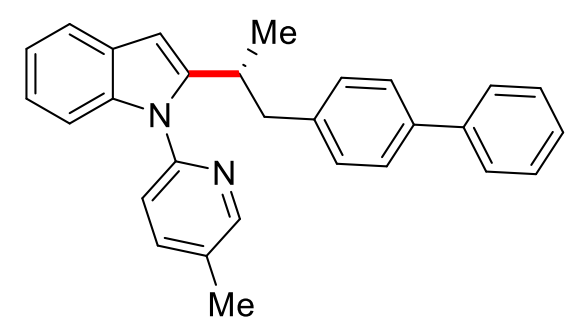

$355 \mathrm{ad}$

$\left.\left(500 \mathrm{MHz}^{\mathrm{CDCl}}\right)_{3}\right)$
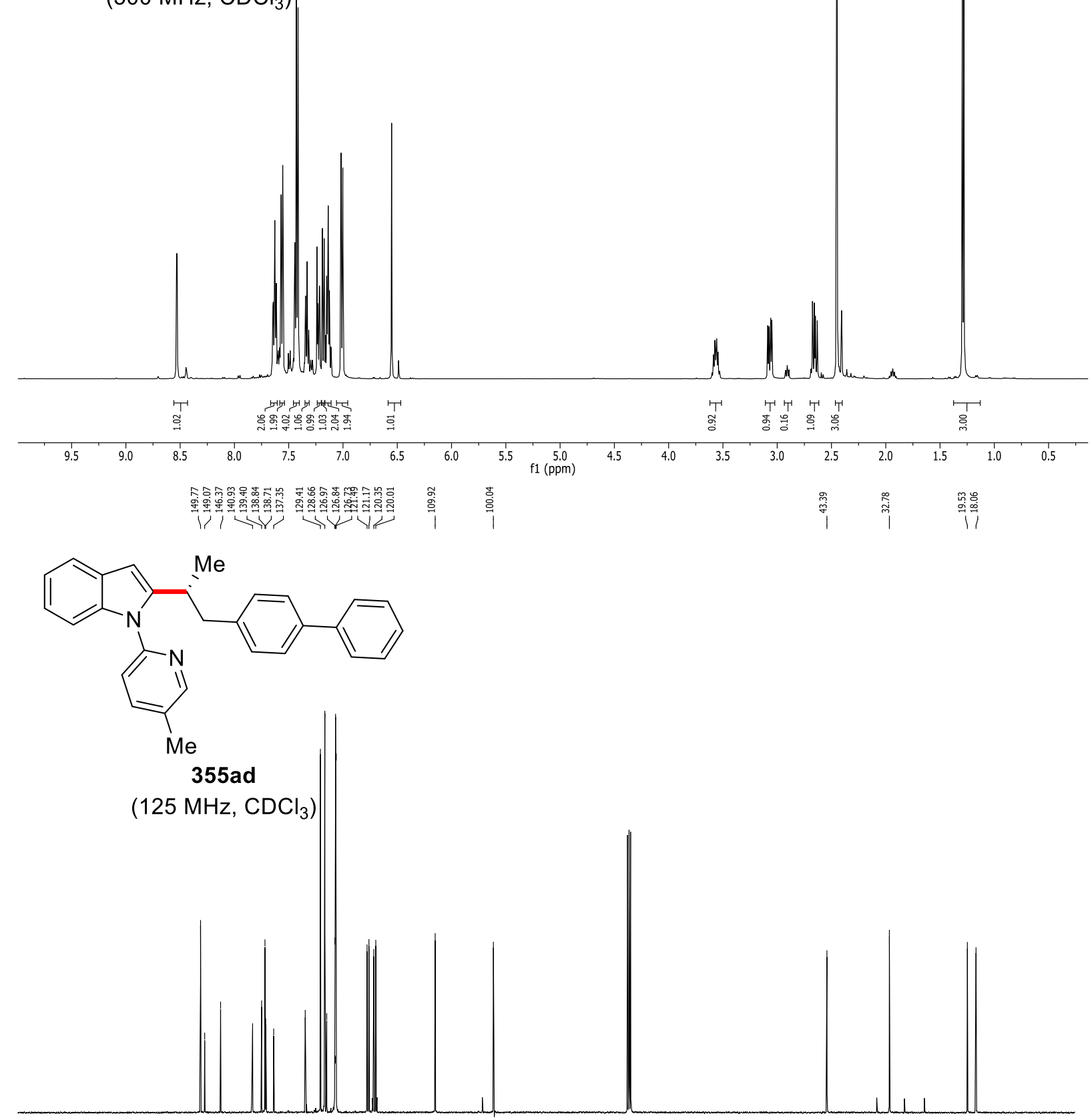

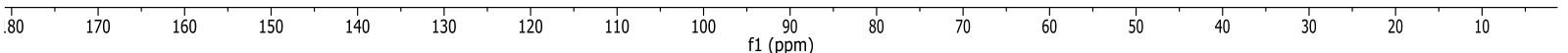


Chiral HPLC of 355ad:

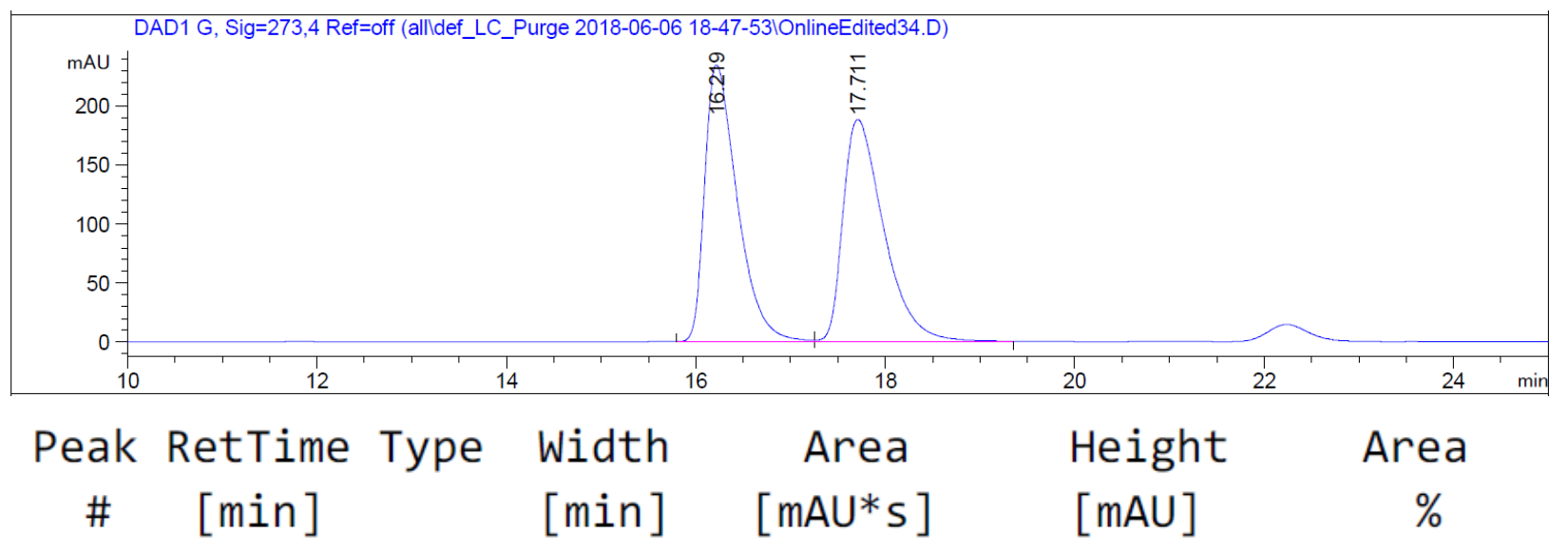

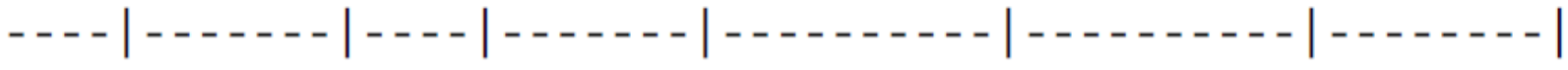

$\begin{array}{lllllll}1 & 16.219 & \text { BV } & 0.3659 & 5600.96582 & 234.31482 & 50.0280\end{array}$

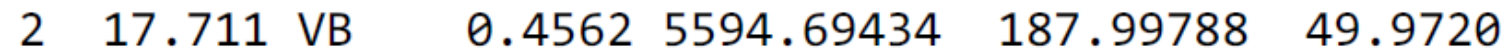

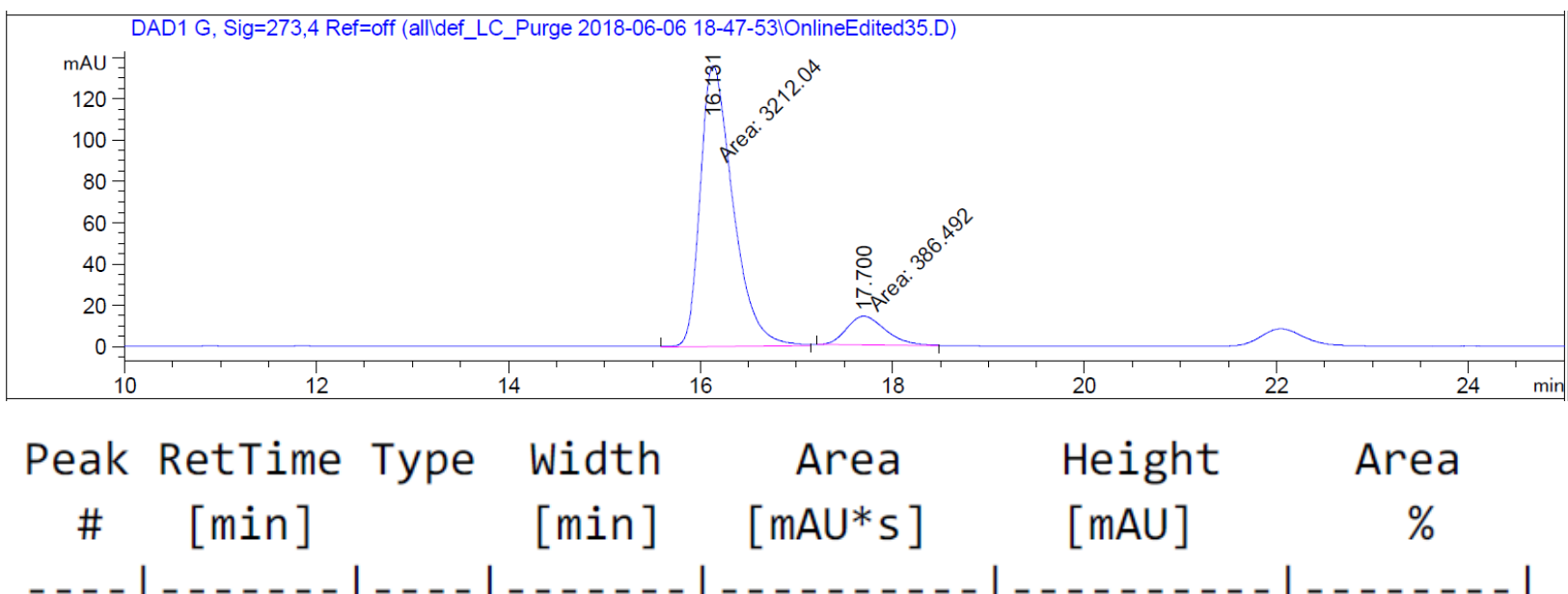
$116.131 \mathrm{MM}$
$0.3943 \quad 3212.03906 \quad 135.76524 \quad 89.2597$
$217.700 \mathrm{MM}$
$\begin{array}{llll}0.4647 \quad 386.49231 & 13.86211 & 10.7403\end{array}$ 


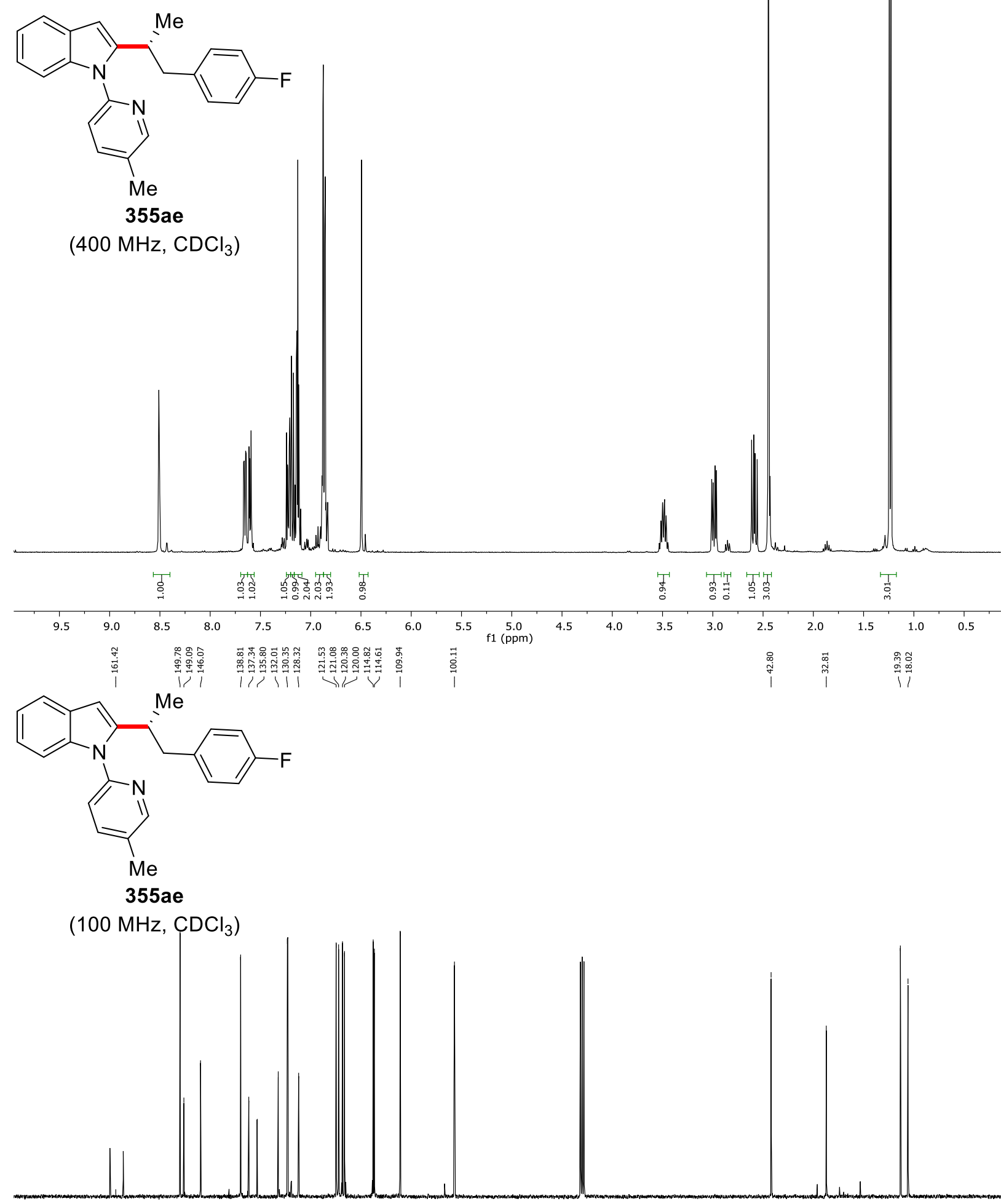




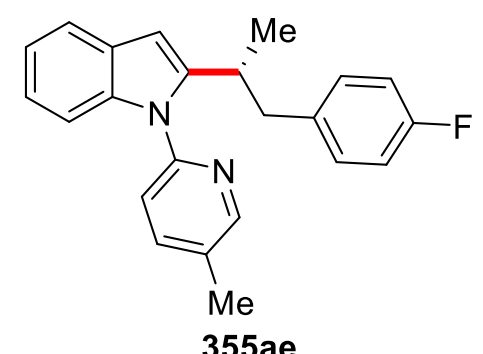

( $375 \mathrm{MHz}, \mathrm{CDCl}_{3}$ )

$\begin{array}{llllllllllllllllllllllllllllllll}50 & -55 & -60 & -65 & -70 & -75 & -80 & -85 & -90 & -95 & -100 & -105 & -110 & -115 & -120 & -125 & -130 & -135 & -140 & -145 & -150 & -155 & -160 & -165 & -17\end{array}$ 
Chiral HPLC of 355ae:

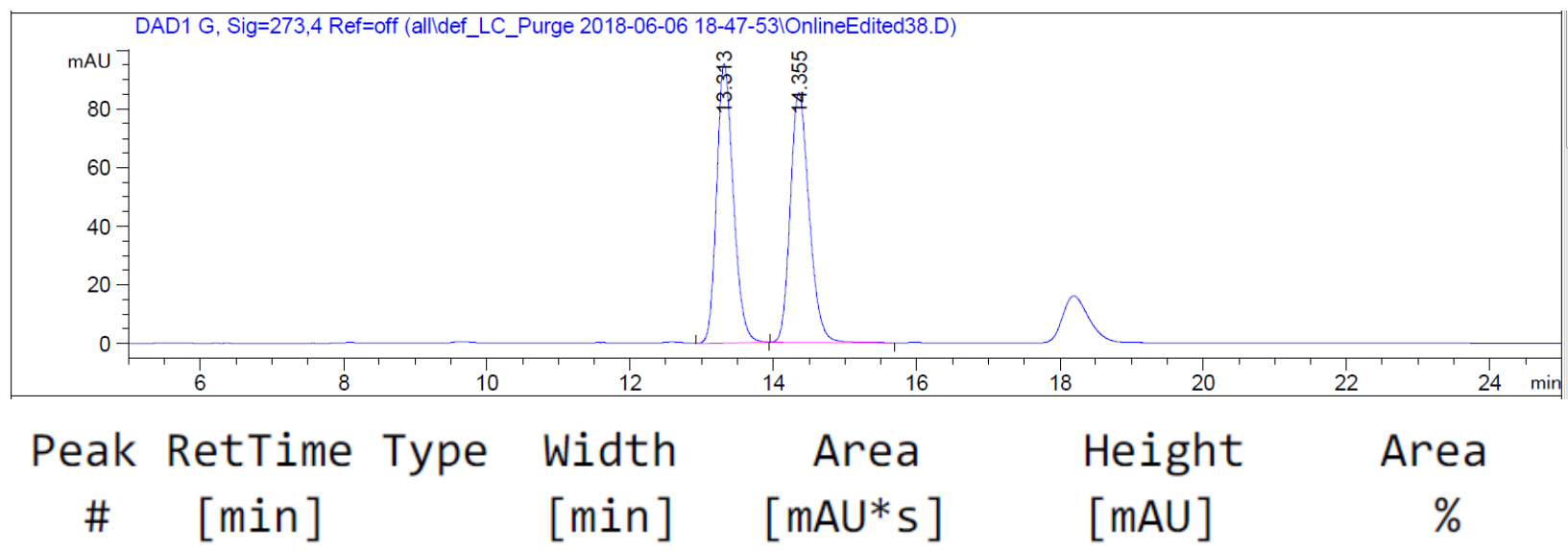

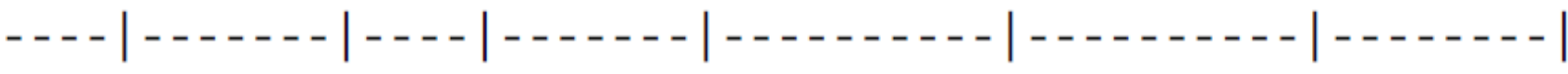

$\begin{array}{lllllll}1 & 13.313 & \text { BB } & 0.2489 & 1542.13428 & 95.23789 & 49.8291\end{array}$

$\begin{array}{lllllll}2 & 14.355 & \text { BB } & 0.2796 & 1552.71533 & 85.20567 & 50.1709\end{array}$

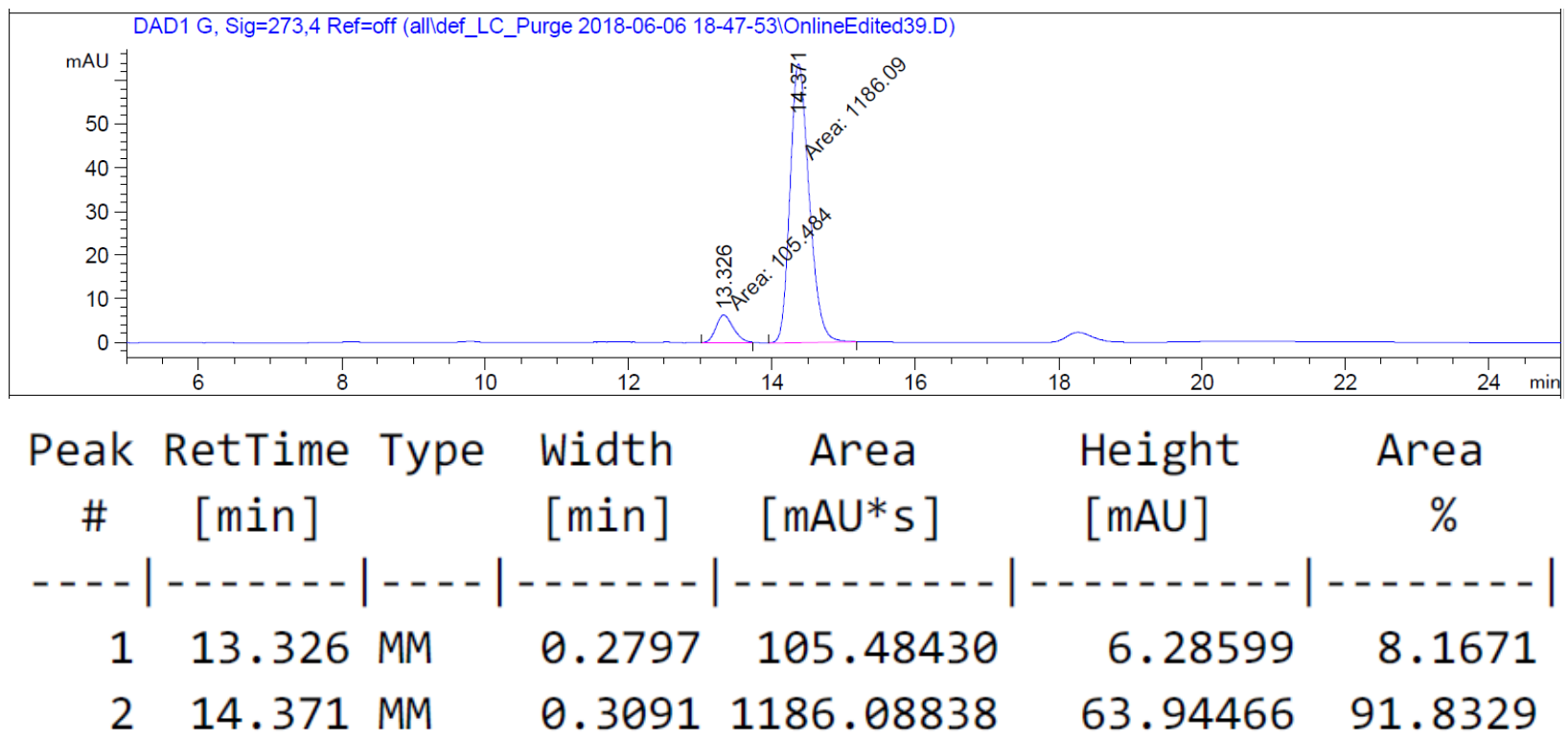




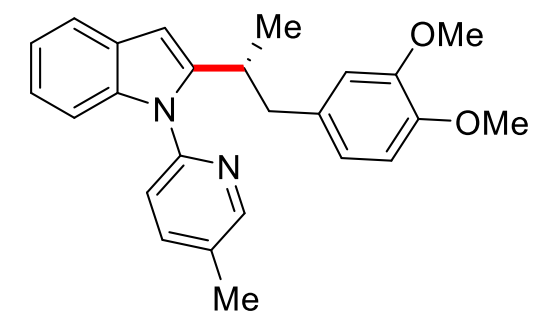

355af

$\left(500 \mathrm{MHz}, \mathrm{CDCl}_{3}\right)$

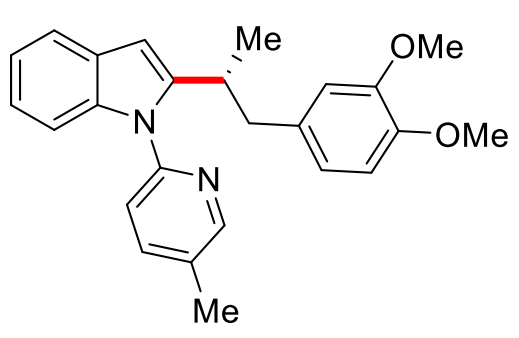

355af

$\left(125 \mathrm{MHz} \mathrm{CDCl}_{3}\right)$

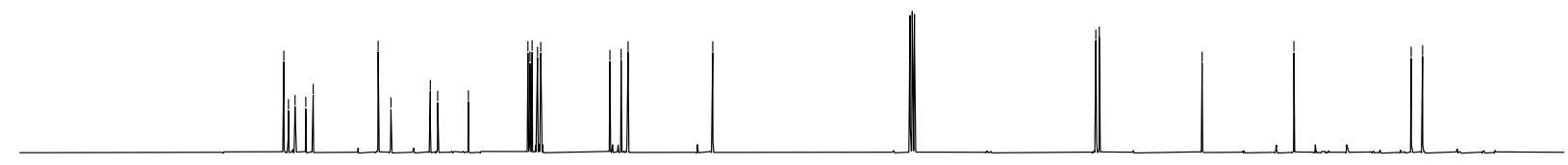

\begin{tabular}{lllllllllllllllllll}
\hline 80 & 170 & 160 & 150 & 140 & 130 & 120 & 110 & 100 & $\underset{f 1}{90}$ & 80 & 70 & 60 & 50 & 40 & 30 & 20 & 10
\end{tabular} 
Chiral HPLC of 355af:

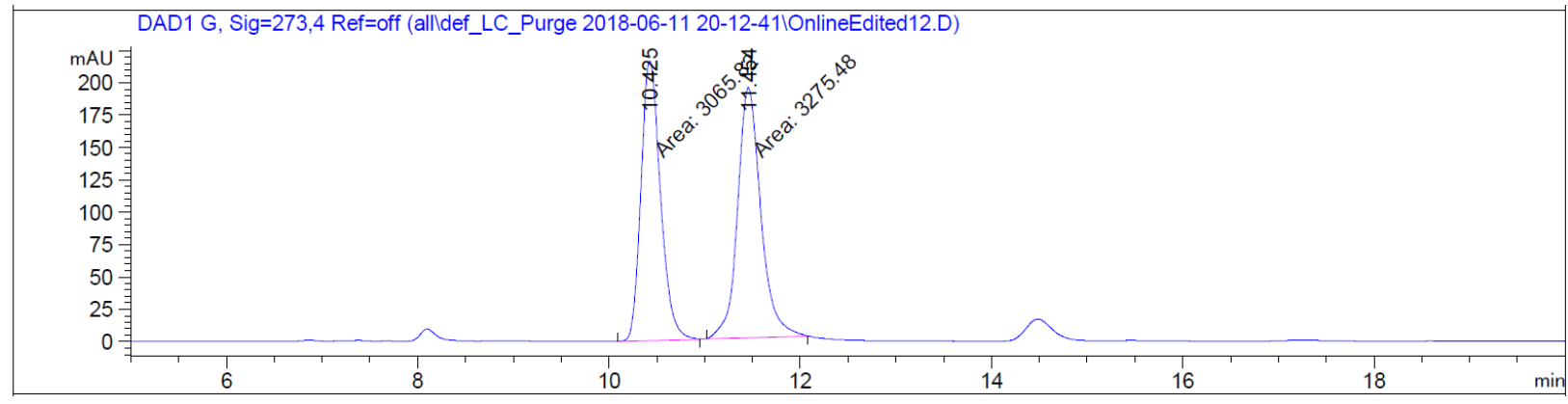

$\begin{array}{cccccc}\text { Peak } & \text { RetTime Type } & \text { width } & \text { Area } & \text { Height } & \text { Area } \\ \# & {[\text { min }]} & {[\text { min }]} & {\left[\text { mAUs }^{*}\right]} & {[\text { mAU }]} & \%\end{array}$

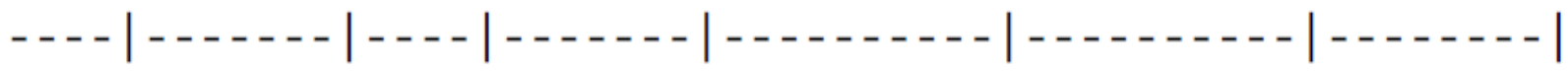

$1 \quad 10.425$ MM $\quad 0.2363 \quad 3065.82056 \quad 216.21277 \quad 48.3469$

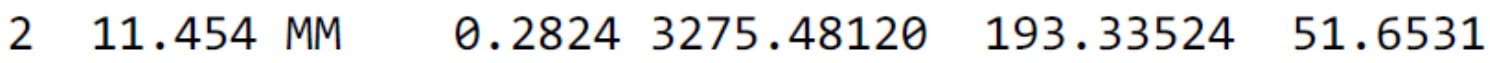

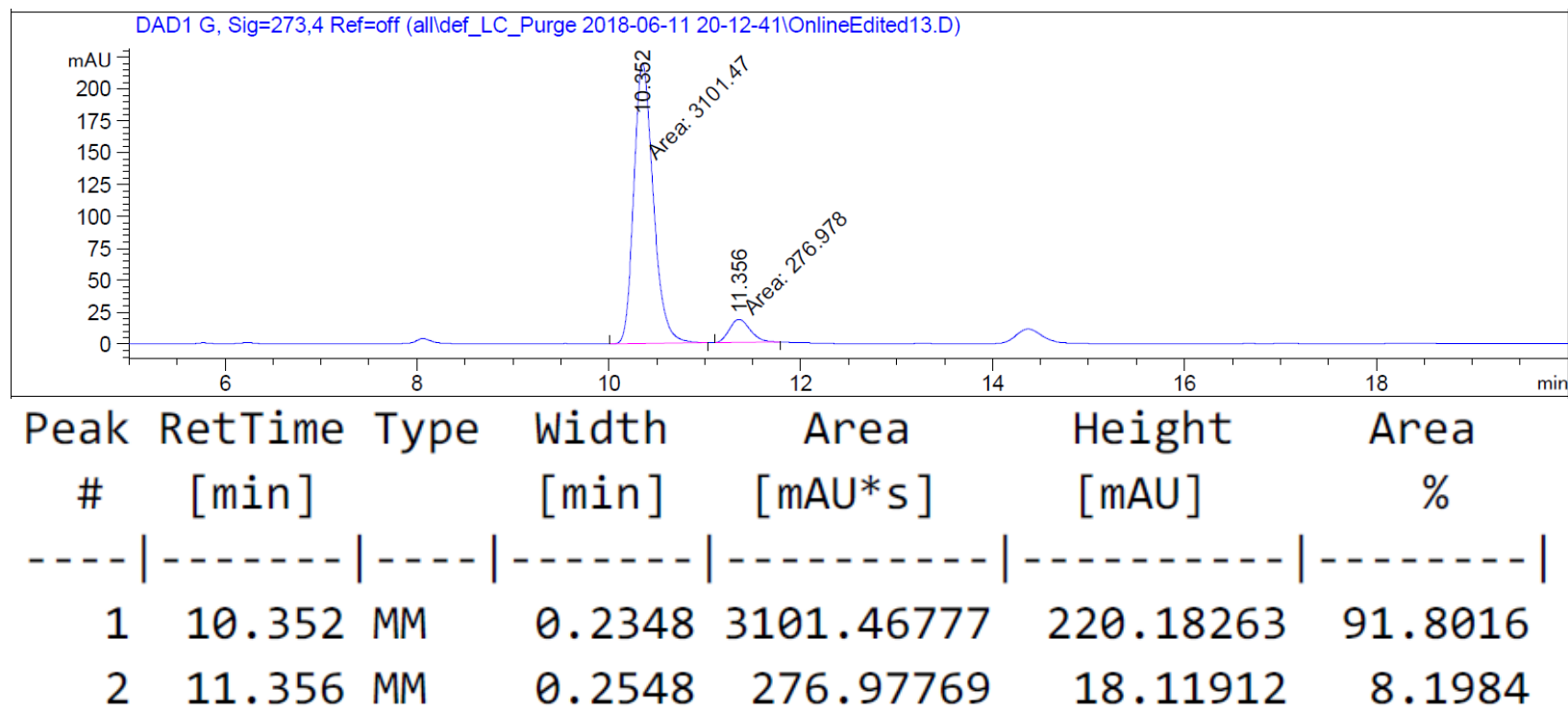




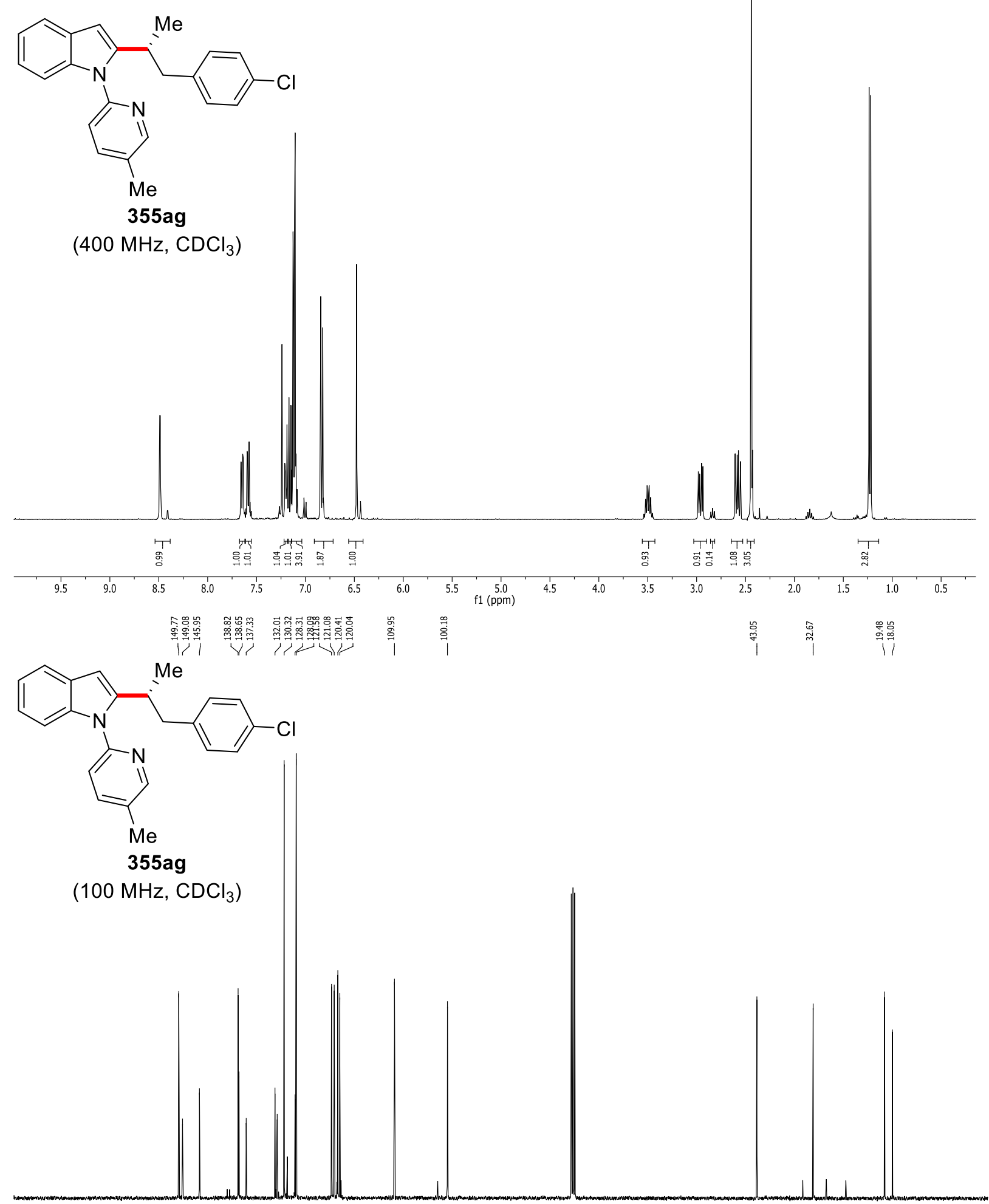

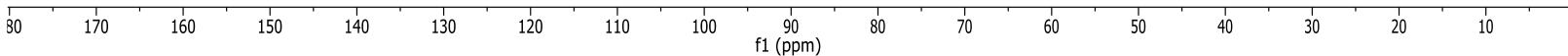


Chiral HPLC of 355ag:
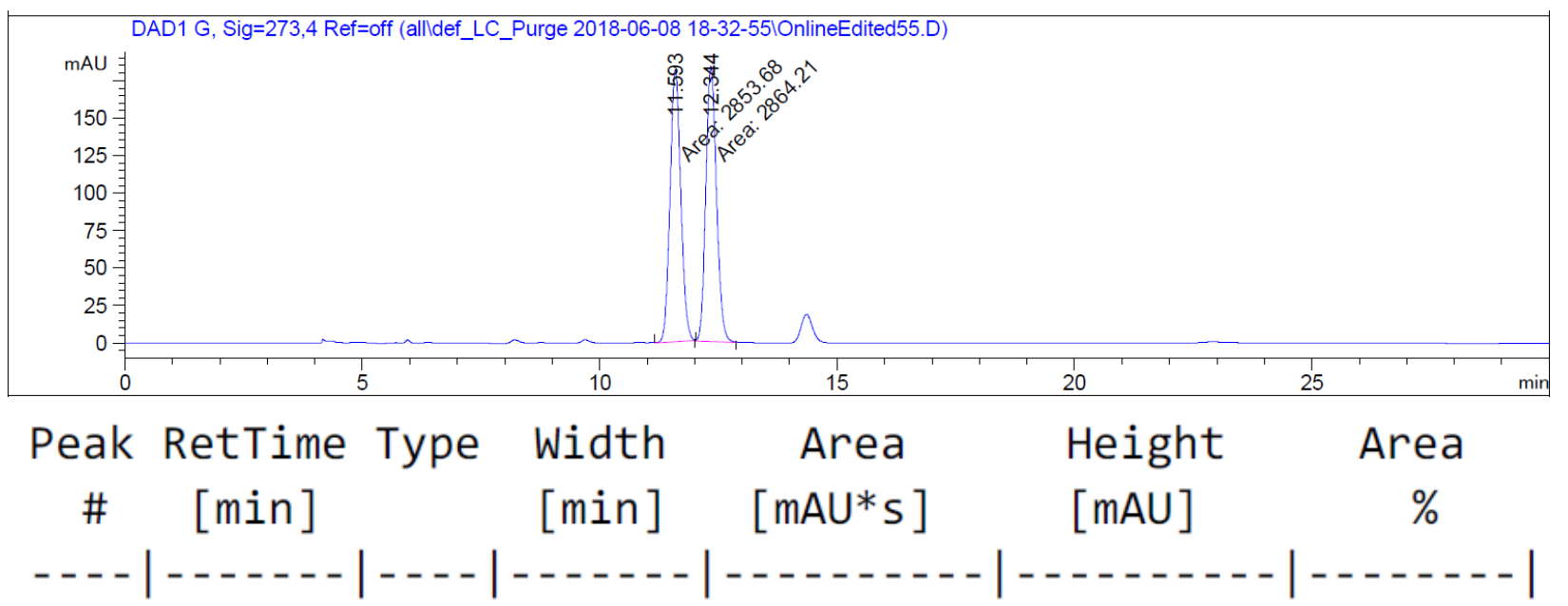
$111.593 \mathrm{MM}$
$\begin{array}{llll}0.2626 & 2853.68335 & 181.14539 & 49.9079\end{array}$
$212.344 \mathrm{MM}$
$\begin{array}{llll}0.2601 & 2864.21436 & 183.54207 & 50.0921\end{array}$

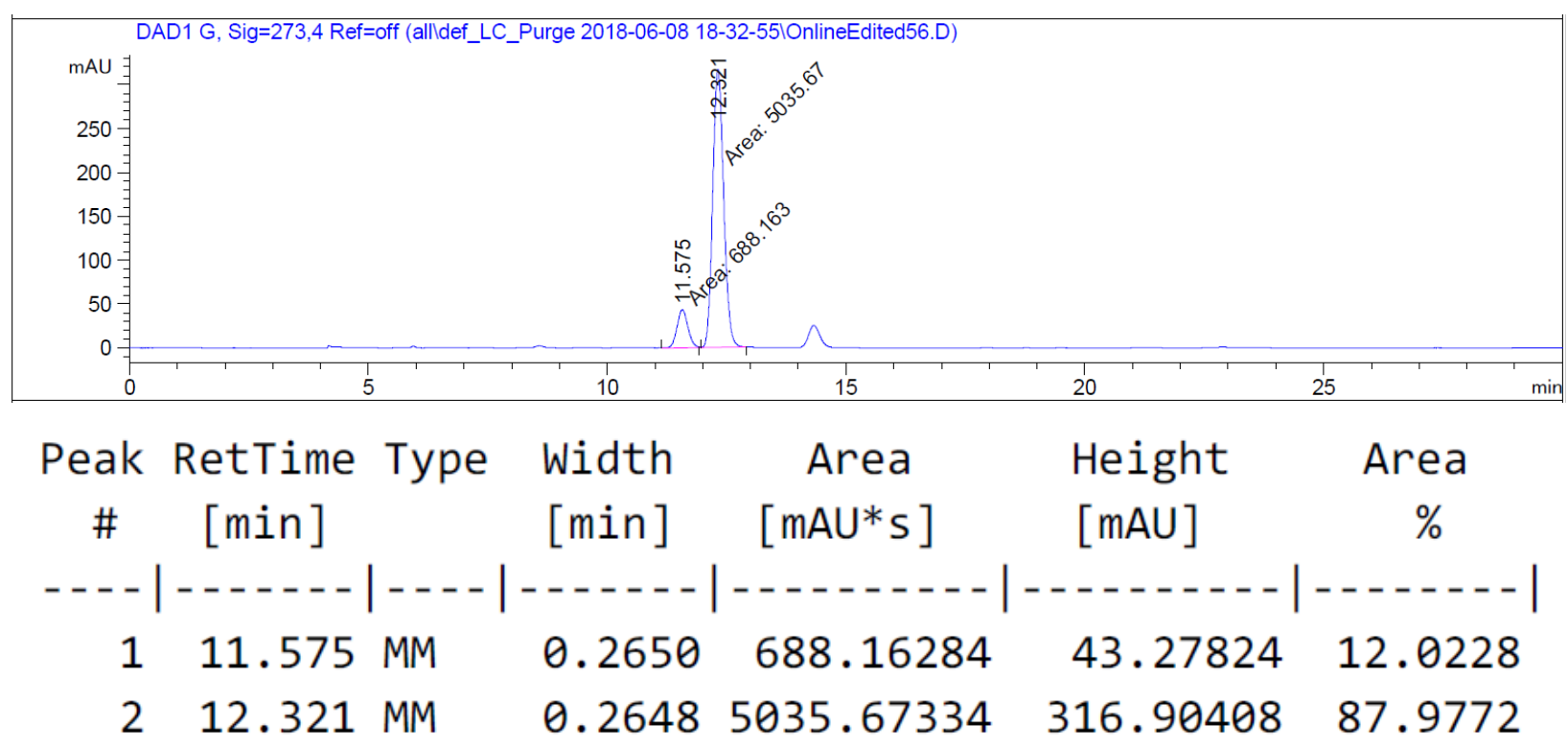




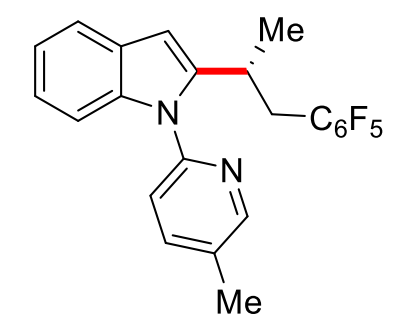

355ah

(400 MHz, $\mathrm{CDCl}_{3}$ )
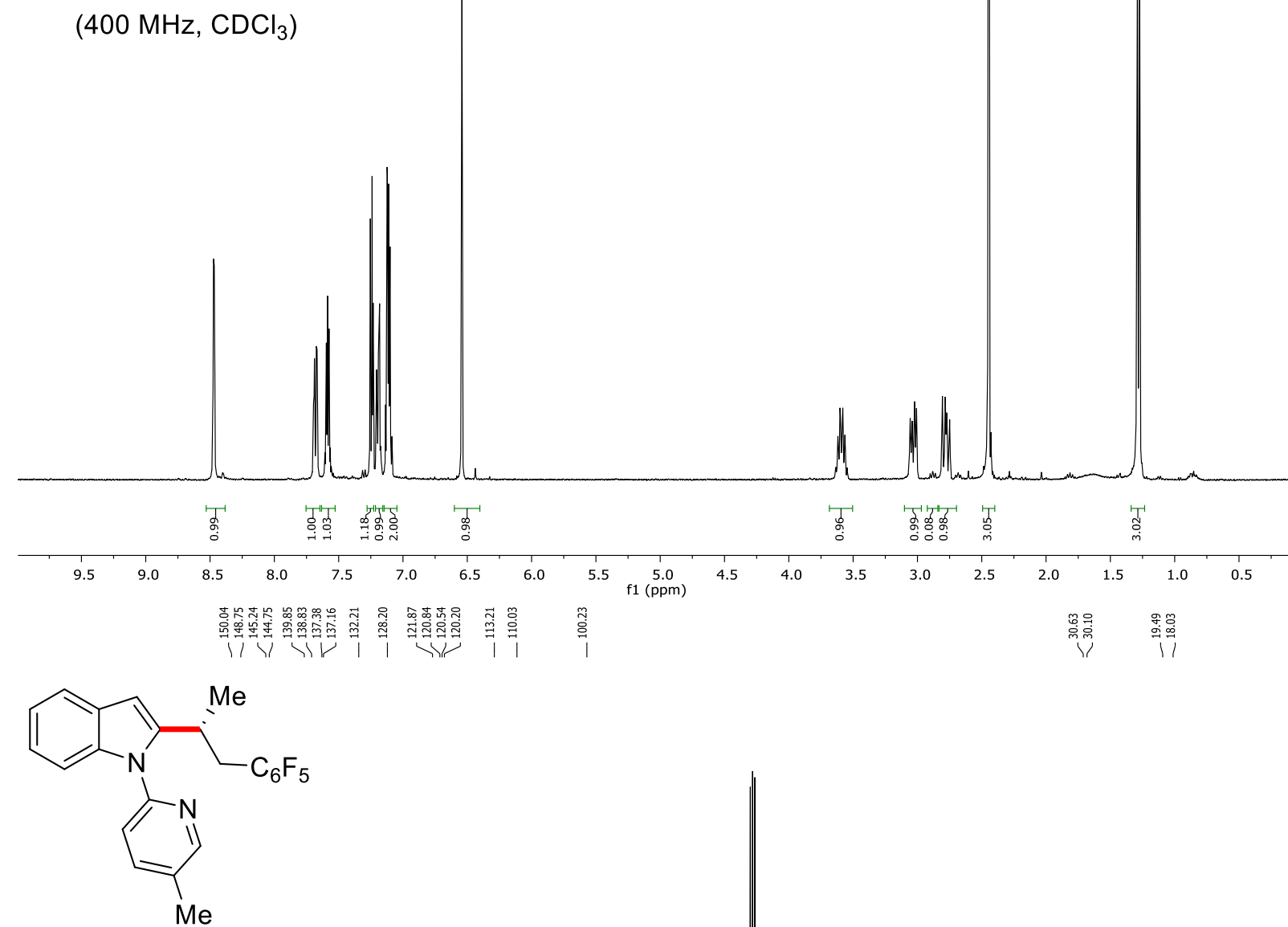

355ah

$\left(100 \mathrm{MHz}, \mathrm{CDCl}_{3}\right)$

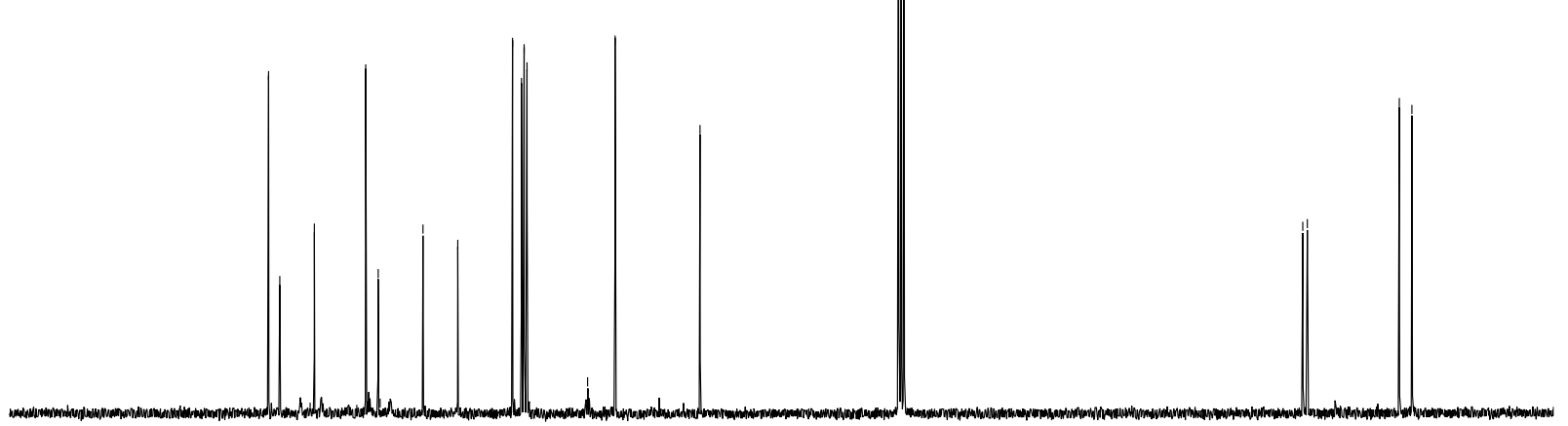

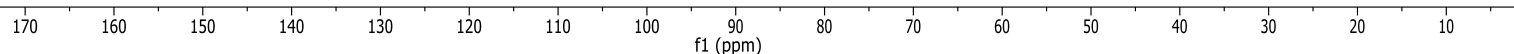




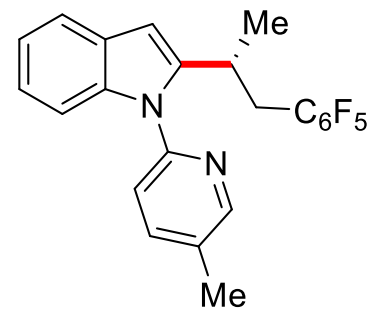

355ah

(375 MHz, $\mathrm{CDCl}_{3}$ )

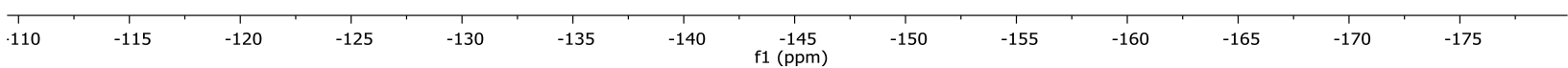


Chiral HPLC of 355ah:
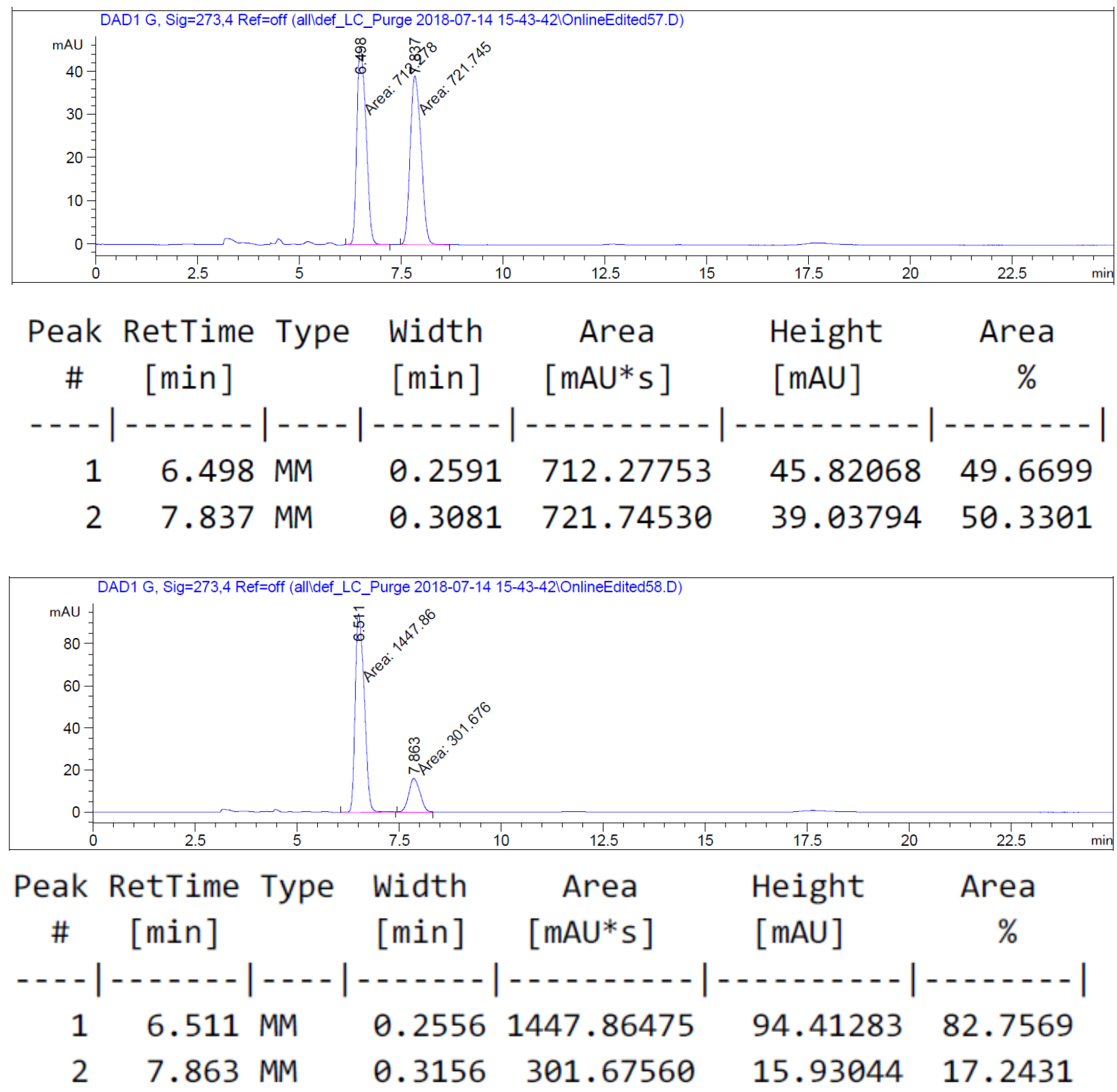


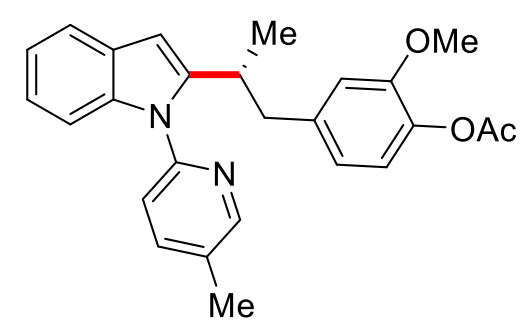

355aj

(500 $\mathrm{MHz}, \mathrm{CDCl}_{3}$ )<smiles>COc1cc(CC(C)c2cc3ccccc3n2-c2ccc(C)cn2)ccc1OC(C)=O</smiles>

355aj

(125 $\mathrm{MHz}, \mathrm{CDCl}_{3}$ )

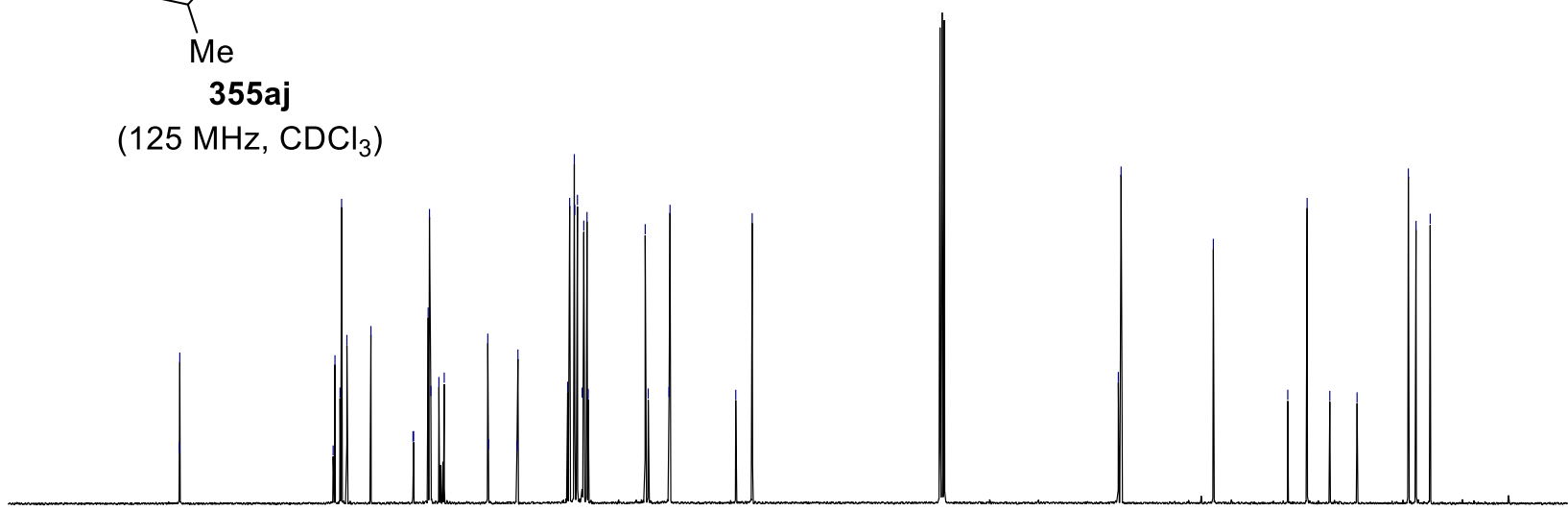

180

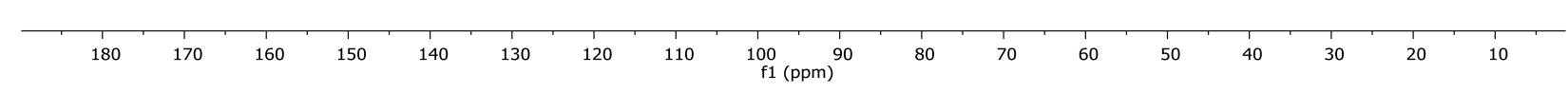

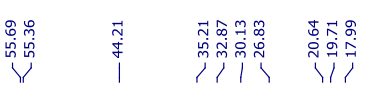


Chiral HPLC of 355aj:

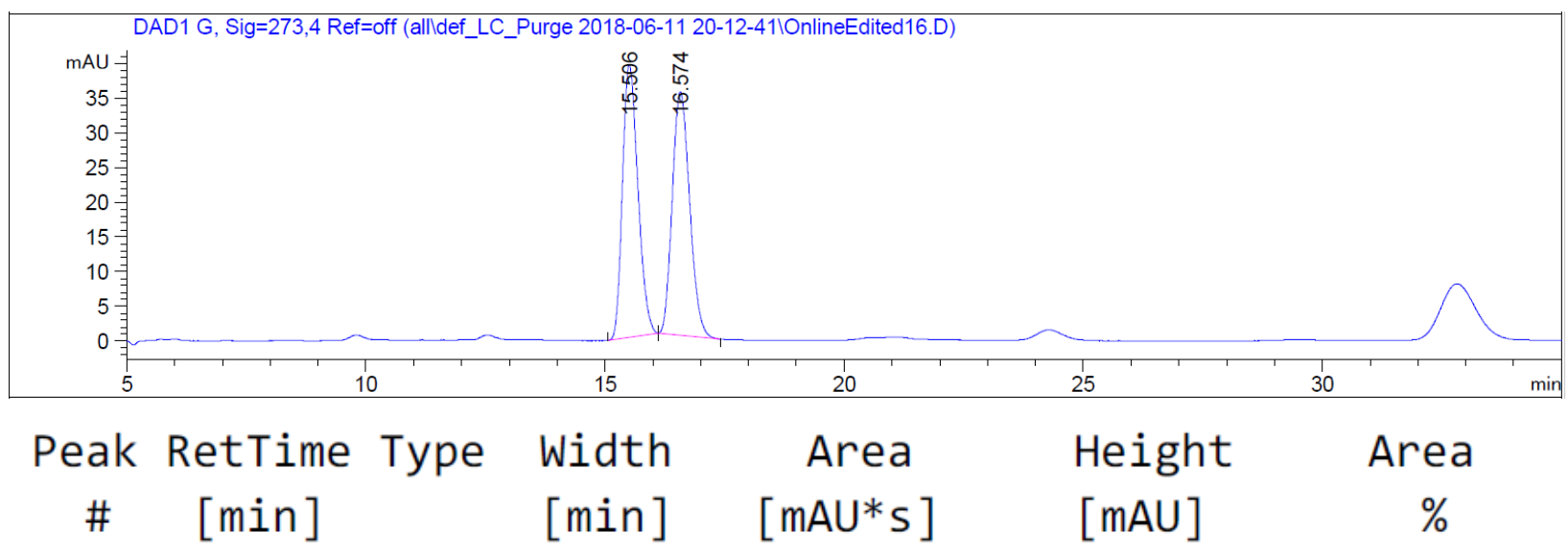

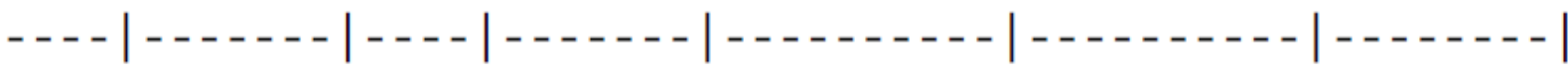

$\begin{array}{lllllll}1 & 15.506 & \text { BB } & 0.3480 & 884.11908 & 39.36467 & 49.8972\end{array}$

$\begin{array}{lllllll}2 & 16.574 & \text { BB } & 0.3886 & 887.76105 & 35.15716 & 50.1028\end{array}$

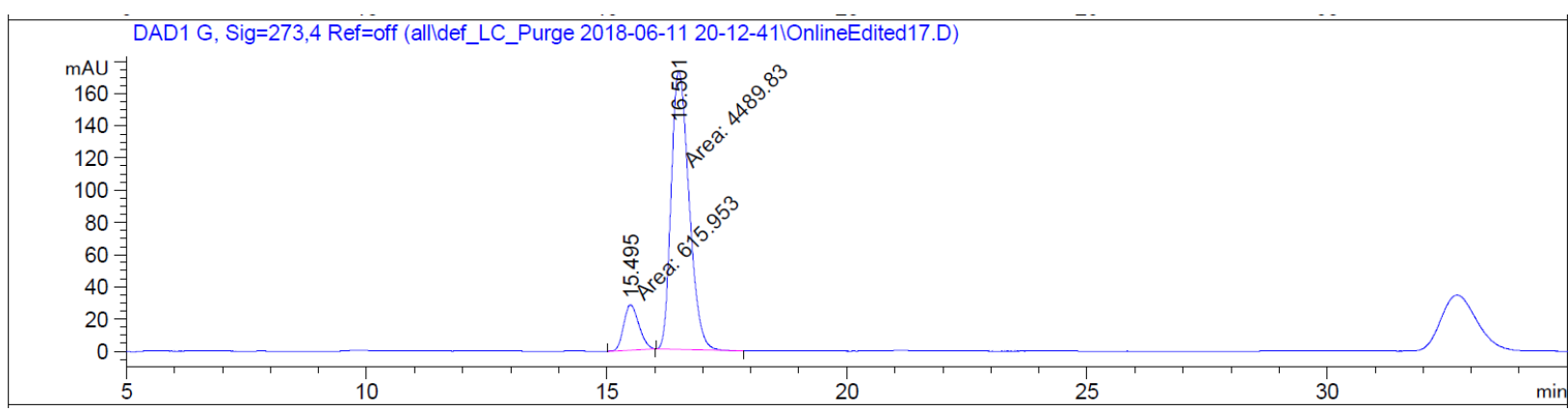

Peak RetTime Type Width Area Height Area

$\begin{array}{llll}\# & {[\mathrm{~min}]} & {[\mathrm{min}]} & {[\mathrm{mAU} * \mathrm{~s}]}\end{array}$

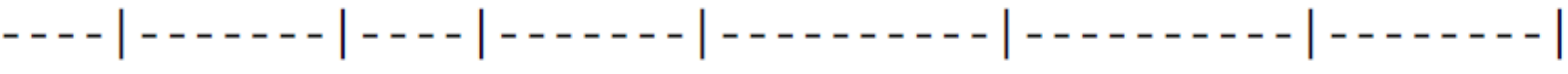

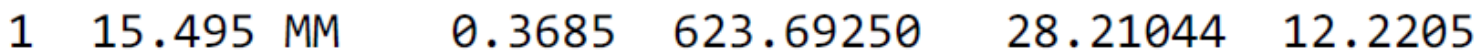

$\begin{array}{lllllll}2 & 16.501 & \text { MM } & 0.4318 & 4479.98438 & 172.92096 & 87.7795\end{array}$ 


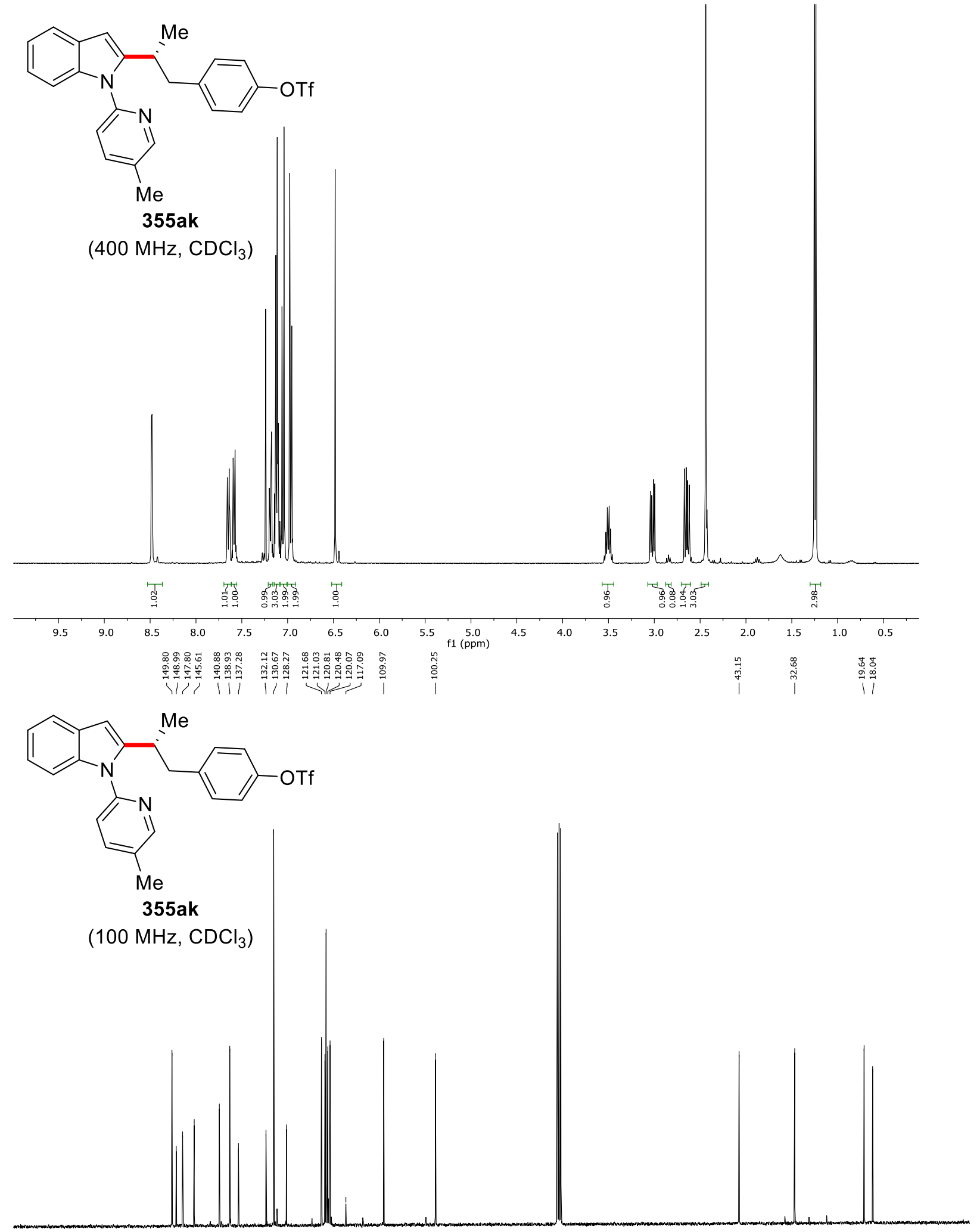

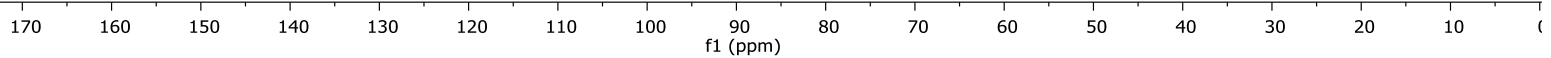




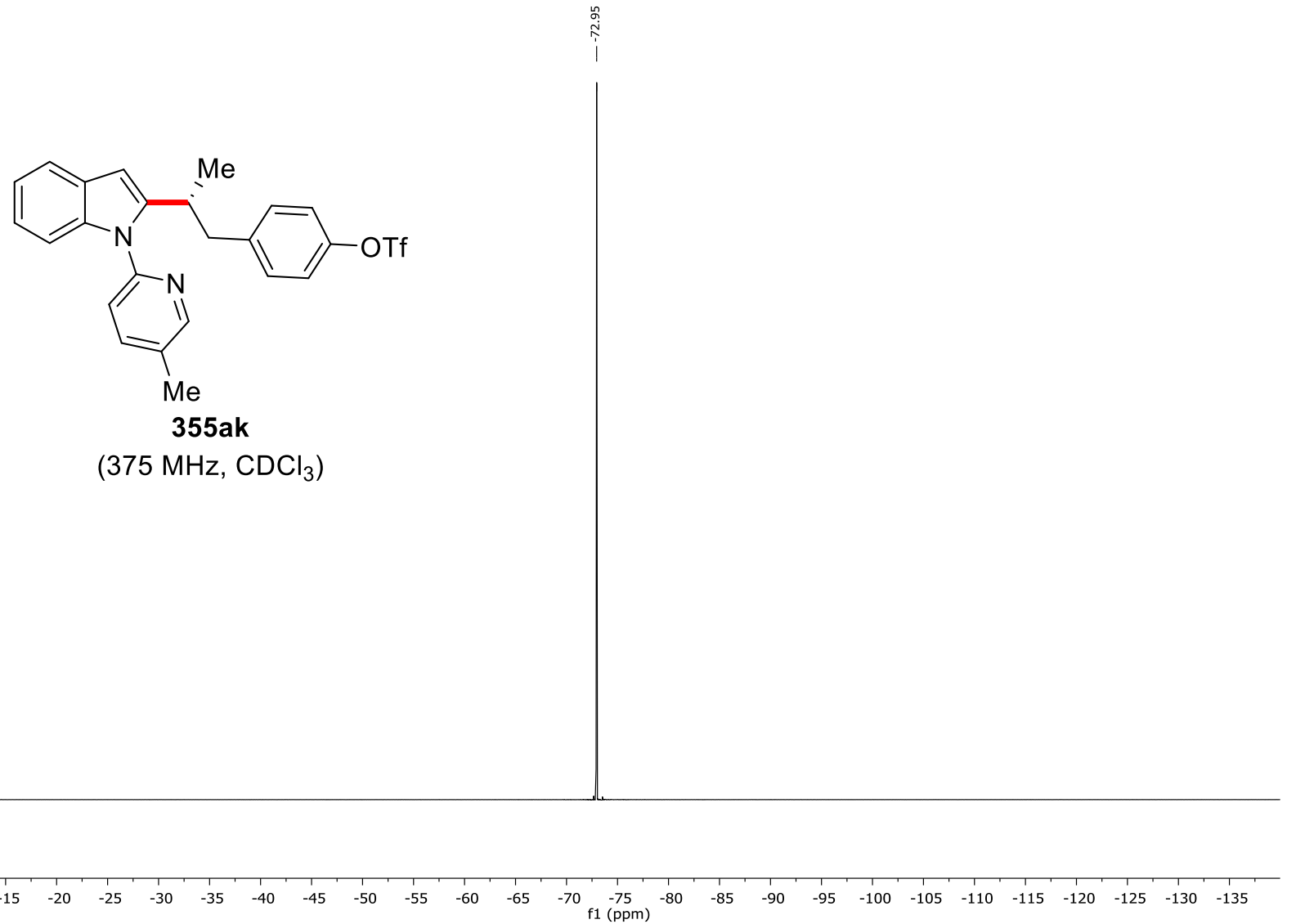


Chiral HPLC of 355ak:
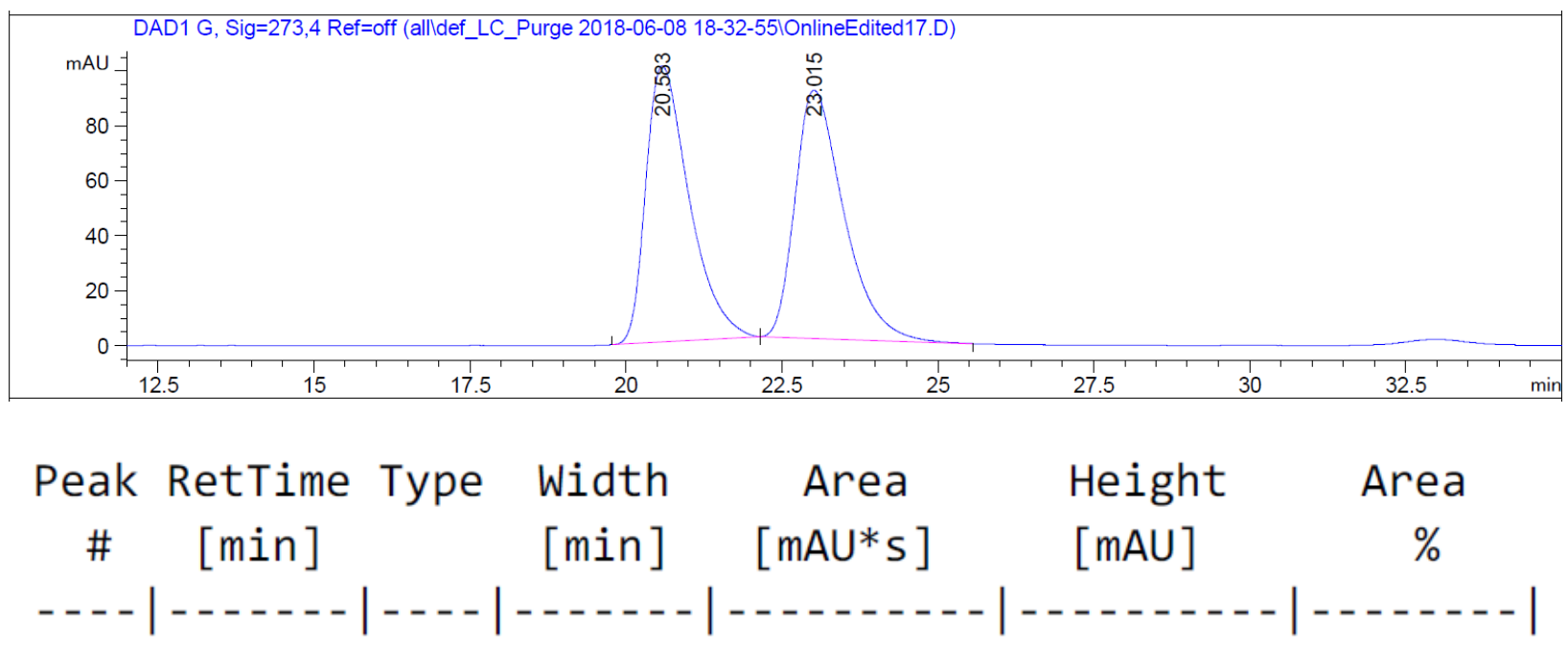

120.583 BB $\quad 0.7153 \quad 4857.50391 \quad 100.60416 \quad 49.6698$

$\begin{array}{lllllll}2 & 23.015 & \text { BB } & 0.7870 & 4922.09814 & 90.42706 & 50.3302\end{array}$

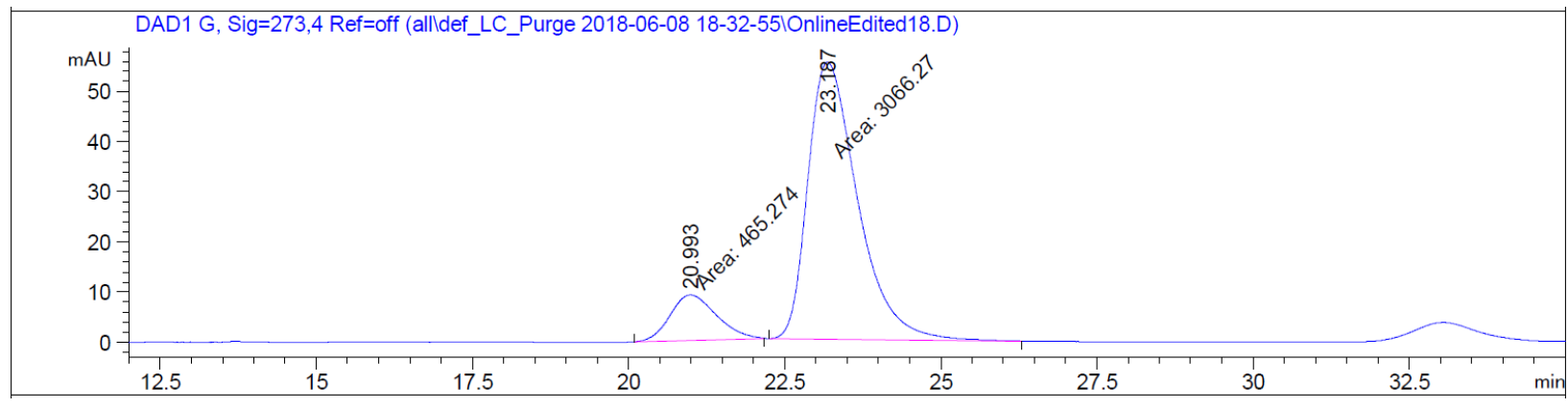

Peak RetTime Type Width Area Height Area

\# $[\mathrm{min}] \quad[\mathrm{min}] \quad[\mathrm{mAU} * \mathrm{~s}] \quad[\mathrm{mAU}] \quad \%$

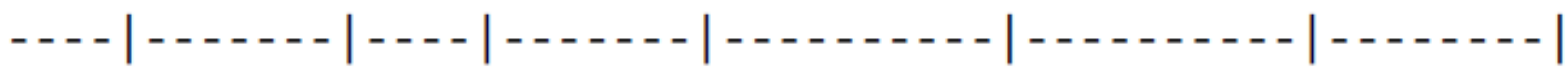
120.993 МM
0.8571465 .27365
$9.04786 \quad 13.1748$
$2 \quad 23.187$ MM
0.92453066 .26782
$55.27755 \quad 86.8252$ 


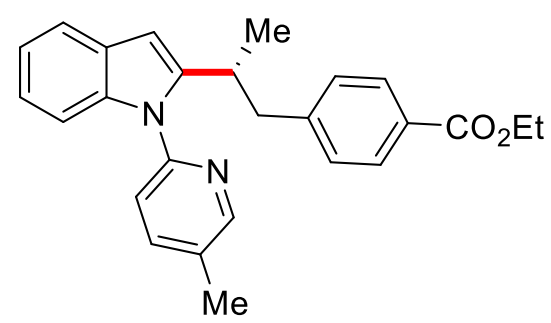

355al

$\left(300 \mathrm{MHz} \mathrm{CDCl}_{3}\right)$

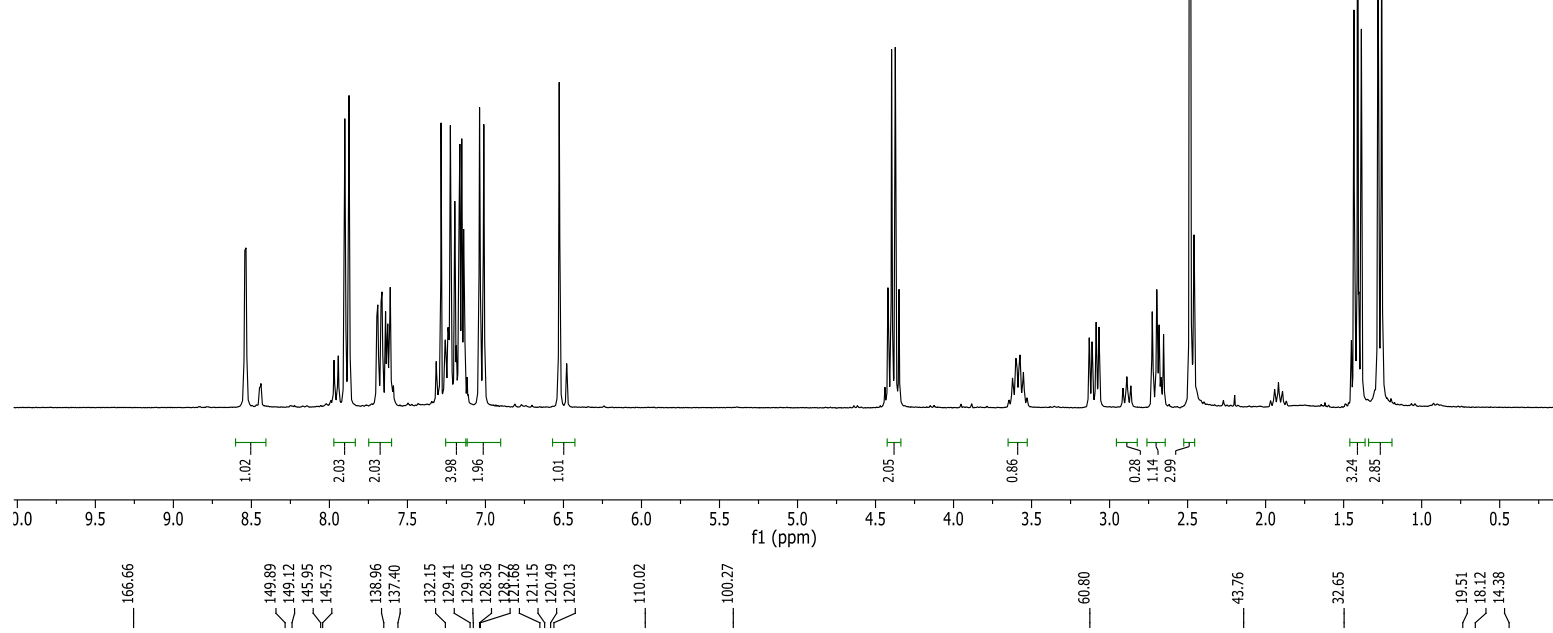<smiles>CCOC(=O)c1ccc(CCc2cc3ccccc3n2-c2ccc(C)cn2)cc1</smiles>

355al

$\left(75 \mathrm{MHz}^{\mathrm{CDCl}}{ }_{3}\right)$

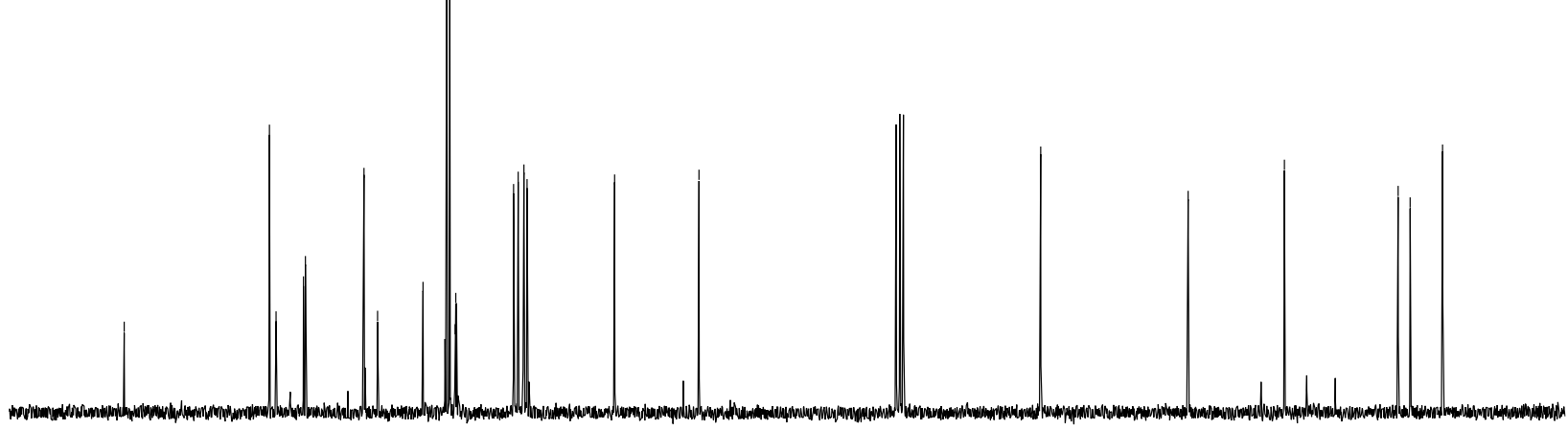

$\begin{array}{lllllllllllllllll}170 & 160 & 150 & 140 & 130 & 120 & 110 & 100 & \underset{f 1}{9}(\mathrm{ppm}) & 80 & 70 & 60 & 50 & 40 & 30 & 20 & 10\end{array}$ 
Chiral HPLC of 355al:

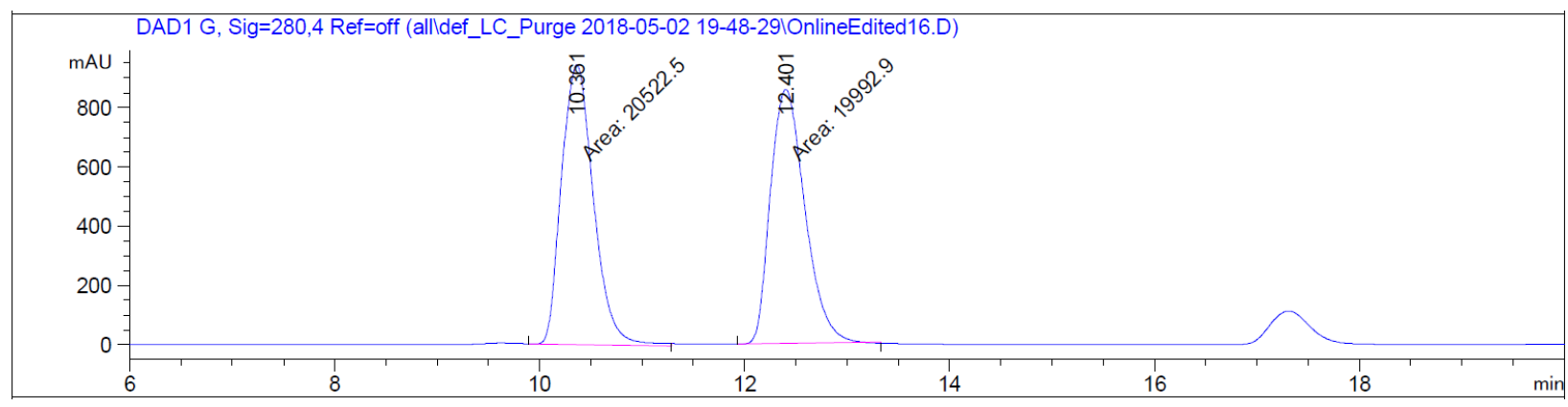

Peak RetTime Type width Area Height Area

\# $[\mathrm{min}] \quad[\mathrm{min}] \quad\left[\mathrm{mAU} \mathrm{U}^{*} \mathrm{~s}\right] \quad[\mathrm{mAU}] \quad \%$

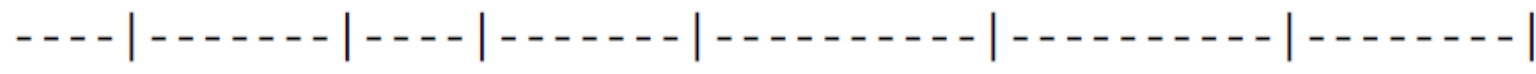

$1 \quad 10.361$ MM $0.36212 .05225 \mathrm{e} 4 \quad 944.63037 \quad 50.6536$

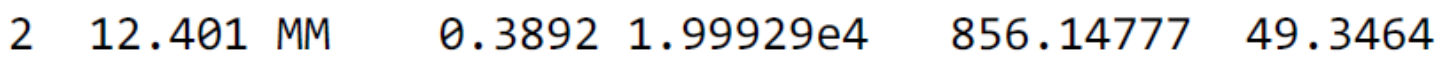

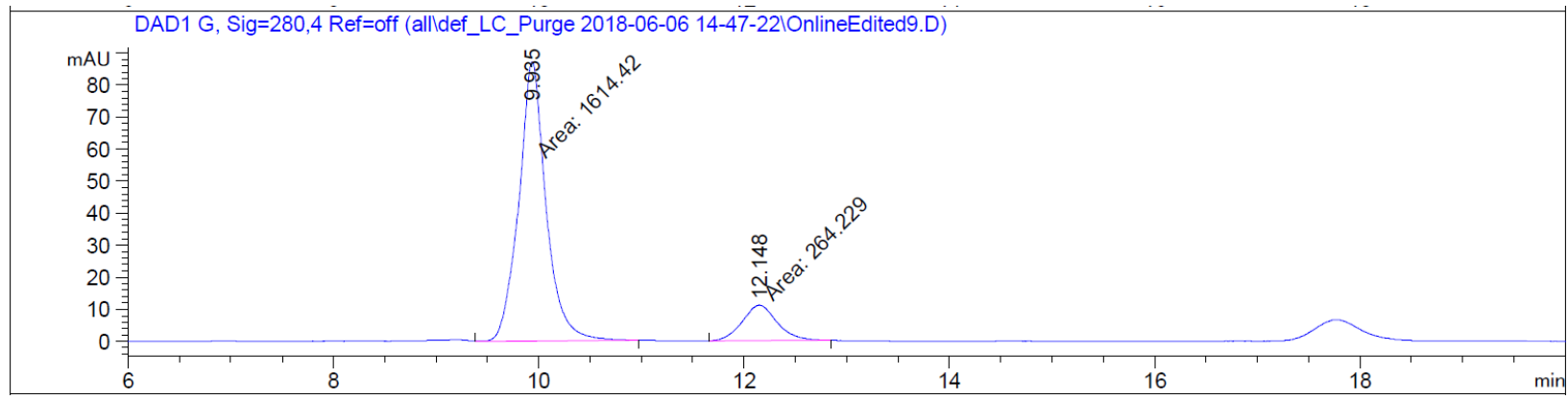

Peak RetTime Type Width Area Height Area

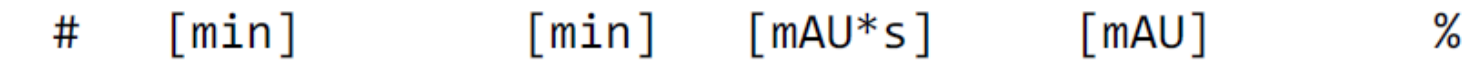

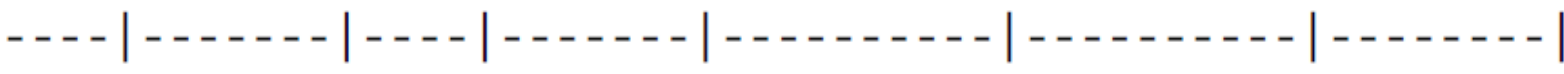

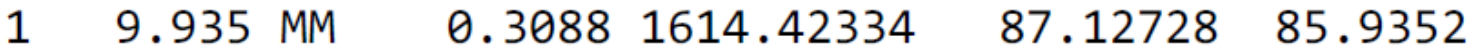

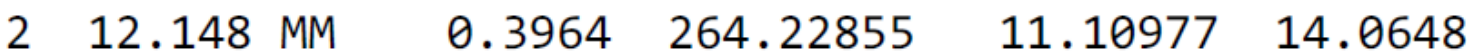




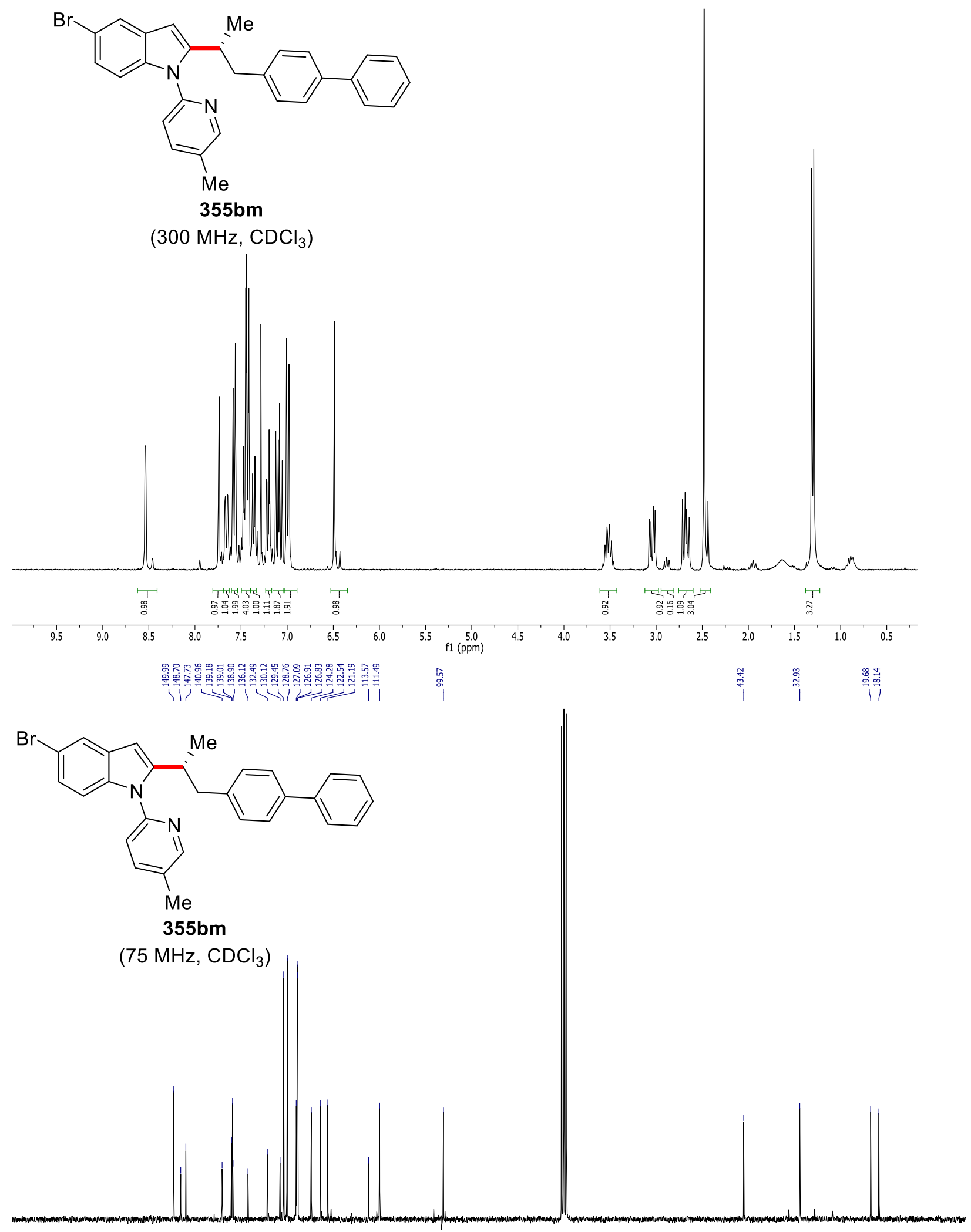

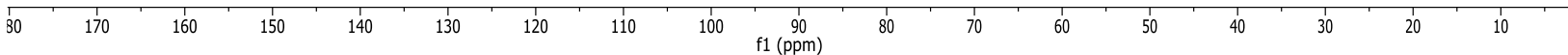


Chiral HPLC of 355bm:
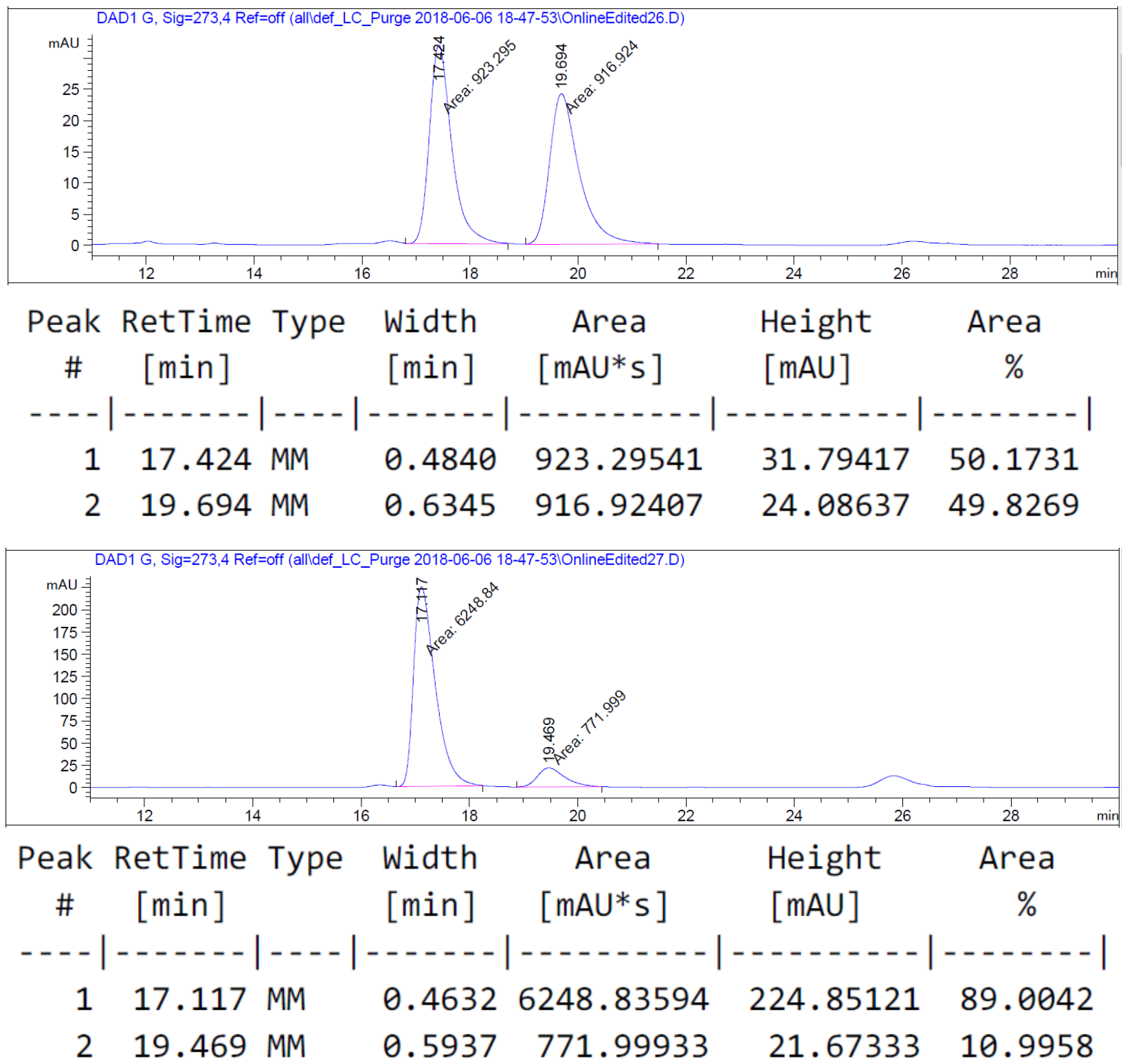


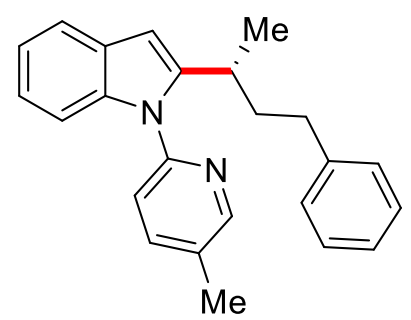

355an

$\left(300 \mathrm{MHz}, \mathrm{CDCl}_{3}\right)$

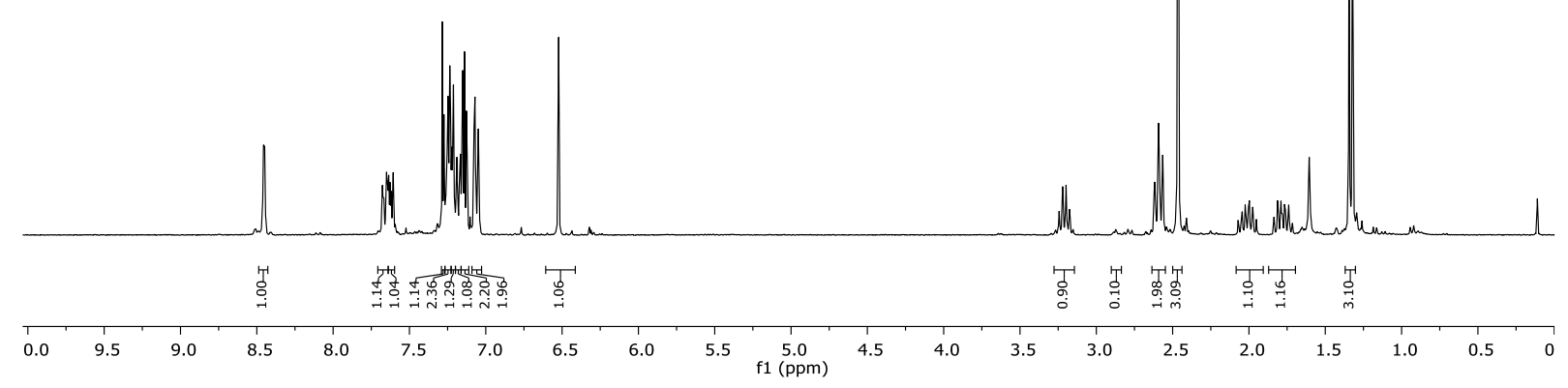

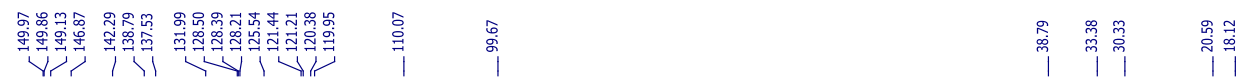

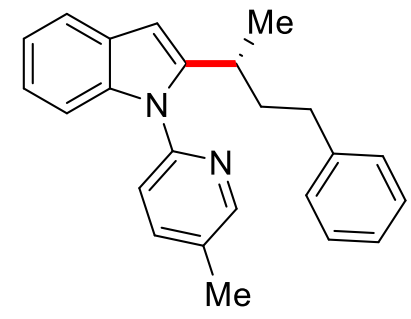

355an

$\left.\left(100 \mathrm{MHz}^{\mathrm{CDCl}}\right)_{3}\right)$

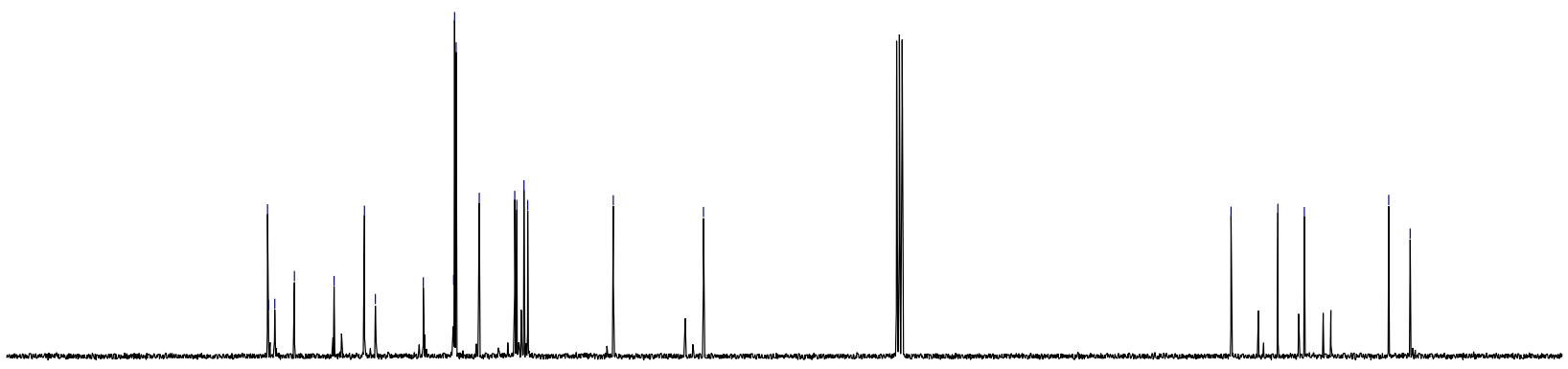

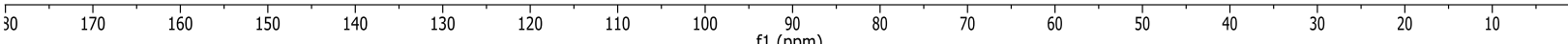




\section{Chiral HPLC of 355an:}

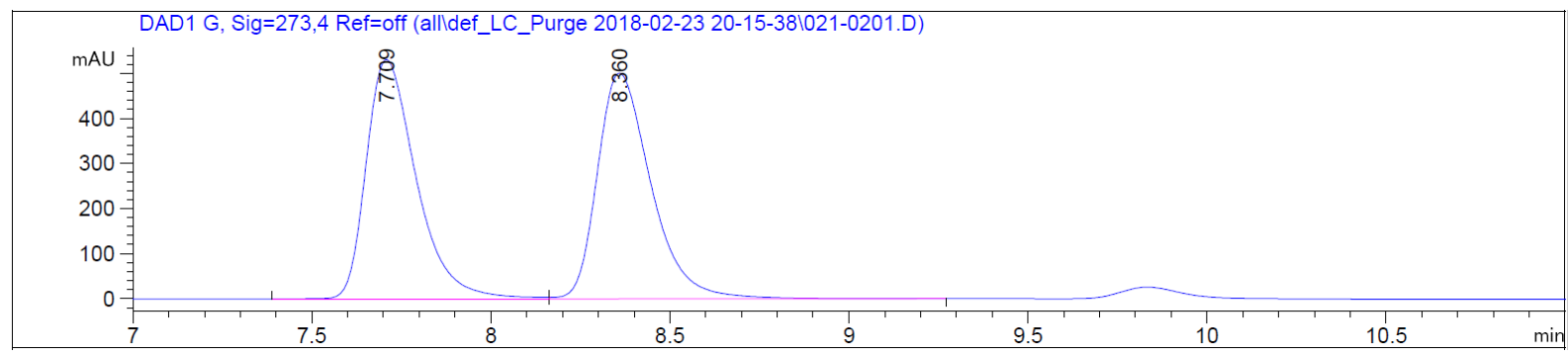

\begin{tabular}{|c|c|c|c|c|c|c|}
\hline $\begin{array}{c}\text { Peak } \\
\#\end{array}$ & $\begin{array}{c}\text { RetTime } \\
\text { [min] }\end{array}$ & Type & $\begin{array}{l}\text { Width } \\
\text { [min] }\end{array}$ & $\begin{array}{c}\text { Area } \\
{\left[\mathrm{mAU}^{*} \mathrm{~s}\right]}\end{array}$ & $\begin{array}{l}\text { Height } \\
\text { [mAU] }\end{array}$ & $\begin{array}{c}\text { Area } \\
\frac{\circ}{\circ}\end{array}$ \\
\hline & & & & & & \\
\hline 7 & & & & 5158.73682 & 83 & 74 \\
\hline , & & $\mathrm{VB}$ & & 5209.05127 & 276 & 426 \\
\hline
\end{tabular}

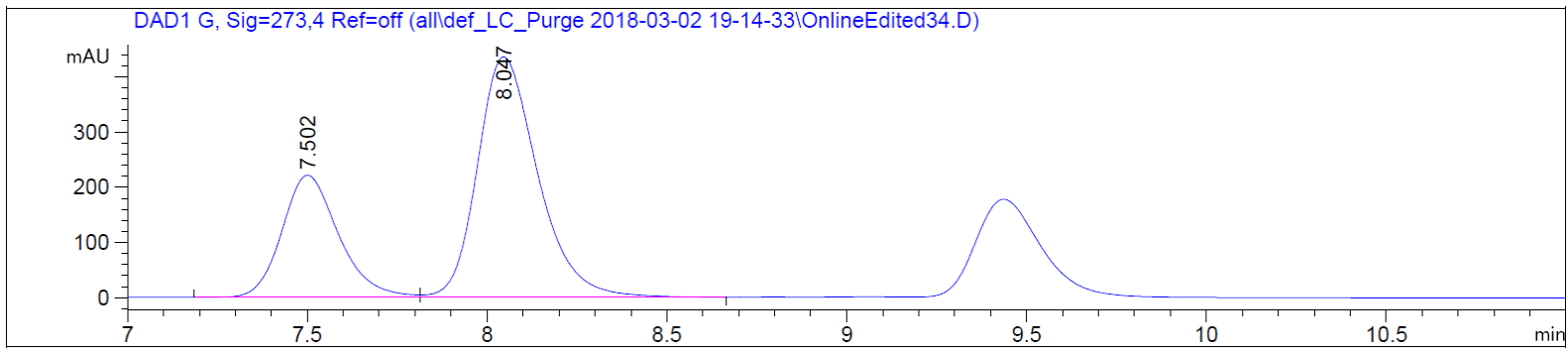

\begin{tabular}{|c|c|c|c|c|c|c|}
\hline $\begin{array}{c}\text { Peak } \\
\quad \#\end{array}$ & $\begin{array}{c}\text { RetTime } \\
\text { [min] }\end{array}$ & Type & $\begin{array}{l}\text { Width } \\
\text { [min] }\end{array}$ & $\begin{array}{c}\text { Area } \\
{\left[\mathrm{mAU}^{\star} \mathrm{s}\right]}\end{array}$ & $\begin{array}{c}\text { Height } \\
{[\mathrm{mAU}]}\end{array}$ & $\begin{array}{c}\text { Area } \\
\frac{\circ}{\delta}\end{array}$ \\
\hline & & & & -------- & --- & \\
\hline 1 & & & & 2422.10693 & 980 & 92 \\
\hline 2 & & & & 5076.86377 & 667 & 008 \\
\hline
\end{tabular}




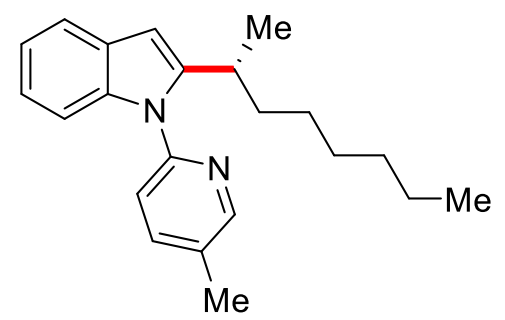

$355 \mathrm{ao}$

$\left(300 \mathrm{MHz} \mathrm{CDCl}_{3}\right)$

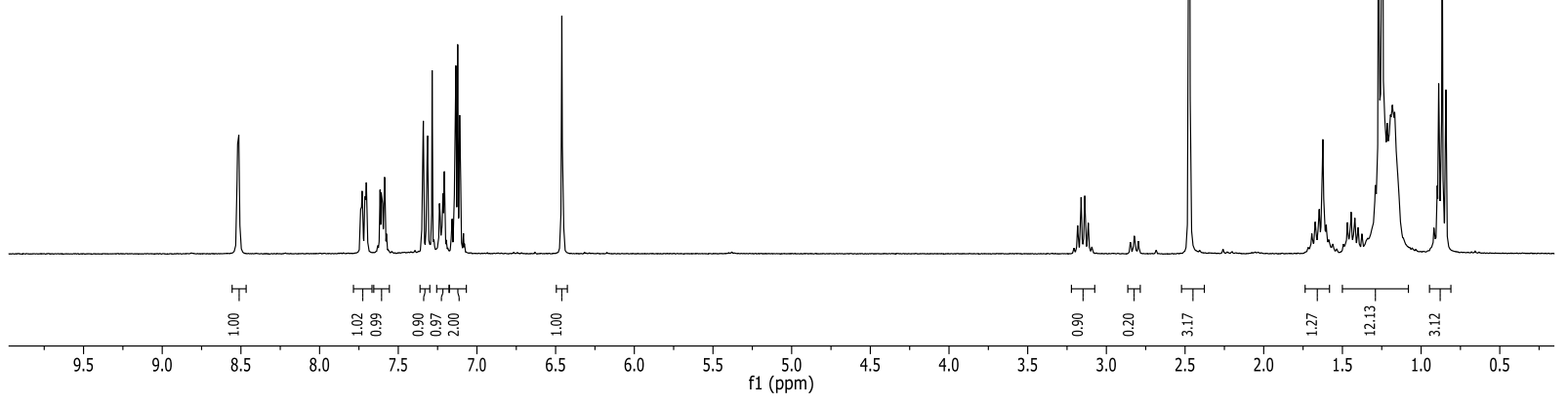

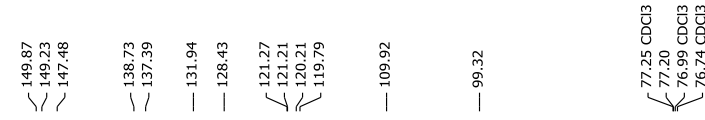

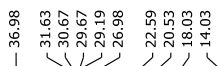

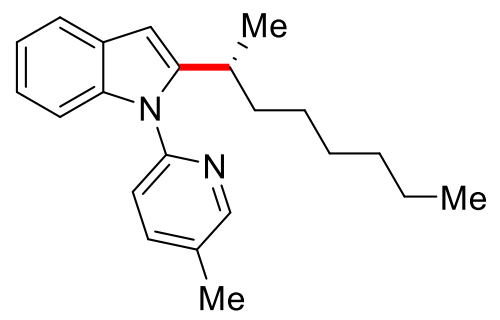

$355 \mathrm{ao}$

$\left(125 \mathrm{MHz} \mathrm{CDCl}_{3}\right)$

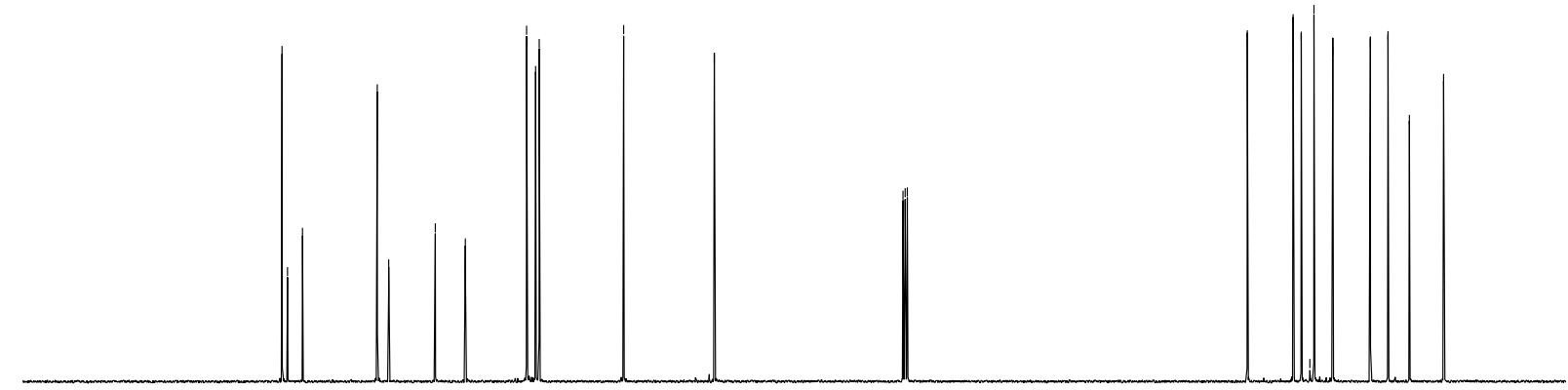

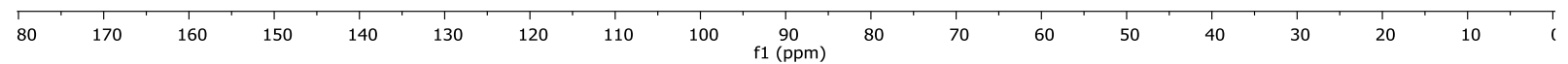


Chiral HPLC of 355ao:

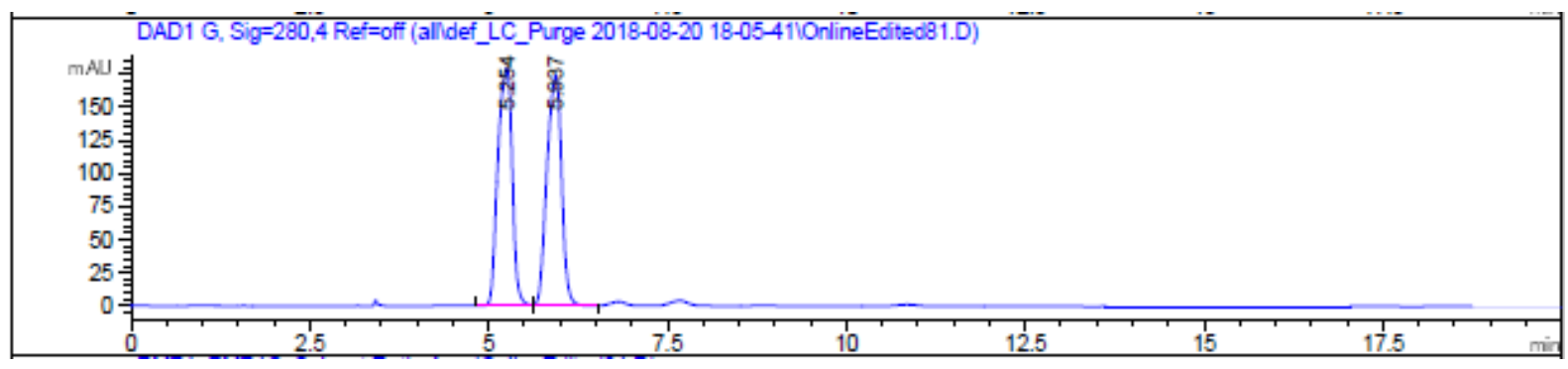

\begin{tabular}{|c|c|c|c|c|c|c|}
\hline $\begin{array}{c}\text { Peak } \\
\quad \#\end{array}$ & $\begin{array}{c}\text { RetTime } \\
\text { [min] }\end{array}$ & Type & $\begin{array}{l}\text { Width } \\
\text { [min] }\end{array}$ & $\begin{array}{c}\text { Area } \\
{\left[\mathrm{mAU}^{*} \mathrm{~s}\right]}\end{array}$ & $\begin{array}{l}\text { Height } \\
\text { [mAU] }\end{array}$ & $\begin{array}{c}\text { Area } \\
\frac{\circ}{0}\end{array}$ \\
\hline & & & & & ---------- & \\
\hline 1 & & & & 2502.3 & 625 & \\
\hline 2 & & VB & 41 & 2481.05249 & 30663 & 67 \\
\hline
\end{tabular}

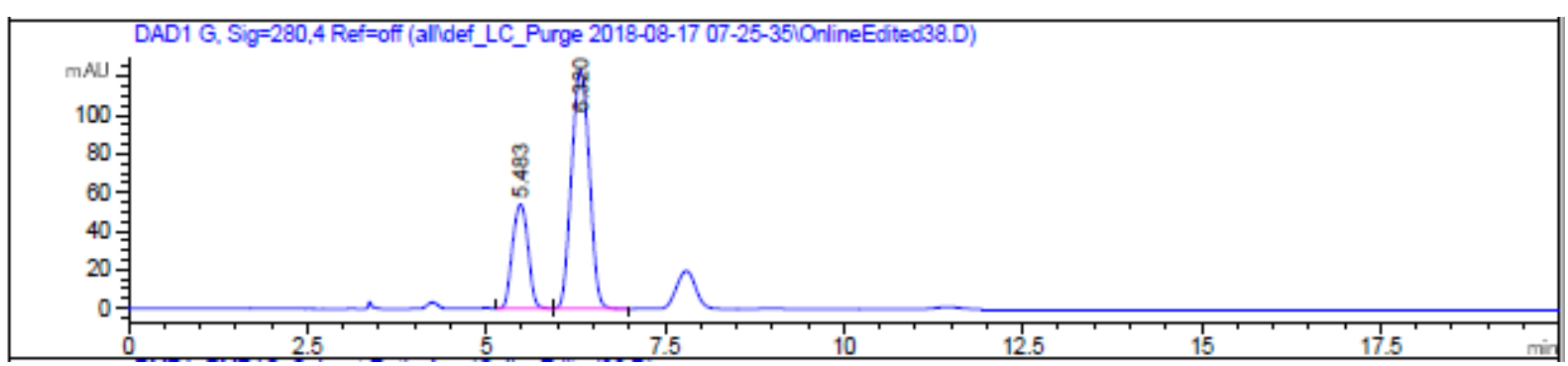

\begin{tabular}{|c|c|c|c|c|c|c|}
\hline $\begin{array}{c}\text { Peak } \\
\#\end{array}$ & $\begin{array}{c}\text { RetTime } \\
\text { [min] }\end{array}$ & Type & $\begin{array}{l}\text { Width } \\
\text { [min] }\end{array}$ & $\begin{array}{c}\text { Area } \\
{\left[\mathrm{mAU}{ }^{*} \mathrm{~S}\right]}\end{array}$ & $\begin{array}{l}\text { Height } \\
{[\mathrm{mAU}]}\end{array}$ & $\begin{array}{c}\text { Area } \\
\text { 응 }\end{array}$ \\
\hline & & & & | ---------- & & \\
\hline & & & 0.2527 & 815.84808 & 852 & 697 \\
\hline & 6 & $\mathrm{BB}$ & 821 & 2143.37598 & 6132 & \pm 303 \\
\hline
\end{tabular}



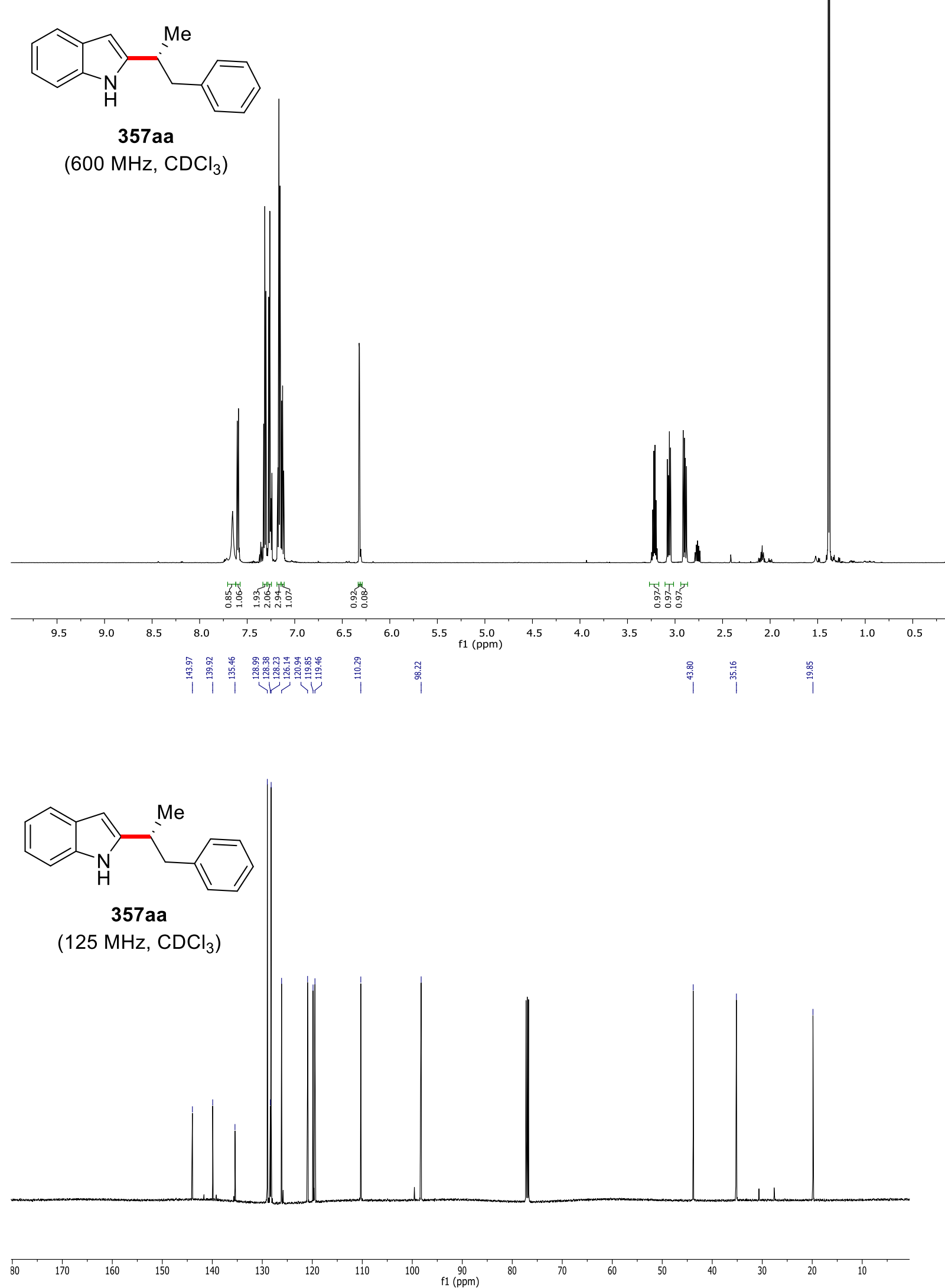
Chiral HPLC of 357aa:
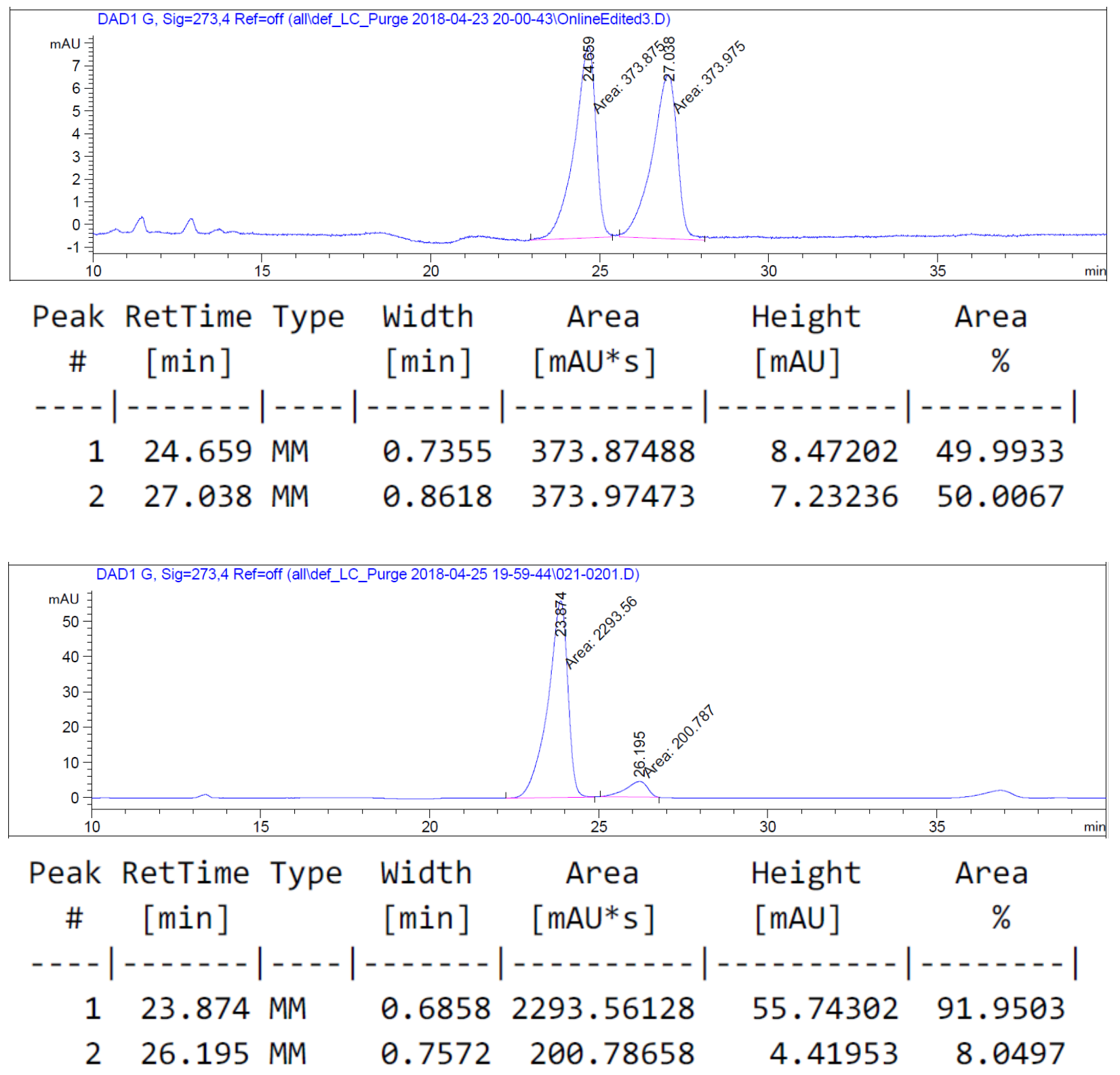

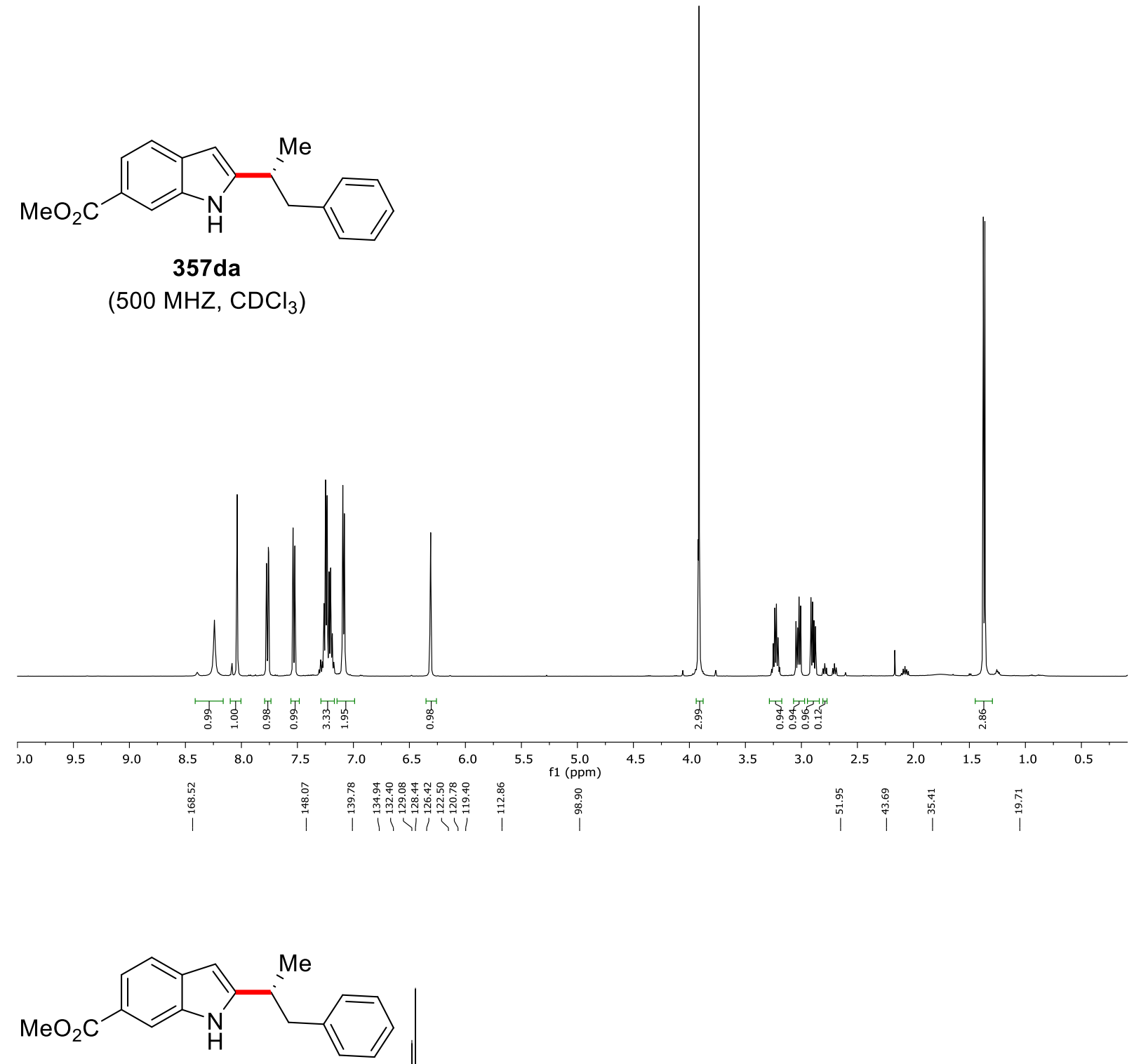

357da

$\left(125 \mathrm{MHZ} \mathrm{CDCl}_{3}\right)$

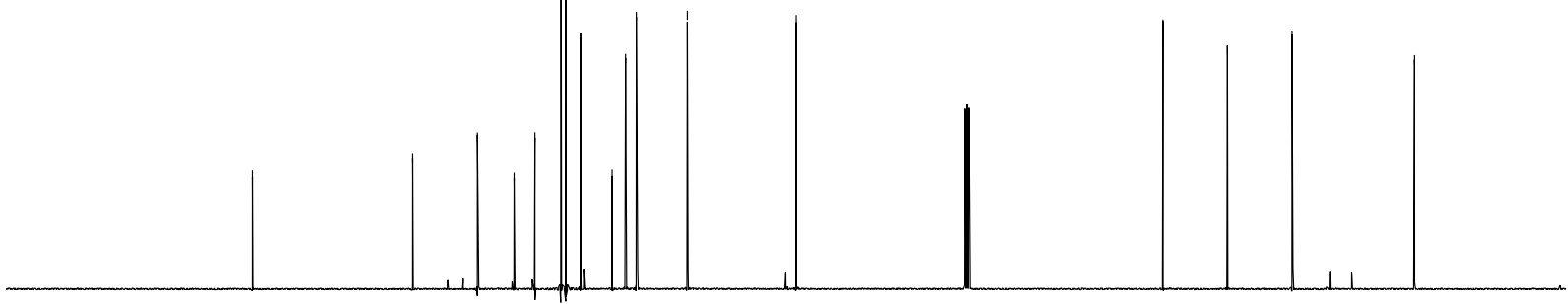

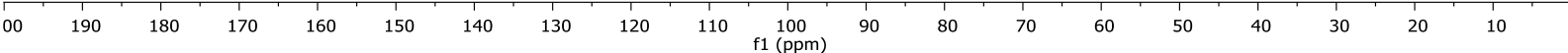


Chiral HPLC of 357da:

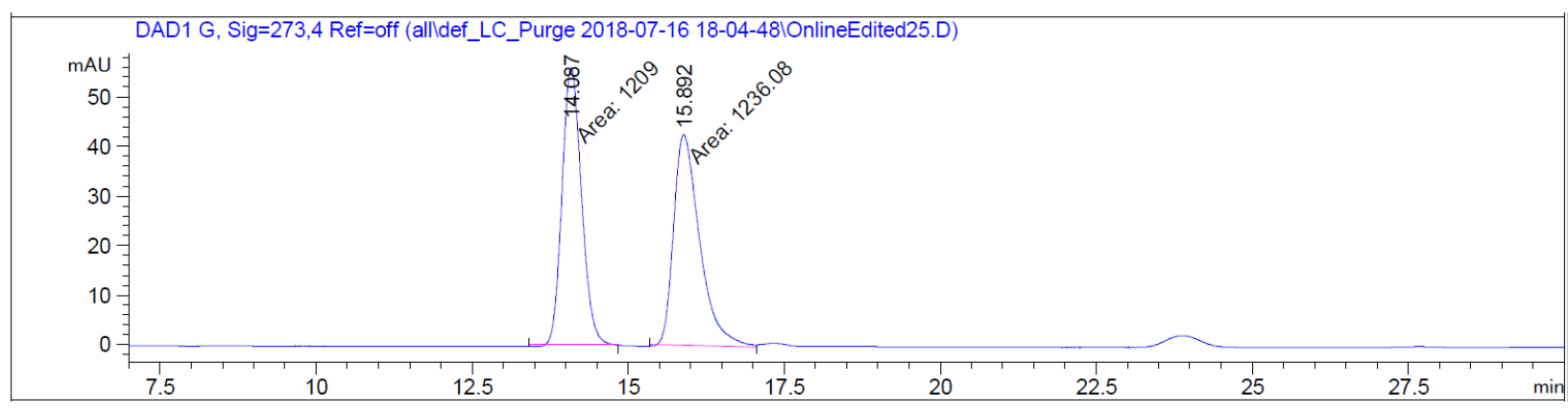

Peak RetTime Type Width Area Height Area

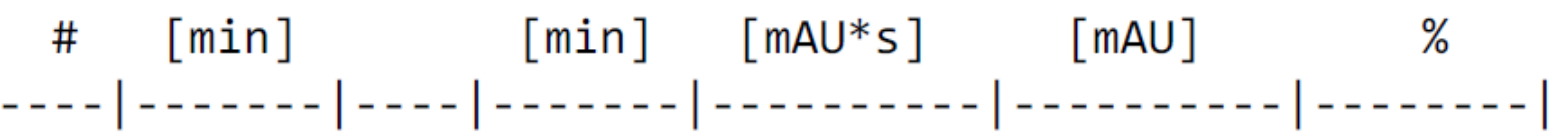
114.087 MM
0.36041208 .99988
$55.91126 \quad 49.4463$
$215.892 \mathrm{MM}$
0.48481236 .07727
$42.49546 \quad 50.5537$

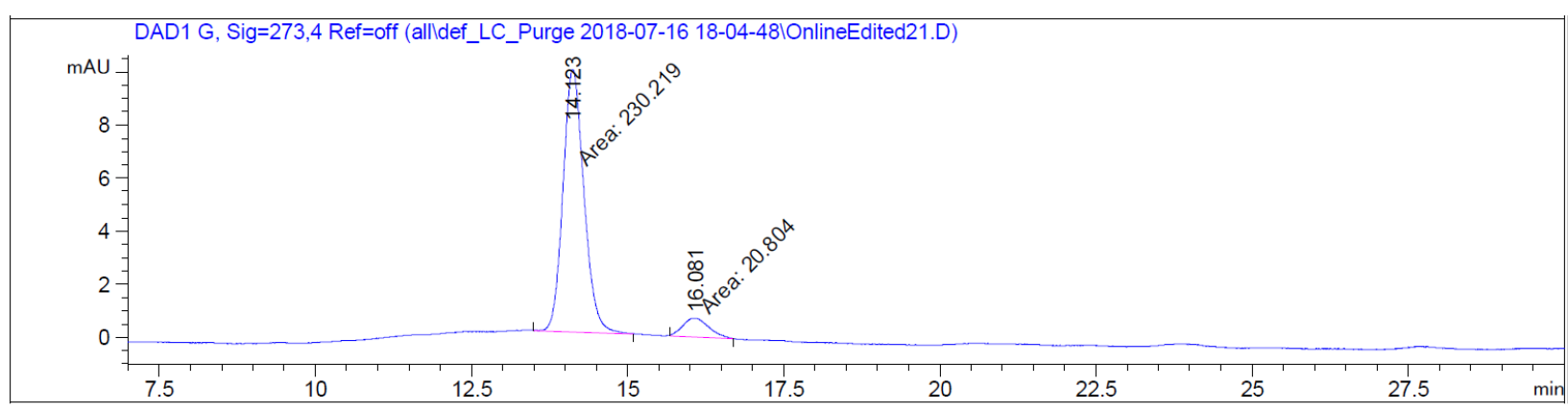

Peak RetTime Type width Area Height Area

$\begin{array}{llll}\# & {[\mathrm{~min}]} & \mathrm{min}] & {\left[\mathrm{mAU} \mathrm{H}^{*} \mathrm{mAU}\right]}\end{array}$

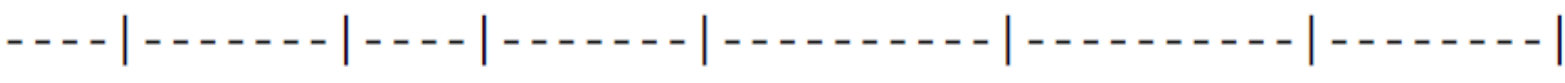
$114.123 \mathrm{MM}$
$0.3880 \quad 230.21918$
9.88896
91.7123
$216.081 \mathrm{MM}$
$0.483920 .804037 .16477 \mathrm{e}-1$
8.2877 

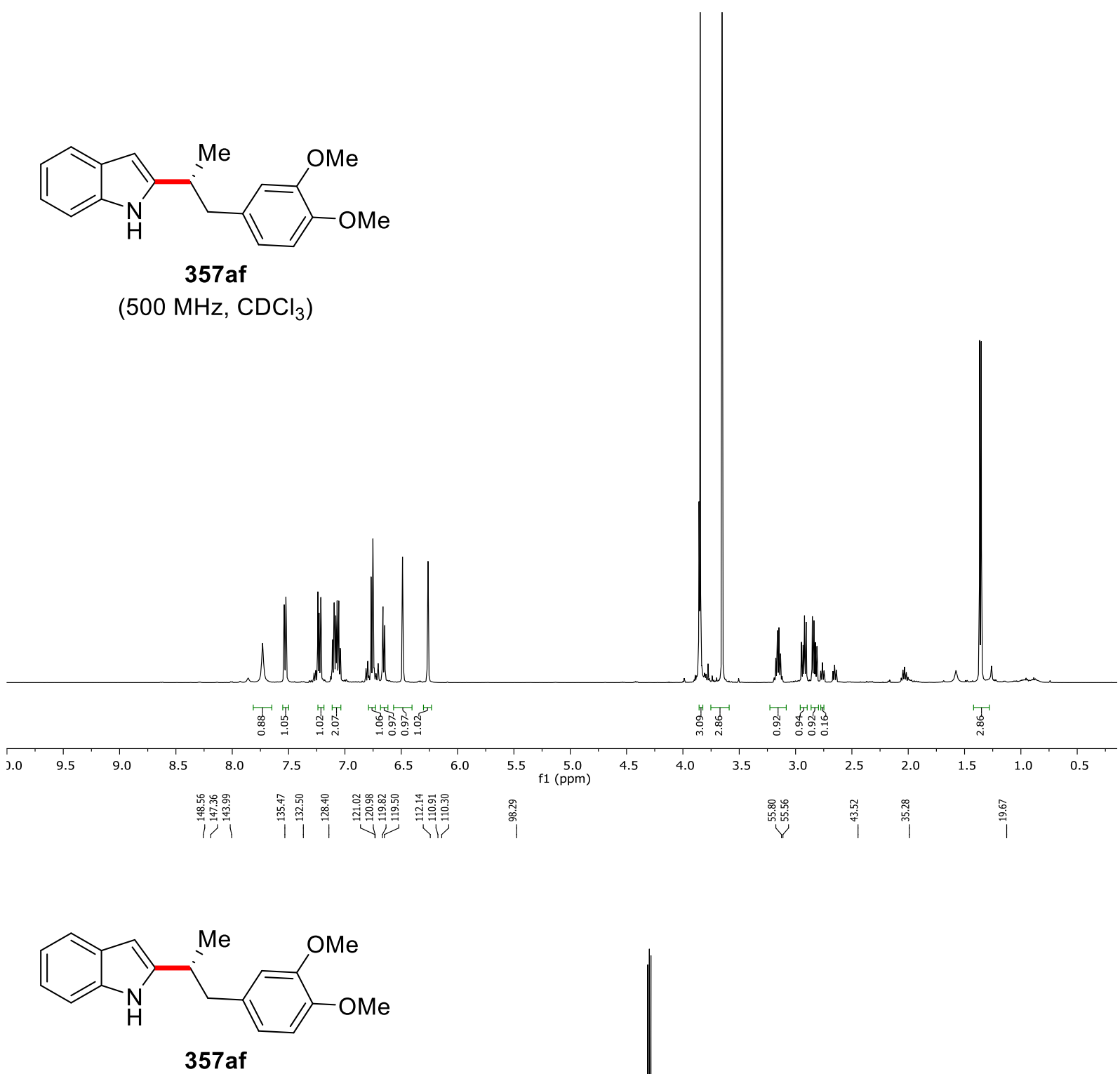

$\left(125 \mathrm{MHz}, \mathrm{CDCl}_{3}\right)$

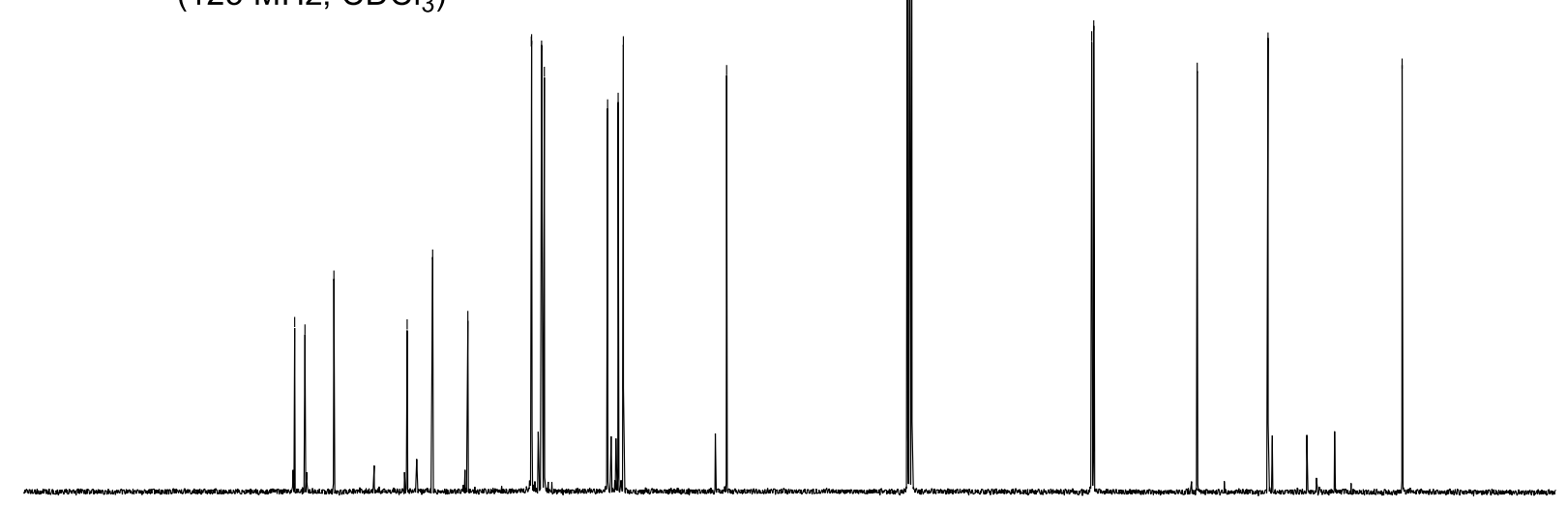

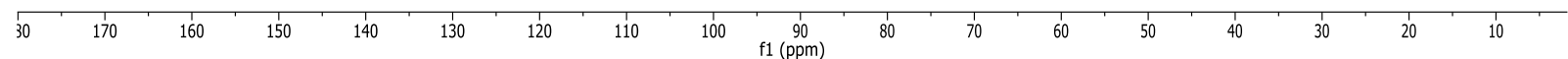


Chiral HPLC of 357af:
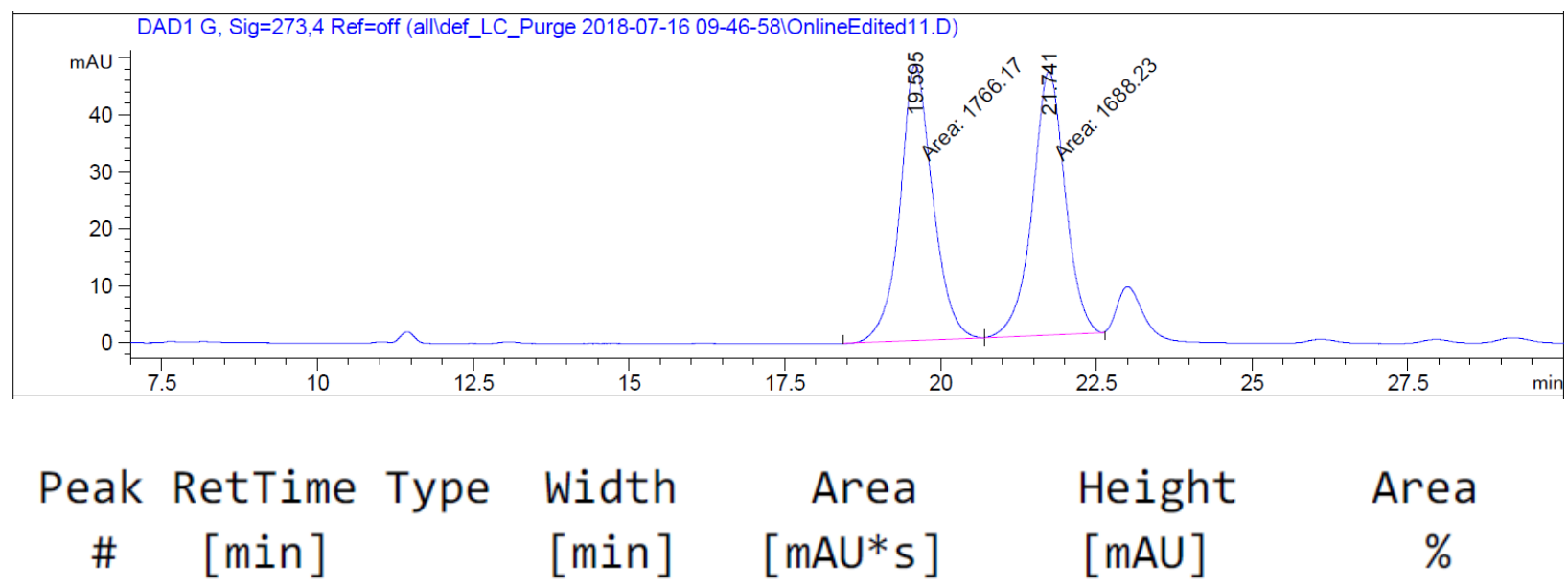

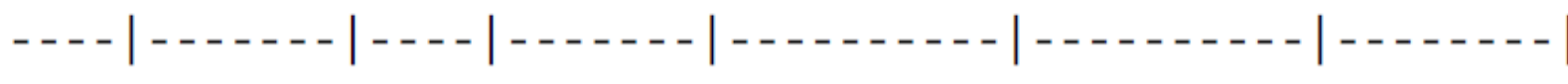

$1 \quad 19.595$ MF $\quad 0.60821766 .16919 \quad 48.39488 \quad 51.1281$

$2 \quad 21.741$ FM $\quad 0.6084 \quad 1688.23096 \quad 46.24706 \quad 48.8719$

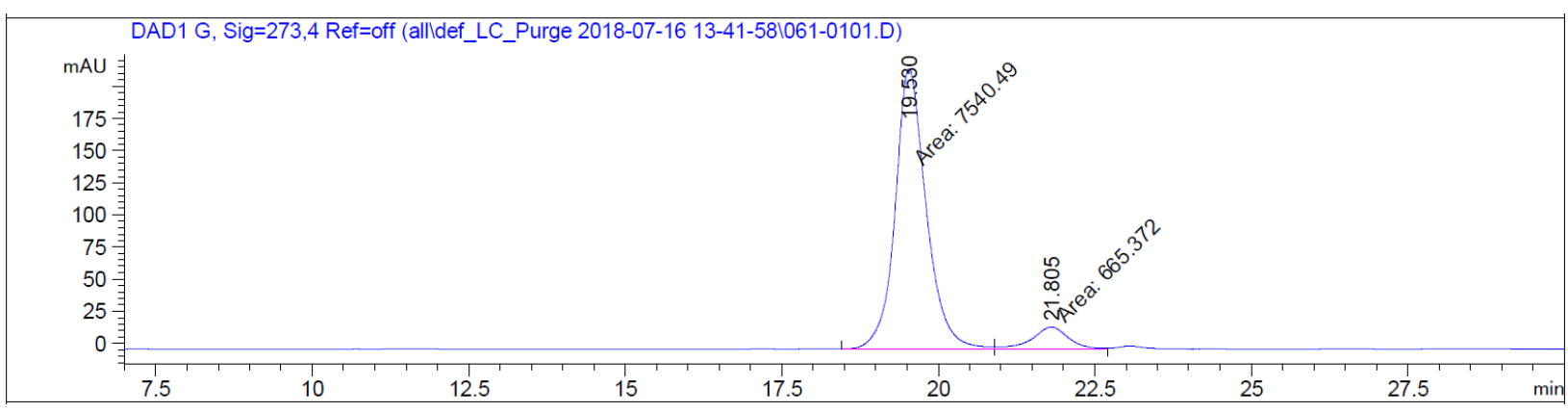

Peak RetTime Type Width Area Height Area

\# [min] [min] [mAU*s] [mAU] \%

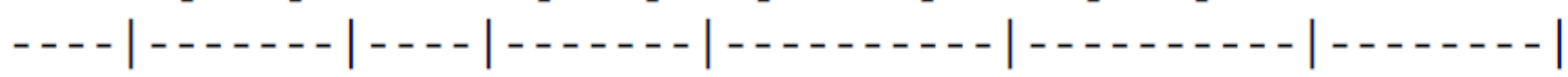

$1 \quad 19.530$ MF $\quad 0.5763 \quad 7540.49170 \quad 218.08086 \quad 91.8915$

$2 \quad 21.805$ FM $\quad 0.6555 \quad 665.37158 \quad 16.91690 \quad 8.1085$ 

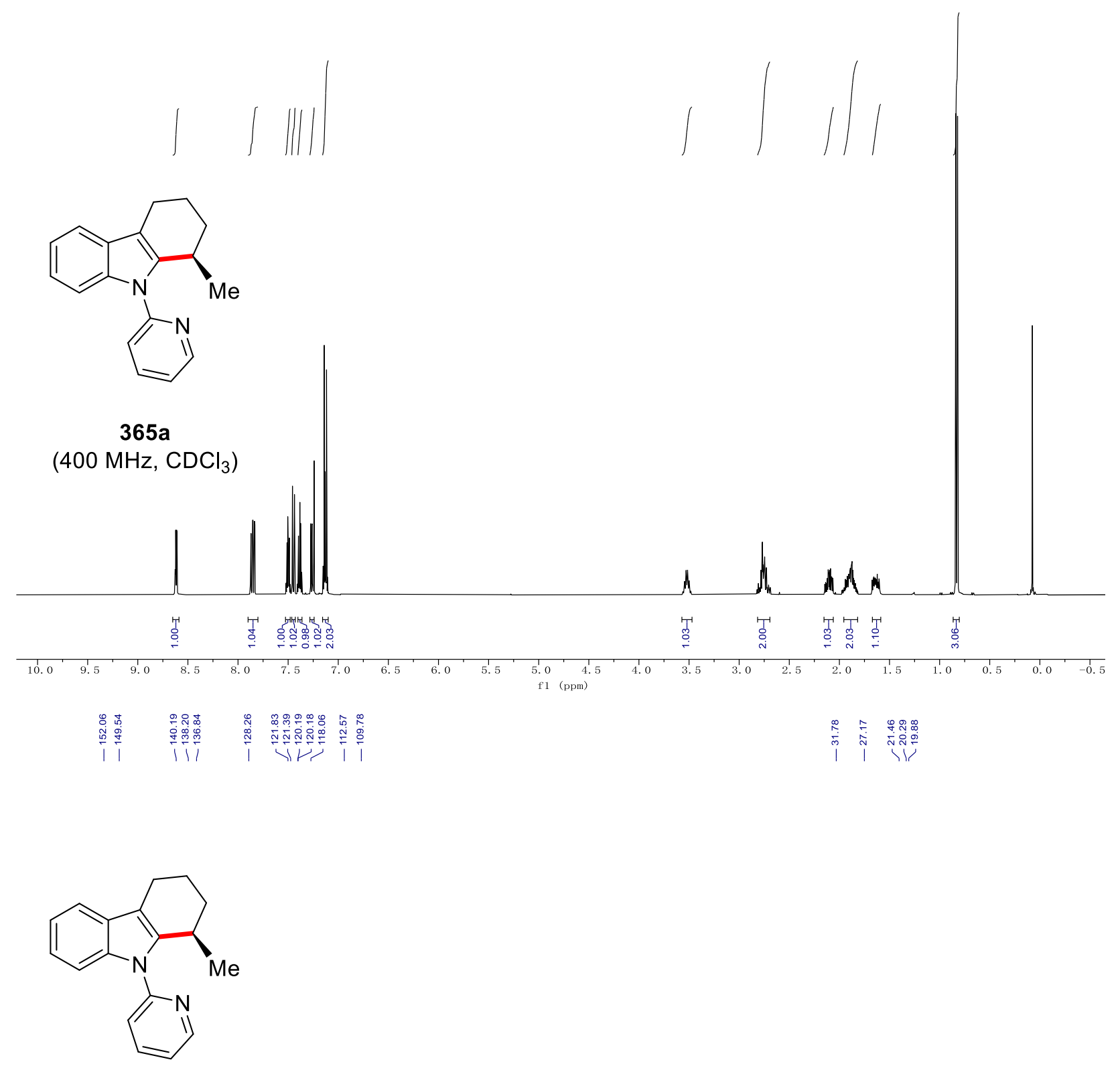

365a

(100 MHz, $\mathrm{CDCl}_{3}$ )
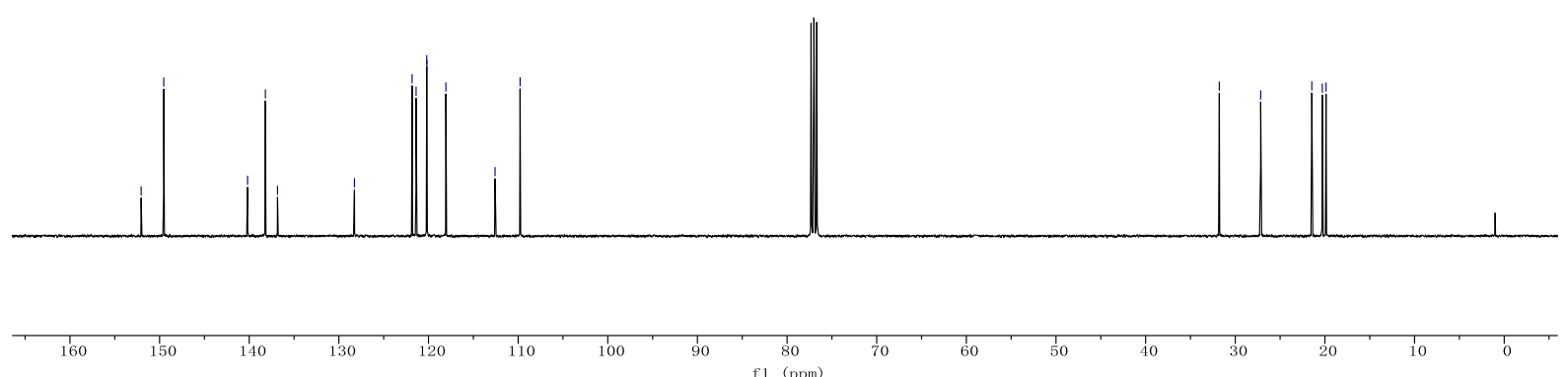
Chiral HPLC of 365a:

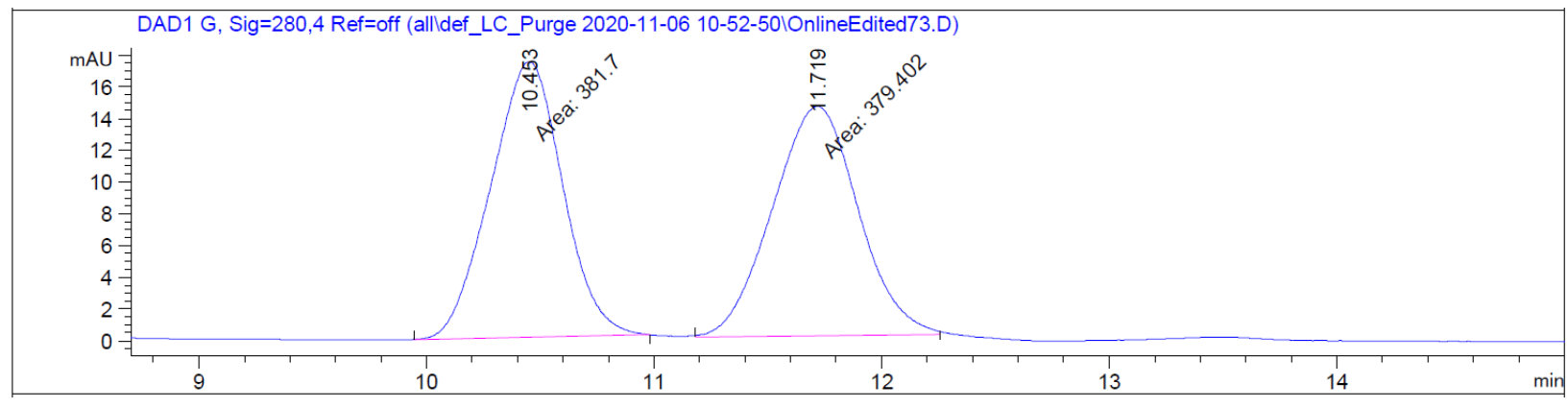

Peak RetTime Type Width Area Height Area

\# $\quad[\min ] \quad[\mathrm{min}] \quad[\mathrm{mAU} * \mathrm{~s}] \quad[\mathrm{mAU}] \quad \%$

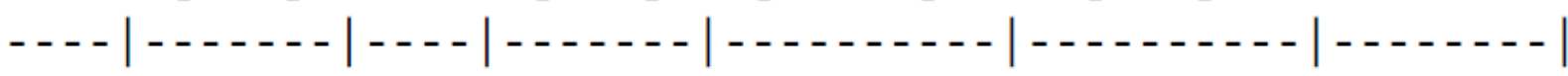

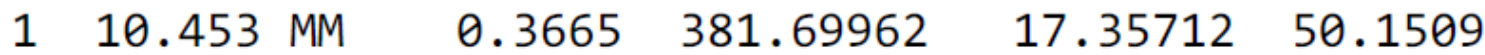

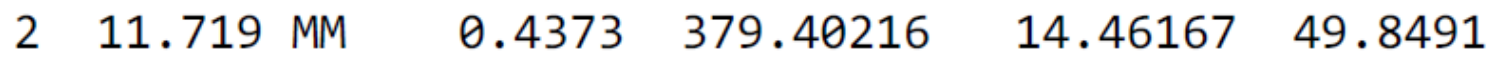

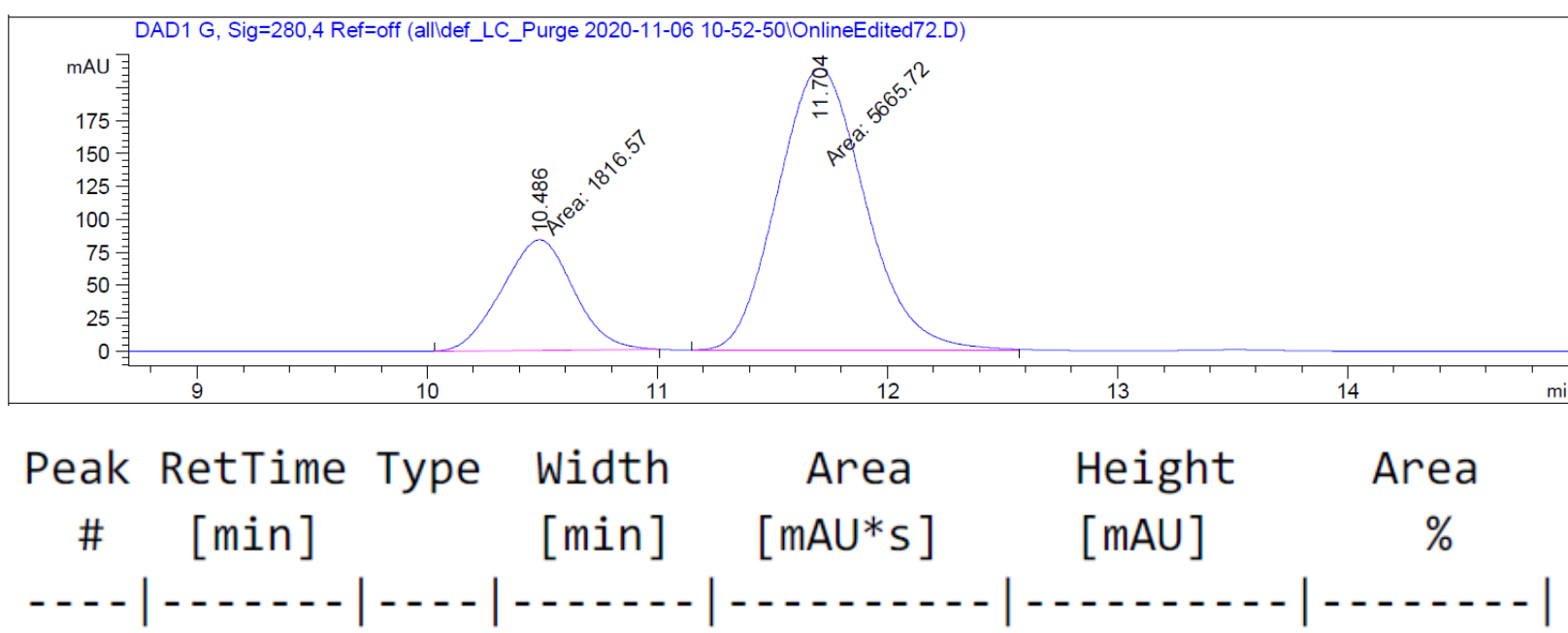

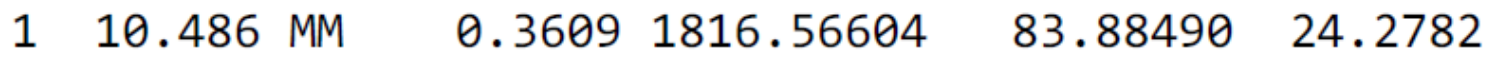

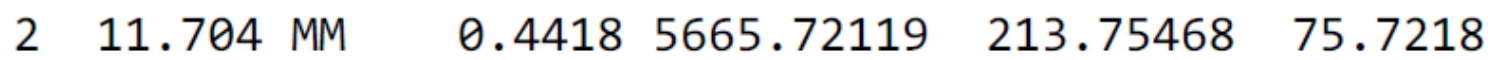



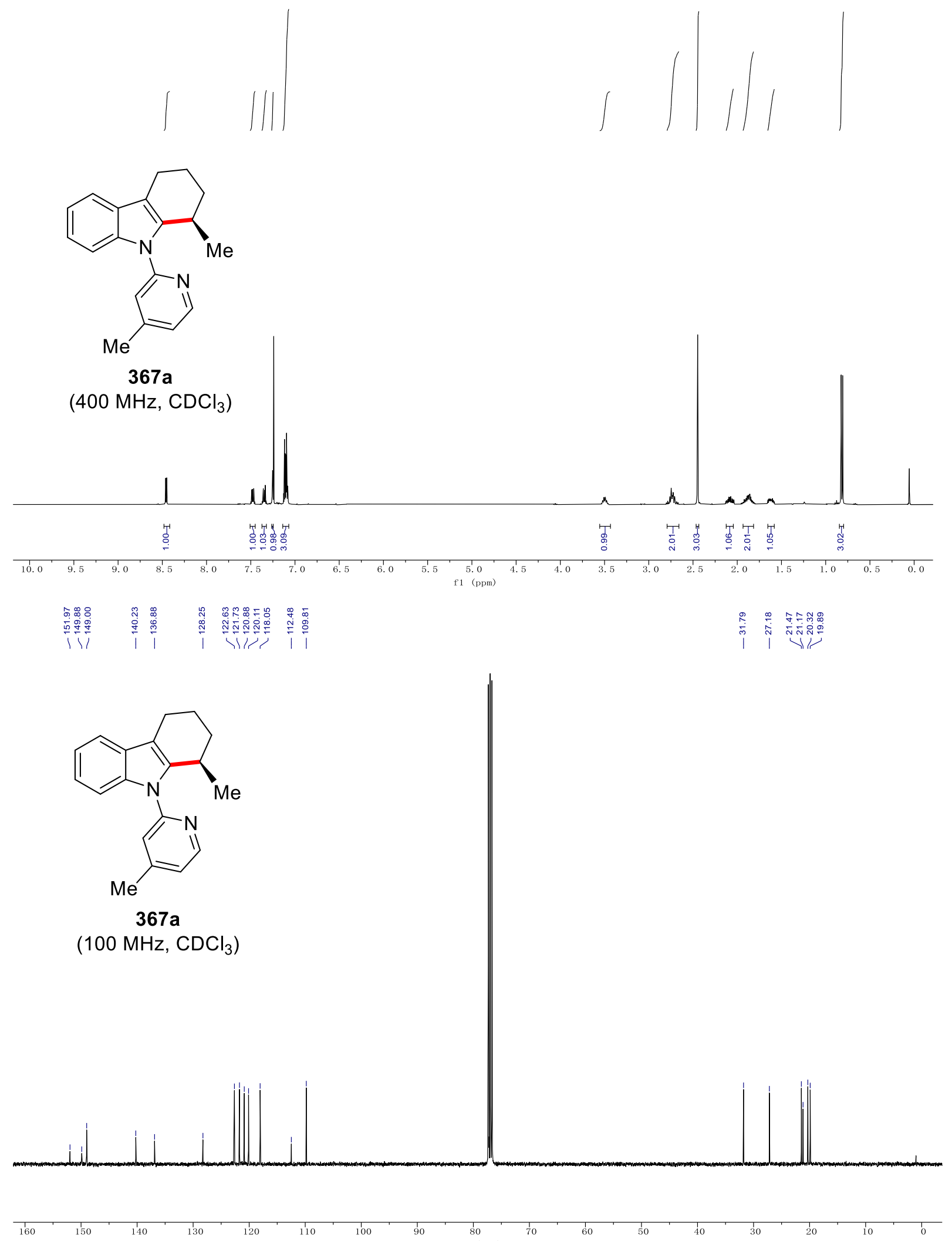

f1 (ppm) 
Chiral HPLC of 367a:
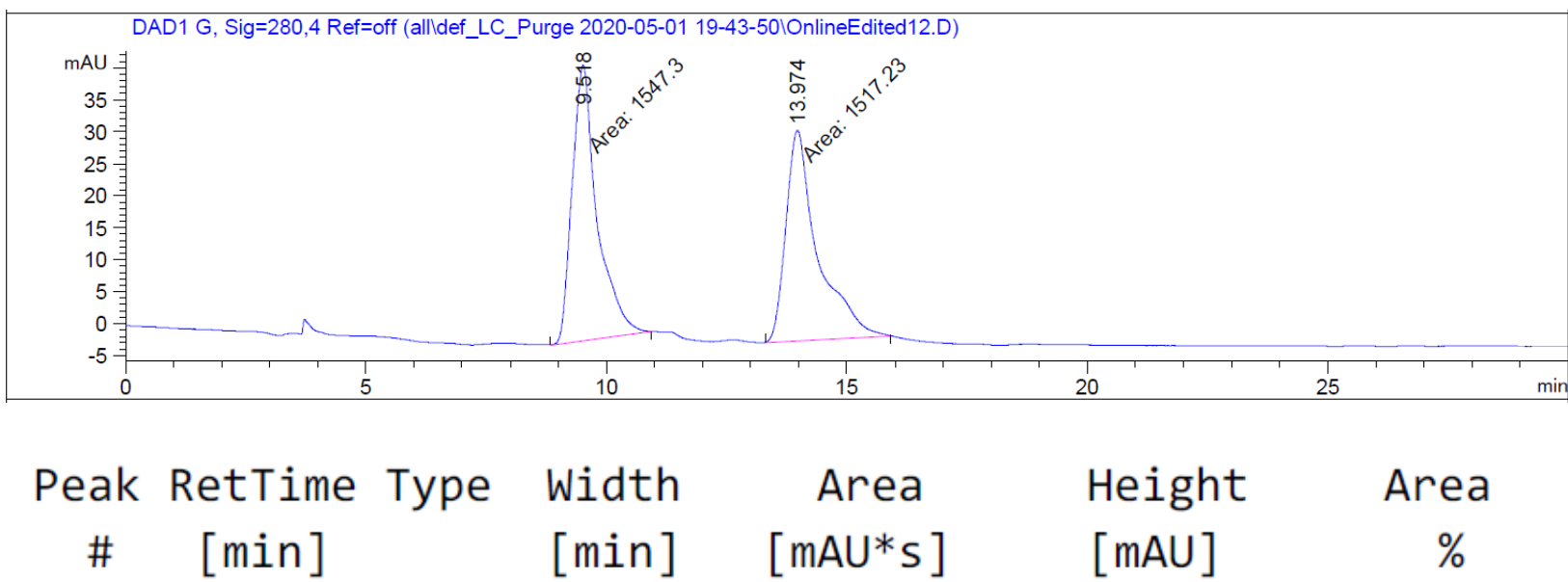

$$
\begin{array}{rr|r|r|r|r|r}
1 & 9.518 & \text { MM } & 0.5983 & 1547.30481 & 43.10374 & 50.4907 \\
2 & 13.974 & \text { MM } & 0.7677 & 1517.22803 & 32.93877 & 49.5093
\end{array}
$$

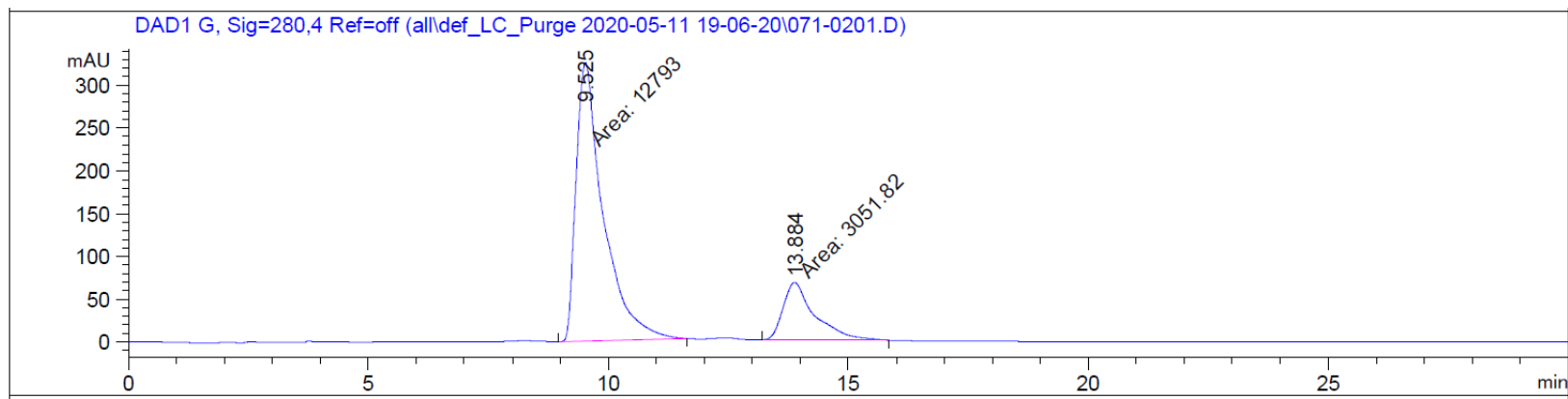

Peak RetTime Type Width Area Height Area

\begin{tabular}{cc|cccc}
$\#$ & {$[\mathrm{~min}]$} & {$[\mathrm{min}]$} & {$[\mathrm{mAU} * \mathrm{~s}]$} & {$[\mathrm{mAU}]$} & $\%$ \\
\hline 1 & $9.525 \mathrm{MM}$ & 0.6555 & $1.27930 \mathrm{e} 4$ & 325.26505 & 80.7393 \\
2 & $13.884 \mathrm{MM}$ & 0.7588 & 3051.82471 & 67.03014 & 19.2607
\end{tabular}




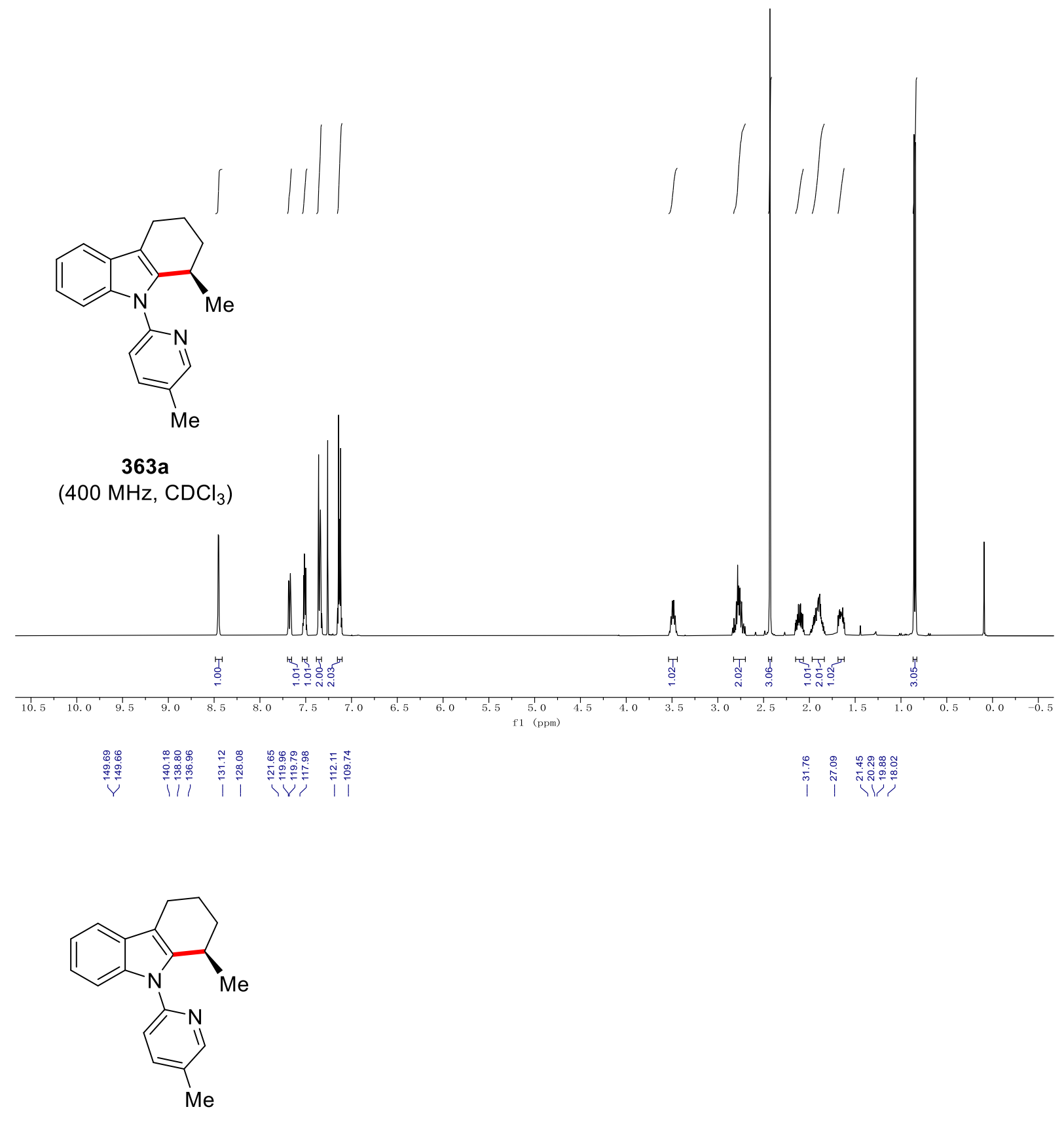

$363 a$

(100 MHz, $\mathrm{CDCl}_{3}$ )

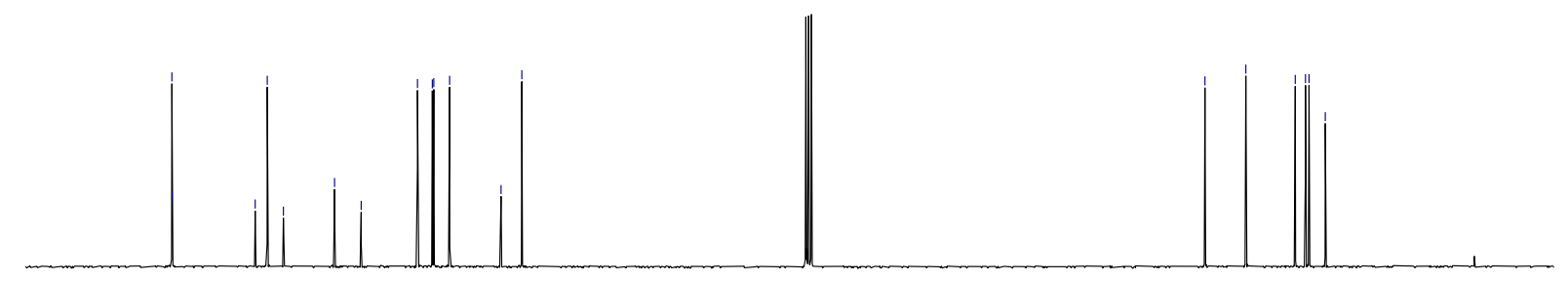

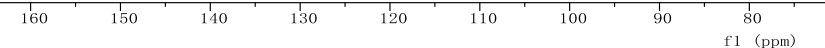


Chiral HPLC of 363a:

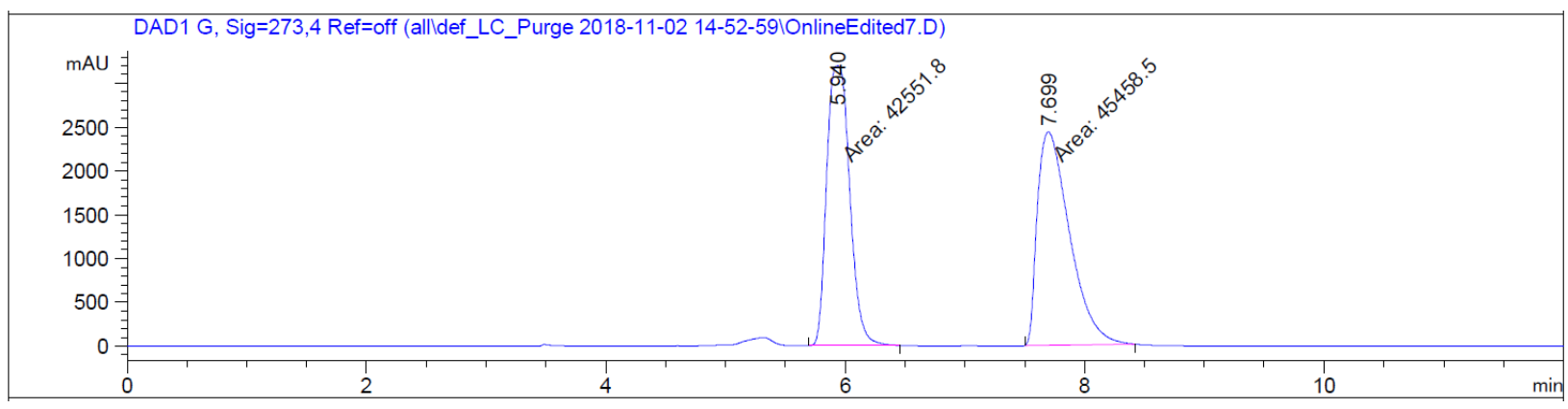

Peak RetTime Type Width Area Height Area

\# $[\mathrm{min}] \quad[\mathrm{min}] \quad\left[\mathrm{mAU}{ }^{*} \mathrm{~s}\right] \quad[\mathrm{mAU}] \quad \%$

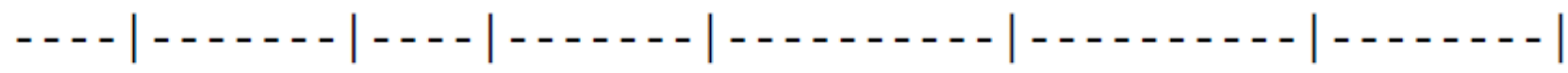
$15.940 \mathrm{MM}$
$0.2220 \quad 4.25518 \mathrm{e} 4 \quad 3194.78467$
48.3486
$27.699 \mathrm{MM}$
$0.31154 .54585 \mathrm{e} 4 \quad 2432.37988$
51.6514

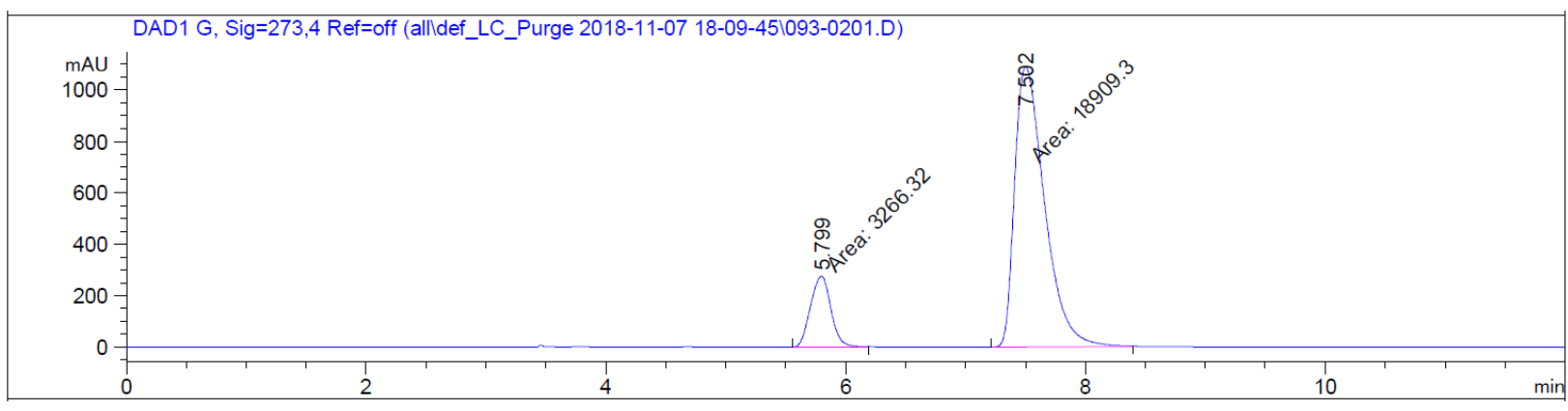

Peak RetTime Type width Area Height Area

\# $[\mathrm{min}] \quad[\mathrm{min}] \quad\left[\mathrm{mAU} U^{*} \mathrm{~s}\right] \quad[\mathrm{mAU}] \quad \%$

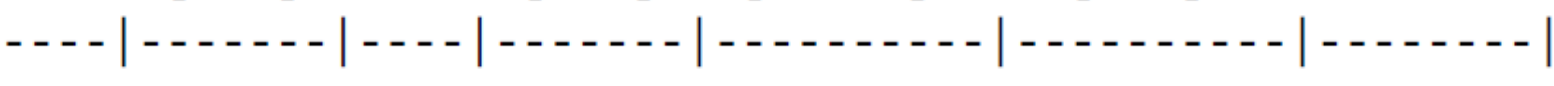

$\begin{array}{lllllll}1 & 5.799 & \text { MM } & 0.1976 & 3266.32373 & 275.56061 & 14.7294\end{array}$

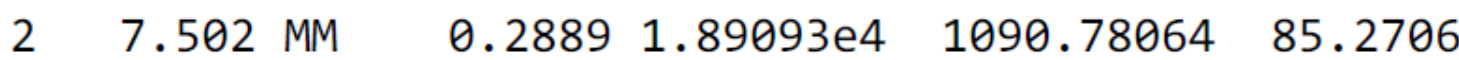


When ent-CA14 was used:

Chiral HPLC of 363a:

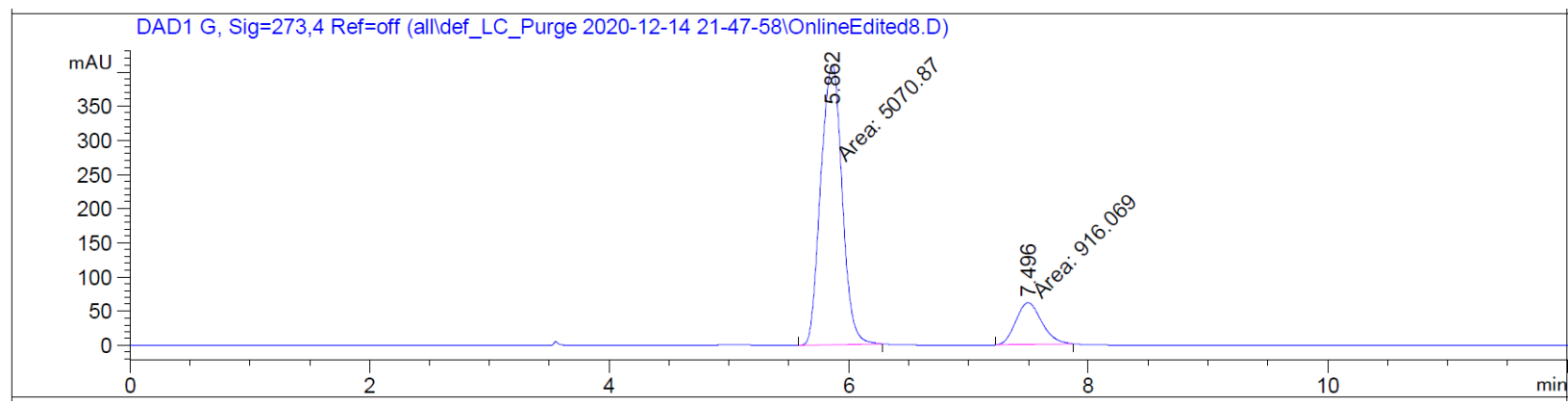

Peak RetTime Type width Area Height Area

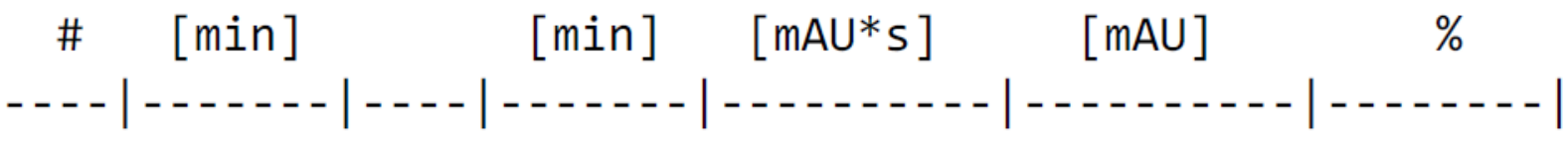

$1 \quad 5.862$ MM $\quad 0.2063 \quad 5070.87109 \quad 409.60330 \quad 84.6989$

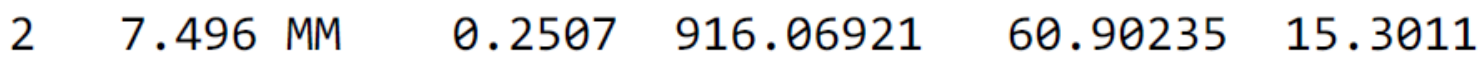



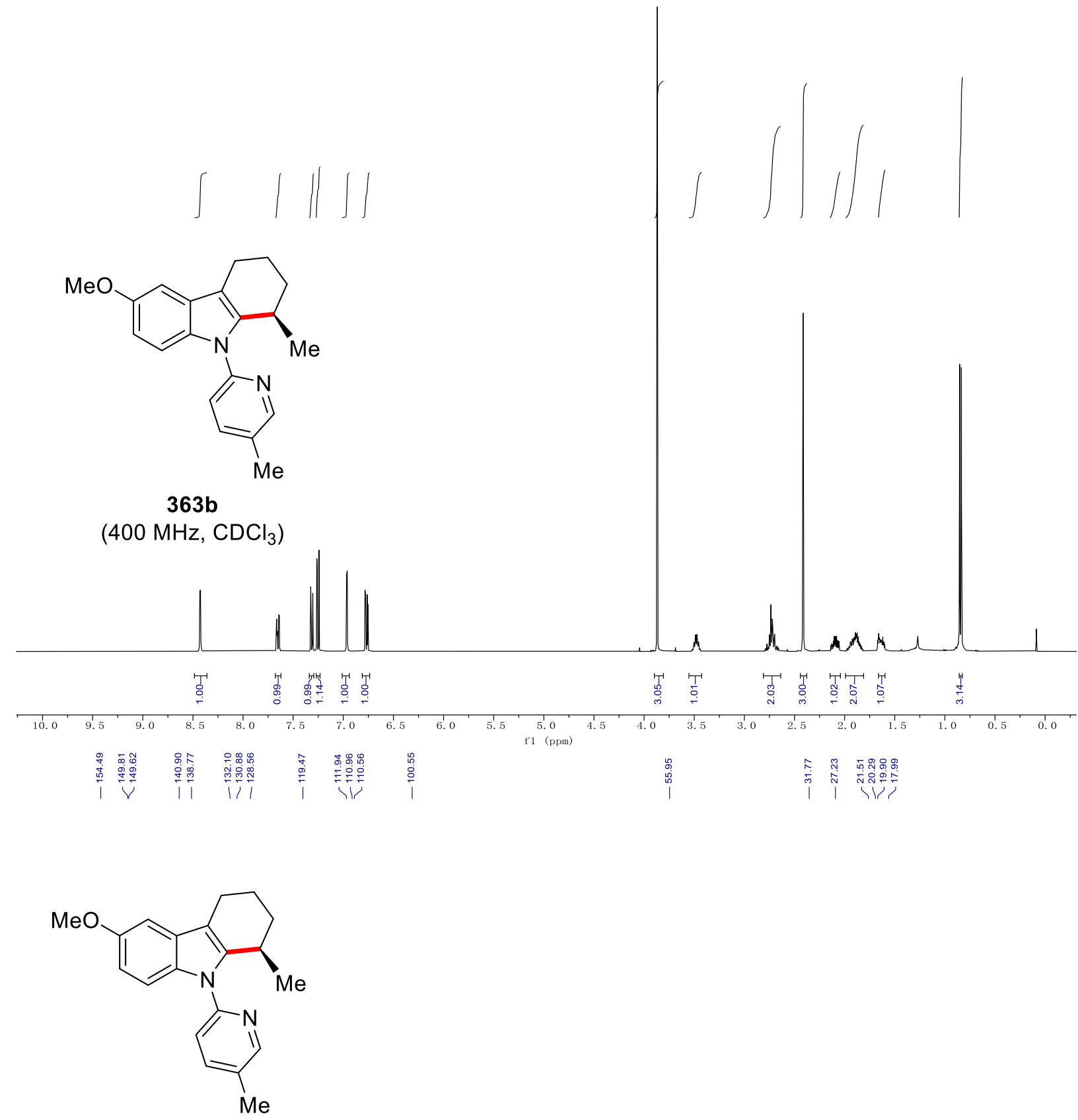

$363 \mathrm{~b}$

$\left(100 \mathrm{MHz}, \mathrm{CDCl}_{3}\right.$ )

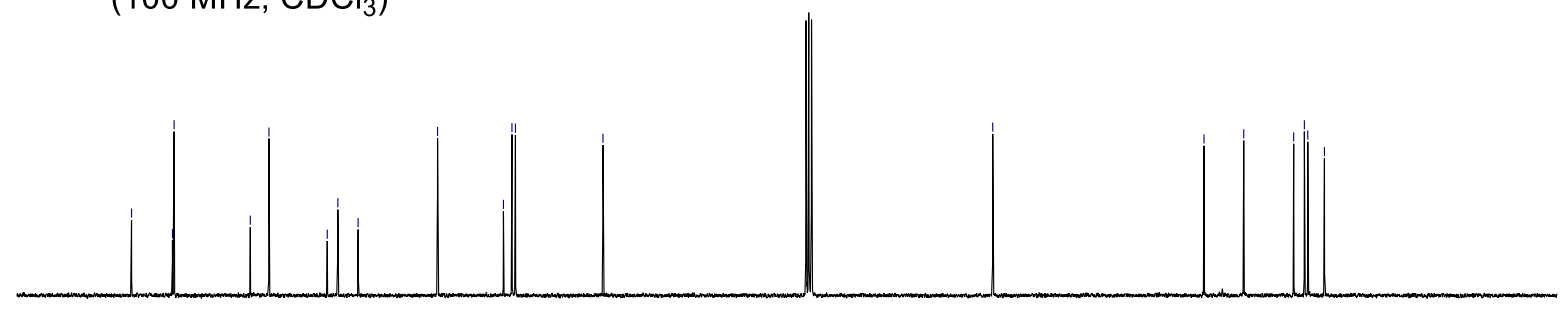


Chiral HPLC of 363b:

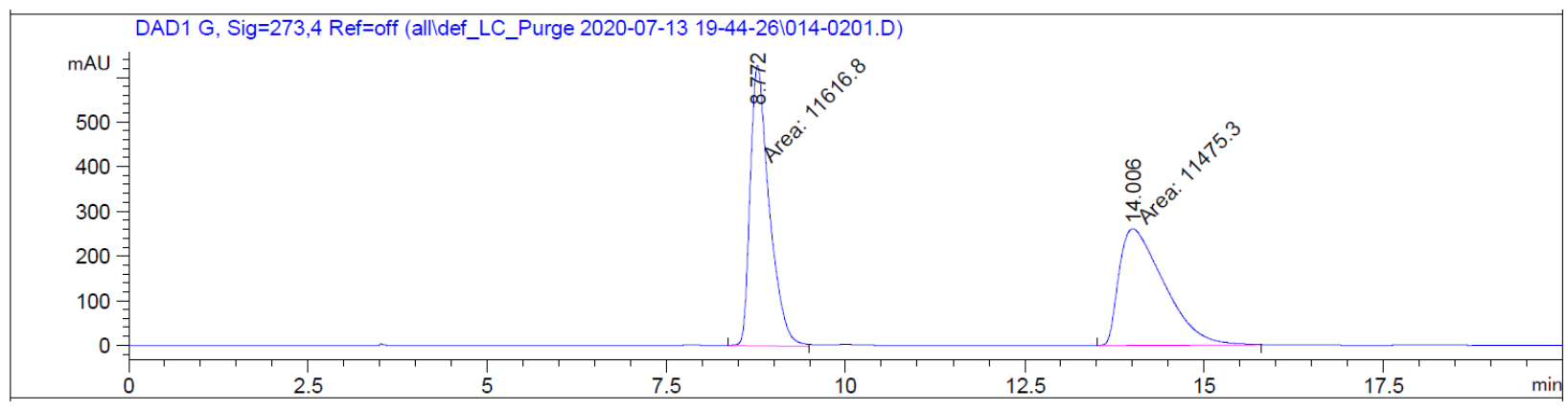

Peak RetTime Type Width Area Height Area

\# [min] [min $] \quad[\mathrm{mAU} * \mathrm{~s}] \quad[\mathrm{mAU}] \quad \%$

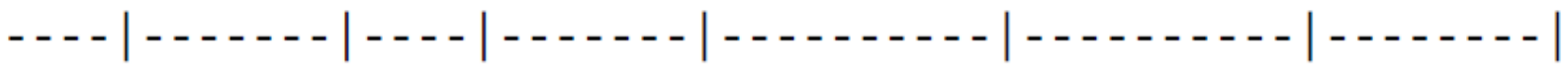

$1 \quad 8.772$ MM $\quad 0.3088 \quad 1.16168 \mathrm{e} 4 \quad 626.98230 \quad 50.3065$

$2 \quad 14.006$ MM $\quad 0.7319 \quad 1.14753 \mathrm{e} 4 \quad 261.32187 \quad 49.6935$

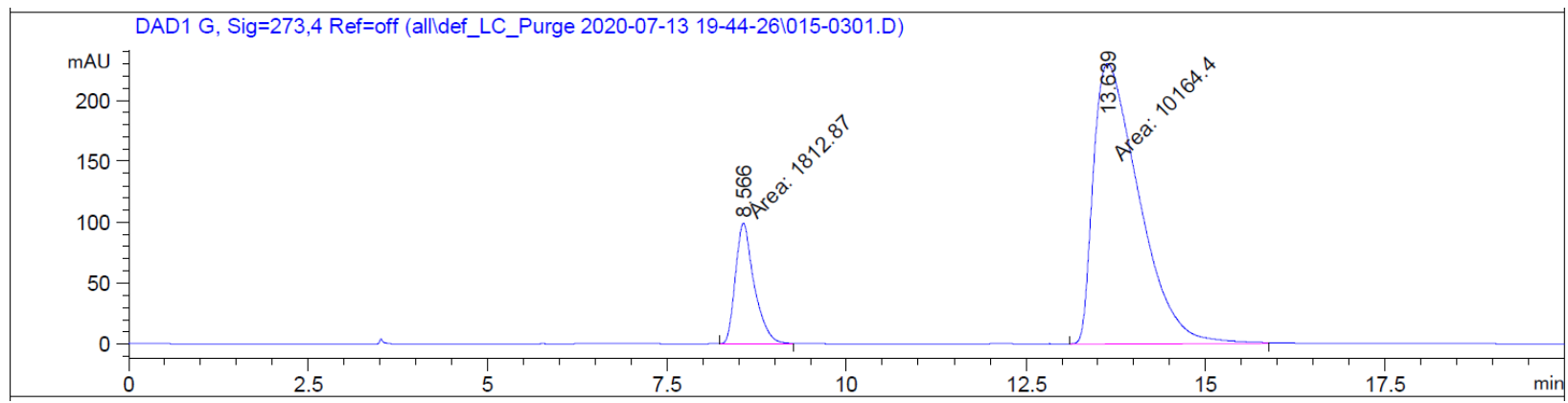

Peak RetTime Type Width Area Height Area

\# $[\mathrm{min}] \quad[\mathrm{min}] \quad\left[\mathrm{mAU}{ }^{*} \mathrm{~s}\right] \quad[\mathrm{mAU}] \quad \%$

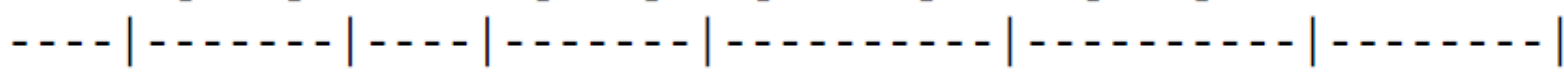

18.566 MM $0.3051 \quad 1812.86841 \quad 99.03856 \quad 15.1360$

$2 \quad 13.639$ MM $\quad 0.7363 \quad 1.01644 \mathrm{e} 4 \quad 230.06743 \quad 84.8640$ 

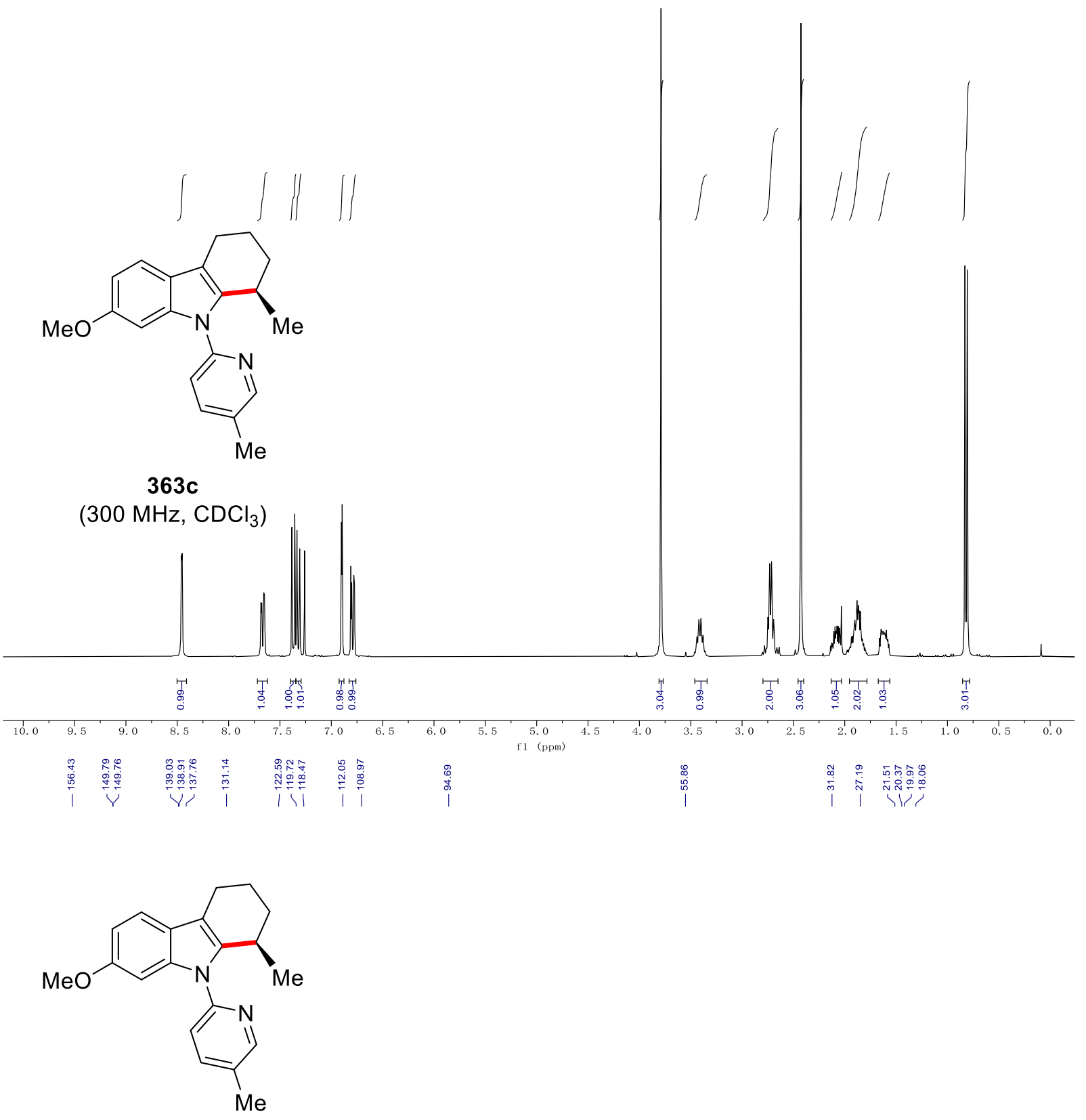

$363 c$

(100 MHz, $\mathrm{CDCl}_{3}$ )

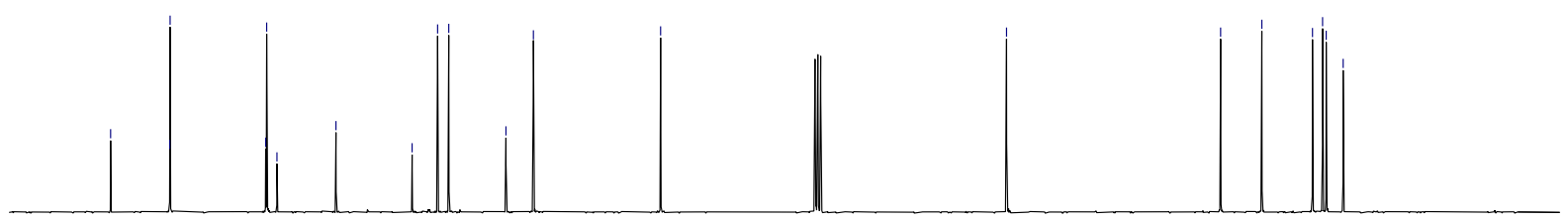


Chiral HPLC of 363c:

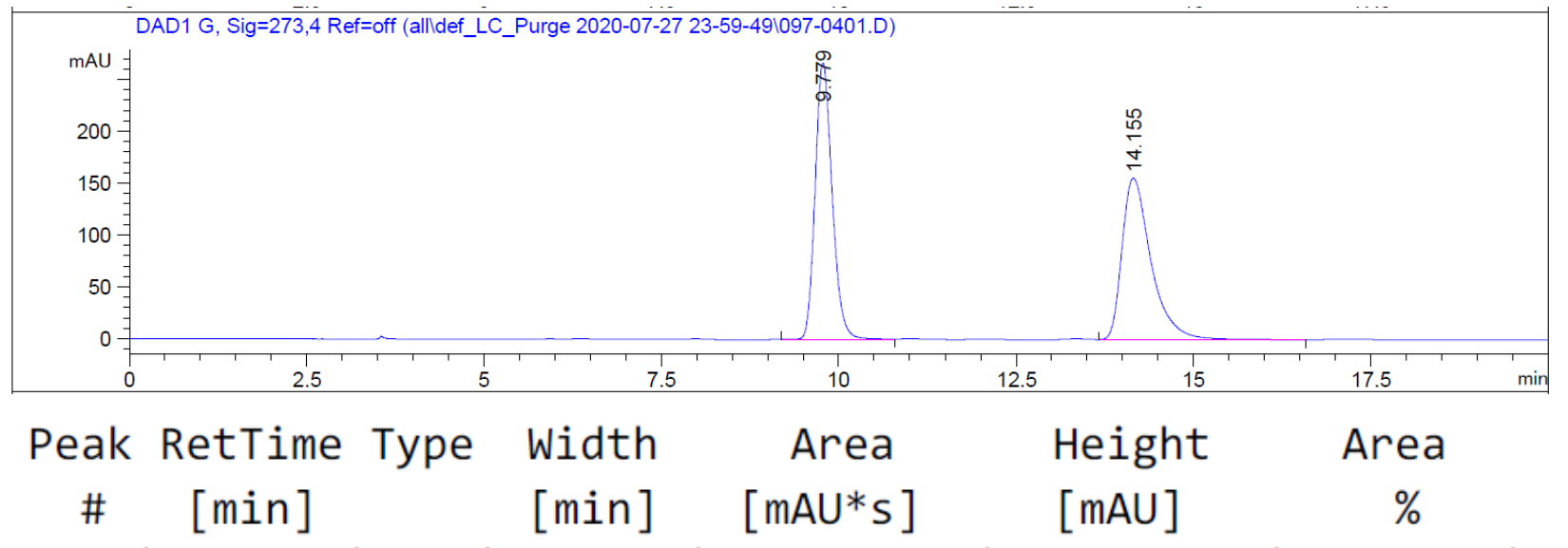

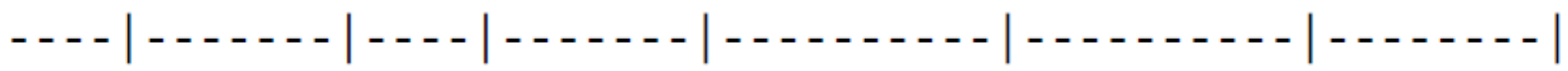

$\begin{array}{lllllll}1 & 9.779 & \text { BB } & 0.2576 & 4441.66455 & 266.29391 & 50.0634\end{array}$

$2 \quad 14.155$ BB $\quad 0.4321 \quad 4430.41992 \quad 155.64459 \quad 49.9366$

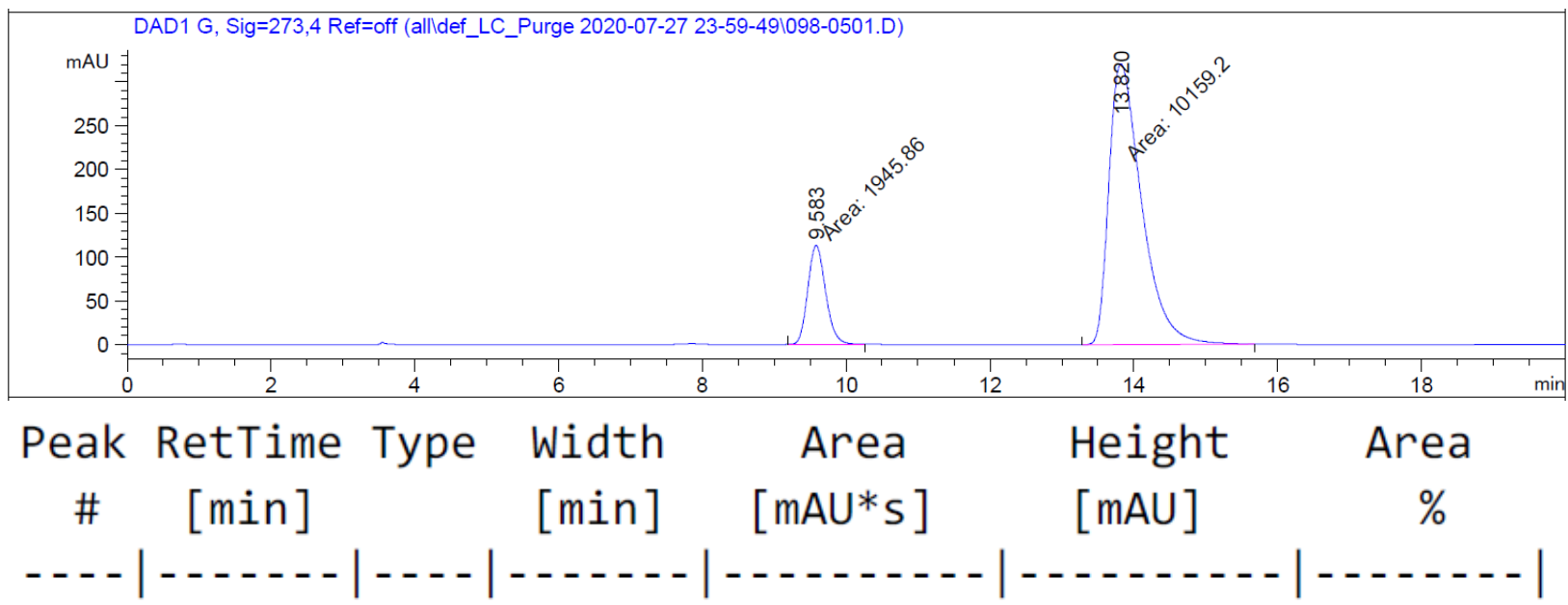

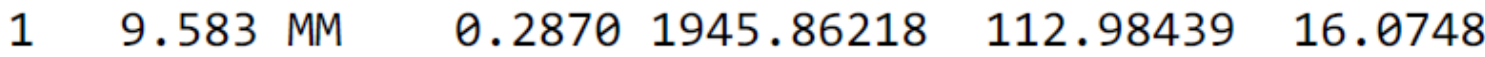

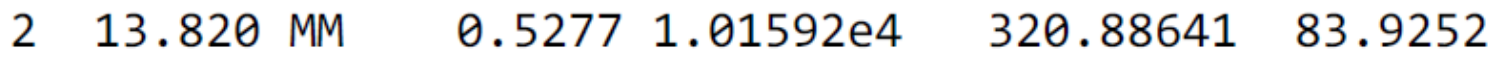



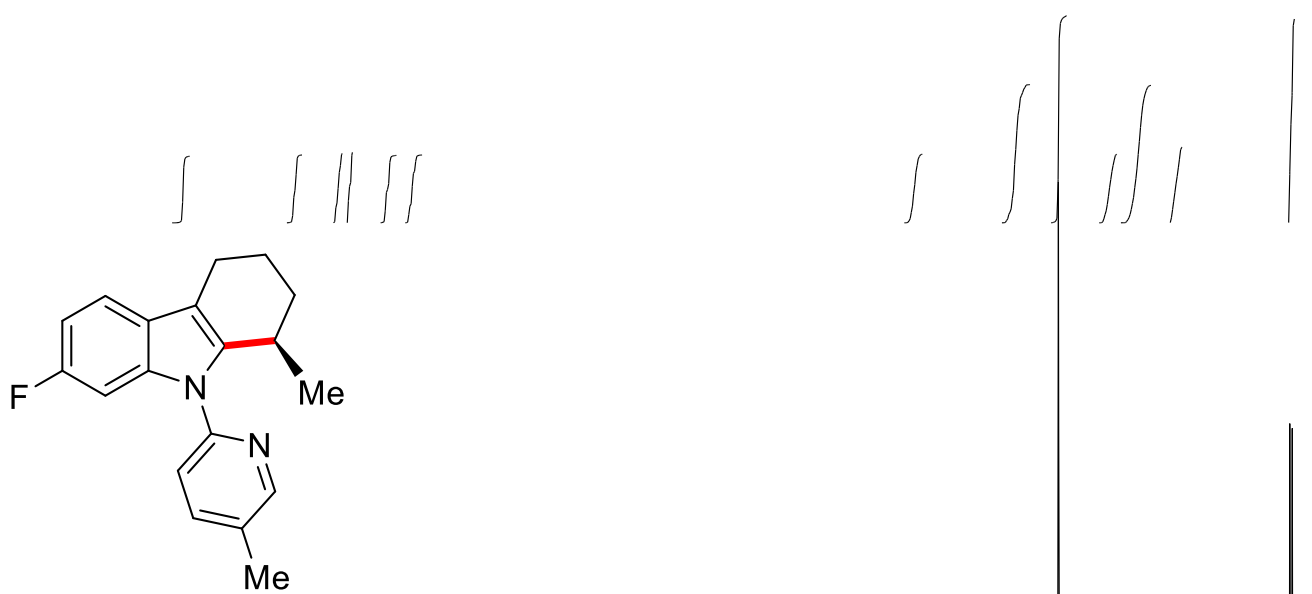

363d

(400 MHz, $\mathrm{CDCl}_{3}$ )
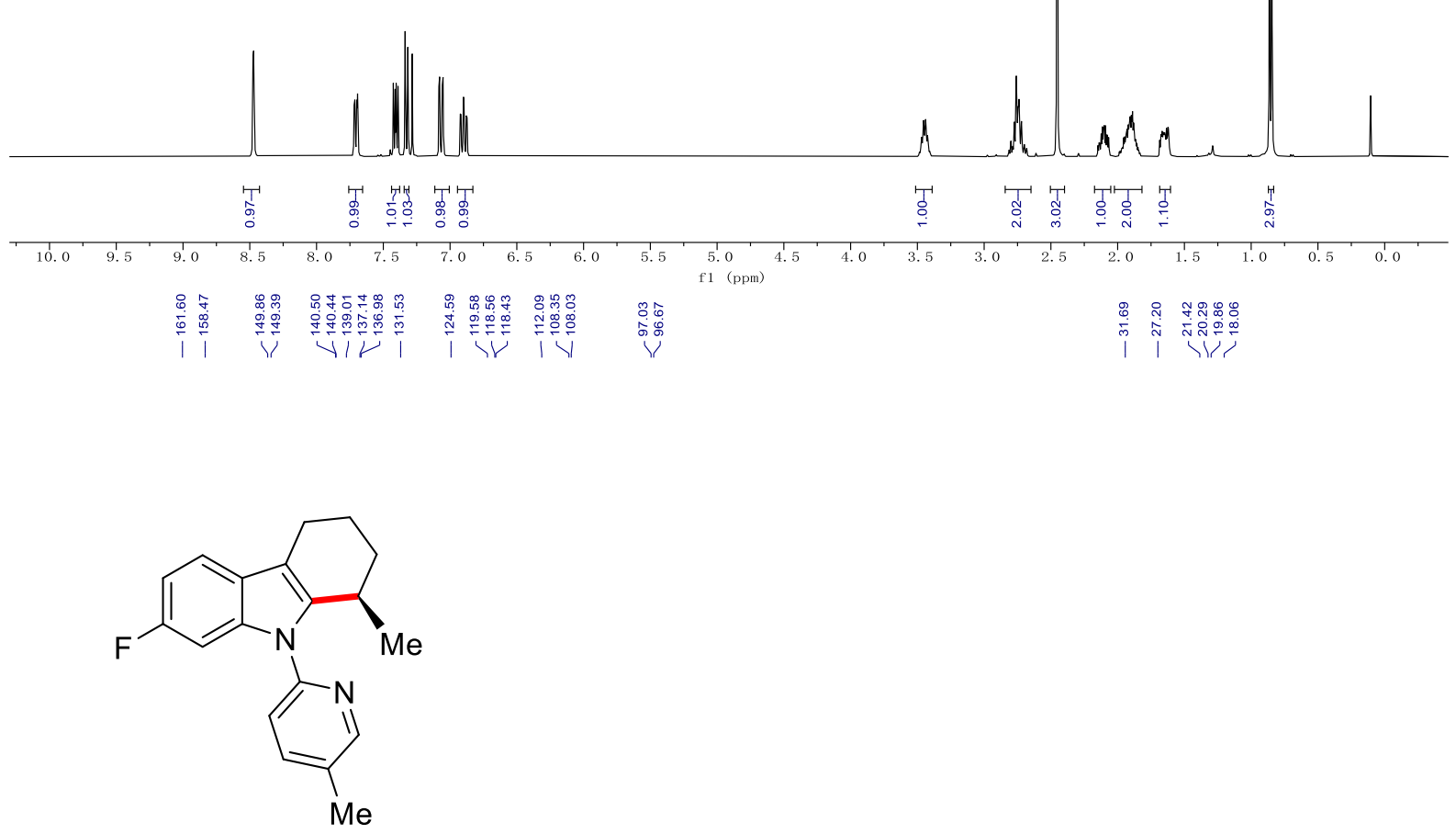

363d

(75 MHz, $\mathrm{CDCl}_{3}$ )

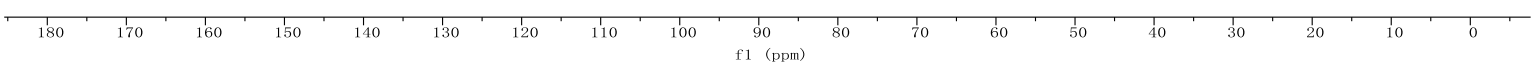




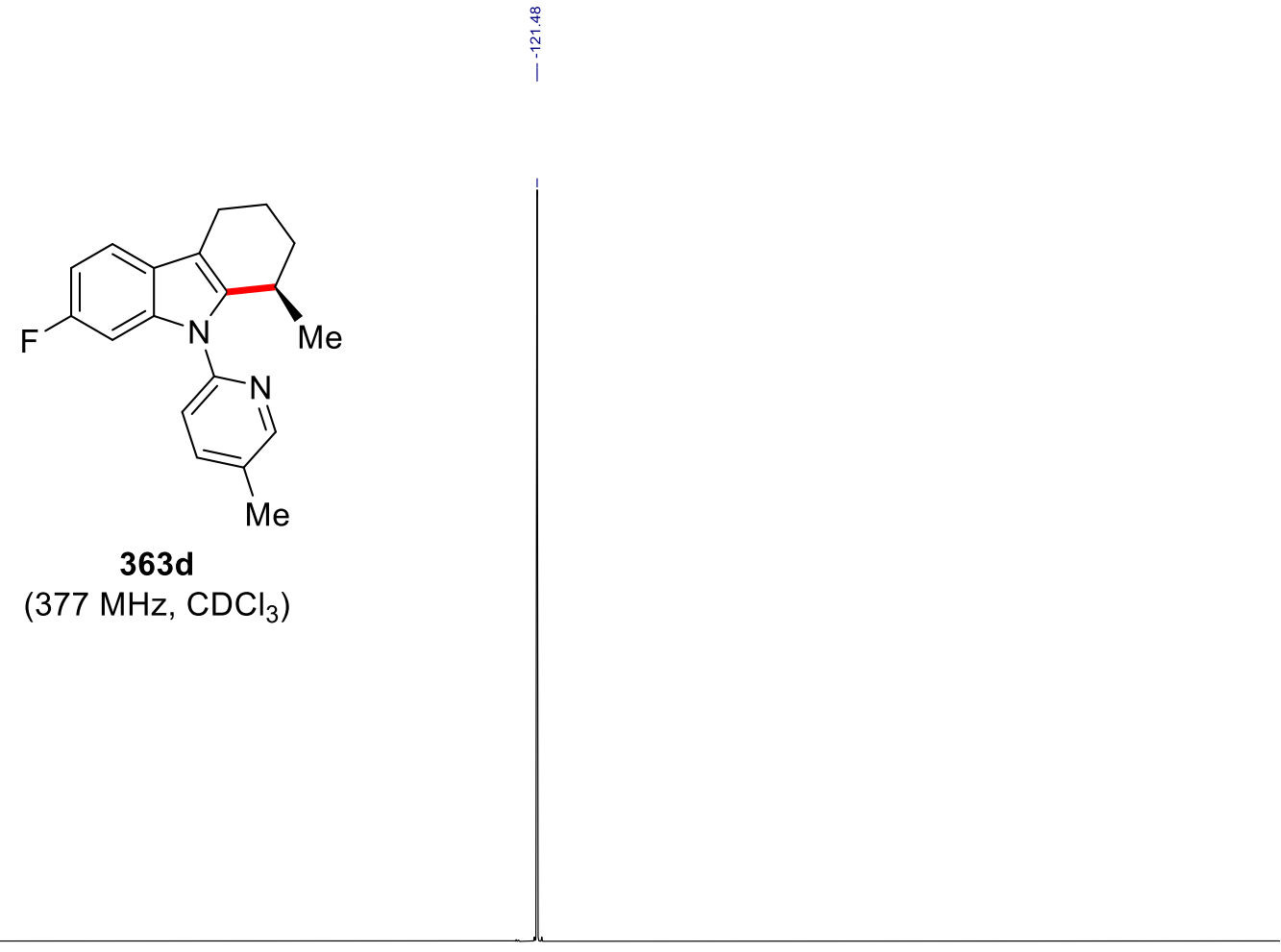

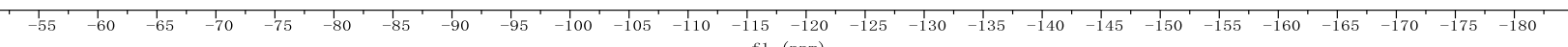


Chiral HPLC of 363d:
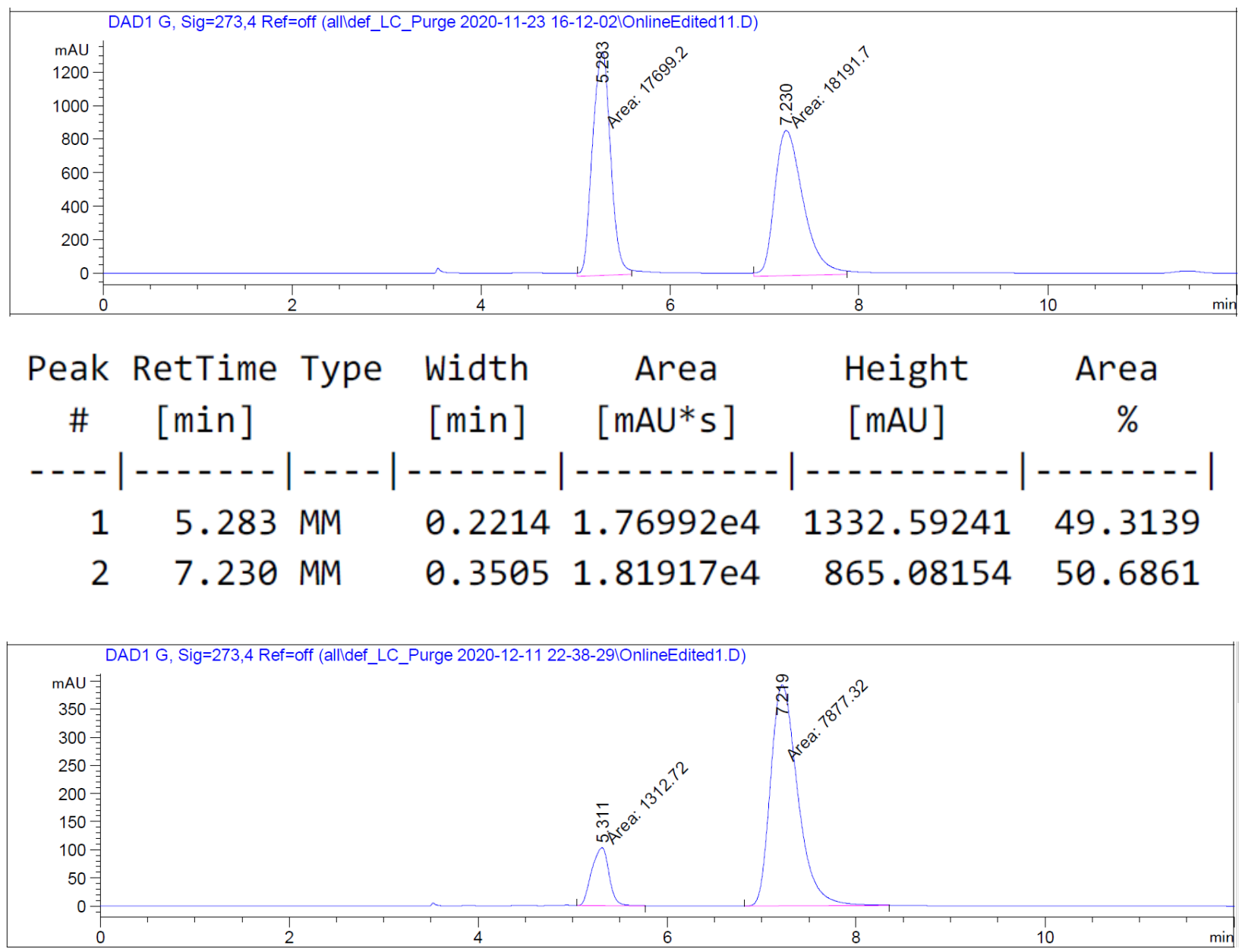

Peak RetTime Type width Area Height Area $\begin{array}{llll}\# & {[\mathrm{~min}]} & \mathrm{min}] & {[\mathrm{mAU} * \mathrm{~s}]}\end{array}$

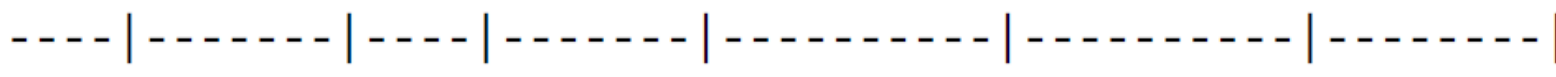

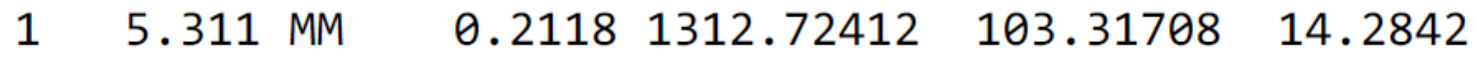

$\begin{array}{lllllll}2 & 7.219 & \text { MM } & 0.3337 & 7877.31885 & 393.40585 & 85.7158\end{array}$ 

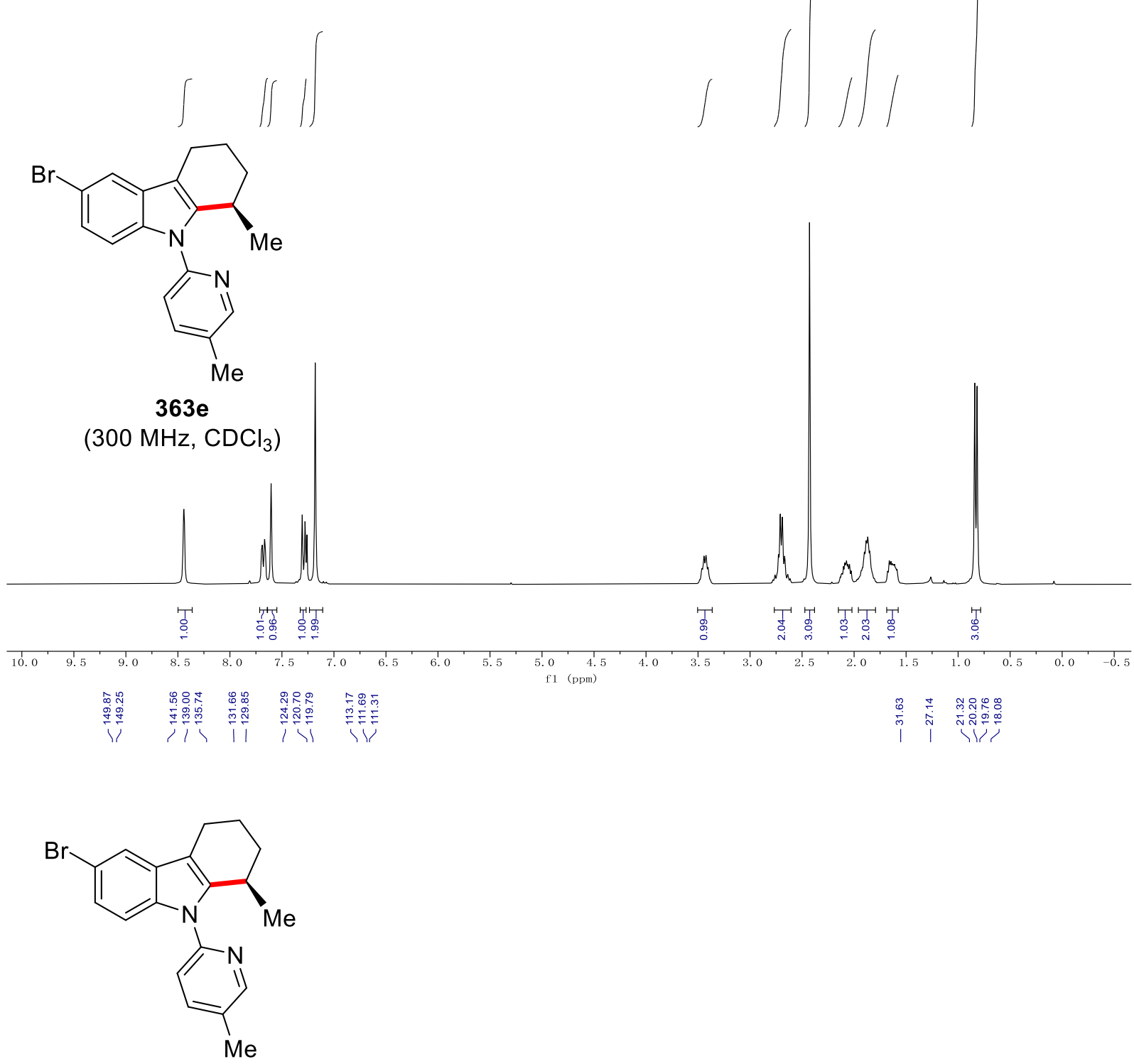

$363 e$

(100 MHz, $\mathrm{CDCl}_{3}$ )

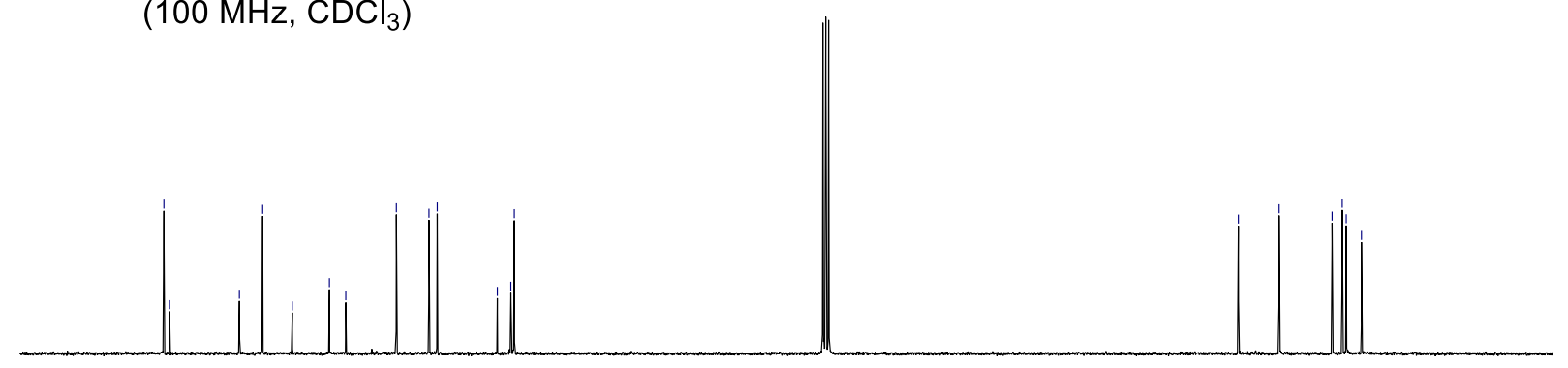


Chiral HPLC of 363e:

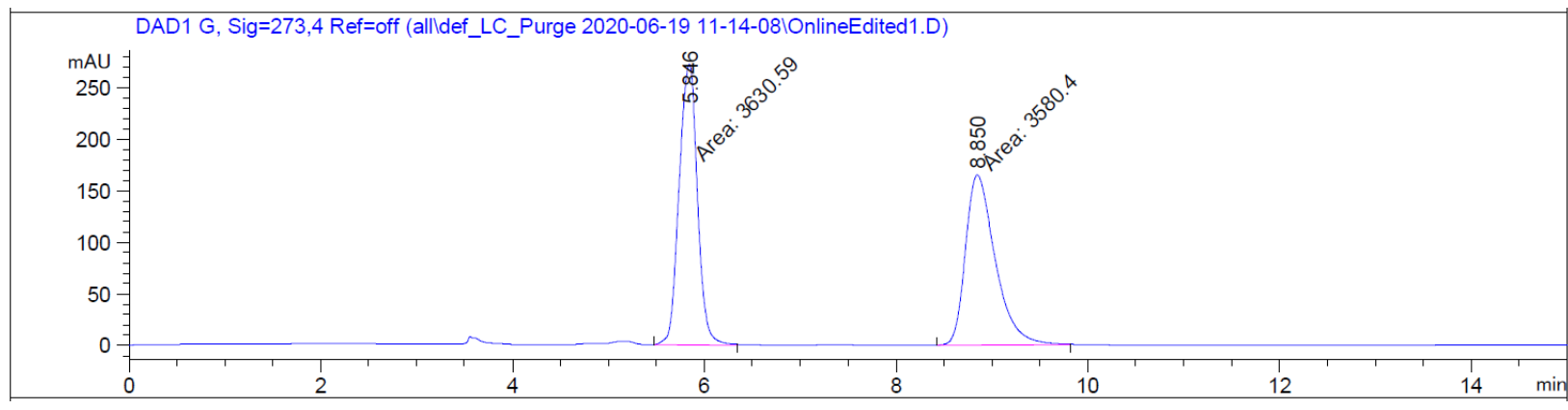

Peak RetTime Type Width Area Height Area

\# $[\mathrm{min}] \quad[\mathrm{min}] \quad\left[\mathrm{mAU}^{*} \mathrm{~s}\right] \quad[\mathrm{mAU}] \quad \%$

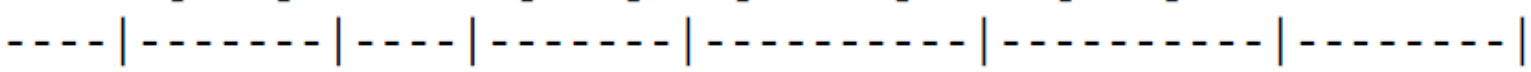

$\begin{array}{lllllll}1 & 5.846 & \text { MM } & 0.2217 & 3630.59351 & 272.88000 & 50.3481\end{array}$

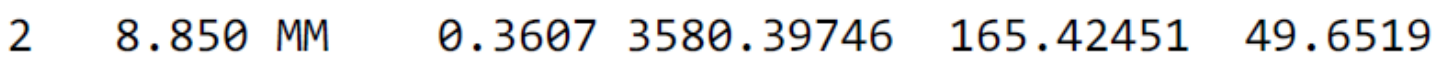

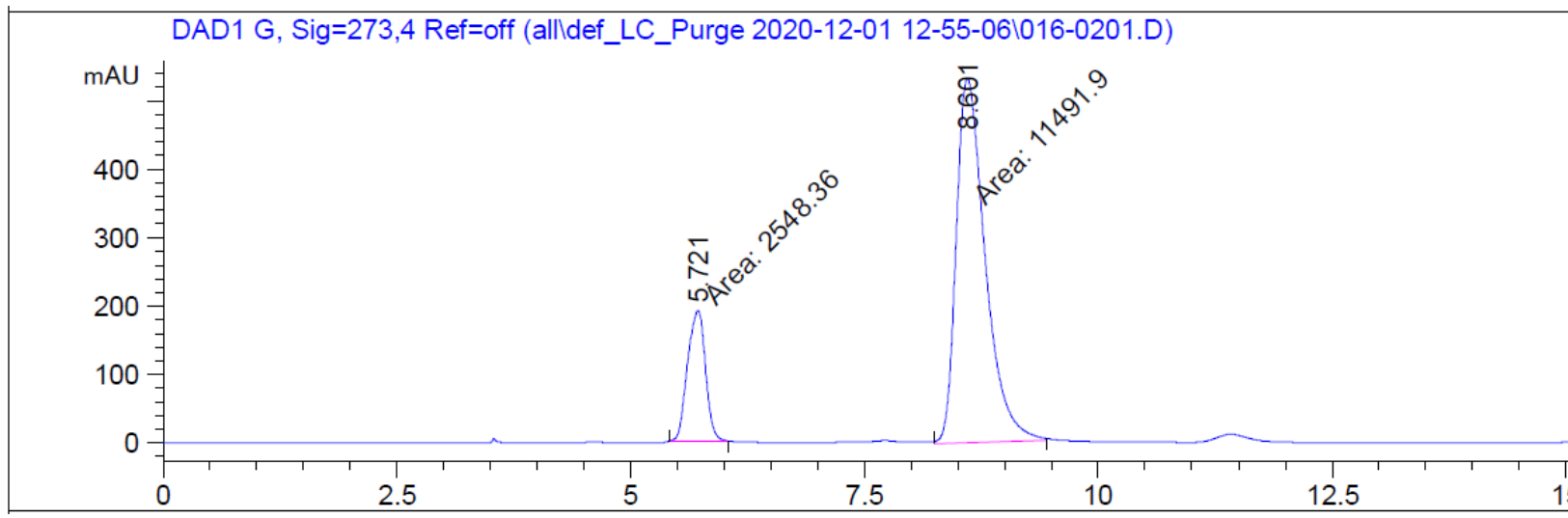

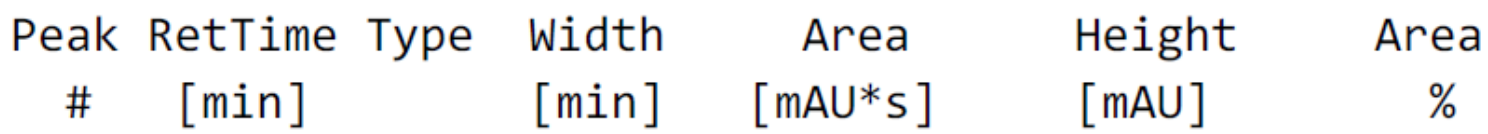

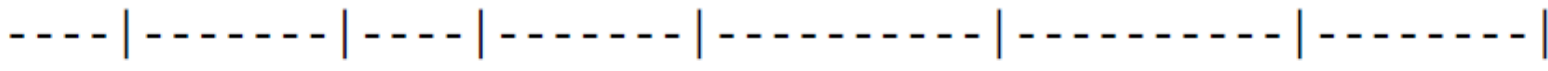

$\begin{array}{lllllll}1 & 5.721 & \text { MM } & 0.2223 & 2548.36377 & 191.08023 & 18.1504\end{array}$

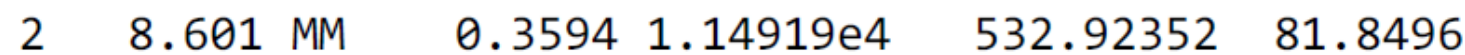


1 mmol scale reaction:

Chiral HPLC of 363e:

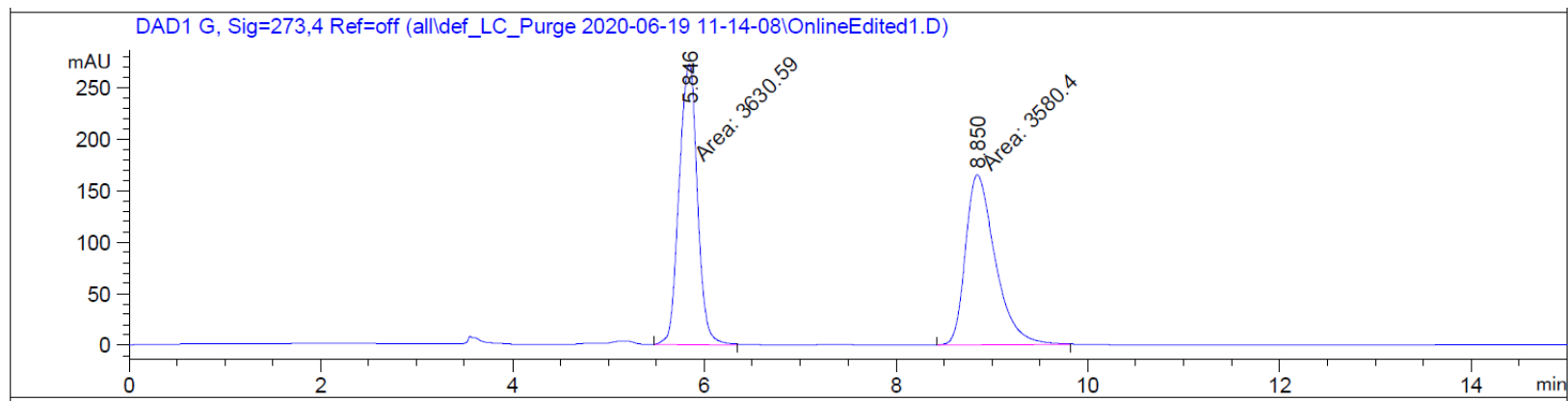

Peak RetTime Type Width Area Height Area

\# $[\mathrm{min}] \quad[\mathrm{min}] \quad[\mathrm{mAU} * \mathrm{~s}] \quad[\mathrm{mAU}] \quad \%$

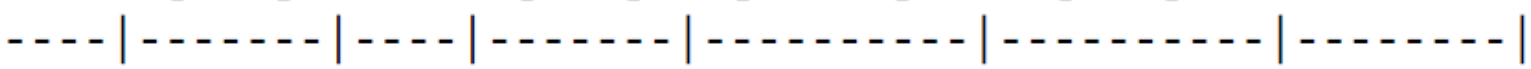

$1 \quad 5.846$ MM $\quad 0.2217 \quad 3630.59351 \quad 272.88000 \quad 50.3481$

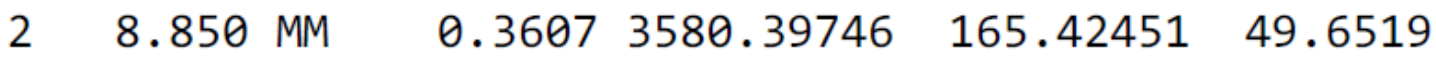

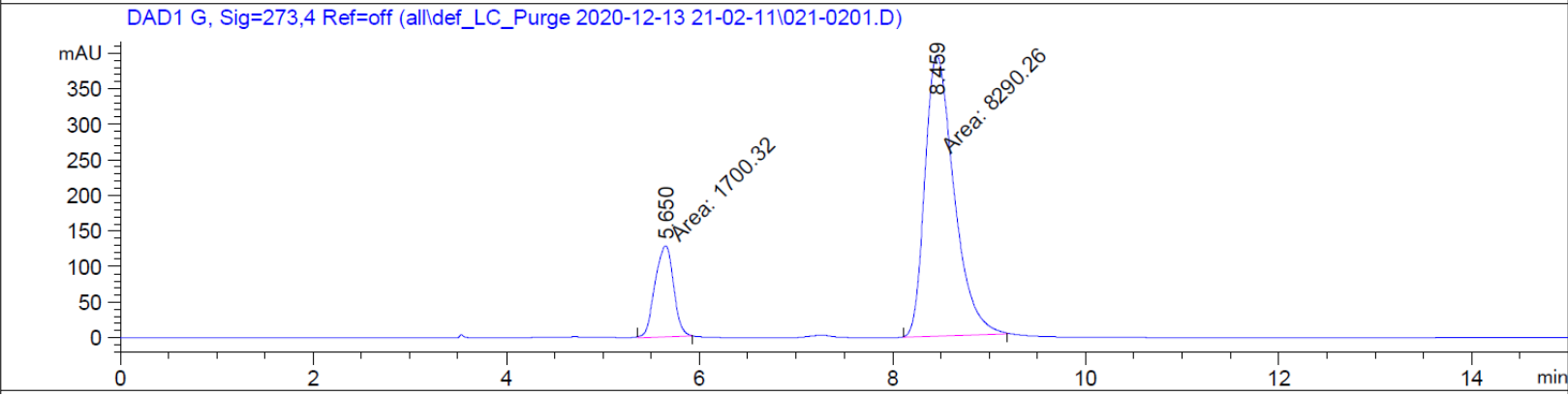

Peak RetTime Type Width Area Height Area

\# $[\mathrm{min}] \quad[\mathrm{min}] \quad[\mathrm{mAU} * \mathrm{~s}] \quad[\mathrm{mAU}] \quad \%$

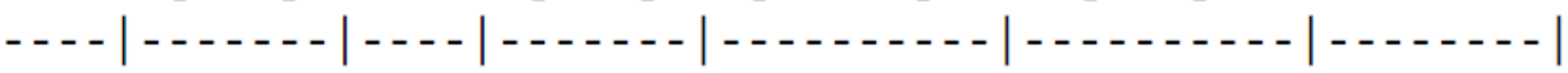

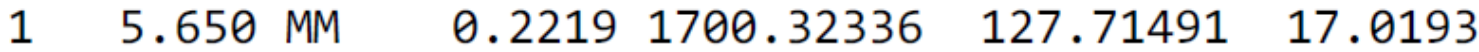

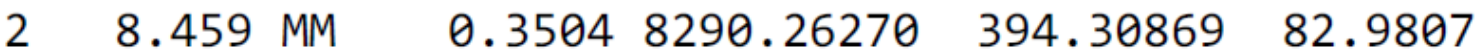




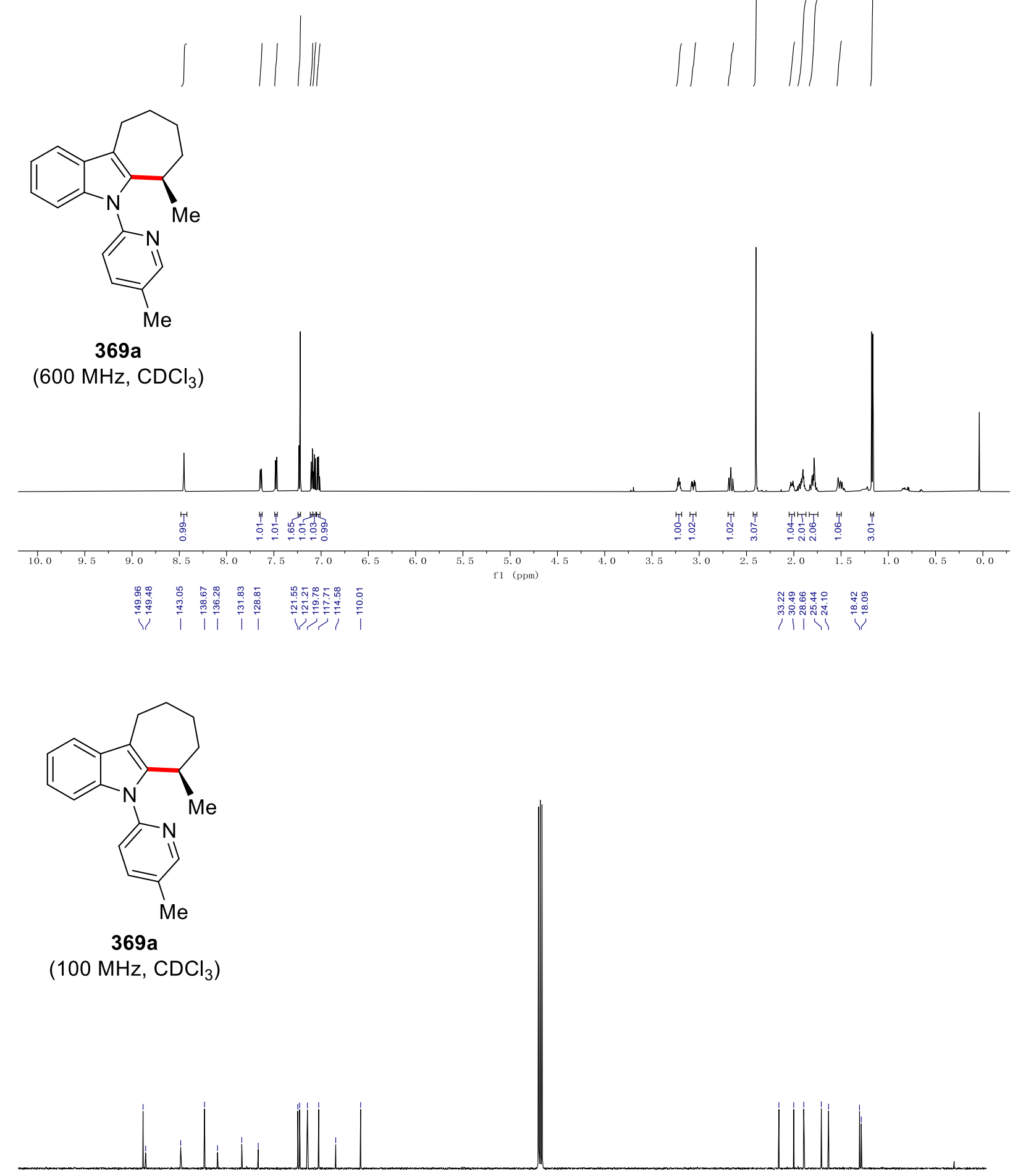

$111 / 11$

(600 MHz, $\mathrm{CDCl}_{3}$ )

$\left(100 \mathrm{MHz}, \mathrm{CDCl}_{3}\right.$ )

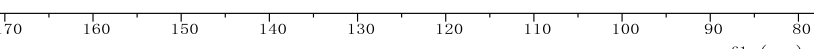

80 
Chiral HPLC of 369a:

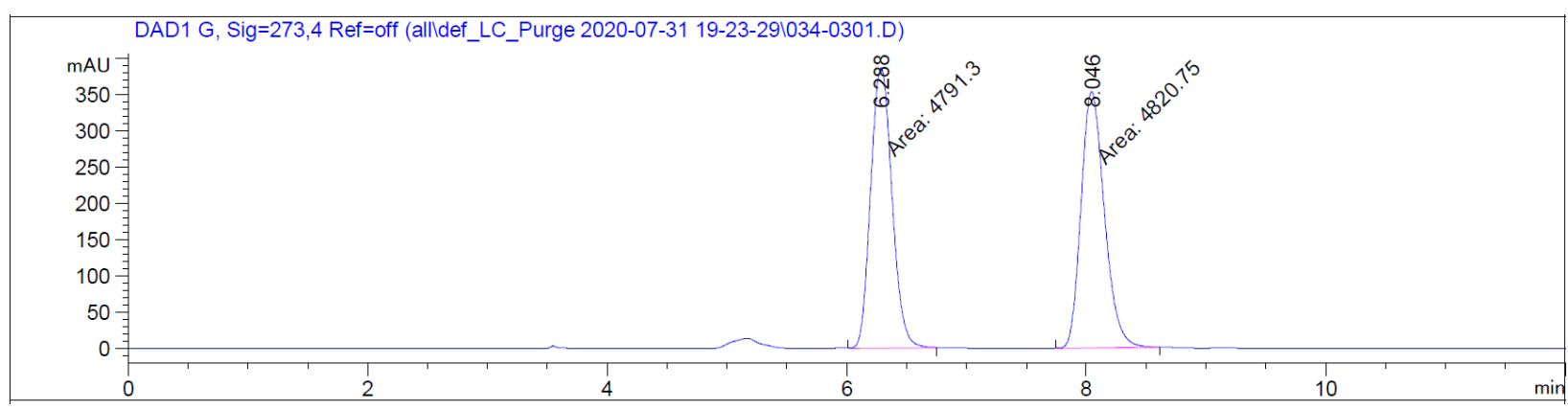

Peak RetTime Type width Area Height Area

\# [min] [min $] \quad\left[m A U^{*} s\right] \quad[m A U] \quad \%$

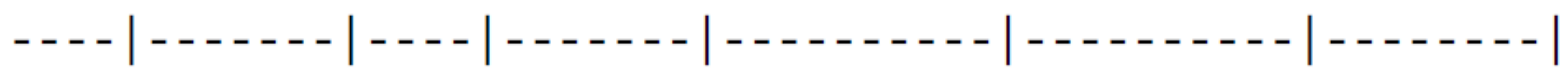

$\begin{array}{lllllll}1 & 6.288 & \text { MM } & 0.2062 & 4791.29688 & 387.28531 & 49.8468\end{array}$

$2 \quad 8.046$ MM $\quad 0.2268 \quad 4820.74707 \quad 354.18680 \quad 50.1532$

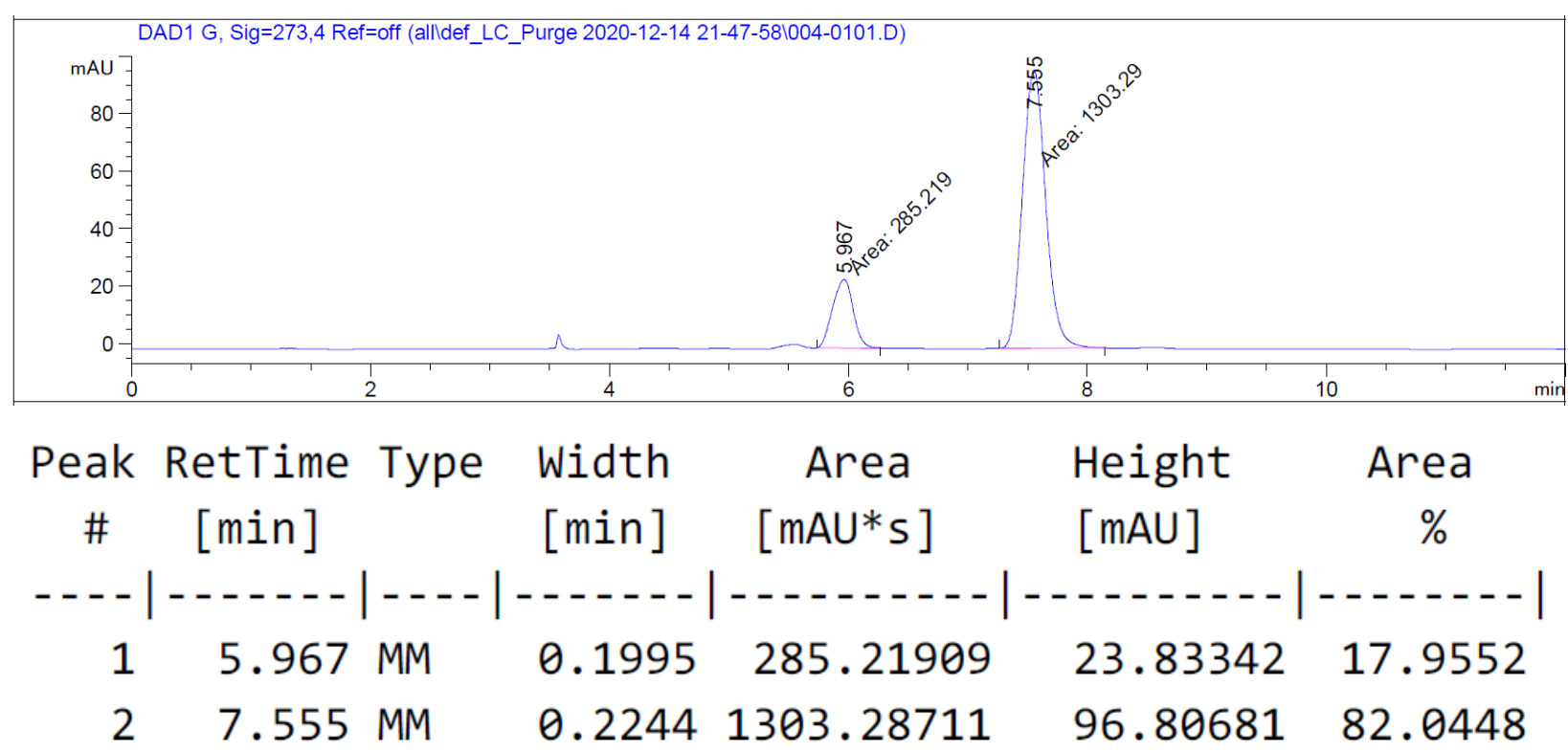




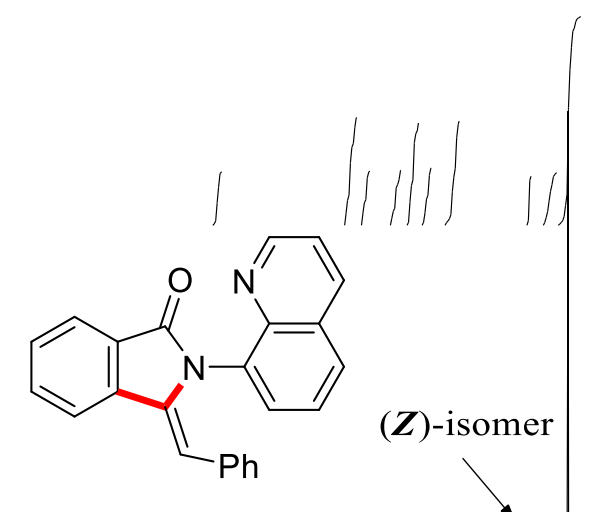

256aa

$\left(300 \mathrm{MHz}, \mathrm{CDCl}_{3}\right)$

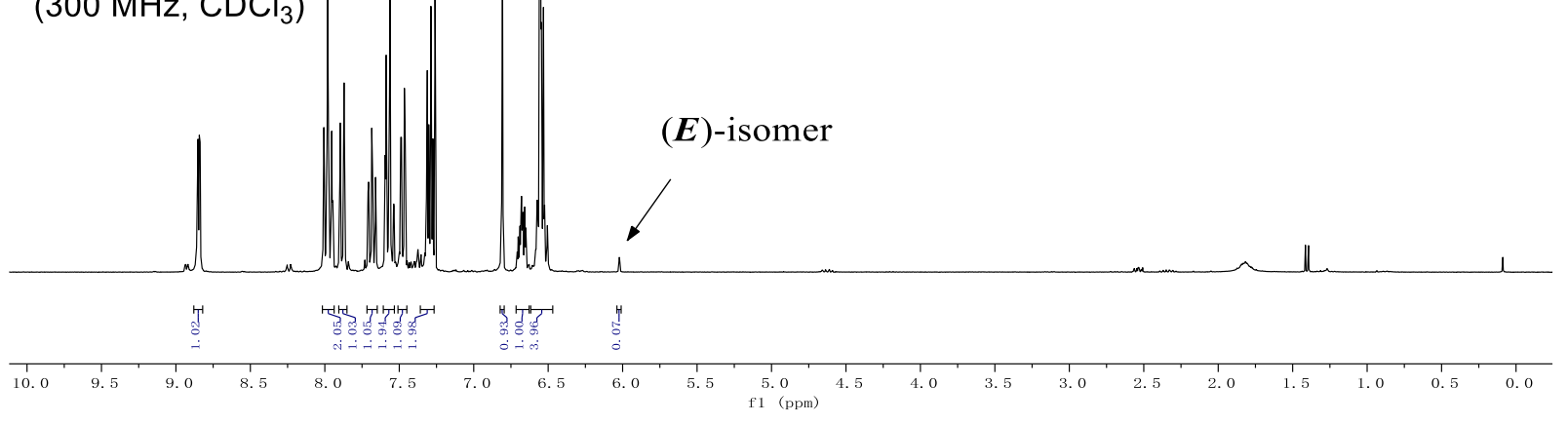

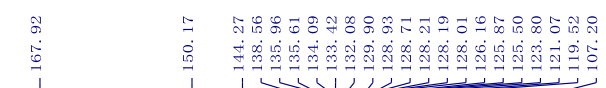<smiles>O=C1c2ccccc2/C(=C/c2ccccc2)N1c1cccc2cccnc12</smiles>

256aa

(125 MHz, $\mathrm{CDCl}_{3}$ )

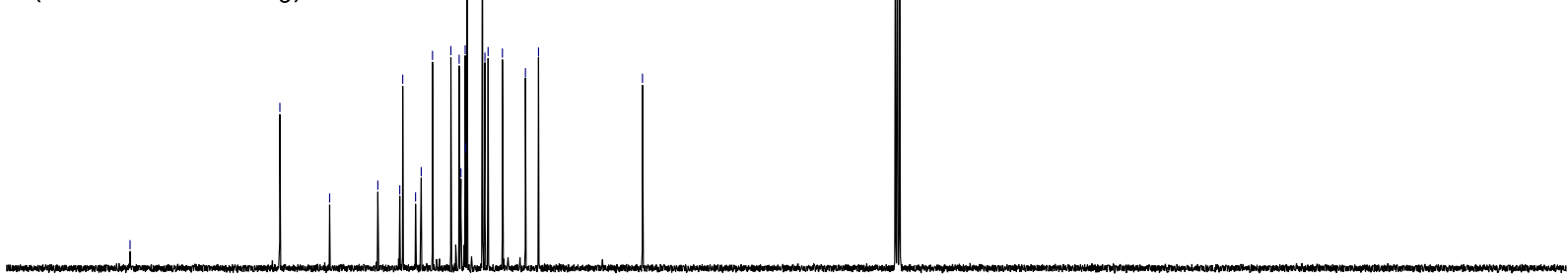

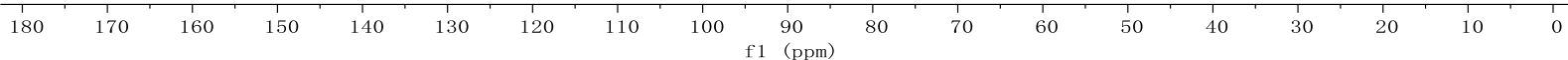




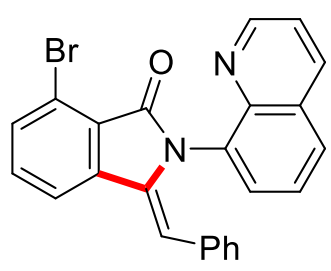

256 ba

(400 MHz, $\mathrm{CDCl}_{3}$ )

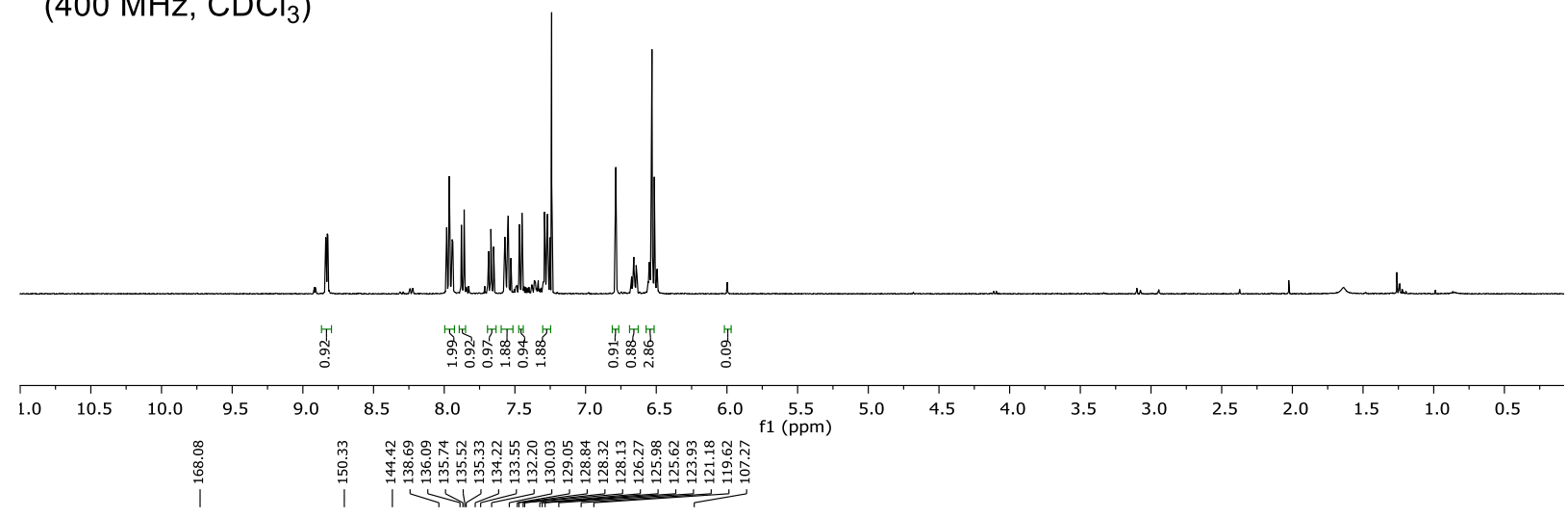<smiles>O=C1c2c(Br)cccc2/C(=C/c2ccccc2)N1c1cccc2cccnc12</smiles>

256ba

$\left(100 \mathrm{MHz}, \mathrm{CDCl}_{3}\right.$ )

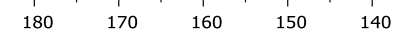

100
$\mathrm{f} 1(\mathrm{ppm})$

80

$70 \quad 60$

50

$\begin{array}{llll}40 & 30 & 20 & 10\end{array}$ 
<smiles>O=C1c2c(cccc2-c2ccccc2)/C(=C/c2ccccc2)N1c1cccc2cccnc12</smiles>

256ca

(400 MHz, $\mathrm{CDCl}_{3}$ )

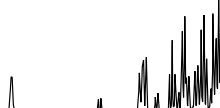

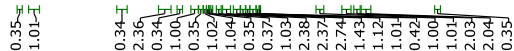

\begin{tabular}{llllllllllllllllllllllllllll}
\hline 1.0 & 10.5 & 10.0 & 9.5 & 9.0 & 8.5 & 8.0 & 7.5 & 7.0 & 6.5 & 6.0 & $\begin{array}{c}5.5 \\
\mathrm{f} 1(\mathrm{ppm})\end{array}$ & 5.0 & 4.5 & 4.0 & 3.5 & 3.0 & 2.5 & 2.0 & 1.5 & 1.0 & 0.5 & 0.0
\end{tabular}

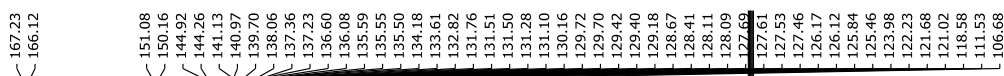<smiles>O=C1c2c(cccc2-c2ccccc2)/C(=C/c2ccccc2)N1c1cccc2cccnc12</smiles>

$256 \mathrm{ca}$

(100 MHz, $\mathrm{CDCl}_{3}$ )

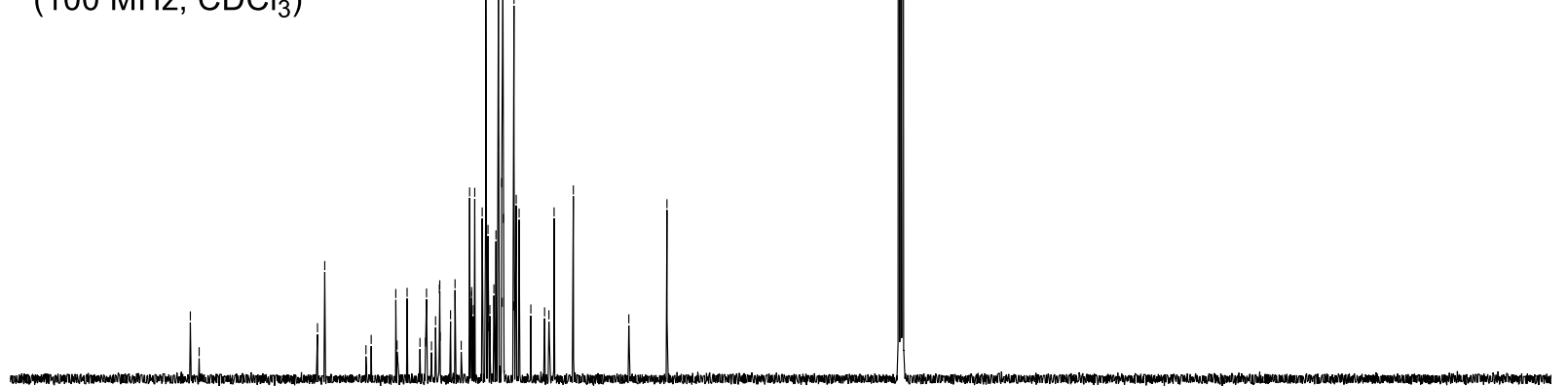

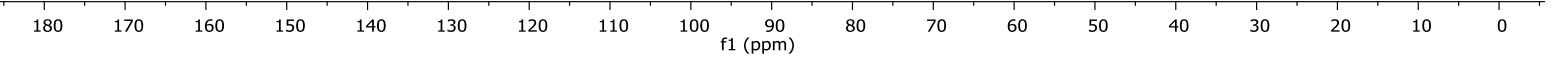


<smiles>O=C1c2ccc([N+](=O)[O-])cc2/C(=C/c2ccccc2)N1c1cccc2cccnc12</smiles>

256da

(400 MHz, $\mathrm{CDCl}_{3}$ )

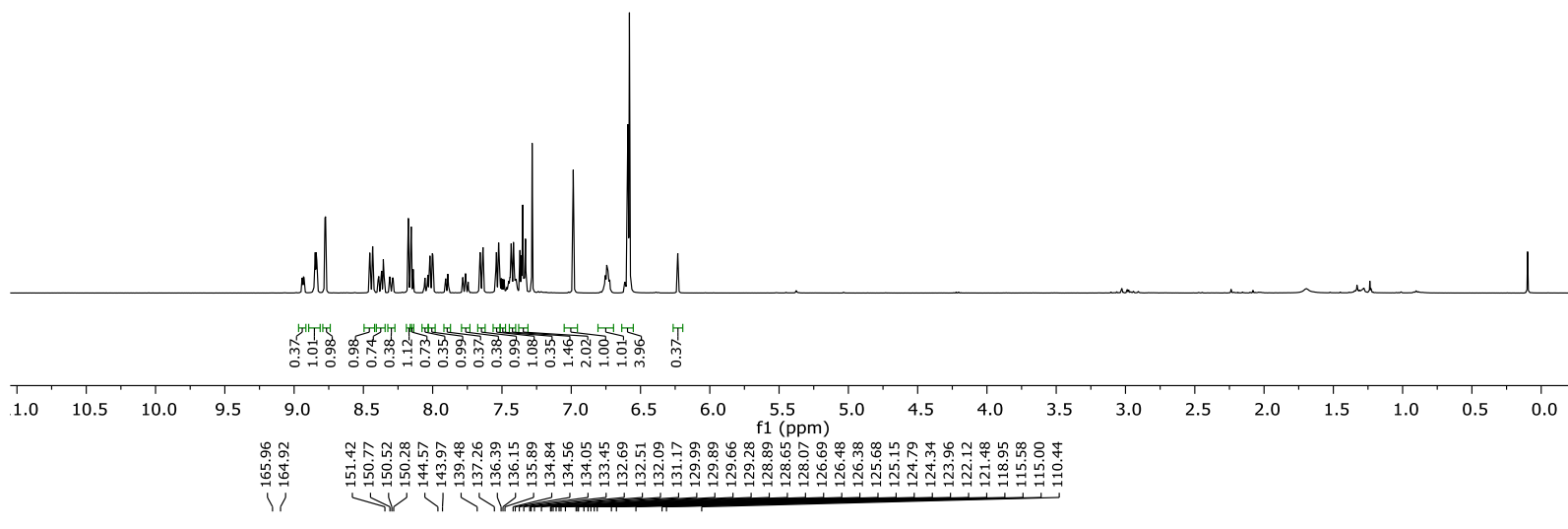<smiles>O=C1c2ccc([N+](=O)[O-])cc2/C(=C/c2ccccc2)N1c1cccc2cccnc12</smiles>

256da

(100 MHz, $\mathrm{CDCl}_{3}$ )

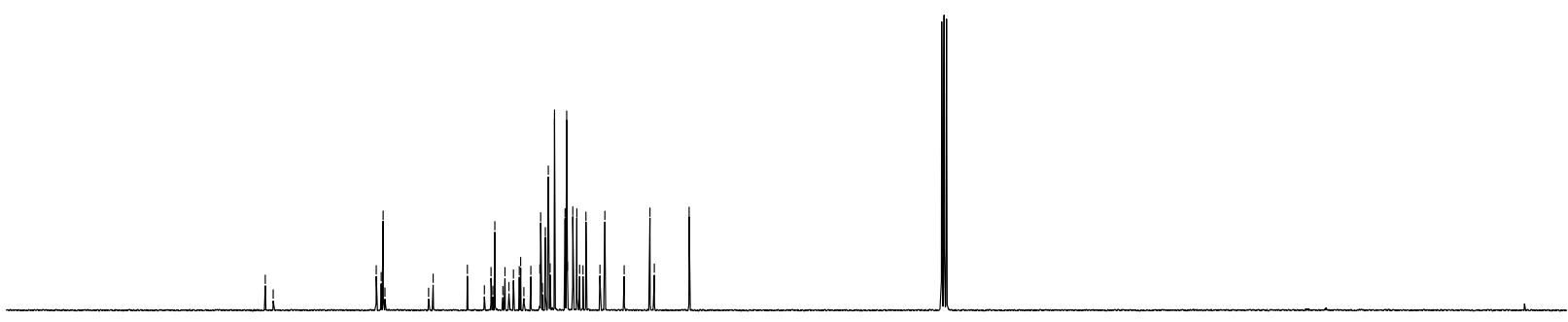

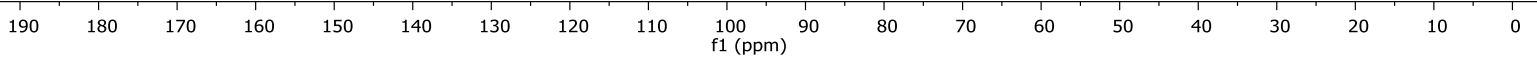




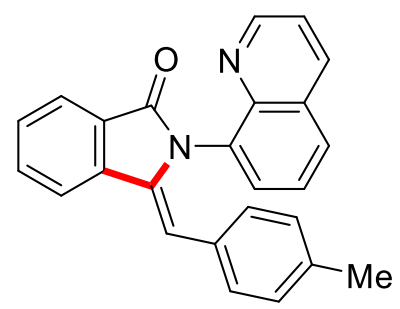

$256 a b$

$\left(400 \mathrm{MHz} \mathrm{CDCl}_{3}\right)$

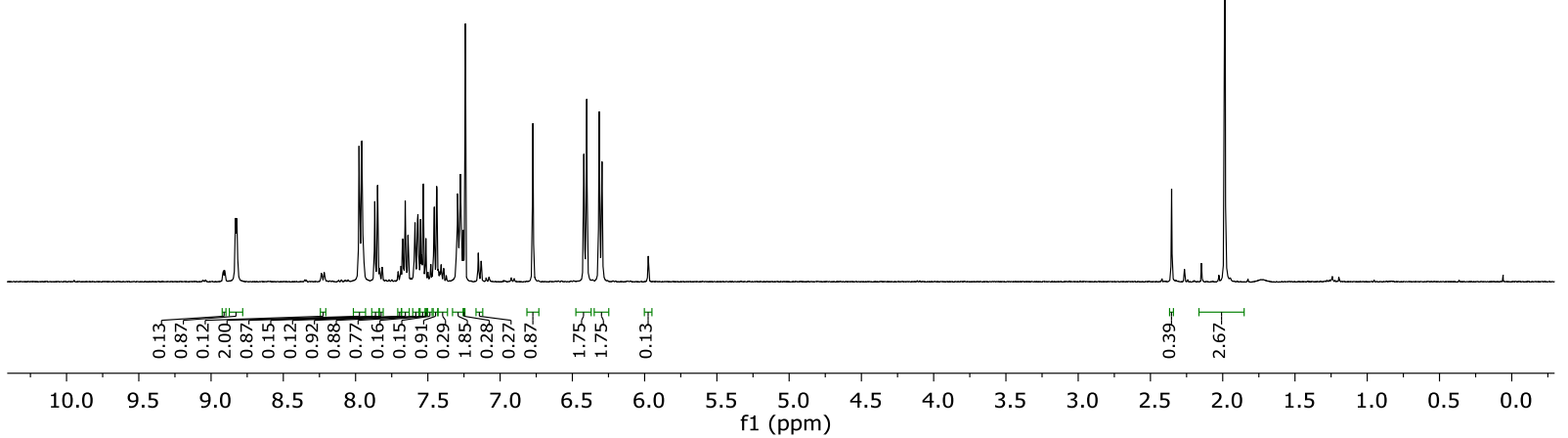

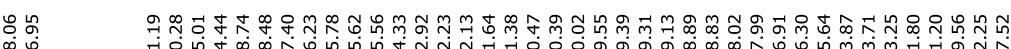

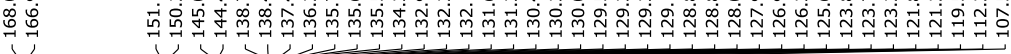<smiles>Cc1ccc(/C=C2\c3ccccc3C(=O)N2c2cccc3cccnc23)cc1</smiles>

256ab

$\left(100 \mathrm{MHz}, \mathrm{CDCl}_{3}\right)$

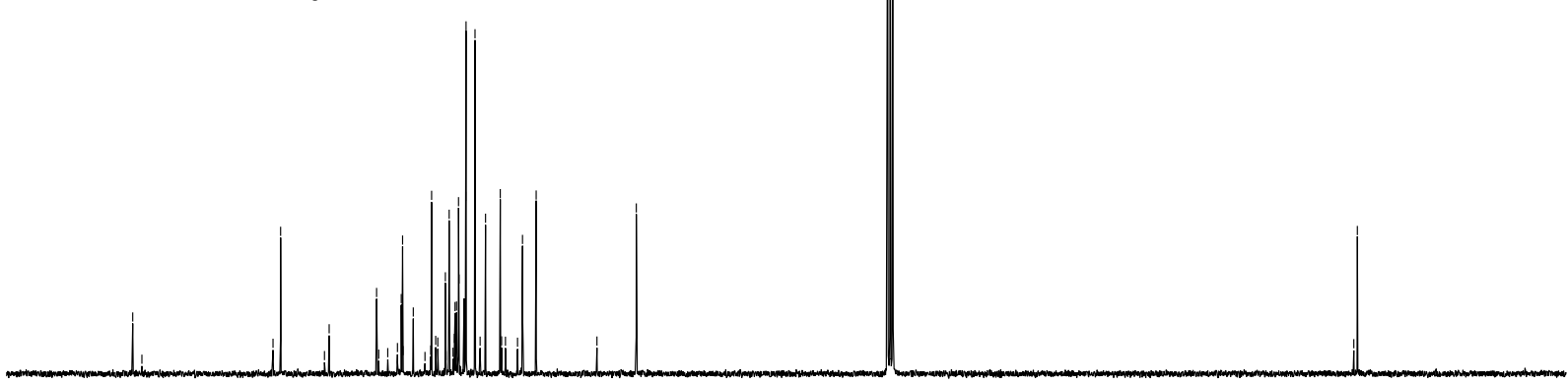




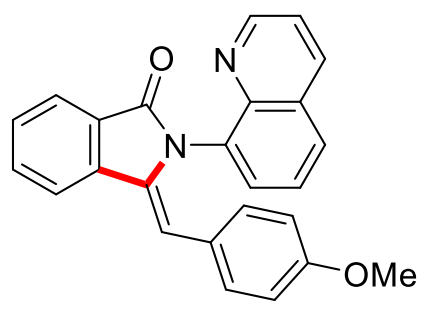

256ac

$\left(400 \mathrm{MHz}, \mathrm{CDCl}_{3}\right.$ )
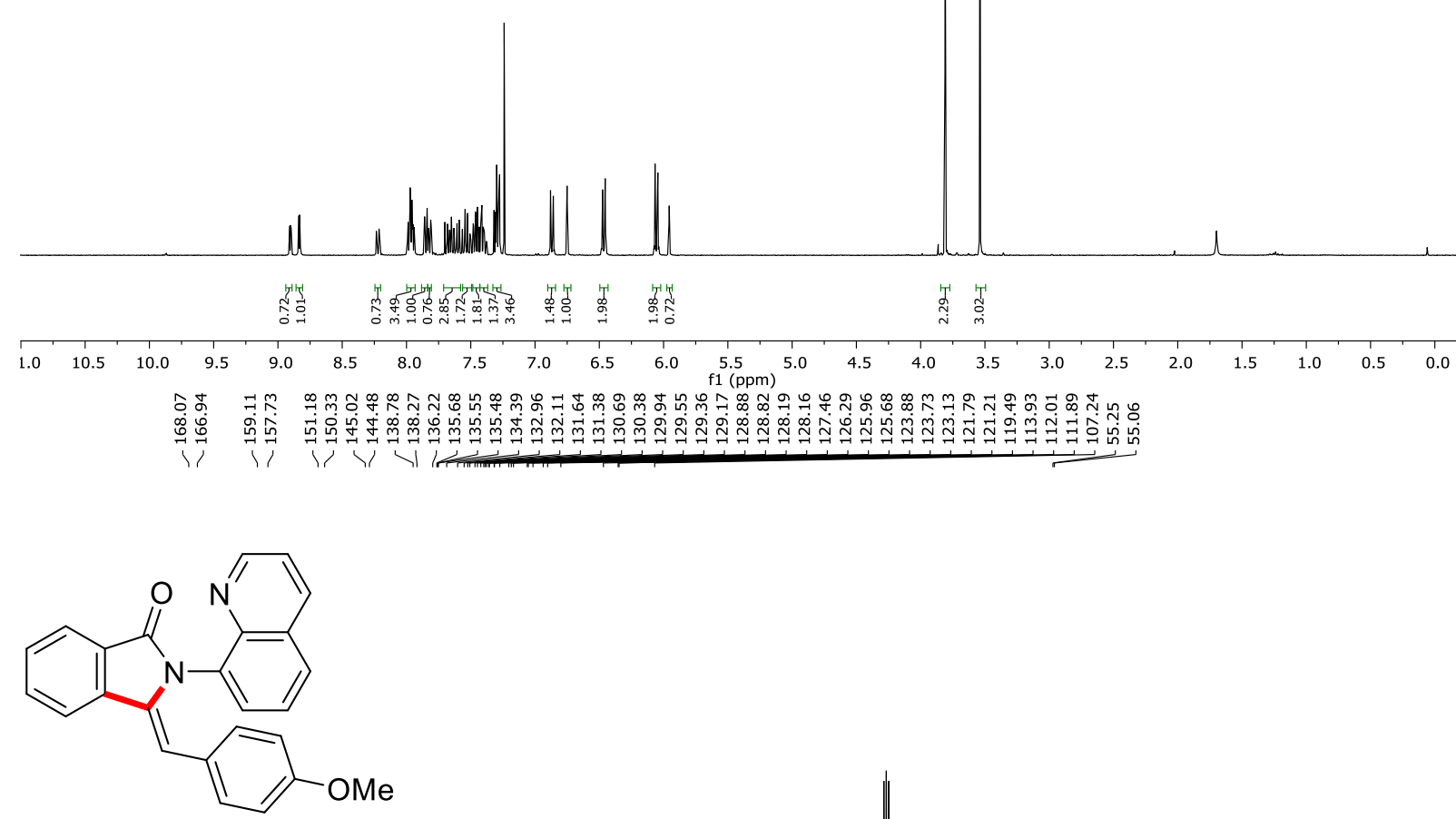

256ac

(100 MHz, $\mathrm{CDCl}_{3}$ )

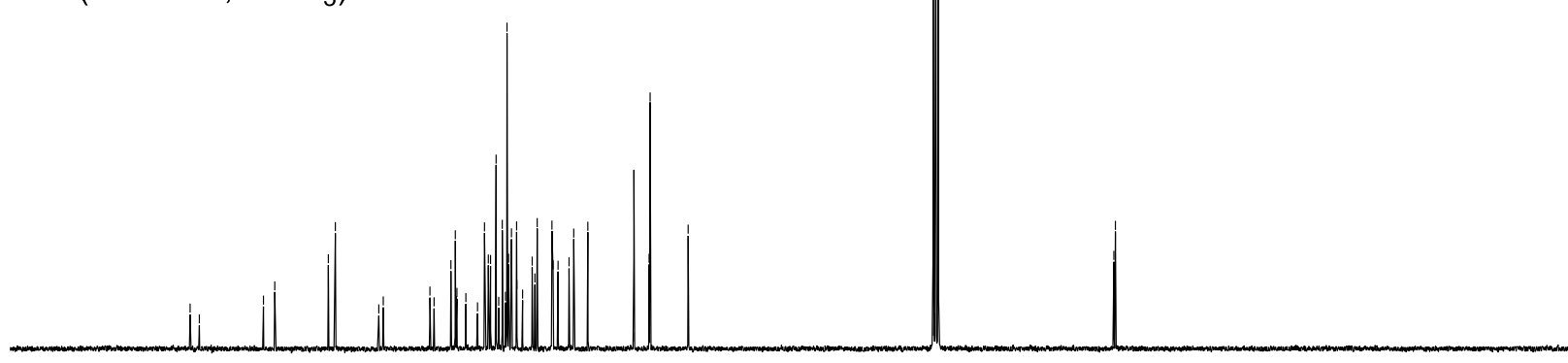

$90 \quad 180$

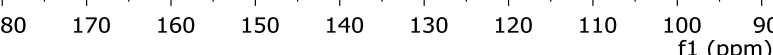
f1 (ppm) 


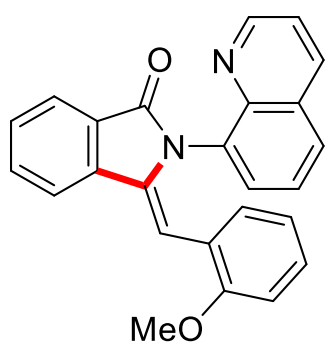

256ad

(300 MHz, $\mathrm{CDCl}_{3}$ )

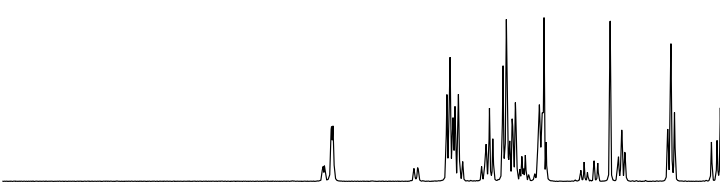

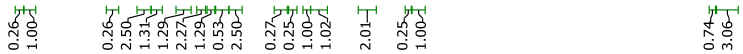

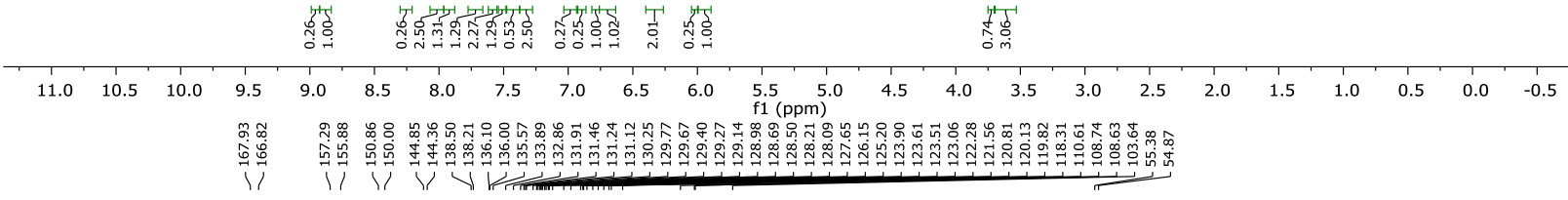<smiles>COc1ccccc1/C=C1\c2ccccc2C(=O)N1c1cccc2cccnc12</smiles>

256ad

$\left(125 \mathrm{MHz}, \mathrm{CDCl}_{3}\right)$

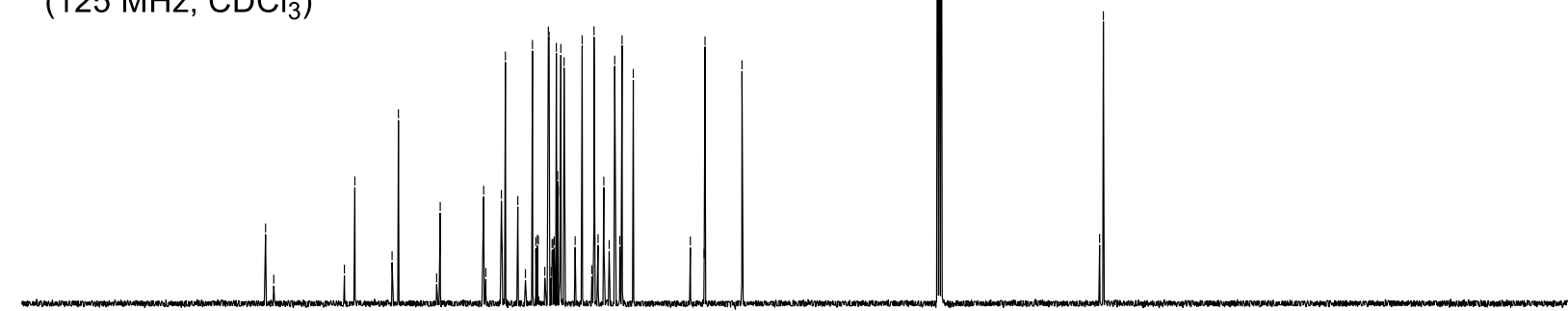

$\begin{array}{llll}130 & 120 & 110 & 100 \\ & & & 100\end{array}$

80

50

$30 \quad 20 \quad 10 \quad 0$ 
<smiles></smiles>

256ae

$\left(400 \mathrm{MHz}, \mathrm{CDCl}_{3}\right)$

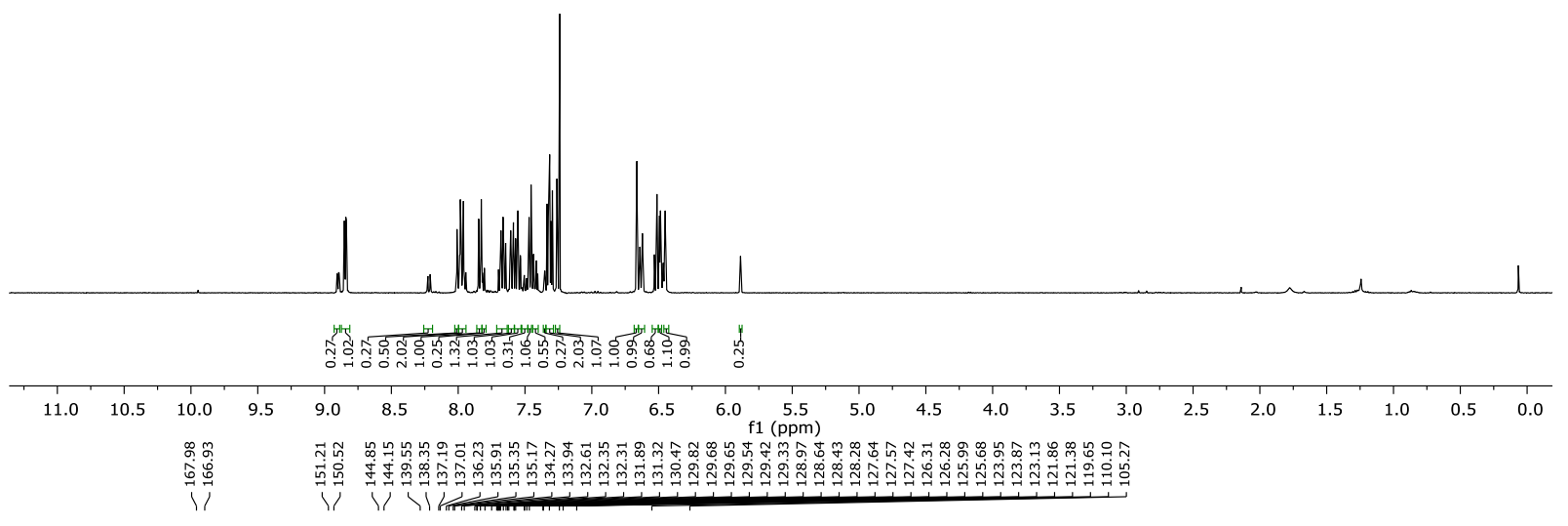<smiles></smiles>

256ae

(100 MHz, $\mathrm{CDCl}_{3}$ )

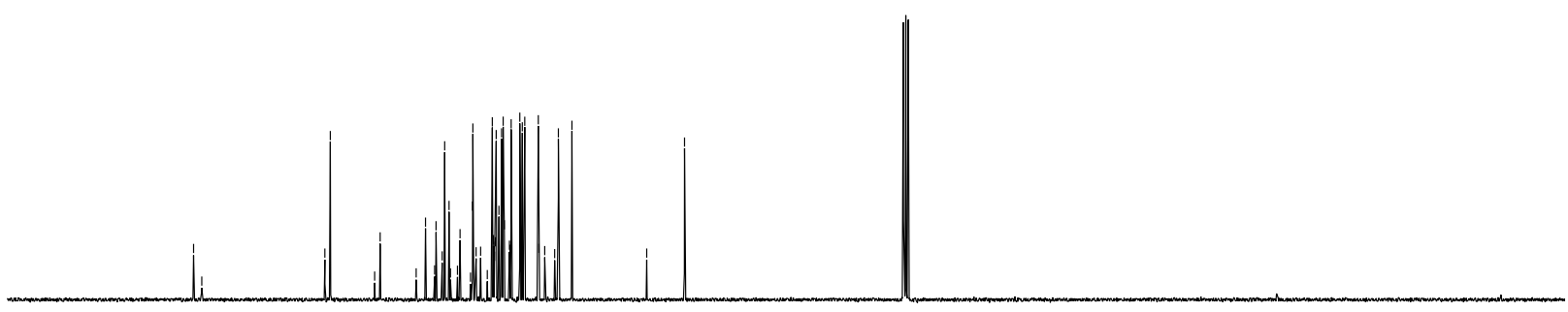

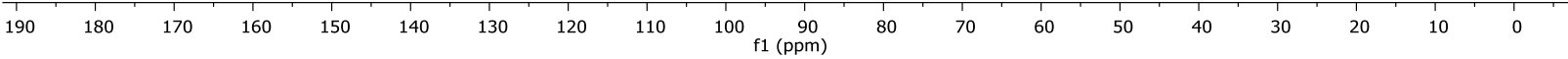




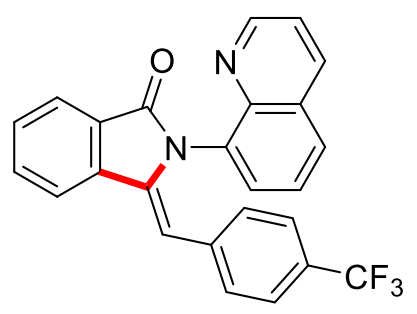

256af

$\left(400 \mathrm{MHz} \mathrm{CDCl}_{3}\right)$
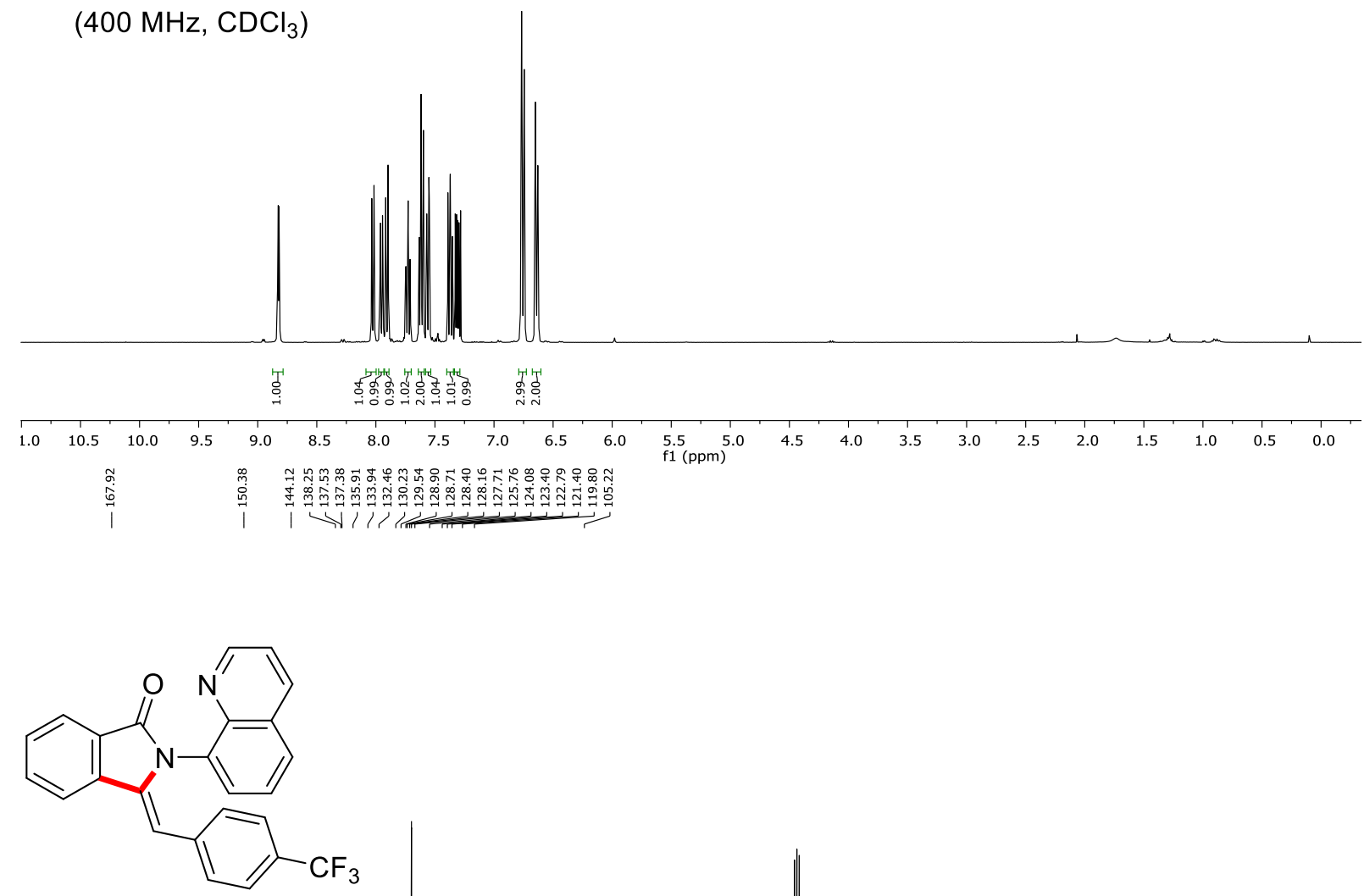

256af

$\left(100 \mathrm{MHz}, \mathrm{CDCl}_{3}\right)$

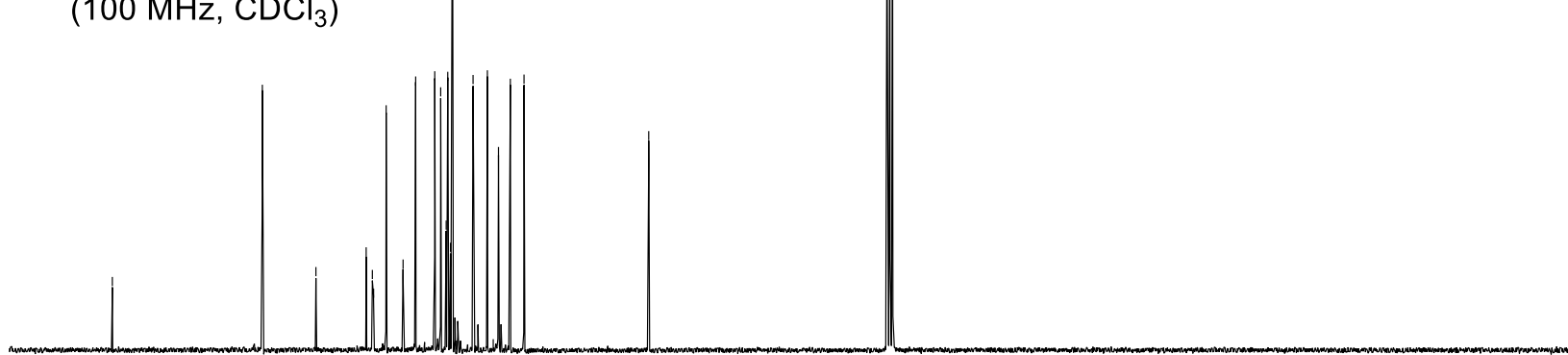

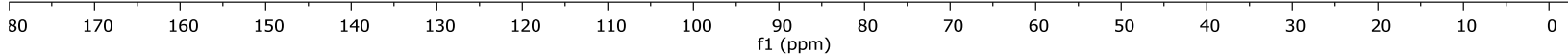




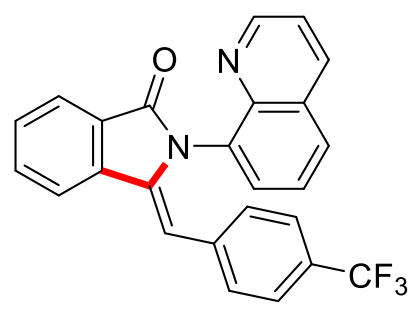

256af

(375 MHz, $\mathrm{CDCl}_{3}$ )

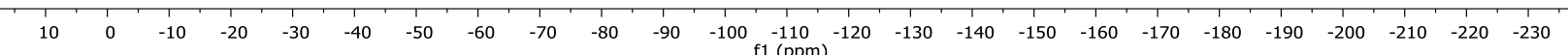




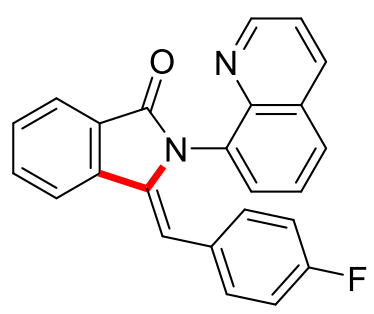

256ag

$\left(100 \mathrm{MHz}, \mathrm{CDCl}_{3}\right.$ )
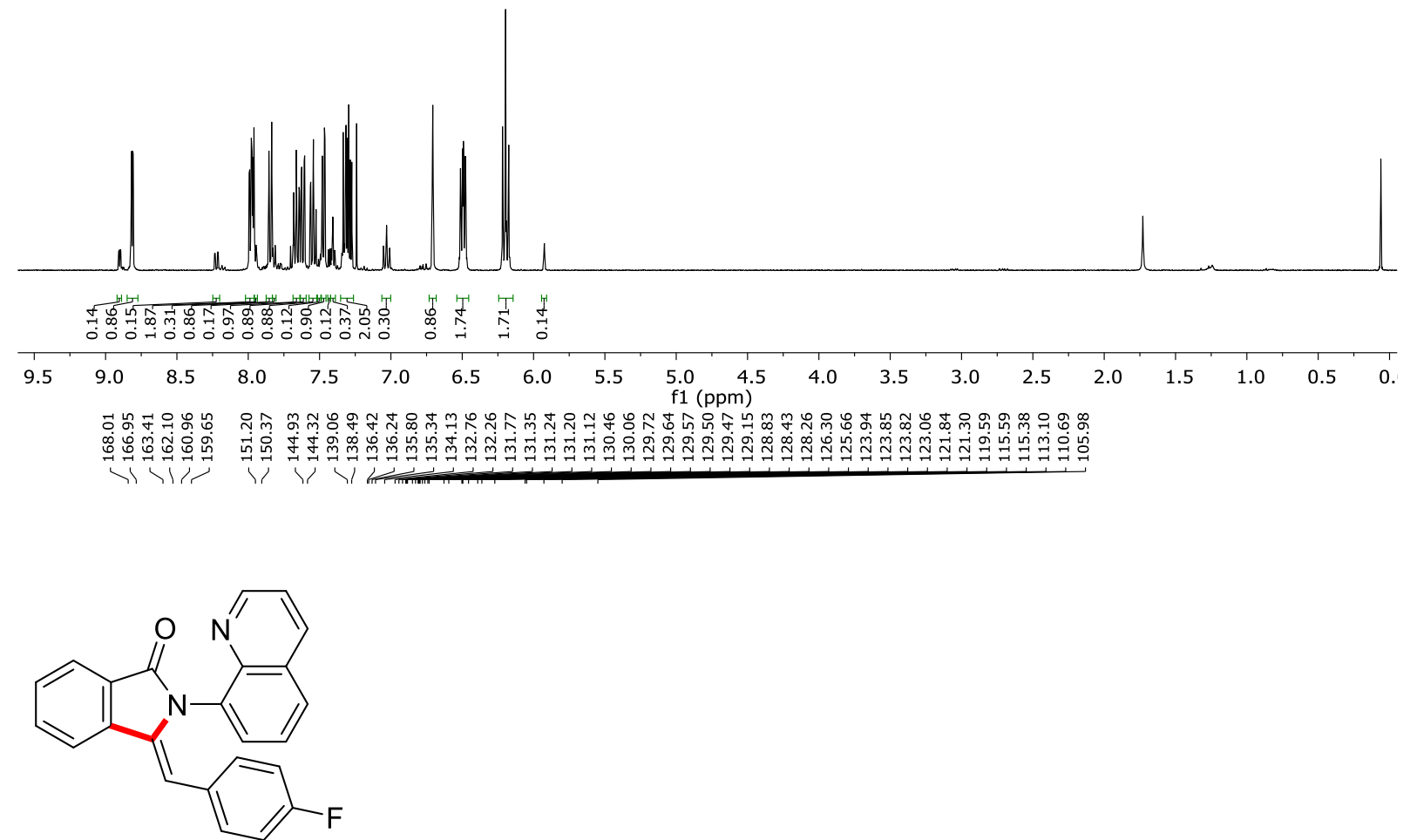

256ag

(400 MHz, $\mathrm{CDCl}_{3}$ )

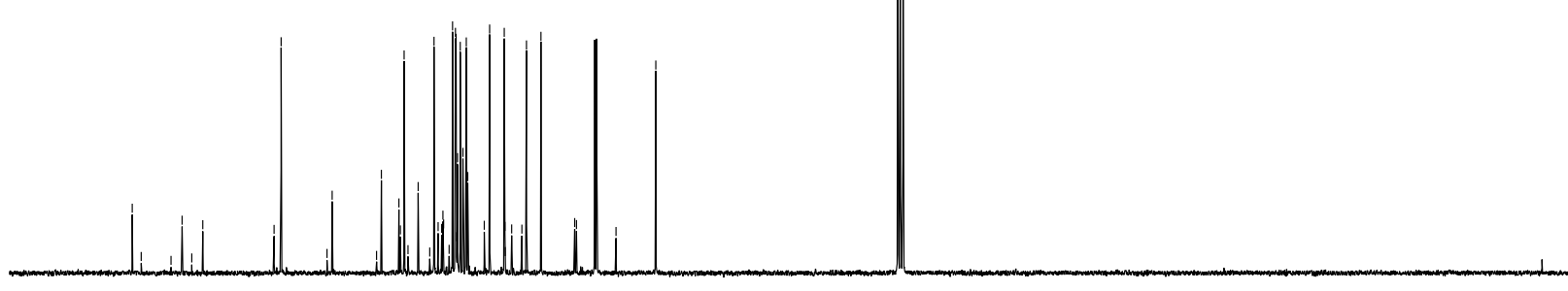

180 $\begin{array}{lllllllll}170 & 160 & 150 & 140 & 130 & 120 & 110 & 100 & \begin{array}{c}90 \\ \mathrm{f} 1(\mathrm{ppm})\end{array}\end{array}$ 


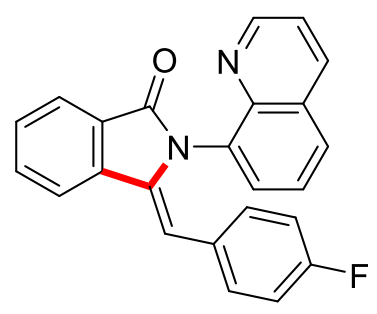

256ag

(375 MHz, $\mathrm{CDCl}_{3}$ )

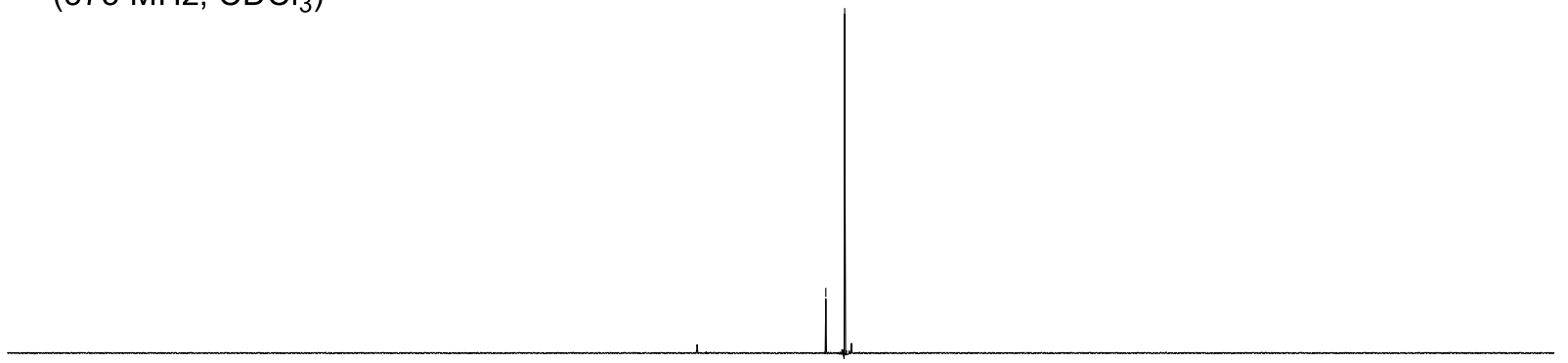

$\begin{array}{lllllllllllllllllllllllllllllll}-45 & -50 & -55 & -60 & -65 & -70 & -75 & -80 & -85 & -90 & -95 & -100 & -105 & -110 & -115 & -120 & -125 & -130 & -135 & -140 & -145 & -150 & -155 & -160 & -165 & -170 & -175\end{array}$ 


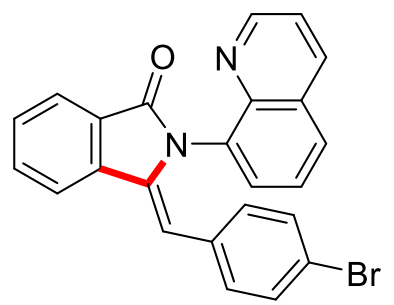

256ah

(400 MHz, $\mathrm{CDCl}_{3}$ )

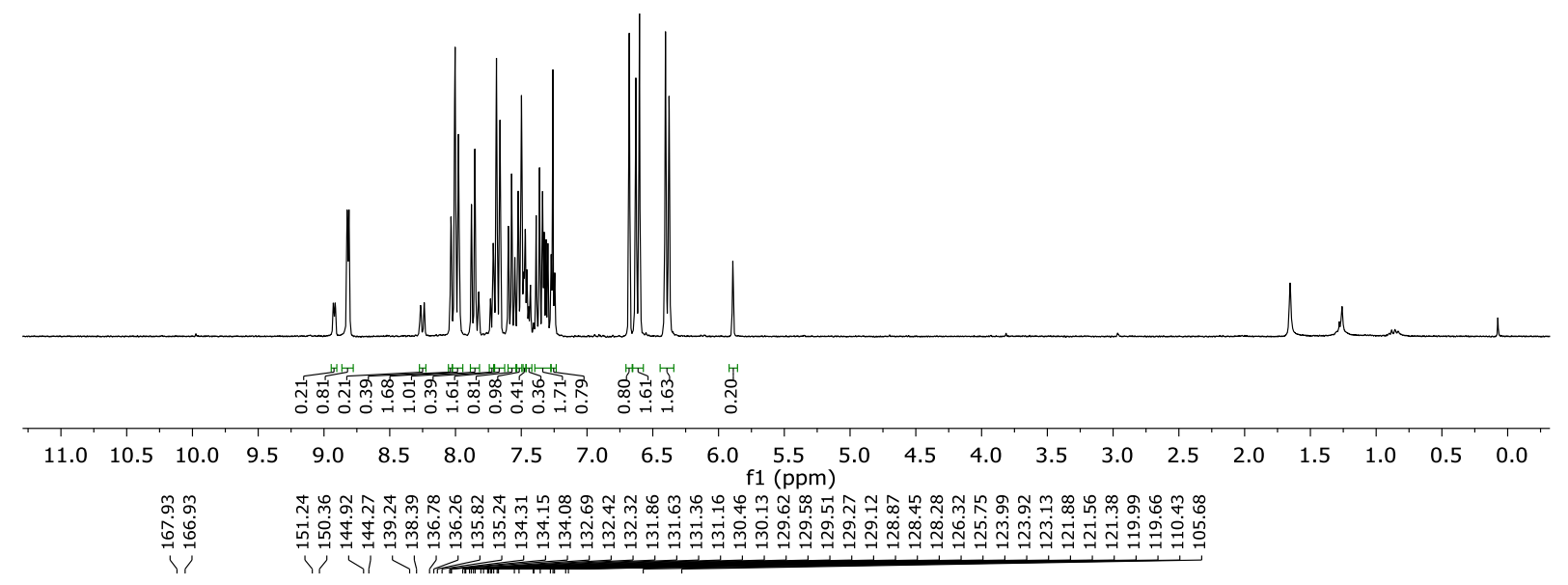<smiles>O=C1/C(=C\c2ccc(Br)cc2)c2ccccc21</smiles>

256ah

$\left(100 \mathrm{MHz}, \mathrm{CDCl}_{3}\right)$

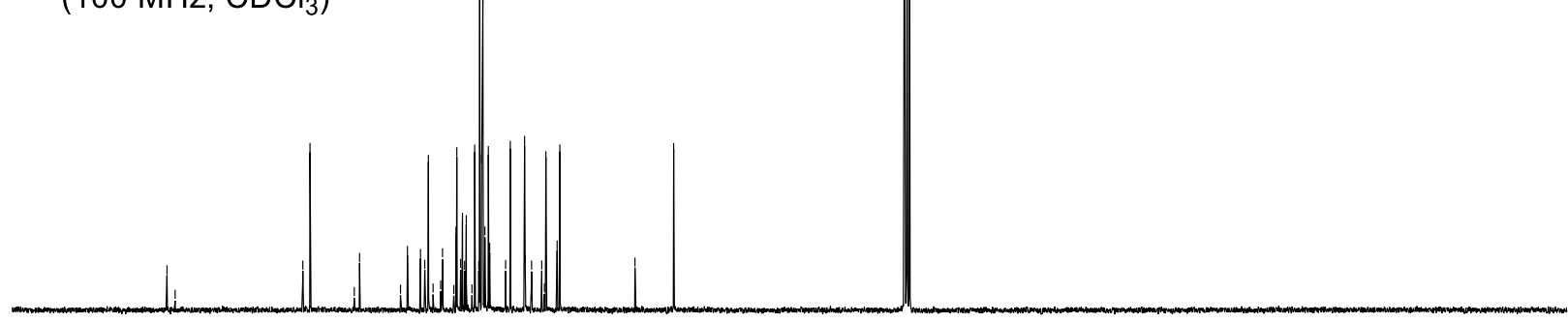

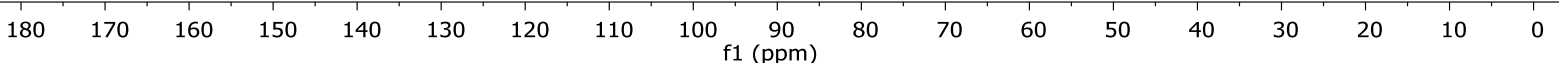




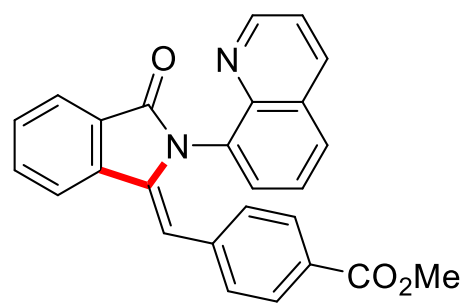

256ai

(400 MHz, $\mathrm{CDCl}_{3}$ )
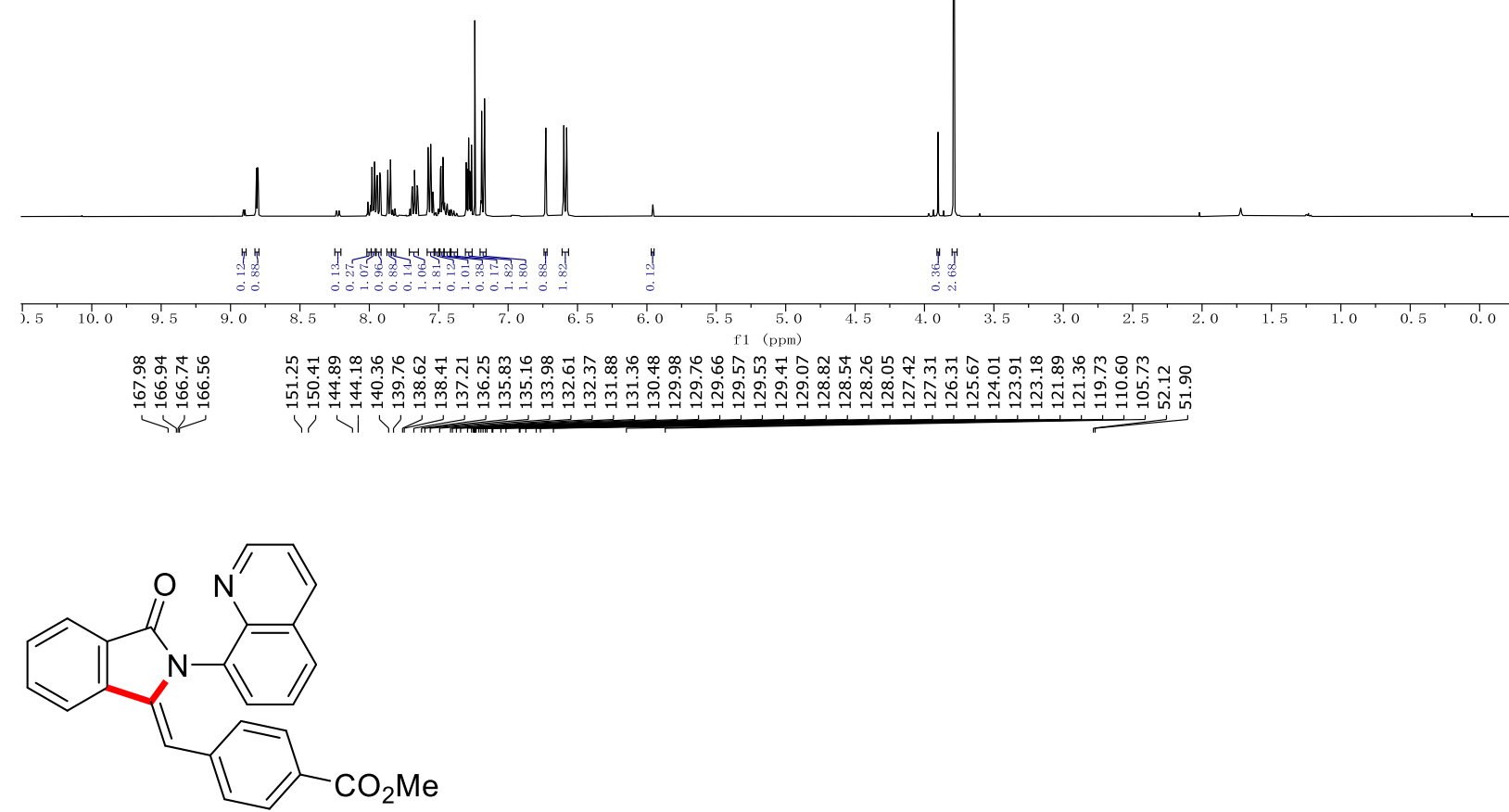

256ai

(100 MHz, $\mathrm{CDCl}_{3}$ )

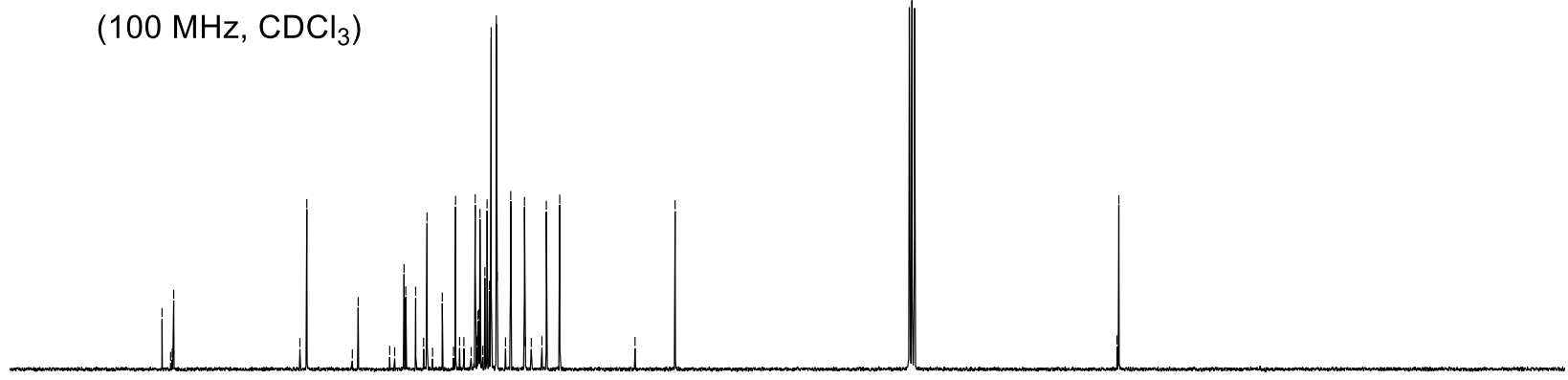

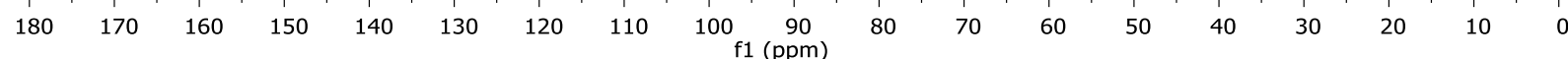




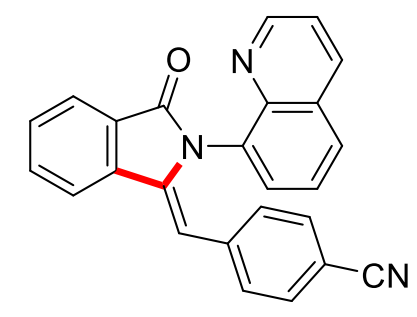

256aj

(400 MHz, $\mathrm{CDCl}_{3}$ )

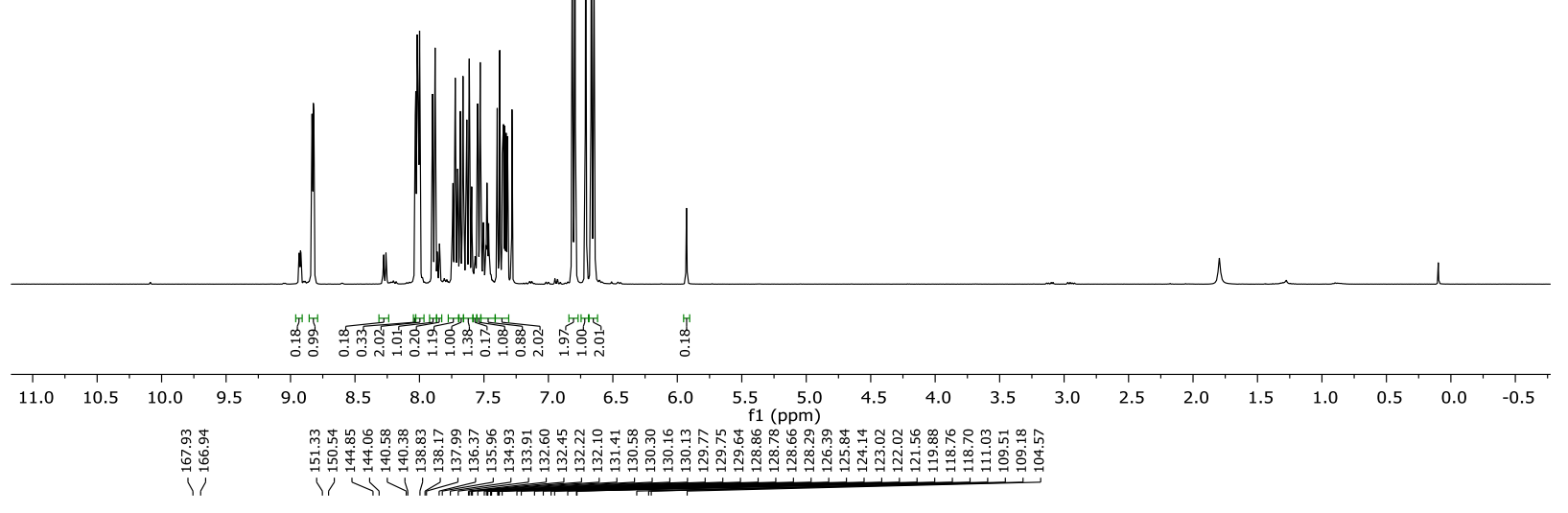<smiles>N#Cc1ccc(/C=C2/c3ccccc3C(=O)N2c2cccc3cccnc23)cc1</smiles>

256aj

(100 MHz, $\mathrm{CDCl}_{3}$ )

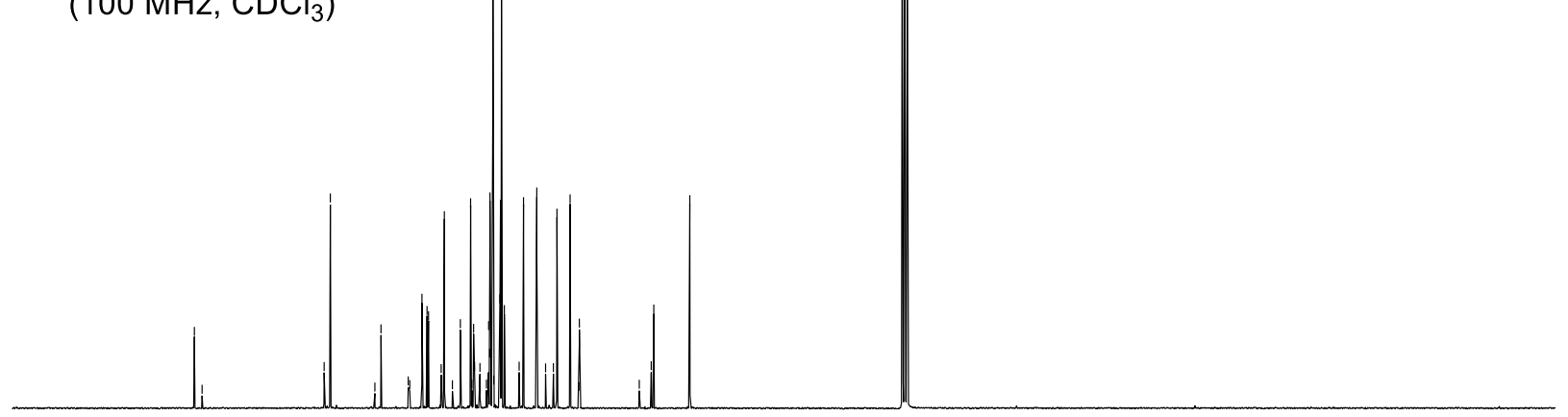

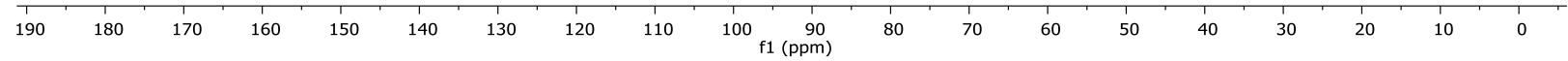


<smiles>O=C1c2ccccc2/C(=C/c2ccsc2)N1c1cccc2cccnc12</smiles>

256ak

(400 MHz, $\mathrm{CDCl}_{3}$ )

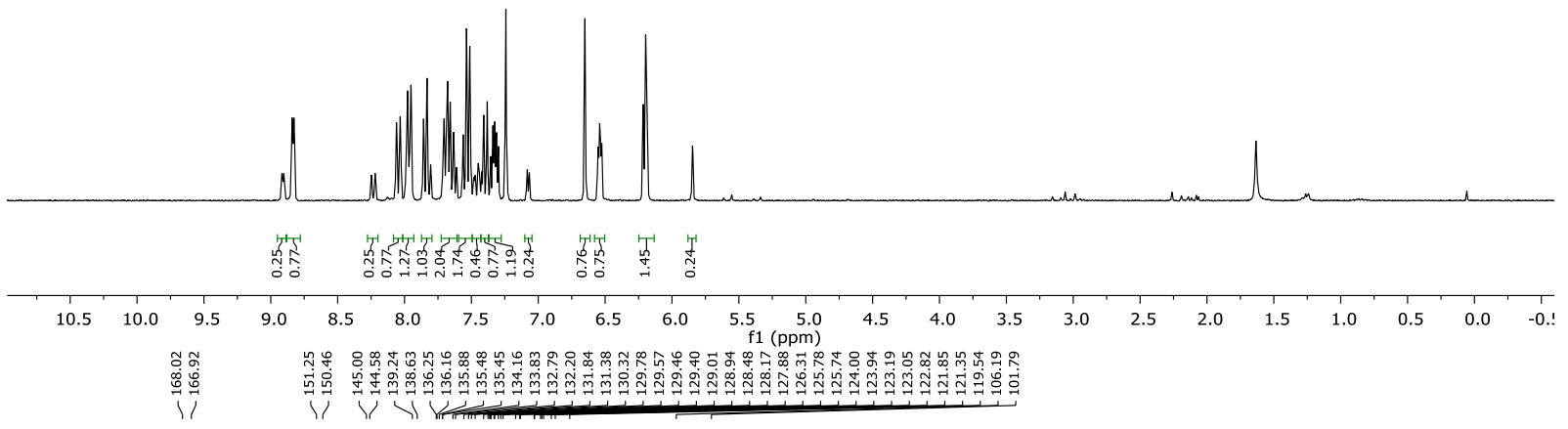<smiles>O=C1c2ccccc2/C(=C/c2ccsc2)N1c1cccc2cccnc12</smiles>

256ak

$\left(100 \mathrm{MHz}, \mathrm{CDCl}_{3}\right.$ )

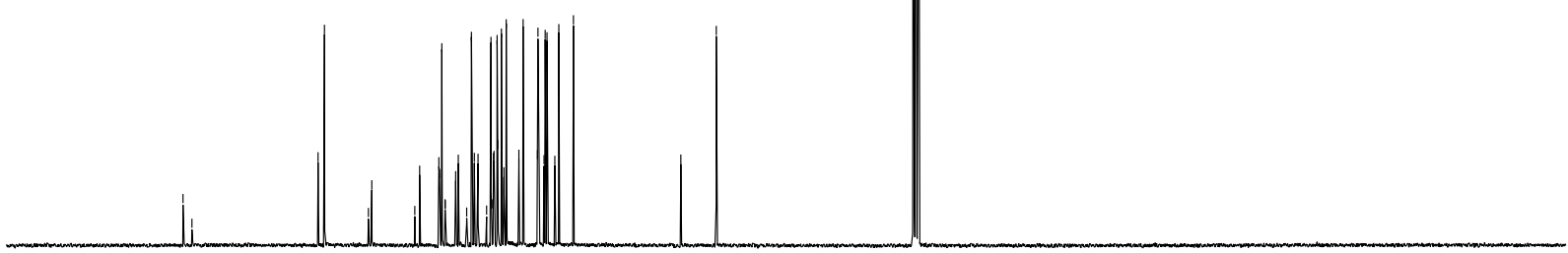

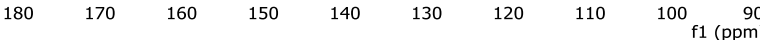


<smiles>CCOC(=O)/C=C1\c2ccccc2C(=O)N1c1cccc2cccnc12</smiles>

256al

$\left(400 \mathrm{MHz}, \mathrm{CDCl}_{3}\right)$

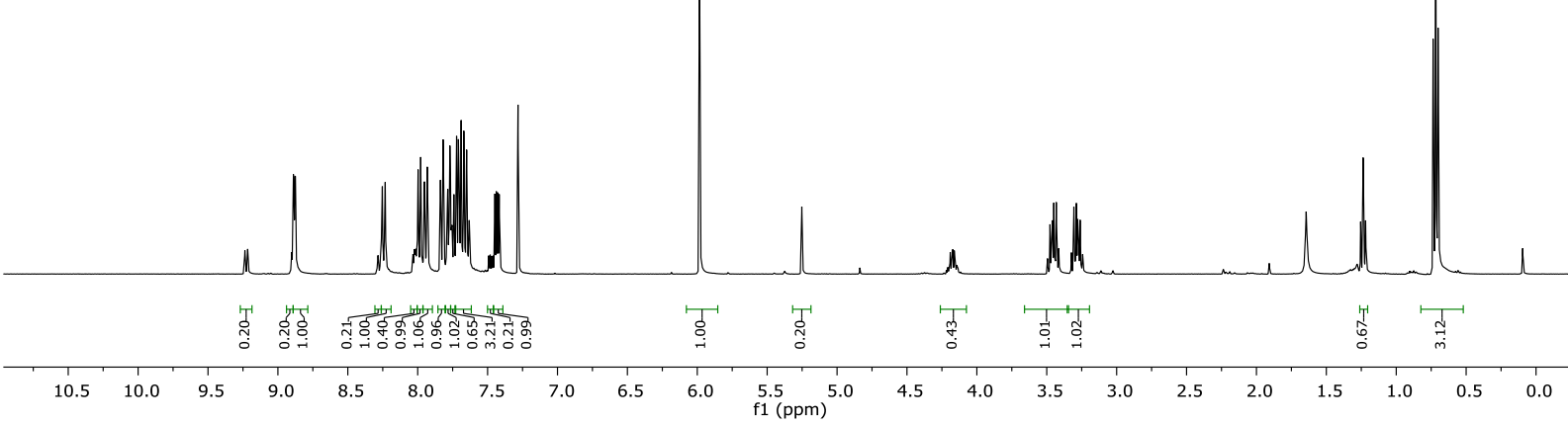

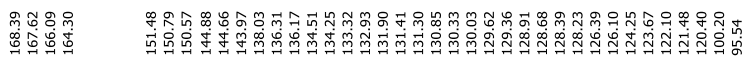

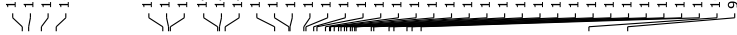

爱参

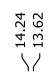<smiles>CCOC(=O)/C=C1\c2ccccc2C(=O)N1c1cccc2cccnc12</smiles>

256al

$\left(100 \mathrm{MHz}, \mathrm{CDCl}_{3}\right.$ )
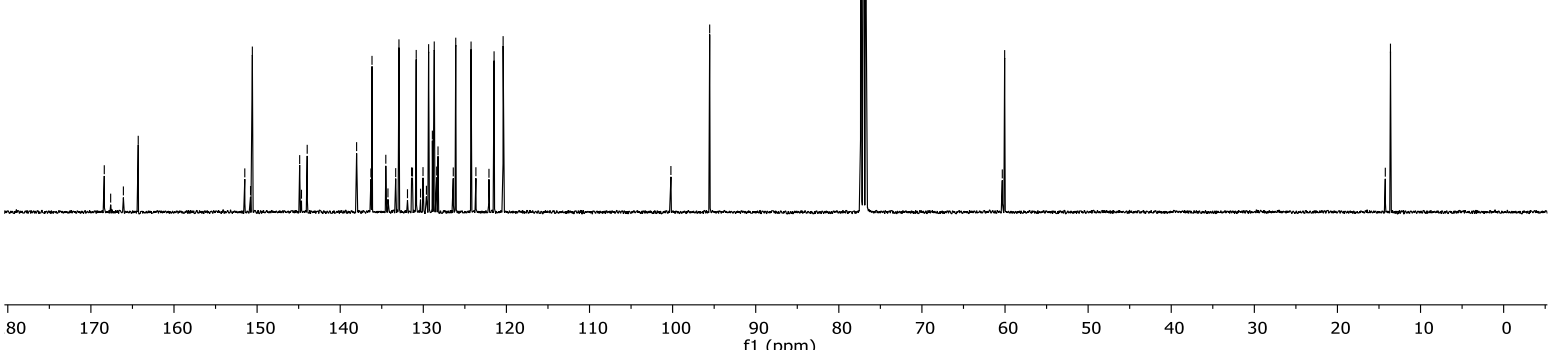


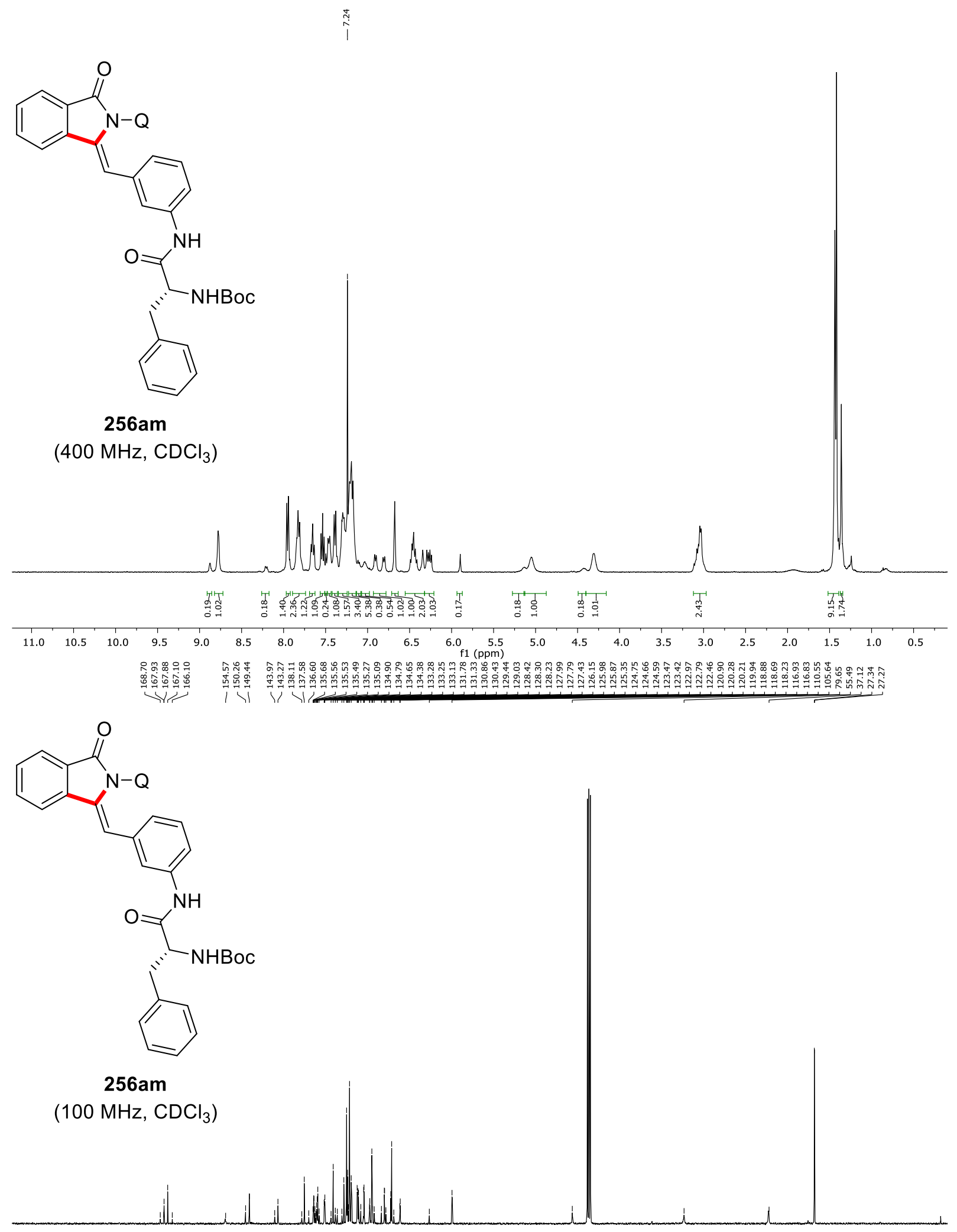

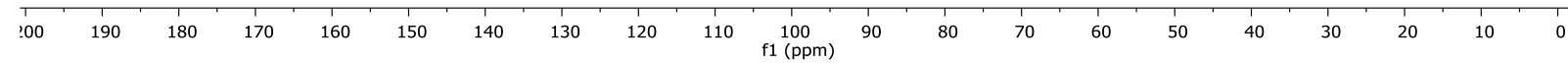



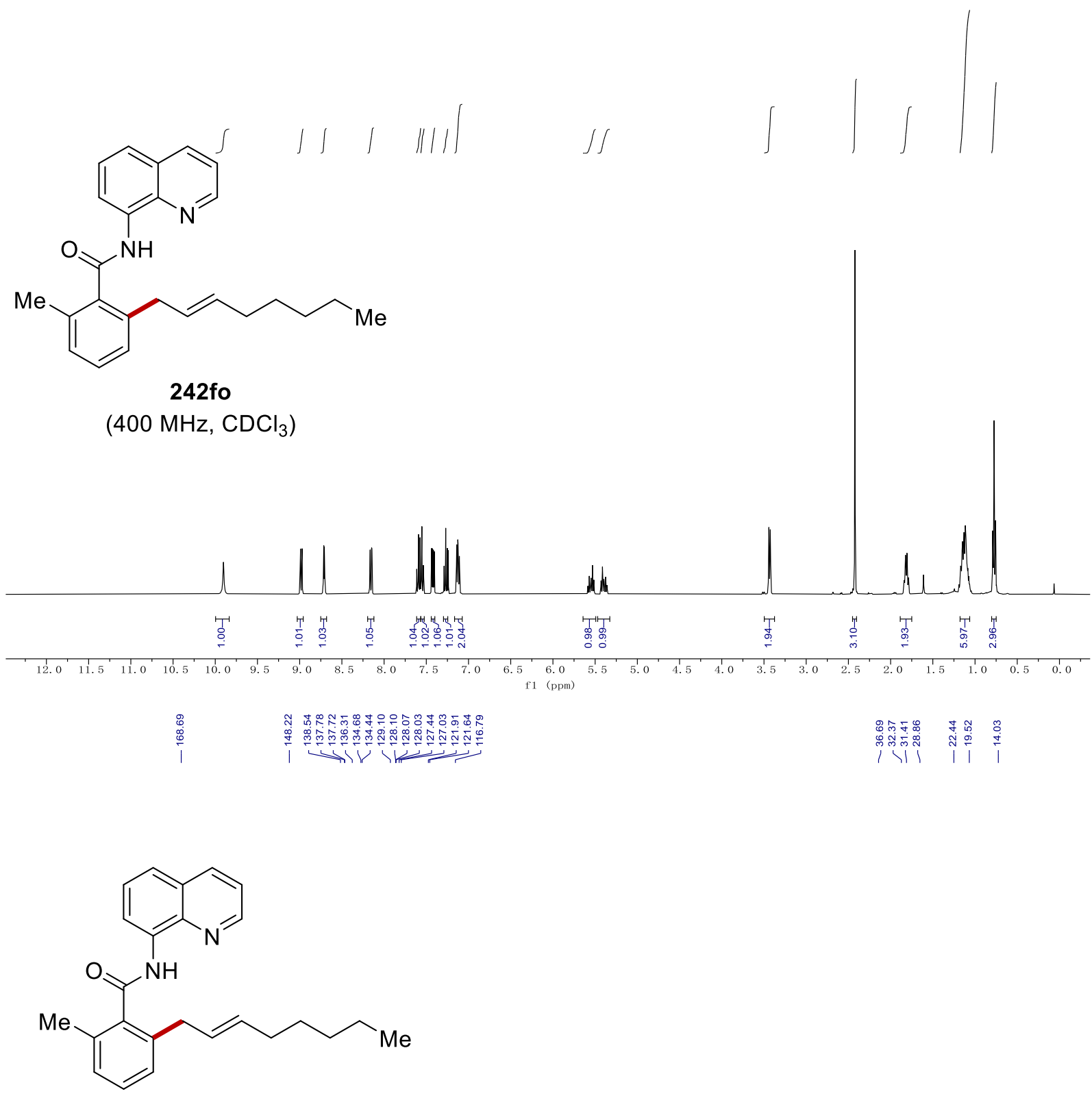

242fo

$\left(100 \mathrm{MHz}, \mathrm{CDCl}_{3}\right)$

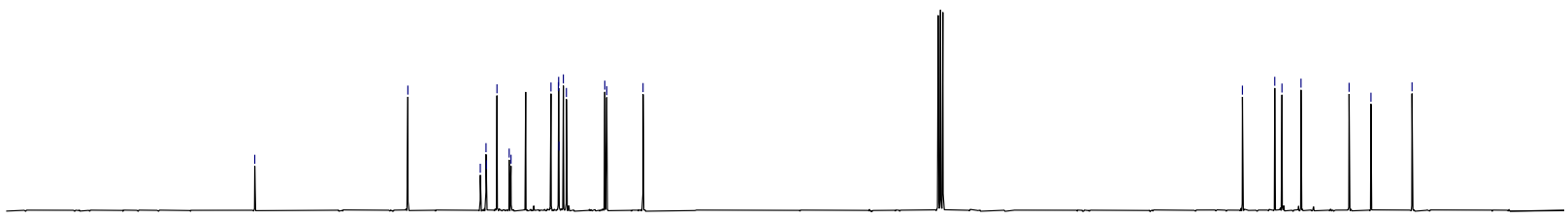

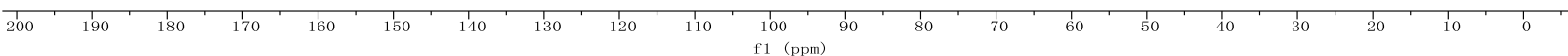



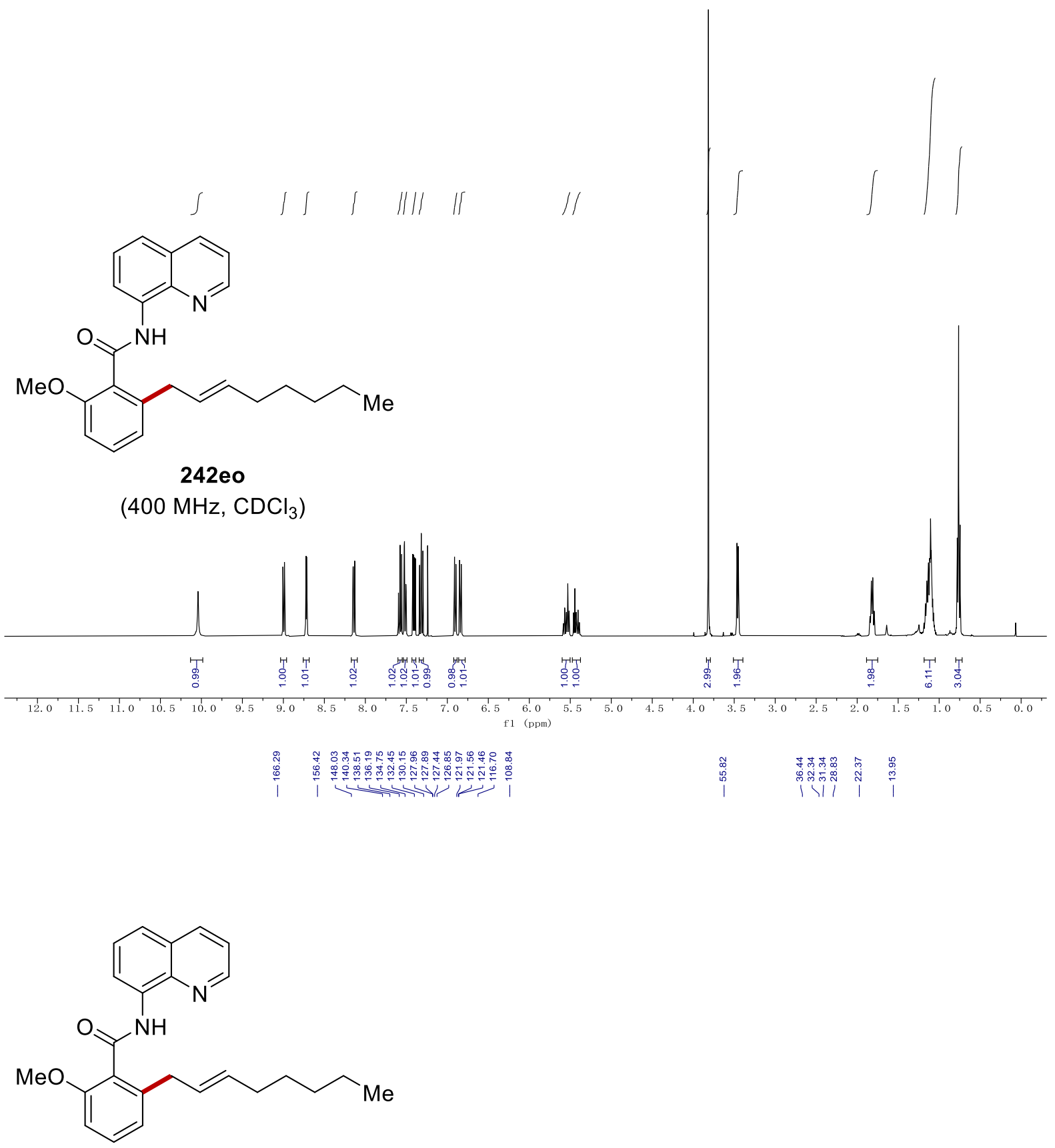

242eo

$\left(100 \mathrm{MHz}, \mathrm{CDCl}_{3}\right)$

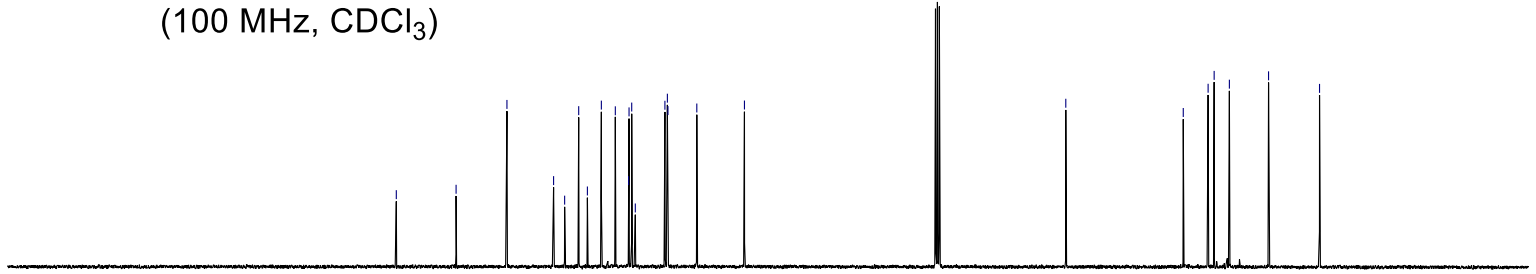

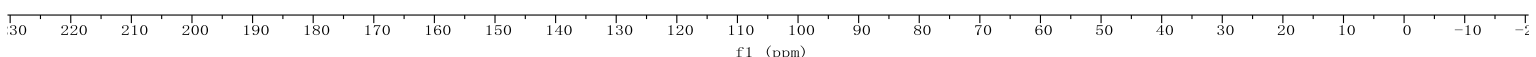



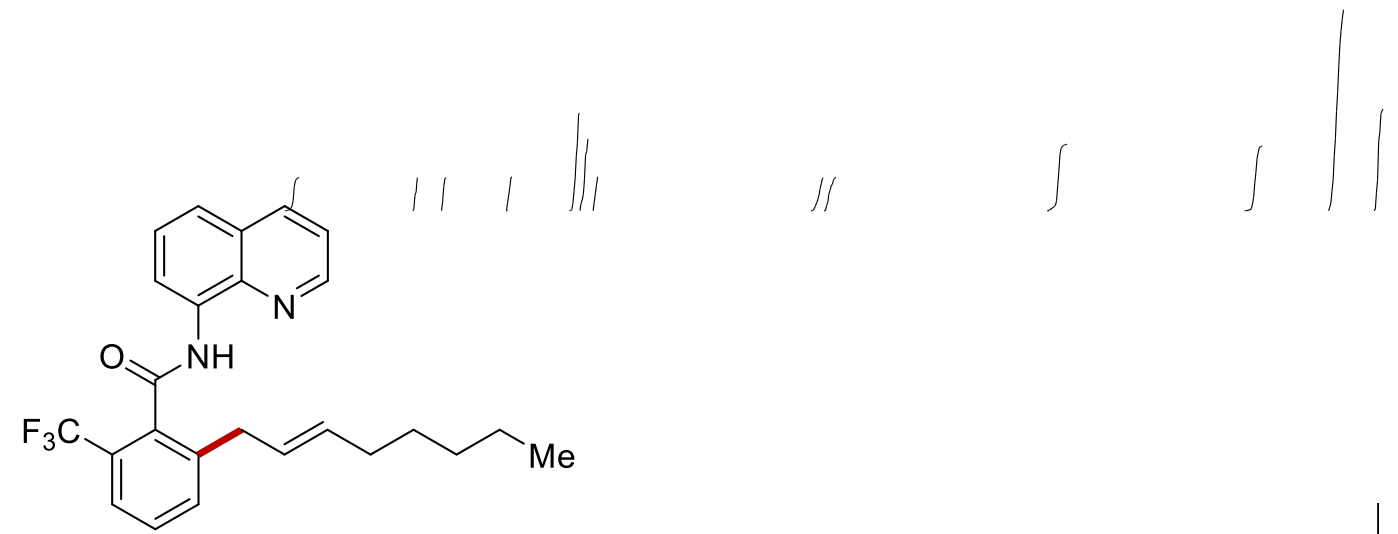

242go

(400 MHz, $\mathrm{CDCl}_{3}$ )
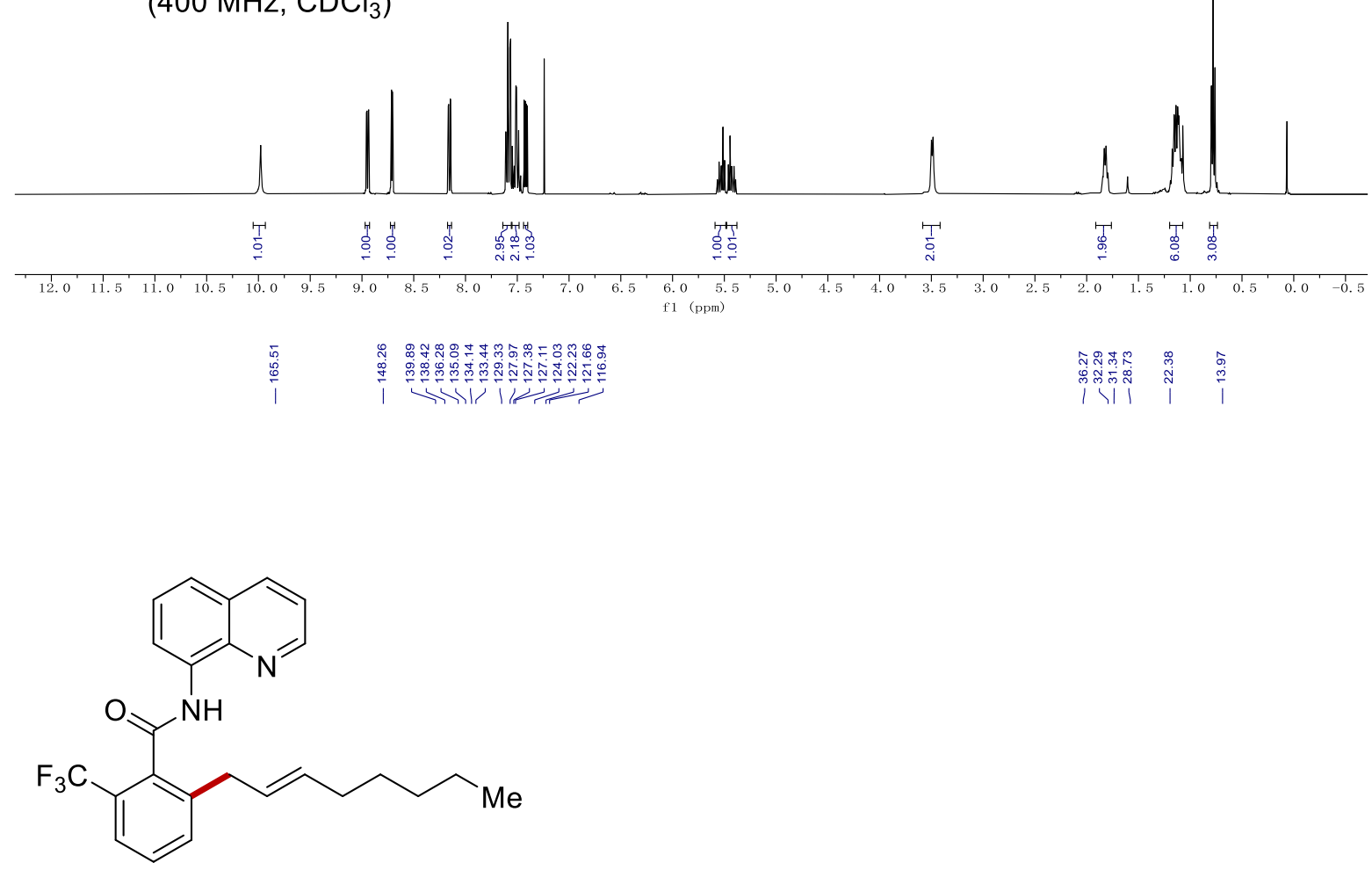

242go

(100 MHz, $\mathrm{CDCl}_{3}$ )

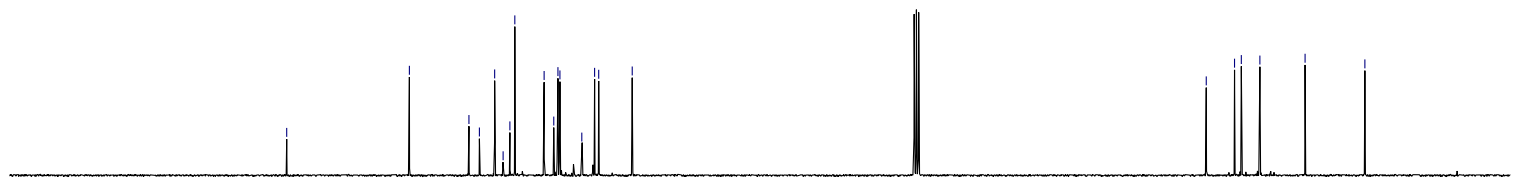

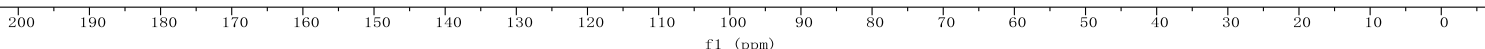




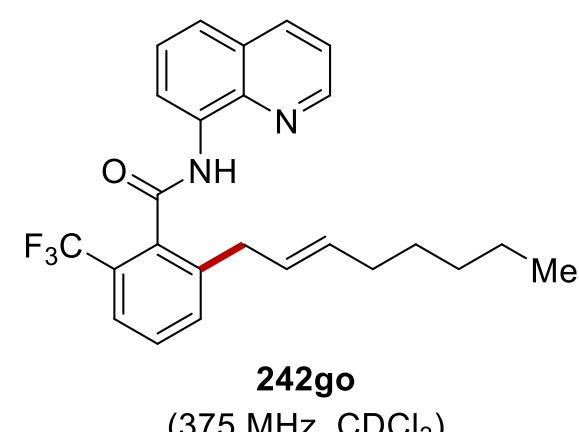

(375 MHz, $\mathrm{CDCl}_{3}$ ) 

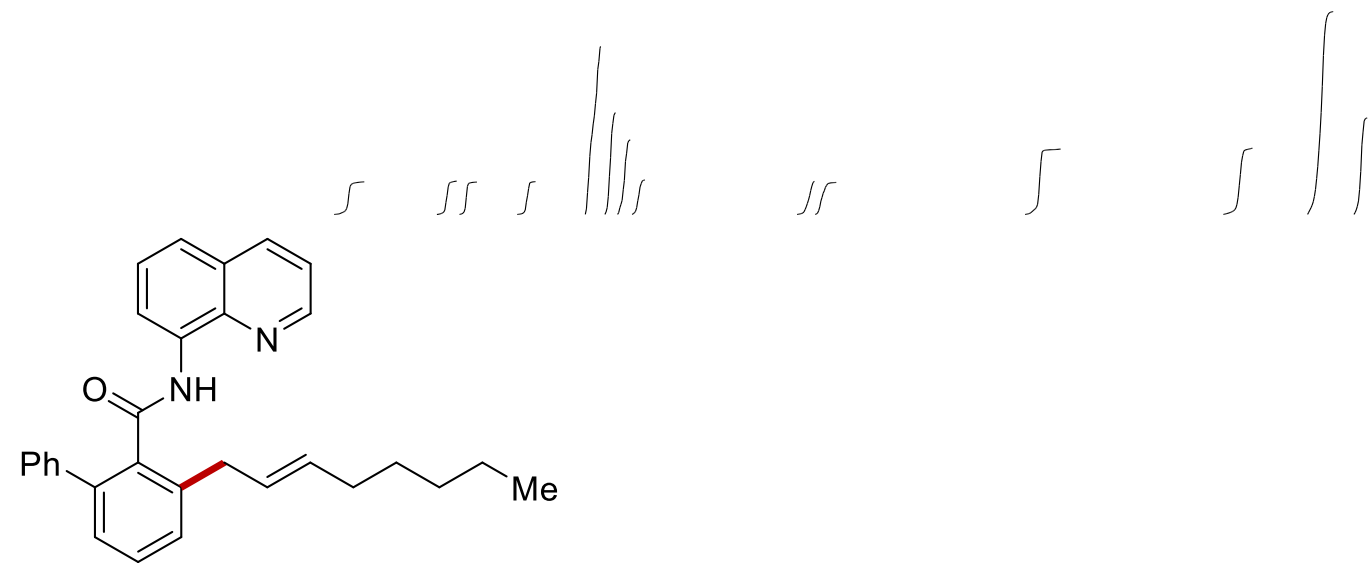

242co
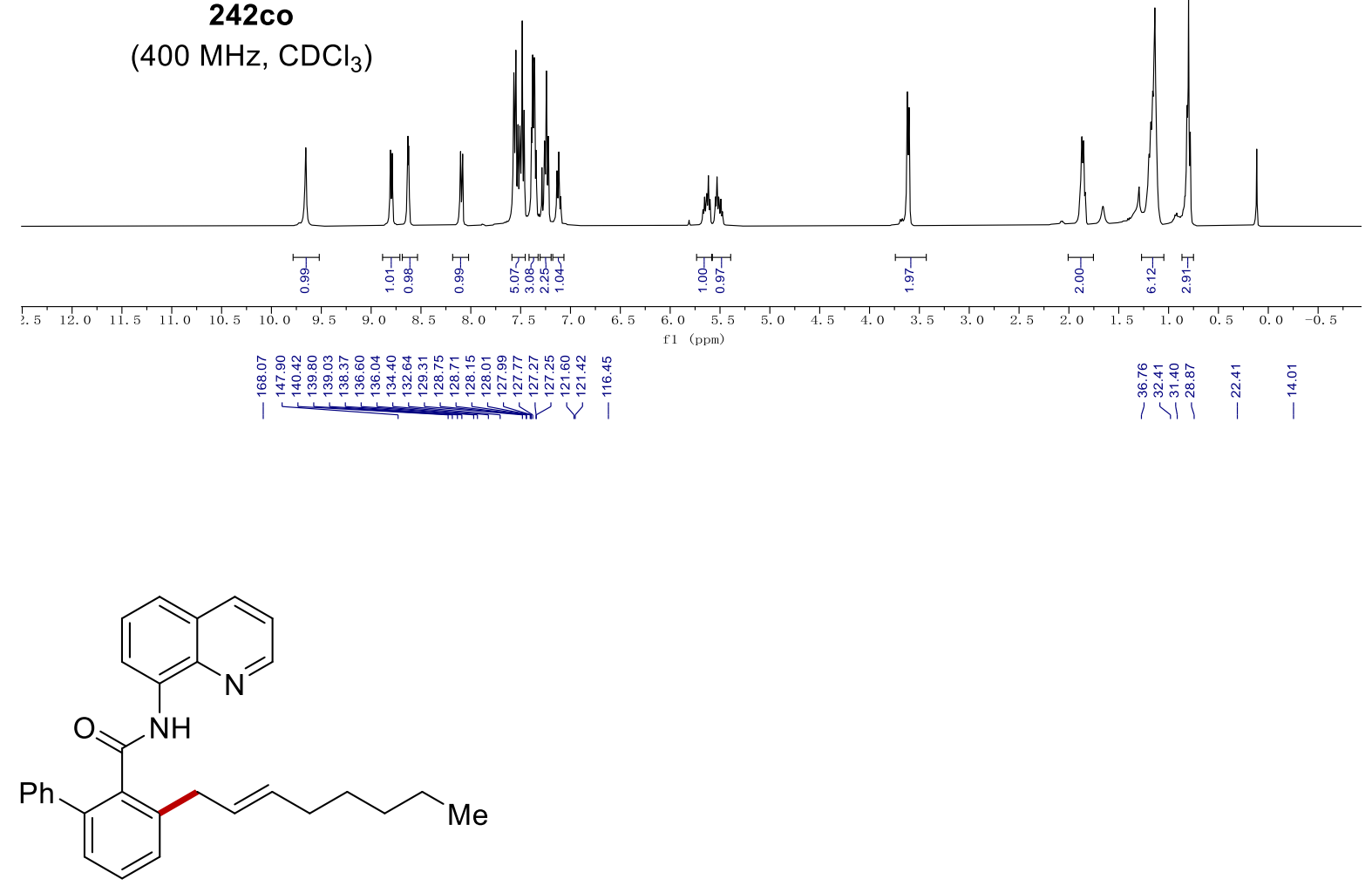

242co

(100 MHz, $\mathrm{CDCl}_{3}$ )

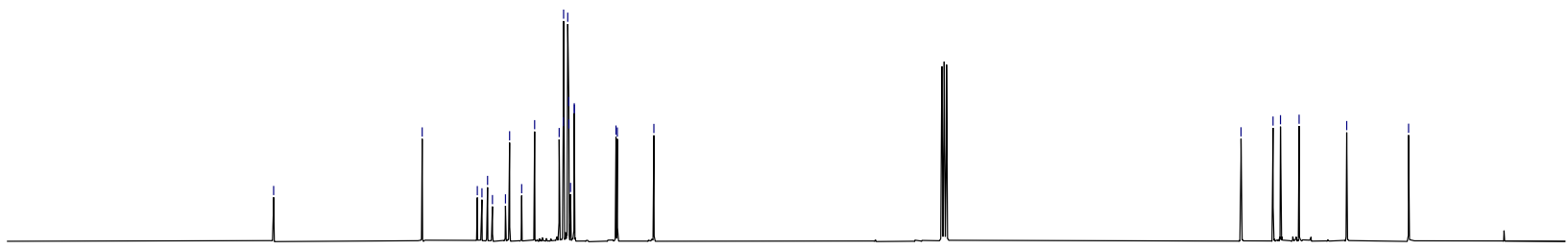

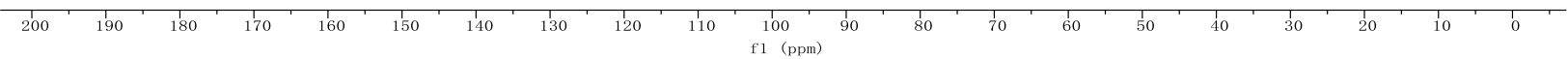



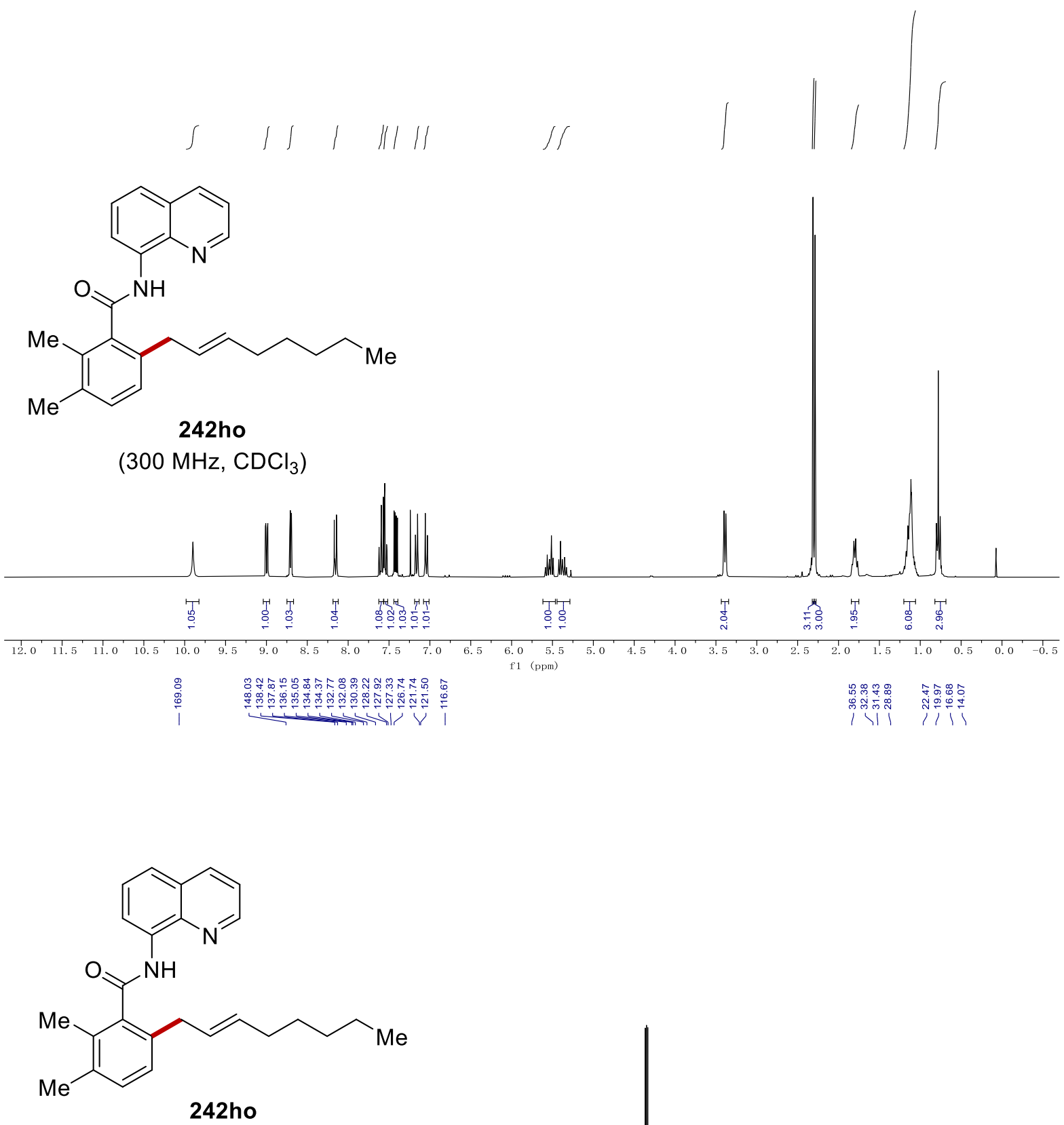

(125 MHz, $\mathrm{CDCl}_{3}$ )

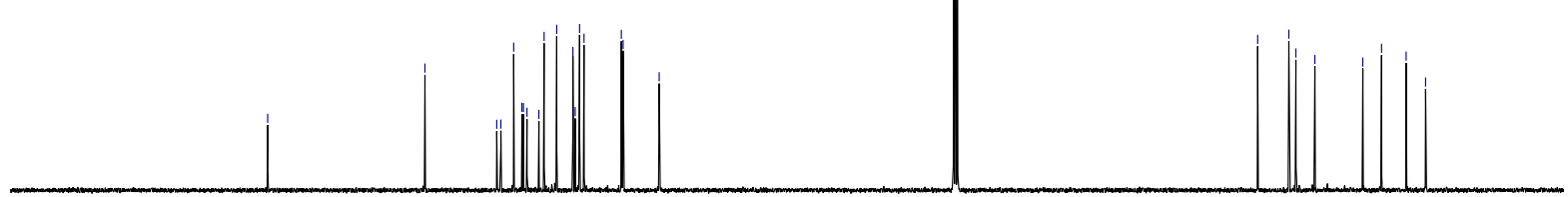



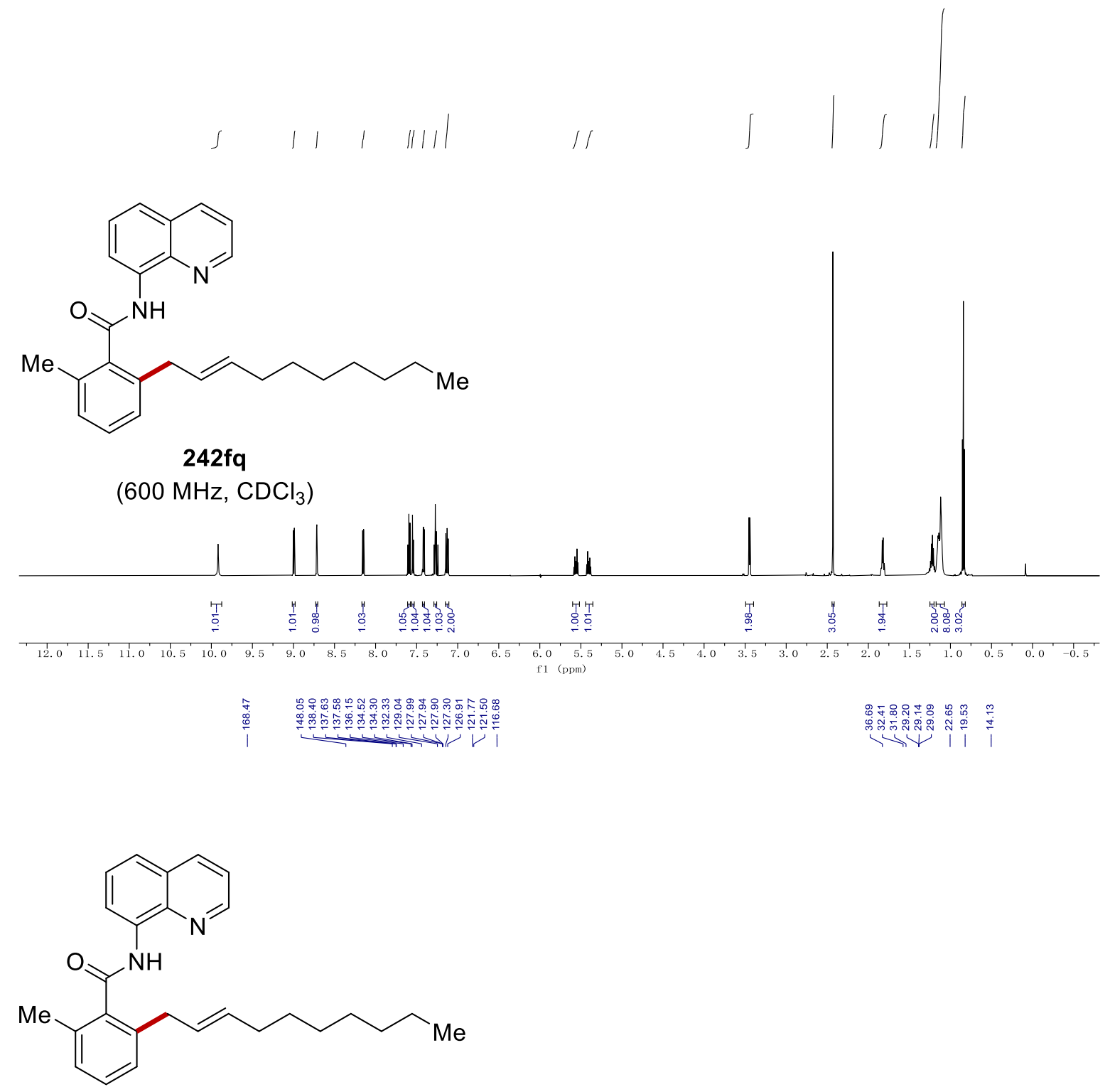

$242 \mathrm{fq}$

(125 MHz, $\mathrm{CDCl}_{3}$ )

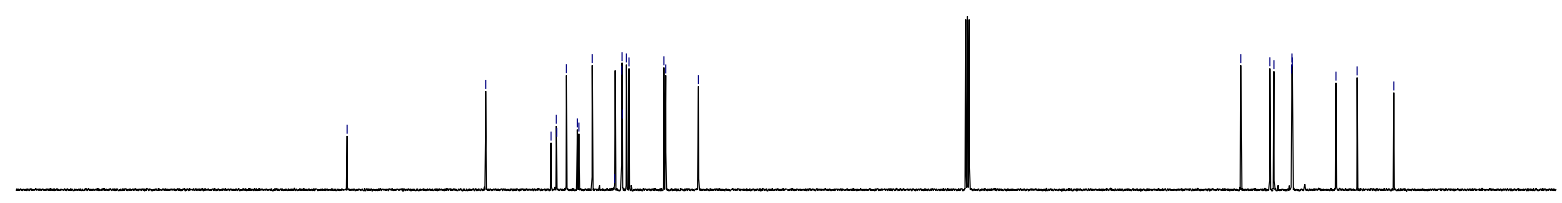



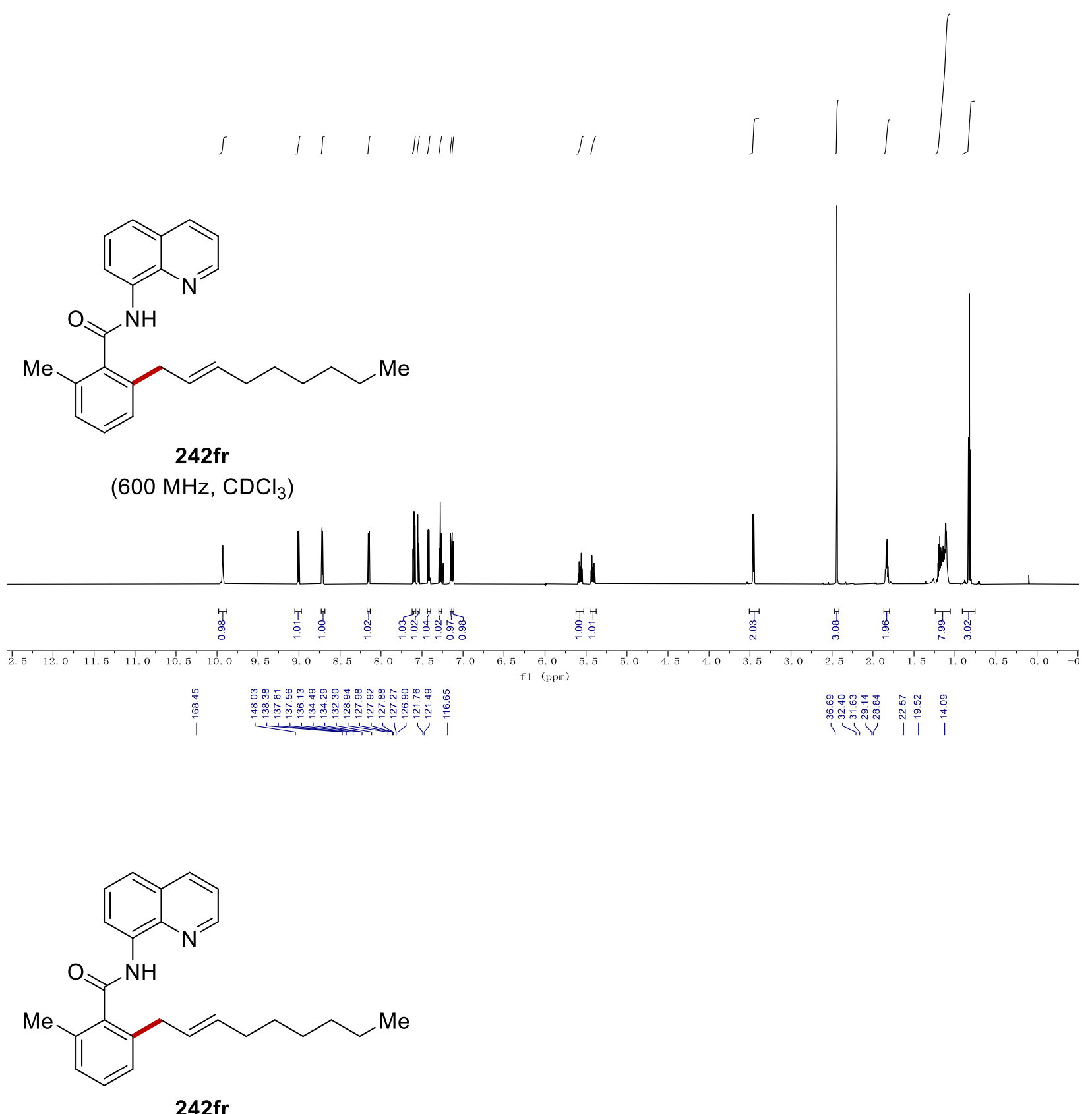

(125 MHz, $\mathrm{CDCl}_{3}$ )

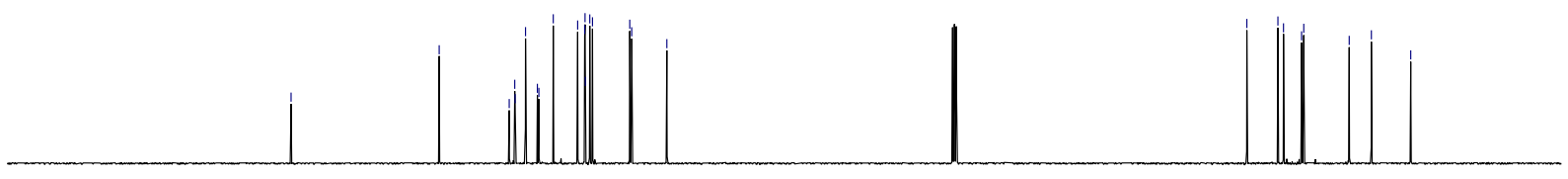




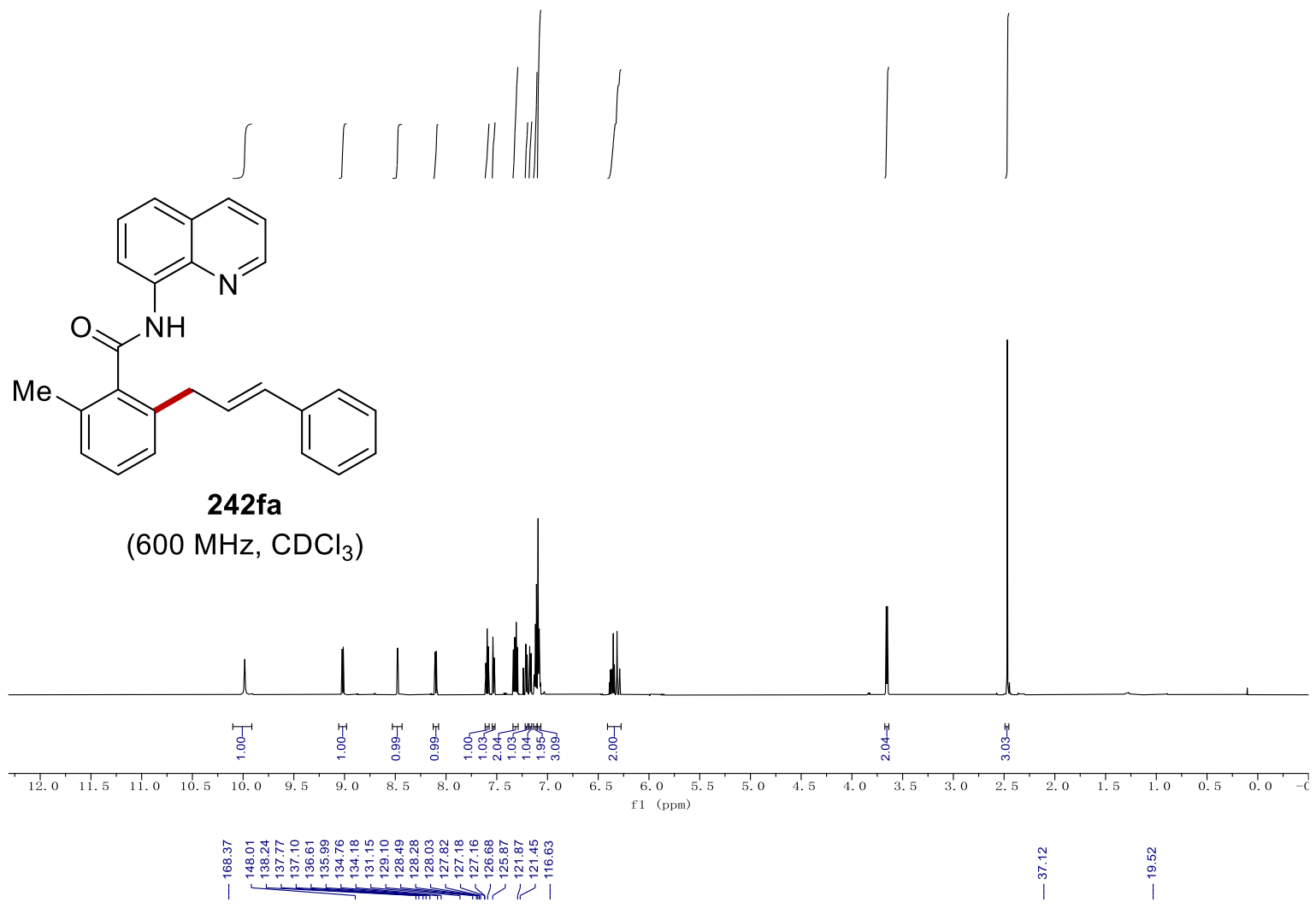<smiles>Cc1cccc(C/C=C/c2ccccc2)c1C(=O)Nc1cccc2cccnc12</smiles>

242fa

$\left(125 \mathrm{MHz}, \mathrm{CDCl}_{3}\right.$ )

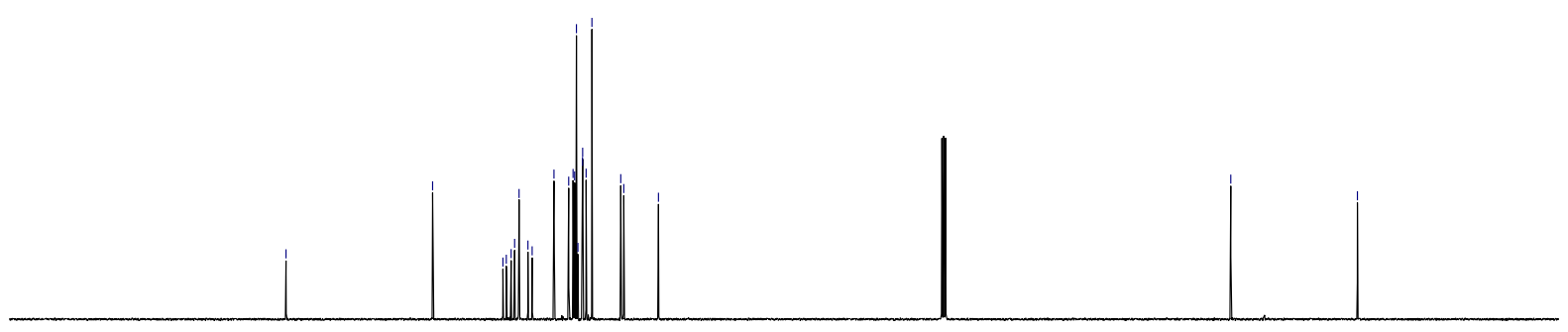

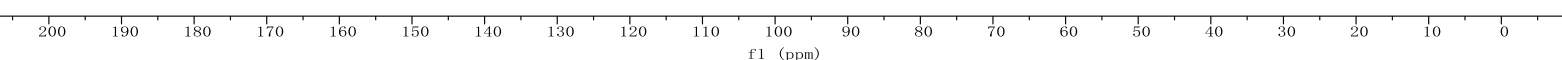



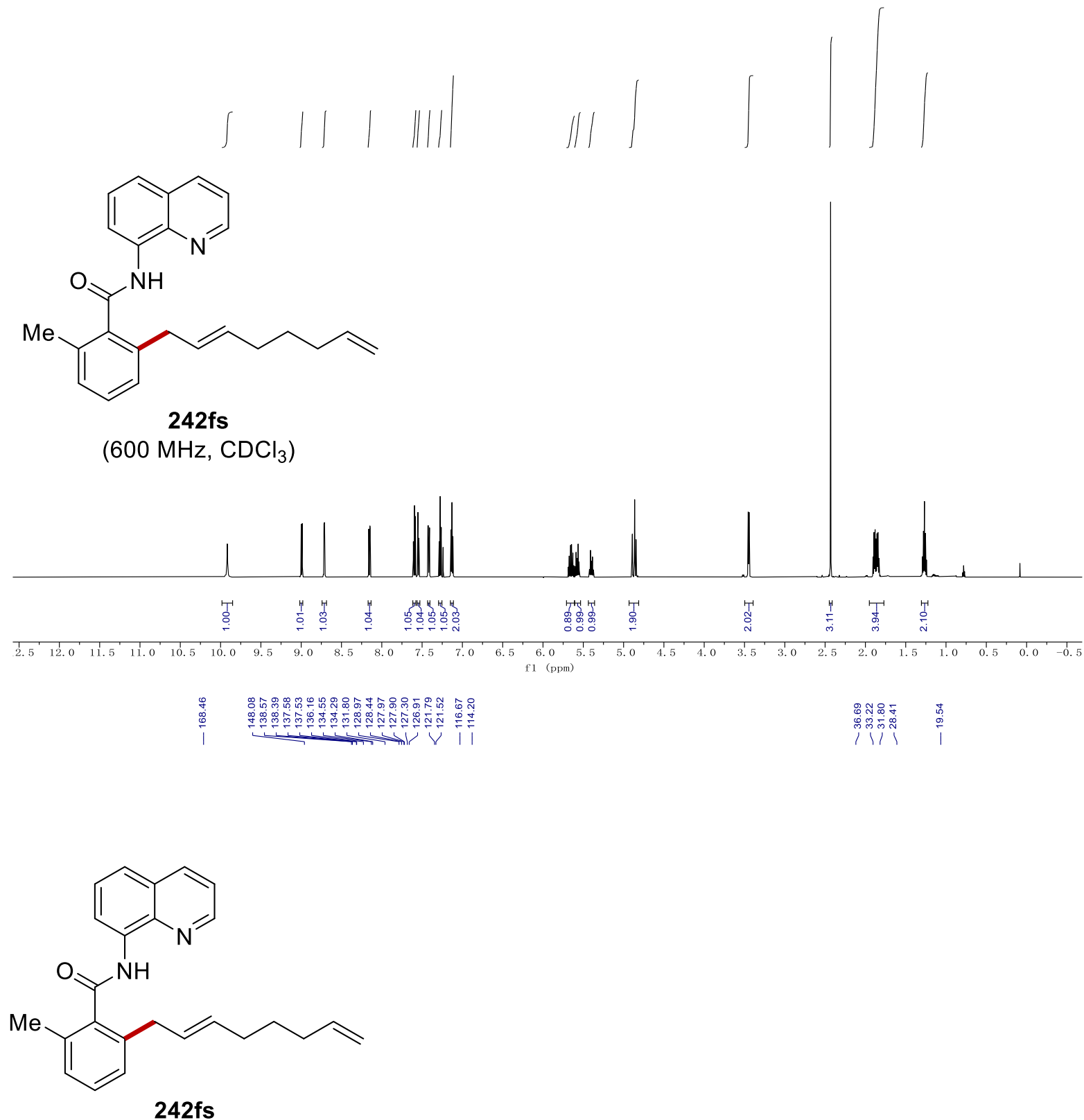

(125 MHz, $\mathrm{CDCl}_{3}$ )

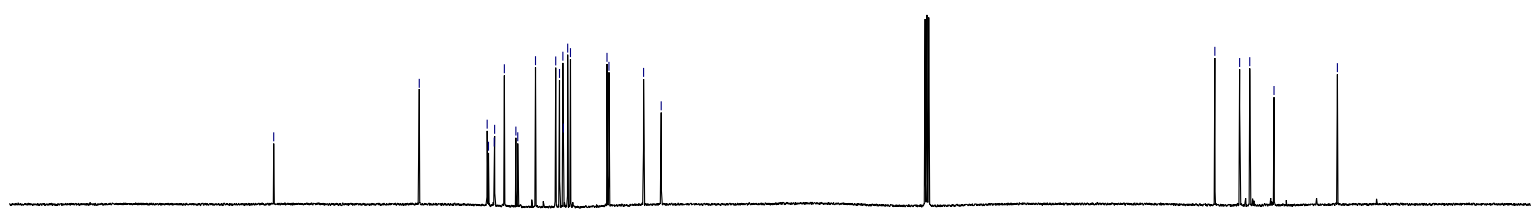



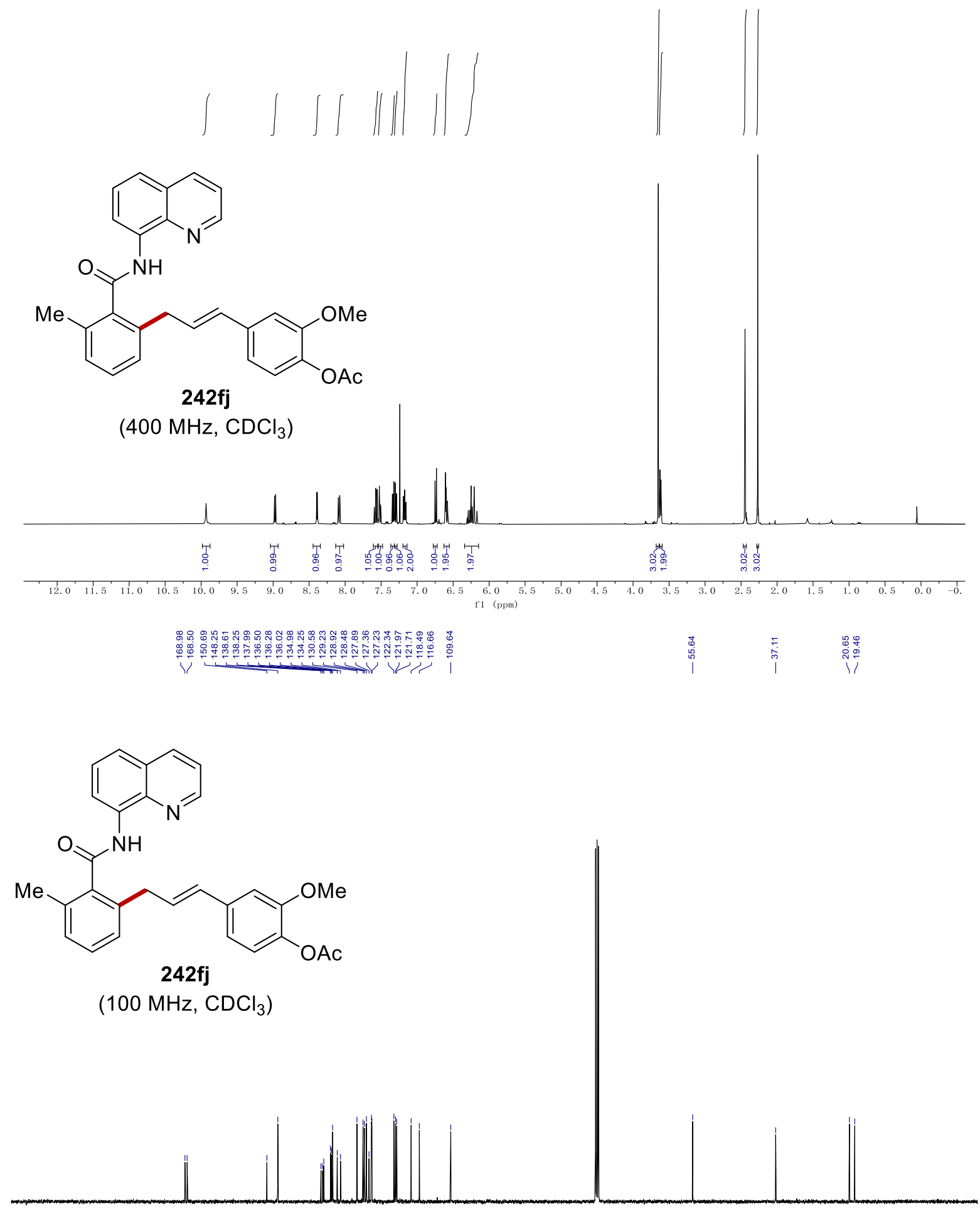

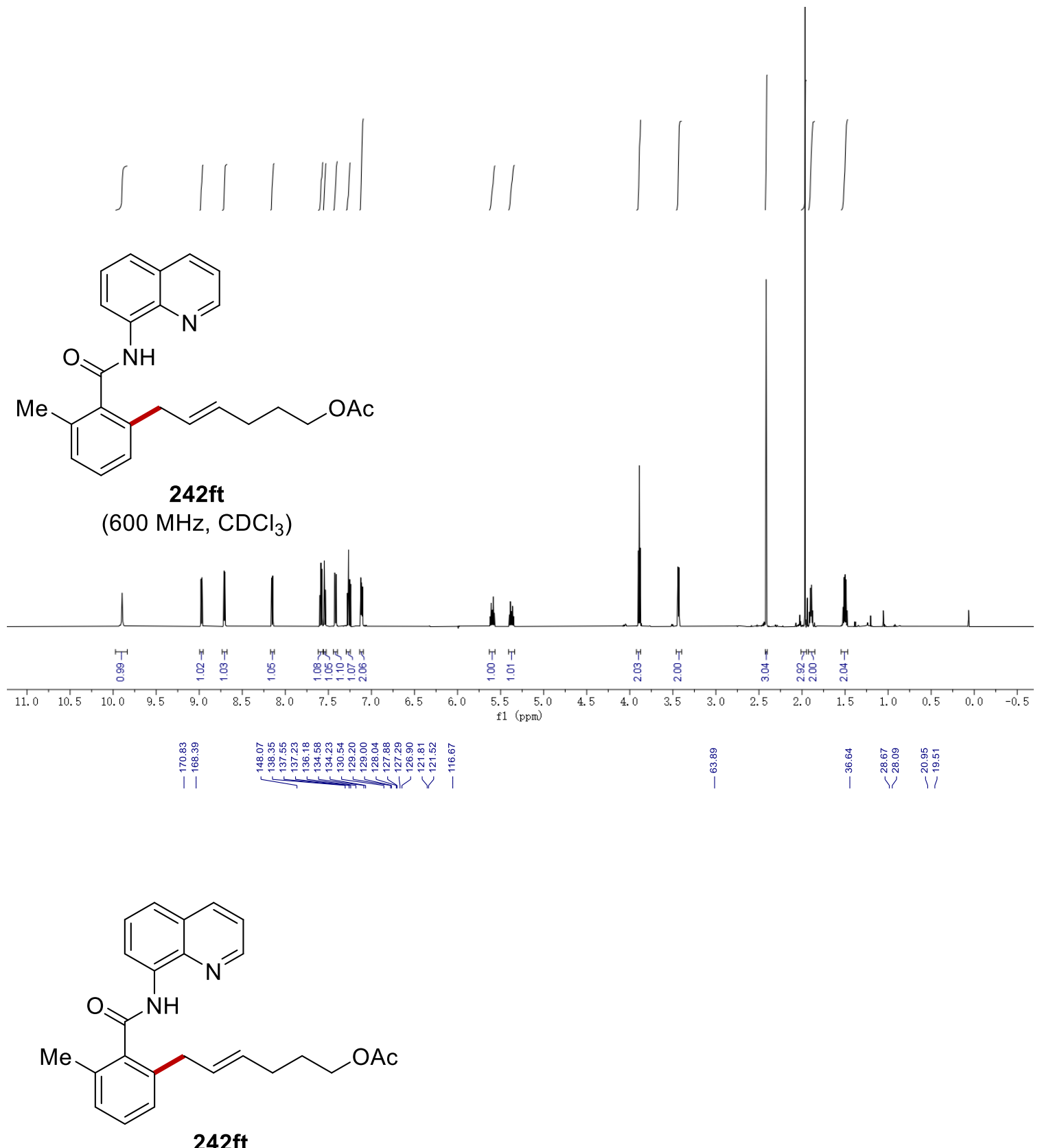

$\left(125 \mathrm{MHz}, \mathrm{CDCl}_{3}\right.$ )

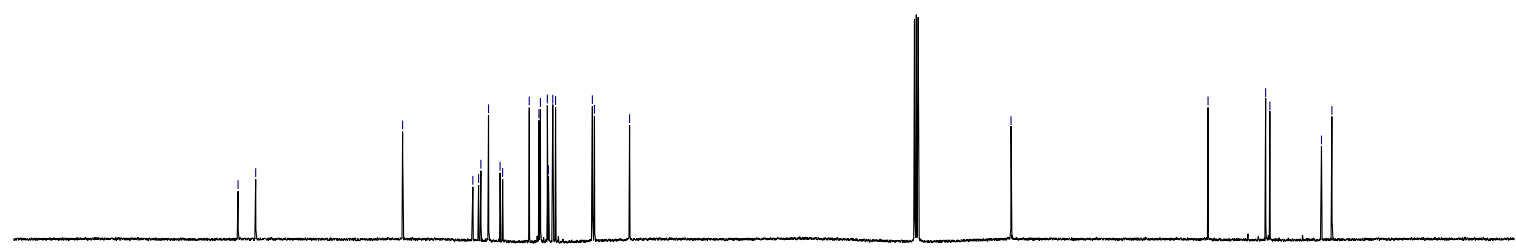

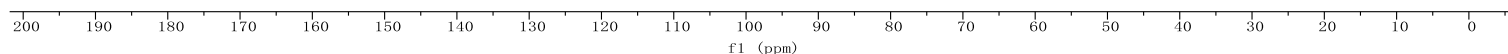



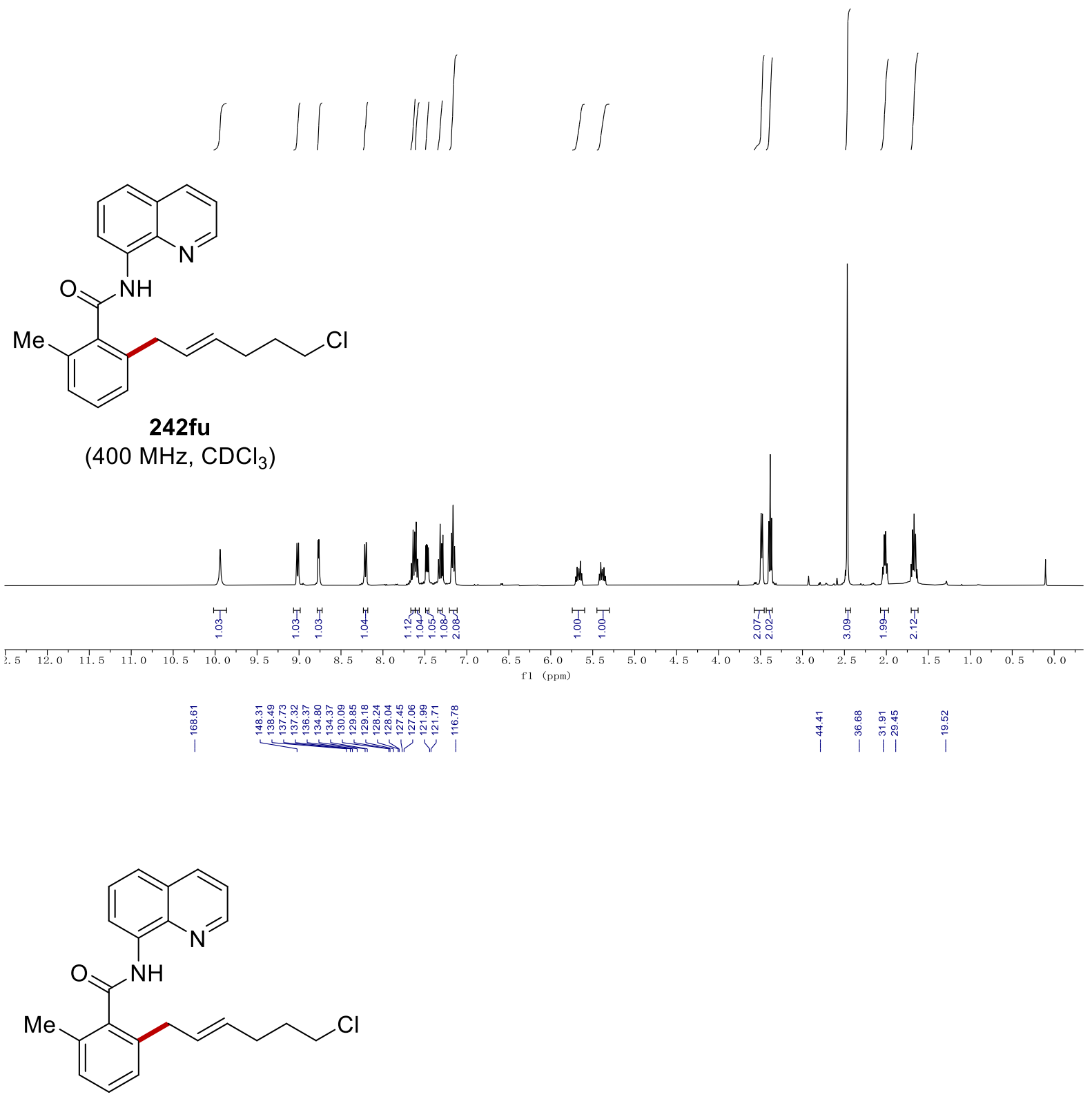

242fu

$\left(100 \mathrm{MHz}, \mathrm{CDCl}_{3}\right)$

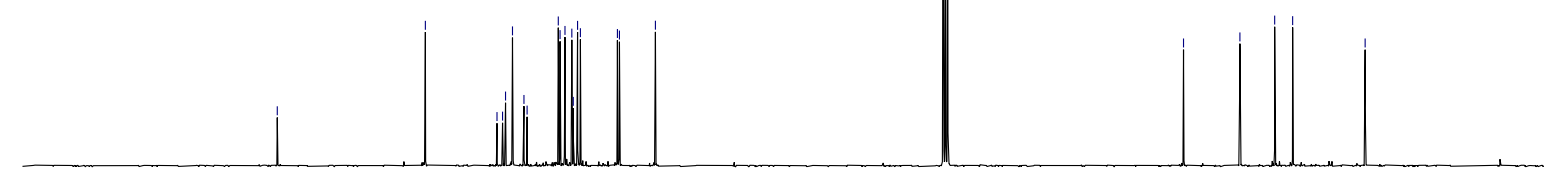

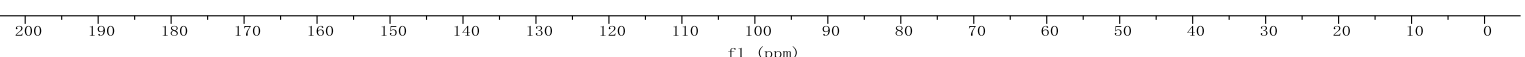



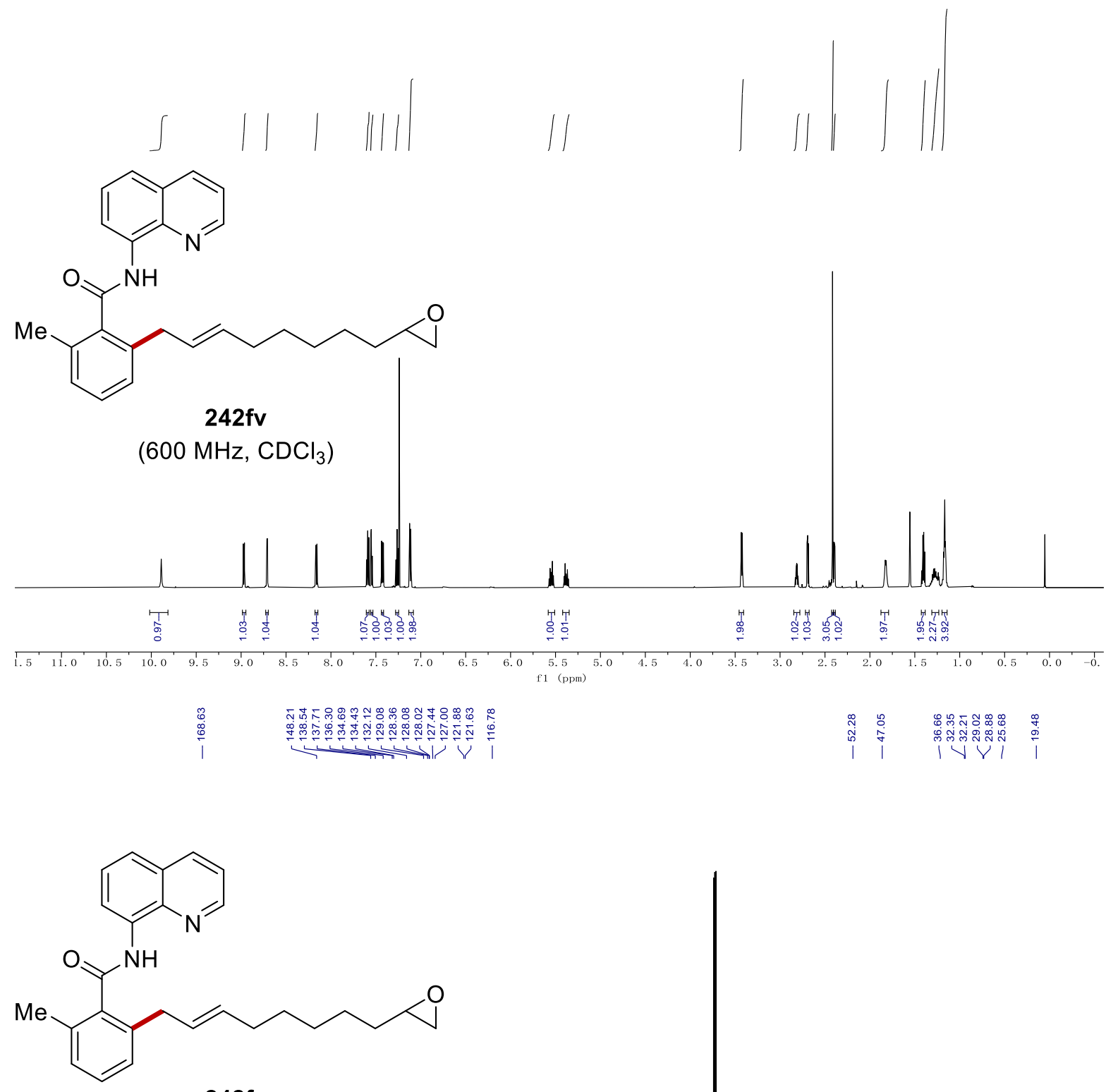

$242 \mathrm{fv}$

(150 MHz, $\mathrm{CDCl}_{3}$ )
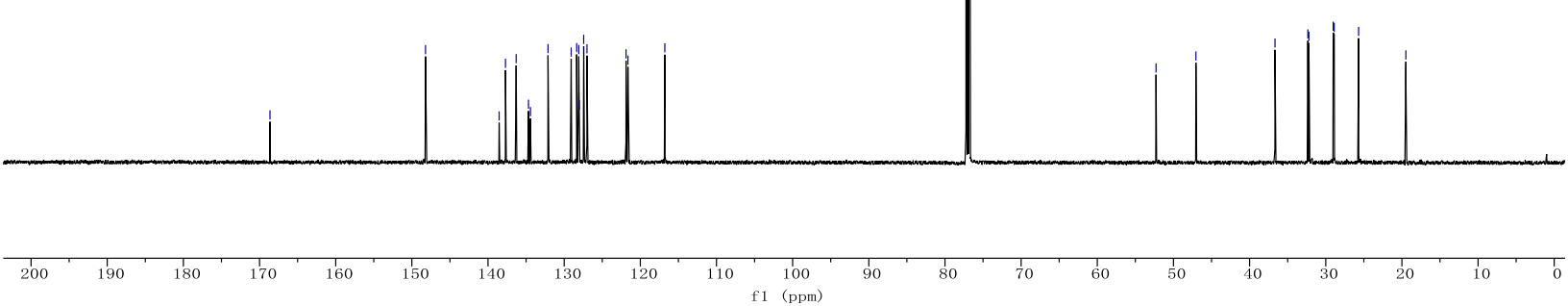

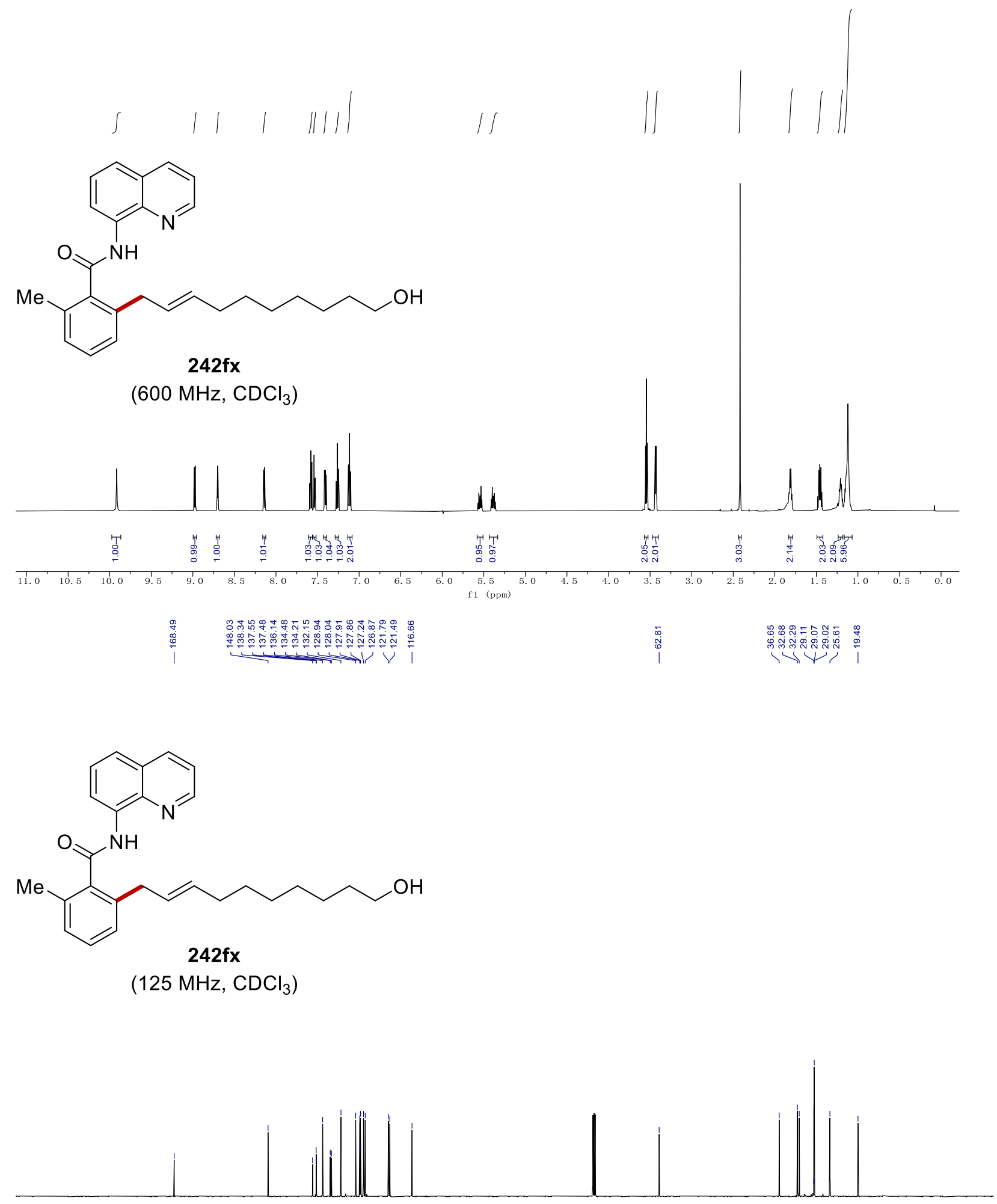


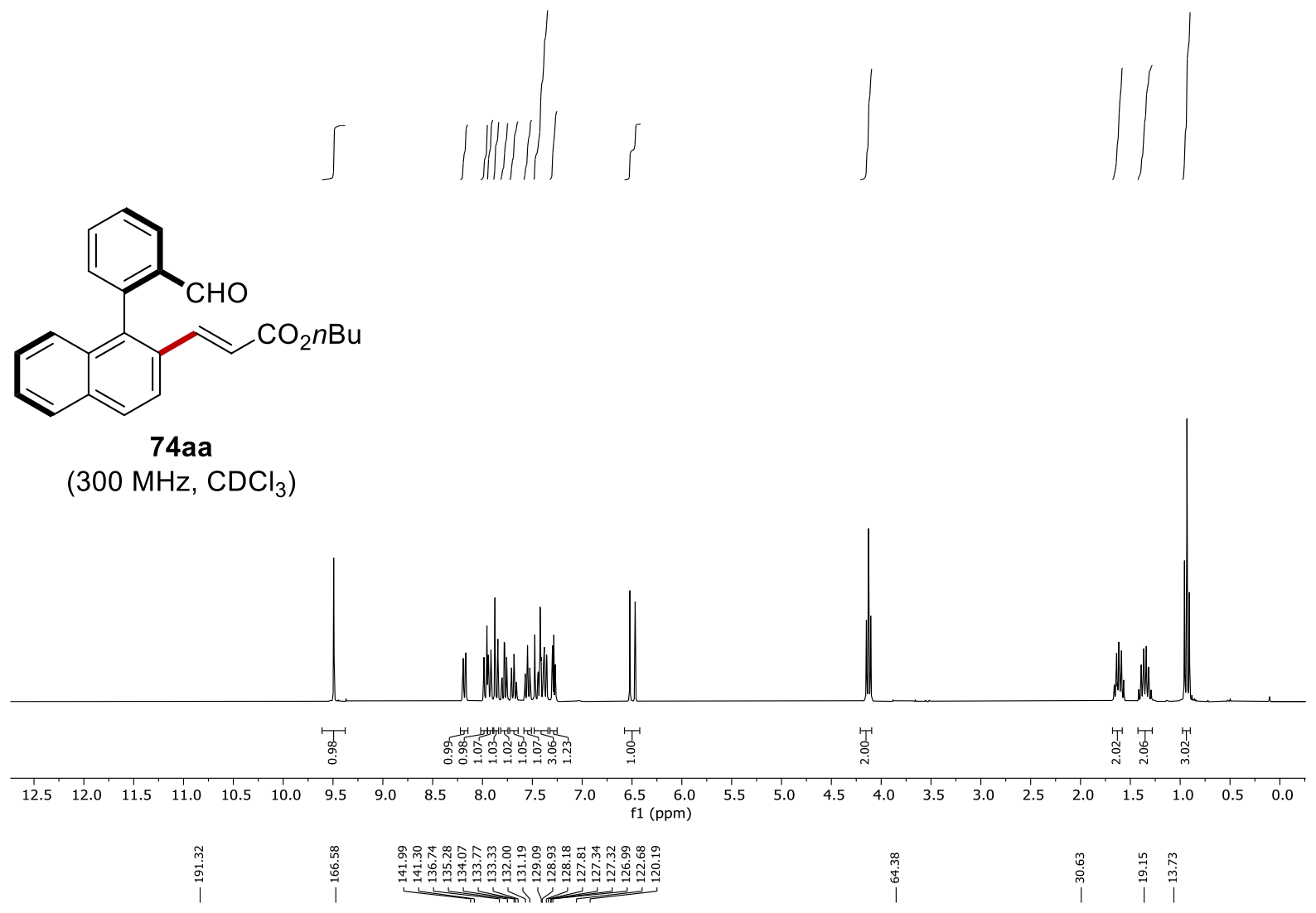<smiles>CCOC(=O)C=Cc1ccc2ccccc2c1-c1ccccc1C=O</smiles>

$74 a a$

$\left(\mathrm{CDCl}_{3}, 75 \mathrm{MHz}\right)$

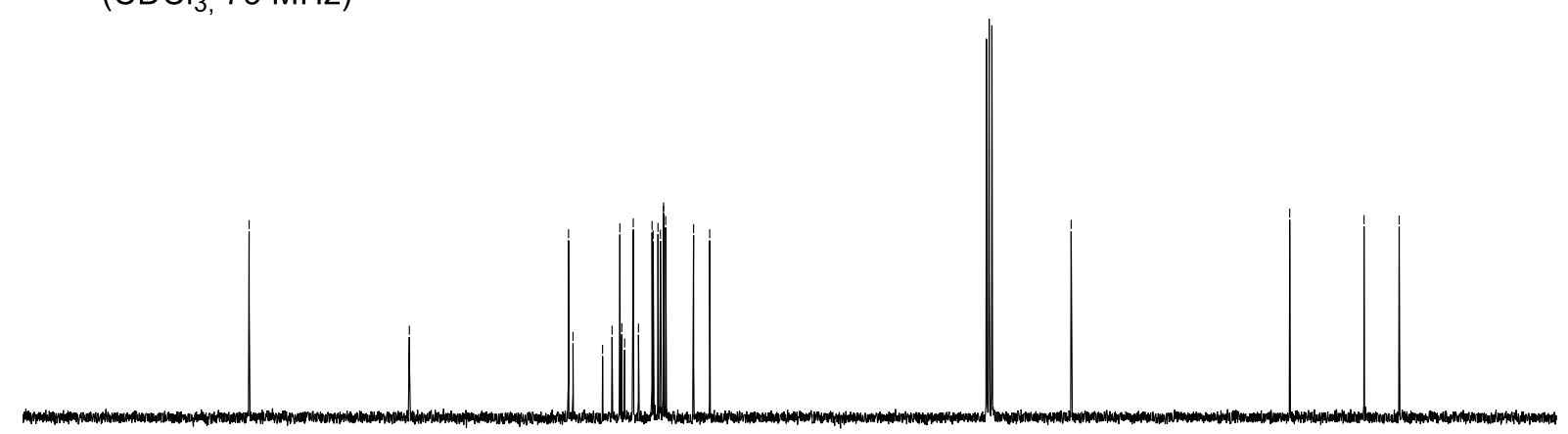

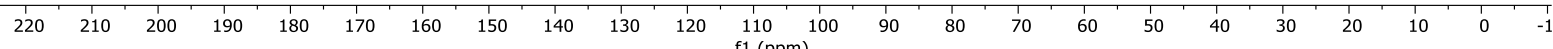


Chiral HPLC of 74aa:

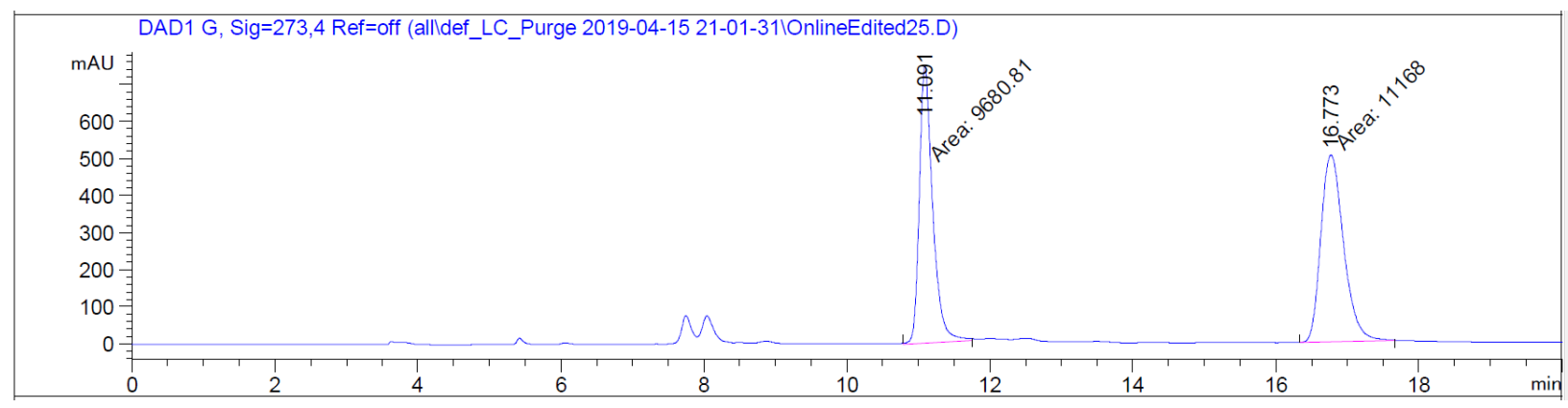

$\begin{array}{cccccc}\text { Peak } & \text { RetTime Type } & \text { Width } & \text { Area } & \text { Height } & \text { Area } \\ \# & {[\mathrm{~min}]} & {[\mathrm{min}]} & {\left[\mathrm{mAU} \mathrm{U}^{*} \mathrm{~s}\right]} & {[\mathrm{mAU}]} & \%\end{array}$

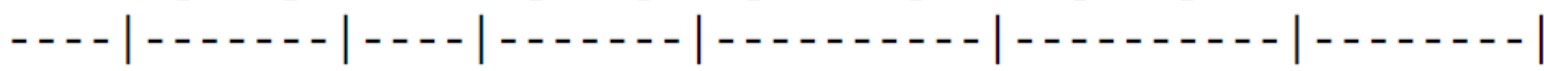

$1 \quad 11.091$ MM $\quad 0.21569680 .80762 \quad 748.30676 \quad 46.4335$

216.773 MM $0.36931 .11680 \mathrm{e} 4 \quad 503.97537 \quad 53.5665$

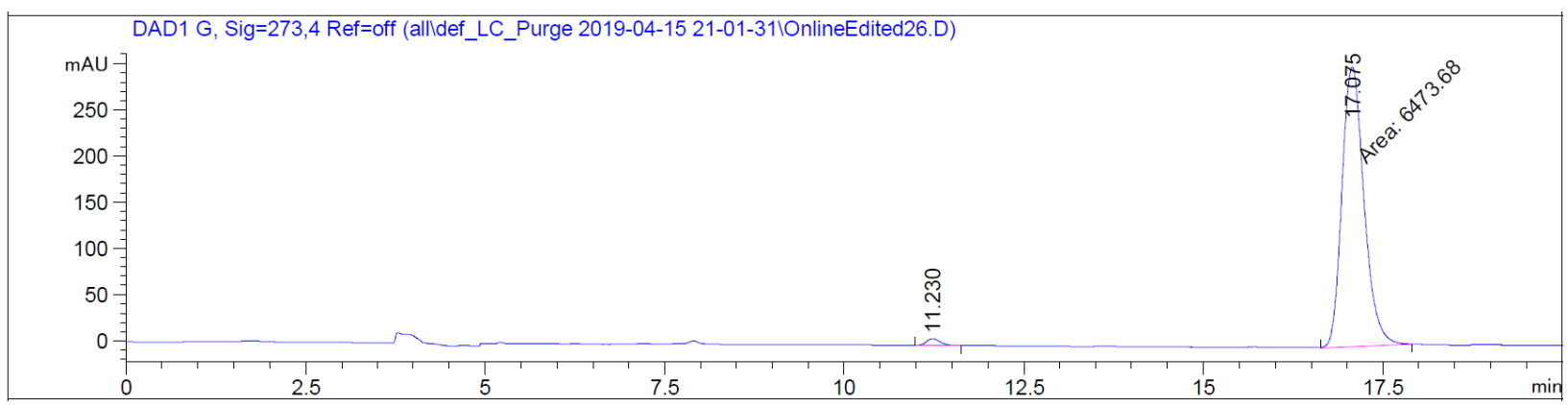

\begin{tabular}{|c|c|c|c|c|c|c|}
\hline $\begin{array}{l}\text { Peak } \\
\quad \#\end{array}$ & $\begin{array}{c}\text { RetTime } \\
\text { [min] }\end{array}$ & Type & $\begin{array}{l}\text { Width } \\
\text { [min] }\end{array}$ & $\begin{array}{c}\text { Area } \\
{\left[\mathrm{mAU}^{*} \mathrm{~s}\right]}\end{array}$ & $\begin{array}{l}\text { Height } \\
{[\mathrm{mAU}]}\end{array}$ & $\begin{array}{c}\text { Area } \\
\%\end{array}$ \\
\hline & & & & $-----{ }_{-1}$ & & \\
\hline 1 & & BB & 0.2030 & 97.61672 & 7.20635 & 855 \\
\hline & & MM & 0.3564 & 6473.67969 & 302.74637 & 5145 \\
\hline
\end{tabular}


<smiles>CCOC(=O)/C=C/c1cccc(C)c1-c1ccccc1C=O</smiles>

74ba

(400 MHz, $\mathrm{CDCl}_{3}$ )
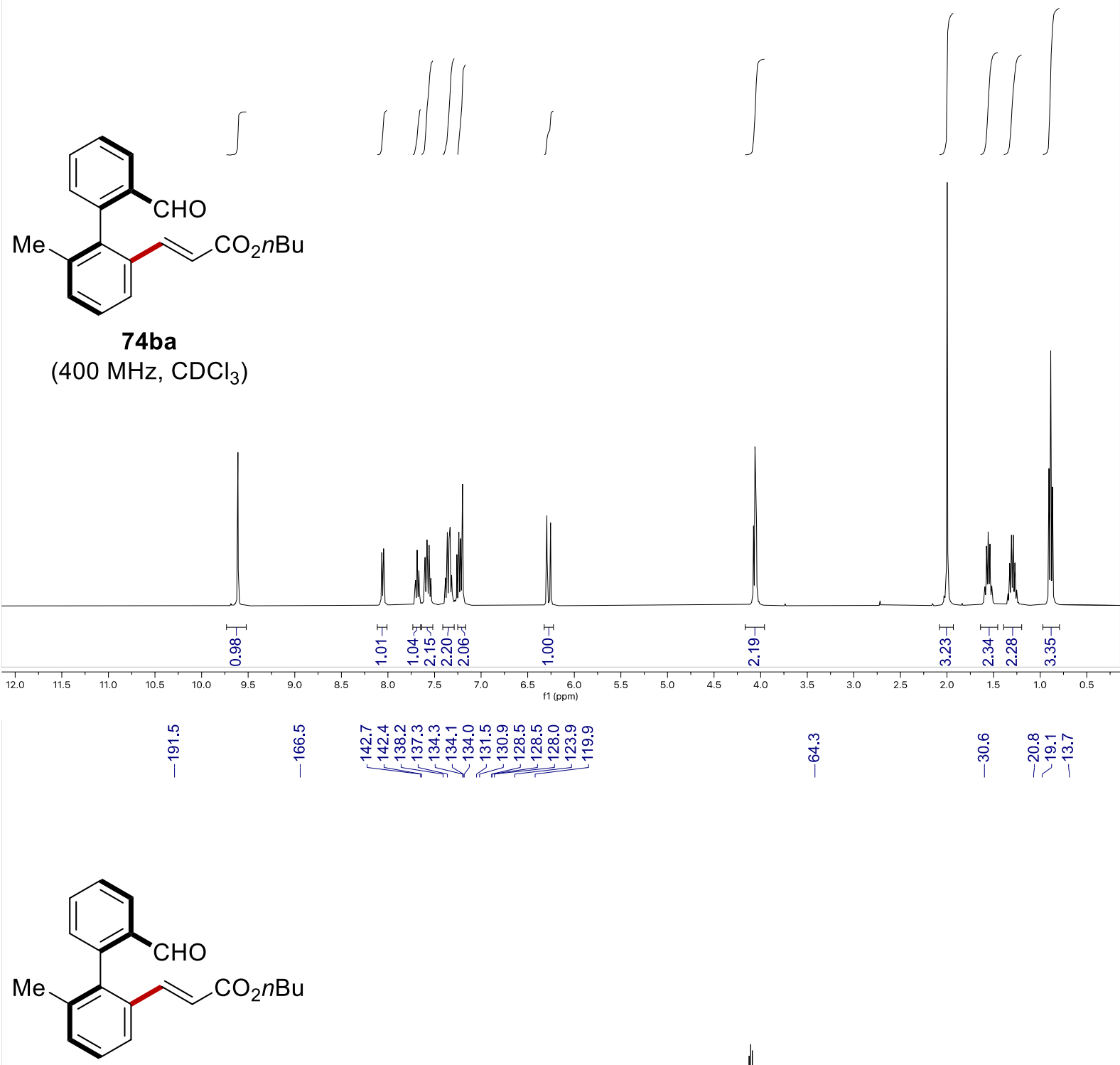

$74 \mathrm{ba}$

(100 MHz, $\mathrm{CDCl}_{3}$ )

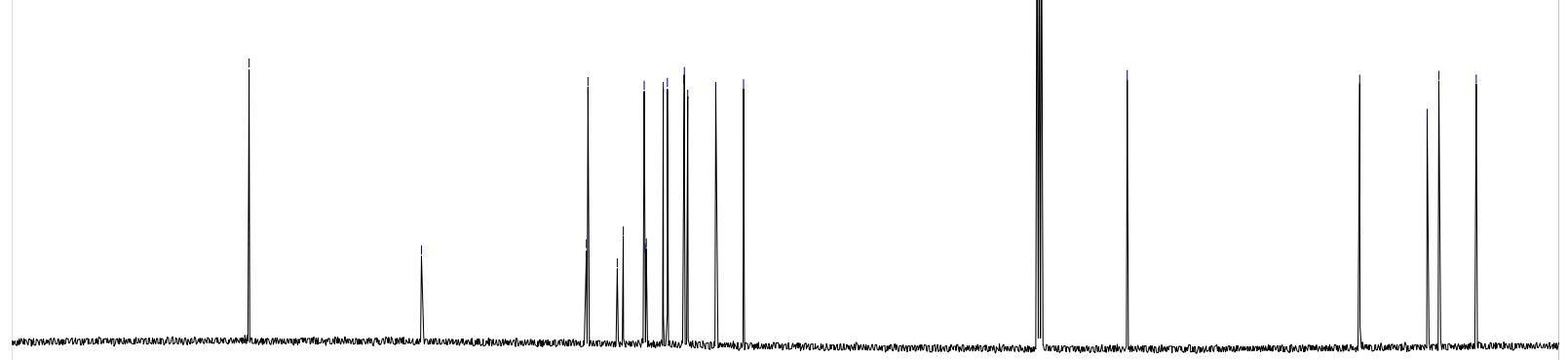


Chiral HPLC of 74ba:

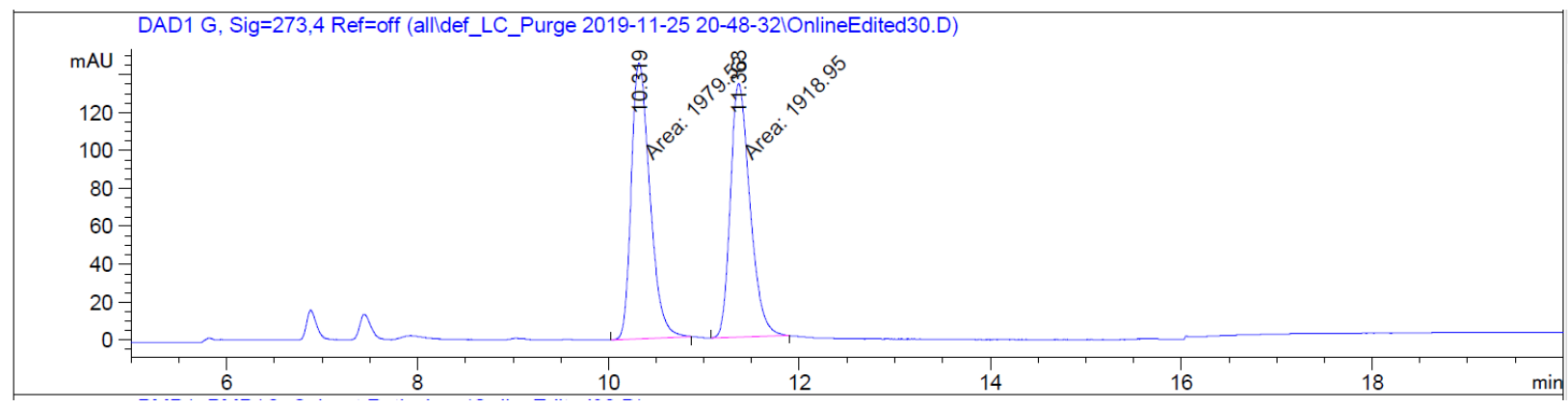

Peak RetTime Type width Area Height Area

$\begin{array}{ccccccc}\# & {[\mathrm{~min}]} & {[\mathrm{min}]} & {[\mathrm{mAU} * \mathrm{~s}]} & {[\mathrm{mAU}]} & \% \\ 1 & 10.319 \text { MM } & 0.2265 & 1979.53455 & 145.64331 & 50.7770 \\ 2 & 11.363 & \text { MM } & 0.2386 & 1918.94910 & 134.01500 & 49.2230\end{array}$

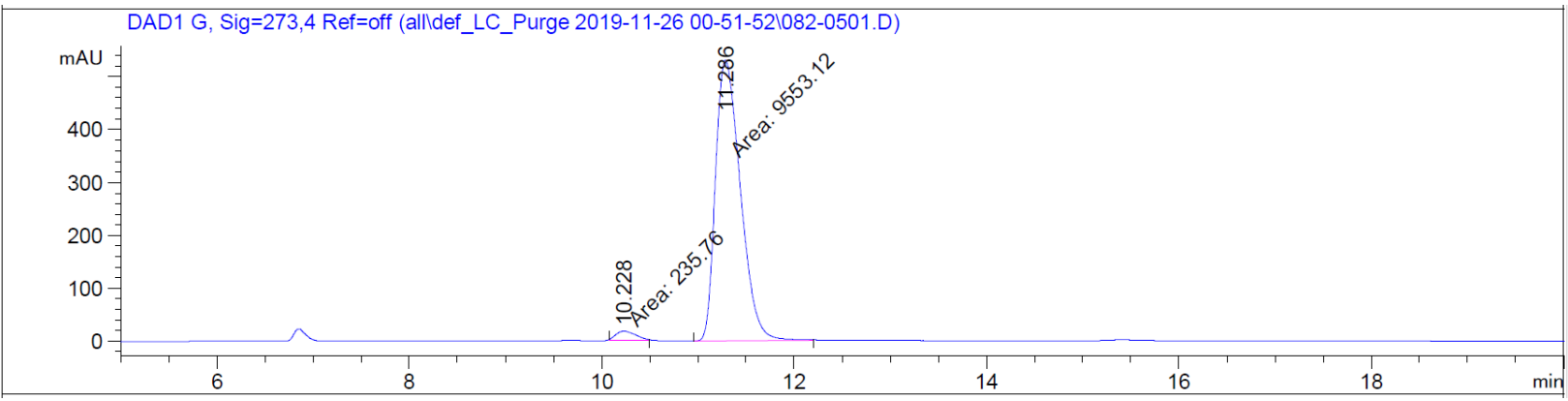

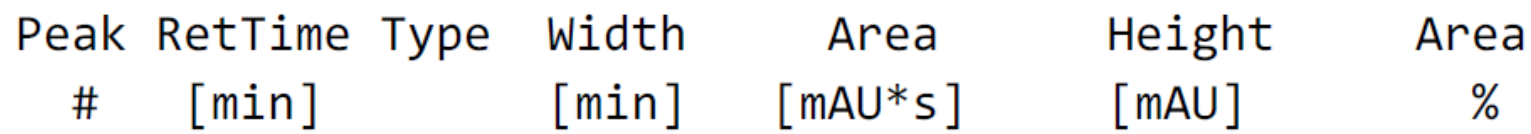

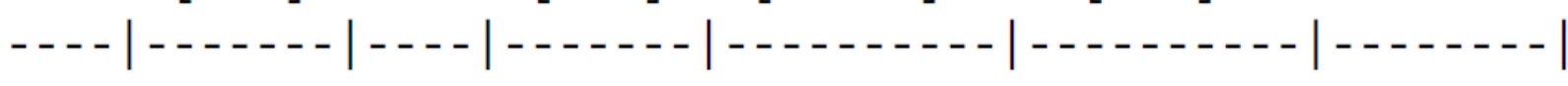

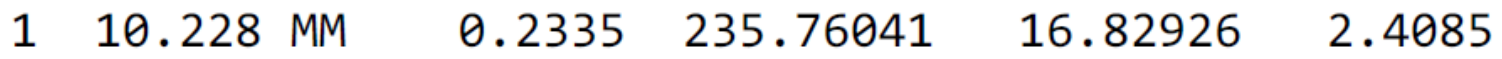

$2 \quad 11.286$ MM $\quad 0.2997 \quad 9553.11816 \quad 531.20819 \quad 97.5915$ 

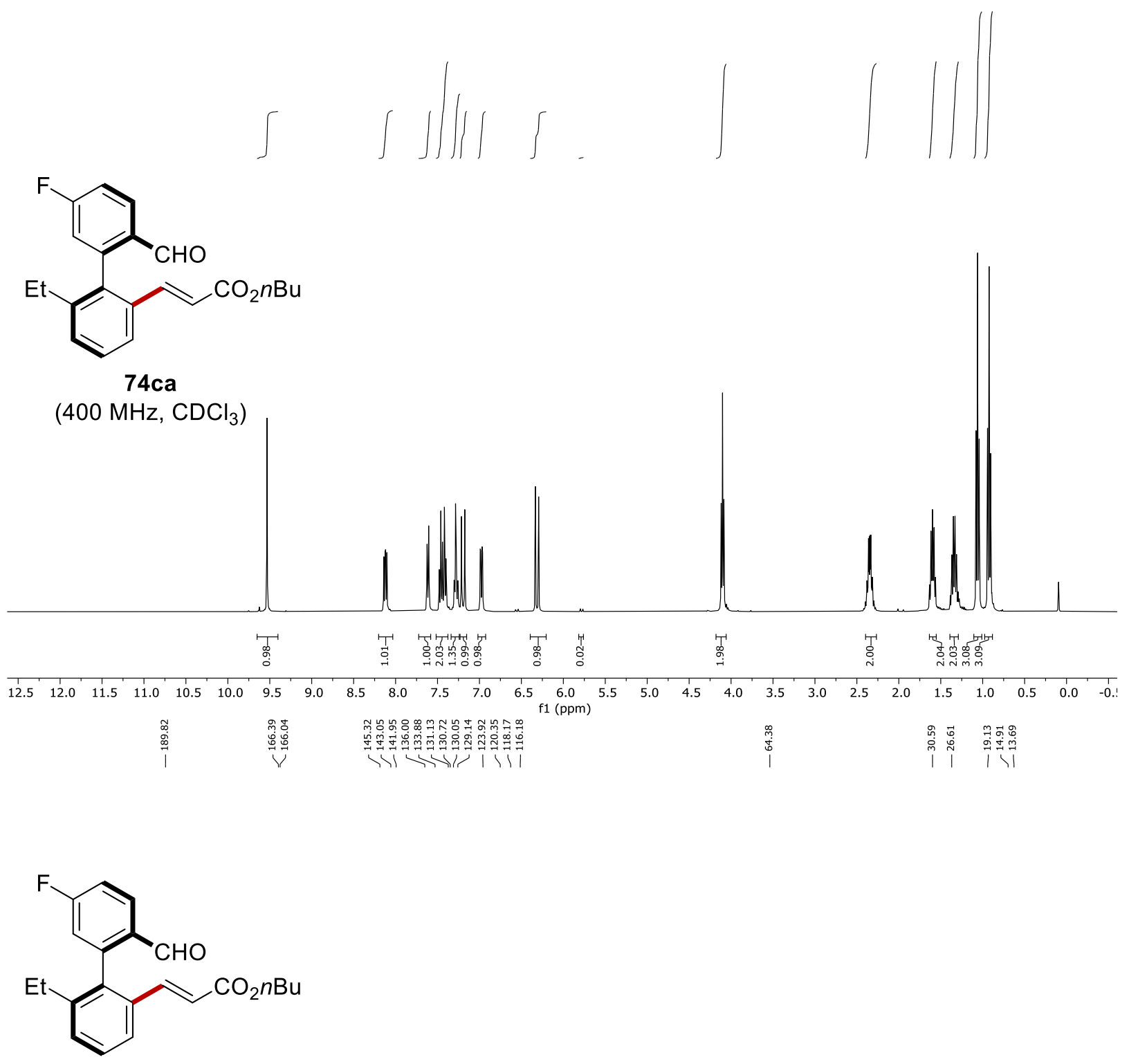

$74 \mathrm{ca}$

$\left(100 \mathrm{MHz}, \mathrm{CDCl}_{3}\right.$ )

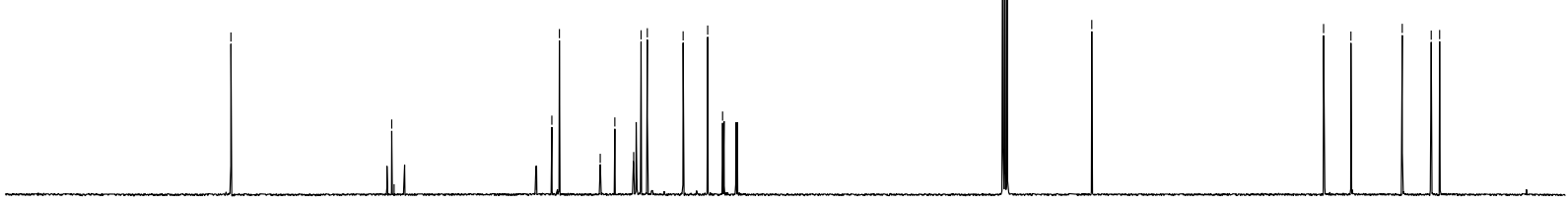

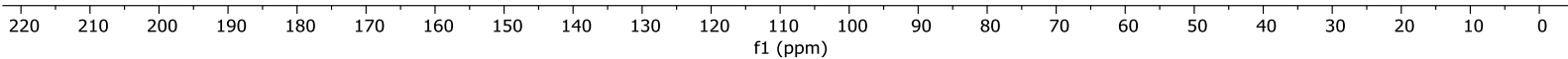




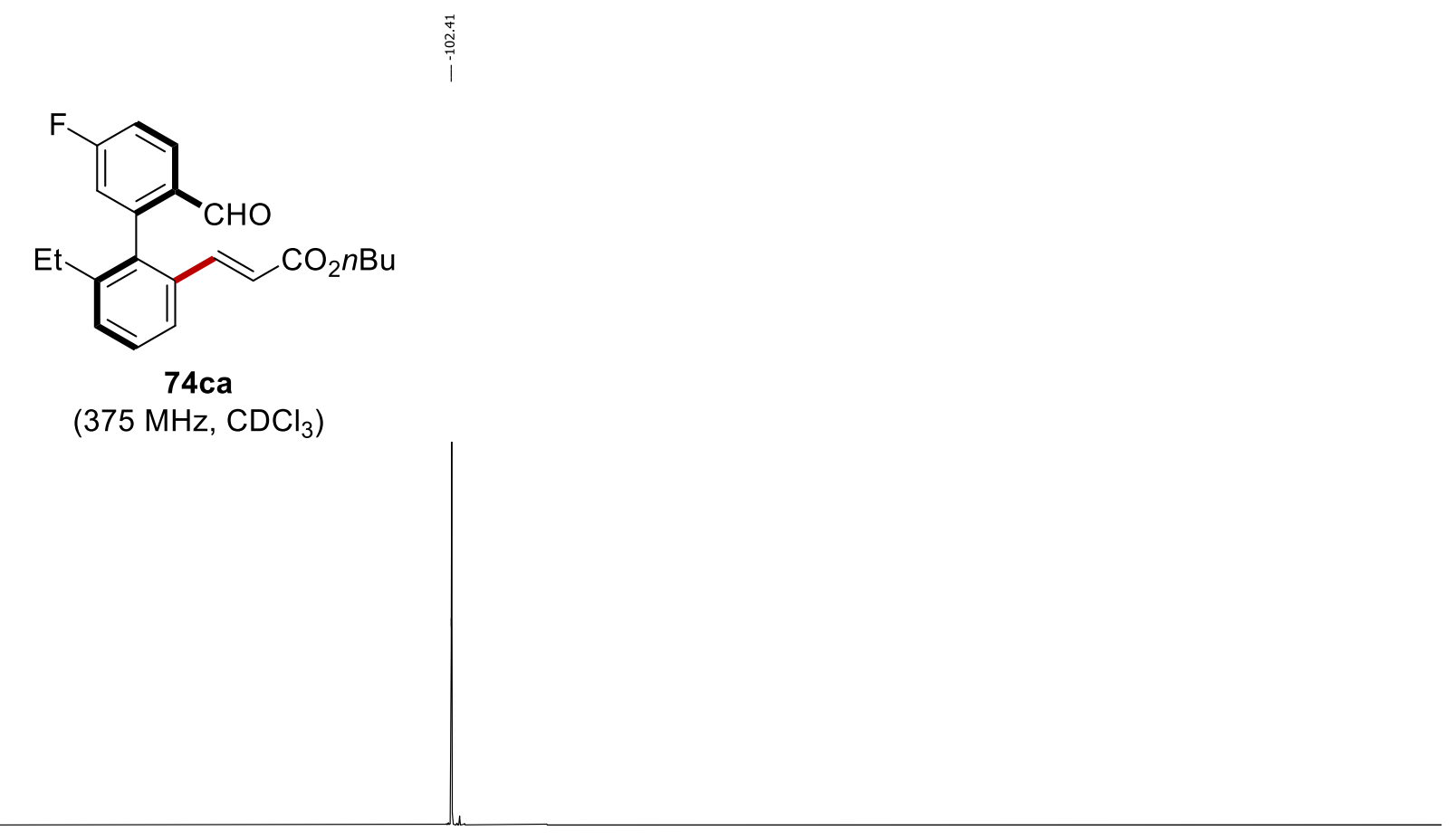

$\begin{array}{lllllllllllllllllllllllllllllllll}165 & -70 & -75 & -80 & -85 & -90 & -95 & -100 & -105 & -110 & -115 & -120 & -125 & -130 & -135 & -140 & -145 & -150 & -155 & -160 & -165 & -170 & -175 & -180\end{array}$ 
Chiral HPLC of 74ca:

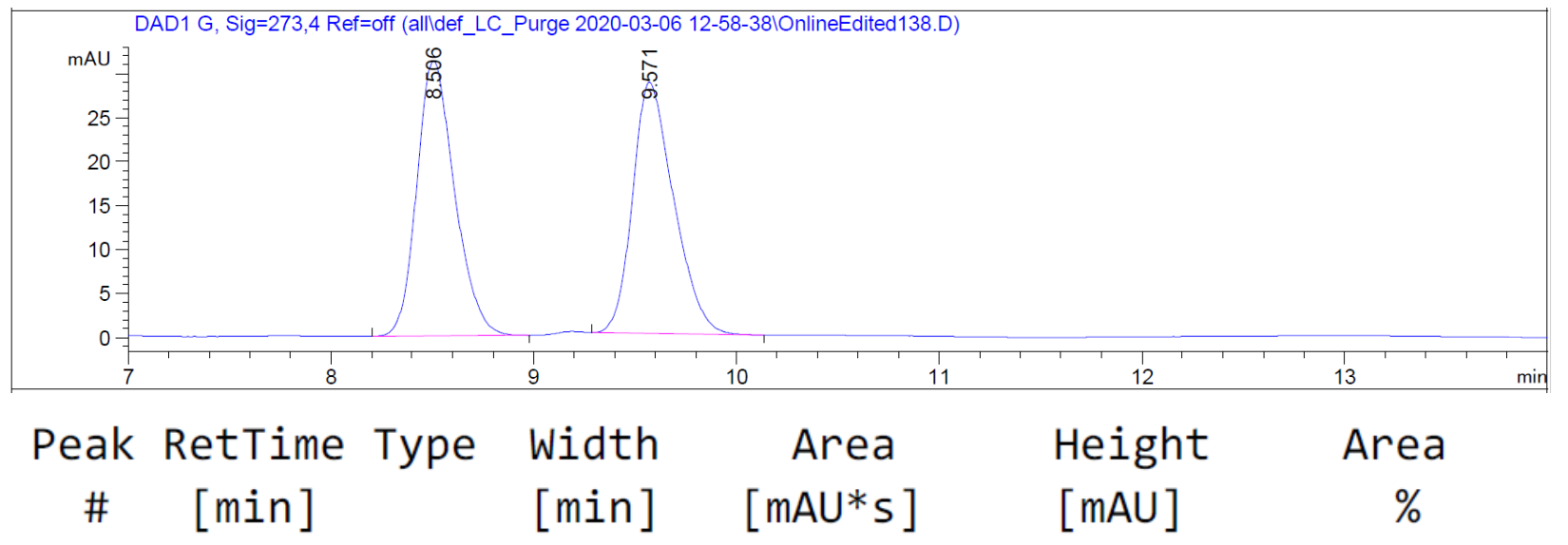

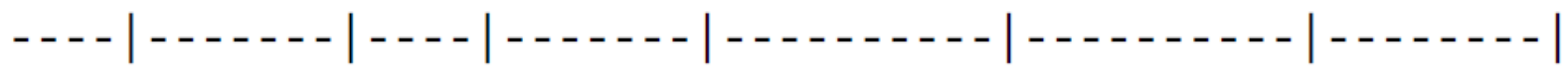
18.506 BB
0.1965406 .28516
$31.27957 \quad 50.1652$
29.571 BB
0.2089403 .60880
$28.56208 \quad 49.8348$

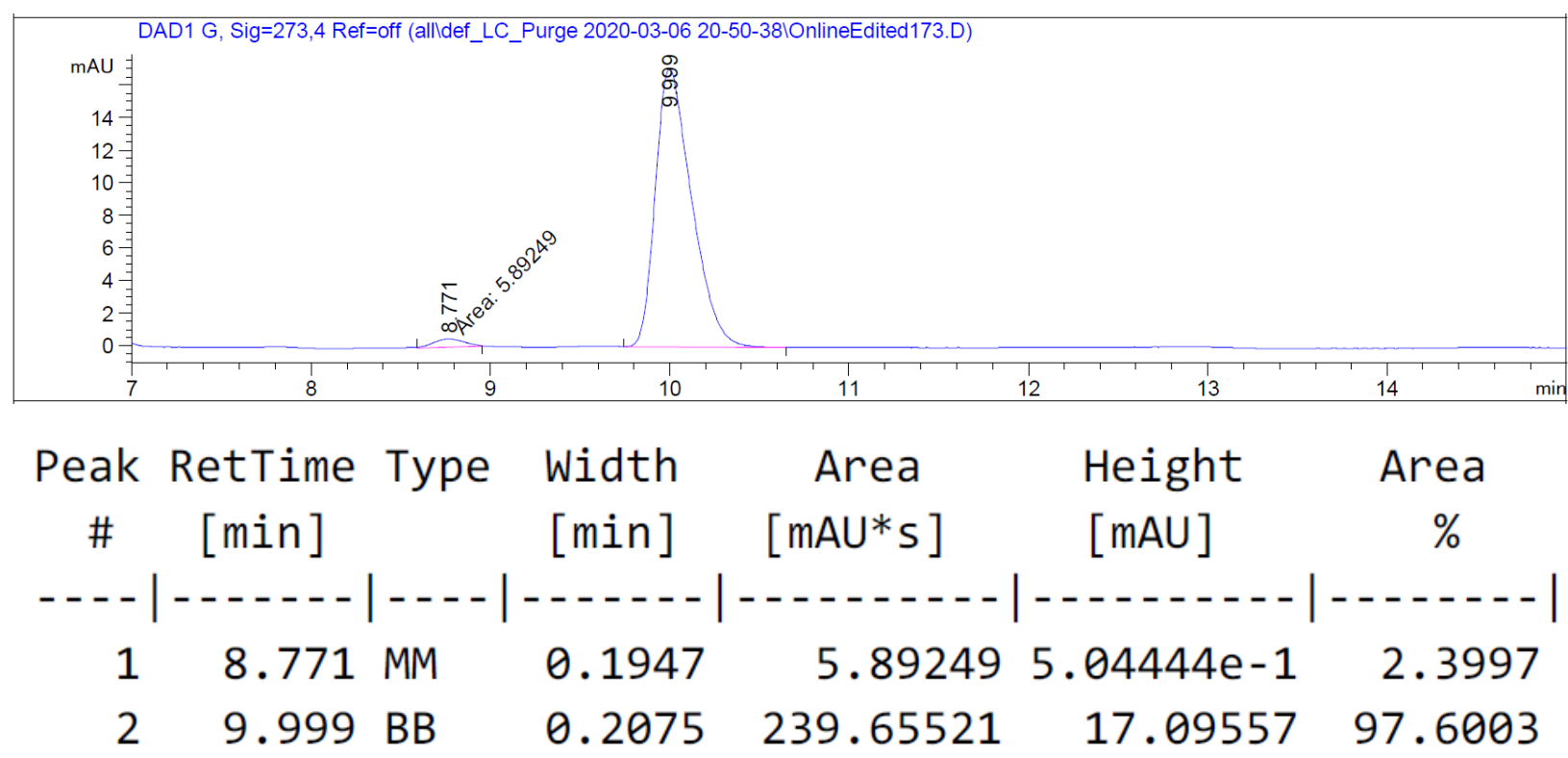


<smiles>CCCCOC(=O)/C=C/c1ccc2ccccc2c1-c1cc2c(cc1C=O)OCO2</smiles>

\section{4da}

$\left(400 \mathrm{MHz}, \mathrm{CDCl}_{3}\right)$

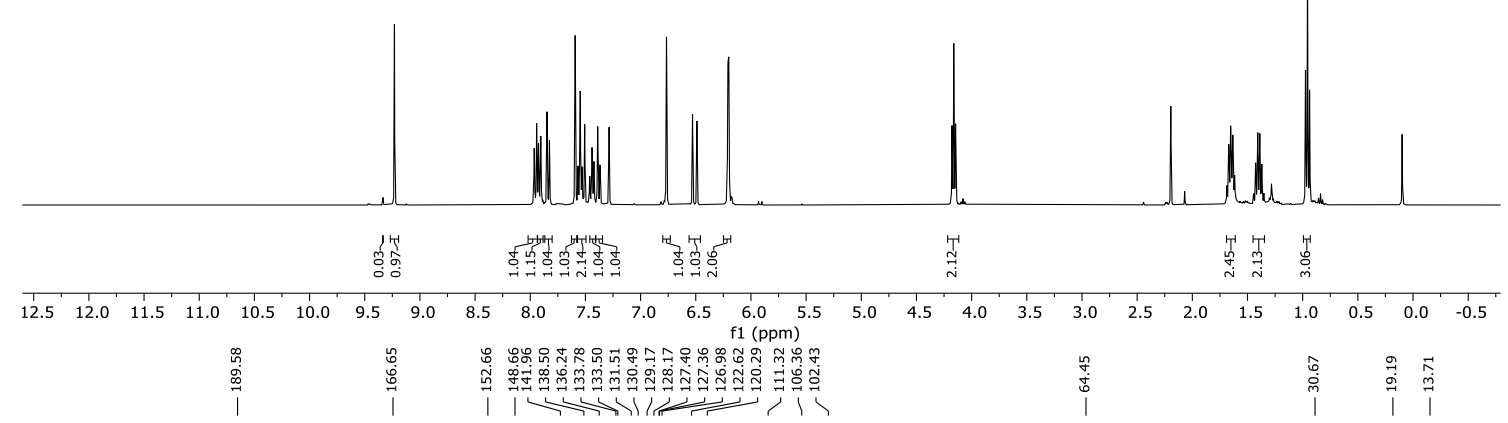<smiles>CCOCC=Cc1ccc2ccccc2c1-c1cc2c(cc1C=O)OCO2</smiles>

\section{4da}

(100 MHz, $\mathrm{CDCl}_{3}$ )

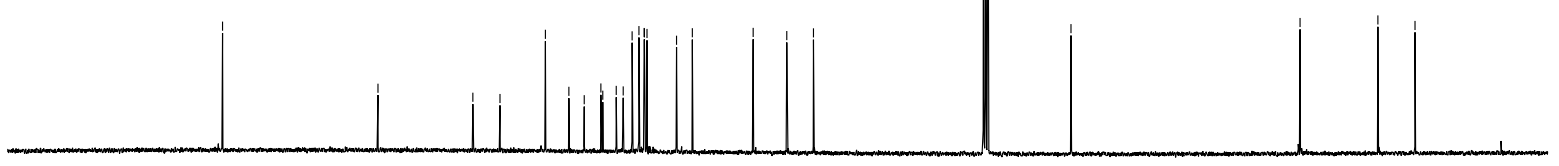

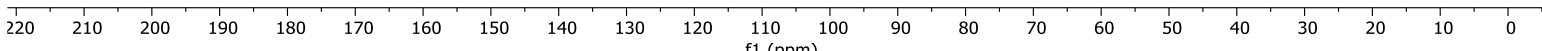


Chiral HPLC of 74da:

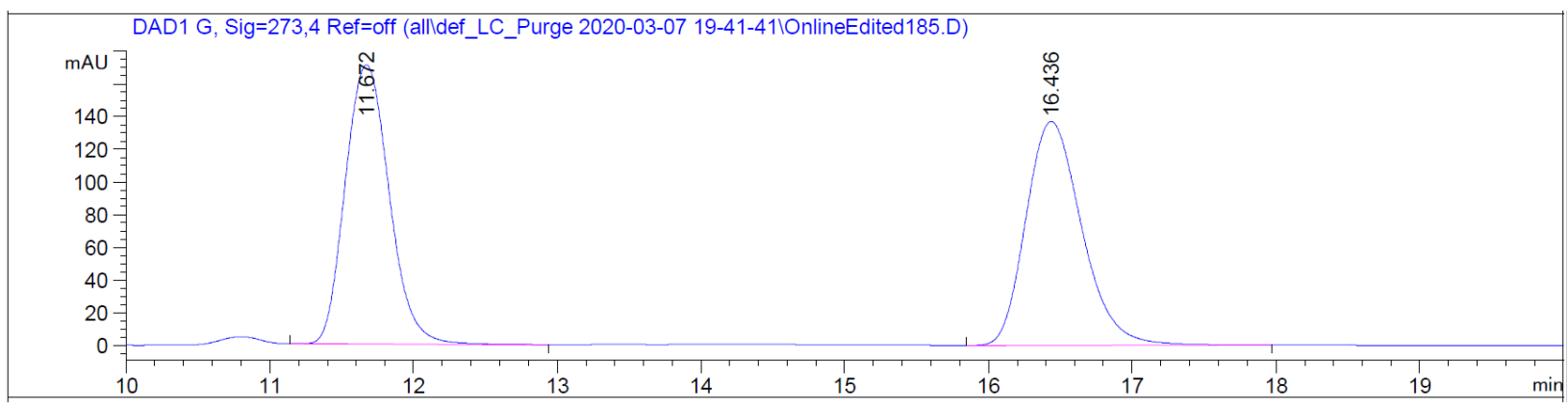

Peak RetTime Type Width Area Height Area

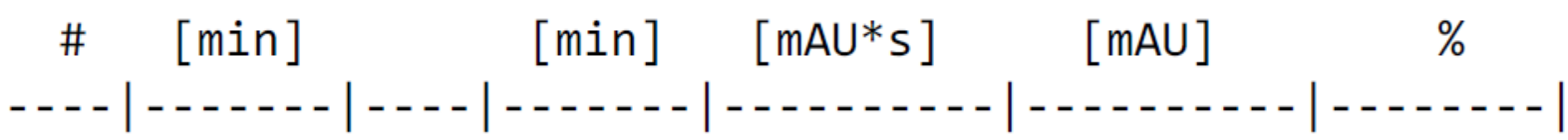
$111.672 \mathrm{BB}$
$0.33813626 .50928 \quad 170.54077 \quad 49.5712$
$216.436 \mathrm{BB}$
$0.41863689 .25098 \quad 136.81537 \quad 50.4288$

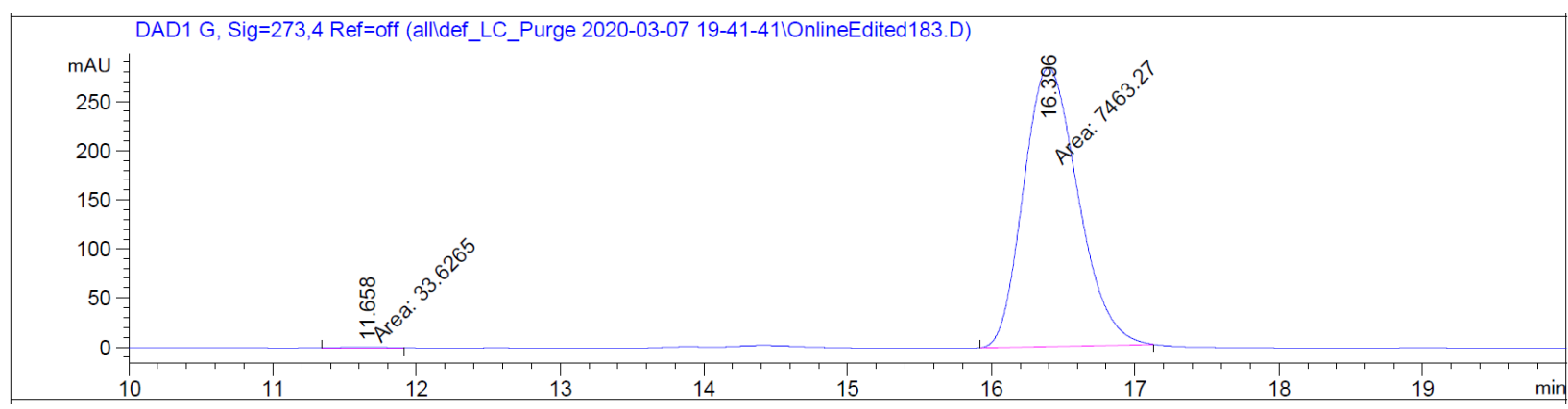

Peak RetTime Type Width Area Height Area

\# $[\mathrm{min}] \quad[\mathrm{min}] \quad[\mathrm{mAU} * \mathrm{~s}] \quad[\mathrm{mAU}] \quad \%$

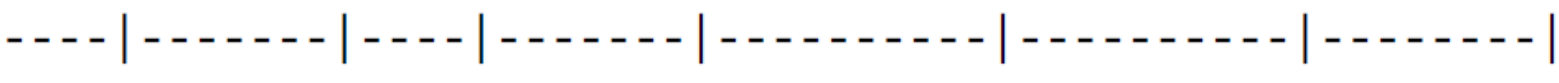

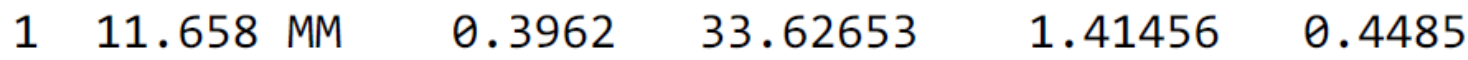

$2 \quad 16.396$ MM $\quad 0.43907463 .27295 \quad 283.31967 \quad 99.5515$ 

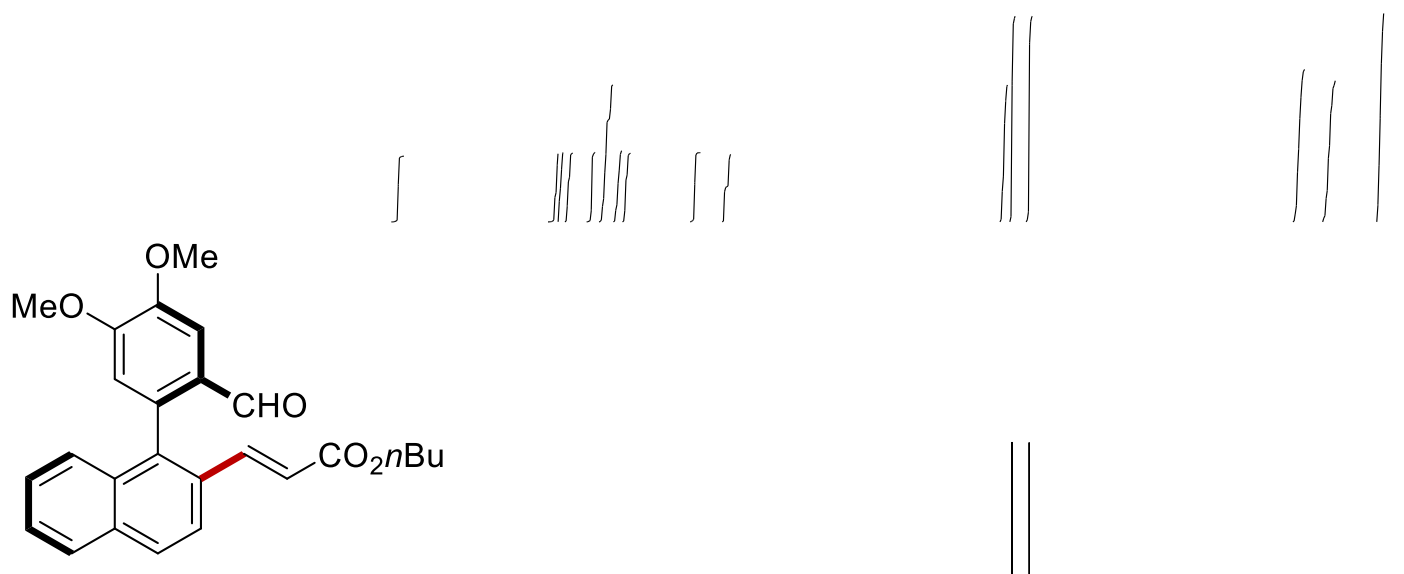

74ea

(400 MHz, $\mathrm{CDCl}_{3}$ )
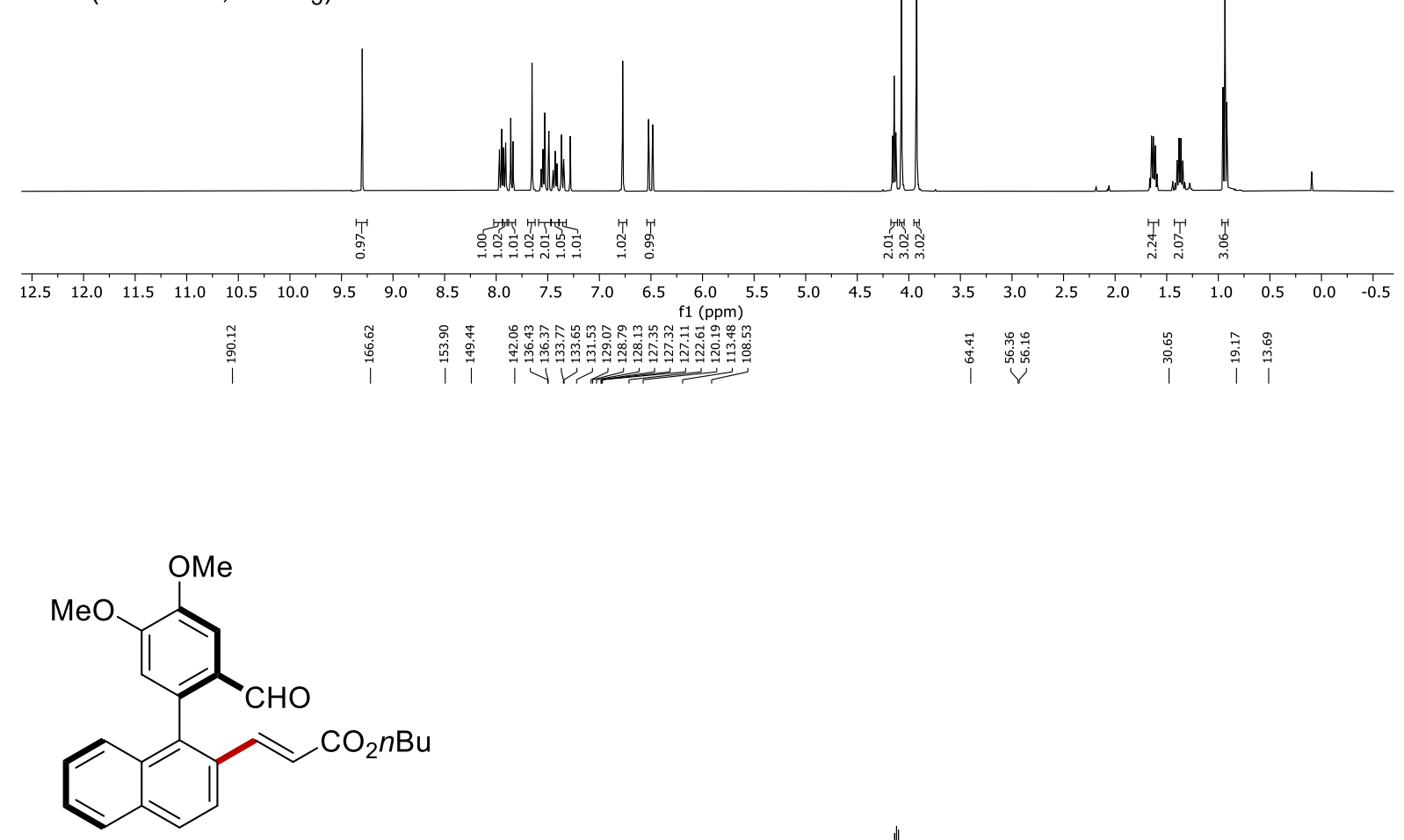

74ea

$\left(100 \mathrm{MHz}, \mathrm{CDCl}_{3}\right)$

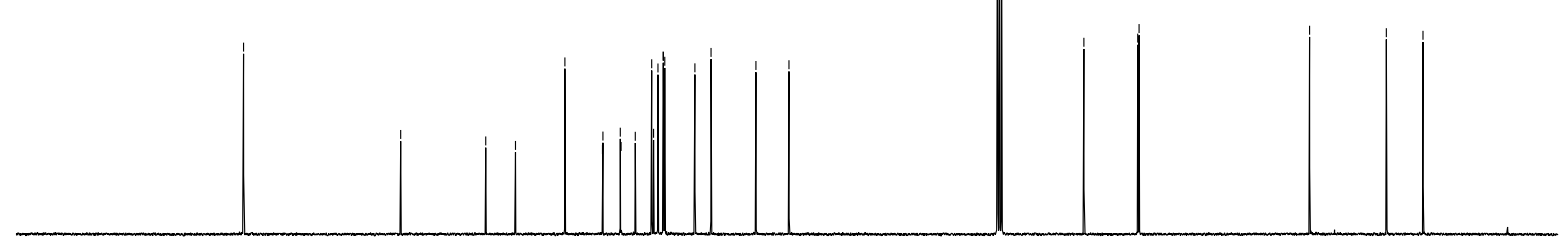

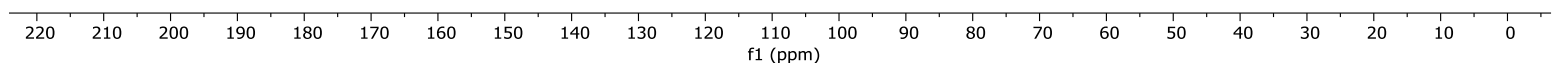


Chiral HPLC of 74ea:

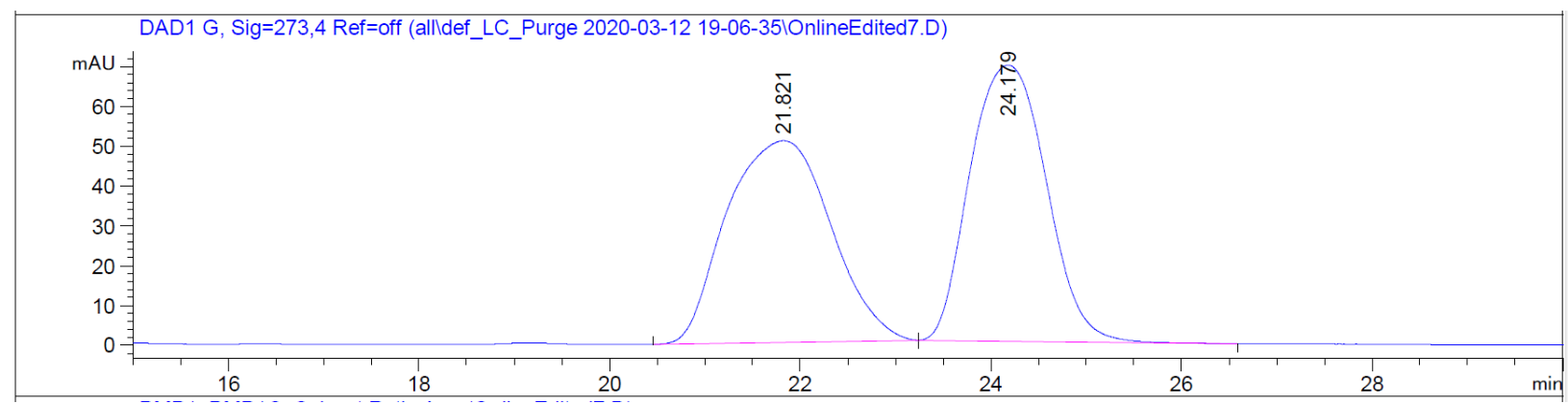

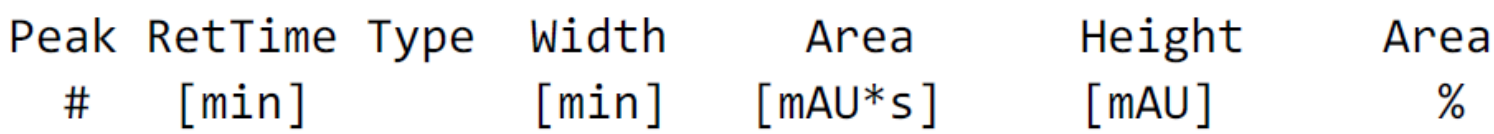

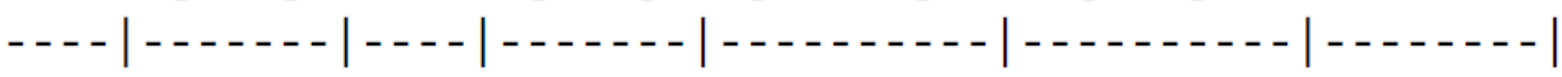
$121.821 \mathrm{BB}$
$0.9015 \quad 3842.27759 \quad 50.67846 \quad 49.8727$

224.179 BB

$\begin{array}{llll}0.8866 & 3861.89331 & 69.36345 \quad 50.1273\end{array}$

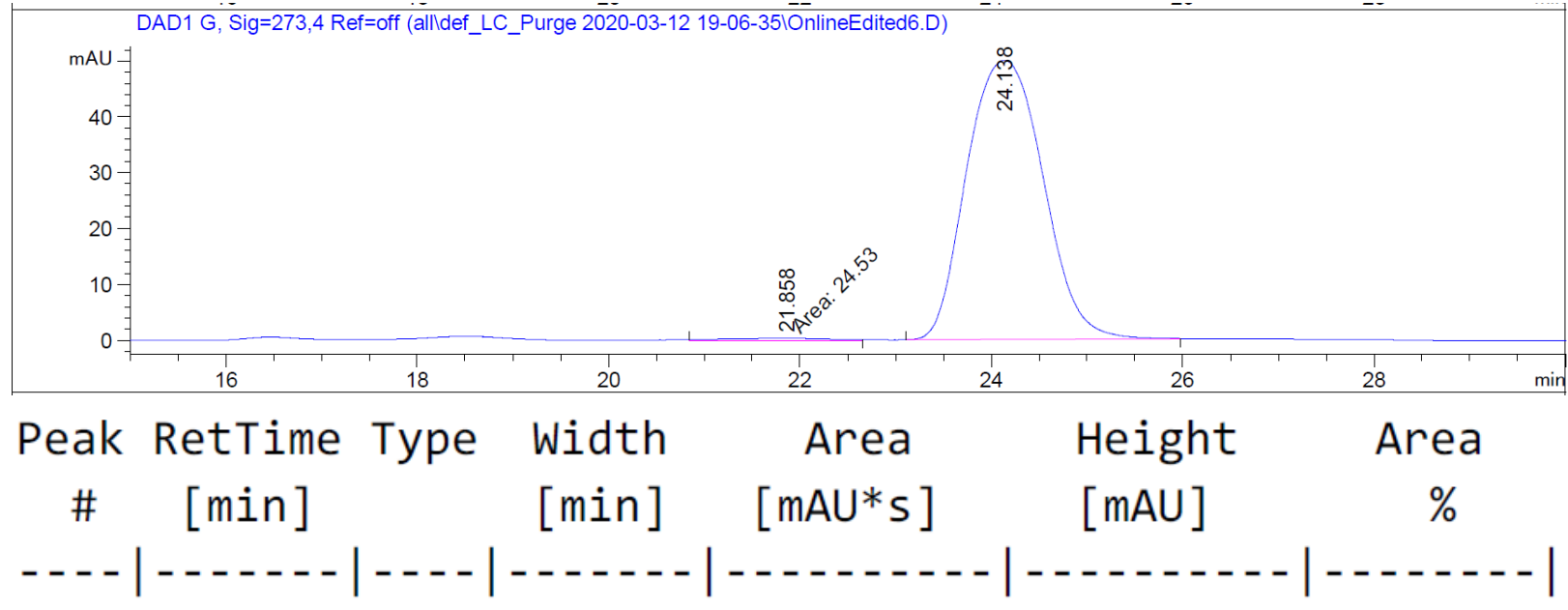

121.858 MM $1.1642 \quad 24.52998 \quad 3.51185 \mathrm{e}-1 \quad 0.8768$

$2 \quad 24.138$ BB $\quad 0.7732 \quad 2773.18164 \quad 49.9931199 .1232$ 
<smiles>CCOC(=O)/C=C/c1ccc2ccccc2c1-c1ccc(C(F)(F)F)cc1C=O</smiles>

$74 f a$

(400 MHz, $\mathrm{CDCl}_{3}$ )

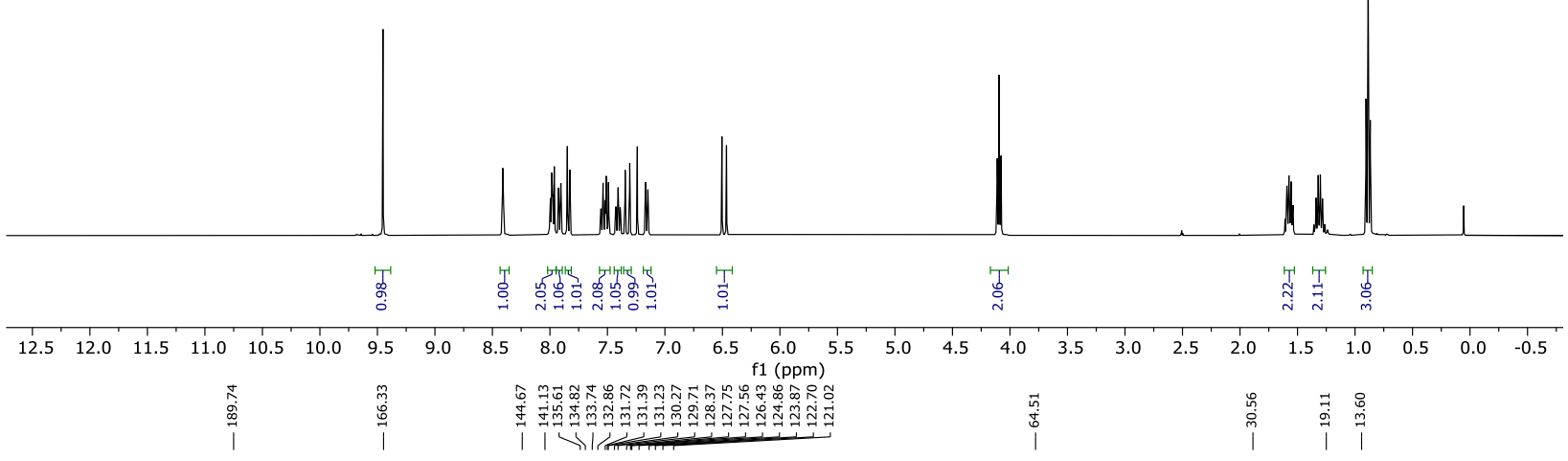<smiles>CCCOC(=O)/C=C/c1ccc2ccccc2c1-c1ccc(C(F)(F)F)cc1C=O</smiles>

$74 f a$

(100 MHz, $\mathrm{CDCl}_{3}$ )

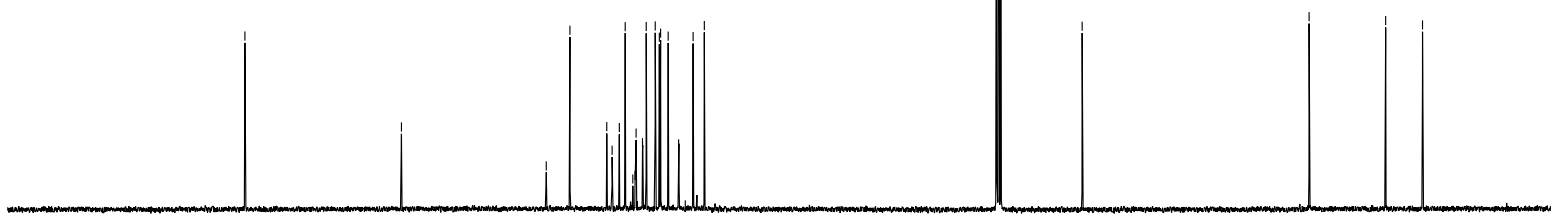

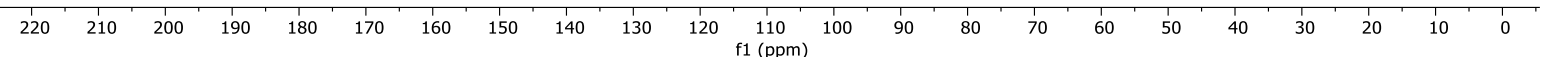




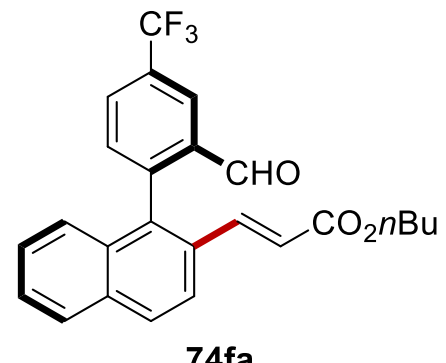

(375 MHz, $\mathrm{CDCl}_{3}$ )

\begin{tabular}{llllllllllllllllllllllllllllllllllllllllllll}
\hline-5 & -10 & -15 & -20 & -25 & -30 & -35 & -40 & -45 & -50 & -55 & -60 & -65 & -70 & -75 & -80 & -85 & -90 & -95 & -100 & -105 & -110 & -115 & -120 & -125 & -130 & -135 & -140 & -145 & -150
\end{tabular} 
Chiral HPLC of 74fa:

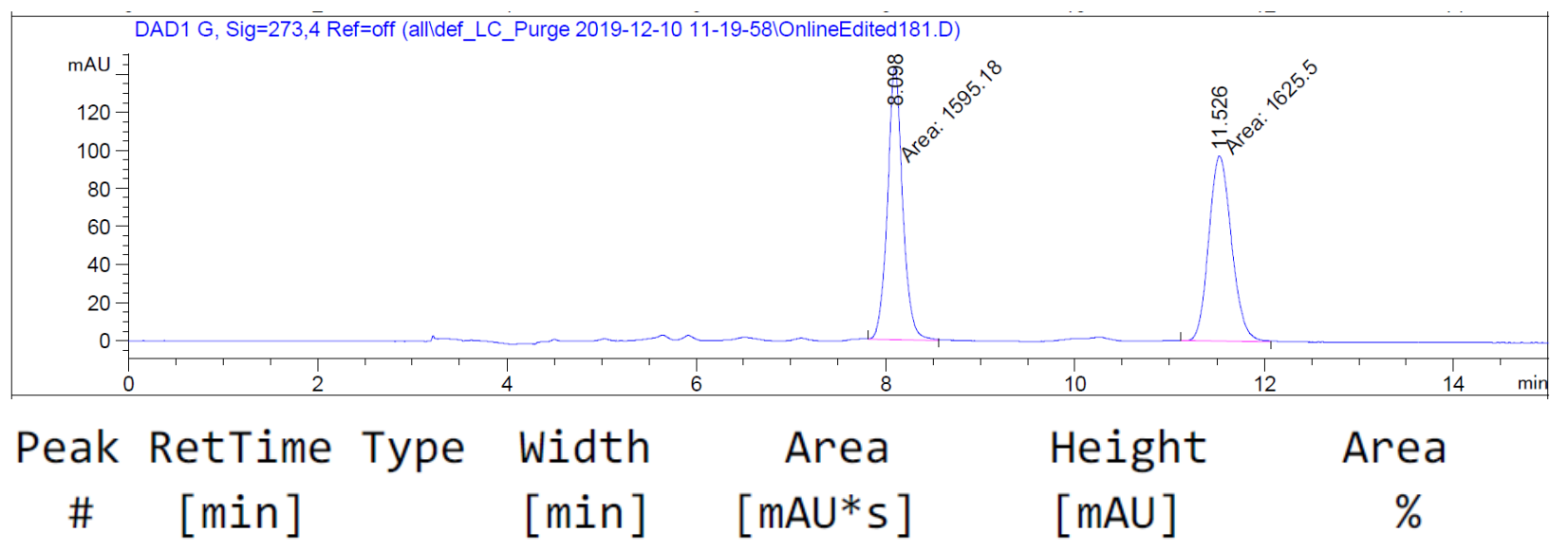

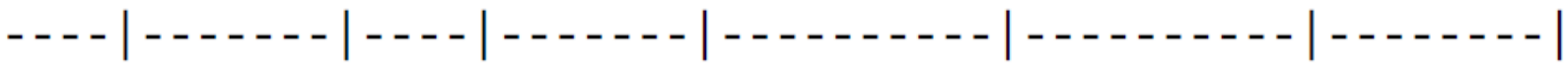

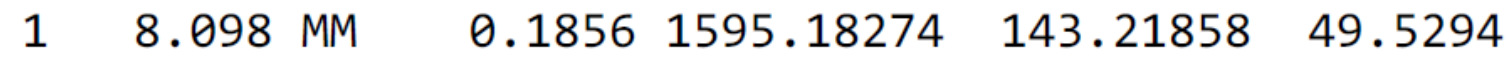

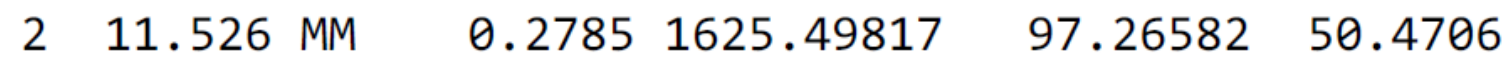

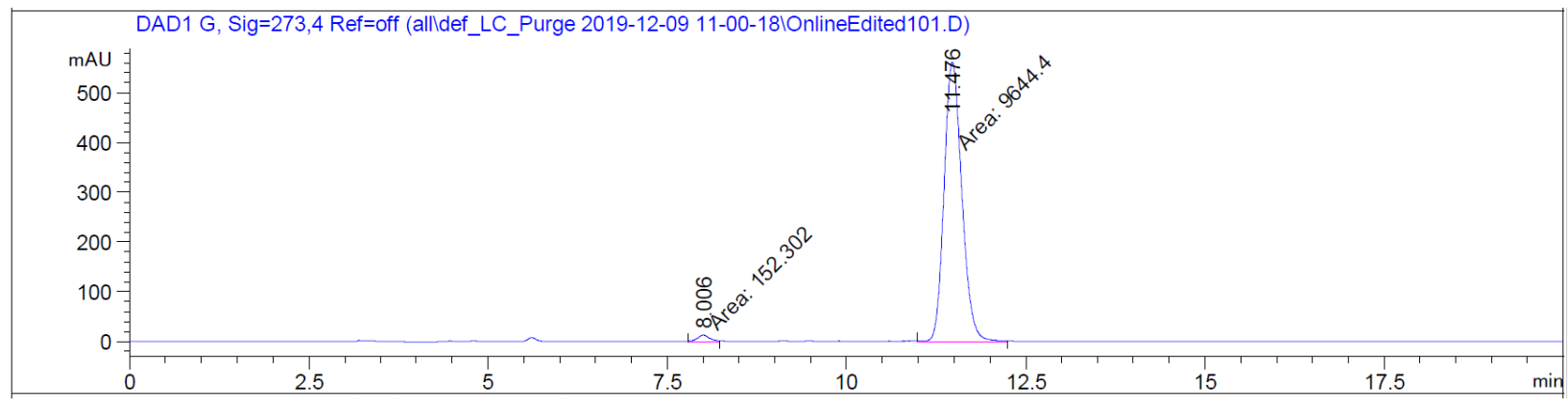

Peak RetTime Type Width Area Height Area

\# $[\mathrm{min}] \quad[\mathrm{min}] \quad[\mathrm{mAU} * \mathrm{~s}] \quad[\mathrm{mAU}] \quad \%$

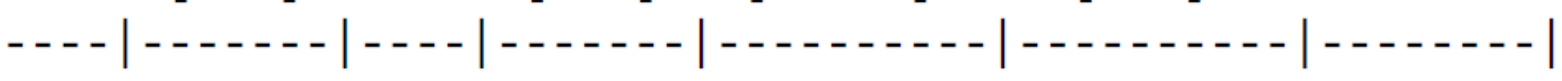

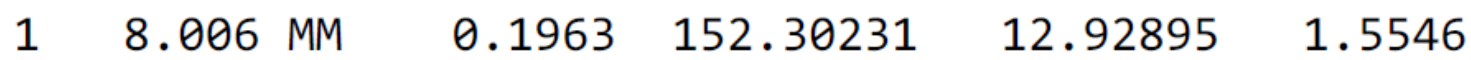

$2 \quad 11.476$ MM $\quad 0.2864 \quad 9644.40430 \quad 561.29364 \quad 98.4454$ 

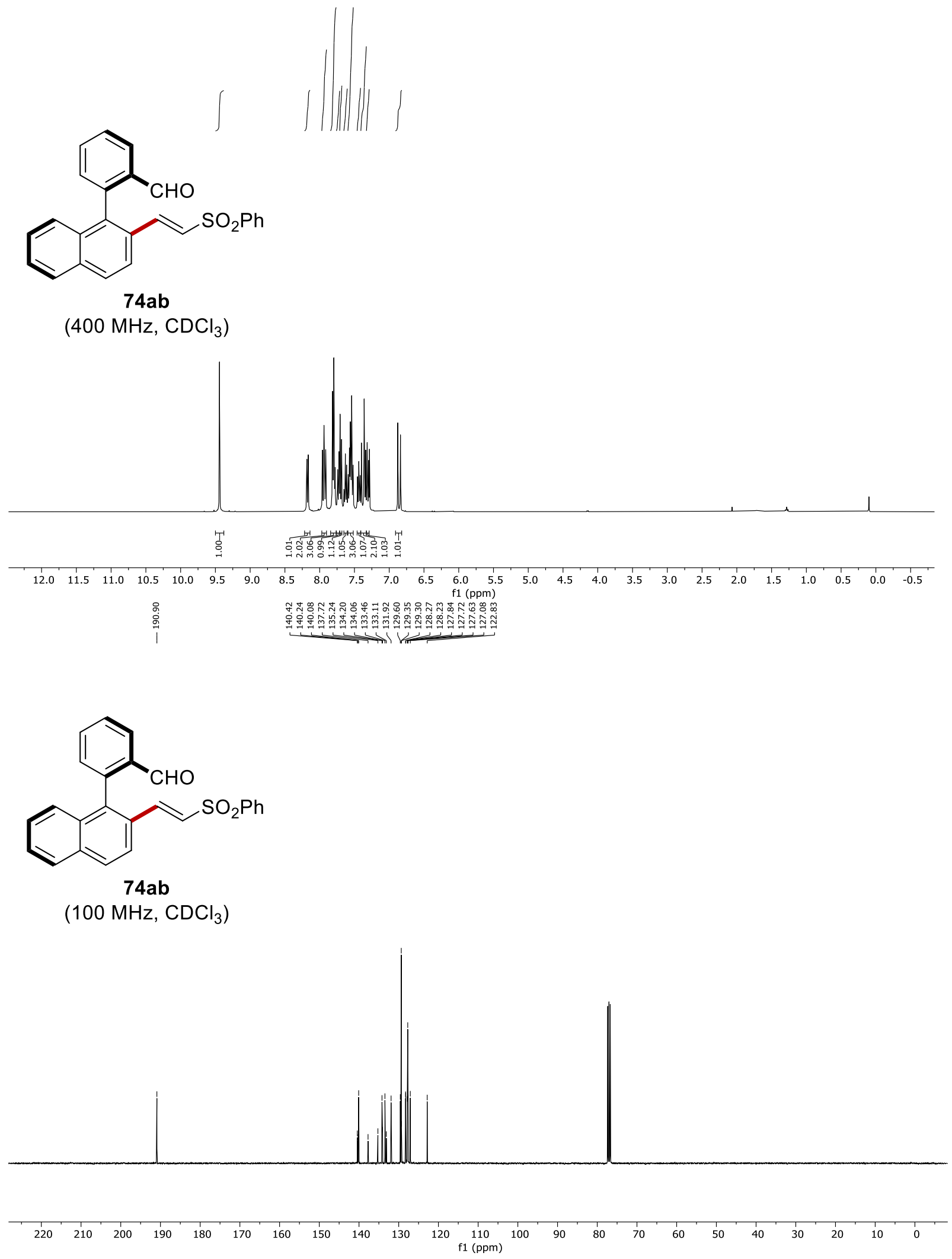

541 
Chiral HPLC of 74ab:

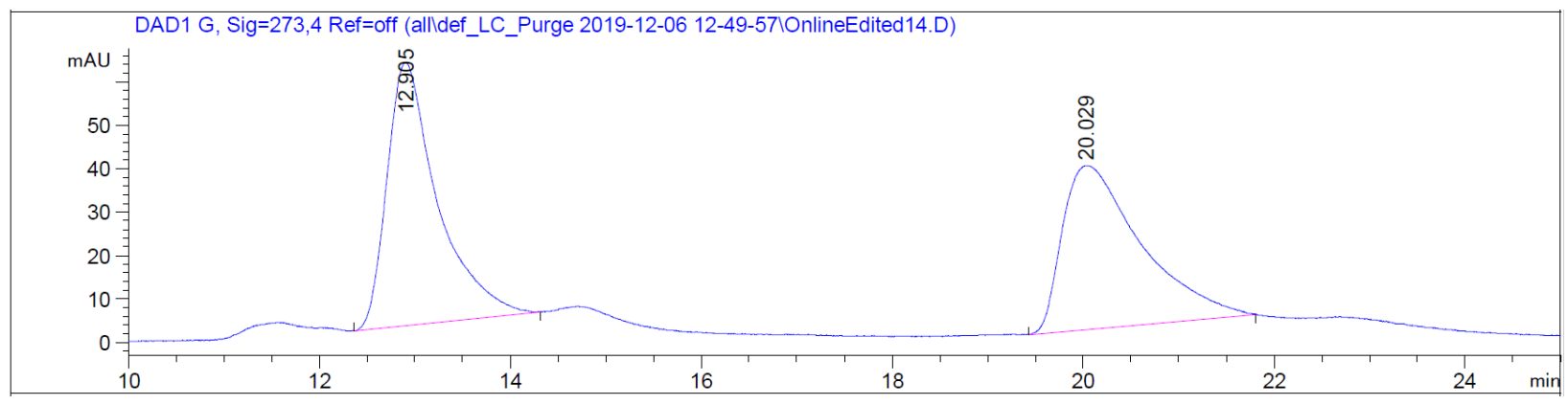

Peak RetTime Type Width Area Height Area

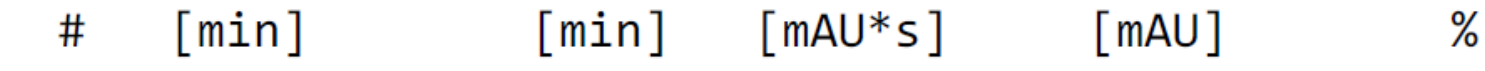

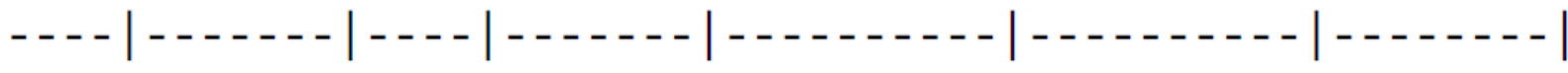

$1 \quad 12.905$ BV R $0.4344 \quad 2233.30713 \quad 60.67965 \quad 50.8991$

$2 \quad 20.029$ BB $\quad 0.66912154 .41016 \quad 37.79290 \quad 49.1009$

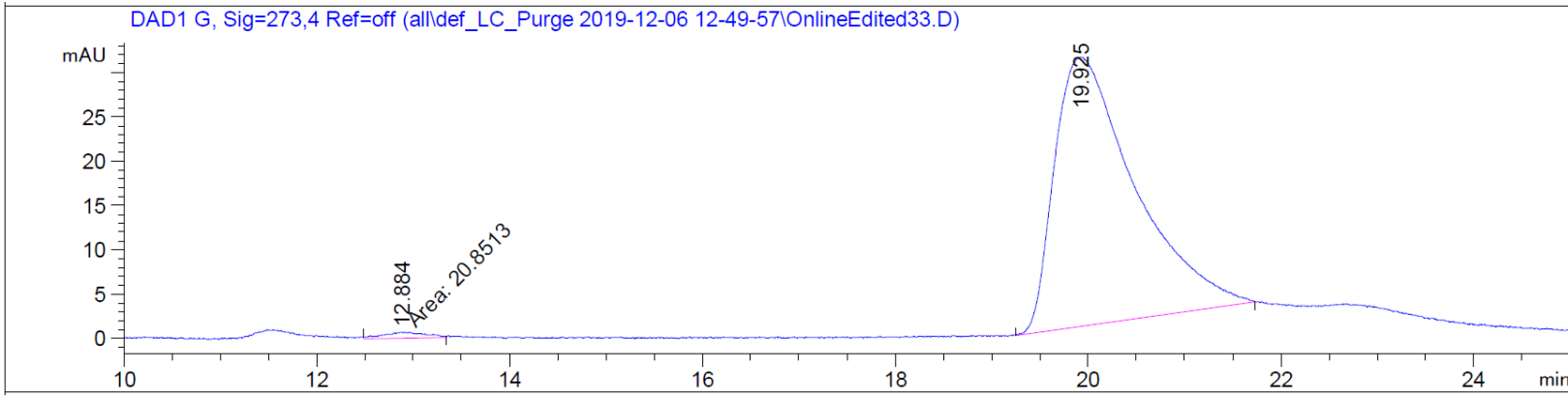

Peak RetTime Type Width Area Height Area

\# $[\mathrm{min}] \quad[\mathrm{min}] \quad[\mathrm{mAU} * \mathrm{~s}] \quad[\mathrm{mAU}] \quad \%$

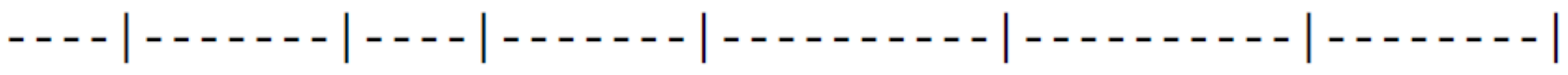

$1 \quad 12.884$ MM $0.5092 \quad 20.851316 .82512 \mathrm{e}-1 \quad 1.1735$

219.925 BV R $0.6788 \quad 1755.97766 \quad 30.35890 \quad 98.8265$ 

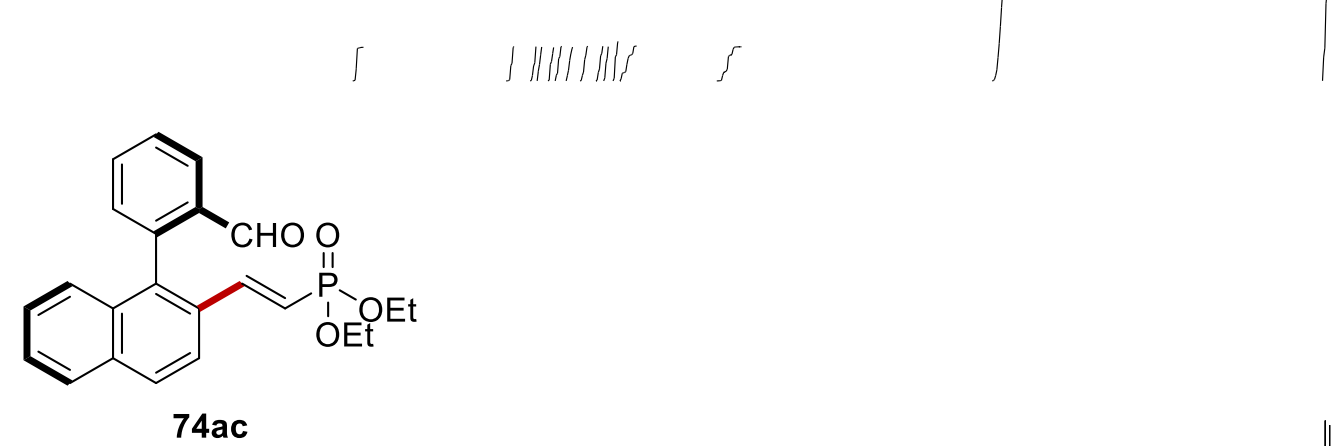

(400 MHz, $\mathrm{CDCl}_{3}$ )
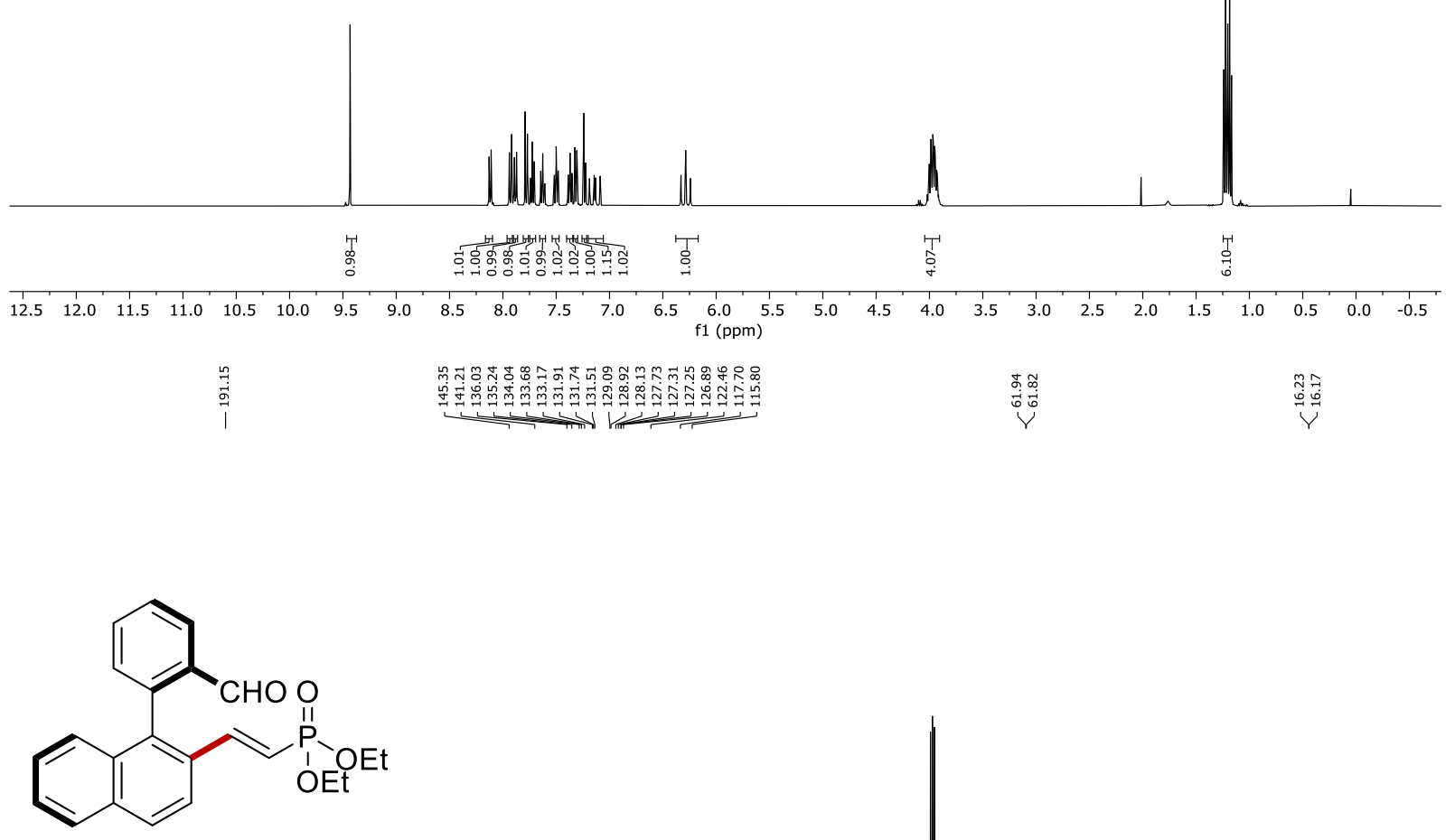

$74 \mathrm{ac}$

$\left(100 \mathrm{MHz}^{\mathrm{CDCl}} \mathrm{CDC}_{3}\right.$

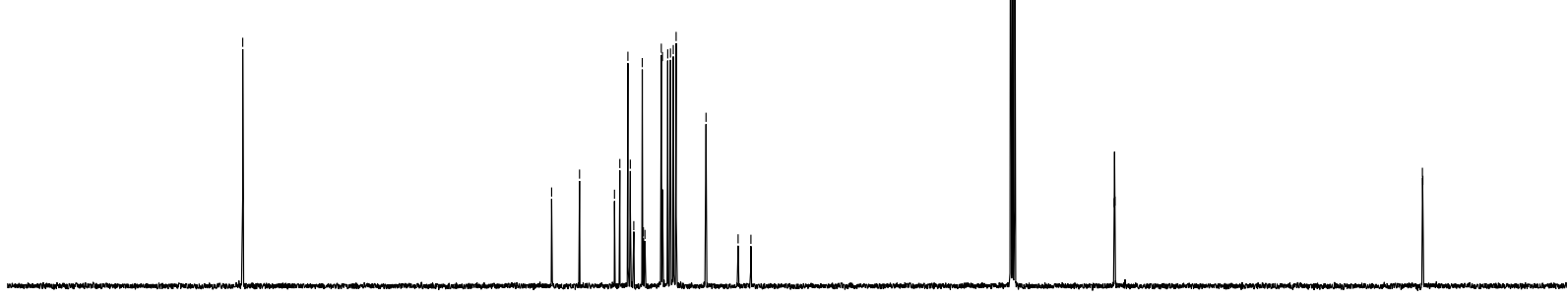

$\begin{array}{lllllllllllllllllllllll}1 & 1 \\ 220 & 210 & 200 & 190 & 180 & 170 & 160 & 150 & 140 & 130 & 120 & 110 & 100 & 90 & 80 & 70 & 60 & 50 & 40 & 30 & 20 & 10 & 0\end{array}$ 


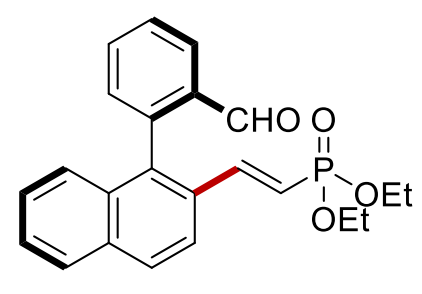

$74 a c$

(160 MHz, $\mathrm{CDCl}_{3}$ )

$\begin{array}{llllllllllllllllllllllllllllllllllllllllllll}200 & 190 & 180 & 170 & 160 & 150 & 140 & 130 & 120 & 110 & 100 & 90 & 80 & 70 & 60 & 50 & 40 & 30 & 20 & 10 & 0 & -10 & -20 & -30 & -40 & -50 & -60 & -70 & -80 & -90 & -16\end{array}$ 
Chiral HPLC of 74ac:

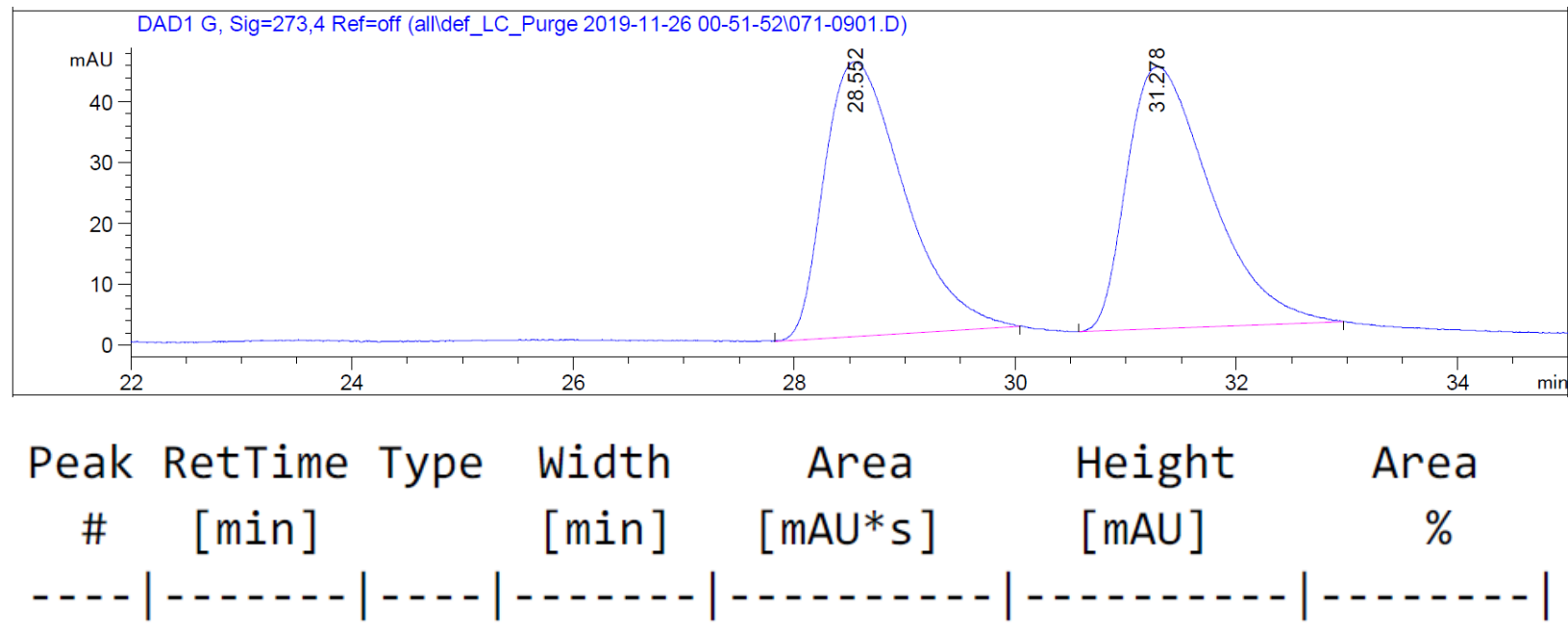

$\begin{array}{lllllll}1 & 28.552 & \text { BV R } & 0.5893 & 2254.54712 & 45.16977 & 49.8997\end{array}$

$2 \quad 31.278$ BV R $0.6184 \quad 2263.60913 \quad 43.12093 \quad 50.1003$

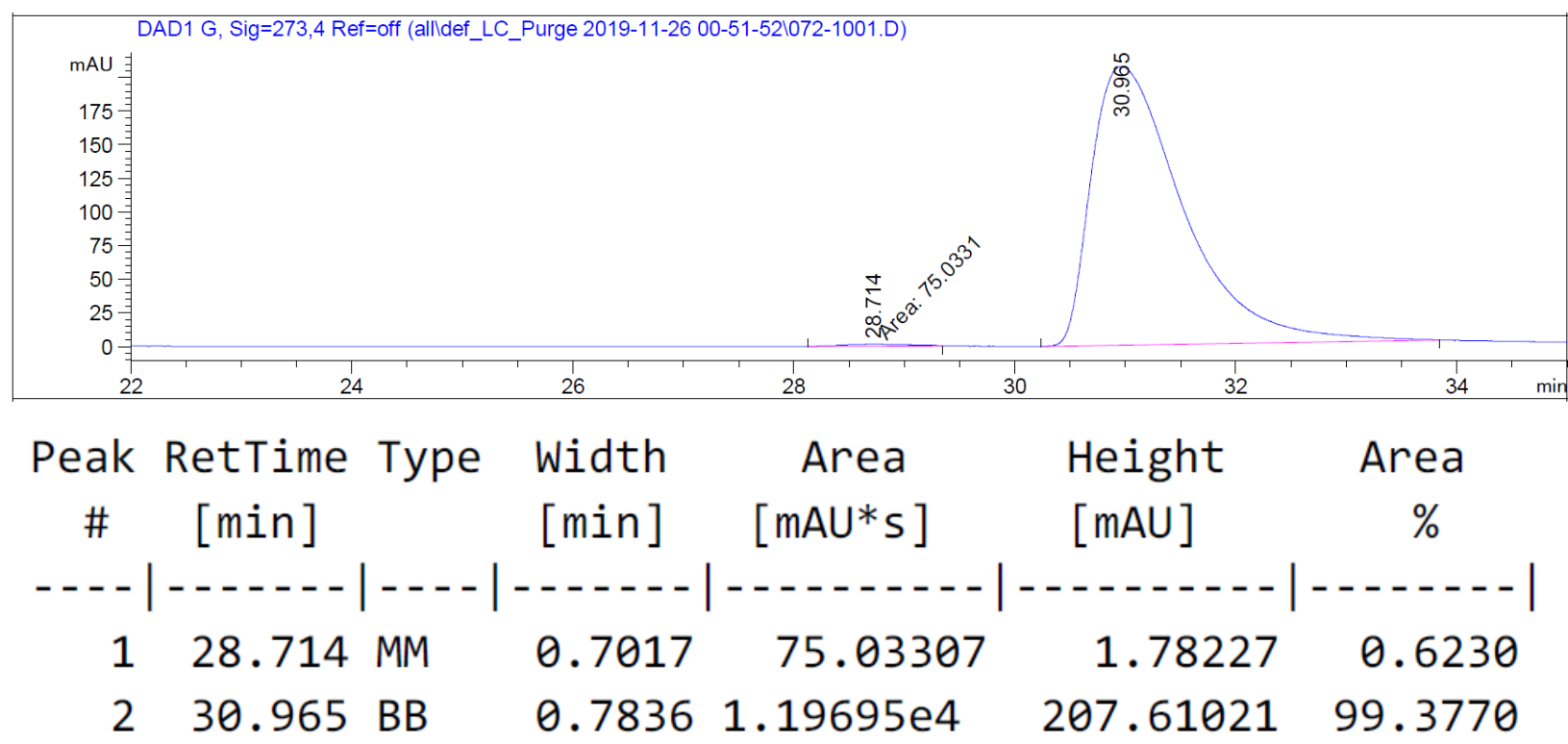



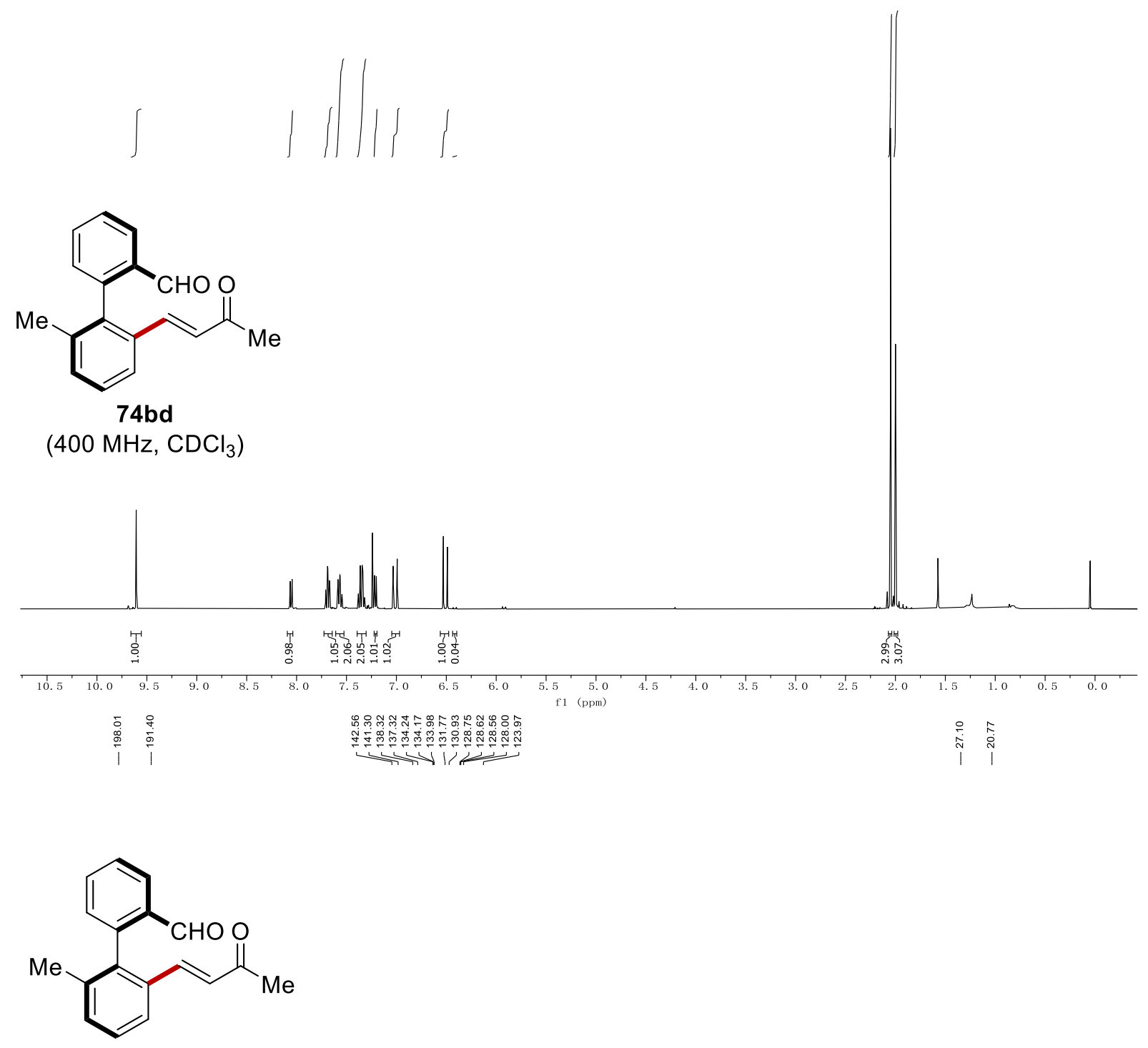

74bd

$\left(100 \mathrm{MHz}, \mathrm{CDCl}_{3}\right)$

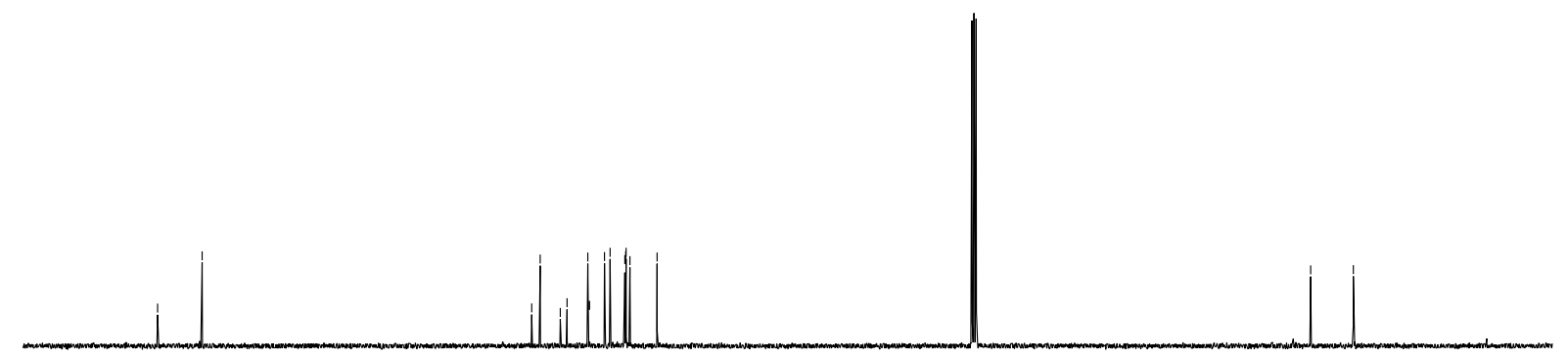

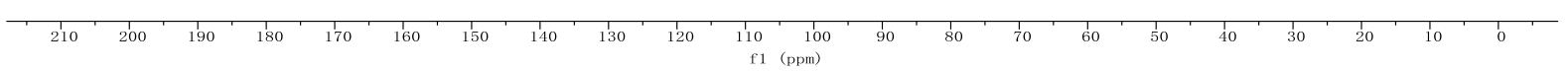


Chiral HPLC of 74bd:

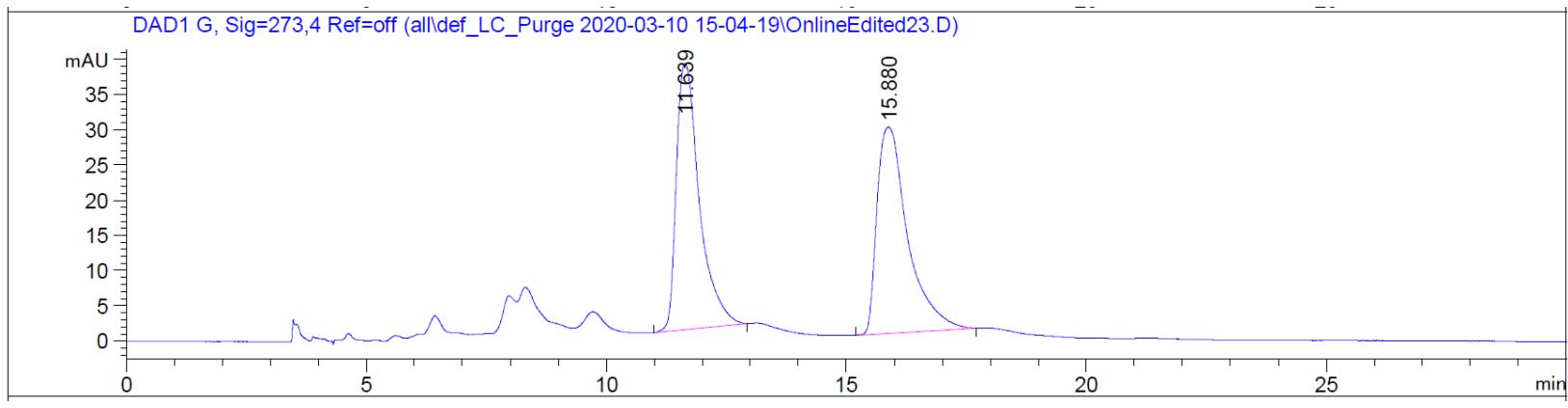

Peak RetTime Type width Area Height Area

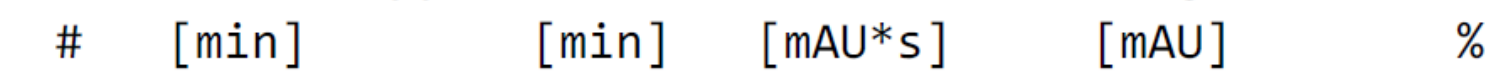
- - - | - - - - - | - - - | - - - - | - - - - - - | - - - - - - | - - - - $\mid$ $\begin{array}{lllllll}1 & 11.639 & \text { BB } & 0.5085 & 1260.75012 & 37.85801 & 49.2290\end{array}$

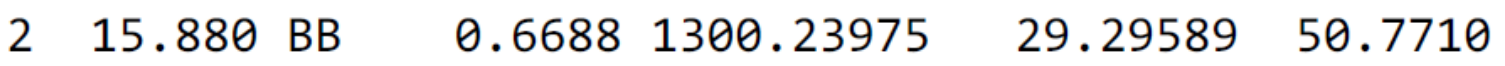

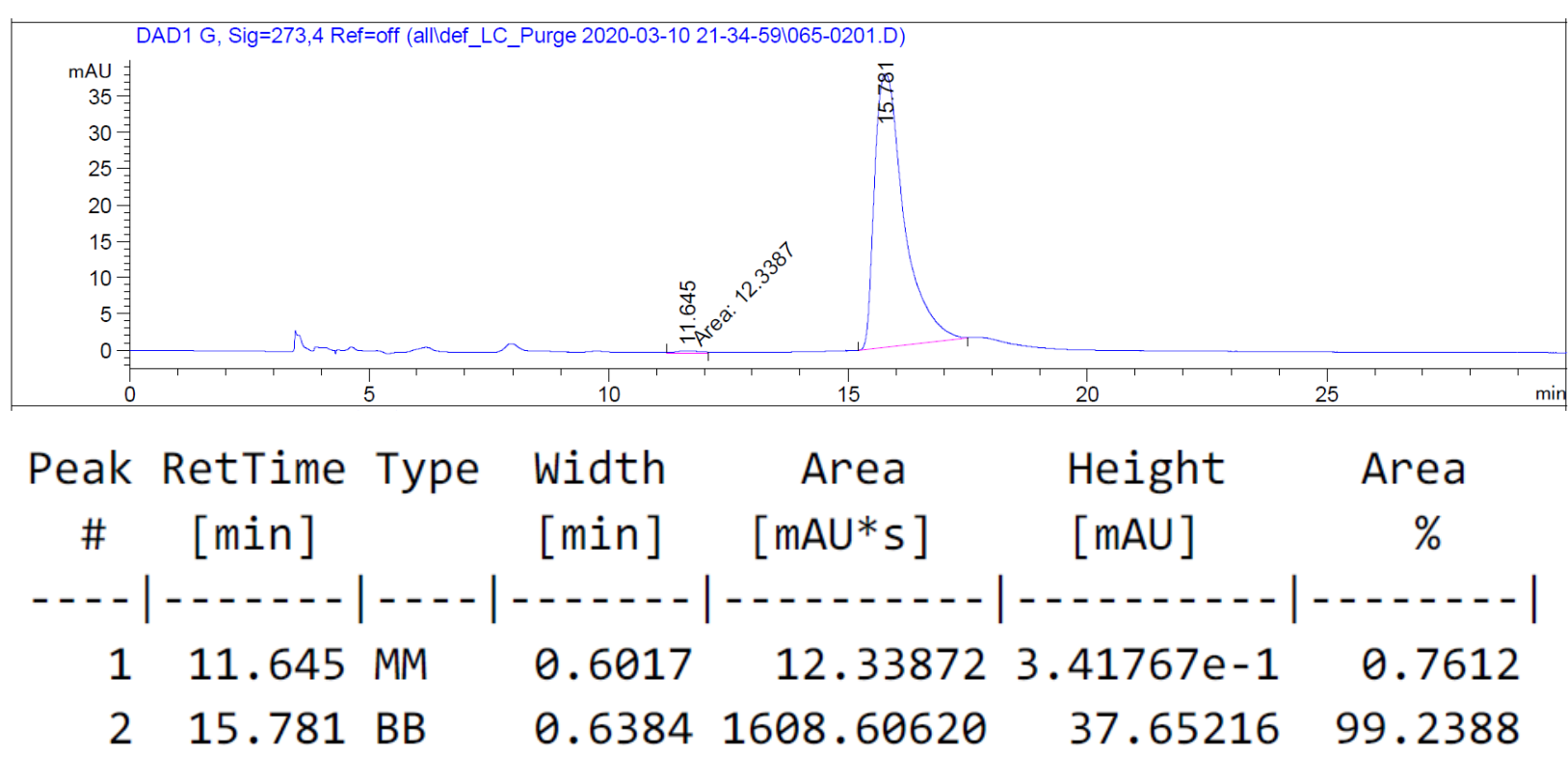




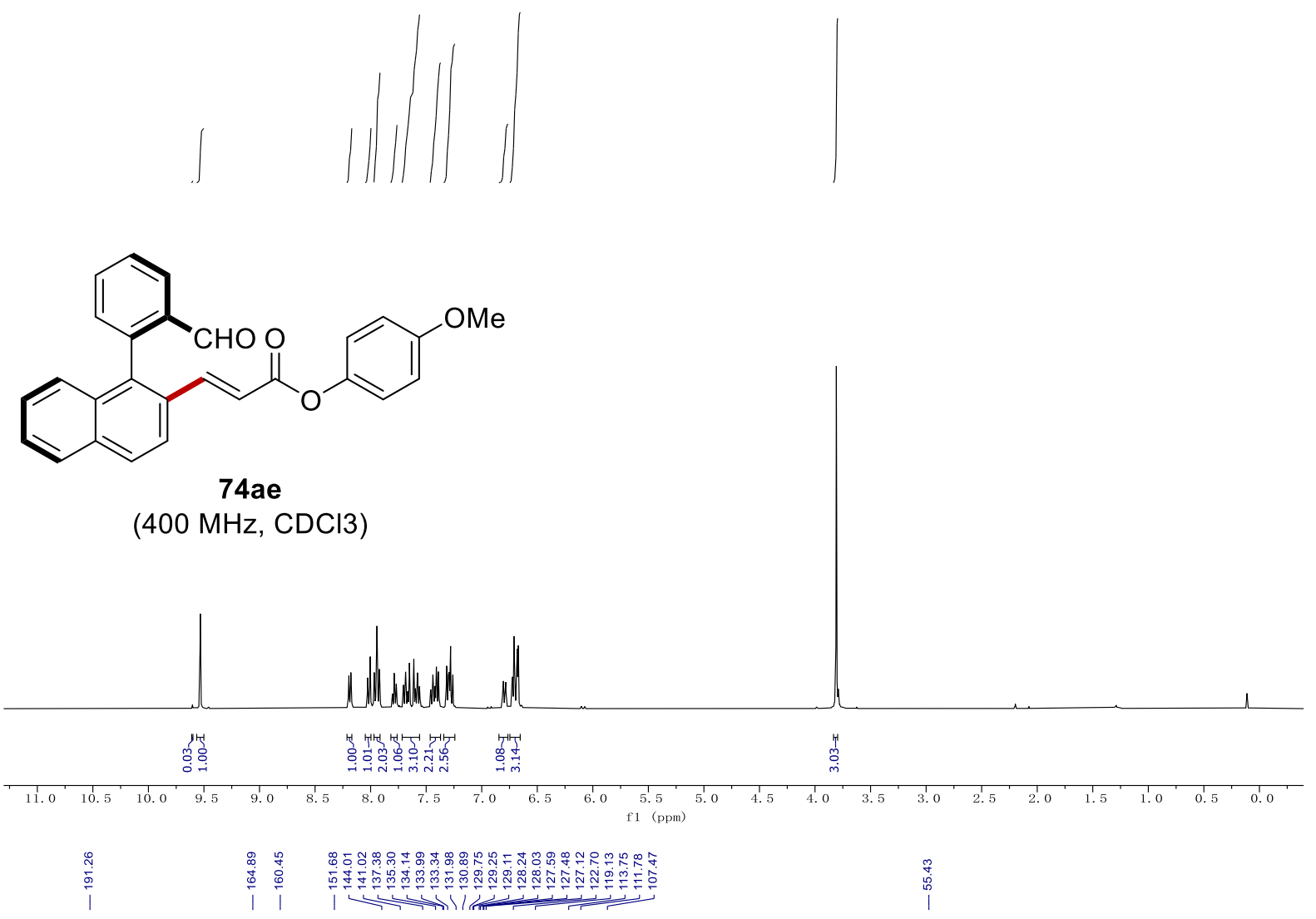<smiles>COc1ccc(OC(=O)/C=C/c2ccc3ccccc3c2-c2ccccc2C)cc1</smiles>

74ae

(100 MHz, CDCl3)

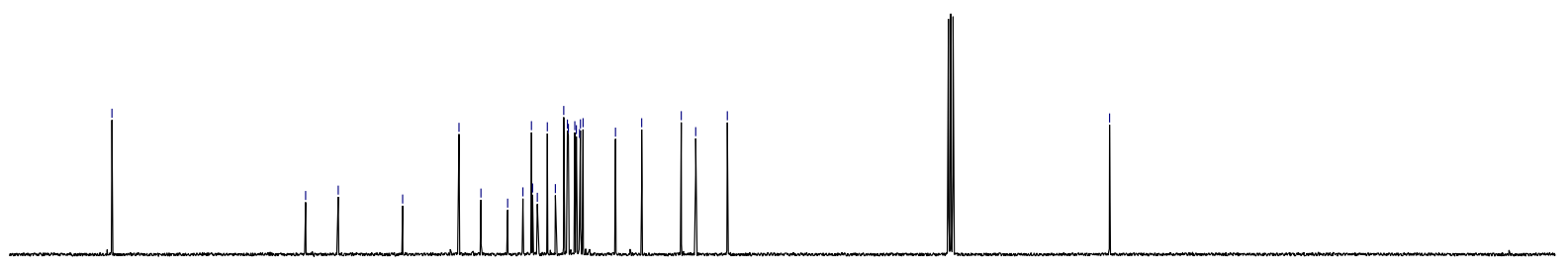

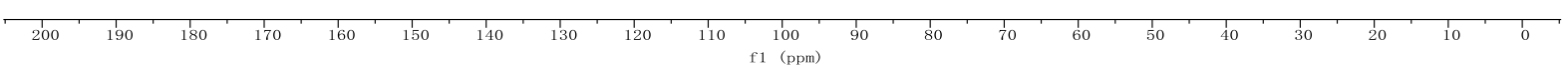


Chiral HPLC of 74ae:

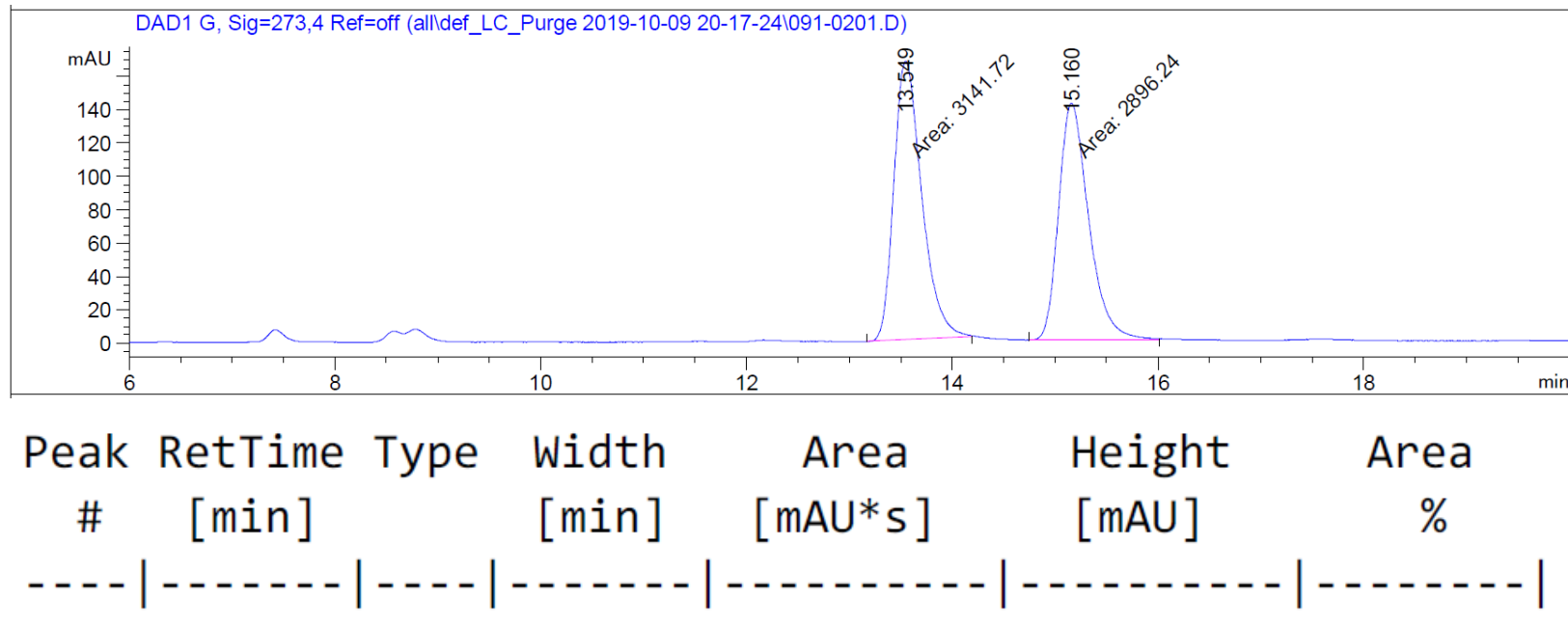
$113.549 \mathrm{MM}$
$\begin{array}{llll}0.3134 & 3141.72144 & 167.06538 & 52.0328\end{array}$
$215.160 \mathrm{MM}$
$\begin{array}{llll}0.3397 & 2896.24219 & 142.08664 & 47.9672\end{array}$

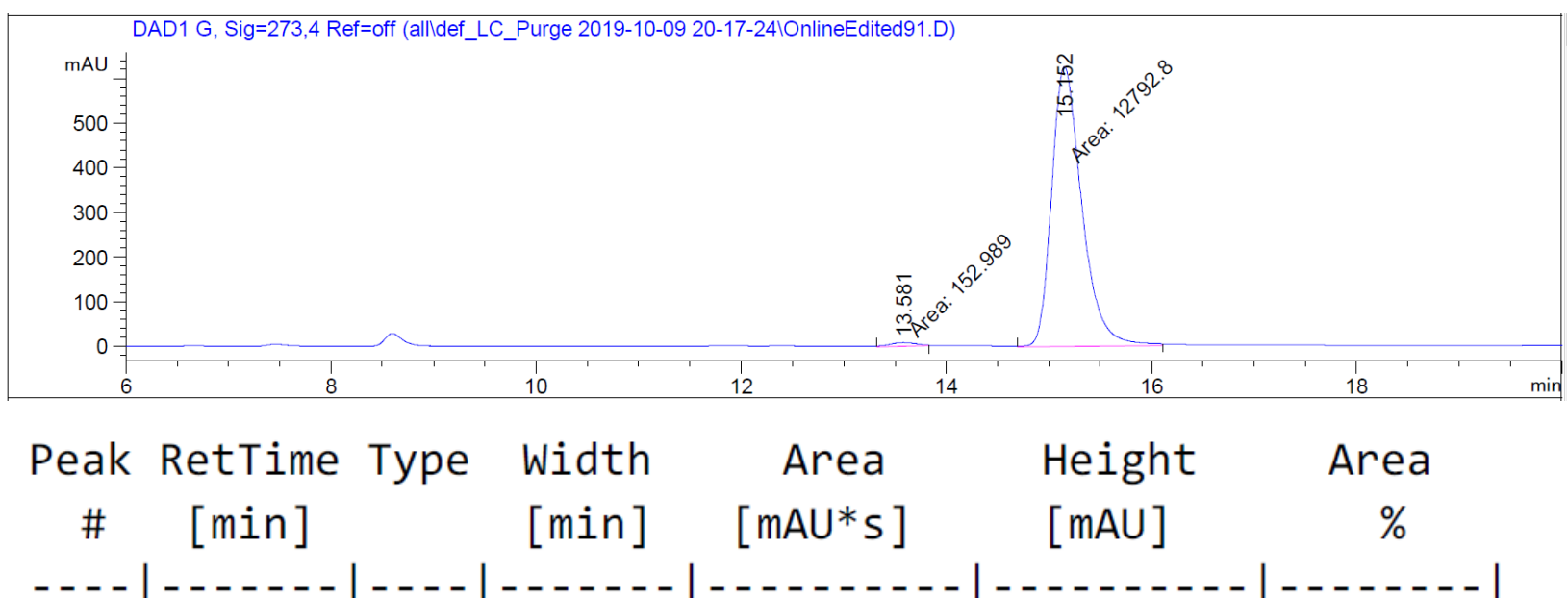
$113.581 \mathrm{MM}$
$0.3040 \quad 152.98878$
8.38777
1.1818
$215.152 \mathrm{MM}$
$0.34031 .27928 \mathrm{e} 4$
626.6022398 .8182 

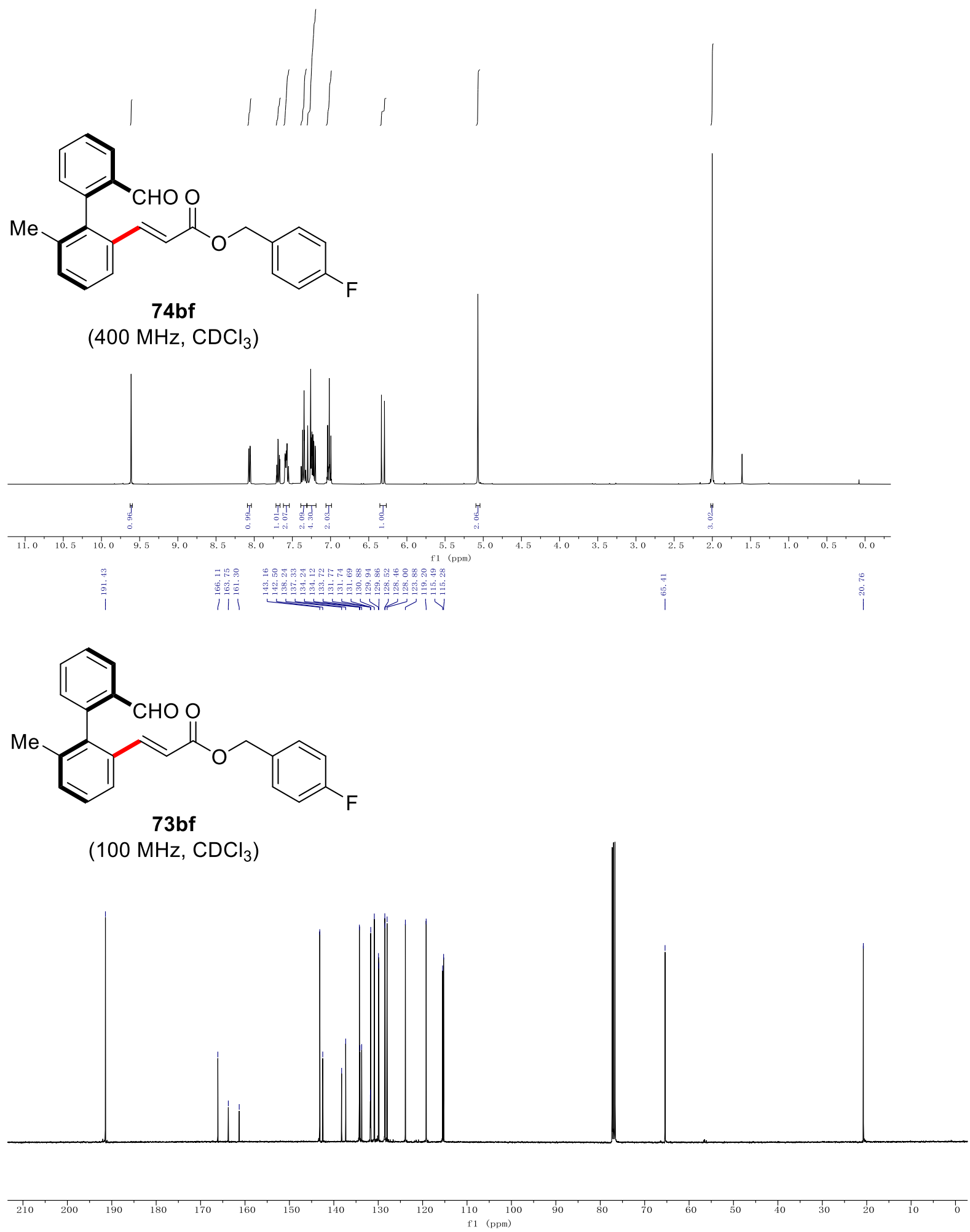

550 


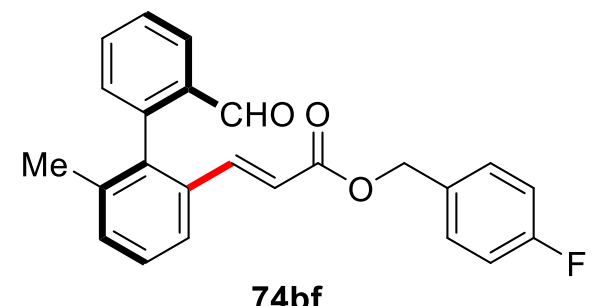

(375 $\left.\mathrm{MHz}, \mathrm{CDCl}_{3}\right)$

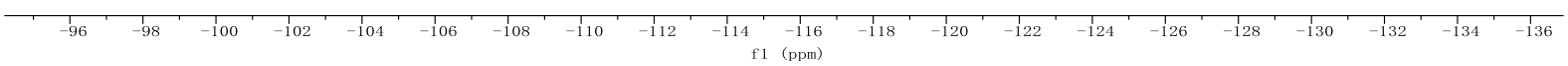


Chiral HPLC of 74bf:

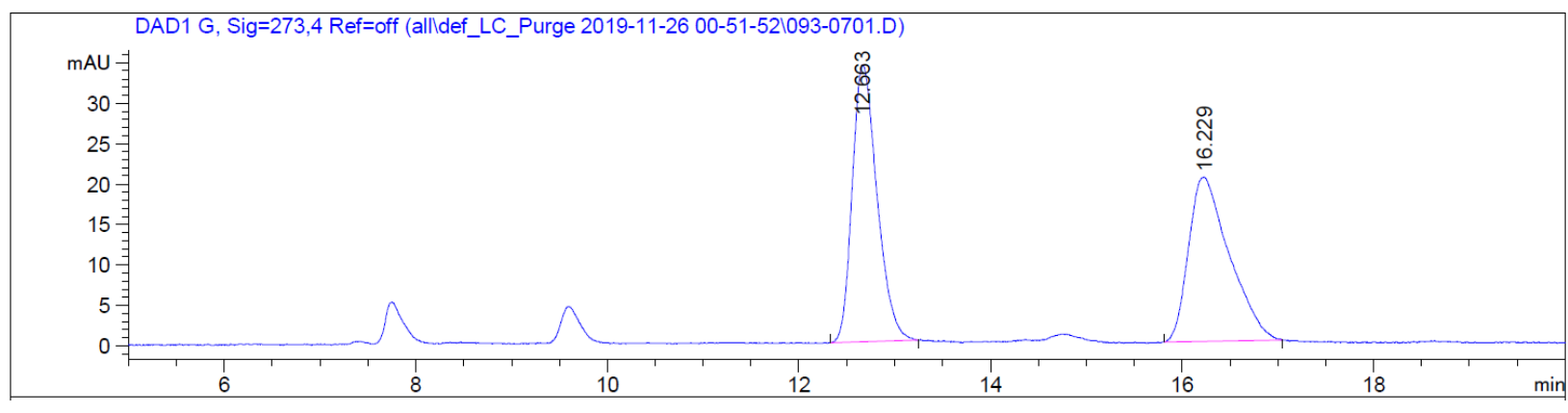

Peak RetTime Type width Area Height Area

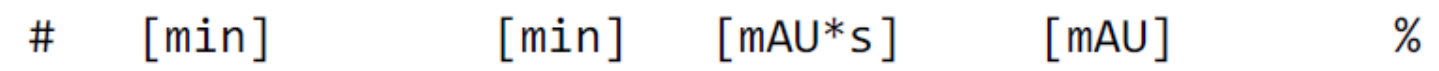

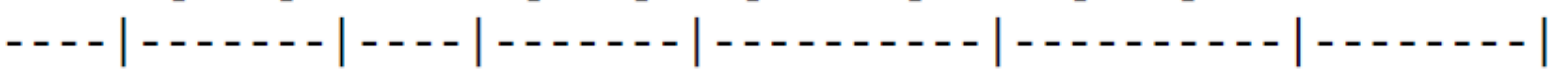

$\begin{array}{lllllll}1 & 12.663 & \text { BB } & 0.2546 & 616.04492 & 34.28500 & 50.6977\end{array}$

$\begin{array}{lllllll}2 & 16.229 & \text { BB } & 0.3553 & 599.08984 & 20.29773 & 49.3023\end{array}$

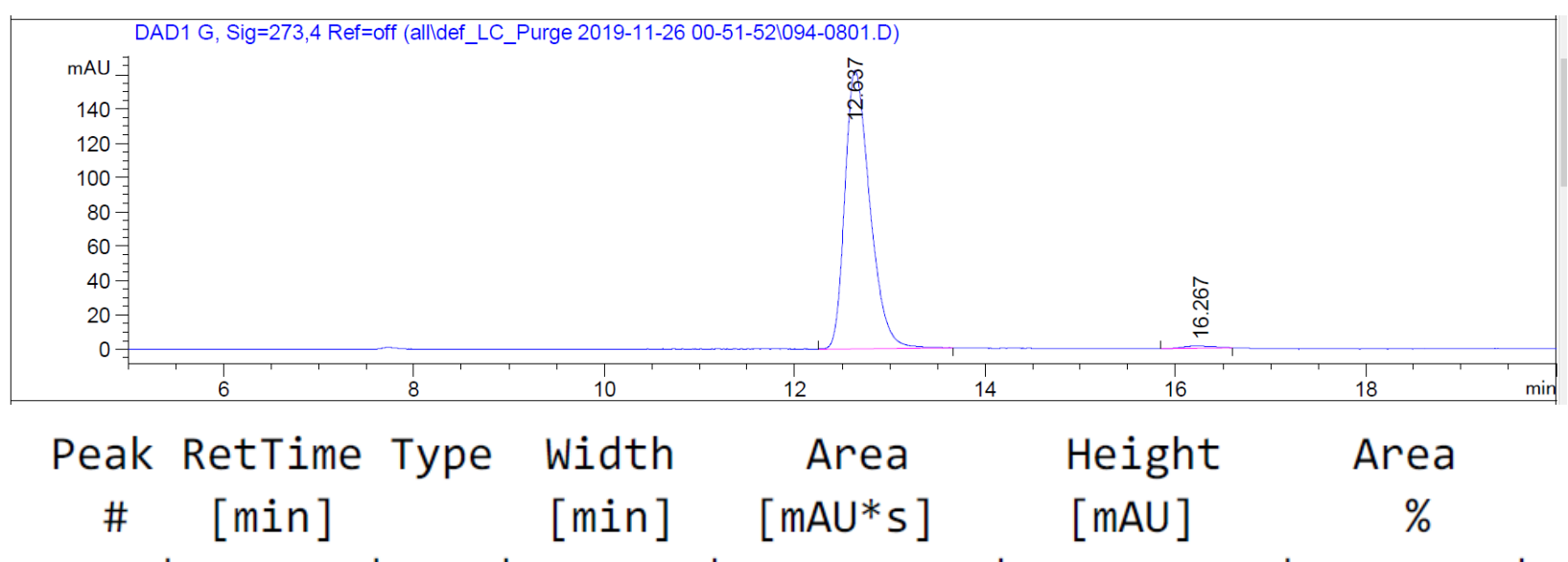

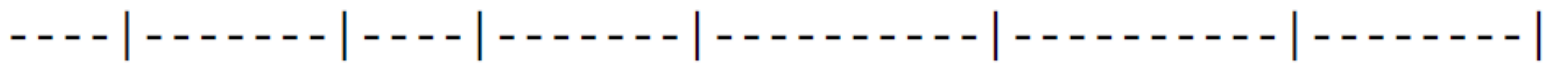

$\begin{array}{lllllll}1 & 12.637 & \text { BV R } & 0.2724 & 2954.47266 & 162.25336 & 99.0154\end{array}$

$\begin{array}{lllllll}2 & 16.267 & \text { VB R } & 0.2722 & 29.38032 & 1.27799 & 0.9846\end{array}$ 

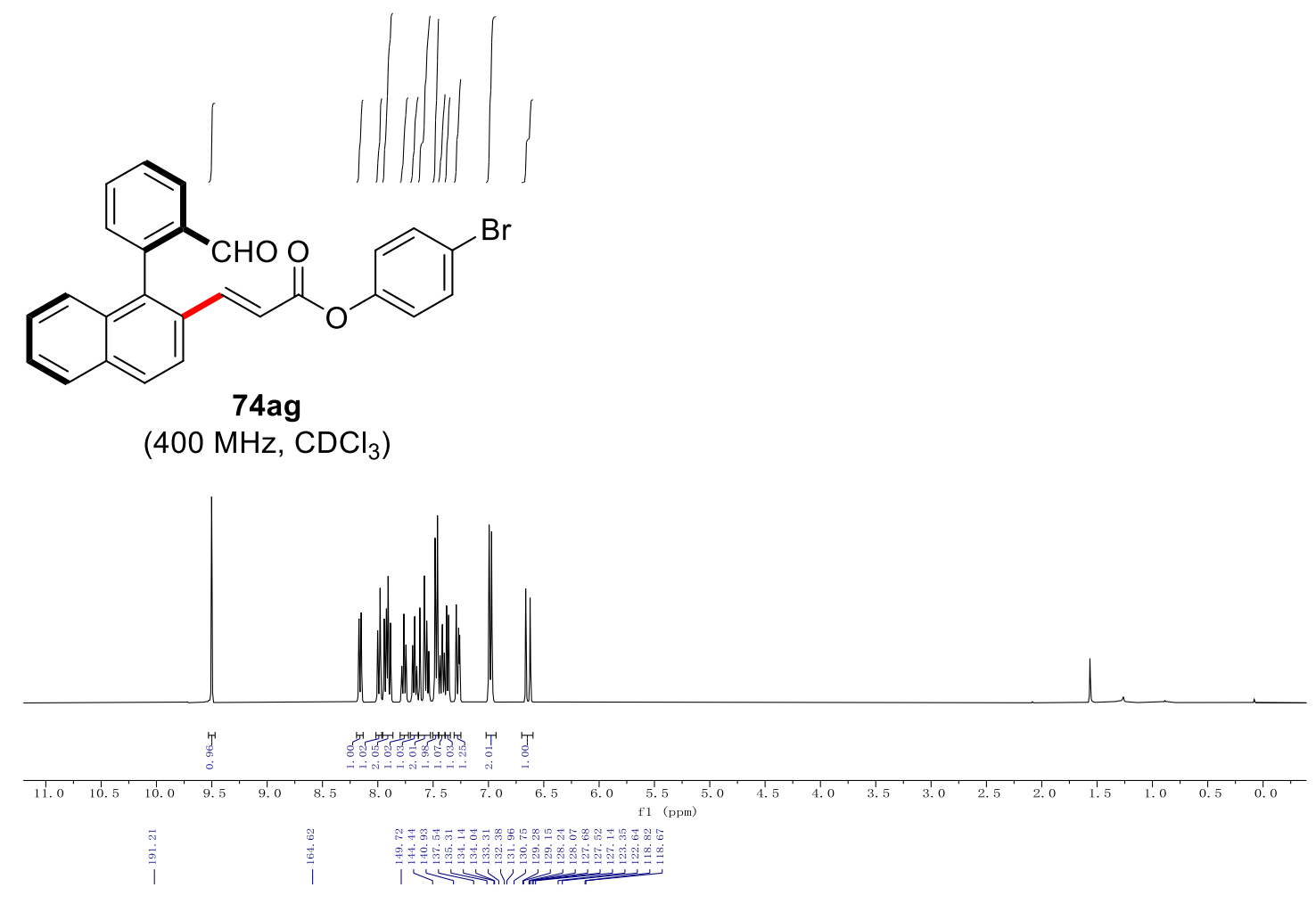<smiles>Cc1ccccc1-c1c(/C=C/C(=O)Oc2ccc(Br)cc2)ccc2ccccc12</smiles>

74ag

$\left(100 \mathrm{MHz}, \mathrm{CDCl}_{3}\right.$ )

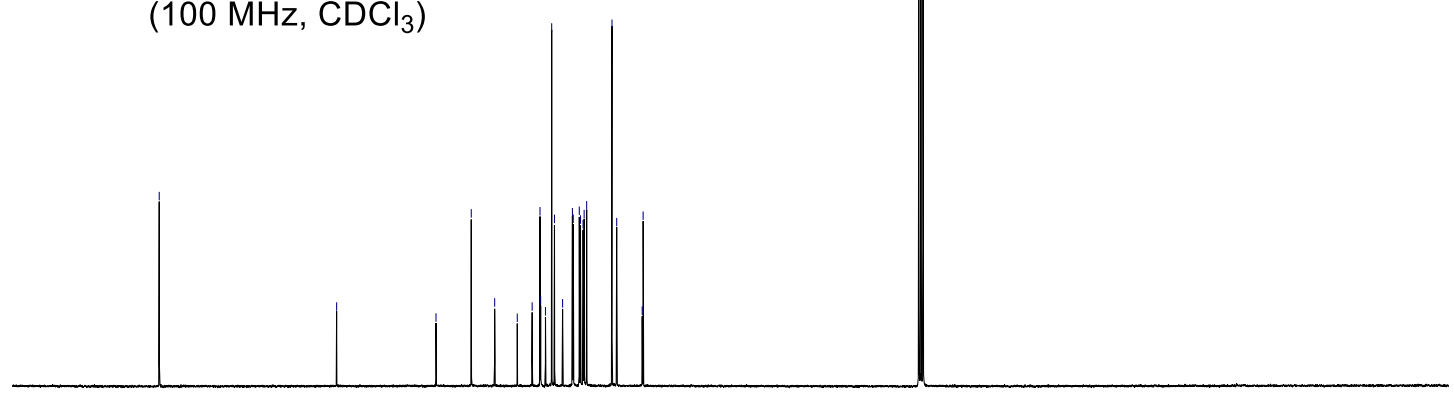

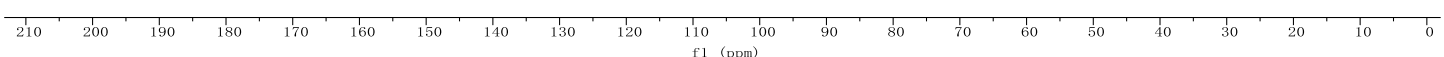


Chiral HPLC of 74ag:

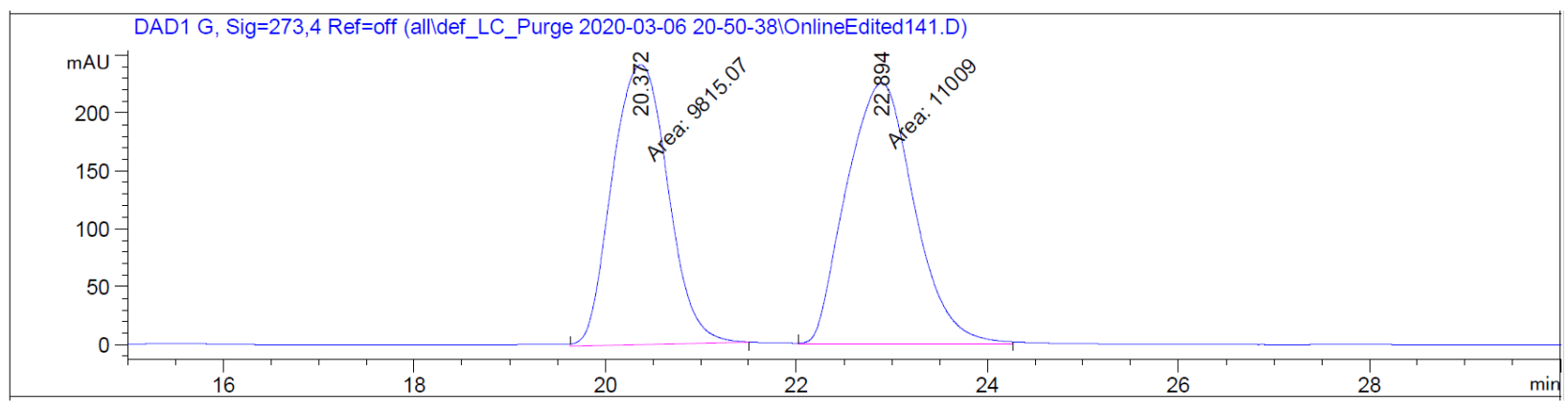

Peak RetTime Type Width Area Height Area

\# $[\mathrm{min}] \quad[\mathrm{min}] \quad[\mathrm{mAU} * \mathrm{~s}] \quad[\mathrm{mAU}] \quad \%$

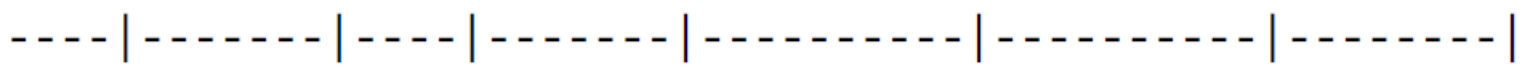

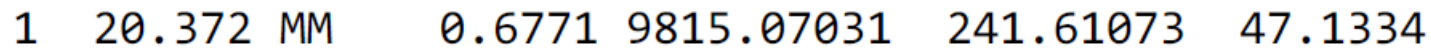

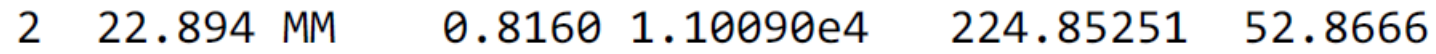

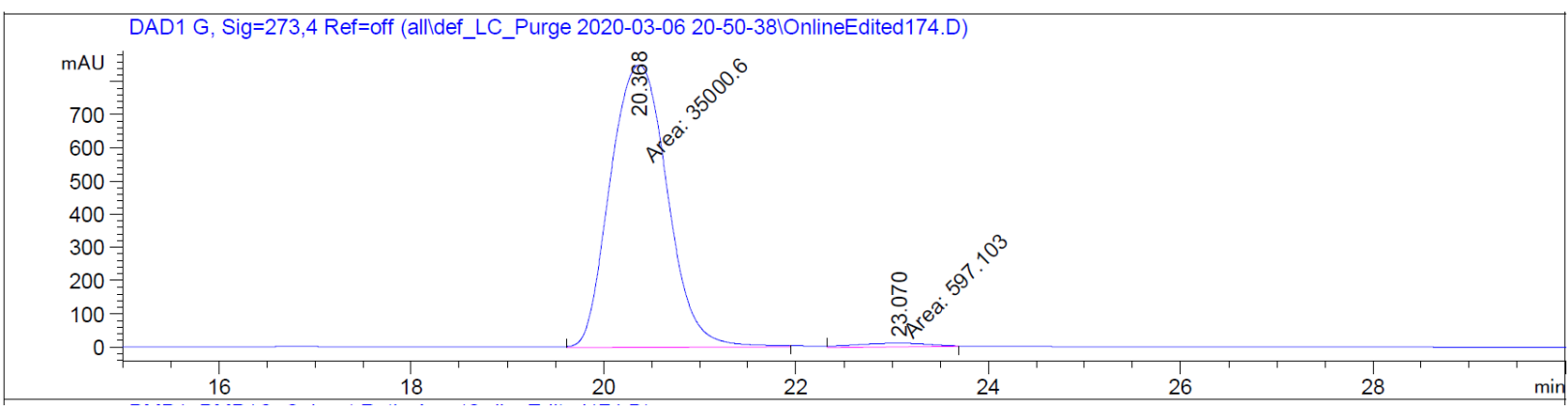

Peak RetTime Type Width Area Height Area

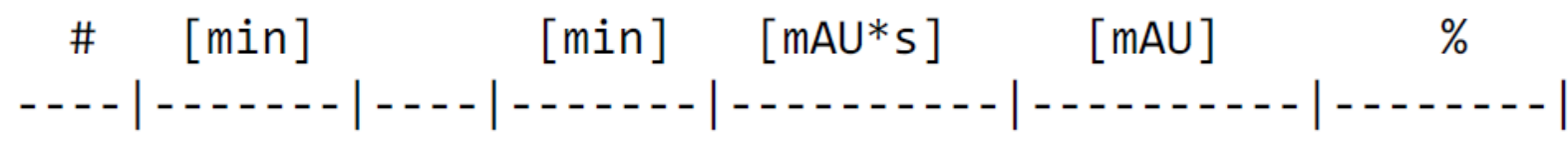

$1 \quad 20.368$ MM $\quad 0.6857 \quad 3.50006 \mathrm{e} 4 \quad 850.66534 \quad 98.3226$

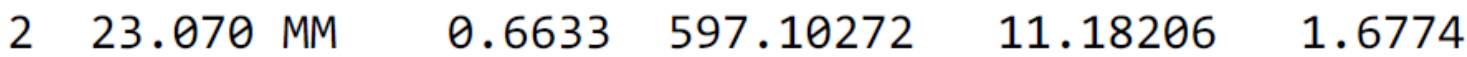




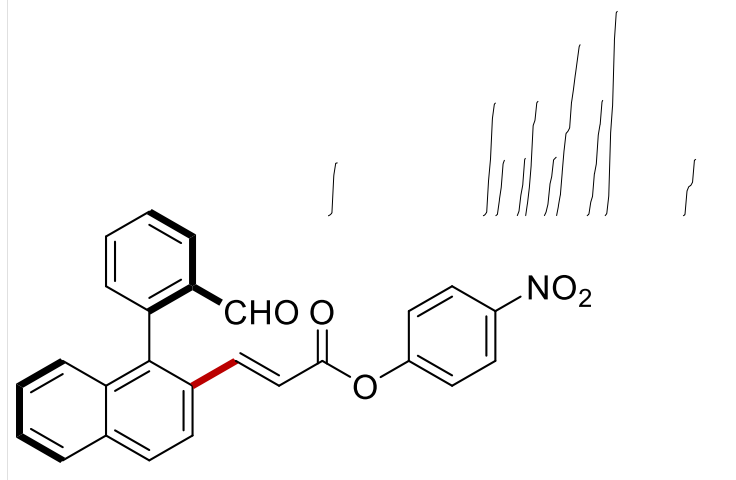

74ah

(400 MHz, $\mathrm{CDCl}_{3}$ )

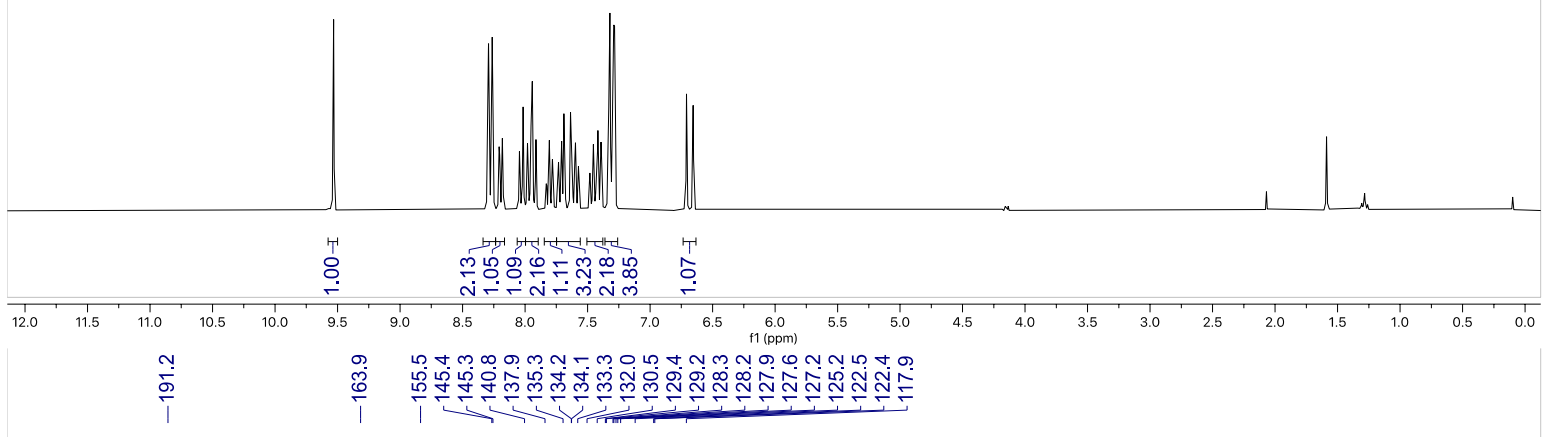<smiles>O=C/C=C/c1ccc2ccccc2c1-c1ccccc1C(=O)Oc1ccc([N+](=O)[O-])cc1</smiles>

74ah

(100 MHz, $\mathrm{CDCl}_{3}$ )

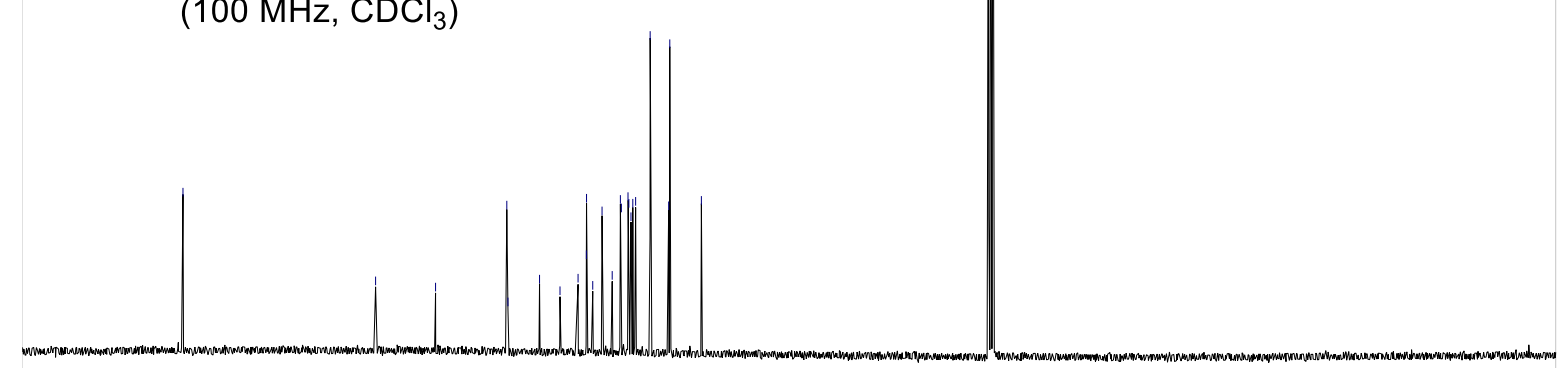

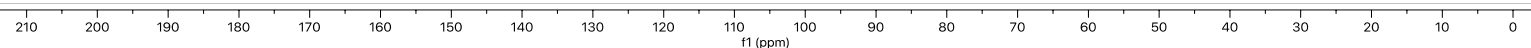


Chiral HPLC of 74ah:

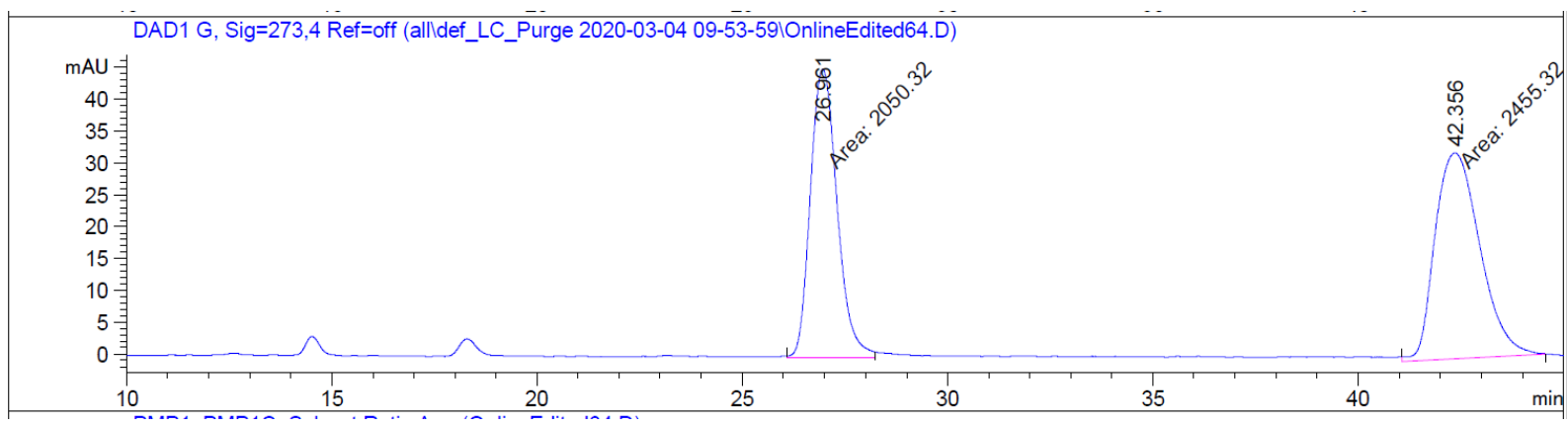

Peak RetTime Type width Area Height Area

\begin{tabular}{c|c|c|c|}
$\#$ & {$[\mathrm{~min}]$} & {$[\mathrm{min}]$} & {$[\mathrm{mAU} * \mathrm{~m}]$}
\end{tabular}

$1 \quad 26.961$ MM $0.7543 \quad 2050.31958 \quad 45.30516 \quad 45.5056$

242.356 MM $\quad 1.26672455 .32104 \quad 32.30606 \quad 54.4944$

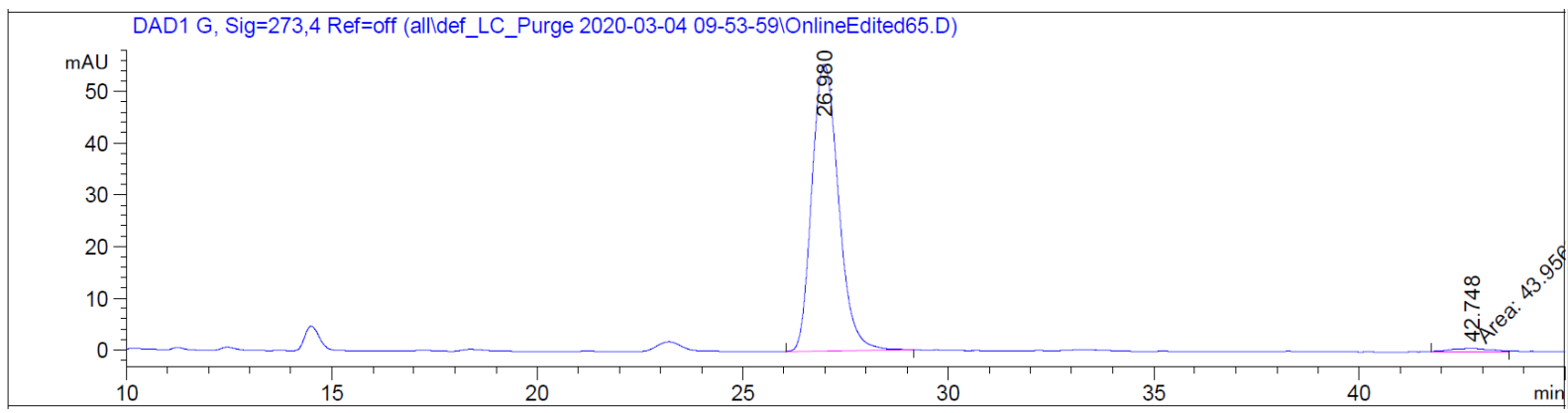

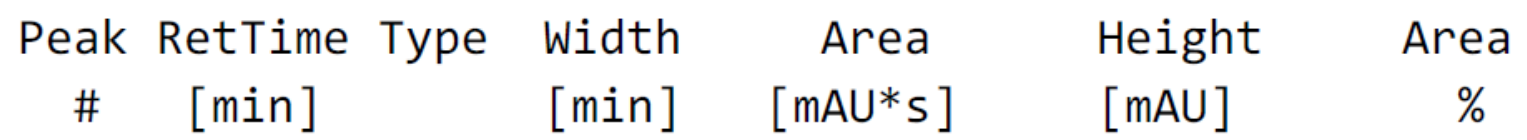

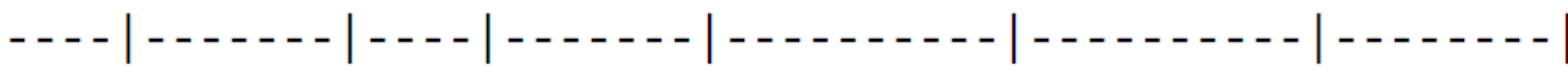

$\begin{array}{lllllll}1 & 26.980 & \text { BB } & 0.6919 & 2494.72827 & 55.44894 & 98.2685\end{array}$

242.748 MM $1.0945 \quad 43.95687 \quad 6.69365 \mathrm{e}-1 \quad 1.7315$ 


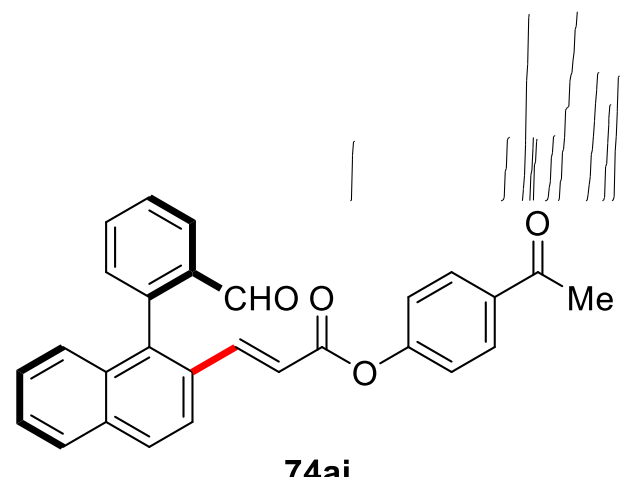

74ai

$\left(400 \mathrm{MHz} \mathrm{CDCl}_{3}\right)$

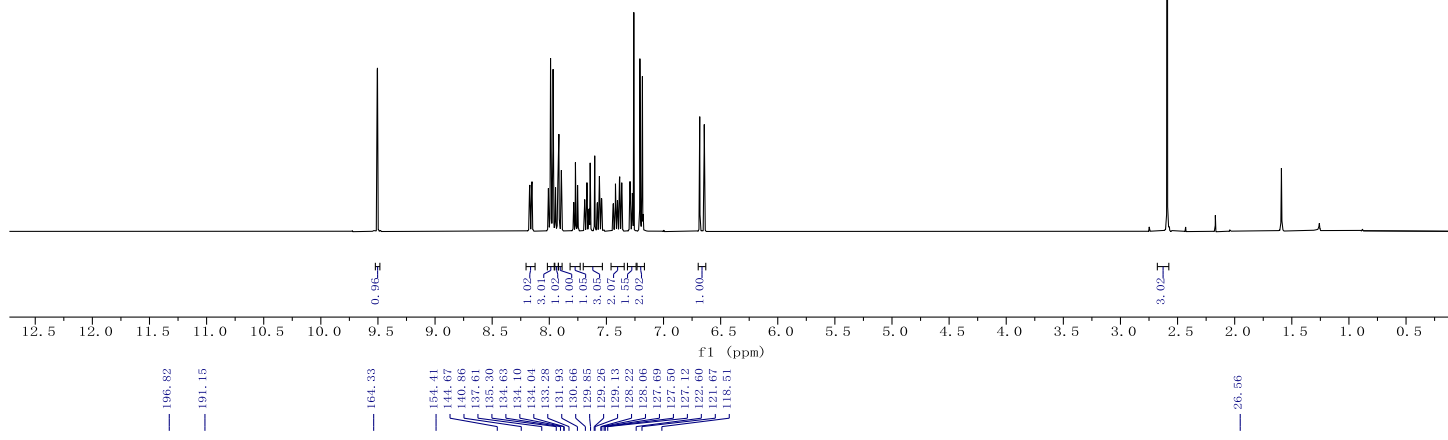<smiles>CC(=O)c1ccc(OC(=O)/C=C/c2ccc3ccccc3c2-c2ccccc2C)cc1</smiles>

74ai

$\left(100 \mathrm{MHz} \mathrm{CDCl}_{3}\right)$

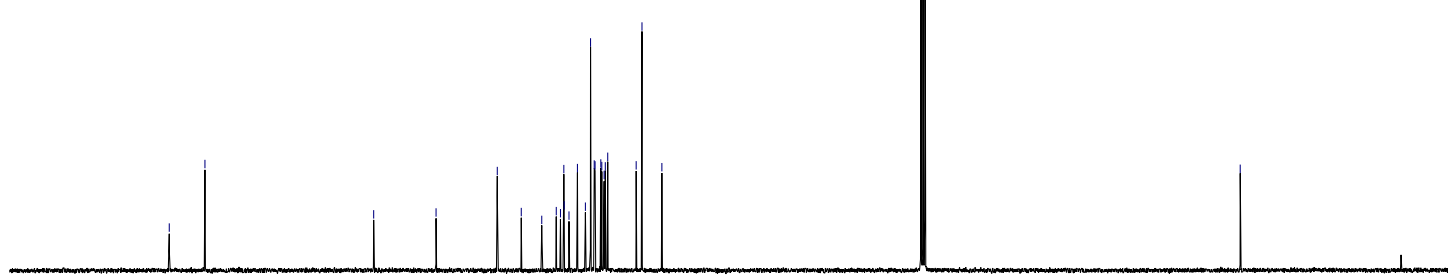

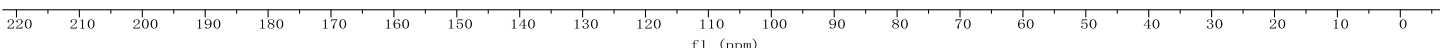


Chiral HPLC of 74ai:

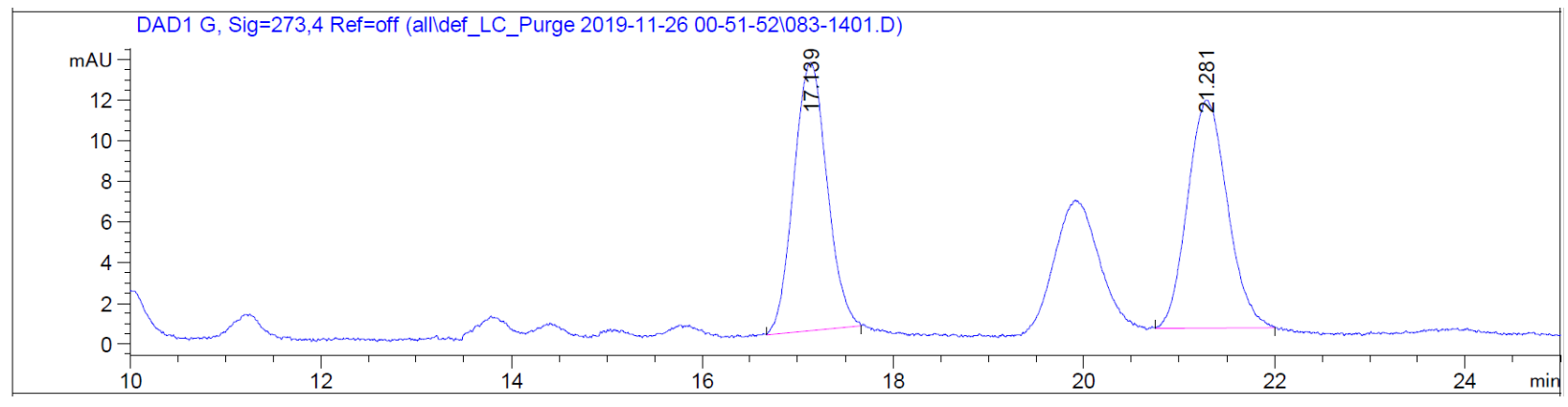

Peak RetTime Type Width Area Height Area

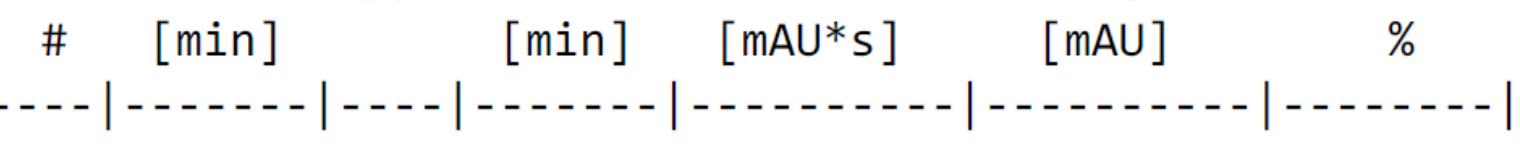
117.139 BB
0.2886319 .62296
13.1938949 .5082
$221.281 \mathrm{BB}$
$0.3452 \quad 325.97256$
$11.21191 \quad 50.4918$

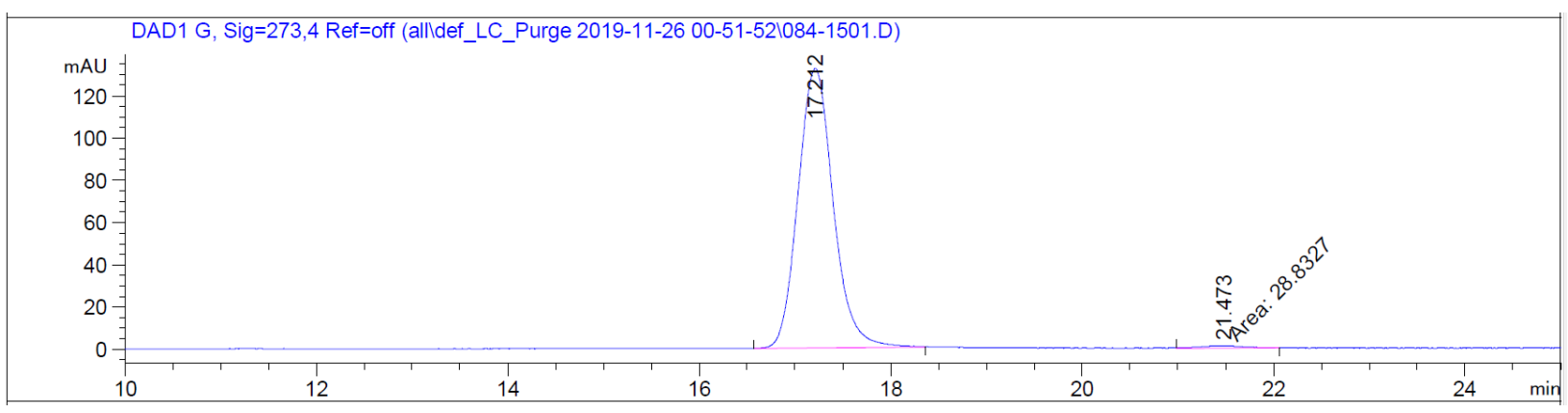

Peak RetTime Type width Area Height Area

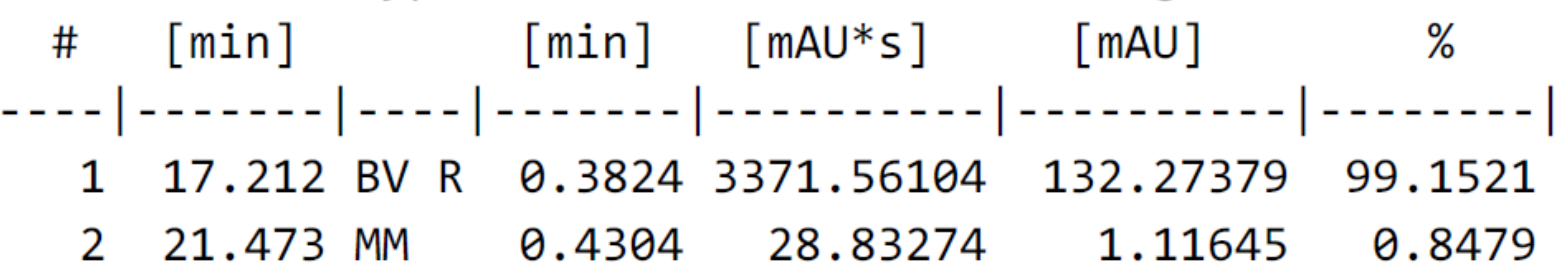



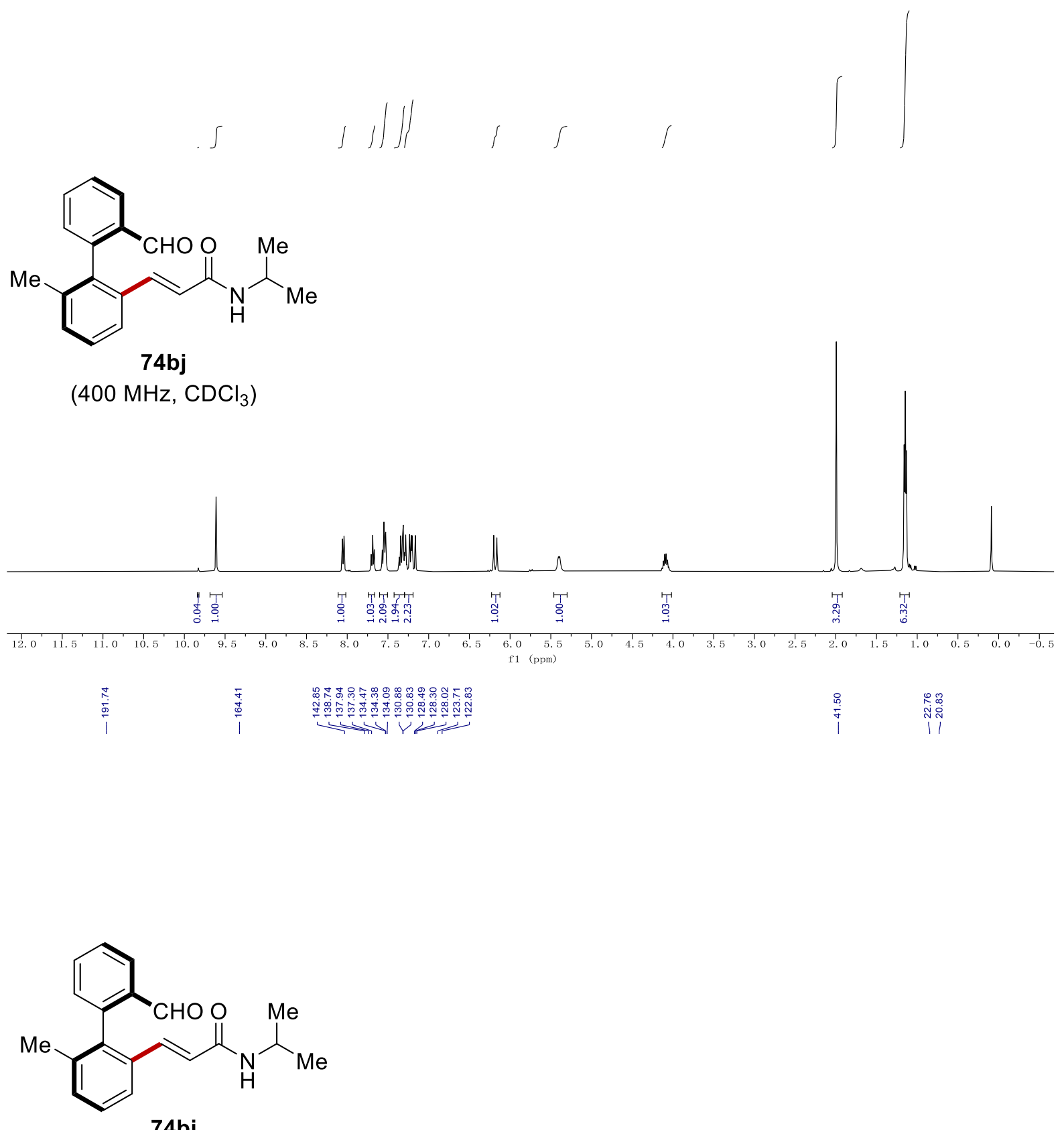

74bj

$\left(100 \mathrm{MHz} \mathrm{CDCl}_{3}\right)$

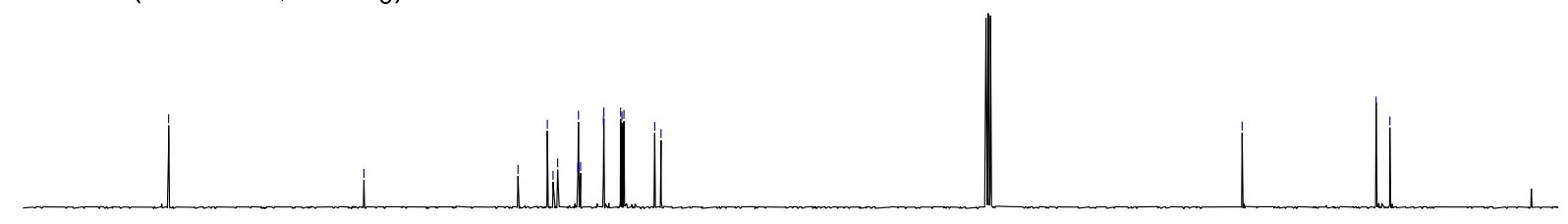

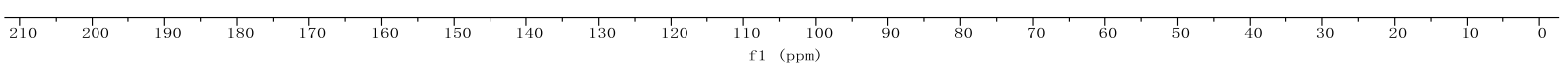


Chiral HPLC of 74bj:

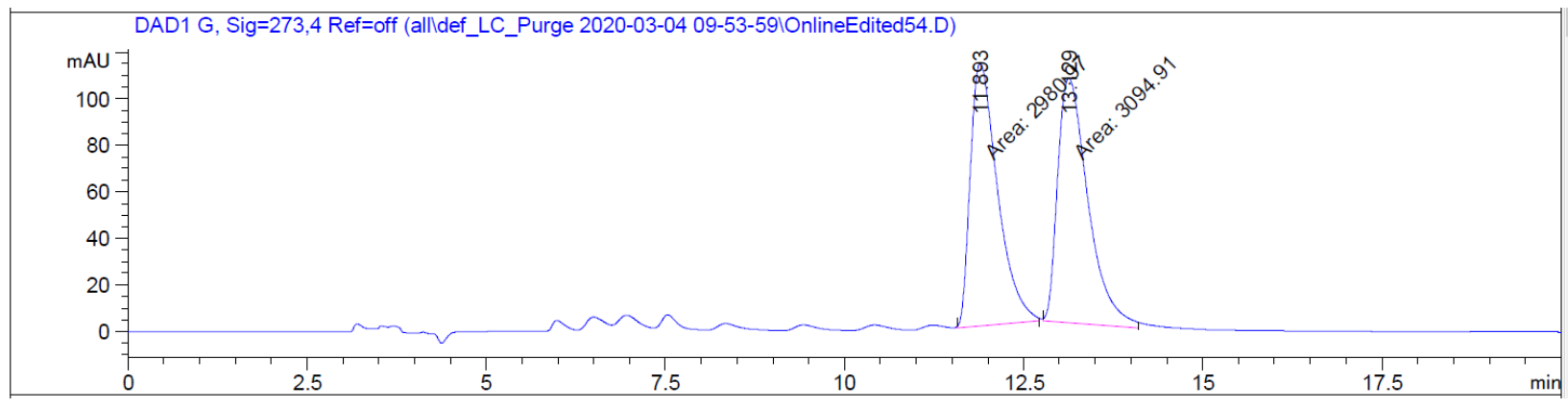

Peak RetTime Type Width Area Height Area

\# [min] $[\mathrm{min}] \quad\left[\mathrm{mAU}^{*} \mathrm{~s}\right] \quad[\mathrm{mAU}] \quad \%$

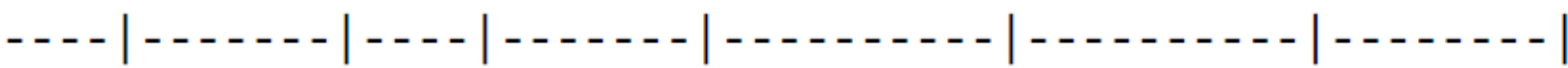

$\begin{array}{lllllll}1 & 11.893 & \text { MM } & 0.4406 & 2980.97485 & 112.75633 & 49.0624\end{array}$

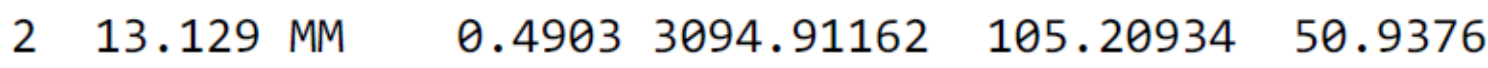

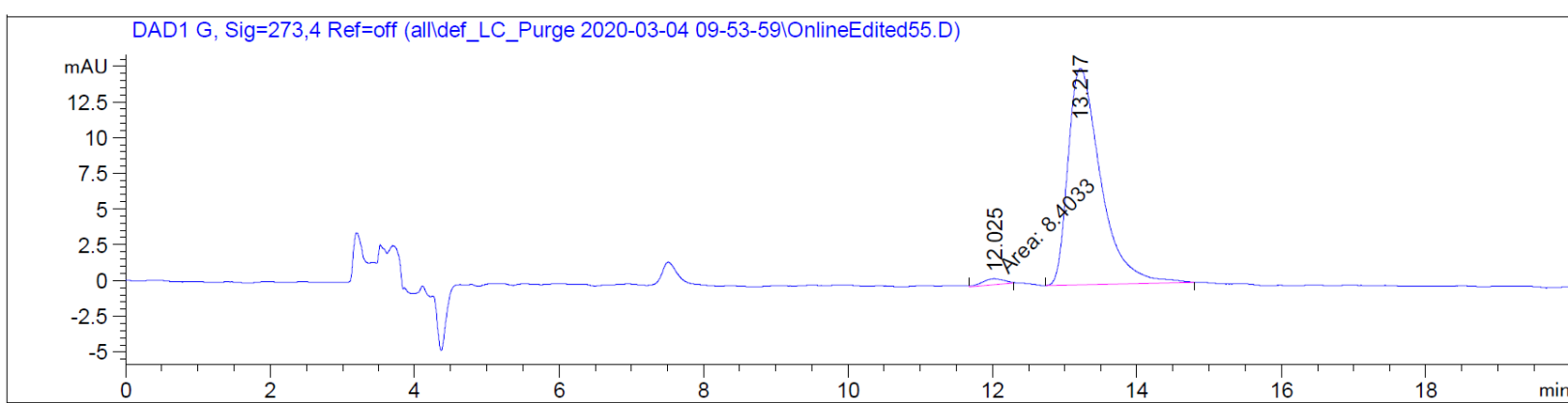

Peak RetTime Type width Area Height Area

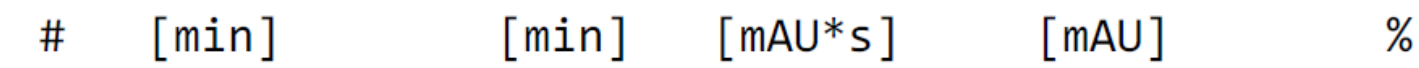

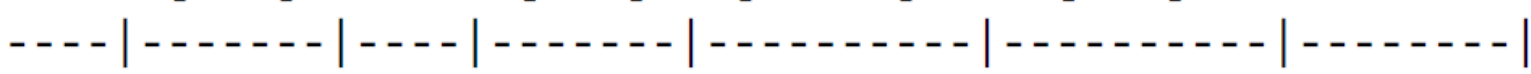

$\begin{array}{lllllll}1 & 12.025 & \text { MM } & 0.3340 & 8.40330 & 4.19342 \mathrm{e}-1 & 1.7344\end{array}$

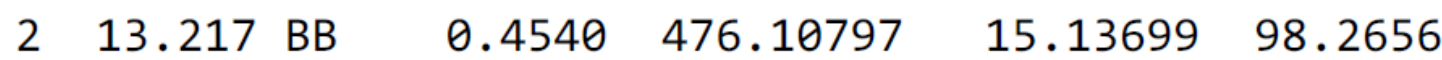




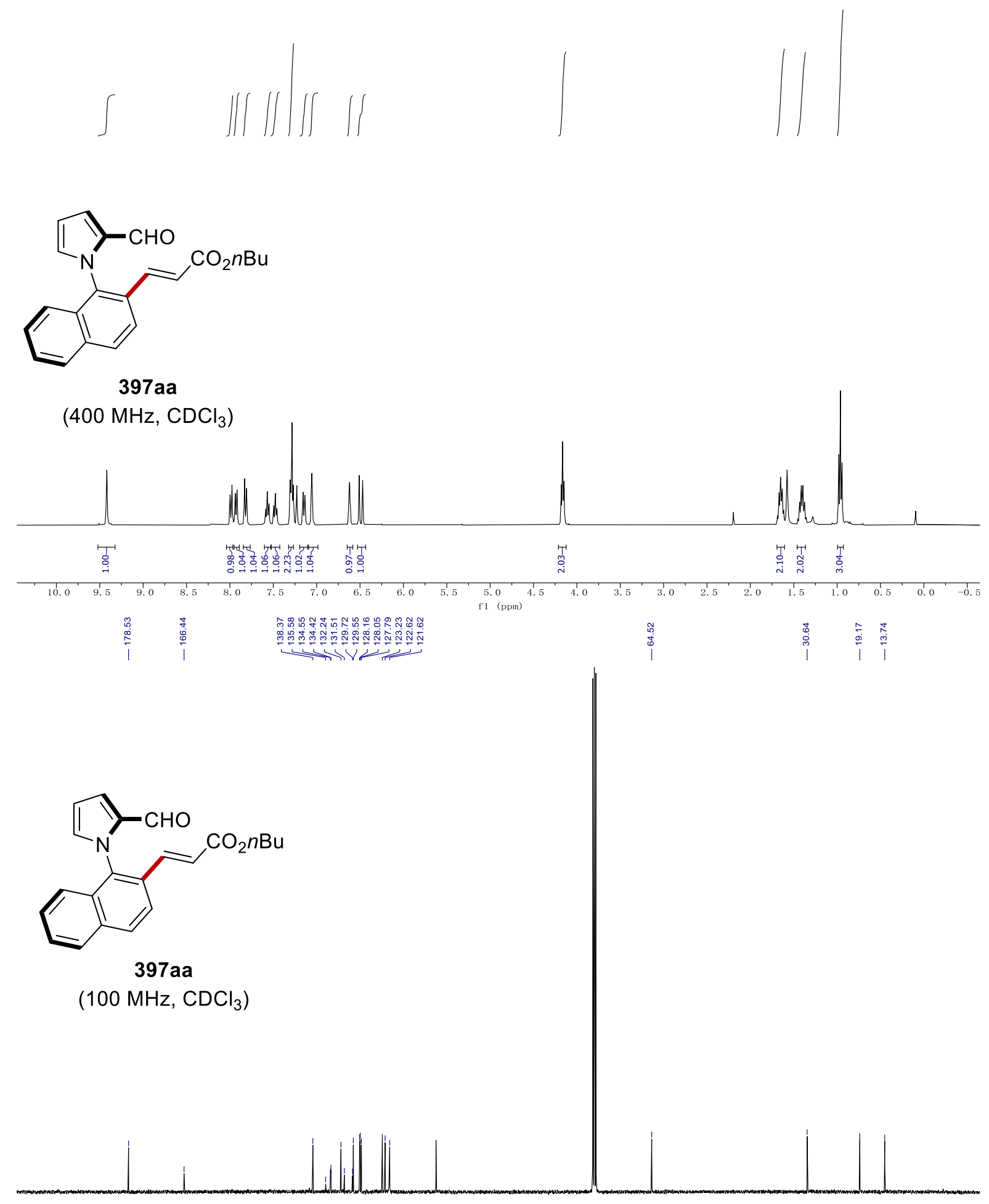

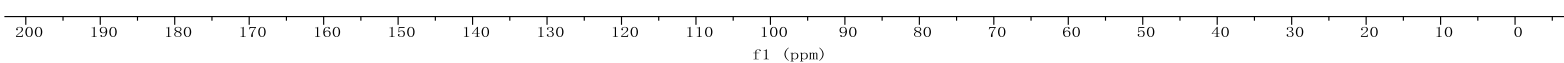


Chiral HPLC of 397aa:
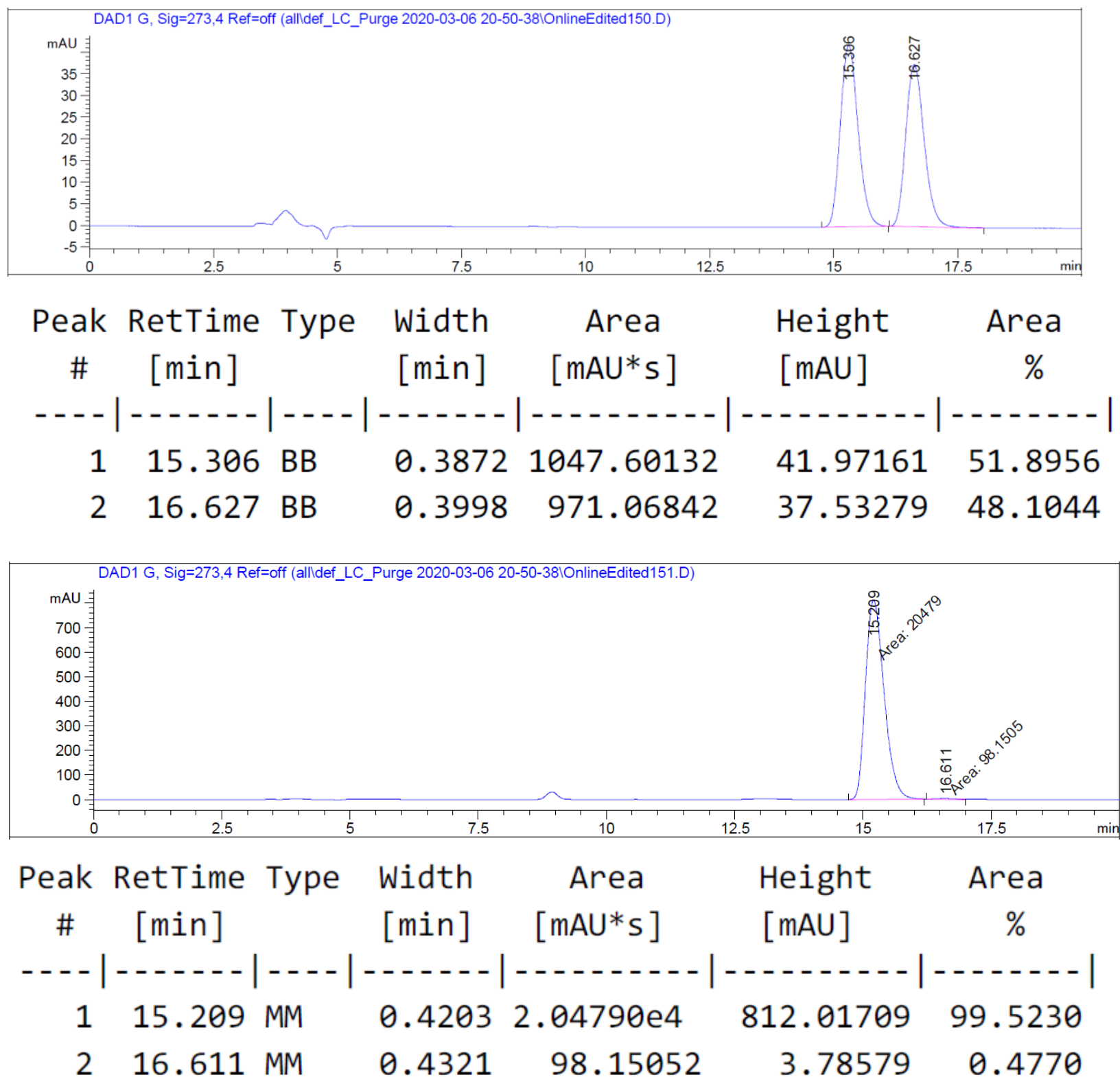

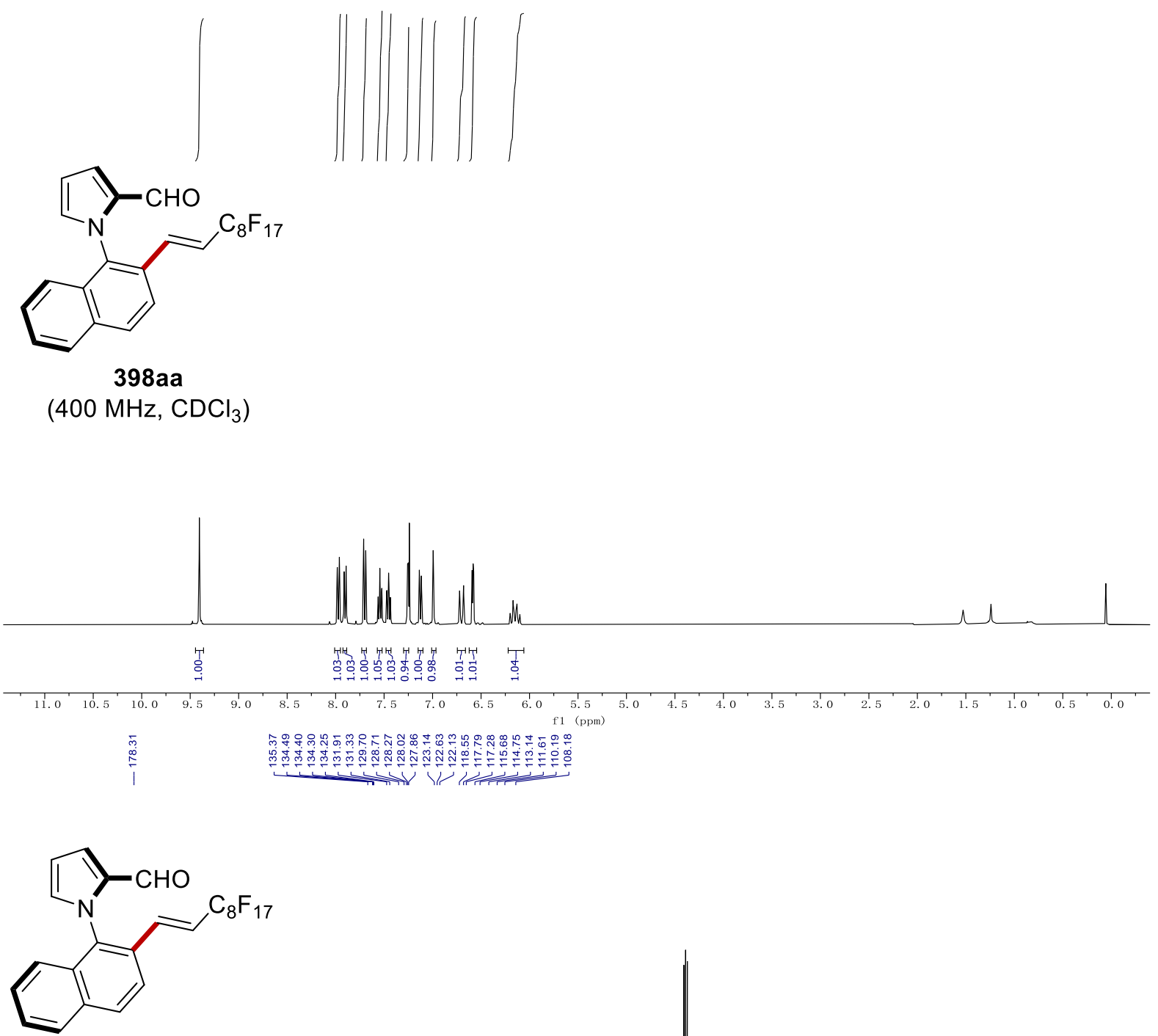

398aa
$\left(100 \mathrm{MHz}, \mathrm{CDCl}_{3}\right)$
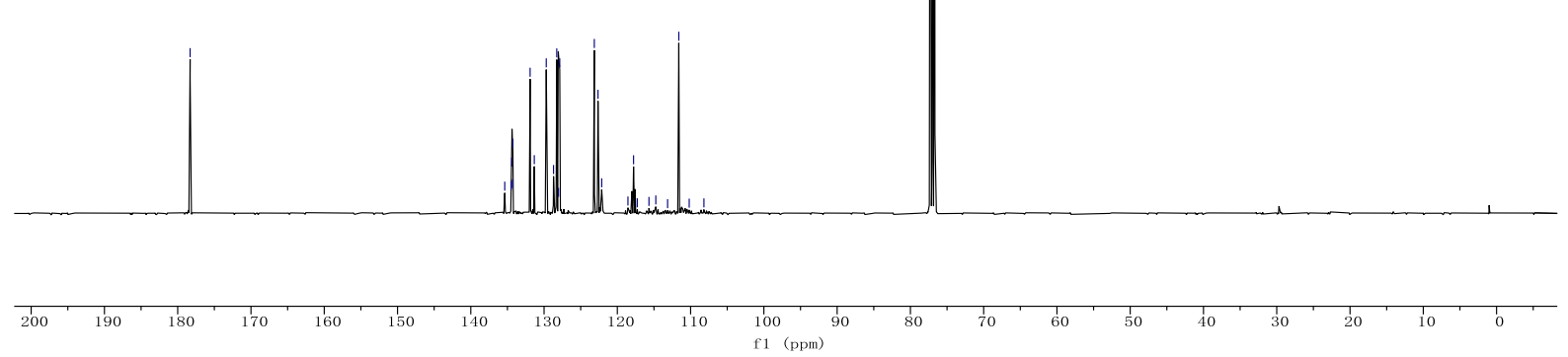

563 


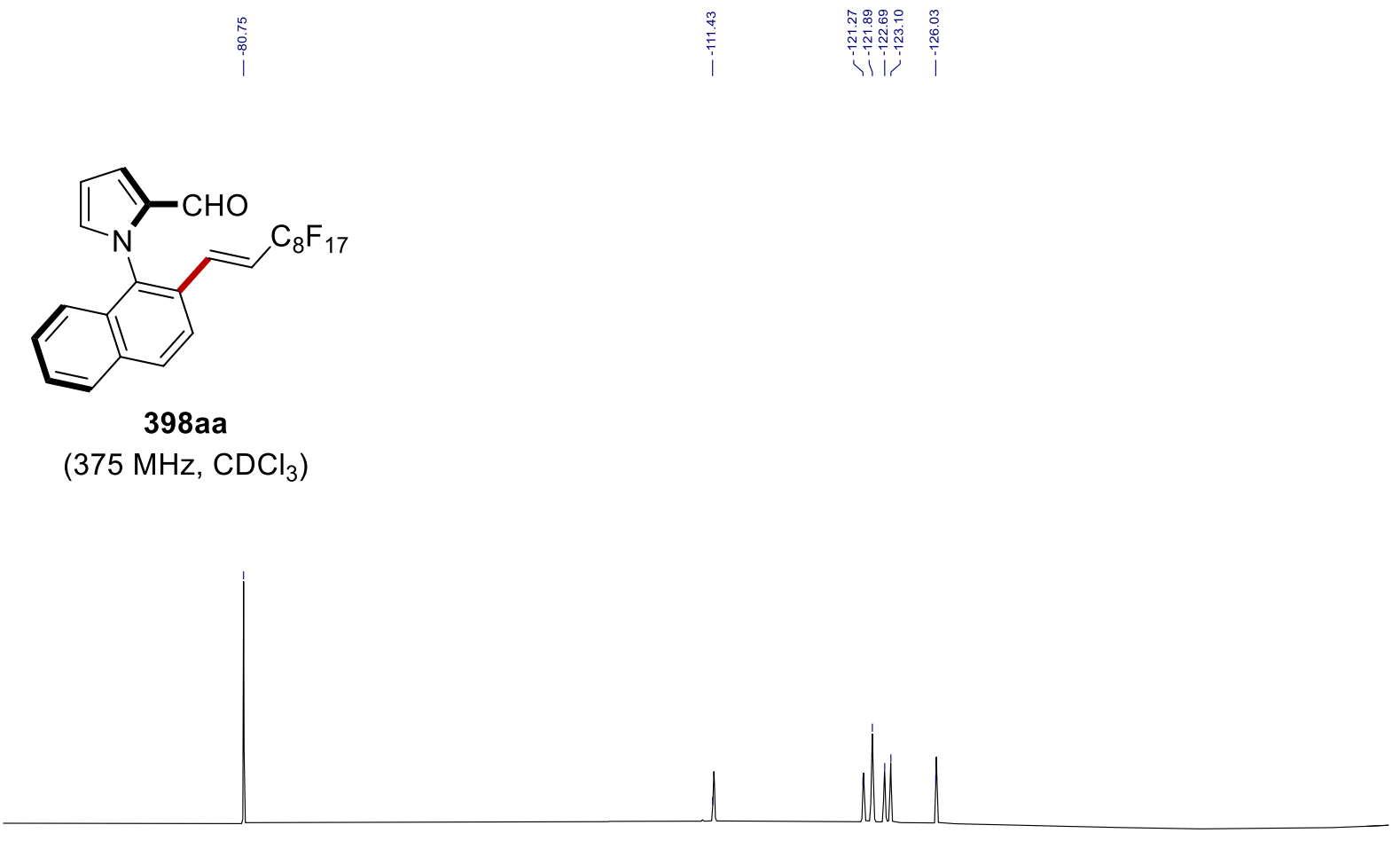

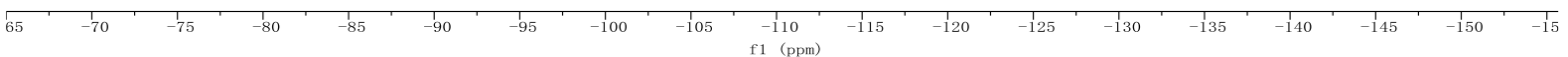


Chiral HPLC of 398aa:

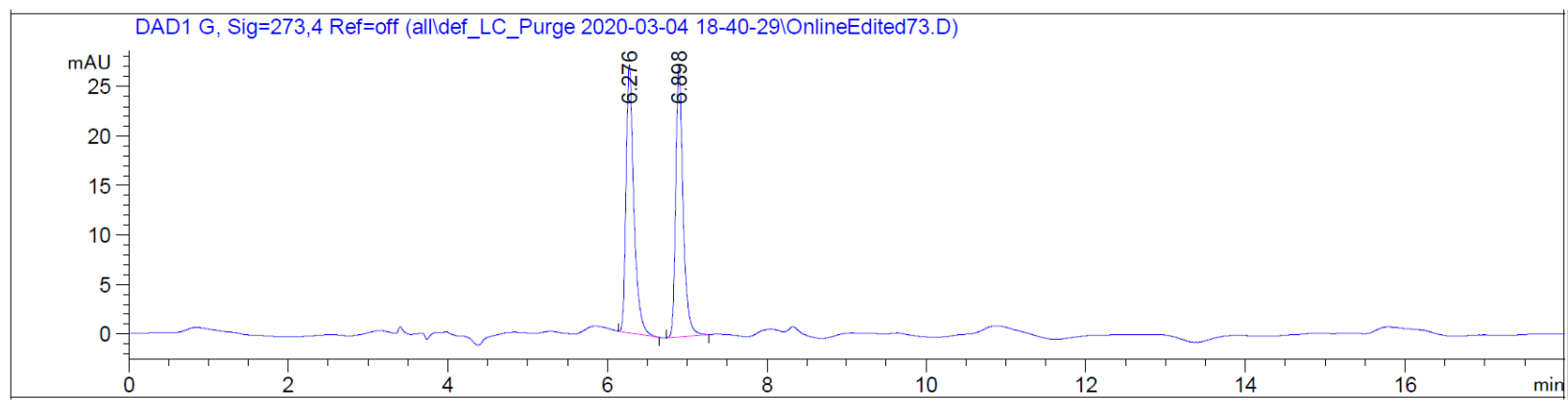

Peak RetTime Type Width Area Height Area

\# $\quad[\min ] \quad[\mathrm{min}] \quad[\mathrm{mAU} * \mathrm{~s}] \quad[\mathrm{mAU}] \quad \%$

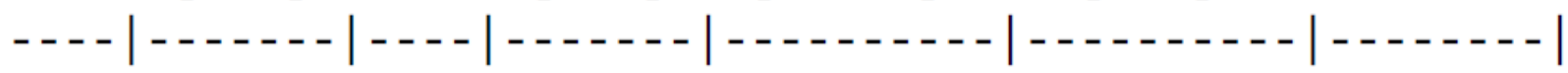

$1 \quad 6.276$ BB $\quad 0.1008 \quad 183.09755 \quad 27.10444 \quad 51.1153$

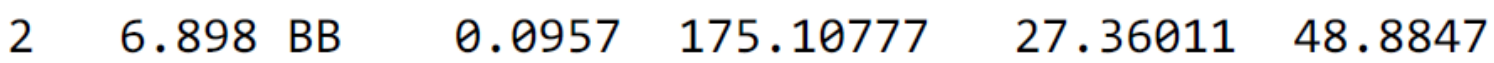

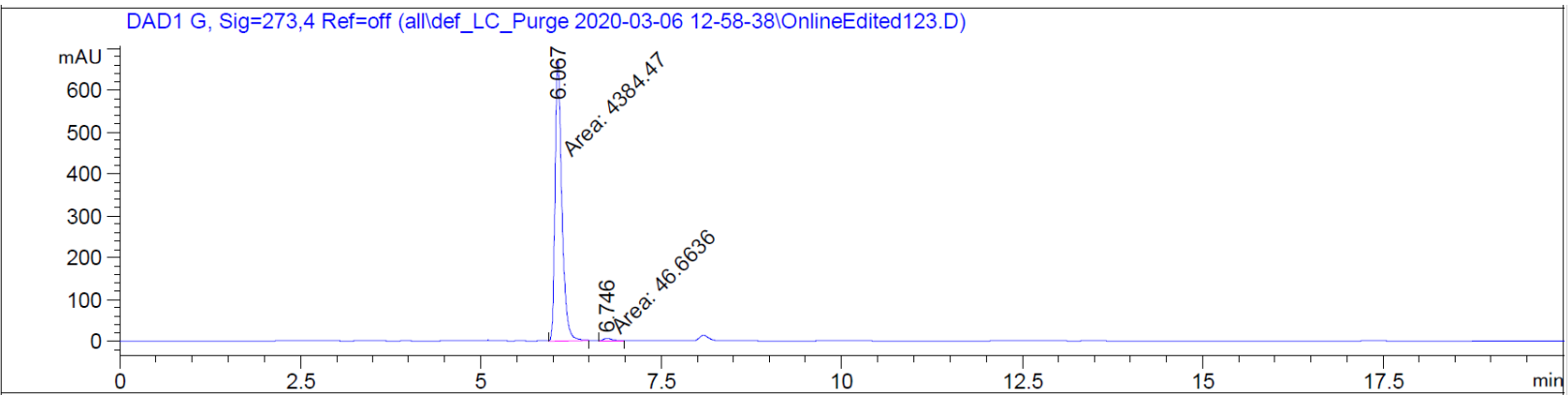

\begin{tabular}{|c|c|c|c|c|c|c|}
\hline Peak & RetTime & Type & Width & Area & Height & Area \\
\hline \# & [min] & & {$[\mathrm{min}]$} & {$\left[\mathrm{mAU}^{*} \mathrm{~s}\right]$} & {$[\mathrm{mAU}]$} & $\%$ \\
\hline
\end{tabular}

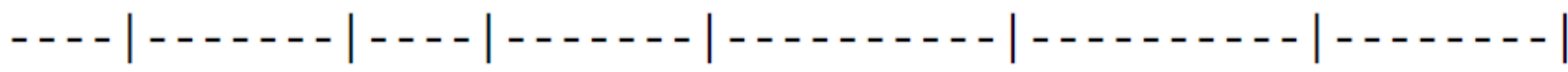

$1 \quad 6.067$ MM $\quad 0.1086 \quad 4384.47314 \quad 672.57892 \quad 98.9469$

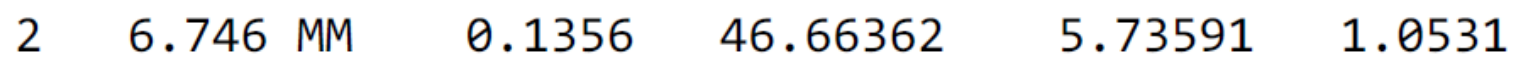



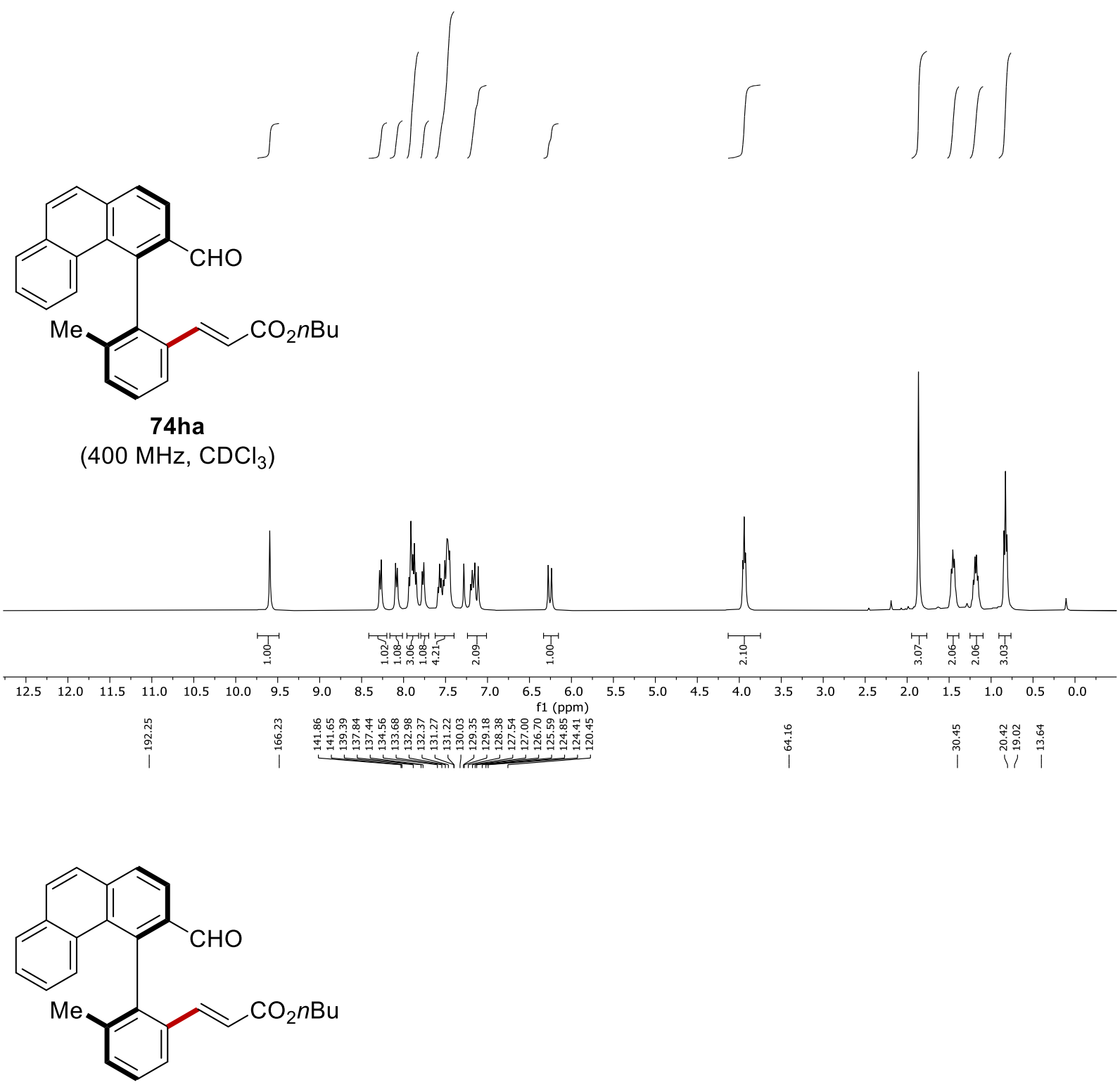

74ha

(100 MHz, $\mathrm{CDCl}_{3}$ )

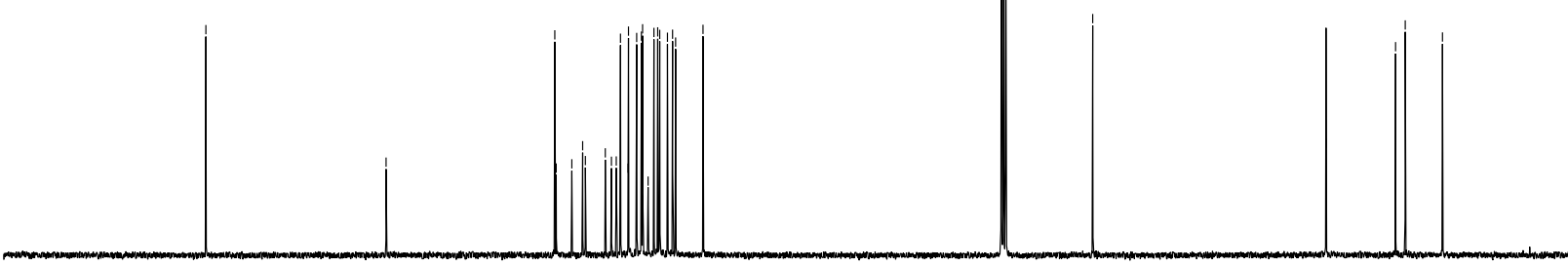

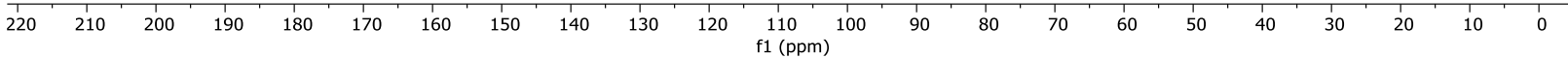


Chiral HPLC of 74ha:

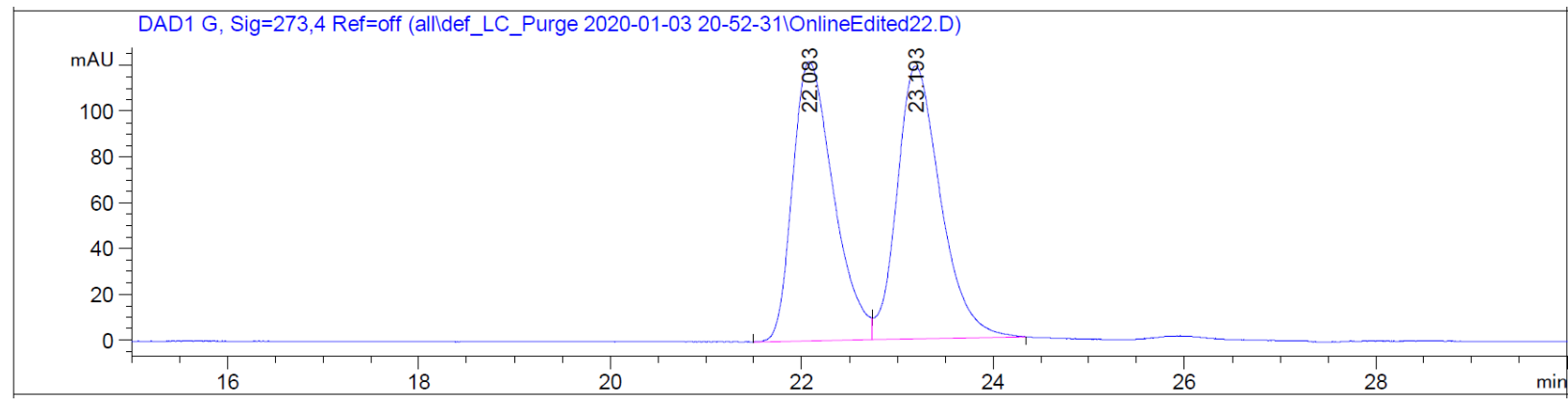

Peak RetTime Type width Area Height Area

\# $[\mathrm{min}] \quad[\mathrm{min}] \quad[\mathrm{mAU} * \mathrm{~s}] \quad[\mathrm{mAU}] \quad \%$

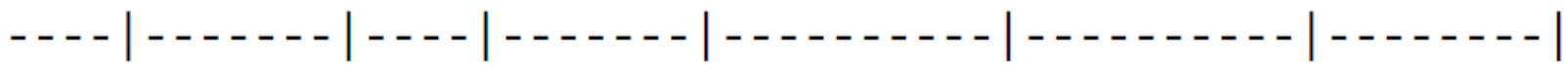
$\begin{array}{lllllll}1 & 22.083 & \text { BV } & 0.4136 & 3627.21289 & 122.07781 & 49.1056\end{array}$ $\begin{array}{lllllll}2 & 23.193 & \text { VV R } & 0.4450 & 3759.34546 & 119.16909 & 50.8944\end{array}$

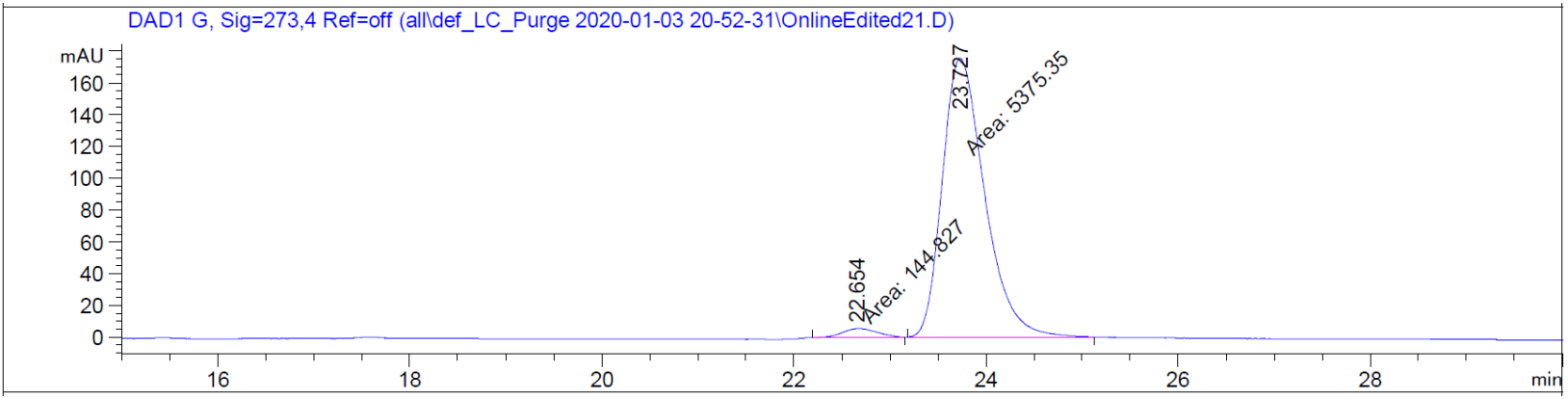

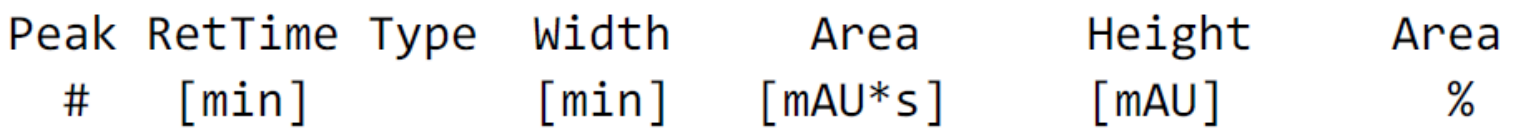

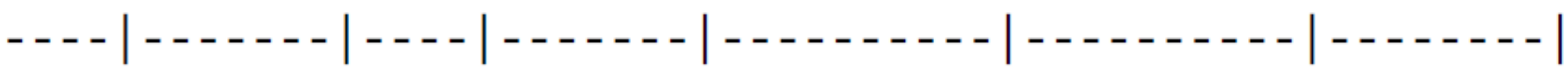

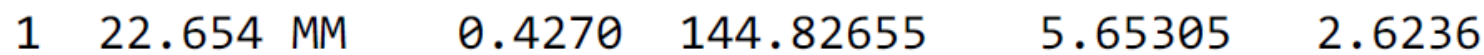
$\begin{array}{lllllll}2 & 23.727 & \text { MM } & 0.5103 & 5375.34961 & 175.55560 & 97.3764\end{array}$ 


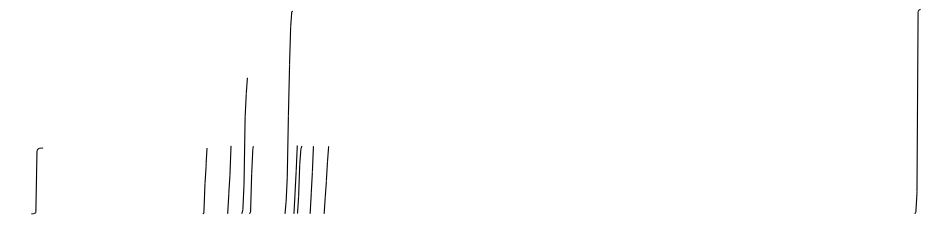<smiles>Cc1ccccc1-c1c(C=O)ccc2ccc3ccccc3c12</smiles>

$73 \mathrm{~h}$

(600 MHz, $\mathrm{CDCl}_{3}$ )

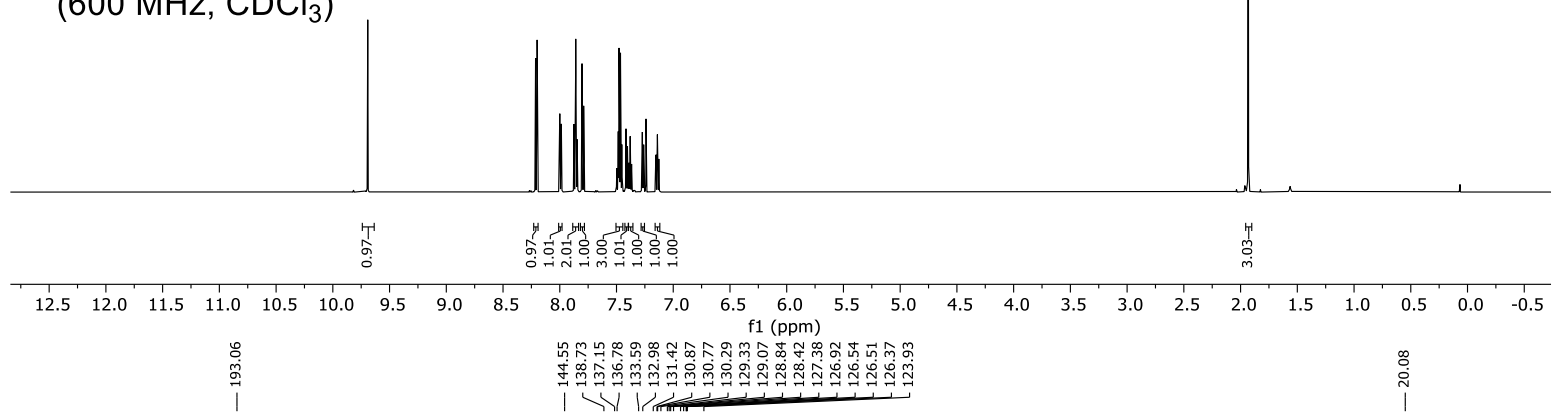<smiles>Cc1ccccc1-c1c(C=O)ccc2ccc3ccccc3c12</smiles>

73h

(150 MHz, $\mathrm{CDCl}_{3}$ )

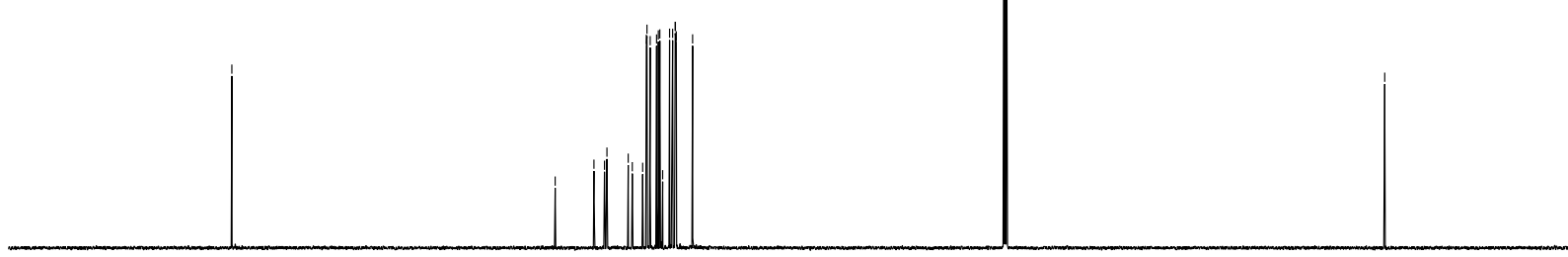

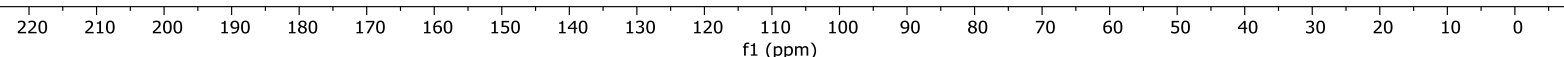


Chiral HPLC of 73h:
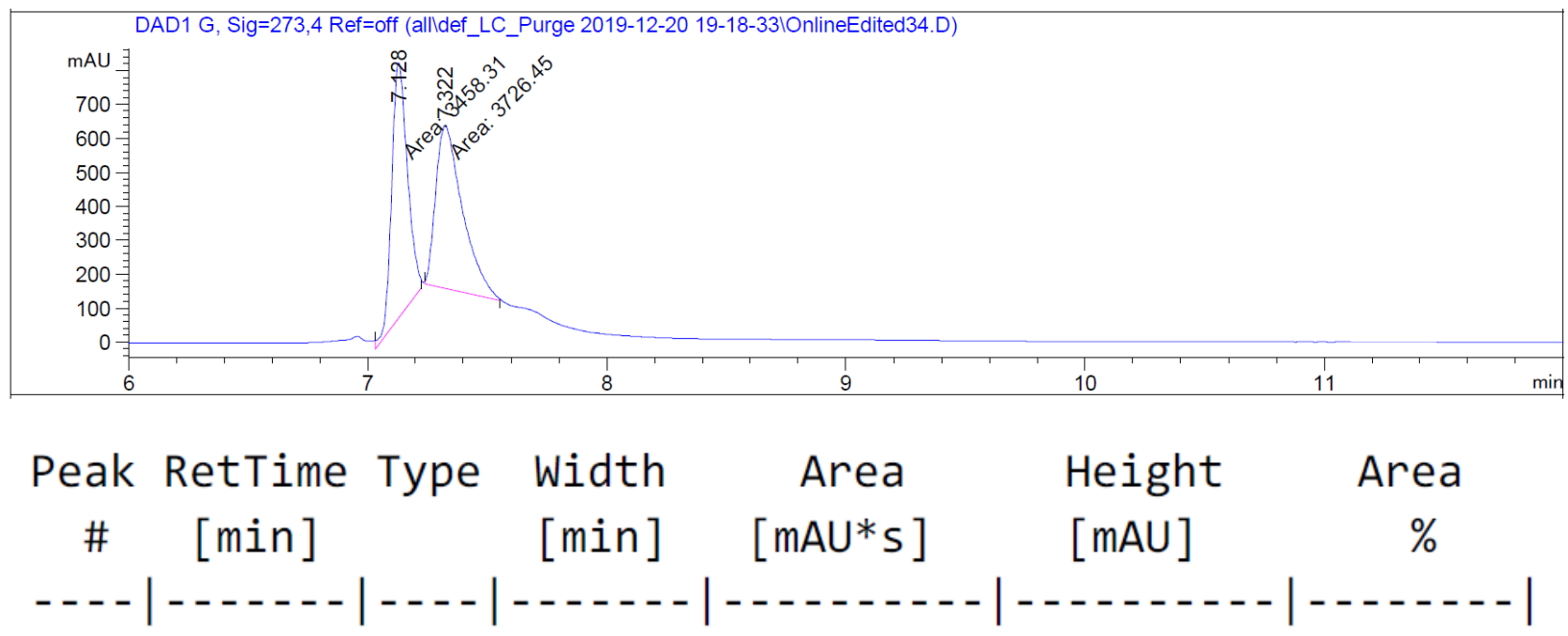

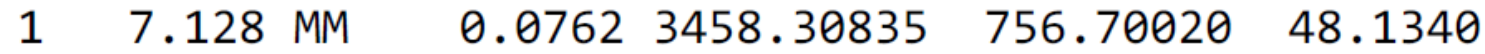

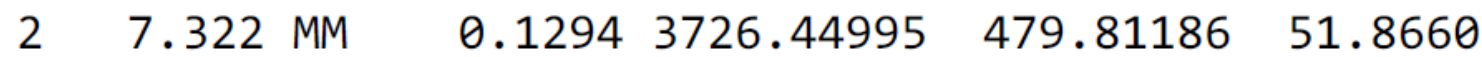

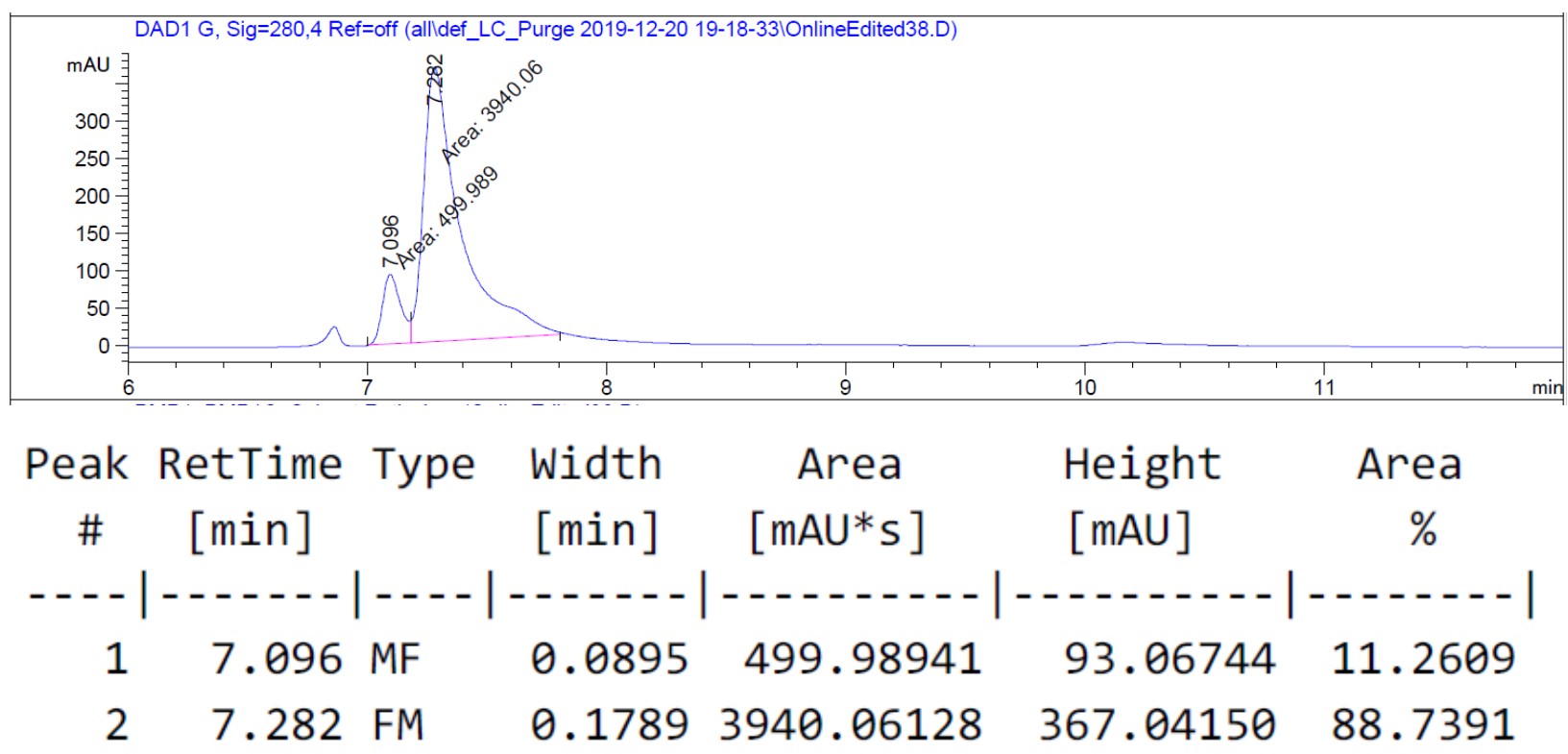




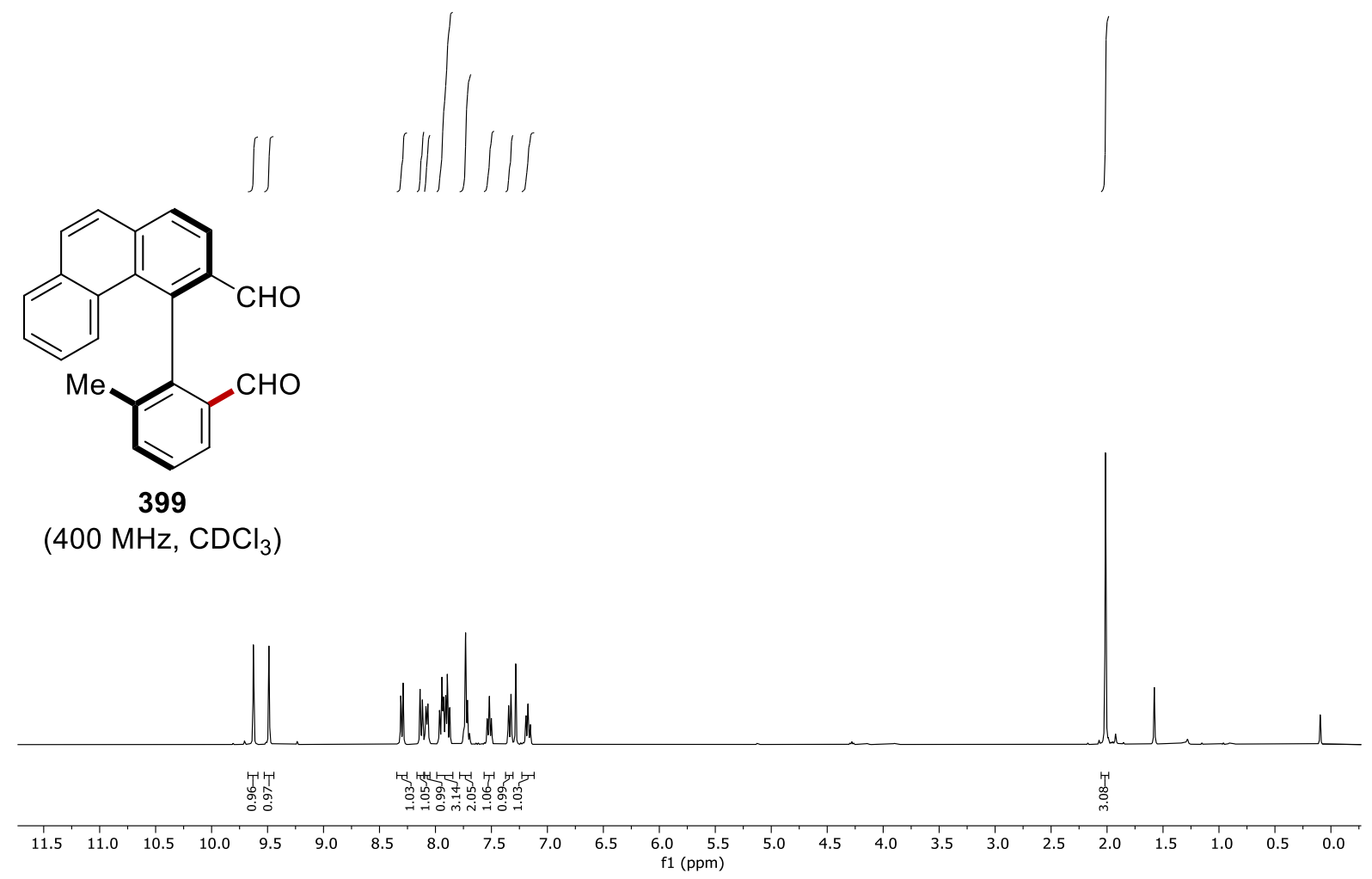

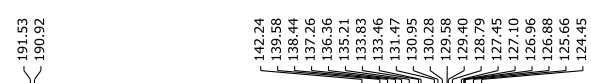

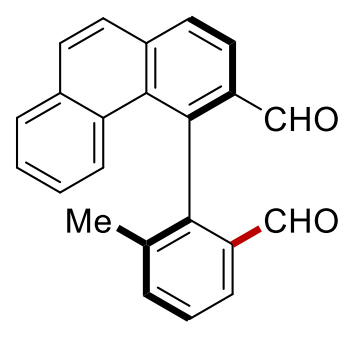

399

(100 MHz, $\mathrm{CDCl}_{3}$ )

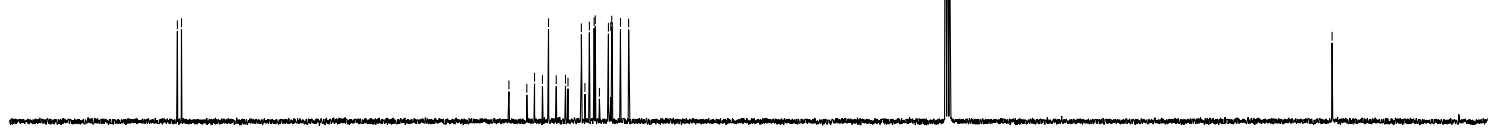

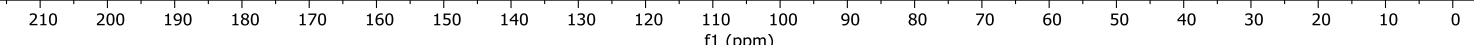



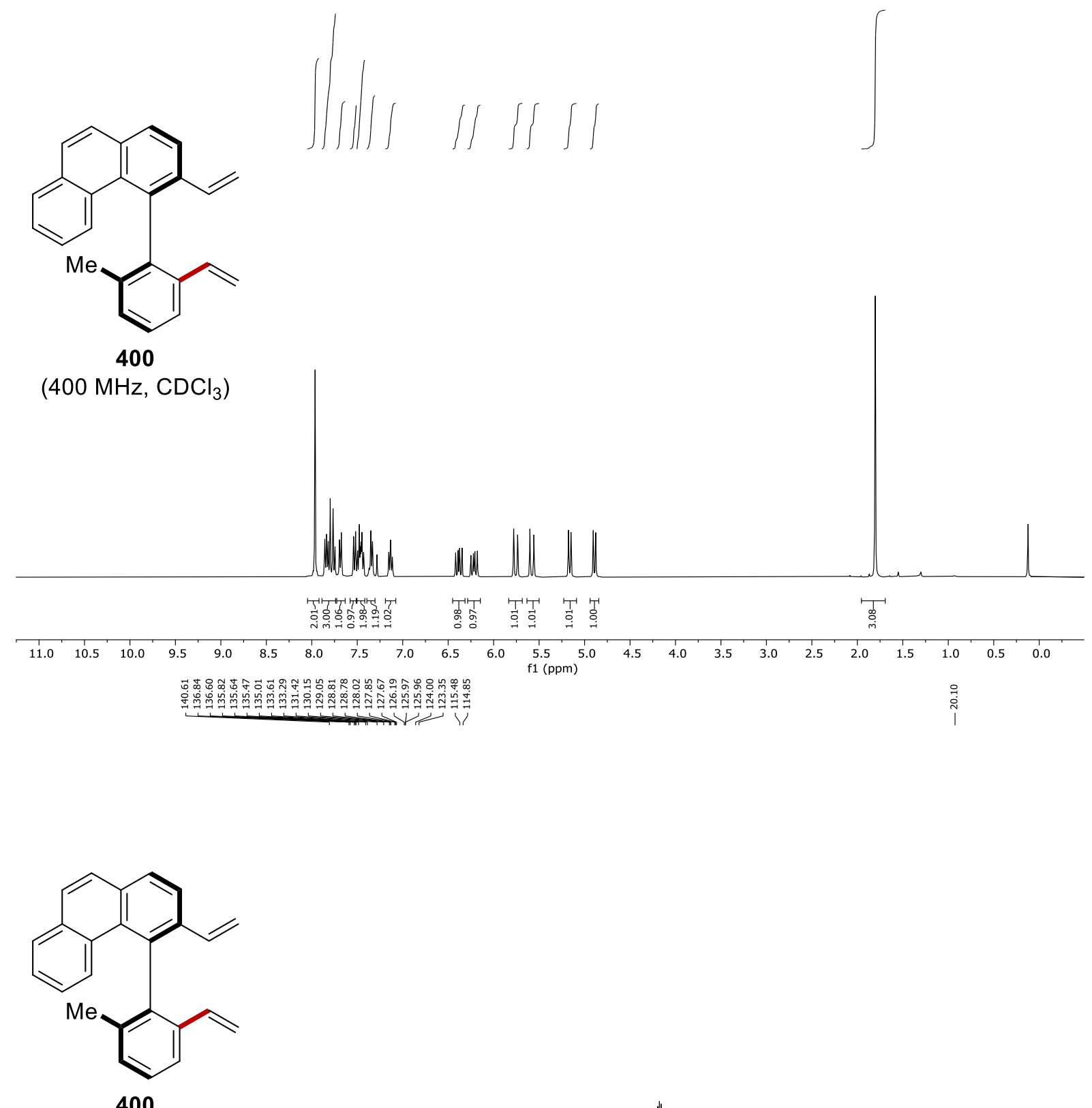

(100 MHz, CDCl3)

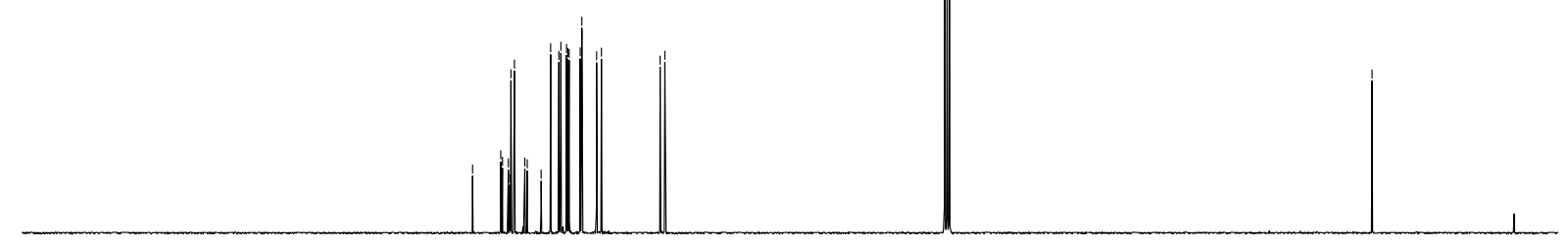

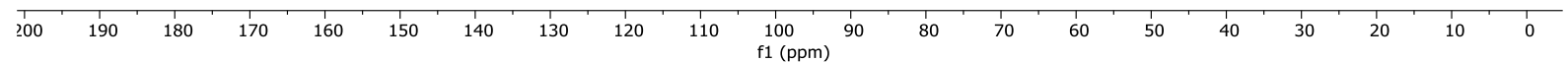




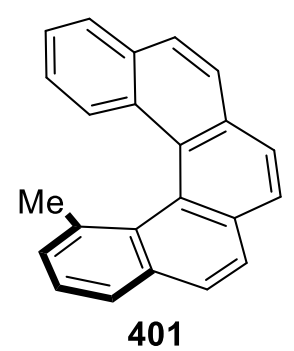

|l| || ||

(600 MHz, $\mathrm{CDCl}_{3}$ )
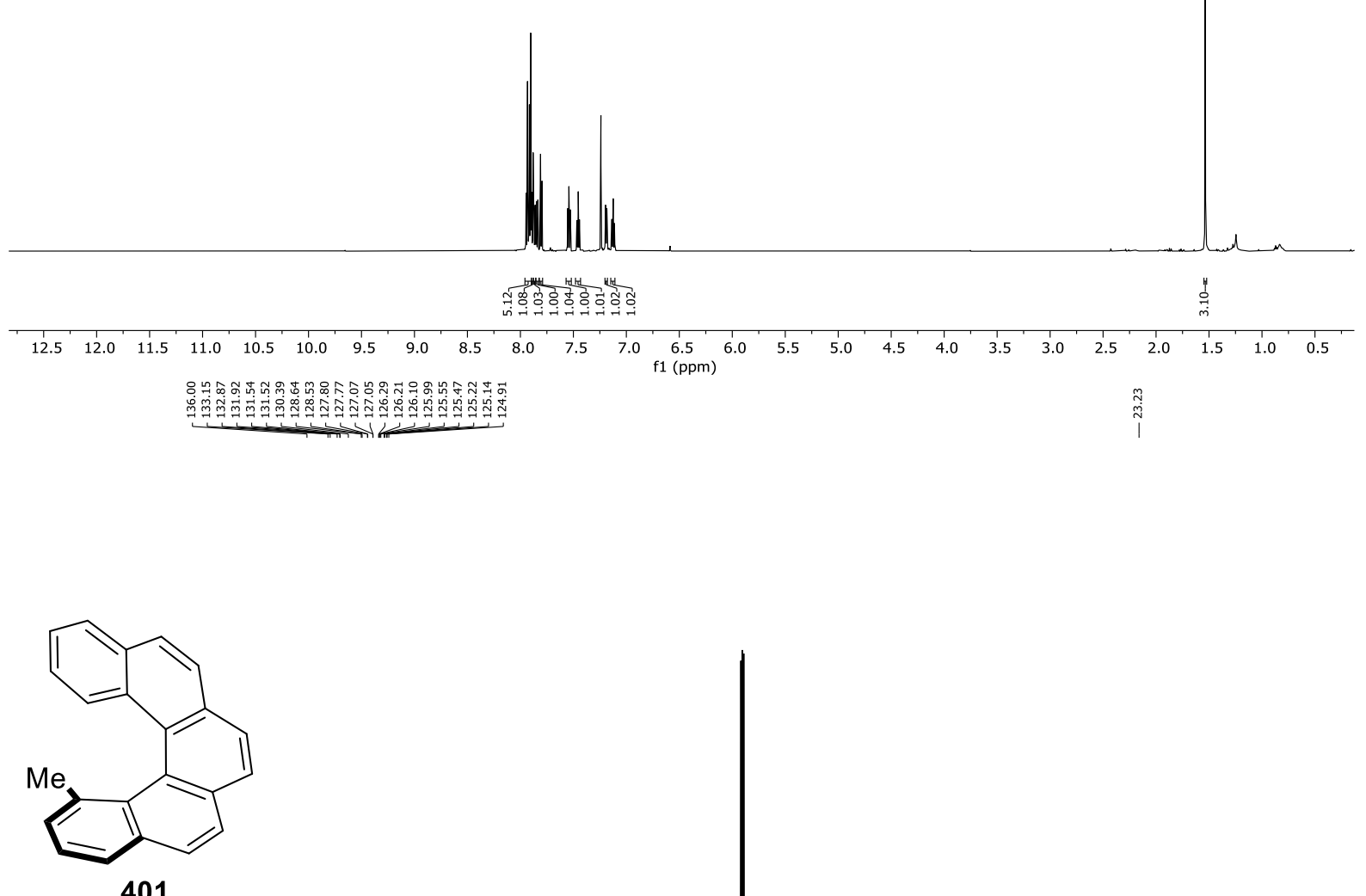

(150 MHz, $\mathrm{CDCl}_{3}$ )
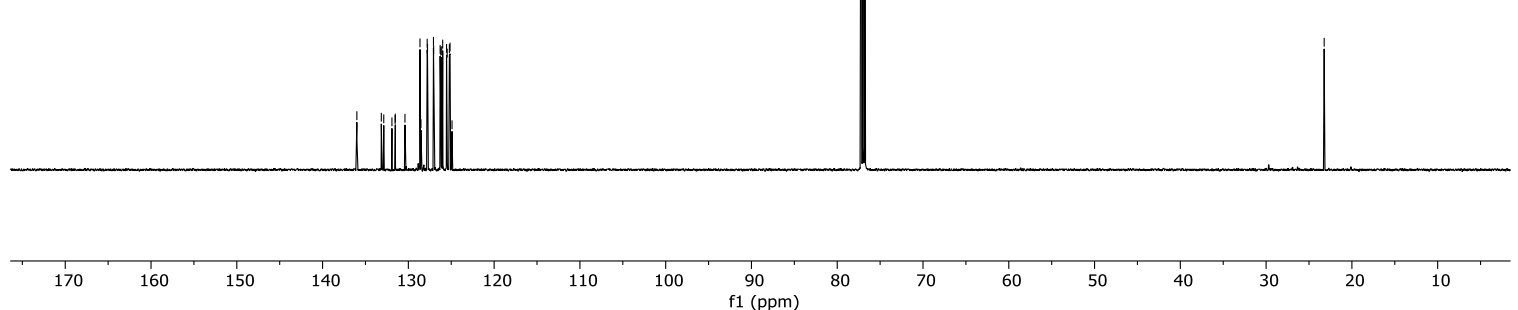
Chiral HPLC of 401:

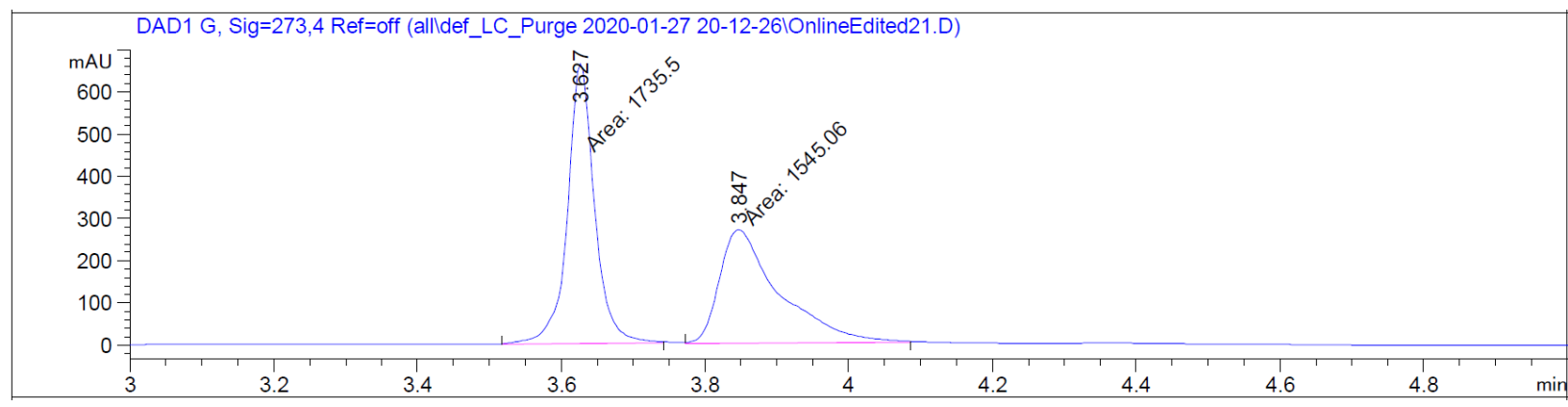

Peak RetTime Type width Area Height Area $\# \quad[\mathrm{~min}]$
$\mathrm{n}$

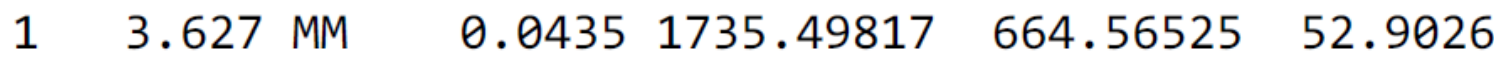

$\begin{array}{lllllll}2 & 3.847 \text { MM } & 0.0956 & 1545.05713 & 269.50018 & 47.0974\end{array}$

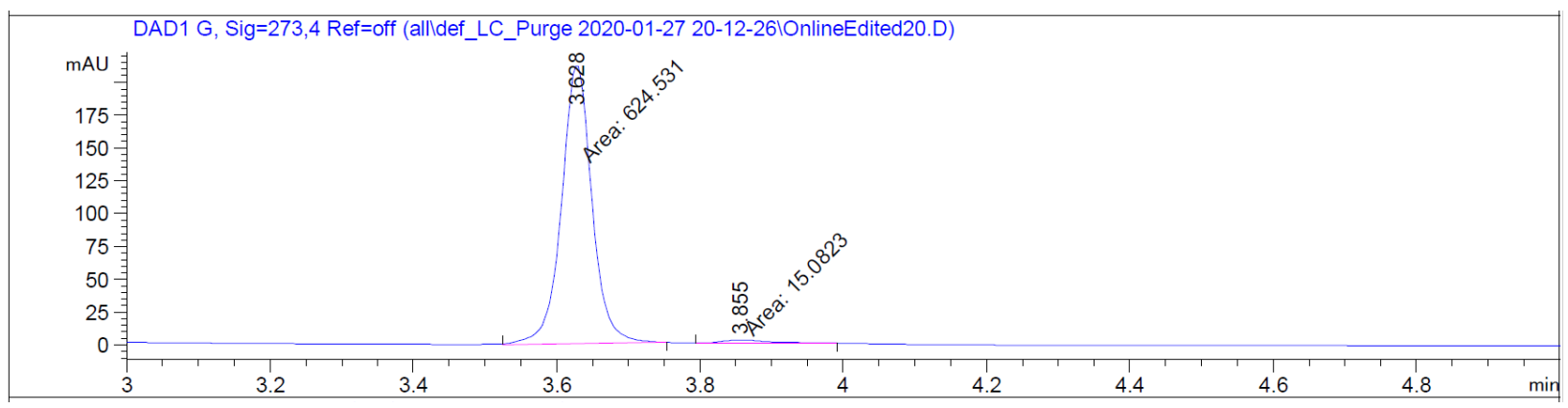

\begin{tabular}{cccccc}
$\begin{array}{c}\text { Peak RetTime Type } \\
\text { \# }\end{array}$ Width & $\begin{array}{c}\text { Area } \\
\text { [min] }\end{array}$ & Height & Area \\
[min] & {$[$ mAU*s $]$} & [mAU] & $\%$ \\
\hline 1 & 3.628 MM & 0.0491 & 624.53143 & 212.18314 & 97.6420 \\
2 & 3.855 MM & 0.0893 & 15.08230 & 2.81371 & 2.3580
\end{tabular}




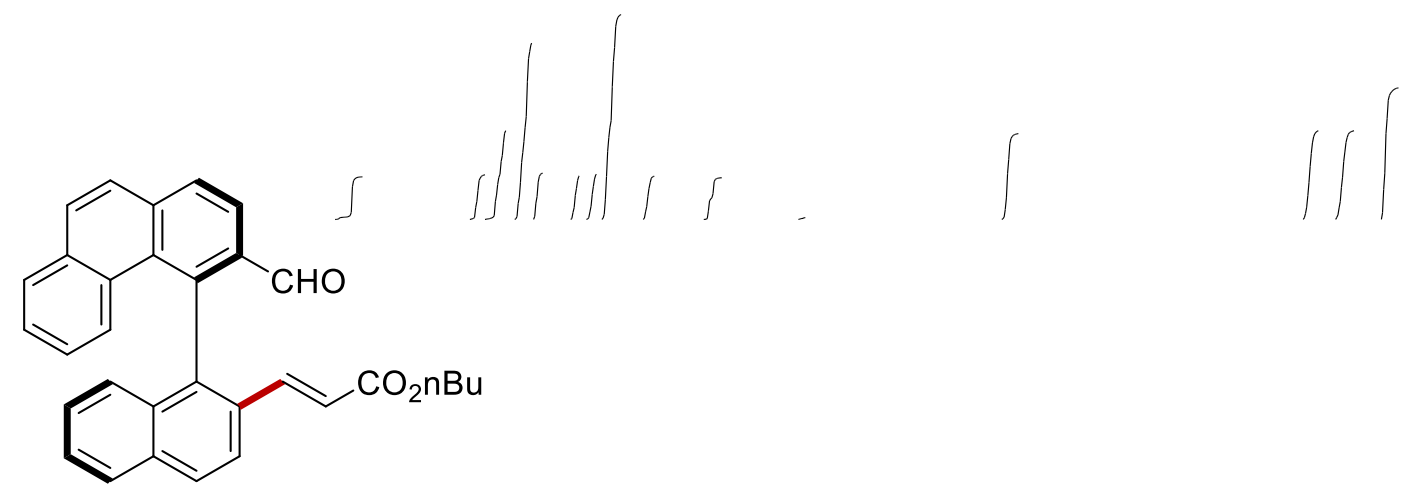

$74 i a$

(400 MHz, $\mathrm{CDCl}_{3}$ )
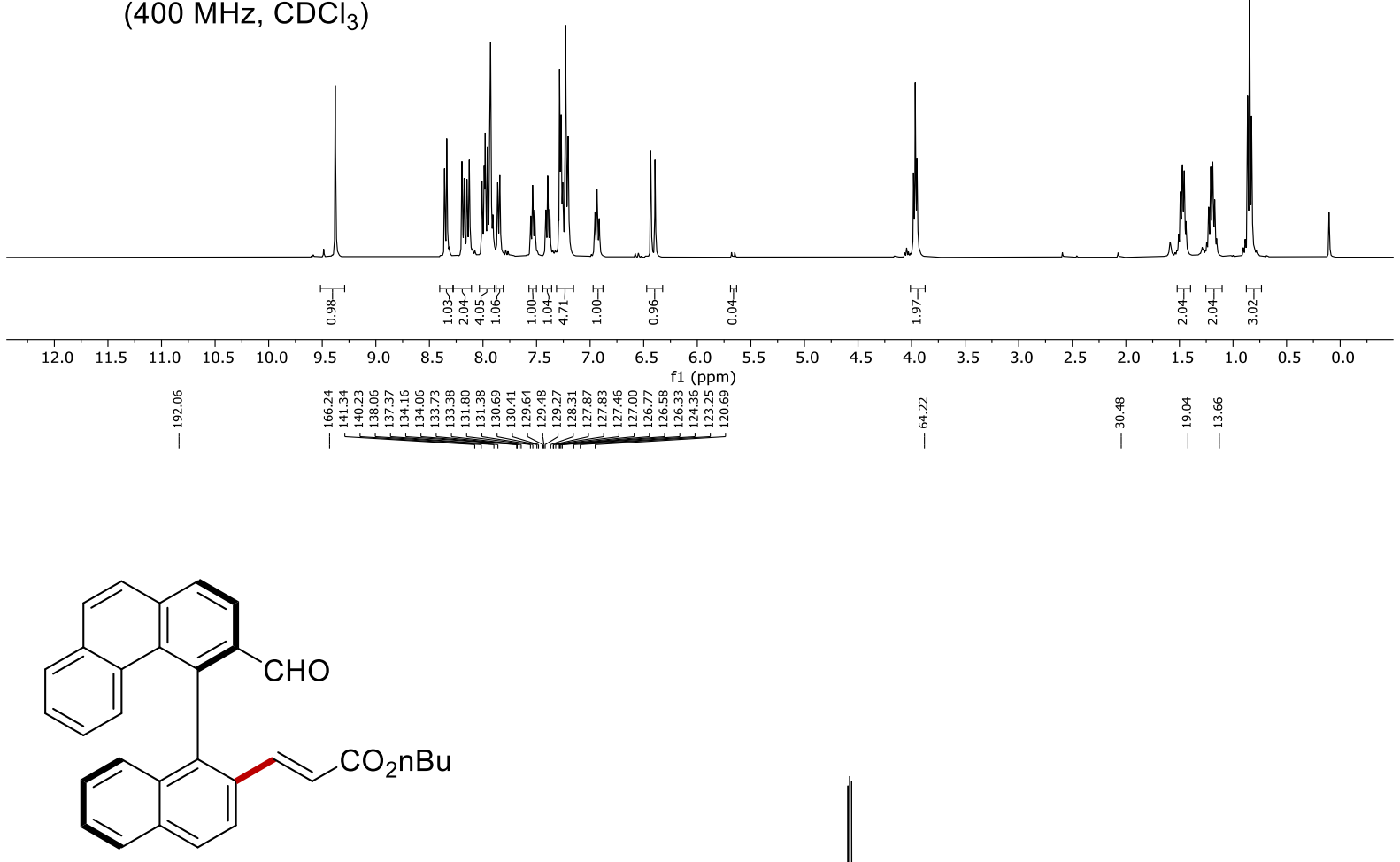

$74 i a$

$\left(100 \mathrm{MHz}, \mathrm{CDCl}_{3}\right)$

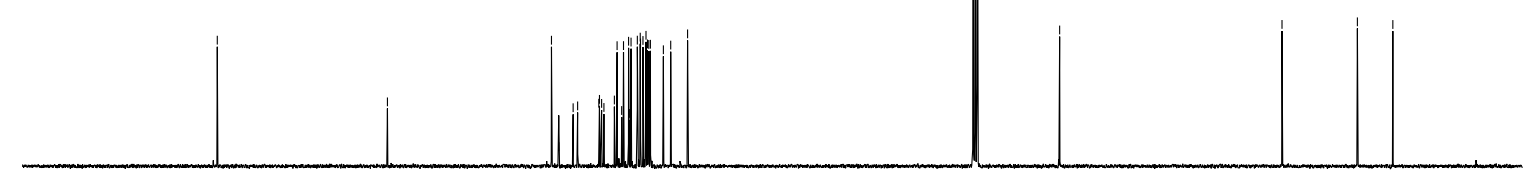

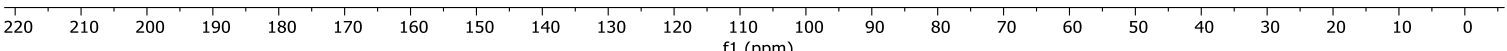


Chiral HPLC of 74ia:

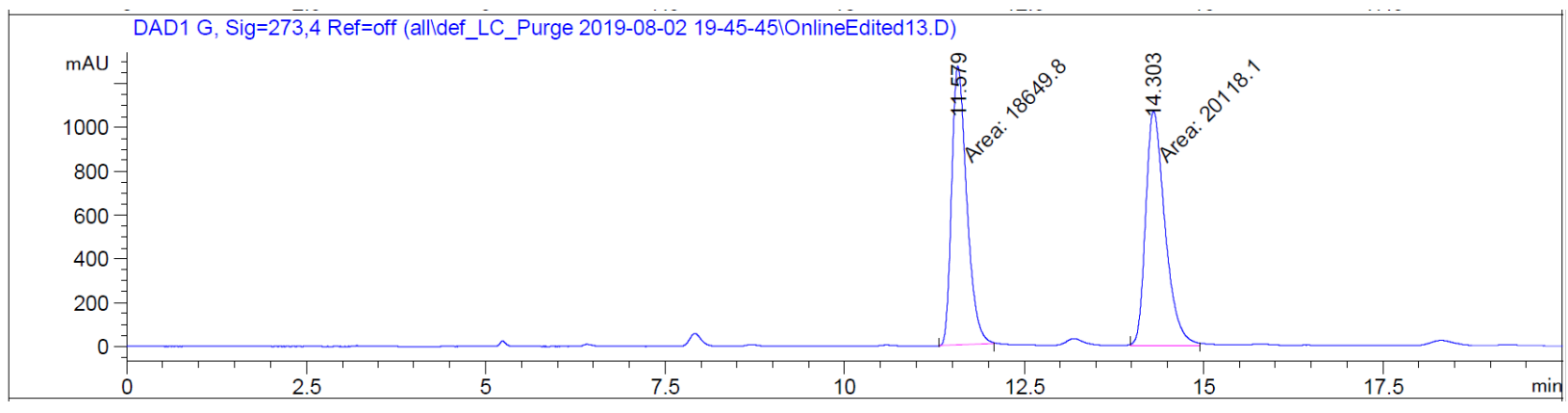

Peak RetTime Type Width Area Height Area
\# [min]
[min $\quad\left[\mathrm{mAU}^{*} \mathrm{~s}\right]$
[mAU]
$\%$

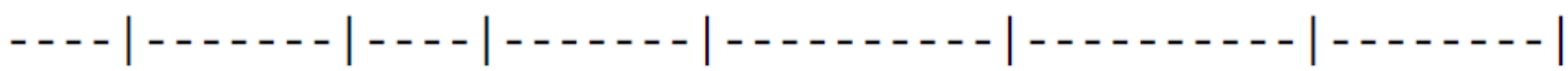

$\begin{array}{lllllll}1 & 11.579 & \text { MM } & 0.2440 & 1.86498 \mathrm{e} 4 & 1273.93860 & 48.1064\end{array}$

214.303 MM $0.3132 \quad 2.01181 \mathrm{e} 4 \quad 1070.61853 \quad 51.8936$

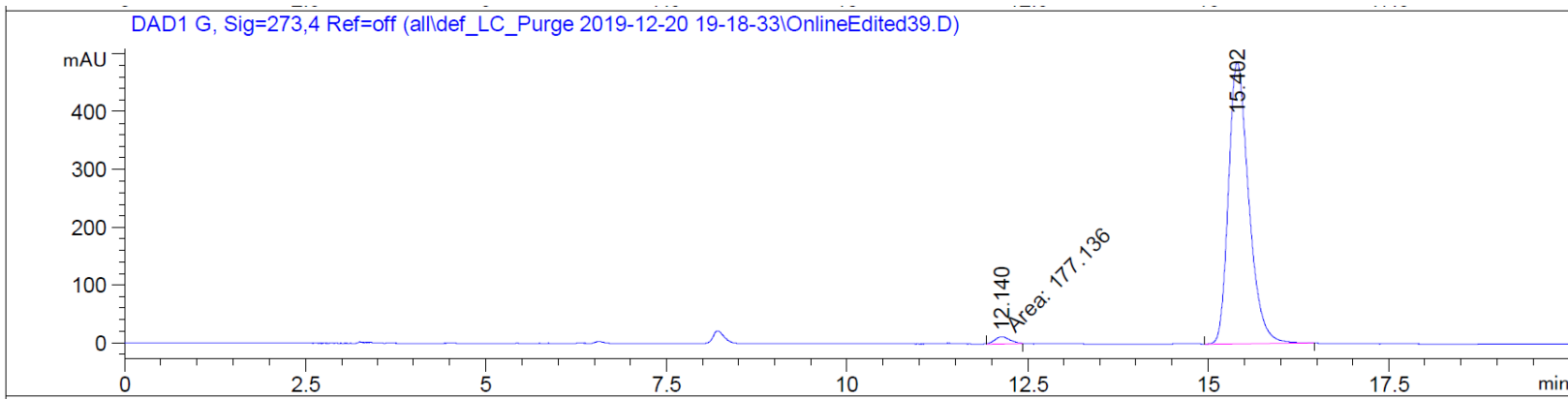

Peak RetTime Type Width Area Height Area

$\begin{array}{lll}\text { \# }[\mathrm{min}] & {[\mathrm{min}] \quad\left[\mathrm{mAU} \mathrm{U}^{*}\right] \quad[\mathrm{mAU}]} & \%\end{array}$

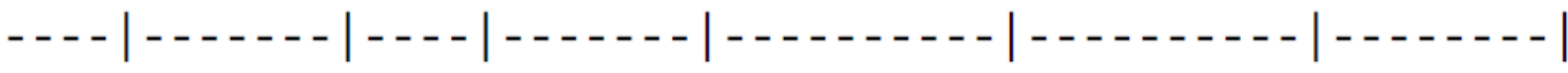

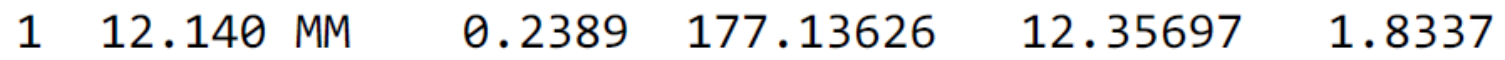

$2 \quad 15.402$ BB $\quad 0.29639483 .09766 \quad 486.6801198 .1663$ 
HPLC spectra (-)74ia

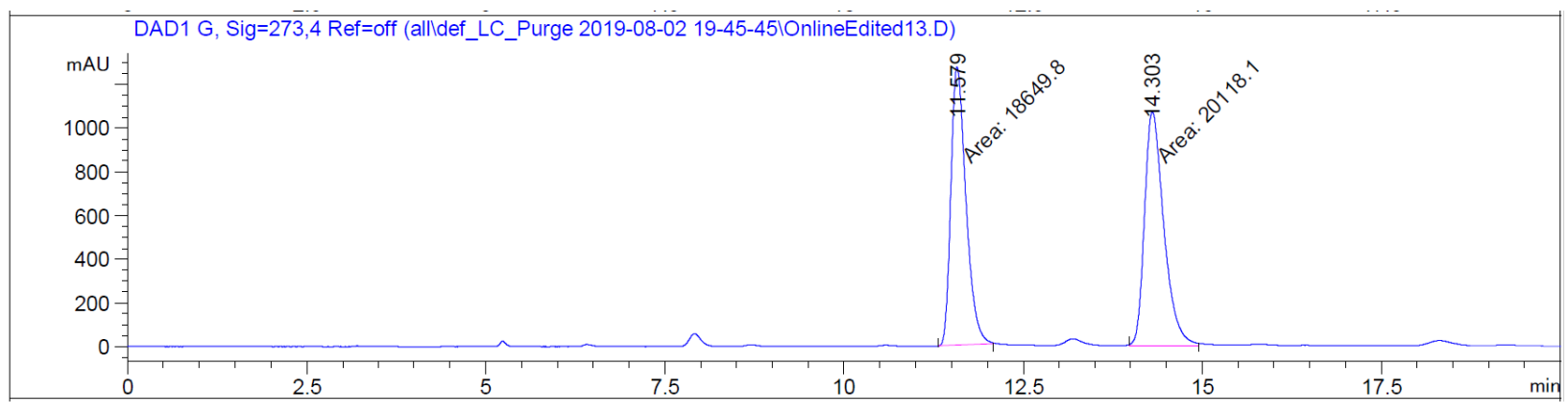

Peak RetTime Type Width Area Height Area
\# [min]
[min] [mAU*s ]
[mAU]
$\%$

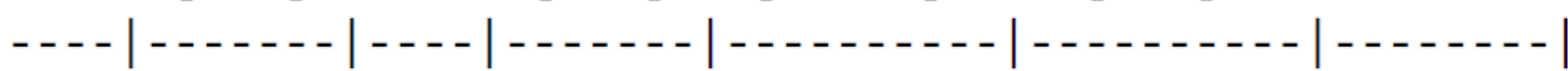

$\begin{array}{lllllll}1 & 11.579 & \text { MM } & 0.2440 & 1.86498 \mathrm{e} 4 & 1273.93860 & 48.1064\end{array}$

$\begin{array}{lllllll}2 & 14.303 & \text { MM } & 0.3132 & 2.01181 \mathrm{e} 4 & 1070.61853 & 51.8936\end{array}$

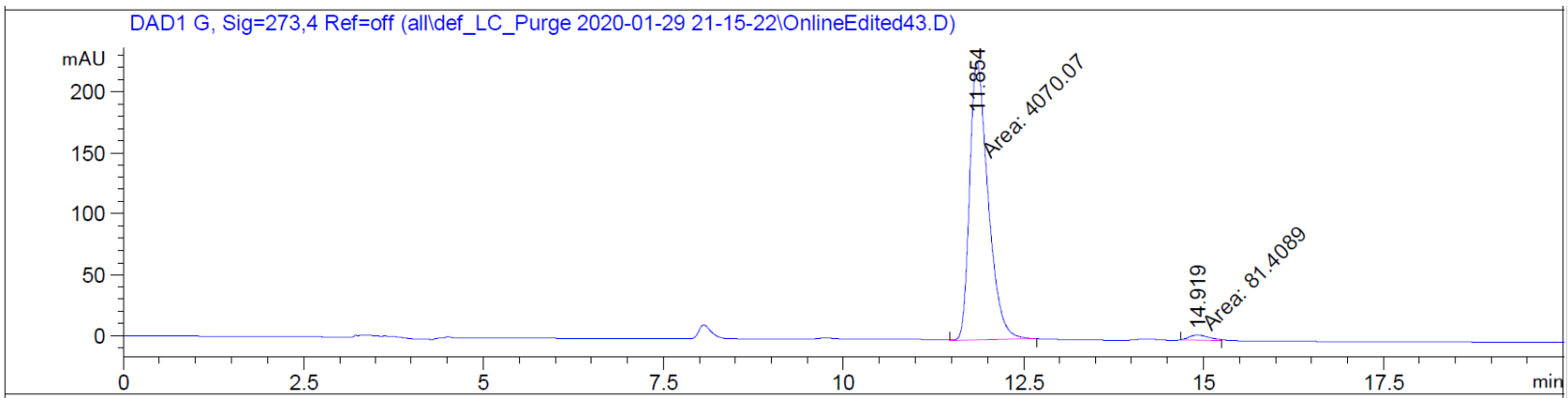

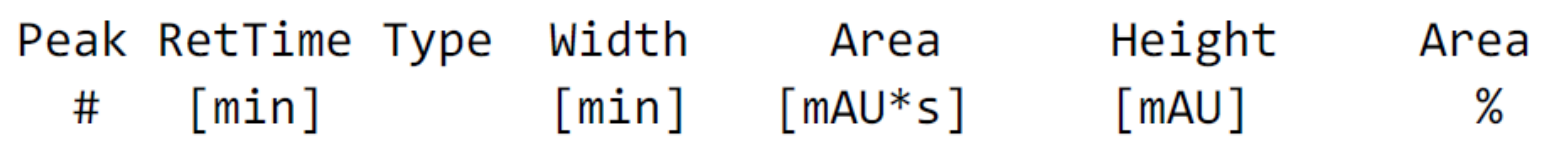

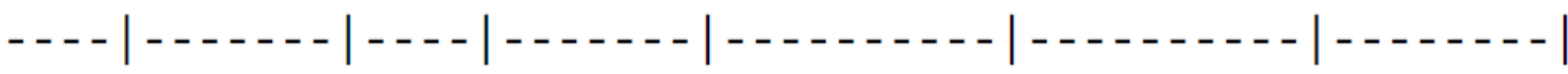

$\begin{array}{lllllll}1 & 11.854 \text { MM } & 0.2967 & 4070.06567 & 228.66187 & 98.0390\end{array}$

$\begin{array}{llllll}2 & 14.919 \text { MM } & 0.3266 & 81.40887 & 4.15379 & 1.9610\end{array}$ 


\section{1 | |ullit}<smiles>O=Cc1ccc2ccc3ccccc3c2c1C=O</smiles>

$73 i$

(600 MHz, $\mathrm{CDCl}_{3}$ )

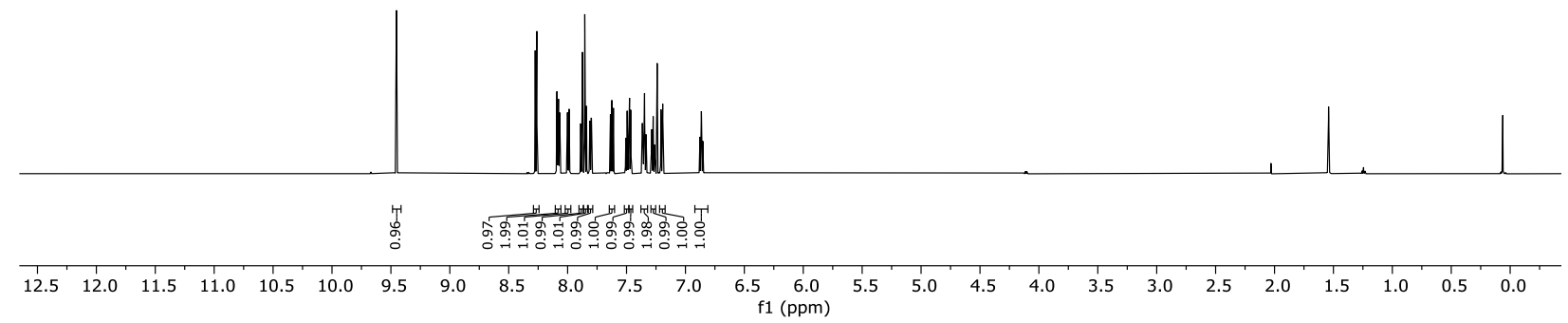

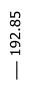

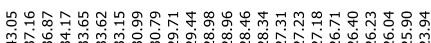

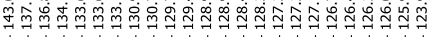<smiles>O=Cc1ccc2ccc3ccccc3c2c1C=O</smiles>

$73 i$

(150 MHz, $\mathrm{CDCl}_{3}$ )

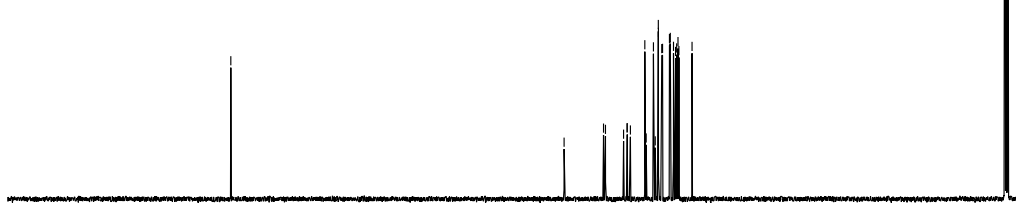

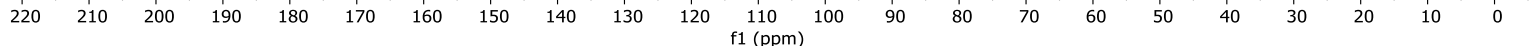


Chiral HPLC of 73i:

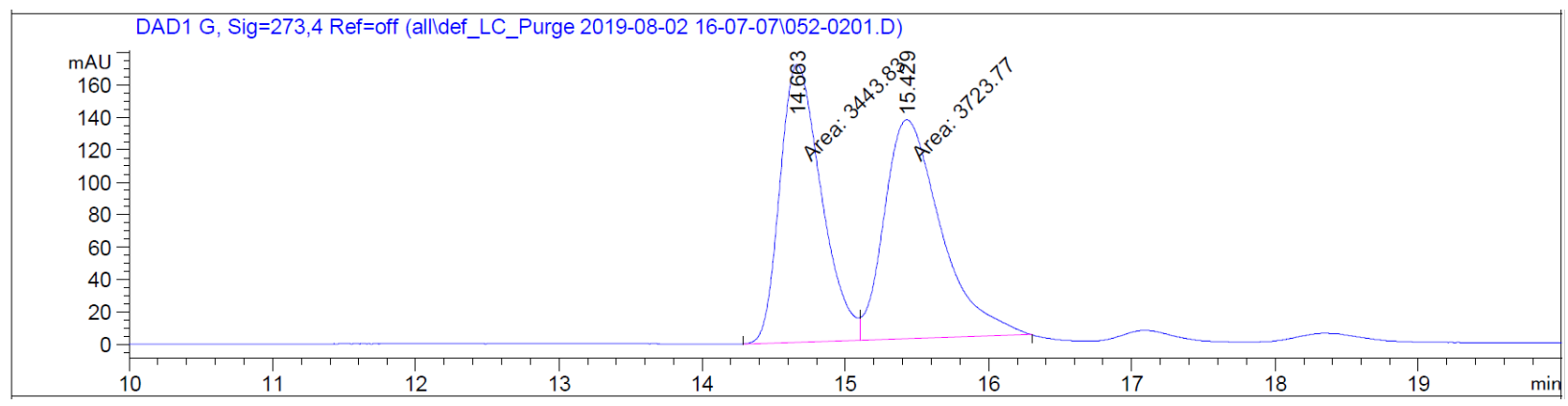

Signal 2: DAD1 G, Sig=273,4 Ref=off

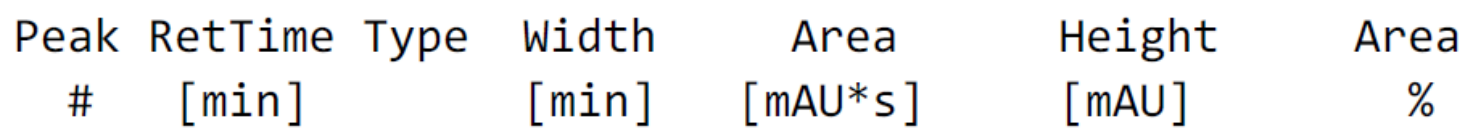

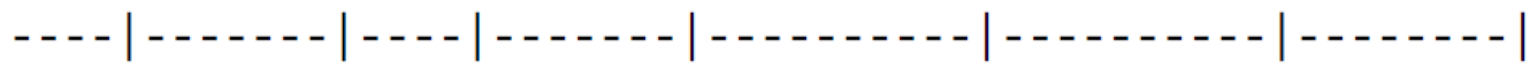

$\begin{array}{lllllll}1 & 14.663 & \text { MF } & 0.3346 & 3443.83179 & 171.54404 & 48.0472\end{array}$

$\begin{array}{lllllll}2 & 15.429 & \text { FM } & 0.4595 & 3723.76880 & 135.05215 & 51.9528\end{array}$

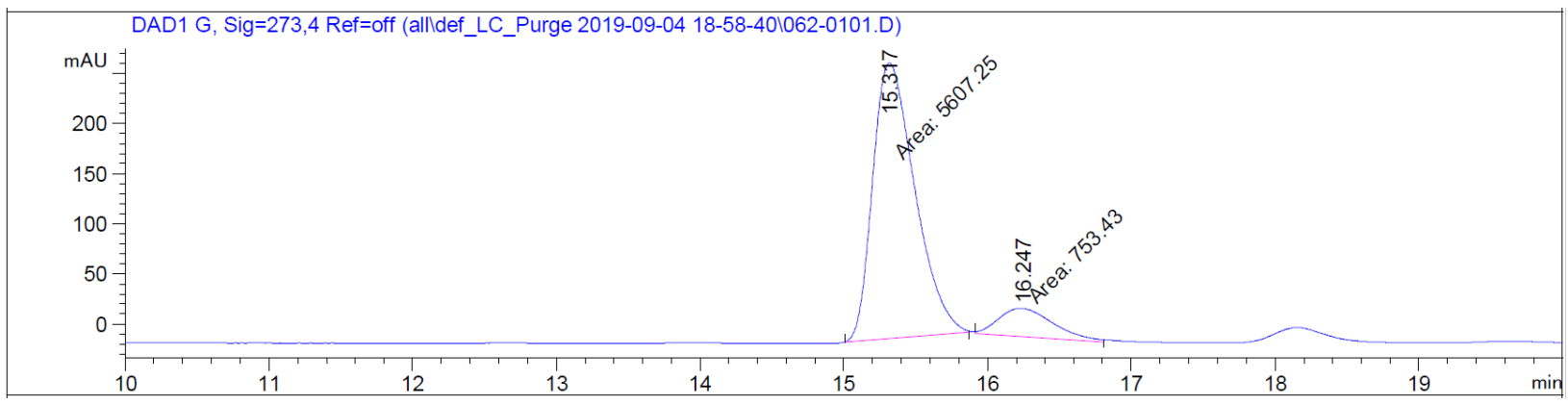

\begin{tabular}{|c|c|c|c|c|c|c|}
\hline $\begin{array}{l}\text { eak } \\
\#\end{array}$ & $\begin{array}{c}\text { RetTime } \\
\text { [min] }\end{array}$ & Type & $\begin{array}{l}\text { Width } \\
\text { [min] }\end{array}$ & $\begin{array}{c}\text { Area } \\
{\left[\mathrm{mAU}^{*} \mathrm{~s}\right]}\end{array}$ & $\begin{array}{l}\text { Height } \\
{[\mathrm{mAU}]}\end{array}$ & $\begin{array}{c}\text { Area } \\
\%\end{array}$ \\
\hline & & & & & & \\
\hline 1 & & & & 5678. & 276 & 88 \\
\hline 2 & & MM & & 758.69177 & 28.44831 & 11.7864 \\
\hline
\end{tabular}




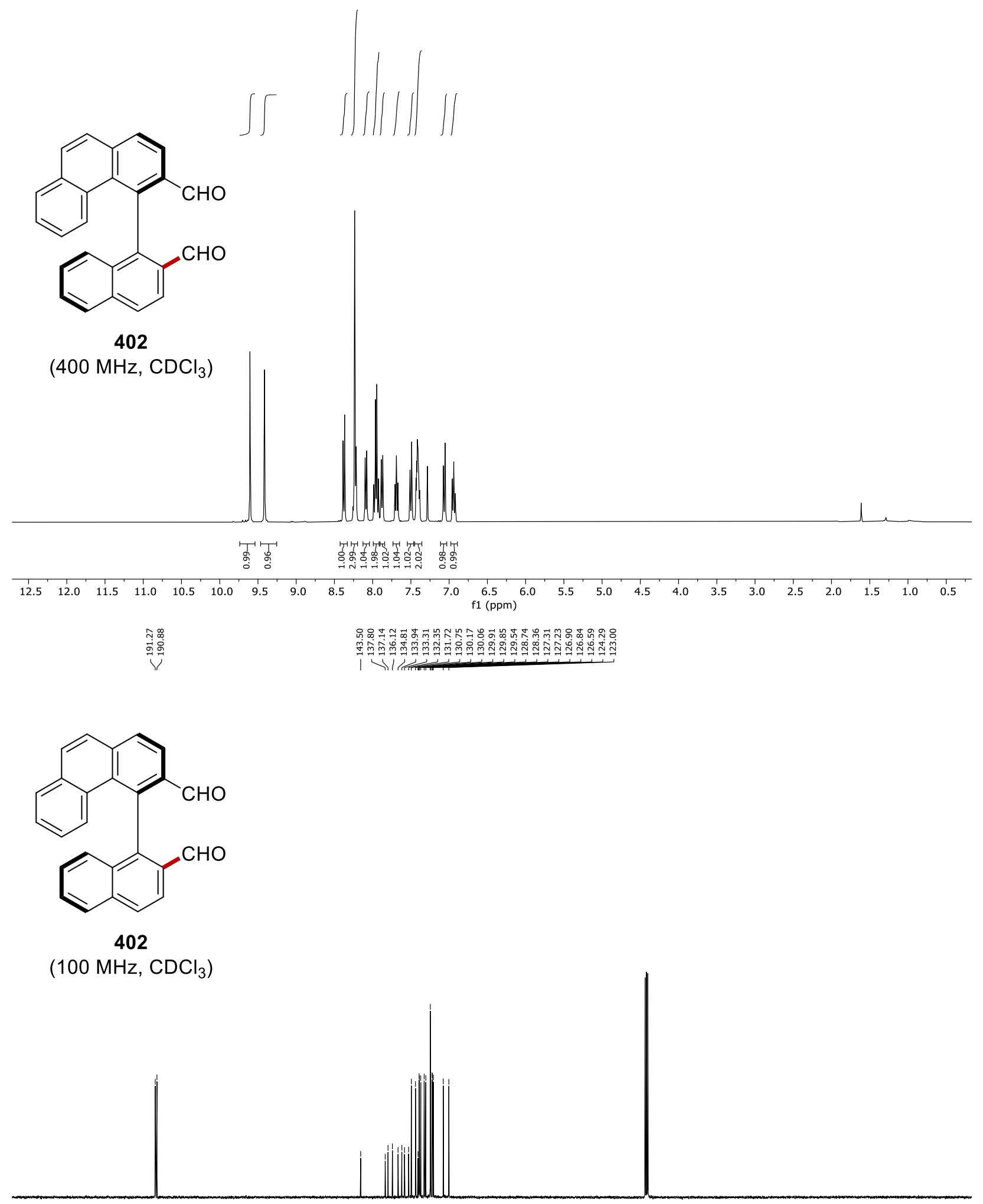

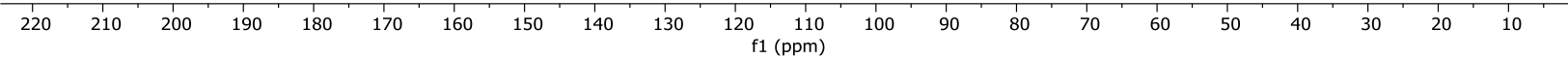


Chiral HPLC of $\mathbf{4 0 2}$ :

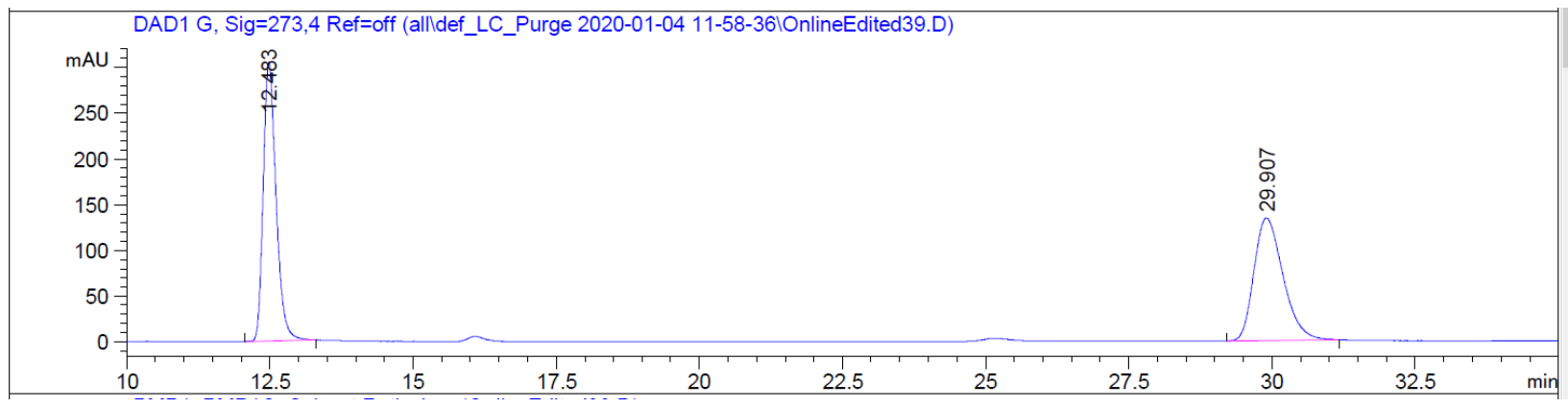

Peak RetTime Type width Area Height Area

\# $[\mathrm{min}] \quad[\mathrm{min}] \quad\left[\mathrm{mAU}^{*} \mathrm{~s}\right] \quad[\mathrm{mAU}] \quad \%$

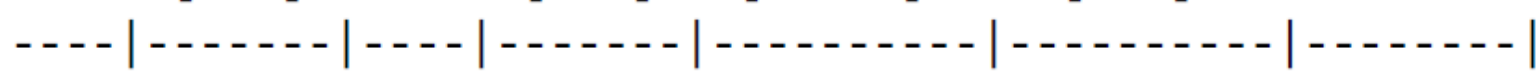

$1 \quad 12.483$ VV R $0.2349 \quad 4733.96582 \quad 305.23483 \quad 50.0029$

$\begin{array}{llllllll}2 & 29.907 & \text { BV R } & 0.4817 & 4733.41602 & 134.13223 & 49.9971\end{array}$

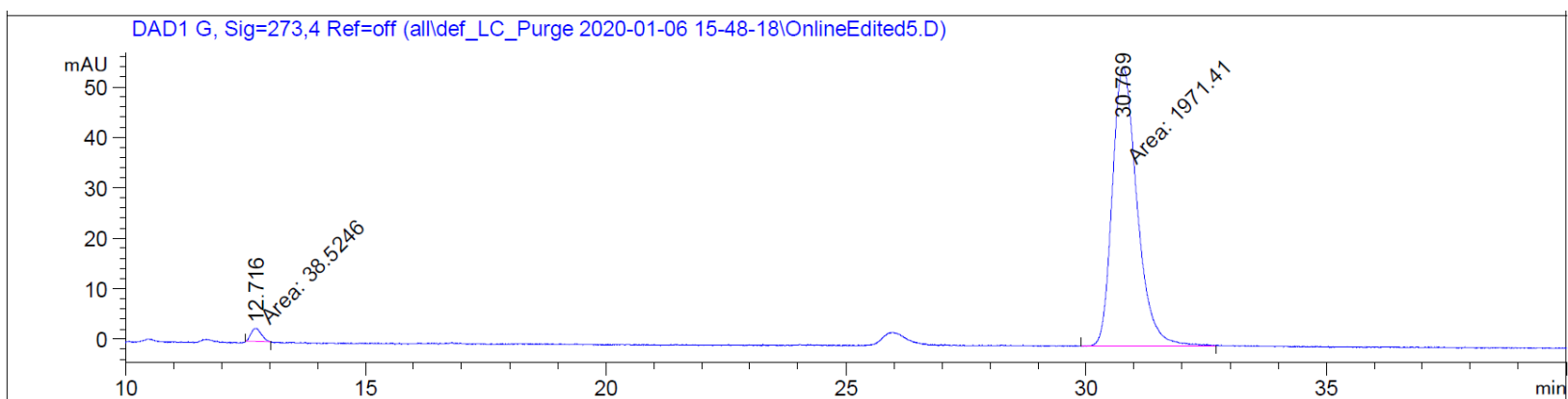

Peak RetTime Type Width Area Height Area

$\begin{array}{lll}\# \quad[\mathrm{~min}] & {[\mathrm{min}] \quad[\mathrm{mAU} * \mathrm{~s}] \quad[\mathrm{mAU}]}\end{array}$

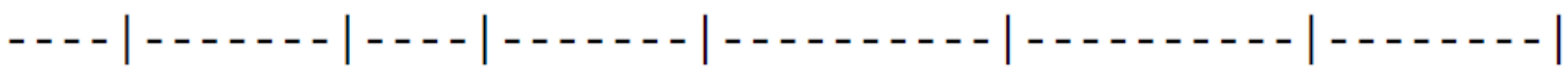

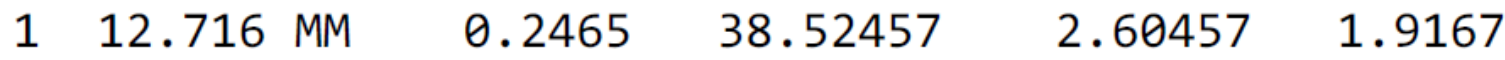

$2 \quad 30.769$ MM $\quad 0.59371971 .40845 \quad 55.33833 \quad 98.0833$ 


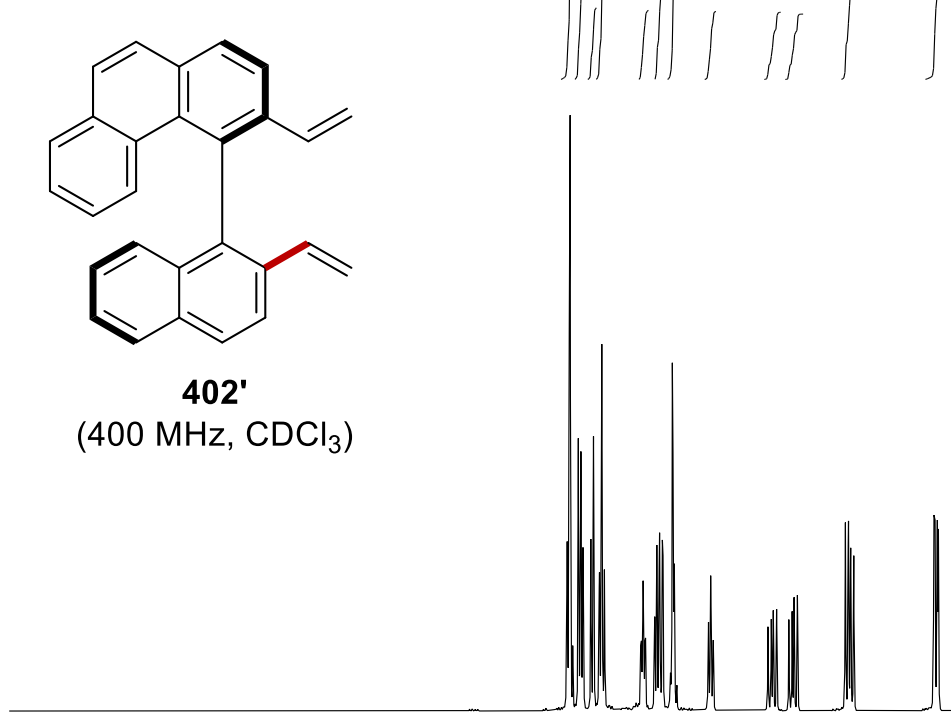

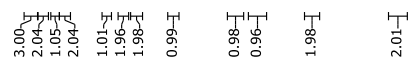

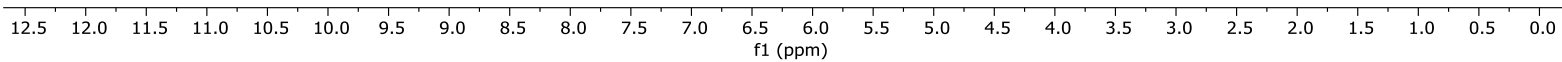

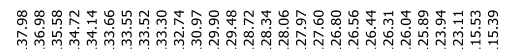

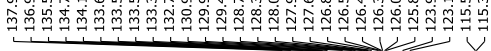<smiles>C=Cc1ccc2ccccc2c1-c1c(C=C)ccc2ccc3ccccc3c12</smiles>

402'

$\left(100 \mathrm{MHz} \mathrm{CDCl}_{3}\right)$

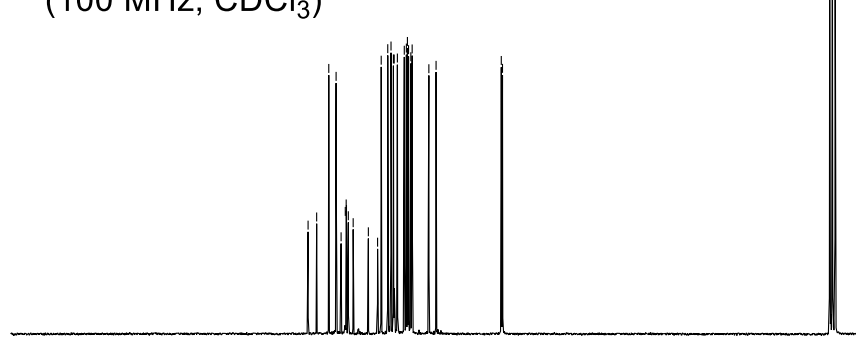

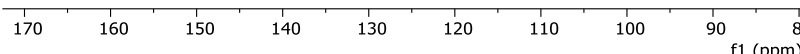



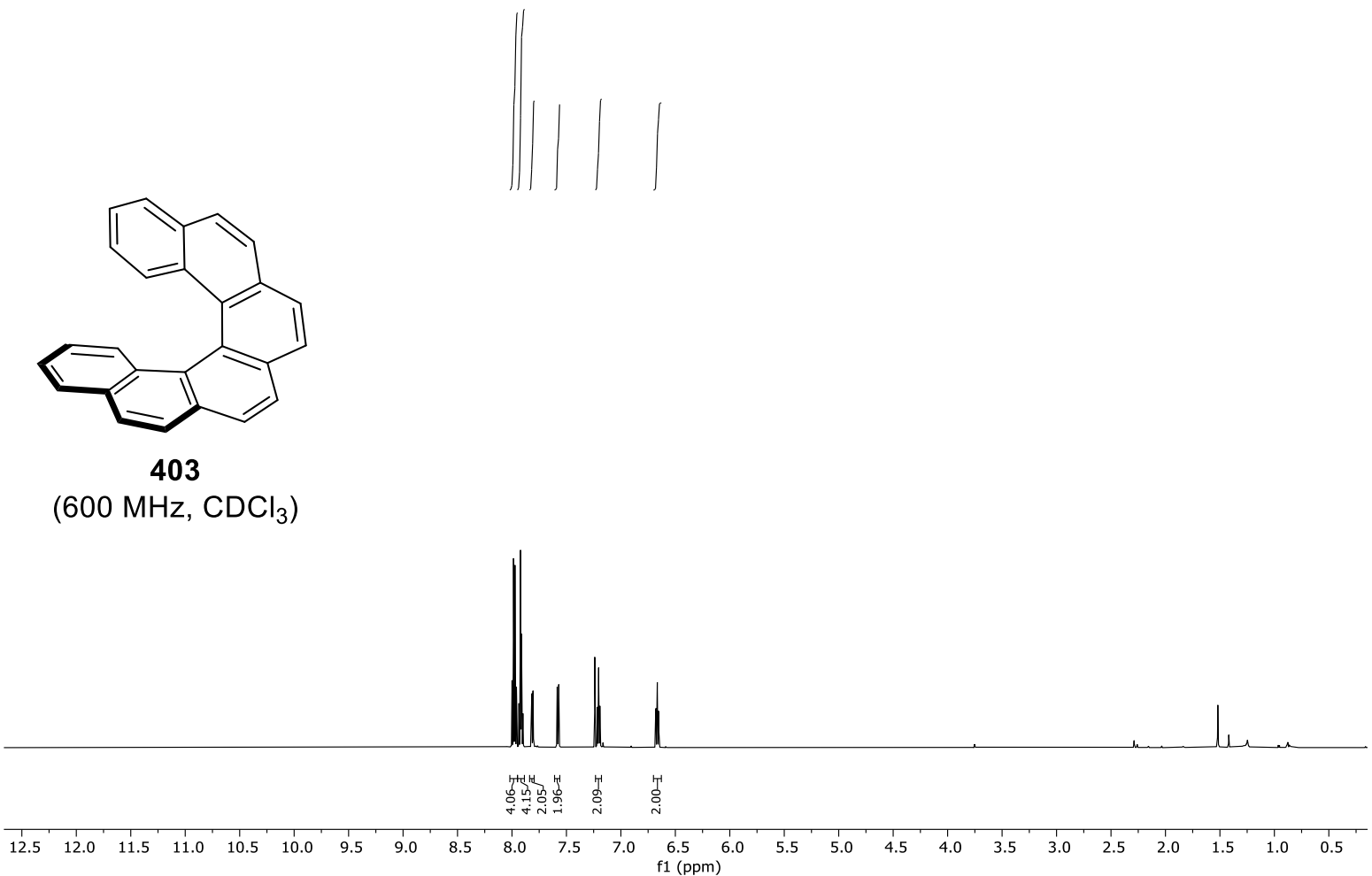

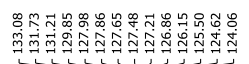

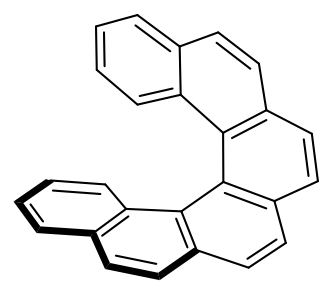

403

(150 $\mathrm{MHz}, \mathrm{CDCl}_{3}$ )
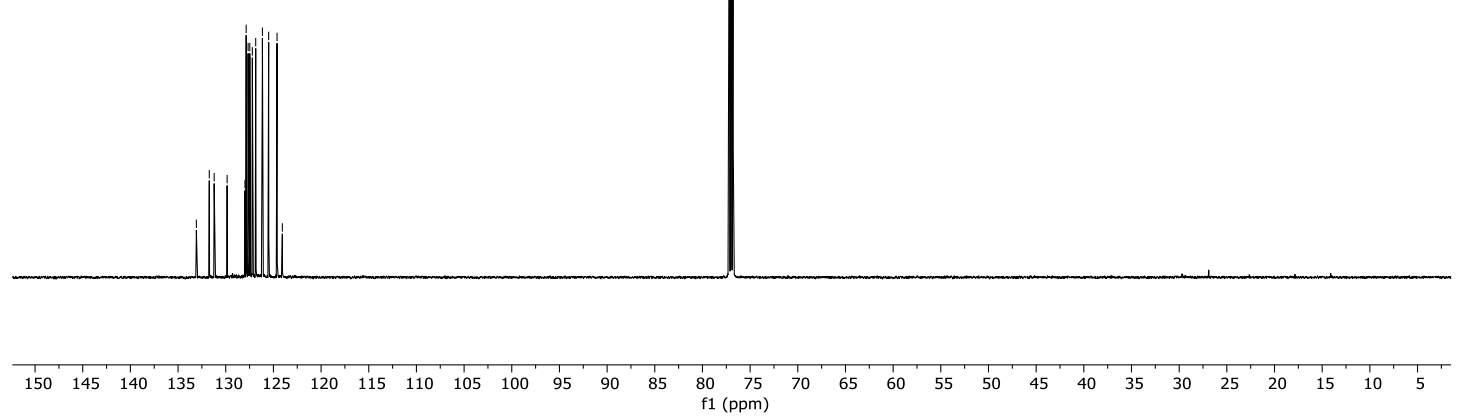

582 
Chiral HPLC of 403:

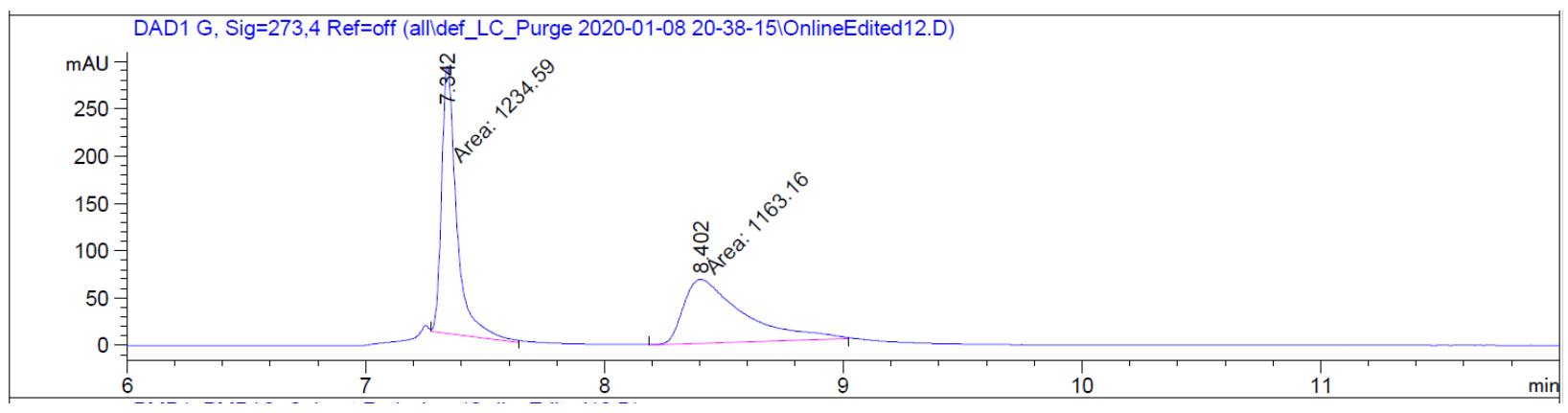

Peak RetTime Type Width Area Height Area

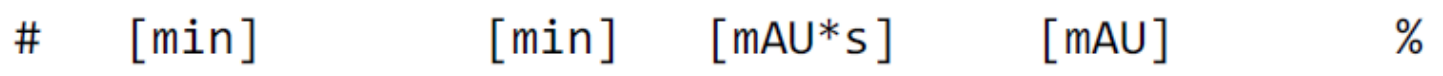
- - - | - - - - | - - |

$\begin{array}{lllllll}1 & 7.342 & \text { MM } & 0.0728 & 1234.59485 & 282.60950 & 51.4897\end{array}$

$\begin{array}{lllllll}2 & 8.402 & \text { MM } & 0.2878 & 1163.15759 & 67.36166 & 48.5103\end{array}$

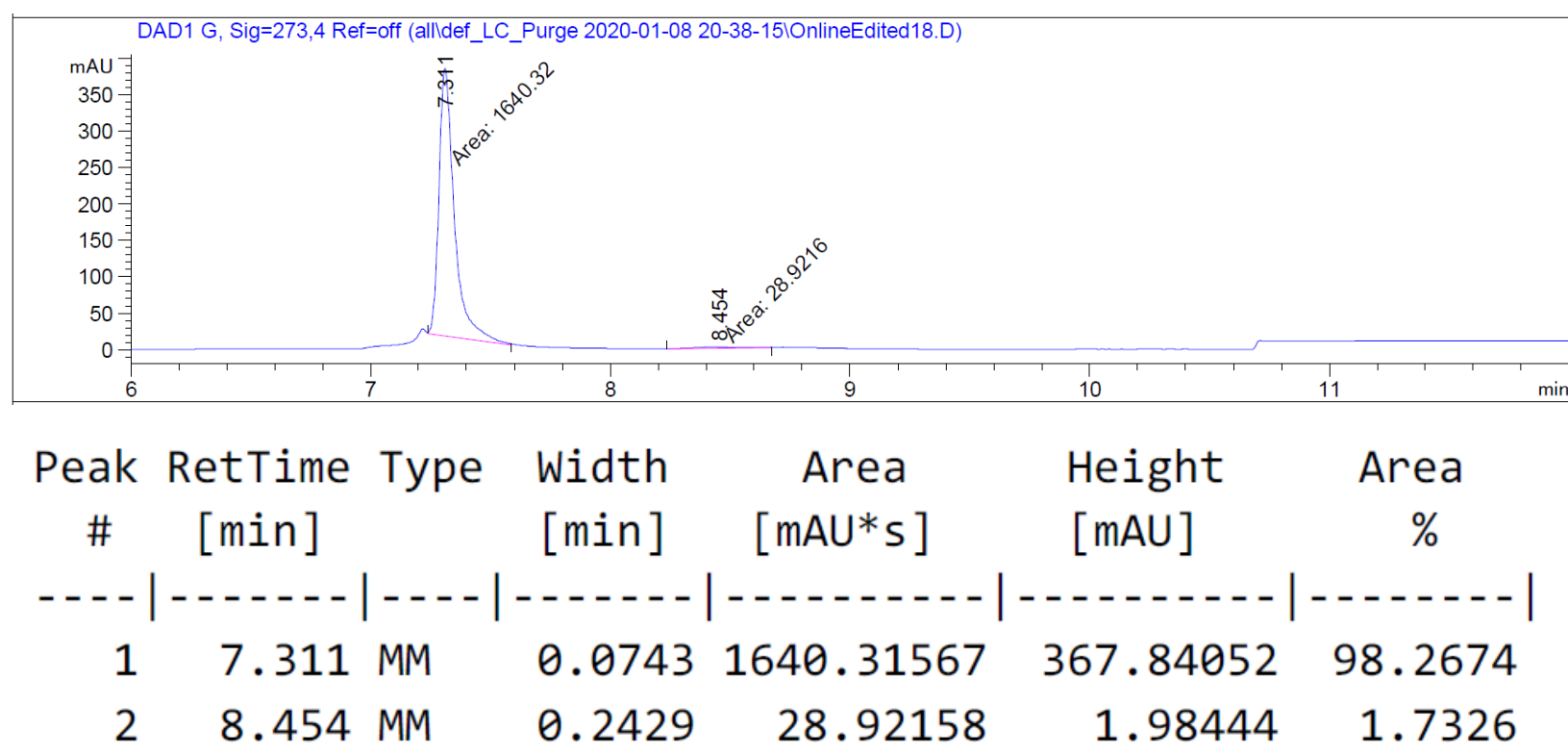



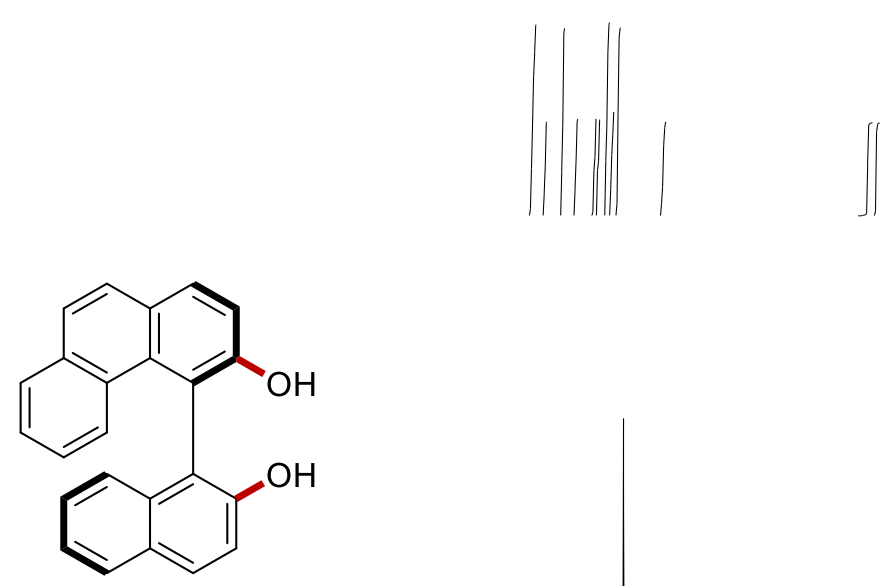

405

(400 MHz, $\mathrm{CDCl}_{3}$ )

Whith

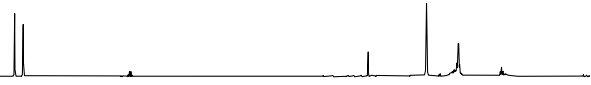

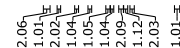

管营

$\begin{array}{llllllllllllllllllllllllllll}12.5 & 12.0 & 11.5 & 11.0 & 10.5 & 10.0 & 9.5 & 9.0 & 8.5 & 8.0 & 7.5 & 7.0 & 6.5 & 6.0 & 5.5 & 5.0 & 4.5 & 4.0 & 3.5 & 3.0 & 2.5 & 2.0 & 1.5 & 1.0 & 0.5\end{array}$

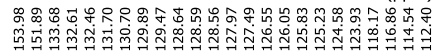<smiles>Oc1ccc2cccc3c2c1C=CC=C3</smiles>

405

(100 MHz, $\mathrm{CDCl}_{3}$ )

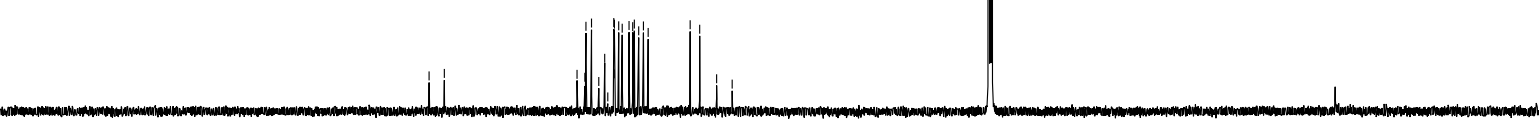

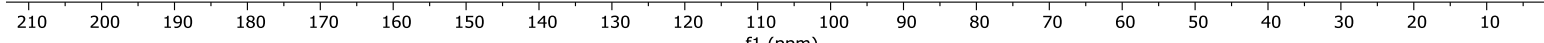


Chiral HPLC of 405:

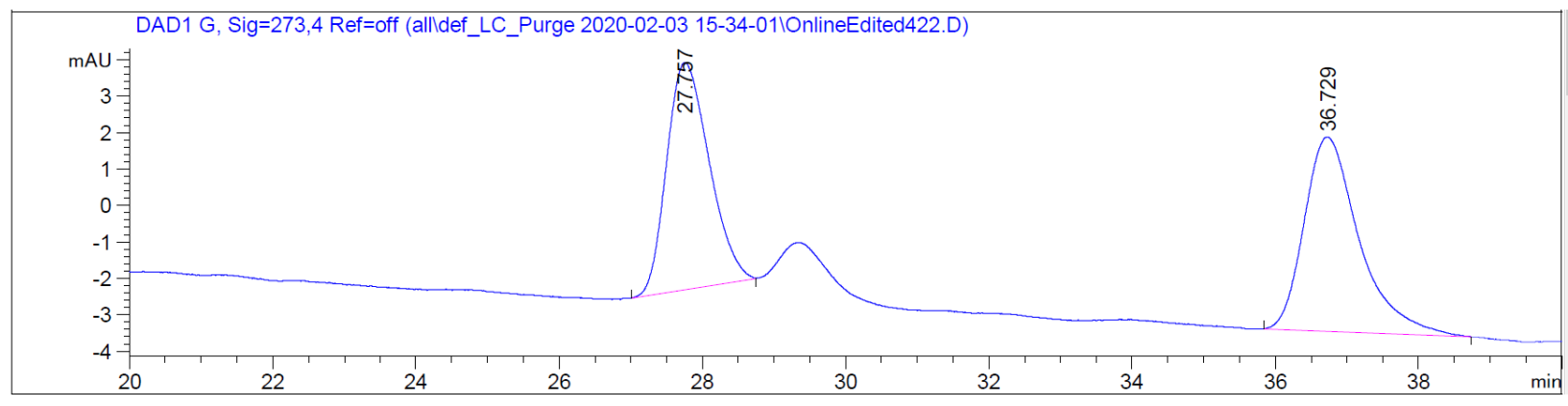

Peak RetTime Type Width Area Height Area

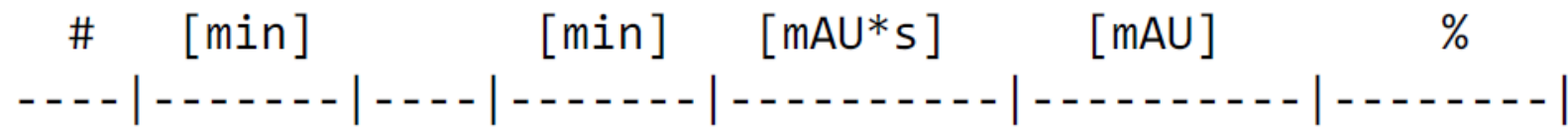
127.757 BB
$0.4912 \quad 256.50980$
$6.23206 \quad 47.4281$
236.729 BB
$0.6254 \quad 284.32904$
$5.32964 \quad 52.5719$

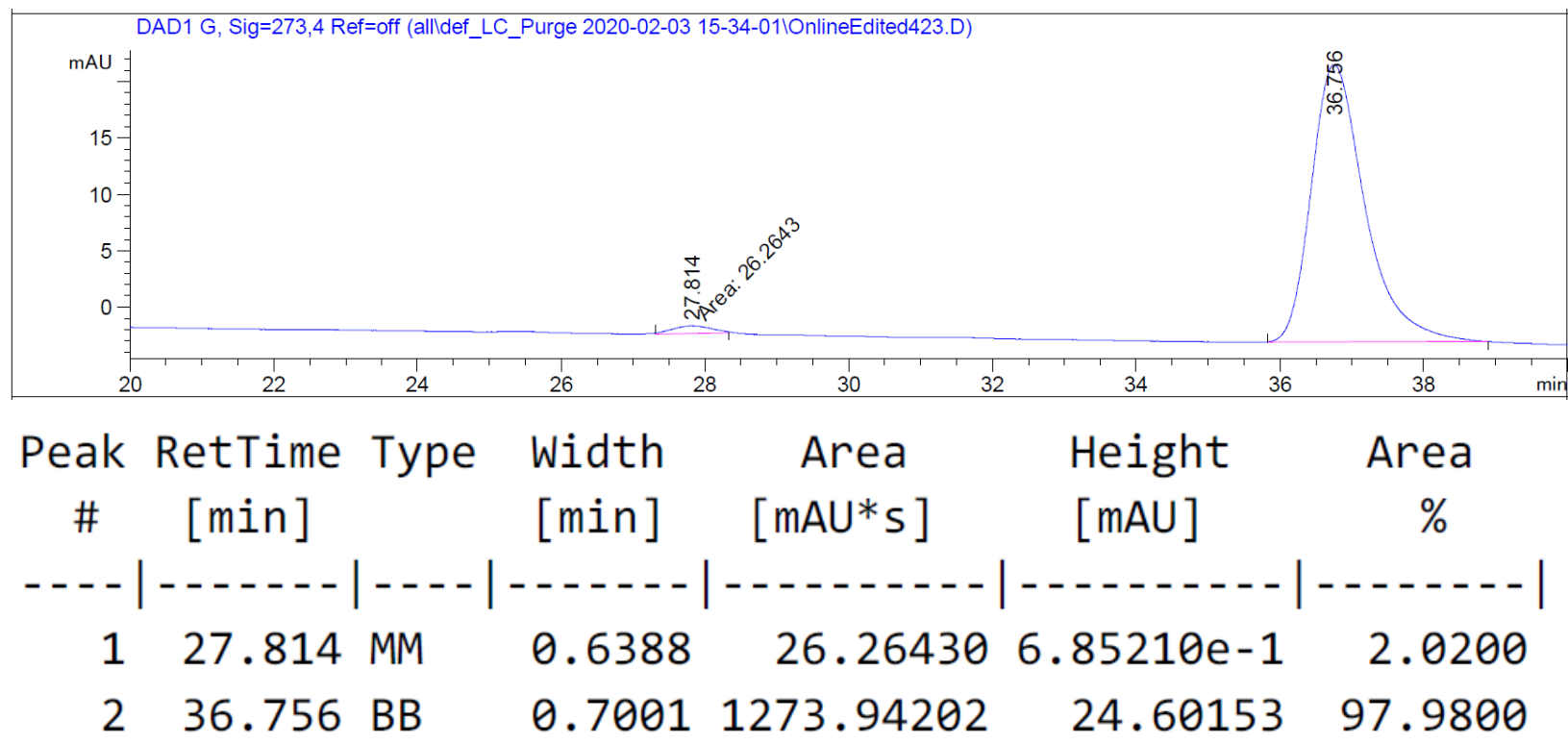




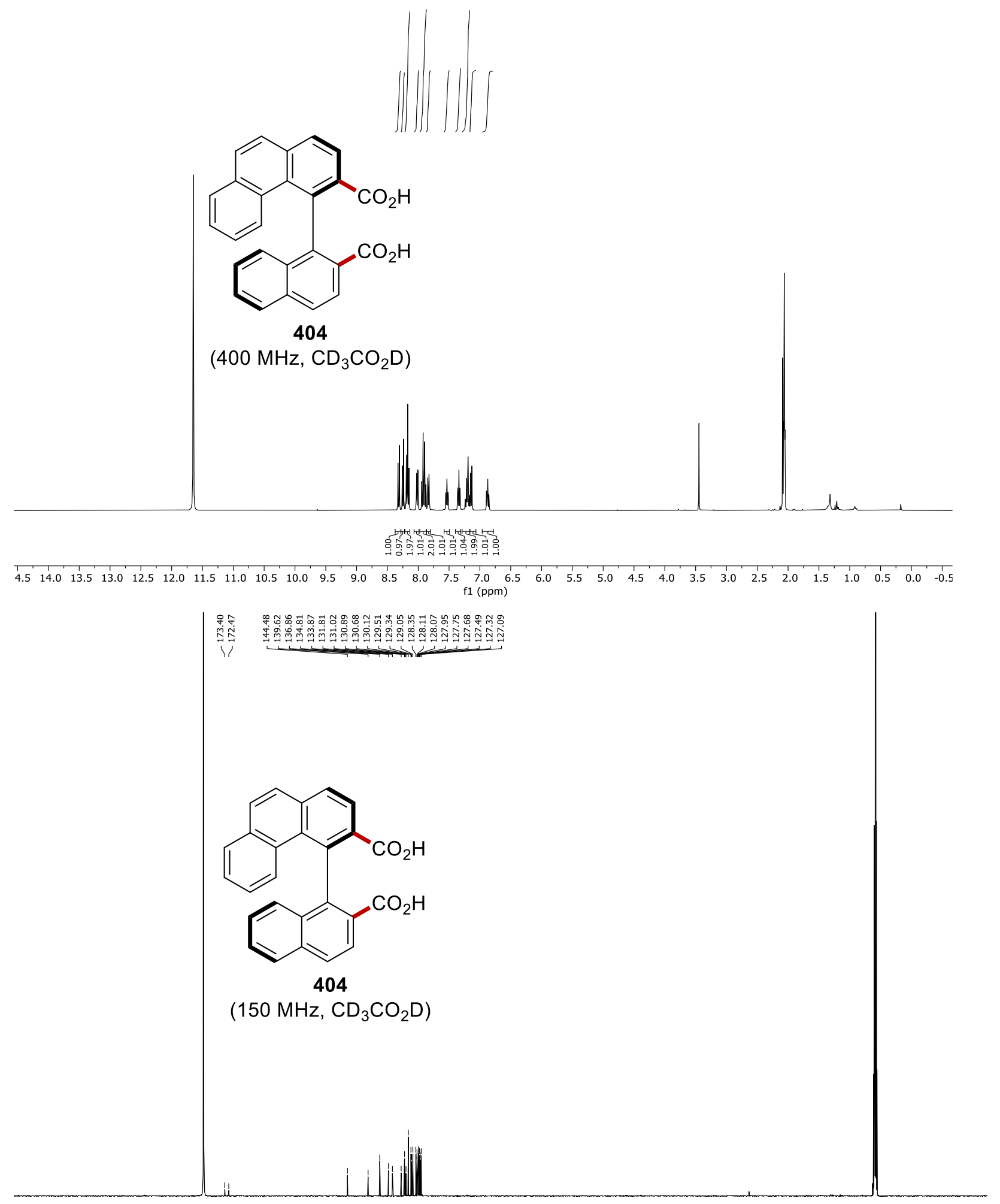

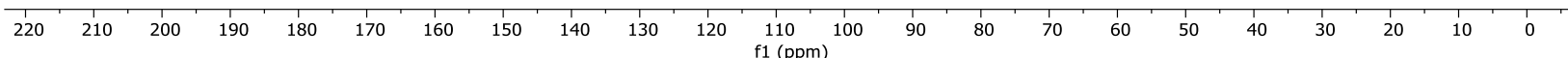


Chiral HPLC of 404:

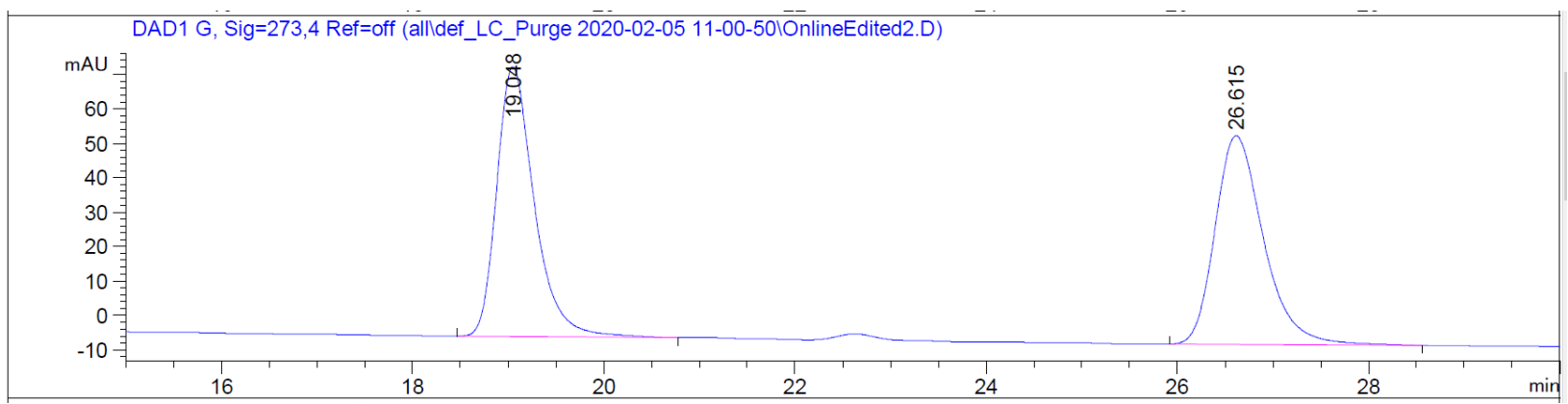

Peak RetTime Type Width Area Height Area

\# [min] $[\mathrm{min}] \quad\left[\mathrm{mAU}^{*} \mathrm{~s}\right] \quad[\mathrm{mAU}] \quad \%$
- - - | - - - - | - - - | - - - - | - - - - - - | - - - - - | - - - - | |

$\begin{array}{lllllll}1 & 19.048 & \text { BB } & 0.4143 & 2144.05420 & 78.34101 & 50.1105\end{array}$

$\begin{array}{lllllll}2 & 26.615 & \text { BB } & 0.5291 & 2134.59570 & 60.57181 & 49.8895\end{array}$

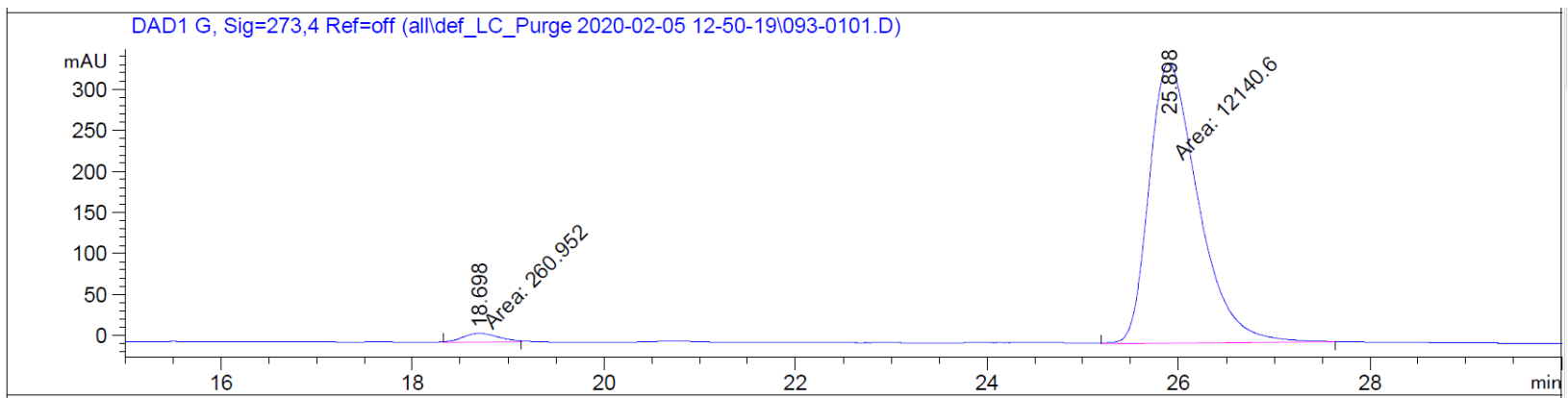

\begin{tabular}{|c|c|c|c|c|c|c|}
\hline $\begin{array}{l}\text { eak } \\
\#\end{array}$ & $\begin{array}{c}\text { RetTime } \\
\text { [min] }\end{array}$ & Type & $\begin{array}{l}\text { Width } \\
\text { [min] }\end{array}$ & $\begin{array}{c}\text { Area } \\
{\left[\mathrm{mAU}^{*} \mathrm{~s}\right]}\end{array}$ & $\begin{array}{l}\text { Height } \\
\text { [mAU] }\end{array}$ & $\begin{array}{c}\text { Area } \\
\%\end{array}$ \\
\hline & & & & & & \\
\hline 1 & & & & 260.95184 & 87 & 342 \\
\hline 2 & 398 & & & $1.21406 \mathrm{e} 4$ & 6617 & 97.8958 \\
\hline
\end{tabular}




\section{Erklärung}

Ich versichere, dass ich die vorliegende Dissertation in dem Zeitraum von Oktober 2016 bis April 2021 am Institut für Organische und Biomolekulare Chemie der Georg-AugustUniversität Göttingen

auf Anregung und unter Anleitung von

\section{Herrn Prof. Dr. Lutz Ackermann}

selbstständig durchgeführt und keine anderen als die angegebenen Hilfsmittel und Quellen verwendet habe.

Göttingen, den 15.04.2021 